\title{
Mercury Control for Plants Firing Texas Lignite and Equipped with ESP-wet FGD
}

\section{Final Project Report}

\author{
Project Start Date: $\quad$ 04/10/06 \\ Project End Date: $\quad$ 12/31/09 \\ Prepared by: \\ Katherine Dombrowski
}

March 2010

Cooperative Agreement No: DE-FC26-06NT42779

Report Number: 42779R16

\author{
URS Group, Inc. \\ 9400 Amberglen Boulevard \\ Austin, Texas 78729 \\ Prepared for: \\ Andrew O'Palko \\ National Energy Technology Laboratory \\ U.S. Department of Energy \\ P.O. Box 880 \\ Morgantown, WV 26508-0880
}




\section{DISCLAIMER}

This report was prepared as an account of work sponsored by an agency of the United States Government. Neither the United States Government nor any agency thereof, nor any of their employees, makes any warranty, express or implied, or assumes any legal liability or responsibility for the accuracy, completeness, or usefulness of any information, apparatus, product, or process disclosed, or represents that its use would not infringe privately owned rights. Reference herein to any specific commercial product, process, or service by trade name, trademark, manufacturer, or otherwise does not necessarily constitute or imply its endorsement, recommendation, or favoring by the United States Government or any agency thereof. The views and opinions of authors expressed herein do not necessarily state or reflect those of the United States Government or any agency thereof. 


\section{ACKNOWLEDGMENTS}

This project was made possible through the generous funding of the U.S. Department of Energy's National Energy Technology Laboratory and industry partners including EPRI, NRG Texas, Luminant, and AEP. NRG Texas provided its Limestone Electric Generating Station as the host site for this project. URS Group was the prime contractor, and Apogee Scientific and ADA-ES were subcontractors.

The team gratefully acknowledges the efforts of John Hudspeth (NRG Limestone Station) to provide all the necessities and more during this four year program.

The team also wishes to thank sorbent vendors, including Norit Americas, Calgon Carbon Corporation, Sorbent Technologies Inc., and BASF, for providing mercury sorbents for this program.

Project management was provided by Andrew O'Palko (DOE/NETL), Carl Richardson and Katherine Dombrowski (URS Group), Ramsay Chang (EPRI), Kevin Fisher and Tim Ebner (Apogee Scientific), Tom Campbell (ADA-ES), Craig Eckberg (NRG Texas), Cliff Clark (Luminant) and Brian Rupp (AEP). 


\section{ABSTRACT}

This report presents the results of a multi-year test program conducted as part of Cooperative Agreement DE-FC26-06NT42779, "Mercury Control for Plants Firing Texas Lignite and Equipped with ESP-wet FGD." The objective of this program was to determine the level of mercury removal achievable using sorbent injection for a plant firing Texas lignite fuel and equipped with an ESP and wet FGD. The project was primarily funded by the U.S. DOE National Energy Technology Laboratory. EPRI, NRG Texas, Luminant (formerly TXU), and AEP were project co-funders. URS Group was the prime contractor, and Apogee Scientific and ADA-ES were subcontractors.

The host site for this program was NRG Texas' Limestone Electric Generating Station (LMS) Units 1 and 2, located in Jewett, Texas. The plant fires a blend of Texas lignite and Powder River Basin (PRB) coal. Full-scale tests were conducted to evaluate the mercury removal performance of powdered sorbents injected into the flue gas upstream of the ESP (traditional configuration), upstream of the air preheater, and/or between electric fields within the ESP (Toxecon ${ }^{\mathrm{TM}}$ II configuration).

Phases I through III of the test program, conducted on Unit 1 in 2006-2007, consisted of three short-term parametric test phases followed by a 60-day continuous operation test. Selected mercury sorbents were injected to treat one quarter of the flue gas (e.g., approximately $225 \mathrm{MW}$ equivalence) produced by Limestone Unit 1 . Six sorbents and three injection configurations were evaluated and results were used to select the best combination of sorbent (Norit Americas' DARCO Hg-LH at $2 \mathrm{lb} / \mathrm{Macf}$ ) and injection location (upstream of the ESP) for a two-month performance evaluation. A mercury removal rate of 50-70\% was targeted for the long-term test. During this continuous-injection test, mercury removal performance and variability were evaluated as the plant operated under normal conditions. Additional evaluations were made to determine any balance-of-plant impacts of the mercury control process, including those associated with ESP performance and fly ash reuse properties.

Upon analysis of the project results, the project team identified several areas of interest for further study. Follow-on testing was conducted on Unit 2 in 2009 with the entire unit treated with injected sorbent so that mercury removal across the FGD could be measured and so that other low-ash impact technologies could be evaluated. Three approaches to minimizing ash impacts were tested: (1) injection of "low ash impact" sorbents, (2) alterations to the injection configuration, and (3) injection of calcium bromide in conjunction with sorbent. These conditions were tested with the goal of identifying the conditions that result in the highest mercury removal while maintaining the sorbent injection at a rate that preserves the beneficial use of ash. 


\section{TABLE OF CONTENTS}

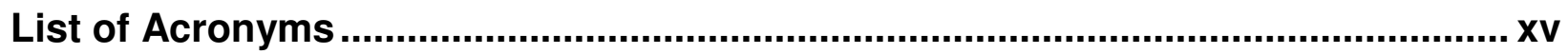

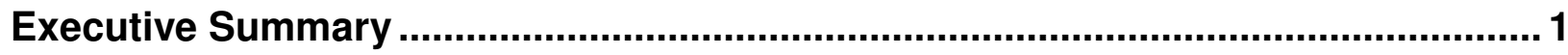

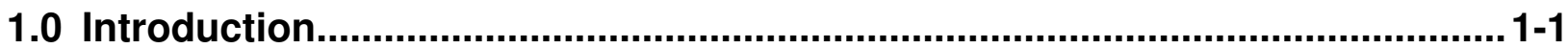

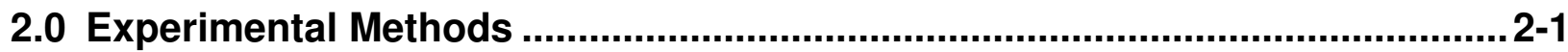

2.1 Host Site Description ..........................................................................

2.2 Mercury Sorbent Selection............................................................ 2-5

2.3 Design and Installation of the Sorbent Injection System ............................ 2-7

Sorbent Feeding System .......................................................................................... 2-7

Injection Lances - Upstream of the ESP (Unit 1 Tests in 2006-2007) ..............................2-8

Injection Lances - Upstream of the Air Heater, ESP (Unit 2 Tests in 2009)....................... 2-8

Toxecon $^{\mathrm{TM}}$ II Injection System ..................................................................................... 2-10

2.4 Calcium Bromide Addition System ....................................................... 2-13

2.5 Flue Gas and Process Sampling Methods........................................... 2-13

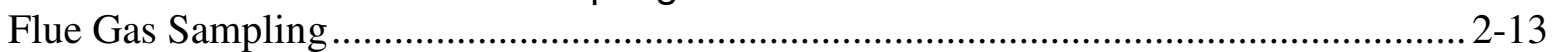

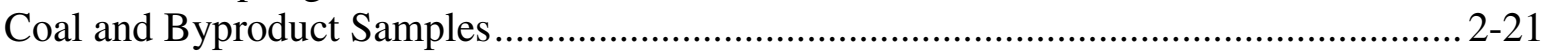

2.5 Parametric Testing Sample Matrix (Phases I-III, 2006-2007) .....................2-24

2.6 Long-Term Testing Sample Matrix.....................................................2-28

2.8 Parametric Phase IV Scope of Work and Plan ........................................2-31

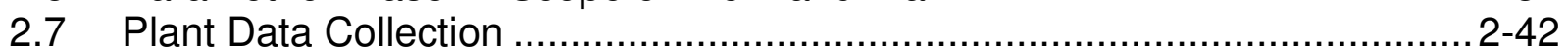

\subsection{Results and Discussion - Phases I-III and Long-Term Test (2006-2007).........3-1}

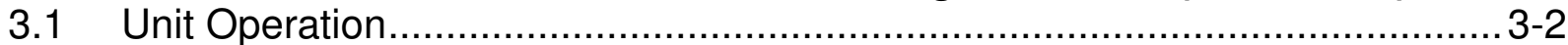

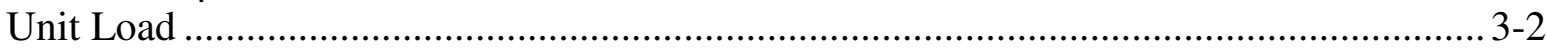

Velocity Traverse Measurements at Duct Sampling and Injection Locations...................... 3-4

3.2 Baseline Mercury Measurements ….....................................................

Baseline Mercury Measurements - SCEM.................................................................. 3-5

Baseline Mercury Measurements - OH Characterization ............................................. 3-9

Baseline Mercury Measurements - Fly Ash ................................................................. 3-11

Baseline Mercury Measurements - Summary ................................................................... 3-11

3.3 Parametric Sorbent Injection Tests - Mercury Removal Results .................. 3-12

Parametric Results for Sorbent Injection Upstream of ESP ........................................... 3-16

Parametric Test Results with Toxecon ${ }^{\text {TM }}$ II and Staged Injection Configurations.............. 3-19

3.4 Long-Term Sorbent Injection - Mercury Removal Results......................... 3-20

Mercury Measurements During Long-Term Sorbent Injection - SCEM Results .............. 3-21

Mercury Measurements During Long Term Sorbent Injection - Ontario Hydro Results . 3-26

Mercury Measurements During Long-Term Sorbent Injection - Fly Ash Results ........... 3-29

Discussion of Mercury Removal During the Long-Term Injection Test............................ 3-30

3.5 Mercury Oxidation during Sorbent Injection ......................................... 3-32

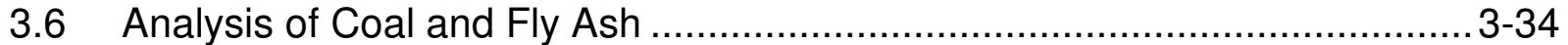

3.7 Effects of Sorbent Injection on ESP Operation ........................................3-39

3.8 ESP Outlet Particulate Matter Measurement Results ................................3-43 
3.9 Effects of Sorbent Injection on Fly Ash Concrete Properties ...................... 3-54

Initial Screen Fly Ash and Concrete Results ................................................................ 3-54

Fly ash and Concrete Results during Long-Term Test ..................................................... 3-57

3.10 Flue Gas Halogen Measurements ……........................................... 3-65

3.11 FGD System Measurements.........................................................

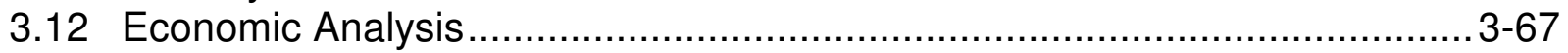

4.0 Results and Discussion - Phase IV (2009) …................................................. 4-1

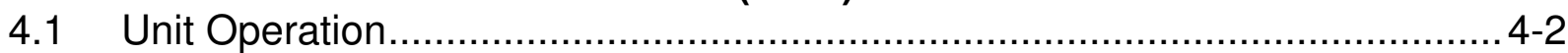

4.2 Baseline - Flue Gas Mercury Measurements ......................................... 4-3

Baseline Mercury Measurements - SCEM.............................................................. 4-3

Baseline Mercury Measurements - Alternate Methods .................................................... 4-5

Baseline Mercury Measurements - Summary ............................................................. 4-7

4.3 Parametric Sorbent Injection Mercury Removal.......................................... 4-8

ACI Upstream of the AH .................................................................................... 4-8

ACI Upstream of the ESP - Full Unit ............................................................... 4-18

Calcium Bromide Addition to Coal ....................................................................... 4-22

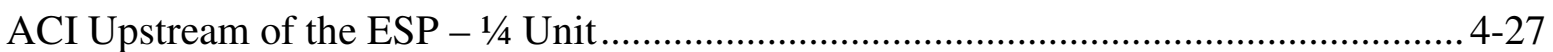

4.4 Effects of Sorbent Injection on Concrete Properties ................................. 4-33

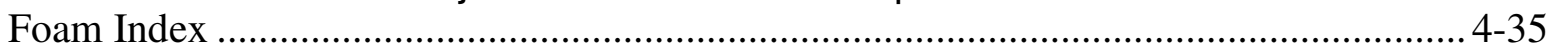

LOI and Carbon Characterization ............................................................................. 4-37

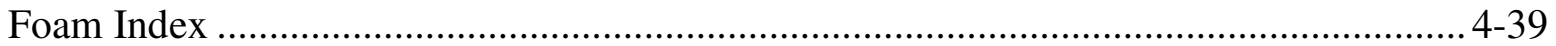

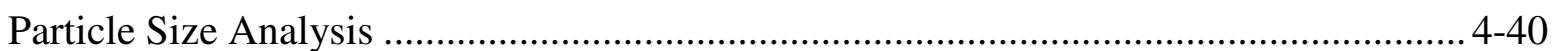

Air Content of Concrete Mixture _................................................................................ 4-40

Slump/Water to Cement Ratio/Compressive Strength ...................................................... 4-41

Petrographic Analyses ..................................................................................................

4.5 Characterization of Coal, Fly Ash, and FGD Absorber Slurry ..................... 4-41

4.6 Trace Metals Measurements .......................................................... 4-49

4.7 In-line Sorbent Particle Size Distribution Analysis ................................... 4-63

4.8 ESP Outlet Particulate Emissions ..................................................... 4-68

5.0 Conclusions and Recommendations............................................................. 5-1

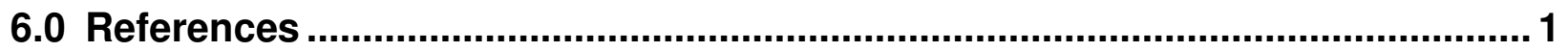




\section{List of Tables}

Table 2-1. Limestone Electric Generating Station Unit 1 and Unit 2 Design Parameters.......... 2-5

Table 2-2. Sorbents Selected for Evaluation at LMS Unit 1 ............................................. 2-6

Table 2-3. Sorbents Selected for Evaluation at LMS Unit 2 ............................................... 2-7

Table 2-4. Executed Test Schedule - Parametric Testing, Phase I....................................... 2-24

Table 2-5. Test Schedule - Parametric Testing, Phase II .................................................... 2-25

Table 2-6. Executed Test Schedule - Parametric Testing, Phase III ...................................... 2-26

Table 2-7. Flue Gas Sampling Matrix for 2006-2007 Parametric Tests .................................. 2-27

Table 2-8. Solid Process Samples Collected for 2006-2007 Parametric Tests....................... 2-27

Table 2-9. Sampling Plan for Concrete Testing for 2006-2007 Parametric Tests................... 2-27

Table 2-10. Coal Schedule for Unit 1 Long-Term Test.................................................... 2-29

Table 2-11. Sample Collection and Analyses for Unit 1 Long-Term Tests ............................. 2-30

Table 2-12. OH Sample Schedule for Unit 1 Long-Term Tests ............................................. 2-30

Table 2-13. Process Sample Schedule for Unit 1 Long-Term Injection Test.......................... 2-31

Table 2-14. Fly Ash Sampling Plan for Concrete Testing for Unit 1 Long-Term Test.............2-31

Table 2-15. Test Schedule - Parametric Testing, Phase IV ................................................ 2-33

Table 2-16. Sorbent Injection Schedule - Parametric Testing, Phase IV ............................... 2-37

Table 2-17. Bromide Addition Schedule - Parametric Testing, Phase IV .............................. 2-39

Table 2-18. OH Sample Schedule for Unit 2 Parametric Tests, Phase IV .............................. 2-40

Table 2-19. M29 Sample Schedule for Unit 2 Parametric Tests, Phase IV (XFM Runs

Conducted during Same Time Periods) .......................................................................... 2-40

Table 2-20. M17 Sample Schedule for Phase IV Parametric Tests ........................................ 2-41

Table 2-21. Sorbent Trap Sample Schedule for Phase IV Parametric Tests ........................... 2-41

Table 2-22. Process Data Collected at Limestone Unit 1 and Unit 2 ................................... 2-43

Table 3-1. Gross Load for Unit 1 during ACI Testing ......................................................... 3-2

Table 3-2. U1A Treated ESP Inlet Temperature during ACI Testing ..................................... 3-3

Table 3-3. Inlet Temperature of Untreated U1B ESP during ACI Testing ............................ 3-3

Table 3-4. Baseline Volumetric Flow Rates Measured at ESP Inlet ........................................ 3-5

Table 3-5. Baseline OH Results at ESP Outlet ............................................................ 3-10

Table 3-6. Comparison of OH to SCEM Baseline Mercury Measurements............................ 3-11

Table 3-7. Average Mercury Concentrations Measured during Parametric Tests with Sorbent

Injection Upstream of ESP................................................................................... 3-13

Table 3-8. Average Mercury Concentrations Measured during Toxecon ${ }^{\mathrm{TM}}$ II \& Staged

Injection Tests (Phases II \& III) ............................................................................ 3-14

Table 3-9. Percent Mercury Reduction and ESP Removal for Parametric Tests with Sorbent

Injection Upstream of ESP............................................................................ 3-15

Table 3-10. Percent Mercury Reductions and Removals for Toxecon ${ }^{\mathrm{TM}}$ II \& Staged Injection

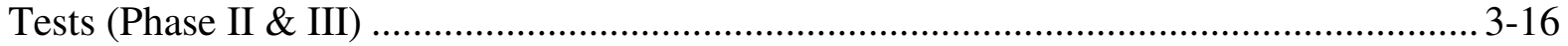

Table 3-11. Sorbent Injection Rate Needed to Achieve 70\% Mercury Reduction at ESP

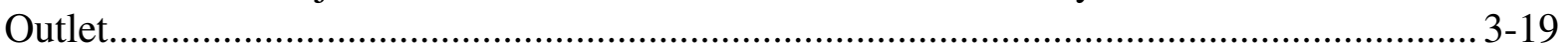

Table 3-12. Long-Term Sorbent Injection Test Schedule ................................................ 3-21

Table 3-13. Average Total Mercury Concentrations $\left(\mu \mathrm{g} / \mathrm{Nm}^{3}\right.$ at $\left.3 \% \mathrm{O}_{2}\right)$ during Long-Term

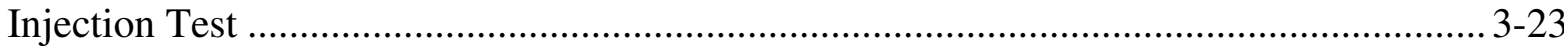


Table 3-14. Average Elemental Mercury Concentrations $\left(\mu \mathrm{g} / \mathrm{Nm}^{3}\right.$ at $\left.3 \% \mathrm{O}_{2}\right)$ during

Long-Term Injection Test .................................................................................... 3-23

Table 3-15. Average Flue Gas Mercury Oxidation Measured during Long-Term Injection..... 3-23

Table 3-16. Mercury Removals Measured during Long-Term Injection Test......................... 3-24

Table 3-17. OH Results for Long-Term Injection Test ................................................. 3-27

Table 3-18. Calculation of Mercury Removal across the ESP Based on OH Outlet

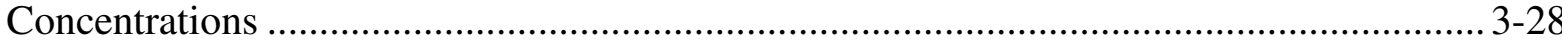

Table 3-19. Comparison of OH and SCEM Mercury Measurements during Long-Term Test. 3-29

Table 3-20. Average Fly Ash Mercury Concentration Measured Across the Treated ESP ...... 3-30

Table 3-21. Theoretical Predictions of Mercury Removal by ESP + FGD ........................... 3-34

Table 3-22. Summary of TxL Coal Analysis Results ...................................................... 3-35

Table 3-23. Summary of PRB Coal Analysis Results ........................................................ 3-36

Table 3-24. Fly Ash LOI Concentrations during Long-Term Sorbent Injection - All Fields ... 3-38

Table 3-25. Comparison of Average Opacity for Treated and Untreated ESPs ..................... 3-41

Table 3-26. Baseline Particulate Loading Measurements at ESP Inlet ................................. 3-43

Table 3-27. Baseline Particulate Loading Measurements at Treated Outlet Duct 1A1

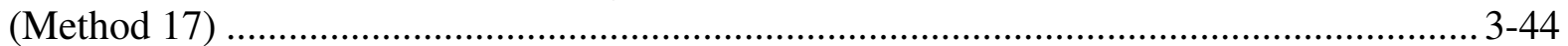

Table 3-28. Baseline Particulate Loading Measurements at Treated Outlet Duct 1A1

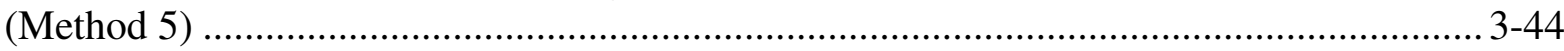

Table 3-29. Baseline Particulate Loading Measurements at Toxecon ${ }^{\mathrm{TM}}$ II Outlet Duct 1A1

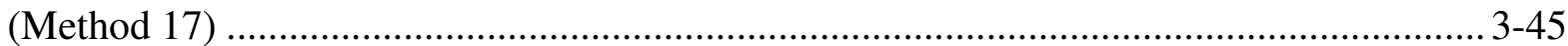

Table 3-30. Method 17 Results from Parametric Sorbent Injection Testing .......................... 3-47

Table 3-31. Method 17 Results from Long-Term Sorbent Injection Tests on Treated ESP

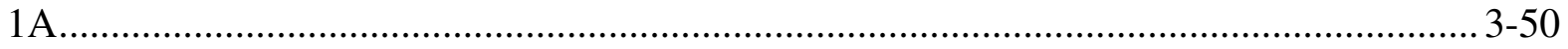

Table 3-32. Method 5 Results from Long-Term Sorbent Injection Tests on Treated ESP 1A.. 3-51

Table 3-33. Method 5 Results during Long-Term Test for Untreated ESP 1B ...................... 3-52

Table 3-34. Headwaters Concrete Testing Results for Simulated Carbon/Ash Mixtures ......... 3-56

Table 3-35. EERC Concrete Results for Simulated Carbon/Ash Mixtures .............................. 3-57

Table 3-36. Headwaters Concrete Results for Baseline and Day 3 (of Long-Term Test)

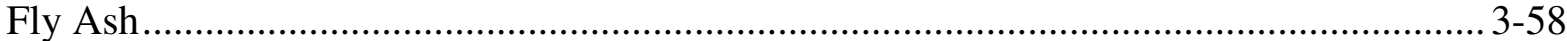

Table 3-37. LMS Foam Index* from All Fields of ESP 1A (Treated ESP) ........................... 3-60

Table 3-38. Carbon by LECO as Measured by Headwaters Laboratory ................................. 3-62

Table 3-39. 325 Mesh Results for Each First-Field Hopper of the Treated ESP.....................3-63

Table 3-40. Median Fly Ash Particle Size as Measured by the Horiba Analyzer .................... 3-64

Table 3-41. Headwaters Concrete Using Ash from Long-Term Injection ............................. 3-65

Table 3-42. Method 26A Results during Long-Term Testing ........................................... 3-66

Table 3-43. FGD Solids Analysis from Long-Term Test ................................................ 3-66

Table 3-44. FGD Liquid Analysis from Long-Term Test ................................................... 3-67

Table 3-45. Process Parameters for Hypothetical Plant in Economic Analysis ...................... 3-68

Table 3-46. Annual Cost Breakdown for Sorbent Injection Implemented Upstream of the

ESP, Based on 2007 Data ........................................................................................... 3-70

Table 4-1. Gross Load during Phase IV Sorbent Injection Tests .......................................... 4-2

Table 4-2. Flue Gas Temperatures during Phase IV Sorbent Injection Tests........................... 4-2

Table 4-3. Baseline, Phase IV: SCEM Measurements and Removals.................................... 4-4

Table 4-4. Baseline, Phase IV: OH vs. SCEM Measurements at the ESP Outlet ..................... 4-5 
Table 4-5. Baseline, Phase IV: Mercury Concentrations and Removals Measured at ESP

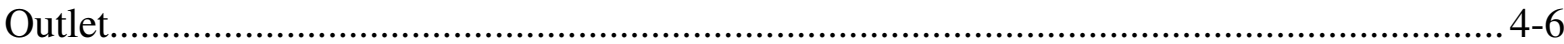

Table 4-6. Baseline, Phase IV: Mercury Concentrations and Removals Measured at Stack ...... 4-7

Table 4-7. ACI Upstream of AH: SCEM Measurements and Mercury Removals.................... 4-9

Table 4-8. ACI Upstream of the AH: Mercury Concentrations and Removals Measured at

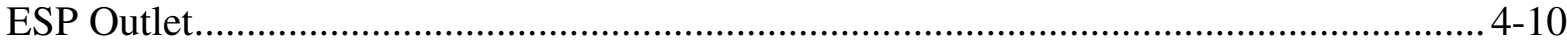

Table 4-9. ACI Upstream of AH: Mercury Concentrations and Removals Measured at

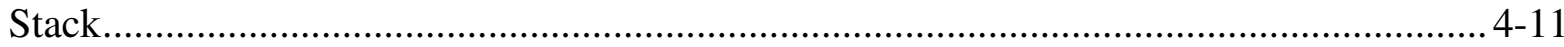

Table 4-10. OH vs. SCEM Results at ESP Outlet (Darco Hg-LH Injected Upstream of the $\mathrm{AH}$ at 1 lb/Macf) .............................................................................................. 4-15

Table 4-11. Alternate Fuel Blend, ACI Upstream of AH: Mercury Concentrations and Removals Measured at ESP Outlet .......................................................................... 4-17

Table 4-12. Alternate Fuel Blend, ACI Upstream of AH: Mercury Concentrations and Removals Measured at Stack ..................................................................................... 4-17

Table 4-13. Average Mercury Concentrations Measured during Parametric Sorbent Injection Upstream of ESP (Full Unit) - Phase IV ................................................................... 4-19

Table 4-14. ACI Upstream of the ESP: Mercury Concentrations and Removals Measured

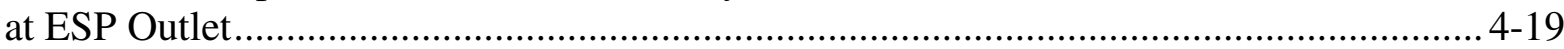

Table 4-15. ACI Upstream of the ESP: Mercury Concentrations and Removals Measured at

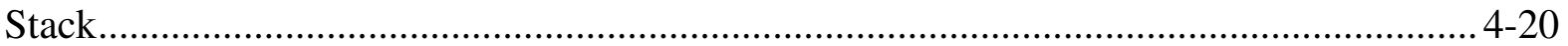

Table 4-16. Average Stack Mercury Concentrations during Coal Bromide Addition and Sorbent Injection Upstream of ESP - Phase IV ........................................................ 4-23

Table 4-17. Bromide Addition: Mercury Concentrations Measured at ESP Outlet ................ 4-24

Table 4-18. Bromide Addition: Mercury Concentrations Measured at Stack ........................ 4-25

Table 4-19. OH Results from Bromide Addition Tests ..................................................... 4-26

Table 4-20. Average Mercury Concentrations Measured during Traditional vs. Dispersion Lance Testing (Injection Upstream of $1 / 4$ of the Unit 2 ESP) ......................... 4-28

Table 4-21. Duct Location for Sorbent Trap Traverse Testing .......................................... 4-31

Table 4-22. Dispersion Lances: Sorbent Trap and SCEM Results at ESP Outlet ................... 4-32

Table 4-23. Silo Fly Ash Characterization Results........................................................... 4-34

Table 4-24. Hopper Fly Ash Sample Characterization Results (Hopper 2F2C)..................... 4-35

Table 4-25. Phase IV ACI Tests, Hopper Samples - Headwaters Concrete Results with Constant AEA Dosage .............................................................................................. 4-36

Table 4-26. Phase IV ACI Tests, Hopper Samples - Headwaters AEA Demand Test Concrete Results 4-37

Table 4-27. Carbon Content in First Field (2F2C) Fly Ash Samples (Theoretical vs.

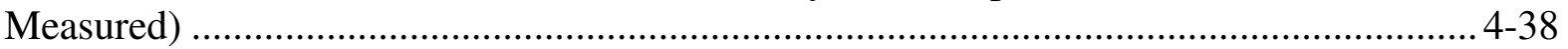

Table 4-28. Foam Index Results for Simulated Fly Ash ................................................... 4-39

Table 4-29. Summary of TxL Coal Analyses Results, Phase IV .......................................... 4-43

Table 4-30. Summary of PRB Coal Analyses Results, Phase IV ......................................... 4-44

Table 4-31. Hg Concentration in Ash Samples from Phase IV Parametric Tests ................... 4-46

Table 4-32. LOI of Ash Samples from Phase IV Parametric Tests ....................................... 4-47

Table 4-33. FGD Absorber Solids Analyses for Phase IV .................................................... 4-48

Table 4-34. FGD Absorber Liquor Analyses for Phase IV ................................................... 4-48

Table 4-35. Trace Elements Concentrations for TxL and PRB Samples for July 12-14, 2009.4-49

Table 4-36. Weighted Average Coal Trace Elements Concentrations for July 12-14, 2009..... 4-50 
Table 4-37. ESP Outlet Flue Gas Trace Metals Concentrations, Average of Three Runs for Each Test Condition ............................................................................................ 4-51

Table 4-38. Stack Flue Gas Trace Metals Concentrations, Average of Three Runs for Each Condition.

Table 4-39. Trace Metals Removal from Coal to ESP Outlet and Coal to Stack ..................... 4-52

Table 4-40. Fly Ash Trace Element Concentrations.............................................................. 4-53

Table 4-41. Percentage of Coal Trace Elements Removed in the Fly Ash........................... 4-54

Table 4-42. Trace Elements Leachate Concentrations for SPLP Tests ................................. 4-54

Table 4-43. Percentage of Trace Element Leached for SPLP Tests ...................................... 4-55

Table 4-44. Trace Elements Concentrations of FGD absorber Solids.................................. 4-56

Table 4-45. Trace Elements Concentrations of FGD Absorber Liquors. ............................... 4-57

Table 4-46. Particle Size and Light Transmission for Two Separate Bags of Standard Darco Hg-LH 4-64

Table 4-47. Impact of Injection Rate on Sorbent Particle Size and Light Transmission -

Standard Darco Hg-LH ............................................................................... 4-65

Table 4-48. Particle Size and SSA for Finely Ground and Standard Darco Hg-LH ............... 4-66

Table 4-49. Baseline Particulate Loading Measurements at Outlet (Method 17).................... 4-69

Table 4-50. Inlet Particulate Loading Measurements for Sorbent Injection Test at 1.0 lb/MMacf (Method 17)

Table 4-51. Process Parameters for Hypothetical Plant in Economic Analysis ....................... 4-72

Table 4-52. Annual Cost Breakdown for ACI Upstream of AH ......................................... 4-74

Table 4-53. Cost of ACI in \$/lb Hg Removed .............................................................. 4-75

Table 4-54. Estimated Range of Costs for Annual Additive Consumption............................. 4-78 


\section{List of Figures}

Figure 2-1. General Unit Configuration for the NRG LMS Plant .......................................2-2

Figure 2-2. LMS Unit 1 ESP Duct Configuration and Sampling Locations ............................. 2-3

Figure 2-3. LMS Unit 2 ESP Duct Configuration and Sampling Locations ............................ 2-4

Figure 2-4. Plan View Particle Trajectory Comparison - Traditional vs. Dispersion Lances..... 2-9

Figure 2-5. Side Elevation View Particle Trajectory Comparison - Traditional vs.

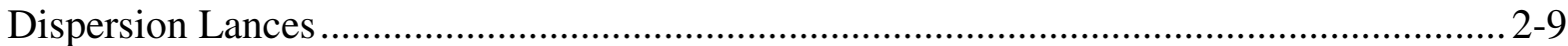

Figure 2-6. Toxecon ${ }^{\mathrm{TM}}$ II Lances Installed - View from ESP Roof ..................................... 2-12

Figure 2-7. Semi-Continuous Mercury Analyzer ............................................................ 2-14

Figure 2-8. Diagram of EPA Method 29 Impinger Train ................................................. 2-17

Figure 2-9. XFM Sampling Assembly ............................................................................ 2-18

Figure 2-10. ESP Inlet Port Locations for Method 17 Measurements..................................... 2-20

Figure 2-11. ESP Outlet Sampling Ports for Method 17 Measurements (Top-Down View) .... 2-20

Figure 2-12. ESP Outlet Sampling Grid for Method 17 Measurements (Side Elevation).........2-21

Figure 2-13. ESP 1A Hopper Configuration................................................................. 2-23

Figure 2-14. Unit 2 ESP Hopper Configuration ............................................................. 2-23

Figure 3-1. Boiler Load and Injection Rate during Long-Term Injection Tests....................... 3-3

Figure 3-2. ESP Inlet Temperature during Long-Term Injection Test .................................. 3-4

Figure 3-3. Baseline Mercury Measurements Prior to Phase I Parametric Tests ...................... 3-6

Figure 3-4. Baseline Mercury Measurements Prior to Phase II Parametric Tests ..................... 3-7

Figure 3-5. Baseline Mercury Measurements Prior to Phase III Parametric Tests..................... 3-8

Figure 3-6. Baseline Hourly-Averaged Mercury Measurements Prior to Long-Term Injection

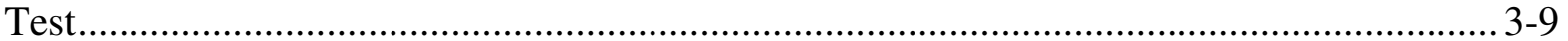

Figure 3-7. Mercury Removal across the LMS ESP (Injection Upstream of ESP)................ 3-17

Figure 3-8. Reduction in Mercury Concentration at the ESP Outlet (Injection Upstream

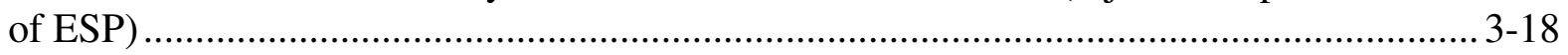

Figure 3-9. Effect of Injection Location on the Reduction of Mercury at the ESP Outlet ........ 3-20

Figure 3-10. Total and Elemental Mercury Concentrations Measured during Long-Term

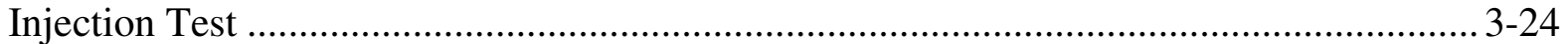

Figure 3-11. Hourly-Averaged Mercury Removal across ESP during Long-Term Injection ... 3-25

Figure 3-12. Mercury Removal Comparison bewteen Long-Term and Parametric Tests, as

Measured by SCEMs .......................................................................................... 3-25

Figure 3-13. Comparison of Daily-Averaged Mercury Removal and ESP Temperature.......... 3-26

Figure 3-14. Comparison of Mercury Removals Calculated from SCEM, Ash, and OH Data. 3-31

Figure 3-15. Percent Mercury Oxidation Measured at Each Sample Location during

Long-Term Test .......................................................................................... 3-34

Figure 3-16. First-Field Fly Ash Hg during Long-Term Sorbent Injection - Comparison of

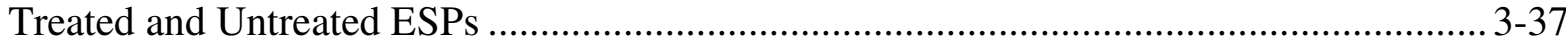

Figure 3-17. Ash Hg Concentration vs. Ash LOI for all Fields, Baseline and Long-Term

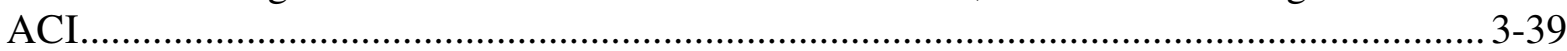

Figure 3-18. Pre-Test Baseline Opacity .......................................................................... 3-40

Figure 3-19. Opacity during Long-Term Test and Post-Test Baseline Operation....................3-41

Figure 3-20. ESP A Field 1 Spark Rates during Long-Term and Post-Test Baseline Periods . 3-42

Figure 3-21. ESP 1A and ESP 1B Spark Rates during Long-Term and Baseline Testing ........ 3-42 
Figure 3-22. ESP 1A and ESP 1D Spark Rates during Long-Term and Baseline Testing....... 3-43 Figure 3-23. Photograph Comparing Method 17 Filters Collected during Toxecon ${ }^{\mathrm{TM}}$ II and

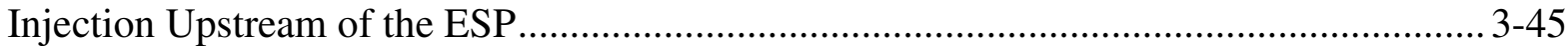

Figure 3-24. Method 17 Results for ESP 1A Outlet from Parametric I, II, and III Testing ...... 3-48

Figure 3-25. Method 17 Results for ESP 1A Outlet during Long-Term Injection Test ............3-48

Figure 3-26. Impact of Temperature on ESP 1A Particulate Emissions for All Test Phases

Involving Darco Hg-LH Injection ........................................................................... 3-49

Figure 3-27. Method 5 Results for ESPs 1A (Treated) and 1B (Untreated) during

Long-Term Injection Test ................................................................................... 3-53

Figure 3-28. Darkening of M5 Particulate Filters during Carbon Injection ........................... 3-53

Figure 3-29. URS Foam Index Results for Simulated Carbon/Ash Mixtures ......................... 3-55

Figure 3-30. Fly Ash Foam Index Results for Samples Collected during the Long-Term

Test......

Figure 3-31. First-Field Fly Ash LOI during the Long-Term Test (LMS Laboratory) ............. 3-61

Figure 3-32. Average Results for 325-Mesh Characterization of First-Field Ash during the

Long-Term Test

Figure 3-33. Total Annual Cost of ACI for Three Different Levels of Mercury Removal at

ESP Outlet While Maintaining Fly Ash Sales

Figure 3-34. Total Annual Cost of ACI for Three Different Levels of Mercury Removal at

ESP Outlet with the Loss of Fly Ash Sales

Figure 4-1. ACI Upstream of AH: Mercury Removal Percentages as Measured by SCEM and Sorbent Traps at the ESP Outlet and Stack

Figure 4-2. ACI Upstream of AH: Comparison of Mercury Removals across AH/ESP for

Darco Hg-LH, Based on Sorbent Trap and SCEM Data

Figure 4-3. ACI Upstream of AH: Mercury Removal across AH/ESP, Based on SCEM

Data

Figure 4-4. ACI Upstream of AH: Mercury Removal across System, Based on SCEM Data.. 4-16

Figure 4-5. ACI Upstream of ESP, Phase IV: Mercury Removal across AH/ESP

Figure 4-6. ACI Upstream of ESP, Phase IV: Mercury Removal across System

Figure 4-7. Mercury Removal across AH/ESP, Traditional Lances vs. Dispersion Lances

(Injection of Upstream of Unit 2C ESP).

Figure 4-8. Mercury Removal across AH/ESP for Calgon Sorbents Injected with the

Dispersion Lances (Injection of Upstream of Unit 2C ESP)

Figure 4-9. LOI versus Carbon Content for Phase IV Ash Samples .................................... 4-37

Figure 4-10. Theoretical vs. Measured Carbon Content for Phase IV Fly Ash Samples ......... 4-39

Figure 4-11. Foam Index Results versus Carbon Content for Phase IV Ash Samples ............. 4-40

Figure 4-12. Coal Mercury Concentrations Measured during Phase IV Parametric Tests....... 4-45

Figure 4-13. Comparison of Average XFM and M29 Metals Concentrations at the ESP

Outlet on $7 / 12 / 09\left(\mathrm{CaBr}_{2}+0.48 \mathrm{lb} / \mathrm{MMacf} \mathrm{ACI}\right)$

Figure 4-14. Comparison of Average XFM and M29 Stack Metals Concentrations on

$7 / 12 / 09\left(\mathrm{CaBr}_{2}+0.48 \mathrm{lb} / \mathrm{MMacf} \mathrm{ACI}\right)$

Figure 4-15. Comparison of Average XFM and M29 Metals Concentrations at the ESP

Outlet on 7/13/09 (Baseline Conditions) 4-60

Figure 4-16. Comparison of Average XFM and M29 Stack Metals Concentrations on

7/13/09 (Baseline Conditions) 4-60 
Figure 4-17. Comparison of Average XFM and M29 Metals Concentrations at the ESP

Outlet on 7/14/09 (1.9 lb/MMacf ACI) ........................................................................... 4-61

Figure 4-18. Comparison of Average XFM and M29 Stack Metals Concentrations on

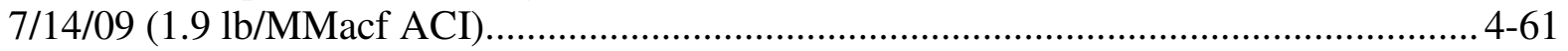

Figure 4-19. Method 29 ESP Outlet Data for Three Test Conditions .................................... 4-62

Figure 4-20. Method 29 Stack Data for Three Test Conditions ............................................. 4-62

Figure 4-21. Particle Size Frequency for Standard Darco Hg-LH Injected at $2 \mathrm{lb} / \mathrm{Macf}$.......... 4-64

Figure 4-22. Particle Size Frequency for Different Injection Rates of Standard Darco

$\mathrm{Hg}-\mathrm{LH}$

Figure 4-23. Particle Size Frequency as a Function of Injection Rate for Finely Ground

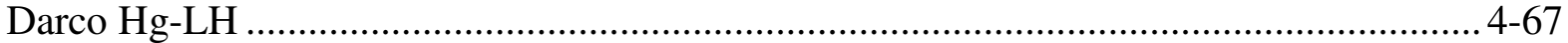

Figure 4-24. PSD Comparison of Standard and Finely-Ground Carbon ................................ 4-67

Figure 4-25. Baseline Particulate Loading Measurements at ESP Inlet by Port Number ........ 4-69

Figure 4-26. Comparison of Outlet Particulate Loading Measurements Made at the

Bottom and Top Portions of the Duct ....................................................................... 4-71

Figure 4-27. Total Annual Cost of ACI for Two Different Levels of Hg Removal at the

Stack

Figure 4-28. Impact of $\mathrm{SO}_{3}$ on $\mathrm{Hg}$ Capture in Ash........................................................... 4-79

Figure 4-29. Predicted Hg Removal across the AH/ESP \& FGD, Solids Dispersion Lance .... 4-80 


\section{LIST OF ACRONYMS}

Acfm

ACI

AEA

Ag

$\mathrm{AH}$

App K

As

ASTM

$\mathrm{Au}$

$\mathrm{Ba}$

BAC

$\mathrm{Be}$

$\mathrm{BH}$

BL

$\mathrm{Br}$

$\mathrm{Br}_{2}$

Btu

$\mathrm{CaBr}_{2}$

$\mathrm{Cd}$

CEM

CFD

$\mathrm{Cl}$

$\mathrm{Cl}_{2}$

$\mathrm{CO}$

$\mathrm{Co}$

$\mathrm{CO}_{2}$

$\mathrm{CO}_{3}$

$\mathrm{Cr}$

$\mathrm{Cu}$

CVAAS

DOE

$\mathrm{dP}$

$\mathrm{dNm}^{3}$

dscf

Dscm

Dv50

Dv90

EDTA

EPA

ESP

${ }^{\circ} \mathrm{C}$

${ }^{\circ} \mathrm{F}$

FGD

FOB
Actual cubic feet per minute (flue gas flow)

Activated carbon injection

Air entrainment admixture

Silver

Air heater

Appendix K (sorbent tube) sampling

Arsenic

American Society for Testing and Materials

Gold

Barium

Bromine (treated) activated carbon

Berillium

Baghouse

Baseline

Bromide

Bromine

British thermal unit

Calcium bromide

Cadmium

Continuous emission monitor

Computational fluid dynamic (modeling)

Chloride

Chlorine

Carbon monoxide

Cobalt

Carbon dioxide

Carbonate

Chromium

Copper

Cold vapor atomic absorption spectrometer

U.S. Department of Energy

Pressure drop

Dry normal cubic meters

Dry standard cubic feet (gas flow)

Dry standard cubic meters (gas flow)

Median particle size (for volumetric psd)

Particle size below which $90 \%$ of population lies

Ethylenediaminetetraacetic acid

U.S. Environmental Protection Agency

Electrostatic precipitator

Degrees Celsius

Degrees Fahrenheit

Flue gas desulfurization

Freight on board 


\begin{tabular}{|c|c|}
\hline gpm & Gallons per minute \\
\hline $\mathrm{H}_{2} \mathrm{O}$ & Water \\
\hline $\mathrm{HBr}$ & Hydrogen bromide \\
\hline $\mathrm{HCl}$ & Hydrochloric acid \\
\hline $\mathrm{Hg}$ & Mercury \\
\hline $\mathrm{Hg}^{0}$ & Elemental mercury \\
\hline $\mathrm{Hg}^{\mathrm{T}}$ & Total mercury \\
\hline $\mathrm{Hr}$ & Hour \\
\hline HX & Hydrogen halide \\
\hline IGS & Inertial gas separation (sampling filter) \\
\hline $\mathrm{KCl}$ & Potassium chloride \\
\hline $\mathrm{Kg}$ & Kilogram \\
\hline KW & Kilowatt \\
\hline Kwh & Kilowatt hour \\
\hline $\mathrm{Lb}$ & Pound \\
\hline Lb/MM Btu & Pounds per million Btu \\
\hline Lb/TBtu & Pounds per trillion Btu \\
\hline LMS & NRG Texas Limestone Station \\
\hline LOI & Loss on ignition \\
\hline Lpm & Liters per minute \\
\hline $\mathrm{M}$ & Molar (moles/liter) \\
\hline $\mathrm{m}^{2} / \mathrm{cc}$ & Square meters per cubic centimeter \\
\hline M5 & EPA Method 5 \\
\hline M17 & EPA Method 17 \\
\hline M26A & EPA Method 26A \\
\hline M29 & EPA Method 29 \\
\hline Macf & Million actual cubic feet (of flue gas) \\
\hline $\mathrm{Mg}$ & Magnesium \\
\hline $\mathrm{mg}$ & Milligrams \\
\hline MMBtu & Million Btu \\
\hline $\mathrm{Mn}$ & Manganese \\
\hline MW & Mega-Watt (boiler load) \\
\hline $\mathrm{Na}$ & Sodium \\
\hline $\mathrm{NC}$ & Not calculable (as pertaining to analytical data) \\
\hline ND & Non-detect \\
\hline NETL & U.S. DOE National Energy Technology Laboratory \\
\hline $\mathrm{Ni}$ & Nickel \\
\hline $\mathrm{Nm}^{3}$ & Normal cubic meters (gas flow) \\
\hline NOx & Nitrogen oxides \\
\hline NSPS & New source performance standard \\
\hline $\mathrm{O}_{2}$ & Oxygen \\
\hline $\mathrm{OH}$ & Ontario Hydro Method \\
\hline ORP & Oxidation-reduction potential \\
\hline $\mathrm{Oz}$ & Ounce \\
\hline $\mathrm{Pb}$ & Lead \\
\hline PC & Portland cement \\
\hline
\end{tabular}




$\begin{array}{ll}\text { PM } & \text { Particulate matter } \\ \text { ppb } & \text { Part per billion } \\ \text { ppm } & \text { Parts per million } \\ \text { PRB } & \text { Powder River Basin } \\ \text { PSD } & \text { Particle size distribution } \\ \text { psi } & \text { Pounds per square inch } \\ \text { psig } & \text { Pound-force per square inch gauge } \\ \text { PTFE } & \text { Polytetrafluoroethylene polymer } \\ \text { QA/QC } & \text { Quality assurance/quality control } \\ \mathrm{R}^{2} & \text { Coefficient of determination } \\ \text { RPD } & \text { Relative percent deviation } \\ \text { rpm } & \text { revolutions per minute } \\ \text { RSD } & \text { Relative standard deviation } \\ \mathrm{S} & \text { Sulfur } \\ \text { SAI } & \text { Strength activity index } \\ \text { Sb } & \text { Antimony } \\ \text { SCA } & \text { Specific collection area (for ESP) } \\ \text { SCEM } & \text { Semi-continuous (mercury) emission monitor } \\ \text { Scfm } & \text { Standard cubic feet per minute (gas flow) } \\ \text { SDA } & \text { Spray dryer absorber } \\ \text { Se } & \text { Selenium } \\ \text { Slpm } & \text { Standard liters per minute } \\ \text { SO } & \text { Sulfur dioxide } \\ \text { SO } & \text { Sulfite } \\ \text { SO } & \text { Sulfate } \\ \text { Spm } & \text { (ESP) Sparks per minute } \\ \text { SSA } & \text { Specific surface area } \\ \text { Tl } & \text { Thallium } \\ \text { Tris } & \text { Tris-hyroxymethylaminomethane } \\ \text { TxL } & \text { Texas lignite } \\ \mu \mathrm{g} & \text { Microgram } \\ \mu \mathrm{m} & \text { Micrometer } \\ \mathrm{U} 1 & \text { LMS Unit 1 } \\ \mathrm{U} 2 & \text { LMS Unit 2 } \\ \mathrm{UV} & \text { Ultra-violet } \\ \mathrm{V} & \text { Vanadium } \\ \text { FGD } & \text { Wet flue gas desulfurization } \\ \mathrm{WPS} & \text { Wet particulate scrubber } \\ \mathrm{Wt} \% & \text { Weight percent } \\ \mathrm{X}_{2} & \text { Diatomic halide } \\ \mathrm{XFM} & \text { X-ray Filter method } \\ \mathrm{XRF} & \text { X-ray fluorescence } \\ \mathrm{Zn} & \text { Zinc } \\ & \end{array}$




\section{EXECUTIVE SUMMARY}

A multi-phase test program was conducted as part of Cooperative Agreement DE-FC2606NT42779, "Mercury Control for Plants Firing Texas Lignite and Equipped with ESP-wet FGD," to evaluate the performance of different sorbent injection options for removing mercury from a power plant firing Texas lignite. The project was primarily funded by the U.S. DOE National Energy Technology Laboratory and co-funding was provided by EPRI, NRG Texas, Luminant (formerly TXU), and AEP. URS Group was the prime contractor, and Apogee Scientific and ADA-ES were subcontractors.

The host site for this program was NRG Texas' Limestone Electric Generating Station (LMS) Units 1 and 2, located in Jewett, Texas. The 900-MW units typically fire a 70/30 wt\% blend of Texas lignite/Powder River Basin coal, and are equipped with cold-side ESPs and limestone forced oxidation FGD systems. The units generate high quality, low LOI fly ash that is used for cement replacement in concrete production. Measurements made during the test program indicated less than 5\% native mercury removal by the fly ash. Baseline mercury concentrations at the ESP outlet averaged $20 \mu \mathrm{g} / \mathrm{dNm}^{3}$ and ranged from $15-25 \mu \mathrm{g} / \mathrm{dNm}^{3}$. Mercury oxidation at the ESP outlet averaged $50 \%$, but varied between $25-75 \%$. With $\sim 15 \%$ of the flue gas bypassing the FGD, the overall system mercury removal averaged $22 \%$, with FGD outlet concentrations ranging from $12-19 \mu \mathrm{g} / \mathrm{dNm}^{3}$. The data suggest there were intermittent mercury re-emissions from the FGD system.

The objective of this project was to achieve $50-70 \%$ system mercury removal with sorbent injection while maintaining fly ash integrity for use in concrete. Activated carbon (AC) sorbent particles present in fly ash can competitively adsorb air-entraining admixtures (AEAs) added to concrete for air entrainment and stabilization. This competition results in a larger volume of AEA being needed, and more significantly to ready-mix concrete manufacturers, it results in variability in the amount of AEA needed. The following technologies were tested to enhance system mercury removal while reducing AC contamination of the fly ash: use of alternate sorbents; changes to the injection system and configuration; and, co-application of calcium bromide to the coal. Mercury removal was primarily characterized with mercury semicontinuous emission monitors (SCEMs); sorbent traps, Ontario Hydro, and other measurements were also used and indicated a wide variability in mercury removal, but generally validated the SCEM observations.

Mercury removal objectives were met by most of the process configurations and conditions evaluated. At $0.5 \mathrm{lb} / \mathrm{Macf}$ Darco $\mathrm{Hg}-\mathrm{LH}$, an overall system removal of $50 \%$ was achieved with fly ash integrity preserved. With $1-2 \mathrm{lb} / \mathrm{Macf}$ Darco Hg-LH injection, system mercury removals (air heater inlet to stack, with 15\% flue gas bypass) of $60-70 \%$ were achieved but ash integrity may have been compromised. The combination of bromide addition to the coal and sorbent injection increased system mercury removals to $75-85 \%$. Increasing the fraction of PRB in the fuel blend to $45 \%$ while injecting sorbent at $1-2 \mathrm{lb} / \mathrm{Macf}$ also resulted in increasing system mercury removal to greater than $75 \%$. Additional removal would be expected by eliminating the FGD bypass and possibly by controlling FGD re-emissions. 
Brominated activated carbons and low-ash impact sorbents from Norit Americas, Calgon Carbon, Sorbent Technologies, and BASF were evaluated. Carbon-based sorbents were able to achieve system mercury removals within the targeted $50-70 \%$ range. For a given injection rate, all low-ash impact sorbents achieved lower mercury removal than their standard brominated counterparts; however, fly ash containing these low-ash-impact sorbents demonstrated better fly ash reuse properties and should be investigated further. Finely ground Darco $\mathrm{Hg}-\mathrm{LH}$ did not perform better than the respective unground material, due possibly to particle agglomeration within the sorbent transfer lines. A non-carbon sorbent from BASF did not achieve greater than $50 \%$ mercury removal, even at elevated injection rates.

ESP mercury removal during a two-month test, with Darco Hg-LH injected at $2 \mathrm{lb} / \mathrm{Macf}$, ranged from 30 to $97 \%$ and averaged $82 \%$. Mercury oxidation averaged $80 \%$ at the ESP outlet suggesting system removals should be higher when including the downstream wet FGD system. Because of the duct configuration and only $1 / 4$ of total flue gas was treated with $\mathrm{AC}$, it was not possible to measure FGD mercury removal during the long-term test. Fly ash quality during the test was diminished but was deemed just within acceptable specifications for use in concrete; however, it may be difficult to maintain ash consistency sufficient for the concrete market.

Several sorbent injection configurations were evaluated in this program. Although each was able to achieve established program removal objectives, none offered a clear advantage over the others. AC injection upstream of the air heater did not improve mercury removal as compared to injection upstream of the ESP. EPRI's Toxecon ${ }^{\mathrm{TM}}$ II process, as implemented, could not achieve $>60 \%$ mercury removal across the ESP. Staging injection such that a small amount of AC was injected upstream of the ESP housing the Toxecon ${ }^{\mathrm{TM}}$ II system, did not offer any improvement in mercury removal over other injection configurations. Alternate lance designs for both the duct injection and Toxecon ${ }^{\mathrm{TM}}$ II systems did not result in increased mercury removal.

The lowest stack mercury concentration achieved was $2.8 \mu \mathrm{g} / \mathrm{dNm}^{3}$ with $280 \mathrm{ppm} \mathrm{Br}$ to the dry coal and $1.6 \mathrm{lb} / \mathrm{Macf}$ finely ground Darco $\mathrm{Hg}-\mathrm{LH}$. The combination of bromide addition and sorbent injection achieved the lowest stack $\mathrm{Hg}$ concentration of all technologies tested at LMS Unit 2. However, the required sorbent injection rate of $1.6 \mathrm{lb} / \mathrm{Macf}$ finely ground Darco Hg-LH is high enough to potentially jeopardize the beneficial use of ash, and the required bromide injection rate could adversely impact the scrubber system. Without changes in scrubber blowdown rates, high bromide addition rates will cause the steady-state FGD Br level to increase, which may possibly lead to corrosion problems in alloy-based scrubbers.

Although test results showed that the program objectives could be achieved using a number of process configurations, sorbents, and $\mathrm{AC}$ addition rates, they also indicated that higher mercury removals at LMS would be challenging to achieve and maintain. None of the technologies tested on Unit 2 were demonstrated to achieve $90 \%$ system mercury removal. For both baseline and for all sorbents evaluated, mercury oxidation and removal performance was extremely variable over time, between units, and across the ducts tested, suggesting one of the many challenges for mercury removal in Texas lignite-derived flue gas. 


\subsection{INTRODUCTION}

A multi-phase sorbent injection test program was conducted under Cooperative Agreement DEFC26-06NT42779, "Mercury Control for Plants Firing Texas Lignite and Equipped with ESPwet FGD," during 2006-2007 and 2009. The objective of this project was to evaluate full-scale sorbent injection for mercury control at a power plant firing Texas lignite and equipped with a cold-side electrostatic precipitator (ESP) followed by a wet flue-gas desulfurization unit (wet FGD). The project was funded by the U.S. DOE National Energy Technology Laboratory under this Cooperative Agreement. EPRI, NRG Texas, Luminant (formerly TXU), and AEP were project co-funders. URS Group was the prime contractor, and Apogee Scientific and ADA-ES were subcontractors. This report presents a comprehensive summary of the results obtained during this test program.

NRG Texas provided co-funding and technical input to this project and provided Limestone Electric Generating Station (LMS) as a host site for testing. Limestone Station, located in Jewett, Texas, consists of two tangentially-fired units that are each approximately $900 \mathrm{MW}$ in size. Units 1 and 2 fire an approximate 70/30 by weight blend of Texas lignite (TxL) and Powder River Basin (PRB) coal and are equipped with cold-side ESPs and limestone FGD systems. Fly ash and gypsum produced at the LMS are marketed for reuse. Testing was performed on Unit 1 during 2006-2007 (Parametric Phases I, II, III, and Long-Term Testing) and on Unit 2 during 2009 (Parametric Phase IV).

Previous studies have shown that the mercury-removal effectiveness of sorbent injection processes is dependent upon the sorbent type, flue gas characteristics and the air pollution control devices installed. For example, untreated activated carbon has provided limited mercury removal (50-60\%) in chloride-deficient flue gases, while halogen-treated activated carbons have achieved more than $90 \%$ mercury reduction in these same gases. Because TxL coal has low but variable chloride content, and the corresponding flue gas mercury speciation is highly variable ( $25 \%$ to $75 \%$ elemental mercury in vapor phase), halogenated carbons may provide enhanced mercury removal over untreated carbons. In this program both standard and halogenated carbons were tested.

Fly ash produced at plants burning TxL coal may be suitable for sale to the concrete industry. However, carbon injected upstream of an ESP partitions to the fly ash and potentially compromises its integrity for use as a cement replacement in concrete. The carbon sorbent in the fly ash competitively adsorbs the air-entraining admixtures (AEAs) that are added to concrete for air entrainment and stabilization. This competition results in a larger volume of AEA being needed, and more significantly to ready-mix concrete manufacturers, it results in variability in the amount of AEA needed. It has been generally assumed that if standard ACI is employed, the resulting fly ash will not be suitable for cement/concrete applications. This poses a liability to the plant due to the loss of environmental benefits of re-use and the loss of the beneficial use of ash and extra disposal cost. Therefore, it is desired to design a sorbent injection process that preserves fly ash integrity. Three approaches are possible: (1) inject a "low ash impact" sorbent, (2) inject an activated carbon sorbent into the process after a majority of the ash has been collected using EPRI's Toxecon ${ }^{\mathrm{TM}}$ II process, or (3) inject a small amount of carbon upstream of the ESP such that the resulting carbon concentration in the ash does not affect beneficial re-use 
or can be "neutralized" with a chemical treatment. All three approaches were evaluated in this program.

During Phases I-III (2006-2007), full-scale sorbent injection tests were performed at NRG's LMS Unit 1 to evaluate mercury removal across the cold-side ESP. Three short-term parametric test phases were followed by a 60-day long-term test. Sorbent was injected to treat one quarter of the Unit 1 flue gas. In the first phase of parametric tests, several sorbents were injected upstream of the ESP. The sorbents were selected based on cost, availability, and previous test results. A standard activated carbon, bromine-treated carbons, and a low-ash impact sorbent were included in the test program. Based on the initial parametric results (Phase I) Norit America's DARCO Hg and DARCO Hg-LH were selected for additional testing in which the Toxecon ${ }^{\mathrm{TM}}$ II injection process and staged injection were evaluated (Phases II \& III).

The best combination of sorbent and injection location were then selected for a two-month evaluation of performance and variability. A mercury removal rate of 50-70\% was targeted for the long-term test. The continuous injection test provided insight to the long-term performance and variability of this process, as well as any effects on plant operations or ash byproduct composition.

Upon analysis of the Phase I-III project results, the project team identified several areas of interest for further study. These areas included: 1) demonstration of lower sorbent injection rates to achieve the targeted mercury removal rate, and 2) evaluating the effect of lower injection rates for improving the viability of the fly ash for sale as a cement replacement. Phase IV follow-on testing was conducted in 2009 with the entire unit treated with sorbent so that mercury removal across the FGD could be measured and so that other low-ash impact technologies could be evaluated. Three approaches to minimizing ash impacts were tested: (1) injection of "low ash impact" sorbents, (2) alterations to the injection configuration, and (3) addition of calcium bromide to the coal in conjunction with sorbent injection to the flue gas. These conditions were tested with the goal of identifying process conditions that result in the highest mercury removal while preserving the beneficial use of fly ash. It was also of interest to investigate how mercury removal changed when the fuel blend ratio was modified.

The remainder of this report is divided into four sections: Experimental Procedures; Results and Discussion - Phases I - III and Long-Term Tests (2006-2007); Results and Discussion - Phase IV (2009); Conclusions and Recommendations. 


\subsection{EXPERIMENTAL METHODS}

This section describes the technical approach and work plan for the LMS ACI evaluation program. The project was composed of four parametric phases and one 60-day, long-term test.

Phase I of the parametric test program involved evaluating the injection of several mercury sorbents, including a standard activated carbon, bromine-treated carbons, and an alternative sorbent designed for minimized impact on fly ash reuse. The sorbent injection rate was varied for each sorbent in an attempt to achieve 50-90\% mercury removal. For this test phase, the sorbent injection lances were installed upstream of the Unit 1 ESP.

Following the initial phase of parametric testing, additional tests were conducted during which two sorbents were selected, based on Phase I results, and evaluated using several process configurations. These Phase II and III tests were conducted over two two-week periods and evaluated sorbent injection using three process configurations: (1) upstream of the ESP, (2) in between ESP fields (Toxecon ${ }^{\mathrm{TM}} \mathrm{II}$ ), and (3) staged injection. The latter configuration involved co-injection of sorbent(s) both upstream of the ESP and via the Toxecon ${ }^{\mathrm{TM}}$ II system. This effort was conducted after a planned unit outage during which the Toxecon ${ }^{\mathrm{TM}}$ II system was installed.

After completion of the Phase II \& III parametric tests, a two-month long-term test was conducted. An optimal combination of sorbent (Norit DARCO Hg-LH) and injection location (upstream of the ESP) were chosen from the results of the parametric testing to use for the longterm test; the objective was to achieve 50-70\% mercury removal. An optimum injection rate (2 $\mathrm{lb} / \mathrm{Macf}$ ) was based on a combination of mercury removal performance and economic factors. Mercury removal and ash byproduct composition were monitored throughout the long-term test in order to evaluate process variability and to determine any effects of carbon injection on plant operations or performance.

Upon analysis of the results obtained during Phases I-III, the project team identified several areas of interest for further study as part of a no-cost extension for Phase IV parametric testing. Phase IV tests were conducted in the second and third quarters of 2009. Unlike the previous phases which were conducted on Unit 1, Phase IV tests were performed on Unit 2. These tests evaluated a wide range of ACI process conditions in an effort to investigate some of the areas of interest identified during the long-term test. Sorbent injection was carried out at two different locations including the air heater inlet of the entire unit and upstream of the ESP. In addition, tests evaluated two types of injection lances, several sorbents at a variety of injection rates, and calcium bromide addition in combination with ACI. Additional funding was provided by EPRI to perform trace metals and in-situ carbon particle size distribution measurements during the Phase IV program. Calgon Carbon Corporation provided funding to screen the performance of additional proprietary sorbents at the conclusion of the DOE-funded program; results from these tests are presented in this report.

\subsection{Host Site Description}

NRG's Limestone Electric Generating Station (LMS) Units 1 and 2 served as the host site for this test program. Both units typically fire a blend by weight of 70\% Texas lignite and 30\% PRB and are rated at approximately $900 \mathrm{MW}$. Each unit is equipped with two air heaters, four ESPs, 
and five scrubber modules. Figure 2-1 shows the basic LMS unit configuration and Table 2-1 summarizes the basic design parameters for Units 1 and 2. Figure 2-2 shows the Unit 1 ESP ductwork along with the injection and sampling locations. Testing for the first three phases of parametric testing and the 60-day continuous test was conducted across the Unit 1A ESP.

Testing for the fourth phase of parametric testing was conducted across the entireity of Unit 2, with limited testing across the Unit 2C ESP. Figure 2-3 shows the Unit 2 ESP ductwork along with the injection and sampling locations.

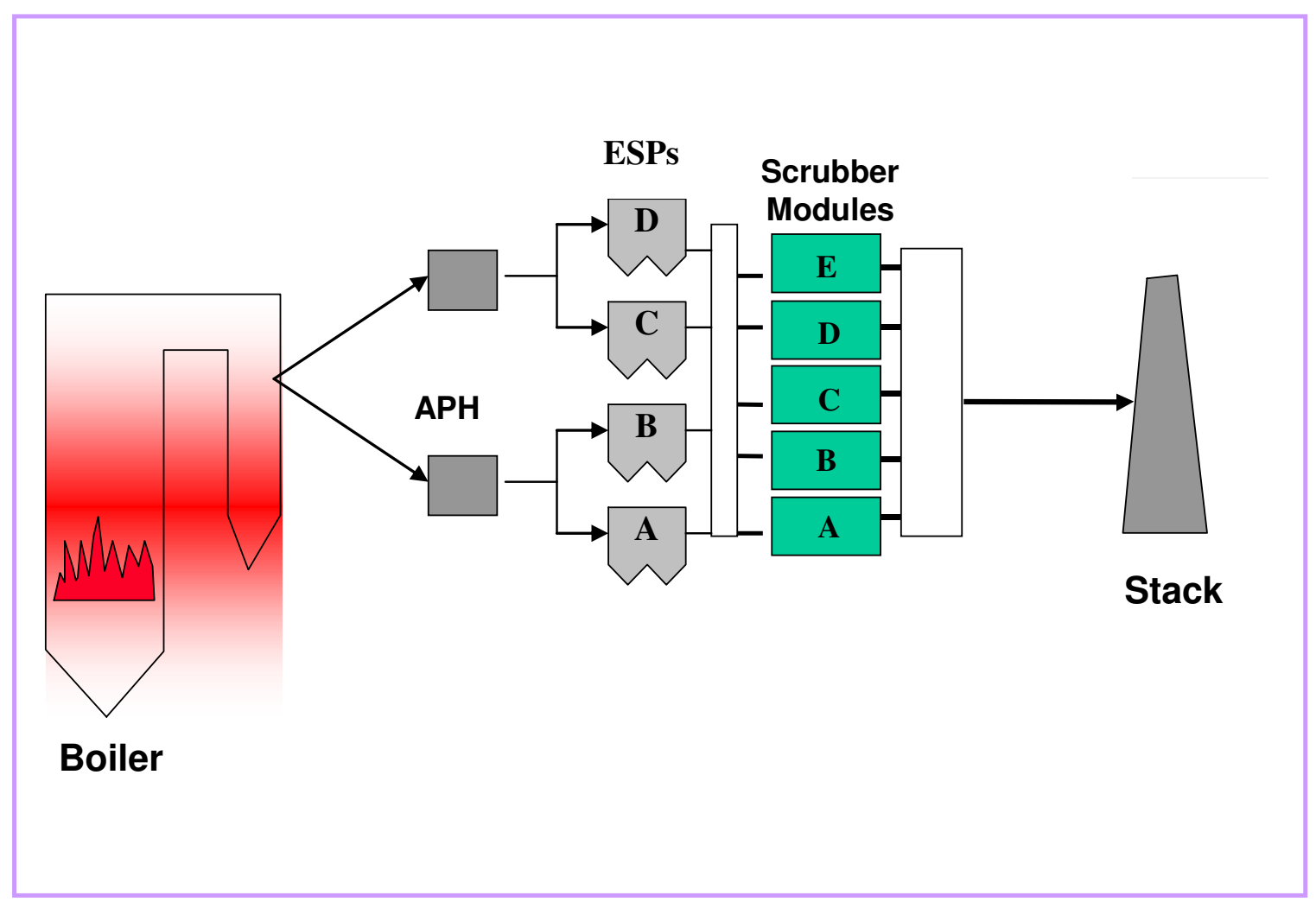

Figure 2-1. General Unit Configuration for the NRG LMS Plant 


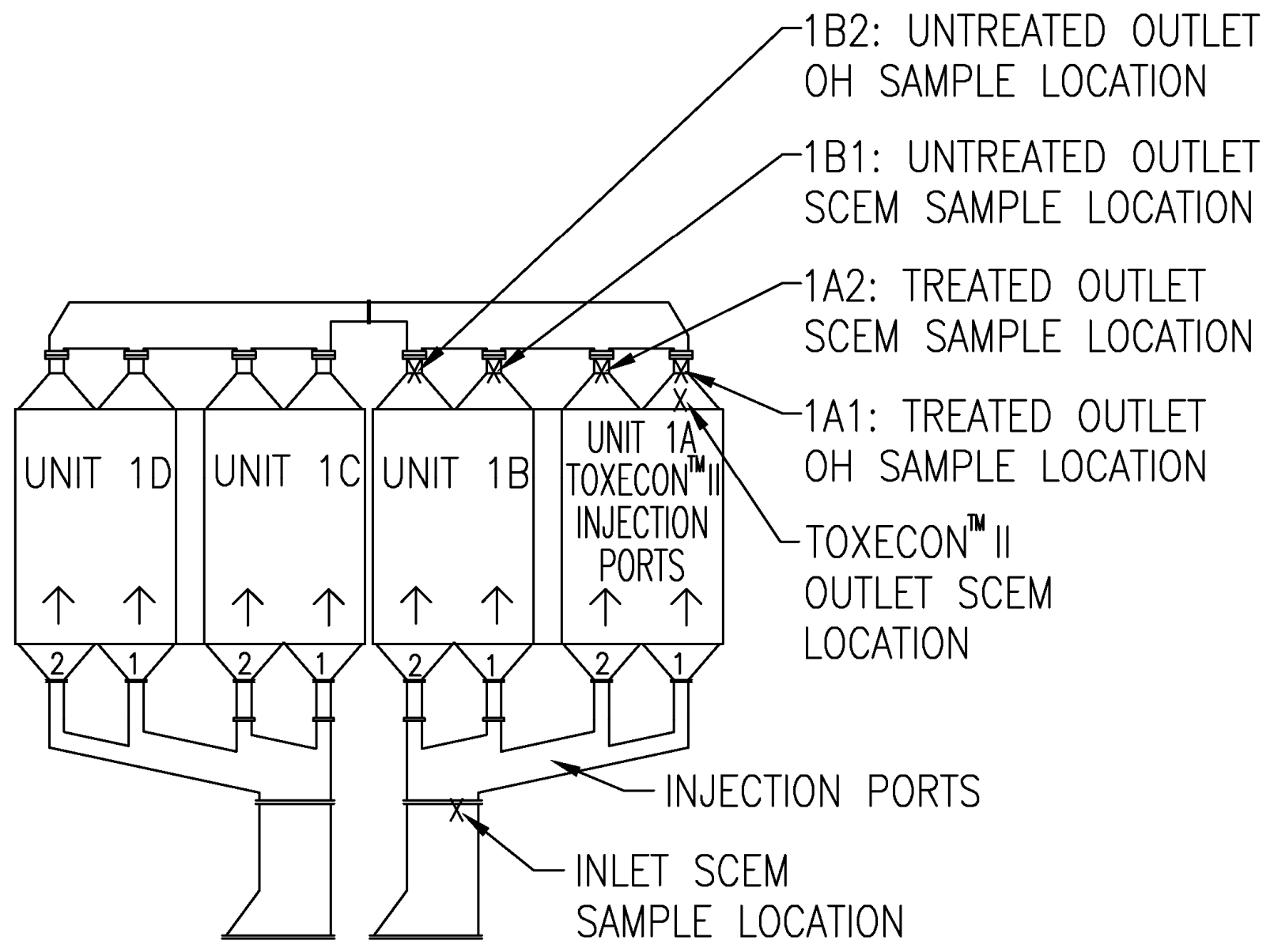

Figure 2-2. LMS Unit 1 ESP Duct Configuration and Sampling Locations 


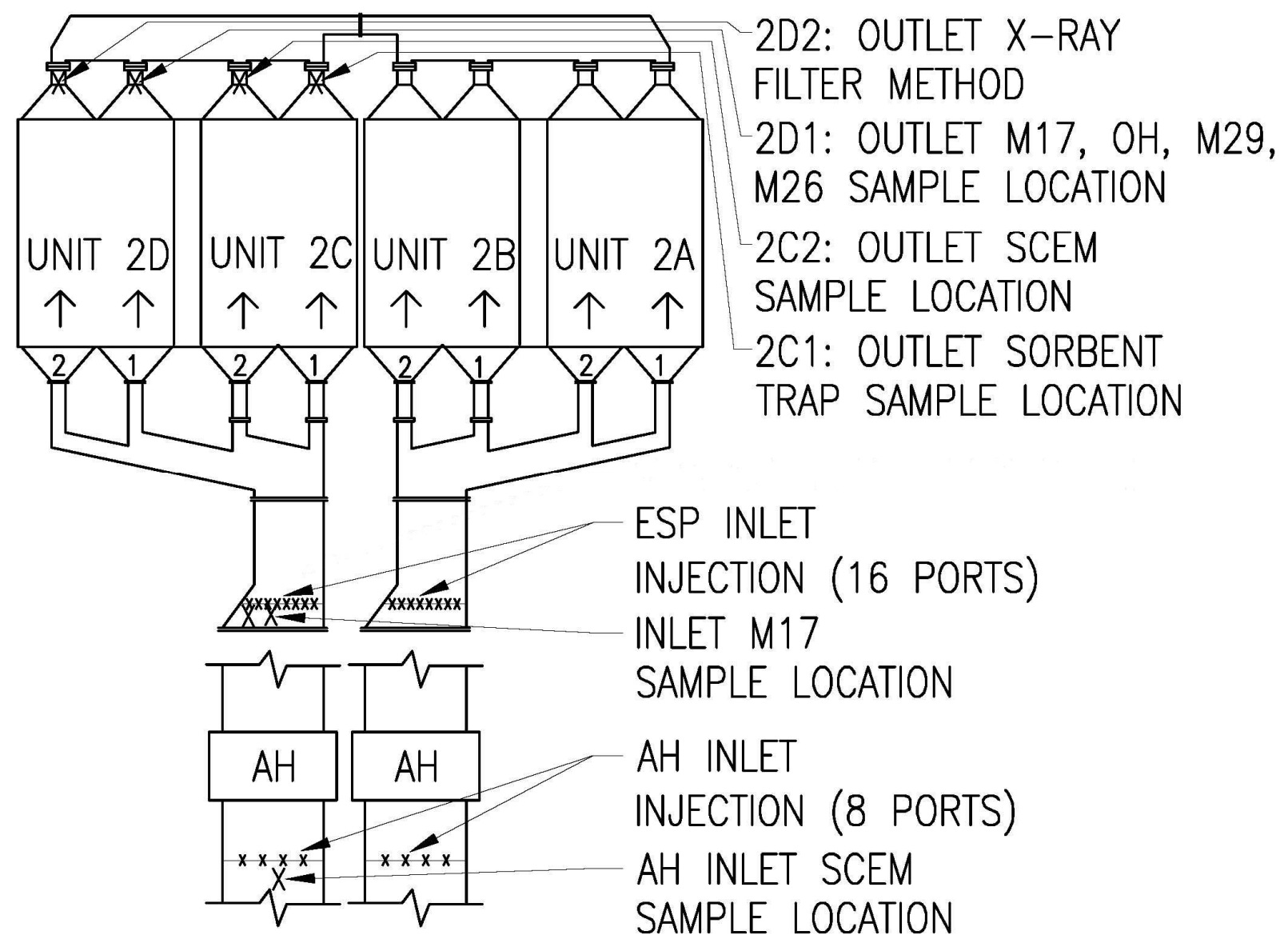

Figure 2-3. LMS Unit 2 ESP Duct Configuration and Sampling Locations 
Table 2-1. Limestone Electric Generating Station Unit 1 and Unit 2 Design Parameters

\begin{tabular}{|c|c|c|}
\hline & \multicolumn{2}{|c|}{ Limestone Electric Generating Station Unit 1} \\
\hline \multicolumn{3}{|l|}{ Boiler } \\
\hline Type & \multicolumn{2}{|c|}{ Tangentially-fired, pulverized coal furnace } \\
\hline Nameplate (MW) & \multicolumn{2}{|c|}{$890(\mathrm{U} 1) / 913$ (U2) } \\
\hline \multicolumn{3}{|l|}{ Coal } \\
\hline Type & Texas Lignite & PRB \\
\hline Weight Fraction in Coal Feed & 0.7 & 0.3 \\
\hline Ash (wt $\%$, dry) & $15-25 \%$ & $7-11 \%$ \\
\hline Sulfur (wt\%, dry) & $0.8-1.2 \%$ & $0.5-0.7 \%$ \\
\hline Mercury (mg/kg, dry) & $0.15-0.25 \mathrm{ppm}$ & $0.08-0.13 \mathrm{ppm}$ \\
\hline Chloride (mg/kg, dry) & $35-70 \mathrm{ppm}$ & $20-40 \mathrm{ppm}$ \\
\hline \multicolumn{3}{|l|}{ ESP } \\
\hline Type & \multicolumn{2}{|c|}{ Cold-side } \\
\hline ESP Manufacturer & \multicolumn{2}{|c|}{ Lodge-Cottrell } \\
\hline ESP Conditioning & \multicolumn{2}{|c|}{ None } \\
\hline $\begin{array}{l}\text { Specific Collection Area } \\
\left(\mathrm{ft}^{2} / 1000 \mathrm{acfm}\right)\end{array}$ & \multicolumn{2}{|c|}{452} \\
\hline Plate Spacing (in) & \multicolumn{2}{|c|}{11} \\
\hline Plate Height $(\mathrm{ft})$ & \multicolumn{2}{|c|}{ 44'-6"' } \\
\hline Electrical Fields & \multicolumn{2}{|c|}{7} \\
\hline ESP Inlet Temperature $\left({ }^{\circ} \mathrm{F}\right)$ & \multicolumn{2}{|c|}{$290-330$} \\
\hline $\mathrm{NO}_{\mathrm{X}}$ Controls & \multicolumn{2}{|c|}{ Low-NO ${ }_{\mathrm{X}}$ Burners } \\
\hline $\mathrm{SO}_{2}$ Controls & \multicolumn{2}{|c|}{$\begin{array}{l}\text { Wet FGD; limestone forced oxidation (as of Jan. 2009); } \\
\text { inhibited oxidation with elemental sulfur emulsion (prion } \\
\text { to Jan. 2009) }\end{array}$} \\
\hline
\end{tabular}

\subsection{Mercury Sorbent Selection}

Several types of mercury sorbents were tested on Unit 1 during the first three phases of testing, including a standard activated carbon, brominated carbons, and low ash-impact sorbents. Table 2-2 lists the sorbents selected for screening tests conducted with the injection lances configured upstream of the ESP. Evaluated sorbents included Norit America's DARCO Hg as the standard activated carbon and four brominated activated carbons: Norit America's DARCO Hg-LH, Sorbent Technology's B-PAC and C-PAC, and Calgon Carbon's Flue PAC MC Plus. The selected sorbents had been previously demonstrated in several full-scale carbon injection tests.

Norit Americas was chosen as a sorbent vendor because of its proximity (158 miles) to the LMS plant. The large volumes of carbon that will be needed for this plant will likely make transportation costs a contributing factor when selecting a sorbent vendor, should LMS decide to employ sorbent injection as its mercury control technology. Sorbent Technology's B-PAC and Calgon Carbon's Flue PAC MC Plus were chosen for testing as competitive sorbents; however, these sorbents would need either a lower cost or higher reactivity to be more cost effective than Norit Americas' sorbents for this plant.

Several vendors were approached for a low ash impact sorbent, including BASF and Amended Silicates. The MS200 sorbent from BASF and C-PAC carbon from Sorbent Technologies were 
evaluated as low ash impact sorbents. Amended Silicates was not able to produce sufficient quantities of its sorbent for the test program.

During Phase IV, three of the sorbents tested during 2006-2007 and several additional types of sorbents were tested on Unit 2. The three sorbents selected from the first three phases of testing were Norit America's DARCO Hg and DARCO Hg-LH carbons and Sorbent Technology's CPAC carbon. The additional carbons tested during Phase IV are listed in Table 2-3 and included Norit America's Finely Ground Darco Hg-LH and Darco Hg-LH EXP224 sorbents, Calgon Carbon's Flue PAC CF Plus and CF Plus Ultra sorbents, as well as several other proprietary sorbents from Calgon Carbon.

Table 2-2. Sorbents Selected for Evaluation at LMS Unit 1

\begin{tabular}{|c|c|c|c|c|}
\hline Sorbent Name & Manufacturer & $\begin{array}{c}\text { Manufacturing } \\
\text { Location }\end{array}$ & Sorbent Description & $\begin{array}{c}d_{50} \\
(\mu \mathrm{m})\end{array}$ \\
\hline DARCO Hg & Norit Americas & Marshall, TX & $\begin{array}{l}\text { Texas lignite derived } \\
\text { activated carbon }\end{array}$ & 19 \\
\hline DARCO Hg-LH & Norit Americas & Marshall, TX & $\begin{array}{l}\text { Texas lignite derived } \\
\text { activated carbon, } \\
\text { brominated }\end{array}$ & 19 \\
\hline B-PAC & $\begin{array}{c}\text { Sorbent } \\
\text { Technologies }\end{array}$ & Twinsburg, $\mathrm{OH}$ & $\begin{array}{l}\text { Activated carbon, } \\
\text { brominated }\end{array}$ & 20 \\
\hline C-PAC & $\begin{array}{c}\text { Sorbent } \\
\text { Technologies }\end{array}$ & Twinsburg, $\mathrm{OH}$ & $\begin{array}{l}\text { Activated carbon treated } \\
\text { with bromine and } \\
\text { passivated to be low-ash } \\
\text { impact }\end{array}$ & 20 \\
\hline Flue PAC MC Plus & Calgon Carbon & Pittsburgh, PA & $\begin{array}{l}\text { Activated carbon, } \\
\text { treated with bromine }\end{array}$ & unknown \\
\hline MS200 & BASF & $\begin{array}{c}\text { Gordon, GA and } \\
\text { Attapulgus, GA }\end{array}$ & $\begin{array}{l}\text { Enhanced molecular } \\
\text { sieve material }\end{array}$ & $15-20$ \\
\hline
\end{tabular}


Table 2-3. Sorbents Selected for Evaluation at LMS Unit 2

\begin{tabular}{|c|c|c|c|c|}
\hline Sorbent Name & Manufacturer & $\begin{array}{c}\text { Manufacturing } \\
\text { Location }\end{array}$ & Sorbent Description & $\begin{array}{c}d_{50} \\
(\mu \mathrm{m})\end{array}$ \\
\hline DARCO Hg & Norit Americas & Marshall, TX & $\begin{array}{l}\text { Texas lignite derived } \\
\text { activated carbon }\end{array}$ & 19 \\
\hline DARCO Hg-LH & Norit Americas & Marshall, TX & $\begin{array}{l}\text { Texas lignite derived } \\
\text { activated carbon, } \\
\text { brominated }\end{array}$ & 19 \\
\hline $\begin{array}{l}\text { Darco Hg-LH } \\
\text { EXP } 224\end{array}$ & Norit Americas & Marshall, TX & $\begin{array}{l}\text { Texas lignite derived } \\
\text { activated carbon, } \\
\text { brominated and } \\
\text { designed to be low-ash } \\
\text { impact }\end{array}$ & \\
\hline $\begin{array}{l}\text { Darco Hg-LH } \\
\text { Finely Ground }\end{array}$ & Norit Americas & Marshall, TX & $\begin{array}{l}\text { Darco } \mathrm{Hg} \text {-LH that } \\
\text { underwent second } \\
\text { milling to finer particle } \\
\text { size }\end{array}$ & 6 \\
\hline C-PAC & $\begin{array}{c}\text { Albemarle } \\
\text { (formlerly } \\
\text { Sorbent } \\
\text { Technologies) } \\
\end{array}$ & Twinsburg, $\mathrm{OH}$ & $\begin{array}{l}\text { Activated carbon, } \\
\text {,brominated and } \\
\text { designed to be low-ash } \\
\text { impact }\end{array}$ & 20 \\
\hline Flue PAC CF Plus & Calgon Carbon & Pittsburgh, PA & $\begin{array}{l}\text { Activated carbon treated } \\
\text { with bromine }\end{array}$ & 16 \\
\hline $\begin{array}{c}\text { Flue PAC CF Plus } \\
\text { Ultra }\end{array}$ & Calgon Carbon & Pittsburgh, PA & $\begin{array}{l}\text { Activated carbon treated } \\
\text { with bromine and } \\
\text { designed to be low-ash } \\
\text { impact }\end{array}$ & 16 \\
\hline A & Calgon Carbon & Pittsburgh, PA & $\begin{array}{l}\text { Activated carbon } \\
\text { designed for sulfur } \\
\text { tolerance }\end{array}$ & \\
\hline $\begin{array}{c}\text { A2, CANG-2, } \\
\text { CNAHF-1, CN6, } \\
\text { CN30, THB }\end{array}$ & Calgon Carbon & Pittsburgh, PA & $\begin{array}{l}\text { Activated carbons of } \\
\text { various sizes and } \\
\text { chemical treatments }\end{array}$ & various \\
\hline
\end{tabular}

\subsection{Design and Installation of the Sorbent Injection System}

The sorbent injection system was designed and installed upstream of the ESP by Apogee Scientific. Apogee also designed, installed, and operated the sorbent feeding system. The Toxecon $^{\mathrm{TM}}$ II injection grid was designed by ADA-ES. ADA-ES provided oversight of the onsite installation. URS Group contracted the required subcontractors to assist with this installation.

\section{Sorbent Feeding System}

For the short-term parametric tests, a portable sorbent injection system was installed to service both the Unit 1 and Unit 2 inlet and Unit 1 mid-ESP injection points. This portable dry injection system pneumatically conveyed a predetermined and adjustable amount of powdered activated carbon (PAC) from 900-lb bulk bags into the flue gas stream via flexible hoses that led to a distribution manifold feeding multiple sorbent injection lances. PAC was metered using a volumetric feeder into a pneumatic eductor, where the air supplied from the regenerative blower provided the motive force needed to transport the carbon to the final injection locations. The 
system could deliver between $15-2000 \mathrm{lb} / \mathrm{hr}$ of activated carbon. For the long-term tests, sorbent was delivered in bulk pneumatic trucks and loaded into a bulk-storage truck, which was equipped with a bin vent bag filter. The same screwfeeder/blower system from the parametric tests was used in the long-term tests.

\section{Injection Lances - Upstream of the ESP (Unit 1 Tests in 2006-2007)}

For sorbent injection upstream of the ESP, injection lances were inserted vertically into eight of the ten existing four-inch ports on the ESP 1A inlet duct. The two centermost ports were not used because of an internal obstruction to flue gas flow. The duct was 20-feet wide by 11.75 -feet deep at the injection location. A flexible pneumatic conveying hose carried the sorbent from the injection system on the ground level, which was approximately 80 feet below the duct. A steel pipe manifold divided the flow via smaller diameter flex lines to each of the eight lances. Each leg of the manifold was designed to have approximately the same pressure drop; however, there was no mechanism by which to monitor or control air/carbon flow distribution between lances. The lances were fabricated from steel pipe and consisted of paired holes or nozzle openings at 1foot intervals along the length to provide for uniform distribution of the sorbent across the duct.

\section{Injection Lances - Upstream of the Air Heater, ESP (Unit 2 Tests in 2009)}

For sorbent injection upstream of the air heater, the lances were inserted into the eight existing sample ports on the AH inlet ducts. After operating for two weeks at this injection location, the injection system was moved to downstream of the $\mathrm{AH}$, and a total of sixteen lances were installed in the ducts upstream of the four Unit 2 ESPs. During sorbent injection across $1 / 4$ of the unit, the lances were left in the same location but only the four lances upstream of the Unit $2 \mathrm{C}$ ESP continued to inject sorbent. A flexible pneumatic conveying hose carried the sorbent from the injection system located at ground level, which was approximately 80 feet below the flue gas duct. A steel pipe manifold divided the sorbent-containing stream via smaller diameter flex lines to each of the injection lances. Each leg of the manifold was designed to have approximately the same pressure drop; however, there was no mechanism by which to monitor or control air/carbon flow distribution between lances.

For most of this test program, a "traditional" simple pipe lance design was used to deliver powdered activated carbon to the flue gas duct. The traditional lance design consisted of paired holes at 1-foot intervals along the length of the lance. The traditional lance was used for all tests performed in 2006-2007 (with exception of Toxecon II), for injection upstream of the AH in 2009, and for selected injection tests upstream of the ESP in 2009.

To improve sorbent dispersion and utilization, URS has developed a proprietary design for carbon injection lances. In the 2009 test program, alternate lances employing this design replaced four of the traditional lances upstream of the Unit 2C ESP for selected injection tests. The dispersion lances were designed to increase gas turbulence and recirculation downstream of the lance and to distribute carbon particles more evenly along the length of the lance. Figures 2-4 and 2-5 provide modeled carbon particle trajectories for both lance types. These figures illustrate the improved distribution of carbon particles through the duct that is expected to be achieved with the distribution lances. This test program represents the first time this lance design has been tested in a flue gas application. 


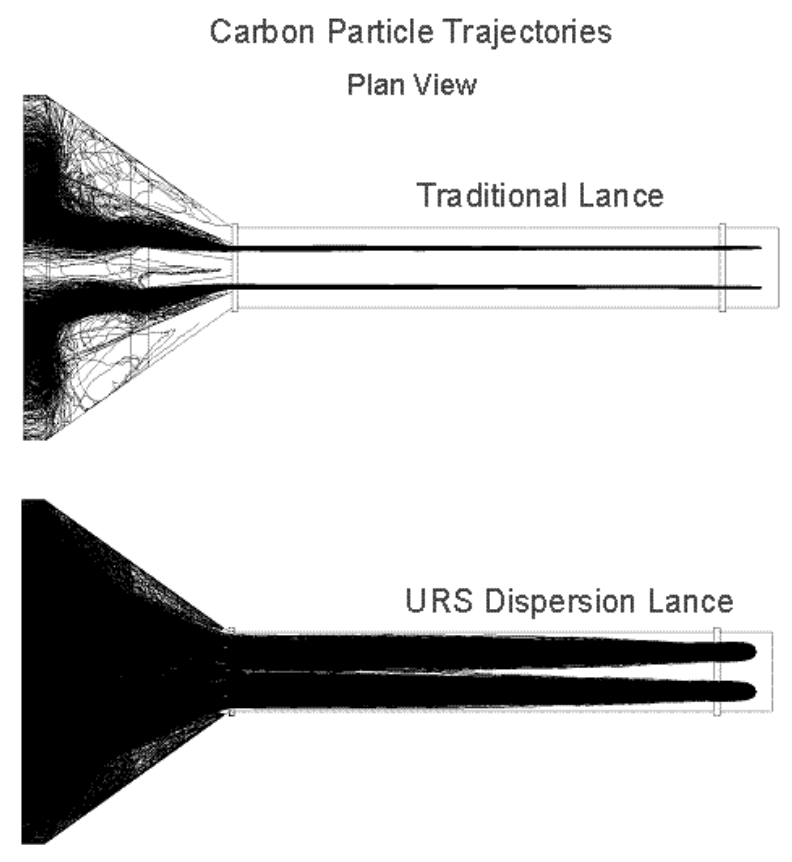

Figure 2-4. Plan View Particle Trajectory Comparison - Traditional vs. Dispersion Lances

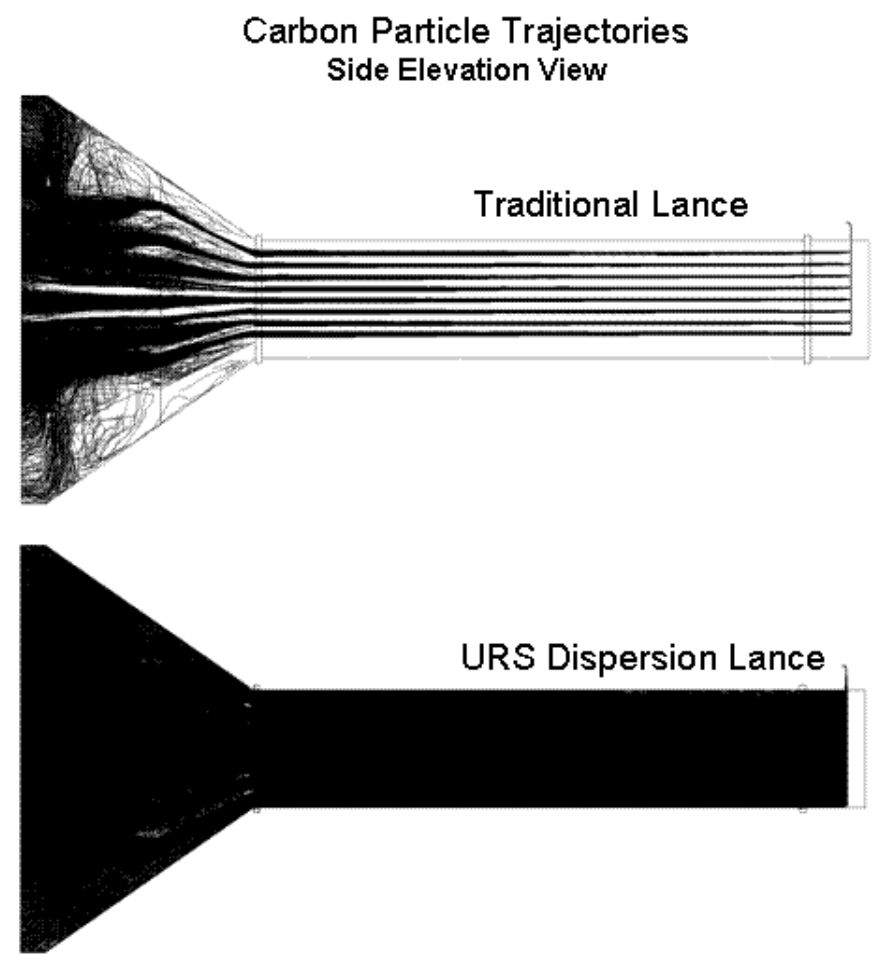

Figure 2-5. Side Elevation View Particle Trajectory Comparison Traditional vs. Dispersion Lances 
$\underline{\text { Toxecon }^{\mathrm{TM}} \text { II Injection System }}$

EPRI's Toxecon ${ }^{\mathrm{TM}} \mathrm{II}$ involves the injection of dry sorbent between the middle fields of an ESP, thus allowing for the untreated ash in the front fields to be segregated from the treated sorbent/ash mixture (pending a re-design of the ash handling system). Toxecon ${ }^{\mathrm{TM}}$ II therefore maintains the integrity of the bulk ( $>90 \%)$ of the fly ash, which is an advantage to plants such as LMS that market their fly ash as a beneficial cement replacement in concrete.

Prior to this test program, the Toxecon ${ }^{\mathrm{TM}}$ II system had been tested in short-term tests at Great River Energy's Coal Creek Station and at Entergy's 842 MW Independence Steam Electric Station (ISES) Unit 2. The Coal Creek tests were a quick proof-of-concept demonstration funded by EPRI. The ISES tests were used to develop the technology to improve sorbent utilization and mercury removal. The ISES tests have been conducted since 2005 as short-term tests lasting several hours to several weeks. Independence fires Powder River Basin (PRB) coal and is configured with a cold-side ESP for particulate control (SCA $542 \mathrm{ft}^{2} / 1,000 \mathrm{acfm}$ ). Funding for ISES Toxecon ${ }^{\mathrm{TM}}$ II testing was provided by DOE-NETL through contract DE-FC26-05NT42307, Entergy, EPRI, and ADA-ES. The primary contractor for Toxecon ${ }^{\mathrm{TM}}$ II testing at Independence was ADA-ES, which also provided the engineering for the Toxecon ${ }^{\mathrm{TM}} \mathrm{II}$ system at LMS. The lessons learned from the ISES test program were applied to the Toxecon ${ }^{\mathrm{TM}}$ II lance design used for LMS and are now summarized.

Ensuring proper sorbent distribution is critical for effective mercury control. Good sorbent distribution is more challenging with Toxecon ${ }^{\mathrm{TM}} \mathrm{II}$ than injection upstream of the ESP for three primary reasons:

- The flue gas velocity within the ESP is typically 3 to $4 \mathrm{ft} / \mathrm{sec}$ compared to 40 to 50 $\mathrm{ft} / \mathrm{sec}$ upstream of the ESP. The velocity is reduced by increasing the cross sectional area in the direction of flow within the ESP. The increased cross sectional area requires a much larger sorbent injection grid and poses a greater challenge for proper sorbent distribution.

- The penetration of the sorbent from the lance into the gas is affected by the velocity in the ESP. Consequently, varying boiler load can significantly impact the sorbent distribution.

- The distance between the injection lances and the downstream collection field is limited to nominally $3 \mathrm{ft}$.

ADA-ES evaluated three lance designs at ISES. Each modified lance design was based on field testing experience with the lances and from extensive modeling efforts by ADA-ES (physical modeling of lance designs), NELS Consulting Services (physical modeling of ESP and injection grid), and Reaction Engineering International (computational fluid dynamics modeling).

From these combined modeling efforts, ADA-ES developed a beta tool to evaluate the potential of the grid design to capture vapor phase mercury. This tool is an evaluation of the potential sorbent coverage of the flue gas stream as it enters the downstream collector plates. It can also include a variable to estimate the impact of residence time on performance. Due to the limited test data available, this tool was in preliminary development status at the time of lance design. 
The first phase of testing at ISES was performed with a series of single multi-nozzle lances that spanned the entire height of the ESP (Design \#1). Mercury removal was limited to $80 \%$ at injection rates as high as $10 \mathrm{lb} / \mathrm{Macf}$. Higher mercury removal had been achieved when injecting upstream of the ESP. CFD modeling by Reaction Engineering and physical modeling by ADAES indicated that the original single lance design resulted in a significant fraction of the sorbent exiting each lance through the nozzle furthest from the blower ( $>50 \%$ according to the CFD model, $>35 \%$ according to the physical model). The CFD model also indicated that roughly twice as much sorbent was exiting the nozzles furthest from the manifold as compared to the other three lances in the grid.

A second lance design (Design \#2) was developed wherein each single 40-foot lance was replaced by three lance sections each feeding 1/3 of the cross section (upper, middle, and lower) to minimize the top-to-bottom bias of the original lance design. Each lance section was configured with 8 nozzles at orientations determined through modeling to optimize distribution when compared to adjacent lances. The nozzles were placed at 4 elevations along the length of each lance section. In addition, rather than feeding an entire grid section through a single penthouse penetration, multiple penetrations were installed to allow more uniform side-to-side sorbent distribution. The penetrations were designed with guides spanning the height of the ESP to allow installation and removal of the lances while the ESP was in service.

The second lance design was tested at ISES in February/March 2007. The mercury removal achieved by Design \#2 increased to $89 \%$ and this removal was sustained at high and low operating loads. However, lance sections became plugged with carbon after a few days of operation. A third lance design was tested at ISES in May 2007 that was designed to provide better maintenance properties than Design \#2. The mercury removal achieved by Design \#3 was significantly affected by unit load, with only $78 \%$ mercury removal at high load and $92 \%$ mercury removal at low load. While the mercury removal performance of the lances decreased, Design \#3 did correct some of the operating and maintenance concerns associated with Design \#2.

The LMS Toxecon ${ }^{\mathrm{TM}}$ II lance design was completed in February 2007 so that the lances could be fabricated in time for a March 2007 installation. The timing of the design/installation of the LMS lances coincided with the testing of the Design \#2 lances at ISES; therefore, the lance design used at LMS was very similar to the lance Design \#2 (i.e. eight three-section lances). The LMS lance design was further modified to allow lance blowback to clear any carbon pluggage. The Toxecon $^{\mathrm{TM}}$ II injection system at LMS included the following design features:

1. The Toxecon ${ }^{\mathrm{TM}}$ II lances were installed to treat one-third of the ESP 1A box, which is one-twelfth of the flue gas flow. Eight lance bundles were installed.

2. The injection grid was installed at the downstream end of the fourth field, injecting in front of the fifth field, in between fields $1 \mathrm{~A} 4 \mathrm{EF}$ and $1 \mathrm{~A} 5 \mathrm{EF}$.

3. The grid design included the capability to insert and retract the injection lances with the unit on line. For safety reasons, the fields immediately upstream and downstream of the grid were out of service during retraction. 
4. The guide system for the grid lances was attached to the walkway at the bottom end of the plates, at a mid-support bar, and at the top of the box. The ports penetrated the ESP roof between the two trailing edge plate rapper hammer supports (Figure 2-6).

5. The distribution manifold was in the ESP penthouse, thus distributing the sorbent and transport air outside of the ESP box.

6. The lances were installed in between every fourth ESP plate.

7. The fourth field was de-energized during operation of the injection system.

8. The design assumed that the flue gas distribution through the ESP was essentially uniform across the plane of the plate trailing edges.

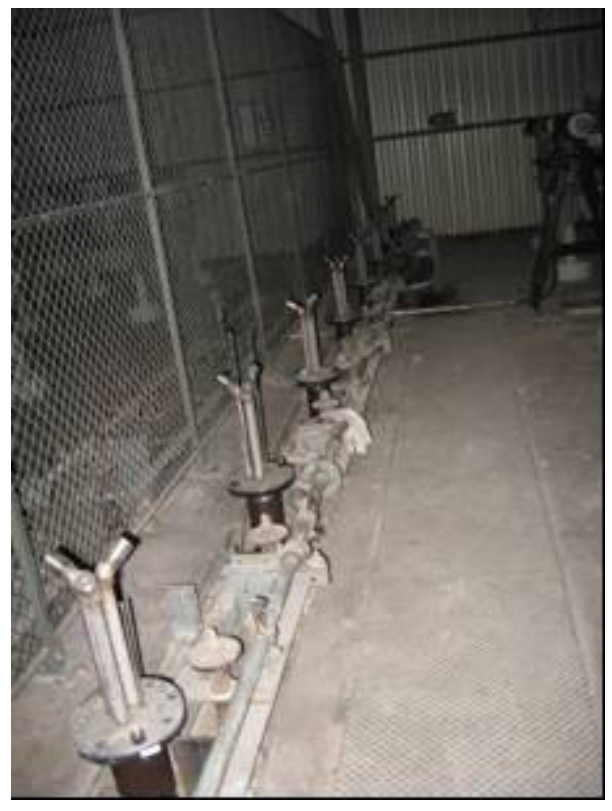

Figure 2-6. Toxecon ${ }^{\mathrm{TM}}$ II Lances Installed - View from ESP Roof

The $\sim 50 \%$ mercury removal achieved by the Design \#2 lances at LMS was significantly lower than the mercury removal achieved by these lances at ISES and lower than the physical model predictions. The internal ESP clearances at LMS prevented an optimal placement of the lances, limiting the ability of the lances to achieve optimized sorbent distribution. The pluggage problems encountered with the Design \#2 lances at ISES were not encountered at LMS and the blowback system was not needed. The pluggage issues at ISES were only clearly discernible during extended continuous injection periods and may not have been evident during the parametric testing at LMS [1].

In May 2007, lance Design \#3 was evaluated at LMS. The mercury removal performance did not improve with this new lance design, likely due to the already limited distribution potential of the lance design.

The results from the testing at ISES indicated that under certain operating conditions, the plant experienced particulate emissions spikes associated with last field plate rapping when operating 
at reduced ESP power levels and with non-brominated PAC. Based on changing the ESP power levels at ISES, it appears that operating at increased power levels for the last field minimized or eliminated these particulate spikes. It also appeared that both the particulate monitors and the opacity monitors respond differently to ash and to carbon particles, giving perhaps a significantly higher reading for the PAC/ash mixture than for a similar amount of straight ash.

At ISES, the last field rapping frequency was increased to 1 rap/hour. At LMS the last fields of the ESPs are rapped once per week and opacity spikes are observed during this rapping. Because of the infrequent rap cycle and the already observed opacity spike, rapping frequency was not changed for Toxecon ${ }^{\mathrm{TM}}$ II operation at LMS.

\subsection{Calcium Bromide Addition System}

During select parts of the Phase IV test program, calcium bromide was added to the coal to evaluate the ability of bromide to enhance the mercury removal achieved by sorbent injection. The LMS Unit 2 furnace is a split tangential furnace with ten coal feeders; each coal feeder services all eight burners on a single furnace level. Feeder A serves the lowest level of the furnace, followed by B, C, D, etc., moving up the furnace.

For this program, calcium bromide was added to two feeders (i.e., bromide was added to two levels of the furnace). From 7/9/09 through 7/15/09, the A and $\mathrm{C}$ feeders were used; from $7 / 16 / 09$ through 7/20/09, the A and D feeders were used. The feeder location was changed due to operational problems with feeder $\mathrm{C}$; these problems were unrelated to the bromide test. No modeling of the furnace was performed, so the effect of changing feeder location is uknown; however, little change is expected as the feeder location only changed by one level in the furnace.

The bromide was added as a $52 \mathrm{wt} \%$ solution of calcium bromide. An electronic metering pump delivered calcium bromide from 260-gallon totes through plastic tubing to a fitting on top of the coal feeder. Each feeder had a dedicated tote and pump. The liquid exited the fitting and fell on the coal as it neared the end of the weigh belt and fell into the pulverizer. The coal and bromide solution mixed in the pulverizer and then traveled through the fuel pipes to the furnace. Pump flow rates were checked with a daily calibration, and bromide feed rates were confirmed by monitoring the depletion rate of the bromide totes.

\subsection{Flue Gas and Process Sampling Methods}

An integral part of this test program was the collection and analysis of flue gas, coal, and process byproduct samples. Project engineers developed a chain-of-custody procedure and coordinated with plant personnel to ensure coal, fly ash, and FGD solid/liquid samples were collected and tracked properly. A quality assurance and control plan was adopted, as provided in Appendix A.

\section{Flue Gas Sampling}

Flue gas mercury concentrations (total and elemental mercury) were measured at the ESP inlet and ESP outlet using EPRI semi-continuous mercury analyzers, provided and operated by Apogee Scientific and URS Group. Four other flue gas mercury measurement methods were used at various points in this test program: Sorbent traps, Ontario Hydro $(\mathrm{OH})$, EPA Method 29 
(M29), and a novel X-ray Filter Method (XFM) developed by Cooper Enviornmental Services (CES). Sorbent trap measurements of total mercury concentration were made at the ESP outlet and stack during Phase IV testing. Ontario Hydro measurements of speciated mercury concentrations were conducted during baseline tests, the long-term injection test, and Phase IV. Also during Phase IV, EPA Method 29 and XFM were used to determine flue gas metals concentrations (including $\mathrm{Hg}$ ) before and after the FGD scrubber.

Flue gas halogen concentrations $\left(\mathrm{HCl}, \mathrm{HBr}, \mathrm{Br}_{2}, \mathrm{Cl}_{2}\right)$ were measured using EPA Method 26 during Parametric Phases I-III and the long-term test; no Method 26 measurements were performed during PHase IV. EPA Method 17 traverses were performed at the ESP inlet and outlet to monitor for particulate and sorbent breakthrough. Additional particulate measurements were made at the ESP outlet using EPA Method 5 (M5). An opacity montitor was used at the ESP outlet to determine the effect of carbon injection on opacity. Each of these methods is described in more detail below.

EPRI SCEM - Flue gas vapor-phase mercury analyses were made using mercury semicontinuous emission monitors (Hg SCEMs) depicted in Figure 2-7. At each testing location, a sample of the flue gas was extracted at a single point from the duct, drawn through an inertial gas separation filter to remove particulate matter, and returned to the duct. A secondary sample stream was pulled across the filter and then directed through the mercury analyzer at a rate of approximately 1-2 L/min, thus providing near real-time feedback during the various test conditions.

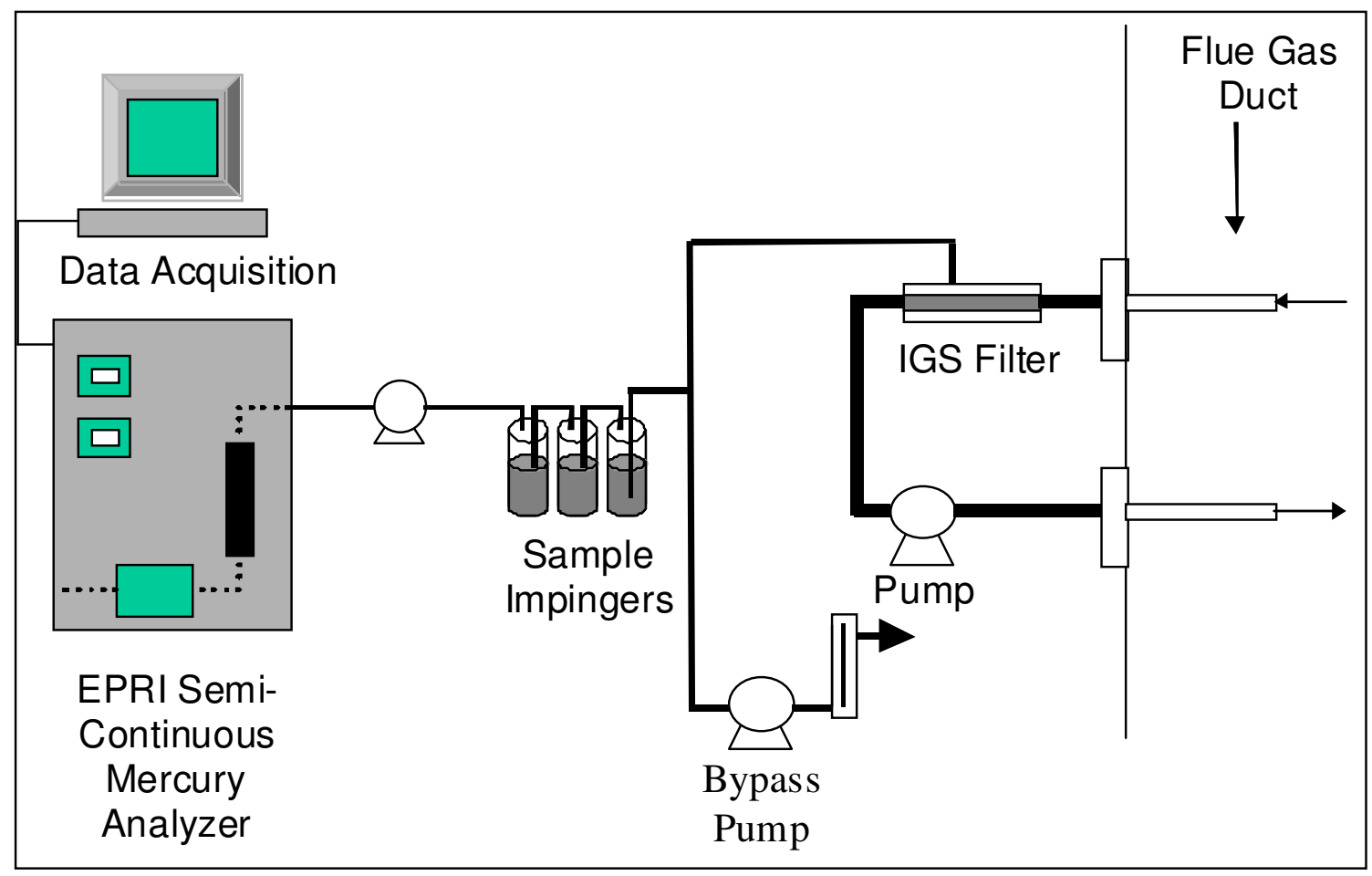

Figure 2-7. Semi-Continuous Mercury Analyzer 
The analyzer consists of a cold vapor atomic absorption spectrometer (CVAAS) coupled with a gold amalgamation system (Au-CVAAS). Since the Au-CVAAS measures mercury by using the distinct lines of the UV absorption characteristics of elemental mercury, the non-elemental fraction is converted to elemental mercury prior to analysis using a chilled reduction solution of acidified stannous chloride. Several impingers containing alkaline solutions are placed downstream of the reducing impingers to remove acidic components from the flue gas; elemental mercury is quantitatively transferred through these impingers.

Gas exiting the impingers flows through a gold amalgamation column where the mercury in the gas is adsorbed $\left(<60^{\circ} \mathrm{C}\right)$. After adsorbing mercury onto the gold for a fixed period of time (typically one to five minutes, depending on the mercury concentration in the gas), the mercury concentrated on the gold is thermally desorbed $\left(>400^{\circ} \mathrm{C}\right)$ in air, and sent as a concentrated mercury stream to a CVAAS for analysis. Therefore, the total flue gas mercury concentration is measured semi-continuously with a one to five-minute sample time followed by a 2-minute analytical period.

To measure elemental mercury only, an impinger containing either $1 \mathrm{M}$ potassium chloride $(\mathrm{KCl})$ or $1 \mathrm{M}$ Tris hydroxymethyl(aminomethane) (Tris) and EDTA is placed upstream of the alkaline solution impingers to capture oxidized mercury. Oxidized forms of mercury are subsequently captured and maintained in the $\mathrm{KCl}$ or Tris impingers while elemental mercury passes through to the gold amalgamation system. Comparison of "total" and "elemental" mercury measurements yields the extent of mercury oxidation in the flue gas. A detailed discussion on the methodology for calculating vapor-phase mercury concentration from the SCEMS data is provided in Appendix B.

When bromide is added to the furnace, highly reactive bromine is produced in the flue gas and the possibility exists for a negative bias in the measurement of flue gas mercury concentrations by SCEMs. This bias has been observed by several measurements groups, including URS Group, with various SCEMs at various power plants. This bias was observed in this test program at LMS with SCEMs at the AH inlet and ESP outlet; therefore, alternate measurement methods such as sorbent traps were used to quantify total flue gas mercury concentrations. Bromine is effectively removed by the FGD, so FGD outlet measurements are typically not subject to the bias. At LMS, where $15 \%$ of the flue gas bypasses the FGD, some bromide will be present in the stack flue gas; it is unknown if this level of bromide was sufficient to bias the Tekran CEMS at the stack. In the discussion of the mercury removal results during bromide addition, flue gas mercury concentrations are presented from the following methods: sorbent traps, M29, and XFM.

Sorbent Trap Method - In the sorbent trap method, a measured volume of flue gas is pulled through a sorbent trap over a set period of time. Flue gas mercury adsorbs to the sorbent material during the sample period. The sorbent is then digested in the laboratory and analyzed for total mercury content. Dividing the mass of mercury collected on the sorbent trap by the amount of flue gas sampled provides an average flue gas mercury concentration over the sample time period.

This method provides a total vapor phase mercury concentration; it does not speciate the mercury. Sorbent trap measurements were collected on most days during the 2009 Unit 2 test program. Measurements were collected at the ESP outlet and at the stack. Each day of sorbent 
trap collection consisted of two runs at each location. The oxygen concentration was measured once during each sorbent trap run to correct the measured mercury concentration to $3 \% \mathrm{O}_{2}$.

While the sorbent trap probe is capable of making dual sorbent trap measurements, only one sorbent trap was used at a time. Dual traps are specified for compliance purposes; as this project was experimental and past experience has indicated very good agreement between the two simultaneous traps, the second trap was not used in this test program. Method blanks were performed over the course of the test program. Both two-bed traps and three-bed, pre-spiked traps, were used for this test program.

It is not anticipated that the sorbent trap method would be subject to bromine-induced measurement bias when measuring total mercury concentration; however, no experimental study has been conducted to explicitly verify this assumption.

Ontario Hydro - Flue gas mercury measurements were made by the Ontario Hydro method (ASTM D 6784-02) during both the long-term test program on Unit 1 and Phase IV parametric testing on Unit 2. The Ontario Hydro method is a manual isokinetic wet chemistry method that obtains speciated flue gas mercury data. The method applies to the determination of elemental, oxidized, particle-bound, and total mercury emissions from coal-fired power plants. ASTM 6784-02 provides a full description of the equipment and procedures associated with the Ontario Hydro method.

During the long-term Unit 1 test program in 2007, the Ontario Hydro method was conducted at the treated ESP outlet and the untreated ESP outlet. The untreated ESP outlet served as the "uncontrolled" Ontario Hydro measurements for the unit. Ontario Hydro samples were not obtained at the ESP inlet, as previous Ontario Hydro tests at plants firing Texas Lignite have shown an appreciable bias in measured mercury oxidation and mercury concentration due to the reactivity of ash collected on the Method 5 filter (i.e., configured upstream of the Ontario Hydro collection impingers).

During the 2009 Unit 2 test program, Ontario Hydro sampling was conducted at the treated ESP outlet only; there were no untreated ESP ducts as the entire unit was treated with mercury controls. $\mathrm{OH}$ measurements were made on outlet duct 2D1, and each run consisted of a three port traverse of that duct.

Flue Gas Trace Metals - Flue gas samples were collected using EPA Method $29^{1}$ (Determination of Metals Emissions from Stationary Sources) and the Cooper XFM method. The methods were conducted simultaneously at both the ESP outlet and the stack. At each location, triplicate runs of each method were performed on one baseline day, on one day of sorbent injection only, and on one day of calcium bromide and sorbent injection. The measurements were collected to measure the concentration of metals in the flue gas before and after the FGD scrubber.

EPA Method 29 was conducted as a single-point, isokinetic measurement. Method 29 consists of a quartz filter to capture particulate matter followed by an impinger train as shown in Figure 2-8. The impinger train contains a knock-out impinger, two acidic hydrogen peroxide impingers, an empty impinger, and two impingers containing an acidified potassium permanganate solution. 
The first three impingers are combined and analyzed for all metals, including mercury. The empty impinger rinse and the two permanganate impingers are analyzed solely for mercury.

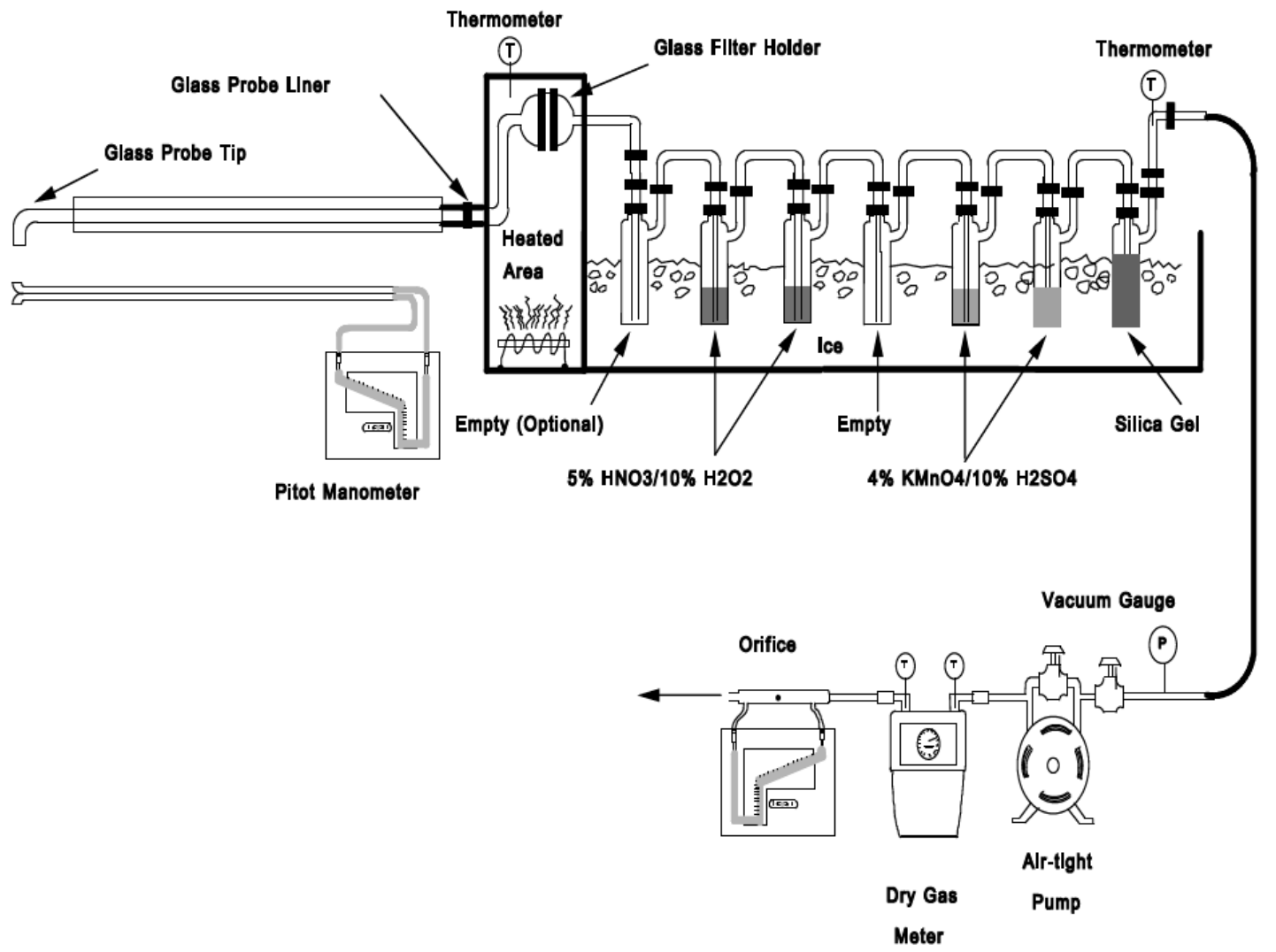

Figure 2-8. Diagram of EPA Method 29 Impinger Train

All sample preparation was carried out in accordance with EPA Method 29; the only deviation from the method was the addition of hydroxylamine sulfate to the permanganate impingers to ensure that no precipitate was present. Samples were analyzed for trace metal concentrations by CONSOL Energy using ICP-OES or ICP-MS (equivalent to EPA 200.7 and 200.8 respectively). Mercury analyses were carried out via CVAA. Continuing calibration verification (CCV) and quality control samples, such as duplicate and spiked samples, were performed periodically during the analyses; reported values were bracketed by CCVs within the range of 82-118\% recovery.

The Cooper XFM method, developed by CES, is an alternative sampling and analysis method for determining the concentrations of particulate and vapor phase metals in flue gas. The method has been validated for use on a hazardous waste incinerator using EPA Method 301. ${ }^{2}$ The X-ray based filter method has the potential to be a more efficient approach to trace-metals measurements as compared to the wet impinger-based Method 29. This program evaluated how an adaptation of the XFM method performed relative to Method 29 when sampling at a coalfired power plant. Other adaptations of the XFM solid sorbent technology include the possible use of in-stack isokinetic sampling cassettes. ${ }^{3}$ 
For this study a large volume (approximately $750 \mathrm{Lpm}$ ) of stack gas was withdrawn from a single point using a heated velocity pressure probe (see Figure 2-9). A subsample (approximately $50 \mathrm{Lpm}$ ) of the stack gas in the probe was then drawn into the XFM extraction assembly using an eductor. Finally, about $1 \mathrm{Lpm}$ of stack gas was drawn from the extraction assembly, diluted approximately 1:1 with clean dry air and passed through a filter cassette.

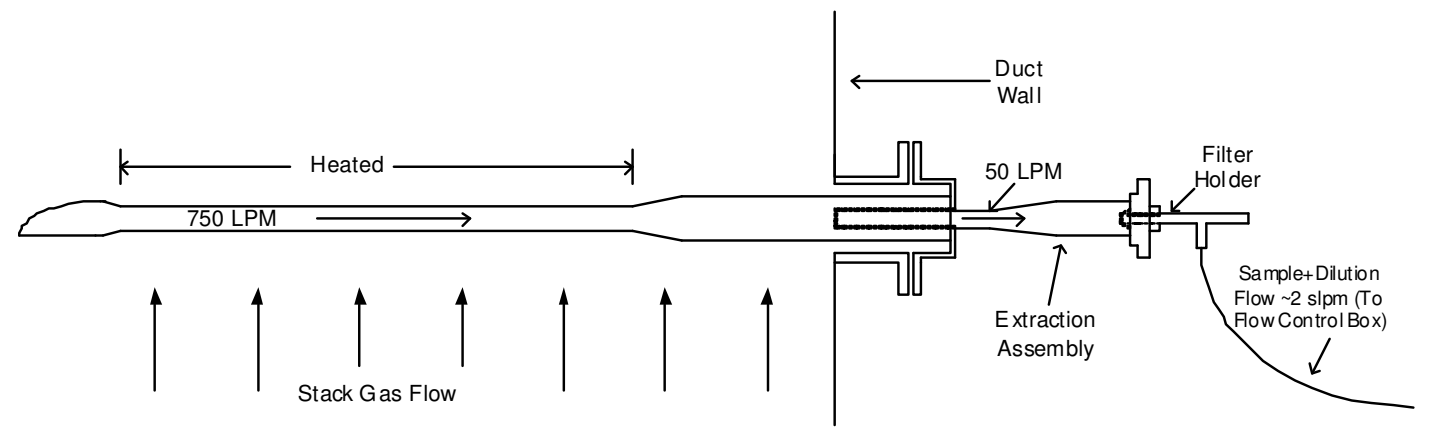

Figure 2-9. XFM Sampling Assembly

The filter cassette consisted of two filters: the first was a PTFE filter which removed the particulate from the gas stream and the second was a reactive filter which removed vapor phase metals from the gas stream, including vapor phase mercury and arsenic. After passing through the filter cassette the sampled flue gas traveled through a series of impingers submerged in ice to remove entrained water, through a carbon trap to remove acid vapors and was then measured using a mass flow meter. A filter cassette with three filters (PTFE filter, reactive filter, and treated reactive filter) enabled determination of mercury speciation.

Both the dilution flow and the total flow (stack gas flow plus dilution flow) were measured and totalized over each sampling period which lasted from 30 minutes to 1 hour. Following sampling, the filter cassette was removed from the filter holder, stored in a petri dish and sent to the laboratory for metals analysis by X-ray fluorescence. Each element has a characteristic wavelength that it emits as it returns to ground state after excitation due to the absorption of radiation; the intensity of this emission is measured and used to determine analyte concentration. The total concentration of each analyte was determined by dividing the XRF determined mass by the sample volume as follows:

$$
C^{i}=\frac{M_{F T F E}^{i}+M_{r}^{i}}{V_{t}-V_{d}}
$$

where:

$$
\begin{array}{ll}
C^{i}= & \text { Concentration of the } \mathrm{i}^{\text {th }} \text { element in flue gas }(\mu \mathrm{g} / \mathrm{dscm}) \\
M_{F T F E}^{i} & =\mathrm{XRF} \text { measured mass of the } \mathrm{i}^{\text {th }} \text { element on the PTFE filter }(\mu \mathrm{g}) \\
M_{r}^{i} & =\text { XRF measured mass of the } \mathrm{i}^{\text {th }} \text { element on the reactive filter }(\mu \mathrm{g}) \\
V_{t}= & \text { Total volume }(\mathrm{dscm}) \\
V_{d}= & \text { Dilution volume }(\mathrm{dscm})
\end{array}
$$


For every nine filters analyzed, CES analyzed a quality control standard to verify the XRF calibration stability. All of these QC standards were within 98-107\% recovery.

Method 26A - Flue gas samples were collected using EPA Method 26A ["Determination of Hydrogen Halide (HX) and Halogen $\left(\mathrm{X}_{2}\right)$ Emissions from Stationary Sources"] during baseline and long-term testing conditions. These measurements were made to characterize the baseline flue gas halogen $\left(\mathrm{HCl} / \mathrm{Cl}_{2}\right.$ and $\left.\mathrm{HBr} / \mathrm{Br}_{2}\right)$ concentrations and determine if bromine species volatilized from the chemically impregnated carbons after being injected into the flue gas. These measurements were only collected during testing on Unit 1. No Method 26A measurements were collected during the Unit 2 testing.

In Method 26A, hydrogen halides are solubilized in an acidic solution, while the halogens pass through to be captured in an alkaline solution. Method 26A has not been validated for flue gas measurements below $20 \mathrm{ppm}$ halide; furthermore, a negative bias has been demonstrated for the quantification of halogen $\left(\mathrm{X}_{2}\right)$ present, with a corresponding positive bias for the quantification of the respective hydrogen halide [2]. In the presence of certain flue gas components $\left(\mathrm{SO}_{2}, \mathrm{O}_{2}\right.$, $\mathrm{NO}_{\mathrm{x}}$ ), a significant fraction of the halogen $\left(\mathrm{X}_{2}\right)$ is captured in the acidic solution. While this bias affects the halogen speciation data, it does not affect the measurement of total halogen (HX + $\left.\mathrm{X}_{2}\right)$ in the flue gas. Therefore, data will be reported as total halogen concentration, expressed in $\mathrm{HCl}$ or $\mathrm{HBr}$ equivalents.

Method 17 and Method 5 - Particulate matter measurements were made using EPA Methods 5 and 17 during the Unit 1 and Unit 2 tests. Method 17 uses an in-duct filter to collect particulate matter, while Method 5 uses a heated filter external to the duct. During the Unit 1 testing, the Method 17 measurements were conducted as a traverse of one duct exiting the ESP 1A outlet (representing 1/2 the treated ESP, or 1/8 of the entire unit). The other duct exiting the ESP 1A was not traversed, as the mercury SCEM was located in that duct. During the Unit 2 testing, Method 17 measurements were collected at both the inlet and the outlet of the 2D duct of the ESP. At the ESP outlet, traverses of both the upper and lower halves of duct 2D1 were performed on each testing day. Here, each of the sample ports were traversed at points across either the upper or lower half of the duct for a given sampling period. At the ESP inlet, measurements were collected from both the 2D1 and 2D2 ducts each day. Filters were weighed at a subcontracted laboratory (Severn Trent Laboratories).

Particulate measurements at the ESP inlet were performed at four existing (4-inch) sampling ports. Each inlet sampling event lasted 25 minutes and was conducted using one of the available ports, as illustrated in Figure 2-10. Each port was traversed in the following manner: the first sample point was located 1 foot into the duct with each subsequent point spaced 2 feet apart. 


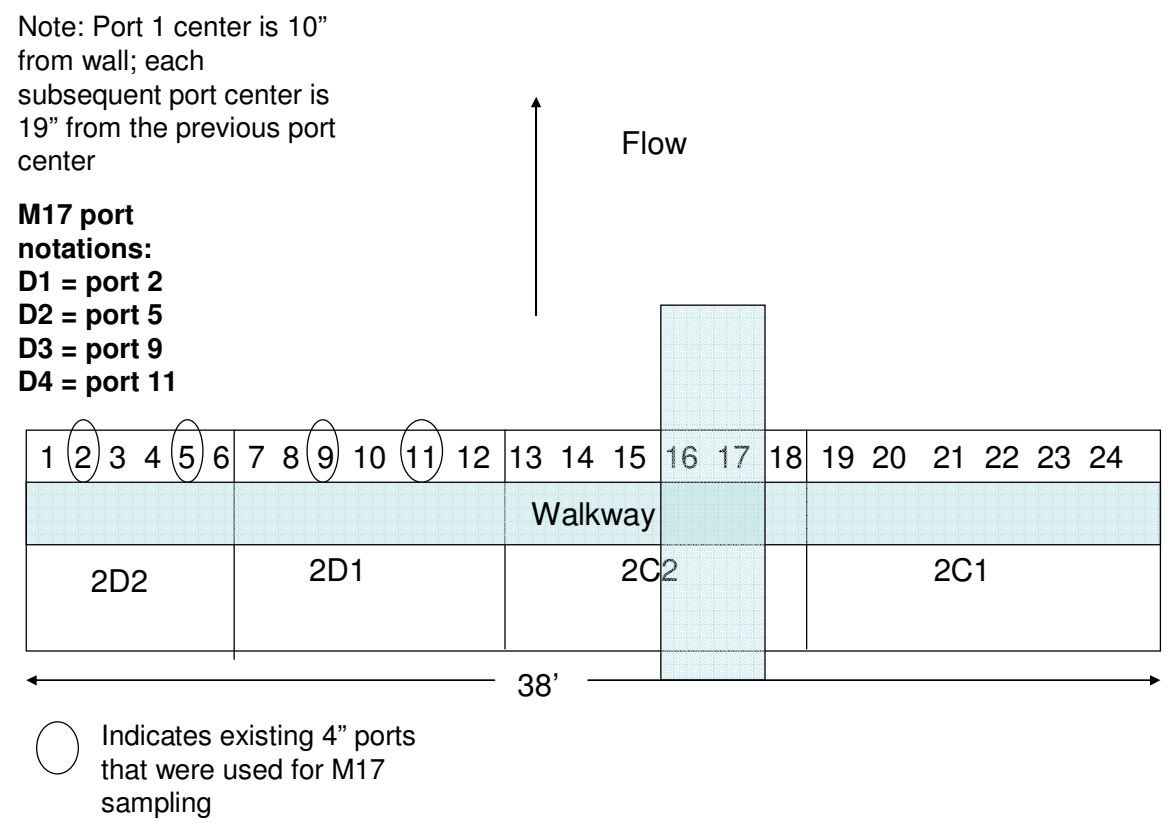

\section{Figure 2-10. ESP Inlet Port Locations for Method 17 Measurements}

The ESP outlet was traversed using three different sampling ports (Figure 2-11) to obtain particulate measurements. The outlet duct measurements were divided into top and bottom half traverses, as illustrated in Figure 2-12, to determine the level of particulate matter stratification across the duct, if any. Because outlet sampling times varied, the averages of outlet particulate concentration measurements for a given test condition were time-weighted.

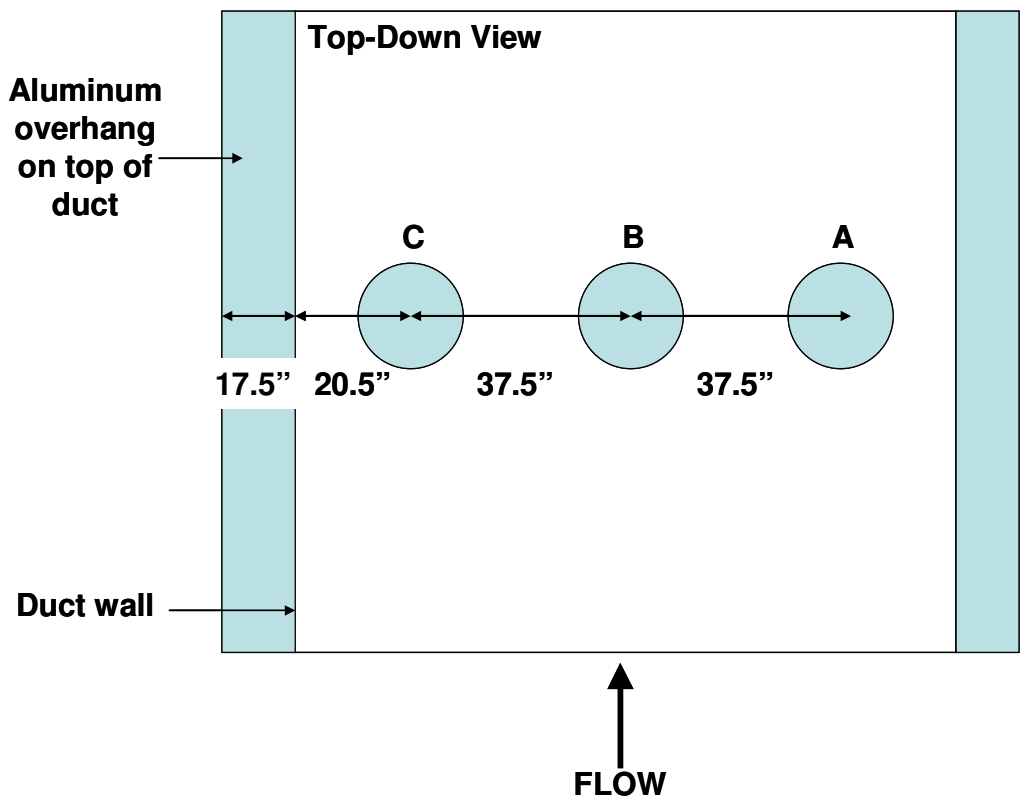

Figure 2-11. ESP Outlet Sampling Ports for Method 17 Measurements (Top-Down View) 


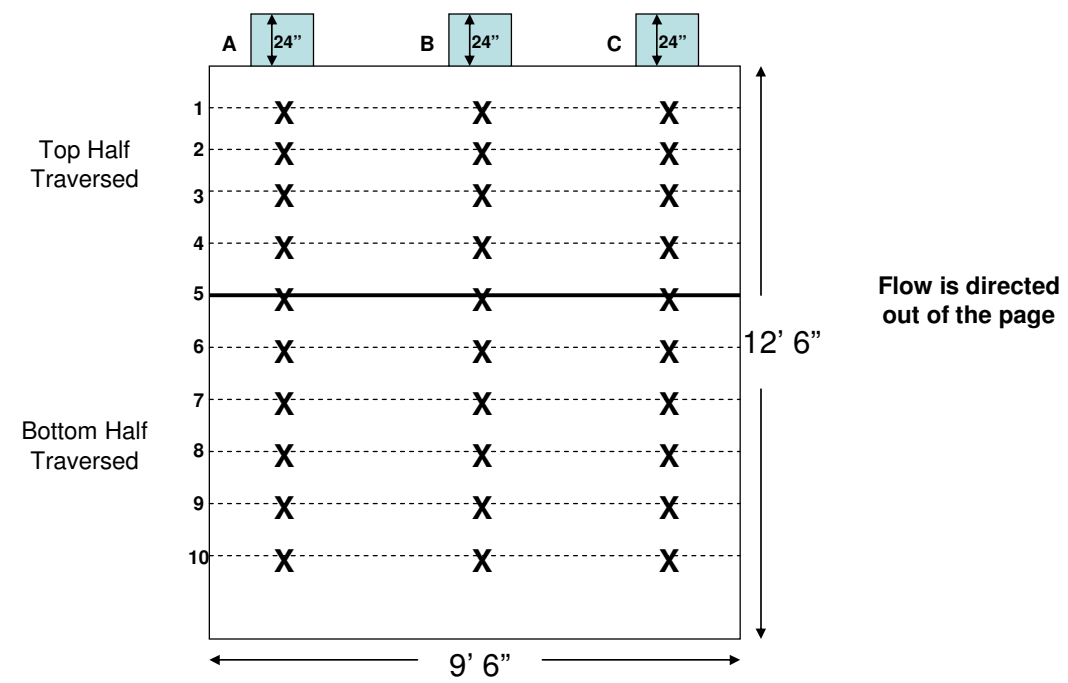

Note: ESPO duct was traversed using ports A through C. Top half consisted of measurements from 1' to 5 ' into the deep at one foot intervals. Bottom half consisted of measurements from 6' to 10 ' deep at one foot intervals.

\section{Figure 2-12. ESP Outlet Sampling Grid for Method 17 Measurements (Side Elevation)}

Opacity Monitor - Each LMS ESP outlet duct is equipped with a Dynatron 1100M opacity monitor. Monitor data were hand-recorded during the parametric tests, but were electronically recorded for the long-term test. During Unit 1 testing in 2006-2007, the data from an untreated duct were compared with that for the treated duct to determine if there were any changes in opacity due to injection of activated carbon.

\section{Coal and Byproduct Samples}

Coal - Samples of both the Texas lignite and PRB coals fired at LMS were obtained each day during parametric testing and several times a week during long-term testing. During the $2006-$ 2007 Phase I-III tests, coal samples were taken from the coal feeder weigh belts on Unit 1. Due to a change in the coal handling system resulting in a mixture of lignite/PRB coal on the weigh belts during the 2009 Phase IV tests, samples were collected as the coals were loaded onto the belt in the coal yard. The delay between coal loading and coal firing was approximately 8 hours. Coal mercury, trace metals, chloride, bromide, and ultimate/proximate parameters were determined by a subcontracted laboratory (Consol).

Fly Ash - Fly ash samples were collected directly from the ESP hoppers. Figure 2-13 shows the layout of the collectors for the Unit 1A ESP, and Figure 2-14 shows the layout of the Unit 2 ESP hoppers. During parametric tests, ash samples were obtained at the end of each test period. During the long-term injection test on Unit 1, fly ash samples were gathered once per day. During the Unit 2 test program, fly ash samples were collected on most test days. Fly ash samples were analyzed in URS' Austin laboratories for loss-on-ignition (LOI), mercury content, 
and foam index. The details for the URS foam index testing procedure are included in Appendix I. Fly ash mercury concentrations were determined by URS using ASTM 3684 digestion and CVAAS analysis. Mercury concentrations are reported as $\mu \mathrm{g} / \mathrm{g}$ on a dry basis. The fly ash samples (and associated leachates) were analyzed for non-mercury trace metals concentration by a subcontracted laboratory (Consol). The fly ash samples were also analyzed by Headwaters Inc. to determine the ash's potential for use as a cement replacement in concrete. These tests included foam index, air entrainment requirements, and concrete strength. The foam index testing procedure used by Headwaters Inc. is included in Appendix I.

The leaching protocol used was the Synthetic Precipitation Leaching Procedure (SPLP). This leaching procedure, also known as EPA Method 1312, uses an acidified, aqueous leaching solution of $\mathrm{pH} 4.2$ for samples collected east of the Mississippi River and $\mathrm{pH} 5.0$ for samples collected west of the Mississippi River. This difference reflects the higher acidity of rainwater east of the Mississippi River. A mixture of nitric and sulfuric acid is used to adjust the $\mathrm{pH}$ of the water for this leaching procedure. The test duration is 18 hours and the test uses a 20:1 liquid-tosolid ratio and a turn rate of $30 \mathrm{rpm}$.

FGD System Samples - All FGD absorber slurry samples were collected from the recycle pump loop of the wet FGD system. Since the Unit 1 long-term test program was concerned with mercury removal across the ESP, only limited scrubber samples were obtained. During the Unit 1 long-term test program, the scrubber operated in an inhibited oxidation mode using the addition of elemental sulfur emulsion. Since only one-fourth of the unit's flue gas was treated with activated carbon and both treated and untreated flue gas combined in a common header prior to the scrubber system, it was impossible to obtain FGD absorber slurry samples representative of a unit treated with activated carbon. However, scrubber samples were obtained during baseline and long-term injection testing to monitor for signs of activated carbon breaking through the ESP and into the scrubber slurry.

The Unit 2 scrubber was converted to a forced oxidation mode in January 2009. During the 2009 Unit 2 test program, scrubber samples were collected on five test days: baseline, full unit Darco $\mathrm{Hg}-\mathrm{LH}$ injection at the air preheater outlet and ESP inlet locations, and bromide boiler injection test conditions. These samples were analyzed for mercury and trace metals content in both the solid and liquid phase of each sample. 


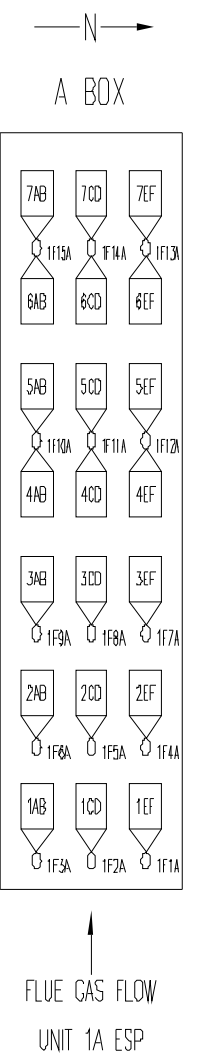

Figure 2-13. ESP 1A Hopper Configuration

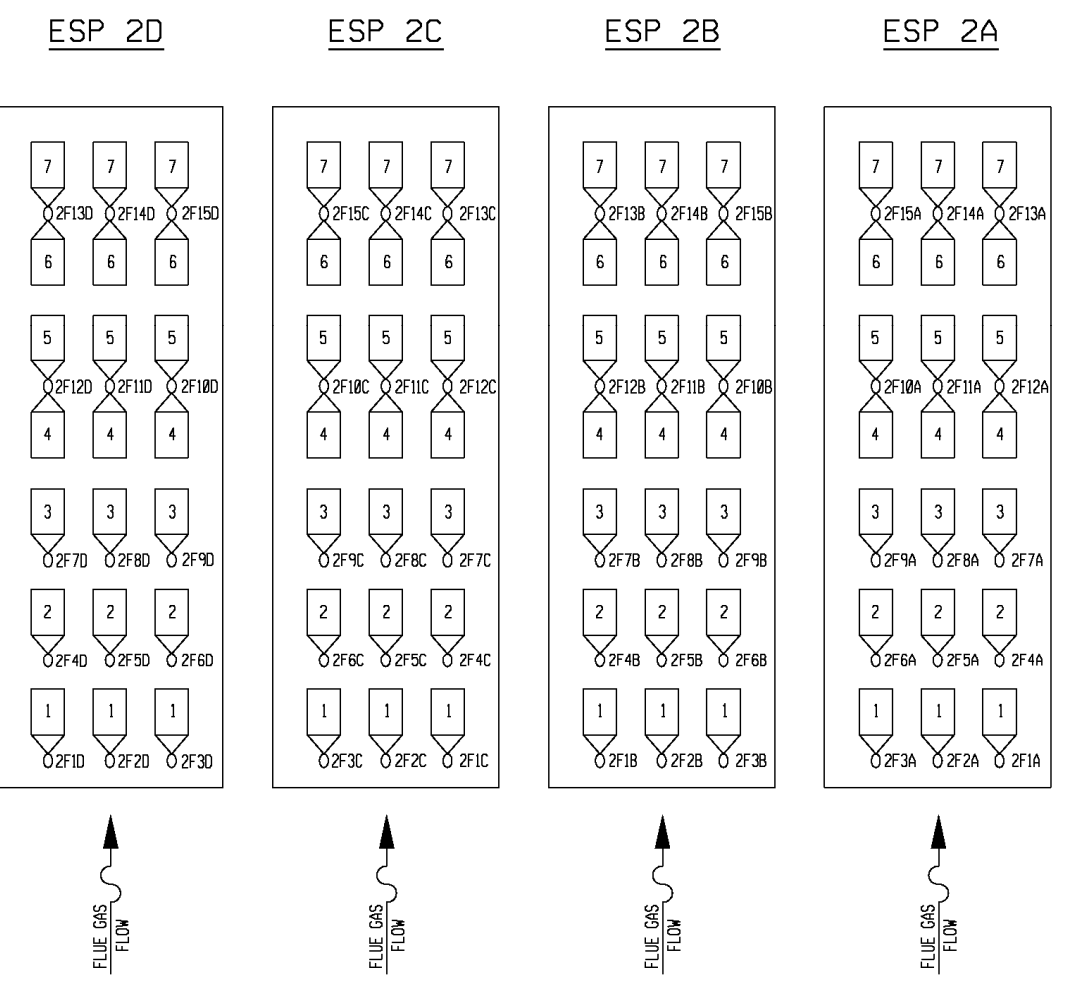

Figure 2-14. Unit 2 ESP Hopper Configuration 


\subsection{Parametric Testing Sample Matrix (Phases I-III, 2006-2007)}

In the first phase of parametric testing, several sorbents were injected upstream of the ESP and evaluated for mercury control performance. Testing occurred over a two-week period. Each sorbent was tested at up to four different injection rates with each rate evaluated for up to four hours. Baseline characterization was scheduled during overnight periods to monitor the unit's return to baseline conditions after stopping carbon injection. Sorbents evaluated in Phase I parametric testing in December 2006 included Norit America's DARCO Hg (activated carbon) and DARCO Hg-LH (brominated carbon), Sorbent Technologies' B-PAC (brominated carbon), and Calgon Carbon's Flue PAC MC Plus (brominated carbon). It was originally planned to test a low ash impact sorbent (from BASF) during this test period; however, the vendor was unable to deliver the sorbent in time for the testing. This low ash impact sorbent was therefore evaluated just prior to the Phase II parametric tests.

The schedule for tests executed during Phase I of the parametric test program is provided in Table 2-4. For the carbon injection tests, SCEM mercury data collected after the flue gas mercury concentrations reached steady-state were analyzed and averaged.

Table 2-4. Executed Test Schedule - Parametric Testing, Phase I

\begin{tabular}{|c|c|c|c|}
\hline Start Time (CT) & End Time (CT) & Injection Activity & $\begin{array}{c}\text { Injection Rate* } \\
\text { (lb/Macf) }\end{array}$ \\
\hline $12 / 3 / 20069: 30$ & 12/3/2006 12:07 & Baseline & 0 \\
\hline 12/3/2006 12:14 & 12/3/2006 15:47 & DARCO Hg-LH & 1.1 \\
\hline 12/3/2006 16:10 & 12/3/2006 19:13 & DARCO Hg-LH & 2.9 \\
\hline $12 / 4 / 20068: 34$ & 12/4/2006 9:50 & Baseline & 0 \\
\hline 12/4/2006 9:45 & 12/4/2006 13:40 & DARCO Hg-LH & 0.5 \\
\hline 12/4/2006 13:40 & 12/4/2006 17:15 & DARCO Hg-LH & 2.5 \\
\hline 12/4/2006 17:15 & 12/4/2006 19:40 & DARCO Hg-LH & 5.1 \\
\hline 12/4/2006 19:45 & 12/4/2006 22:10 & DARCO Hg-LH & 1.7 \\
\hline 12/5/2006 8:27 & 12/5/2006 9:17 & Baseline & 0 \\
\hline 12/5/2006 9:15 & 12/5/2006 12:02 & B-PAC & 0.5 \\
\hline 12/5/2006 12:02 & 12/5/2006 15:15 & B-PAC & 1.3 \\
\hline 12/5/2006 15:15 & $12 / 5 / 200618: 35$ & B-PAC & 3.3 \\
\hline 12/5/2006 18:35 & 12/5/2006 20:24 & B-PAC & 1.9 \\
\hline 12/6/2006 8:15 & 12/6/2006 9:56 & Baseline & 0 \\
\hline 12/6/2006 9:56 & 12/6/2006 12:23 & DARCO Hg & 3.4 \\
\hline 12/6/2006 12:23 & 12/6/2006 16:36 & DARCO Hg & 8.2 \\
\hline 12/6/2006 16:36 & 12/6/2006 19:12 & DARCO Hg & 5.6 \\
\hline 12/7/2006 9:18 & $12 / 7 / 20069: 55$ & Baseline & 0 \\
\hline 12/7/2006 9:55 & 12/7/2006 12:24 & DARCO Hg & 0.4 \\
\hline 12/7/2006 12:24 & 12/7/2006 15:05 & DARCO Hg & 1.5 \\
\hline 12/7/2006 15:05 & 12/7/2006 18:05 & DARCO Hg & 1.7 \\
\hline 12/7/2006 18:05 & 12/7/2006 20:00 & DARCO Hg & 8.9 \\
\hline 12/8/2006 8:00 & $12 / 8 / 20069: 57$ & Baseline & 0 \\
\hline 12/8/2006 9:57 & 12/8/2006 12:10 & Flue PAC MC Plus & 0.5 \\
\hline 12/8/2006 12:10 & 12/8/2006 15:02 & Flue PAC MC Plus & 1.9 \\
\hline $12 / 8 / 2006$ 15:02 & $12 / 8 / 200617: 38$ & Flue PAC MC Plus & 5.8 \\
\hline 12/9/2006 8:45 & 12/9/2006 9:47 & Baseline & 0 \\
\hline 12/9/2006 9:47 & $12 / 10 / 200610: 50$ & DARCO Hg & 0.6 \\
\hline $12 / 10 / 2006$ 10:50 & 12/10/2006 13:02 & DARCO Hg & 1.1 \\
\hline
\end{tabular}

* Injection rates based on treating $1 / 4$ of Unit 1 flue gas $(770,000 \mathrm{acfm})$. 
Table 2-5 displays the testing schedule for Phase II of the parametric testing, which was conducted in late April and early May 2007. In the Phase II tests, several promising low ash impact sorbents and injection configurations were tested. The BASF MS200 and C-PAC sorbents were tested as low ash impact sorbents. The Toxecon ${ }^{\mathrm{TM}} \mathrm{II}$ and staged injection configurations were tested using the DARCO Hg sorbent as possible low ash impact sorbent injection configurations.

Table 2-5. Test Schedule - Parametric Testing, Phase II

\begin{tabular}{|c|c|c|c|}
\hline Start Time (CT) & End Time (CT) & Injection Activity & $\begin{array}{c}\text { Injection Rate* } \\
\text { (lb/Macf) }\end{array}$ \\
\hline 4/20/2007 9:38 & 4/21/2007 7:12 & Baseline & 0 \\
\hline 4/21/2007 7:13 & $4 / 21 / 20078: 55$ & Baseline & 0 \\
\hline 4/21/2007 8:55 & $4 / 21 / 200714: 30$ & BASF MS200 & 6 \\
\hline 4/21/2007 14:30 & 4/21/2007 18:10 & BASF MS200 & 8 \\
\hline 4/22/2007 9:28 & 4/22/2007 13:36 & BASF MS200 & 10 \\
\hline 4/22/2007 13:36 & 4/22/2007 17:43 & BASF MS200 & 12 \\
\hline $4 / 22 / 200717: 43$ & 4/22/2007 18:18 & BASF MS200 & 20 \\
\hline 4/22/2007 21:30 & 4/22/2007 8:50 & Baseline & 0 \\
\hline 4/23/2007 10:00 & 4/23/2007 14:35 & C-PAC & 0.5 \\
\hline 4/23/2007 14:35 & 4/23/2007 19:07 & C-PAC & 1.5 \\
\hline 4/23/2007 22:00 & 4/24/2007 10:00 & Baseline & 0 \\
\hline 4/24/2007 10:07 & 4/24/2007 14:04 & DARCO Hg & 1 \\
\hline 4/24/2007 14:04 & $4 / 24 / 200718: 49$ & DARCO Hg & 2 \\
\hline 4/25/2007 9:00 & 4/25/2007 11:30 & Baseline & 0 \\
\hline 4/25/2007 11:03 & $4 / 25 / 200714: 24$ & Calgon HGR-LH & 1 \\
\hline $4 / 25 / 200714: 24$ & $4 / 25 / 200718: 21$ & Calgon HGR-LH & 2 \\
\hline 4/26/2007 10:00 & 4/26/2007 10:30 & Baseline & 0 \\
\hline 4/26/2007 10:33 & 4/26/2007 13:03 & DARCO Hg-LH & 1 \\
\hline 4/26/2007 17:44 & 4/26/2007 18:20 & DARCO Hg-LH & 2 \\
\hline 4/27/2007 10:19 & 4/28/2007 0:00 & Baseline & 0 \\
\hline 4/28/2007 0:01 & $4 / 28 / 200723: 59$ & Baseline & 0 \\
\hline 4/29/2007 0:01 & 4/29/2007 17:30 & Baseline & 0 \\
\hline 4/30/2007 0:01 & 4/30/2007 10:00 & Baseline & 0 \\
\hline 4/30/2007 10:11 & $4 / 30 / 200714: 58$ & $\begin{array}{l}\text { Toxecon }^{\mathrm{TM}} \mathrm{II} \\
\text { DARCO Hg }\end{array}$ & 2 \\
\hline 4/30/2007 14:58 & $4 / 30 / 200719: 34$ & $\begin{array}{l}\text { Toxecon }^{\mathrm{TM}} \mathrm{II} \\
\text { DARCO Hg }\end{array}$ & 5 \\
\hline 5/1/2007 0:01 & $5 / 1 / 20079: 30$ & Baseline & 0 \\
\hline 5/1/2007 12:26 & 5/1/2007 15:05 & $\begin{array}{l}\text { Toxecon }^{\mathrm{TM}} \mathrm{II} \\
\text { DARCO Hg }\end{array}$ & 5 \\
\hline 5/1/2007 18:00 & $5 / 2 / 20077: 26$ & Baseline & 0 \\
\hline 5/2/2007 11:15 & $5 / 2 / 200714: 29$ & DARCO Hg & 2 \\
\hline $5 / 2 / 200714: 31$ & $5 / 2 / 200718: 10$ & DARCO Hg & 3 \\
\hline 5/2/2007 18:11 & $5 / 2 / 200722: 15$ & Baseline & 0 \\
\hline 5/3/2007 12:00 & 5/3/2007 13:02 & BASF MS200 & 8 \\
\hline 5/4/2007 12:14 & $5 / 4 / 200718: 48$ & B-PAC & 1 \\
\hline
\end{tabular}

* Injection rates based on treating $1 / 4$ of Unit 1 flue gas $(770,000 \mathrm{acfm})$. 
A third phase of parametric testing was conducted to investigate an alternate design for the Toxecon $^{\text {TM }}$ II lances. Table 2-6 shows the schedule for the Phase III parametric testing.

Table 2-6. Executed Test Schedule - Parametric Testing, Phase III

\begin{tabular}{|c|c|c|c|}
\hline Start Time (CT) & End Time (CT) & Injection Activity & $\begin{array}{c}\begin{array}{c}\text { Injection Rate* } \\
\text { (lb/Macf) }\end{array} \\
\end{array}$ \\
\hline 5/22/2007 19:01 & 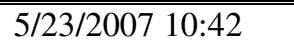 & Baseline & 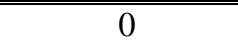 \\
\hline $5 / 23 / 200711: 45$ & $5 / 23 / 200713: 30$ & $\begin{array}{l}\text { Toxecon }^{\mathrm{TM}} \mathrm{II} \\
\text { DARCO Hg }\end{array}$ & 2.0 \\
\hline 5/23/2007 13:30 & $5 / 23 / 200718: 40$ & $\begin{array}{l}\text { Toxecon }^{\mathrm{TM}} \mathrm{II} \\
\text { DARCO Hg }\end{array}$ & 6.0 \\
\hline 5/23/2007 18:40 & 5/24/2007 5:00 & Baseline & 0 \\
\hline $5 / 24 / 20078: 50$ & $5 / 24 / 20079: 30$ & Baseline & 0 \\
\hline 5/24/2007 10:05 & $5 / 24 / 200713: 30$ & $\begin{array}{l}\text { Toxecon }^{\mathrm{TM}} \mathrm{II} \\
\text { DARCO Hg }\end{array}$ & 3.0 \\
\hline $5 / 24 / 200713: 35$ & 5/24/2007 16:05 & Staged Injection DARCO Hg & $0.5 / 3.0$ \\
\hline 5/24/2007 16:05 & 5/24/2007 17:40 & Staged Injection DARCO Hg & $0.5 / 5.0$ \\
\hline 5/24/2007 21:00 & 5/25/2007 7:00 & Baseline & 0 \\
\hline $5 / 25 / 20078: 30$ & 5/25/2007 12:45 & Baseline & 0 \\
\hline 5/25/2007 12:45 & $5 / 25 / 200717: 10$ & Toxecon $^{\text {TM }}$ II DARCO Hg-LH & 5.0 \\
\hline 5/25/2007 22:00 & $5 / 26 / 20079: 30$ & Baseline & 0 \\
\hline 5/26/2007 9:31 & $5 / 26 / 200710: 45$ & Baseline & 0 \\
\hline 5/26/2007 10:45 & $5 / 26 / 200711: 30$ & DARCO Hg-LH w/o forced air & 0.5 \\
\hline $5 / 26 / 200711: 30$ & 5/26/2007 12:10 & DARCO Hg-LH w/ forced air & 0.5 \\
\hline 5/26/2007 12:10 & $5 / 26 / 200714: 55$ & DARCO Hg-LH w/ forced air & 0.7 \\
\hline 5/26/2007 15:00 & $5 / 26 / 200715: 25$ & DARCO Hg-LH w/ forced air & 1.0 \\
\hline $5 / 26 / 200715: 25$ & $5 / 26 / 200716: 20$ & DARCO Hg-LH w/o forced air & 1.0 \\
\hline $5 / 26 / 200716: 25$ & 5/26/2007 18:10 & Staged Injection DARCO Hg-LH & $1.0 / 5.0$ \\
\hline
\end{tabular}

*Injection rates based on treating $1 / 4$ of Unit 1 flue gas $(770,000 \mathrm{acfm})$.

Table 2-7 lists the flue gas parameters measured during the parametric tests. Flue gas mercury concentrations were measured continuously with two mercury SCEMs. The first SCEM measured mercury at the ESP inlet; the second SCEM alternated between measuring speciated mercury at the ESP 1A2 outlet (treated duct) and ESP 1B1 outlet (untreated duct).

Prior to installing the mercury analyzer extraction probes, a duct velocity traverse was conducted during full-load conditions to determine profiles for identifying appropriate sampling locations and for modeling sorbent distribution in the duct. During baseline and each parametric carbon injection test condition, ESP outlet flue gas particulate concentrations were measured with a Method 17 traverse of one half of ESP 1A. 
Table 2-7. Flue Gas Sampling Matrix for 2006-2007 Parametric Tests

\begin{tabular}{|c|c|c|c|}
\hline Location & Sample Method & Parameter(s) & $\begin{array}{c}\text { Frequency Per Test } \\
\text { Condition }\end{array}$ \\
\hline \multirow[t]{2}{*}{ ESP 1A Inlet } & M2 & Velocity Profile & $\begin{array}{l}\text { Once prior to installation } \\
\text { of SCEM and injection } \\
\text { lances }\end{array}$ \\
\hline & SCEM & Speciated Hg & Continuous \\
\hline \multirow[t]{4}{*}{ ESP 1A Outlet } & M2 & Velocity Profile & $\begin{array}{l}\text { Once prior to installation } \\
\text { of SCEM }\end{array}$ \\
\hline & SCEM & Speciated Hg & Continuous \\
\hline & M17 & $\begin{array}{l}\text { Particulate Loading, } \\
\text { traverse of } 1 / 2 \text { ESP } 1 \mathrm{~A}\end{array}$ & Once per test condition \\
\hline & $\begin{array}{l}\text { Dynatron 1100M } \\
\text { Opacity Monitor }\end{array}$ & Opacity & $\begin{array}{l}\text { Hand recorded (2-5 times } \\
\text { per day) }\end{array}$ \\
\hline ESP 1B Outlet & SCEM & Total $\mathrm{Hg}$ & Limited \\
\hline
\end{tabular}

Solid process samples were collected with the help of plant personnel. Table 2-8 shows the process sampling schedule during the short-term parametric testing. Coal and ash samples were taken daily; however, not all collected samples were analyzed.

Table 2-8. Solid Process Samples Collected for 2006-2007 Parametric Tests

\begin{tabular}{||l|c|c|c|c||}
\hline \multicolumn{1}{||}{ Sample } & Sample Frequency & Sample Size & $\begin{array}{c}\text { Responsible } \\
\text { Party for } \\
\text { Collection }\end{array}$ & $\begin{array}{c}\text { Parameters for } \\
\text { Analysis }\end{array}$ \\
\hline \hline $\begin{array}{l}\text { Coal }- \\
\text { Feeder Weigh } \\
\text { Belt }\end{array}$ & Once per day & $\begin{array}{c}\text { One gallon size bag of } \\
\text { each coal type }\end{array}$ & LMS & $\begin{array}{c}\text { Hg, Halogens, } \\
\text { Ultimate/Proximate }\end{array}$ \\
\hline $\begin{array}{l}\text { Fly Ash }- \\
\text { Unit 1 ESP A }\end{array}$ & Once per test condition & $\begin{array}{c}\text { One quart size sample per } \\
\text { hopper }\end{array}$ & URS & $\begin{array}{c}\text { Hg, LOI, Concrete } \\
\text { Testing }\end{array}$ \\
\hline
\end{tabular}

Sorbent injection test conditions were not maintained long enough in the parametric tests to obtain representative fly ash samples; therefore, simulated ash/carbon mixtures were made in the laboratory and underwent concrete testing as shown in Table 2-9. Previous testing by URS and EPRI has shown that representative samples, for the evaluation of fly ash reuse properties, can be prepared from actual fly ash mixed with known amounts of activated carbon.

Table 2-9. Sampling Plan for Concrete Testing for 2006-2007 Parametric Tests

\begin{tabular}{||l|l||}
\hline \hline Test Parameters & Samples Tested \\
\hline \hline AEA Demand & Baseline, Simulated Ash + Sorbent \\
\hline Slump & Baseline, Simulated Ash + Sorbent \\
\hline Air \% Pressure & Baseline, Simulated Ash + Sorbent \\
\hline 7 day compressive strength & Baseline, Simulated Ash + Sorbent \\
\hline 28 day compressive strength & Baseline, Simulated Ash + Sorbent \\
\hline \hline
\end{tabular}




\subsection{Long-Term Testing Sample Matrix}

The best overall combination of sorbent type and injection feed location (factoring in mercury removal efficiency, sorbent cost, fly ash reuse properties and any short-term balance-of-plant impacts such as ESP particulate collection efficiency) was selected for a 60-day continuous injection evaluation.

Based on the parametric test results, the project team decided to conduct the 60-day test with Norit's DARCO Hg-LH injected upstream of the ESP at $2 \mathrm{lb} / \mathrm{Macf}$. While the non-brominated DARCO Hg performed nearly as well as the DARCO Hg-LH and was available at a lower cost, it was not selected for the long-term test. A brominated sorbent was selected because the plant sometimes fires $100 \%$ PRB coal, and a brominated sorbent was needed to overcome the low halogen content of the PRB coal. In addition, a brominated sorbent was expected to be less sensitive to higher flue gas temperatures, which would be encountered during the summer test months. Norit's DARCO Hg-LH sorbent was selected over Sorbent Technologies B-PAC because it had the overall lower cost, when factoring in transportation of the sorbent. In addition, B-PAC did not perform as well as DARCO Hg-LH in simulated concrete foam index tests. Both brominated sorbents performed similarly in terms of mercury removal during the test program and were available at the same F.O.B. cost.

The Toxecon ${ }^{\mathrm{TM}}$ II and staged injection configurations were not selected for the long-term test, as neither configuration was able to consistently achieve the mercury removal target $(>50 \%)$ for this project. Furthermore, the risk of particulate matter breaking through the ESP was higher with Toxecon $^{\mathrm{TM}}$ II. Therefore, the project team elected to inject sorbent upstream of the ESP.

The injection rate of $2 \mathrm{lb} / \mathrm{Macf}$ was chosen because the parametric tests showed that the mercury removal target of at least $50 \%$ could be achieved at this rate. Concrete testing results (foam index, air entrainment, and compressive strength) for simulated ash/carbon mixtures for this injection rate indicated that the ash might still be marketable to the concrete industry. Higher injection rates were not considered as they would pose a higher risk of the ash not being marketable. Lower injection rates were not considered as they would pose the risk of not meeting the project's mercury removal target.

Flue gas and byproduct mercury concentrations were monitored throughout the long-term test along with plant operating data to evaluate mercury removal performance variability and any balance-of-plant impacts that occurred. During the long-term test, the plant typically fired a 70/30 mixture of Texas lignite and PRB coals. However, for four short periods (less than 2 days each) the unit fired 100\% PRB coal when Texas lignite was not available. Table 2-10 summarizes the coal firing schedule during the long-term test. 


\section{Table 2-10. Coal Schedule for Unit 1 Long-Term Test}

\begin{tabular}{||l|r|r||}
\hline \hline Coal Fired & \multicolumn{1}{c|}{ Start } & \multicolumn{1}{c|}{ End } \\
\hline \hline 70/30 TxL/PRB & $6 / 19 / 0719: 00$ & $6 / 26 / 0723: 00$ \\
\hline 100\% PRB & $6 / 27 / 074: 00$ & $6 / 28 / 0715: 00$ \\
\hline 70/30 TxL/PRB & $6 / 28 / 0719: 00$ & $7 / 2 / 0720: 00$ \\
\hline 100\% PRB & $7 / 4 / 071: 00$ & $7 / 5 / 074: 00$ \\
\hline 70/30 TxL/PRB & $7 / 5 / 0713: 00$ & $7 / 5 / 0721: 00$ \\
\hline 100\% PRB & $7 / 5 / 0723: 00$ & $7 / 7 / 076: 00$ \\
\hline 70/30 TxL/PRB & $7 / 7 / 0710: 00$ & $7 / 13 / 072: 00$ \\
\hline Unit outage & $7 / 13 / 077: 25$ & $7 / 18 / 0711: 45$ \\
\hline 70/30 TxL/PRB & $7 / 18 / 0714: 00$ & $8 / 2 / 0712: 00$ \\
\hline 100\% PRB & $8 / 2 / 0717: 00$ & $8 / 3 / 079: 00$ \\
\hline 70/30 TxL/PRB & $8 / 3 / 0714: 00$ & $8 / 22 / 0717: 00$ \\
\hline
\end{tabular}

Table 2-11 provides a summary of the flue gas samples collected during the long-term baseline and sorbent injection test periods. Ontario Hydro measurements were conducted at the ESP outlet at baseline conditions and at the beginning, middle, and end of the long-term test. Table 2-12 provides the Ontario Hydro sample schedule. Two mercury SCEMs were operated continuously throughout the test period; one at the ESP inlet (e.g., upstream of sorbent injection), and one at the ESP outlet. Method 26 measurements were made at the treated and untreated ESP outlets to determine how much bromine volatilized from the DARCO Hg-LH sorbent. Particulate loading was measured at the ESP inlet and outlet as a Method 5 train in conjunction with Ontario Hydro and Method 26A. Method 17 measurements were conducted three times during the long term test at the ESP outlet. For OH, M5, M26A, and M17, only one-half of the 1A and 1B ESPs was traversed due to port availability. SCEM probes were installed in ports on the other half of each ESP. 
Table 2-11. Sample Collection and Analyses for Unit 1 Long-Term Tests

\begin{tabular}{|c|c|c|c|c|}
\hline \multirow[b]{2}{*}{ Location } & \multirow[b]{2}{*}{ Sample Method } & \multirow[b]{2}{*}{ Parameter(s) } & \multicolumn{2}{|c|}{ Frequency $^{\text {a }}$} \\
\hline & & & Baseline & Injection \\
\hline ESP 1A Inlet & SCEM & Speciated Hg & Continuous & Continuous \\
\hline \multirow[t]{4}{*}{$\begin{array}{l}\text { ESP 1A1 Outlet } \\
\text { (Treated ESP) }\end{array}$} & Ontario Hydro & $\begin{array}{l}\text { Speciated } \mathrm{Hg}, \\
\text { Particulate Loading }\end{array}$ & $\begin{array}{l}1 \text { set of three } \\
\text { runs }\end{array}$ & $\begin{array}{l}3 \text { sets of three } \\
\text { runs }\end{array}$ \\
\hline & M26A & $\begin{array}{l}\mathrm{HCl} / \mathrm{Cl}_{2}, \text { Particulate } \\
\text { Loading }\end{array}$ & & Once \\
\hline & M17 & Particulate Loading & & 3 sets of six runs \\
\hline & Dynatron $1100 \mathrm{M}$ & Opacity & Continuous & Continuous \\
\hline $\begin{array}{l}\text { ESP 1A2 Outlet } \\
\text { (Treated ESP) }\end{array}$ & SCEM & Speciated $\mathrm{Hg}$ & Continuous & Continuous \\
\hline $\begin{array}{l}\text { ESP 1B1 Outlet } \\
\text { (Untreated ESP) }\end{array}$ & SCEM & Speciated $\mathrm{Hg}$ & Continuous & Continuous \\
\hline \multirow[t]{3}{*}{$\begin{array}{l}\text { ESP 1B2 Outlet } \\
\text { (Untreated ESP) }\end{array}$} & Ontario Hydro & $\begin{array}{l}\text { Speciated Hg, } \\
\text { Particulate Loading }\end{array}$ & $\begin{array}{l}1 \text { set of three } \\
\text { runs }\end{array}$ & $\begin{array}{l}3 \text { sets of three } \\
\text { runs }\end{array}$ \\
\hline & M26A & $\begin{array}{l}\mathrm{HCl} / \mathrm{Cl}_{2}, \text { Particulate } \\
\text { Loading }\end{array}$ & & Once \\
\hline & Dynatron $1100 \mathrm{M}$ & Opacity & Continuous & Continuous \\
\hline $\begin{array}{l}\text { ESP 1C Outlet } \\
\text { (Untreated ESP) }\end{array}$ & Dynatron $1100 \mathrm{M}$ & Opacity & Continuous & Continuous \\
\hline $\begin{array}{l}\text { ESP 1D Outlet } \\
\text { (Untreated ESP) }\end{array}$ & Dynatron 1100M & Opacity & Continuous & Continuous \\
\hline
\end{tabular}

${ }^{a}$ Frequency during the baseline and the 8 -week long-term injection test periods.

Table 2-12. OH Sample Schedule for Unit 1 Long-Term Tests

\begin{tabular}{|c|c|c|c|c|}
\hline & \multicolumn{2}{|c|}{ Untreated Duct } & \multicolumn{2}{|c|}{ Treated Duct } \\
\hline & Date & $\begin{array}{c}\text { Start \& Stop } \\
\text { Times }\end{array}$ & Date & $\begin{array}{c}\text { Start \& Stop } \\
\text { Times }\end{array}$ \\
\hline \multicolumn{5}{|l|}{ Baseline (Trip 1) } \\
\hline Run 1 & 20-Jun-07 & $10: 10-12: 24$ & 20-Jun-07 & $10: 10-12: 25$ \\
\hline Run 2 & 20-Jun-07 & $13: 50-16: 04$ & 20-Jun-07 & 13:50-16:00 \\
\hline Run 3 & 21-Jun-07 & $11: 01-15: 29$ & 21-Jun-07 & 11:01-15:32 \\
\hline \multicolumn{5}{|c|}{ Injection Round 1 (Trip 2) } \\
\hline Run 1 & 10-Jul-07 & $12: 10-14: 27$ & 10-Jul-07 & 12:10-14:24 \\
\hline Run 2 & 10-Jul-07 & $15: 20-17: 35$ & 10-Jul-07 & $15: 20-17: 23$ \\
\hline Run 3 & 11-Jul-07 & 09:32-11:45 & 11-Jul-07 & 9:32-11:43 \\
\hline \multicolumn{5}{|c|}{ Injection Round 2 (Trip 3) } \\
\hline Run 1 & 31-Jul-07 & $10: 00-12: 45$ & 31-Jul-07 & 10:00-12:11 \\
\hline Run 2 & 31-Jul-07 & 14:01-16:09 & 31-Jul-07 & 14:01-16:13 \\
\hline Run 3 & 1-Aug-07 & 09:20-11:32 & 1-Aug-07 & 09:23-11:36 \\
\hline \multicolumn{5}{|c|}{ Injection Round 3 (Trip 4) } \\
\hline Run 1 & 14-Aug-07 & $11: 30-13: 40$ & 14-Aug-07 & $11: 30-13: 45$ \\
\hline Run 2 & 14-Aug-07 & 15:00-17:10 & 14-Aug-07 & $15: 00-17: 10$ \\
\hline Run 3 & 15-Aug-07 & 09:30-11:35 & 15-Aug-07 & $09: 30-11: 38$ \\
\hline
\end{tabular}


Table 2-13 shows the process sampling frequency during the continuous injection tests. Coal samples were obtained a few times per week, ash samples were taken daily, and FGD samples were collected once per week. As part of this program, samples were obtained for DOE NETL's byproduct testing program.

Table 2-13. Process Sample Schedule for Unit 1 Long-Term Injection Test

\begin{tabular}{|c|c|c|c|c|}
\hline Sample & Frequency & Sample Size & $\begin{array}{l}\text { Responsible } \\
\text { Party }\end{array}$ & $\begin{array}{c}\text { Parameters for } \\
\text { Analysis }\end{array}$ \\
\hline Coal - Unit 1 & 3 times per week & $\begin{array}{l}\text { One gallon size bag of } \\
\text { each coal type }\end{array}$ & LMS & $\begin{array}{c}\text { Hg, Halogens, } \\
\text { Ultimate/ Proximate }\end{array}$ \\
\hline $\begin{array}{l}\text { Fly Ash - } \\
\text { Unit 1A ESP }\end{array}$ & Once per day & $\begin{array}{l}\text { One pint per hopper in } \\
\text { first fields }\end{array}$ & URS & $\mathrm{Hg}, \mathrm{LOI}$ \\
\hline $\begin{array}{l}\text { Fly Ash - } \\
\text { Unit 1A ESP }\end{array}$ & Once per week & $\begin{array}{c}\text { Two 5-gallon buckets in } \\
\text { first field }\end{array}$ & URS & Concrete Testing \\
\hline $\begin{array}{l}\text { Fly Ash - } \\
\text { Unit 1A ESP }\end{array}$ & $\begin{array}{l}\text { Collected at } \\
\text { baseline, one } \\
\text { month and two } \\
\text { month marks }\end{array}$ & Three 5-gallon buckets & URS & $\begin{array}{l}\text { DOE Byproduct } \\
\text { Testing }\end{array}$ \\
\hline $\begin{array}{l}\text { Fly Ash - } \\
\text { Unit 1A ESP }\end{array}$ & Once per week & $\begin{array}{l}\text { One pint per hopper in } \\
\text { all fields }\end{array}$ & URS & $\begin{array}{c}\mathrm{Hg}, \mathrm{LOI}, \\
\text { Concrete Testing }\end{array}$ \\
\hline $\begin{array}{l}\text { Fly Ash - } \\
\text { Unit 1B ESP }\end{array}$ & Once per week & $\begin{array}{l}\text { One pint per hopper in } \\
\text { first field }\end{array}$ & URS & $\begin{array}{c}\mathrm{Hg}, \mathrm{LOI}, \\
\text { Concrete Testing }\end{array}$ \\
\hline FGD Sample-Unit 1A & Once per week & One 500-mL sample & URS & $\begin{array}{l}\text { Visual determination } \\
\text { of carbon } \\
\text { breakthrough, Hg and } \\
\text { FGD Analyses } \\
\end{array}$ \\
\hline
\end{tabular}

Ash samples collected during baseline and long-term testing were subjected to various characterization tests to determine the suitability of the ash for use in concrete production. Foam index and LOI tests were performed by URS, strength activity tests were performed by UNDEERC, and Headwaters Inc. performed the tests listed in Table 2-14.

Table 2-14. Fly Ash Sampling Plan for Concrete Testing for Unit 1 Long-Term Test

\begin{tabular}{||l|l||}
\hline Tests Performed by Headwaters & Method(s) Used \\
\hline AEA Demand (Foam Index Testing) & ASTM C 618 \\
\hline \% Carbon & LOI \& total carbon by LECO \\
\hline Particle Size & 325 mesh \& Horiba \\
\hline Compressive Strength on Mortar Cubes & ASTM C 109 \\
\hline Compressive Strength on Concrete Cylinders & ASTM C 39 \\
\hline
\end{tabular}

\subsection{Parametric Phase IV Scope of Work and Plan}

The fourth and final round of parametric testing was performed at LMS Unit 2 over seven weeks. Table 2-15 shows the executed test schedule for Phase IV. This test program was designed to evaluate several sorbents and injection configurations. Flue gas mercury measurements were made at the AH inlet, ESP outlet and stack. The entire unit (all four ESPs) was treated during the 
first several weeks of the test program, thus allowing for measurement of mercury removal across the combined ESP/FGD system. During the remainder of the test program, only one ESP (one quarter of Unit 2) was treated; an alternate lance configuration and several experimental sorbents were tested during this period.

Several tests were conducted with Norit Americas' DARCO Hg and DARCO Hg-LH to allow for comparisons to previous LMS test data. In addition, three different ash compatible sorbents and several proprietary sorbents, provided by Calgon Carbon, were evaluated.

Sorbent injection was tested for several days while the unit fired an alternate fuel blend consisting of 55/45 (percent by mass) TxL/PRB coals. The unit typically fires a 70/30 TxL/PRB blend.

In conjunction with this test program, EPRI and NRG funded tests to evaluate the impact of calcium bromide injection to the furnace on the fate of mercury across the LMS gas path. These tests were conducted in cooperation with Alstom, who owns the North American license for the technology. Tests were conducted with bromide injection alone and in conjunction with activated carbon injection.

The LMS scrubbers recently underwent a conversion from inhibited oxidation to forced oxidation operation. Baseline mercury removal across the FGD was evaluated under both FGD chemistries; however, the parametric sorbent injection program was conducted with the unit operating at steady-state forced oxidation chemistry.

During this test program, the FGD scrubber was operated with some of the flue gas bypassing the FGD system. The fraction of gas bypassing the scrubber was calculated using plant data according to the following equation:

$$
\text { BypassFraction }=\frac{\mathrm{SO}_{2}, \text { out }-\left(0.15 \times \mathrm{SO}_{2}, \text { in }\right)}{\left(0.85 \times \mathrm{SO}_{2}, \text { in }\right)}
$$

Here, $\mathrm{SO}_{2}$, in and $\mathrm{SO}_{2}$, out are the flue gas $\mathrm{SO}_{2}$ concentrations at the scrubber inlet and outlet (post re-introduction of bypassed gas to the stack flue gas), respectively. The scrubber bypass flow at LMS was not measured. The equation thus uses known inlet and outlet $\mathrm{SO}_{2}$ values and the scrubber removal efficiency to estimate the fraction of flue gas bypassing the FGD system. This equation assumes an average $\mathrm{SO}_{2}$ removal of $85 \%$ across the wet FGD scrubber. This was determined, through system performance tests, to be an average removal obtained across the FGD absorbers when operating at the conditions employed during the ACI testing period.

With some flue gas bypassing the FGD, the actual mercury removal achieved by LMS Unit 2 was lower than what would be possible if all the flue gas was scrubbed. Theoretical total and elemental mercury concentrations at the stack, assuming no gas bypass, no re-emissions, and 95\% removal of oxidized $\mathrm{Hg}$, were calculated using the bypass fraction and the ESP outlet concentrations. Where appropriate, theoretical mercury removal at the stack was then calculated using these theoretical stack mercury concentrations and measured ESP outlet concentrations. 
Table 2-15. Test Schedule - Parametric Testing, Phase IV

\begin{tabular}{|c|c|c|c|c|c|c|c|c|c|c|c|c|c|c|c|c|}
\hline 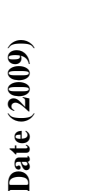 & \# & 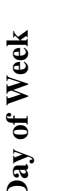 & & 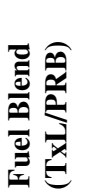 & لَّ & Sorbent & 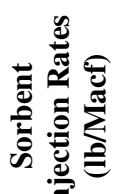 & 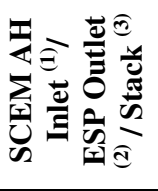 & 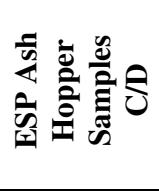 & 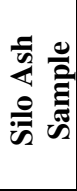 & 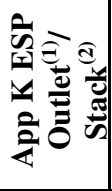 & 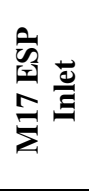 & 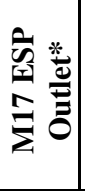 & 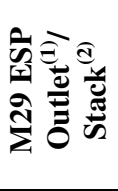 & 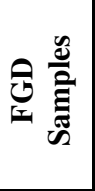 & 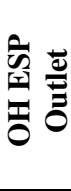 \\
\hline & & & Activity & & & $\chi$ & & & $\Delta$ & $\Delta$ & $\sigma$ & & & $\tau$ & $\nabla$ & $\psi$ \\
\hline 8 8-Jun & 1 & $\mathrm{M}$ & Travel/Setup & & & & & & & & & \multicolumn{2}{|c|}{$\begin{array}{l}\text { VT at AH } \\
\text { Inlet }\end{array}$} & & & \\
\hline 9-Jun & 2 & $\mathrm{~T}$ & Setup & & & & & & & & & \multicolumn{2}{|c|}{$\begin{array}{l}\text { VT at ESP } \\
\text { Out }\end{array}$} & & & \\
\hline 10-Jun & 3 & $\mathrm{~W}$ & Setup & & & & & & & & & $\mathrm{X}$ & $\mathrm{X}$ & & & \\
\hline 11-Jun & 4 & $\mathrm{Th}$ & Baseline & $70 / 30$ & & & 0 & $1 / 2 / 3$ & $\mathrm{C}$ & $\mathrm{X}$ & $1 / 2$ & $\mathrm{X}$ & $\mathrm{X}$ & & & \\
\hline 12-Jun & 5 & $\bar{F}$ & Baseline & $70 / 30$ & & & 0 & $1 / 2 / 3$ & $\mathrm{C}$ & $\mathrm{X}$ & $1 / 2$ & & & & $\bar{Z}$ & 3 \\
\hline 13-Jun & 6 & $\mathrm{Sa}$ & \multirow[t]{6}{*}{ Continuous Injection } & $70 / 30$ & $\mathrm{AH}$ & Darco Hg-LH & 2 & $1 / 2 / 3$ & $\mathrm{C}, \mathrm{D}$ & & $1 / 2$ & & $\mathrm{X}$ & & & \\
\hline 14-Jun & 7 & $\mathrm{Su}$ & & $70 / 30$ & $\mathrm{AH}$ & Darco Hg-LH & 2 & $1 / 2 / 3$ & C,D & $\mathrm{X}$ & $1 / 2$ & & $\mathrm{X}$ & & & \\
\hline 15-Jun & 8 & $\mathrm{M}$ & & $70 / 30$ & $\mathrm{AH}$ & Darco Hg-LH & .5 & $1 / 2 / 3$ & $\mathrm{C}, \mathrm{D}$ & & $1 / 2$ & & $\mathrm{X}$ & & & \\
\hline 16-Jun & 9 & $\mathrm{~T}$ & & $70 / 30$ & $\mathrm{AH}$ & Darco Hg-LH & .5 & $1 / 2 / 3$ & $\mathrm{C}, \mathrm{D}$ & $\mathrm{X}$ & $1 / 2$ & $\mathrm{X}$ & $\mathrm{X}$ & & & \\
\hline 17-Jun & 10 & $\mathrm{~W}$ & & $70 / 30$ & $\mathrm{AH}$ & Darco Hg-LH & 1 & $1 / 2 / 3$ & $\mathrm{C}, \mathrm{D}$ & & $1 / 2$ & $\mathrm{X}$ & $\mathrm{X}$ & & & \\
\hline 18-Jun & 11 & Th & & $70 / 30$ & $\mathrm{AH}$ & Darco Hg-LH & 1 & $1 / 2 / 3$ & $\mathrm{C}$ & $X$ & $1 / 2$ & & & & $\mathrm{Z}$ & 3 \\
\hline 19-Jun & 12 & $\mathrm{~F}$ & No Testing & & & & & & & & & & & & & \\
\hline 20-Jun & 13 & $\mathrm{Sa}$ & No Testing & & & & & & & & & & & & & \\
\hline 21-Jun & 14 & $\mathrm{Su}$ & Baseline & $70 / 30$ & $\mathrm{AH}$ & & 0 & $1 / 2 / 3$ & & & $1 / 2$ & & & & & \\
\hline 22-Jun & 15 & $\mathrm{M}$ & \multirow{3}{*}{$\begin{array}{l}\text { Concrete Compatible } \\
\text { Parametric }\end{array}$} & $70 / 30$ & $\mathrm{AH}$ & Sorbtech C-PAC & 1 & $1 / 2 / 3$ & $\mathrm{C}$ & & $1 / 2$ & & & & & \\
\hline 23-Jun & 16 & $\mathrm{~T}$ & & $70 / 30$ & $\mathrm{AH}$ & $\begin{array}{l}\text { Calgon } \\
\text { FLUEPAC CF } \\
\text { Plus }\end{array}$ & 1 & $1 / 2 / 3$ & $\mathrm{C}$ & & $1 / 2$ & & & & & \\
\hline 24-Jun & 17 & $\mathrm{~W}$ & & $70 / 30$ & $\mathrm{AH}$ & $\begin{array}{l}\text { Norit } \mathrm{Hg}-\mathrm{LH} \\
\text { EXP224 }\end{array}$ & 1 & $1 / 2 / 3$ & $\mathrm{C}$ & & $1 / 2$ & & & & & \\
\hline
\end{tabular}




\begin{tabular}{|c|c|c|c|c|c|c|c|c|c|c|c|c|c|c|c|c|}
\hline \multirow[t]{2}{*}{ 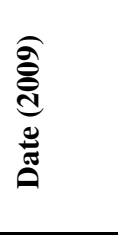 } & \multirow[t]{2}{*}{$\stackrel{\#}{\#}$} & \multirow[t]{2}{*}{ 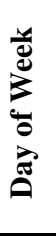 } & \multirow[b]{2}{*}{ Activity } & \multirow[t]{2}{*}{ 高鱿 } & \multirow[t]{2}{*}{.气 } & Sorbent & \multirow[t]{2}{*}{ 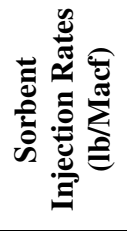 } & \multirow[t]{2}{*}{ 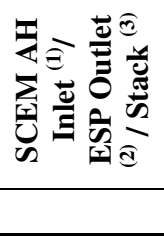 } & \multirow[t]{2}{*}{ 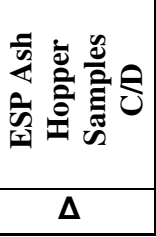 } & \multirow{2}{*}{ 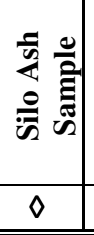 } & \multirow[t]{2}{*}{ 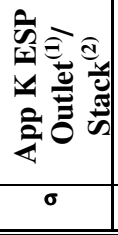 } & \multirow[t]{2}{*}{ 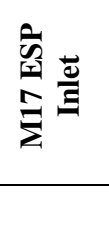 } & \multirow[t]{2}{*}{ 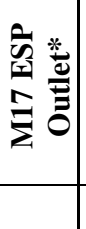 } & \multirow{2}{*}{ 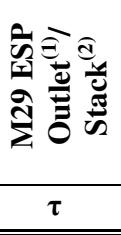 } & \multirow[t]{2}{*}{ 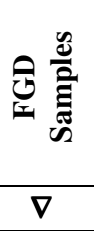 } & \multirow[t]{2}{*}{ 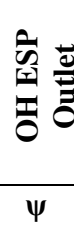 } \\
\hline & & & & & & $\chi$ & & & & & & & & & & \\
\hline 25-Jun & 18 & $\overline{\mathrm{Th}}$ & $\begin{array}{l}\text { Calgon Funded; Concrete } \\
\text { Compatible Parametric }\end{array}$ & $70 / 30$ & $\overline{\mathrm{AH}}$ & $\begin{array}{l}\text { Calgon CF Plus } \\
\text { Ultra ( } 2 \text { bags); } \\
\text { Darco Hg-LH (1 } \\
\text { bag) }\end{array}$ & 1 & $1 / 2 / 3$ & & & none & & & & & \\
\hline 26-Jun & 19 & $\mathrm{~F}$ & Alternate Fuel Blend & $30 / 70$ & $\mathrm{AH}$ & Baseline & 0 & $1 / 2 / 3$ & $\mathrm{C}$ & & $1 / 2$ & & & & & \\
\hline 27-Jun & 20 & $\mathrm{Sa}$ & \multirow{2}{*}{$\begin{array}{l}\text { Alt Fuel; Continuous } \\
\text { ACI }\end{array}$} & $30 / 70$ & $\mathrm{AH}$ & Darco Hg-LH & 1 & $1 / 2 / 3$ & $\mathrm{C}$ & & $1 / 2$ & & & & & \\
\hline 28-Jun & 21 & $\mathrm{Su}$ & & $30 / 70$ & $\mathrm{AH}$ & Darco Hg-LH & 2 & $1 / 2 / 3$ & $\mathrm{C}$ & & $1 / 2$ & & & & & \\
\hline $\begin{array}{l}6 / 29 / 09 \\
-7 / 6 / 09\end{array}$ & $\begin{array}{c}22 \\
- \\
29 \\
\end{array}$ & $\begin{array}{c}\text { M- } \\
\text { M }\end{array}$ & No Testing & & & & 0 & & & & & & & & & \\
\hline 7-Jul & 30 & $\mathrm{~T}$ & $\begin{array}{l}\text { Baseline; move lances to } \\
\text { ESP }\end{array}$ & $70 / 30$ & & & 0 & $1 / 2 / 3$ & & & & & & & & \\
\hline 8-Jul & 31 & $\mathrm{~W}$ & Parametric ACI & $70 / 30$ & ESP & Darco Hg & $0.5 / 1 / 2$ & $1 / 2 / 3$ & & & $1 / 2$ & & & & & \\
\hline 9-Jul & 32 & Th & $\begin{array}{l}\text { Begin Continuous Br to } \\
\text { Coal }\end{array}$ & $70 / 30$ & ESP & & 0 & $1 / 2 / 3$ & $\mathrm{C}$ & & $1 / 2$ & & & & & 2 \\
\hline 10-Jul & 33 & $\mathrm{~F}$ & $\mathrm{Br}$ to $\mathrm{Coal}+\mathrm{ACI}$ & $70 / 30$ & ESP & Darco $\mathrm{Hg}$ & 0.5 & $1 / 2 / 3$ & $\mathrm{C}$ & & $1 / 2$ & & & & & 2 \\
\hline 11-Jul & 34 & $\mathrm{Sa}$ & $\mathrm{Br}$ to Coal + ACI & $70 / 30$ & ESP & Darco Hg & 0.5 & $1 / 2 / 3$ & $\mathrm{C}$ & & $1 / 2$ & & & & & 2 \\
\hline 12-Jul & 35 & $\mathrm{Su}$ & Br to Coal + ACI & $70 / 30$ & ESP & Darco $\mathrm{Hg}$ & 0.5 & $1 / 2 / 3$ & $\mathrm{C}$ & & $1 / 2$ & & & $\begin{array}{c}1 / 2+ \\
\text { Cooper } \\
\end{array}$ & $\mathrm{Z}$ & \\
\hline 13-Jul & 36 & $\mathrm{M}$ & Baseline & $70 / 30$ & & & 0 & $1 / 2 / 3$ & & & $1 / 2$ & $\begin{array}{c}\text { Mal. } \\
\text { Travel }\end{array}$ & & $\begin{array}{c}1 / 2+ \\
\text { Cooper } \\
\end{array}$ & $\mathrm{Z}$ & \\
\hline 14-Jul & 37 & $\mathrm{~T}$ & Upstream ESP Injection & $70 / 30$ & ESP & Darco Hg-LH & 2 & $1 / 2 / 3$ & $\mathrm{C}$ & & $1 / 2$ & $\begin{array}{l}\text { Mal. } \\
\text { Setup }\end{array}$ & & $\begin{array}{c}1 / 2+ \\
\text { Cooper } \\
\end{array}$ & $\mathrm{Z}$ & \\
\hline 15-Jul & 38 & $\mathrm{~W}$ & Upstream ESP Injection & $70 / 30$ & ESP & Darco Hg-LH & $\begin{array}{l}\text { Varying } \\
\text { rates } \\
0.5-2 \\
\end{array}$ & $1 / 2 / 3$ & $\mathrm{C}$ & $\mathrm{X}$ & $1 / 2$ & $\begin{array}{l}\text { Mal. } \\
\text { Test }\end{array}$ & & & & \\
\hline 16-Jul & 39 & Th & $\mathrm{Br}$ to $\mathrm{Coal}+\mathrm{ACI}$ & $70 / 30$ & ESP & $\begin{array}{l}\text { Darco Hg-LH } \\
\text { Finely Ground }\end{array}$ & $0.5 / 2 / 1$ & $1 / 2 / 3$ & & & $1 / 2$ & $\begin{array}{l}\text { Mal. } \\
\text { Test }\end{array}$ & & & & \\
\hline 18-Jul & 41 & $\mathrm{Sa}$ & $1 / 4$ unit test & $70 / 30$ & ESP & $\begin{array}{l}\text { Norit Darco } \\
\text { HgLH } \\
\end{array}$ & $0.5 / 1 / 2$ & $1 / 2 / 3$ & & & & & & & & \\
\hline
\end{tabular}




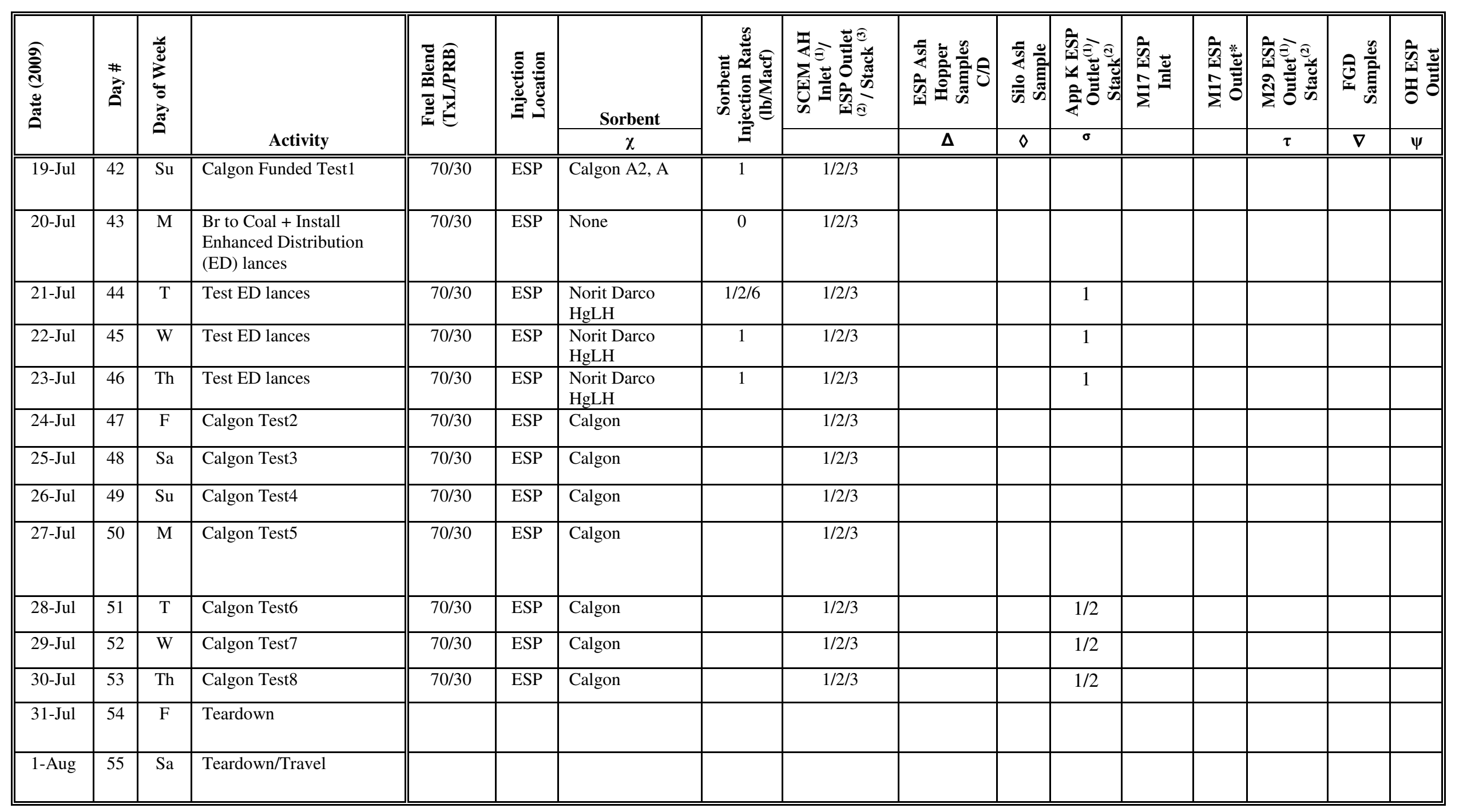




\section{Notes:}

$\chi$ Sample of each sorbent lot will be collected by Apogee.

$\triangle \mathrm{C}$ - ESP C: 5 -gal 2F2C; quart 2F11C, quart 2F14C

D - ESP D: quart 2F1D, 2F2D, 2F3D, 2F11D, 2F14D

Silo ash samples will be collected by Headwaters. Headwaters will collect an amount sufficient for their analysis plus a 5 gallon bucket for URS testing.

$\sigma$ Each day of sorbent trap collection consists of two runs at indicated location. Single point measurements. Runs at each location will alternate between two-bed traps and third-bed spiked traps. ESP outlet sorbent trap will be conducted in duct $2 \mathrm{C} 1$.

* Method 17 runs will be 3.5 hours long; two runs per day; first run will be for upper half traverse of duct; second run will be for lower half traverse of duct, conducted in ESP outlet duct 2D1; Inlet ports sampled should correspond to the 2D ESP (sample 2D1 ports with 1 filter, then 2D2 ports with another filter; kep alternating for duration of M17 outlet run)

$\tau$ M29 will be conducted in ESP outlet duct 2D1 and at the stack (single point or traverse?)

$\Psi \quad$ 2-3 runs per day of $\mathrm{OH}$ at ESP outlet, three port traverse of ESP outlet duct 2D1

$\mathrm{Z}$ - DF, Hg, Trace Metals, wt\% at the Absorber Blowdown, pH, ORP (Field Blank per sampler)

Mal = Malvern PSD analyzer system 
Table 2-16 displays the sorbent injection schedule for Phase IV of this test program, and Table 217 displays the bromide addition test schedule.

Table 2-16. Sorbent Injection Schedule - Parametric Testing, Phase IV

\begin{tabular}{|c|c|c|c|c|}
\hline Start Time (CT) & End Time (CT) & Injection Activity & $\begin{array}{l}\text { Injection } \\
\text { Location }\end{array}$ & $\begin{array}{c}\begin{array}{c}\text { Injection Rate* } \\
\text { (lb/Macf) }\end{array} \\
\end{array}$ \\
\hline 6/9/2009 0:00 & 6/13/2009 10:00 & Baseline & - & 0 \\
\hline 6/13/2009 10:00 & $6 / 15 / 20092: 30$ & DARCO Hg-LH & $\mathrm{AH}$ & 1.89 \\
\hline $6 / 15 / 20092: 30$ & 6/17/2009 0:00 & DARCO Hg-LH & $\mathrm{AH}$ & 0.48 \\
\hline 6/17/2009 0:00 & 6/18/2009 22:05 & DARCO Hg-LH & $\mathrm{AH}$ & 0.99 \\
\hline 6/18/2009 22:05 & $6 / 22 / 200910: 58$ & Baseline & -- & 0 \\
\hline $6 / 22 / 200910: 58$ & 6/22/2009 22:15 & Sorbtech C-PAC & $\mathrm{AH}$ & 0.96 \\
\hline $6 / 22 / 200922: 15$ & 6/23/2009 10:25 & Baseline & -- & 0 \\
\hline $6 / 23 / 2009$ 10:25 & 6/23/2009 20:00 & Calgon CF Plus & $\mathrm{AH}$ & 0.95 \\
\hline 6/23/2009 20:00 & 6/24/2009 9:50 & Baseline & -- & 0 \\
\hline $6 / 24 / 20099: 50$ & 6/24/2009 19:10 & Norit EXP224 & $\mathrm{AH}$ & 0.95 \\
\hline $6 / 24 / 2009$ 19:10 & $6 / 25 / 200913: 58$ & Baseline & -- & 0 \\
\hline $6 / 25 / 200913: 58$ & $6 / 25 / 2009$ 18:20 & CF Plus Ultra & $\mathrm{AH}$ & 0.98 \\
\hline $6 / 25 / 2009$ 18:20 & $6 / 25 / 2009$ 18:25 & Baseline & -- & 0 \\
\hline $6 / 25 / 2009$ 18:25 & $6 / 25 / 200922: 55$ & DARCO Hg-LH & $\mathrm{AH}$ & 0.91 \\
\hline $6 / 25 / 200922: 55$ & 6/27/2009 11:27 & Baseline & -- & 0 \\
\hline $6 / 27 / 2009$ 11:27 & 6/28/2009 9:30 & DARCO Hg-LH & $\mathrm{AH}$ & 1.00 \\
\hline 6/28/2009 9:30 & 6/28/2009 17:00 & DARCO Hg-LH & $\mathrm{AH}$ & 1.83 \\
\hline $6 / 28 / 2009$ 17:00 & $7 / 8 / 2009$ 10:50 & Baseline & -- & 0 \\
\hline $7 / 8 / 2009$ 10:50 & $7 / 8 / 200914: 55$ & DARCO Hg & ESP (Full) & 0.47 \\
\hline $7 / 8 / 200914: 55$ & $7 / 8 / 2009$ 15:50 & DARCO Hg-LH & ESP (Full) & 0.98 \\
\hline $7 / 8 / 200915: 50$ & $7 / 8 / 2009$ 17:20 & DARCO Hg-LH & ESP (Full) & 1.84 \\
\hline 7/8/2009 17:20 & $7 / 10 / 200912: 10$ & Baseline & -- & 0 \\
\hline $7 / 10 / 200912: 10$ & $7 / 10 / 2009$ 18:30 & DARCO Hg & ESP (Full) & 0.47 \\
\hline 7/10/2009 18:30 & 7/11/2009 13:15 & Baseline & -- & 0 \\
\hline 7/11/2009 13:15 & 7/11/2009 17:35 & DARCO Hg & ESP (Full) & 0.61 \\
\hline 7/11/2009 17:35 & $7 / 12 / 20096: 15$ & Baseline & -- & 0 \\
\hline $7 / 12 / 20096: 15$ & $7 / 12 / 200916: 55$ & DARCO Hg & ESP (Full) & 0.48 \\
\hline $7 / 12 / 200916: 55$ & $7 / 14 / 20096: 30$ & Baseline & -- & 0 \\
\hline $7 / 14 / 20096: 30$ & 7/14/2009 15:20 & DARCO Hg-LH & ESP (Full) & 1.89 \\
\hline 7/14/2009 15:20 & $7 / 15 / 20099: 25$ & Baseline & -- & 0 \\
\hline $7 / 15 / 20099: 25$ & 7/15/2009 13:00 & DARCO Hg-LH & ESP (Full) & 0.48 \\
\hline 7/15/2009 13:00 & 7/15/2009 13:30 & DARCO Hg-LH & ESP (Full) & 0.69 \\
\hline 7/15/2009 13:30 & 7/15/2009 14:00 & DARCO Hg-LH & ESP (Full) & 0.95 \\
\hline 7/15/2009 14:00 & $7 / 15 / 200914: 30$ & DARCO Hg-LH & ESP (Full) & 1.17 \\
\hline $7 / 15 / 200914: 30$ & 7/15/2009 15:00 & DARCO Hg-LH & ESP (Full) & 1.39 \\
\hline 7/15/2009 15:00 & 7/15/2009 15:30 & DARCO Hg-LH & ESP (Full) & 1.51 \\
\hline $7 / 15 / 2009$ 15:30 & 7/15/2009 16:00 & DARCO Hg-LH & ESP (Full) & 1.73 \\
\hline 7/15/2009 16:00 & $7 / 16 / 20099: 00$ & Baseline & -- & 0 \\
\hline 7/16/2009 9:00 & 7/16/2009 13:00 & Darco Hg-LH Fine & ESP (Full) & 0.46 \\
\hline 7/16/2009 13:00 & $7 / 16 / 2009$ 14:15 & Darco Hg-LH Fine & ESP (Full) & 1.64 \\
\hline $7 / 16 / 200914: 15$ & $7 / 16 / 200920: 30$ & Darco Hg-LH Fine & ESP (Full) & 0.91 \\
\hline $7 / 16 / 200920: 30$ & 7/17/2009 10:05 & Baseline & -- & 0 \\
\hline 7/17/2009 10:05 & 7/17/2009 18:10 & DARCO Hg-LH & $\operatorname{ESP}(1 / 4)$ & 0.98 \\
\hline 7/17/2009 18:10 & 7/18/2009 9:00 & Baseline & -- & 0 \\
\hline 7/18/2009 9:00 & 7/18/2009 13:00 & DARCO Hg-LH & $\operatorname{ESP}(1 / 4)$ & 0.44 \\
\hline 7/18/2009 13:00 & 7/18/2009 15:30 & DARCO Hg-LH & $\operatorname{ESP}(1 / 4)$ & 0.98 \\
\hline 7/18/2009 15:30 & $7 / 18 / 2009$ 18:30 & DARCO Hg-LH & $\operatorname{ESP}(1 / 4)$ & 1.85 \\
\hline $7 / 18 / 2009$ 18:30 & 7/19/2009 9:30 & Baseline & -- & 0 \\
\hline
\end{tabular}




\begin{tabular}{|c|c|c|c|c|}
\hline Start Time (CT) & End Time (CT) & Injection Activity & $\begin{array}{l}\text { Injection } \\
\text { Location }\end{array}$ & $\begin{array}{c}\text { Injection Rate* } \\
\text { (lb/Macf) }\end{array}$ \\
\hline $7 / 19 / 20099: 30$ & $7 / 19 / 200913: 30$ & Calgon A2 & $\bar{E} \operatorname{ESP}(1 / 4)$ & 0.96 \\
\hline $7 / 19 / 2009$ 13:30 & 7/19/2009 14:10 & Baseline & -- & 0 \\
\hline 7/19/2009 14:10 & 7/19/2009 18:00 & Calgon A & $\operatorname{ESP}(1 / 4)$ & 0.88 \\
\hline 7/19/2009 18:00 & $7 / 21 / 2009$ 10:47 & Baseline & -- & 0 \\
\hline $7 / 21 / 2009$ 10:47 & $7 / 21 / 2009$ 13:23 & DARCO Hg-LH & $\operatorname{ESP}(1 / 4)$ & 0.95 \\
\hline $7 / 21 / 200913: 23$ & 7/21/2009 16:00 & DARCO Hg-LH & $\operatorname{ESP}(1 / 4)$ & 1.85 \\
\hline $7 / 21 / 2009$ 16:00 & $7 / 21 / 200918: 50$ & DARCO Hg-LH & $\operatorname{ESP}(1 / 4)$ & 5.49 \\
\hline $7 / 21 / 2009$ 18:50 & $7 / 22 / 2009$ 10:17 & Baseline & -- & 0 \\
\hline $7 / 22 / 2009$ 10:17 & $7 / 22 / 2009$ 17:25 & DARCO Hg-LH & $\operatorname{ESP}(1 / 4)$ & 1.06 \\
\hline $7 / 22 / 2009$ 17:25 & $7 / 23 / 2009$ 10:40 & Baseline & -- & 0 \\
\hline $7 / 23 / 2009$ 10:40 & $7 / 23 / 200920: 20$ & DARCO Hg-LH & $\operatorname{ESP}(1 / 4)$ & 1.01 \\
\hline $7 / 23 / 2009$ 20:20 & $7 / 24 / 20099: 18$ & Baseline & -- & 0 \\
\hline 7/24/2009 9:18 & $7 / 24 / 2009$ 11:15 & CANG-2 & $\operatorname{ESP}(1 / 4)$ & 1.14 \\
\hline $7 / 24 / 2009$ 11:15 & $7 / 24 / 2009$ 12:55 & CANG-2 & $\operatorname{ESP}(1 / 4)$ & 1.82 \\
\hline $7 / 24 / 2009$ 12:55 & $7 / 24 / 200913: 50$ & CANG-2 & $\operatorname{ESP}(1 / 4)$ & 3.49 \\
\hline 7/24/2009 13:50 & 7/24/2009 14:40 & Baseline & -- & 0 \\
\hline 7/24/2009 14:40 & 7/24/2009 16:03 & CNAHF-1 & $\operatorname{ESP}(1 / 4)$ & 1.93 \\
\hline 7/24/2009 16:03 & $7 / 24 / 2009$ 17:20 & CNAHF-1 & $\operatorname{ESP}(1 / 4)$ & 4.00 \\
\hline 7/24/2009 17:20 & 7/25/2009 10:50 & Baseline & -- & 0 \\
\hline $7 / 25 / 2009$ 10:50 & 7/25/2009 12:14 & CNAHF-1 & $\operatorname{ESP}(1 / 4)$ & 1.60 \\
\hline $7 / 25 / 2009$ 12:14 & 7/25/2009 13:50 & CNAHF-1 & $\operatorname{ESP}(1 / 4)$ & 4.06 \\
\hline 7/25/2009 13:50 & 7/25/2009 14:36 & Baseline & -- & 0 \\
\hline $7 / 25 / 2009$ 14:36 & 7/25/2009 15:55 & CANG-2 & $\operatorname{ESP}(1 / 4)$ & 1.66 \\
\hline $7 / 25 / 2009$ 15:55 & $7 / 25 / 2009$ 17:20 & CANG-2 & $\operatorname{ESP}(1 / 4)$ & 4.13 \\
\hline $7 / 25 / 2009$ 17:20 & 7/25/2009 17:52 & Baseline & -- & 0 \\
\hline $7 / 25 / 2009$ 17:52 & $7 / 25 / 200918: 30$ & DARCO Hg-LH & $\operatorname{ESP}(1 / 4)$ & 1.80 \\
\hline $7 / 25 / 200918: 30$ & $7 / 25 / 200922: 25$ & DARCO Hg-LH & $\operatorname{ESP}(1 / 4)$ & 3.85 \\
\hline $7 / 25 / 200922: 25$ & $7 / 26 / 200910: 35$ & Baseline & -- & 0 \\
\hline $7 / 26 / 2009$ 10:35 & $7 / 26 / 200912: 30$ & Calgon A2 & $\operatorname{ESP}(1 / 4)$ & 2.41 \\
\hline $7 / 26 / 2009$ 12:30 & $7 / 26 / 200914: 30$ & Calgon A2 & $\operatorname{ESP}(1 / 4)$ & 2.93 \\
\hline $7 / 26 / 2009$ 14:30 & $7 / 26 / 2009$ 14:49 & Baseline & -- & 0 \\
\hline $7 / 26 / 2009$ 14:49 & $7 / 26 / 200916: 50$ & Calgon A & $\operatorname{ESP}(1 / 4)$ & 1.73 \\
\hline $7 / 26 / 2009$ 16:50 & $7 / 26 / 2009$ 17:47 & Baseline & -- & 0 \\
\hline $7 / 26 / 2009$ 17:47 & $7 / 26 / 2009$ 19:15 & Calgon CN6 & $\operatorname{ESP}(1 / 4)$ & 1.87 \\
\hline $7 / 26 / 2009$ 19:15 & $7 / 27 / 2009$ 11:57 & Baseline & -- & 0 \\
\hline $7 / 27 / 2009$ 11:57 & $7 / 27 / 2009$ 13:15 & Calgon CN30 & $\operatorname{ESP}(1 / 4)$ & 1.76 \\
\hline $7 / 27 / 2009$ 13:15 & $7 / 27 / 200913: 40$ & Baseline & -- & 0 \\
\hline $7 / 27 / 2009$ 13:40 & $7 / 27 / 2009$ 15:25 & Calgon CN6 & $\operatorname{ESP}(1 / 4)$ & 1.59 \\
\hline $7 / 27 / 2009$ 15:25 & 7/27/2009 19:05 & Baseline & -- & 0 \\
\hline $7 / 27 / 2009$ 19:05 & $7 / 27 / 200922: 00$ & Calgon THB & $\operatorname{ESP}(1 / 4)$ & 2.10 \\
\hline $7 / 27 / 2009$ 22:00 & 7/28/2009 10:00 & Baseline & -- & 0 \\
\hline $7 / 28 / 2009$ 10:00 & $7 / 28 / 2009$ 11:15 & Calgon A2 & $\operatorname{ESP}(1 / 4)$ & 0.90 \\
\hline $7 / 28 / 2009$ 11:15 & $7 / 28 / 2009$ 13:10 & Calgon A2 & $\operatorname{ESP}(1 / 4)$ & 2.06 \\
\hline $7 / 28 / 2009$ 13:10 & $7 / 28 / 200914: 00$ & Baseline & -- & 0 \\
\hline $7 / 28 / 2009$ 14:00 & $7 / 28 / 2009$ 15:10 & Calgon A & $\operatorname{ESP}(1 / 4)$ & 1.89 \\
\hline $7 / 28 / 2009$ 15:10 & $7 / 28 / 2009$ 16:00 & Baseline & -- & 0 \\
\hline $7 / 28 / 2009$ 16:00 & $7 / 28 / 2009$ 17:10 & Calgon A & $\operatorname{ESP}(1 / 4)$ & 0.90 \\
\hline $7 / 28 / 2009$ 17:10 & $7 / 28 / 2009$ 17:20 & Baseline & -- & 0 \\
\hline $7 / 28 / 2009$ 17:20 & $7 / 28 / 200918: 45$ & Calgon A & $\operatorname{ESP}(1 / 4)$ & 1.83 \\
\hline $7 / 28 / 2009$ 18:45 & $7 / 28 / 2009$ 19:45 & Baseline & -- & 0 \\
\hline $7 / 28 / 2009$ 19:45 & $7 / 28 / 200920: 50$ & Calgon CF Plus & $\operatorname{ESP}(1 / 4)$ & 2.00 \\
\hline $7 / 28 / 200920: 50$ & $7 / 29 / 20098: 35$ & Baseline & -- & 0 \\
\hline $7 / 29 / 20098: 35$ & $7 / 29 / 2009$ 10:45 & Calgon CF Plus & $\operatorname{ESP}(1 / 4)$ & 0.48 \\
\hline $7 / 29 / 2009$ 10:45 & $7 / 29 / 2009$ 11:45 & Baseline & -- & 0 \\
\hline
\end{tabular}




\begin{tabular}{||l|c|c|c|c||}
\hline \hline Start Time $(\mathbf{C T})$ & End Time $(\mathbf{C T})$ & Injection Activity & $\begin{array}{c}\text { Injection } \\
\text { Location }\end{array}$ & $\begin{array}{c}\text { Injection Rate* } \\
\text { (lb/Macf) }\end{array}$ \\
\hline \hline $7 / 29 / 200911: 45$ & $7 / 29 / 200913: 00$ & Calgon CF & ESP $(1 / 4)$ & 0.99 \\
\hline $7 / 29 / 200913: 00$ & $7 / 29 / 200913: 45$ & Baseline & -- & 0 \\
\hline $7 / 29 / 200913: 45$ & $7 / 29 / 200915: 15$ & Calgon N & ESP $(1 / 4)$ & 0.96 \\
\hline $7 / 29 / 200915: 15$ & $7 / 29 / 200915: 40$ & Calgon N & ESP $(1 / 4)$ & 0.95 \\
\hline $7 / 29 / 200915: 40$ & $7 / 29 / 200917: 00$ & Baseline & -- & 0 \\
\hline $7 / 29 / 200917: 00$ & $7 / 29 / 200917: 45$ & Calgon CAN & ESP $(1 / 4)$ & 0.95 \\
\hline $7 / 29 / 200917: 45$ & $7 / 29 / 200918: 30$ & Baseline & -- & 0 \\
\hline $7 / 29 / 200918: 30$ & $7 / 29 / 200919: 45$ & Calgon CNA-HF & ESP $(1 / 4)$ & 0.98 \\
\hline $7 / 29 / 200919: 45$ & $7 / 29 / 200920: 00$ & Baseline & -- & 0 \\
\hline $7 / 29 / 200920: 00$ & $7 / 29 / 200922: 00$ & Calgon NB & ESP $(1 / 4)$ & 0.91 \\
\hline $7 / 29 / 200922: 00$ & $7 / 30 / 20099: 23$ & Baseline & -- & 0 \\
\hline $7 / 30 / 20099: 23$ & $7 / 30 / 200911: 00$ & Calgon A & ESP $(1 / 4)$ & 1.55 \\
\hline
\end{tabular}

* Injection rates based on treating all of Unit 2 flue gas if the location is AH or ESP(Full) and 1/4 of Unit 2 flue gas if the location is $\operatorname{ESP}(1 / 4)$.

Table 2-17. Bromide Addition Schedule - Parametric Testing, Phase IV

\begin{tabular}{||l|l|c||}
\hline \hline Start Time $(\mathbf{C T})$ & \multicolumn{1}{|c||}{ End Time (CT) } & $\begin{array}{c}\text { Addition Rate } \\
\text { (ppm Br to coal, dry) }\end{array}$ \\
\hline \hline $7 / 9 / 20090: 00$ & $7 / 9 / 200911: 05$ & 0 \\
\hline $7 / 9 / 200911: 05$ & $7 / 9 / 200913: 30$ & 172 \\
\hline $7 / 9 / 200913: 30$ & $7 / 9 / 200913: 40$ & 0 \\
\hline $7 / 9 / 200913: 40$ & $7 / 9 / 200918: 24$ & 172 \\
\hline $7 / 9 / 200918: 24$ & $7 / 10 / 20097: 33$ & 85 \\
\hline $7 / 10 / 20097: 33$ & $7 / 10 / 200917: 01$ & 97 \\
\hline $7 / 10 / 200917: 01$ & $7 / 11 / 20097: 15$ & 176 \\
\hline $7 / 11 / 20097: 15$ & $7 / 11 / 200917: 40$ & 164 \\
\hline $7 / 11 / 200917: 40$ & $7 / 11 / 200918: 45$ & 78 \\
\hline $7 / 11 / 200918: 45$ & $7 / 12 / 20093: 00$ & 57 \\
\hline $7 / 12 / 20093: 00$ & $7 / 12 / 20096: 30$ & 112 \\
\hline $7 / 12 / 20096: 30$ & $7 / 12 / 200916: 00$ & 122 \\
\hline $7 / 12 / 200916: 00$ & $7 / 16 / 200911: 00$ & 0 \\
\hline $7 / 16 / 200911: 00$ & $7 / 16 / 200916: 00$ & 280 \\
\hline $7 / 16 / 200916: 00$ & $7 / 16 / 200917: 00$ & 173 \\
\hline $7 / 16 / 200917: 00$ & $7 / 20 / 20099: 52$ & 0 \\
\hline $7 / 20 / 20099: 52$ & $7 / 20 / 200917: 01$ & 182 \\
\hline
\end{tabular}

Tables 2-18 through 2-21 present the start and stop times for the $\mathrm{OH}, \mathrm{M} 29, \mathrm{M} 17$, and the sorbent trap measurements, respectively. 
Table 2-18. OH Sample Schedule for Unit 2 Parametric Tests, Phase IV

\begin{tabular}{|l|c|c|}
\hline \multicolumn{1}{|c|}{ Conditions } & Date & $\begin{array}{c}\text { Start \& Stop } \\
\text { Times }\end{array}$ \\
\hline \hline Baseline & & \\
\hline Run 1 & 12-Jun-09 & $9: 42-12: 04$ \\
\hline Run 2 & 12-Jun-09 & $12: 40-14: 50$ \\
\hline Run 3 & 12-Jun-09 & $15: 16-17: 27$ \\
\hline AH Injection - Darco Hg-LH & & \\
\hline Run 1 & 18-Jun-09 & $10: 04-12: 15$ \\
\hline Run 2 & 18-Jun-09 & $13: 28-15: 47$ \\
\hline Run 3 & 18-Jun-09 & $16: 22-18: 32$ \\
\hline ESP Injection $-\mathrm{CaBr}_{2}$ & & \\
\hline Run 1 & 9-Jul-09 & $12: 21-14: 38$ \\
\hline Run 2 & 9-Jul-09 & $15: 57-17: 40$ \\
\hline ESP Injection - Darco Hg and & & \\
\hline CaBr 2 & & \\
\hline Run 1 & 10-Jul-09 & $9: 13-11: 13$ \\
\hline Run 2 & 10-Jul-09 & $14: 30-16: 15$ \\
\hline ESP Injection - Darco Hg and & & \\
\hline CaBr 2 & & \\
\hline Run 1 & 11-Jul-09 & $9: 34-11: 19$ \\
\hline Run 2 & 11-Jul-09 & $14: 09-16: 09$ \\
\hline
\end{tabular}
Table 2-19. M29 Sample Schedule for Unit 2 Parametric Tests, Phase IV
(XFM Runs Conducted during Same Time Periods)

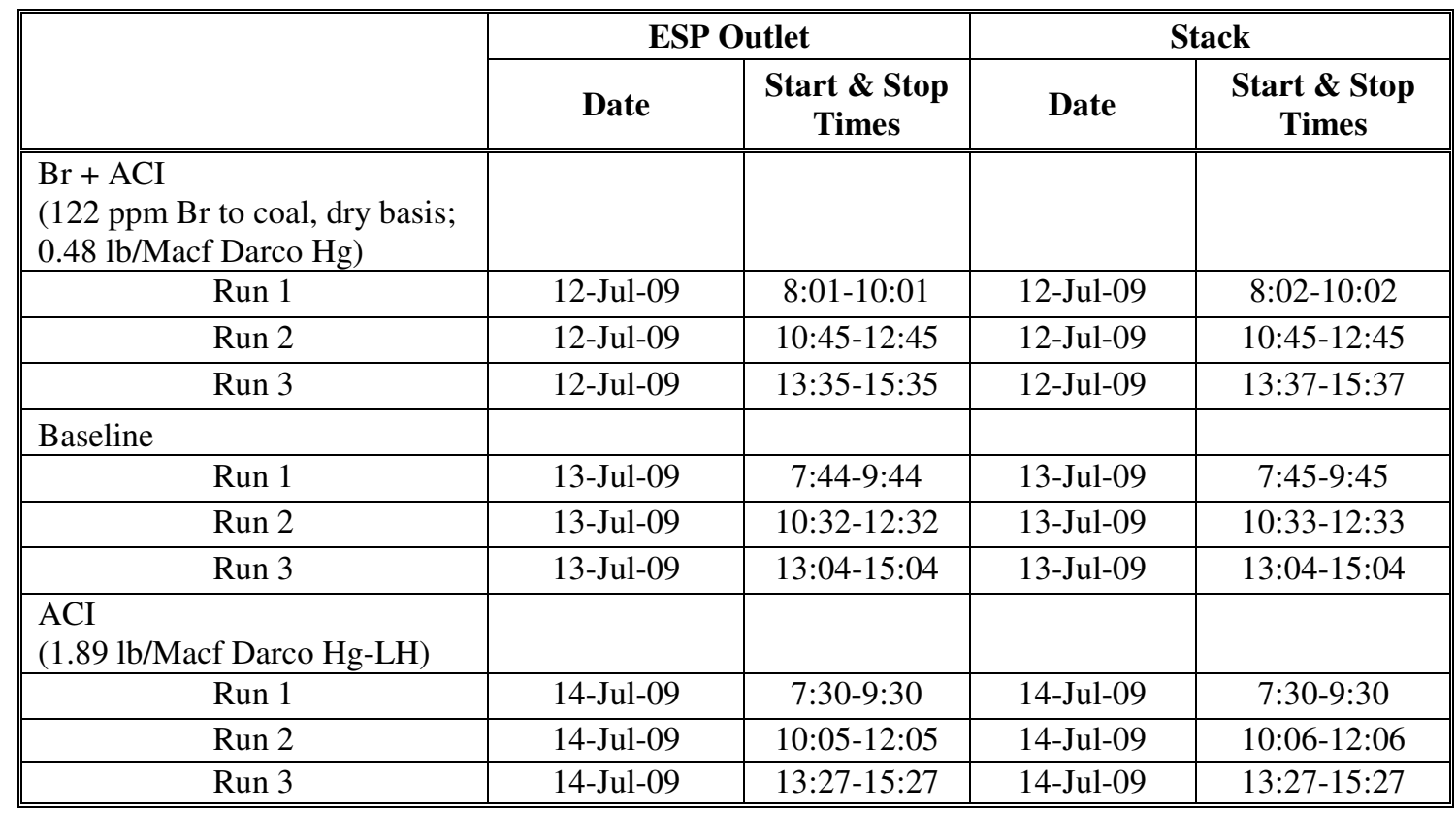


Table 2-20. M17 Sample Schedule for Phase IV Parametric Tests

\begin{tabular}{|c|c|c|c||}
\hline \multirow{3}{*}{ Condition } & $\begin{array}{c}\text { Injection } \\
\text { Rate } \\
\text { (lbs/MMacf) }\end{array}$ & Date & Condition Time \\
\hline \hline \multirow{3}{*}{ Baseline } & N/A & $6 / 10 / 2009$ & $9: 08-17: 44$ \\
\cline { 2 - 4 } & N/A & $6 / 11 / 2009$ & $8: 43-16: 25$ \\
\hline \multirow{4}{*}{ ACI } & 1.89 & $6 / 13 / 2009$ & $10: 50-17: 00$ \\
\cline { 2 - 4 } & 1.89 & $6 / 14 / 2009$ & $7: 40-15: 21$ \\
\cline { 2 - 4 } & 1.89 & $6 / 15 / 2009$ & $8: 05-16: 19$ \\
\cline { 2 - 4 } & 0.48 & $6 / 16 / 2009$ & $9: 01-18: 00$ \\
\cline { 2 - 4 } & 0.99 & $6 / 17 / 2009$ & $8: 30-17: 00$ \\
\hline
\end{tabular}

Table 2-21. Sorbent Trap Sample Schedule for Phase IV Parametric Tests

\begin{tabular}{|c|c|c|c|c|c|}
\hline \multicolumn{3}{|c|}{ ESP Outlet } & \multicolumn{3}{|c|}{ Stack } \\
\hline Date (in 2009) & Start Time & Stop Time & Date (in 2009) & Start Time & Stop Time \\
\hline 6/11 & 9:16 & $17: 16$ & $6 / 11$ & $9: 16$ & $17: 16$ \\
\hline $6 / 11$ & $17: 42$ & $1: 43$ & $6 / 11$ & $17: 31$ & $1: 31$ \\
\hline $6 / 12$ & $8: 55$ & $16: 55$ & $6 / 12$ & $8: 10$ & 16:04 \\
\hline $6 / 12$ & $17: 24$ & $1: 24$ & $6 / 12$ & $16: 22$ & $00: 22$ \\
\hline $6 / 13$ & $10: 52$ & 16:53 & $6 / 13$ & 11:39 & $17: 47$ \\
\hline $6 / 13$ & $17: 21$ & $1: 22$ & $6 / 13$ & 18:00 & $2: 00$ \\
\hline $6 / 14$ & $7: 57$ & 15:07 & $6 / 14$ & $8: 57$ & 16:01 \\
\hline $6 / 14$ & $15: 25$ & $23: 26$ & $6 / 14$ & $16: 20$ & 00:20 \\
\hline $6 / 15$ & $8: 53$ & $16: 53$ & $6 / 15$ & $10: 21$ & $16: 30$ \\
\hline $6 / 15$ & $18: 00$ & 2:01 & $6 / 15$ & $17: 23$ & $1: 24$ \\
\hline $6 / 16$ & $7: 53$ & $15: 54$ & $6 / 16$ & $9: 12$ & $17: 13$ \\
\hline $6 / 16$ & $17: 58$ & $22: 58$ & $6 / 16$ & 19:01 & $0: 02$ \\
\hline $6 / 17$ & $7: 52$ & $15: 45$ & $6 / 17$ & $9: 17$ & $17: 17$ \\
\hline $6 / 17$ & $16: 15$ & $0: 15$ & $6 / 17$ & 18:06 & $2: 07$ \\
\hline $6 / 18$ & $7: 53$ & $15: 54$ & $6 / 18$ & $8: 55$ & $16: 55$ \\
\hline $6 / 21$ & $8: 42$ & $16: 42$ & $6 / 21$ & $9: 48$ & $17: 48$ \\
\hline $6 / 21$ & $17: 31$ & $1: 31$ & $6 / 21$ & $18: 52$ & $2: 53$ \\
\hline $6 / 22$ & $11: 57$ & $14: 57$ & $6 / 22$ & $11: 56$ & $14: 56$ \\
\hline $6 / 22$ & $15: 44$ & 19:44 & $6 / 22$ & $15: 44$ & $19: 42$ \\
\hline $6 / 23$ & $11: 15$ & $15: 15$ & $6 / 23$ & $11: 15$ & $15: 15$ \\
\hline $6 / 23$ & $15: 59$ & 19:59 & $6 / 23$ & $15: 57$ & 19:57 \\
\hline $6 / 24$ & $10: 42$ & $13: 42$ & $6 / 24$ & $10: 40$ & $13: 40$ \\
\hline $6 / 24$ & $14: 18$ & $16: 18$ & $6 / 24$ & $14: 13$ & $15: 43$ \\
\hline $6 / 26$ & $9: 42$ & $12: 42$ & $6 / 26$ & $9: 30$ & 13:00 \\
\hline $6 / 26$ & $13: 58$ & 18:58 & $6 / 26$ & $13: 52$ & $18: 53$ \\
\hline $6 / 27$ & $11: 58$ & $16: 29$ & $6 / 27$ & 12:00 & $16: 30$ \\
\hline $6 / 27$ & 17:11 & $20: 11$ & $6 / 27$ & $16: 57$ & 19:57 \\
\hline $6 / 28$ & $9: 59$ & $12: 59$ & $6 / 28$ & 10:00 & $13: 00$ \\
\hline $6 / 28$ & $13: 24$ & $15: 54$ & $6 / 28$ & $13: 21$ & $15: 51$ \\
\hline $7 / 8$ & 11:30 & $14: 30$ & $7 / 8$ & $11: 25$ & $14: 25$ \\
\hline $7 / 8$ & $16: 15$ & 17:09 & $7 / 8$ & $16: 15$ & $17: 10$ \\
\hline $7 / 9$ & $11: 55$ & $14: 55$ & $7 / 9$ & $11: 55$ & $14: 55$ \\
\hline
\end{tabular}




\begin{tabular}{|c|c|c|c||c|c||}
\hline \multicolumn{7}{|c||}{ ESP Outlet } & \multicolumn{2}{c||}{ Stack } \\
\hline \hline Date (in 2009) & Start Time & \multicolumn{1}{c|}{ Stop Time } & \multicolumn{1}{c|}{ Date (in 2009) } & Start Time & Stop Time \\
\hline \hline $7 / 10$ & $8: 49$ & $11: 49$ & $7 / 10$ & $8: 30$ & $11: 30$ \\
\hline $7 / 10$ & $14: 20$ & $16: 40$ & $7 / 10$ & $14: 20$ & $16: 56$ \\
\hline $7 / 11$ & $9: 10$ & $11: 35$ & $7 / 11$ & $9: 10$ & $12: 10$ \\
\hline $7 / 11$ & $14: 00$ & $16: 03$ & $7 / 11$ & $14: 00$ & $16: 09$ \\
\hline $7 / 12$ & $8: 14$ & $11: 15$ & $7 / 12$ & $8: 23$ & $11: 23$ \\
\hline $7 / 12$ & $12: 56$ & $15: 36$ & $7 / 12$ & $12: 30$ & $15: 30$ \\
\hline $7 / 13$ & $7: 55$ & $10: 55$ & $7 / 13$ & $7: 51$ & $10: 51$ \\
\hline & & & $7 / 13$ & $12: 53$ & $15: 53$ \\
\hline $7 / 14$ & $7: 37$ & $10: 37$ & $7 / 14$ & $7: 35$ & $10: 36$ \\
\hline $7 / 14$ & $13: 33$ & $16: 34$ & $7 / 14$ & $13: 30$ & $16: 31$ \\
\hline $7 / 15$ & $9: 48$ & $12: 48$ & $7 / 15$ & $9: 47$ & $12: 47$ \\
\hline $7 / 15$ & $13: 26$ & $16: 24$ & $7 / 15$ & $13: 25$ & $16: 22$ \\
\hline $7 / 16$ & $9: 50$ & $12: 50$ & $7 / 16$ & $9: 48$ & $12: 48$ \\
\hline $7 / 16$ & $13: 18$ & $16: 18$ & $7 / 16$ & $13: 18$ & $16: 18$ \\
\hline $7 / 21$ & $11: 29$ & $13: 09$ & & & \\
\hline $7 / 21$ & $14: 10$ & $15: 49$ & & & \\
\hline $7 / 22$ & $10: 54$ & $12: 36$ & & & \\
\hline $7 / 22$ & $13: 15$ & $14: 53$ & & & \\
\hline $7 / 22$ & $15: 31$ & $17: 09$ & & & \\
\hline $7 / 23$ & $11: 23$ & $12: 58$ & & & \\
\hline $7 / 23$ & $13: 40$ & $15: 14$ & & & \\
\hline $7 / 23$ & $15: 58$ & $17: 33$ & & & \\
\hline \hline
\end{tabular}

\subsection{Plant Data Collection}

The project team coordinated with plant personnel to retrieve the necessary historical plant operating data files. Process data collected by the plant and by the project team for Unit 1 are summarized in Table 2-22. Process data collected from Unit 2 were similar, with the exception of the ESP operational parameters. The plant system that saved the ESP operational parameters malfunctioned and the data were lost. Since Phase IV tests on Unit 2 did not include long-term test conditions, the ESP operational data would have been of limited value in evaluating the impacts of sorbent injection on ESP operations.

A table of plant data collected for all parametric and long-term testing is provided in Appendix C. 
Table 2-22. Process Data Collected at Limestone Unit 1 and Unit 2

\begin{tabular}{||l|l||}
\hline Parameter & Sample/Signal/Test \\
\hline \hline Coal & Coal feed rate (ton/hr) \\
& Fraction of PRB and TxL fed by weight \\
\hline Unit operation & Boiler load (Gross MW) \\
& Heat Rate (Gross Btu/kwh) \\
& Boiler steam flow, temperature, and pressure \\
& Furnace $\mathrm{O}_{2}$ \\
\hline Flue Gas Temperatures & Air heater inlet, air heater outlet, ESP outlet \\
\hline ESP Operation & ESP power, current, voltage by field \\
(for ESPs A, B, C, D) & Sparking and arcing data \\
(for Unit 1 only) & Opacity \\
\hline Stack data & $\mathrm{NO}_{\mathrm{x}}(\mathrm{CEM})$ \\
& $\mathrm{SO}_{2}(\mathrm{CEM})$ \\
& $\mathrm{CO}$ \\
& $\mathrm{CO}$ \\
& Opacity \\
& Flow rate \\
\hline
\end{tabular}




\subsection{RESULTS AND DISCUSSION - PHASES I-III AND LONG-TERM TEST (2006-2007)}

This section presents results from Unit 1 parametric tests Phases I-III and the long-term test conducted in 2006 - 2007. Chapter 4 will present the 2009 test results, in a series of parametric tests was conducted on Unit 2. In 2009 the entire unit was treated with ACI so that mercury removal across the FGD could be measured. The 2009 results showed lower mercury removal across the ESP than the 2006-2007 results; a comparison of the two sets of data is provided in Chapter 5.

Phase I parametric testing was completed in December 2006. During this phase, several different sorbents were injected upstream of the Limestone Unit 1A ESP and evaluated for mercury removal performance. The effect of carbon injection on particulate emissions was also evaluated. As part of this testing, a velocity traverse was conducted at each sample location, coal and ash samples were collected, and baseline mercury removal performance was characterized across the Unit 1A ESP.

Phase II parametric testing was conducted in April 2007. During this phase potential "ashfriendly" sorbents and process configurations were evaluated. Norit America's DARCO Hg and DARCO Hg-LH sorbents were injected in three configurations: upstream of the ESP, Toxecon ${ }^{\mathrm{TM}}$ II, and staged injection. Phase III parametric tests were conducted in May 2007 with a revised Toxecon $^{\mathrm{TM}}$ II lance design. For both phases II and III, mercury removal performance and ESP operation and performance were evaluated.

The 60-day long-term injection test was started on June 22, 2007 and ran until August 21, 2007. Long-term testing was conducted with Norit's DARCO Hg-LH carbon injected upstream of the ESP at $2 \mathrm{lb} /$ Macf. In addition to evaluating mercury removal and ESP performance, fly ash was routinely sampled and analyzed for concrete properties.

The discussion of the 2006 - 2007 test results in this chapter is organized into the following sections:

- Unit operation;

- Baseline mercury measurements;

- Parametric sorbent injection mercury removal results;

- Long-term sorbent injection mercury removal results;

- Long-term sorbent injection mercury oxidation results;

- Effects of sorbent injection on ESP operation;

- Coal and ash mercury characterization;

- Concrete testing results;

- Flue gas halogen measurements;

- FGD measurements;

- Economic analysis. 


\subsection{Unit Operation}

\section{Unit Load}

Table 3-1 shows Unit 1 boiler load information for each test phase. The minimum and average values shown include process fluctuations and minor upsets, but data collected during unit outages were not included in the calculations. The average unit loads during Phases I and II and the long-term test were very similar, ranging from $869-882 \mathrm{MW}$. The average load during Phase III was slightly lower ( $823 \mathrm{MW})$. There were several hour-long process upsets during Phases II and III, specifically on May 3 and May 4, and May 22-24. During these upsets, the load decreased to values ranging from 400-600 MW for periods of approximately 2-3 hours.

Boiler load during the long-term injection test is plotted along with sorbent injection rate in Figure 3-1. During normal operation within the test period, the unit load was relatively stable and averaged $875 \mathrm{MW}$. Three short-term unplanned outages occurred during the test; these occurred on July 2, July 13-16, and briefly on July 17. The unit operated at a lower load of $800 \mathrm{MW}$ from July $18-22$.

Tables 3-2 and 3-3 show ESP inlet duct temperatures for each phase of ACI testing. Figure 3-2 plots ESP inlet temperature during long term testing. ESP inlet temperatures were typically between $280^{\circ} \mathrm{F}$ and $340^{\circ} \mathrm{F}$ throughout all phases of testing. Temperatures during long term testing were higher on average than during the other phases of testing. This can be attributed to the increased ambient temperatures and slightly higher load encountered during the summer months. The treated (U1A) and untreated (U1B) ESPs displayed similar temperature profiles, with the U1A ESP operating about $7^{\circ} \mathrm{F}$ higher than U1B ESP. The flue gas temperature fluctuated daily throughout the testing period. The pattern of flue gas temperature fluctuations correlated with ambient temperature and changes in unit load. In Section 3.4, an analysis is conducted to determine how these changes in flue gas temperature affected the mercury removal performance of the activated carbon.

Table 3-1. Gross Load for Unit 1 during ACI Testing

\begin{tabular}{|c|c|c|c|c|c||}
\hline Test Type & Date Start & Date Stop & $\begin{array}{c}\text { Boiler Load } \\
\text { Minimum } \\
\text { (MW) }\end{array}$ & $\begin{array}{c}\text { Boiler Load } \\
\text { Maximum } \\
\text { (MW) }\end{array}$ & $\begin{array}{c}\text { Boiler Load } \\
\text { Average } \\
\text { (MW) }\end{array}$ \\
\hline \hline Phase I & $11 / 28 / 06$ & $12 / 11 / 06$ & 784 & 899 & 882 \\
\hline Phase II & $04 / 26 / 07$ & $05 / 04 / 07$ & 583 & 901 & 869 \\
\hline Phase III & $05 / 22 / 07$ & $05 / 26 / 07$ & 494 & 900 & 823 \\
\hline Long Term & $06 / 19 / 07$ & $08 / 22 / 07$ & 280 & 907 & 875 \\
\hline
\end{tabular}


Table 3-2. U1A Treated ESP Inlet Temperature during ACI Testing

\begin{tabular}{|c|c|c|c|c|c||}
\hline Test Type & Date Start & Date Stop & $\begin{array}{c}\text { ESP A Inlet } \\
\text { Temperature } \\
\text { Minimum } \\
\left({ }^{\circ} \mathrm{F}\right)\end{array}$ & $\begin{array}{c}\text { ESP A Inlet } \\
\text { Temperature } \\
\text { Maximum } \\
\left({ }^{\circ} \mathrm{F}\right)\end{array}$ & $\begin{array}{c}\text { ESP A Inlet } \\
\text { Temperature } \\
\text { Average } \\
\left({ }^{\circ} \mathrm{F}\right)\end{array}$ \\
\hline \hline Phase I & $11 / 28 / 06$ & $12 / 11 / 06$ & 242 & 308 & 288 \\
\hline Phase II & $04 / 26 / 07$ & $05 / 04 / 07$ & 280 & 319 & 300 \\
\hline Phase III & $05 / 22 / 07$ & $05 / 26 / 07$ & 287 & 318 & 302 \\
\hline Long Term & $06 / 19 / 07^{1}$ & $08 / 22 / 07^{1}$ & 217 & 341 & 310 \\
\hline
\end{tabular}

Table 3-3. Inlet Temperature of Untreated U1B ESP during ACI Testing

\begin{tabular}{|c|c|c|c|c|c||}
\hline Test Type & Date Start & Date Stop & $\begin{array}{c}\text { ESP B Inlet } \\
\text { Temperature } \\
\text { Minimum } \\
\left({ }^{\circ} \mathrm{F}\right)\end{array}$ & $\begin{array}{c}\text { ESP B Inlet } \\
\text { Temperature } \\
\text { Max } \\
\left({ }^{\circ} \mathrm{F}\right)\end{array}$ & $\begin{array}{c}\text { ESP B Inlet } \\
\text { Temperature } \\
\text { Average } \\
\left({ }^{\circ} \mathrm{F}\right)\end{array}$ \\
\hline \hline Phase I & $11 / 28 / 06$ & $12 / 11 / 06$ & $\mathrm{n} / \mathrm{a}$ & $\mathrm{n} / \mathrm{a}$ & $\mathrm{n} / \mathrm{a}$ \\
\hline Phase II & $04 / 26 / 07$ & $05 / 04 / 07$ & 247 & 315 & 296 \\
\hline Phase III & $05 / 22 / 07$ & $05 / 26 / 07$ & 246 & 310 & 295 \\
\hline Long Term & $06 / 19 / 07^{1}$ & $08 / 22 / 07^{1}$ & 262 & 332 & 303 \\
\hline
\end{tabular}

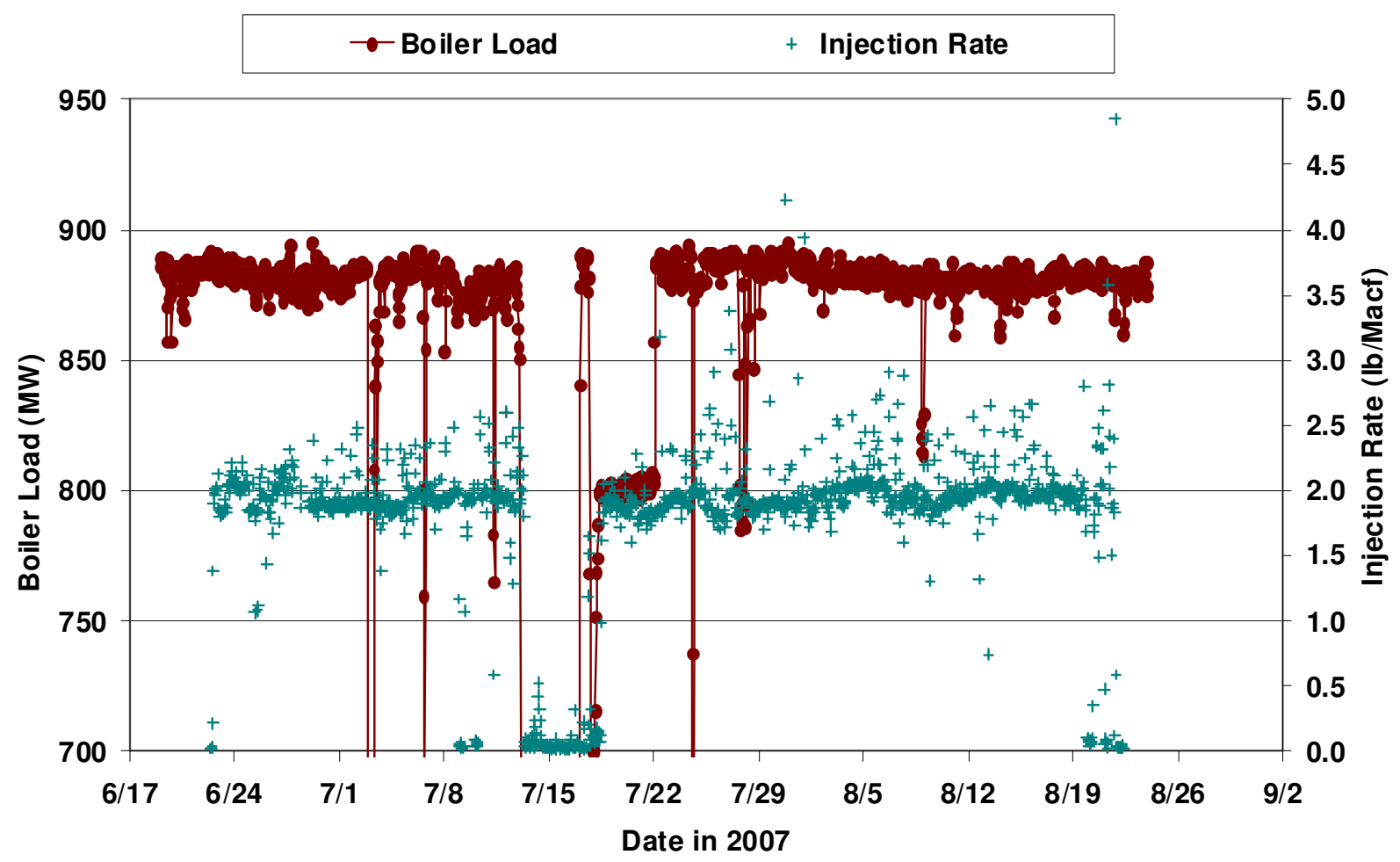

Figure 3-1. Boiler Load and Injection Rate during Long-Term Injection Tests 


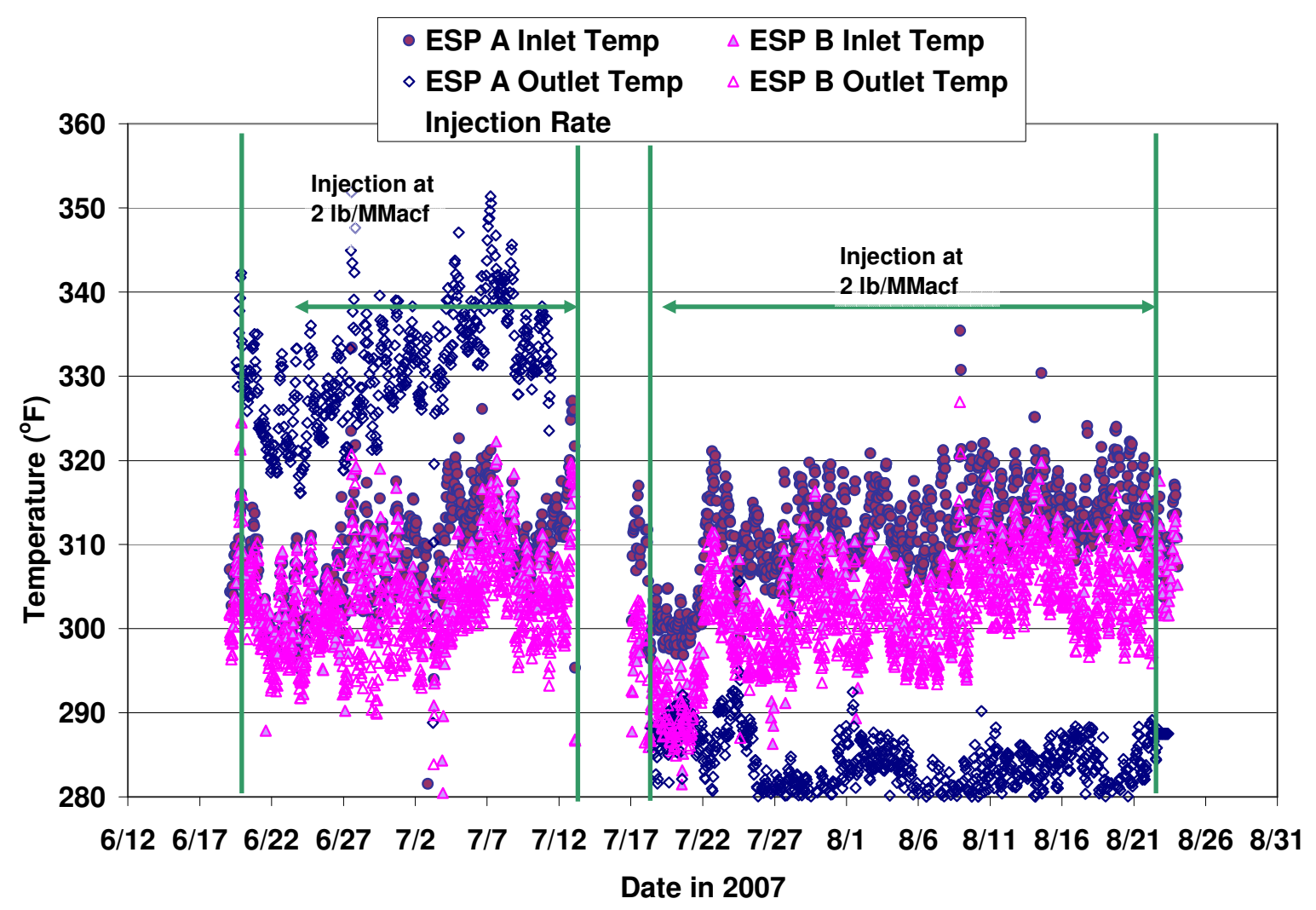

Figure 3-2. ESP Inlet Temperature during Long-Term Injection Test

\section{Velocity Traverse Measurements at Duct Sampling and Injection Locations}

Velocity traverses were conducted at the following flue gas duct locations: ESP inlet at the SCEM ports, ESP inlet at the carbon injection lance location, ESP outlet locations 1A1 and 1A2 (treated duct) and 1B1 and 1B2 (untreated duct), and the Toxecon II injection and measurement ports. Refer to Figure 2-2 for a drawing of the duct configuration and locations for these ports. Test results are listed in Appendix D. Velocity traverse measurements were conducted at each of the sampling ports in order to determine appropriate sampling probe placement in areas of average duct flue gas flow. Velocity traverses were conducted at injection locations to select the ports used for carbon injection lance installation. There were nine available ports at the carbon injection location. Flue gas velocity measured at the middle port (port E) was low due to a duct obstruction; therefore, a carbon injection lance was not placed in this middle port. Injection lances were placed in the other eight available ports.

The flow rates and temperatures measured at each ESP inlet location during the baseline period are summarized in Table 3-4. The flue gas flow rate measured at the ESP inlet ports used for mercury measurements was approximately $1.75 \times 10^{6} \mathrm{acfm}$. This represented the flow rate for the $1 \mathrm{~A}$ and $1 \mathrm{~B}$ ducts, or half of the total unit flow. At the ESP inlet ports used for the carbon injection lances, the measured flow rate was approximately $0.79 \times 10^{6} \mathrm{acfm}$. This represented the flow entering only the 1A ESP, and was approximately half the flow rate in the 1A/1B combined duct. 
Table 3-4. Baseline Volumetric Flow Rates Measured at ESP Inlet $($ Load $=880 \mathrm{MW})$

\begin{tabular}{|l|c|c|c|c|}
\hline \multicolumn{1}{|c|}{ Measurement Location } & $\begin{array}{c}\text { Flow Rate } \\
(\mathrm{acfm})\end{array}$ & $\begin{array}{c}\text { Temperature } \\
\left({ }^{\circ} \mathrm{F}\right)\end{array}$ & $\begin{array}{c}\text { Oxygen } \\
(\%)\end{array}$ & $\begin{array}{c}\text { Moisture } \\
(\text { vol \%) }\end{array}$ \\
\hline \hline $\begin{array}{l}\text { ESP 1A/1B Inlet } \\
\text { (Hg Measurement Ports) }\end{array}$ & $1,747,605$ & 316 & 5.0 & 15 \\
\hline $\begin{array}{l}\text { ESP 1A Inlet } \\
\text { (Carbon Injection Ports) }\end{array}$ & 787,774 & 325 & 5.0 & 13 \\
\hline
\end{tabular}

\subsection{Baseline Mercury Measurements}

\section{Baseline Mercury Measurements - SCEM}

Several days of baseline measurements were made with SCEM analyzers prior to each phase of parametric testing and the long-term test. During the baseline periods, flue gas mercury concentrations were measured at the following locations: ESP 1A/1B inlet, ESP 1A2 outlet (treated ESP outlet), ESP 1B1 outlet (untreated ESP outlet), and special ports installed on the ESP 1A1 outlet for Toxecon ${ }^{\mathrm{TM}}$ II testing (Toxecon ${ }^{\mathrm{TM}}$ II outlet). The ducts are referred to as treated and untreated outlets even when discussing baseline results when no carbon was injected into the system.

Baseline flue gas mercury concentrations were measured with SCEMs prior to the first parametric test, from 9:30 December 1, 2006 through 12:00 December 3, 2006. Figure 3-3 plots the inlet and outlet total and elemental mercury concentrations measured during this period. The inlet total vapor phase mercury concentration ranged from 13 to $37 \mu \mathrm{g} / \mathrm{dNm}^{3}$ at $3 \% \mathrm{O}_{2}$, with an average of $25 \mu \mathrm{g} / \mathrm{dNm}^{3}$. The outlet total vapor phase mercury concentration ranged from 13 to $30 \mu \mathrm{g} / \mathrm{dNm}^{3}$, with an average of $19 \mu \mathrm{g} / \mathrm{dNm}^{3}$. The average baseline removal of vapor-phase mercury across the ESP was $26 \%$. The unit fluctuated between periods of $10 \%$ mercury removal to periods with up to $36 \%$ mercury removal. The mercury concentrations in the treated and untreated outlet ducts were equivalent to each other during December testing. Approximately $21 \%$ of the ESP inlet vapor-phase mercury was present as oxidized mercury, and $24 \%$ of the ESP outlet vapor-phase mercury was present as oxidized mercury. Only a small amount of mercury oxidation occurred across the ESP.

Baseline measurements were also made during the overnight periods between the daily parametric sorbent injection tests. The purpose of these measurements was to verify that the unit had returned to baseline operation prior to starting injection tests each day. Similar behavior was noted between these overnight baseline periods and the initial baseline measurement days. Thus, these measurments showed that upon ending a given ACI parametric test at the end of a day the system returned to normal (baseline) conditions overnight prior to starting the next test. 


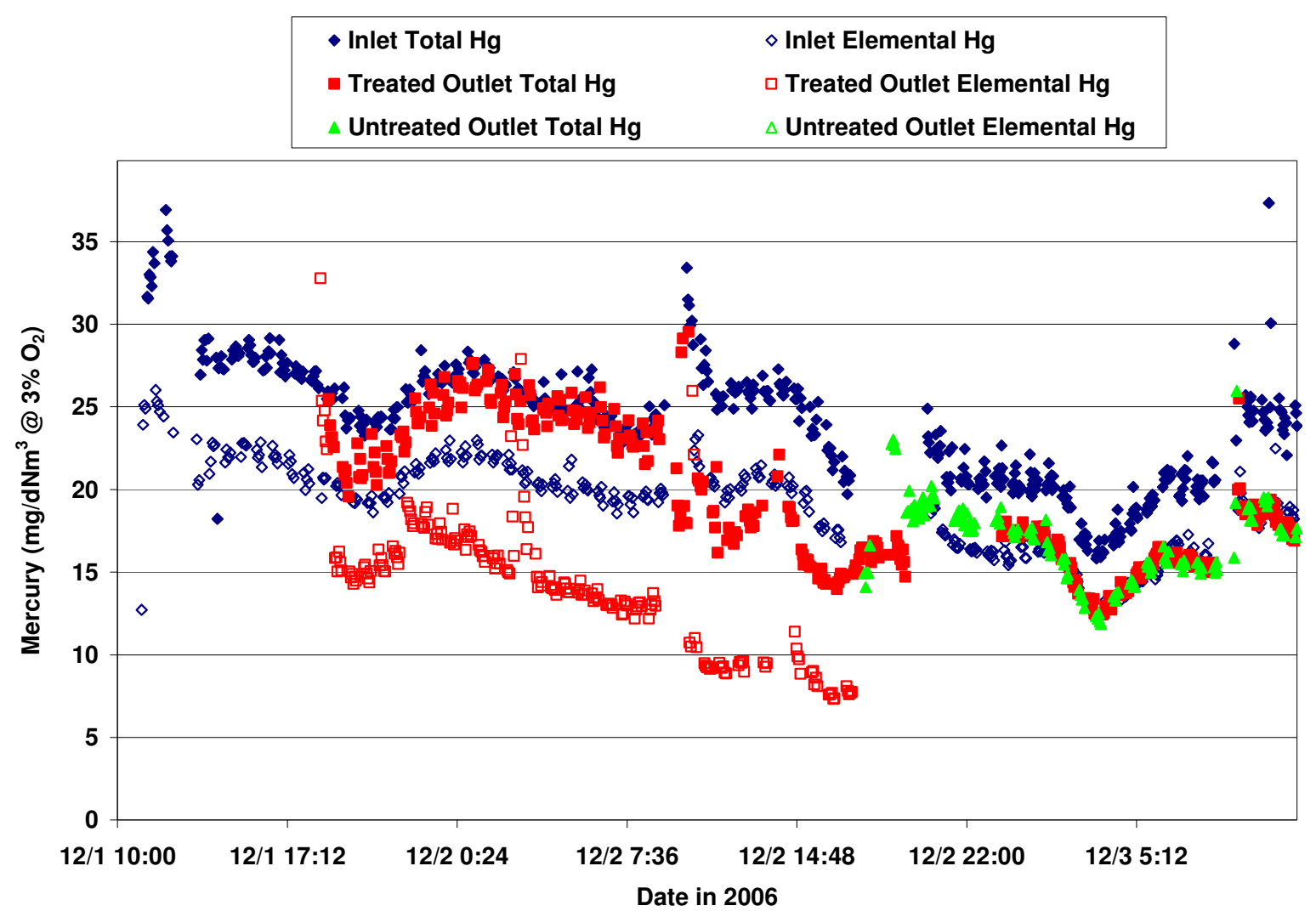

Figure 3-3. Baseline Mercury Measurements Prior to Phase I Parametric Tests

Baseline flue gas mercury concentrations were measured with SCEMs from 10:00 April 19, 2007 through 12:00 April 21, 2007, prior to the Phase II parametric tests. Figure 3-4 plots the inlet and outlet total and elemental mercury concentrations measured during this period. The inlet total vapor phase mercury concentration ranged from 20 to $34 \mu \mathrm{g} / \mathrm{dNm}^{3}$ at $3 \% \mathrm{O}_{2}$, with an average of $28 \mu \mathrm{g} / \mathrm{dNm}^{3}$. The outlet total vapor phase mercury concentration at the treated outlet ranged from 13 to $23 \mu \mathrm{g} / \mathrm{dNm}^{3}$, with an average of $18 \mu \mathrm{g} / \mathrm{dNm}^{3}$, and the untreated outlet mercury concentration ranged from 19 to $23 \mu \mathrm{g} / \mathrm{dNm}^{3}$ with an average of $21 \mu \mathrm{g} / \mathrm{dNm}^{3}$. There was good correlation between the treated and untreated outlet baseline mercury concentration. The average baseline removal of vapor-phase mercury across the ESP was $34 \%$ prior to the Phase II parametric tests. Approximately $31 \%$ of the ESP inlet vapor-phase mercury was present as oxidized mercury, and $35 \%$ of the ESP outlet vapor-phase mercury was present as oxidized mercury. 


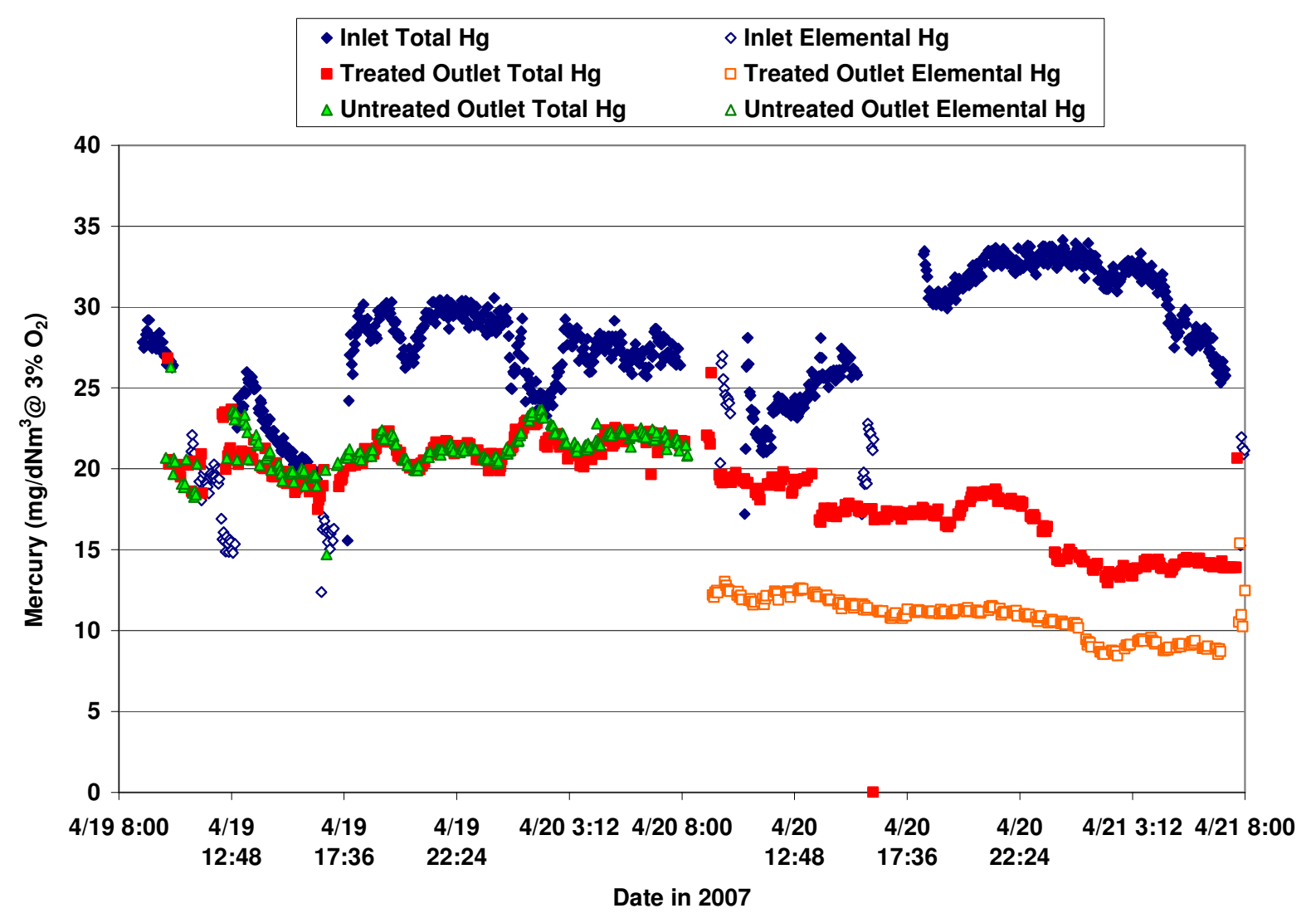

Figure 3-4. Baseline Mercury Measurements Prior to Phase II Parametric Tests

Additional baseline mercury measurements were made between 9:00 on May 22, 2007 through 7:00 May 21, 2007 8:00. Figure 3-5 plots the inlet and outlet total and elemental mercury concentrations measured during this time period. The inlet total vapor phase mercury concentration ranged from 18 to $25 \mu \mathrm{g} / \mathrm{dNm}^{3}$ at $3 \% \mathrm{O}_{2}$, with an average of $22 \mu \mathrm{g} / \mathrm{dNm}^{3}$. The outlet total vapor phase mercury concentration at the Toxecon ${ }^{\mathrm{TM}}$ II outlet ranged from 15 to 29 $\mu \mathrm{g} / \mathrm{dNm}^{3}$, with an average of $20 \mu \mathrm{g} / \mathrm{dNm}^{3}$, and the untreated outlet mercury concentration ranged from 13 to $29 \mu \mathrm{g} / \mathrm{dNm}^{3}$ with an average of $20 \mu \mathrm{g} / \mathrm{dNm}^{3}$. The average baseline removal of vaporphase mercury measured at the Toxecon ${ }^{\mathrm{TM}}$ II ports was $8 \%$. Approximately $29 \%$ of the ESP inlet vapor-phase mercury was present as oxidized mercury, and $73 \%$ of the baseline mercury at the Toxecon ${ }^{\mathrm{TM}}$ II outlet ports was present as oxidized mercury during this period. Mercury oxidation was greater at the outlet during Phase III than during previous measurement periods. 


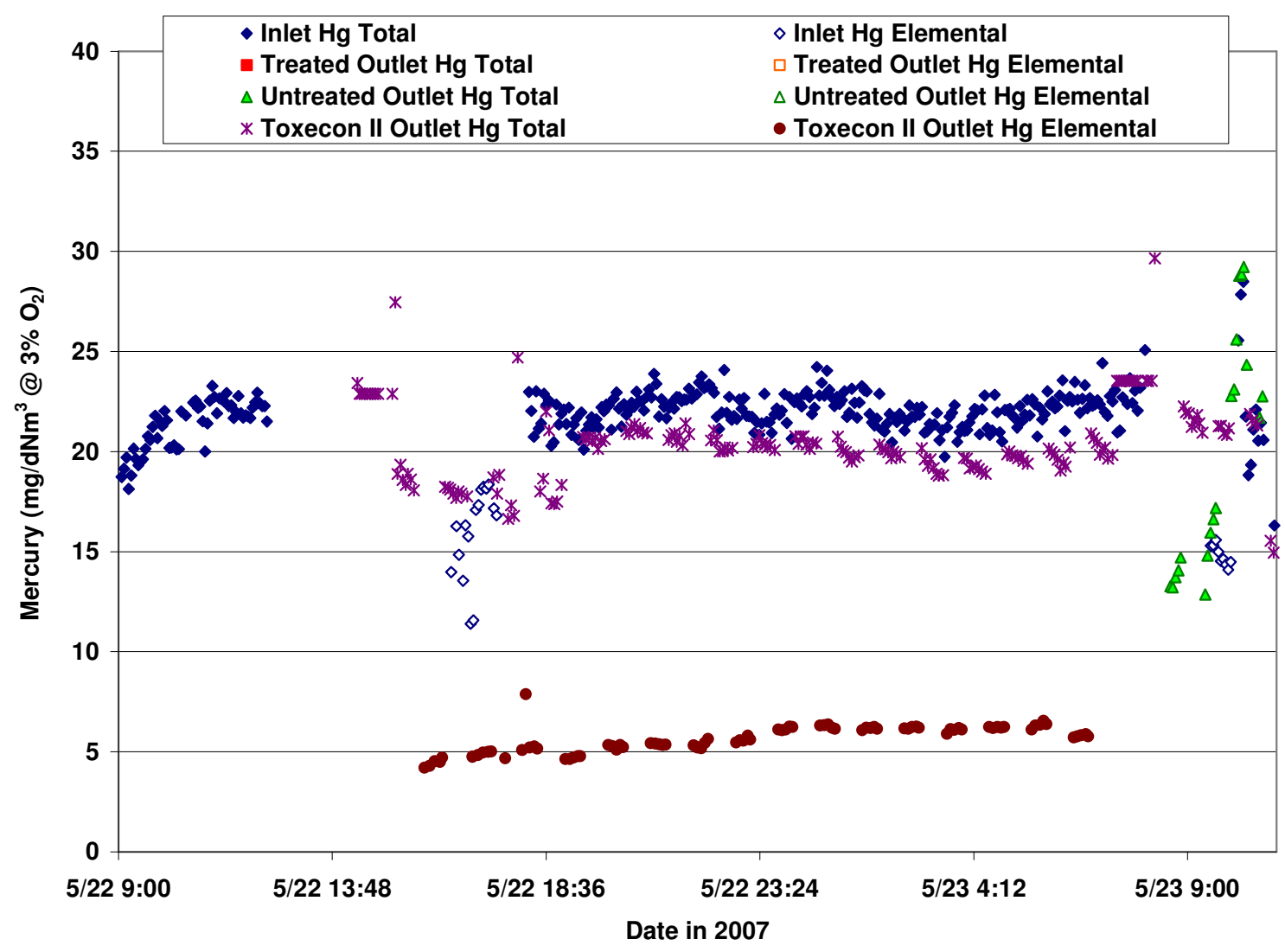

Figure 3-5. Baseline Mercury Measurements Prior to Phase III Parametric Tests

Baseline measurements were made prior to the long-term test from June 19, 2007 17:00 through June 22, 2007 13:00. Flue gas mercury concentrations were measured at the following locations: ESP 1A/1B inlet, ESP 1A2 outlet (treated ESP outlet), and ESP 1B1 outlet (untreated ESP outlet). Figure 3-6 plots the total and elemental mercury concentrations measured at the ESP inlet and outlet locations. Inlet total vapor phase mercury concentrations ranged from 16 to 29 $\mu \mathrm{g} / \mathrm{dNm}^{3}$ at $3 \% \mathrm{O}_{2}$, with an average of $22 \mu \mathrm{g} / \mathrm{dNm}^{3}$. The treated outlet total vapor phase mercury concentration ranged from 18 to $33 \mu \mathrm{g} / \mathrm{dNm}^{3}$, with an average of $22 \mu \mathrm{g} / \mathrm{dNm}^{3}$. The untreated outlet mercury concentration was somewhat higher than the inlet concentration, averaging around $25 \mu \mathrm{g} / \mathrm{dNm}^{3}$. During the baseline measurement period prior to the long-term injection test, the average removal of vapor-phase mercury across the ESP was 7\%. Approximately $24 \%$ of the ESP inlet vapor-phase mercury was present as oxidized mercury, and $61 \%$ of the ESP outlet vapor-phase mercury was present in an oxidized form. 


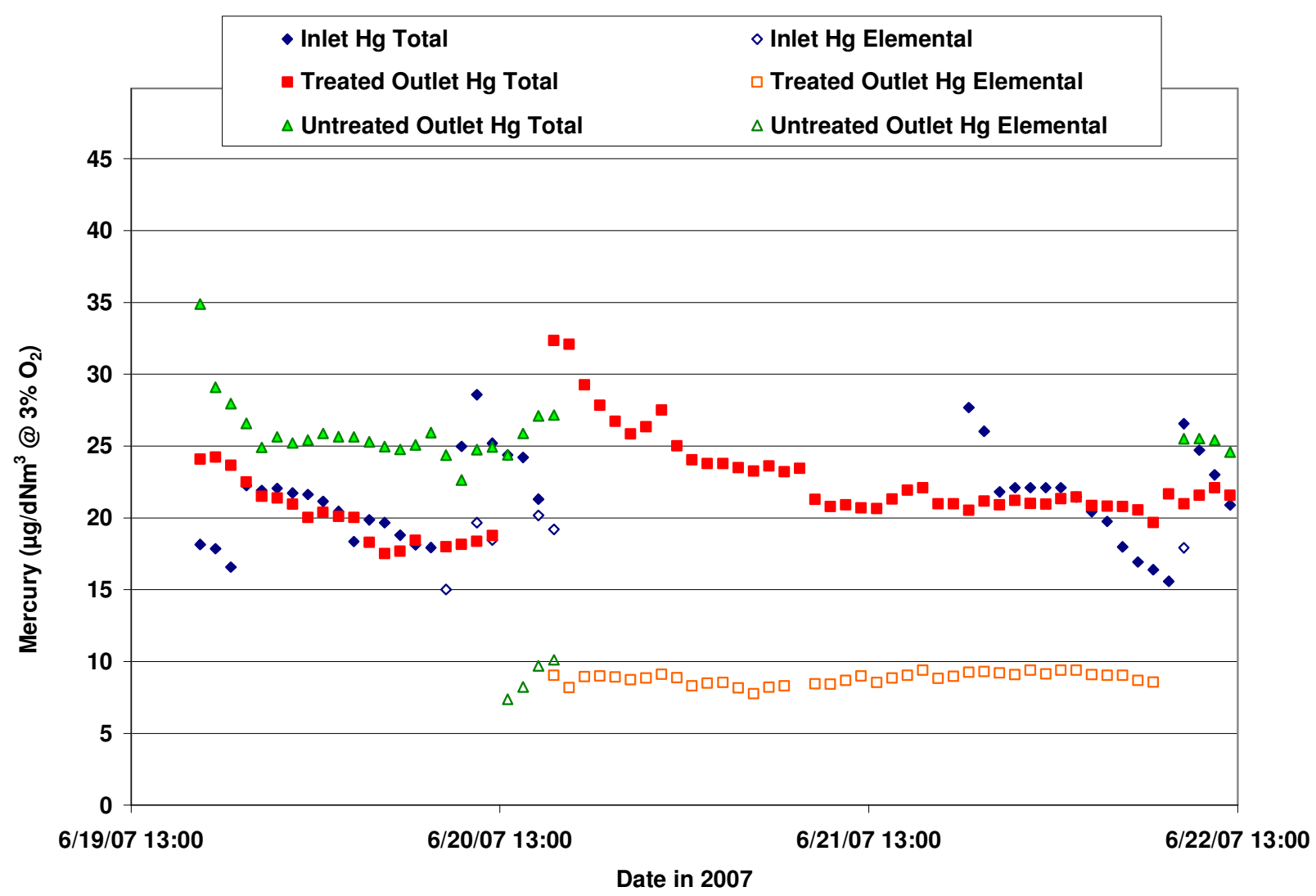

Figure 3-6. Baseline Hourly-Averaged Mercury Measurements Prior to Long-Term Injection Test

\section{Baseline Mercury Measurements - $\mathrm{OH}$ Characterization}

Ontario Hydro $(\mathrm{OH})$ measurement results obtained during the baseline tests are summarized in Table 3-5. OH measures three phases of mercury: particulate, oxidized and elemental. Previous experiences with $\mathrm{OH}$ measurements conducted at the ESP inlet (i.e., flue gas with high ash loading) of a TxL fired unit have shown a positive bias for particulate and oxidized forms of mercury. The reason for this bias is believed to be the relatively high reactivity of the fly ash when it forms a filter cake. Therefore, $\mathrm{OH}$ measurements at LMS were conducted only at the ESP outlet, where little particulate matter is present. Mercury concentrations were compared between the untreated ESP outlet and treated ESP outlet ducts.

The average baseline total vapor-phase mercury concentrations measured by $\mathrm{OH}$ were 24.1 and $26.1 \mu \mathrm{g} / \mathrm{dNm}^{3}$ at $3 \% \mathrm{O}_{2}$ for the untreated and treated outlet ducts, respectively. Approximately $50 \%$ of the flue gas mercury was present as oxidized mercury. There was no detectable particulate phase mercury.

While on average the total vapor phase mercury concentrations at the treated and untreated outlet ducts were within $2 \mu \mathrm{g} / \mathrm{dNm}^{3}$, the differences in measured concentrations between the ducts for each individual run were as high as $6 \mu \mathrm{g} / \mathrm{dNm}^{3}$. For two of the runs, the treated duct mercury 
concentration was higher by $6 \mu \mathrm{g} / \mathrm{dNm}^{3}$, while for the other run the untreated duct mercury concentration was higher.

The variability in mercury concentrations between the treated and untreated ESPs, as measured by $\mathrm{OH}$, is similar to the variability measured by the SCEMs over the previous several months of testing. On average, the mercury concentrations measured at the outlet of the two ESPs was very similar; however, there were periods when one of the ESP outlet ducts experienced mercury concentrations several $\mu \mathrm{g} / \mathrm{dNm}^{3}$ units higher than the other ESP.

A comparison of $\mathrm{OH}$ and SCEM total and elemental mercury measurements over the baseline period is provided in Table 3-6. The two methods were in good agreement at the untreated outlet duct (4\% difference). At the treated outlet duct, the SCEM measurements were approximately $30 \%$ lower than the $\mathrm{OH}$ measurements. It should be noted that the $\mathrm{OH}$ and SCEM measurements in Table 3-6 were conducted in four different ducts. The treated ESP outlet is comprised of two ducts: one duct was used to make SCEM measurements, while the other was used to make $\mathrm{OH}$ measurements. A similar measurement arrangement was used for the untreated ESP outlet duct. Just as $\pm 30 \%$ differences were observed between the treated and untreated outlet ducts for the $\mathrm{OH}$ measurements, similar variations could be expected between the OH and SCEM for the two ducts at the treated ESP outlet. These results suggest that mercury concentration gradients may exist across the flue gas ducts tested.

Table 3-5. Baseline OH Results at ESP Outlet

\begin{tabular}{|c|c|c|c|c|c|c|c|c|}
\hline Date & Time & $\begin{array}{c}\text { Duct } \\
\text { Sampled }\end{array}$ & $\begin{array}{c}\text { Total Hg } \\
\text { (gas phase } \\
+ \\
\text { particulate) } \\
\mu^{2} / \mathbf{d N m}^{3} \\
\end{array}$ & $\underset{\mu \mathrm{g} / \mathrm{dNm}^{3}}{\mathrm{Hg}_{\mathrm{p}}}$ & $\underset{\mu \mathrm{g} / \mathrm{dNm}^{3}}{\mathrm{Hg}^{2+}}$ & $\underset{\mu \mathrm{g} / \mathbf{d N m}^{3}}{\mathbf{H g}^{0}}$ & $\begin{array}{c}\% \text { of } \\
\text { Total Hg } \\
\text { as } \\
\text { Oxidized } \\
\text { Hg } \\
\end{array}$ & $\begin{array}{c}\% \mathrm{Hg} \\
\text { Removal } \\
\text { (Treated vs. } \\
\text { Untreated ) } \\
\end{array}$ \\
\hline 20-Jun-07 & $10: 10-12: 24$ & \multirow{2}{*}{$\begin{array}{c}\text { Untreated } \\
\text { Treated } \\
\end{array}$} & 22.7 & $<0.03$ & 11.5 & 11.2 & $51 \%$ & \multirow[b]{2}{*}{$-27 \%$} \\
\hline 20-Jun-07 & $10: 10-12: 25$ & & 28.8 & 0.09 & 15.6 & 13.1 & $54 \%$ & \\
\hline 20-Jun-07 & $13: 50-16: 04$ & \multirow{2}{*}{$\begin{array}{c}\text { Untreated } \\
\text { Treated } \\
\end{array}$} & 28.6 & $<0.08$ & 17.5 & 11.1 & $61 \%$ & \multirow[b]{2}{*}{$20 \%$} \\
\hline 20-Jun-07 & 13:50-16:00 & & 22.9 & $<0.08$ & 8.9 & 14.0 & $39 \%$ & \\
\hline 21-Jun-07 & $11: 01-15: 29$ & \multirow{2}{*}{$\begin{array}{c}\text { Untreated } \\
\text { Treated }\end{array}$} & 20.9 & $<0.05$ & 9.8 & 11.1 & $47 \%$ & \multirow[b]{2}{*}{$-27 \%$} \\
\hline \multirow[t]{3}{*}{ 21-Jun-07 } & 11:01-15:32 & & 26.5 & $<0.05$ & 14.3 & 12.2 & $54 \%$ & \\
\hline & Average & Untreated & 24.1 & $<0.05$ & 12.9 & 11.1 & $53 \%$ & \multirow[b]{2}{*}{$-8 \%$} \\
\hline & Average & Treated & 26.1 & $<0.07$ & 12.9 & 13.1 & $49 \%$ & \\
\hline
\end{tabular}


Table 3-6. Comparison of $\mathrm{OH}$ to SCEM Baseline Mercury Measurements

\begin{tabular}{|c|c|c|c|c|c|c|c|}
\hline Date & Time & Location & $\begin{array}{l}\text { Total Hg, } \\
\mu \mathrm{g} / \mathrm{dNm}^{3}\end{array}$ & $\begin{array}{l}\text { Total } \mathrm{Hg} \text {, } \\
\mu \mathrm{g} / \mathrm{dNm}^{3}\end{array}$ & $\begin{array}{c}\% \\
\text { Difference* } \\
\text { in Total Hg } \\
\end{array}$ & $\begin{array}{c}\mathrm{OH} \\
\\
\begin{array}{c}\text { Elemental } \\
\mathrm{Hg}, \\
\mu \mathrm{g} / \mathrm{dNm}^{3}\end{array} \\
\end{array}$ & $\begin{array}{c}\text { SCEM } \\
\text { Elementa } \\
\text { Hg, } \\
\mu \mathrm{g} / \mathbf{d N m}^{3} \\
\end{array}$ \\
\hline 20-Jun-07 & $10: 10-12: 24$ & \multirow{2}{*}{$\begin{array}{c}\text { Untreated } \\
\text { Treated } \\
\end{array}$} & 22.7 & 24.14 & $-6 \%$ & 11.2 & -- \\
\hline 20-Jun-07 & $10: 10-12: 25$ & & 28.8 & 18.51 & $44 \%$ & 13.1 & -- \\
\hline 20-Jun-07 & $13: 50-16: 04$ & \multirow{2}{*}{$\begin{array}{c}\text { Untreated } \\
\text { Treated } \\
\end{array}$} & 30.1 & 26.57 & $12 \%$ & 11.1 & 9.4 \\
\hline 20-Jun-07 & 13:50-16:00 & & 22.9 & -- & -- & 14.0 & -- \\
\hline 21-Jun-07 & $11: 01-15: 29$ & \multirow{2}{*}{$\begin{array}{c}\text { Untreated } \\
\text { Treated } \\
\end{array}$} & 20.9 & -- & -- & 11.1 & -- \\
\hline \multirow{3}{*}{ 21-Jun-07 } & $11: 01-15: 32$ & & 26.5 & 21.11 & $23 \%$ & 12.2 & 8.9 \\
\hline & \multirow[t]{2}{*}{ Average** } & Untreated & 26.4 & 25.36 & $4 \%$ & 11.1 & 9.4 \\
\hline & & Treated & 27.7 & 19.81 & $33 \%$ & 12.2 & 8.9 \\
\hline
\end{tabular}

*\% Difference calculated as (OH Total Hg - SCEM Total Hg)/(Average of SCEM and OH Total Hg)*100

** Average does not include runs where SCEM data were not available.

-- No data available

\section{Baseline Mercury Measurements - Fly Ash}

For the two-day period in which baseline $\mathrm{OH}$ measurements were conducted, the fly ash mercury concentration in the treated ESP was less than $0.03 \mathrm{ppm}$, indicating that less than $2 \%$ of the mercury entering with the coal was removed by the fly ash. These results generally agreed with the SCEM measurements over the same time period, which indicated 7\% vapor-phase mercury removal between the ESP inlet and outlet ducts. The fly ash mercury data are tabulated in Section 3.4 under the subheading "Mercury Measurements during Long-Term Sorbent Injection Fly Ash Results".

\section{Baseline Mercury Measurements - Summary}

From the baseline tests conducted in conjunction with the parametric and long term test periods, the following observations were made:

- Baseline total vapor phase mercury concentrations at the ESP inlet ranged from 13 to $40 \mu \mathrm{g} / \mathrm{dNm}^{3}$ at $3 \% \mathrm{O}_{2}$, and averaged approximately $22 \mu \mathrm{g} / \mathrm{dNm}^{3}$;

- The total vapor phase mercury concentration at the treated ESP outlet ranged from 12 to $32 \mu \mathrm{g} / \mathrm{dNm}^{3}$, and averaged $20 \mu \mathrm{g} / \mathrm{dNm}^{3}$ during baseline periods;

- The untreated ESP outlet total vapor phase mercury concentration ranged from 13 to $29 \mu \mathrm{g} / \mathrm{dNm}^{3}$, with an average of $22 \mu \mathrm{g} / \mathrm{dNm}^{3}$;

- Total mercury concentrations at the treated and untreated outlet ports typically corresponded well with each other; however, there were periods when $\pm 30 \%$ difference was observed; 
- Flue gas mercury concentrations as measured by SCEM and OH at the ESP outlet agreed well with each other;

- The average native removal of vapor-phase mercury across the ESP, as measured by the SCEMs, varied between 8 and 33\% during baseline measurement periods; the variability in measured removal may be a function of the variability in the flue gas mercury profile at the ESP outlet;

- Fly ash mercury concentrations measured during baseline periods indicated that the native removal of vapor-phase mercury across the ESP was less than 10\%; and

- Baseline vapor-phase mercury speciation measurements showed that 21 to $29 \%$ of the mercury at the ESP inlet was present in an oxidized form and that 25 to $73 \%$ of the mercury present at the ESP outlet was oxidized. Flue gas mercury oxidation measurements by SCEM and $\mathrm{OH}$ methods agreed well with each other.

\subsection{Parametric Sorbent Injection Tests - Mercury Removal Results}

During the sorbent injection tests at LMS, flue gas mercury concentrations were measured at the following four locations: ESP 1A/1B inlet, ESP 1A2 outlet (treated ESP outlet), ESP 1B1outlet (untreated ESP outlet), and special ports installed on the ESP 1A1 outlet for Toxecon ${ }^{\mathrm{TM}}$ II testing (Toxecon ${ }^{\text {TM }}$ II outlet). Table 3-7 shows average mercury concentrations measured when injecting sorbent upstream of the ESP and Table 3-8 shows mercury concentrations measured in the tests employing the Toxecon ${ }^{\mathrm{TM}}$ II and staged injection configurations.

Mercury removal at the outlet of the treated ESP was calculated for each test run using the following equation:

$$
\% \text { Mercury Reduction at ESP outlet }=\left[1-\mathrm{Hg}_{\mathrm{ESP} 1 \mathrm{~A}, \text { out }} / \mathrm{Hg}_{\mathrm{ESP} 1 \mathrm{~B}, \text { out }}\right] * 100
$$

where,

$\mathrm{Hg}_{\mathrm{ESP}} 1 \mathrm{~A}$, out $=$ the total vapor phase mercury concentration at the treated ESP 1A outlet $\mathrm{Hg}_{\mathrm{ESP} 1 \mathrm{~B} \text {, out }}=$ the total vapor phase mercury concentration at the untreated ESP 1B outlet.

This calculation represents the percent mercury reduction achieved at the outlet of the treated ESP relative to that for the untreated ESP (i.e., 'baseline' condition).

Vapor-phase mercury removal across the treated ESP was calculated as:

$$
\% \text { Mercury Removal across ESP }=\left[1-\operatorname{Hg}_{\mathrm{ESP} 1 \mathrm{~A}, \text { out }} / \mathrm{Hg}_{\mathrm{ESP} 1 \mathrm{~A} / \mathrm{B}, \text { in }}\right] * 100
$$

where,

$$
\operatorname{Hg}_{\mathrm{ESP}} 1 \mathrm{~A} / \mathrm{B} \text {, in }=\text { the total vapor phase mercury concentration at the ESP } 1 \mathrm{~A} / 1 \mathrm{~B} \text { inlet. }
$$

Tables 3-9 and 3-10 summarize the mercury reduction observed at the ESP outlet and across the ESP for injection upstream of the ESP and for Toxecon ${ }^{\top \mathrm{M}}$ II injection, respectively. A detailed summary of the parametric tests conducted for each sorbent injection configuration is provided below. 
Table 3-7. Average Mercury Concentrations Measured during Parametric Tests with Sorbent Injection Upstream of ESP

\begin{tabular}{|c|c|c|c|c|c|c|}
\hline \multirow[b]{2}{*}{ Sorbent Type } & \multirow{2}{*}{$\begin{array}{c}\text { Date of } \\
\text { Test }\end{array}$} & \multirow{2}{*}{$\begin{array}{c}\text { Injection } \\
\text { Rate } \\
\text { (lb/Macf) }\end{array}$} & \multicolumn{4}{|c|}{$\begin{array}{c}\text { Vapor Phase Mercury Concentration } \\
\left(\mu \mathrm{g} / \mathrm{dNm}^{3} \text { at } 3 \% \mathrm{O}_{2}\right)\end{array}$} \\
\hline & & & $\begin{array}{c}\text { ESP } \\
\text { Inlet } \\
\left(\mathrm{Hg}^{\text {Total }}\right) \\
\end{array}$ & $\begin{array}{l}\text { ESP } \\
\text { Inlet } \\
\left(\mathrm{Hg}^{0}\right) \\
\end{array}$ & $\begin{array}{c}\text { Treated } \\
\text { Outlet } \\
\left(\mathrm{Hg}^{\text {Total }}\right)\end{array}$ & $\begin{array}{c}\text { Untreated } \\
\text { Outlet } \\
\left(\mathrm{Hg}^{\text {Total }}\right)\end{array}$ \\
\hline DARCO Hg-LH & $12 / 03 / 06$ & 1.1 & 24.9 & 19.5 & 5.9 & 18.1 \\
\hline DARCO Hg-LH & $12 / 03 / 06$ & 2.9 & 21.7 & 17.0 & 1.4 & 15.9 \\
\hline DARCO Hg-LH & $12 / 04 / 06$ & 0.5 & 28.7 & 19.4 & 9.2 & 19.0 \\
\hline DARCO Hg-LH & $12 / 04 / 06$ & 2.5 & 23.6 & 17.8 & 1.9 & 11.8 \\
\hline DARCO Hg-LH & $12 / 04 / 06$ & 5.1 & 24.4 & 17.9 & 0.7 & 20.9 \\
\hline DARCO Hg-LH & $12 / 04 / 06$ & 1.7 & 24.6 & 18.1 & 2.1 & 20.2 \\
\hline B-PAC & $12 / 05 / 06$ & 0.5 & 21.3 & 17.0 & 9.1 & 18.8 \\
\hline B-PAC & $12 / 05 / 06$ & 1.3 & 20.5 & 16.8 & 4.6 & 18.3 \\
\hline B-PAC & $12 / 05 / 06$ & 3.3 & 20.0 & 16.2 & 1.7 & 18.2 \\
\hline B-PAC & $12 / 05 / 06$ & 1.9 & 19.8 & 15.6 & 2.7 & 17.4 \\
\hline DARCO Hg & $12 / 06 / 06$ & 3.4 & 28.1 & 20.2 & 3.3 & 22.2 \\
\hline DARCO Hg & $12 / 06 / 06$ & 8.2 & 27.0 & 19.9 & 1.6 & 19.9 \\
\hline DARCO Hg & $12 / 06 / 06$ & 5.6 & 26.3 & 18.7 & 1.9 & 20.0 \\
\hline DARCO Hg & $12 / 07 / 06$ & 0.4 & 20.5 & 16.0 & 7.5 & 16.4 \\
\hline DARCO Hg & $12 / 07 / 06$ & 1.5 & 21.8 & 16.2 & 5.5 & NA \\
\hline DARCO Hg & $12 / 07 / 06$ & 1.7 & 22.0 & 15.1 & 3.4 & NA \\
\hline DARCO Hg & $12 / 07 / 06$ & 8.9 & 21.7 & 15.5 & 1.2 & 16.3 \\
\hline Flue PAC MC Plus & $12 / 08 / 06$ & 0.5 & 28.2 & 17.2 & 14.9 & 18.3 \\
\hline Flue PAC MC Plus & $12 / 08 / 06$ & 1.9 & 26.7 & 17.7 & 9.6 & 18.6 \\
\hline Flue PAC MC Plus & $12 / 08 / 06$ & 5.8 & 24.9 & 16.0 & 3.2 & 17.2 \\
\hline DARCO Hg & $12 / 09 / 06$ & 0.6 & 21.4 & 14.8 & 9.8 & 19.0 \\
\hline BASF MS200 & $04 / 21 / 07$ & 6.0 & 24.5 & 21.8 & 12.4 & NA \\
\hline BASF MS200 & $04 / 21 / 07$ & 8.0 & 29.1 & 21.2 & 8.9 & 20.6 \\
\hline BASF MS200 & $04 / 22 / 07$ & 10.0 & 22.4 & NA & 11.1 & 16.5 \\
\hline BASF MS200 & $04 / 22 / 07$ & 12.0 & 22.9 & 19.9 & 10.6 & 16.9 \\
\hline C-PAC & $04 / 23 / 07$ & 0.5 & 27.0 & NA & 8.3 & NA \\
\hline C-PAC & $04 / 23 / 07$ & 1.5 & 25.9 & NA & 4.6 & 17.0 \\
\hline DARCO Hg & $04 / 24 / 07$ & 1.0 & 27.5 & 19.3 & 7.4 & 16.7 \\
\hline DARCO Hg & $04 / 24 / 07$ & 2.0 & 31.5 & 20.8 & 4.8 & NA \\
\hline Flue PAC MC Plus \#2 & $04 / 25 / 07$ & 1.0 & NA & NA & 11.9 & 17.4 \\
\hline Flue PAC MC Plus \#2 & $04 / 25 / 07$ & 2.0 & 17.2 & NA & 8.6 & 17.6 \\
\hline DARCO Hg-LH & $04 / 26 / 07$ & 1.0 & 20.7 & 13.3 & 9.3 & 20.9 \\
\hline DARCO Hg-LH & $04 / 26 / 07$ & 2.0 & 19.2 & NA & 5.6 & NA \\
\hline DARCO Hg & $05 / 02 / 07$ & 5.0 & 24.4 & 14.6 & NA & 23.3 \\
\hline DARCO Hg & $05 / 02 / 07$ & 2.0 & 24.0 & $\mathrm{NA}$ & 8.8 & 20.3 \\
\hline DARCO Hg & $05 / 02 / 07$ & 3.0 & 20.4 & 6.4 & 6.1 & 24.8 \\
\hline BASF MS200 & $05 / 03 / 07$ & 8.0 & NA & NA & 2.9 & 7.8 \\
\hline B-PAC & $05 / 04 / 07$ & 1.0 & NA & NA & 4.5 & NA \\
\hline DARCO Hg-LH w/o forced air & $05 / 26 / 07$ & 0.5 & 27.6 & NA & 22.6 & 15.3 \\
\hline DARCO Hg-LH w/ forced air & $05 / 26 / 07$ & 0.5 & 31.1 & NA & 19.9 & 15.9 \\
\hline DARCO Hg-LH w/ forced air & $05 / 26 / 07$ & 0.7 & 28.6 & NA & 21.3 & 16.1 \\
\hline DARCO Hg-LH w/ forced air & $05 / 26 / 07$ & 1.0 & 28.9 & NA & 22.2 & 15.4 \\
\hline DARCO Hg-LH w/o forced air & $05 / 26 / 07$ & 1.0 & 28.6 & NA & 20.7 & 15.0 \\
\hline
\end{tabular}


Table 3-8. Average Mercury Concentrations Measured during Toxecon ${ }^{\mathrm{TM}}$ II \& Staged Injection Tests (Phases II \& III)

\begin{tabular}{|c|c|c|c|c|c|c|}
\hline \multirow[b]{2}{*}{ Sorbent Type } & \multirow[b]{2}{*}{$\begin{array}{l}\text { Date of } \\
\text { Test }\end{array}$} & \multirow[b]{2}{*}{$\begin{array}{c}\text { Injection } \\
\text { Rate } \\
\text { (lb/Macf) }\end{array}$} & \multicolumn{4}{|c|}{$\begin{array}{c}\text { Vapor Phase Mercury Concentration } \\
\left(\mu \mathrm{g} / \mathrm{dNm}^{3} \text { at } 3 \% \mathrm{O}_{2}\right)\end{array}$} \\
\hline & & & $\begin{array}{c}\text { ESP } \\
\text { Inlet } \\
\left(\mathrm{Hg}^{\text {Total }}\right) \\
\end{array}$ & $\begin{array}{c}\text { ESP } \\
\text { Inlet } \\
\left(\mathrm{Hg}^{0}\right)\end{array}$ & $\begin{array}{c}\text { Untreated } \\
\text { Outlet } \\
\left(\mathrm{Hg}^{\text {Total }}\right)\end{array}$ & $\begin{array}{c}\text { ESP 1A } \\
\text { Toxecon }^{\text {TM }} \mathbf{I I} \\
\text { Outlet }^{\text {I }}\left(\mathrm{Hg}^{\text {Total }}\right) \\
\end{array}$ \\
\hline Toxecon $^{\text {TM }}$ II DARCO Hg & $04 / 30 / 07$ & 2.0 & 26.8 & 20.0 & 25.0 & 13.2 \\
\hline Toxecon $^{\text {TM }}$ II DARCO Hg & $04 / 30 / 07$ & 5.0 & 33.2 & NA & 25.0 & 10.7 \\
\hline Toxecon $^{\text {TM }}$ II DARCO Hg & $05 / 01 / 07$ & 5.0 & 24.8 & NA & 23.6 & 14.3 \\
\hline Toxecon $^{\mathrm{TM}}$ II DARCO Hg & $05 / 23 / 07$ & 2.0 & 26.4 & 14.1 & 24.1 & 13.2 \\
\hline Toxecon $^{\text {TM }}$ II DARCO Hg & $05 / 23 / 07$ & 6.0 & 22.2 & 11.9 & 22.0 & 9.0 \\
\hline Toxecon $^{\text {TM }}$ II DARCO Hg & $05 / 24 / 07$ & 3.0 & 21.6 & NA & 23.0 & 14.0 \\
\hline Staged Injection DARCO Hg & $05 / 24 / 07$ & $0.5 / 3.0 *$ & 22.1 & NA & 22.8 & 9.3 \\
\hline Staged Injection DARCO Hg & $05 / 24 / 07$ & $0.5 / 5.0 *$ & NA & NA & 21.8 & 7.5 \\
\hline Toxecon $^{\text {TM }}$ II DARCO Hg-LH & $05 / 25 / 07$ & 5.0 & 10.0 & 8.5 & 9.7 & 3.8 \\
\hline $\begin{array}{c}\text { Staged Injection DARCO Hg- } \\
\text { LH }\end{array}$ & $05 / 26 / 07$ & $1.0 / 5.0^{*}$ & 25.0 & 15.0 & 20.9 & 9.5 \\
\hline
\end{tabular}

* For staged injection, first value indicates injection rate upstream of ESP; second value indicates injection rate mid-stream of ESP (Toxecon $^{\text {TM }}$ II injection rate). 
Table 3-9. Percent Mercury Reduction and ESP Removal for Parametric Tests with Sorbent Injection Upstream of ESP

\begin{tabular}{|c|c|c|c|c|}
\hline Sorbent Type & $\begin{array}{c}\text { Date of } \\
\text { Test }\end{array}$ & $\begin{array}{c}\text { Injection Rate } \\
\text { (lb/Macf) }\end{array}$ & $\begin{array}{c}\text { \% Mercury } \\
\text { Reduction at } \\
\text { ESP Outlet }\end{array}$ & $\begin{array}{c}\% \text { Mercury } \\
\text { Removal across } \\
\text { ESP }\end{array}$ \\
\hline DARCO Hg-LH & $12 / 03 / 06$ & 1.1 & 68 & 76 \\
\hline DARCO Hg-LH & $12 / 03 / 06$ & 2.9 & 91 & 94 \\
\hline DARCO Hg-LH & $12 / 04 / 06$ & 0.5 & 51 & 68 \\
\hline DARCO Hg-LH & $12 / 04 / 06$ & 2.5 & 84 & 92 \\
\hline DARCO Hg-LH & $12 / 04 / 06$ & 5.1 & 97 & 97 \\
\hline DARCO Hg-LH & $12 / 04 / 06$ & 1.7 & 90 & 92 \\
\hline B-PAC & $12 / 05 / 06$ & 0.5 & 52 & 57 \\
\hline B-PAC & $12 / 05 / 06$ & 1.3 & 75 & 78 \\
\hline B-PAC & $12 / 05 / 06$ & 3.3 & 91 & 91 \\
\hline B-PAC & $12 / 05 / 06$ & 1.9 & 85 & 87 \\
\hline DARCO Hg & $12 / 06 / 06$ & 3.4 & 85 & 88 \\
\hline DARCO Hg & $12 / 06 / 06$ & 8.2 & 92 & 94 \\
\hline DARCO Hg & $12 / 06 / 06$ & 5.6 & 90 & 93 \\
\hline DARCO Hg & $12 / 07 / 06$ & 0.4 & 54 & 64 \\
\hline DARCO Hg & $12 / 07 / 06$ & 1.5 & 67 & 75 \\
\hline DARCO Hg & $12 / 07 / 06$ & 1.7 & 79 & 84 \\
\hline DARCO Hg & $12 / 07 / 06$ & 8.9 & 93 & 94 \\
\hline Flue PAC MC Plus & $12 / 08 / 06$ & 0.5 & 19 & 47 \\
\hline Flue PAC MC Plus & $12 / 08 / 06$ & 1.9 & 48 & 64 \\
\hline Flue PAC MC Plus & $12 / 08 / 06$ & 5.8 & 82 & 87 \\
\hline DARCO Hg & $12 / 09 / 06$ & 0.6 & 49 & 54 \\
\hline BASF MS200 & $04 / 21 / 07$ & 6.0 & 40 & 49 \\
\hline BASF MS200 & $04 / 21 / 07$ & 8.0 & 57 & 70 \\
\hline BASF MS200 & $04 / 22 / 07$ & 10.0 & 33 & 51 \\
\hline BASF MS200 & $04 / 22 / 07$ & 12.0 & 37 & 54 \\
\hline C-PAC & $04 / 23 / 07$ & 0.5 & 52 & 69 \\
\hline C-PAC & $04 / 23 / 07$ & 1.5 & 73 & 82 \\
\hline DARCO Hg & $04 / 24 / 07$ & 1.0 & 56 & 73 \\
\hline DARCO Hg & $04 / 24 / 07$ & 2.0 & 71 & 84 \\
\hline Calgon HGR-LH & $04 / 25 / 07$ & 1.0 & 31 & 31 \\
\hline Calgon HGR-LH & $04 / 25 / 07$ & 2.0 & 51 & 50 \\
\hline DARCO Hg-LH & $04 / 26 / 07$ & 1.0 & 55 & 55 \\
\hline DARCO Hg-LH & $04 / 26 / 07$ & 2.0 & 73 & 71 \\
\hline DARCO Hg & $05 / 02 / 07$ & 5.0 & NA & 43 \\
\hline DARCO Hg & $05 / 02 / 07$ & 2.0 & 57 & 63 \\
\hline DARCO Hg & $05 / 02 / 07$ & 3.0 & 75 & 70 \\
\hline BASF MS200 & $05 / 03 / 07$ & 8.0 & 63 & NA \\
\hline B-PAC & $05 / 04 / 07$ & 1.0 & NA & NA \\
\hline DARCO Hg-LH w/o forced air & $05 / 26 / 07$ & 0.5 & 33 & 45 \\
\hline DARCO Hg-LH w/ forced air & $05 / 26 / 07$ & 0.5 & 20 & 49 \\
\hline DARCO Hg-LH w/ forced air & $05 / 26 / 07$ & 0.7 & 24 & 44 \\
\hline DARCO Hg-LH w/ forced air & $05 / 26 / 07$ & 1.0 & 31 & 47 \\
\hline DARCO Hg-LH w/o forced air & $05 / 26 / 07$ & 1.0 & 27 & 47 \\
\hline
\end{tabular}


Table 3-10. Percent Mercury Reductions and Removals for Toxecon ${ }^{\mathrm{TM}}$ II \& Staged Injection Tests (Phase II \& III)

\begin{tabular}{|c|c|c|c|c|}
\hline Sorbent Type & $\begin{array}{l}\text { Date of } \\
\text { Testing }\end{array}$ & $\begin{array}{c}\text { Injection Rate } \\
(\mathrm{lb} / \mathrm{Macf}) \\
\end{array}$ & $\begin{array}{c}\text { \% Mercury } \\
\text { Reduction at } \\
\text { ESP Outlet } \\
\end{array}$ & $\begin{array}{c}\% \text { Mercury } \\
\text { Removal across } \\
\text { ESP }\end{array}$ \\
\hline Toxecon $^{\text {TM II DARCO Hg }}$ & $4 / 30 / 2007$ & 2.0 & 49 & 63 \\
\hline Toxecon $^{\text {TM }}$ II DARCO Hg & $4 / 30 / 2007$ & 5.0 & 58 & 69 \\
\hline Toxecon $^{\text {TM }}$ II DARCO Hg & $5 / 1 / 2007$ & 5.0 & 39 & 42 \\
\hline Toxecon $^{\text {TM II DARCO Hg }}$ & $5 / 23 / 2007$ & 2.0 & 45 & 50 \\
\hline Toxecon $^{\text {TM II DARCO Hg }}$ & $5 / 23 / 2007$ & 6.0 & 59 & 60 \\
\hline Toxecon $^{\text {TM }}$ II DARCO Hg & $5 / 24 / 2007$ & 3.0 & 39 & 35 \\
\hline Staged DARCO Hg & $5 / 24 / 2007$ & $0.5 / 3.0 *$ & 59 & 58 \\
\hline Staged DARCO Hg & $5 / 24 / 2007$ & $0.5 / 5.0 *$ & 65 & NA \\
\hline Toxecon $^{\text {TM }}$ II DARCO Hg-LH & $5 / 25 / 2007$ & 5.0 & 61 & 62 \\
\hline Staged DARCO Hg-LH & $5 / 26 / 2007$ & $1.0 / 5.0 *$ & 55 & 62 \\
\hline
\end{tabular}

*For staged injection, first value indicates injection rate upstream of ESP; second value indicates injection rate mid-stream of ESP (Toxecon ${ }^{\mathrm{TM}}$ II injection rate).

\section{Parametric Results for Sorbent Injection Upstream of ESP}

Parametric tests were performed to evaluate sorbent injection upstream of the ESP. Three separate test periods were conducted over a six-month period. Each mercury sorbent was tested at several injection rates to develop a mercury removal performance curve.

Figure 3-7 shows the results for all sorbents injected upstream of the LMS ESP. Data points in the plot represent two- to four-hour averaged SCEM data. The plot shows how vapor-phase mercury removal across the ESP varied with sorbent injection rate. Removal across the ESP was calculated by comparing the treated ESP outlet mercury concentration to the ESP inlet mercury concentration. In Figure 3-7, baseline removal is represented by the points that fall along the yaxis (i.e. an injection rate of $0 \mathrm{lb} / \mathrm{Macf}$ ). Baseline mercury removal across the ESP varied from $5 \%$ to $50 \%$ over the parametric test program.

Because the baseline mercury removal varied so greatly over the program, the data are also presented in terms of the percent reduction of mercury at the ESP outlet (Figure 3-8). The data for this evaluation was obtained by simultaneously measuring flue gas mercury downstream of a sorbent-treated and an untreated ESP module. The percent reduction was calculated by comparing the treated ESP outlet mercury concentration to the untreated ESP outlet mercury concentration. Since any changes to the baseline removal occurring during the tests would be expected to impact both ESPs, this comparison allows for the impact of the just the injected sorbent to be determined. The calculation of percent reduction thus indicates the amount of mercury removal the sorbent achieves beyond the baseline removal.

From Figure 3-8, it is readily noted that several DARCO Hg and DARCO Hg-LH datum points did not fall on the generally established curve. One cluster of these points occurred on a single day when the LMS unit was undergoing a fuel transition from PRB (exclusively) to a PRB/TxL blend. It is unclear why the sorbents demonstrated poorer performance during this isolated period. Excluding this period, three of the brominated sorbents (DARCO Hg-LH, B-PAC, and CPAC) performed very similarly with results indicating that $90 \%$ reduction of mercury was 
attainable at injection rates of $2-3 \mathrm{lb} / \mathrm{Macf}$; results from 2009 tests indicated lower removal, as will be discussed in Chapter 4. The similar performance of the fly ash compatible C-PAC to the non-passivated brominated carbons suggests that higher levels of mercury removal may be attained at acceptable injection rates (for fly ash reuse) with this sorbent. The mercury removal performance curve of the fourth tested brominated sorbent (Flue PAC MC Plus) fell significantly below the others. Flue PAC MC Plus was tested at two different times during the six-month program and on days when the other brominated sorbents were performing better. The performance of the non-carbon BASF MS200 sorbent was limited to 50\% reduction in mercury at the ESP outlet.

The non-halogenated activated carbon (DARCO Hg) performed nearly as well as its brominated counterpart, DARCO Hg-LH, on a percent reduction of mercury basis (Figure 3-8). Previous comparisons of these two sorbents in low-chloride flue gases have been made on units firing $100 \%$ PRB. Results of these previous tests showed that the DARCO Hg sorbent had significant limitations in the extent of mercury removal achieved as compared to the DARCO Hg-LH. For example, at Great River Energy's Stanton Station Unit 1, the DARCO Hg was limited to approximately 50\% removal, even at the highest injection rates, while the DARCO Hg-LH achieved greater than $90 \%$ removal [3]. While Texas lignite is considered a low chloride coal (50-100 ppm), it does have higher chloride content than PRB coal (20-60 ppm). This modest increase in chloride may be sufficient to enable the DARCO Hg to achieve higher levels of mercury removal in a 70/30 TxL/PRB blended gas than in a PRB gas.

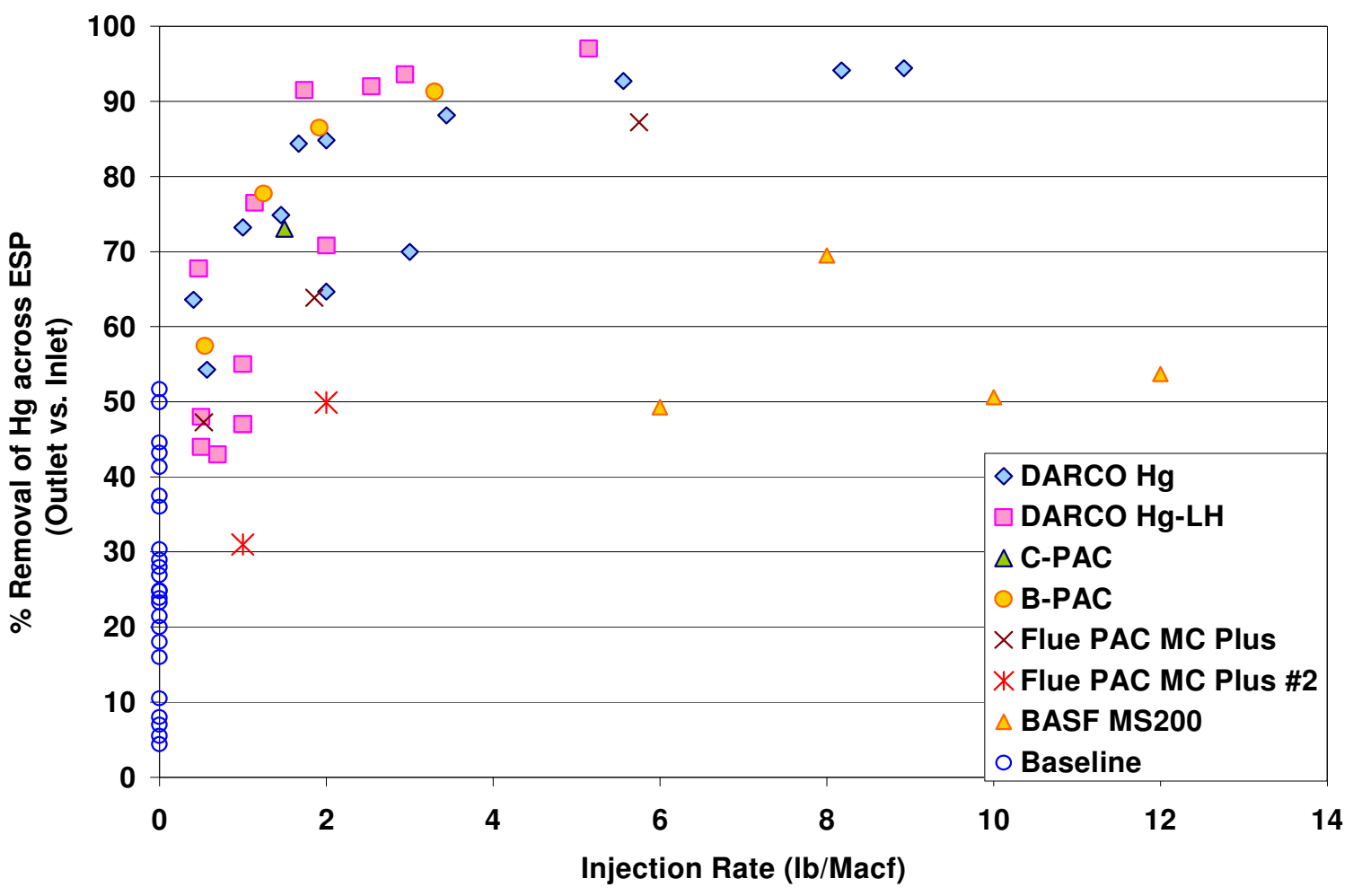

Figure 3-7. Mercury Removal across the LMS ESP (Injection Upstream of ESP) 


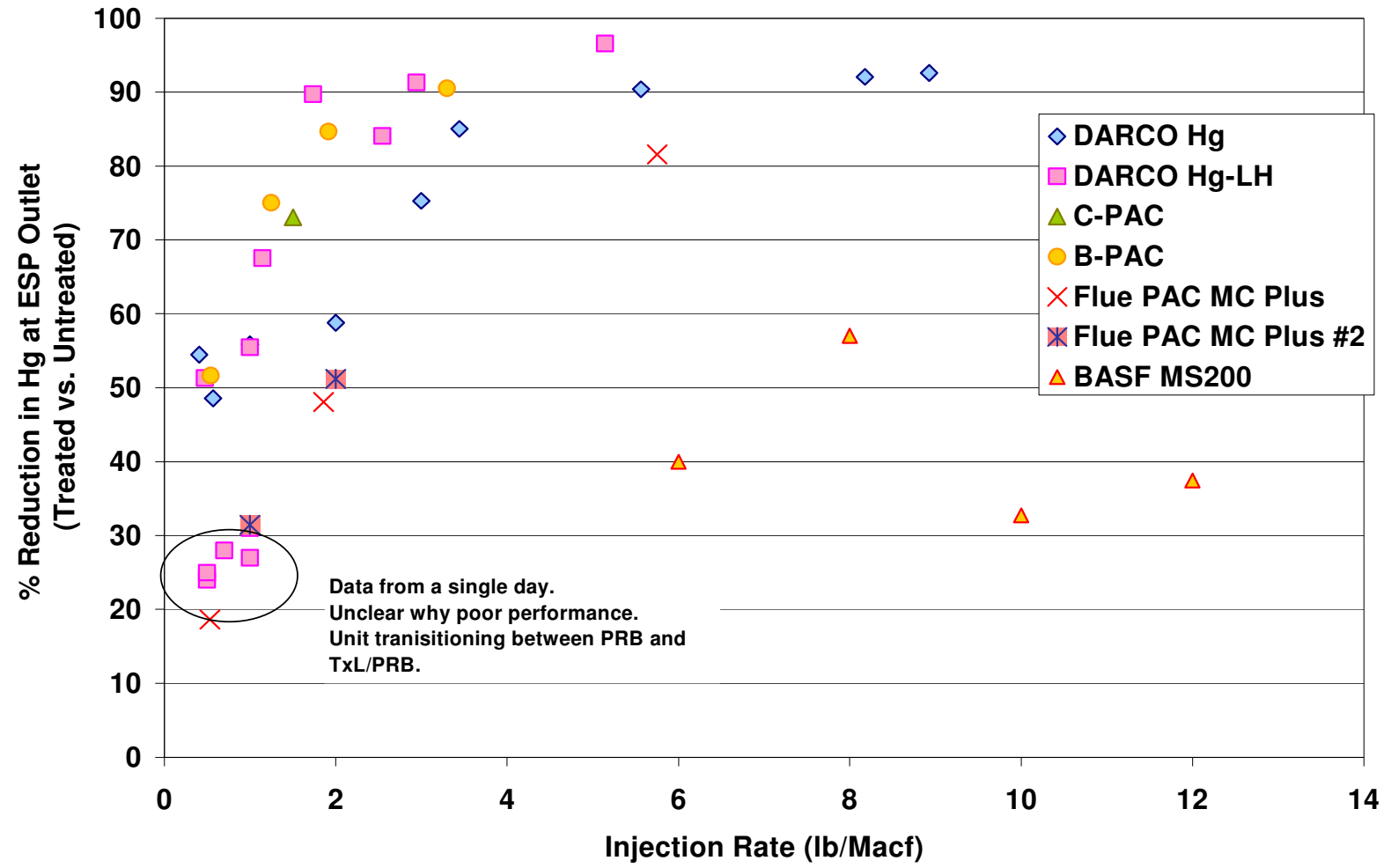

Figure 3-8. Reduction in Mercury Concentration at the ESP Outlet (Injection Upstream of ESP)

Table 3-11 summarizes the injection rates estimated for each sorbent to achieve $70 \%$ mercury reduction at the ESP outlet. These rates were interpolated from logarithmic fits to the data shown in Figure 3-8. Parametric test results indicate that the DARCO Hg, DARCO Hg-LH, and B-PAC would require between 1.0 and $2.0 \mathrm{lb} / \mathrm{Macf}$ of injected sorbent to achieve $70 \%$ mercury reduction. Results indicated that $70 \%$ removal would not be achievable with the non-carbon MS200 sorbent. 


\section{Table 3-11. Sorbent Injection Rate Needed to Achieve}

$70 \%$ Mercury Reduction at ESP Outlet

\begin{tabular}{|c|c|}
\hline Sorbent & $\begin{array}{c}\text { Injection Rate (lb/Macf) Needed to Achieve 70\% } \\
\text { Hg Reduction at ESP Outlet }\end{array}$ \\
\hline DARCO Hg-LH & $1.3 / 1.8^{*}$ \\
\hline B-PAC & 1.1 \\
\hline DARCO Hg & 2.0 \\
\hline Calgon Flue PAC MC Plus & 3.9 \\
\hline C-PAC & 1.5 \\
\hline BASF MS200 & $\mathrm{NA}^{* *}$ \\
\hline
\end{tabular}

\section{Parametric Test Results with Toxecon ${ }^{\mathrm{TM}}$ II and Staged Injection Configurations}

A series of tests was conducted to evaluate mercury removal with a Toxecon ${ }^{\mathrm{TM}}$ II sorbent injection configuration at LMS. Tests included exclusive use of the Toxecon ${ }^{\mathrm{TM}}$ II system as well as the combined use of Toxecon II with sorbent injection upstream of the ESP (i.e., staged injection). The objective of the tests was to determine if high levels of mercury removal could be achieved across the ESP while maintaining low activated carbon in the bulk of the fly ash.

Based on the results from the previous parametric tests conducted upstream of the ESP, Norit Americas' DARCO Hg and DARCO Hg-LH sorbents were selected for testing in the Toxecon ${ }^{\mathrm{TM}}$ II and staged injection configurations. These sorbents were selected because they were among the highest performing sorbents and because of the proximity of the Norit Americas' manufacturing center to the LMS plant (i.e., lower transportation costs than the other evaluated sorbents).

Figure 3-9 shows the mercury reduction results for these two sorbents with the various sorbent injection configurations evaluated. Toxecon ${ }^{\mathrm{TM}}$ II (injection mid-stream of the ESP) was tested during two different weeks in this program. The original tests were performed in April 2007. Despite the lances providing poor theoretical cross-sectional coverage of carbon across the ESP ( $20 \%$ area coverage predicted), mercury reductions up to $60 \%$ were measured at the ESP outlet. A Toxecon $^{\text {TM }}$ II lance re-design was implemented and tested in May 2007; the system was modified in an attempt to improve carbon distribution within the ESP. Subsequent results obtained in May 2007 were similar to the April 2007 results, indicating no improvement in mercury removal performance. The volume and pressure of the air delivered to the Toxecon ${ }^{\mathrm{TM}}$ II lances were varied during the tests, but no associated improvements in mercury removal performance were observed.

A series of tests was conducted with staged injection, in which a small amount of carbon was injected upstream of the ESP, with the bulk of the carbon injected in the Toxecon ${ }^{\mathrm{TM}}$ II lances. This configuration did not provide any improvements in mercury removal over the Toxecon ${ }^{\mathrm{TM}}$ IIonly arrangement. Analysis of the results suggests that the injection upstream of the ESP was not 
performing as well as in previous tests (see circled points in lower left corner of Figure 3-9, indicating data collected during same test week with injection upstream of ESP only).

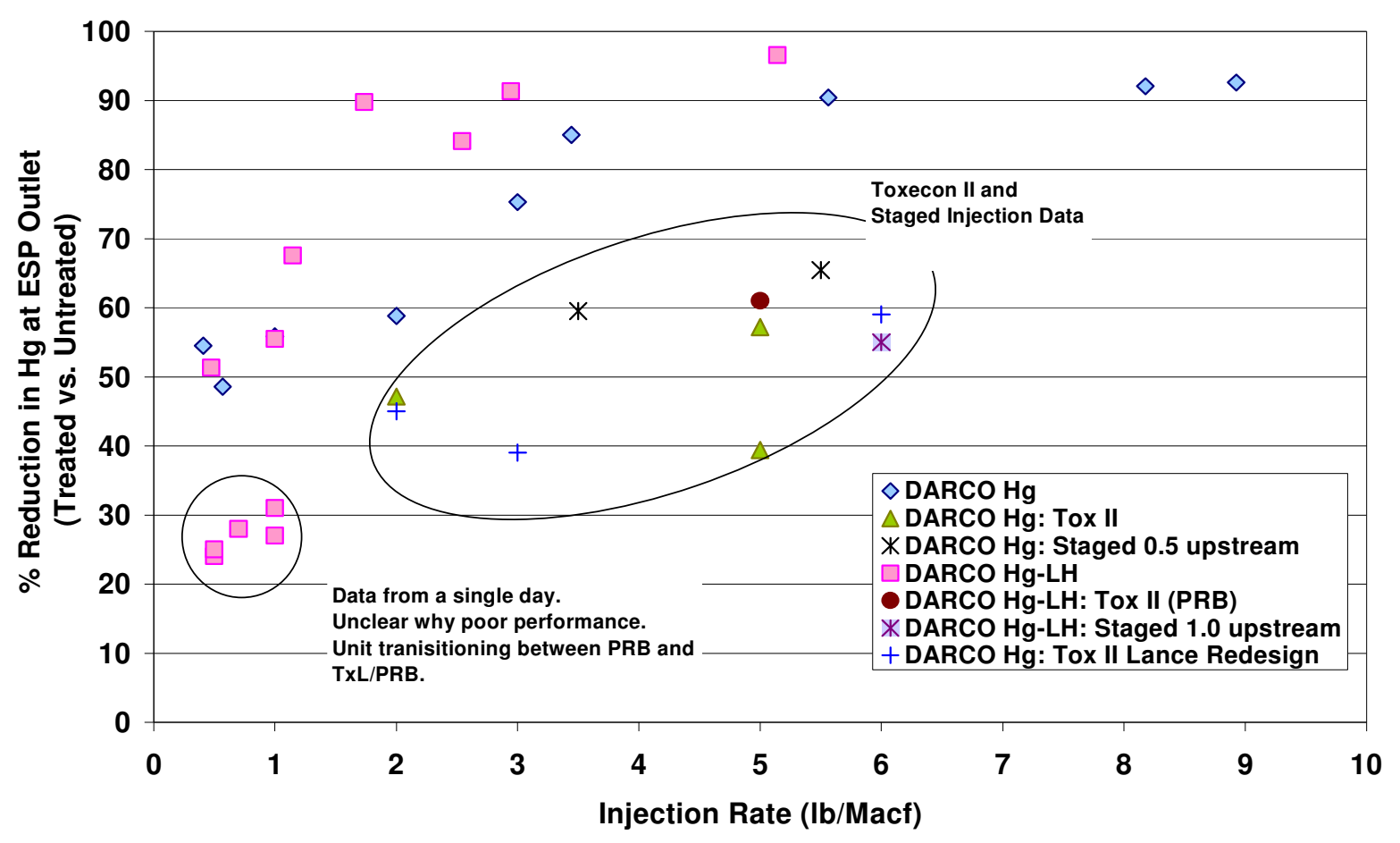

Figure 3-9. Effect of Injection Location on the Reduction of Mercury at the ESP Outlet

\subsection{Long-Term Sorbent Injection - Mercury Removal Results}

Based on the results from parametric tests conducted upstream of the ESP, Norit Americas' DARCO Hg-LH sorbent was selected for the sixty-day continuous mercury control evaluation. This sorbent was selected because it was among the highest performing sorbents and because of the proximity of the Norit Americas' manufacturing center to the power plant. DARCO Hg-LH was selected over DARCO Hg because the unit occasionally burns $100 \%$ PRB coal, in which case the DARCO Hg-LH is more effective than the DARCO Hg. Toxecon ${ }^{\mathrm{TM}}$ II and staged injection did not consistently achieve the test program's targeted mercury removal; therefore, carbon was injected upstream of the ESP for the long term tests. An injection rate of $2 \mathrm{lb} / \mathrm{Macf}$ was selected based on parametric results indicating that this rate should meet the program target mercury removal while still preserving the beneficial use of ash.

Table 3-12 presents a timeline for the sixty-day DARCO Hg-LH injection test. Sorbent injection commenced on June 22, 2007 at 1:00 PM and continued for 60 days at an average rate of 2.0 $\mathrm{lb} /$ Macf. As presented in the table, the unit occasionally burned $100 \%$ PRB during the test period. Sorbent injection was maintained for most of the test duration, but was lost for several brief periods (Table 3-12); data for these periods were excluded from data averaging. 
Table 3-12. Long-Term Sorbent Injection Test Schedule

\begin{tabular}{|l|c|c|}
\hline Periods & Start & End \\
\hline \hline Baseline & $6 / 19 / 0719: 00$ & $6 / 22 / 0712: 00$ \\
\hline Typical $^{\ddagger}$ & $6 / 22 / 0715: 00$ & $6 / 26 / 0723: 00$ \\
\hline High PRB $^{\dagger}$ & $6 / 27 / 074: 00$ & $6 / 27 / 07$ 0:00 \\
\hline Lost injection - EXCLUDE $^{*}$ & $6 / 27 / 0712: 40$ & $6 / 27 / 0717: 20$ \\
\hline High PRB & $6 / 27 / 0718: 00$ & $6 / 27 / 0723: 00$ \\
\hline Lost injection - EXCLUDE & $6 / 27 / 0723: 10$ & $6 / 28 / 078: 55$ \\
\hline High PRB & $6 / 28 / 079: 00$ & $6 / 28 / 0715: 00$ \\
\hline Lost injection - EXCLUDE & $6 / 28 / 0715: 05$ & $6 / 28 / 0718: 15$ \\
\hline Typical & $6 / 28 / 0719: 00$ & $7 / 2 / 0720: 00$ \\
\hline High PRB & $7 / 4 / 071: 00$ & $7 / 5 / 074: 00$ \\
\hline Lost injection - EXCLUDE & $7 / 5 / 0710: 45$ & $7 / 5 / 0712: 40$ \\
\hline Typical & $7 / 5 / 0713: 00$ & $7 / 5 / 0721: 00$ \\
\hline High PRB & $7 / 5 / 0723: 00$ & $7 / 7 / 076: 00$ \\
\hline Typical & $7 / 7 / 0710: 00$ & $7 / 8 / 0722: 00$ \\
\hline Lost injection - EXCLUDE & $7 / 8 / 0722: 50$ & $7 / 9 / 077: 30$ \\
\hline Typical & $7 / 9 / 078: 00$ & $7 / 10 / 07$ 0:00 \\
\hline Lost injection - EXCLUDE & $7 / 10 / 070: 35$ & $7 / 10 / 079: 00$ \\
\hline Typical & $7 / 10 / 0710: 00$ & $7 / 13 / 072: 00$ \\
\hline Unit outage (Forced) & $7 / 13 / 077: 25$ & $7 / 18 / 0711: 45$ \\
\hline Typical & $7 / 18 / 0714: 00$ & $8 / 2 / 0712: 00$ \\
\hline High PRB & $8 / 2 / 0717: 00$ & $8 / 3 / 079: 00$ \\
\hline Typical & $8 / 3 / 0714: 00$ & $8 / 13 / 077: 00$ \\
\hline Lost injection - EXCLUDE & $8 / 13 / 077: 55$ & $8 / 13 / 079: 45$ \\
\hline Typical & $8 / 13 / 0710: 00$ & $8 / 19 / 0718: 00$ \\
\hline Lost injection - EXCLUDE & $8 / 19 / 0718: 10$ & $8 / 20 / 077: 45$ \\
\hline Typical & $8 / 20 / 078: 00$ & $8 / 20 / 0717: 00$ \\
\hline Lost injection - EXCLUDE & $8 / 20 / 0717: 35$ & $8 / 20 / 0719: 00$ \\
\hline Typical & $8 / 20 / 0719: 00$ & $8 / 21 / 070: 00$ \\
\hline Lost injection - EXCLUDE & $8 / 21 / 070: 50$ & $8 / 21 / 077: 30$ \\
\hline Typical & $8 / 21 / 078: 00$ & $8 / 21 / 0715: 00$ \\
\hline Return to Baseline & $8 / 21 / 0722: 00$ & \\
\hline Typica = & \\
\hline
\end{tabular}

Typical $=$ data from time periods when unit fired typical mix of $70 \%$ Lignite and $30 \%$ PRB

${ }^{\dagger}$ High PRB = data from time periods when unit fired greater than 95\% PRB coal

* EXCLUDE = data from this period not included in average of long-term results

\section{Mercury Measurements During Long-Term Sorbent Injection - SCEM Results}

Flue gas mercury concentrations during the long-term sorbent injection test were measured by SCEMs at the following locations: ESP 1A/1B inlet, ESP 1A2 outlet (treated ESP outlet), and ESP 1B1 outlet (untreated ESP outlet). Typically the plant fired a mixture of 70\% lignite and $30 \%$ PRB; however, occasionally over the 60-day evaluation period the plant fired $100 \%$ PRB. Because mercury removal and speciation can vary based on the coal type, results are reported separately for each coal type (i.e., PRB only or TxL/PRB blend) in Tables 3-13 through 3-16. 
Tables 3-13 and 3-14 summarize the average total and elemental mercury concentrations measured for each coal type. Table 3-15 shows percent oxidized mercury in the flue gas at the different measurement locations, and Table 3-16 summarizes the percent mercury reduction at the ESP outlet and percent mercury removal measured across the ESP. Figure 3-10 plots total and elemental mercury concentrations measured throughout the two-month period. Figure 3-11 plots the hourly-averaged mercury removal over the long-term test; results indicated that mercury removal varied from 30 to $97 \%$ during the test.

When firing the typical 70/30 TxL/PRB fuel mix, the daily Unit 1 inlet total vapor phase mercury concentration ranged from 18.0 to $30.5 \mu \mathrm{g} / \mathrm{dNm}^{3}$ at $3 \% \mathrm{O}_{2}$, with an average of 25.4 $\mu \mathrm{g} / \mathrm{dNm}^{3}$. The treated outlet total vapor phase mercury concentration ranged from 1.4 to 10.8 $\mu \mathrm{g} / \mathrm{dNm}^{3}$, with an average of $4.9 \mu \mathrm{g} / \mathrm{dNm}^{3}$. The average daily removal of vapor-phase mercury across the treated ESP was $81 \%$. In comparison, the daily average removal of vapor-phase mercury across the untreated ESP was $26 \%$. On average, 37\% of the ESP inlet, $81 \%$ of the treated ESP outlet, and $49 \%$ of the untreated ESP outlet vapor-phase mercury was present as oxidized mercury. These values represent daily averages; more variability was observed in hourly data over the two-month period.

While firing $100 \% \mathrm{PRB}$, the hourly inlet total vapor phase mercury concentration ranged from 8.0 to $19.3 \mu \mathrm{g} / \mathrm{dNm}^{3}$ at $3 \% \mathrm{O}_{2}$, with an average of $11.7 \mu \mathrm{g} / \mathrm{dNm}^{3}$. The hourly treated outlet total vapor phase mercury concentration ranged from 0.3 to $3.6 \mu \mathrm{g} / \mathrm{dNm}^{3}$, with an average of 1.0 $\mu \mathrm{g} / \mathrm{dNm}^{3}$. Hourly elemental mercury concentration measurements were not available. The hourly average removal of vapor-phase mercury across the treated ESP was 93\%. In comparison, the hourly average removal of vapor-phase mercury across the untreated ESP was $27 \%$. Approximately $35 \%$ of the ESP inlet vapor-phase mercury was present as oxidized mercury.

Figure 3-12 compares the average mercury removal achieved over the two-month injection test to the parametric test results for the Darco $\mathrm{Hg}-\mathrm{LH}$ sorbent. At $2 \mathrm{lb} / \mathrm{Macf}$, three different parametric tests resulted in mercury removals ranging between $70 \%$ and $95 \%$. The average removal of $82 \%$ achieved over the two-month period falls within the performance predicted by the parametric tests.

Figure 3-13 plots daily-averaged mercury removal across the ESP versus the daily-averaged operating temperature of the ESP. As shown by the low $\mathrm{R}^{2}$ value, there was no correlation between mercury removal and ESP operating temperature. 
Table 3-13. Average Total Mercury Concentrations $\left(\mu \mathrm{g} / \mathrm{Nm}^{3}\right.$ at $\left.3 \% \mathrm{O}_{2}\right)$ during Long-Term Injection Test

\begin{tabular}{|l|c|c|c|c|c|c||}
\hline & $\begin{array}{c}\text { Typical } \\
\mathbf{7 0 / 3 0} \\
\text { TxL/PRB }\end{array}$ & $\begin{array}{c}\text { Typical } \\
\mathbf{7 0 / 3 0} \\
\text { TxL/PRB }\end{array}$ & $\begin{array}{c}\text { Typical } \\
\mathbf{7 0 / 3 0} \\
\text { TxL/PRB }\end{array}$ & $\begin{array}{c}\text { High } \\
\text { PRB }\end{array}$ & $\begin{array}{c}\text { High } \\
\text { PRB }\end{array}$ & $\begin{array}{c}\text { High } \\
\text { PRB }\end{array}$ \\
\hline & Average & $\begin{array}{c}\text { Daily } \\
\text { Average } \\
\text { Maximum }\end{array}$ & $\begin{array}{c}\text { Daily } \\
\text { Average } \\
\text { Minimum }\end{array}$ & Average & $\begin{array}{c}\text { Hourly } \\
\text { Maximum }\end{array}$ & $\begin{array}{c}\text { Hourly } \\
\text { Minimum }\end{array}$ \\
\hline \hline Inlet & 25.4 & 30.5 & 18.0 & 11.7 & 19.3 & 8.0 \\
\hline Treated Outlet & 4.9 & 10.8 & 1.4 & 1.0 & 3.6 & 0.3 \\
\hline Untreated Outlet & 18.5 & 25.0 & 14.8 & 9.0 & 18.7 & 5.0 \\
\hline
\end{tabular}
Table 3-14. Average Elemental Mercury Concentrations $\left(\mu \mathrm{g} / \mathrm{Nm}^{3}\right.$ at $\left.3 \% \mathrm{O}_{2}\right)$
during Long-Term Injection Test

\begin{tabular}{|l|c|c|c|c|c|c|}
\hline & $\begin{array}{c}\text { Typical } \\
\mathbf{7 0 / 3 0} \\
\text { TxL/PRB }\end{array}$ & $\begin{array}{c}\text { Typical } \\
\mathbf{7 0 / 3 0} \\
\text { TxL/PRB }\end{array}$ & $\begin{array}{c}\text { Typical } \\
\mathbf{7 0 / 3 0} \\
\text { TxL/PRB }\end{array}$ & $\begin{array}{c}\text { High } \\
\text { PRB }\end{array}$ & $\begin{array}{c}\text { High } \\
\text { PRB }\end{array}$ & $\begin{array}{c}\text { High } \\
\text { PRB }\end{array}$ \\
\hline & Average & $\begin{array}{c}\text { Daily } \\
\text { Average } \\
\text { Maximum }\end{array}$ & $\begin{array}{c}\text { Daily } \\
\text { Average } \\
\text { Minimum }\end{array}$ & Average & $\begin{array}{c}\text { Hourly } \\
\text { Maximum }\end{array}$ & $\begin{array}{c}\text { Hourly } \\
\text { Minimum }\end{array}$ \\
\hline \hline Inlet & 15.2 & 21.5 & 4.9 & 8.6 & 15.7 & 5.3 \\
\hline Treated Outlet & 0.9 & 1.3 & 0.3 & no data & no data & no data \\
\hline Untreated Outlet & 9.0 & 12.4 & 3.4 & 3.4 & 4.4 & 2.5 \\
\hline
\end{tabular}

Table 3-15. Average Flue Gas Mercury Oxidation Measured during Long-Term Injection

\begin{tabular}{|l|c|c|c|c|c|c||}
\hline & $\begin{array}{c}\text { Typical } \\
\mathbf{7 0 / 3 0} \\
\text { TxL/PRB }\end{array}$ & $\begin{array}{c}\text { Typical } \\
\mathbf{7 0 / 3 0} \\
\text { TxL/PRB }\end{array}$ & $\begin{array}{c}\text { Typical } \\
\mathbf{7 0 / 3 0} \\
\text { TxL/PRB }\end{array}$ & $\begin{array}{c}\text { High } \\
\text { PRB }\end{array}$ & $\begin{array}{c}\text { High } \\
\text { PRB }\end{array}$ & $\begin{array}{c}\text { High } \\
\text { PRB }\end{array}$ \\
\hline & Average & $\begin{array}{c}\text { Daily } \\
\text { Average } \\
\text { Maximum }\end{array}$ & $\begin{array}{c}\text { Daily } \\
\text { Average } \\
\text { Minimum }\end{array}$ & Average & $\begin{array}{c}\text { Hourly } \\
\text { Maximum }\end{array}$ & $\begin{array}{c}\text { Hourly } \\
\text { Minimum }\end{array}$ \\
\hline Inlet & $37 \%$ & $75 \%$ & $13 \%$ & $35 \%$ & $57 \%$ & $0 \%$ \\
\hline Treated Outlet & $81 \%$ & $93 \%$ & $54 \%$ & $\mathrm{n} / \mathrm{a}$ & $\mathrm{n} / \mathrm{a}$ & $\mathrm{n} / \mathrm{a}$ \\
\hline Untreated Outlet & $49 \%$ & $82 \%$ & $35 \%$ & $54 \%$ & $73 \%$ & $30 \%$ \\
\hline
\end{tabular}


Table 3-16. Mercury Removals Measured during Long-Term Injection Test

\begin{tabular}{||l|c|c|c|c|c|c||}
\hline & $\begin{array}{c}\text { Typical } \\
\mathbf{7 0 / 3 0} \\
\text { TxL/PRB }\end{array}$ & $\begin{array}{c}\text { Typical } \\
\mathbf{7 0 / 3 0} \\
\text { TxL/PRB }\end{array}$ & $\begin{array}{c}\text { Typical } \\
\mathbf{7 0 / 3 0} \\
\text { TxL/PRB }\end{array}$ & $\begin{array}{c}\text { High } \\
\text { PRB }\end{array}$ & $\begin{array}{c}\text { High } \\
\text { PRB }\end{array}$ & $\begin{array}{c}\text { High } \\
\text { PRB }\end{array}$ \\
\hline & Average & $\begin{array}{c}\text { Daily } \\
\text { Average } \\
\text { Maximum }\end{array}$ & $\begin{array}{c}\text { Daily } \\
\text { Aerage } \\
\text { Minimum }\end{array}$ & Average & $\begin{array}{c}\text { Hourly } \\
\text { Maximum }\end{array}$ & $\begin{array}{c}\text { Hourly } \\
\text { Minimum }\end{array}$ \\
\hline $\begin{array}{l}\text { Untreated Outlet vs. Inlet } \\
\text { (Native Removal) }\end{array}$ & $26 \%$ & $51 \%$ & $0 \%$ & $27 \%$ & $49 \%$ & $0 \%$ \\
\hline $\begin{array}{l}\text { Treated Outlet vs .Inlet } \\
\text { (\% Removal) }\end{array}$ & $81 \%$ & $95 \%$ & $58 \%$ & $93 \%$ & $97 \%$ & $86 \%$ \\
\hline $\begin{array}{l}\text { Treated Outlet vs. } \\
\begin{array}{l}\text { Untreated Outlet } \\
\text { (\% Reduction) }\end{array}\end{array}$ & $73 \%$ & $92 \%$ & $57 \%$ & $89 \%$ & $95 \%$ & $78 \%$ \\
\hline
\end{tabular}

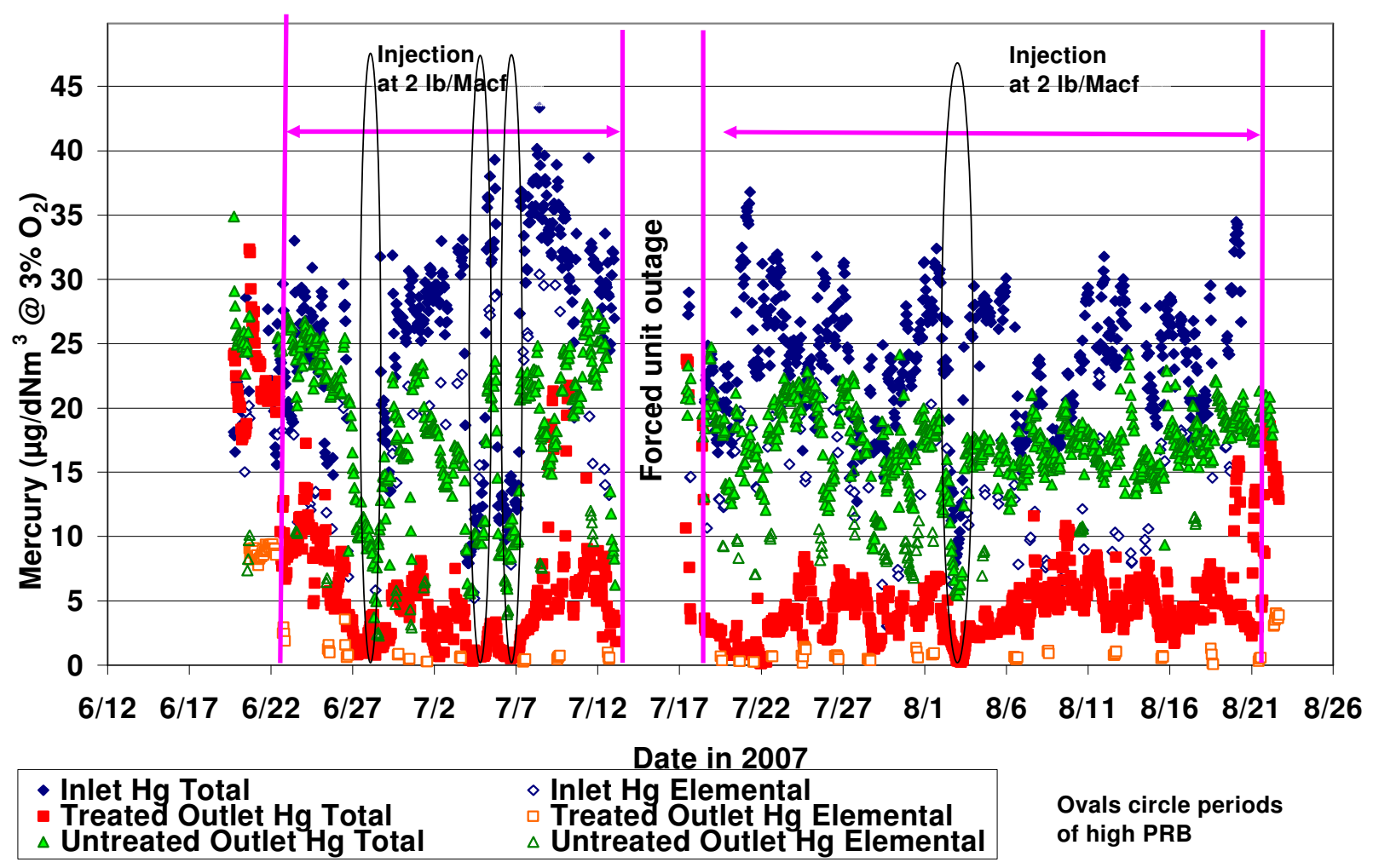

Figure 3-10. Total and Elemental Mercury Concentrations Measured during Long-Term Injection Test 


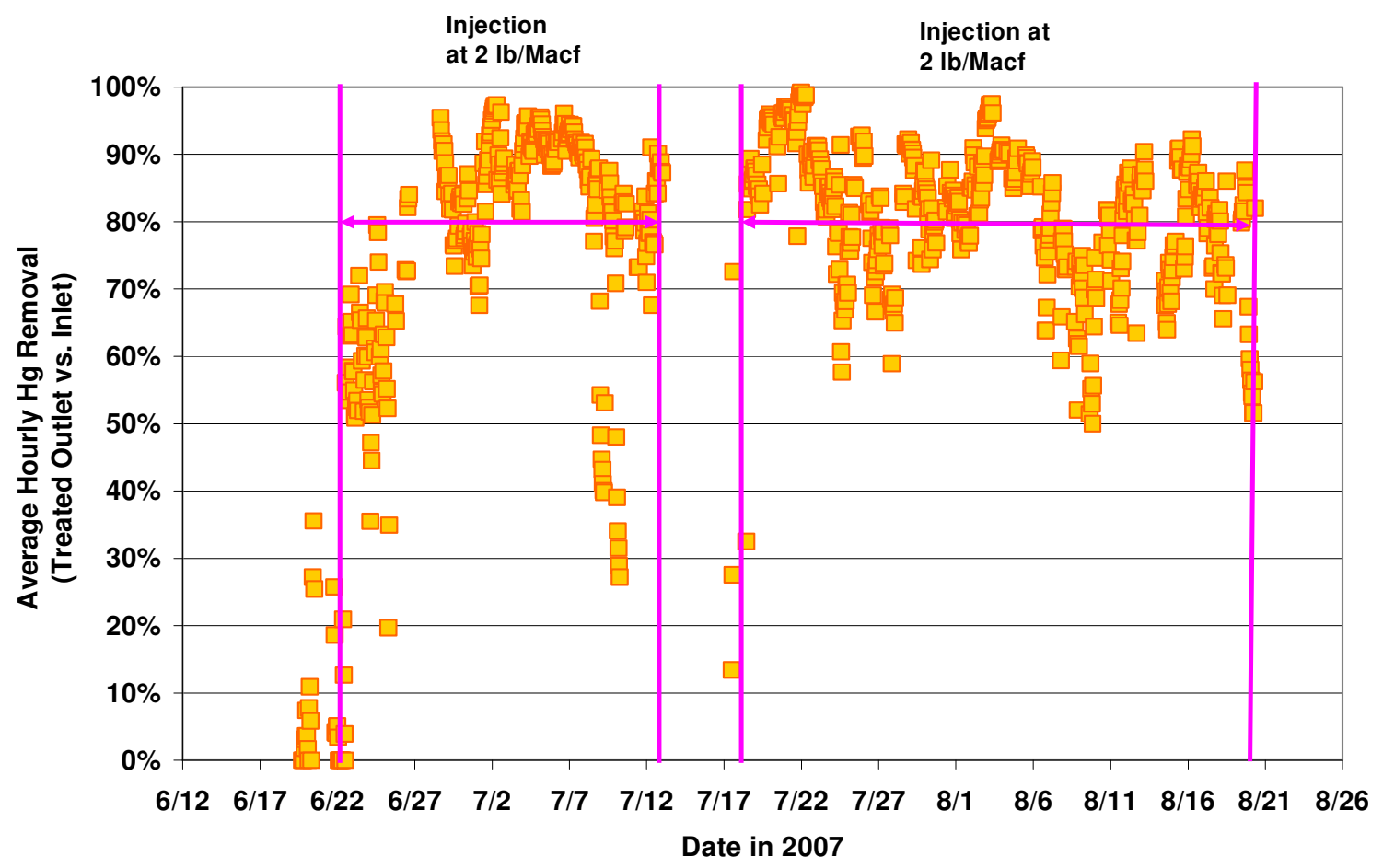

Figure 3-11. Hourly-Averaged Mercury Removal across ESP during Long-Term Injection

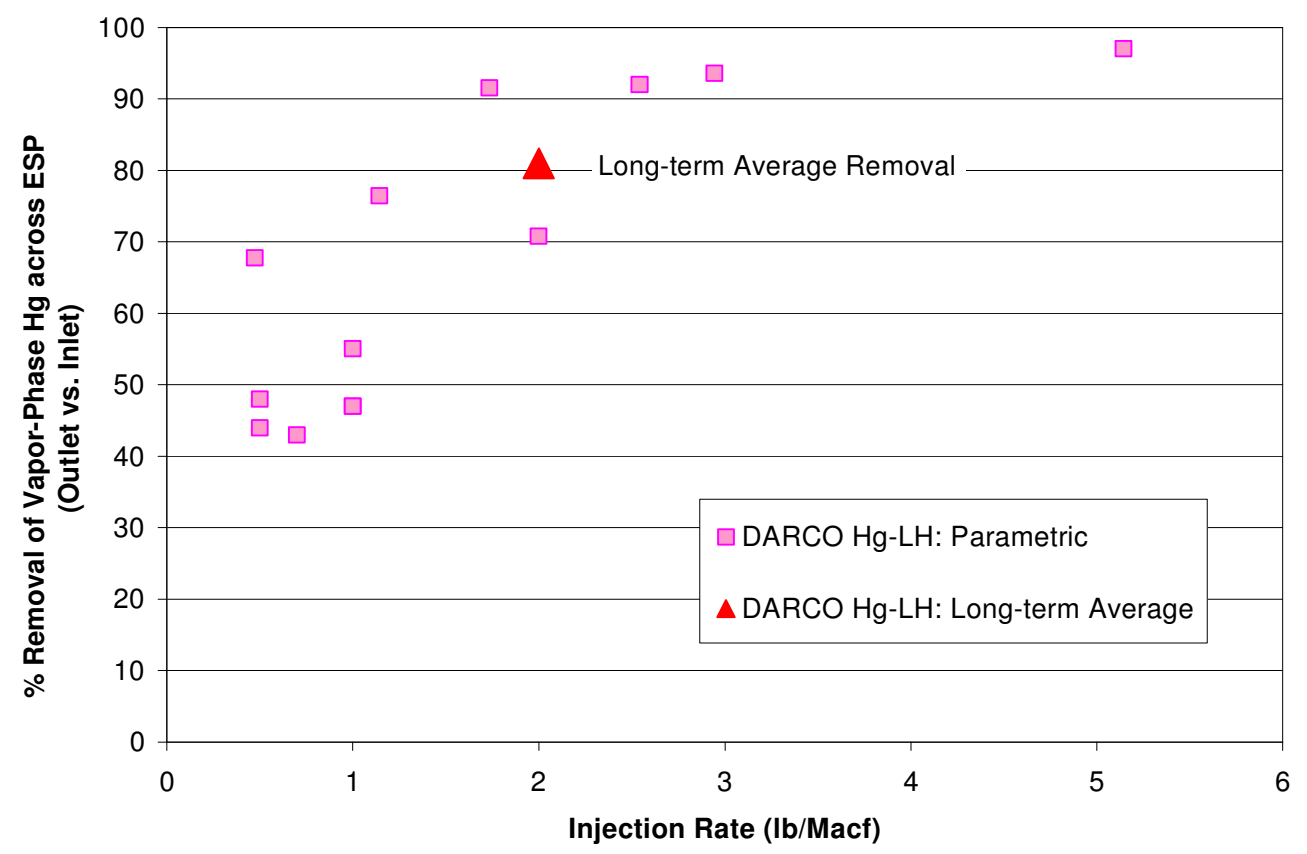

Figure 3-12. Mercury Removal Comparison bewteen Long-Term and Parametric Tests, as Measured by SCEMs 


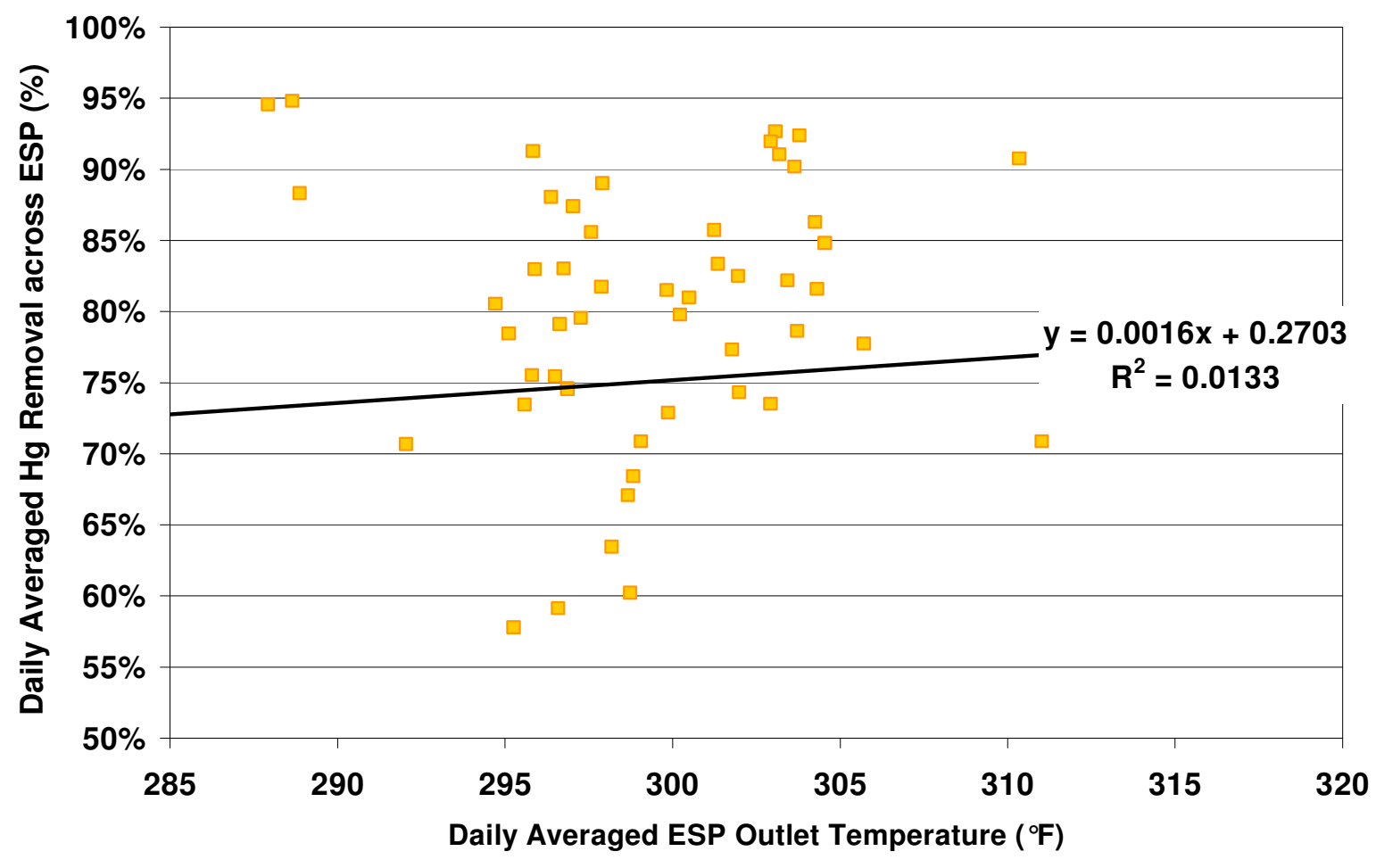

Figure 3-13. Comparison of Daily-Averaged Mercury Removal and ESP Temperature

\section{Mercury Measurements During Long Term Sorbent Injection - Ontario Hydro Results}

$\mathrm{OH}$ measurements were conducted at three different times during the two-month continuous injection test and are summarized in Table 3-17. OH measurements were made at the treated and untreated ESP outlet ducts.

The average $\mathrm{OH}$ total gas phase mercury concentration at the untreated outlet was $32.8 \mu \mathrm{g} / \mathrm{dNm}^{3}$ at $3 \% \mathrm{O}_{2}$. The $\mathrm{OH}$ total gas phase mercury concentration at the treated outlet ranged from 9 to 22 $\mu \mathrm{g} / \mathrm{dNm}^{3}$ at $3 \% \mathrm{O}_{2}$ and averaged $16 \mu \mathrm{g} / \mathrm{dNm}^{3}$ at $3 \% \mathrm{O}_{2}$. The percent mercury reduction at the ESP outlet averaged 51\%, and ranged from $27 \%$ to $71 \%$ over the nine $\mathrm{OH}$ runs that were conducted. Mercury removal across the ESP was calculated by comparing the treated ESP outlet $\mathrm{OH}$ data to the ESP inlet SCEM data (Table 3-18). Mercury removal across the ESP ranged from $0 \%$ to $63 \%$, and averaged $40 \%$.

On average, the flue gas mercury at the untreated outlet duct was $54 \%$ oxidized, while at the treated outlet duct it was $77 \%$ oxidized. Treated outlet duct elemental mercury concentrations ranged from 2.1 to $5.3 \mu \mathrm{g} / \mathrm{dNm}^{3}$, and averaged $3.3 \mu \mathrm{g} / \mathrm{dNm}^{3}$. These results indicate that the injection of activated carbon resulted in increased oxidation of mercury in the flue gas.

$\mathrm{OH}$ results are compared to SCEM results in Table 3-19. The $\mathrm{OH}$ mercury concentration measurements were higher than the SCEM measurements at both the treated and untreated outlet 
ducts. However, both $\mathrm{OH}$ and SCEM showed significant oxidation of mercury due to the injection of activated carbon.

Table 3-17. OH Results for Long-Term Injection Test

\begin{tabular}{|c|c|c|c|c|c|c|c|c|}
\hline Date & Time & Location & $\begin{array}{c}\text { Total Hg } \\
\text { (gas phase } \\
+ \\
\text { particulate) } \\
\mu \mathrm{g} / \mathrm{dNm}^{3} \\
\end{array}$ & $\underset{\mu \mathrm{g} / \mathrm{dNm}_{\mathrm{p}}}{\mathbf{H}}$ & $\underset{\mu \mathrm{g} / \mathrm{dNm}^{3}}{\mathrm{Hg}^{2+}}$ & $\underset{\mu \mathrm{g} / \mathrm{dNm}^{3}}{\mathrm{Hg}^{0}}$ & $\begin{array}{c}\text { Oxidized } \\
\% \text { of } \\
\text { Total Hg }\end{array}$ & $\begin{array}{c}\% \text { Hg } \\
\text { Removal } \\
\text { Untreated } \\
\text { vs. } \\
\text { Treated } \\
\end{array}$ \\
\hline 10-Jul-07 & $12: 10-14: 27$ & Untreated & 35.5 & $<0.03$ & 21.2 & 14.3 & $60 \%$ & \\
\hline 10-Jul-07 & $12: 10-14: 24$ & Treated & 15.0 & 0.08 & 10.9 & 4.0 & $73 \%$ & $58 \%$ \\
\hline 10-Jul-07 & $15: 20-17: 35$ & Untreated & 38.7 & $<0.04$ & 22.8 & 15.9 & $59 \%$ & \\
\hline 10-Jul-07 & $15: 20-17: 23$ & Treated & 20.0 & $<0.05$ & 14.7 & 5.3 & $73 \%$ & $48 \%$ \\
\hline 11-Jul-07 & $09: 32-11: 45$ & Untreated & 41.7 & $<0.04$ & 25.5 & 16.2 & $61 \%$ & \\
\hline 11-Jul-07 & $09: 32-11: 43$ & Treated & 18.5 & $<0.07$ & 14.0 & 4.5 & $76 \%$ & $56 \%$ \\
\hline 31-Jul-07 & $10: 00-12: 45$ & Untreated & 30.8 & $<0.04$ & 16.1 & 14.7 & $52 \%$ & \\
\hline 31-Jul-07 & 10:00-12:11 & Treated & 9.8 & 0.14 & 7.4 & 2.2 & $77 \%$ & $69 \%$ \\
\hline 31-Jul-07 & 14:01-16:09 & Untreated & 31.8 & $<0.04$ & 17.0 & 14.9 & $53 \%$ & \\
\hline 31-Jul-07 & 14:01-16:13 & Treated & 9.3 & $<0.06$ & 7.3 & 2.1 & $78 \%$ & $71 \%$ \\
\hline 1-Aug-07 & 09:20-11:32 & Untreated & 26.5 & $<0.04$ & 12.4 & 14.1 & $47 \%$ & \\
\hline 1-Aug-07 & 09:23-11:36 & Treated & 17.0 & $<0.07$ & 14.3 & 2.8 & $84 \%$ & $36 \%$ \\
\hline 14-Aug-07 & $11: 30-13: 40$ & Untreated & 33.4 & $<0.01$ & 16.8 & 16.6 & $50 \%$ & \\
\hline 14-Aug-07 & $11: 30-13: 45$ & Treated & 21.9 & $<0.01$ & 17.3 & 4.6 & $79 \%$ & $34 \%$ \\
\hline 14-Aug-07 & $15: 00-17: 10$ & Untreated & 30.6 & $<0.01$ & 15.1 & 15.5 & $49 \%$ & \\
\hline 14-Aug-07 & $15: 00-17: 10$ & Treated & 22.4 & $<0.01$ & 17.3 & 5.1 & $77 \%$ & $27 \%$ \\
\hline 15-Aug-07 & 09:30-11:35 & Untreated & 26.5 & $<0.01$ & 14.8 & 11.7 & $56 \%$ & \\
\hline \multirow[t]{3}{*}{ 15-Aug-07 } & 09:30-11:38 & Treated & 10.8 & $<0.01$ & 7.9 & 2.9 & $73 \%$ & $59 \%$ \\
\hline & Average & Untreated & 32.8 & $<0.03$ & 16.2 & 13.4 & $54 \%$ & \\
\hline & Average & Treated & 16.1 & $<0.05$ & 11.1 & 3.3 & $77 \%$ & $51 \%$ \\
\hline
\end{tabular}


Table 3-18. Calculation of Mercury Removal across the ESP Based on OH Outlet Concentrations

\begin{tabular}{||c|c|c|c|c||}
\hline Date & Time & $\begin{array}{c}\text { ESP Inlet } \\
\text { Hg } \\
(\mathbf{S C E M}) \\
\boldsymbol{\mu g} / \mathbf{d N m}^{3}\end{array}$ & $\begin{array}{c}\text { Treated ESP } \\
\text { Outlet Hg } \\
\mathbf{( O H )} \\
\boldsymbol{\mu g} / \mathbf{d N m}^{3}\end{array}$ & $\begin{array}{c}\text { \% Hg } \\
\text { Removal } \\
\text { across } \\
\text { ESP }\end{array}$ \\
\hline 10-Jul-07 & $12: 10-14: 27$ & 26.5 & 14.9 & $44 \%$ \\
\hline 10-Jul-07 & $15: 20-17: 35$ & 32.9 & 20.0 & $39 \%$ \\
\hline 11-Jul-07 & $09: 32-11: 45$ & $\mathrm{n} / \mathrm{a}$ & 18.5 & $\mathrm{n} / \mathrm{a}$ \\
\hline 31-Jul-07 & $10: 00-12: 45$ & 23.5 & 9.6 & $59 \%$ \\
\hline 31-Jul-07 & $14: 01-16: 09$ & 25.6 & 9.3 & $63 \%$ \\
\hline 1-Aug-07 & $09: 20-11: 32$ & 27.8 & 17.0 & $39 \%$ \\
\hline 14-Aug-07 & $11: 30-13: 40$ & 25.9 & 21.9 & $15 \%$ \\
\hline 14-Aug-07 & $15: 00-17: 10$ & 21.6 & 22.4 & $0 \%$ \\
\hline 15-Aug-07 & $09: 30-11: 35$ & 26.8 & 10.8 & $60 \%$ \\
\hline & Average & & & $40 \%$ \\
\hline
\end{tabular}


Table 3-19. Comparison of $\mathrm{OH}$ and SCEM Mercury Measurements during Long-Term Test

\begin{tabular}{|c|c|c|c|c|c|c|c|c|}
\hline Date & Time & $\begin{array}{c}\text { ESP } \\
\text { Outlet } \\
\text { Location }\end{array}$ & $\begin{array}{c}\text { OH O } \\
\text { Vapor- } \\
\text { phase } \\
\text { Total Hg, } \\
\mu \mathrm{g} / \mathrm{dNm}^{3}\end{array}$ & $\% 0 x$ & $\begin{array}{r}\text { SCEM O } \\
\text { Vapor-phase } \\
\text { Total Hg, } \\
\mu \mathrm{g} / \mathbf{d N m}^{3}\end{array}$ & $\% 0 x$ & $\begin{array}{c}\text { OH } \\
\% \\
\text { Removal } \\
\text { Untreated } \\
\text { vs. } \\
\text { Treated } \\
\end{array}$ & $\begin{array}{c}\text { SCEM } \\
\% \\
\text { Removal } \\
\text { Untreated } \\
\text { vs. } \\
\text { Treated } \\
\end{array}$ \\
\hline 10-Jul-07 & $12: 10-14: 27$ & Untreated & 35.5 & $60 \%$ & 20.9 & \multicolumn{2}{|l|}{-} & \multirow[b]{2}{*}{$79 \%$} \\
\hline 10-Jul-07 & $12: 10-14: 24$ & Treated & 15.0 & $73 \%$ & 4.5 & - & $58 \%$ & \\
\hline 10-Jul-07 & $15: 20-17: 35$ & Untreated & 38.7 & $59 \%$ & 20.9 & \multicolumn{2}{|l|}{ - } & \multirow[b]{2}{*}{$71 \%$} \\
\hline 10-Jul-07 & $15: 20-1723$ & Treated & 20.0 & $73 \%$ & 6.0 & - & $48 \%$ & \\
\hline 11-Jul-07 & $09: 32-11: 45$ & Untreated & 41.7 & $61 \%$ & 27.0 & \multicolumn{2}{|l|}{-} & \multirow[b]{2}{*}{$69 \%$} \\
\hline 11-Jul-07 & 09:32-11:43 & Treated & 18.5 & $76 \%$ & 8.4 & - & $56 \%$ & \\
\hline 31-Jul-07 & $10: 00-12: 45$ & Untreated & 30.8 & $52 \%$ & 16.1 & \multirow{2}{*}{$\begin{array}{c}- \\
58 \% \\
\end{array}$} & & \multirow[b]{2}{*}{$75 \%$} \\
\hline 31-Jul-07 & 10:00-12:11 & Treated & 9.8 & $77 \%$ & 4.0 & & $68 \%$ & \\
\hline 31-Jul-07 & 14:01-16:09 & Untreated & 31.8 & $53 \%$ & 19.5 & \multicolumn{2}{|l|}{$42 \%$} & \multirow[b]{2}{*}{$83 \%$} \\
\hline 31-Jul-07 & 14:01-16:13 & Treated & 9.3 & $78 \%$ & 3.2 & - & $71 \%$ & \\
\hline 1-Aug-07 & $09: 20-11: 32$ & Untreated & 26.5 & $47 \%$ & 17.7 & \multicolumn{2}{|l|}{-} & \multirow[b]{2}{*}{$66 \%$} \\
\hline 1-Aug-07 & $09: 23-11: 36$ & Treated & 17.1 & $84 \%$ & 6.0 & $84 \%$ & $36 \%$ & \\
\hline 14-Aug-07 & $11: 30-13: 40$ & Untreated & 33.4 & $50 \%$ & 16.5 & \multicolumn{2}{|l|}{-} & \multirow[b]{2}{*}{$54 \%$} \\
\hline 14-Aug-07 & $11: 30-13: 45$ & Treated & 21.9 & $79 \%$ & 7.7 & $\begin{array}{cc}- \\
-\end{array}$ & $34 \%$ & \\
\hline 14-Aug-07 & $15: 00-17: 10$ & Untreated & 30.6 & $49 \%$ & 16.4 & \multicolumn{2}{|l|}{-} & \multirow[b]{2}{*}{$53 \%$} \\
\hline 14-Aug-07 & $15: 00-17: 10$ & Treated & 22.4 & $77 \%$ & 7.7 & $\begin{array}{c}- \\
-\end{array}$ & $27 \%$ & \\
\hline 15-Aug-07 & $09: 30-11: 35$ & Untreated & 26.5 & $56 \%$ & 15.2 & \multicolumn{2}{|l|}{-} & \multirow[b]{2}{*}{$84 \%$} \\
\hline 15-Aug-07 & 09:30-11:38 & Treated & 10.8 & $73 \%$ & 2.4 & $72 \%$ & $59 \%$ & \\
\hline & Average & Untreated & 32.8 & $54 \%$ & 18.9 & \multicolumn{2}{|l|}{$42 \%$} & \multirow[b]{2}{*}{$70 \%$} \\
\hline & & Treated & 15.8 & $77 \%$ & 5.2 & $71 \%$ & $51 \%$ & \\
\hline
\end{tabular}

\section{Mercury Measurements During Long-Term Sorbent Injection - Fly Ash Results}

Fly ash from the first field of the ESP was obtained daily and samples from every other day were analyzed for mercury content. Because it was more difficult to collect, ash from the back fields of the ESP was sampled and analyzed on a weekly basis. Results from the daily analyses of the first-field ash are summarized in Appendix E. The weekly analyses of all fields are summarized in Table 3-20. As expected, carbon injection resulted in a large increase in the fly ash mercury content. The mercury concentration of the first-field ash increased from $0.04 \mathrm{ppm}$ at baseline conditions to an average of $0.75 \mathrm{ppm}$ during carbon injection. Most hopper 3A samples after July $4^{\text {th }}$ were not used in averages presented in this section due to economizer ash carry-over contamination. During the long-term injection test, fly ash mercury concentration was even higher for the back fields of the ESP. The second field ash mercury concentration averaged 1.9 ppm, and the third field ash mercury concentration averaged $3.2 \mathrm{ppm}$. The combined fourth and fifth field fly ash had an average mercury concentration of $3.7 \mathrm{ppm}$, while the last field averaged just under $2.0 \mathrm{ppm}$. Higher ash mercury content in the back field of the ESP was expected, based on previous experience, and is believed to be related to the higher carbon content (on a mass 
percent basis) and smaller particle size (i.e., higher specific surface area) of the ash captured there.

Fly ash mercury concentrations were compared to the inlet SCEM data to calculate the mercury removal across the ESP. This calculation was performed for each of the thirty days in which the first-field ash mercury concentration was analyzed. Because the back fields were only analyzed once per week and the results were fairly consistent over the course of the test program, test average mercury concentrations for the second through seventh fields were used in the calculation. Detailed calculations of the amount of mercury captured in the fly ash and exiting with the flue gas are provided in Appendix F. Daily averaged mercury removal, as calculated from the ash and inlet SCEM data, ranged from $44 \%$ to $100 \%$, with an overall average of $66 \%$.

Table 3-20. Average Fly Ash Mercury Concentration Measured Across the Treated ESP

\begin{tabular}{|c|c|c|c|c|c|c|c|}
\hline \multirow[b]{3}{*}{ Condition } & \multirow{3}{*}{$\begin{array}{l}\text { Date of } \\
\text { Sample }\end{array}$} & \multirow{3}{*}{$\begin{array}{l}\text { Time of } \\
\text { Sample }\end{array}$} & \multicolumn{5}{|c|}{ Ash Hg Content (ppm) } \\
\hline & & & \multicolumn{5}{|c|}{ Field } \\
\hline & & & 1 & 2 & 3 & $4 \& 5$ & $6 \& 7$ \\
\hline Baseline & $6 / 22 / 2007^{*}$ & $11: 30$ & 0.04 & 0.03 & 0.03 & 0.92 & 0.78 \\
\hline $\begin{array}{l}\text { LT Darco Hg-LH @ } \\
\text { 2.0lb/Macf }\end{array}$ & $6 / 29 / 2007^{*}$ & 13:00 & 0.78 & 1.59 & 2.99 & 3.59 & \\
\hline $\begin{array}{l}\text { LT Darco Hg-LH @ } \\
\text { 2.0lb/Macf }\end{array}$ & $7 / 5 / 2007^{ \pm}$ & $14: 10$ & 0.68 & 1.82 & 3.12 & 3.82 & 1.95 \\
\hline $\begin{array}{l}\text { LT Darco Hg-LH @ } \\
\text { 2.0lb/Macf }\end{array}$ & $7 / 21 / 2007^{ \pm}$ & $12: 12$ & 1.02 & 2.49 & 3.74 & 3.34 & 1.88 \\
\hline $\begin{array}{l}\text { LT Darco Hg-LH @ } \\
\text { 2.0lb/Macf }\end{array}$ & $7 / 28 / 2007^{ \pm}$ & $15: 10$ & 0.58 & 1.78 & 3.66 & 3.89 & 2.73 \\
\hline $\begin{array}{l}\text { LT Darco Hg-LH @ } \\
\text { 2.0lb/Macf }\end{array}$ & $8 / 5 / 2007^{ \pm}$ & $15: 30$ & 0.76 & 2.16 & 3.22 & 3.89 & 1.31 \\
\hline $\begin{array}{l}\text { LT Darco Hg-LH @ } \\
\text { 2.0lb/Macf }\end{array}$ & $8 / 18 / 2007^{ \pm}$ & $13: 00$ & 0.66 & 1.66 & 2.75 & & \\
\hline LT Average & & & 0.75 & 1.91 & 3.25 & 3.71 & 1.96 \\
\hline LT Std Dev & & & 0.15 & 0.34 & 0.39 & 0.24 & 0.58 \\
\hline
\end{tabular}

* $\mathrm{Hg}$ content of the ash is reported as an average of hoppers $1 \mathrm{~A}, 2 \mathrm{~A}$, and $3 \mathrm{~A}$ for each field

$\pm \mathrm{Hg}$ content of the ash is reported as an average of hoppers $1 \mathrm{~A}$ and $2 \mathrm{~A}$ for each field. Hopper $3 \mathrm{~A}$ ash was contaminated with economizer ash for all periods after 7/4/2007.

\section{Discussion of Mercury Removal During the Long-Term Injection Test}

Three different measurement methods were used to calculate the mercury removal achieved by activated carbon injection during the long-term test: SCEM measurements, $\mathrm{OH}$ measurements, and fly ash mercury analysis. Mercury removal was calculated by comparing the mercury measured by each method to SCEM inlet mercury measurements made during the same time period. The calculation of mercury removal based on the inlet SCEM data is predicated on the assumption that inlet SCEM data are accurate. A comparison of inlet SCEM data to coal mercury 
data collected over the two month period indicated agreement within 10\%, thus suggesting that the assumption is valid.

Figure 3-14 compares the results obtained from these three calculation methods. The data points indicate the calculated mercury removal for each day. Removal is calculated for a discrete time period in the day corresponding to the period when fly ash was sampled; it is not the average of the entire 24-hour period. Dashed lines in the plot indicate the average removals over the course of the two-month injection test. For all methods, there was a wide scatter in the measured mercury removal over the test period. Mercury removal, as determined solely from SCEM measurements, ranged from $64 \%$ to $99 \%$, and averaged $82 \%$. The use of fly ash mercury data predicted lower mercury removal, averaging $66 \%$; however, the ash data also indicated a wider range of mercury removal from $44 \%$ to $100 \%$.

The $\mathrm{OH}$ data indicated an average of $40 \%$ mercury removal. This average was obtained from nine two-hour runs that were made over the two-month injection test; thus, the $\mathrm{OH}$ data are not representative of the entire two-month test program. For the $\mathrm{OH}$ data collected the sixth week of the long-term test, there is good agreement with the removal calculated from the ash mercury concentration. Two of the three $\mathrm{OH}$ runs collected during the eighth week of the long-term test indicated significantly lower mercury removals than did the fly ash or SCEM data. These data indicated only $0-15 \%$ removal, which does not agree with any of the other $\mathrm{OH}$, ash, or SCEM data collected over the two month period. However, an analysis of these runs does not indicate any quality control problems. When excluding these two runs, the average mercury removal predicted by the $\mathrm{OH}$ method increases to $50 \%$, which is still lower than the removal measured by the fly ash or the SCEMs.

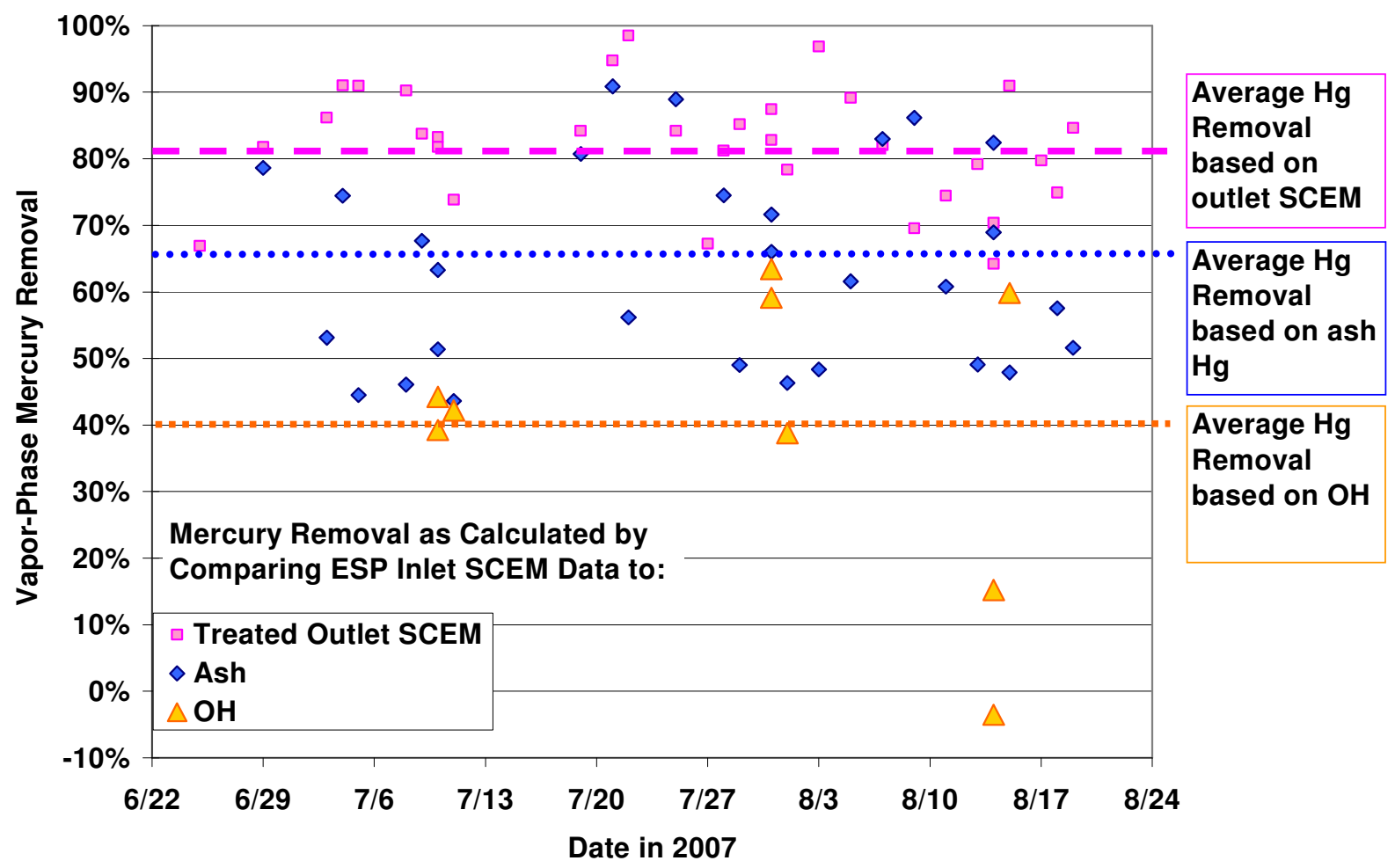

Figure 3-14. Comparison of Mercury Removals Calculated from SCEM, Ash, and OH Data 
Results from this comparison show a large discrepancy between the mercury removals calculated from the SCEM, OH, and fly ash data evaluation. A review of the QA/QC data associated with the SCEM, OH, and fly ash measurements does not identify any problems that could have led to the discrepancy between the methods. The SCEM probe at the ESP outlet was changed three times during the course of the long-term test; no changes in measured mercury concentrations were observed with the new probes (Appendix G). All analytical parameters associated with the $\mathrm{OH}$ and fly ash characterization procedures passed stringent QC criteria (Appendix A).

The discrepancy between the data may result from differences in the sample collection techniques for the methods. SCEM data were collected at a single point in one of the two treated ESP outlet ducts whereas the $\mathrm{OH}$ data were collected as a traverse of the other treated ESP outlet duct. While the SCEM probe was located at a point with average flow for the duct, it is possible that the selected point corresponded to a location in the duct with higher than average carbon contact and, thus, mercury removal. Although care was taken to achieve good sorbent distribution across the flue gas duct, the actual extent of the (duct) coverage attained is not known. Computational flow dynamic (CFD) modeling would be required to more accurately evaluate this.

\subsection{Mercury Oxidation during Sorbent Injection}

The long-term injection test was used to evaluate the effectiveness of injecting $2 \mathrm{lb} / \mathrm{Macf}$ of DARCO Hg-LH to achieve mercury removal and oxidation. Appreciable levels of both would be expected to result in high overall removal across the unit configured with an ESP and wet FGD system. Mercury removal across the ESP was discussed in the previous section. Figure 3-15 shows the measured flue gas mercury oxidation at the inlet and the treated and untreated ESP outlet ducts, based on SCEM data. Tables 3-14 and 3-15 list the average elemental mercury concentrations and percent oxidation measured by SCEM, respectively. The mercury oxidation at each location varied greatly over the course of the two-month injection test.

As discussed in the previous section, the SCEM and OH measurements did not agree well for the prediction of mercury removal during the sorbent injection test. Despite the general disagreement in total mercury concentrations, both methods indicated that activated carbon resulted in significant oxidation of flue gas mercury. OH measurements showed an average mercury oxidation of $54 \%$ at the untreated ESP outlet and $77 \%$ at the treated ESP outlet. SCEM measurements showed an average mercury oxidation of $49 \%$ at the untreated ESP outlet and $81 \%$ mercury oxidation at the treated ESP outlet.

Limestone Unit 1 is equipped with an FGD scrubber that can remove oxidized mercury at high efficiency, so these results suggest that the overall system mercury removal from a sorbent injection process would be higher than the removal measured at the ESP outlet. The results also suggest that it might be possible to optimize the sorbent injection process to maximize overall removal across the ESP-FGD system. Thus, a lower sorbent injection rate might be used for the Limestone units than for other units that are not equipped with FGD scrubbers.

Table 3-21 lists the results of theoretical calculations of overall system (ESP + FGD) removal for the long-term test. These calculations assume that the FGD scrubber removes $95 \%$ of oxidized mercury present in the flue gas and that there are no mercury re-emissions. Two sets of 
calculations were made: (1) based on SCEM outlet measurements, and, (2) based on OH outlet measurements. For both sets of calculations, the overall system removal was based on an average ESP inlet mercury concentration of $25.4 \mu \mathrm{g} / \mathrm{dNm}^{3}$, as measured by the SCEM.

Using the SCEM data, the average mercury removal across the ESP was $81 \%$, which would result in an ESP outlet mercury concentration of $4.8 \mu \mathrm{g} / \mathrm{dNm}^{3}$. The average mercury oxidation at the ESP outlet was $81 \%$; therefore $0.9 \mu \mathrm{g} / \mathrm{dNm}^{3}$ would be present as elemental mercury and 3.9 $\mu \mathrm{g} / \mathrm{dNm}^{3}$ would be present as oxidized mercury. Assuming $95 \%$ net removal of oxidized mercury across the FGD scrubber and $100 \%$ transmission of elemental mercury, the FGD outlet mercury concentration would be $0.9+0.05 * 3.9=1.1 \mu \mathrm{g} / \mathrm{dNm}^{3}$. The overall system removal would thus be greater than $90 \%$.

Using the $\mathrm{OH}$ data, the average mercury removal across the ESP was $40 \%$, which would result in an ESP outlet mercury concentration of $15.2 \mu \mathrm{g} / \mathrm{dNm}^{3}$. The average mercury oxidation at the ESP outlet was $77 \%$; therefore $3.5 \mu \mathrm{g} / \mathrm{dNm}^{3}$ would be present as elemental mercury and 11.7 $\mu \mathrm{g} / \mathrm{dNm}^{3}$ would be present as oxidized mercury. Using the same assumptions for FGD mercury removal, the FGD outlet mercury concentration would be $3.5+0.05 * 11.7=4.1 \mu \mathrm{g} / \mathrm{dNm}^{3}$. The overall system removal would then be $84 \%$.

To verify these theoretical calculations, in 2009 flue gas mercury measurements were made across the entire LMS unit including the FGD during ACI. The 2009 results indicated lower levels of mercury removal than the $90+\%$ mercury removal predicted from the theoretical calculations using the 2007 SCEM data. As will be discussed in Chapter 4, with injection of Darco $\mathrm{Hg}$-LH at $1.89 \mathrm{lb} / \mathrm{Macf}$, mercury removals across the system were $65 \%$ and $79 \%$ on two different days; if no flue gas bypassed the FGD and there were no re-emissions, as was assumed in the theoretical calculations with the 2007 data, mercury removals would increase to $70 \%$ and $84 \%$, for those two days. These 2009 measurements indicate wide variability in mercury removal performance of the LMS system and the potential for lower removal than the $2007 \mathrm{OH}$ theoretical prediction of $84 \%$ removal. 


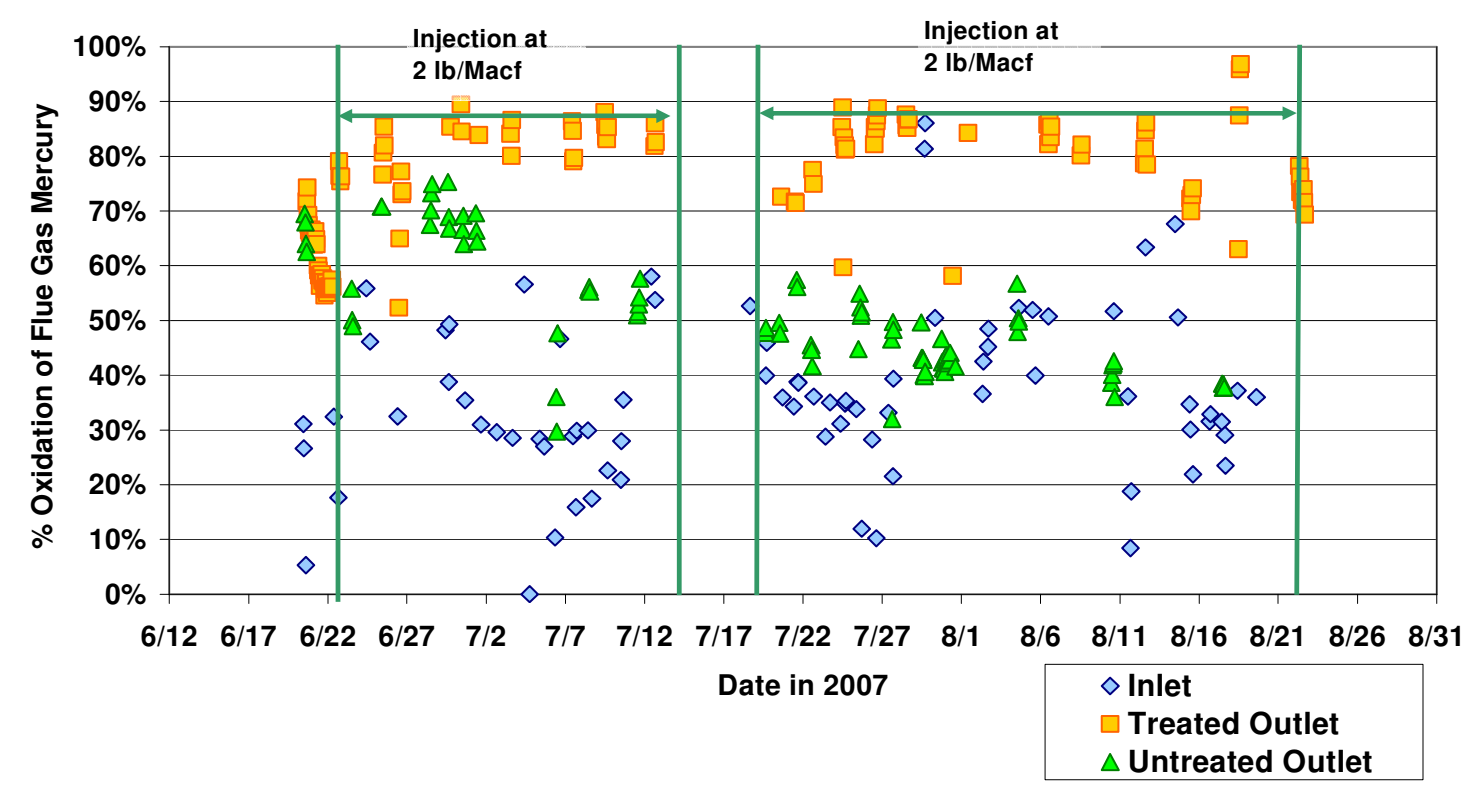
Figure 3-15. Percent Mercury Oxidation Measured at Each Sample Location
during Long-Term Test

Table 3-21. Theoretical Predictions of Mercury Removal by ESP + FGD

\begin{tabular}{||c|c|c||}
\hline \hline & $\begin{array}{c}\text { Calculations Based on SCEM } \\
\text { Outlet Data }\end{array}$ & $\begin{array}{c}\text { Calculations Based on } \\
\text { OH Outlet Data }\end{array}$ \\
\hline $\begin{array}{c}\text { Inlet Hg by SCEM } \\
\left(\mu \mathrm{g} / \mathrm{dNm}^{3}\right)\end{array}$ & 25.4 & 25.4 \\
\hline Removal Across ESP & $81 \%$ & $40 \%$ \\
\hline Predicted ESP Outlet Total Hg $\left(\mu \mathrm{g} / \mathrm{dNm}^{3}\right)$ & 4.8 & 15.2 \\
\hline Oxidation at ESP Outlet & $81 \%$ & $77 \%$ \\
\hline Predicted Outlet $\mathrm{Hg}^{0} / \mathrm{Hg}^{2+}\left(\mu \mathrm{g} / \mathrm{dNm}^{3}\right)$ & $0.9 / 3.9$ & $95 \%$ \\
\hline $\begin{array}{c}\text { Assumed Net Removal of } \mathrm{Hg}^{2+} \mathrm{Across} \\
\mathrm{FGD}\end{array}$ & $95 \%$ & $0 \%$ \\
\hline Assumed Removal of $\mathrm{Hg}^{0} \mathrm{Across} \mathrm{FGD}$ & $0 \%$ & 4.1 \\
\hline $\begin{array}{c}\text { Predicted FGD Outlet Total Hg } \\
\left(\mu \mathrm{g} / \mathrm{dNm}^{3}\right)\end{array}$ & 1.1 & $84 \%$ \\
\hline $\begin{array}{c}\text { Predicted Overall System }(\mathrm{ESP}+\mathrm{FGD}) \mathrm{Hg} \\
\text { Removal }\end{array}$ & $>90 \%$ & 2.7 \\
\hline
\end{tabular}

\subsection{Analysis of Coal and Fly Ash}

In addition to flue gas mercury measurements, coal and fly ash samples were obtained and characterized so that a mercury mass balance across the Unit 2 gas path could be performed. PRB and TxL coals were fired over the course of testing at LMS; most tests involved a 70/30 blend of TxL and PRB, respectively. Both coal types were collected and analyzed separately, as presented in Appendix H. Average coal analysis results for each coal type are summarized in Tables 3-22 and 3-23 for each phase of testing. No coal samples from Phase III were analyzed. 
For TxL coal, the mercury concentration averaged 0.22 ppmd and the chloride concentration averaged $59 \mathrm{ppm}$ during the long-term test. PRB coal the mercury concentrations averaged 0.10 ppmd and chloride concentrations averaged $22 \mathrm{ppm}$ during the long-term test. There was significant sample to sample variation in the chloride concentration for both coal types. Bromide concentrations were generally higher for the TxL coal than for the PRB coal; however, the average bromide concentration for both coals during the long-term test was less than $1.0 \mathrm{ppm}$.

Table 3-22. Summary of TxL Coal Analysis Results

\begin{tabular}{|c|c|c|c|c|c|c|}
\hline \multirow[b]{2}{*}{ Parameter, Unit } & \multicolumn{2}{|c|}{$\begin{array}{c}\text { December } 2006 \\
\text { Phase I Parametric } \\
\text { Testing } \\
\text { Texas Lignite }\end{array}$} & \multicolumn{2}{|c|}{$\begin{array}{c}\text { April } 2007 \\
\text { Phase II Parametric } \\
\text { Testing } \\
\text { Texas Lignite }\end{array}$} & \multicolumn{2}{|c|}{$\begin{array}{c}\text { June-August } 2007 \\
\text { Long-Term Testing } \\
\text { Texas Lignite }\end{array}$} \\
\hline & Average & Std. Dev. & Average & Std. Dev. & Average & Std. Dev. \\
\hline Mercury, ppm (dry) & 0.186 & 0.043 & 0.175 & 0.045 & 0.216 & 0.086 \\
\hline Chloride, ppm (dry) & 33 & 14 & 42 & 8 & 59 & 65 \\
\hline Bromide, ppm (dry) & 9.8 & 0.5 & 5.8 & 0.0 & 1.0 & 0.0 \\
\hline Fluoride, ppm (dry) & 58 & 22 & 83 & 9 & $\mathrm{n} / \mathrm{a}$ & \\
\hline \multicolumn{7}{|l|}{ Dry Basis } \\
\hline$\%$ Moisture & 31.9 & 0.7 & 32.7 & 0.4 & 32.5 & 3.1 \\
\hline$\%$ Ash & 18.3 & 3.3 & 20.3 & 5.5 & 21.0 & 3.1 \\
\hline Carbon, wt $\%$ & 60.1 & 4.1 & $\mathrm{n} / \mathrm{a}$ & & 58.1 & 3.1 \\
\hline Hydrogen, wt $\%$ & 4.25 & 0.26 & $\mathrm{n} / \mathrm{a}$ & & 4.96 & 0.21 \\
\hline Nitrogen, wt $\%$ & 0.87 & 0.01 & $\mathrm{n} / \mathrm{a}$ & & 0.84 & 0.05 \\
\hline Sulfur, wt $\%$ & 0.88 & 0.17 & 0.86 & 0.10 & 1.25 & 0.89 \\
\hline Oxygen, wt $\%$ & 15.2 & 0.9 & $\mathrm{n} / \mathrm{a}$ & & 13.8 & 0.8 \\
\hline Heating Value, Btu/lb & 10645 & 435 & 9979 & 695 & 10007 & 540 \\
\hline \multicolumn{7}{|l|}{$\begin{array}{l}\text { Calculated Parameters (from } \\
\text { average values above) }\end{array}$} \\
\hline $\mathrm{F}_{\mathrm{d}}, \mathrm{dscf} / 10^{6} \mathrm{Btu}, 0 \% \mathrm{O}_{2}$ & 9565 & & $\mathrm{n} / \mathrm{a}$ & & 10133 & \\
\hline Sulfur, wt $\%$ (as recieved) & 0.60 & & 0.58 & & 0.84 & \\
\hline $\begin{array}{l}\text { Heating value, Btu/lb } \\
\text { (as received) }\end{array}$ & 7248 & & 6721 & & 6754 & \\
\hline $\mathrm{Hg}, \mathrm{lb} / \mathrm{Tbtu}$ & 25.6 & & $\mathrm{n} / \mathrm{a}$ & & 32.0 & \\
\hline
\end{tabular}


Table 3-23. Summary of PRB Coal Analysis Results

\begin{tabular}{|c|c|c|c|c|c|c|}
\hline \multirow[b]{2}{*}{ Parameter, Unit } & \multicolumn{2}{|c|}{$\begin{array}{c}\text { December } 2006 \\
\text { Phase I Parametric } \\
\text { Testing } \\
\text { PRB }\end{array}$} & \multicolumn{2}{|c|}{$\begin{array}{c}\text { April } 2007 \\
\text { Phase II Parametric } \\
\text { Testing } \\
\text { PRB }\end{array}$} & \multicolumn{2}{|c|}{$\begin{array}{c}\text { June-August } 2007 \\
\text { Long-Term Testing } \\
\text { PRB }\end{array}$} \\
\hline & Average & Std. Dev. & Average & Std. Dev. & Average & Std. Dev. \\
\hline Mercury, ppm (dry) & 0.121 & 0.020 & 0.143 & 0.033 & 0.095 & 0.024 \\
\hline Chloride, ppm (dry) & 16 & 6 & 25 & 18 & 22 & 31 \\
\hline Bromide, ppm (dry) & $<1$ & 0.0 & 4.8 & 0.2 & $<1.0$ & 0.0 \\
\hline Fluoride, ppm (dry) & 67 & 5 & 61 & 25 & $\mathrm{n} / \mathrm{a}$ & \\
\hline \multicolumn{7}{|l|}{ Dry Basis } \\
\hline$\%$ Moisture & 30.4 & 0.7 & 31.7 & 0.3 & 32.8 & 4.3 \\
\hline$\%$ Ash & 8.1 & 1.4 & 10.5 & 0.0 & 8.1 & 1.2 \\
\hline Carbon, wt $\%$ & 68.5 & 0.8 & $\mathrm{n} / \mathrm{a}$ & & 68.4 & 0.9 \\
\hline Hydrogen, wt $\%$ & 4.47 & 0.04 & $\mathrm{n} / \mathrm{a}$ & & 5.40 & 0.29 \\
\hline Nitrogen, wt $\%$ & 0.75 & 0.05 & $\mathrm{n} / \mathrm{a}$ & & 0.74 & 0.04 \\
\hline Sulfur, wt $\%$ & 0.55 & 0.18 & 0.57 & 0.01 & 0.56 & 0.06 \\
\hline Oxygen, wt $\%$ & 17.6 & 0.7 & $\mathrm{n} / \mathrm{a}$ & & 16.7 & 0.5 \\
\hline Heating Value, Btu/lb & 11784 & 165 & 11285 & 23 & 11643 & 400 \\
\hline \multicolumn{7}{|l|}{$\begin{array}{l}\text { Calculated Parameters (from } \\
\text { average values above) }\end{array}$} \\
\hline $\mathrm{F}_{\mathrm{d}}, \mathrm{dscf} / 10^{6} \mathrm{Btu}, 0 \% \mathrm{O}_{2}$ & 9617 & & $\mathrm{n} / \mathrm{a}$ & & 10237 & \\
\hline Sulfur, wt $\%$ (wet) & 0.38 & & 0.39 & & 0.38 & \\
\hline $\begin{array}{l}\text { Heating value, Btu/lb } \\
\text { (as received) }\end{array}$ & 8200 & & 7710 & & 7822 & \\
\hline $\mathrm{Hg}, \mathrm{lb} / \mathrm{Tbtu}$ & 14.8 & & $\mathrm{n} / \mathrm{a}$ & & 12.2 & \\
\hline
\end{tabular}

Fly ash samples were collected during baseline operation, parametric testing, and the long-term injection test. Because parametric tests were too short in duration to obtain representative ash samples, the results from these analyses are not reported. This section presents the results from the analysis of baseline ESP 1A ash, fly ash from the untreated ESP 1B (sampled weekly), and ash collected from the treated ESP 1A during long-term sorbent injection. Daily first-field fly ash samples from ESP 1A were collected during the long-term injection test, while back-field ash samples were obtained on a weekly basis (due to difficulty in obtaining samples). After July 4, 2007, all hopper 3A samples from ESP 1A were contaminated by economizer ash that carried over into the hoppers during the injection test period. The results from the daily analyses of the first field ash are summarized in Appendix E. Hopper 3A (ESP 1A) data are recorded in the appendix, but were not used to tabulate average field measurements after July 4, 2007 because of contamination from economizer ash. 
Figure 3-16 compares the first-field fly ash mercury concentrations for the treated and untreated ESPs. The untreated ash mercury concentration was consistently below $0.1 \mathrm{ppm}$, indicating less than $10 \%$ mercury removal (from the flue gas) by the fly ash across the ESP. The first-field treated ash concentration from the long-term test ranged from 0.4 to $1.0 \mathrm{ppm}$, with an average of $0.66 \mathrm{ppm}$. The fly ash mercury concentration was even higher for the back fields of the ESP; the second- and third-field ash mercury concentrations averaged $1.91 \mathrm{ppm}$ and $3.25 \mathrm{ppm}$, respectively (Table 3-20). As discussed previously and tabulated in Appendix F, the fly ash mercury concentrations indicated ESP removals between 44 and 100\%, with an average of 66\%, during the long-term sorbent injection test.

Loss on ignition (LOI) tests are used to determine the amount of unburned carbon in the fly ash. From a concrete standpoint, ash containing little LOI is most desirable since finely divided materials, such as carbon, have been known to reduce the entrained air content of concrete. Table 3-24 documents ash LOI content in all fields during long-term injection. The first field LOI content increased for sorbent injection as compared to baseline. Back fields were enriched in carbon for both baseline and sorbent injection. Figure 3-17 shows fly ash $\mathrm{Hg}$ concentration versus fly ash LOI. There is a distinct trend of $\mathrm{Hg}$ content increasing as LOI content increased.

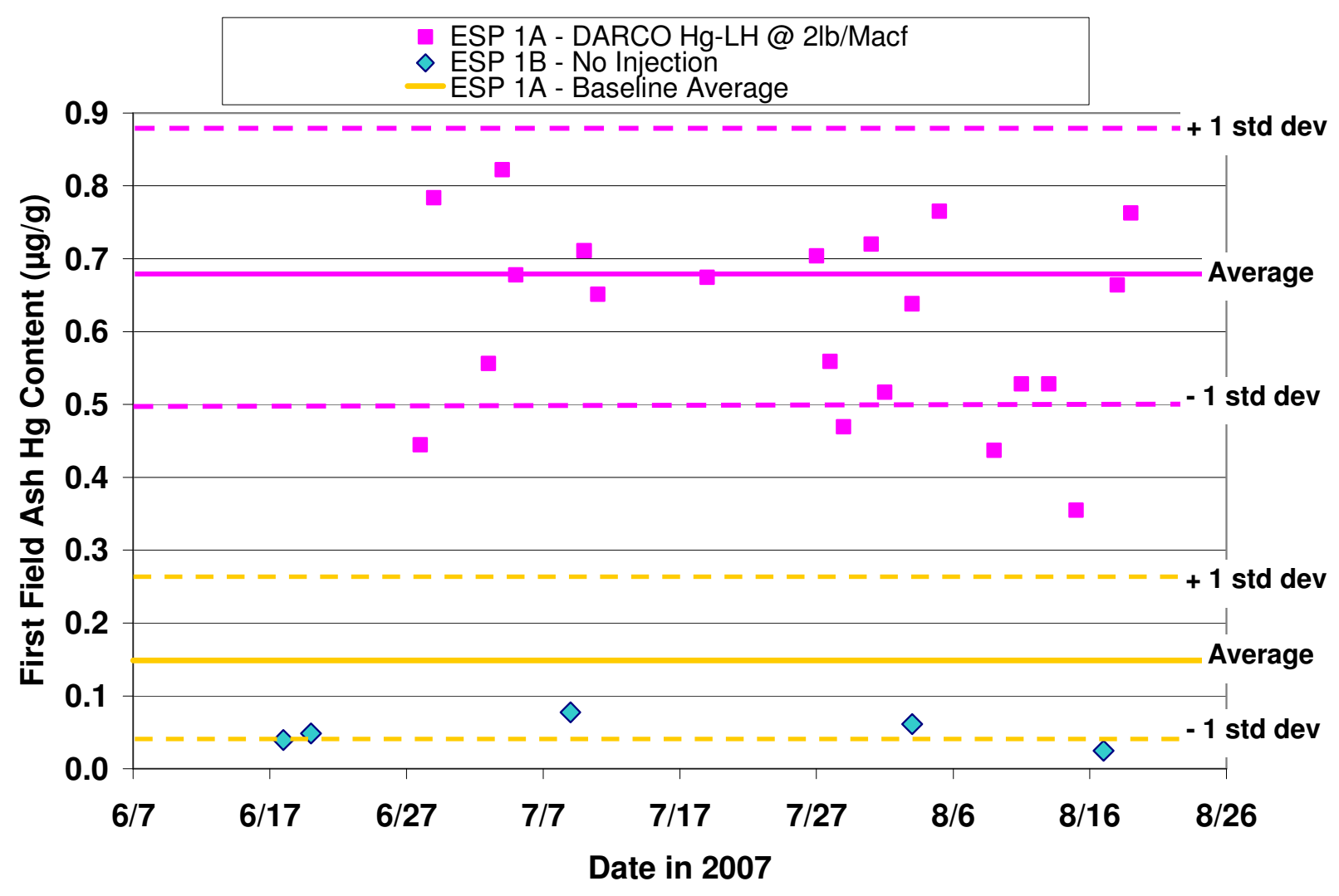

Figure 3-16. First-Field Fly Ash Hg during Long-Term Sorbent Injection Comparison of Treated and Untreated ESPs 
Table 3-24. Fly Ash LOI Concentrations during Long-Term Sorbent Injection - All Fields

\begin{tabular}{|c|c|c|c|c|c|c|c|}
\hline \multirow{3}{*}{ Condition } & \multirow{3}{*}{$\begin{array}{l}\text { Date of } \\
\text { Sample }\end{array}$} & \multirow{3}{*}{$\begin{array}{l}\text { Time of } \\
\text { Sample }\end{array}$} & \multicolumn{5}{|c|}{ Fly Ash LOI Content (\%) } \\
\hline & & & \multicolumn{5}{|c|}{ Field } \\
\hline & & & 1 & 2 & 3 & $4 \& 5$ & $6 \& 7$ \\
\hline $\begin{array}{l}\text { Average of all } \\
\text { Baseline Data }\end{array}$ & & & 0.13 & & & & 1.03 \\
\hline Baseline & $6 / 22 / 2007^{*}$ & $11: 30$ & 0.03 & 0.16 & 0.31 & 1.36 & 2.58 \\
\hline $\begin{array}{l}\text { LT Darco Hg-LH @ } \\
\text { 2.0lb/Macf }\end{array}$ & $6 / 29 / 2007^{*}$ & $13: 00$ & $\mathrm{n} / \mathrm{a}$ & 0.54 & 0.71 & 0.81 & $\mathrm{n} / \mathrm{a}$ \\
\hline $\begin{array}{l}\text { LT Darco Hg-LH @ } \\
\text { 2.0lb/Macf }\end{array}$ & $7 / 5 / 2007^{ \pm}$ & $14: 10$ & 0.61 & 1.07 & 1.27 & 1.36 & 1.63 \\
\hline $\begin{array}{l}\text { LT Darco Hg-LH @ } \\
\text { 2.0lb/Macf }\end{array}$ & $7 / 21 / 2007^{ \pm}$ & $12: 12$ & 0.54 & 0.79 & 1.15 & 1.40 & 1.76 \\
\hline $\begin{array}{l}\text { LT Darco Hg-LH @ } \\
\text { 2.0lb/Macf }\end{array}$ & $7 / 28 / 2007^{ \pm}$ & $15: 30$ & 0.64 & 0.93 & 0.74 & 0.87 & 1.36 \\
\hline $\begin{array}{l}\text { LT Darco Hg-LH @ } \\
\text { 2.0lb/Macf }\end{array}$ & $8 / 5 / 2007^{ \pm}$ & $15: 10$ & 0.39 & 0.63 & 0.86 & 1.44 & 2.15 \\
\hline $\begin{array}{l}\text { LT Darco Hg-LH @ } \\
\text { 2.0lb/Macf }\end{array}$ & $8 / 18 / 2007^{ \pm}$ & 13:00 & 0.40 & 0.63 & 0.89 & 1.00 & 1.39 \\
\hline LT Average & & & 0.52 & 0.77 & 0.94 & 1.15 & 1.66 \\
\hline LT St Dev & & & 0.12 & 0.20 & 0.23 & 0.28 & 0.32 \\
\hline
\end{tabular}

*LOI content of the ash are reported as an average of hoppers 1A, 2A, and 3A for each field \pm LOI content of the ash are reported as an average of hoppers $1 \mathrm{~A}$ and $2 \mathrm{~A}$ for each field. Hopper $3 \mathrm{~A}$ ash was contaminated with economizer ash for all periods after 7/4/2007. 


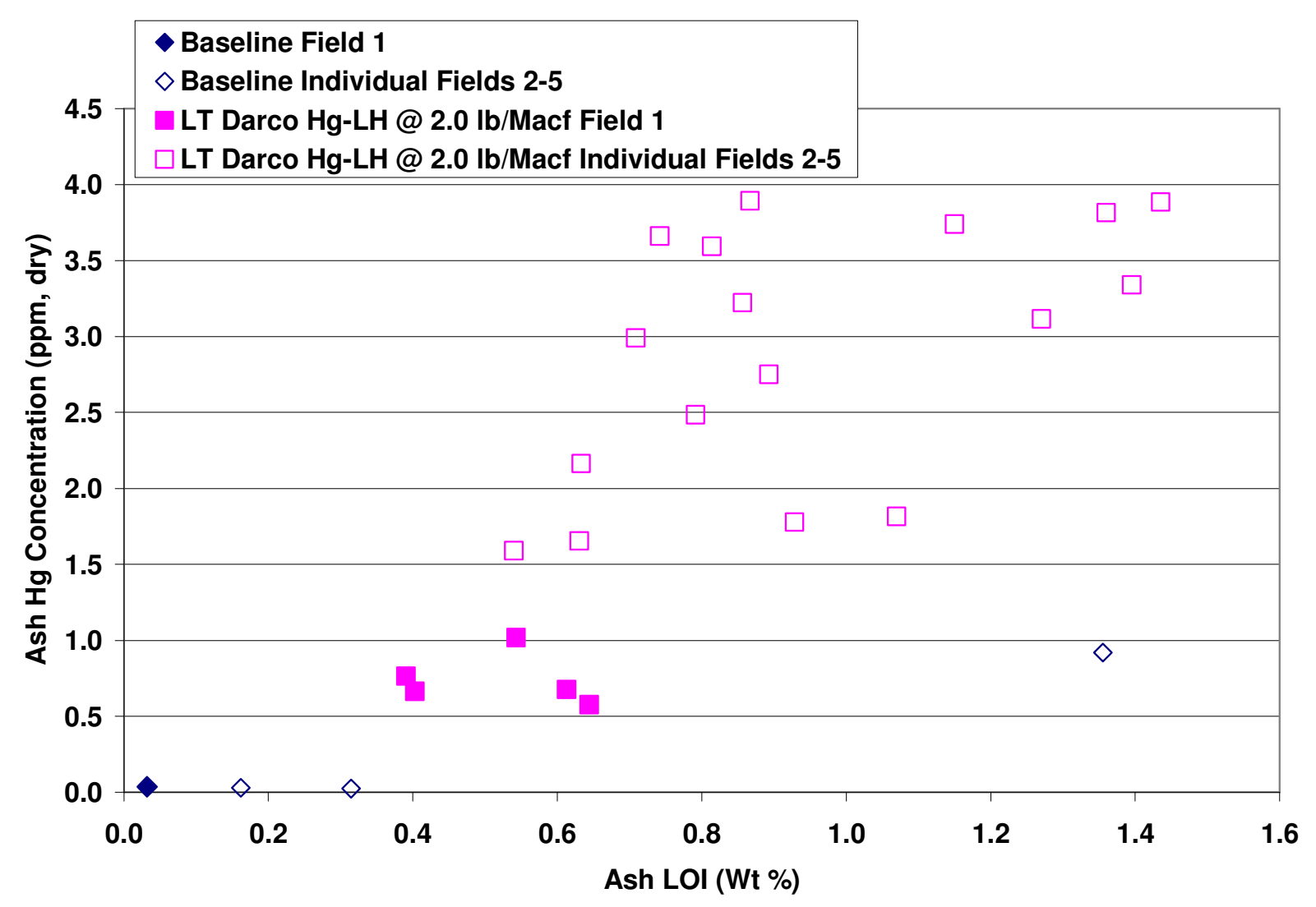

Figure 3-17. Ash Hg Concentration vs. Ash LOI for all Fields, Baseline and Long-Term ACI

\subsection{Effects of Sorbent Injection on ESP Operation}

The injection of activated carbon can have an effect on ESP operation. ESP electrical data and opacity data were gathered during baseline, parametric, and long term testing with a data logger starting on April 26 and ending on September 19, 2007. Due to several data storage problems, data from May 27 until July 31 were lost. The lost data were from the baseline testing period just prior to the long-term test and approximately the first half of the 60-day sorbent injection test. ESP electrical data included sparking, power use, and current for each field. Opacity monitors were located at the outlet of each ESP module and were not compliance monitors; the latter were located downstream of the FGD units. As such, the ESP outlet opacity was used only to determine relative trends. Data from the FGD outlet opacity monitors were not analyzed, as only one-fourth of the gas exiting the FGD units was treated with activated carbon.

Due to the brevity of each parametric test, no accurate conclusions could be drawn about the effect of different sorbents or respective injection rates on ESP performance. As such, the analysis presented in this report was confined to pre-test baseline, long-term test, and post-test baseline data.

Figure 3-18 shows pre-test baseline opacity for ESPs 1A and 1D. ESP 1A is the ACI-treated ESP, and ESP 1D is an untreated ESP. The baseline opacity data from ESP 1D (more than ESPs 
1B and 1C) trended similarly to ESP 1A, so it was used as the control basis for analysis of the effect of carbon injection on opacity.

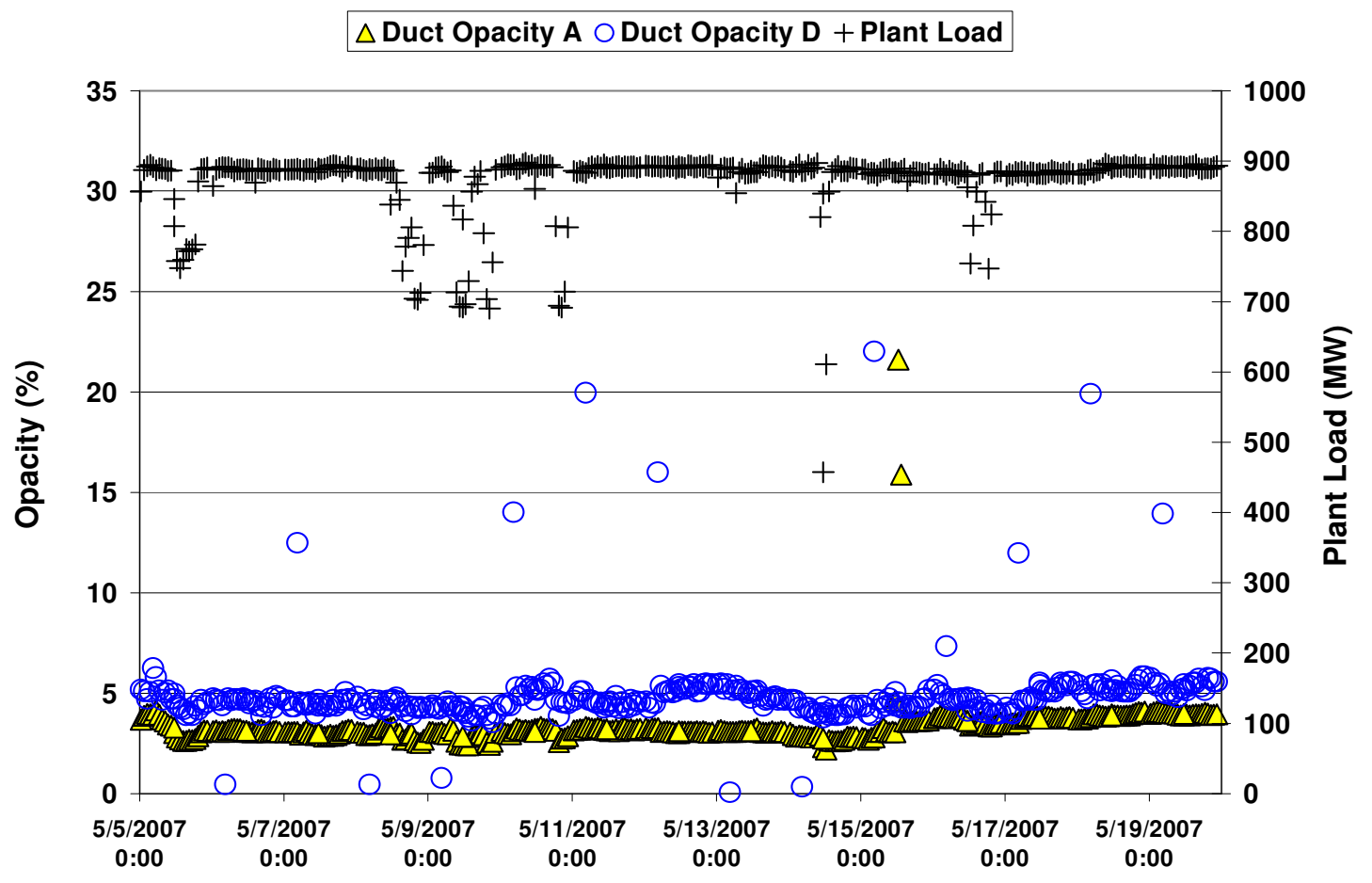

Figure 3-18. Pre-Test Baseline Opacity

Figure 3-19 shows duct opacity for ESP 1A and ESP 1D during the long-term test and during post-test baseline operation. ESPs 1A and 1D showed similar behavior during carbon injection and non-carbon injection test periods, indicating that carbon injection had no impact on the opacity measured at the ESP outlet. Table 3-25 shows the average opacity during all three phases for ESPs 1A and 1D. For both ESPs, the opacity increased slightly during the sorbent injection period and then increased even further during the post-test baseline period. 


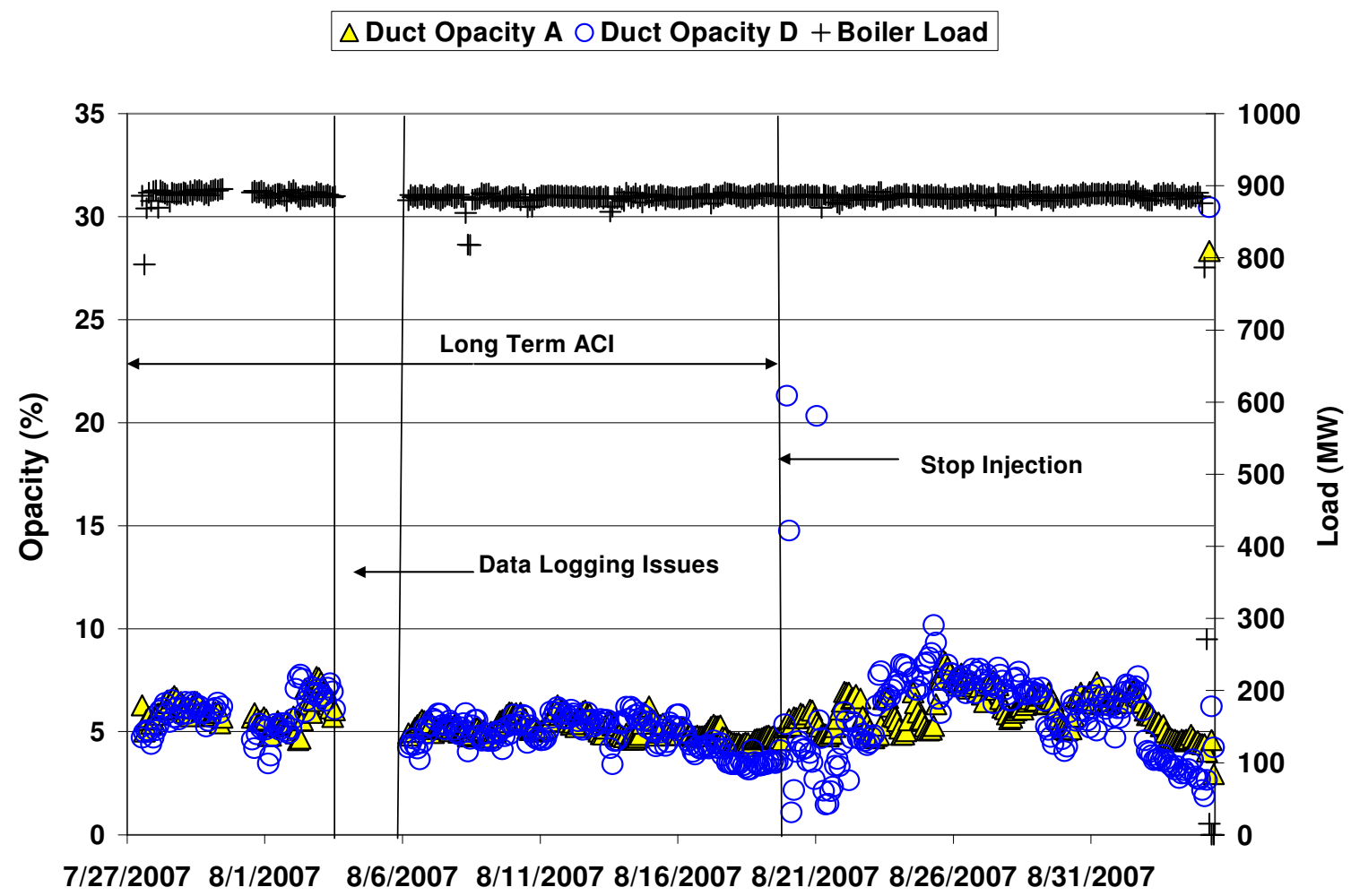

Figure 3-19. Opacity during Long-Term Test and Post-Test Baseline Operation

Table 3-25. Comparison of Average Opacity for Treated and Untreated ESPs

\begin{tabular}{|c|c|c|}
\hline Testing Phase & $\begin{array}{c}\text { Average Opacity ESP 1A } \\
\text { (Treated) }\end{array}$ & $\begin{array}{c}\text { Average Opacity ESP 1D } \\
\text { (Untreated) }\end{array}$ \\
\hline Pre-Test Baseline & $5.3 \%$ & $4.8 \%$ \\
\hline Long Term ACI & $5.4 \%$ & $5.2 \%$ \\
\hline Post-Test Baseline & $6.3 \%$ & $6.5 \%$ \\
\hline
\end{tabular}

Analysis of the ESP electrical data was more complicated than the opacity data analysis due mainly to the size of the LMS ESP. The ESP has 84 separate measurement points with 21 in each ESP (1A through 1D) broken up into 3 rows (AB, CD, and EF), with 7 fields each. Figures 3-20 through 3-22 show that the behavior from location to location was quite erratic. Some locations, like $\mathrm{A} 1 \mathrm{AB}$ and $\mathrm{A} 1 \mathrm{EF}$, experienced high sparking rates $(>30 \mathrm{spm})$ throughout the test period with only occasional temporary reductions in sparking observed (Figure 3-20). Locations such as A1CD and A3CD experienced relatively lower spark rates $(<10 \mathrm{spm})$ for most of the test period (Figure 3-21). Other locations, such as A2AB and D2AB, showed essentially no sparking for the duration of the testing (Figure 3-22). For all of these fields, there was no discernible difference in sparking rates between sorbent injection and non-injection test periods. The ESP electrical data was too complex to undergo a mathematical analysis to evaluate the effect of ACI on ESP performance. 


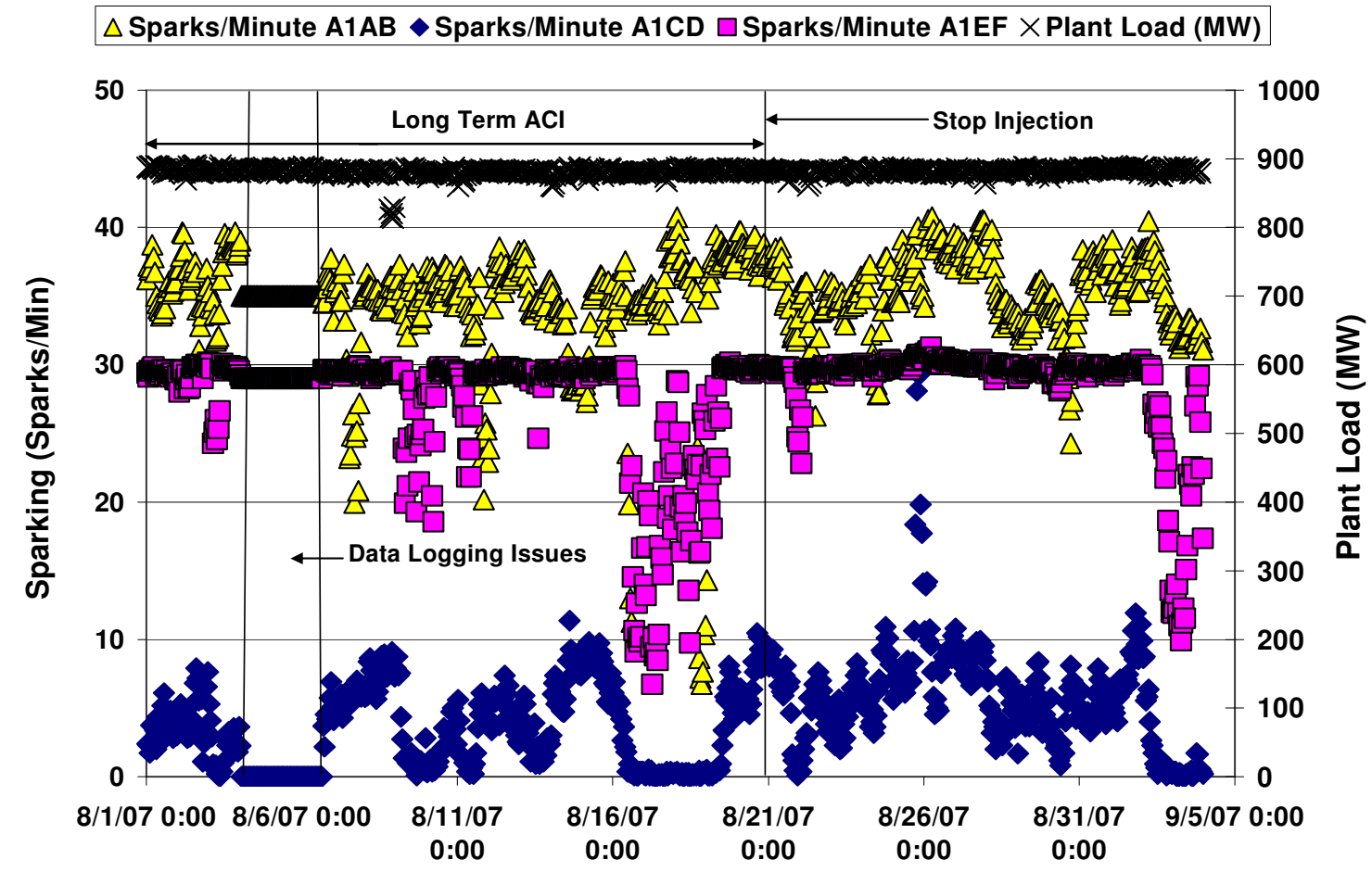

Figure 3-20. ESP A Field 1 Spark Rates during Long-Term and Post-Test Baseline Periods

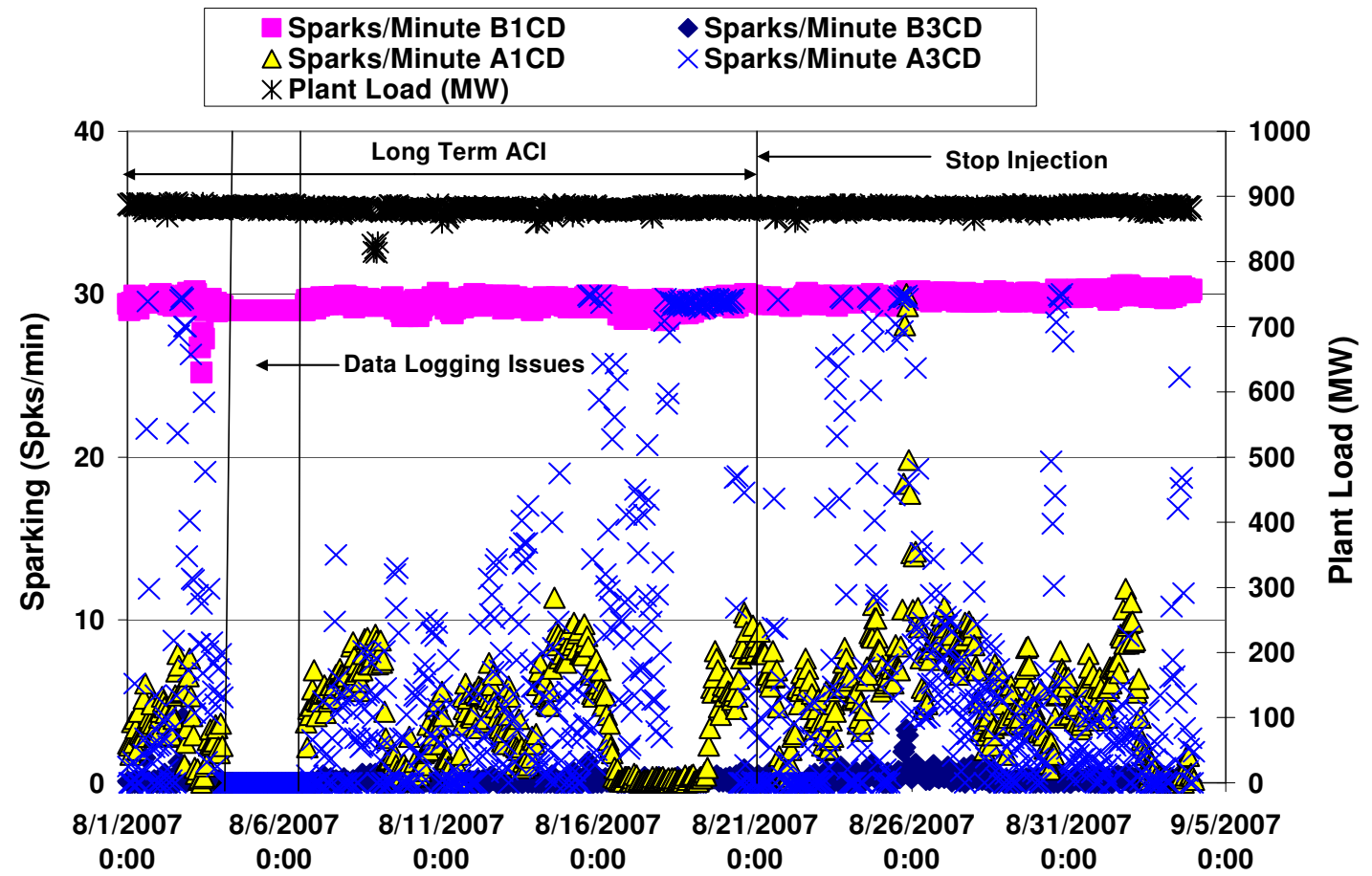

Figure 3-21. ESP 1A and ESP 1B Spark Rates during Long-Term and Baseline Testing 


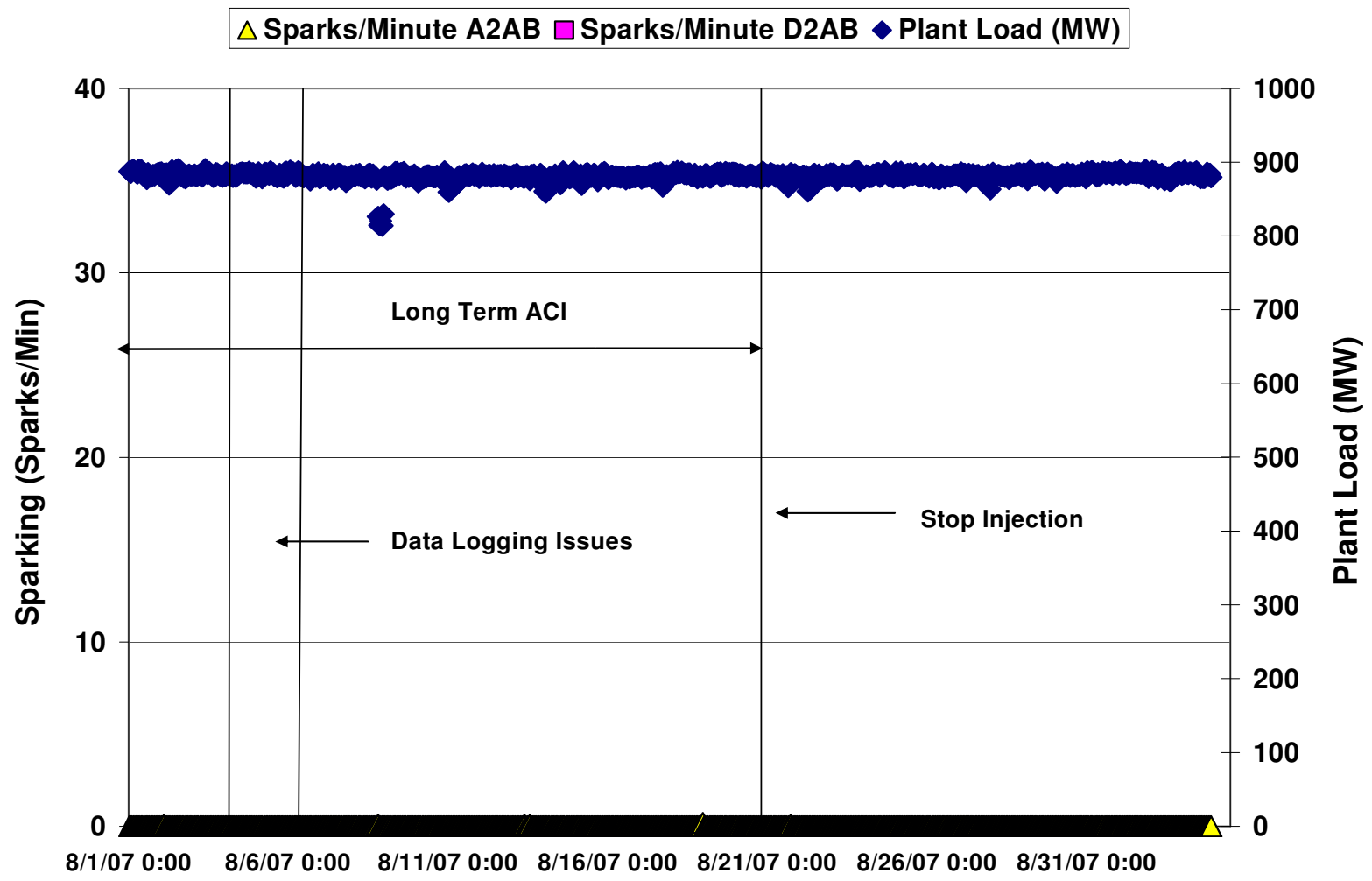

Figure 3-22. ESP 1A and ESP 1D Spark Rates during Long-Term and Baseline Testing

\subsection{ESP Outlet Particulate Matter Measurement Results}

Baseline particulate concentration measurements were made using EPA Method 17 at the ESP inlet ports that served both the 1A and 1B ESPs and at the ESP outlet duct 1A1. All particulate measurement values are presented in milligrain/dscf at $7 \% \mathrm{O}_{2}$ and $10^{-3} \mathrm{lb} / \mathrm{MMBtu}$ for the ease of the reader. The inlet baseline Method 17 results are summarized in Table 3-26. The inlet particulate loading averaged 6,775 milligrain/dscf. During baseline operation and all sorbent injection periods, measured ESP outlet particulate concentrations were below the NSPS 78(d)(a) standard of $0.03 \mathrm{lb} / \mathrm{MMBtu}$.

Table 3-26. Baseline Particulate Loading Measurements at ESP Inlet

\begin{tabular}{|c|c|c|c|c|c||}
\hline \hline Run \# & Date & Start Time & End Time & $\begin{array}{c}\text { Inlet Particulate } \\
\text { Loading } \\
(\text { milligrain/dscf at } \\
\left.7 \% \mathrm{O}_{2}\right)\end{array}$ & $\begin{array}{c}\text { Inlet Particulate } \\
\text { Loading } \\
\left(10^{-3} \text { lb/MMBtu }\right)\end{array}$ \\
\hline \hline 1 & $11 / 30 / 06$ & $10: 32$ & $12: 57$ & 8140 & 17910 \\
\hline 2 & $11 / 30 / 06$ & $14: 22$ & $15: 20$ & 5410 & 11900 \\
\hline Average & & & & $\mathbf{6 7 7 5}$ & $\mathbf{1 4 9 0 0}$ \\
\hline
\end{tabular}


Tables 3-27 and 3-28 summarize the baseline Method 17 and Method 5 particulate loading results, respectively, at the treated outlet of duct $1 \mathrm{~A} 1$. The baseline outlet particulate loading measurements averaged 4.03 milligrain/dscf for Method 17 and 4.27 milligrain/dscf for Method 5. Results from these two methods should not be directly compared to each other because they use different particulate collection techniques.

Table 3-27. Baseline Particulate Loading Measurements at Treated Outlet Duct 1A1 (Method 17)

\begin{tabular}{|c|c|c|c|c|}
\hline Date & Start Time & End Time & $\begin{array}{c}\text { Outlet Particulate Loading } \\
\text { (milligrain/dscf at } 7 \% \mathrm{O}_{2} \text { ) }\end{array}$ & $\begin{array}{c}\text { Outlet Particulate Loading } \\
\left(10^{-3} \mathrm{lb} / \mathrm{MMBtu}\right)\end{array}$ \\
\hline $\begin{array}{l}12 / 1 / 2006 \\
\end{array}$ & 9:48 & $1011: 47$ & 2.74 & 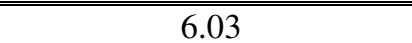 \\
\hline $12 / 1 / 2006$ & $12: 20$ & $14: 21$ & 2.10 & 4.62 \\
\hline $12 / 1 / 2006$ & $14: 42$ & $16: 41$ & 2.17 & 4.77 \\
\hline $12 / 2 / 2006$ & $8: 23$ & $10: 23$ & 3.93 & 8.65 \\
\hline $12 / 2 / 2006$ & 11:03 & $13: 00$ & 4.28 & 9.42 \\
\hline $12 / 2 / 2006$ & $13: 39$ & $15: 35$ & 3.94 & 8.67 \\
\hline $4 / 20 / 2007$ & $13: 38$ & $15: 45$ & 7.06 & 15.53 \\
\hline $4 / 26 / 2007$ & $7: 49$ & $9: 28$ & 5.70 & 12.54 \\
\hline $6 / 19 / 2007$ & $9: 40$ & $11: 50$ & 5.55 & 12.21 \\
\hline $6 / 19 / 2007$ & $12: 15$ & $14: 22$ & 3.92 & 8.63 \\
\hline $6 / 19 / 2007$ & $15: 00$ & $17: 15$ & 2.97 & 6.52 \\
\hline Average & & & 4.03 & 8.87 \\
\hline Std Dev & & & 1.56 & 3.48 \\
\hline
\end{tabular}

Table 3-28. Baseline Particulate Loading Measurements at Treated Outlet Duct 1A1 (Method 5)

\begin{tabular}{|c|c|c|c|c||}
\hline Date & Start Time & End Time & $\begin{array}{c}\text { Outlet Particulate Loading } \\
\left(\text { milligrain/dscf at 7\% } \mathrm{O}_{2}\right)\end{array}$ & $\begin{array}{c}\text { Outlet Particulate Loading } \\
\left(10^{-3} \mathrm{lb} / \mathrm{MMBtu}\right)\end{array}$ \\
\hline \hline $6 / 20 / 2007$ & $10: 10$ & $12: 25$ & 4.05 & 12.21 \\
\hline $6 / 20 / 2007$ & $13: 50$ & $16: 00$ & 4.72 & 8.63 \\
\hline $6 / 21 / 2007$ & $11: 01$ & $15: 32$ & 4.05 & 6.52 \\
\hline Average & & & $\mathbf{4 . 2 7}$ & $\mathbf{9 . 1 2}$ \\
\hline
\end{tabular}

The average baseline particulate loading (as measured by Method 17) was 1.44 milligrain/dscf for the Toxecon ${ }^{\mathrm{TM}}$ II ports (Table 3-29). The Toxecon ${ }^{\mathrm{TM}}$ II particulate measurements cannot be compared to the measurements at the treated outlet duct $1 \mathrm{~A} 1$ in Table 3-27. The Toxecon ${ }^{\mathrm{TM}}$ II ports were not an ideal location because they were located in the widest part of the duct where the flue gas velocity was very low. However, these measurements can be used to identify differences in behavior between periods of sorbent injection and no injection. During Toxecon ${ }^{\mathrm{TM}}$ II injection, the ESP outlet particulate loading did not increase; however, the Method 17 filters darkened considerably (Figure 3-23) as compared to filters collected when injecting carbon upstream of the ESP. This indicated that Toxecon ${ }^{\mathrm{TM}}$ II resulted in increased penetration of carbon through the ESP. 
Table 3-29. Baseline Particulate Loading Measurements at Toxecon ${ }^{\mathrm{TM}}$ II Outlet Duct $1 \mathrm{~A} 1$ (Method 17)

\begin{tabular}{|c|c|c|c|c|}
\hline Date & Start Time & End Time & $\begin{array}{c}\text { Outlet Particulate } \\
\text { Loading } \\
\left.\text { (milligrain/dscf at 7\% } \mathrm{O}_{2}\right)\end{array}$ & $\begin{array}{c}\text { Outlet Particulate } \\
\text { Loading } \\
\left(10^{-3} \text { lb/MMBtu }\right)\end{array}$ \\
\hline \hline $5 / 22 / 2007$ & $13: 50$ & $15: 36$ & 1.01 & 2.22 \\
\hline $5 / 23 / 2007$ & $8: 15$ & $10: 01$ & 2.16 & 4.75 \\
\hline $5 / 24 / 2007$ & $8: 10$ & $9: 52$ & 1.26 & 2.77 \\
\hline $5 / 25 / 2007$ & $8: 29$ & $10: 11$ & 1.33 & 2.93 \\
\hline Average & & $\mathbf{1 . 4 4}$ & $\mathbf{3 . 1 7}$ \\
\hline
\end{tabular}

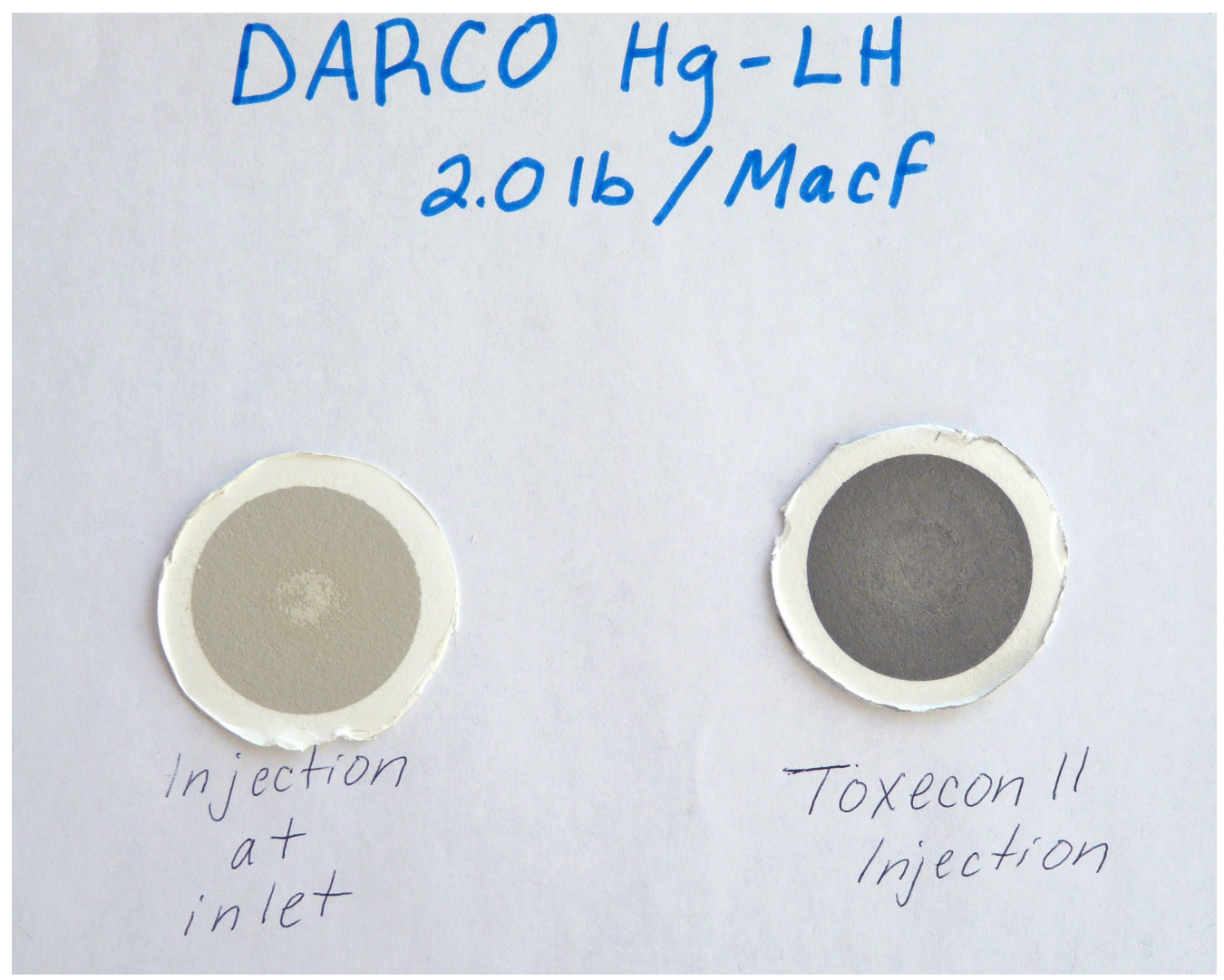

Figure 3-23. Photograph Comparing Method 17 Filters Collected during Toxecon ${ }^{\mathrm{TM}}$ II and Injection Upstream of the ESP

Method 17 results from parametric test periods are presented in Table 3-30 and Figure 3-24. The Method 17 measurements ranged from 2.1 to 7.1 milligrain/dscf at $7 \% \mathrm{O}_{2}$. Confidence intervals of $95 \%$ confidence were created for baseline data. While particulate loadings during several short-term carbon injection tests were higher than during baseline, there was significant variability in the data. The parametric measurements indicated that outlet particulate values did not trend with sorbent injection rate or sorbent type.

ESP outlet particulate concentrations were measured during long-term injection testing using both Method 17 and Method 5 procedures. Results from the two methods can not be compared 
directly because they use different filter collection mechanisms. However, the conclusions drawn from the two methods can be compared to determine if there is corroboration.

Method 17 results from the long-term test are presented in Table 3-31 and Figure 3-25. Baseline particulate measurements at the treated ESP outlet averaged 4.0 milligrain/dscf at $7 \% \mathrm{O}_{2}$, with data ranging from 2.1 to 7.1 milligrain/dscf at $7 \% \mathrm{O}_{2}$ (Table 3-26). During the long-term test, Method 17 measurements showed increased ESP outlet particulate concentrations, averaging 6.1 milligrain/dscf at $7 \% \mathrm{O}_{2}$, with measurements ranging from 2.4 to 11.0 milligrain/dscf at $7 \% \mathrm{O}_{2}$. Approximately half of the M17 measurements obtained during the long-term test were higher than the range observed during baseline operation. The variability in baseline particulate loadings (which ranged by a factor of three) makes it difficult to ascertain whether the outlier points (for particulate concentration) obtained during the sorbent injection period were due to carbon injection or normal variability for the ESP. To further compare baseline and long-term sorbent injection measurements, 95\% confidence intervals were created around the average baseline and long-term injection particulate measurements. Although there is significant variability with both sets of measurements, and there is slight overlap in both sets of confidence intervals, there appears to be an increase in particulate concentration due to sorbent injection. In Figure 3-26, Method 17 data from Darco Hg-LH injection upstream of the ESP are plotted versus operating temperature. There was no discernible impact of temperature on particulate emissions.

Method 5 results from the long-term test are presented in Table 3-32 and Figure 3-27. Baseline Method 5 measurements averaged 4.3 milligrain/dscf at $7 \% \mathrm{O}_{2}$, with a range of 4.0 to 4.7 over three measurements (Table 3-29). Method 5 measurements collected during long-term sorbent injection averaged 7.7 milligrain/dscf at $7 \% \mathrm{O}_{2}$, with measurements ranging from 4.9 to 11.6 milligrain/dscf. Method 5 results corroborate the Method 17 results, showing an increase in particulate loading during sorbent injection.

Fewer baseline Method 5 measurements were obtained as compared to Method 17 measurements, so the natural variability in the ESP outlet particulate loading was not adequately assessed by Method 5. However, several sets of M5 particulate loading measurements were made on the untreated outlet duct (Table 3-33). A comparison of measured particulate loadings for the treated and untreated ESPs is plotted in Figure 3-27. Baseline M5 measurements were made on 6/20/07 and 6/21/07. The treated outlet duct particulate emissions averaged 4.3 milligrain/dscf, and the untreated outlet duct averaged 2.1 milligram/dscf during baseline operation. The untreated ESP 1B thus showed lower particulate emissions than the treated ESP 1A. Furthermore, during the two month injection test, the untreated ESP 1B particulate emissions remained very steady averaging 2.3 milligrain/dscf. In contrast, the treated ESP 1A particulate emissions were 1.5 to 2.5 times greater during long-term sorbent injection than during baseline operation. While this analysis implies that the increase in particulate loading during long-term sorbent injection may have been due to the activated carbon, it is unknown if the untreated ESP 1B has a more steady baseline particulate emissions profile than the treated ESP 1A.

Figure 3-28 shows a photograph of the Method 17 filters collected during baseline and during carbon injection test periods. While measurement uncertainty makes it difficult to conclude whether carbon injection resulted in increased particulate emissions, the darkening of the sample filters collected during carbon injection provides visual evidence of carbon penetrating the ESP. 
Table 3-30. Method 17 Results from Parametric Sorbent Injection Testing

\begin{tabular}{|c|c|c|c|c|c|c|}
\hline Sorbent & $\begin{array}{l}\text { Injection } \\
\text { Rate } \\
\text { (lb/Macf) }\end{array}$ & Date & Start Time & End Time & $\begin{array}{c}\text { Outlet } \\
\text { Particulate } \\
\text { Loading } \\
\text { (milligrain/dscf } \\
\text { at } 7 \% \mathrm{O}_{2} \text { ) } \\
\end{array}$ & $\begin{array}{c}\text { Outlet } \\
\text { Particulate } \\
\text { Loading } \\
\left(10^{-3} \mathrm{lb} / \mathrm{MMBtu}\right)\end{array}$ \\
\hline B-PAC & 0.5 & $12 / 5 / 2006$ & 953 & 1147 & 10.60 & 23.32 \\
\hline B-PAC & 1.3 & $12 / 5 / 2006$ & 1302 & 1456 & 6.02 & 13.24 \\
\hline B-PAC & 3.3 & $12 / 5 / 2006$ & 1605 & 1759 & 5.64 & 12.41 \\
\hline BASF MS200 & 6 & $4 / 21 / 2007$ & $10: 46$ & $12: 28$ & 6.36 & 13.99 \\
\hline BASF MS200 & 6 & $4 / 21 / 2007$ & $12: 48$ & $14: 33$ & 7.17 & 15.77 \\
\hline BASF MS200 & 8 & $4 / 21 / 2007$ & $14: 45$ & $16: 25$ & 7.32 & 16.10 \\
\hline BASF MS200 & 10 & $4 / 22 / 2007$ & $9: 38$ & $11: 20$ & 7.02 & 15.44 \\
\hline BASF MS200 & 12 & $4 / 22 / 2007$ & $15: 50$ & $17: 35$ & 7.63 & 16.79 \\
\hline C-PAC & 0.5 & $4 / 23 / 2007$ & 10:05 & $11: 45$ & 8.28 & 18.21 \\
\hline C-PAC & 1.5 & $4 / 23 / 2007$ & $13: 55$ & $15: 37$ & 18.20 & 40.04 \\
\hline DARCO Hg & 0.4 & $12 / 7 / 2006$ & 1012 & 1206 & 13.20 & 29.04 \\
\hline DARCO $\mathrm{Hg}$ & 0.6 & $12 / 9 / 2006$ & $10: 19$ & $12: 12$ & 5.30 & 11.66 \\
\hline DARCO Hg & 0.6 & $12 / 9 / 2006$ & $12: 39$ & $14: 32$ & 4.72 & 10.38 \\
\hline DARCO Hg & 0.6 & $12 / 9 / 2006$ & $15: 04$ & $16: 57$ & 9.07 & 19.95 \\
\hline DARCO Hg & 1 & $4 / 24 / 2007$ & $10: 16$ & $11: 57$ & 7.66 & 16.85 \\
\hline DARCO Hg & 1 & $4 / 24 / 2007$ & $12: 14$ & $13: 55$ & 6.44 & 14.17 \\
\hline DARCO Hg & 2 & $4 / 24 / 2007$ & $16: 14$ & $17: 19$ & 8.87 & 19.51 \\
\hline DARCO Hg & 1.7 & $12 / 7 / 2006$ & $15: 25$ & $17: 18$ & 10.10 & 22.22 \\
\hline DARCO Hg & 3.4 & $12 / 6 / 2006$ & $10: 15$ & 12:09 & 8.32 & 18.30 \\
\hline DARCO $\mathrm{Hg}$ & 5.6 & $12 / 6 / 2006$ & $16: 50$ & $18: 45$ & 8.82 & 19.40 \\
\hline DARCO Hg & 8.2 & $12 / 6 / 2006$ & $13: 15$ & $15: 11$ & 9.24 & 20.33 \\
\hline Flue PAC MC Plus & 0.5 & $12 / 8 / 2006$ & 1016 & 1210 & 4.35 & 9.57 \\
\hline Flue PAC MC Plus & 1.9 & $12 / 8 / 2006$ & 1245 & 1440 & 5.47 & 12.03 \\
\hline Flue PAC MC Plus & 5.8 & $12 / 8 / 2006$ & 1533 & 1727 & 4.72 & 10.38 \\
\hline Flue PAC MC Plus \#2 & 1 & $4 / 25 / 2007$ & 1113 & 1430 & 7.47 & 16.43 \\
\hline Flue PAC MC Plus \#2 & 2 & $4 / 25 / 2007$ & 1317 & 1635 & 10.90 & 23.98 \\
\hline DARCO Hg-LH & 0.5 & $12 / 4 / 2006$ & 1001 & 1157 & 10.60 & 23.32 \\
\hline DARCO Hg-LH & 1 & $4 / 26 / 2007$ & $10: 46$ & $12: 26$ & 7.36 & 16.19 \\
\hline DARCO Hg-LH & 1.1 & $12 / 3 / 2006$ & 13:03 & $14: 57$ & 2.51 & 5.52 \\
\hline DARCO Hg-LH & 2 & $4 / 26 / 2007$ & $13: 22$ & $15: 02$ & 9.35 & 20.57 \\
\hline DARCO Hg-LH & 2 & $4 / 26 / 2007$ & $15: 26$ & 17:06 & 6.42 & 14.12 \\
\hline DARCO Hg-LH & 2.5 & $12 / 4 / 2006$ & $14: 00$ & $15: 56$ & 4.98 & 10.96 \\
\hline DARCO Hg-LH & 2.9 & $12 / 3 / 2006$ & $16: 40$ & $18: 34$ & 5.20 & 11.44 \\
\hline DARCO Hg-LH & 5.1 & $12 / 4 / 2006$ & $17: 27$ & $19: 21$ & 7.48 & 16.46 \\
\hline
\end{tabular}




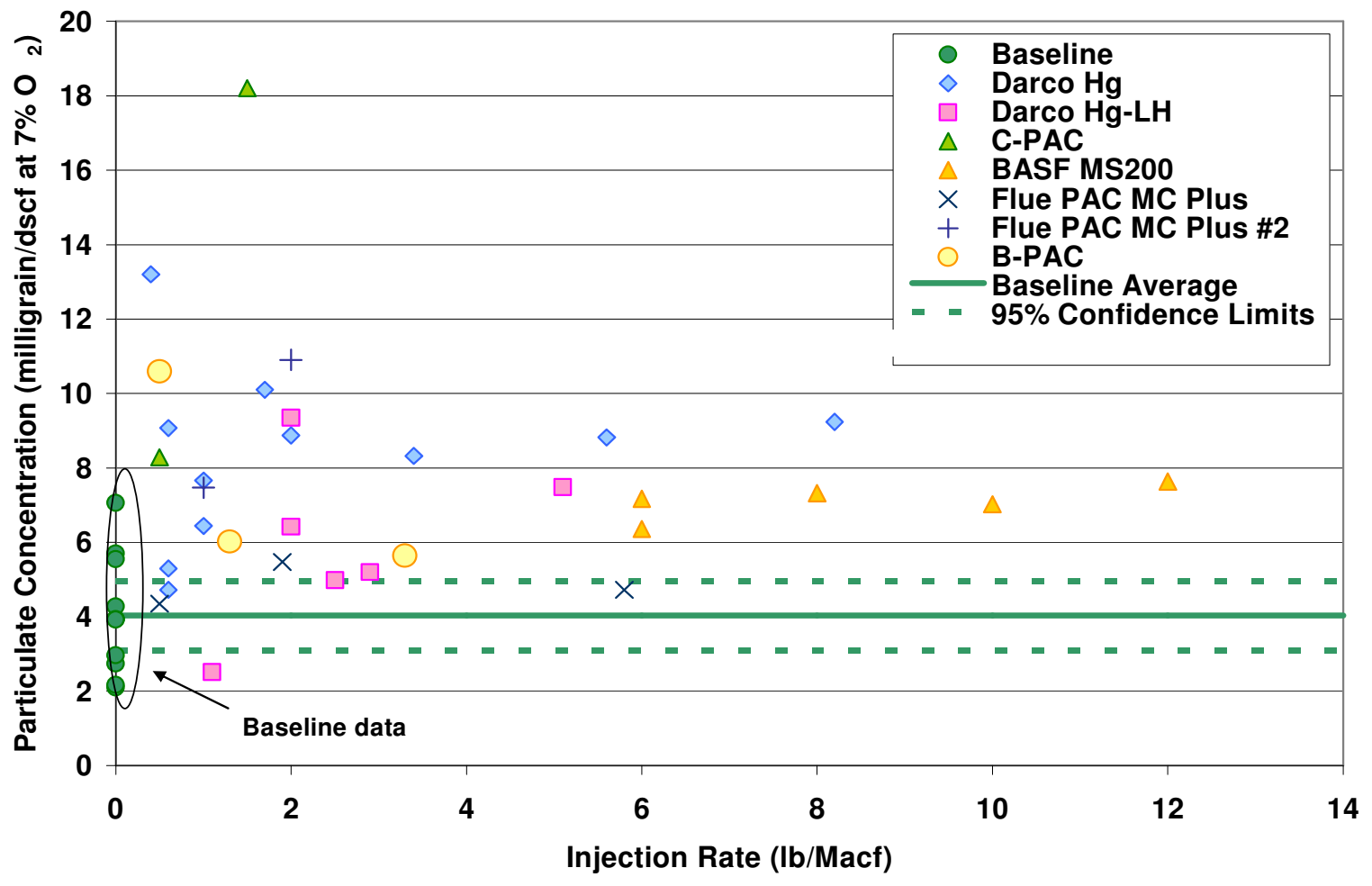

Figure 3-24. Method 17 Results for ESP 1A Outlet from Parametric I, II, and III Testing

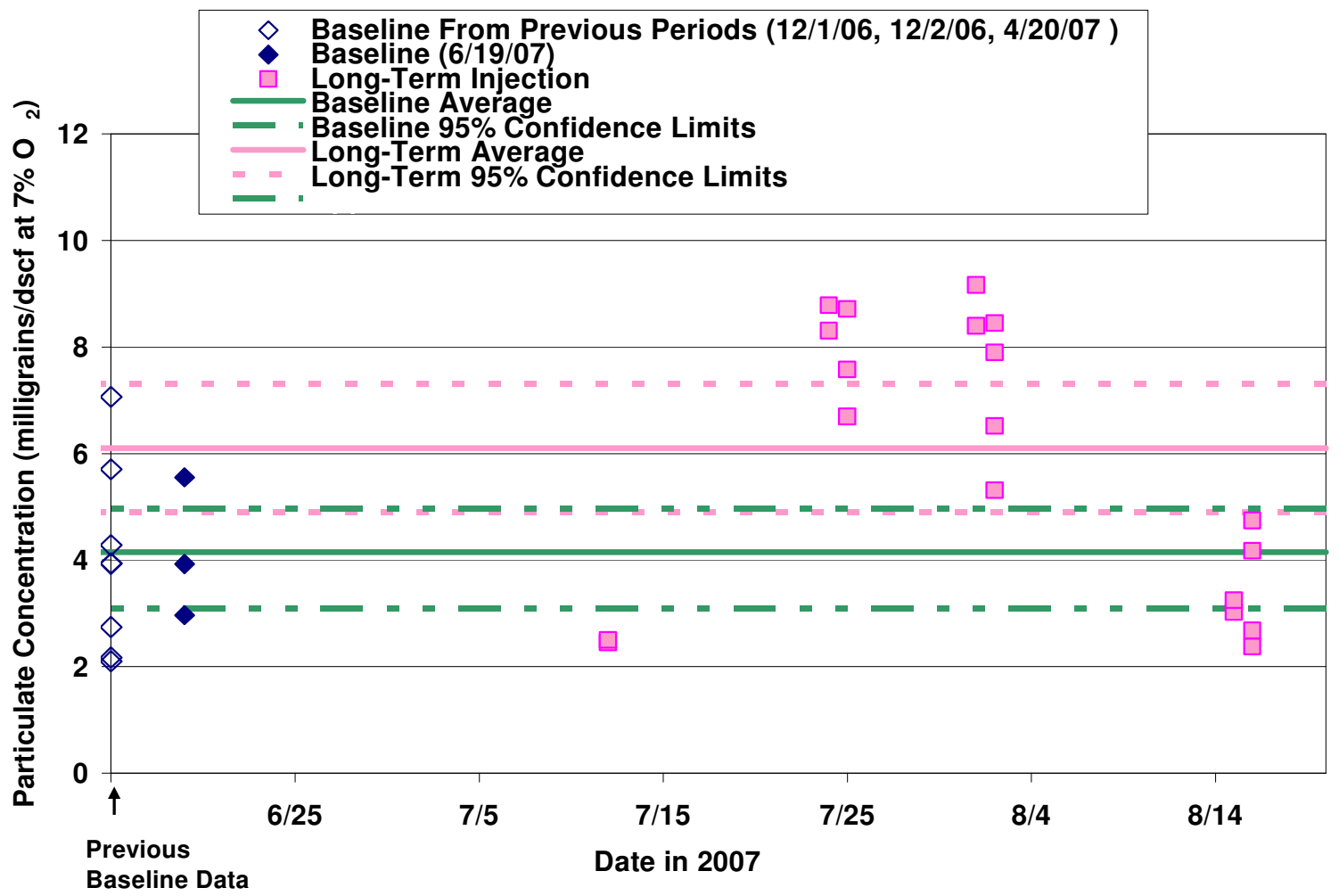

Figure 3-25. Method 17 Results for ESP 1A Outlet during Long-Term Injection Test 


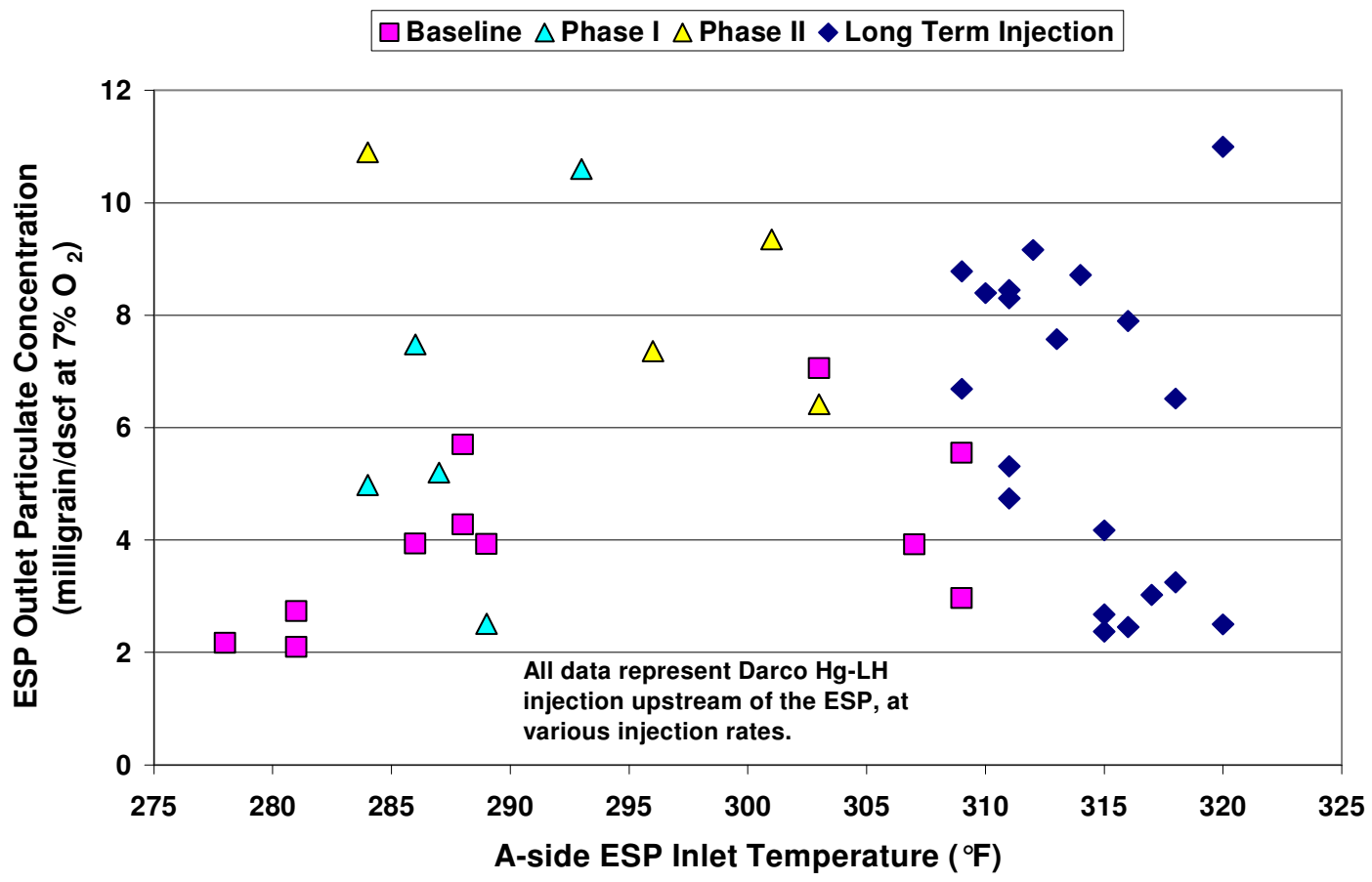

Figure 3-26. Impact of Temperature on ESP 1A Particulate Emissions for All Test Phases Involving Darco Hg-LH Injection 
Table 3-31. Method 17 Results from Long-Term Sorbent Injection Tests on Treated ESP 1A

\begin{tabular}{|c|c|c|c|c|}
\hline Date & Start Time & $\begin{array}{l}\text { End } \\
\text { Time }\end{array}$ & $\begin{array}{c}\text { Outlet Particulate } \\
\text { Loading } \\
\text { (milligrain/dscf at 7\% } \mathrm{O}_{2} \text { ) }\end{array}$ & $\begin{array}{c}\text { Outlet Particulate } \\
\text { Loading } \\
\left(10^{-3} \mathrm{lb} / \mathrm{MMBtu}\right) \\
\end{array}$ \\
\hline $\begin{array}{l}\text { Average } \\
\text { Baseline }\end{array}$ & & & 4.03 & 8.87 \\
\hline Std Dev & & & 1.56 & 3.48 \\
\hline $7 / 12 / 2007$ & $12: 37$ & $14: 41$ & 2.45 & 5.40 \\
\hline $7 / 12 / 2007$ & $14: 54$ & $16: 58$ & 2.50 & 5.50 \\
\hline $7 / 24 / 2007$ & $14: 37$ & $16: 54$ & 8.78 & 19.32 \\
\hline $7 / 24 / 2007$ & 17:07 & 19:11 & 11.00 & 24.19 \\
\hline $7 / 24 / 2007$ & 19:25 & $21: 29$ & 8.30 & 18.26 \\
\hline $7 / 25 / 2007$ & $8: 26$ & $10: 28$ & 6.69 & 14.72 \\
\hline $7 / 25 / 2007$ & $10: 40$ & $12: 44$ & 8.71 & 19.17 \\
\hline $7 / 25 / 2007$ & $12: 53$ & $14: 57$ & 7.58 & 16.67 \\
\hline $8 / 1 / 2007$ & 13:27 & $15: 38$ & 9.16 & 20.16 \\
\hline $8 / 1 / 2007$ & 16:13 & $18: 18$ & 8.40 & 18.47 \\
\hline $8 / 2 / 2007$ & 8:03 & $10: 11$ & 8.45 & 18.59 \\
\hline $8 / 2 / 2007$ & 10:19 & $12: 27$ & 5.31 & 11.69 \\
\hline $8 / 2 / 2007$ & $12: 40$ & $14: 47$ & 6.51 & 14.33 \\
\hline $8 / 2 / 2007$ & $14: 57$ & $17: 02$ & 7.90 & 17.38 \\
\hline $8 / 15 / 2007$ & 13:14 & $15: 18$ & 3.03 & 6.65 \\
\hline $8 / 15 / 2007$ & $15: 32$ & $17: 38$ & 3.25 & 7.15 \\
\hline $8 / 16 / 2007$ & $8: 57$ & 11:02 & 2.37 & 5.22 \\
\hline $8 / 16 / 2007$ & $11: 12$ & $13: 18$ & 2.68 & 5.89 \\
\hline $8 / 16 / 2007$ & 13:28 & $15: 35$ & 4.17 & 9.18 \\
\hline $8 / 16 / 2007$ & $15: 46$ & $17: 51$ & 4.74 & 10.43 \\
\hline $\begin{array}{c}\text { Long Term } \\
\text { Average }\end{array}$ & & & 6.10 & 13.42 \\
\hline St Dev & & & 2.76 & 6.07 \\
\hline
\end{tabular}


Table 3-32. Method 5 Results from Long-Term Sorbent Injection Tests on Treated ESP 1A

\begin{tabular}{|c|c|c|c|c|}
\hline Date & Start Time & End Time & $\begin{array}{c}\text { Outlet } \\
\text { Particulate } \\
\text { Loading } \\
\text { (milligrain/dscf } \\
\text { at } 7 \% \mathrm{O}_{2} \text { ) } \\
\end{array}$ & $\begin{array}{c}\text { Outlet } \\
\text { Particulate } \\
\text { Loading } \\
\left(10^{-3} \mathrm{lb} / \mathrm{MMBtu}\right) \\
\end{array}$ \\
\hline $\begin{array}{l}\text { Average } \\
\text { Baseline }\end{array}$ & & & 4.27 & 9.40 \\
\hline St Dev & & & 0.38 & 0.84 \\
\hline $7 / 10 / 2007$ & $12: 10$ & $14: 24$ & 7.85 & 17.27 \\
\hline $7 / 10 / 2007$ & $15: 20$ & $17: 33$ & 8.11 & 17.85 \\
\hline $7 / 11 / 2007$ & $9: 32$ & $11: 43$ & 6.76 & 14.88 \\
\hline $7 / 11 / 2007$ & $12: 51$ & 15:02 & 5.76 & 12.67 \\
\hline $7 / 11 / 2007$ & 16:05 & $18: 15$ & 6.18 & 13.60 \\
\hline $7 / 12 / 2007$ & $8: 40$ & $10: 50$ & 4.90 & 10.79 \\
\hline $7 / 31 / 2007$ & 10:00 & 12:11 & 11.65 & 25.64 \\
\hline $7 / 31 / 2007$ & 14:01 & $16: 13$ & 10.92 & 24.02 \\
\hline $7 / 30 / 2007$ & 9:23 & $11: 36$ & 10.25 & 22.55 \\
\hline $8 / 14 / 2007$ & $11: 30$ & $13: 45$ & 5.98 & 13.16 \\
\hline $8 / 14 / 2007$ & $15: 00$ & $17: 10$ & 6.56 & 14.44 \\
\hline $8 / 15 / 2007$ & $9: 30$ & $11: 38$ & 7.78 & 17.12 \\
\hline $\begin{array}{c}\text { Long Term } \\
\text { Average }\end{array}$ & & & 7.73 & 17.00 \\
\hline Std Dev & & & 2.17 & 4.77 \\
\hline
\end{tabular}


Table 3-33. Method 5 Results during Long-Term Test for Untreated ESP

\begin{tabular}{|c|c|c|c|c|}
\hline Date & Start Time & $\begin{array}{l}\text { End } \\
\text { Time }\end{array}$ & $\begin{array}{c}\text { Outlet } \\
\text { Particulate } \\
\text { Loading } \\
\text { (milligrain/dscf } \\
\text { at } 7 \% \mathrm{O}_{2} \text { ) } \\
\end{array}$ & $\begin{array}{c}\text { Outlet } \\
\text { Particulate } \\
\text { Loading } \\
\left(10^{-3} \mathrm{lb} / \mathrm{MMBtu}\right)\end{array}$ \\
\hline $06 / 20 / 07$ & $10: 10$ & $12: 24$ & 1.22 & 2.69 \\
\hline $06 / 20 / 07$ & $13: 50$ & $16: 04$ & 2.56 & 5.62 \\
\hline $06 / 21 / 07$ & 11:01 & $15: 29$ & 2.46 & 5.42 \\
\hline $\begin{array}{l}\text { Baseline } \\
\text { Average }\end{array}$ & & & 2.08 & 4.58 \\
\hline St. Dev. & & & 0.75 & 1.64 \\
\hline 07/10/07 & $12: 10$ & $14: 27$ & 2.69 & 5.91 \\
\hline 07/10/07 & $15: 20$ & $17: 35$ & 2.41 & 5.31 \\
\hline $07 / 11 / 07$ & 09:32 & $11: 45$ & 2.84 & 6.26 \\
\hline $07 / 11 / 07$ & $12: 51$ & $15: 03$ & 2.33 & 5.12 \\
\hline $07 / 11 / 07$ & $16: 05$ & $18: 17$ & 2.36 & 5.19 \\
\hline $07 / 12 / 07$ & $08: 40$ & $10: 49$ & 2.01 & 4.43 \\
\hline $07 / 31 / 07$ & 10:00 & $12: 45$ & 2.13 & 4.68 \\
\hline $07 / 31 / 07$ & 14:01 & $16: 09$ & 4.07 & 8.95 \\
\hline 08/01/07 & 09:20 & $11: 32$ & 1.92 & 4.23 \\
\hline $08 / 14 / 07$ & $11: 30$ & $13: 40$ & 1.78 & 3.92 \\
\hline 08/14/07 & $15: 00$ & $17: 10$ & 1.76 & 3.86 \\
\hline $08 / 15 / 07$ & 09:30 & $11: 35$ & 1.58 & 3.48 \\
\hline $\begin{array}{c}\text { Long Term } \\
\text { Average }\end{array}$ & & & 2.32 & 5.11 \\
\hline St. Dev. & & & 0.67 & 1.47 \\
\hline
\end{tabular}




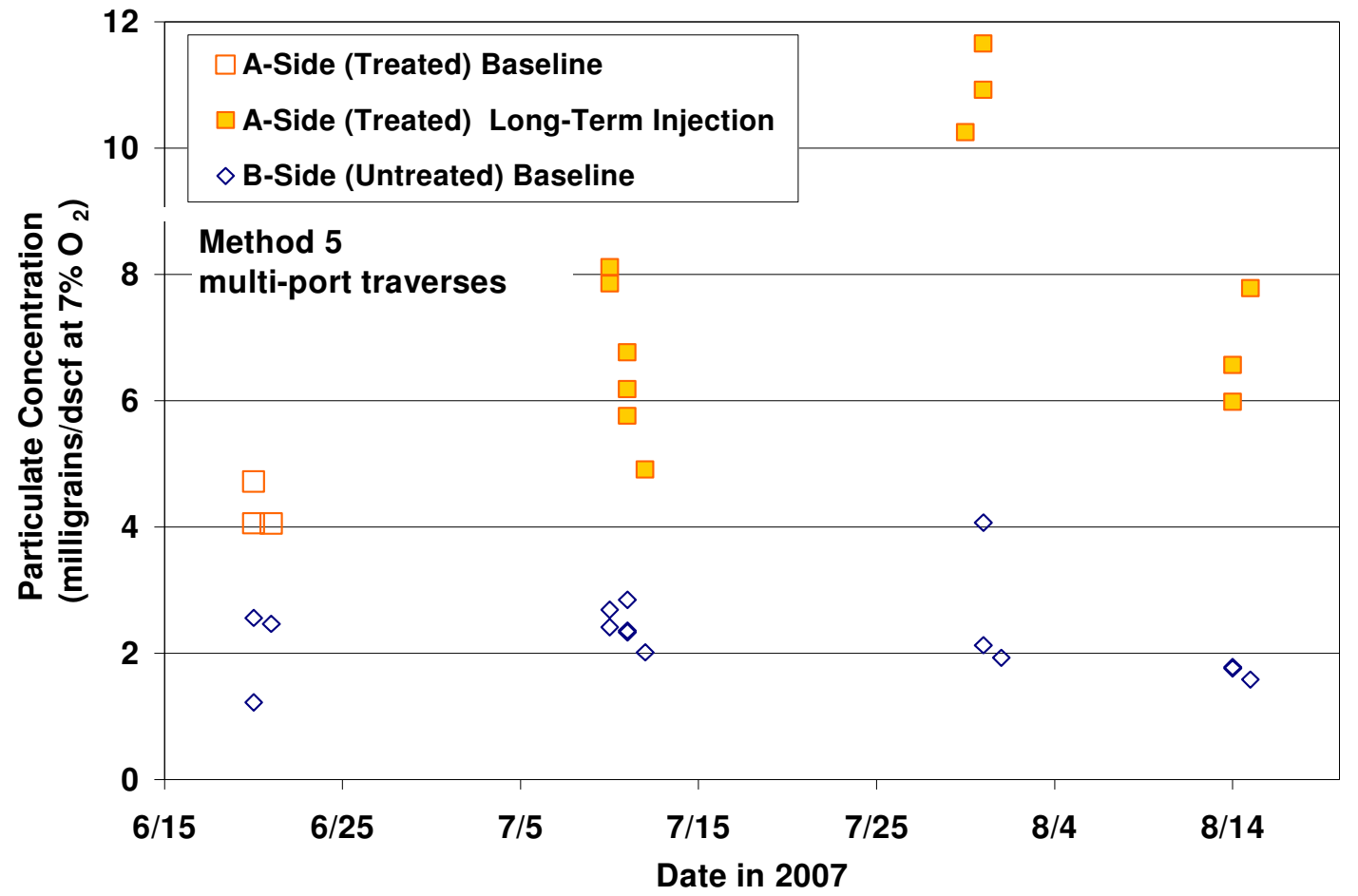

Figure 3-27. Method 5 Results for ESPs 1A (Treated) and 1B (Untreated) during Long-Term Injection Test

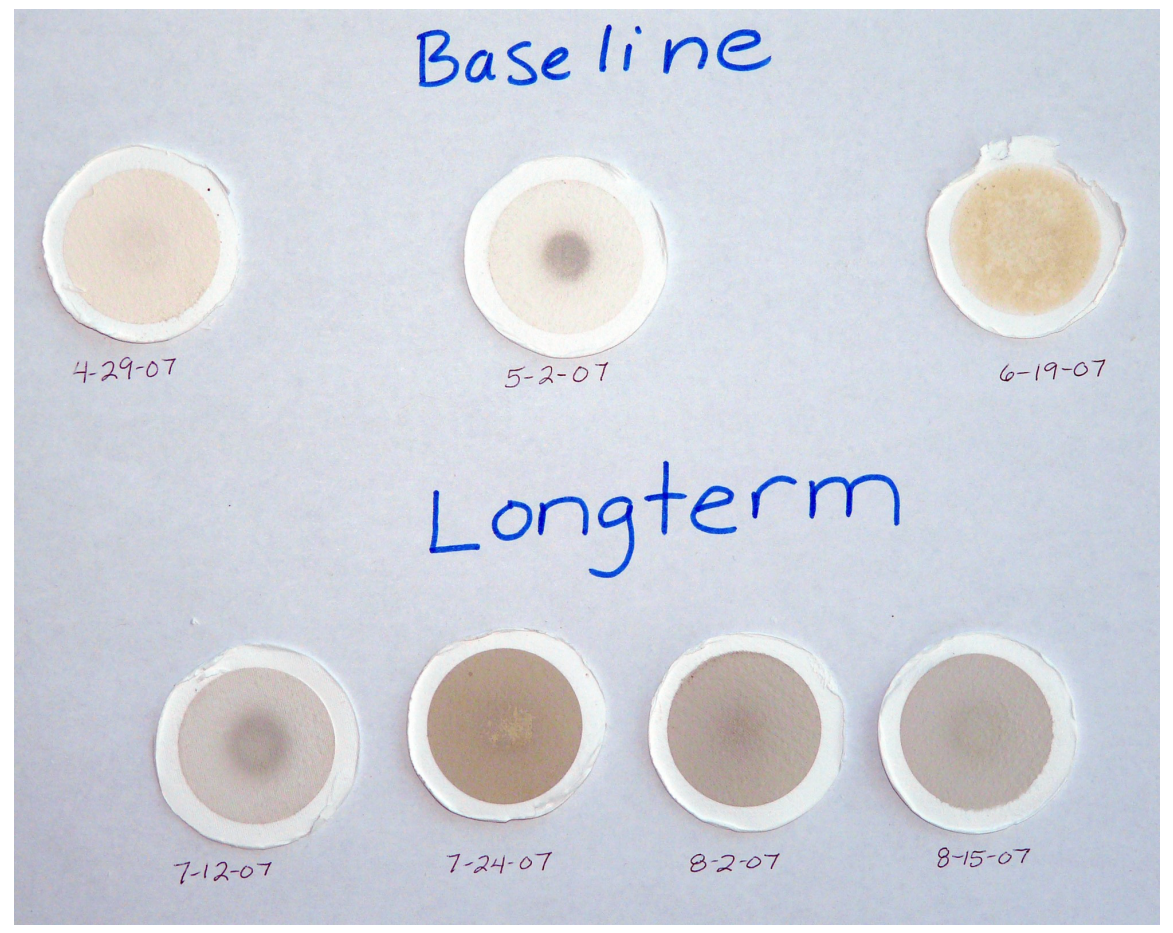

Figure 3-28. Darkening of M5 Particulate Filters during Carbon Injection 


\subsection{Effects of Sorbent Injection on Fly Ash Concrete Properties}

One objective of this test program was to determine the effect of ACI on fly ash quality as it relates to reuse as a cement replacement for concrete production. Fly ash samples collected during parametric sorbent injection tests were analyzed to establish how the presence of sorbent material affected the quality of concrete prepared from the fly ash. Based on the results obtained from the parametric tests, the sorbent and injection rate for the long-term test were chosen to maximize mercury removal while maintaining acceptable fly ash quality. During the long-term test, fly ash samples were collected weekly and subjected to concrete testing. To determine if carbon-containing fly ash might be acceptable for concrete manufacturing, the following properties were examined:

- Air Entraining Agent (AEA) demand;

- LOI and total carbon content;

- 325 mesh and average particle size;

- Compressive Strength;

- Slump;

- Air pressure; and

- $\quad$ Strength Activity Index (SAI).

Throughout the testing, four laboratories (URS, Headwaters Inc., EERC, and LMS) performed various parts of the aforementioned analyses. Some of the measured parameters are very specific to the operator of the measurement technique, so each laboratory's results are presented individually in the following paragraphs.

\section{$\underline{\text { Initial Screen Fly Ash and Concrete Results }}$}

\section{Foam Index Testing on Simulated Ash/Carbon Mixtures}

Carbon in ash is problematic for concrete because of its impact on air entrainment in concrete. The natural air content of concrete is about $2 \%$; however an air content of $6 \%$ is generally required to prevent cracking during cold weather. Air entrainment in concrete is achieved by using surfactants called Air Entraining Agents (AEAs) to stabilize a well distributed air void system in the concrete. Carbon in fly ash has a strong tendency to adsorb these surfactants, thus making it more difficult to entrain air in concrete. Ash with elevated carbon content requires additional AEA (i.e. higher AEA demand) to create the necessary spacing between ash pores. While low AEA demand is desired, ashes with higher AEA demand may be acceptable for manufacturing so long as the demand is consistent over time. The foam index test is a rapid method used to determine the amount of AEA needed during concrete mixing. The foam index test is a titration with a subjective endpoint, so there is significant variability in results obtained by different operators. In addition, the use of different air entraining agents, laboratory equipment, drop size variability, technique, and use of non-standard methods create further confusion when comparing data between laboratories. For this report, each laboratory's results are presented individually and are not compared to each other. 
Figure 3-29 provides URS foam index results for several simulated carbon/ash mixtures. These samples were created by mixing an appropriate amount of B-PAC, C-PAC, DARCO Hg, or DARCO Hg-LH carbon to baseline fly ash collected at LMS on 12/2/2006 from the first row of hoppers on ESP 1A. Baseline ash (containing no added carbon) required three drops of AEA in the foam index titration. Samples of DARCO Hg-LH and C-PAC simulating $0.5 \mathrm{lb} / \mathrm{Macf}$ also required only three drops of AEA. This carbon concentration (in the fly ash) appeared to have no affect on the foam index properties of the ash. As the simulated sorbent injection rate increased, more drops of AEA were required. B-PAC carbon displayed the steepest response curve, while C-PAC had the shallowest response curve; this indicates improved ash properties with the passivated 'concrete compatible' sorbent. At 2 lb/Macf, C-PAC required 5 drops AEA while DARCO Hg-LH needed 6 drops to reach the titration endpoint. Parametric test results indicated that this injection rate was appropriate for meeting the targeted mercury removal $(50-70 \%)$ objective of the program. Because the DARCO Hg-LH AEA dose/response curve was deemed potentially acceptable by Headwaters, and the sorbent was available at a lower cost than C-PAC, it was selected for evaluation in the long-term test.

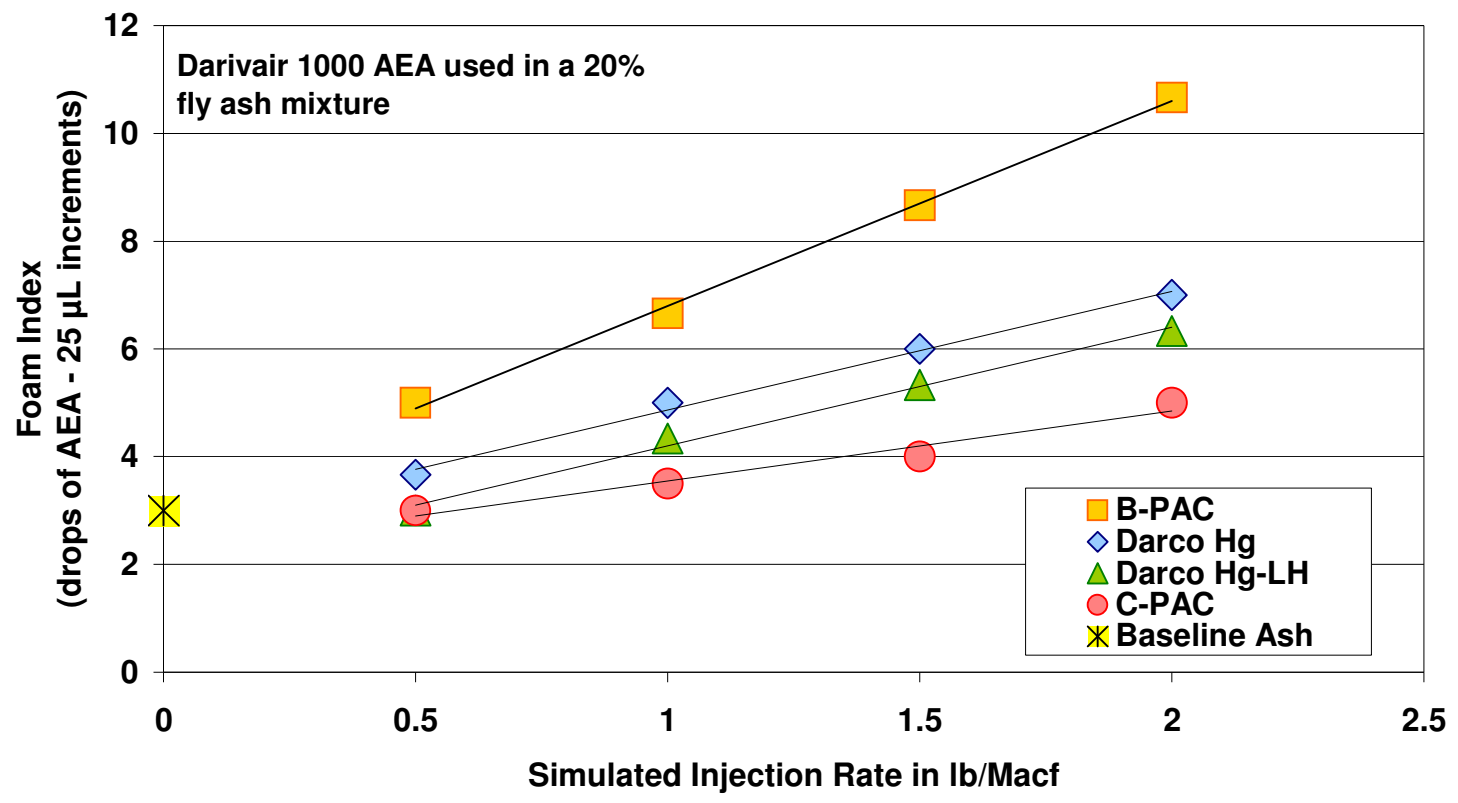

Figure 3-29. URS Foam Index Results for Simulated Carbon/Ash Mixtures

\section{Laboratory Generated Concrete Samples from Simulated Ash/Carbon Mixtures}

Prior to the long-term injection test, concrete tests were performed with simulated carbon-ash mixtures. Samples were prepared simulating injection rates of $1.0 \mathrm{lb} / \mathrm{Macf}$ and $2.0 \mathrm{lb} / \mathrm{Macf}$ DARCO Hg-LH. These were prepared by mixing appropriate amounts of DARCO Hg-LH sorbent with baseline LMS fly ash. The samples were subjected to foam index and concrete characterization tests by Headwaters. The concrete tests determined the unconfined compressive strength of samples made with aggregates, chemical admixtures, sand, ash and water. 
Table 3-34 provides the results of the 1.0 and 2.0 lb/Macf DARCO Hg-LH fly ash simulation tests. The sample simulating 2.0 lb/Macf showed a doubling in AEA requirement as compared to the baseline fly ash. The same relative effect of carbon on AEA demand was seen in the URS results, described above. Concrete was made using the amount of AEA indicated in Table 3-34. Actual air levels entrained in the prepared concrete was measured to ensure that air content was both stable and met the targeted content of 5-7\%. Results showed that the air content of the samples decreased slightly with increasing carbon content, but remained within the targeted range.

Slump is the measure of workability of the concrete. Headwaters targets a value between 5-7 inches for concrete prepared with LMS ash. Test results showed that both simulated samples met this criterion. Fly ash usually behaves as a natural water reducing agent. All fly ash mixtures reduced the water/cement ratio from 0.57 to 0.52 , and at the same time produced the same slump (6-inches). Excess water tends to lower strength development.

Compressive strength results for the two simulated ash/carbon samples were higher than for the control sample. The target for the control sample typically depends on the application desired for the concrete. Although it may seem desirable to increase the strength of the concrete, as can result from increasing the LOI content of the ash, the increased strength is undesirable if it causes the concrete to fail a freeze/thaw analysis. The freeze/thaw analysis simulates the temperature swings concrete can be exposed to that could cause the concrete to crack and fail. This failure can occur if the concrete becomes too dense (does not have enough voids) because of the addition of high LOI ash [4]. No freeze/thaw analyses were performed during this program.

Table 3-34. Headwaters Concrete Testing Results for Simulated Carbon/Ash Mixtures

\begin{tabular}{|c|c|c|c|c|c|c||}
\hline $\begin{array}{c}\text { Test } \\
\text { Parameter }\end{array}$ & Units & $\begin{array}{c}\text { Passing } \\
\text { Criteria }\end{array}$ & $\begin{array}{c}\text { Control with } \\
\text { Portland } \\
\text { Cement } \\
\text { (no ash) }\end{array}$ & $\begin{array}{c}\text { Saseline } \\
\text { Ash 1F2A } \\
\text { (4/19/07) }\end{array}$ & $\begin{array}{c}\text { Simulated* } \\
\text { 1.0 lb/Macf } \\
\text { DARCO Hg- } \\
\text { LH }\end{array}$ & $\begin{array}{c}\text { Simulated* } \\
\text { 2.0 lb/Macf } \\
\text { DARCO Hg- } \\
\text { LH }\end{array}$ \\
\hline \hline AEA & oz/cwt & $\begin{array}{c}\text { Steady } \\
\text { and low }\end{array}$ & 0.22 & 0.22 & 0.35 & 0.46 \\
\hline $\begin{array}{c}\text { Air Pressure } \\
\text { Slump .25 } \\
\text { inch }\end{array}$ & inches & $5-7$ & 6.5 & 6.3 & 6.0 & 5.8 \\
\hline $\begin{array}{c}\text { Water to } \\
\text { Cement } \\
\text { Ratio }\end{array}$ & none & $\begin{array}{c}\text { Similar to } \\
\text { Control }\end{array}$ & 0.57 & 0.52 & 0.52 & 6 \\
\hline $\begin{array}{c}\text { 7-Day } \\
\text { Compressive } \\
\text { Strength }\end{array}$ & $\begin{array}{c}\text { Psi of unconfined } \\
\text { compressive } \\
\text { strength }\end{array}$ & $\begin{array}{c}\text { Similar to } \\
\text { Control }\end{array}$ & 2777 & 3054 & 2934 & 3193 \\
\hline $\begin{array}{c}\text { 28-Day } \\
\text { Compressive } \\
\text { Strength }\end{array}$ & $\begin{array}{c}\text { Psi of unconfined } \\
\text { compressive } \\
\text { strength }\end{array}$ & $\begin{array}{c}\text { Similar to } \\
\text { Control }\end{array}$ & 3344 & 3958 & 3862 & 4013 \\
\hline \hline
\end{tabular}

* The simulated ashes were made by combining baseline ash from $1 \mathrm{~F} 2 \mathrm{~A}$ on 4/19/07 with the appropriate amount of DARCO Hg-LH to produce the designated injection conditions. 
Table 3-35 shows the results of mortar tests performed by EERC. SAI testing was performed using an LMS fly ash sample collected on 12/9/06 when $0.6 \mathrm{lb} / \mathrm{Macf}$ DARCO was injected for a 24-hour period, and on a sample containing baseline fly ash collected on 12/1/06 and mixed with DARCO Hg-LH to yield a simulated $2.0 \mathrm{lb} / \mathrm{Macf}$ ash. SAI tests or mortar cube tests use only sand, cement, water and ash. SAI is an indicator of how the fly ash performs in a simulated matrix relative to a control based on a vendor's specifications. The SAI is calculated by dividing the compressive strength of a given sample made with fly ash by the compressive strength of the control, which does not contain fly ash. Meeting the minimum 7 day or 28 day strength activity index of 75\% indicates compliance with ASTM C618; ASTM C618 is a specification that covers coal fly ash and raw or calcined natural pozzolan for use in concrete. The maximum allowed water requirement is $105 \%$. In all LMS ash samples tested, the SAI and water requirements were shown to be acceptable.

Table 3-35. EERC Concrete Results for Simulated Carbon/Ash Mixtures

\begin{tabular}{||c|c|c|c|c||}
\hline Test Parameter & $\begin{array}{c}\text { Passing } \\
\text { Criteria* }\end{array}$ & $\begin{array}{c}\text { Baseline } \\
(\mathbf{1 2 / 1 / 0 7 )}\end{array}$ & $\begin{array}{c}\text { 12/9/07 0.6 } \\
\text { lb/Macf } \\
\text { DARCO } \\
\text { (24-hr test) }\end{array}$ & $\begin{array}{c}\text { Simulated } \\
\text { 2.0 lb/Macf } \\
\text { DARCO Hg-LH }\end{array}$ \\
\hline \hline $\begin{array}{c}\text { 7-Day Strength Activity } \\
\text { Index (\%) }\end{array}$ & $>75$ & 71 & 83 & 79 \\
\hline $\begin{array}{c}\text { 28-Day Strength Activity } \\
\text { Index (\%) }\end{array}$ & $>75$ & 82 & 88 & 87 \\
\hline Water Requirement (\%) & $<105$ & 95 & 95 & 95 \\
\hline
\end{tabular}

* Passing criteria based on ASTM C 618 specifications.

\section{Fly ash and Concrete Results during Long-Term Test}

\section{Concrete Results from Day 3 of Injection}

Although the results for simulated carbon-fly ash samples indicated that 1-2 lb/Macf activated carbon injection rates at LMS should be acceptable for subsequent fly ash reuse, actual field samples provide a more accurate indicator of fly ash fitness since certain air entraining agents might be more sensitive to carbon exposed to flue gas. Three days into the long-term injection test, first-field fly ash samples were obtained and analyzed by Headwaters for concrete testing. The purpose of this screening test was to confirm that the chosen sorbent injection rate (for the long-term test) was suitable for generating fly ash that was concrete compatible. Concrete was prepared from fly ash collected from each of the three rows of the first field. Results of the concrete tests are shown in Table 3-36. AEA, slump, water content, air pressure, and compressive strength were all determined to be satisfactory. Thus, the long-term test was continued at the $2 \mathrm{lb} / \mathrm{Macf}$ injection rate. Results from the long-term test samples (Table 3-36) were very similar to results obtained from the simulated carbon/ash mixtures (Table 3-34), thereby validating the simulation tests as a viable screening method. 
Table 3-36. Headwaters Concrete Results for Baseline and Day 3 (of Long-Term Test) Fly Ash

\begin{tabular}{|c|c|c|c|c|c|c|c|c|c|}
\hline \multirow{2}{*}{$\begin{array}{c}\text { Test } \\
\text { Parameter } \\
\text { Date }\end{array}$} & \multirow[t]{2}{*}{ Units } & \multirow[t]{2}{*}{$\begin{array}{l}\text { Passing } \\
\text { Criteria }\end{array}$} & \multirow{2}{*}{$\begin{array}{c}\text { Control } \\
\text { with } \\
\text { Portland } \\
\text { Cement } \\
\text { (no ash) } \\
\end{array}$} & \multicolumn{2}{|c|}{$\begin{array}{c}\text { Hopper 1F1A } \\
1^{\text {st }} \text { Field, } 1^{\text {st }} \text { Row }\end{array}$} & \multicolumn{2}{|c|}{$\begin{array}{c}\text { Hopper 1F2A } \\
1^{\text {st }} \text { Field, } 2^{\text {nd }} \text { Row }\end{array}$} & \multicolumn{2}{|c|}{$\begin{array}{c}\text { Hopper 1F3A } \\
1^{\text {st }} \text { Field, } 3^{\text {rd }} \text { Row }\end{array}$} \\
\hline & & & & $\begin{array}{c}\text { Baseline } \\
6 / 22 / 07 \\
\end{array}$ & $\begin{array}{c}\text { Injection } \\
\text { Day } 3 \\
6 / 25 / 07 \\
\end{array}$ & $\begin{array}{c}\text { Baseline } \\
6 / 22 / 07 \\
\end{array}$ & $\begin{array}{c}\text { Injection } \\
\text { Day } 3 \\
6 / 25 / 07 \\
\end{array}$ & $\begin{array}{c}\text { Baseline } \\
6 / 22 / 07 \\
\end{array}$ & $\begin{array}{c}\text { Injection } \\
\text { Day } 3 \\
6 / 25 / 07 \\
\end{array}$ \\
\hline AEA & $\mathrm{oz} / \mathrm{cwt}$ & $\begin{array}{c}\text { Steady } \\
\text { and low }\end{array}$ & 0.21 & 0.22 & 0.46 & 0.20 & 0.40 & 0.20 & 0.43 \\
\hline $\begin{array}{l}\text { Slump .25 } \\
\text { inch }\end{array}$ & $\%$ & $5-7$ & 5.5 & 5.8 & 6.0 & 6.0 & 5.5 & 5.5 & 6.0 \\
\hline Air Pressure & $\%$ & $5-7$ & 6.2 & 6.8 & 6.0 & 6.6 & 5.5 & 6.4 & 5.5 \\
\hline $\begin{array}{c}\text { Water to } \\
\text { Cement Ratio }\end{array}$ & none & $\begin{array}{l}\text { Similar to } \\
\text { Control }\end{array}$ & 0.56 & 0.51 & 0.53 & 0.51 & 0.53 & 0.51 & 0.52 \\
\hline $\begin{array}{c}\text { 7-Day } \\
\text { Compressive } \\
\text { Strength }\end{array}$ & $\begin{array}{c}\text { Psi of } \\
\text { unconfined } \\
\text { compressive } \\
\text { strength } \\
\end{array}$ & $\begin{array}{l}\text { Similar to } \\
\text { Control }\end{array}$ & 2966 & 2825 & 2994 & 2932 & 3271 & 2932 & 2847 \\
\hline $\begin{array}{c}\text { 28-Day } \\
\text { Compressive } \\
\text { Strength }\end{array}$ & $\begin{array}{c}\text { Psi of } \\
\text { unconfined } \\
\text { compressive } \\
\text { strength }\end{array}$ & $\begin{array}{l}\text { Similar to } \\
\text { Control }\end{array}$ & 4222 & 4072 & 3905 & 4405 & 4827 & 4049 & 4355 \\
\hline
\end{tabular}




\section{Foam Index Testing}

Headwaters performed on site foam index testing on fly ash samples collected weekly during the long-term test (Appendix I). Figure 3-30 shows results for these tests. Each datum point is the average of all three hoppers in the first field for either the untreated ESP $1 \mathrm{~B}$ (hoppers $1 \mathrm{~B}, 2 \mathrm{~B}$ and 3B), or the treated ESP 1A (hoppers 1A, 2A, and 3A). A line is drawn to indicate the overall average foam index result for each duct, as well as one standard deviation difference. The overall average does not include days where only PRB coal was fired. Results showed that the untreated duct produced more steady foam index results, and demanded less AEA than the treated duct. The higher variability observed with fly ash collected from the treated ESP may be related to possible variability with the sorbent injection delivery, sorbent duct coverage, or that associated with obtaining representative samples of fly ash-carbon mixtures.

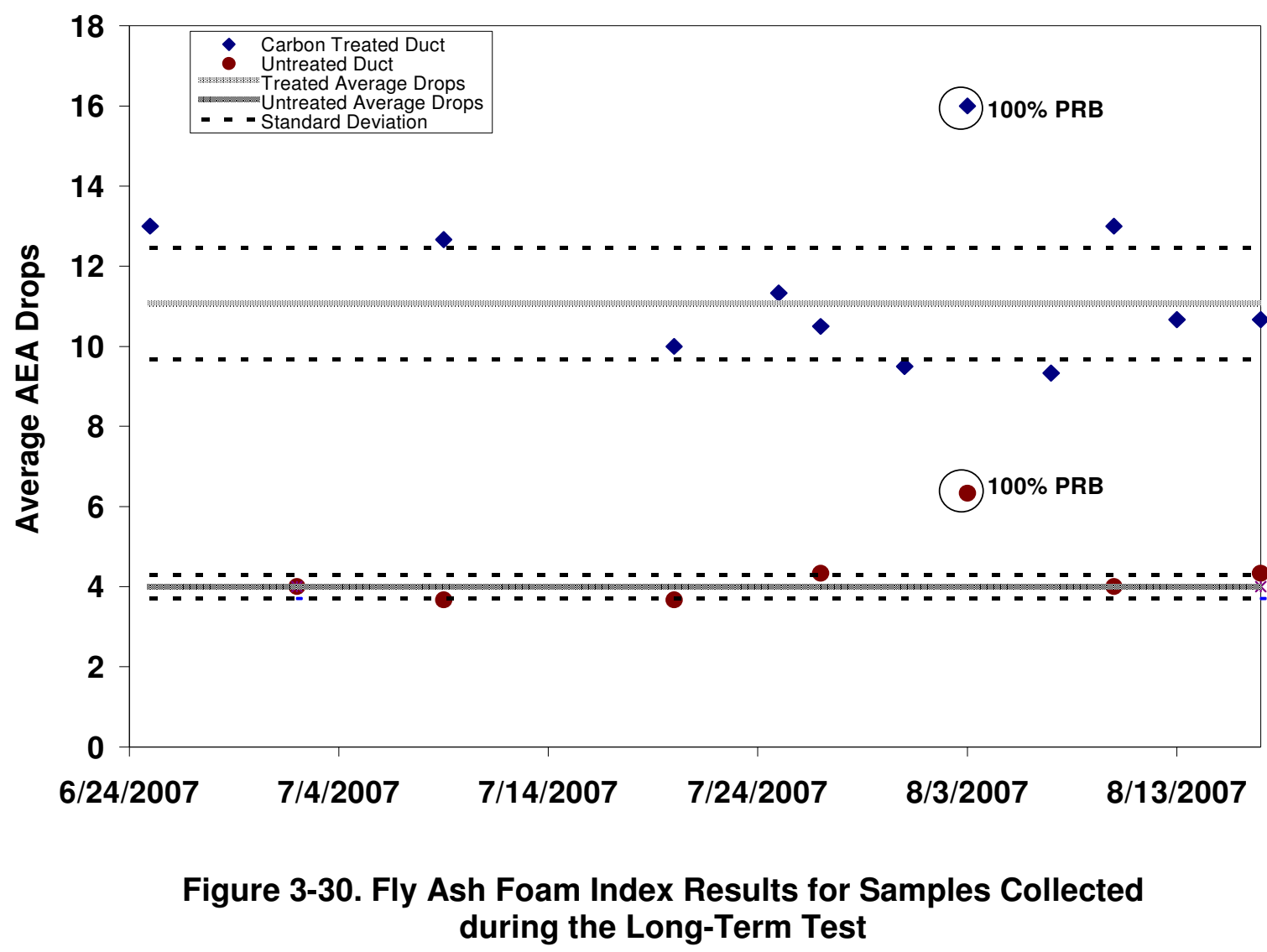

Most of the ash and concrete analyses for this program were performed on samples collected from the first field of the ESP since $90 \%$ of the fly ash is typically collected there. However, fly ash from all ESP fields would be incorporated into concrete, so it is important to evaluate the back-field ash characteristics as well. Because so little ash is captured in these backfields, limited samples were available. Table 3-37 lists foam index data for ash collected from the back-field hoppers of ESP 1A. Results for the baseline fly ash collected on June $22^{\text {nd }}$ showed higher foam index properties from fields 4 and 5 hopper 1A, and fields 6 and 7 hoppers $1 \mathrm{~A}$ and $2 \mathrm{~A}$. It is believed that this was likely due to residual carbon from Toxecon ${ }^{\mathrm{TM}}$ II testing that occurred in 
prior weeks. These hoppers are cleared approximately once per week, so it could take several weeks to fully clear the injected carbon from the backfields. Because only the fields downstream of the Toxecon ${ }^{\mathrm{TM}}$ II location showed increased foam index results, it is believed that residual carbon from Toxecon ${ }^{\mathrm{TM}}$ II caused the high results.

Table 3-37. LMS Foam Index* from All Fields of ESP 1A (Treated ESP)

\begin{tabular}{|c|c|c|c|c|c|c|c|c|c|c|c|c|c|c|c|}
\hline \multirow[t]{2}{*}{ Date } & \multicolumn{3}{|c|}{ Field 1} & \multicolumn{3}{|c|}{ Field 2} & \multicolumn{3}{|c|}{ Field 3} & \multicolumn{3}{|c|}{ Fields $4 \& 5$} & \multicolumn{3}{|c|}{ Fields 6\&7 } \\
\hline & $1 \mathrm{~A}$ & $2 \mathrm{~A}$ & $\mathbf{3 A}$ & $\mathbf{1 A}$ & $2 \mathrm{~A}$ & $\mathbf{3 A}$ & $\mathbf{1 A}$ & $2 \mathrm{~A}$ & $\mathbf{3 A}$ & $1 \mathrm{~A}$ & $2 \mathrm{~A}$ & $\mathbf{3 A}$ & $\mathbf{1 A}$ & $2 \mathrm{~A}$ & $\mathbf{3 A}$ \\
\hline \multicolumn{16}{|l|}{ Baseline } \\
\hline $6 / 22 / 2007$ & 5 & 5 & 4 & 4 & 5 & 5 & 5 & 6 & 6 & 31 & 6 & 6 & 32 & 30 & 7 \\
\hline \multicolumn{16}{|l|}{ Long Term } \\
\hline $6 / 25 / 2007$ & 12 & 12 & 14 & 10 & 11 & 18 & NA & 8 & 20 & NA & 10 & NA & NA & NA & 21 \\
\hline $8 / 2 / 2007$ & NA & NA & NA & 19 & 15 & 15 & 17 & 19 & 14 & 15 & 22 & 24 & 27 & 36 & 30 \\
\hline
\end{tabular}

* Foam Index units are in drops of AEA.

\section{LOI and Carbon by LECO}

Headwaters conducted on site LOI testing (Appendix I) during the test program. Figure 3-31 displays the overall average LOI result for both treated and untreated ducts, as well as the calculated standard deviation of the collective measurements. Each datum point represents the average from all three hoppers in the first field. The average does not include days where only PRB coal was fired. The treated duct produced higher and more variable LOI results than the untreated duct. According to ASTM C 618 the maximum LOI should not exceed $6.0 \%$ for a Class $\mathrm{C}$ ash; however, concrete manufacturers may set an even lower limit. Samples collected from both ducts were well below the LOI requirements for a Class $\mathrm{C}$ fly ash. 


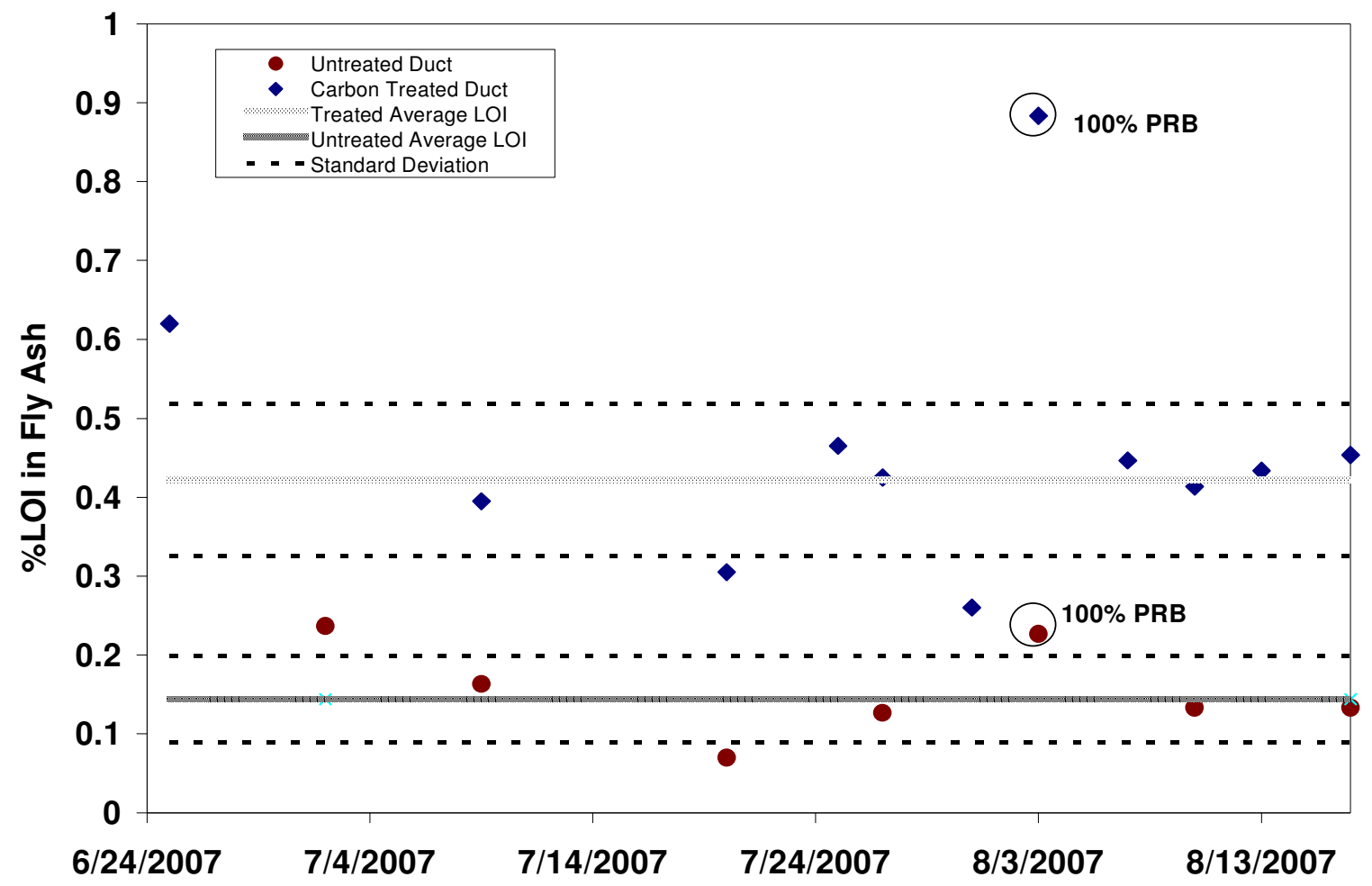

Figure 3-31. First-Field Fly Ash LOI during the Long-Term Test (LMS Laboratory)

LOI measures loss of any weight (net weight loss) upon ignition. Not only will unburned carbon become incinerated, but sulfur compounds present in the ash can be released as well. For these reasons, an alternative method is often used to produce unburned carbon results. More accurate carbon results can be obtained using an instrument such as LECO. LECO heats a sample and oxidizes carbon in the ash to carbon dioxide, which is then measured by an infrared detector providing increased speed and accuracy, and lower detection limits. LOI measurements determine a net weight loss of a sample whereas LECO measures only the carbon content (Table 3-38); therefore, LOI measurements tend to be higher than those determined by LECO. 
Table 3-38. Carbon by LECO as Measured by Headwaters Laboratory

\begin{tabular}{|c|c|c|c|}
\hline Date & $\begin{array}{c}\text { Hopper 1F1A } \\
1^{\text {st }} \text { Field, } \mathbf{1}^{\text {st }} \text { Row } \\
\text { (\% Carbon) }\end{array}$ & $\begin{array}{c}\text { Hopper 1F2A } \\
1^{\text {st }} \text { Field, } 2^{\text {nd }} \text { Row } \\
(\% \text { Carbon })\end{array}$ & $\begin{array}{c}\text { Hopper 1F3A } \\
1^{\text {st }} \text { Field, } 3^{\text {rd }} \text { Row } \\
(\% \text { Carbon })\end{array}$ \\
\hline $7 / 9 / 07$ & 0.32 & 0.32 & 0.14 \\
\hline 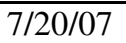 & 0.30 & 0.38 & - \\
\hline $7 / 25 / 07$ & 0.47 & 0.47 & 0.29 \\
\hline $8 / 3 / 07$ & 0.91 & 0.81 & 0.70 \\
\hline $8 / 7 / 07$ & - & 0.31 & - \\
\hline $8 / 10 / 07$ & 0.30 & - & - \\
\hline $8 / 13 / 07$ & 0.26 & 0.38 & 0.53 \\
\hline $8 / 17 / 07$ & 0.33 & 0.35 & 0.23 \\
\hline $8 / 21 / 07$ & 0.26 & 0.32 & 0.10 \\
\hline
\end{tabular}

- Data not available

\section{Particle Size Characterization}

Concrete consists of air, Portland cement, gravel, sand, and water. The reactive constituents of Portland cement (PC) are lime and silica. PC is an expensive material, so concrete manufacturers replace up to $20 \%$ PC with fly ash and receive a beneficial effect on concrete properties. Fly ash particles are smaller than those in PC allowing them to flow and fill voids more easily. When water and PC are mixed, two products are created: (1) a durable binder that glues concrete aggregates together and (2) free lime. Free lime reacts with the fly ash replacement creating a more desirable binder.

The reactivity of the fly ash with lime in a concrete matrix increases with smaller fly ash particle size. Finer sized particles have higher surface areas and create a higher probability of contact between the lime and fly ash. LMS performed on-site particle size characterization of selected fly ash samples using both a sieving method and analysis using a Horiba particle size analyzer (for median particle size). A 325-mesh sieve test was conducted in which the coarser ash particles are retained on the mesh while the finer particles pass through it. A 325-mesh sieve corresponds to a particle size of $45 \mu \mathrm{m}$. Results of the 325-mesh sieve test are reported as the percent of ash material retained on the sieve, with higher values indicated larger particle size. Fineness, or the amount of material retained when wet-sieved on a 325-mesh screen, is a physical requirement used for defining a suitable Class $\mathrm{C}$ fly ash. This number should not exceed $34 \%$ according to ASTM C 618.

Figure 3-32 shows the overall 325-mesh sieve results for the treated and untreated ducts. Each Bside datum point represents the average of all three hoppers in the first field. For the A-side, only hoppers $1 \mathrm{~A}$ and $2 \mathrm{~A}$ data points were included. Due to the coarseness of the material coming from the 3A hopper, it appears as though ash from the economizer was carrying over into it. Headwaters indicated that this phenomenon has been seen before in this hopper and is not a result of carbon injection. Therefore, none of the ash from the first field 3A hopper was used in the concrete simulations, nor was it included in the data presented in Figure 3-32. Table 3-39 shows how the $3 \mathrm{~A}$ hopper particles were more coarse (i.e. higher 325-mesh) than the $1 \mathrm{~A}$ and $2 \mathrm{~A}$ hoppers. 


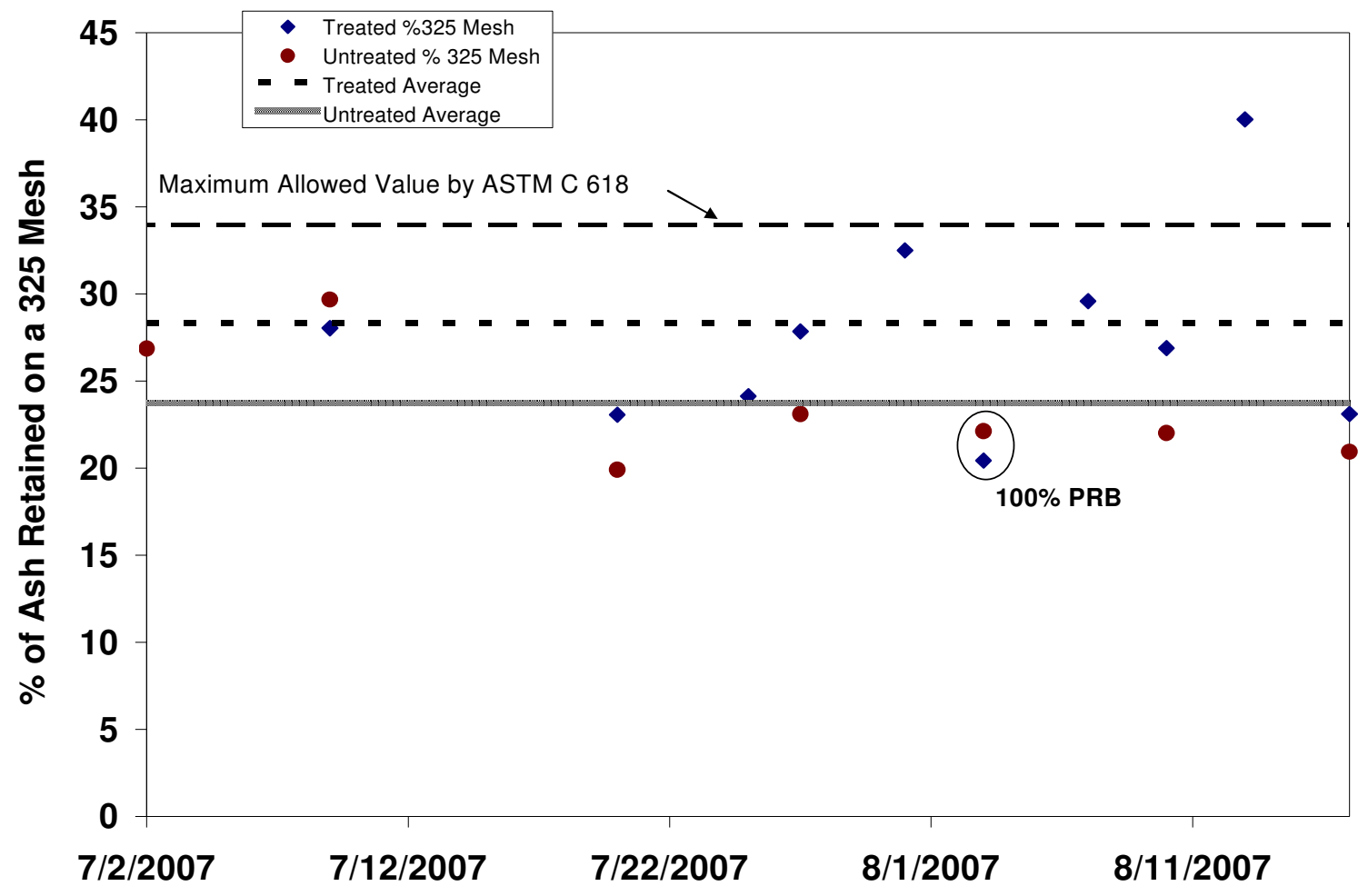

Figure 3-32. Average Results for 325-Mesh Characterization of First-Field Ash during the Long-Term Test

Table 3-39. 325 Mesh Results for Each First-Field Hopper of the Treated ESP

\begin{tabular}{|c|c|c|c|}
\hline Date & $\begin{array}{c}\text { Hopper 1F1A } \\
1^{\text {st }} \text { Field, } 1^{\text {st }} \text { Row } \\
\text { (\% Retained on a } 325 \text { mesh) }\end{array}$ & $\begin{array}{c}\text { Hopper 1F2A } \\
1^{\text {st }} \text { Field, }{ }^{\text {nd }} \text { Row } \\
\text { (\% Retained on a } 325 \text { mesh) }\end{array}$ & $\begin{array}{c}\text { Hopper 1F3A } \\
1^{\text {st }} \text { Field, } 3^{\text {rd }} \text { Row } \\
\text { (\% Retained on a } 325 \text { mesh) }\end{array}$ \\
\hline $7 / 9 / 2007$ & 29.9 & 26.2 & 83.7 \\
\hline $7 / 20 / 2007$ & 27.0 & 19.1 & - \\
\hline $7 / 25 / 2007$ & 23.8 & 24.5 & 52.9 \\
\hline $7 / 27 / 2007$ & 29.3 & 26.4 & - \\
\hline $7 / 31 / 2007$ & 34.3 & 30.7 & - \\
\hline $8 / 3 / 2007$ & 20.9 & 19.9 & 33.0 \\
\hline $8 / 7 / 2007$ & 32.8 & 26.4 & 36.8 \\
\hline $8 / 10 / 2007$ & 27.0 & 26.8 & 42.7 \\
\hline $8 / 13 / 2007$ & 43.8 & 37.4 & 38.9 \\
\hline $8 / 17 / 2007$ & 21.5 & 24.7 & 48.1 \\
\hline
\end{tabular}

-Data not available.

The Horiba particle size instrument uses laser diffraction, and provides much more accurate information than a 325-mesh sieve measurement. The Horiba particle size measurements (Table $3-40$ ) obtained for hopper $3 \mathrm{~A}$ were significantly higher than those for hoppers $1 \mathrm{~A}$ and $2 \mathrm{~A}$, again providing evidence that the hopper was tainted by economizer ash. It is unclear why particle sizes of all three fields on 8/13/07 are nearly triple the typical value of $\sim 15 \mu \mathrm{m}$. 
Table 3-40. Median Fly Ash Particle Size as Measured by the Horiba Analyzer

\begin{tabular}{|c|c|c|c|}
\hline \multirow[t]{2}{*}{ Date } & $\begin{array}{c}\text { Hopper 1F1A } \\
1^{\text {st }} \text { Field, } 1^{\text {st }} \text { Row }\end{array}$ & $\begin{array}{c}\text { Hopper 1F2A } \\
1^{\text {st }}{\text { Field, } 2^{\text {nd }} \text { Row }}^{\text {Row }}\end{array}$ & $\begin{array}{c}\text { Hopper 1F3A } \\
\mathbf{1}^{\text {st }} \text { Field, } 3^{\text {rd }} \text { Row }\end{array}$ \\
\hline & Particle Size $(\mu \mathrm{m})$ & Particle Size $(\mu \mathrm{m})$ & Particle Size $(\mu \mathrm{m})$ \\
\hline $7 / 7 / 9 / 07$ & 19.5 & 17.1 & 296.4 \\
\hline $7 / 20 / 07$ & 18.4 & 13.1 & - \\
\hline $7 / 25 / 07$ & 14.4 & 15.5 & 46.6 \\
\hline $8 / 3 / 07$ & 16.1 & 15.0 & 25.1 \\
\hline $8 / 7 / 07$ & - & 18.4 & - \\
\hline $8 / 10 / 07$ & 19.5 & - & - \\
\hline $8 / 13 / 07$ & 47.6 & 40.1 & 42.1 \\
\hline $8 / 17 / 07$ & 14.2 & 14.7 & 43.9 \\
\hline $8 / 21 / 07$ & 17.6 & 16.7 & 35.5 \\
\hline
\end{tabular}

- Data not available

\section{Additional Compressive Strength Results}

Concrete test results presented previously in this report were for fly ash samples collected from the first field of the ESP. In reality, ash from all ESP fields is combined in a silo (where stratification often occurs) and then transported to a truck (where mixing occurs) and shipped to the concrete manufacturer. Because ash fineness changes from field to field, silo samples will have different characteristics than first-field fly ash. During ACI testing, fly ash from the treated ESP was transferred to a non-marketing silo where it was mixed with economizer ash. This silo ash was not appropriate for concrete testing (due to the inclusion of economizer ash). Therefore, in order to obtain an ash sample representative of that captured across the entire Unit 1 ESP, Headwaters combined individual samples from multiple fields to simulate the fineness of untreated bulk fly ash.

A blended ash sample was made to mimic fly ash that would be transported for reuse. This was accomplished by using the best possible combination of individual hopper samples, given the limited number and quantity available. To prepare a representative ash sample, first field samples from hoppers $1 \mathrm{~A}$ and $2 \mathrm{~A}$ collected on 7/9/07 were blended in a 50:50 ratio. As stated previously, ash from hopper 1F3A was not used due to its unusual coarseness. The 50:50 first-field blend was then mixed 80:20 with finer ash from field 3F3A (collected on 8/2/07) to produce a sample that simulated the fineness of the final marketed fly ash sample (i.e., "truck sample"). This final blend was tested for foam index, slump, air pressure, and compressive strength by Headwaters.

The multiple-field blend showed higher compressive strength than individual first-field samples (Table 3-41). Truck samples of untreated ash (i.e., not containing activated carbon) and multiple field treated ash behaved similarly except in AEA demand. Injection of activated carbon thus appeared to have no adverse impact on fly ash quality. 
Table 3-41. Headwaters Concrete Using Ash from Long-Term Injection

\begin{tabular}{|c|c|c|c|c|c|}
\hline Test Parameter & Units & $\begin{array}{l}\text { Passing } \\
\text { Criteria }\end{array}$ & $\begin{array}{c}\begin{array}{c}\text { Control with } \\
\text { Portland Cement } \\
\text { (no ash) }\end{array} \\
\end{array}$ & $\begin{array}{l}\text { Untreated Ash } \\
\text { Truck Sample }\end{array}$ & $\begin{array}{l}\text { Multi-Field } \\
\text { Blend* }\end{array}$ \\
\hline Date & & & $10 / 30 / 07$ & $6 / 26 / 07$ & $7 / 9 / 07 \& 8 / 2 / 07$ \\
\hline AEA & $\mathrm{oz} / \mathrm{cwt}$ & $\begin{array}{c}\text { Steady and } \\
\text { low }\end{array}$ & 0.16 & 0.19 & 0.32 \\
\hline Slump .25 inch & inches & $5-7$ & 5.5 & 6.0 & 6.0 \\
\hline Air Pressure (\%) & $\%$ & $5-7$ & 6.0 & 5.8 & 5.5 \\
\hline Water to Cement Ratio & none & $\begin{array}{c}\text { Similar to } \\
\text { Control }\end{array}$ & 0.52 & 0.51 & 0.51 \\
\hline 7-Day Average ${ }^{* *}$ & $\begin{array}{c}\text { Psi of } \\
\text { unconfined } \\
\text { compressive } \\
\text { strength } \\
\end{array}$ & $\begin{array}{l}\text { Similar to } \\
\text { Control }\end{array}$ & 4016 & 3713 & 3663 \\
\hline$\%$ RSD & & & 3.2 & 1.2 & 3.2 \\
\hline 28-Day Average** & $\begin{array}{c}\text { Psi of } \\
\text { unconfined } \\
\text { compressive } \\
\text { strength }\end{array}$ & $\begin{array}{l}\text { Similar to } \\
\text { Control }\end{array}$ & 5989 & 5561 & 5328 \\
\hline$\%$ RSD & & & 2.8 & 3.7 & 1.7 \\
\hline
\end{tabular}

* Blended sample made by mixing 50:50 first field samples from hoppers 1A and 2A collected on 7/9/07. Ash from hopper 1F3A on 7/9/07 was not used due to its coarseness. This 50:50 blend was then mixed 80:20 with Field $3 \mathrm{~F} 3 \mathrm{~A}$ from $8 / 2 / 07$ to give a final blend of hoppers used to prepare concrete mixes. No first field ash from 8/2/07 was used because plant went to all PRB before it could be collected.

** Reported average of three individual cylinders. See Appendix I for the individual cylinder results.

\subsection{Flue Gas Halogen Measurements}

Flue gas halogen concentrations were measured to determine the potential for bromide compounds, impregnated on the DARCO Hg-LH sorbent, to volatilize after being injected into the duct. Flue gas samples were collected using EPA Method 26A (isokinetic, full traverse measurements), which is a standard method used to determine hydrogen halide and halogen emissions from stationary sources. Samples were collected simultaneously on the injection side (A) of the ESP and the non-injection side (B).

As discussed in previous sections, a bias exists in determining the speciation of the halogen and hydrogen halide at low concentrations in coal-derived flue gas. The halogen concentration can be biased low, resulting in the hydrogen halide concentration being biased high. However, the total concentration of halogen and hydrogen halide concentration is still accurate. In Table 3-42, the halogen $\left(\mathrm{Br}_{2} / \mathrm{Cl}_{2}\right)$ data are presented along with the hydrogen halide $(\mathrm{HBr} / \mathrm{HCl})$ data. In all cases, the halogen concentrations are near or below the detection limit. Because of the sampling bias, there may indeed have been $\mathrm{Br}_{2}$ and $\mathrm{Cl}_{2}$ present in the flue gas, but it was detected only in the hydrogen halide impinger.

As presented in Table 3-42, chloride was detected in both the injection and non-injection sides at concentrations between 4.1 and 6.2 ppmvd @ 3\% $\mathrm{O}_{2}$. Flue gas bromide concentrations averaged 0.50 ppmvd at $3 \% \mathrm{O}_{2}$ in the treated duct, and 0.09 ppmvd in the untreated duct. This result indicates bromine is volatizing from the impregnated sorbent. It is expected that the volatilized bromide would be removed across the FGD scrubber. 
Table 3-42. Method 26A Results during Long-Term Testing

\begin{tabular}{|c|c|c|c|c|c|c|c|}
\hline Location & Run & Date & Time & $\begin{array}{c}\mathbf{C l}_{\mathbf{2}} \\
(\mathrm{ppmvd} @ \\
\left.3 \% \mathrm{O}_{2}\right)\end{array}$ & $\begin{array}{c}\mathbf{H C l} \\
(\mathrm{ppmvd} @ \\
\left.3 \% \mathrm{O}_{2}\right)\end{array}$ & $\begin{array}{c}\mathbf{B r}_{2} \\
(\mathrm{ppmvd} @ \\
\left.3 \% \mathrm{O}_{2}\right)\end{array}$ & $\begin{array}{c}\mathbf{H B r} \\
(\mathrm{ppmvd} @ \\
3 \% \mathrm{O}_{2} \text { ) }\end{array}$ \\
\hline Untreated Side & 1 & 7/11/07 & 12:51-15:03 & $<0.002$ & 6.23 & $<0.001$ & 0.09 \\
\hline Untreated Side & 2 & $7 / 11 / 07$ & 16:05-18:17 & 0.003 & 6.20 & $<0.001$ & 0.08 \\
\hline Untreated Side & 3 & $7 / 12 / 07$ & 08:40-10:49 & $<0.002$ & 4.18 & $<0.001$ & 0.09 \\
\hline Treated Side & 1 & 7/11/07 & 12:51-15:02 & $<0.002$ & 5.87 & $<0.001$ & 0.54 \\
\hline Treated Side & 2 & $7 / 11 / 07$ & 16:05-18:15 & 0.003 & 6.13 & $<0.001$ & 0.48 \\
\hline Treated Side & 3 & $7 / 12 / 07$ & $08: 40-10: 50$ & $<0.003$ & 4.12 & $<0.001$ & 0.47 \\
\hline
\end{tabular}

\subsection{FGD System Measurements}

Flue gas desulfurization absorber slurry solid and liquid samples were collected during baseline and long-term tests and analyzed. Measured concentrations of various analytes for solids and liquids are presented in Tables 3-43 and 3-44, respectively. The FGD liquor Br concentration would be expected to increase due to an increase in flue gas $\mathrm{Br}$ concentration during injection of the brominated Darco Hg-LH carbon. However, only $1 / 4$ of Unit 1 was treated for the long-term test and the treated and untreated gas mix prior to the FGD. Therefore, the concentrations presented in Tables 3-43 and 3-44 do not reflect the FGD concentrations that would be achieved at steady-state had all of Unit 1 been treated with ACI.

Table 3-43. FGD Solids Analysis from Long-Term Test

\begin{tabular}{|l|c|l|l|c|c|c|c|c|}
\hline Description & $\begin{array}{l}\text { Module A } \\
\text { Solids }\end{array}$ & $\begin{array}{l}\text { Module A } \\
\text { Solids }\end{array}$ & $\begin{array}{l}\text { Module A } \\
\text { Solids }\end{array}$ & $\begin{array}{l}\text { Module A } \\
\text { Solids }\end{array}$ & $\begin{array}{l}\text { Module A } \\
\text { Solids }\end{array}$ & $\begin{array}{l}\text { Module A } \\
\text { Solids }\end{array}$ & $\begin{array}{l}\text { Module A } \\
\text { Solids }\end{array}$ & $\begin{array}{l}\text { Module A } \\
\text { Solids }\end{array}$ \\
\hline \hline Date & $6 / 18 / 2007$ & $6 / 20 / 2007$ & $6 / 25 / 2007$ & $7 / 4 / 2007$ & $7 / 10 / 2007$ & $7 / 22 / 2007$ & $7 / 30 / 2007$ & $8 / 3 / 2007$ \\
\hline Time & $17: 15$ & $15: 00$ & $16: 40$ & $11: 15$ & $15: 00$ & $12: 20$ & $14: 15$ & $15: 50$ \\
\hline $\mathrm{pH}$ & 5.48 & 5.48 & 5.50 & 5.54 & 5.49 & 5.47 & 5.25 & 5.16 \\
\hline Temperature & 57.3 & 52.5 & 60 & 59.2 & 60.3 & 59.4 & 56.3 & 57 \\
\hline $\mathrm{Ca}, \mathrm{mg} / \mathrm{g}$ & 303 & 303 & 302 & 293 & 297 & 298 & 287 & 299 \\
\hline $\mathrm{Mg}, \mathrm{mg} / \mathrm{g}$ & $<0.2$ & 0.3 & 0.3 & $<0.2$ & $<0.2$ & $<0.2$ & $<0.2$ & $<0.2$ \\
\hline $\mathrm{SO}_{3}, \mathrm{mg} / \mathrm{g}$ & 512.8 & 482.8 & 496.4 & 435.6 & 427.4 & 487.0 & 471.4 & 438.5 \\
\hline $\mathrm{SO}_{4}, \mathrm{mg} / \mathrm{g}$ & 89 & 128 & 111 & 171 & 177 & 111 & 112 & 171 \\
\hline $\mathrm{CO}_{3}, \mathrm{mg} / \mathrm{g}$ & 3 & 7 & 3 & 2 & 4 & 2 & 2 & 3 \\
\hline Inerts, wt\% & 0.96 & 1.12 & 0.88 & 0.84 & 0.76 & 0.88 & 1.08 & 1.04 \\
\hline Solids, wt\% & 7.90 & 12.42 & 13.41 & 10.42 & 9.19 & 6.06 & 13.46 & 11.90 \\
\hline Oxidation, \% & 12.6 & 18.1 & 15.8 & 24.7 & 25.7 & 16.0 & 16.5 & 24.5 \\
\hline Utilization, \% & 98.5 & 98.0 & 98.7 & 99.2 & 98.3 & 98.7 & 99.1 & 98.5 \\
\hline
\end{tabular}


Table 3-44. FGD Liquid Analysis from Long-Term Test

\begin{tabular}{|l|c|c|c|c|c|c|c|c||}
\hline Description & $\begin{array}{c}\text { Module A } \\
\text { Liquids }\end{array}$ & $\begin{array}{c}\text { Module A } \\
\text { Liquids }\end{array}$ & $\begin{array}{c}\text { Module A } \\
\text { Liquids }\end{array}$ & $\begin{array}{c}\text { Module A } \\
\text { Liquids }\end{array}$ & $\begin{array}{c}\text { Module A } \\
\text { Liquids }\end{array}$ & $\begin{array}{c}\text { Module A } \\
\text { Liquids }\end{array}$ & $\begin{array}{c}\text { Module A } \\
\text { Liquids }\end{array}$ & $\begin{array}{c}\text { Module A } \\
\text { Liquids }\end{array}$ \\
\hline \hline Date & $6 / 18 / 2007$ & $6 / 20 / 2007$ & $6 / 25 / 2007$ & $7 / 4 / 2007$ & $7 / 10 / 2007$ & $7 / 22 / 2007$ & $7 / 30 / 2007$ & $8 / 3 / 2007$ \\
\hline Time & $17: 15$ & $15: 00$ & $16: 40$ & $11: 15$ & $15: 00$ & $12: 20$ & $14: 15$ & $15: 50$ \\
\hline $\mathrm{Ca}, \mathrm{mg} / \mathrm{L}$ & 1127 & 1303 & 1270 & 1188 & 1179 & 1186 & 1184 & 1195 \\
\hline $\mathrm{Mg}, \mathrm{mg} / \mathrm{L}$ & 1774 & 2686 & 2297 & 2578 & 2351 & 2205 & 3641 & 3888 \\
\hline $\mathrm{Na}, \mathrm{mg} / \mathrm{L}$ & 2937 & 4364 & 3726 & 4361 & 4124 & 3722 & 5895 & 6388 \\
\hline $\mathrm{Cl}, \mathrm{mg} / \mathrm{L}$ & 5265 & 7928 & 6710 & 7756 & 7096 & 6462 & 10888 & 11909 \\
\hline $\mathrm{Br}, \mathrm{mg} / \mathrm{L}$ & 63 & 96 & 89 & 109 & 104 & 94 & 161 & 181 \\
\hline $\mathrm{CO}_{3}, \mathrm{mg} / \mathrm{L}$ & $<12$ & $<12$ & $<12$ & $<12$ & $<12$ & 23 & 27 & 17 \\
\hline $\mathrm{SO}_{3}, \mathrm{mg} / \mathrm{L}$ & 1328 & 1861 & 1335 & 1417 & 1382 & 1350 & 1688 & 2080 \\
\hline $\mathrm{SO}_{4}, \mathrm{mg} / \mathrm{L}$ & 5953 & 7157 & 7738 & 7167 & 6765 & 6015 & 9201 & 9448 \\
\hline
\end{tabular}

\subsection{Economic Analysis}

\section{Activated Carbon Injection Process Economics}

Results obtained during Phases I-III were used to conduct a preliminary cost analysis for the use of sorbent injection to control mercury at a power plant similar in nature to LMS. The objective of this analysis was to verify the feasibility of sorbent injection technology at LMS and to help establish testing priorities for Phase IV. This section describes the assumptions used and results obtained for the interim economic analysis. The economic analysis was repeated after the conclusion of the Phase IV parametric tests in 2009 and those results are reported in Chapter 4. Data from sorbent injection indicated better performance for mercury removal and ash properties in 2007 than in 2009, with no clear reason for the change in performance. In light of the poorer performance achieved in 2009, the results presented in this section based on the 2007 results represent an optimistic estimation of the costs of sorbent injection for a plant similar in configuration to LMS.

Capital and operating costs associated with various targeted mercury control levels were developed for sorbent injection implemented at a hypothetical 500-MW electric generating station firing primarily Texas Lignite. The assumed configuration for this hypothetical plant was similar to LMS in that it fired a 70/30 blend of Texas Lignite/PRB and was equipped with both a large-SCA ESP for particulate control and an FGD system for $\mathrm{SO}_{2}$ control. The FGD system was assumed to operate in a limestone inhibited oxidation mode and did not produce a salable gypsum byproduct. The activated carbon injection lances were assumed to be installed upstream of the ESP.

Plant characteristics for the model plant are summarized in Table 3-45. Average TxL and PRB coal compositions from the Phase III two-month injection test at LMS were used to calculate an average coal mercury input of $639 \mathrm{lb} / \mathrm{yr}$ and ESP inlet mercury concentration of $26 \mu \mathrm{g} / \mathrm{dNm}^{3}$ at $3 \% \mathrm{O}_{2}$. Baseline mercury removal across the ESP was assumed to be $10 \%$. 
Table 3-45. Process Parameters for Hypothetical Plant in Economic Analysis

\begin{tabular}{||l|l||}
\hline Parameter & Value \\
\hline Coal Type & $70 / 30$ TxL/PRB blend \\
\hline Particulate Control & Large-SCA ESP \\
\hline $\mathrm{SO}_{2}$ Control & $\begin{array}{l}\text { Wet Limestone FGD, Inhibited } \\
\text { Oxidation (Sulfur Emulsion) }\end{array}$ \\
\hline Net Unit Load & $500 \mathrm{MW}$ \\
\hline Net Heat Rate & $9800 \mathrm{Btu} / \mathrm{kwh}$ \\
\hline Unit Capacity Factor & 0.85 \\
\hline Flue Gas Temperature at ESP Inlet & $310^{\circ} \mathrm{F}$ \\
\hline Flue Gas Flow Rate at ESP Inlet & $1.9 \times 10^{6} \mathrm{acfm}$ \\
\hline Baseline Vapor Phase Hg Concentration at ESP Inlet & $26 \mu \mathrm{g} / \mathrm{dNm}^{3}$ at $3 \% \mathrm{O}_{2}$ \\
\hline Baseline Hg Removal across ESP & $10 \%$ \\
\hline Baseline Vapor Phase Hg Concentration at ESP Outlet & $23 \mu \mathrm{g} / \mathrm{dNm}^{3}$ at $3 \% \mathrm{O}_{2}$ \\
\hline
\end{tabular}

The economic analyses included the estimation of costs for achieving targeted mercury reductions of $50 \%, 70 \%$, and $90 \%$ at the ESP outlet. The annual cost associated with a carbon injection system was composed of the following components:

- Sorbent cost - This is the yearly cost of the sorbent. For this analysis, the chosen sorbent was Norit Americas' DARCO Hg-LH, available at \$1.00/lb F.O.B as of 3/31/08. The delivery cost of the sorbent from Norit's plant in Marshall, Texas was assumed to be $\$ 0.02125 / \mathrm{lb}$. The DARCO Hg-LH sorbent performance curve generated during Phase I-III parametric tests was used to estimate the sorbent injection rates needed to achieve 50\%, 70\%, and 90\% mercury reduction at the ESP outlet. In the 2009 tests, there was difficulty consistently achieving even 50\% reduction at the ESP outlet. Therefore, this economic analysis is repeated in Chapter 4 with the 2009 data.

Other brominated sorbents were not chosen for this analysis because either (1) they were less effective for mercury capture or (2) had to be shipped from considerably farther distances without providing increased mercury removal performance or decreased sorbent cost. Only sorbent types that met the program mercury removal performance target were considered. From the laboratory simulations performed as part of this test program, the potentially ash friendly C-PAC sorbent did not offer any substantive advantage over Darco $\mathrm{Hg}-\mathrm{LH}$ for maintaining fly ash quality. Like Darco $\mathrm{Hg}-\mathrm{LH}$, the C-PAC caused an increase in AEA demand, albeit a somewhat smaller increase.

- Ash mitigation cost - This is the cost associated with treatment of the ash to make it viable for use by the concrete industry. Several different ash mitigation scenarios were considered.

- In the case of 50\% mercury reduction at the ESP, the injection rate needed was only 0.5 lb/Macf. Based on the data gathered from 2007, ash containing this amount of carbon can be marketed directly to the concrete industry without the use of any ash mitigation techniques. Although ash quality was more diminished in 2009 than 2007, data gathered in 2009 indicated that ash at $0.5 \mathrm{lb} / \mathrm{Macf}$ carbon injection was viable as-is for use by concrete industry (see Chapter 4). 
- For the case of $70 \%$ mercury reduction, an injection rate of $1.2 \mathrm{lb} / \mathrm{Macf}$ was needed. In this case, the 2007 results indicate the ash is viable to sell for concrete; however, more AEA will be needed at the concrete manufacturer resulting in a lower cost procured for the ash. Depending on variations in unit operation, it is possible that some truckloads of ash may not pass the ash marketer's criteria for carbon content and may need to be landfilled (at a cost of $\$ 22.6 /$ ton for lost sales and landfilling). The frequency of rejection was assumed to be $5 \%$ for a required $50 \%$ mercury removal and $10 \%$ for higher removal levels.

- For the case of $90 \%$ mercury reduction at the ESP outlet, Phase I-III test results indicated that an injection rate of $3.2 \mathrm{lb} / \mathrm{Macf}$ would be needed. The AEA demand was estimated to be triple the demand of the untreated ash and thus unacceptable to sell as-is to concrete manufacturers. For this case, it was assumed that a proprietary surfactant would be applied to the fly ash at the power plant. The cost to apply this surfactant was assumed to be $\$ 10 /$ ton of fly ash, based on capital and operating costs estimated by Headwaters.

- The cost of $\$ 22.6 /$ ton for lost ash sales and land filling assumes that the ash can be landfilled locally. A landfill has a finite volume; once filled, ash will need to be trucked to a location farther away, which will significantly increase landfill costs.

- Operating and maintenance cost - Labor is required to monitor the operation of the sorbent injection system, coordinate sorbent shipments, and provide routine maintenance. It was assumed that over the course of one year, an average of one hour per day would be needed, at a loaded labor rate of $\$ 50 / \mathrm{hr}$. A spare parts budget of $\$ 5,000 / y r$ was allocated. The capital cost estimate already included a spare feeder.

- Amortized capital cost - This is the cost associated with installation of the carbon injection system. The economic life of the equipment was assumed to be 15 years at an interest rate of $8 \%$, for a capital recovery factor of 0.12 .

Table 3-46 shows the estimated annual cost to achieve 50\%, 70\% and 90\% mercury reduction at the ESP outlet, based on the 2007 data. Figures 3-33 and 3-34 illustrate the nature of the annual costs for a plant where fly ash sales are maintained and lost, respectively. For each case the annual cost is broken down into its contributing components: sorbent cost, amortized capital cost, and fly ash related costs. For the case where fly ash sales are maintained, costs for mitigating the byproduct are included. For the case where fly ash sales are lost, costs associated with lost revenues and byproduct landfilling are included. Costs for operations and maintenance are not presented in the Figures as they are too small $(\sim 25,000)$ to appear. The results presented here are "first-year" costs with the sorbent costs presented in current U.S. dollars while capital costs are amortized over fifteen years.

To achieve $50 \%$ mercury reduction at the ESP outlet, the annual cost was estimated to be $\$ 1.2 \mathrm{M}$ assuming that fly ash integrity is maintained. To achieve $70 \%$ mercury reduction, the annual cost increased to $\$ 3.3 \mathrm{M}$. The cost associated with ash mitigation (i.e., increased AEA usage and disposal of $10 \%$ of fly ash) contributed $50 \%$ of the annual cost. At $90 \%$ mercury reduction at the ESP outlet, the annual cost increased to $\$ 6.4 \mathrm{M}$. Again, sorbent costs and ash mitigation costs contributed nearly equally to the annual cost. 
If the mercury control implementation results in the inability to preserve the fly ash quality, all of the ash would need to be landfilled; this case is shown at the bottom of Table 3-46 and in Figure 3 -34. In this case, the cost for $50 \%$ mercury reduction increases from $\$ 1.2 \mathrm{M}$ (with ash sales) to $\$ 6.6 \mathrm{M}$; the respective cost for $90 \%$ mercury reduction increases from $\$ 6.4 \mathrm{M}$ to $\$ 9.0 \mathrm{M}$.

\section{Table 3-46. Annual Cost Breakdown for Sorbent Injection Implemented Upstream of the ESP, Based on 2007 Data}

\begin{tabular}{|c|c|c|c|c|}
\hline Case Name & & $\begin{array}{c}50 \% \text { Hg Reduction; } \\
\text { Sell Fly Ash }\end{array}$ & $\begin{array}{c}70 \% \text { Hg Reduction; } \\
\text { Sell Fly Ash }\end{array}$ & $\begin{array}{c}90 \% \text { Hg Reduction; } \\
\text { Sell Fly Ash }\end{array}$ \\
\hline Targeted \% Hg Reduction at ESP Outlet & & $50 \%$ & $70 \%$ & $90 \%$ \\
\hline Injection Location & & Upstream of ESP & Upstream of ESP & Upstream of ESP \\
\hline Sorbent & & Darco Hg-LH & Darco $\mathrm{Hg}-\mathrm{LH}$ & Darco Hg-LH \\
\hline ACI Injection rate & $\mathrm{lb} / \mathrm{Macf}$ & 0.5 & 1.3 & 3.2 \\
\hline ACI Injection rate at full load & $\mathrm{lb} / \mathrm{hr}$ & 59 & 148 & 373 \\
\hline ACI Injection & $\mathrm{lb} / \mathrm{yr}$ & 439,443 & $1,104,521$ & $2,776,165$ \\
\hline Foam Index Result (drops; $\mathrm{BL}=3$ drops) & & 3 & 5 & 9 \\
\hline Ash Disposal Plan & & Sell all ash & $\begin{array}{c}\text { Sell all ash, extra } \\
\text { AEA needed }\end{array}$ & $\begin{array}{c}\text { Sell all ash, } \\
\text { surfactant used }\end{array}$ \\
\hline Rejection Rate of Fly Ash & $\%$ & $5 \%$ & $10 \%$ & $10 \%$ \\
\hline Total Annual Cost: Carbon+Capital+Ash Mitigation & $\$ / \mathbf{y r}$ & $\$ 1,237,401$ & $\$ 3,254,465$ & $\$ 6,435,039$ \\
\hline Annual carbon cost (including shipping) & $\$ / y r$ & $\$ 448,781$ & $\$ 1,127,992$ & $\$ 2,835,159$ \\
\hline Operating and Maintenance & $\$ / y r$ & $\$ 23,200$ & $\$ 23,200$ & $\$ 23,200$ \\
\hline Amortized Capital Cost For ACI System & $\$ / y r$ & $\$ 480,000$ & $\$ 480,000$ & $\$ 480,000$ \\
\hline Ash Mitigation Cost & $\$ / y r$ & $\$ 285,420$ & $\$ 1,623,273$ & $\$ 3,096,680$ \\
\hline AEA Cost & $\$ / y r$ & $\$ 0$ & $\$ 1,052,433$ & $\$ 0$ \\
\hline Surfactant Cost & $\$ / y r$ & $\$ 0$ & $\$ 0$ & $\$ 2,525,840$ \\
\hline Lost Ash Sales + Landfill Cost & $\$ / y r$ & $\$ 285,420$ & $\$ 570,840$ & $\$ 570,840$ \\
\hline
\end{tabular}

Table 3-47 calculates the cost of the ACI process in units of $\$ / 1 b$ mercury removed.

Table 3-47. Cost of Implementing ACl for Mercury Control, in Terms of $\$ / \mathrm{lb} \mathbf{~ H g}$ Removed, Based on 2007 Data

\begin{tabular}{|l|c|c|c|c|}
\hline Targeted \% Hg Reduction at ESP Outlet & $\mathbf{\%}$ & $\mathbf{5 0 \%}$ & $\mathbf{7 0 \%}$ & $\mathbf{9 0 \%}$ \\
\hline Hg removed by ACI across ESP & $\mathrm{lb} / \mathrm{yr}$ & 288 & 403 & 518 \\
\hline \$/lb Hg removed by ACI (ESP only) & $\mathbf{\$ l l b}$ & $\mathbf{\$ 4 , 3 0 0}$ & $\mathbf{\$ 8 , 0 7 8}$ & $\mathbf{\$ 1 2 , 4 2 3}$ \\
\hline
\end{tabular}




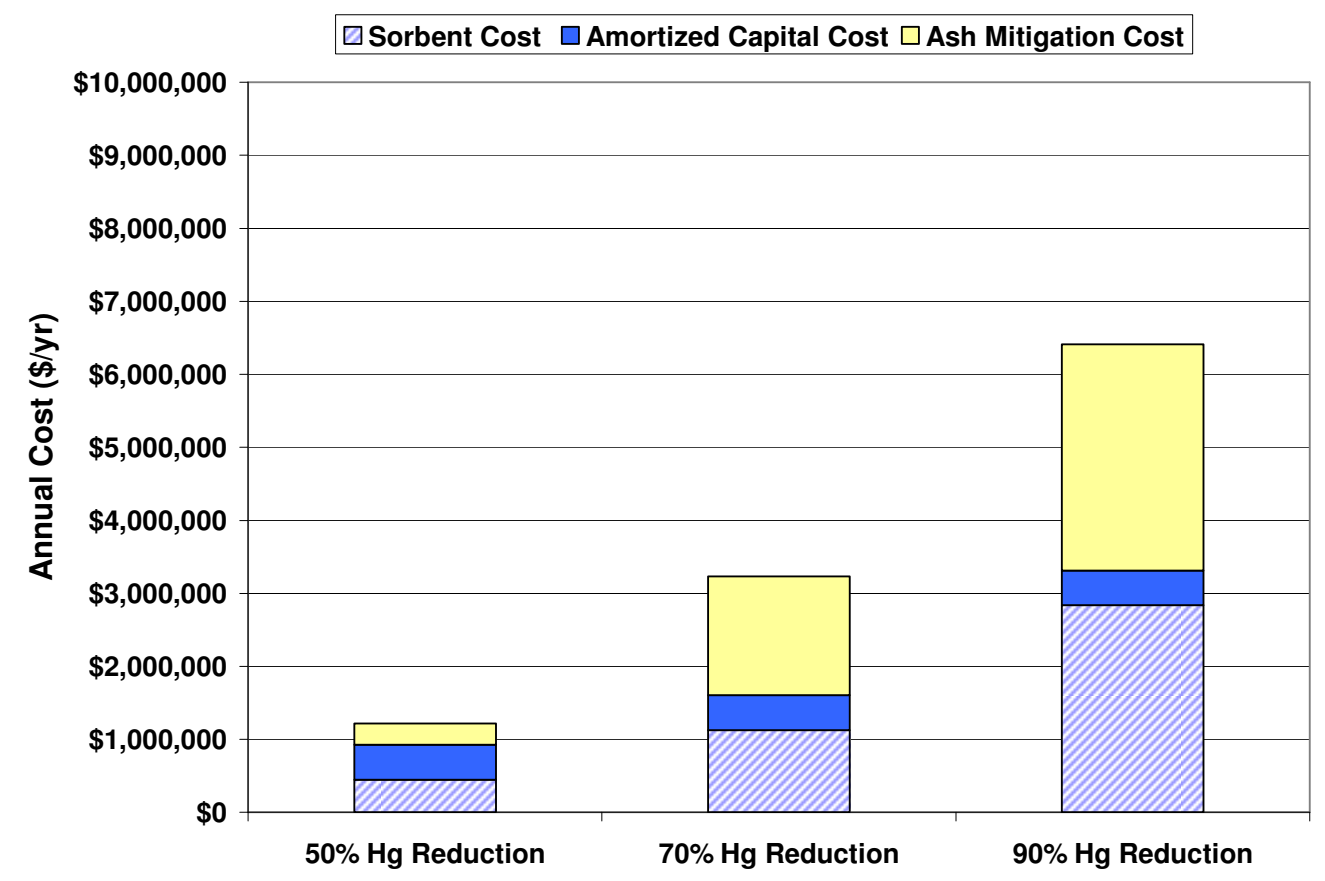

Figure 3-33. Total Annual Cost of ACl for Three Different Levels of Mercury Removal at ESP Outlet While Maintaining Fly Ash Sales

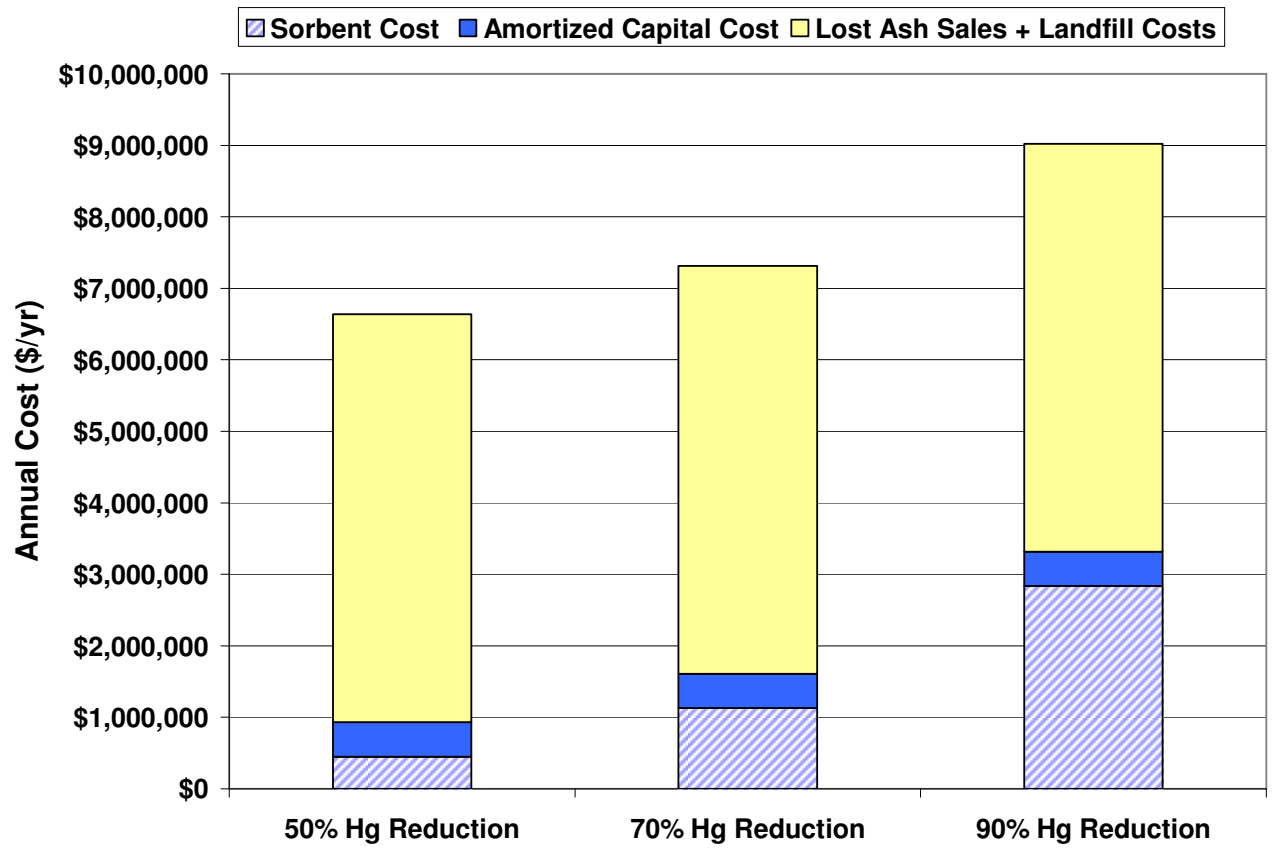

Figure 3-34. Total Annual Cost of ACl for Three Different Levels of Mercury Removal at ESP Outlet with the Loss of Fly Ash Sales 
Phase I-III testing at LMS showed that ACI resulted in mercury removal across the ESP and increased mercury oxidation at the ESP outlet. Both $\mathrm{OH}$ and SCEM data indicated that baseline mercury oxidation at the ESP outlet was approximately $50 \%$ while during the long-term injection of $2 \mathrm{lb} / \mathrm{Macf}$ of activated carbon, the average mercury oxidation at the ESP outlet was $81 \%$. Short-term parametric tests conducted several months earlier at LMS indicated that similarly high levels of mercury oxidation were obtained with only $0.5 \mathrm{lb} / \mathrm{Macf}$. Oxidized mercury in the flue gas at this location would be expected to be removed across the wet FGD system. Thus, the process economics described above, which only consider mercury removal across up to the ESP outlet, would improve when considering FGD mercury removal. See Section 3.5 for a discussion of theoretical calculations of oxidized mercury removal across the FGD.

In 2009 flue gas mercury measurements were made across the entire LMS unit including the FGD during ACI. The 2009 results indicated lower levels of mercury removal than the $90+\%$ mercury removal predicted from the theoretical calculations using the 2007 SCEM data. Therefore, economic analysis of ACI for the combined ESP/FGD system was performed for only the 2009 data (see Chapter 4), since the 2007 data were based on theoretical calculations of removal across the FGD, rather than measurements. 


\subsection{RESULTS AND DISCUSSION - PHASE IV (2009)}

This section presents the results from Phase IV parametric testing conducted on Unit 2 in 2009. Three approaches to minimizing ash impacts of ACI were tested: (1) injection of "low ash impact" sorbents, (2) alterations to the injection configuration and injection lance design, and (3) injection of calcium bromide in conjunction with sorbent injection. The primary goal was to identify the conditions that result in the highest mercury removal across the AH/ESP/FGD system while maintaining the sorbent injection at a rate that has minimal impact on fly ash properties and potential for beneficial use.

The discussion of the test results is organized into the following sections:

- Unit operation;

- Baseline - flue gas mercury measurements;

- Parametric testing - flue gas mercury measurements;

- Effects of sorbent injection on concrete properties;

- Characterization of coal, fly ash and FGD absorber slurry;

- Trace metals measurements;

- In-line particle size measurements of sorbents;

- ESP outlet particulate emissions.

Testing in 2006-2007 at LMS demonstrated spatial variability of mercury concentration within each duct and between ducts at the ESP outlet. This made it difficult to accurately quantify the effectiveness of mercury controls for the entire system. Therefore, for the 2009 test program, the entire unit was treated so that stack mercury concentrations could be used to characterize performance. The flue gas at the stack should be better mixed after passing through the FGD scrubber.

In the 2009 program, several flue gas mercury measurement methods were used to better characterize the spatial variability of mercury measurements at the ESP outlet. SCEM measurements at the ESP outlet were made in the $2 \mathrm{C} 2$ duct, sorbent trap measurements were made in the 2C1 duct, limited $\mathrm{OH}$ and Method 29 measurements were made in the 2D1 duct, and limited XFM measurements were made in the 2D2 duct. The SCEM, sorbent trap, M29 and XFM methods each measured mercury concentrations at a single point in their respective ducts, allowing for an evaluation of concentration changes over time at a single point. Each $\mathrm{OH}$ method measurement consisted of a three-port, multi-point traverse, providing an indication of average mercury concentration within the duct.

Because the SCEM method measured semi-continuously and operated at all three sampling locations throughout the test program, including overnight periods, it was the primary source of data used to characterize system performance. Data from the other methods used at the ESP outlet and stack are presented to show the range of mercury concentrations and removal percentages obtained at different locations downstream of the same ESP rather than to verify the 
SCEM results. In the case of the bromide addition tests, SCEMs operating upstream of the FGD system have historically demonstrated a low bias as has the $\mathrm{OH}$ method. Therefore in this instance, sorbent trap data were used as the primary characterization of system performance.

All mercury and trace metals data presented in this chapter are in units of $\mu \mathrm{g} / \mathrm{dNm}^{3}$ at $3 \% \mathrm{O}_{2}$, except as explicitly noted in text and figures. Concentrations listed as $\mu \mathrm{g} / \mathrm{dNm}^{3}$ should be assumed to be at $3 \% \mathrm{O}_{2}$, unless stated otherwise.

\subsection{Unit Operation}

Table 4-1 shows Unit 2 boiler load for each phase of the Phase IV parametric test periods. The minimum and average values shown include process dips and minor upsets, but do not include overnight periods during which no sorbent testing was conducted. For the Phase IV test program Unit 2 operated near its maximum load rating of $913 \mathrm{MW}$. Average air heater outlet duct temperatures for the Phase IV program were within $\pm 4^{\circ} \mathrm{F}$ of the average temperature $\left(310^{\circ} \mathrm{F}\right)$ of the 2007 long-term injection test (Table 4-2).

Detailed data for all process parameters for Unit 2 are provided in Appendix $\mathbf{J}$

Table 4-1. Gross Load during Phase IV Sorbent Injection Tests

\begin{tabular}{||c|c|c|c|c|c||}
\hline Test Block & Date Start & Date Stop & $\begin{array}{c}\text { Boiler Load } \\
\text { Minimum } \\
(\mathrm{MW})\end{array}$ & $\begin{array}{c}\text { Boiler Load } \\
\text { Maximum } \\
(\mathrm{MW})\end{array}$ & $\begin{array}{c}\text { Boiler Load } \\
\text { Average } \\
(\mathrm{MW})\end{array}$ \\
\hline $\begin{array}{c}\text { AH Injection } \\
- \text { Full Unit }\end{array}$ & $06 / 13 / 09$ & $06 / 28 / 09$ & 715 & 921 & 894 \\
\hline $\begin{array}{c}\text { ESP Injection } \\
- \text { Full Unit }\end{array}$ & $07 / 8 / 09$ & $07 / 16 / 09$ & 771 & 917 & 895 \\
\hline $\begin{array}{c}\text { ESP Injection } \\
-1 / 4 \text { Unit }\end{array}$ & $07 / 18 / 09$ & $07 / 30 / 09$ & 845 & 919 & 906 \\
\hline
\end{tabular}

Table 4-2. Flue Gas Temperatures during Phase IV Sorbent Injection Tests

\begin{tabular}{||c|c|c|c|c|c|c||}
\hline Test Type & Unit/AH* & Date Start & Date Stop & $\begin{array}{c}\text { AH Outlet } \\
\text { Temperature } \\
\text { Minimum } \\
\left({ }^{\circ} \mathrm{F}\right)\end{array}$ & $\begin{array}{c}\text { AH Outlet } \\
\text { Temperature } \\
\text { Maximum } \\
\left({ }^{\circ} \mathrm{F}\right)\end{array}$ & $\begin{array}{c}\text { AH Outlet } \\
\text { Temperature } \\
\text { Average } \\
\left({ }^{\circ} \mathrm{F}\right)\end{array}$ \\
\hline \hline Phase I & $1-\mathrm{A}$ & $11 / 28 / 06$ & $12 / 11 / 06$ & 242 & 308 & 288 \\
\hline Phase II & $1-\mathrm{A}$ & $04 / 26 / 07$ & $05 / 04 / 07$ & 280 & 319 & 300 \\
\hline Phase III & $1-\mathrm{A}$ & $05 / 22 / 07$ & $05 / 26 / 07$ & 287 & 318 & 302 \\
\hline Long Term & $1-\mathrm{A}$ & $06 / 19 / 07^{1}$ & $08 / 22 / 07^{1}$ & 217 & 341 & 310 \\
\hline $\begin{array}{c}\text { AH Injection - } \\
\text { Full Unit }\end{array}$ & $2-\mathrm{B}$ & $06 / 13 / 09$ & $06 / 28 / 09$ & 287 & 334 & 314 \\
\hline $\begin{array}{c}\text { ESP Injection } \\
- \text { Full Unit }\end{array}$ & $2-\mathrm{B}$ & $07 / 8 / 09$ & $07 / 16 / 09$ & 285 & 322 & 308 \\
\hline $\begin{array}{c}\text { ESP Injection } \\
-1 / 4 \text { Unit }\end{array}$ & $2-\mathrm{B}$ & $07 / 18 / 09$ & $07 / 30 / 09$ & 291 & 319 & 307 \\
\hline
\end{tabular}

*AH outlet duct 1-A feeds ESP 1-A and ESP 1-B. AH outlet duct 2-B feeds ESP 2-C and ESP 2-D. 
Velocity traverses were conducted at the following flue gas duct locations: ESP inlet at 2D1, ESP outlet at 2D1, ESP outlet at 2C1, and the stack. Refer to Figure 2-3 for a drawing of the duct configuration and locations for these ports. At full load, flue gas temperatures ranged from 329$346^{\circ} \mathrm{F}$ at the ESP inlet 2D1 and $323-341^{\circ} \mathrm{F}$ at ESP outlet 2D1. Velocity traverse results are listed in Appendix D along with the velocity traverse results from previous test phases.

\subsection{Baseline - Flue Gas Mercury Measurements}

Baseline flue gas mercury concentrations were measured prior to the start of the Phase IV parametric tests, from 8:00 on June 11, 2009 through 10:00 on June 13, 2009. Additional complete days of baseline measurements were made on June 21, July 7, and July 13. During these baseline periods and throughout this test program, mercury concentrations were measured at the AH inlet using a SCEM and at both the ESP outlet and stack using SCEM, sorbent traps, Method 29, and XFM. In addition, OH measurements were performed at the ESP outlet on one baseline day.

\section{Baseline Mercury Measurements - SCEM}

Table 4-3 presents the average total and elemental mercury concentrations as measured by SCEM at all three locations on each baseline testing day. The AH inlet total vapor phase mercury concentration ranged from 15 to $27 \mu \mathrm{g} / \mathrm{dNm}^{3}$ at $3 \% \mathrm{O}_{2}$ throughout baseline testing. The ESP outlet total vapor phase mercury concentration ranged from 15 to $25 \mu \mathrm{g} / \mathrm{dNm}^{3}$. The stack total vapor phase mercury concentration ranged from 10 to $16 \mu \mathrm{g} / \mathrm{dNm}^{3}$.

Based on the average data for each baseline day, less than $15 \%$ of the $\mathrm{AH}$ inlet vapor-phase mercury was present as oxidized mercury, while $40-50 \%$ of the ESP outlet vapor-phase mercury was oxidized, indicating that a significant amount of mercury oxidation occurred across the AH/ESP. The average baseline removal of vapor-phase mercury across the AH/ESP, calculated for each baseline day, ranged from -16 to $20 \%$. The average baseline removal across the combined AH/ESP/FGD system ranged from $14 \%$ to $45 \%$ based on SCEM measurements at the stack. The average percentage of flue gas bypassing the FGD system was approximately $15 \%$ during the baseline test period. The FGD outlet elemental and oxidized mercury concentrations were estimated based on the bypass percentage, ESP outlet and stack mercury concentrations. The percent of ESP outlet oxidized mercury re-emitted from the FGD during baseline ranged from $-25 \%$ to $17 \%$.

Baseline measurements were also made during the overnight periods between daily parametric sorbent injection tests. The purpose of these measurements was to verify that the unit had returned to baseline operation prior to starting the injection tests for each day. Data from these overnight periods are not presented in Table 4-3 because the Unit 2 load was often unsteady during these overnight periods; however, they are presented in the daily SCEM data plots in Appendix K. 
Table 4-3. Baseline, Phase IV: SCEM Measurements and Removals

\begin{tabular}{|c|c|c|c|c|c|c|c|c|c|c|c|}
\hline \multirow[b]{2}{*}{$\begin{array}{l}\text { Condition } \\
\text { Start Time }\end{array}$} & \multirow[b]{2}{*}{$\begin{array}{l}\text { Condition End } \\
\text { Time }\end{array}$} & \multicolumn{3}{|c|}{$\begin{array}{c}\text { Avg. AH Inlet } \mathrm{Hg} \\
\text { Concentration }\left(\mu \mathrm{g} / \mathrm{dNm}^{3}\right)\end{array}$} & \multicolumn{3}{|c|}{$\begin{array}{c}\text { Avg. ESP Outlet } \mathrm{Hg} \\
\text { Concentration }\left(\mu \mathrm{g} / \mathrm{dNm}^{3}\right)\end{array}$} & \multirow{2}{*}{$\begin{array}{c}\% \\
\text { Removal } \\
\text { Across } \\
\text { AH/ESP }\end{array}$} & \multirow{2}{*}{$\begin{array}{c}\text { Avg. } \\
\text { Measured } \\
\begin{array}{c}\text { Stack Hg } \\
\text { Concentration } \\
\left(\mu \mathrm{g} / \mathrm{dNm}^{3}\right)\end{array} \\
\text { Total } \mathrm{Hg}\end{array}$} & \multirow{2}{*}{$\begin{array}{c}\% \\
\text { Removal } \\
\text { Across } \\
\text { System } \\
\text { (AH vs. } \\
\text { Stack) }\end{array}$} & \multirow[b]{2}{*}{$\begin{array}{c}\text { FGD } \\
\text { Bypass } \%\end{array}$} \\
\hline & & $\begin{array}{c}\text { Total } \\
\mathrm{Hg}\end{array}$ & $\begin{array}{c}\text { Elem. } \\
\mathrm{Hg}\end{array}$ & $\%$ Oxid. & $\begin{array}{c}\text { Total } \\
\mathrm{Hg}\end{array}$ & $\begin{array}{c}\text { Elem. } \\
\mathrm{Hg}\end{array}$ & $\%$ Oxid. & & & & \\
\hline 6/11/09 8:00 & $6 / 11 / 09$ 20:00 & 21.7 & 20.3 & $6 \%$ & 17.3 & 8.3 & $52 \%$ & $20 \%$ & 12.2 & $44 \%$ & $14 \%$ \\
\hline $6 / 12 / 098: 00$ & 6/12/09 20:00 & 21.6 & 19.4 & $10 \%$ & 19.1 & 10.4 & $46 \%$ & $12 \%$ & 16.2 & $25 \%$ & $13 \%$ \\
\hline $6 / 21 / 09$ 8:00 & $6 / 21 / 09$ 21:00 & 16.8 & 14.8 & $12 \%$ & 19.5 & 11.4 & $42 \%$ & $-16 \%$ & 14.4 & $14 \%$ & $15 \%$ \\
\hline 7/7/09 8:00 & 7/7/09 20:00 & 18.0 & 17.5 & $3 \%$ & 20.5 & 10.6 & $48 \%$ & $-14 \%$ & 14.1 & $22 \%$ & $15 \%$ \\
\hline 7/13/09 8:00 & 7/13/09 20:00 & 24.6 & 21.2 & $14 \%$ & 22.7 & 8.3 & $64 \%$ & $8 \%$ & 13.5 & $45 \%$ & $15 \%$ \\
\hline
\end{tabular}




\section{Baseline Mercury Measurements - Alternate Methods}

Table 4-4 summarizes the mercury concentrations measured by $\mathrm{OH}$ at the ESP outlet during a single baseline test day. The mercury oxidation percentages measured at the ESP outlet using both SCEMs and $\mathrm{OH}$ were similar, nearly $50 \%$. The average baseline total vapor-phase mercury concentration measured by $\mathrm{OH}$ was $31 \mu \mathrm{g} / \mathrm{dNm}^{3}$ at $3 \% \mathrm{O}_{2}$ which was $40-60 \%$ higher than the total mercury measurements obtained with SCEMs at both the AH inlet and ESP outlet 2C2. This degree of duct-to-duct variability in total mercury concentration, but consistency in mercury oxidation, was also observed with $\mathrm{OH}$ and SCEM measurements on Unit 1 in 2007.

Table 4-4. Baseline, Phase IV: OH vs. SCEM Measurements at the ESP Outlet

\begin{tabular}{|c|c|c|c|c|c|c|c|c|c|c|c|}
\hline \multirow{2}{*}{ 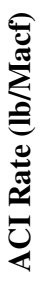 } & \multirow{2}{*}{ 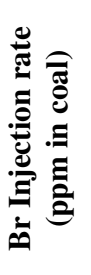 } & \multirow[b]{2}{*}{$\begin{array}{l}\text { Date } \\
\text { in } \\
2009\end{array}$} & \multicolumn{2}{|c|}{$\begin{array}{c}\text { Averaging } \\
\text { Period }\end{array}$} & \multirow{2}{*}{$\begin{array}{c}\text { AH Inlet } \\
\text { SCEM } \\
\begin{array}{l}\text { Total Hg } \\
\left(\mu \mathrm{g} / \mathrm{Nm}^{3}\right)\end{array}\end{array}$} & \multicolumn{3}{|c|}{$\begin{array}{c}\text { ESP Outlet 2D1 } \\
\text { OH }\end{array}$} & \multicolumn{3}{|c|}{$\begin{array}{c}\text { ESP Outlet 2C2 } \\
\text { SCEM }\end{array}$} \\
\hline & & & $\begin{array}{l}\text { Start } \\
\text { Time }\end{array}$ & $\begin{array}{l}\text { End } \\
\text { Time }\end{array}$ & & $\begin{array}{l}\text { Total Hg } \\
\left(\mu \mathrm{g} / \mathrm{Nm}^{3}\right)\end{array}$ & $\begin{array}{l}\text { Elem. Hg } \\
\left(\mu \mathrm{g} / \mathbf{N m}^{3}\right)\end{array}$ & $\begin{array}{c}\% \\
\text { Oxid }\end{array}$ & $\begin{array}{l}\text { Total Hg } \\
\left(\mu \mathrm{g} / \mathrm{Nm}^{3}\right)\end{array}$ & $\begin{array}{l}\text { Elem. Hg } \\
\left(\mu \mathrm{g} / \mathrm{Nm}^{3}\right)\end{array}$ & $\begin{array}{c}\% \\
\text { Oxid }\end{array}$ \\
\hline $\mathrm{BL}$ & BL & $6 / 12$ & $9: 42$ & $12: 04$ & 23.2 & 29.7 & 14.97 & 50 & 19.6 & 10.2 & 48 \\
\hline BL & BL & $6 / 12$ & $12: 40$ & $14: 50$ & 23.0 & 31.8 & 16.74 & 47 & 18.7 & 10.5 & 44 \\
\hline BL & BL & $6 / 12$ & $15: 16$ & $17: 27$ & 21.4 & 30.5 & 15.73 & 48 & 19.8 & 10.3 & 48 \\
\hline
\end{tabular}

In addition to SCEM and OH, mercury measurements at the ESP outlet were made with sorbent traps in duct 2C1, XFM in duct 2D2, and Method 29 in duct 2D1, as presented in Table 4-5. SCEM concentrations ranged from $15-22 \mu \mathrm{g} / \mathrm{dNm}^{3}$, sorbent traps ranged from $20-25$ $\mu \mathrm{g} / \mathrm{dNm}^{3}$, Method 29 ranged from $18-34 \mu \mathrm{g} / \mathrm{dNm}^{3}$, XFM ranged from $25-27 \mu \mathrm{g} / \mathrm{dNm}^{3}$, and $\mathrm{OH}$ ranged from $30-32 \mu \mathrm{g} / \mathrm{dNm}^{3}$.

Table 4-5 presents the average mercury concentrations and standard deviation for the measurements made during each time period, as well as an overall average and standard deviation for all data collected during baseline operation. The AH inlet concentration averaged $20.2 \mu \mathrm{g} / \mathrm{dNm}^{3}$ and the ESP outlet averaged $21.7 \mu \mathrm{g} / \mathrm{dNm}^{3}$. The overall standard deviation was $20 \%$ of the average value. Tests conducted in 2006-2007 (Phases I-III and Long-Term) also showed appreciable variability from one duct location to another even when measured with the same sampling method, as discussed in Section 3.2 Baseline Hg Measurements.

Total mercury removal across the AH/ESP was calculated in two ways. First, it was calculated using both the SCEM data at the AH inlet and the SCEM data at the ESP outlet. Second, it was calculated using the SCEM data at the AH inlet and the average mercury concentration measurement (of all methods for which data were available) at the ESP outlet. The SCEM data from ESP outlet duct 2C2 indicated an average mercury removal of 5\% across the AH/ESP, while the average of all ESP outlet data indicated -8\% mercury removal across the AH/ESP. 
Table 4-5. Baseline, Phase IV: Mercury Concentrations and Removals Measured at ESP Outlet

\begin{tabular}{|c|c|c|c|c|c|c|c|c|c|c|c|c|c|}
\hline \multicolumn{4}{|c|}{$\begin{array}{c}\text { BASELINE } \\
70 / 30 \mathrm{TxL} / \mathrm{PRB}\end{array}$} & $\mathrm{AH}$ Inlet & \multicolumn{7}{|c|}{$\begin{array}{l}\text { Hg Measurement Method } \\
\text { ESP Outlet Duct \# }\end{array}$} & \multicolumn{2}{|c|}{$\begin{array}{c}\begin{array}{c}\% \text { Removal Across } \\
\text { AH/ESP }\end{array} \\
\end{array}$} \\
\hline \multirow{2}{*}{$\begin{array}{c}\text { Test } \\
\text { Condition }\end{array}$} & \multirow{2}{*}{$\begin{array}{c}\text { Date in } \\
2009\end{array}$} & \multicolumn{2}{|c|}{$\begin{array}{l}\text { Averaging } \\
\text { Period }\end{array}$} & SCEM & $\begin{array}{l}\mathrm{OH} \\
2 \mathrm{D} 1\end{array}$ & $\begin{array}{c}\text { ST } \\
\text { 2C1 }\end{array}$ & $\begin{array}{l}\text { XFM } \\
\text { 2D2 }\end{array}$ & $\begin{array}{l}\text { M29 } \\
\text { 2D1 }\end{array}$ & \begin{tabular}{|c|} 
SCEM \\
2 C2
\end{tabular} & $\mathrm{AVG}^{1}$ & STD DEV ${ }^{1}$ & SCEM & AVG \\
\hline & & Start & End & \multicolumn{8}{|c|}{ Total $\mathrm{Hg}\left(\mu \mathrm{g} / \mathrm{dNm}^{3}\right.$ at $\left.3 \% \mathrm{O}_{2}\right)$} & & \\
\hline Baseline & 11-Jun & $9: 16$ & $17: 16$ & 21.8 & -- & 21.8 & -- & -- & -- & 21.8 & -- & -- & $0 \%$ \\
\hline Baseline & 11-Jun & $17: 42$ & $1: 43$ & 20.3 & -- & 20.3 & -- & -- & 15.5 & 17.9 & 3.4 & $24 \%$ & $12 \%$ \\
\hline Baseline & 12-Jun & $8: 55$ & $16: 55$ & 22.7 & 30.7 & 22.5 & -- & -- & 19.2 & 24.1 & 5.9 & $15 \%$ & $-6 \%$ \\
\hline Baseline & 12-Jun & $17: 24$ & $1: 24$ & 18.4 & -- & 25.4 & -- & -- & 18.4 & 21.9 & 4.9 & $0 \%$ & $-19 \%$ \\
\hline Baseline & 21-Jun & $8: 42$ & $16: 42$ & 16.4 & -- & 22.7 & -- & -- & 19.4 & 21.1 & 2.3 & $-18 \%$ & $-28 \%$ \\
\hline Baseline & 21-Jun & $17: 31$ & $1: 31$ & 18.2 & -- & 23.5 & -- & -- & 18.7 & 21.1 & 3.4 & $-3 \%$ & $-16 \%$ \\
\hline Baseline & 13-Jul & $7: 55$ & $10: 55$ & 23.0 & -- & 24.4 & 27.0 & 18.2 & 21.6 & 22.8 & 3.8 & $6 \%$ & $1 \%$ \\
\hline Baseline & 13-Jul & $10: 32$ & $12: 32$ & 24.3 & -- & -- & 25.6 & 27.0 & 19.9 & 24.2 & 3.8 & $18 \%$ & $1 \%$ \\
\hline Baseline & 13-Jul & 13:04 & 15:04 & 25.7 & -- & -- & 24.5 & 33.7 & 21.6 & 26.6 & 6.3 & $16 \%$ & $-4 \%$ \\
\hline \multicolumn{4}{|c|}{ Baseline AVERAGE } & 20.2 & 30.7 & 22.8 & 25.9 & 25.1 & 18.7 & 21.7 & 4.1 & $5 \%$ & $-8 \%$ \\
\hline
\end{tabular}

${ }^{1}$ Average and standard deviations calculated for all measurement methods for which mercury concentration data available at ESP outlet.

${ }^{2}$ Mercury removals calculated by comparing the AH inlet SCEM data to (a) ESP outlet SCEM and (b) average ESP outlet Hg concentratior

Table 4-6 presents mercury concentrations measured at the stack by the various methods, along with averages, standard deviations, and percent removals. Stack SCEM mercury concentrations ranged from $12-16 \mu \mathrm{g} / \mathrm{dNm}^{3}$, sorbent traps ranged from $15-19 \mu \mathrm{g} / \mathrm{dNm}^{3}$, Method 29 ranged from $14-21 \mu \mathrm{g} / \mathrm{dNm}^{3}$, and XFM ranged from $17-18 \mu \mathrm{g} / \mathrm{dNm}^{3}$. The time-weighted average of all baseline mercury concentration data at the stack was $15.5 \mu \mathrm{g} / \mathrm{dNm}^{3}$. Stack mercury measurements were somewhat less variable than the ESP outlet measurements; the overall standard deviation was $15 \%$ of the average value. The trends in data variability at the stack were similar to those observed at the ESP outlet, with the SCEMs measuring the lowest concentrations, Method 29 providing the widest range of results, XFM showing the tightest range of concentrations, and sorbent trap mercury concentrations falling in the middle of all measured values.

The total mercury removal across the Unit 2 gas path (i.e., AH inlet vs. stack) was calculated with both the stack SCEM data and the average stack data. The SCEM data indicated an average $28 \%$ system mercury removal, while the average of all stack data indicated $22 \%$ system mercury removal. 
Table 4-6. Baseline, Phase IV: Mercury Concentrations and Removals Measured at Stack

\begin{tabular}{|c|c|c|c|c|c|c|c|c|c|c|c|c|}
\hline \multicolumn{4}{|c|}{$\begin{array}{c}\text { BASELINE } \\
70 / 30 \text { TxL/PRB }\end{array}$} & \multirow{2}{*}{$\begin{array}{c}\text { AH Inlet } \\
\text { SCEM }\end{array}$} & \multicolumn{6}{|c|}{ Hg Measurement Method used at Stack } & \multicolumn{2}{|c|}{$\begin{array}{c}\% \text { Removal } \\
(\text { AH Inlet vs. Stack })^{2}\end{array}$} \\
\hline \multirow{2}{*}{$\begin{array}{c}\text { Test } \\
\text { Condition }\end{array}$} & \multirow{2}{*}{$\begin{array}{c}\text { Date in } \\
2009\end{array}$} & \multicolumn{2}{|c|}{$\begin{array}{l}\text { Averaging } \\
\text { Period }\end{array}$} & & $\begin{array}{c}\text { Sorbent } \\
\text { Traps }\end{array}$ & XFM & M29 & SCEM & $\mathrm{AVG}^{1}$ & STD DEV ${ }^{1}$ & \multirow[t]{2}{*}{ SCEM } & \multirow[t]{2}{*}{ AVG } \\
\hline & & Start & End & \multicolumn{7}{|c|}{ Total $\mathrm{Hg}\left(\mu \mathrm{g} / \mathrm{dNm}^{3}\right.$ at $\left.3 \% \mathrm{O}_{2}\right)$} & & \\
\hline Baseline & 11-Jun & $9: 16$ & $17: 16$ & 21.8 & 15.2 & -- & -- & 12.0 & 13.6 & 2.3 & $45 \%$ & $38 \%$ \\
\hline Baseline & 11-Jun & $17: 31$ & $1: 31$ & 20.3 & 14.7 & -- & -- & 11.9 & 13.3 & 2.0 & $41 \%$ & $34 \%$ \\
\hline Baseline & 12-Jun & $8: 10$ & $16: 04$ & 22.7 & 18.2 & -- & -- & 16.2 & 17.2 & 1.4 & $29 \%$ & $24 \%$ \\
\hline Baseline & 12-Jun & $16: 22$ & $0: 22$ & 18.4 & 19.3 & -- & -- & 16.0 & 17.7 & 2.3 & $13 \%$ & $4 \%$ \\
\hline Baseline & 21-Jun & $9: 48$ & $17: 48$ & 16.4 & 15.1 & -- & -- & 14.5 & 14.8 & 0.4 & $12 \%$ & $10 \%$ \\
\hline Baseline & 21-Jun & $18: 52$ & $2: 53$ & 18.2 & 17.0 & -- & -- & 15.0 & 16.0 & 1.4 & $18 \%$ & $12 \%$ \\
\hline Baseline & 13-Jul & 7:45 & 9:45 & 22.3 & 17.1 & 18.4 & 15.5 & 13.2 & 16.1 & 2.2 & $41 \%$ & $28 \%$ \\
\hline Baseline & 13-Jul & $10: 33$ & $12: 33$ & 24.3 & -- & 17.3 & 14.2 & 13.1 & 14.9 & 2.2 & $46 \%$ & $39 \%$ \\
\hline Baseline & 13-Jul & 13:04 & $15: 04$ & 25.7 & 16.9 & 18.0 & 21.4 & 12.6 & 17.2 & 3.6 & $51 \%$ & $33 \%$ \\
\hline \multicolumn{4}{|c|}{ Baseline AVERAGE } & 20.1 & 16.6 & 17.9 & 17.0 & 14.1 & 15.5 & 1.8 & $28 \%$ & $22 \%$ \\
\hline
\end{tabular}

${ }^{1}$ Average and standard deviations calculated for all measurement methods for which mercury concentration data available at stack.

${ }^{2} \mathrm{Hg}$ removals calculated by comparing the AH inlet SCEM data to (a) stack SCEM and (b) average stack Hg concentration.

\section{Baseline Mercury Measurements - Summary}

Throughout the Phase IV baseline testing, the following observations were made:

- Baseline SCEM measurements of AH inlet total vapor phase mercury concentrations ranged from 15 to $27 \mu \mathrm{g} / \mathrm{dNm}^{3}$ at $3 \% \mathrm{O}_{2}$, with an average of $20 \mu \mathrm{g} / \mathrm{dNm}^{3}$. AH inlet vapor-phase mercury was present as 3 to $14 \%$ oxidized mercury during baseline testing.

- ESP outlet total vapor phase mercury concentrations measured ranged from 15 to 32 $\mu \mathrm{g} / \mathrm{dNm}^{3}$, and averaged approximately $22 \mu \mathrm{g} / \mathrm{dNm}^{3}$. Flue gas mercury concentration results showed appreciable variability based on the ducts sampled and measurement methods used. SCEM data were at the low end of the measurements obtained and sorbent trap data fell in the middle of the measured range.

- While total $\mathrm{Hg}$ concentrations in ducts $2 \mathrm{C} 2$ and 2D1 were significantly different (as measured by SCEM and $\mathrm{OH}$, respectively), the baseline mercury oxidation measured in both locations were very similar during the $\mathrm{OH}$ test periods, ranging from 40 to $50 \%$.

- The stack total vapor phase mercury concentration ranged from 12 to $18 \mu \mathrm{g} / \mathrm{dNm}^{3}$. XFM and Method 29 data were typically higher than the SCEM and sorbent trap measurements.

- The average baseline removal of vapor-phase mercury across the AH/ESP was -8\% and the average AH/ESP/FGD system removal was $22 \%$, with an average of $13-$ $15 \%$ of the flue gas bypassing the scrubber. 


\subsection{Parametric Sorbent Injection Mercury Removal}

\section{ACI Upstream of the $\mathrm{AH}$}

Tests were conducted in Phase IV to evaluate the mercury removal performance of Darco Hg-LH and four low-ash impact sorbents injected upstream of the AH. Previous testing at LMS evaluated sorbent injection upstream of the ESP. In Phase IV, the injection location was moved upstream of the $\mathrm{AH}$ in an attempt to improve mercury removal by providing additional mixing and duct residence time. During ACI at the AH inlet, flue gas mercury concentrations were measured with SCEMs at the AH inlet, ESP outlet, and stack and with sorbent traps at the ESP outlet and stack. ACI tests were conducted with the normal fuel blend (70/30 TxL/PRB) and an alternate fuel blend (55/45 TxL/PRB).

\section{Normal Fuel Blend (70/30 TxL/PRB)}

ACI upstream of the AH was tested while Unit 2 fired its normal fuel blend of 70/30 TxL/PRB. Four low-ash impact carbons were tested at a single injection rate with each test lasting three to nine hours; Darco Hg-LH was tested at three injection rates, each lasting 48 hours.

Table 4-7 shows average SCEM mercury concentrations measured during each sorbent injection test. Each datum point in Table 4-7 represents the calculated average removal once steady-state ESP outlet concentrations were achieved for each test. While the Darco Hg-LH tests lasted 48 hours, the datum points in Table 4-7 represent averages during day-time operation (generally the 12 hour period between 8 am and $8 \mathrm{pm}$ ). Measurements collected overnight were excluded from these averages because of fluctuations in unit load during these periods.

Tables 4-8 and 4-9 compare the SCEM measurements to $\mathrm{OH}$ and sorbent trap measurements for the ESP outlet and stack, respectively. Figure 4-1 compares the calculated mercury removals using the sorbent trap and SCEM data across the AH/ESP and across the system. While the removals calculated from the two measurement methods did not agree (as evidenced by data not falling along 1:1 line), there was a consistent correlation, indicating that both measurement methods show the same trends in mercury removal, if not the same values. Almost all datum points fell below the 1:1 line, indicating that mercury removal measured by the sorbent trap measurements was lower than that measured by the SCEM. The sorbent trap and SCEM removals were in closer agreement and were correlated more predictably at the stack than at the ESP outlet. 
Table 4-7. ACI Upstream of AH: SCEM Measurements and Mercury Removals

\begin{tabular}{|c|c|c|c|c|c|c|c|c|c|c|c|c|c|}
\hline \multirow[b]{2}{*}{$\begin{array}{c}\text { Condition } \\
\text { Start Time } \\
\end{array}$} & \multirow[b]{2}{*}{$\begin{array}{l}\text { Condition } \\
\text { End Time }\end{array}$} & \multirow[b]{2}{*}{ Sorbent Type } & \multirow[b]{2}{*}{$\begin{array}{c}\text { Injection } \\
\text { Rate } \\
\text { (lb/Macf) }\end{array}$} & \multicolumn{3}{|c|}{$\begin{array}{c}\text { Avg. AH Inlet Hg } \\
\text { Concentrations } \\
\left(\mu \mathrm{g} / \mathrm{dNm}^{3}\right)\end{array}$} & \multicolumn{3}{|c|}{$\begin{array}{c}\text { Avg. ESP Outlet Hg } \\
\text { Concentrations } \\
\left(\mu \mathrm{g} / \mathrm{dNm}^{3}\right)\end{array}$} & \multirow{2}{*}{$\begin{array}{c}\% \\
\text { Removal } \\
\text { Across } \\
\text { AH/ESP }\end{array}$} & \multirow{2}{*}{$\begin{array}{c}\begin{array}{c}\text { Avg. Stack } \\
\text { Hg }\end{array} \\
\text { Concentratio } \\
\text { ns }\left(\mu \mathrm{g} / \mathrm{dNm}^{3}\right) \\
\\
\text { Total Hg } \\
\end{array}$} & \multirow{2}{*}{$\begin{array}{c}\% \\
\text { Removal } \\
\text { Across } \\
\text { System } \\
\text { (AH } \\
\text { Inlet vs. } \\
\text { Stack) } \\
\end{array}$} & \multirow[b]{2}{*}{$\begin{array}{c}\text { FGD } \\
\text { Bypass } \\
\%\end{array}$} \\
\hline & & & & $\begin{array}{c}\text { Total } \\
\text { Hg }\end{array}$ & $\begin{array}{c}\text { Elem. } \\
\text { Hg }\end{array}$ & $\begin{array}{c}\% \\
\text { Oxid. }\end{array}$ & $\begin{array}{c}\text { Total } \\
\text { Hg }\end{array}$ & $\begin{array}{c}\text { Elem. } \\
\text { Hg }\end{array}$ & $\begin{array}{c}\% \\
\text { Oxid. }\end{array}$ & & & & \\
\hline 6/13/09 11:45 & 6/13/09 20:00 & Darco Hg-LH & 1.89 & 18.4 & 18.9 & $-3 \%$ & 11.2 & 3.6 & $68 \%$ & $39 \%$ & 6.5 & $65 \%$ & $13 \%$ \\
\hline $6 / 14 / 09$ 8:00 & 6/14/09 20:00 & Darco Hg-LH & 1.89 & 23.1 & 22.0 & $5 \%$ & 12.6 & 3.6 & $71 \%$ & $45 \%$ & 4.8 & $79 \%$ & $11 \%$ \\
\hline $6 / 15 / 09$ 8:00 & $6 / 15 / 0920: 00$ & Darco Hg-LH & 0.48 & 21.6 & 20.3 & $6 \%$ & 15.9 & 5.0 & $69 \%$ & $26 \%$ & 8.1 & $62 \%$ & $10 \%$ \\
\hline $6 / 16 / 09$ 8:00 & $6 / 16 / 09$ 20:00 & Darco Hg-LH & 0.48 & 16.5 & 15.1 & $8 \%$ & 12.8 & 4.3 & $66 \%$ & $22 \%$ & 6.5 & $61 \%$ & $11 \%$ \\
\hline 6/17/09 3:00 & 6/17/09 20:00 & Darco Hg-LH & 0.99 & 18.5 & 17.7 & $4 \%$ & 8.6 & 4.7 & $45 \%$ & $54 \%$ & 5.0 & $73 \%$ & $13 \%$ \\
\hline 6/18/09 8:00 & 6/18/09 20:00 & Darco Hg-LH & 0.99 & 15.7 & 16.8 & $-7 \%$ & 12.7 & 5.4 & $58 \%$ & $19 \%$ & 6.1 & $61 \%$ & $14 \%$ \\
\hline 6/22/09 13:00 & $6 / 22 / 0921: 30$ & C-PAC & 0.96 & 17.7 & 15.8 & $11 \%$ & 10.4 & 6.0 & $42 \%$ & $42 \%$ & 8.0 & $55 \%$ & $12 \%$ \\
\hline $6 / 23 / 0913: 30$ & $6 / 23 / 09$ 19:30 & CF Plus & 0.95 & 23.7 & 17.3 & $27 \%$ & 7.0 & 2.3 & $67 \%$ & $70 \%$ & 4.9 & $79 \%$ & $15 \%$ \\
\hline $6 / 24 / 09$ 12:00 & $6 / 24 / 09$ 19:00 & EXP224 & 0.95 & 17.0 & 17.7 & $-4 \%$ & 15.3 & 6.1 & $60 \%$ & $10 \%$ & 6.7 & $61 \%$ & $12 \%$ \\
\hline $6 / 25 / 09$ 15:00 & $6 / 25 / 0918: 00$ & CF Plus Ultra & 0.98 & 18.1 & 18.0 & $0 \%$ & 7.8 & 3.4 & $57 \%$ & $57 \%$ & 6.4 & $64 \%$ & $12 \%$ \\
\hline $6 / 27 / 0912: 30$ & $6 / 27 / 0923: 00$ & Darco Hg-LH* & 1.00 & 14.9 & 13.2 & $11 \%$ & 6.1 & 3.9 & $37 \%$ & $59 \%$ & 3.7 & $75 \%$ & $12 \%$ \\
\hline $6 / 28 / 09$ 8:30 & $6 / 28 / 09$ 16:00 & Darco Hg-LH* & 1.83 & 17.2 & 15.8 & $8 \%$ & 4.8 & 2.8 & $42 \%$ & $72 \%$ & 3.1 & $82 \%$ & $9 \%$ \\
\hline
\end{tabular}

*These measurements were collected during combustion of the alternate 30/70 TxL/PRB fuel blend. 
Table 4-8. ACI Upstream of the AH: Mercury Concentrations and Removals Measured at ESP Outlet

\begin{tabular}{|c|c|c|c|c|c|c|c|c|c|c|c|c|c|}
\hline \multirow{3}{*}{$\frac{\text { ACI Rate }}{\text { (Ib/Macf) }}$} & \multicolumn{4}{|c|}{ AH Inlet ACI 70/30 TxL/PRB } & \multirow{2}{*}{$\begin{array}{c}\text { AH Inlet } \\
\text { SCEM } \\
\end{array}$} & \multicolumn{5}{|c|}{$\mathrm{Hg}$ Measurement Method used at ESP Outlet } & \multicolumn{3}{|c|}{$\%$ Removal Across AH/ESP ${ }^{2}$} \\
\hline & \multirow{2}{*}{$\begin{array}{l}\text { Carbon } \\
\text { Injected }\end{array}$} & \multirow{2}{*}{$\begin{array}{c}\text { Date in } \\
2009\end{array}$} & \multicolumn{2}{|c|}{$\begin{array}{c}\text { Averaging } \\
\text { Period }\end{array}$} & & $\mathrm{OH}$ & $\begin{array}{c}\text { Sorbent } \\
\text { Traps }\end{array}$ & SCEM & $\mathrm{AVG}^{1}$ & STD DEV ${ }^{1}$ & \multirow[t]{2}{*}{$\begin{array}{c}\text { Sorbent } \\
\text { Traps }\end{array}$} & \multirow[t]{2}{*}{ SCEM } & \multirow[t]{2}{*}{ AVG } \\
\hline & & & Start & End & \multicolumn{6}{|c|}{ Total $\mathrm{Hg}\left(\mu \mathrm{g} / \mathrm{dNm}^{3}\right.$ at $\left.3 \% \mathrm{O}_{2}\right)$} & & & \\
\hline 0.48 & Darco Hg-LH & 15-Jun & $8: 53$ & $16: 53$ & 22.6 & -- & 23.1 & 16.8 & 20.0 & 4.5 & $-2 \%$ & $26 \%$ & $12 \%$ \\
\hline 0.48 & Darco Hg-LH & 15-Jun & $18: 00$ & $2: 01$ & 20.1 & -- & 20.1 & 12.6 & 16.4 & 5.3 & $0 \%$ & $37 \%$ & $19 \%$ \\
\hline 0.48 & Darco Hg-LH & 16-Jun & $7: 53$ & $15: 54$ & 17.7 & -- & 15.5 & 11.9 & 13.7 & 2.5 & $12 \%$ & $33 \%$ & $23 \%$ \\
\hline 0.48 & Darco Hg-LH & 16-Jun & $17: 58$ & $22: 58$ & 15.1 & -- & 17.7 & 13.5 & 15.6 & 3.0 & $-17 \%$ & $11 \%$ & $-3 \%$ \\
\hline 0.99 & Darco Hg-LH & 17-Jun & $7: 52$ & $15: 45$ & 19.3 & -- & 12.6 & 8.3 & 10.5 & 3.0 & $35 \%$ & $57 \%$ & $46 \%$ \\
\hline 0.99 & Darco Hg-LH & 17-Jun & $16: 15$ & $0: 15$ & 15.7 & -- & 12.6 & 7.5 & 10.1 & 3.6 & $20 \%$ & $52 \%$ & $36 \%$ \\
\hline 0.99 & Darco Hg-LH & 18-Jun & $7: 53$ & $15: 54$ & 14.9 & 9.8 & 15.8 & 12.7 & 12.8 & 3.0 & $-6 \%$ & $15 \%$ & $14 \%$ \\
\hline 0.99 & Darco Hg-LH & 18-Jun & $16: 22$ & $18: 32$ & 17.3 & 7.1 & -- & 12.3 & 9.7 & 3.7 & $\# N / A$ & $29 \%$ & $44 \%$ \\
\hline 1.89 & Darco Hg-LH & 13-Jun & $10: 52$ & $16: 53$ & 17.2 & -- & 14.8 & 10.2 & 12.5 & 3.3 & $14 \%$ & $41 \%$ & $27 \%$ \\
\hline 1.89 & Darco Hg-LH & 13-Jun & $17: 21$ & $1: 22$ & 21.5 & -- & 13.4 & 11.4 & 12.4 & 1.4 & $38 \%$ & $47 \%$ & $42 \%$ \\
\hline 1.89 & Darco Hg-LH & 14-Jun & $7: 57$ & $15: 07$ & 24.5 & -- & 12.5 & 10.7 & 11.6 & 1.3 & $49 \%$ & $56 \%$ & $53 \%$ \\
\hline 1.89 & Darco Hg-LH & 14-Jun & $15: 25$ & $23: 26$ & 21.0 & -- & -- & 12.9 & 12.9 & -- & \#N/A & $39 \%$ & $39 \%$ \\
\hline 0.96 & C-PAC & 22-Jun & $11: 57$ & $14: 57$ & 16.4 & -- & 13.9 & 10.5 & 12.2 & 2.4 & $15 \%$ & $36 \%$ & $26 \%$ \\
\hline 0.96 & C-PAC & 22-Jun & $15: 44$ & $19: 44$ & 17.5 & -- & 14.9 & 10.3 & 12.6 & 3.3 & $15 \%$ & $41 \%$ & $28 \%$ \\
\hline 0.95 & CF Plus & 23-Jun & $11: 15$ & $15: 15$ & 25.5 & -- & 8.7 & 7.9 & 8.3 & 0.6 & $66 \%$ & $69 \%$ & $67 \%$ \\
\hline 0.95 & CF Plus & 23-Jun & $15: 59$ & $19: 59$ & 21.4 & -- & 10.1 & 7.1 & 8.6 & 2.1 & $53 \%$ & $67 \%$ & $60 \%$ \\
\hline 0.95 & EXP224 & 24-Jun & $10: 42$ & $13: 42$ & 18.9 & -- & 13.8 & 18.4 & 16.1 & 3.3 & $27 \%$ & $3 \%$ & $15 \%$ \\
\hline 0.95 & EXP224 & 24-Jun & $14: 18$ & $16: 18$ & 14.9 & -- & 11.9 & 12.1 & 12.0 & 0.1 & $20 \%$ & $19 \%$ & $19 \%$ \\
\hline
\end{tabular}

${ }_{1}^{1}$ Average and standard deviations calculated for all measurement methods for which mercury concentration data available at ESP outlet.

${ }^{2} \mathrm{Hg}$ removal calculated by comparing the AH Inlet SCEM data to (a) ESP outlet sorbent traps, (b) ESP outlet SCEM , (c) all ESP outlet measurements. 
Table 4-9. ACI Upstream of AH: Mercury Concentrations and Removals Measured at Stack

\begin{tabular}{|c|c|c|c|c|c|c|c|c|c|c|c|c|}
\hline \multicolumn{5}{|c|}{ AH Inlet ACI 70/30 TxL/PRB } & AH Inlet & \multicolumn{4}{|c|}{$\begin{array}{l}\text { Hg Measurement Method used at } \\
\text { Stack }\end{array}$} & \multicolumn{3}{|c|}{$\begin{array}{l}\text { \% Removal } \\
\text { (Inlet vs. Stack) }\end{array}$} \\
\hline \multirow{2}{*}{$\begin{array}{l}\text { ACl Rate } \\
\text { (Ib/Macf) }\end{array}$} & \multirow{2}{*}{$\begin{array}{l}\text { Carbon } \\
\text { Injected }\end{array}$} & \multirow[b]{2}{*}{ Date } & \multicolumn{2}{|c|}{$\begin{array}{l}\text { Averaging } \\
\text { Period }\end{array}$} & SCEM & $\begin{array}{l}\text { Sorbent } \\
\text { Traps }\end{array}$ & SCEM & $\mathrm{AVG}^{1}$ & STD DEV ${ }^{1}$ & \multirow[t]{2}{*}{$\begin{array}{c}\text { Sorbent } \\
\text { Traps }\end{array}$} & \multirow[t]{2}{*}{ SCEM } & \multirow[t]{2}{*}{ AVG } \\
\hline & & & Start & End & \multicolumn{5}{|c|}{ Total $\mathrm{Hg}\left(\mu \mathrm{g} / \mathrm{dNm}^{3}\right.$ at $\left.3 \% \mathrm{O}_{2}\right)$} & & & \\
\hline 0.48 & Darco Hg-LH & 15-Jun & $10: 21$ & $16: 30$ & 22.8 & 9.6 & 8.1 & 8.9 & 1.1 & $58 \%$ & $65 \%$ & $61 \%$ \\
\hline 0.48 & Darco Hg-LH & 15-Jun & $17: 23$ & $1: 24$ & 19.9 & 10.0 & 8.4 & 9.2 & 1.1 & $50 \%$ & $58 \%$ & $54 \%$ \\
\hline 0.48 & Darco Hg-LH & 16-Jun & $9: 12$ & $17: 13$ & 17.1 & 7.9 & 6.5 & 7.2 & 1.0 & $54 \%$ & $62 \%$ & $58 \%$ \\
\hline 0.48 & Darco Hg-LH & 16-Jun & 19:01 & $0: 02$ & 15.0 & 8.0 & 6.9 & 7.5 & 0.8 & $47 \%$ & $54 \%$ & $50 \%$ \\
\hline 0.99 & Darco Hg-LH & 17-Jun & $9: 17$ & $17: 17$ & 19.1 & 6.6 & 5.1 & 5.9 & 1.1 & $65 \%$ & $73 \%$ & $69 \%$ \\
\hline 0.99 & Darco Hg-LH & 17-Jun & 18:06 & $2: 07$ & 15.3 & 5.5 & 4.9 & 5.2 & 0.4 & $64 \%$ & $68 \%$ & $66 \%$ \\
\hline 0.99 & Darco Hg-LH & 18-Jun & $8: 55$ & $16: 55$ & 14.3 & 7.7 & 6.0 & 6.9 & 1.2 & $46 \%$ & $58 \%$ & $52 \%$ \\
\hline 1.89 & Darco Hg-LH & 13-Jun & $11: 39$ & $17: 47$ & 17.2 & 8.0 & 6.5 & 7.3 & 1.1 & $53 \%$ & $62 \%$ & $58 \%$ \\
\hline 1.89 & Darco Hg-LH & 13-Jun & $18: 00$ & $2: 00$ & 21.5 & 7.4 & 6.1 & 6.8 & 0.9 & $66 \%$ & $72 \%$ & $69 \%$ \\
\hline 1.89 & Darco Hg-LH & 14-Jun & $8: 57$ & $16: 01$ & 24.4 & 5.5 & 4.6 & 5.1 & 0.6 & $78 \%$ & $81 \%$ & $79 \%$ \\
\hline 1.89 & Darco Hg-LH & 14-Jun & $16: 20$ & $0: 20$ & 20.5 & 7.1 & 5.4 & 6.3 & 1.2 & $66 \%$ & $74 \%$ & $70 \%$ \\
\hline 0.96 & C-PAC & 22-Jun & $11: 56$ & $14: 56$ & 16.4 & 8.9 & 7.8 & 8.4 & 0.8 & $46 \%$ & $52 \%$ & $49 \%$ \\
\hline 0.96 & C-PAC & 22-Jun & $15: 44$ & $19: 42$ & 17.5 & 8.1 & 8.1 & 8.1 & 0.0 & $54 \%$ & $54 \%$ & $54 \%$ \\
\hline 0.95 & CF Plus & 23-Jun & $11: 15$ & $15: 15$ & 25.5 & 6.0 & 5.3 & 5.7 & 0.5 & $76 \%$ & $79 \%$ & $78 \%$ \\
\hline 0.95 & CF Plus & 23-Jun & $15: 57$ & $19: 57$ & 21.5 & 6.2 & 4.8 & 5.5 & 1.0 & $71 \%$ & $78 \%$ & $74 \%$ \\
\hline 0.95 & EXP224 & 24-Jun & $10: 40$ & $13: 40$ & 18.9 & 9.2 & 7.9 & 8.6 & 0.9 & $51 \%$ & $58 \%$ & $55 \%$ \\
\hline 0.95 & EXP224 & 24-Jun & $14: 13$ & $15: 43$ & 14.3 & 8.4 & 6.8 & 7.6 & 1.1 & $41 \%$ & $52 \%$ & $47 \%$ \\
\hline
\end{tabular}

Average and standard deviations calculated for all measurement methods for which mercury concentration data available at stack.

${ }^{\complement} \mathrm{Hg}$ removals calculated by comparing AH Inlet SCEM data to (a) stack Sorbent Traps, (b) stack SCEM, (c) average stack Hg concentration 


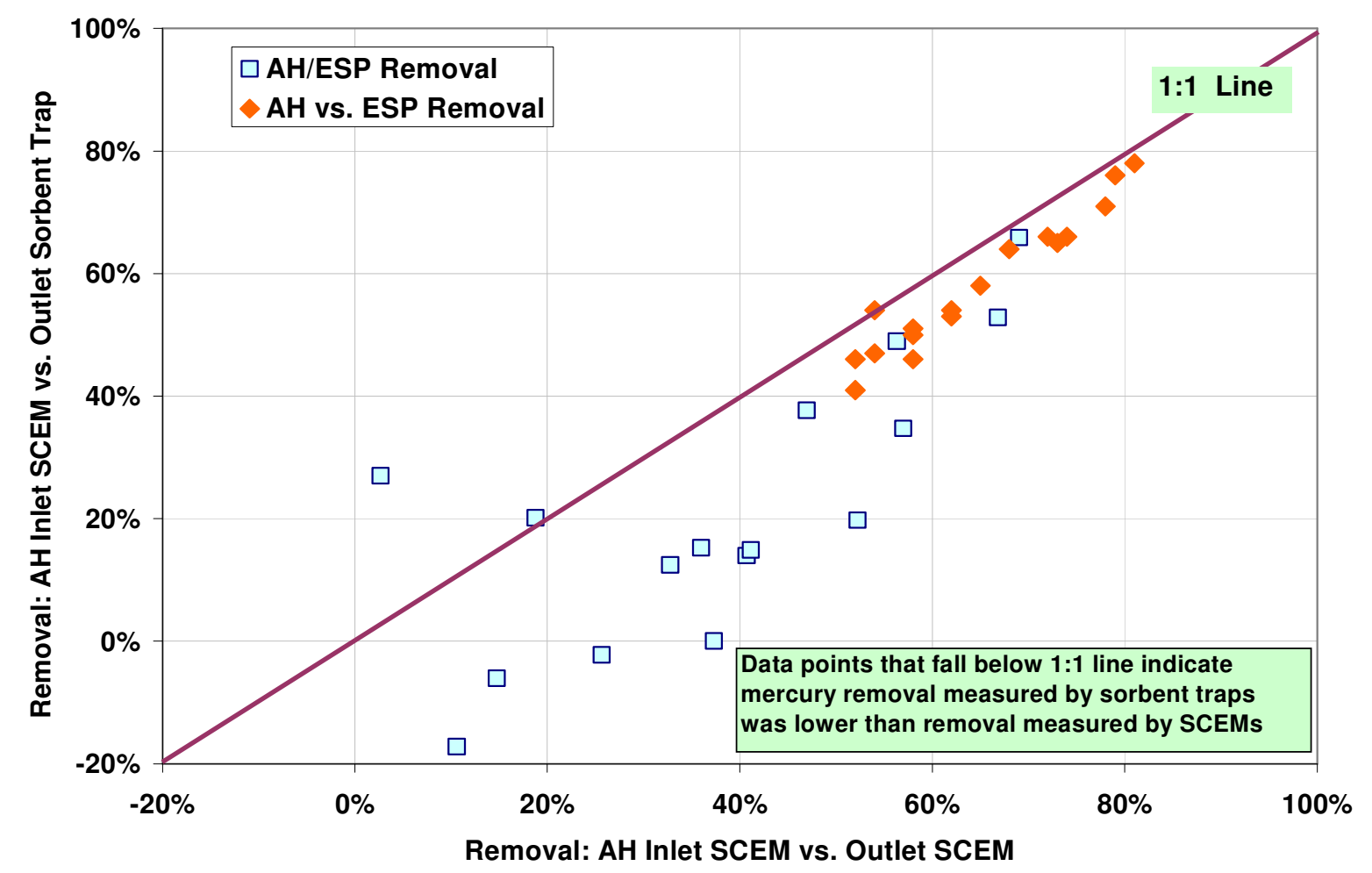

Figure 4-1. ACI Upstream of AH: Mercury Removal Percentages as Measured by SCEM and Sorbent Traps at the ESP Outlet and Stack

Figure 4-2 shows the calculated mercury removals across the AH/ESP vs. injection rate based on sorbent trap and SCEM data for Darco Hg-LH injection upstream of the AH. Both the SCEM and sorbent trap data indicate increasing mercury removal with injection rate and indicate a possible plateau in mercury removal between 1.0 and $2.0 \mathrm{lb} / \mathrm{Macf}$. Both measurement methods indicate a maximum achieved mercury removal of $\sim 55 \%$ (albeit at different injection rates), and data from both methods indicate a wide variation in measured mercury removal at each injection rate. Higher mercury removal was achieved with this sorbent on Unit 1 in 2007, when 70\% mercury reduction was achieved at an injection rate of $1.8 \mathrm{lb} / \mathrm{Macf}$. 


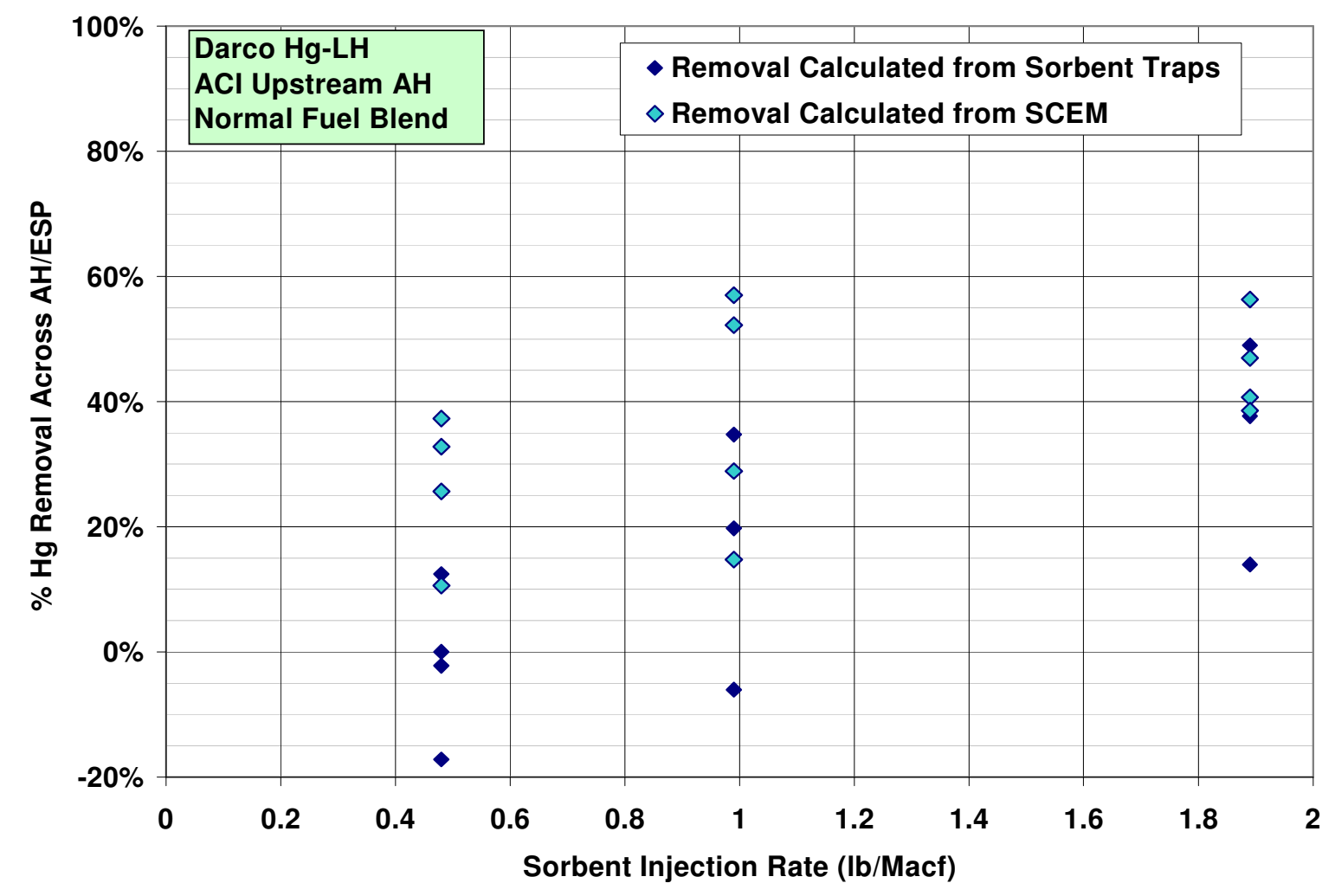

Figure 4-2. ACI Upstream of AH: Comparison of Mercury Removals across AH/ESP for Darco Hg-LH, Based on Sorbent Trap and SCEM Data

Figure 4-3 compares the mercury removal (based on SCEM data) across the AH/ESP of the low ash impact sorbents to Darco Hg-LH. Each datum point in the plot represents a daily test average. Removals based on sorbent trap data are provided in Table 4-8. The low ash impact carbons were only tested for one day each at a rate of $1.0 \mathrm{lb} / \mathrm{Macf}$, so there are not sufficient data to determine if these sorbents would have experienced the same degree of performance variability in performance as Darco Hg-LH. Both sorbent trap and SCEM data indicated that CF Plus achieved the highest mercury removal (68\% by SCEM, $60 \%$ by sorbent trap) across the AH/ESP for all sorbents tested. CF Plus Ultra achieved lower removal (57\%) than CF Plus. Both sorbent trap and SCEM data indicated that and EXP-224 achieved the lowest mercury removal across the AH/ESP of the sorbents tested, ranging from $10 \%$ to $41 \%$. The passivation of the carbons to make them concrete friendly appears to have led to a decrease in mercury removal performance for EXP-224 and CF Plus Ultra, as compared to their standard counterpart sorbents (Darco Hg-LH and CF Plus). In non-TxL flue gas both C-PAC [8] and EXP 224 have been demonstrated to perform nearly as well as their non-ash compatible counterparts. 


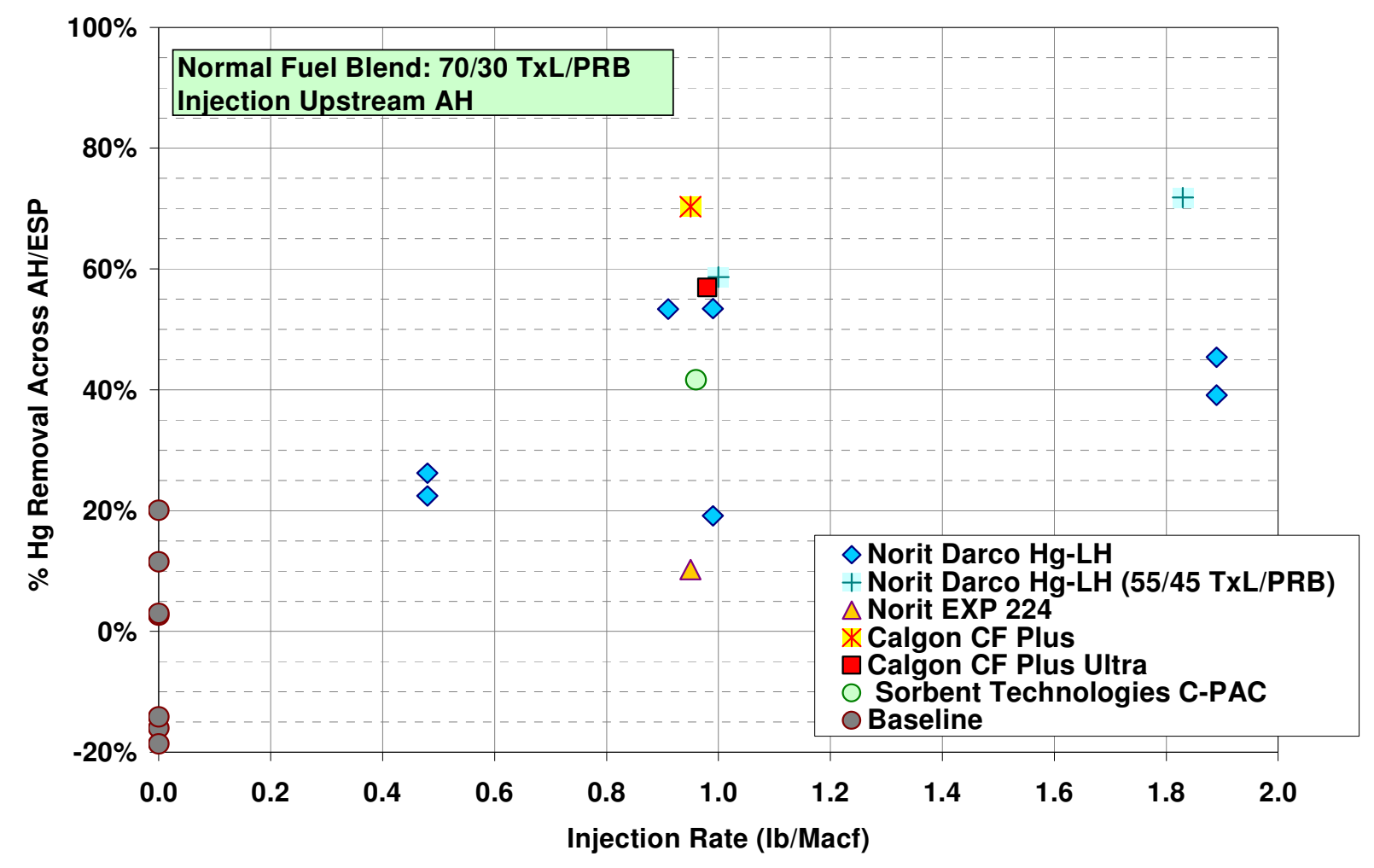

Figure 4-3. ACI Upstream of AH: Mercury Removal across AH/ESP, Based on SCEM Data

During baseline testing, flue gas mercury oxidation at the ESP outlet was typically $40-50 \%$, as measured by SCEM. During injection of the Darco Hg-LH sorbent, mercury oxidation at the ESP outlet increased, ranging from $44-70 \%$, but typically $60-70 \%$. The mercury oxidation achieved by the Darco Hg -LH sorbent was independent of injection rate; an injection rate of 0.5 lb/Macf Darco Hg-LH was sufficient to increase ESP outlet mercury oxidation to 69\%. During injection of the ash-compatible sorbents, mercury oxidation at the ESP outlet was higher than baseline but lower than during injection of Darco Hg-LH. Mercury oxidation measurements were also made by $\mathrm{OH}$ during one test day of Darco Hg-LH at $1.0 \mathrm{lb} / \mathrm{Macf}$ (Table 4-10). Despite the variability in total $\mathrm{Hg}$ concentration measured by $\mathrm{OH}$, both $\mathrm{OH}$ and SCEM measurements indicated the ESP outlet elemental concentration was consistently $\sim 5 \mu \mathrm{g} / \mathrm{dNm}^{3}$ throughout the test day. Mercury oxidation at the ESP outlet was lower on Unit 2 in 2009 than on Unit 1 in 2007 (when it ranged from $70-80 \%$ ); this decrease in oxidation may be due to differences in operation of the two units or just the natural variability associated with Texas Lignite. 
Table 4-10. OH vs. SCEM Results at ESP Outlet (Darco Hg-LH Injected Upstream of the $\mathrm{AH}$ at $\sim 1 \mathrm{lb} /$ Macf)

\begin{tabular}{|c|c|c|c|c|c|c|c|c|c|c|c|c|}
\hline \multirow{2}{*}{ 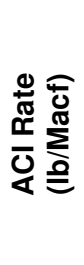 } & \multirow[b]{2}{*}{$\begin{array}{l}\text { Date } \\
\text { in } \\
2009\end{array}$} & \multicolumn{2}{|c|}{$\begin{array}{l}\text { Averaging } \\
\text { Period }\end{array}$} & \multirow{2}{*}{$\begin{array}{l}\text { AH Inlet } \\
\begin{array}{l}\text { Total } \mathrm{Hg} \\
\left(\mu \mathrm{g} / \mathrm{Nm}^{3}\right)\end{array}\end{array}$} & \multicolumn{3}{|c|}{$\begin{array}{l}\text { ESP Outlet Duct 2D1 } \\
\qquad \text { OH Results }\end{array}$} & \multicolumn{3}{|c|}{$\begin{array}{l}\text { ESP Outlet Duct 2C2 } \\
\text { SCEM Results }\end{array}$} & \multicolumn{2}{|c|}{$\begin{array}{c}\text { \% Removal } \\
\text { Across } \\
\text { AH/ESP } 1\end{array}$} \\
\hline & & $\begin{array}{l}\text { Start } \\
\text { Time }\end{array}$ & $\begin{array}{l}\text { End } \\
\text { Time }\end{array}$ & & $\begin{array}{l}\text { Total } \mathrm{Hg} \\
\left(\mu \mathrm{g} / \mathrm{Nm}^{3}\right)\end{array}$ & $\begin{array}{c}\text { Elem. } \\
\mathrm{Hg} \\
\left(\mu \mathrm{g} / \mathrm{Nm}^{3}\right)\end{array}$ & $\begin{array}{c}\% \\
\text { Oxid }\end{array}$ & $\begin{array}{l}\text { Total } \mathrm{Hg} \\
\left(\mu \mathrm{g} / \mathrm{Nm}^{3}\right)\end{array}$ & $\begin{array}{c}\text { Elem. } \\
\mathrm{Hg} \\
\left(\mu \mathrm{g} / \mathrm{Nm}^{3}\right)\end{array}$ & $\begin{array}{c}\% \\
\text { Oxid }\end{array}$ & $\mathrm{OH}$ & SCEM \\
\hline 1.0 & $6 / 18$ & $10: 04$ & $12: 15$ & 14.9 & 13.6 & 4.4 & 68 & 11.8 & 5.0 & 57 & $8 \%$ & $21 \%$ \\
\hline 1.0 & $6 / 18$ & $13: 28$ & $15: 47$ & $16.1^{2}$ & 5.9 & 4.6 & 22 & 13.6 & 5.5 & 59 & $63 \%$ & $16 \%$ \\
\hline 1.0 & $6 / 18$ & $16: 22$ & 18:32 & 17.3 & 7.1 & 5.9 & 17 & 12.3 & -- & -- & $59 \%$ & $29 \%$ \\
\hline
\end{tabular}

${ }^{1}$ Mercury removal calculated by comparing the AH inlet SCEM data to each measurement method at the ESP outlet.

${ }^{2} \mathrm{AH}$ inlet $\mathrm{Hg}$ SCEM failed quality control check after this second $\mathrm{OH}$ run; therefore, reported average of run 1 and run 3 data (16.1) rather than measured value (12.8).

Mercury removal across the entire system, calculated as AH inlet vs. stack SCEM Hg concentration, is plotted in Figure 4-4. Approximately 15\% of the flue gas bypassed the FGD during the test period. The increase in mercury oxidation at the ESP outlet due to sorbent injection resulted in increased mercury removal across the FGD. Baseline removal across the entire system ranged from $20 \%-56 \%$. Calgon's CF Plus sorbent achieved the highest removal $(70-80 \%)$ of the sorbents tested at $\sim 1 \mathrm{lb} / \mathrm{Macf}$. Darco Hg-LH achieved a similar level of removal when injected at $2 \mathrm{lb} / \mathrm{Macf}$, but only $50-70 \%$ removal at $1 \mathrm{lb} / \mathrm{Macf}$. EXP-224 and CPAC achieved the lowest system removals of the sorbent tested, ranging from $40-60 \%$. These are both passivated carbons designed to be concrete friendly (insuffient data from LMS exist to confirm this would be case in long-term operation), so there may be some benefit to their use despite the lower mercury removal. Analysis of both stack sorbent trap data (tabulated in Table 4-9) resulted in similar conclusions about the relative performance of the sorbents and level of mercury removal achieved. 


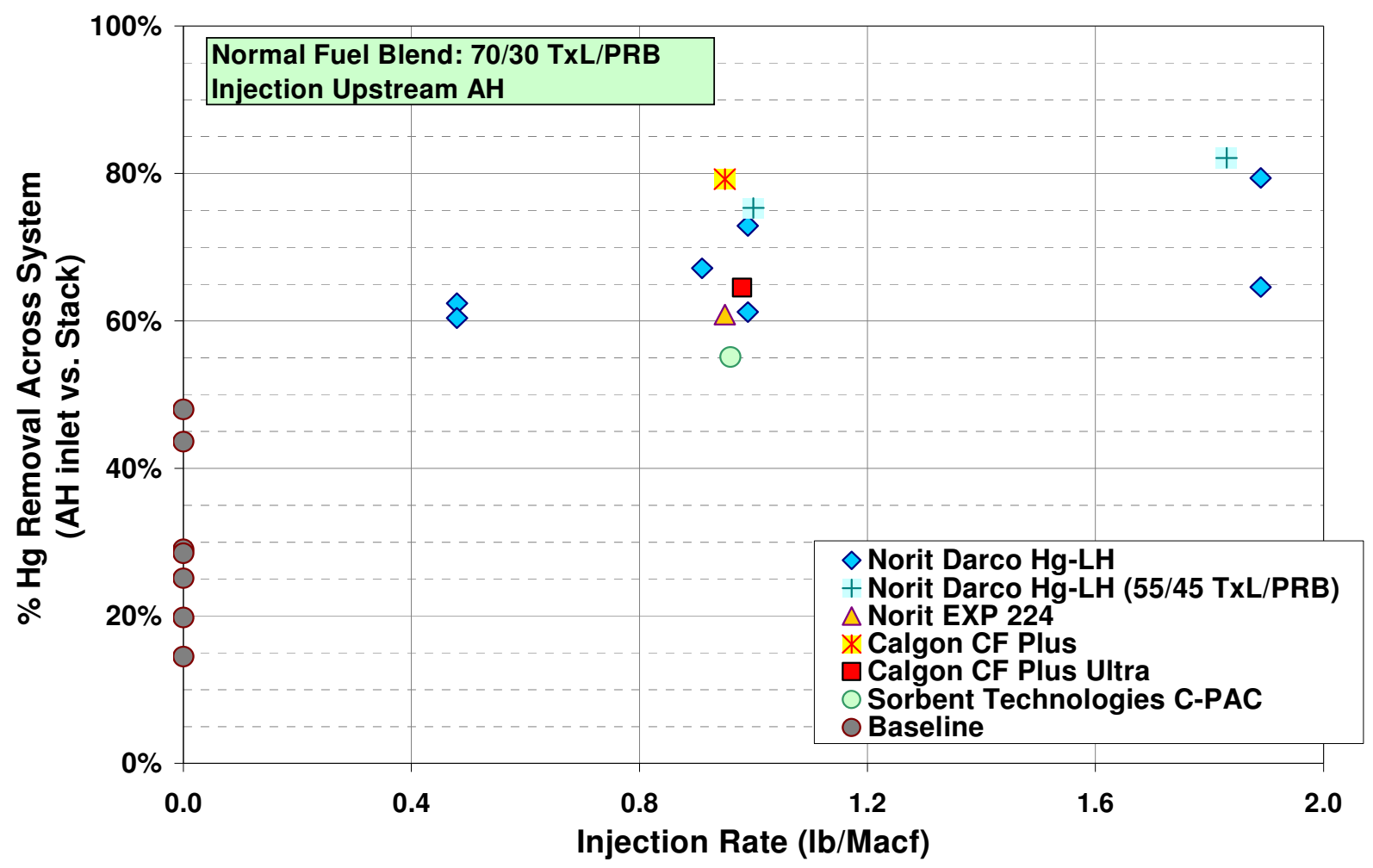

Figure 4-4. ACI Upstream of AH: Mercury Removal across System, Based on SCEM Data

\section{Alternative Fuel Blend}

During the last three days of sorbent injection upstream of the AH, an alternative fuel blend of 55\% Texas lignite and 45\% PRB was combusted. One day of baseline data was collected on 6/26/09, and Darco Hg-LH sorbent was tested at two rates to evaluate the fuel blend impact on mercury removal performance. Each injection rate was tested for only one day, so variability in sorbent $\mathrm{Hg}$ removal performance could not be quantified.

Tables 4-11 and 4-12 present the mercury concentration and removal data from the alternate fuel testing at the ESP outlet and stack, respectively. For baseline and sorbent injection periods, the sorbent trap and SCEM data agreed very well at both the ESP outlet and stack. Mercury removals for the alternate blend were included previously in Figures 4-3 and 4-4. 
Table 4-11. Alternate Fuel Blend, ACI Upstream of AH: Mercury Concentrations and Removals Measured at ESP Outlet

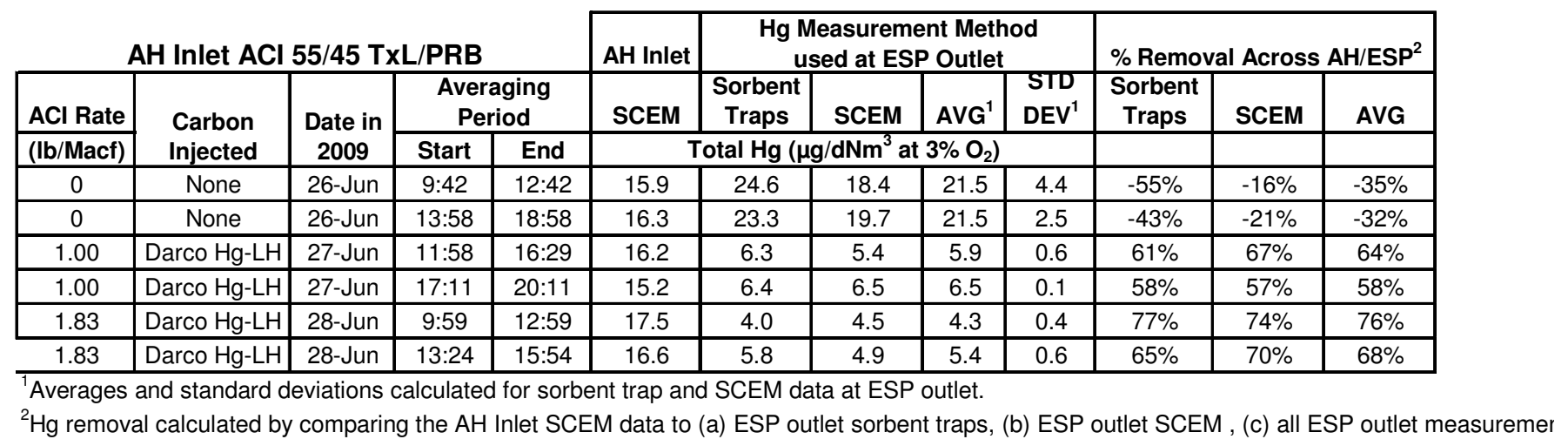

Table 4-12. Alternate Fuel Blend, ACI Upstream of AH: Mercury Concentrations and Removals Measured at Stack

\begin{tabular}{|c|c|c|c|c|c|c|c|c|c|c|c|c|}
\hline \multicolumn{5}{|c|}{ AH Inlet ACI 55/45 TxL/PRB } & AH Inlet & \multicolumn{4}{|c|}{$\begin{array}{c}\text { Hg Measurement Method } \\
\text { used at Stack }\end{array}$} & \multicolumn{3}{|c|}{$\begin{array}{l}\% \text { Removal } \\
\text { Unlet vs. Stack) }{ }^{2}\end{array}$} \\
\hline ACl Rate & \multirow{2}{*}{$\begin{array}{l}\text { Carbon } \\
\text { Injected }\end{array}$} & \multirow[b]{2}{*}{ Date } & \multicolumn{2}{|c|}{$\begin{array}{c}\text { Averaging } \\
\text { Period }\end{array}$} & SCEM & \begin{tabular}{|c|} 
Sorbent \\
Traps \\
\end{tabular} & SCEM & AVG $^{1}$ & STD DEV ${ }^{1}$ & $\begin{array}{l}\text { Sorbent } \\
\text { Traps }\end{array}$ & SCEM & AVG \\
\hline (Ib/Macf) & & & Start & End & & Total Hg & $\mu \mathrm{g} / \mathrm{dNm}$ & at $3 \%$ & & & & \\
\hline 0 & None & 26-Jun & $9: 30$ & $13: 00$ & 16.2 & 16.7 & 13.3 & 15.0 & 2.4 & $-3 \%$ & $18 \%$ & $7 \%$ \\
\hline 0 & None & 26-Jun & $13: 52$ & $18: 53$ & 16.3 & 16.2 & 13.0 & 14.6 & 2.3 & $1 \%$ & $20 \%$ & $10 \%$ \\
\hline 1.00 & Darco Hg-LH & 27-Jun & $12: 00$ & $16: 30$ & 16.2 & 4.1 & 3.7 & 3.9 & 0.3 & $75 \%$ & $77 \%$ & $76 \%$ \\
\hline 1.00 & Darco Hg-LH & 27-Jun & $16: 57$ & $19: 57$ & 15.4 & 3.4 & 3.7 & 3.6 & 0.2 & $78 \%$ & $76 \%$ & $77 \%$ \\
\hline 1.83 & Darco Hg-LH & 28-Jun & $10: 00$ & $13: 00$ & 17.5 & 3.3 & 3.0 & 3.2 & 0.2 & $81 \%$ & $83 \%$ & $82 \%$ \\
\hline 1.83 & Darco Hg-LH & 28-Jun & $13: 21$ & $15: 51$ & 16.6 & 2.9 & 2.8 & 2.9 & 0.1 & $83 \%$ & $83 \%$ & $83 \%$ \\
\hline
\end{tabular}

${ }^{1}$ Average and standard deviations calculated for sorbent trap and SCEM data at stack.

${ }^{2} \mathrm{Hg}$ removals calculated by comparing AH Inlet SCEM data to (a) stack Sorbent Traps, (b) stack SCEM, (c) average stack Hg concentration

Baseline data collected during combustion of the alternative fuel blend indicates that air heater inlet flue gas mercury concentrations are similar or slightly lower than air heater inlet concentrations measured during the normal fuel blend. This result is not surprising as the alternate blend has an average mercury concentration of $0.24 \mathrm{ppm}$, dry, while the normal fuel blend has an average mercury concentration of 0.27 ppm, dry.

Mercury oxidation at the ESP outlet was $\sim 50 \%$, which was also similar to that observed at that location during normal fuel combustion. No mercury removal was measured across the AH/ESP and mercury removal across the AH/ESP/FGD system was $~ 20 \%$; again, these results are similar to the results from combustion of the normal fuel blend.

During sorbent injection, higher mercury removals were achieved across the AH/ESP and across the system when the fraction of PRB in the fuel increased from 30\% to 45\%. At $\sim 1 \mathrm{lb} / \mathrm{Macf}$ Darco Hg-LH, mercury removal across the AH/ESP increased from $40 \%$ to $57-67 \%$, and system removal increased from $65 \%$ to $77 \%$. ESP outlet mercury concentrations decreased when firing the alternate fuel blend $\left(12 \mathrm{vs} .6 \mu \mathrm{g} / \mathrm{dNm}^{3}\right)$; likewise, stack mercury concentration decreased from $\sim 6.0$ to $3.7 \mu \mathrm{g} / \mathrm{dNm}^{3}$. At $\sim 1.8 \mathrm{lb} / \mathrm{Macf}$ Darco $\mathrm{Hg}$ - $\mathrm{LH}$, system mercury removal 
with the alternate fuel blend increased from $69 \%$ to $83 \%$ and the stack mercury concentration decreased from 6.4 to $3.0 \mu \mathrm{g} / \mathrm{dNm}^{3}$.

\section{ACI Upstream of the ESP - Full Unit}

At the conclusion of injection tests upstream of the $\mathrm{AH}$ (with eight lances), the sorbent injection lances were moved downstream of the AH. A total of sixteen traditional style lances were installed upstream of the four ESPs on Unit 2. Table 4-13 presents the SCEM results for test periods when sorbent was injected upstream of the ESP; only test periods of 2 hours or longer are included in the table. Tables 4-14 and 4-15 compare the SCEM measurements to XFM, M29, and sorbent traps for the ESP outlet and stack, respectively. At the ESP outlet, the standard deviation averaged $20 \%$ of the average value for each time period; at the stack, the overall standard deviation averaged $10 \%$ of the average value for each time period. There was good agreement in the calculated system removals based on stack SCEM and average stack Hg data. 
Table 4-13. Average Mercury Concentrations Measured during Parametric Sorbent Injection Upstream of ESP (Full Unit) - Phase IV

\begin{tabular}{|c|c|c|c|c|c|c|c|c|c|c|c|c|c|}
\hline \multirow[b]{2}{*}{$\begin{array}{l}\text { Condition } \\
\text { Start Time }\end{array}$} & \multirow[b]{2}{*}{$\begin{array}{l}\text { Condition } \\
\text { End Time }\end{array}$} & \multirow[b]{2}{*}{ Sorbent } & \multirow{2}{*}{$\begin{array}{l}\text { Injection } \\
\text { Rate } \\
\text { (lb/Macf) }\end{array}$} & \multicolumn{3}{|c|}{$\begin{array}{c}\text { Avg. AH Inlet Hg } \\
\text { Concentrations } \\
\left(\mu \mathrm{g} / \mathrm{dNm}^{3}\right)\end{array}$} & \multicolumn{3}{|c|}{$\begin{array}{c}\text { Avg. ESP Outlet Hg } \\
\text { Concentrations } \\
\left(\mu \mathrm{g} / \mathrm{dNm}^{3}\right)\end{array}$} & \multirow{2}{*}{$\begin{array}{c}\% \\
\text { Removal } \\
\text { Across } \\
\text { AH/ESP }\end{array}$} & \multirow{2}{*}{$\begin{array}{c}\text { Avg. } \\
\text { Measured } \\
\text { Stack Hg } \\
\text { Concentratio } \\
\text { ns }\left(\mu \mathrm{g} / \mathrm{dNm}^{3}\right) \\
\text { Total } \mathrm{Hg} \\
\end{array}$} & \multirow{2}{*}{$\begin{array}{c}\% \\
\text { Removal } \\
\text { Across } \\
\text { System }\end{array}$} & \multirow{2}{*}{$\begin{array}{c}\text { FGD } \\
\text { Bypass } \\
\%\end{array}$} \\
\hline & & & & $\begin{array}{c}\text { Total } \\
\text { Hg }\end{array}$ & $\begin{array}{c}\text { Elem. } \\
\text { Hg }\end{array}$ & $\begin{array}{c}\% \\
\text { Oxid. }\end{array}$ & $\begin{array}{c}\text { Total } \\
\text { Hg }\end{array}$ & $\begin{array}{c}\text { Elem. } \\
\text { Hg }\end{array}$ & $\begin{array}{c}\% \\
\text { Oxid. }\end{array}$ & & & & \\
\hline 7/8/09 12:00 & $7 / 8 / 0914: 45$ & Darco Hg & 0.5 & 18.6 & 17.5 & $6 \%$ & 17.2 & 10.3 & $40 \%$ & $8 \%$ & 9.5 & $49 \%$ & $15 \%$ \\
\hline $7 / 14 / 096: 30$ & $7 / 14 / 09$ 15:20 & Darco Hg-LH & 1.9 & 24.9 & 22.4 & $10 \%$ & 20.3 & 8.0 & $61 \%$ & $18 \%$ & 7.7 & $69 \%$ & $16 \%$ \\
\hline $7 / 15 / 09$ 9:25 & 7/15/09 13:00 & Darco Hg-LH & 0.5 & 24.5 & 21.9 & $11 \%$ & 12.5 & 5.7 & $55 \%$ & $49 \%$ & 9.3 & $62 \%$ & $11 \%$ \\
\hline $7 / 16 / 09$ 17:45 & $7 / 16 / 09$ 20:00 & $\begin{array}{l}\text { Darco Hg-LH } \\
\text { Finely Ground }\end{array}$ & 0.9 & 24.5 & 21.8 & $11 \%$ & 13.9 & 6.9 & $50 \%$ & $43 \%$ & 5.2 & $79 \%$ & $13 \%$ \\
\hline
\end{tabular}

Table 4-14. ACI Upstream of the ESP: Mercury Concentrations and Removals Measured at ESP Outlet

\begin{tabular}{|c|c|c|c|c|c|c|c|c|c|c|c|c|c|}
\hline \multicolumn{5}{|c|}{ Full Unit ESP Inlet ACI 70/30 TxL/PRB } & AH Inlet & \multicolumn{6}{|c|}{$\begin{array}{l}\text { Hg Measurement Method } \\
\text { ESP Outlet Duct \# }\end{array}$} & \multicolumn{2}{|c|}{$\begin{array}{c}\% \text { Removal Across } \\
\text { AH/ESP }\end{array}$} \\
\hline ACl Rate & \multirow{2}{*}{$\begin{array}{l}\text { Carbon } \\
\text { Injected }\end{array}$} & \multirow[b]{2}{*}{ Date } & \multicolumn{2}{|c|}{$\begin{array}{l}\text { Averaging } \\
\text { Period }\end{array}$} & SCEM & $\begin{array}{l}\text { XFM } \\
\text { 2D2 }\end{array}$ & $\begin{array}{l}\text { M29 } \\
\text { 2D1 }\end{array}$ & $\begin{array}{l}\text { Sorbent } \\
\text { Traps } 2 \mathrm{C} 1\end{array}$ & \begin{tabular}{|c|} 
SCEM \\
$2 \mathrm{C} 2$
\end{tabular} & AVG $^{1}$ & STD DEV ${ }^{1}$ & SCEM & AVG \\
\hline (Ib/Macf) & & & Start & End & & $\mathrm{tal} \mathrm{Hg}$ & $\mu \mathrm{g} / \mathrm{dN}$ & $n^{3}$ at $3 \% O_{2}$ ) & & & & & \\
\hline 0.47 & Darco Hg & 8-Jul & $11: 30$ & $14: 30$ & 18.8 & -- & -- & 20.7 & 17.1 & 18.9 & 2.5 & $9 \%$ & $-1 \%$ \\
\hline 0.91 & $\begin{array}{l}\text { Darco Hg-LH } \\
\text { Finely Ground }\end{array}$ & 16-Jul & $17: 45$ & $20: 00$ & 24.5 & -- & -- & -- & 13.9 & -- & -- & $43 \%$ & -- \\
\hline 0.48 & Darco Hg-LH & 15-Jul & 9:48 & $12: 48$ & 24.7 & -- & -- & 15.8 & 12.5 & 14.2 & 2.3 & $49 \%$ & $43 \%$ \\
\hline 1.84 & Darco Hg-LH & 8-Jul & $16: 15$ & $17: 09$ & 16.7 & -- & -- & 9.0 & 12.7 & 10.9 & 2.6 & $24 \%$ & $35 \%$ \\
\hline 1.89 & Darco Hg-LH & 14-Jul & $7: 30$ & 9:30 & 25.8 & 17.4 & 15.7 & 16.1 & 13.4 & 15.7 & 1.7 & $48 \%$ & $39 \%$ \\
\hline 1.89 & Darco Hg-LH & 14-Jul & $10: 05$ & $12: 05$ & 24.6 & 11.0 & 11.7 & -- & 17.3 & 13.3 & 3.5 & $30 \%$ & $46 \%$ \\
\hline 1.89 & Darco Hg-LH & 14-Jul & $13: 27$ & $15: 27$ & 24.5 & 12.6 & 15.7 & 13.5 & 24.0 & 16.5 & 5.2 & $2 \%$ & $33 \%$ \\
\hline $\begin{array}{c}0.95,1.17 \\
1.38,1.51 \\
1.73\end{array}$ & Darco Hg-LH & 15-Jul & $13: 26$ & $16: 24$ & 27.4 & -- & -- & 15.7 & 12.9 & 14.3 & 2.0 & $53 \%$ & $48 \%$ \\
\hline
\end{tabular}

${ }^{1}$ Average and standard deviations calculated for all measurement methods for which mercury concentration data available at ESP outlet.

${ }^{2}$ Mercury removals calculated by comparing the AH inlet SCEM data to (a) ESP outlet SCEM and (b) average ESP outlet Hg concentration. 
Table 4-15. ACI Upstream of the ESP: Mercury Concentrations and Removals Measured at Stack

\begin{tabular}{|c|c|c|c|c|c|c|c|c|c|c|c|c|c|}
\hline \multirow{3}{*}{$\begin{array}{r}\text { ACl Rate } \\
\text { (Ib/Macf) }\end{array}$} & \multirow{3}{*}{$\begin{array}{l}\text { Carbon } \\
\text { Injected }\end{array}$} & \multirow[b]{3}{*}{ Date } & & & AH Inlet & \multicolumn{6}{|c|}{$\begin{array}{c}\text { Hg Measurement Method } \\
\text { used at Stack }\end{array}$} & \multicolumn{2}{|c|}{$\begin{array}{c}\% \text { Removal } \\
(\text { AH Inlet vs. Stack })^{2}\end{array}$} \\
\hline & & & \multicolumn{2}{|c|}{$\begin{array}{l}\text { Averaging } \\
\text { Period }\end{array}$} & SCEM & XFM & M29 & $\begin{array}{c}\text { Sorbent } \\
\text { Traps }\end{array}$ & SCEM & \multirow[t]{2}{*}{$\mathrm{AVG}^{1}$} & \multirow[t]{2}{*}{ STD DEV ${ }^{1}$} & SCEM & AVG \\
\hline & & & Start & End & \multicolumn{5}{|c|}{ Total $\mathrm{Hg}\left(\mu \mathrm{g} / \mathrm{dNm}^{3}\right.$ at $\left.3 \% \mathrm{O}_{2}\right)$} & & & & \\
\hline 0.47 & Darco Hg & 8-Jul & $11: 25$ & $14: 25$ & 18.8 & -- & -- & 12.2 & 9.8 & 11.0 & 1.7 & $48 \%$ & $41 \%$ \\
\hline 0.91 & $\begin{array}{l}\text { Darco Hg-LH } \\
\text { Finely Ground }\end{array}$ & 16-Jul & $17: 45$ & $20: 00$ & 24.5 & -- & -- & -- & 5.2 & -- & -- & $79 \%$ & -- \\
\hline 0.48 & Darco Hg-LH & 15-Jul & $9: 47$ & $12: 47$ & 24.7 & -- & -- & 9.9 & 9.2 & 9.6 & 0.5 & $63 \%$ & $61 \%$ \\
\hline 1.84 & Darco Hg-LH & 8-Jul & $16: 15$ & $17: 10$ & 16.7 & -- & -- & 6.5 & 4.8 & 5.7 & 1.2 & $71 \%$ & $66 \%$ \\
\hline 1.89 & Darco Hg-LH & 14-Jul & $7: 35$ & 9:30 & 25.5 & 11.0 & 9.6 & 9.1 & 8.9 & 9.7 & 0.9 & $65 \%$ & $62 \%$ \\
\hline 1.89 & Darco Hg-LH & 14-Jul & $10: 06$ & 12:06 & 24.6 & 9.4 & 7.1 & & 6.6 & 7.7 & 1.5 & $73 \%$ & $69 \%$ \\
\hline 1.89 & Darco Hg-LH & 14-Jul & $13: 30$ & $16: 31$ & 25.1 & 9.2 & 8.7 & 8.3 & 6.5 & 8.2 & 1.2 & $74 \%$ & $67 \%$ \\
\hline $\begin{array}{c}0.95,1.17 \\
1.38,1.51 \\
1.73\end{array}$ & Darco Hg-LH & 15-Jul & $13: 25$ & $16: 22$ & 27.4 & -- & -- & 8.8 & 7.8 & 8.3 & 0.7 & $72 \%$ & $70 \%$ \\
\hline
\end{tabular}

${ }^{1}$ Average and standard deviations calculated for all measurement methods for which mercury concentration data available at stack.

${ }^{2}$ Mercury removals calculated by comparing the AH inlet SCEM data to (a) stack SCEM and (b) average stack Hg concentration. 
Figure 4-5 shows mercury removal across the AH/ESP for injection upstream of the ESP for the various sorbents tested. Only the Darco Hg-LH sorbent was tested both upstream of the ESP and upstream of the AH. At $1.9 \mathrm{lb} / \mathrm{Macf}$, comparable $\mathrm{Hg}$ removal was observed for the ESP and AH injection locations; at $0.5 \mathrm{lb} / \mathrm{Macf}$, mercury removal improved when injecting upstream of the ESP. Due to port constraints, there were only eight lances used upstream of the AH, compared to 16 lances upstream of ESP. Any gains in residence time from injecting upstream of the AH may have been offset by decreased lateral sorbent distribution due to the reduced number of lances. Alternatively, mercury removal performance at LMS may have been reaction-limited rather than mass transfer-limited, in which case improvements to sorbent distribution would not have resulted in increased mercury removal.

Mercury removal by finely ground Darco $\mathrm{Hg}-\mathrm{LH}$ was comparable to the standard Darco $\mathrm{Hg}-\mathrm{LH}$. As will be discussed in Section 4.8 the Darco $\mathrm{Hg}-\mathrm{LH}$ finely ground carbon particles agglomerated when transported through the conveying lines; the agglomeration worsened as injection rate increased. At the injection rate of $0.5 \mathrm{lb} / \mathrm{Macf}$ shown in Figure 4-5, the average particle size was $13 \mu \mathrm{m}$, which was larger than the $6 \mu \mathrm{m}$ particle size of the as-received finely ground carbon but less than the $20 \mu \mathrm{m}$ average particle size of the standard Darco Hg-LH.

Mercury removal by Darco $\mathrm{Hg}$ at $0.5 \mathrm{lb} / \mathrm{Macf}$ was only $10 \%$, as compared to $49 \%$ by Darco $\mathrm{Hg}$ LH. In contrast, the Unit 1 tests in 2007 showed that Darco Hg performed nearly as well as Darco $\mathrm{Hg}-\mathrm{LH}$ for mercury removal across the AH/ESP.

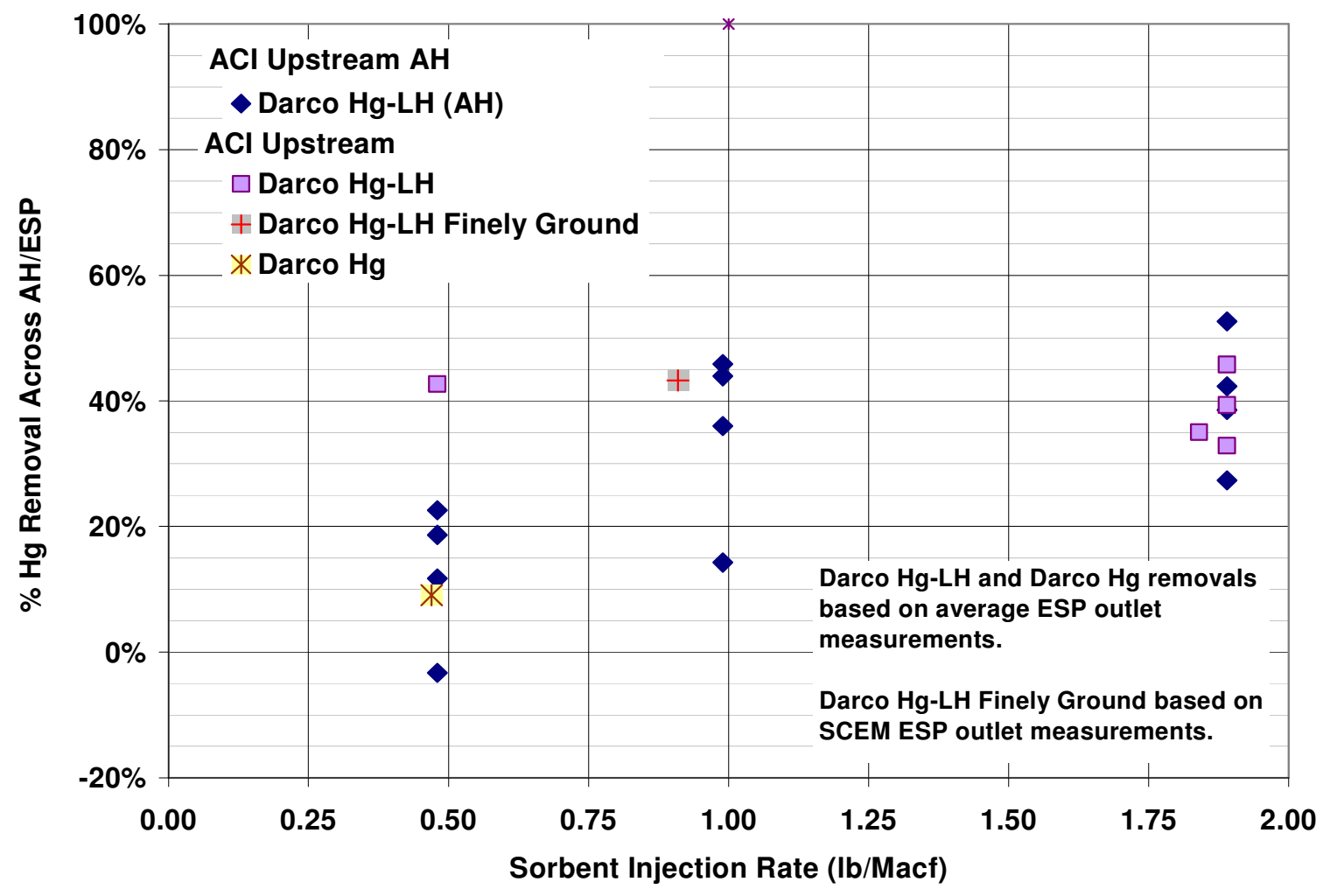

Figure 4-5. ACI Upstream of ESP, Phase IV: Mercury Removal across AH/ESP 
During injection upstream of the ESP, the mercury oxidation percentages at the ESP outlet during the two injection tests conducted with Darco Hg-LH sorbent were 55 and $61 \%$. These oxidation percentages were comparable to the oxidation achieved with this same sorbent during injection upstream of the $\mathrm{AH}$, indicating that the injection location did not have an impact on mercury oxidation at the ESP outlet. The mercury oxidation percentage achieved with Darco Hg sorbent was $40 \%$, which was no more than the low end of the oxidation percentages observed during baseline testing, and the oxidation achieved with the finely ground Darco Hg-LH sorbent was $50 \%$, which was lower than the oxidation percentages observed during injection of the standard size Darco Hg-LH sorbent. Mercury oxidation data for Darco $\mathrm{Hg}$ and finely ground Darco Hg-LH represent only one day of testing for each sorbent.

Mercury removal across the system (AH inlet vs. stack) is presented in Figure 4-6 for ACI upstream of the ESP. Only Darco Hg-LH was tested both upstream of the ESP and upstream of the $\mathrm{AH}$; mercury removal across the system was similar for both injection locations, averaging $\sim 55 \%$ at $0.5 \mathrm{lb} / \mathrm{Macf}$ and $\sim 65 \%$ at $1.9 \mathrm{lb} / \mathrm{Macf}$. The highest system removal (79\%) during sorbent injection upstream of the ESP was achieved with finely ground Darco $\mathrm{Hg}-\mathrm{LH}$ at 0.9lb/Macf.

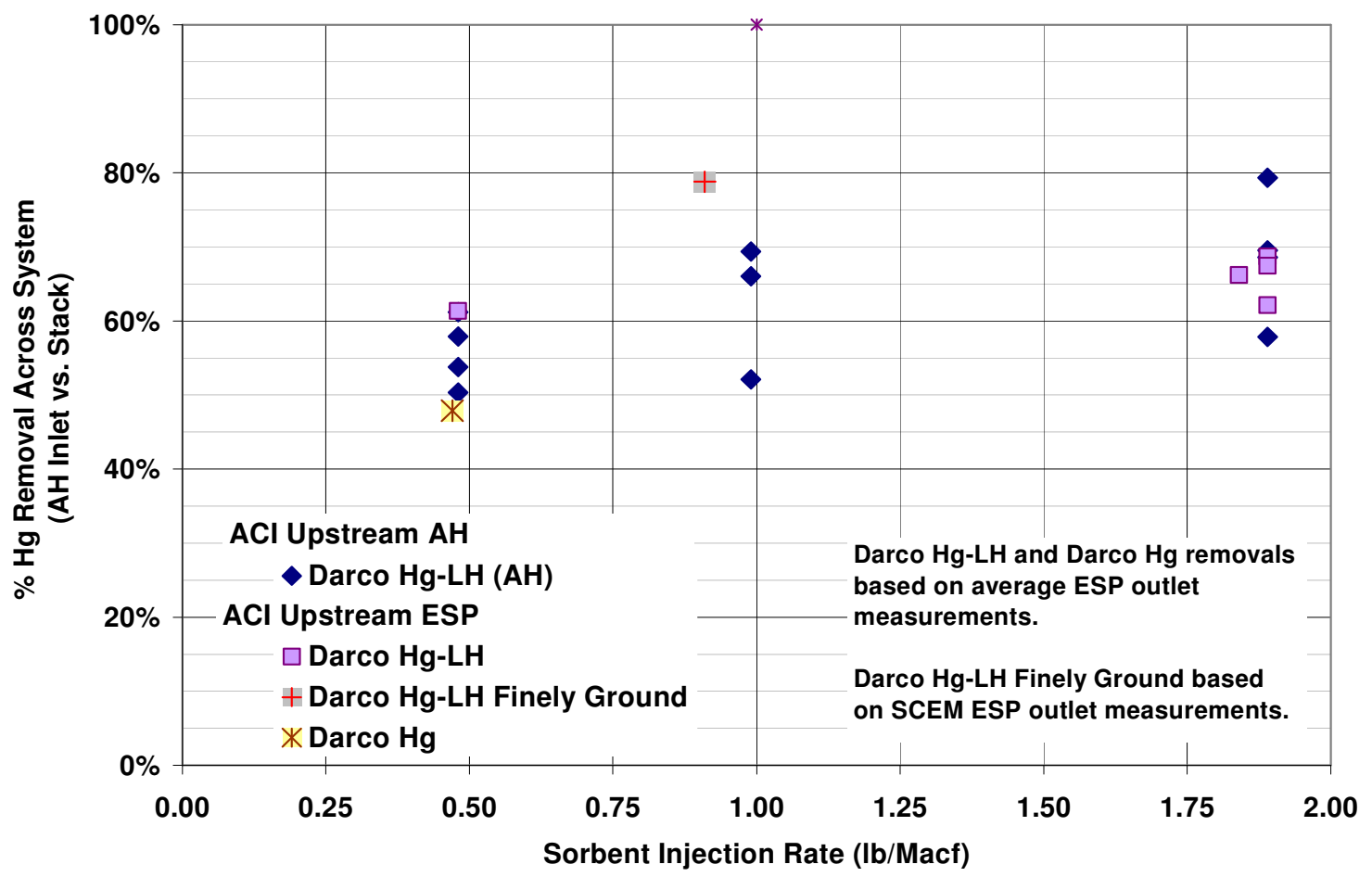

Figure 4-6. ACI Upstream of ESP, Phase IV: Mercury Removal across System

\section{Calcium Bromide Addition to Coal}

In conjunction with sorbent injection testing, calcium bromide was added to the coal to determine if there were synergistic effects of the two technologies for mercury removal. The presence of bromine in the flue gas biased low the SCEM mercury measurements made upstream 
of the FGD. Historically, SCEM measurements at an FGD outlet location have been more reliable because the FGD removes bromide from the flue gas. However, at LMS $15 \%$ of the flue gas bypassed the FGD so some bromide was present in the stack gas; it is unknown if this level of bromide was sufficient to bias low the mercury SCEMs measurements. Because none of the measurement methods are validated for flue gas containing bromide, all measurements were averaged to characterize mercury removal for each test condition. However, during bromide addition, the SCEM measurements at the stack were even lower than the other measurements methods as compared to non-bromide conditions.

Table 4-16 summarizes the average stack mercury concentrations for each test condition involving bromide and/or sorbent injection. Tables 4-17 and 4-18 summarize the ESP outlet and stack mercury concentrations measured by the various methods.

Table 4-16. Average Stack Mercury Concentrations during Coal Bromide Addition and Sorbent Injection Upstream of ESP - Phase IV

\begin{tabular}{|c|c|c|c|c|}
\hline & \multicolumn{4}{|c|}{ Stack $\mathrm{Hg}$ Concentration $\left(\mu \mathrm{g} / \mathrm{dNm}^{3}\right.$ at $\left.3 \% \mathrm{O}_{2}\right)$} \\
\hline $\begin{array}{c}\text { Bromide } \\
\text { Addition Rate } \\
\text { ppm Br to Coal, } \\
\text { dry basis }\end{array}$ & $\begin{array}{l}\text { Bromide Only } \\
\text { (No Sorbent) }\end{array}$ & $\begin{array}{c}\text { Bromide + } \\
0.5 \mathrm{lb} / \text { Macf Darco } \\
\mathrm{Hg}\end{array}$ & $\begin{array}{c}\text { Bromide + } \\
0.5 \mathrm{lb} / \text { Macf Darco } \\
\text { Hg-LH Fine }\end{array}$ & $\begin{array}{c}\text { Bromide + } \\
1.6 \mathrm{lb} / \mathrm{Macf} \\
\text { Darco Hg-LH } \\
\text { Fine }\end{array}$ \\
\hline 0 & $13-18$ & 11.0 & 5.2 & \\
\hline 97 & 9.8 & 5.9 & & \\
\hline 122 & & & & \\
\hline $164 / 172$ & $11.8 / 6.7$ & 5.7 & & \\
\hline 280 & & & 6.1 & 2.6 \\
\hline
\end{tabular}

Referring to Table 4-16, at baseline (no bromide, no sorbent), stack mercury concentrations ranged from $13-18 \mu \mathrm{g} / \mathrm{dNm}^{3}$ at $3 \% \mathrm{O}_{2}$. When bromide was added to the coal at rates ranging from 97 to $172 \mathrm{ppm}$, dry, the stack SCEM mercury concentration decreased to $4-7 \mu \mathrm{g} / \mathrm{dNm}^{3}$; whereas, the sorbent trap measurements indicated stack mercury concentrations ranging from 9 $17 \mu \mathrm{g} / \mathrm{dNm}^{3}$. For the application of bromide only, the SCEMs show a benefit for mercury removal while the sorbent traps show perhaps a modest benefit.

The combination of $0.5 \mathrm{lb} / \mathrm{Macf}$ Darco $\mathrm{Hg}$ carbon and $97 \mathrm{ppm} \mathrm{Br}$ resulted in stack mercury concentrations decreasing to $5.9 \mu \mathrm{g} / \mathrm{dNm}^{3}$, as compared to $11.0 \mu \mathrm{g} / \mathrm{dNm}^{3}$ with sorbent alone. Further increases in the bromide adition rate did not result in lower stack $\mathrm{Hg}$ concentrations. The SCEMs, sorbent traps, and Method 29 measurements all confirm the benefit of employing bromide addition in addition to sorbent injection. 
Table 4-17. Bromide Addition: Mercury Concentrations Measured at ESP Outlet

\begin{tabular}{|c|c|c|c|c|c|c|c|c|c|c|c|}
\hline \multicolumn{6}{|c|}{$\begin{array}{l}\text { Bromide Addition to Furnace } \\
\text { 70/30 TxL/PRB }\end{array}$} & \multicolumn{6}{|c|}{$\begin{array}{l}\text { Hg Measurement Method } \\
\text { ESP Outlet Duct \# }\end{array}$} \\
\hline ACI Rate & \multirow[b]{2}{*}{ Carbon Injected } & \multirow{2}{*}{$\begin{array}{c}\text { Br Injection } \\
\text { Rate (ppm in } \\
\text { coal) } \\
\end{array}$} & \multirow[b]{2}{*}{ Date } & \multicolumn{2}{|c|}{$\begin{array}{l}\text { Averaging } \\
\text { Period }\end{array}$} & $\begin{array}{l}\mathrm{OH} \\
\text { 2D1 }\end{array}$ & $\begin{array}{l}\mathrm{XFM} \\
\text { 2D2 } \\
\end{array}$ & $\begin{array}{l}\text { M29 } \\
\text { 2D1 }\end{array}$ & $\begin{array}{c}\text { Sorbent } \\
\text { Traps } 2 \mathrm{C} 1\end{array}$ & \multirow[t]{2}{*}{ AVG $^{1}$} & \multirow[t]{2}{*}{ STD DEV ${ }^{1}$} \\
\hline (Ib/Macf) & & & & Start & End & \multicolumn{4}{|c|}{ Total $\mathrm{Hg}\left(\mu \mathrm{g} / \mathrm{dNm}^{3}\right.$ at $\left.3 \% \mathrm{O}_{2}\right)$} & & \\
\hline 0 & None & 97 & 10-Jul & $8: 49$ & $11: 49$ & 10.3 & -- & -- & 19.9 & 15.1 & 6.8 \\
\hline 0 & None & 164 & 11-Jul & $9: 10$ & $11: 35$ & 25.2 & -- & -- & 27.2 & 26.2 & 1.4 \\
\hline 0 & None & 172 & 9-Jul & $11: 55$ & $14: 55$ & 26.8 & -- & -- & 19.6 & 23.2 & 5.1 \\
\hline 0.47 & Darco Hg & 97 & 10-Jul & $14: 20$ & $16: 40$ & 8.8 & -- & -- & 9.1 & 9.0 & 0.2 \\
\hline 0.48 & Darco Hg & 122 & 12-Jul & $8: 01$ & $10: 01$ & -- & 12.6 & 14.8 & 12.0 & 13.1 & 1.5 \\
\hline 0.48 & Darco Hg & 122 & 12-Jul & $10: 45$ & $12: 45$ & -- & 12.7 & 14.1 & -- & 13.4 & 1.0 \\
\hline 0.48 & Darco Hg & 122 & 12-Jul & 13:35 & $15: 35$ & -- & 11.5 & 13.3 & 12.4 & 12.4 & 0.9 \\
\hline 0.61 & Darco Hg & 164 & 11-Jul & $14: 00$ & $16: 03$ & 7.3 & -- & -- & 9.2 & 8.3 & 1.3 \\
\hline 0.46 & $\begin{array}{l}\text { Darco Hg-LH } \\
\text { Finely Ground } \\
\end{array}$ & 0,280 & 16-Jul & $9: 50$ & $12: 50$ & -- & -- & -- & 12.8 & -- & -- \\
\hline $1.64,0.91$ & $\begin{array}{l}\text { Darco Hg-LH } \\
\text { Finely Ground }\end{array}$ & 280,173 & 16-Jul & $13: 18$ & $16: 18$ & -- & -- & -- & 8.3 & -- & -- \\
\hline
\end{tabular}

${ }^{1}$ Average and standard deviations calculated for all measurement methods for which mercury concentration data available at ESP outlet. 
Table 4-18. Bromide Addition: Mercury Concentrations Measured at Stack

\begin{tabular}{|c|c|c|c|c|c|c|c|c|c|c|c|}
\hline \multicolumn{3}{|c|}{$\begin{array}{c}\text { Bromide Addition to Furnace } \\
\text { 70/30 TxL/PRB }\end{array}$} & \multicolumn{5}{c|}{ Hg Measurement Method } \\
Used at Stack
\end{tabular}

${ }^{1}$ Average and standard deviations calculated for all measurement methods for which mercury concentration data available at stack. 
The lowest stack mercury concentration achieved was $2.6 \mu \mathrm{g} / \mathrm{dNm}^{3}$ with $280 \mathrm{ppm} \mathrm{Br}$ and 1.6 lb/Macf finely ground Darco Hg-LH, with very good agreement between the sorbent trap and SCEM measurements. The combination of bromide addition and sorbent injection achieved the lowest stack $\mathrm{Hg}$ concentration of all technologies tested at LMS Unit 2. However, the required sorbent injection rate of $1.6 \mathrm{lb} /$ Macf finely ground Darco $\mathrm{Hg}-\mathrm{LH}$ is high enough to potentially jeopardize ash sales, and the required bromide injection rate could adversely impact the scrubber system. Without changes in scrubber blowdown rates, high bromide addition rates will cause the steady-state FGD Br level to increase, which may lead to corrosion problems in alloy-based scrubbers.

Four $\mathrm{OH}$ runs were performed during bromide addition (no sorbent injection), at rates of 97, 164, 171, and $171 \mathrm{ppm} \mathrm{Br}$ to coal. The ESP outlet $\mathrm{OH}$ results for these tests were erratic, with measured mercury concentrations of $10,25,27$, and $5 \mu \mathrm{g} / \mathrm{Nm}^{3}$, respectively. Results for these $\mathrm{OH}$ tests are shown in Table 4-19. At LMS, with its very low LOI ash, little to no mercury removal would be expected across the ESP when adding bromide to the coal. The sorbent trap results support this supposition, with ESP outlet mercury concentrations ranging from $20-28$ $\mu \mathrm{g} / \mathrm{dNm}^{3}$ durng bromide-only addiiton. The ash mercury concentrations during bromide addition tests were not significantly higher than during sorbent addition tests. Therefore, it is likely the $\mathrm{OH}$ method experienced an intermittent low bias in the measurement of total mercury concentration when bromide was present in the flue gas.

As stated previously, the SCEM experiences negative biases when measuring flue gas containing bromide; however, the elemental mercury concentrations measured by OH and SCEM at the ESP outlet agreed well for five of six runs, indicating between 2.0 and $4.0 \mu \mathrm{g} / \mathrm{dNm}^{3}$. Total mercury concentrations agreed well for three of the six runs.

Table 4-19. OH Results from Bromide Addition Tests

\begin{tabular}{|c|c|c|c|c|c|c|c|c|c|c|}
\hline \multirow{2}{*}{ 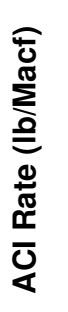 } & \multirow{2}{*}{ 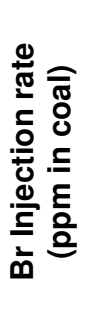 } & \multirow[b]{2}{*}{$\begin{array}{l}\text { Date } \\
\text { in } \\
2009\end{array}$} & \multicolumn{2}{|c|}{$\begin{array}{c}\text { Averaging } \\
\text { Period }\end{array}$} & \multicolumn{3}{|c|}{$\begin{array}{c}\text { ESP Outlet 2D1 } \\
\text { Ontario Hydro Results }\end{array}$} & \multicolumn{3}{|c|}{$\begin{array}{l}\text { ESP Outlet } 2 \text { C2 } \\
\text { SCEM Results* }\end{array}$} \\
\hline & & & $\begin{array}{l}\text { Start } \\
\text { Time }\end{array}$ & $\begin{array}{l}\text { End } \\
\text { Time }\end{array}$ & $\begin{array}{l}\text { Total } \mathrm{Hg} \\
\left(\mu \mathrm{g} / \mathrm{Nm}^{3}\right)\end{array}$ & $\begin{array}{l}\text { Elem. Hg } \\
\left(\mu \mathrm{g} / \mathrm{Nm}^{3}\right)\end{array}$ & $\begin{array}{c}\% \\
\text { Oxid }\end{array}$ & $\begin{array}{l}\text { Total Hg } \\
\left(\mu \mathrm{g} / \mathrm{Nm}^{3}\right)\end{array}$ & $\begin{array}{l}\text { Elem. Hg } \\
\left(\mu \mathrm{g} / \mathrm{Nm}^{3}\right)\end{array}$ & $\begin{array}{c}\% \\
\text { Oxid }\end{array}$ \\
\hline 0 & 97 & $7 / 10$ & 9:13 & $11: 13$ & 10.3 & 3.8 & 63 & 11.2 & 2.9 & 74 \\
\hline 0.47 & 97 & $7 / 10$ & $14: 30$ & $16: 15$ & 8.8 & 2.6 & 70 & 7.0 & 2.2 & 69 \\
\hline 0 & 164 & $7 / 11$ & 9:34 & $11: 19$ & 25.2 & 3.6 & 86 & 13.9 & 2.3 & 83 \\
\hline 0.61 & 164 & $7 / 11$ & $14: 09$ & $16: 09$ & 7.3 & 2.0 & 72 & 8.0 & -- & -- \\
\hline 0 & 171 & $7 / 9$ & $12: 21$ & $14: 38$ & 26.8 & 2.6 & 90 & 8.6 & 2.0 & 77 \\
\hline 0 & 171 & $7 / 9$ & $15: 57$ & $17: 40$ & 4.8 & 2.4 & 51 & 8.0 & 0.6 & 93 \\
\hline
\end{tabular}

*SCEM total Hg concentrations at ESP outlet known to be biased low due to bromide bias. 


\section{$\underline{\text { ACI Upstream of the ESP }-1 / 4 \text { Unit }}$}

For the final two weeks of the test program, sorbent injection was limited to $1 / 4$ of Unit 2 (specifically, Unit 2C ESP). Because only part of the unit was treated during this portion of the test program, mercury concentrations measured at the stack were not representative of the test condition and could not be included in the mercury removal analysis. Two types of lances were used in this final part of the test program: the traditional lances used previously during this test program, and dispersion lances. The dispersion lances were designed to improve the distribution of sorbent in the duct and increase the contact between flue gas mercury and the sorbent. For the $1 / 4$ unit testing, four lances were used for the traditional setup and then replaced with four dispersion lances. The remaining twelve traditional lances (servicing 2A, 2B, and 2D ESPs) were taken out of service.

Table 4-20 presents average mercury concentrations measured at the AH inlet and the ESP outlet during each sorbent injection test involving Darco Hg-LH, Calgon A, and Calgon A2 sorbents. These sorbents were injected with both types of lances during the Unit 2C ESP injection testing and formed the basis for evaluating the performance of the dispersion lances. 
Table 4-20. Average Mercury Concentrations Measured during Traditional vs. Dispersion Lance Testing (Injection Upstream of $1 / 4$ of the Unit 2 ESP)

\begin{tabular}{|c|c|c|c|c|c|c|c|c|c|c|c|}
\hline \multirow[b]{2}{*}{ Start Time } & \multirow[b]{2}{*}{ End Time } & \multirow[b]{2}{*}{ Sorbent } & \multirow[b]{2}{*}{ Lance Type } & \multirow{2}{*}{$\begin{array}{c}\text { Injection } \\
\text { Rate } \\
\text { (lb/Macf) } \\
\end{array}$} & \multicolumn{3}{|c|}{$\begin{array}{c}\text { Avg. AH Inlet } \mathrm{Hg} \\
\text { Concentrations }\left(\mu \mathrm{g} / \mathrm{dNm}^{3}\right)\end{array}$} & \multicolumn{3}{|c|}{$\begin{array}{c}\text { Avg. ESP Outlet } \mathrm{Hg} \\
\text { Concentrations }\left(\mu \mathrm{g} / \mathrm{dNm}^{3}\right)\end{array}$} & \multirow{2}{*}{$\begin{array}{c}\text { \% Removal } \\
\text { Across } \\
\text { AH/ESP }\end{array}$} \\
\hline & & & & & $\begin{array}{c}\text { Total } \\
\mathrm{Hg} \\
\end{array}$ & $\begin{array}{c}\text { Elem. } \\
\text { Hg }\end{array}$ & $\begin{array}{c}\% \\
\text { Oxid. }\end{array}$ & $\begin{array}{c}\text { Total } \\
\mathrm{Hg} \\
\end{array}$ & $\begin{array}{c}\text { Elem. } \\
\mathrm{Hg}\end{array}$ & $\begin{array}{c}\% \\
\text { Oxid. }\end{array}$ & \\
\hline 7/17/09 10:05 & 7/17/09 18:10 & Darco Hg-LH & Traditional & 0.98 & 21.5 & 17.4 & $19 \%$ & 12.3 & 7.4 & $39 \%$ & $43 \%$ \\
\hline 7/18/09 9:00 & 7/18/09 13:00 & Darco Hg-LH & Traditional & 0.44 & 19.2 & 16.8 & $12 \%$ & 14.5 & 6.2 & $57 \%$ & $24 \%$ \\
\hline 7/18/09 13:00 & 7/18/09 15:30 & Darco Hg-LH & Traditional & 0.98 & 21.3 & 16.3 & $24 \%$ & 13.2 & 6.6 & $50 \%$ & $38 \%$ \\
\hline $7 / 18 / 09$ 15:30 & 7/18/09 18:30 & Darco Hg-LH & Traditional & 1.85 & 21.5 & 17.2 & $20 \%$ & 14.6 & -- & -- & $32 \%$ \\
\hline 7/19/09 10:30 & $7 / 19 / 09$ 12:50 & Calgon A2 & Traditional & 1 & 19.8 & 16.8 & $15 \%$ & 11.6 & 5.6 & $52 \%$ & $41 \%$ \\
\hline 7/19/09 15:00 & 7/19/09 17:10 & Calgon A & Traditional & 1 & 20.4 & 17.7 & $13 \%$ & 11.7 & 5.8 & $51 \%$ & $42 \%$ \\
\hline 7/21/09 10:47 & $7 / 21 / 09$ 13:23 & Darco Hg-LH & Dispersion & 0.95 & 21.7 & 20.5 & $5 \%$ & 11.0 & 5.3 & $52 \%$ & $49 \%$ \\
\hline $7 / 21 / 09$ 13:23 & $7 / 21 / 09$ 16:00 & Darco Hg-LH & Dispersion & 1.85 & 22.4 & 21.8 & $3 \%$ & 9.1 & 4.6 & $49 \%$ & $59 \%$ \\
\hline $7 / 22 / 09$ 10:17 & $7 / 22 / 09$ 17:25 & Darco Hg-LH & Dispersion & 1.06 & 22.9 & 21.7 & $5 \%$ & 17.6 & 8.1 & $54 \%$ & $23 \%$ \\
\hline $7 / 23 / 0910: 40$ & 7/23/09 17:40 & Darco Hg-LH & $\begin{array}{c}\text { Dispersion } \\
\text { (Low Pressure) }\end{array}$ & 1.01 & 19.6 & 14.1 & $28 \%$ & 14.2 & 8.4 & $41 \%$ & $28 \%$ \\
\hline $7 / 23 / 09$ 17:40 & $7 / 23 / 09$ 20:20 & Darco Hg-LH & $\begin{array}{c}\text { Dispersion } \\
\text { (High Pressure) }\end{array}$ & 1.01 & 20.0 & 14.5 & $28 \%$ & 11.5 & 6.5 & $44 \%$ & $43 \%$ \\
\hline 7/28/09 10:09 & 7/28/09 11:19 & Calgon A2 & Dispersion & 1 & 19.9 & 18.5 & $7 \%$ & 12.9 & 4.8 & $63 \%$ & $35 \%$ \\
\hline $7 / 28 / 09$ 16:22 & 7/28/09 17:13 & Calgon A & Dispersion & 1 & 18.8 & 17.8 & $5 \%$ & 7.7 & 3.2 & $59 \%$ & $65 \%$ \\
\hline
\end{tabular}


Figure 4-7 shows mercury removal results versus sorbent injection rate for the three sorbents injected with both lance types. There was no consistent trend in performance associated with using the dispersion lances instead of the traditional lances. All three of the sorbents included in the figure were injected at $\sim 1 \mathrm{lb} /$ Macf. For the Calgon A sorbent, the dispersion lances achieved higher removal (59\%) than the traditional lances (42\%). For the Calgon A2 sorbent, the traditional lances achieved similar removal (41\%) to the dispersion lances (35\%). For the Darco $\mathrm{Hg}-\mathrm{LH}$ sorbent, the dispersion lances achieved higher removal than the traditional lances during some test periods and lower removal during others. The variability in performance between the lances was similar to the run-to-run variability at a single test condition. Mercury removal performance at LMS may have been reaction-limited rather than mass transfer-limited, in which case improvements to sorbent distribution would not have resulted in increased mercury removal.

During initial evaluation of the dispersion lances, mercury measurements were made traversing different locations at the ESP outlet using the sorbent trap method. Sorbent trap tests run on July $21^{\text {st }}$ and $22^{\text {nd }}$ were performed in three ports per run, half an hour per port. The ports were labeled $\mathrm{A}, \mathrm{B}$, and $\mathrm{C}$ and were located BLANK. For sorbent trap tests conducted on July $23^{\text {rd }}$ each test was run in one port, run 1 was $\mathrm{A}$, run $2 \mathrm{~B}$, and run $3 \mathrm{C}$. For each test on the $23^{\text {rd }}$ three different duct depths were tested for 30 minutes for each run; the depths were six feet, four feet, and two feet. Sampling locations for each sorbent trap test are shown in Table 4-21. Results for the sorbent trap testing are provided in Table 4-22.

The mercury concentrations measured with the SCEM and with the sorbent traps trended together throughout this part of the test program. The removal percentages across the AH/ESP calculated using each set of data were similar, although the removal indicated by the SCEM measurements was generally higher than the removal indicated by the sorbent trap measurements.

At the conclusion of this test program, the dispersion lances were removed from the duct and inspected. This inspection revealed that some plugging occurred during injection. On one of the four dispersion lances, half of the nozzles were completely plugged and the inlet plenum was $80 \%$ plugged with sorbent. Another lance had one plugged nozzle, and the inlet plenum on a third lance was $60 \%$ plugged with debris and sorbent. Since the inspection occurred at the end of the test program, it is unknown how much of an effect the plugging had on the distribution of carbon in the duct and the resulting perceived performance of the dispersion lances. 


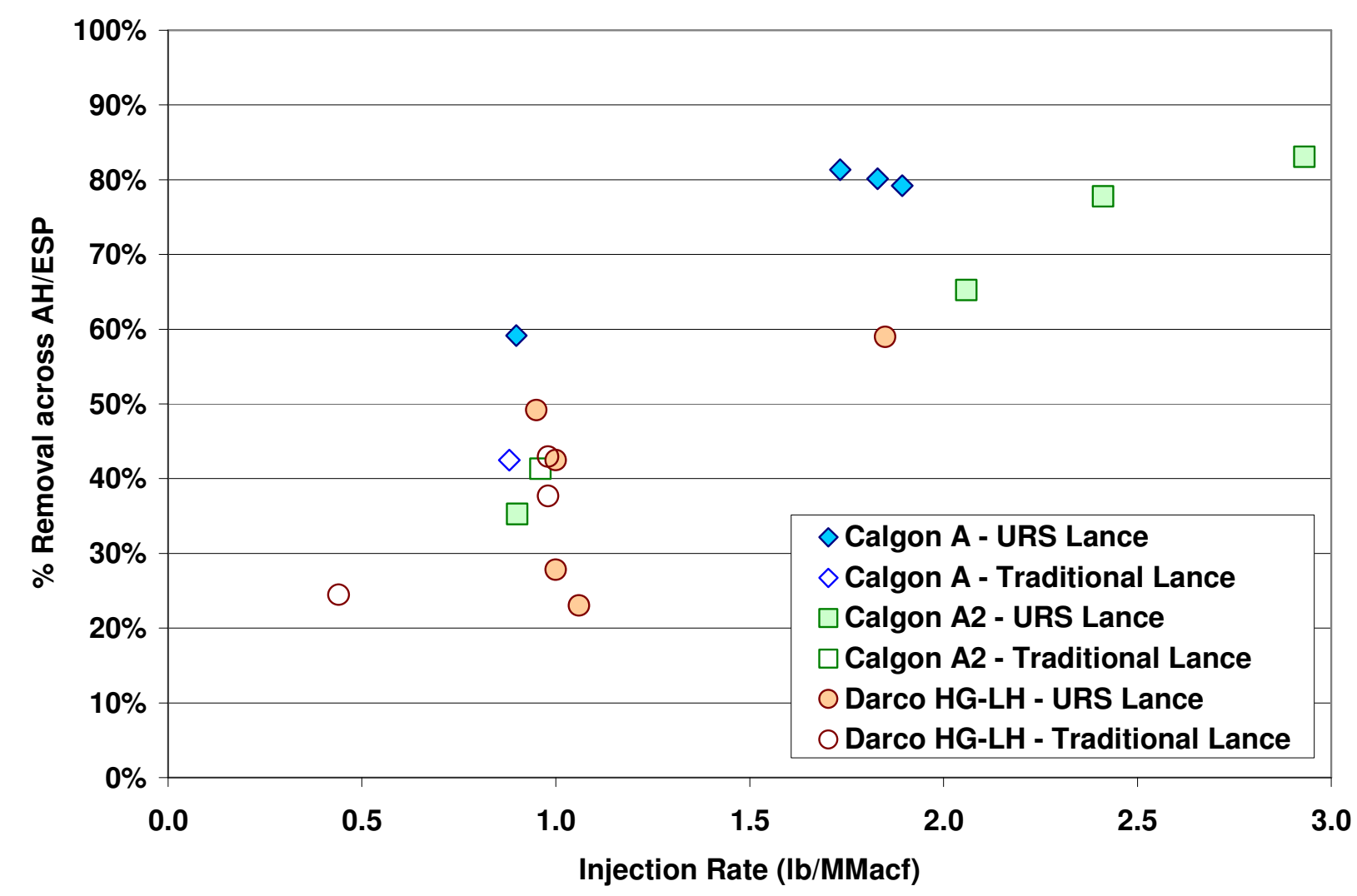

Figure 4-7. Mercury Removal across AH/ESP, Traditional Lances vs. Dispersion Lances (Injection of Upstream of Unit 2C ESP).

Because there was no obvious difference in mercury removals achieved for the traditional and dispersion lances, the dispersion lances were left in place for the remainder of the test program in which several proprietary Calgon sorbents were injected at varying rates to evaluate mercury removal performance.

Figure 4-8 presents the mercury removal percentages across the AH/ESP for all of the Calgon carbons injected with the dispersion lances during this program. Several of the injection tests lasted less than one hour. Only the data collected after the ESP outlet concentrations steadied were included in the averages in Figure 4-8, resulting in averaging periods as short as 22 minutes. Of the carbons tested, Calgon A carbon achieved the highest removal (80\%) at the lowest injection rate ( 1.8 lb/Macf). Only the Calgon A carbon, which was designed for sulfur tolerance, performed consistently better than Darco Hg-LH. 


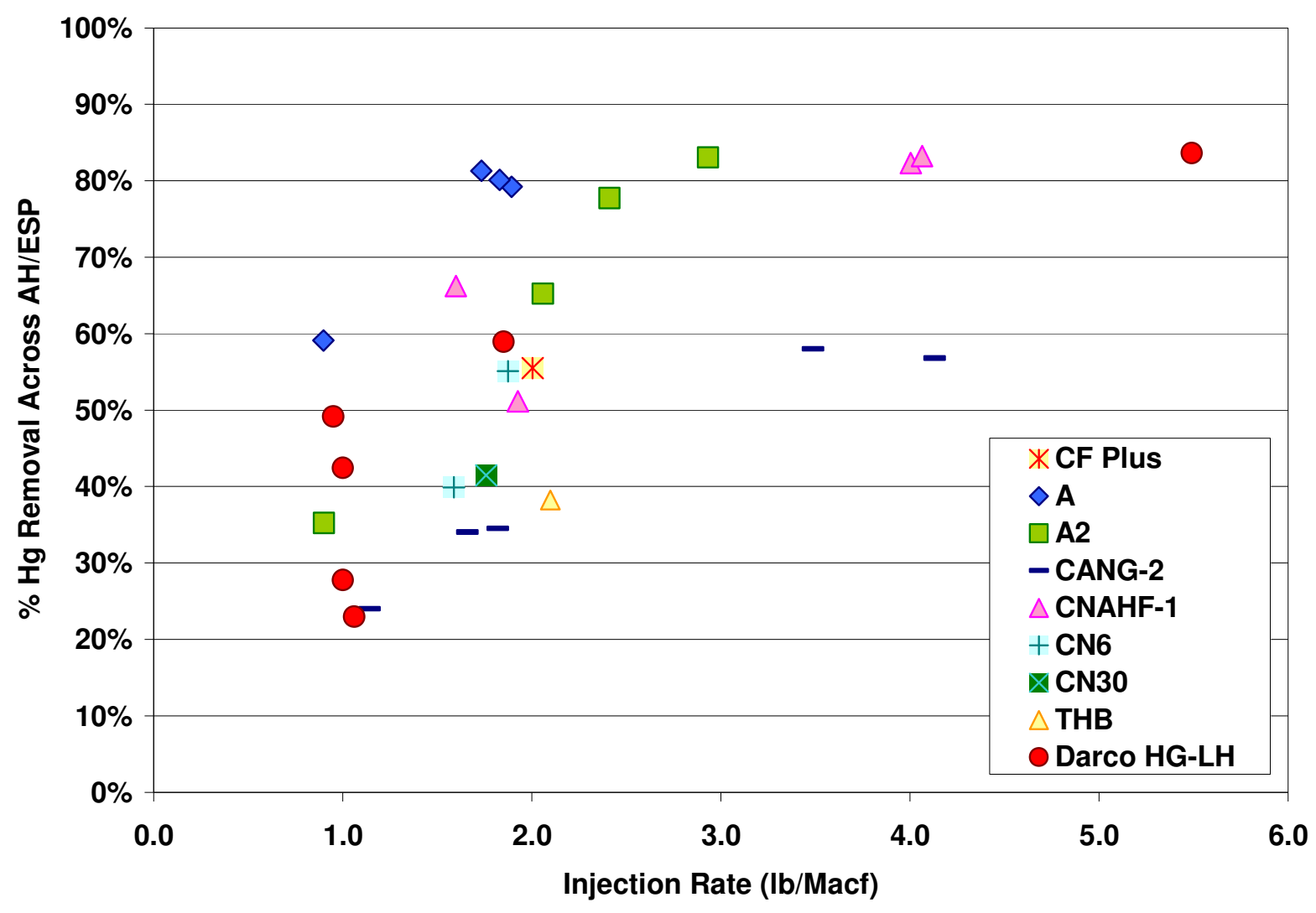

Figure 4-8. Mercury Removal across AH/ESP for Calgon Sorbents Injected with the Dispersion Lances (Injection of Upstream of Unit 2C ESP)

Table 4-21. Duct Location for Sorbent Trap Traverse Testing

\begin{tabular}{||c|c|c|c|c|c|c||}
\hline \hline $\begin{array}{c}\text { ACI Rate } \\
\text { (lb/Macf) }\end{array}$ & $\begin{array}{c}\text { Carbon } \\
\text { Injected }\end{array}$ & $\begin{array}{c}\text { Date in } \\
\mathbf{2 0 0 9}\end{array}$ & Start Time & End Time & Duct Location & Duct Depth (ft) \\
\hline 0.95 & Darco Hg-LH & $7 / 21$ & $11: 29$ & $13: 09$ & A,B,C & 6 \\
\hline 1.85 & Darco Hg-LH & $7 / 21$ & $14: 10$ & $15: 49$ & A,B,C & 6 \\
\hline 1.06 & Darco Hg-LH & $7 / 22$ & $10: 54$ & $12: 36$ & A,B,C & 6 \\
\hline 1.06 & Darco Hg-LH & $7 / 22$ & $13: 15$ & $14: 53$ & A,B,C & 6 \\
\hline 1.06 & Darco Hg-LH & $7 / 22$ & $15: 31$ & $17: 09$ & A,B,C & 6 \\
\hline 1.01 & Darco Hg-LH & $7 / 23$ & $11: 23$ & $12: 58$ & A & $2,4,6$ \\
\hline 1.01 & Darco Hg-LH & $7 / 23$ & $13: 40$ & $15: 14$ & B & $2,4,6$ \\
\hline 1.01 & Darco Hg-LH & $7 / 23$ & $15: 58$ & $17: 33$ & C & $2,4,6$ \\
\hline
\end{tabular}


Table 4-22. Dispersion Lances: Sorbent Trap and SCEM Results at ESP Outlet

\begin{tabular}{|c|c|c|c|c|c|c|c|c|c|c|}
\hline \multirow{2}{*}{$\begin{array}{l}\text { ACI Rate } \\
\text { (lb/Macf) }\end{array}$} & \multirow{2}{*}{$\begin{array}{l}\text { Carbon } \\
\text { Injected }\end{array}$} & \multirow{2}{*}{ Date in 2009} & \multicolumn{2}{|c|}{ AveragingPeriod } & \multirow{2}{*}{$\begin{array}{c}\text { AH Inlet } \\
\text { Total } \mathrm{Hg}^{3} \\
\left(\mu \mathrm{g} / \mathrm{dNm}^{3}\right. \\
\left.\text { at } 3 \% \mathrm{O}_{2}\right)\end{array}$} & \multirow{2}{*}{$\begin{array}{c}\text { Sorbent } \\
\text { Trap } \\
\text { Traverse } \\
\text { Location }^{1}\end{array}$} & \multirow{2}{*}{\begin{tabular}{|c}
$\begin{array}{c}\text { ESP Outlet } \\
\text { Sorbent } \\
\text { Traps }\end{array}$ \\
$\mathbf{T} \square$ tal H \\
$(\mu \mathrm{g} / \mathrm{dNm} 3$ \\
at $\left.3 \% \mathrm{O}_{2}\right)$ \\
\end{tabular}} & \multirow{2}{*}{\begin{tabular}{|c|}
$\begin{array}{c}\text { ESP Outlet } \\
\text { SCEM }\end{array}$ \\
$\begin{array}{c}\text { Total } \mathbf{~ H g} \\
\left(\mu \mathrm{g} / \mathbf{d N m}^{3}\right.\end{array}$ \\
at 3\% $\left.\mathrm{O}_{2}\right)$ \\
\end{tabular}} & \multicolumn{2}{|c|}{$\begin{array}{c}\text { \% RemovalAcross } \\
\text { AH/ESP }\end{array}$} \\
\hline & & & Start Time & EndTime & & & & & $\begin{array}{c}\text { Sorbent } \\
\text { Trap }\end{array}$ & SCEM \\
\hline 0.95 & $\begin{array}{c}\text { Darco Hg- } \\
\text { LH }\end{array}$ & $7 / 21$ & $11: 29$ & 13:09 & 21.9 & Bottom & 12.9 & 10.6 & $41 \%$ & $52 \%$ \\
\hline 1.85 & $\begin{array}{c}\text { Darco Hg- } \\
\text { LH }\end{array}$ & $7 / 21$ & $14: 10$ & $15: 49$ & 22.6 & Bottom & 8.8 & 9 & $61 \%$ & $60 \%$ \\
\hline 1.06 & $\begin{array}{l}\text { Darco Hg- } \\
\text { LH }\end{array}$ & $7 / 22$ & $10: 54$ & $12: 36$ & 24.1 & Bottom & 15.8 & 17.4 & $34 \%$ & $28 \%$ \\
\hline 1.06 & $\begin{array}{c}\text { Darco Hg- } \\
\text { LH }\end{array}$ & $7 / 22$ & $13: 15$ & $14: 53$ & 23.3 & Middle & 18.4 & 17.8 & $21 \%$ & $23 \%$ \\
\hline 1.06 & $\begin{array}{c}\text { Darco Hg- } \\
\text { LH }\end{array}$ & $7 / 22$ & $15: 31$ & 17:09 & 19.7 & Top & 19.6 & 17.6 & $1 \%$ & $10 \%$ \\
\hline 1.01 & $\begin{array}{c}\text { Darco Hg- } \\
\text { LH }\end{array}$ & $7 / 23$ & $11: 23$ & $12: 58$ & 21.2 & North & 17.9 & 14.7 & $16 \%$ & $31 \%$ \\
\hline 1.01 & $\begin{array}{l}\text { Darco Hg- } \\
\text { LH }\end{array}$ & $7 / 23$ & $13: 40$ & $15: 14$ & 19 & Center & 15.3 & 14.3 & $19 \%$ & $25 \%$ \\
\hline 1.01 & $\begin{array}{c}\text { Darco Hg- } \\
\text { LH }\end{array}$ & $7 / 23$ & $15: 58$ & $17: 33$ & 18.6 & South & 16.8 & 12.7 & $10 \%$ & $32 \%$ \\
\hline
\end{tabular}

${ }^{1}$ Bottom indicates that all three ports in duct were traversed at 6' depth; middle indicates that all three ports were traversed at 4' depth; top indicates that all three ports in duct were traversed at 2' depth; north indicates north-most port traversed at three depths $\left(2^{\prime}, 4^{\prime}, 6^{\prime}\right)$; center indicates center-most port traversed at three depths; south indicates south-most port traversed at three depths.

${ }^{2}$ Mercury removal calculated by comparing the AH Inlet SCEM data to each measurement method at the ESP outlet. 


\subsection{Effects of Sorbent Injection on Concrete Properties}

An objective of this test program was to determine the effect of ACI on fly ash quality. Refer to Section 3.9 for a general explanation of the effect of ACI on replacement of cement with fly ash in concrete mixtures.

Fly ash samples were collected during parametric sorbent injection tests and analyzed to determine how sorbent content impacted the fly ash properties applicable to its use as a cement replacement in concrete. Concrete tests conducted on samples from the 20062007 tests at LMS indicated that a carbon injection rate of $2 \mathrm{lb} / \mathrm{Macf}$ Darco Hg-LH was marginally acceptable for maintaining fly ash integrity for use as a cement replacement. During Phase IV testing, carbon injection rates ranged from $0.5 \mathrm{lb} / \mathrm{Macf}$ to $2.0 \mathrm{lb} / \mathrm{Macf}$. Two types of sorbents were were evaluated, including brominated sorbents and ash compatible sorbents (some of which were also brominated).

The Phase IV test results showed that a carbon injection rate of $2 \mathrm{lb} / \mathrm{Macf}$ may be too high to sell fly ash for cement replacement due to its significant effects on the air entraining properties of the resulting concrete mixture. Phase IV tests also showed that ash compatible sorbents had no impact on the air entrainment properties of a concrete mixture at injection rates of up to $1 \mathrm{lb} / \mathrm{Macf}$, whereas injection of brominated carbon at rates as low as $0.5 \mathrm{lb} / \mathrm{Macf}$ significantly affected concrete air content. Higher injection rates of ash compatible sorbents were not tested.

Headwaters, Inc. evaluated the following fly ash properties of samples obtained from either first field hopper $2 \mathrm{~F} 2 \mathrm{C}$ or from the top of the silo used to store fly ash collected from the ESP:

- Foam index;

- LOI and carbon analysis; and

- Particle size analysis.

A series of concrete mixtures were made with $25 \%$ of the cement replaced by fly ash samples obtained from first field hopper $2 \mathrm{~F} 2 \mathrm{C}$. The following properties of the concrete were compared to a control sample prepared with no fly ash:

- Air pressure;

- Air entraining agent (AEA) demand;

- Slump;

- Compressive strength; and

- Petrographic analyses on hardened concrete.

Obtaining a representative sample of fly ash for testing is difficult. The fly ash that is used to make concrete has been somewhat mixed by the various handling processes that 
take it from the ESP through storage silos to the truck that conveys it offsite. In contrast, fly ash from the storage silo is more stratified because the ESP is evacuated one field at a time. Fly ash sampled from the top of the silo may be from a front field or a back field of the ESP. Because the back field ash at Limestone is richer in carbon conent and finer in particle size than the front field, silo samples obtained after a back field has been evacuated tend to have high foam index titration results. The ideal fly ash sampling scheme is to collect individual hopper samples from each field of the ESP and then mix them in proportion to the amount of ash collected by the hopper. During this program, only the first and fourth fields of the U2 ESP were equipped with sampling valves; most days, little to no ash could be obtained from the fourth field. Therefore, individual hopper samples are presented for the first field only. The first field of the ESP collects $94 \%$ of the fly ash.

During Phase IV tests, samples were gathered almost daily from the top of the silo by Headwaters LMS staff and from hopper 2F2C by URS staff. Headwaters analyzed selected silo and hopper samples for foam index, LOI, carbon, and particle size (Tables 4-23 and 4-24). Concrete samples made with selected hopper samples were characterized for air pressure, slump, water/cement ratio, and compressive strength. The results in Table 4-25 are for concrete mixtures made at a fixed dose of AEA (4.5 g of Micro Air additive), while the results in Table 4-26 are for samples where the AEA dose was modified to obtain a target percentage of air in the concrete mixture (5-7\% air).

Table 4-23. Silo Fly Ash Characterization Results

\begin{tabular}{||l|c|c|c|c|c|c||}
\hline Date/Time & $\begin{array}{c}\text { Carbon } \\
\text { Type }\end{array}$ & $\begin{array}{c}\text { Injection Rate } \\
(\mathbf{l b} / \text { Macf) }\end{array}$ & $\begin{array}{c}\text { Foam Index } \\
\text { (Drops) }\end{array}$ & $\begin{array}{c}\text { Carbon } \\
\text { by Leco } \\
(\%)\end{array}$ & LOI (\%) & $\begin{array}{c}\text { Mean } \\
\text { Particle } \\
\text { Size }(\mu \mathbf{m})\end{array}$ \\
\hline \hline $\begin{array}{l}6 / 11 / 09 \\
13: 30\end{array}$ & None & N/A & 4 & 0.08 & 0.06 & 22.7 \\
\hline $\begin{array}{l}6 / 15 / 09 \\
08: 10\end{array}$ & $\begin{array}{c}\text { Darco Hg } \\
\text { LH }\end{array}$ & $0.48^{*}$ & 23 & 0.33 & 0.44 & 10.2 \\
\hline $\begin{array}{l}6 / 15 / 09 \\
16: 00\end{array}$ & $\begin{array}{c}\text { Darco Hg } \\
\text { LH }\end{array}$ & 0.48 & 14 & 0.18 & 0.20 & 30.8 \\
\hline $\begin{array}{l}6 / 16 / 09 \\
14: 30\end{array}$ & $\begin{array}{c}\text { Darco Hg } \\
\text { LH }\end{array}$ & 0.48 & 12 & 0.14 & 0.14 & 27.0 \\
\hline $\begin{array}{l}6 / 13 / 09 \\
16: 40\end{array}$ & $\begin{array}{c}\text { Darco Hg } \\
\text { LH }\end{array}$ & 1.89 & 3 & 0.07 & 0.07 & 15.0 \\
\hline $\begin{array}{l}6 / 14 / 09 \\
16: 40\end{array}$ & $\begin{array}{c}\text { Darco Hg } \\
\text { LH }\end{array}$ & 1.89 & 20 & 0.28 & 0.35 & 10.9 \\
\hline \hline
\end{tabular}

* Silo sample taken after only six hours at $0.48 \mathrm{lb} / \mathrm{Macf}$ injection rate. Previous injection rate had been 1.89 lb/Macf. Silo sample likely biased high by presence of ash from the higher injection rate. 
Table 4-24. Hopper Fly Ash Sample Characterization Results (Hopper 2F2C)

\begin{tabular}{||c|c|c|c|c|c|c||}
\hline Date/Time & $\begin{array}{c}\text { Carbon } \\
\text { Type }\end{array}$ & $\begin{array}{c}\text { Injection Rate } \\
\text { (lb/Macf) }\end{array}$ & $\begin{array}{c}\text { Foam Index } \\
\text { (Drops) }\end{array}$ & $\begin{array}{c}\text { Carbon } \\
\text { by Leco } \\
(\%)\end{array}$ & LOI (\%) & $\begin{array}{c}\text { Mean } \\
\text { Particle } \\
\text { Size ( } \mu \text { m) }\end{array}$ \\
\hline \hline $\begin{array}{l}6 / 11 / 09 \\
17: 54\end{array}$ & None & N/A & 5 & 0.08 & 0.06 & 11.9 \\
\hline $\begin{array}{l}6 / 12 / 09 \\
17: 00\end{array}$ & None & N/A & 5 & 0.07 & 0.09 & 11.0 \\
\hline $\begin{array}{l}6 / 16 / 2009 \\
15: 40\end{array}$ & $\begin{array}{c}\text { Darco Hg } \\
\text { LH }\end{array}$ & 0.48 & 9 & 0.14 & 0.20 & 12.0 \\
\hline $\begin{array}{l}6 / 18 / 2009 \\
16: 00\end{array}$ & $\begin{array}{c}\text { Darco Hg } \\
\text { LH }\end{array}$ & 0.99 & 8 & 0.18 & 0.21 & 12.2 \\
\hline $\begin{array}{l}6 / 28 / 2009 \\
8: 20\end{array}$ & $\begin{array}{c}\text { Darco Hg } \\
\text { LH }\end{array}$ & 1.00 & 8 & 0.20 & 0.24 & 12.5 \\
\hline $\begin{array}{l}6 / 28 / 2009 \\
15: 00\end{array}$ & $\begin{array}{c}\text { Darco Hg } \\
\text { LH }\end{array}$ & 1.83 & 10 & 0.24 & 0.22 & 11.9 \\
\hline $\begin{array}{l}6 / 14 / 2009 \\
16: 10\end{array}$ & $\begin{array}{c}\text { Darco Hg } \\
\text { LH }\end{array}$ & 1.89 & 16 & 0.29 & 0.31 & 10.7 \\
\hline $\begin{array}{l}6 / 23 / 09 \\
16: 10\end{array}$ & CF Plus & 0.95 & 4 & 0.08 & 0.07 & 15.5 \\
\hline $\begin{array}{l}6 / 24 / 09 \\
16: 00\end{array}$ & EXP224 & 0.95 & 4 & 0.11 & 0.13 & 11.9 \\
\hline $\begin{array}{l}6 / 22 / 09 \\
16: 30\end{array}$ & CPAC & 0.96 & 4 & 0.17 & 0.17 & 11.7 \\
\hline \hline
\end{tabular}

\section{Foam Index}

Foam index is the primary test used to determine whether fly ash from LMS can be sold for cement replacement applications. Headwaters prefers that the foam index remain below 10 drops, but will sometimes accept foam index results that are several drops higher. Foam index results for silo ash samples obtained during the first several days of injection testing (6/14/09 at 16:40 and 6/15/09 at 08:10) exceeded Headwater's established limit for fly ash cement replacement. The 6/14/09 sample was taken after two days of injection at $1.89 \mathrm{lb} / \mathrm{Macf}$ Darco Hg-LH. The foam index of 16 for this sample was on the outer limits of acceptability for sale of the LMS fly ash as a cement replacement product. The silo ash sample from the same time period had a higher foam index of 20, likely due to inclusion of carbon-rich fly ash captured in the back fields of the ESP.

The injection rate was decreased to $0.48 \mathrm{lb} / \mathrm{Macf}$ on 6/15/09 at 02:30. The next silo sample was taken six hours later and had a foam index of 23 , which was higher than expected and is most likely due to the carryover of ash from the $1.89 \mathrm{lb} / \mathrm{Macf}$ test. Subsequent silo samples taken at $0.48 \mathrm{lb} / \mathrm{Macf}$ had foam indices between $12-14$, which was just within Headwater's criterion for acceptability.

Based on foam index results from the first three days of ACI tests, no Unit 2 fly ash was marketed for concrete use when an injection rate greater than $0.5 \mathrm{lb} / \mathrm{Macf}$ Darco $\mathrm{Hg}-\mathrm{LH}$ was used during the Phase IV test program. Ash for injection rates of $0.5 \mathrm{lb} / \mathrm{Macf}$ and lower of Darco $\mathrm{Hg}-\mathrm{LH}$ was deemed acceptable to market to the concrete industry. 
Table 4-25. Phase IV ACI Tests, Hopper Samples - Headwaters Concrete Results with Constant AEA Dosage

\begin{tabular}{|c|c|c|c|c|c|c|c|c|c|c|c|c|}
\hline $\begin{array}{c}\text { Test } \\
\text { Parameter }\end{array}$ & Units & $\begin{array}{l}\text { Passing } \\
\text { Criteria }\end{array}$ & $\begin{array}{c}\text { Control } \\
\text { with } \\
\text { Portland } \\
\text { Cement } \\
\text { (no ash) } \\
\end{array}$ & $\begin{array}{c}\text { Baseline } \\
\text { Fly Ash } \\
\text { 06/11/09 \& } \\
\text { 6/12/09 } \\
\end{array}$ & $\begin{array}{c}\text { Darco } \\
\text { Hg LH } \\
\text { 0.48 } \\
\text { lb/Macf } \\
\text { 06/16/09 } \\
\end{array}$ & $\begin{array}{c}\text { Darco Hg } \\
\text { LH 0.99 } \\
\text { lb/Macf } \\
\text { 06/18/09 }\end{array}$ & $\begin{array}{c}\text { Darco Hg } \\
\text { LH 1.0 } \\
\text { lb/Macf } \\
\text { 06/28/09 }\end{array}$ & $\begin{array}{c}\text { Darco Hg } \\
\text { LH 1.89 } \\
\text { lb/Macf } \\
\text { 06/14/09 }\end{array}$ & $\begin{array}{l}\text { Darco Hg } \\
\text { LH 1.83 } \\
\text { lb/Macf } \\
\text { 06/28/09 }\end{array}$ & $\begin{array}{c}\text { C-PAC } \\
0.96 \\
\text { lb/Macf } \\
\text { 06/22/09 } \\
\end{array}$ & $\begin{array}{c}\text { CF Plus } \\
0.95 \\
\text { lb/Macf } \\
06 / 23 / 09 \\
\end{array}$ & $\begin{array}{c}\text { EXP224 } \\
\text { 0.95 } \\
\text { lb/Macf } \\
\text { 06/24/09 } \\
\end{array}$ \\
\hline AEA & oz/cwt & $\begin{array}{c}\text { Steady } \\
\text { and low }\end{array}$ & 0.12 & 0.12 & 0.12 & 0.12 & 0.12 & 0.12 & 0.12 & 0.12 & 0.12 & 0.12 \\
\hline Air Pressure & $\%$ & $5-7$ & 6.2 & $7.2 / 6.2$ & 2.6 & 3.8 & 3.7 & 2.2 & 3.4 & 6.4 & 7.2 & 7.2 \\
\hline $\begin{array}{c}\text { Slump .25 } \\
\text { inch }\end{array}$ & Inches & $5-7$ & 6 & $6.5 / 6.25$ & 6 & 6.5 & 6.5 & 6 & 5.75 & 6 & 6.25 & 6.25 \\
\hline $\begin{array}{c}\text { Water to } \\
\text { Cement } \\
\text { Ratio }\end{array}$ & None & $\begin{array}{l}\text { Similar } \\
\text { to } \\
\text { Control }\end{array}$ & 0.53 & $0.48 / 0.51$ & 0.53 & 0.53 & 0.52 & 0.55 & 0.51 & 0.50 & 0.49 & 0.49 \\
\hline $\begin{array}{c}\text { 7-Day } \\
\text { Compressive } \\
\text { Strength }\end{array}$ & $\begin{array}{c}\text { Psi of } \\
\text { unconfined } \\
\text { compressive } \\
\text { strength }\end{array}$ & $\begin{array}{l}\text { Similar } \\
\text { to } \\
\text { Control }\end{array}$ & 3978 & $3482 / 3332$ & 3874 & 3565 & 3798 & 3180 & 3702 & 3565 & 3158 & 3324 \\
\hline $\begin{array}{c}\text { 28-Day } \\
\text { Compressive } \\
\text { Strength }\end{array}$ & $\begin{array}{c}\text { Psi of } \\
\text { unconfined } \\
\text { compressive } \\
\text { strength } \\
\end{array}$ & $\begin{array}{l}\text { Similar } \\
\text { to } \\
\text { Control }\end{array}$ & 5551 & $4963 / 5035$ & 5706 & 5484 & 5374 & 5117 & 5469 & 5527 & 4733 & 4886 \\
\hline
\end{tabular}


Table 4-26. Phase IV ACI Tests, Hopper Samples - Headwaters AEA Demand Test Concrete Results

\begin{tabular}{|c|c|c|c|c|c|c|}
\hline Test Parameter & Units & $\begin{array}{l}\text { Passing } \\
\text { Criteria }\end{array}$ & $\begin{array}{c}\text { Control } \\
\text { with } \\
\text { Portland } \\
\text { Cement } \\
\text { (no ash) }\end{array}$ & $\begin{array}{c}\text { Darco } \\
\text { Hg-LH } \\
1.0 \\
\text { lb/Macf } \\
\text { 06/18/09 }\end{array}$ & $\begin{array}{c}\text { Darco } \\
\text { Hg-LH } \\
1.0 \\
\text { lb/Macf } \\
06 / 28 / 09 \\
\end{array}$ & $\begin{array}{c}\text { Darco } \\
\text { Hg-LH } \\
1.9 \\
\text { lb/Macf } \\
\text { 06/14/09 }\end{array}$ \\
\hline AEA & oz/cwt & $\begin{array}{l}\text { Steady } \\
\text { and low }\end{array}$ & 0.12 & 0.16 & 0.19 & 0.32 \\
\hline Air Pressure & $\%$ & $5-7$ & 6.2 & 5.3 & 5.5 & 6.3 \\
\hline Slump .25 inch & inches & $5-7$ & 6 & 6.25 & 6.25 & 6.00 \\
\hline Water to Cement Ratio & none & $\begin{array}{l}\text { Similar } \\
\text { to } \\
\text { Control }\end{array}$ & 0.53 & 0.53 & 0.53 & 0.53 \\
\hline $\begin{array}{l}\text { 28-Day Compressive } \\
\text { Strength }\end{array}$ & $\begin{array}{l}\text { Psi of unconfined } \\
\text { compressive } \\
\text { strength }\end{array}$ & $\begin{array}{l}\text { Similar } \\
\text { to } \\
\text { Control }\end{array}$ & 5076 & 5535 & 5995 & 5080 \\
\hline
\end{tabular}

\section{$\underline{\text { LOI and Carbon Characterization }}$}

Carbon and LOI content were measured for silo and ESP hopper ash samples collected during from Phase IV tests; results of these analyses were shown in Tables 4-23 and 4-24, respectively. A strong linear correlation existed between the carbon and LOI results (Figure 4-9), with LOI levels on average $25 \%$ higher than the measured values for carbon content. LOI measurements determine a net weight loss of a sample whereas the LECO carbon analysis measures only the carbon content of the ash. Therefore, LOI measurements tend to be higher than the LECO carbon measurements.

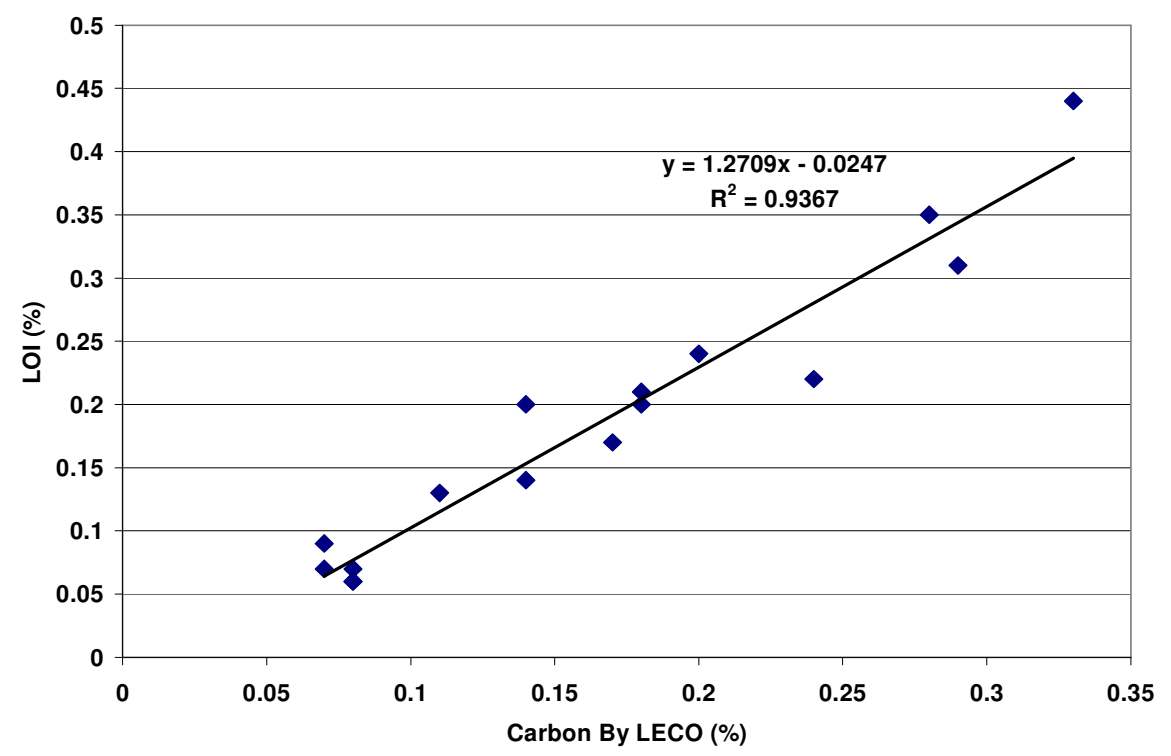

Figure 4-9. LOI versus Carbon Content for Phase IV Ash Samples 
Table 4-27 compares the measured carbon content of the fly ash to a theoretical carbon content based on the assumptions that $100 \%$ of the injected activated carbon was captured across the ESP and $85 \%$ of the coal ash reported as fly ash. The ash content was calculated for each day's coal blend percentage, using test-average ash contents of the PRB and TxL coals. For days where both hopper and silo data were available, there was excellent agreement between these samples. Figure 4-10 shows how the theoretical carbon content compared with the measured carbon content of the silo and hopper fly ash samples for various injection rates. Good agreement was observed for ash samples obtained when activated carbon was injected at a rate of $0.5 \mathrm{lb} / \mathrm{Macf}$; however, at higher injection rates both hopper and silo samples had carbon contents lower than the predicted values. This suggests that (1) these samples were not good representations of the actual carbon injection rates employed, and/or (2) the assumptions (such as average ash content) used to calculate the theoretical carbon content were not accurate for these sample periods.

Table 4-27. Carbon Content in First Field (2F2C) Fly Ash Samples (Theoretical vs. Measured)

\begin{tabular}{|l|l|c|c|c|c||}
\hline \multicolumn{1}{|c|}{ Date } & Carbon Type & $\begin{array}{c}\text { Injection Rate } \\
\text { (lb/Macf) }\end{array}$ & $\begin{array}{c}\text { Theoretical } \\
\text { Carbon } \\
\text { Content of Fly } \\
\text { Ash (\%) }\end{array}$ & $\begin{array}{c}\text { Hopper Fly } \\
\text { Ash Sample } \\
\text { Measured } \\
\text { Carbon } \\
\text { Content* (\%) }\end{array}$ & $\begin{array}{c}\text { Silo Fly Ash } \\
\text { Sample } \\
\text { Measured } \\
\text { Carbon } \\
\text { Content* (\%) }\end{array}$ \\
\hline \hline $6 / 11 / 09$ & None & N/A & & 0.08 & 0.08 \\
\hline $6 / 12 / 09$ & None & N/A & & 0.07 & - \\
\hline $6 / 13 / 09$ & Darco Hg LH & 1.89 & 0.37 & - & 0.07 \\
\hline $6 / 14 / 09$ & Darco Hg LH & 1.89 & 0.38 & 0.29 & 0.28 \\
\hline $6 / 15 / 09$ & Darco Hg LH & 0.48 & 0.15 & - & $0.33 / 0.18$ \\
\hline $6 / 16 / 09$ & Darco Hg LH & 0.48 & 0.16 & 0.14 & 0.14 \\
\hline $6 / 18 / 09$ & Darco Hg LH & 0.99 & 0.25 & 0.18 & - \\
\hline $6 / 22 / 09$ & C-PAC & 0.96 & 0.24 & 0.17 & - \\
\hline $6 / 23 / 09$ & EXP224 & 0.95 & 0.24 & 0.08 & - \\
\hline $6 / 24 / 09$ & CF Plus & 0.95 & 0.28 & 0.11 & - \\
\hline $6 / 28 / 09$ & Darco Hg LH & 1.0 & 0.26 & 0.20 & - \\
\hline $6 / 28 / 09$ & Darco Hg LH & 1.83 & 0.42 & 0.24 & - \\
\hline
\end{tabular}

*measured by the LECO method 


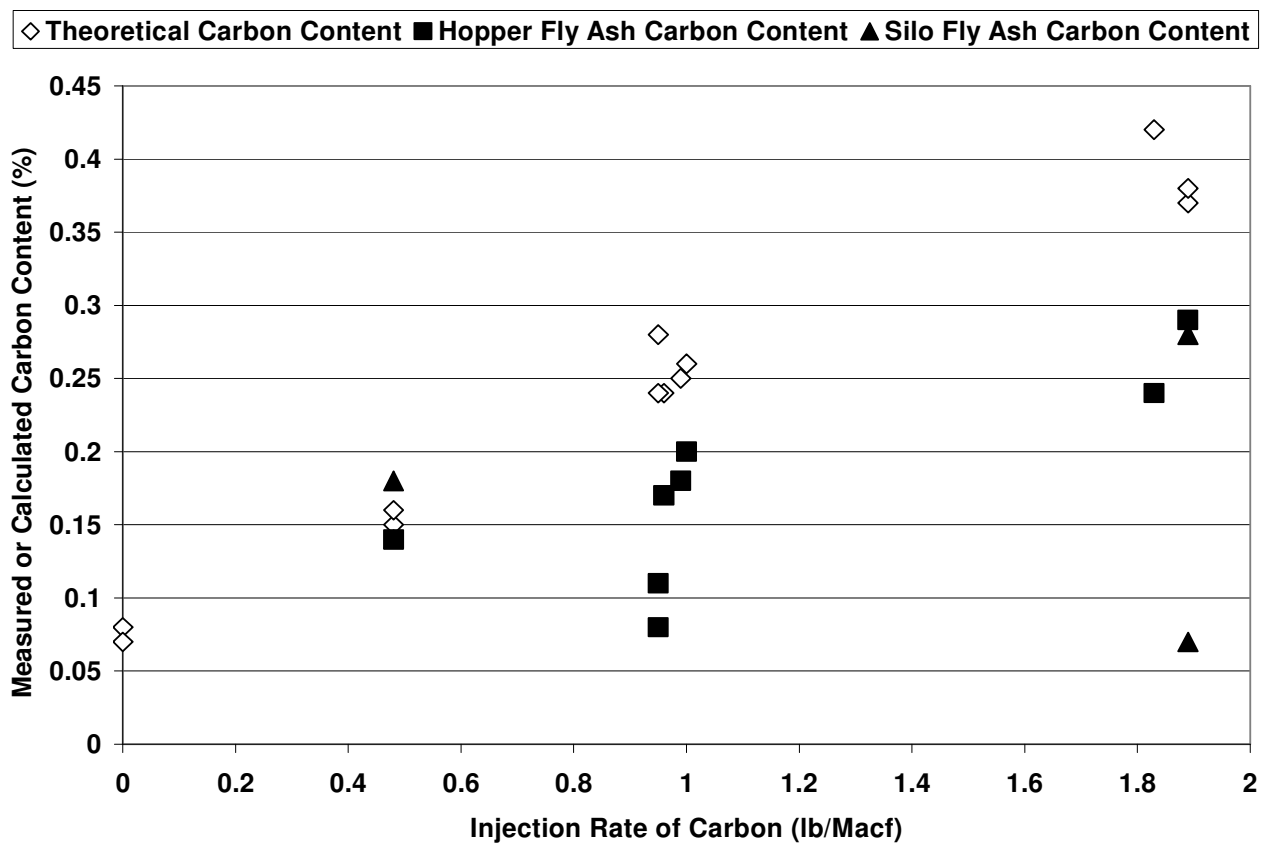

\section{Figure 4-10. Theoretical vs. Measured Carbon Content for Phase IV Fly Ash Samples}

\section{Foam Index}

Table 4-28 shows foam index results for simulated ash/carbon mixtures, while Figure 4-11 plots foam index for both hopper and silo fly ash samples taken during Phase IV parametric testing. The foam index increased with increased addition rate of Darco Hg-LH. In contrast, the foam index of the ash containing the ash-compatible carbons (EXP 224, CF Plus, CF Plus Ultra, CPAC) had a much slower rate of increase, indicating that these carbons offer an advantage over standard brominated carbons for preserving fly ash integrity. However, the ash-compatible carbons had lower mercury removals than their standard counterparts, so higher injection rates would be required for these sorbents to achieve a specific mercury removal target. The highest foam index results were seen for the Norit Finely Ground Darco Hg, even higher than the Darco $\mathrm{Hg}$-LH. This is likely due to a combination of two reasons; non-brominated carbons have a slightly higher foam index than their brominated counter parts, and as a finely ground carbon it has a larger surface area for the same mass of carbon than the non-ground carbons.

Table 4-28. Foam Index Results for Simulated Fly Ash

\begin{tabular}{||l|c|c|c|c|c||}
\hline \multirow{2}{*}{ Carbon } & \multicolumn{4}{|c||}{ Drops AEA Required at Simulated Injection Rate } \\
\cline { 2 - 6 } & $\begin{array}{c}\mathbf{0 . 0} \\
\text { (lb/Macf) }\end{array}$ & $\begin{array}{c}\mathbf{0 . 5} \\
\text { (lb/Macf) }\end{array}$ & $\begin{array}{c}\mathbf{1 . 0} \\
\text { (lb/Macf) }\end{array}$ & $\begin{array}{c}\mathbf{2 . 0} \\
\text { (lb/Macf) }\end{array}$ & $\begin{array}{c}\mathbf{3 . 0} \\
\text { (lb/Macf) }\end{array}$ \\
\hline EXP 224 & 3 & 3 & 3 & 4 & 7 \\
\hline Darco Hg-LH & 3 & 6 & 7 & 8 & 9 \\
\hline $\begin{array}{l}\text { Norit Finely Ground } \\
\text { Darco Hg }\end{array}$ & 3 & 6 & 7 & 10 & 14 \\
\hline CF Plus & 3 & 3 & 3 & 4 & 5 \\
\hline CF Plus Ultra & 3 & 3 & 3 & & 4 \\
\hline C-PAC & 3 & 3 & 3 & 4 & 6 \\
\hline
\end{tabular}




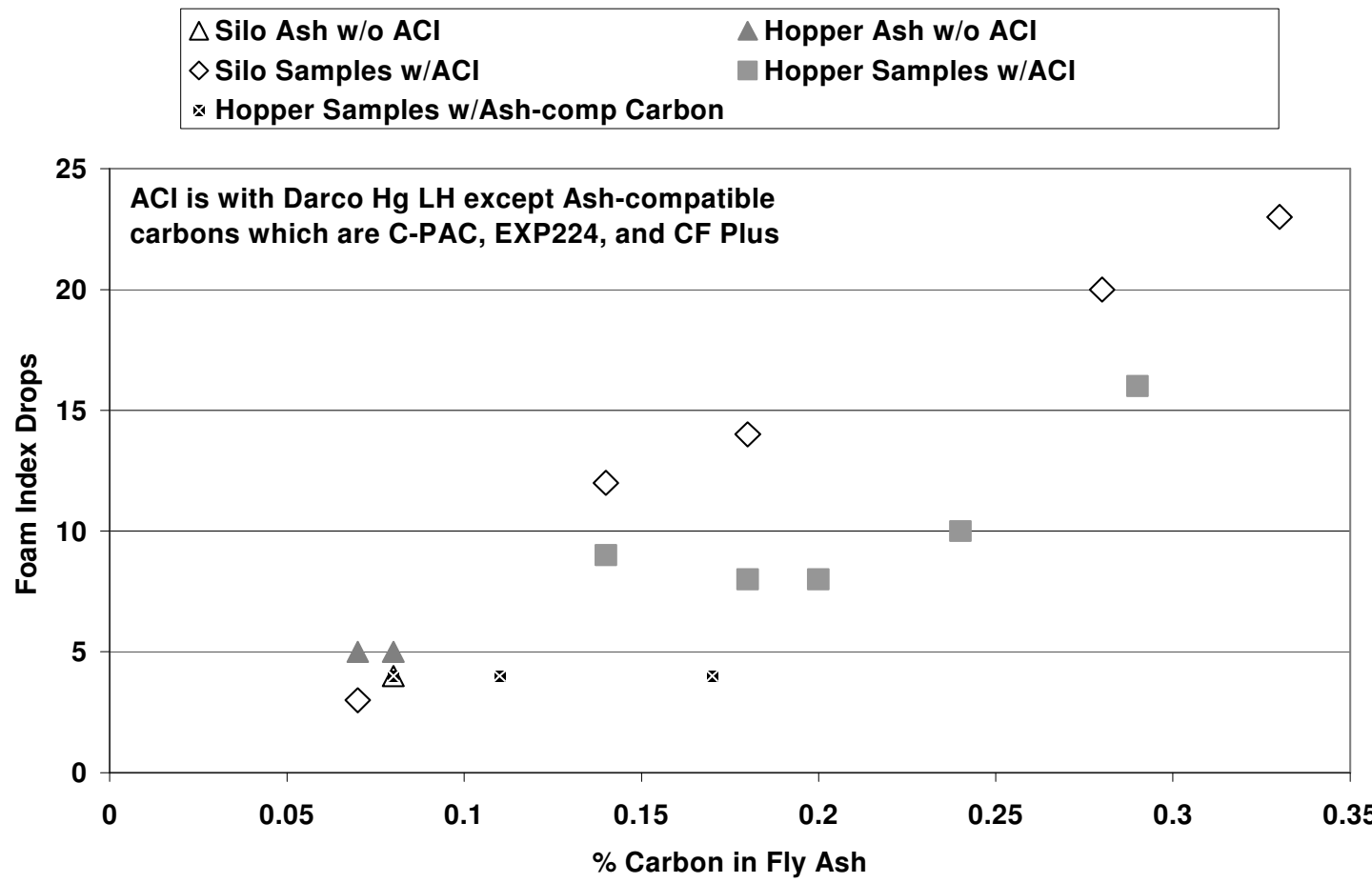

Figure 4-11. Foam Index Results versus Carbon Content for Phase IV Ash Samples

\section{$\underline{\text { Particle Size Analysis }}$}

Headwaters measured the median particle size of selected fly ash samples using a Horiba analyzer. There are no ASTM guidelines on median particle size of a fly ash sample for reuse as a cement replacement additive. As a guideline for fly ash particle size ASTM C618 does specify the acceptable range for percent retained on a 325 mesh sieve, but these tests were not conducted for the Phase IV tests.

Median particle size for Unit 2 hopper ash samples from the Phase IV tests ranged from 10.7 to $15.5 \mu \mathrm{m}$, which was lower than the Unit 1 typical median hopper ash particle size range of 13.1 to $19.5 \mu \mathrm{m}$. However, the median particle size of the Unit 2 silo ash samples ranged from 10.2 to $30.8 \mu \mathrm{m}$ providing evidence for the existence of larger particles than what were present in the hopper samples. There were no silo ash samples obtained from Unit 1 tests since the injected activated carbon treated only one-quarter of the Unit 1 flue gas.

\section{$\underline{\text { Air Content of Concrete Mixture }}$}

Table 4-25 shows the measured air content for concrete mixtures made at a fixed dose of AEA (4.5 $\mathrm{g}$ of Micro Air additive). The air content of the control concrete made with no fly ash was $6.2 \%$. Concrete made with the baseline fly ash samples (6/11/09 and 6/12/09; no ACI) had air contents of $7.2 \%$ and $6.2 \%$, respectively. An injection rate as low as $0.48 \mathrm{lb} / \mathrm{Macf}$ lowered the air pressure to $2.6 \%$, which was below the minimum acceptable value of $5 \%$. All of the concrete 
mixtures made with fly ash containing $1.0 \mathrm{lb} / \mathrm{Macf}$ ash-compatible sorbent had air contents in the acceptable range of 5\%-7\%. Due to time constraints, tests of the ash-compatible carbons were limited to a single day at $1.0 \mathrm{lb} / \mathrm{Macf}$. Based on these air entrainment results, further testing of the ash-compatible carbons at higher injection rates and for longer time periods is warranted.

The results in Table 4-26 are for samples where the AEA dose was modified to obtain a target percentage of air in the concrete mixture (5-7\% air). With additional AEA it is possible to make acceptable concrete mixtures from fly ash containing Darco $\mathrm{Hg} \mathrm{LH}$ carbon that meet the required air content specifications. An injection rate of $1 \mathrm{lb} /$ Macf required an AEA dose 30-60\% higher than the control concrete; an injection rate of 1.89 required an AEA does $166 \%$ greater than the control. In practice the higher AEA demand may not be acceptable beause it would likely be more unpredictable.

\section{Slump/Water to Cement Ratio/Compressive Strength}

Table 4-25 and 4-26 show results for slump, water-to-cement ratio, and compressive strength for the various concrete mixtures made with fly ash. All parameters were within the acceptable ranges for all samples.

\section{Petrographic Analyses}

In addition to freeze thaw testing, air void spacing is another commonly accepted test parameter to determine freeze thaw resistance. Petrographic analysis by ASTM C457 gives the air void spacing in cured concrete samples. ASTM C457 states that the air void spacing should be 0.004 to 0.008 inches to adequately protect against freeze thaw damage. Petrographic analyses were performed on concrete cylinders formed with hopper fly ash samples obtained from injection rates of 1.89, 0.99, and 1.0 lb/Macf Darco Hg-LH. All three samples met ASTM standards for void spacing values of $0.004,0.005$, and 0.005 inches, respectively. Complete petrographic analysis reults are in Appendix I.

\subsection{Characterization of Coal, Fly Ash, and FGD Absorber Slurry}

During Phase IV parametric tests several liquid and solid process streams were characterized including fly ash, coal, and FGD absorber solids and liquids. Coal samples were analyzed for ultimate and proximate composition. Tables 4-29 and 4-30 show the coal compositions for the TXL and PRB coals, respectively. Compared to PRB, the TXL coal had larger sample to sample variability in composition, as evidenced by the larger standard deviations for most coal properties. As shown in Figure 4-12, the TxL coal had significantly higher mercury content than the PRB coal (0.34 vs. $0.12 \mathrm{ppm}$, dry). Concentrations for other trace metals are presented in Section 4.6 which covers various trace metals measurements made at LMS during this test program.

Fly ash was tested for mercury content and LOI content. Table 4-31 shows ash mercury content for the different test conditions by field and a collection weighted average of the fields. The collection weighted average is based on plant data showing $94 \%$ of fly ash was collected in first field and $0.4 \%$ was collected in Fields $4 \& 5$. As expected, mercury content of the fly ash 
increased with activated carbon injection. Table 4-32 shows ash LOI for the different test conditions by field and a collection weighted average of the fields. Ash LOI increased during ACI, and in general was higher in Fields $4 \& 5$ and $6 \& 7$ than in Field 1.

FGD absorber solids and liquors were analyzed. Solids analyses are presented in Table 4-33 and liquor analyses are presented in Table 4-34. As expected, liquor bromide concentration increased by a factor of two during bromide injection compared to baseline. This heightened bromide concentration persisted during ACI the following two days due to the residence time of the liquor in the FGD system. The liquor bromide concentration of $500 \mathrm{ppm}$ was lower than the estimated value of $\sim 100,000 \mathrm{ppm}$ that would have been achieved if the bromide addition tests had lasted long enough for the FGD to achieve steady state operation. This estimated FGD Br concentration is based on the fact that bromide addition rate was approximately five times greater than $\mathrm{Cl}$ concentration of coal, and the FGD baseline $\mathrm{Cl}$ level is $\sim 20,000 \mathrm{ppm}$. 
Table 4-29. Summary of TxL Coal Analyses Results, Phase IV

\begin{tabular}{|c|c|c|c|c|c|c|c|c|c|c|c|c|c|}
\hline \multicolumn{14}{|c|}{ Coal Type: TxL } \\
\hline Date & $6 / 12 / 2009$ & 6/15/2009 & 6/18/2009 & $6 / 25 / 2009$ & $6 / 28 / 2009$ & $7 / 10 / 2009$ & $7 / 12 / 2009$ & $7 / 13 / 2009$ & 7/14/2009 & $7 / 16 / 2009$ & 7/18/2009 & Average & Std Dev \\
\hline Time & $13: 45$ & $6: 25$ & $8: 20$ & 16:00 & $8: 25$ & $8: 45$ & $8: 55$ & $7: 30$ & $8: 30$ & $7: 00$ & $8: 30$ & & \\
\hline$\%$ Total Moisture & 33.2 & 27.89 & 28.32 & 15.43 & 30.54 & 33.35 & 31.08 & 30.69 & 29.45 & 31.49 & 32.61 & 29.62 & 5.23 \\
\hline \multicolumn{14}{|l|}{ Dry Basis: } \\
\hline Heating Value Btu/lb & 10847 & 6910 & 8151 & 10641 & 8683 & 10641 & 9035 & 10075 & 7996 & 9716 & 10911 & 9670 & 1129 \\
\hline \% Carbon & 63.83 & & 48.58 & & & 62.71 & & & & & & 58.37 & 8.50 \\
\hline$\%$ Hydrogen & 4.52 & & 3.34 & & & 4.27 & & & & & & 4.04 & 0.62 \\
\hline$\%$ Nitrogen & 0.97 & & 0.7 & & & 0.97 & & & & & & 0.88 & 0.16 \\
\hline$\%$ Sulfur & 1.3 & 1.2 & 1.9 & 1.8 & 1.1 & 1.0 & 0.8 & 0.9 & 1.1 & 2.0 & 1.5 & 1.3 & 0.4 \\
\hline$\%$ Ash & 13.9 & 41.7 & 33.4 & 17.1 & 29.1 & 14.9 & 26.3 & 19.8 & 35.2 & 23.3 & 15.0 & 22.8 & 7.9 \\
\hline$\%$ Oxygen & 15.5 & & 12.0 & & & 16.1 & & & & & & 14.6 & 2.2 \\
\hline $\mathrm{Cl}(\mathrm{ppm})$ & 50 & 25 & 32 & 31 & 39 & 35 & 80 & & & 39 & 38 & 41 & 16 \\
\hline $\mathrm{Br}(\mathrm{ppm})$ & $<1$ & $<1$ & $<1$ & 9.6 & 10 & $<1$ & 10.6 & & & $<1$ & $<1$ & 4 & 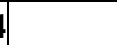 \\
\hline $\mathrm{Hg}(\mu \mathrm{g} / \mathrm{g})$ & 0.189 & 0.168 & 0.420 & 0.709 & 0.200 & 0.286 & 0.250 & 0.350 & 0.323 & 0.585 & 0.250 & 0.339 & 0.171 \\
\hline
\end{tabular}


Table 4-30. Summary of PRB Coal Analyses Results, Phase IV

\begin{tabular}{|c|c|c|c|c|c|c|c|c|c|c|c|c|c|}
\hline \multicolumn{14}{|c|}{ Coal Type: PRB } \\
\hline Date & $6 / 12 / 2009$ & $6 / 15 / 2009$ & $6 / 18 / 2009$ & $6 / 25 / 2009$ & $6 / 28 / 2009$ & 7/10/2009 & $7 / 12 / 2009$ & 7/13/2009 & $7 / 14 / 2009$ & 7/16/2009 & 7/18/2009 & Average & Std Dev \\
\hline Time & $13: 50$ & $6: 20$ & $8: 25$ & $15: 55$ & $8: 15$ & $8: 40$ & $8: 59$ & $7: 30$ & $8: 30$ & 7:00 & $8: 30$ & & \\
\hline$\%$ Total Moisture & 32.47 & 31.48 & 31.55 & 11.49 & 30.78 & 29.78 & 30.57 & 29.91 & 31.85 & 30.87 & 31.95 & 29.12 & 6.26 \\
\hline \multicolumn{14}{|l|}{ Dry Basis: } \\
\hline Heating Value Btu/lb & 11642 & 11611 & 11548 & 11725 & 11538 & 11857 & 11773 & 11741 & 11788 & 11792 & 11778 & 11718 & 107 \\
\hline$\%$ Carbon & 68.46 & & 67.13 & & & 68.7 & & & & & & 68.10 & 0.85 \\
\hline$\%$ Hydrogen & 4.64 & & 4.54 & & & 4.72 & & & & & & 4.63 & 0.09 \\
\hline$\%$ Nitrogen & 0.83 & & 0.73 & & & 0.75 & & & & & & 0.77 & 0.05 \\
\hline$\%$ Sulfur & 0.8 & 0.5 & 0.5 & 0.4 & 0.4 & 0.5 & 0.4 & 0.5 & 0.4 & 0.5 & 0.6 & 0.5 & 0.1 \\
\hline$\%$ Ash & 8.5 & 8.4 & 9.2 & 7.5 & 8.3 & 7.1 & 6.8 & 7.3 & 5.7 & 7.4 & 7.0 & 7.5 & 1.0 \\
\hline$\%$ Oxygen & 16.9 & & 17.9 & & & 18.2 & & & & & & 17.7 & 0.7 \\
\hline $\mathrm{Cl}(\mathrm{ppm})$ & 24 & 24 & 15 & 17 & 19 & 13 & 13 & & & 20 & 15 & 17 & 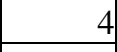 \\
\hline $\mathrm{Br}(\mathrm{ppm})$ & $<1$ & $<1$ & $<1$ & $<1$ & $<1$ & $<1$ & $<1$ & & & $<1$ & $<1$ & $<1$ & \\
\hline $\mathrm{Hg}(\mu \mathrm{g} / \mathrm{g})$ & 0.174 & 0.151 & 0.129 & 0.261 & & 0.092 & 0.063 & 0.104 & 0.071 & 0.070 & 0.087 & 0.120 & 0.062 \\
\hline
\end{tabular}




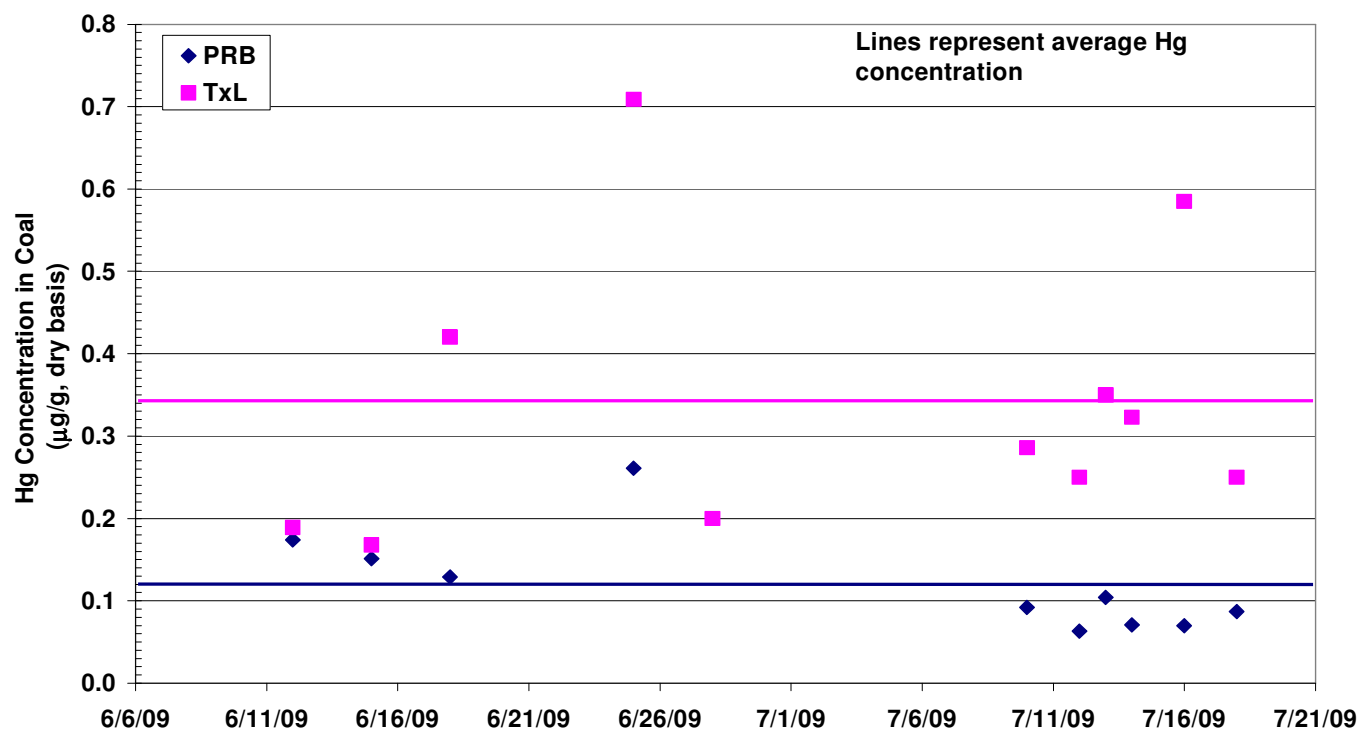

Figure 4-12. Coal Mercury Concentrations Measured during Phase IV Parametric Tests 
Table 4-31. Hg Concentration in Ash Samples from Phase IV Parametric Tests

\begin{tabular}{|c|c|c|c|c|c|c|}
\hline \multirow{3}{*}{ Condition } & \multirow{3}{*}{ Date } & \multirow{3}{*}{ Time } & \multicolumn{4}{|c|}{ Ash Hg Content $(\mu \mathrm{g} / \mathrm{g})$} \\
\hline & & & \multicolumn{4}{|c|}{ Field } \\
\hline & & & 1 & $4 \& 5$ & $6 \& 7$ & $\begin{array}{c}\text { All } \\
\text { Fields* }\end{array}$ \\
\hline & & & Avg & Avg & Avg & Avg \\
\hline Baseline & $6 / 11 / 2009$ & 1800 & 0.043 & 0.040 & 0.028 & 0.04 \\
\hline Baseline & $6 / 12 / 2009$ & 1700 & 0.047 & 0.039 & N/A & 0.05 \\
\hline Darco Hg LH 1.89 lb/Macf & $6 / 13 / 2009$ & 1755 & 0.128 & 0.084 & N/A & 0.13 \\
\hline Darco Hg LH 1.89 lb/Macf & $6 / 14 / 2009$ & 1615 & 0.586 & 0.177 & 0.061 & 0.58 \\
\hline Darco Hg LH 0.48lb/Macf & $6 / 15 / 2009$ & 1555 & 0.477 & 1.307 & 0.126 & 0.48 \\
\hline Darco Hg LH 0.48 lb/Macf & $6 / 16 / 2009$ & 1540 & 0.287 & 1.224 & 0.148 & 0.29 \\
\hline Darco Hg LH 0.99 lb/Macf & $6 / 17 / 2009$ & 1615 & 0.380 & 0.547 & 0.166 & 0.38 \\
\hline Darco Hg LH 0.99 lb/Macf & $6 / 18 / 2009$ & 1600 & 0.471 & 0.541 & 0.142 & 0.47 \\
\hline Baseline & $6 / 21 / 2009$ & 1615 & 0.033 & 0.809 & 0.064 & 0.04 \\
\hline Sorbtech C-PAC 0.96 lb/Macf & $6 / 22 / 2009$ & 1440 & 0.435 & 0.194 & 0.044 & 0.43 \\
\hline $\begin{array}{l}\text { Norit Hg LH EXP-224 } 0.95 \\
\text { lb/Macf }\end{array}$ & $6 / 23 / 2009$ & 1600 & 0.263 & 0.272 & 0.282 & 0.26 \\
\hline $\begin{array}{l}\text { Calgon FLUEPAC CF Plus } 0.95 \\
\text { lb/Macf }\end{array}$ & $6 / 24 / 2009$ & 1600 & 0.202 & 0.563 & 0.261 & 0.20 \\
\hline $\begin{array}{l}\text { Calgon CF Plus Ultra ( } 2 \text { bags); } \\
\text { Darco Hg-LH ( } 1 \text { bag) }\end{array}$ & $6 / 25 / 2009$ & $1630 / 1745$ & 0.279 & N/A & N/A & 0.28 \\
\hline $\begin{array}{l}\text { Alt fuel, Continuous ACI, Darco } \\
\mathrm{Hg} \text { LH } 1.00 \mathrm{lb} / \text { Macf }\end{array}$ & $6 / 28 / 2009$ & $820 / 1500$ & 0.630 & N/A & 0.254 & 0.63 \\
\hline Darco Hg 0.47 lb/Macf & $7 / 8 / 2009$ & 900 & 0.240 & 0.447 & N/A & 0.24 \\
\hline 171ppm Br to Coal & $7 / 9 / 2009$ & 1850 & 0.272 & N/A & N/A & 0.27 \\
\hline $\begin{array}{l}\text { 176ppm Br to Coal + Darco Hg } \\
0.47 \mathrm{lb} / \mathrm{Macf}\end{array}$ & $7 / 10 / 2009$ & 1600 & 0.484 & 0.375 & 0.397 & 0.48 \\
\hline $\begin{array}{l}\text { 164ppm Br to Coal + Darco Hg } \\
0.61 \mathrm{lb} / \mathrm{Macf}\end{array}$ & $7 / 11 / 2009$ & 1100 & 0.286 & 0.703 & N/A & 0.29 \\
\hline $\begin{array}{l}\text { 122ppm Br to Coal + Darco Hg } \\
0.48 \mathrm{lb} / \mathrm{Macf}\end{array}$ & $7 / 12 / 2009$ & $1200 / 1500$ & 0.708 & 0.592 & N/A & 0.71 \\
\hline $\begin{array}{l}\text { Darco Hg LH } 1.89 \mathrm{lb} / \mathrm{Macf} \\
\text { upstream ESP injection }\end{array}$ & $7 / 14 / 2009$ & 1420 & 0.627 & 0.646 & 0.105 & 0.63 \\
\hline $\begin{array}{l}\text { Darco Hg LH 0.48lb Macf/1.73 } \\
\text { lb/Macf upstream ESP injection }\end{array}$ & $7 / 15 / 2009$ & 1220 & 0.397 & 0.425 & 0.093 & 0.40 \\
\hline $\begin{array}{l}\text { Darco Hg LH } 1.06 \text { lb/Macf } \\
\text { upstream ESP injection }\end{array}$ & $7 / 22 / 2009$ & 1715 & 0.811 & N/A & N/A & 0.81 \\
\hline $\begin{array}{l}\text { Darco Hg LH } 1.01 \mathrm{lb} / \mathrm{Macf} \\
\text { upstream ESP injection }\end{array}$ & $7 / 23 / 2009$ & 1730 & 0.623 & N/A & N/A & 0.62 \\
\hline
\end{tabular}

* All fields average is a collection percentage weighted average of the fields, not a linear average. The fractional split is $0.994 / 0.004 / 0.002$ for fields $1 / 4 \& 5 / 6 \& 7$, respectively. 
Table 4-32. LOI of Ash Samples from Phase IV Parametric Tests

\begin{tabular}{|c|c|c|c|c|c|c|}
\hline \multirow{3}{*}{ Condition } & \multirow{3}{*}{ Date } & \multirow{3}{*}{ Time } & \multicolumn{3}{|c|}{ Ash LOI (\%) } & \multirow[b]{3}{*}{$\begin{array}{c}\text { All } \\
\text { Fields* }\end{array}$} \\
\hline & & & \multicolumn{3}{|c|}{ Field } & \\
\hline & & & 1 & $4 \& 5$ & $6 \& 7$ & \\
\hline & & & Avg & Avg & Avg & Avg \\
\hline Baseline & $6 / 11 / 2009$ & 1800 & 0.08 & 0.39 & 1.48 & 0.08 \\
\hline Baseline & $6 / 12 / 2009$ & 1700 & 0.10 & 0.45 & N/A & 0.10 \\
\hline Darco Hg LH 1.89 lb/Macf & $6 / 13 / 2009$ & 1755 & 0.16 & 0.27 & N/A & 0.16 \\
\hline Darco Hg LH 1.89 lb/Macf & $6 / 14 / 2009$ & 1615 & 0.30 & 0.43 & 0.98 & 0.30 \\
\hline Darco Hg LH 0.48lb/Macf & $6 / 15 / 2009$ & 1555 & 0.28 & 0.50 & 1.17 & 0.28 \\
\hline Darco Hg LH 0.48 lb/Macf & $6 / 16 / 2009$ & 1540 & 0.19 & 0.57 & 1.15 & 0.19 \\
\hline Darco Hg LH 0.99 lb/Macf & $6 / 17 / 2009$ & 1615 & 0.18 & 0.54 & 0.98 & 0.19 \\
\hline Darco Hg LH 0.99 lb/Macf & $6 / 18 / 2009$ & 1600 & 0.18 & 0.54 & 1.06 & 0.19 \\
\hline Baseline & $6 / 21 / 2009$ & 1615 & 0.04 & 0.58 & 1.32 & 0.04 \\
\hline Sorbtech C-PAC 0.96 lb/Macf & $6 / 22 / 2009$ & 1440 & 0.19 & 0.59 & 1.24 & 0.19 \\
\hline Norit Hg LH EXP-224 0.95 lb/Macf & $6 / 23 / 2009$ & 1600 & 0.14 & 0.54 & 0.42 & 0.14 \\
\hline Calgon FLUEPAC CF Plus 0.95 lb/Macf & $6 / 24 / 2009$ & 1600 & 0.13 & 0.37 & 0.27 & 0.13 \\
\hline $\begin{array}{l}\text { Calgon CF Plus Ultra ( } 2 \text { bags); Darco Hg-LH } \\
\text { (1 bag) }\end{array}$ & $6 / 25 / 2009$ & $1630 / 1745$ & 0.14 & $\mathrm{~N} / \mathrm{A}$ & $\mathrm{N} / \mathrm{A}$ & 0.13 \\
\hline $\begin{array}{l}\text { Alt fuel, Continuous ACI, Darco Hg LH } 1.00 \\
\text { lb/Macf }\end{array}$ & $6 / 28 / 2009$ & $820 / 1500$ & 0.25 & $\mathrm{~N} / \mathrm{A}$ & 0.86 & 0.25 \\
\hline Darco Hg 0.47 lb/Macf & $7 / 8 / 2009$ & 900 & 0.07 & 0.54 & $\mathrm{~N} / \mathrm{A}$ & 0.07 \\
\hline $171 \mathrm{ppm} \mathrm{Br}$ to Coal & $7 / 9 / 2009$ & 1850 & 0.06 & N/A & $\mathrm{N} / \mathrm{A}$ & 0.06 \\
\hline 176ppm Br to Coal + Darco Hg 0.47 lb/Macf & $7 / 10 / 2009$ & 1600 & 0.06 & 0.42 & 0.22 & 0.06 \\
\hline 164ppm Br to Coal + Darco Hg 0.61 lb/Macf & $7 / 11 / 2009$ & 1100 & 0.11 & 0.43 & N/A & 0.11 \\
\hline 122ppm Br to Coal + Darco Hg 0.48 lb/Macf & $7 / 12 / 2009$ & $1200 / 1500$ & 0.11 & 0.44 & $\mathrm{~N} / \mathrm{A}$ & 0.11 \\
\hline $\begin{array}{l}\text { Darco Hg LH } 1.89 \text { lb/Macf upstream ESP } \\
\text { injection }\end{array}$ & $7 / 14 / 2009$ & 1420 & 0.17 & 0.52 & 1.46 & 0.17 \\
\hline $\begin{array}{l}\text { Darco Hg LH 0.481b Macf/1.73 lb/Macf } \\
\text { upstream ESP injection }\end{array}$ & $7 / 15 / 2009$ & 1220 & 0.13 & 0.68 & 1.37 & 0.13 \\
\hline $\begin{array}{l}\text { Darco Hg LH } 1.06 \text { lb/Macf upstream ESP } \\
\text { injection }\end{array}$ & $7 / 22 / 2009$ & 1715 & 0.28 & N/A & N/A & 0.28 \\
\hline $\begin{array}{l}\text { Darco Hg LH } 1.01 \text { lb/Macf upstream ESP } \\
\text { injection }\end{array}$ & $7 / 23 / 2009$ & 1730 & 0.18 & $\mathrm{~N} / \mathrm{A}$ & N/A & 0.18 \\
\hline
\end{tabular}

* All fields average is a collection percentage weighted average of the fields, not a linear average. The fractional split is $0.994 / 0.004 / 0.002$ for fields $1 / 4 \& 5$ / $6 \& 7$, respectively. 
Table 4-33. FGD Absorber Solids Analyses for Phase IV

\begin{tabular}{|c|c|c|c|c|c|c|}
\hline Date & $6 / 11 / 2009$ & $6 / 12 / 2009$ & $6 / 18 / 2009$ & $7 / 12 / 2009$ & $7 / 13 / 2009$ & $7 / 14 / 2009$ \\
\hline Condition & Baseline & Baseline & ACI & $\mathrm{Br}+\mathrm{ACI}$ & Baseline & $\begin{array}{l}\text { Upstream } \\
\text { ESP ACI }\end{array}$ \\
\hline Time & $12: 15$ & $10: 30$ & $16: 45$ & $10: 45$ & $12: 50$ & $11: 20$ \\
\hline pH & & 5.82 & 5.68 & 5.60 & 5.62 & 5.64 \\
\hline Temperature & & & & 56 & 60 & 60.4 \\
\hline ORP & & 55 & -48.6 & & & \\
\hline ORP, actual & & 272 & 168.4 & 196.2 & 176.3 & 164 \\
\hline $\mathrm{Ca}, \mathrm{mg} / \mathrm{g}$ & 232 & 238 & 239 & 231 & 236 & 239 \\
\hline $\mathrm{Mg}, \mathrm{mg} / \mathrm{g}$ & 1.03 & 0.67 & 0.54 & 0.69 & 0.33 & 0.50 \\
\hline $\mathrm{SO3}, \mathrm{mg} / \mathrm{g}$ & $<7$ & $<7$ & $<7$ & $<7$ & $<7$ & $<7$ \\
\hline SO4, mg/g & 481 & 493 & 474 & 478 & 505 & 485 \\
\hline $\mathrm{CO3}, \mathrm{mg} / \mathrm{g}$ & 30.7 & 29.9 & 49.7 & 29.8 & 24.1 & 29.0 \\
\hline inerts, wt\% & 3.20 & 1.83 & 2.27 & 3.22 & 1.26 & 1.72 \\
\hline solids, wt \% & 2.18 & 2.92 & 2.38 & 3.00 & 7.91 & 7.68 \\
\hline oxidation, \% & 100.0 & 100.0 & 100.0 & 100.0 & 100.0 & 100.0 \\
\hline utilization, $\%$ & 89.3 & 89.6 & 84.8 & 89.4 & 91.7 & 89.1 \\
\hline \multicolumn{7}{|l|}{ Closures } \\
\hline Weight, \% & -4.2 & -3.5 & -3.6 & -4.8 & -3.3 & -4.7 \\
\hline Molar, \% & 2.8 & 2.9 & 1.9 & 2.9 & 2.2 & 4.1 \\
\hline
\end{tabular}

Table 4-34. FGD Absorber Liquor Analyses for Phase IV

\begin{tabular}{|c|c|c|c|c|c|c|}
\hline Date & $6 / 11 / 2009$ & $6 / 12 / 2009$ & $6 / 18 / 2009$ & $7 / 12 / 2009$ & $7 / 13 / 2009$ & $7 / 14 / 2009$ \\
\hline Condition & Baseline & Baseline & $\mathrm{ACI}$ & $\mathrm{Br}+\mathrm{ACI}$ & Baseline & $\begin{array}{l}\text { Upstream } \\
\text { ESP ACI }\end{array}$ \\
\hline $\mathrm{Ca}, \mathrm{mg} / \mathrm{L}$ & 855 & 861 & 843 & 832 & 867 & 861 \\
\hline Mg, mg/L & 2985 & 2791 & 3333 & 3302 & 3568 & 3705 \\
\hline $\mathrm{Na}, \mathrm{mg} / \mathrm{L}$ & 9837 & 8981 & 11014 & 11660 & 12657 & 12904 \\
\hline Br, mg/L & 203 & 184 & 235 & 508 & 529 & 503 \\
\hline $\mathrm{Cl}, \mathrm{mg} / \mathrm{L}$ & 15739 & 15097 & 18340 & 19089 & 20926 & 19901 \\
\hline $\mathrm{CO3}, \mathrm{mg} / \mathrm{L}$ & 210 & 145 & 169 & 169 & 173 & 184 \\
\hline SO3, mg/L & 5.29 & 3.94 & 3.08 & 3.02 & 3.17 & 4.45 \\
\hline SO4, mg/L & 13109 & 12107 & 14490 & 15438 & 15411 & 14735 \\
\hline \multicolumn{7}{|l|}{ Charge Imbalance } \\
\hline Calculated, \% & -2.3 & -3.2 & -3.5 & -4.3 & -3.5 & -0.1 \\
\hline
\end{tabular}




\subsection{Trace Metals Measurements}

\section{Trace Metals Measurements in Coal, Fly Ash, FGD, and Flue Gas}

During baseline, ACI (1.89 lb/Macf Darco Hg-LH), and ACI + Br (0.48 lb/Macf Darco Hg + 122 ppm Br to coal, dry basis) test days, trace element characterizations were performed on several process streams including coal, ESP ash, FGD liquors and solids, and flue gas at the ESP outlet and stack. These measurements were made to determine the effects of bromide addition and sorbent addition on the fate of trace elements across the system.

One sample of each coal type, PRB and TxL, was obtained for each test condition (baseline, ACI, ACI + Br). Table 4-35 shows the daily sample trace element concentrations as well as the averages over the three days. The 7/14/09 TxL sample was significantly lower in most trace metals concentrations than the 7/12/09 and 7/13/09 TxL samples. The trace metals concentrations of the three daily PRB samples were more consistent than the TxL samples. Because of the difficulties in obtaining representative coal samples, the average trace metals concentrations for each coal type were used for conducting mass balance calculations. A weighted average, blended fuel, trace element concentration was calculated for each day using the average PRB and TxL individual trace element concentrations measured. The daily weighted averages were based upon the BTU percentage of each type of fuel burned that day and are shown in Table 4-36.

Table 4-35. Trace Elements Concentrations for TxL and PRB Samples for July 12-14, 2009

\begin{tabular}{|c|c|c|c|c|c|c|c|c|}
\hline Date & \multicolumn{2}{|c|}{$7 / 7 / 12 / 09$} & \multicolumn{2}{|c|}{$7 / 7 / 13 / 09$} & \multicolumn{2}{|c|}{$\overline{7 / 74 / 09}$} & \multicolumn{2}{|c|}{ Average } \\
\hline Coal Type & PRB & TxL & PRB & TxL & PRB & TxL & PRB & TxL \\
\hline & \multicolumn{8}{|c|}{ Coal Trace Element Concentration (ppm, dry) } \\
\hline Ag & 0.1 & 0.2 & 0.1 & 0.4 & 0.1 & 0.1 & 0.1 & 0.2 \\
\hline As & 4.3 & 2.2 & 2.6 & 1.7 & 1.3 & 1.0 & 2.7 & 1.7 \\
\hline $\mathbf{B a}$ & 380 & 350 & 356 & 197 & 400 & 89.4 & 379 & 212 \\
\hline Be & 10 & NR & NR & NR & NR & NR & NR & NR \\
\hline Cd & 0.05 & 0.09 & 0.09 & 0.10 & 0.07 & 0.04 & 0.07 & 0.08 \\
\hline Co & 2.0 & 3.9 & 3.0 & 3.2 & 2.3 & 1.5 & 2.4 & 2.9 \\
\hline $\mathrm{Cr}$ & 5.8 & 23.3 & 5.2 & 17.2 & 4.6 & 4.9 & 5.2 & 15.1 \\
\hline $\mathbf{C u}$ & 8.9 & 16.7 & 11.9 & 20.7 & 9.1 & 4.5 & 10.0 & 14.0 \\
\hline $\mathbf{H g}$ & 0.1 & 0.3 & 0.1 & 0.4 & 0.1 & 0.3 & 0.1 & 0.3 \\
\hline Mn & 13.4 & 143 & 27.7 & 133 & 14.4 & 26.0 & 18.5 & 101 \\
\hline $\mathbf{N i}$ & 7.7 & 13.9 & 9.6 & 11.5 & 8.0 & 3.7 & 8.4 & 9.7 \\
\hline $\mathbf{P b}$ & 2.5 & 8.2 & 2.5 & 6.7 & 2.3 & 2.0 & 2.4 & 5.6 \\
\hline Sb & NR & NR & NR & NR & NR & NR & NR & NR \\
\hline Se & $<1$ & 7.4 & $<1$ & 5.3 & $<1$ & 4.1 & 1.0 & 5.6 \\
\hline Tl & 0.19 & 0.19 & 0.04 & 0.09 & 0.04 & 0.07 & 0.09 & 0.12 \\
\hline $\mathrm{V}$ & 12.7 & 48.5 & 18.1 & 40.9 & 14.8 & 10.7 & 15.2 & 33.4 \\
\hline $\mathbf{Z n}$ & 9.5 & 13.2 & 29.8 & 13.2 & 8.8 & 7.2 & 16.0 & 11.2 \\
\hline
\end{tabular}

$*$ NR indicates that that element was not analyzed. 


\section{Table 4-36. Weighted Average Coal Trace Elements Concentrations for July 12-14, 2009}

\begin{tabular}{|c|c|c|c|}
\hline Date & $7 / 13 / 09$ & $7 / 7 / 14 / 09$ & $\overline{77 / 12 / 09}$ \\
\hline Condition & Baseline & ACI & $\mathbf{A C I}+\mathbf{B r}$ \\
\hline $\begin{array}{r}\text { Coal Blend } \\
\text { Wt\% } \\
\text { TxL/PRB }\end{array}$ & $63 / 37$ & $64 / 36$ & $60 / 40$ \\
\hline & \multicolumn{3}{|c|}{ Coal Trace Element Concentration (lb/TBTU) } \\
\hline $\mathbf{A g}$ & 19.1 & 19.2 & 18.7 \\
\hline As & 205 & 204 & 209 \\
\hline Ba & 27246 & 27078 & 27812 \\
\hline Be & NR & NR & NR \\
\hline Cd & 7.3 & 7.3 & 7.3 \\
\hline Co & 268 & 269 & 267 \\
\hline $\mathbf{C r}$ & 1140 & 1151 & 1107 \\
\hline $\mathbf{C u}$ & 1244 & 1248 & 1230 \\
\hline $\mathbf{H g}$ & 22.2 & 22.5 & 21.5 \\
\hline Mn & 6998 & 7081 & 6719 \\
\hline Ni & 919 & 920 & 915 \\
\hline $\mathbf{P b}$ & 441 & 444 & 430 \\
\hline Sb & NR & NR & NR \\
\hline $\mathbf{S e}$ & 388 & 392 & 373 \\
\hline Tl & 10.6 & 10.6 & 10.5 \\
\hline $\mathbf{V}$ & 2653 & 2672 & 2591 \\
\hline $\mathbf{Z n}$ & 1293 & 1288 & 1309 \\
\hline
\end{tabular}

* NR indicates that that element was not analyzed.

Method 29 measurements were made in triplicate for each condition (baseline, ACI, and ACI + $\mathrm{Br}$ ) at the ESP outlet and stack locations; data for each run are listed in Appendix L. Tables 4-37 and 4-38 present the average emissions and 95\% confidence intervals for each measured species at the ESP outlet and stack, respectively, for each mercury control condition evaluated. The entry "ND" followed by parentheses indicates that the measured value was below the method detection limit, with the detection limit listed in the parentheses. 
Table 4-37. ESP Outlet Flue Gas Trace Metals Concentrations, Average of Three Runs for Each Test Condition

\begin{tabular}{|c|c|c|c|c|c|c|}
\hline \multirow{3}{*}{$\begin{array}{r}\text { Date } \\
\text { Condition }\end{array}$} & \multirow{2}{*}{\multicolumn{2}{|c|}{$\begin{array}{l}\text { 7/13/09 } \\
\text { Baseline }\end{array}$}} & \multirow{2}{*}{\multicolumn{2}{|c|}{$\begin{array}{c}7 / 14 / 09 \\
\text { ACI }\end{array}$}} & \multirow{2}{*}{\multicolumn{2}{|c|}{$\begin{array}{c}7 / 12 / 09 \\
\mathrm{ACI}+\mathrm{Br}\end{array}$}} \\
\hline & & & & & & \\
\hline & $\begin{array}{l}\text { ESP Outlet } \\
\text { Emissions } \\
\text { (lb/TBTU) }\end{array}$ & $\begin{array}{c}95 \% \\
\text { Confidence } \\
\text { Interval }\end{array}$ & $\begin{array}{l}\text { ESP Outlet } \\
\text { Emissions } \\
\text { (lb/TBTU) }\end{array}$ & $\begin{array}{c}95 \% \\
\text { Confidence } \\
\text { Interval }\end{array}$ & $\begin{array}{l}\text { ESP Outlet } \\
\text { Emissions } \\
\text { (lb/TBTU) }\end{array}$ & $\begin{array}{c}95 \% \\
\text { Confidence } \\
\text { Interval }\end{array}$ \\
\hline Ag & ND (0.3) & 0.2 & 0.4 & 0.1 & ND (0.2) & 0.0 \\
\hline As & ND (0.7) & 0.4 & ND (1.4) & 0.3 & ND (0.6) & 0.0 \\
\hline $\mathbf{B a}$ & 86.4 & 166 & 214 & 56.9 & 34.4 & 36.3 \\
\hline $\mathrm{Be}$ & 0.1 & 0.1 & 0.2 & 0.0 & 0.0 & 0.0 \\
\hline Cd & ND (0.1) & 0.0 & ND (0.1) & 0.1 & ND (0.1) & 0.0 \\
\hline Co & 0.8 & 1.0 & 2.3 & 0.3 & 0.3 & 0.4 \\
\hline $\mathrm{Cr}$ & ND (3.8) & 0.2 & 6.4 & 0.7 & 3.4 & 1.1 \\
\hline $\mathbf{C u}$ & 2.9 & 3.2 & 6.5 & 1.2 & 2.4 & 1.6 \\
\hline $\mathrm{Hg}$ & 17.6 & 12.9 & 9.6 & 3.9 & 9.4 & 1.3 \\
\hline Mn & 29.6 & 45.5 & 71.5 & 68.0 & 14.9 & 11.2 \\
\hline $\mathbf{N i}$ & ND (3.0) & 0.7 & ND (4.3) & 0.3 & 3.7 & 2.3 \\
\hline $\mathbf{P b}$ & 2.7 & 6.6 & 4.7 & 0.9 & ND (2.4) & 5.3 \\
\hline Sb & ND (0.4) & 0.2 & $\mathrm{ND}(0.7)$ & 0.1 & ND (0.4) & 0.1 \\
\hline Se & 471 & 485 & 548 & 126 & 580 & 96.5 \\
\hline Tl & ND (0.1) & 0.1 & $\mathrm{ND}(0.2)$ & 0.0 & $\mathrm{ND}(0.1)$ & 0.0 \\
\hline $\mathbf{V}$ & 6.8 & 13.3 & 19.8 & 4.6 & 3.2 & 4.1 \\
\hline $\mathbf{Z n}$ & 10.9 & 4.0 & 13.7 & 2.5 & 10.0 & 10.4 \\
\hline
\end{tabular}

Table 4-38. Stack Flue Gas Trace Metals Concentrations, Average of Three Runs for Each Condition

\begin{tabular}{|c|c|c|c|c|c|c|}
\hline \multirow{3}{*}{\begin{tabular}{|r|} 
Date \\
Condition \\
\end{tabular}} & \multirow{2}{*}{\multicolumn{2}{|c|}{\begin{tabular}{|c|} 
7/13/09 \\
Baseline
\end{tabular}}} & \multirow{2}{*}{\multicolumn{2}{|c|}{$\begin{array}{c}7 / 14 / 09 \\
\text { ACI }\end{array}$}} & \multirow{2}{*}{\multicolumn{2}{|c|}{$\begin{array}{c}7 / 12 / 09 \\
\mathrm{ACI}+\mathrm{Br}\end{array}$}} \\
\hline & & & & & & \\
\hline & $\begin{array}{c}\text { Stack } \\
\text { Emissions } \\
\text { (lb/TBTU) }\end{array}$ & $\begin{array}{c}95 \% \\
\text { Confidence } \\
\text { Interval }\end{array}$ & $\begin{array}{c}\text { Stack } \\
\text { Emissions } \\
\text { (lb/TBTU) }\end{array}$ & $\begin{array}{c}95 \% \\
\text { Confidence } \\
\text { Interval }\end{array}$ & $\begin{array}{c}\text { Stack } \\
\text { Emissions } \\
\text { (lb/TBTU) }\end{array}$ & $\begin{array}{c}95 \% \\
\text { Confidence } \\
\text { Interval }\end{array}$ \\
\hline Ag & $\mathrm{ND}(0.2)$ & 0.0 & $\mathrm{ND}(0.2)$ & 0.0 & ND (0.3) & 0.1 \\
\hline As & ND (0.7) & 0.0 & $\mathrm{ND}(0.7)$ & 0.0 & $\mathrm{ND}(0.7)$ & 0.1 \\
\hline Ba & 22.7 & 13.1 & 38.3 & 19.3 & 18.8 & 3.9 \\
\hline Be & ND (0.0) & 0.0 & 0.0 & 0.0 & $\mathrm{ND}(0.0)$ & 0.0 \\
\hline Cd & ND (0.1) & 0.0 & ND (0.1) & 0.0 & ND (0.2) & 0.3 \\
\hline Co & 0.2 & 0.0 & 0.3 & 0.2 & 0.1 & 0.0 \\
\hline $\mathrm{Cr}$ & ND (2.9) & 0.8 & 12.0 & 36.7 & ND (3.2) & 0.8 \\
\hline $\mathbf{C u}$ & 1.2 & 0.3 & 2.0 & 0.5 & 1.3 & 0.4 \\
\hline $\mathrm{Hg}$ & 11.4 & 6.4 & 5.7 & 2.0 & 5.3 & 0.5 \\
\hline Mn & 48.6 & 19.8 & 57.5 & 63.3 & 15.2 & 9.1 \\
\hline $\mathbf{N i}$ & ND (2.9) & 1.8 & ND (4.3) & 4.1 & ND (2.6) & 0.8 \\
\hline $\mathbf{P b}$ & ND (1.2) & 0.2 & ND (1.6) & 0.19 & ND (1.6) & 0.3 \\
\hline $\mathbf{S b}$ & ND (0.4) & 0.0 & ND (0.4) & 0.1 & ND (0.4) & 0.0 \\
\hline Se & 62.9 & 9.8 & 58.2 & 6.4 & 81.0 & 25.5 \\
\hline Tl & ND (0.1) & 0.0 & ND (0.1) & 0.0 & ND (0.1) & 0.0 \\
\hline $\mathbf{V}$ & 1.8 & 0.9 & 3.8 & 2.0 & 1.6 & 0.6 \\
\hline $\mathbf{Z n}$ & 6.8 & 3.2 & 6.7 & 4.7 & 11.8 & 5.1 \\
\hline
\end{tabular}


Trace metal removals were calculated by comparing the measured emission rates of the various species at each sampling location (ESP outlet or stack) to the coal input rate; results are tabulated in Table 4-39. Those values marked with an NC were not calculable because both the coal and M29 concentrations were below the analytical detection limit. Those values with a greater than symbol indicate that removal was at least that value because the M29 measurement values were below the detection limit.

Table 4-39. Trace Metals Removal from Coal to ESP Outlet and Coal to Stack

\begin{tabular}{|c|c|c|c|c|c|c|}
\hline Date & \multicolumn{2}{|c|}{$7 / 13 / 09$} & \multirow{2}{*}{\multicolumn{2}{|c|}{$\begin{array}{c}7 / 14 / 09 \\
\text { ACI }\end{array}$}} & \multicolumn{2}{|c|}{$7 / 7 / 12 / 09$} \\
\hline Condition & \multicolumn{2}{|c|}{ Baseline } & & & \multicolumn{2}{|c|}{$\mathrm{ACI}+\mathrm{Br}$} \\
\hline & $\begin{array}{c}\text { Coal to ESP } \\
\text { Outlet } \\
\text { Removal }\end{array}$ & $\begin{array}{c}\text { Coal to } \\
\text { Stack } \\
\text { Removal }\end{array}$ & $\begin{array}{c}\text { Coal to ESP } \\
\text { Outlet } \\
\text { Removal }\end{array}$ & $\begin{array}{c}\text { Coal to } \\
\text { Stack } \\
\text { Removal }\end{array}$ & $\begin{array}{c}\text { Coal to ESP } \\
\text { Outlet } \\
\text { Removal }\end{array}$ & $\begin{array}{c}\text { Coal to } \\
\text { Stack } \\
\text { Removal }\end{array}$ \\
\hline Ag & $>98.5 \%$ & $>98.8 \%$ & $97.8 \%$ & $>98.9 \%$ & $>98.8 \%$ & $>98.5 \%$ \\
\hline As & $>99.7 \%$ & $>99.7 \%$ & $>99.3 \%$ & $>99.7 \%$ & $>99.7 \%$ & $>99.7 \%$ \\
\hline $\mathbf{B a}$ & $99.7 \%$ & $99.9 \%$ & $99.2 \%$ & $99.9 \%$ & $99.9 \%$ & $99.9 \%$ \\
\hline $\mathbf{B e}$ & $\mathrm{NC}$ & $\mathrm{NC}$ & $\mathrm{NC}$ & $\mathrm{NC}$ & $\mathrm{NC}$ & $\mathrm{NC}$ \\
\hline Cd & $>98.8 \%$ & $>98.9 \%$ & $>98.2 \%$ & $>98.8 \%$ & $>99.0 \%$ & $>97.7 \%$ \\
\hline Co & $99.7 \%$ & $99.9 \%$ & $99.2 \%$ & $99.9 \%$ & $99.9 \%$ & $99.9 \%$ \\
\hline $\mathrm{Cr}$ & $>99.7 \%$ & $>99.7 \%$ & $99.4 \%$ & $99.0 \%$ & $99.7 \%$ & $>99.7 \%$ \\
\hline $\mathrm{Cu}$ & $99.8 \%$ & $99.9 \%$ & $99.5 \%$ & $99.8 \%$ & $99.8 \%$ & $99.9 \%$ \\
\hline $\mathbf{H g}$ & $20.9 \%$ & $48.8 \%$ & $57.3 \%$ & $74.8 \%$ & $56.3 \%$ & $75.5 \%$ \\
\hline Mn & $99.6 \%$ & $99.3 \%$ & $99.0 \%$ & $99.2 \%$ & $99.8 \%$ & $99.8 \%$ \\
\hline $\mathbf{N i}$ & $>99.7 \%$ & $>99.7 \%$ & $>99.5 \%$ & $>99.5 \%$ & $99.6 \%$ & $>99.7 \%$ \\
\hline $\mathbf{P b}$ & $99.4 \%$ & $>99.7 \%$ & $98.9 \%$ & $>99.6 \%$ & $>99.4 \%$ & $>99.6 \%$ \\
\hline Sb & $\mathrm{NC}$ & $\mathrm{NC}$ & $\mathrm{NC}$ & $\mathrm{NC}$ & $\mathrm{NC}$ & $\mathrm{NC}$ \\
\hline Se & $-21.4 \%$ & $83.8 \%$ & $-39.6 \%$ & $85.2 \%$ & $-55.7 \%$ & $78.3 \%$ \\
\hline $\mathbf{T l}$ & $>99.2 \%$ & $>99.3 \%$ & $>98.5 \%$ & $>99.2 \%$ & $>99.3 \%$ & $>99.3 \%$ \\
\hline $\mathbf{V}$ & $99.7 \%$ & $99.9 \%$ & $99.3 \%$ & $99.9 \%$ & $99.9 \%$ & $99.9 \%$ \\
\hline $\mathbf{Z n}$ & $99.2 \%$ & $99.5 \%$ & $98.9 \%$ & $99.5 \%$ & $99.2 \%$ & $99.1 \%$ \\
\hline
\end{tabular}

Trace element removal across the ESP was very high (>98.5\%; most metals exceeding 99\%) for all metals except selenium and mercury. Because selenium and mercury existed primarily in the vapor-phase, removal of these elements across the ESP was expected to be lower than that of the other metals which existed primarily in the particulate phase at flue gas temperatures experienced downstream of the air heater. Measured mercury removal across the ESP was $21 \%$ at baseline conditions and increased to $\sim 57 \%$ during $\mathrm{ACI}$ and $\mathrm{ACI}+\mathrm{Br}$ testing. Mercury was the only element that consistently experienced increased removal with the application of ACI and $\mathrm{ACI}+\mathrm{Br}$. For the other elements, small increases or decreases in removal were experienced at the two $\mathrm{Hg}$ control test conditions when compared to baseline operation. No trends in trace metals removal should be extracted from these small changes because the obtained data set was small, measured flue gas concentrations were low, and the variability in trace metals concentrations was high.

The FGD scrubber provided additional removal of all trace metals, as shown by an increase in coal-to-stack trace element removal as compared to coal-to-ESP outlet removal. Flue gas measurements showed no selenium removal across the ESP, but the FGD removed a significant amount of selenium $(78-85 \%)$. Selenium was most likely present in the flue gas as an acid gas 
$\left(\mathrm{SeO}_{2}\right)$ that would be expected to be readily removed by the FGD. The selenium removal across the FGD system was somewhat higher than the coal-to-stack $\mathrm{SO}_{2}$ removal of $\sim 73 \%$.

There was little difference in coal-to-stack trace metals removal between the three test conditions (baseline, ACI, ACI + Br) evaluated. Any differences in calculated removal may have arisen due to the difficulty in obtaining accurate trace metals concentrations at low flue gas concentrations.

Table 4-40 shows the concentration of each measured element in fly ash sampled from the ESP during each test condition. The listed values represent a weighted average of analysis conducted on fly ash from the first field (which captured $94.1 \%$ of fly ash) and the $4^{\text {th }} / 5^{\text {th }}$ fields (which captured $0.9 \%$ of the fly ash). Ash trace element concentrations by ESP field are provided in Appendix M.

Table 4-40. Fly Ash Trace Element Concentrations

\begin{tabular}{|c|c|c|c|}
\hline & \multicolumn{3}{|c|}{$\begin{array}{l}\text { Ash Trace Element Concentration (lb/TBTU) } \\
\end{array}$} \\
\hline Date & $6 / 12 / 09$ & $7 / 14 / 09$ & $7 / 12 / 09$ \\
\hline Condition & Baseline & ACI & $\mathrm{ACI}+\mathrm{Br}$ \\
\hline Ag & 17.3 & 18.2 & 15.9 \\
\hline As & 300 & 225 & 198 \\
\hline Ba & 40278 & 26274 & 26676 \\
\hline Be & 85.5 & 68.3 & 62.2 \\
\hline Cd & 11.9 & 12.4 & 9.9 \\
\hline Co & 364 & 322 & 299 \\
\hline $\mathrm{Cr}$ & 1414 & 1325 & 1266 \\
\hline $\mathbf{C u}$ & 1764 & 1627 & 1538 \\
\hline $\mathrm{Hg}$ & 0.5 & 8.8 & 11.7 \\
\hline Mn & 5894 & 7836 & 7931 \\
\hline $\mathrm{Ni}$ & 1036 & 937 & 871 \\
\hline $\mathbf{P b}$ & 623 & 619 & 542 \\
\hline Sb & 51.3 & 54.2 & 48.3 \\
\hline Se & 253 & 309 & 225 \\
\hline Tl & 19.1 & 12.8 & 8.9 \\
\hline V & 3020 & 2984 & 2819 \\
\hline Zn & 1350 & 1234 & 1239 \\
\hline
\end{tabular}

Table 4-41 shows the percentage of each trace element present in the coal, captured in the fly ash. The removal values were greater than $90 \%$ for all elements except selenium and were often greater than $100 \%$. These high removal levels agree with the M29 measurements at the ESP outlet which indicated $>99 \%$ removal for these metals. Fly ash selenium values indicated $65-$ $80 \%$ removal in the ESP ash, which does not agree with the $0 \%$ removal predicted by M29 measurements at the ESP outlet. The fraction of mercury captured by the fly ash trended with the mercury removal calculated from M29 measurements.

The difficulties in obtaining representative coal and ash trace metals concentrations is evidenced by this selenium result as well as by calculated trace metals removal by the fly ash often exceeding 100\%; however, the mass balance closure was acceptable for most metals, being within $\pm 20 \%$. 
Table 4-41. Percentage of Coal Trace Elements Removed in the Fly Ash

\begin{tabular}{|c|c|c|c|}
\hline \multirow[b]{2}{*}{ Date } & \multicolumn{3}{|c|}{$\begin{array}{l}\text { Percentage of Trace Element Removal from Coal by Fly } \\
\text { Ash (\%) }\end{array}$} \\
\hline & $6 / 12 / 09$ & $7 / 14 / 09$ & $7 / 12 / 09$ \\
\hline Condition & Baseline & ACI & $\mathbf{A C I}+\mathbf{B r}$ \\
\hline Ag & $90.6 \%$ & $94.8 \%$ & $85.0 \%$ \\
\hline As & $146 \%$ & $110 \%$ & $94.7 \%$ \\
\hline Ba & $148 \%$ & $97.0 \%$ & $95.9 \%$ \\
\hline Be & $\mathrm{NC}$ & $\mathrm{NC}$ & $\mathrm{NC}$ \\
\hline Cd & $163 \%$ & $170 \%$ & $136 \%$ \\
\hline Co & $136 \%$ & $120 \%$ & $112 \%$ \\
\hline $\mathrm{Cr}$ & $124 \%$ & $115 \%$ & $114 \%$ \\
\hline $\mathrm{Cu}$ & $142 \%$ & $130 \%$ & $125 \%$ \\
\hline $\mathbf{H g}$ & $2.3 \%$ & $39.1 \%$ & $54.4 \%$ \\
\hline Mn & $84.2 \%$ & $111 \%$ & $118 \%$ \\
\hline $\mathrm{Ni}$ & $113 \%$ & $102 \%$ & $95.2 \%$ \\
\hline $\mathbf{P b}$ & $141 \%$ & $139 \%$ & $126 \%$ \\
\hline $\mathbf{S b}$ & $\mathrm{NC}$ & $\mathrm{NC}$ & $\mathrm{NC}$ \\
\hline Se & $65.0 \%$ & $78.6 \%$ & $60.4 \%$ \\
\hline Tl & $180 \%$ & $121 \%$ & $84.8 \%$ \\
\hline V & $114 \%$ & $112 \%$ & $109 \%$ \\
\hline Zn & $105 \%$ & $95.8 \%$ & $94.7 \%$ \\
\hline
\end{tabular}

Collected fly ash from Limestone was also tested for trace metals leaching. The fly ash samples were leached using the SPLP test protocol. Table 4-42 below shows the leaching concentration results for the different test conditions. Table 4-43 shows the percentage of each trace metal that leached.

Table 4-42. Trace Elements Leachate Concentrations for SPLP Tests

\begin{tabular}{|c|c|c|c|c|c|c|}
\hline \multirow[b]{3}{*}{ Element } & \multicolumn{6}{|c|}{ Leachate Concentration $(\mu \mathrm{g} / \mathrm{L})$} \\
\hline & \multicolumn{2}{|c|}{ Baseline } & \multicolumn{2}{|c|}{ ACI } & \multicolumn{2}{|c|}{$\mathrm{ACI}+\mathrm{Br}$} \\
\hline & Field 1 & Fields $4 \& 5$ & Field 1 & Fields $4 \& 5$ & Field 1 & Fields $4 \& 5$ \\
\hline $\mathrm{Ag}$ & $<0.5$ & $<0.5$ & $<0.5$ & $<0.5$ & $<0.5$ & $<0.5$ \\
\hline As & $<1$ & 1.49 & $<1$ & $<1$ & 1.06 & 2.63 \\
\hline $\mathrm{Ba}$ & 336 & 310 & 1930 & 485 & 2040 & 575 \\
\hline $\mathrm{Be}$ & $<0.2$ & $<0.2$ & $<0.2$ & $<0.2$ & $<0.2$ & $<0.2$ \\
\hline $\mathrm{Cd}$ & 0.464 & 1.21 & 0.642 & 1.17 & 0.502 & 1.24 \\
\hline Co & 0.804 & 1.18 & 1.15 & 1.38 & 1.22 & 1.26 \\
\hline $\mathrm{Cr}$ & 413 & 1040 & 680 & 2530 & 565 & 1260 \\
\hline $\mathrm{Cu}$ & 1.03 & 1.76 & 1.68 & 1.56 & 1.27 & 1.15 \\
\hline $\mathrm{Hg}$ & 0.023 & 0.018 & 0.008 & 0.008 & 0.013 & 0.009 \\
\hline $\mathrm{Mn}$ & 3.74 & 5.52 & 5.64 & 6.14 & 5.23 & 5.31 \\
\hline $\mathrm{Ni}$ & 1.35 & 2.14 & 1.81 & 2.64 & 1.67 & 2.22 \\
\hline $\mathrm{Pb}$ & $<2$ & $<2$ & $<2$ & $<2$ & $<2$ & $<2$ \\
\hline $\mathrm{Sb}$ & $<0.4$ & $<0.4$ & $<0.4$ & $<0.4$ & $<0.4$ & $<0.4$ \\
\hline $\mathrm{Se}$ & 454 & 2300 & 536 & 1660 & 316 & 1370 \\
\hline $\mathrm{Tl}$ & 0.488 & 0.754 & 0.06 & 0.83 & 0.043 & 0.816 \\
\hline $\mathrm{V}$ & 61.1 & 134 & 98.7 & 146 & 93.3 & 176 \\
\hline $\mathrm{Zn}$ & 1.27 & 2.65 & 12.1 & 4.72 & 10.25 & 4.99 \\
\hline
\end{tabular}


Table 4-43. Percentage of Trace Element Leached for SPLP Tests

\begin{tabular}{|c|c|c|c|c|c|c|}
\hline \multirow[b]{3}{*}{ Element } & \multicolumn{6}{|c|}{$\%$ of Ash Element Leached } \\
\hline & \multicolumn{2}{|c|}{ Baseline } & \multicolumn{2}{|c|}{$\mathrm{ACI}$} & \multicolumn{2}{|c|}{$\mathrm{ACI}+\mathrm{Br}$} \\
\hline & Field 1 & Fields $4 \& 5$ & Field 1 & Fields $4 \& 5$ & Field 1 & Fields $4 \& 5$ \\
\hline $\mathrm{Ag}$ & $<0.83 \%$ & $<0.71 \%$ & $<0.83 \%$ & $<0.67 \%$ & $<0.91 \%$ & $<0.71 \%$ \\
\hline As & $<0.10 \%$ & $0.07 \%$ & $<0.13 \%$ & $<0.05 \%$ & $0.15 \%$ & $0.13 \%$ \\
\hline $\mathrm{Ba}$ & $0.24 \%$ & $0.21 \%$ & $2.18 \%$ & $0.29 \%$ & $2.17 \%$ & $0.34 \%$ \\
\hline $\mathrm{Be}$ & $<0.07 \%$ & $<0.07 \%$ & $<0.09 \%$ & $<0.07 \%$ & $<0.09 \%$ & $<0.09 \%$ \\
\hline $\mathrm{Cd}$ & $1.16 \%$ & $1.42 \%$ & $1.61 \%$ & $1.23 \%$ & $1.43 \%$ & $1.31 \%$ \\
\hline Co & $0.06 \%$ & $0.07 \%$ & $0.11 \%$ & $0.09 \%$ & $0.12 \%$ & $0.08 \%$ \\
\hline $\mathrm{Cr}$ & $8.56 \%$ & $16.64 \%$ & $15.21 \%$ & $39.53 \%$ & $12.64 \%$ & $19.24 \%$ \\
\hline $\mathrm{Cu}$ & $0.02 \%$ & $0.02 \%$ & $0.03 \%$ & $0.02 \%$ & $0.02 \%$ & $0.01 \%$ \\
\hline $\mathrm{Hg}$ & $0.92 \%$ & $0.90 \%$ & $0.03 \%$ & $0.02 \%$ & $0.04 \%$ & $0.03 \%$ \\
\hline $\mathrm{Mn}$ & $0.02 \%$ & $0.02 \%$ & $0.02 \%$ & $0.02 \%$ & $0.02 \%$ & $0.02 \%$ \\
\hline $\mathrm{Ni}$ & $0.04 \%$ & $0.05 \%$ & $0.06 \%$ & $0.06 \%$ & $0.05 \%$ & $0.05 \%$ \\
\hline $\mathrm{Pb}$ & $<0.09 \%$ & $<0.06 \%$ & $<0.10 \%$ & $<0.06 \%$ & $<0.10 \%$ & $<0.06 \%$ \\
\hline $\mathrm{Sb}$ & $<0.23 \%$ & $<0.11 \%$ & $<0.22 \%$ & $<0.10 \%$ & $<0.24 \%$ & $<0.11 \%$ \\
\hline $\mathrm{Se}$ & $55.37 \%$ & $21.60 \%$ & $53.07 \%$ & $17.66 \%$ & $41.58 \%$ & $15.57 \%$ \\
\hline $\mathrm{Tl}$ & $0.75 \%$ & $0.84 \%$ & $0.13 \%$ & $0.87 \%$ & $0.14 \%$ & $0.82 \%$ \\
\hline $\mathrm{V}$ & $0.59 \%$ & $0.79 \%$ & $0.98 \%$ & $0.77 \%$ & $0.94 \%$ & $0.93 \%$ \\
\hline $\mathrm{Zn}$ & $0.03 \%$ & $0.03 \%$ & $0.29 \%$ & $0.05 \%$ & $0.24 \%$ & $0.05 \%$ \\
\hline
\end{tabular}

As shown in Table 4-42, the leachate concentrations for most elements were less than $10 \mathrm{ppb}$, with the exception of $\mathrm{Ba}, \mathrm{Cr}, \mathrm{Se}$, and V. Of those elements, as shown in Table 4-40, only $\mathrm{Cr}$ and Se showed a percent leached of greater than $2 \%$.

Most elements showed few significant differences in leaching behavior between baseline and test conditions. A significant difference occurred when the difference between the two results was greater than a factor of $2(>100 \%) . \mathrm{Hg}$ concentration in the leachate and percentage of $\mathrm{Hg}$ leached both decreased from baseline to the test conditions. Ba and $\mathrm{Zn}$ concentrations in the leachate and percentage of $\mathrm{Ba}$ and $\mathrm{Zn}$ leached both increased from baseline to the test conditions.

Table 4-44 and 4-45 present the concentrations of trace metals in the FGD absorber solids and liquor phases, respectively. Because the ACI and ACI+Br test conditions were each only maintained for $\sim 12$ hours, the FGD system did not achieve steady-state for these conditions. Data are presented here to document the trace metals concentrations, but are not intended to be used to analyze the impacts of mercury controls on FGD metals concentrations. To make such evaluations, test conditions would need to be maintained longer, more samples would need to be obtained, and the FGD input streams (limestone, makeup water) would need to be characterized. 
Table 4-44. Trace Elements Concentrations of FGD absorber Solids.

\begin{tabular}{|c|c|c|c|}
\hline & \multicolumn{3}{|c|}{ Trace Element Concentration $(\mu \mathrm{g} / \mathrm{g})$} \\
\hline Date & 7/13/09 & 7/14/09 & 7/12/09 \\
\hline Condition & Baseline & ACI & $\mathbf{A C I}+\mathbf{B r}$ \\
\hline Ag & ND (0.4) & ND (0.4) & ND (0.4) \\
\hline Al & 1140 & 710 & 683 \\
\hline As & 2.7 & 1.7 & 1.8 \\
\hline Ba & 30.6 & 19.1 & 18.1 \\
\hline Be & $\mathrm{ND}(0.2)$ & ND (0.2) & ND (0.2) \\
\hline Cd & ND $(0.1)$ & ND $(0.1)$ & ND (0.1) \\
\hline Co & 1.6 & 1.5 & 1.7 \\
\hline $\mathrm{Cr}$ & 14.2 & 5.4 & 6.1 \\
\hline $\mathbf{C u}$ & 6.0 & 3.9 & 4.3 \\
\hline $\mathbf{F e}$ & 2580 & 1450 & 1710 \\
\hline $\mathbf{H g}$ & 2.2 & 1.5 & 1.5 \\
\hline Mn & 120 & 72.6 & 86.6 \\
\hline Mo & 1.3 & 0.65 & 0.93 \\
\hline $\mathbf{N i}$ & 23.6 & 22.5 & 21.9 \\
\hline $\mathbf{P b}$ & 0.82 & 0.60 & 0.42 \\
\hline $\mathbf{S b}$ & 0.18 & 0.11 & 0.12 \\
\hline Se & 142 & 84.2 & 107 \\
\hline Sn & ND (4) & ND (4) & ND (4) \\
\hline $\mathrm{Sr}$ & 247 & 243 & 233 \\
\hline Ti & 97.5 & 67.2 & 63.6 \\
\hline Tl & 0.075 & 0.042 & 0.047 \\
\hline V & 12.6 & 19.1 & 10.5 \\
\hline $\mathrm{Zn}$ & 12.1 & 12.4 & 14.3 \\
\hline
\end{tabular}


Table 4-45. Trace Elements Concentrations of FGD Absorber Liquors.

\begin{tabular}{|c|c|c|c|}
\hline & \multicolumn{3}{|c|}{ Trace Element Concentration $(\mu \mathrm{g} / \mathrm{L})$} \\
\hline Date & 7/13/09 & 7/14/09 & $7 / 12 / 09$ \\
\hline Element & Baseline & ACI & $\mathbf{A C I}+\mathbf{B r}$ \\
\hline Ag & ND (0.4) & ND (0.4) & ND (0.4) \\
\hline Al & 1250 & 1380 & 904 \\
\hline As & 91.9 & 85.7 & 89.1 \\
\hline Ba & 441 & 498 & 444 \\
\hline Be & 2.7 & 2.8 & ND (2) \\
\hline Cd & 12.9 & 12.1 & 12.2 \\
\hline Co & 74.9 & 74 & 71.9 \\
\hline $\mathbf{C r}$ & 37.4 & 39.1 & 37.1 \\
\hline $\mathbf{C u}$ & 328 & 334 & 297 \\
\hline $\mathbf{F e}$ & 67.8 & 116 & 82 \\
\hline $\mathbf{H g}$ & ND (2.7) & 3.4 & 3.3 \\
\hline Mn & 530000 & 520000 & 494000 \\
\hline Mo & 1770 & 1760 & 1680 \\
\hline Ni & 1170 & 1160 & 1120 \\
\hline $\mathbf{P b}$ & ND (10) & ND (10) & ND (10) \\
\hline Sb & 9.3 & 10.0 & 9.2 \\
\hline $\mathbf{S e}$ & 19300 & 18800 & 17700 \\
\hline Sn & ND (40) & ND (40) & ND (40) \\
\hline $\mathbf{S r}$ & 7550 & 7570 & 7580 \\
\hline $\mathbf{T i}$ & ND (50) & ND (50) & ND (50) \\
\hline TI & 8.4 & 8.4 & 7.7 \\
\hline $\mathrm{V}$ & 76.5 & 74.3 & 49.8 \\
\hline $\mathbf{Z n}$ & 251 & 238 & 254 \\
\hline
\end{tabular}

\section{Evaluation of Cooper XFM Trace Metals Measurement Technique}

This section compares the results from EPA Method 29 and an adaptation of CES' XFM method for arsenic, cadmium, chromium, iron, mercury, lead, selenium, and strontium. Most of these metals were chosen for their regulatory importance; however, iron and strontium were evaluated because both metals were well above their detection limits and thus provided a good means of comparison between the two methods. Although the XFM has not been optimized for this measurement application, the primary objective of this comparison was to evaluate the XFM method's potential to facilitate more efficient and timely evaluation of control options for mercury and other trace metals. Additional XFM metals data for aluminum, silver, barium, beryllium, cobalt, copper, manganese, molybdenum, nickel, lead, antimony, tin, titanium, thallium, vanadium, and zinc are provided in the Appendix N.

Simultaneous flue gas samples were collected using both EPA Method 29 and Cooper XFM at the ESP outlet and at the stack. At both locations, three Method 29 runs were performed on one baseline day, one day during which $1.89 \mathrm{lb} / \mathrm{Macf}$ ACI was carried out, and one day during $\mathrm{CaBr}_{2}$ injection. In an adjacent duct at both locations, six XFM runs were performed per day; i.e., two XFM runs per single Method 29 run. The XFM runs were collected during the same time period as the Method 29 runs to enable direct comparison of results. 
Results from the trace metal characterization measurements are illustrated in Figures 4-13 through 4-18; the y-axis on each plot is a log scale so all the obtained data can be clearly illustrated. Figures 4-19 and 4-20 illustrate Method 29 data for all three conditions at the ESP outlet and stack, respectively. All reported values represent the sum of particulate and vapor phase data and are presented as $\mu \mathrm{g} / \mathrm{Nm}^{3}$ dry normalized to $3 \% \mathrm{O}_{2}$. Stack arsenic results obtained with XFM are not presented because the data did not pass quality validation checks, likely due to probe contamination.

In the case of Method 29, many of the measured metals concentrations were below the detection limit. In the event that one portion of a given sample (i.e. the particulate) showed a detectable amount of a specific metal while the other portion (i.e. vapor phase) was a non-detect, the two portions were added together and designated with a less than symbol (* above the bar in the figures) if the non-detect was greater than $50 \%$ of the detected value. If the non-detect was less than $50 \%$ of the detected value, only the detected value was reported.

Although all metals were at least partially removed across the FGD, the limited amount of data available showed no general trend of increased removal of metals, except for mercury, with the implementation of mercury control technologies (see Figures 4-19 and 4-20). The collected data were too limited to allow for conclusions to be drawn as to the impact of mercury control technologies on the emissions of other trace metals. More data are necessary to account for the fluctuations associated with operating variability.

In general, the results obtained with the two measurement methods were comparable, although no specific numerical criteria were established to characterize equivalency. The two methods provided comparable results for the vapor-phase metals ( $\mathrm{Se}, \mathrm{As}, \mathrm{Hg}$ ). In cases where metal concentrations were below the Method 29 detection limit (DL; i.e. As, Cd, Cr), the XFM results were also very low, albeit still above the DL of the method.

The lower concentrations measured by XFM for the ash-related elements may be due to a bias associated with the XFM sampling procedure, which was performed sub-isokinetically; fly ash deposited in the probe was not analyzed. However, the Method 29 and XFM sampling events occurred in adjoining ducts as single point measurements. Stratification across the ESP outlet is a documented phenomenon at LMS; therefore, the measured concentration differences may be real. 


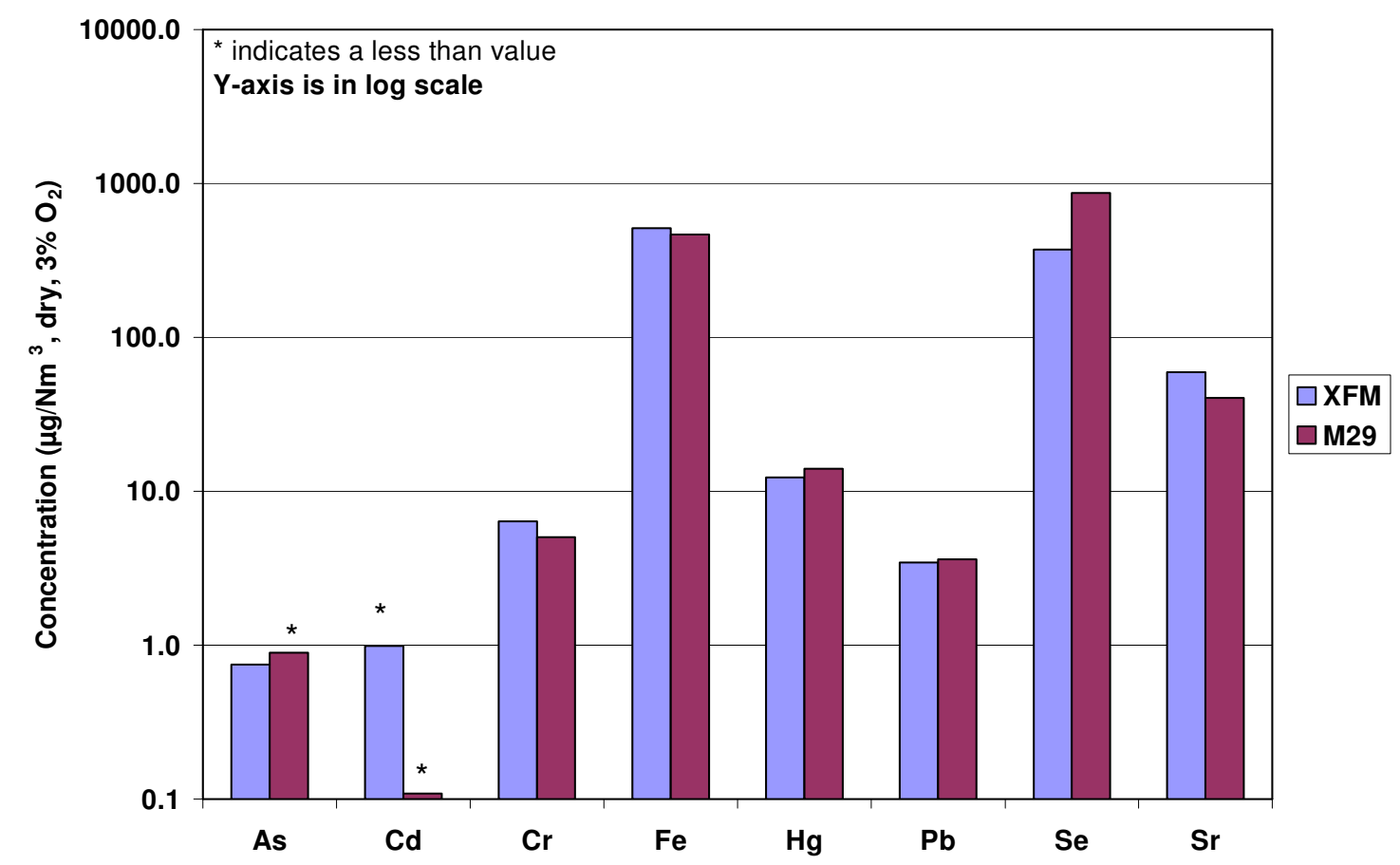

Figure 4-13. Comparison of Average XFM and M29 Metals Concentrations at the ESP Outlet on 7/12/09 $\left(\mathrm{CaBr}_{2}+0.48 \mathrm{Ib} / \mathrm{MMacf} \mathrm{ACl}\right)$

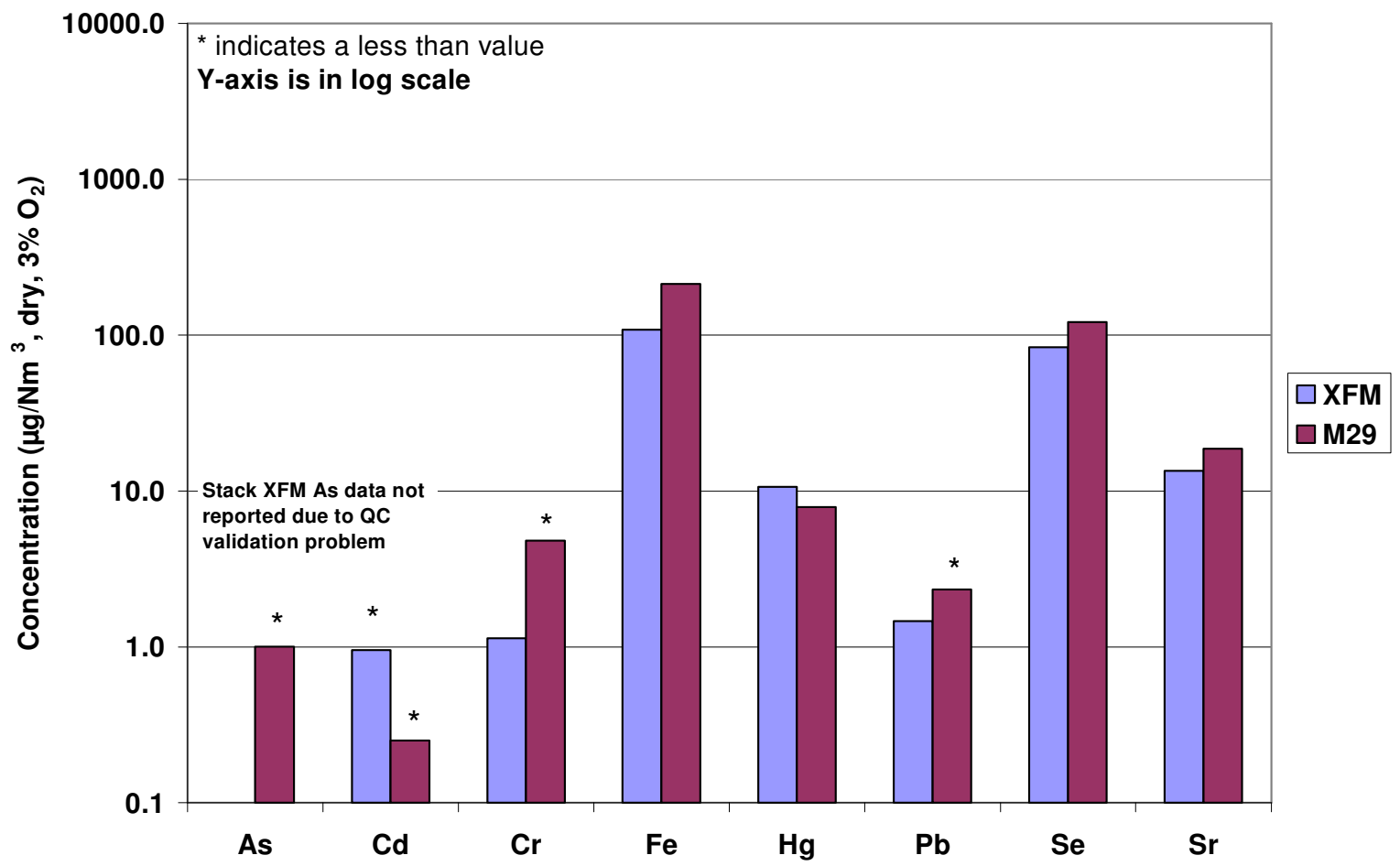

Figure 4-14. Comparison of Average XFM and M29 Stack Metals Concentrations on $7 / 12 / 09\left(\mathrm{CaBr}_{2}+0.48 \mathrm{lb} / \mathrm{MMacf} \mathrm{ACl}\right)$ 


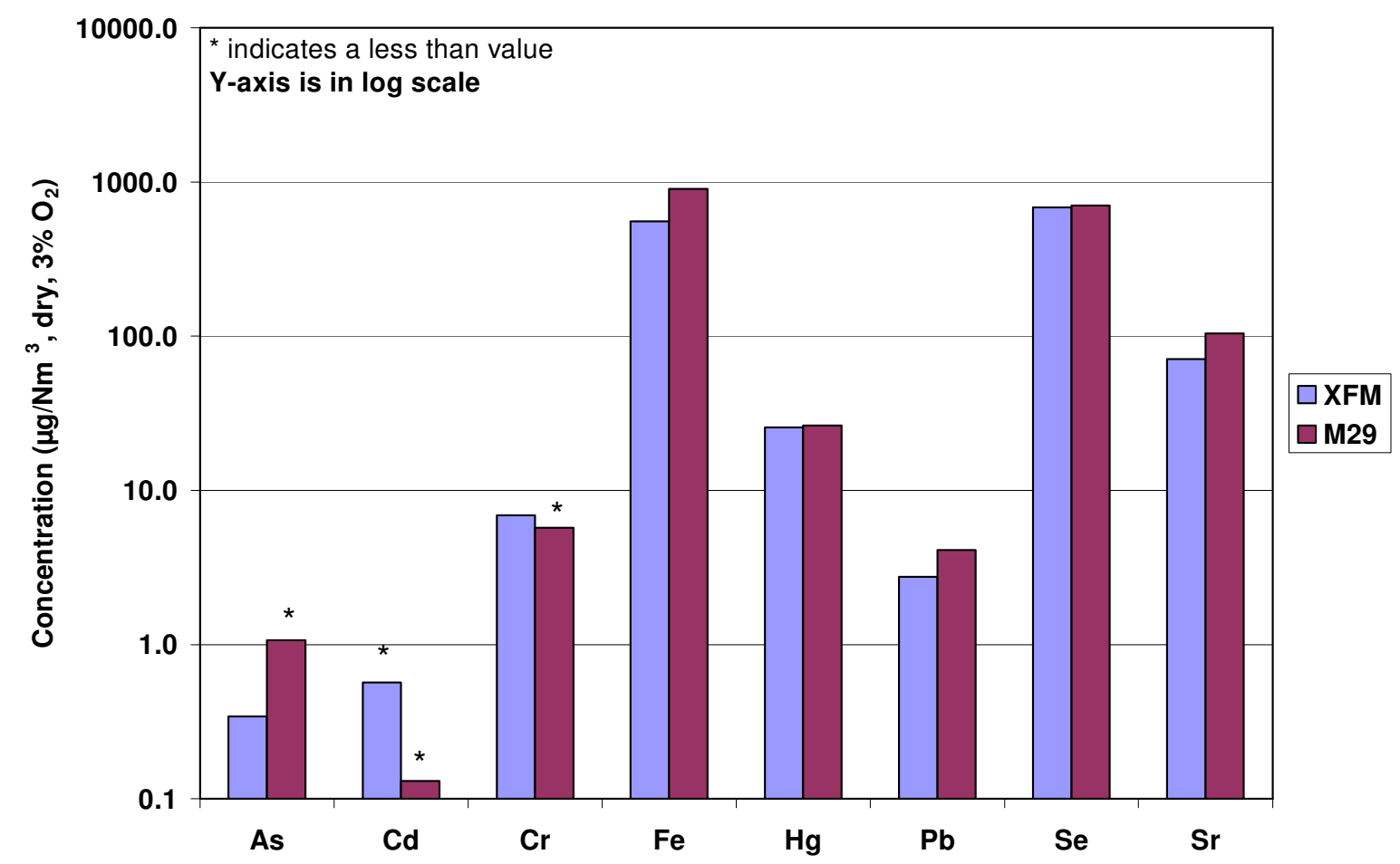

Figure 4-15. Comparison of Average XFM and M29 Metals Concentrations at the ESP Outlet on 7/13/09 (Baseline Conditions)

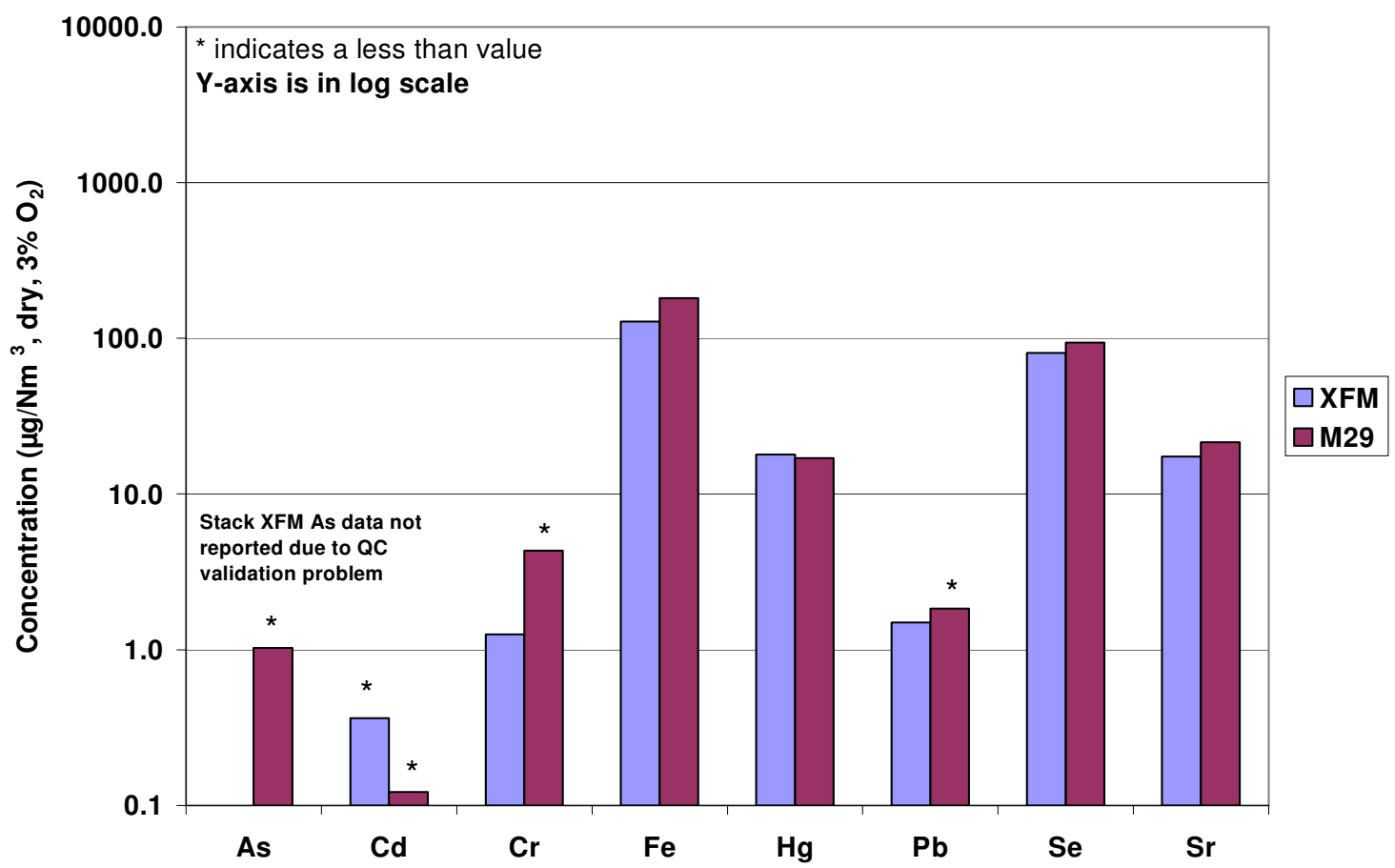

Figure 4-16. Comparison of Average XFM and M29 Stack Metals Concentrations on 7/13/09 (Baseline Conditions) 


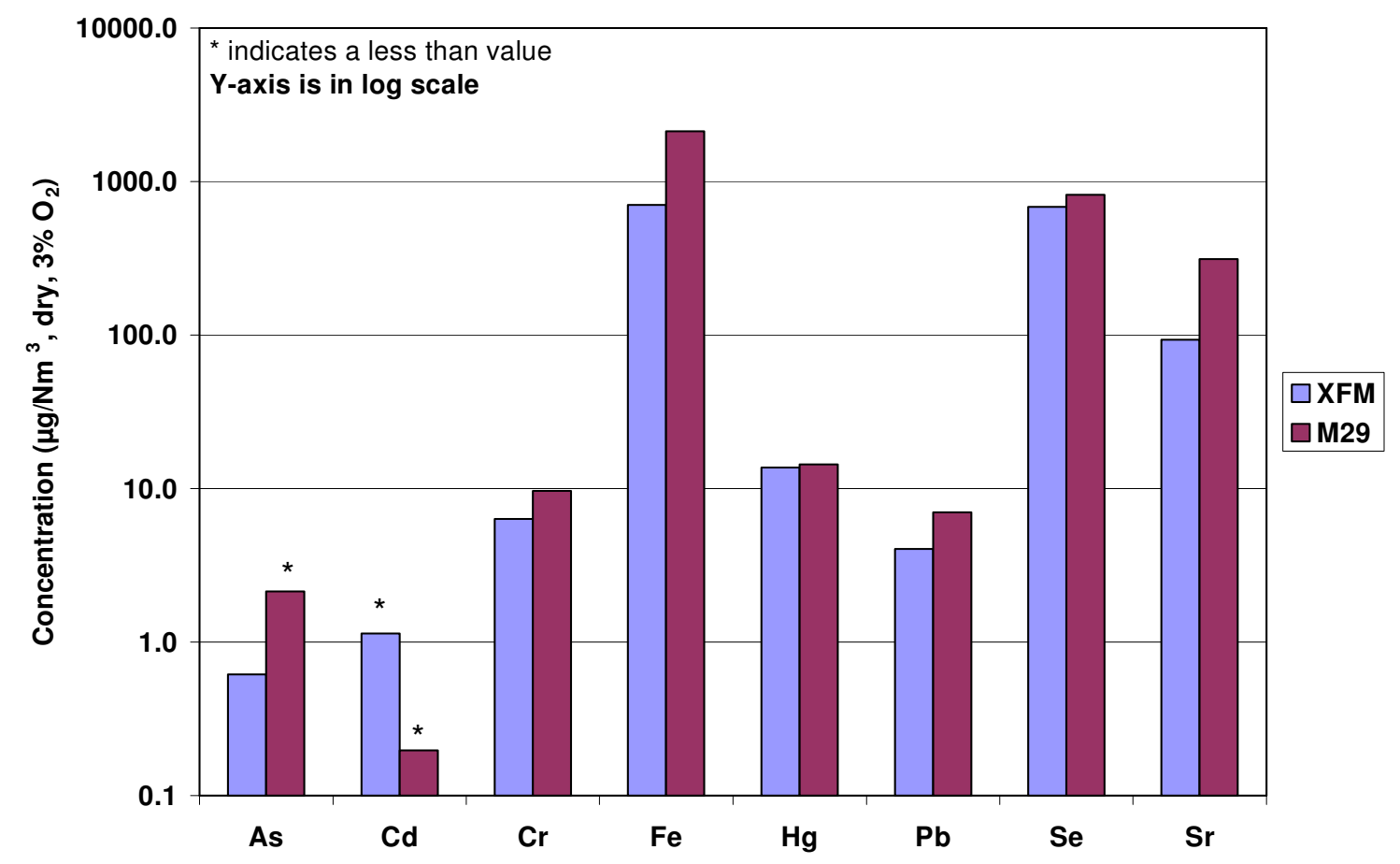

Figure 4-17. Comparison of Average XFM and M29 Metals Concentrations at the ESP Outlet on 7/14/09 (1.9 lb/MMacf ACI)

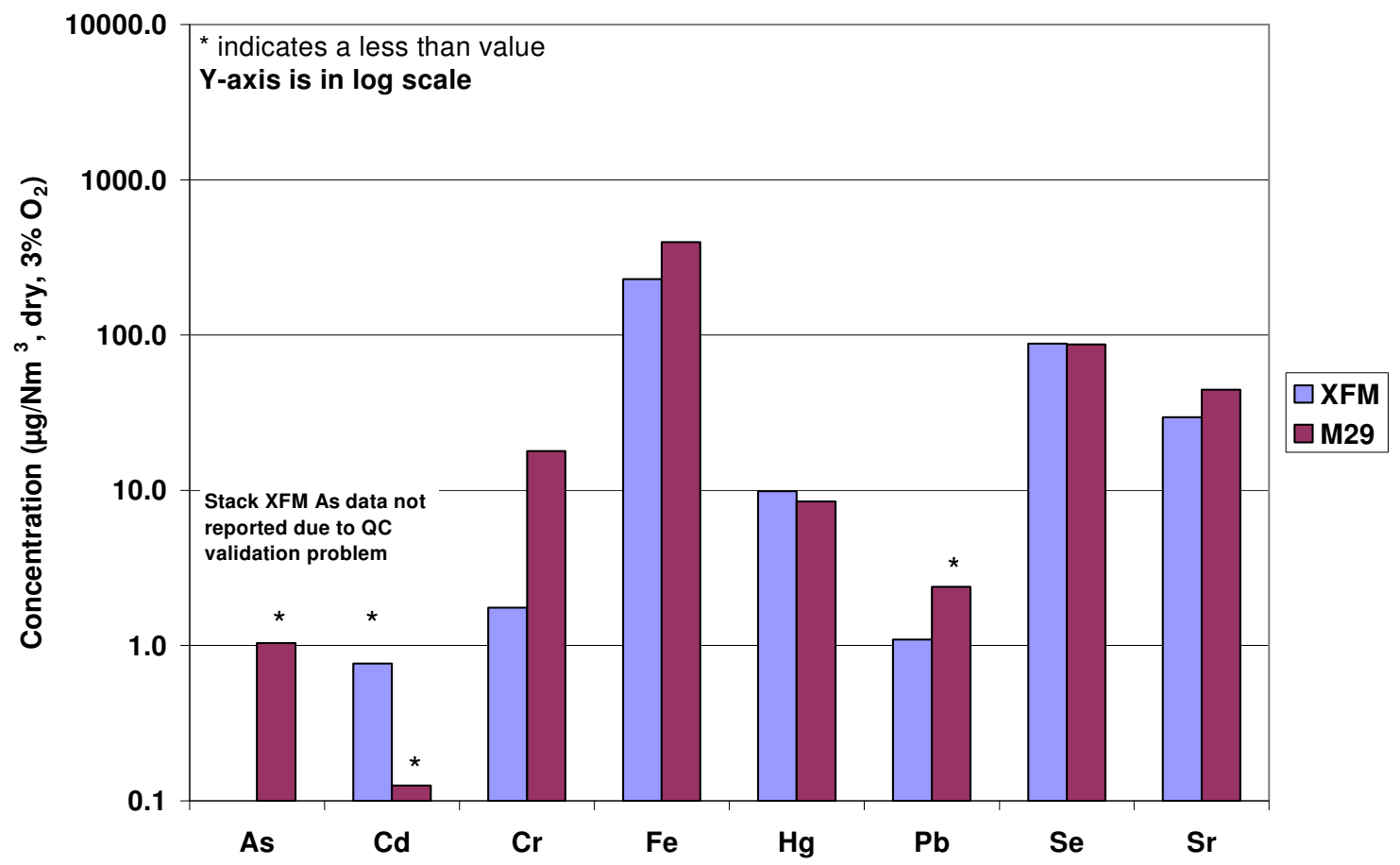

Figure 4-18. Comparison of Average XFM and M29 Stack Metals Concentrations on 7/14/09 (1.9 Ib/MMacf ACl) 


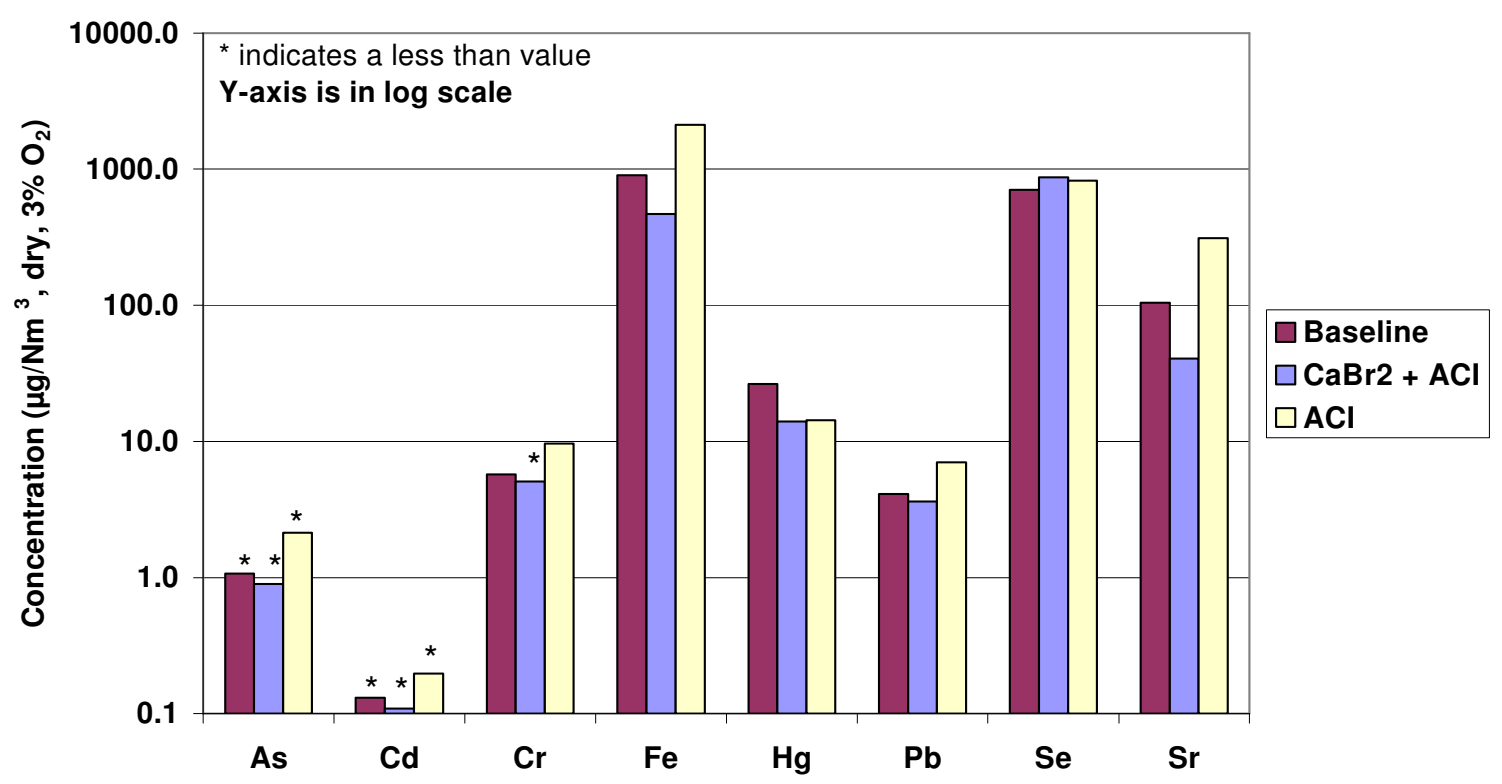

Figure 4-19. Method 29 ESP Outlet Data for Three Test Conditions

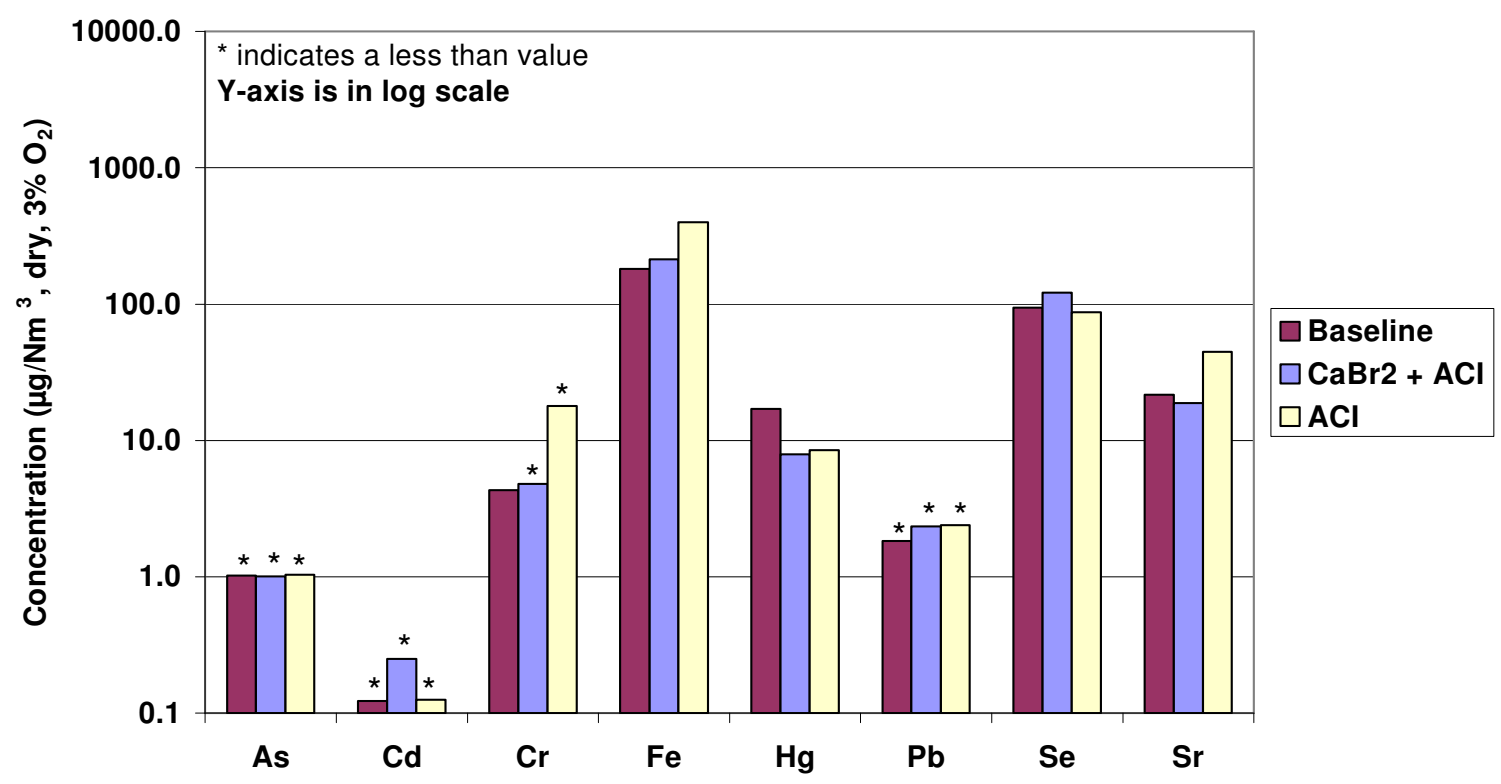

Figure 4-20. Method 29 Stack Data for Three Test Conditions 


\subsection{In-line Sorbent Particle Size Distribution Analysis}

Measurements were conducted to evaluate the particle size of suspended sorbent material just prior to being injected into the flue gas. The objective of this characterization was to determine if the mean sorbent particle size changed, primarily through agglomeration, as it was transferred across the sorbent injection system. Results obtained at the sorbent lance location were compared to those for the respective sorbent prior to addition to the transfer line. This information is important as it provides indication of the sorbent particle size, and subsequently its effective surface area, as it is injected into the flue gas duct. The particle size measurements were conducted by Malvern Instruments, Inc.

Malvern used an Insitec Laser Diffraction system to measure in-situ particle size distribution (PSD) of activated carbon as it traveled through transfer lines from the carbon feeder to the injection lances. The Insitec system operates by continuously aspirating a representative sample of material out of the main process stream using a venturi eductor, dispersing the sample into a measurement chamber, then returning the sample to the main line using the same undiluted, aspirated gas stream. The optical portion of the system is cleaned with an air purge stream. A Malvern Instruments J-probe was employed to ensure that a representative sample was obtained by allowing for isokinetic sampling while minimizing collisions of particles with the sample tube walls. The installation included a Vortab® flow conditioner to straighten and homogenize flow.

PSD measurements were made over a range of injection rates for two different carbons: (1) a normal ground Darco Hg-LH with approximate mean diameter of $20 \mu \mathrm{m}$ (denoted as standard Darco $\mathrm{Hg}-\mathrm{LH}$ in this section), and, (2) a finely ground Darco $\mathrm{Hg}-\mathrm{LH}$, which was prepared by further grinding the normal sorbent to a mean diameter of $\sim 6 \mu \mathrm{m}$. For each test condition, measurements were made over intervals ranging from 30 minutes to 3 hours. Data were analyzed to determine average values for each test period. Since each test condition was only performed once, the PSD data analyses presented below are not statistically rigorous; however, several observations can be made from the available data.

A test was conducted on 7/14/09 to evaluate bag-to-bag carbon PSD variability for the standard Darco Hg-LH sorbent. Grab samples were taken from totes 8090537 and 8081606 and analyzed for PSD. The PSD was also determined for carbon from each bag during injection at a rate of 2 lb/Macf. Table 4-46 compares Dv50, Dv90, and light transmission for the four different tests. Figure 4-21 shows a particle size frequency distribution for the two injection tests. Dv50 and Dv90 represent the particle size at which 50 and $90 \%$ of the particles are smaller than those sizes, respectively. Light transmission is the percentage of light that passes through the sample stream and is measured by the detector. An equipment error resulted in insufficient light transmission for samples taken during sorbent injection periods for this first test only. This issue was corrected for all other tests. While this error makes quantitative comparisons between injection and noninjection tests difficult to make, qualitative comparisons between the two injection tests can still be made.

Measurements showed that the carbon particles from bag 8090537 were approximately $15 \%$ larger than those from bag 8081606 when considering both Dv50 and Dv90 values obtained during offline measurements of sorbent collected directly from the bags. Malvern indicated that historic measurements with milled particles have shown that this level of variation between 
storage bags is common and does not represent a significant size difference. The variation between particle size distributions from the bag or injection at $2 \mathrm{lb} / \mathrm{Macf}$ cannot be compared due to the light transmission error noted previously for the injected samples.

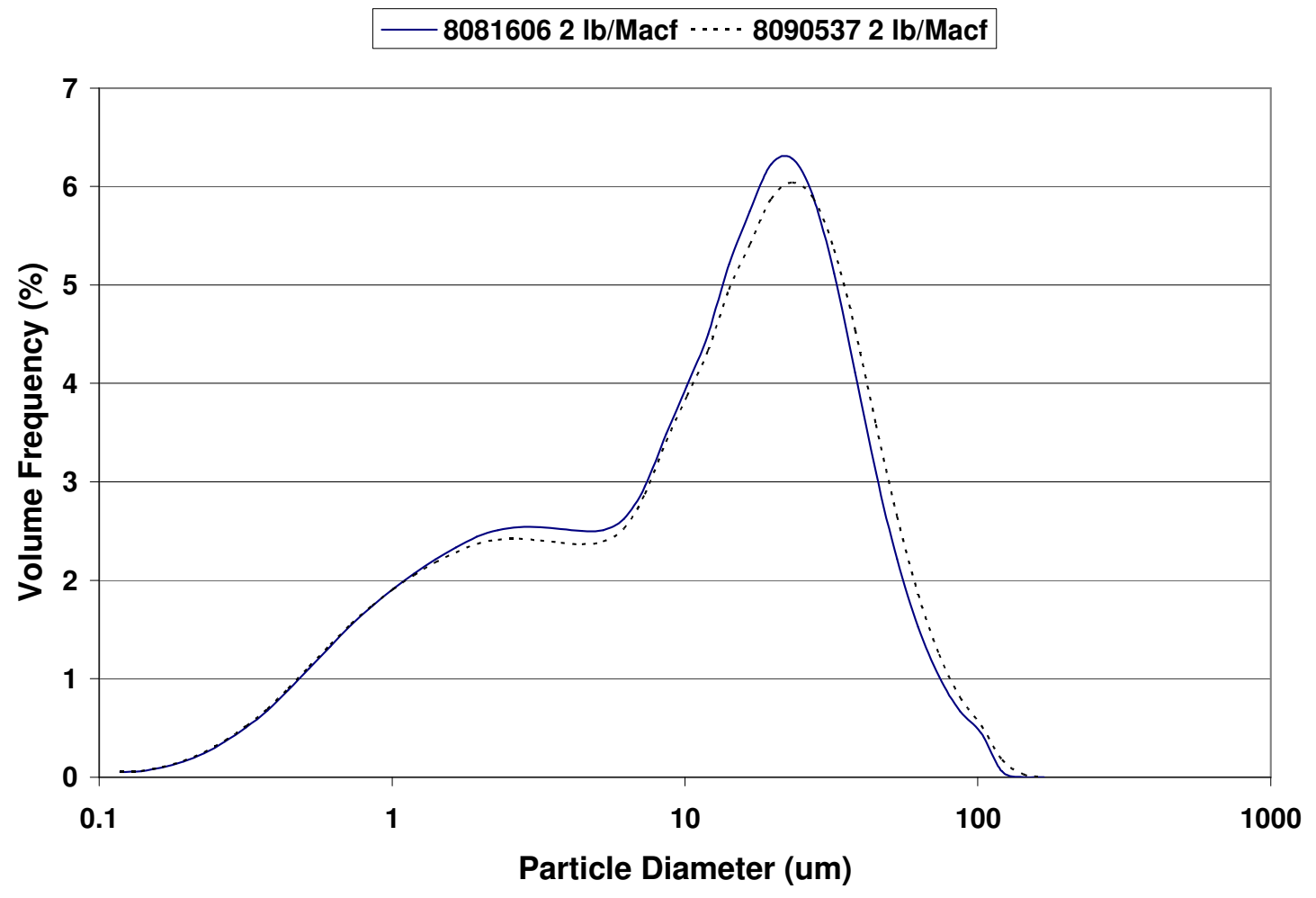

Figure 4-21. Particle Size Frequency for Standard Darco Hg-LH Injected at $2 \mathrm{lb} / \mathrm{Macf}$

Table 4-46. Particle Size and Light Transmission for Two Separate Bags of Standard Darco Hg-LH

\begin{tabular}{|c|c|c|c||}
\hline Test Condition & $\begin{array}{c}\text { Dv 50 } \\
(\boldsymbol{\mu m})\end{array}$ & $\begin{array}{c}\text { Dv 90 } \\
(\boldsymbol{\mu m})\end{array}$ & Light Transmission (\%) \\
\hline Bag 8081606 Offline & 12.29 & 40.63 & 44.5 \\
\hline Bag 8081606 2 lb/Macf & $11.04^{*}$ & $36.72^{*}$ & $2.7^{*}$ \\
\hline Bag 8090537 Offline & 14.37 & 46.69 & 43.7 \\
\hline Bag 8090537 2 lb/Macf & $11.55^{*}$ & $39.75^{*}$ & $3.0^{*}$ \\
\hline
\end{tabular}

* These numbers are inaccurate due to an equipment error; however, they can be used for relative comparisons to other data obtained with the same equipment error.

The impact of injection rate on the PSD of suspended carbon in the sorbent transfer line was tested on 7/15/09. Continuous PSD measurements were made while sorbent injection rates were varied from 0.5 to $2 \mathrm{lb} /$ Macf in increments of $0.25 \mathrm{lb} /$ Macf. Table 4-47 shows Dv50, Dv90, light transmission, and specific surface area (SSA) results obtained during these tests. Specific surface area is calculated as the ratio of the surface area of a particle to its volume; this calculation assumes a solid particle and does not account for any accessible internal surface area. As shown in Table 4-47, transmission decreased as injection rate increased. The decrease in light transmission combined with the relatively constant SSA indicates that no significant particle 
agglomeration occurred in the carbon transfer line. Light transmission would be expected to decrease as the carbon concentration in the stream increases. The constant SSA indicates that particle size remained constant. There was no consistent trend of Dv50 and Dv90 with injection rate. Particle size frequency did not significantly change with injection rate (Figure 4-22); the variation in particle size between injection rates was similar to the observed bag-to-bag PSD variation (Table 4-46).

Table 4-47. Impact of Injection Rate on Sorbent Particle Size and Light Transmission Standard Darco Hg-LH

\begin{tabular}{||c|c|c|c|c||}
\hline $\begin{array}{c}\text { Injection Rate } \\
(\mathbf{l b} / \mathbf{M a c f})\end{array}$ & $\begin{array}{c}\text { Dv 50 } \\
(\boldsymbol{\mu m})\end{array}$ & $\begin{array}{c}\text { Dv 90 } \\
(\boldsymbol{\mu m})\end{array}$ & $\begin{array}{c}\text { Light Transmission } \\
(\mathbf{\%})\end{array}$ & SSA $\left(\mathbf{m}^{\mathbf{2}} / \mathbf{c c}\right)$ \\
\hline $\mathbf{0 . 5}$ & 19.51 & 56.09 & 48.4 & 1.452 \\
\hline $\mathbf{0 . 7 5}$ & 20.52 & 59.60 & 34.3 & 1.434 \\
\hline $\mathbf{1 . 0}$ & 20.18 & 55.51 & 23.8 & 1.460 \\
\hline $\mathbf{1 . 2 5}$ & 18.59 & 50.8 & 20.3 & 1.537 \\
\hline $\mathbf{1 . 5}$ & 17.76 & 47.04 & 17.3 & 1.593 \\
\hline $\mathbf{1 . 7 5}$ & 20.03 & 53.43 & 14.0 & 1.461 \\
\hline $\mathbf{2 . 0}$ & 22.66 & 60.11 & 11.0 & 1.349 \\
\hline
\end{tabular}

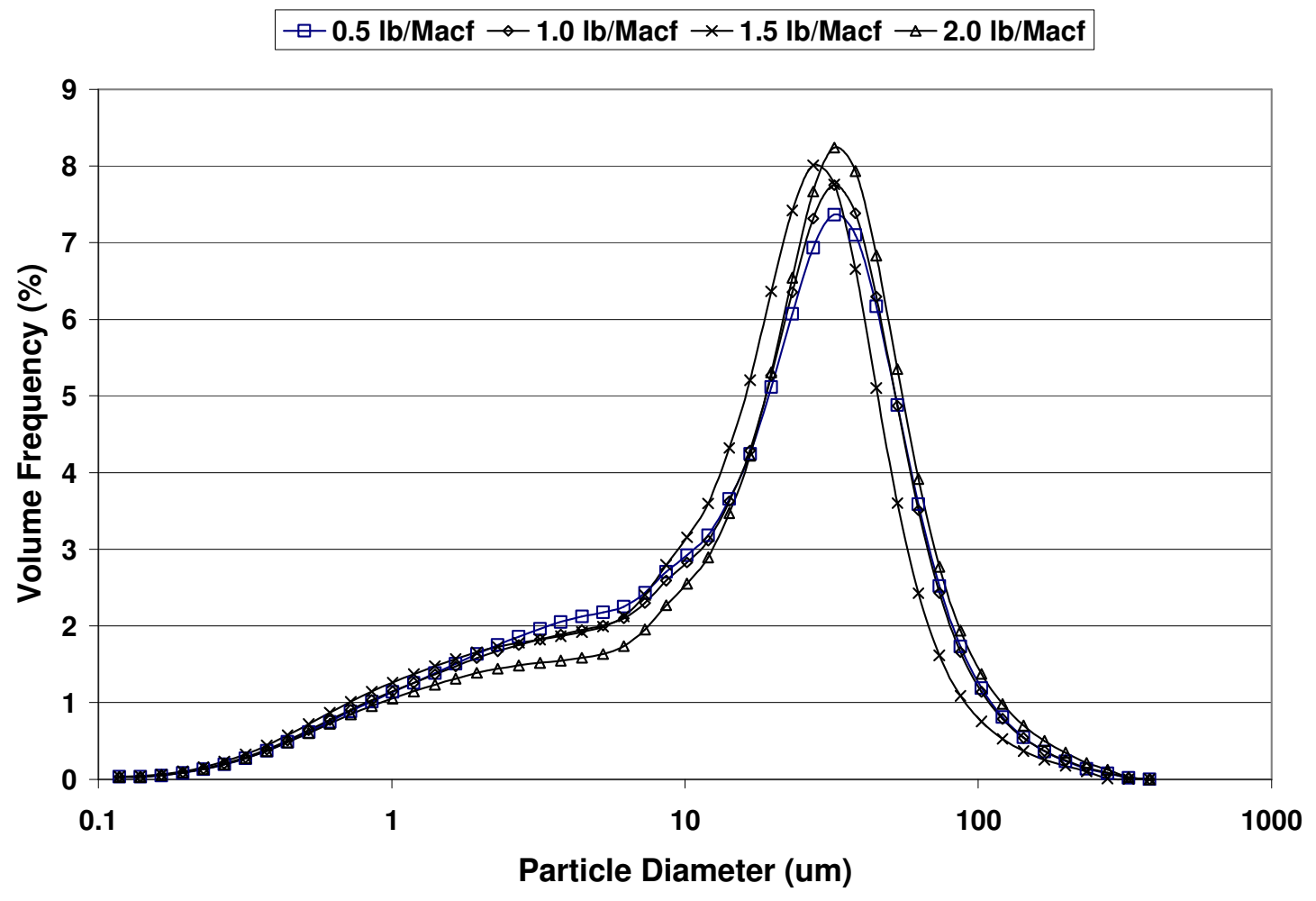

Figure 4-22. Particle Size Frequency for Different Injection Rates of Standard Darco Hg-LH

PSD measurements were made on 7/16/09 to evaluate the finely-ground Darco Hg-LH activated carbon. Figure 4-23 shows the particle frequency plots for four different injection rates. For the injection rate labeled "dispersed", the data represent the first few minutes of injection when the 
rate should be low and agglomeration effects minimal. For the dispersed sample, a bimodal size distribution was seen with primary peaks near $3 \mu \mathrm{m}$ and $15 \mu \mathrm{m}$. This bimodal distribution is common for re-ground samples which are usually first ground to a specific size and then ground again to a second smaller size. In the case of finely ground Darco $\mathrm{Hg}-\mathrm{LH}$, the carbon was ground to Dv50 size of $\sim 20 \mu \mathrm{m}$ and then re-ground to a size of $\sim 6 \mu \mathrm{m}$. Particle size in the transfer line increased with feed rate for the finely ground carbon, while little increase was observed with the standard carbon over the same range of injection rates (Figure 4-22). At injection rates of 1 $\mathrm{lb} / \mathrm{Macf}$ and greater, the particle size of the finely ground carbon was even larger than that of the normal ground carbon (Figure 4-24). The carbon feeder plugged at the highest tested injection rate $(2 \mathrm{lb} / \mathrm{Macf})$ of the finely ground carbon. The PSD for the finely ground carbon was broader than that of the standard carbon. These data suggest that particle agglomeration occurred with the finely-ground Darco $\mathrm{Hg}$ - LH carbon.

Table 4-48 shows Dv50 and SSA values for the finely ground and normal ground carbons measured at different feed rates. SSA measurements underestimate available surface area because it assumes a solid particle and does not account for pore space. SSA measurements for agglomerated particles may further under-represent the available surface area because the SSA model treats the agglomerated particle as a single solid entity of a uniform diameter. In reality, the agglomerated particle is comprised of several small particles, which create additional internal surface area that is not captured by the SSA model.

Table 4-48. Particle Size and SSA for Finely Ground and Standard Darco Hg-LH

\begin{tabular}{||c|c|c|c|c||}
\hline \hline Injection Rate & \multicolumn{2}{|c|}{ Darco Hg-LH - Normal Grind } & \multicolumn{2}{c||}{ Darco Hg-LH - Finely Ground } \\
\hline (lb/Macf) & Dv50 $(\boldsymbol{\mu m})$ & SSA $\left(\mathbf{m}^{\mathbf{2}} / \mathbf{c c}\right)$ & Dv50 $(\boldsymbol{\mu m})$ & SSA $\left(\mathbf{m}^{\mathbf{2}} / \mathbf{c c}\right)$ \\
\hline Dispersed & - & - & 6.73 & 2.768 \\
\hline 0.5 & 19.51 & 1.452 & 12.89 & 1.775 \\
\hline 1.0 & 20.18 & 1.460 & 23.19 & 1.417 \\
\hline 2.0 & 22.66 & 1.349 & 43.13 & 1.087 \\
\hline
\end{tabular}




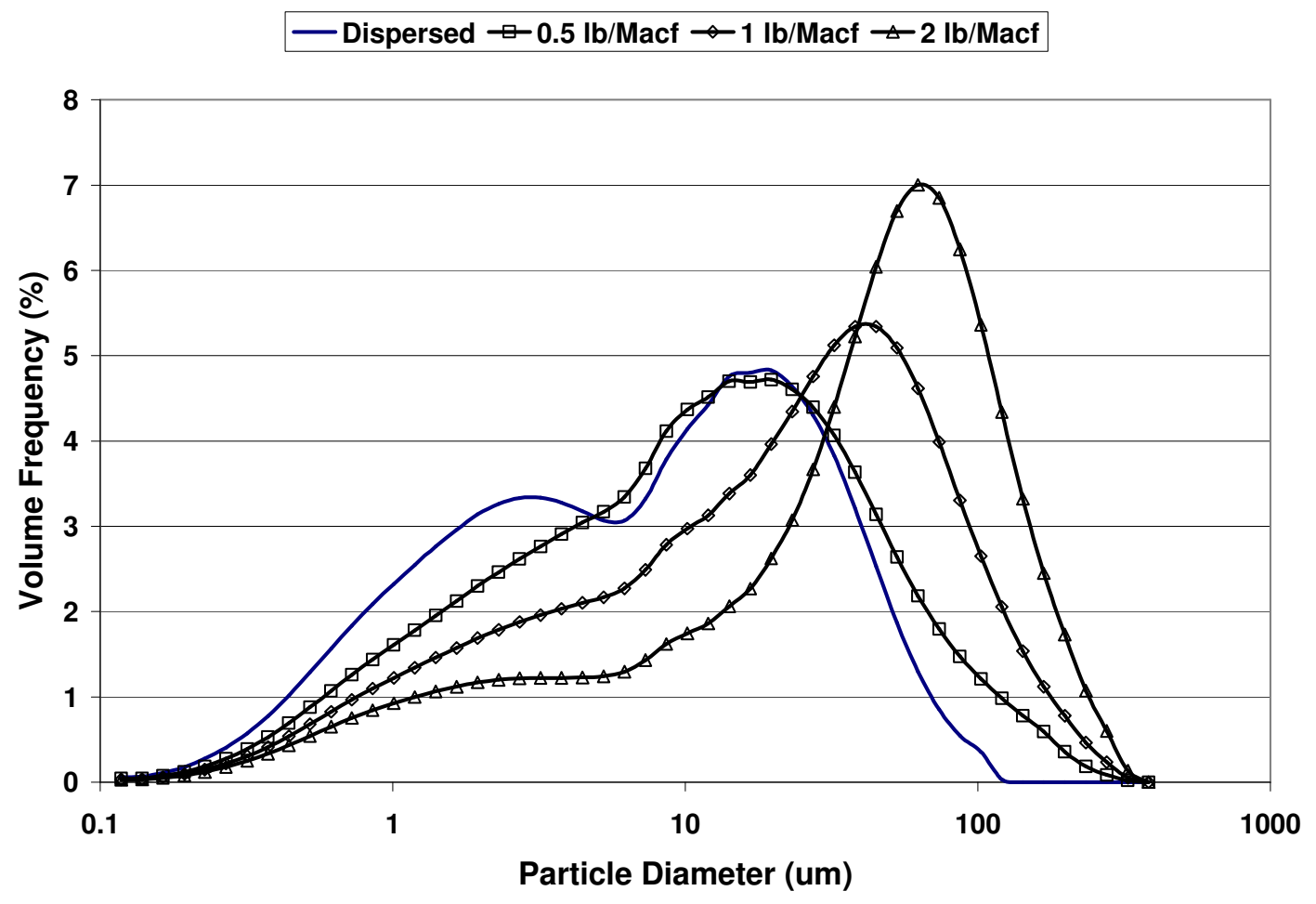

Figure 4-23. Particle Size Frequency as a Function of Injection Rate for Finely Ground Darco Hg-LH

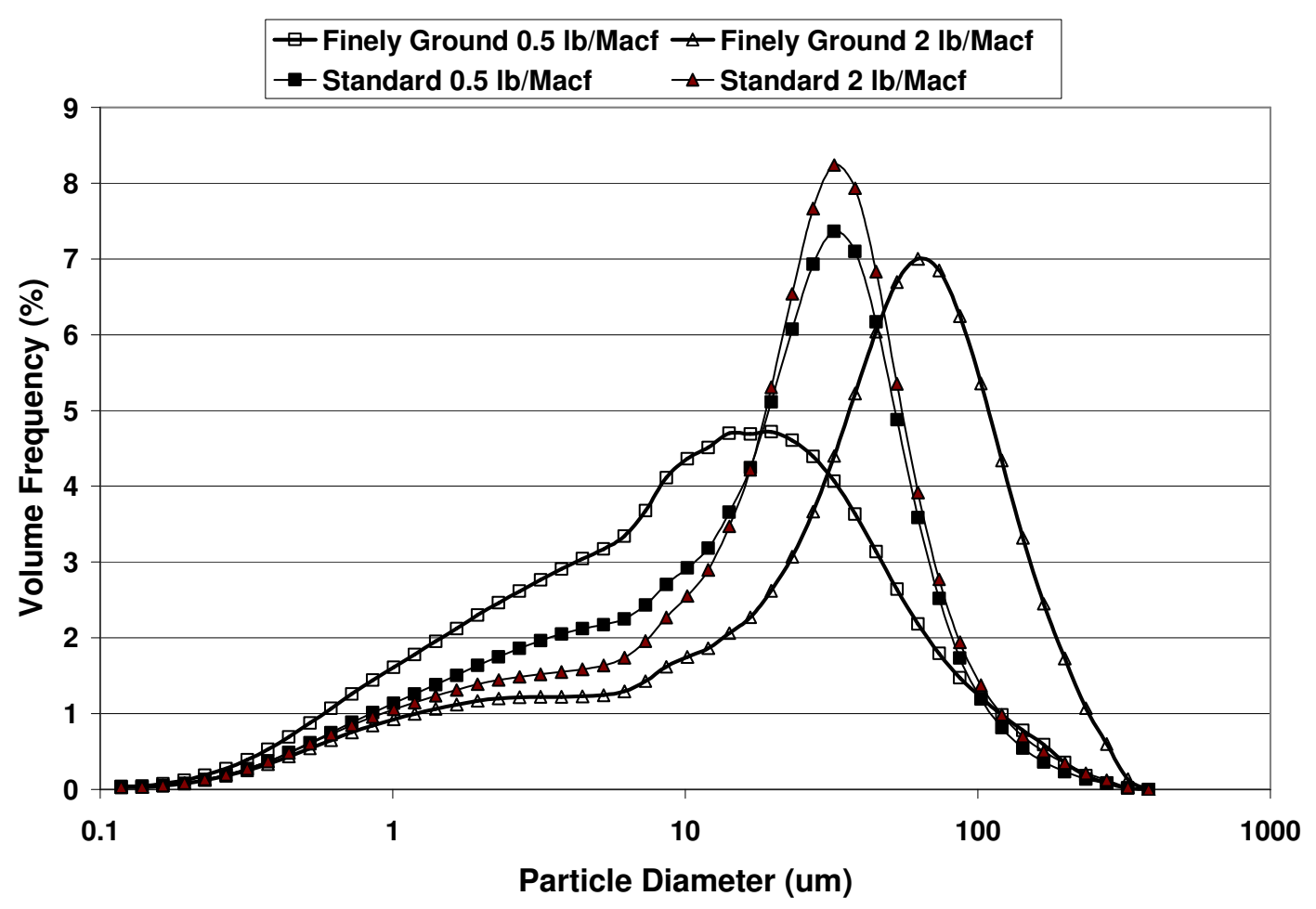

Figure 4-24. PSD Comparison of Standard and Finely-Ground Carbon 
The standard Darco Hg-LH carbon evaluated at LMS showed typical bag to bag variation in size distribution, and no significant agglomeration with increased injection rate. The finely ground version of this carbon showed a broader particle size distribution than the standard carbon and showed increased particle agglomeration with increased injection rate. This agglomeration effect was large enough that at injection rates of $1 \mathrm{lb} / \mathrm{Macf}$ and higher the mean particle size for the finely ground carbon was greater than that for the standard carbon. This increased particle size has implications on the effectiveness of particle grinding as a way to enhance carbon coverage within the duct and, subsequently, mercury capture with $\mathrm{ACI}$, and thus warrants further study. Additional testing of different carbons and particle sizes, as well as more replicate data, are needed to determine if the phenomena observed for the finely ground Darco $\mathrm{Hg}-\mathrm{LH}$ were specific to this particular carbon, to all finely ground carbons, or whether this single day of test results was an anomaly. If carbon particle agglomeration is a problem, agglomerated particles should be mechanically cleaved immediately upstream of the sorbent lances.

\subsection{ESP Outlet Particulate Emissions}

Particulate concentration measurements were made with Method 17 at ESP inlet ports that serve both the 2C and 2D ESPs and at the ESP outlet duct 2D2. For all particulate measurements, tabulated values are presented as milligrain/dscf at $7 \% \mathrm{O}_{2}$ and as $10^{-3} \mathrm{lb} / \mathrm{MMBtu}$. Method 17 measurements were made for baseline operation and three activated carbon injection rates: 0.5 , 1.0 , and $1.9 \mathrm{lb} / \mathrm{MMacf}$.

Particulate concentration measurements were also made with Method 5 as part of the M29 measurements conducted at three test conditions: baseline operation, calcium bromide plus ACI, and $\mathrm{ACI}$ at $1.9 \mathrm{lb} / \mathrm{MMacf}$. Method 5 results, as well as a comparison to Method 17 results, are provided in Appendix O. Inlet particulate loading measurements by port are presented in Figure $4-25$. 


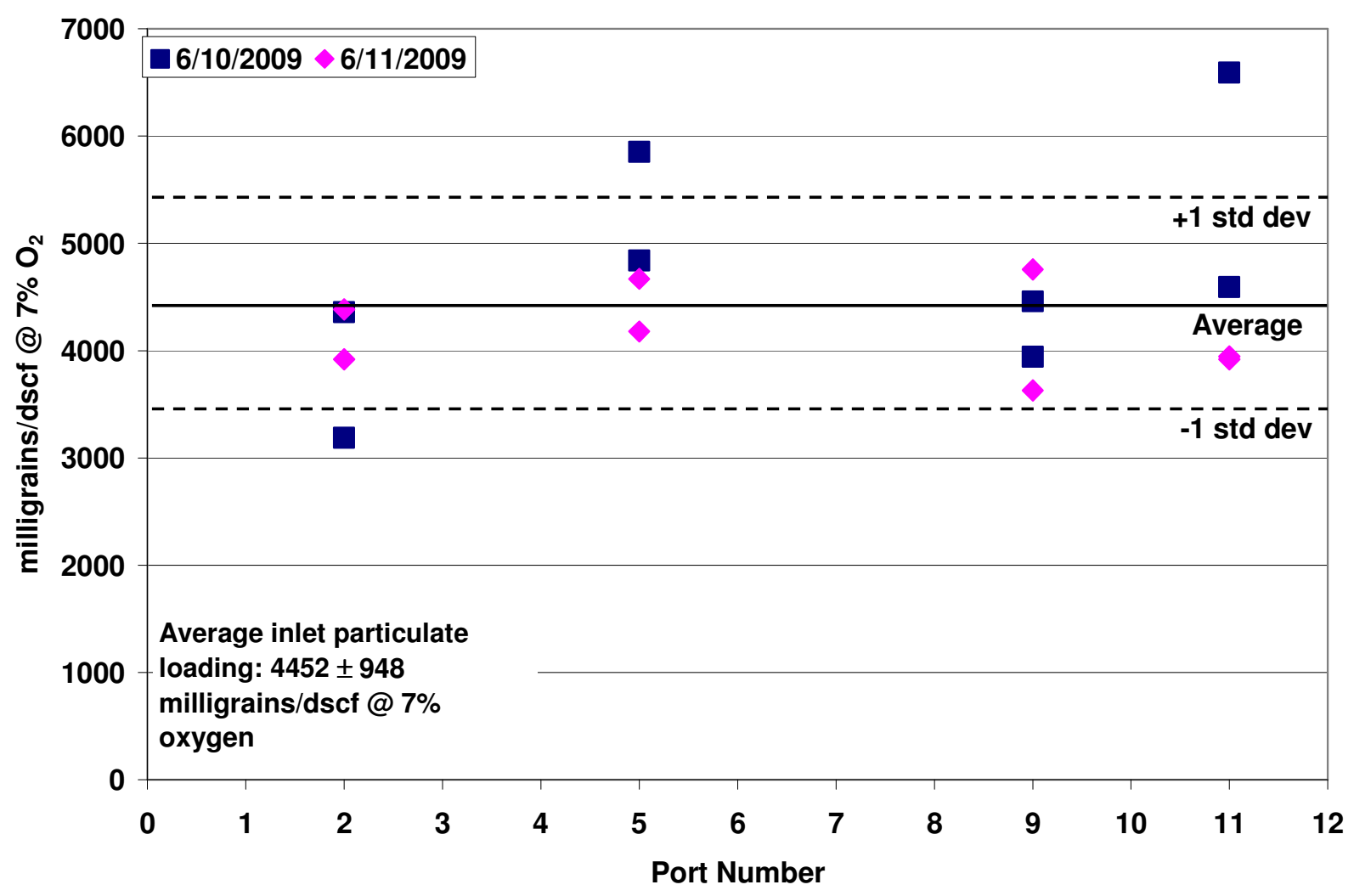

Figure 4-25. Baseline Particulate Loading Measurements at ESP Inlet by Port Number

Baseline particulate loading measurements at the ESP outlet are summarized in Table 4-49. Measured loadings ranged from $2.4-3.7$ milligrain/dscf $\left(7 \% \mathrm{O}_{2}\right)$, with an average duct loading of $3.0 \pm 0.65$ milligrain/dscf, with the highest concentration measured at the bottom of the duct and the lowest measured at the top. Although all sampling was conducted within a 2-hour time period, each duct section was sampled sequentially, thus at a different time than the others.

Table 4-49. Baseline Particulate Loading Measurements at Outlet (Method 17)

\begin{tabular}{||c|c|c|c|c|c||}
\hline $\begin{array}{c}\text { Top or } \\
\text { Bottom Half } \\
\text { Traverse of } \\
\text { Duct? }\end{array}$ & Date & $\begin{array}{c}\text { Start } \\
\text { Time }\end{array}$ & $\begin{array}{c}\text { End } \\
\text { Time }\end{array}$ & $\begin{array}{c}\text { Outlet Particulate Loading } \\
(\text { milligrain/dscf at 7\% O })\end{array}$ & $\begin{array}{c}\text { Outlet Particulate Loading } \\
(\mathbf{1 0}-\mathbf{3} \text { lb/MMBtu) }\end{array}$ \\
\hline Top & $6 / 10 / 2009$ & $14: 11$ & $14: 36$ & 2.37 & 5.02 \\
\hline Bottom & $6 / 11 / 2009$ & $14: 54$ & $15: 19$ & 3.67 & 7.78 \\
\hline Top & $6 / 11 / 2009$ & $15: 42$ & $16: 07$ & 3.00 & 6.35 \\
\hline Average & & & & $\mathbf{3 . 0 1}$ & $\mathbf{6 . 3 8}$ \\
\hline Std Dev & & & & $\mathbf{0 . 6 5}$ & $\mathbf{1 . 3 8}$ \\
\hline
\end{tabular}


Particulate loading measurements were made for three different activated carbon injection rates: $0.5 \mathrm{lb} / \mathrm{MMacf}, 1.0 \mathrm{lb} / \mathrm{MMacf}$, and $1.9 \mathrm{lb} / \mathrm{MMacf}$. Inlet and outlet particulate loading measurements were collected for $0.5 \mathrm{lb} / \mathrm{MMacf}$ and $1.0 \mathrm{lb} / \mathrm{MMacf}$; however, only outlet measurements were collected for $1.9 \mathrm{lb} / \mathrm{MMacf}$. The data for $1.0 \mathrm{lb} / \mathrm{MMacf}$ is shown in Table 450 , the rest of the data are located in Appendix $\mathrm{O}$.

Table 4-50. Inlet Particulate Loading Measurements for Sorbent Injection Test at 1.0 Ib/MMacf (Method 17)

\begin{tabular}{||c|c|c|c|c|c|c||}
\hline \hline Run \# & Port \# & Date & $\begin{array}{c}\text { Start } \\
\text { Time }\end{array}$ & $\begin{array}{c}\text { End } \\
\text { Time }\end{array}$ & $\begin{array}{c}\text { Inlet Particulate } \\
\text { Loading } \\
\text { (milligrain/dsc at 7\% } \\
\left.\mathbf{O}_{\mathbf{2}}\right)\end{array}$ & $\begin{array}{c}\text { Inlet Particulate } \\
\text { Loading } \\
(\mathbf{1 0} \text {-3 Ib/MMBtu) }\end{array}$ \\
\hline 1 & $2 \mathrm{D} 2-2$ & $6 / 17 / 2009$ & $08: 30$ & $08: 55$ & 3130 & 6629 \\
\hline 2 & $2 \mathrm{D} 2-5$ & $6 / 17 / 2009$ & $09: 31$ & $09: 56$ & 5372 & 11377 \\
\hline 3 & $2 \mathrm{D} 2-9$ & $6 / 17 / 2009$ & $10: 45$ & $11: 10$ & 3605 & 7635 \\
\hline 4 & $2 \mathrm{D} 2-11$ & $6 / 17 / 2009$ & $11: 23$ & $11: 48$ & 4358 & 9231 \\
\hline 5 & $2 \mathrm{D} 2-11$ & $6 / 17 / 2009$ & $13: 10$ & $13: 35$ & 4515 & 9563 \\
\hline 6 & $2 \mathrm{D} 2-9$ & $6 / 17 / 2009$ & $13: 47$ & $14: 12$ & 3774 & 9010 \\
\hline 7 & $2 \mathrm{D} 2-5$ & $6 / 17 / 2009$ & $14: 24$ & $14: 49$ & 4254 & 6102 \\
\hline 8 & $2 \mathrm{D} 2-2$ & $6 / 17 / 2009$ & $14: 58$ & $15: 23$ & 2881 & $\mathbf{8 4 4 2}$ \\
\hline Average & & & & & $\mathbf{3 9 8 6}$ & $\mathbf{1 7 0 8}$ \\
\hline Std Dev & & & & & $\mathbf{8 0 7}$ & \\
\hline
\end{tabular}

Figure 4-26 compares particulate loading measurements made at the top and bottom of the ESP outlet duct for the various sorbent injection rates. During both baseline and sorbent injection, particulate concentrations were higher at the bottom of the duct than at the top. At the bottom of the duct, particulate concentrations were not affected by carbon injection; at the top of the duct, particulate concentrations were lower during sorbent injection than during baseline operation. 


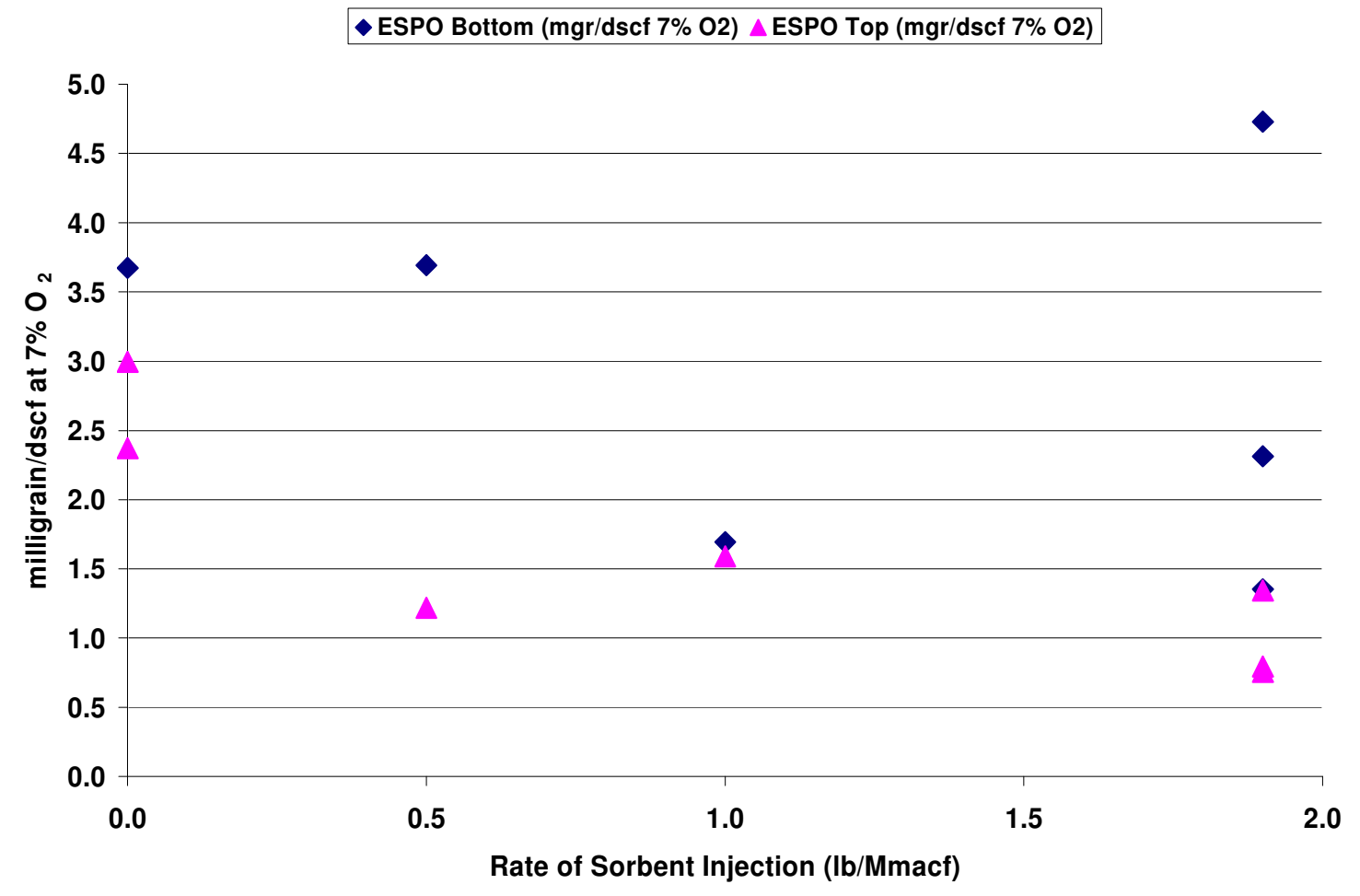

Figure 4-26. Comparison of Outlet Particulate Loading Measurements Made at the Bottom and Top Portions of the Duct

The average inlet particulate loading was relatively steady over the three days tested. Activated carbon injection into the ESP did not negatively effect measured particulate removal across the ESP for injection rates up to $1.0 \mathrm{lb} / \mathrm{MMacf}$. The baseline removal was calculated as $99.93 \%$, with an increase to $99.95 \%$ removal at an ACI rate of $0.5 \mathrm{lb} / \mathrm{MMacf}$, and $99.96 \%$ removal at an ACI rate of $1.0 \mathrm{lb} / \mathrm{MMacf}$. Since the average outlet concentration measurements for 1.9 $\mathrm{lb} / \mathrm{MMacf}$ were in the same range as the average outlet concentration measurements of the other conditions, it is probable there was no negative effect on particulate matter removal at this rate either.

\section{Activated Carbon Injection Process Economics}

Capital and operating costs associated with various targeted levels of mercury control were developed for ACI at a hypothetical 500-MW electric generating station firing primarily Texas Lignite. The assumed configuration for this hypothetical plant is similar to LMS - it fires a 70/30 blend of Texas Lignite/PRB; it is equipped with a large-SCA ESP for particulate control and a limestone forced oxidation FGD for $\mathrm{SO}_{2}$ control. The FGD does not create a salable gypsum byproduct. The activated carbon injection lances are installed upstream of the AH. The characteristics of the plant are summarized in Table 4-51. Average TxL and PRB coal compositions from the phase IV test at LMS were used to calculate an average coal mercury input of $970 \mathrm{lb} / \mathrm{yr}$ and ESP inlet mercury concentration of $40 \mu \mathrm{g} / \mathrm{dNm}^{3}$ at $3 \% \mathrm{O}_{2}$. Baseline mercury removal across the ESP was measured to be $5 \%$. 
Table 4-51. Process Parameters for Hypothetical Plant in Economic Analysis

\begin{tabular}{||l|l||}
\hline Parameter & Value \\
\hline Coal Type & $70 / 30$ TxL/PRB blend \\
\hline Particulate Control & Large-SCA ESP \\
\hline $\mathrm{SO}_{2}$ Control & $\begin{array}{l}\text { Wet Limestone FGD, Inhibited } \\
\text { Oxidation (Sulfur Emulsion) }\end{array}$ \\
\hline Net Unit Load & $500 \mathrm{MW}$ \\
\hline Net Heat Rate & $9800 \mathrm{Btu} / \mathrm{kwh}$ \\
\hline Unit Capacity Factor & 0.85 \\
\hline Flue Gas Temperature at ESP Inlet & $310^{\circ} \mathrm{F}$ \\
\hline Flue Gas Flow Rate at ESP Inlet & $1.9 \times 10^{6} \mathrm{acfm}$ \\
\hline Baseline Vapor Phase Hg Concentration at ESP Inlet & $40 \mu \mathrm{g} / \mathrm{dNm}^{3}$ at $3 \% \mathrm{O}_{2}$ \\
\hline Baseline Hg Removal across ESP & $5 \%$ \\
\hline Baseline Vapor Phase Hg Concentration at ESP Outlet & $38 \mu \mathrm{g} / \mathrm{dNm}^{3}$ at $3 \% \mathrm{O}_{2}$ \\
\hline \hline
\end{tabular}

Note: Flue gas conditions and activated carbon injection rates are provided as if injecting at the ESP Inlet to maintain uniformity for reference and comparison; however, the economic analysis was completed using the data while injecting at the AH Inlet injection location.

Economic analyses were derived for targeted mercury reductions of $50 \%$ and $70 \%$ across the system with recommendations on how to achieve $90 \%$ removal. The projected annual cost associated with a carbon injection system was composed of the following components:

Sorbent cost - This is the yearly cost of the sorbent. For this analysis, the chosen sorbent was Norit Americas' DARCO Hg-LH, currently available at an estimated \$1.20/lb to $\$ 1.50 / 1 b$ F.O.B. The delivery cost of the sorbent to the LMS plant from Norit's plant in Marshall, Texas was assumed to be $\$ 0.02125 / \mathrm{lb}$. The DARCO Hg-LH sorbent performance curve generated during the Phase IV parametric tests (performed in 2009) with injection upstream of the air heater was used to estimate the sorbent injection rates needed to achieve $50 \%$ and $70 \%$ mercury reduction at the stack. As a means of easy comparison between economic analyses, this analysis focuses solely on Darco Hg-LH.

- Ash mitigation cost - This is the cost associated with treatment of the fly ash to make it viable for sale to the concrete industry. Several different ash mitigation scenarios were considered.

○ In the case of $50 \%$ mercury reduction at the stack, the required sorbent injection rate is only $0.18 \mathrm{lb} / \mathrm{Macf}$. Based on the data obtained in this project, the fly ash containing this amount of carbon can be sold directly without the use of any ash mitigation techniques.

- For the case of $70 \%$ mercury reduction, a sorbent injection rate of $1.3 \mathrm{lb} / \mathrm{Macf}$ is needed. In this case, the fly ash is not viable to sell for concrete and will need to be landfilled (at a cost of $\$ 22.6 /$ ton for lost sales and landfilling). Phase IV data suggests this to be the case for all sorbent injection rates above $0.5 \mathrm{lb} / \mathrm{Macf}$.

- Operating and maintenance cost - Labor is required to monitor the operation of the sorbent injection system, coordinate sorbent shipments, and provide routine maintenance. It was assumed that over the course of one year, an average of one hour per day would be needed, at a loaded labor rate of $\$ 50 / \mathrm{hr}$. A spare parts budget of $\$ 5000 / \mathrm{yr}$ was allocated. The capital cost estimate already includes a spare feeder. 
- Amortized capital cost - This is the cost associated with installation of the carbon injection system. The economic life of the equipment was assumed to be 15 years at an interest rate of $8 \%$, for a capital recovery factor of 0.12 .

Table 4-52 and Figure 4-27 show the annual cost to achieve 50\% and 70\% mercury reduction at the stack. For each case the annual cost is broken down into its contributing components: sorbent cost, amortized capital cost, and ash mitigation costs. The cost for operating and maintaining the process is not presented in Figure 1 as it is too small $(\sim 25,000)$ to appear. The results presented here are "first-year" costs, meaning the sorbent costs are presented in 2010 dollars while capital costs have been amortized over fifteen years.

To achieve 50\% mercury reduction at the stack, the annual cost is projected to be $\$ 1.00 \mathrm{M}$ $\$ 1.05 \mathrm{M}$. To achieve $70 \%$ mercury reduction, the annual cost increases to $\$ 8.1 \mathrm{M}-\$ 8.4 \mathrm{M}$. The cost associated with ash mitigation (i.e. disposal of $100 \%$ of fly ash) contributes $73-77 \%$ of the annual cost associated with $70 \%$ mercury reduction.

The cost breakdown for 50\% mercury removal assumes that a control scenario is implemented that is sufficient to preserve the ability to sell the fly ash by maintaining proper activated carbon injection rates. Should the engineering controls be insufficient to preserve the fly ash quality, all of the ash would need to be landfilled; this case is shown at the bottom of Table 2. The cost for $50 \%$ mercury reduction increases from $\$ 1.00 \mathrm{M}-\$ 1.05 \mathrm{M}$ to $\$ 6.90 \mathrm{M}-\$ 6.94 \mathrm{M}$ when all of the fly ash must be landfilled. 
Table 4-52. Annual Cost Breakdown for ACI Upstream of AH

\begin{tabular}{|c|c|c|c|}
\hline Targeted \% Hg Reduction at Stack & & $50 \%$ & $70 \%$ \\
\hline Injection Location & & Upstream of $\mathrm{AH}$ & Upstream of $\mathrm{AH}$ \\
\hline Sorbent & & Darco Hg-LH & Darco Hg-LH \\
\hline ACI Injection rate & $\mathrm{lb} / \mathrm{Macf}$ & 0.18 & 1.3 \\
\hline ACI Injection rate at full load & $\mathrm{lb} / \mathrm{hr}$ & 21 & 153 \\
\hline ACI Injection & $\mathrm{lb} / \mathrm{yr}$ & 155,171 & $1,140,281$ \\
\hline Foam Index Result (drops; BL = 3 drops) & & 9 & 14 \\
\hline Ash Disposal Plan & & Sell all ash & $\begin{array}{l}\text { Landfill Fly Ash } \\
\text { (see below) }\end{array}$ \\
\hline Rejection Rate of Fly Ash & $\%$ & $5 \%$ & N/A \\
\hline $\begin{array}{l}\text { Total Annual Cost: Carbon+Capital+Ash } \\
\text { Mitigation }\end{array}$ & $\$ / y \mathbf{r}$ & $\begin{array}{l}\$ 1,002,957- \\
\$ 1,049,508\end{array}$ & N/A \\
\hline Annual carbon cost (including shipping) & $\$ / \mathrm{yr}$ & $\$ 189,503-\$ 236,054$ & $\begin{array}{l}\$ 1,392,568- \\
\$ 1,734,652\end{array}$ \\
\hline Operating and Maintenance & $\$ / y r$ & $\$ 23,200$ & $\$ 23,200$ \\
\hline Amortized Capital Cost For ACI System & $\$ / y r$ & $\$ 480,000$ & $\$ 480,000$ \\
\hline Ash Mitigation Cost & $\$ / y r$ & $\$ 310,254$ & N/A \\
\hline Lost Ash Sales + Landfill Cost & $\$ / \mathrm{yr}$ & $\$ 310,254$ & N/A \\
\hline Case Name & & $\begin{array}{c}50 \% \mathrm{Hg} \\
\text { Reduction; Landfill } \\
\text { Fly Ash } \\
\end{array}$ & $\begin{array}{c}70 \% \mathrm{Hg} \\
\text { Reduction; Landfill } \\
\text { Fly Ash } \\
\end{array}$ \\
\hline Ash Disposal Plan & & Landfill all ash & Landfill all ash \\
\hline Rejection Rate of Fly Ash & $\%$ & $100 \%$ & $100 \%$ \\
\hline $\begin{array}{l}\text { Total Annual Cost: Carbon+Capital+Lost } \\
\text { Ash Sales + Landfill }\end{array}$ & $\$ / \mathbf{y r}$ & $\begin{array}{l}\$ 6,897,784- \\
\$ 6,944,335 \\
\end{array}$ & $\begin{array}{l}\$ 8,100,849- \\
\$ 8,442,933 \\
\end{array}$ \\
\hline Lost Ash Sales + Landfill Cost & $\$ / \mathrm{yr}$ & $\$ 6,205,081$ & $\$ 6,205,081$ \\
\hline
\end{tabular}




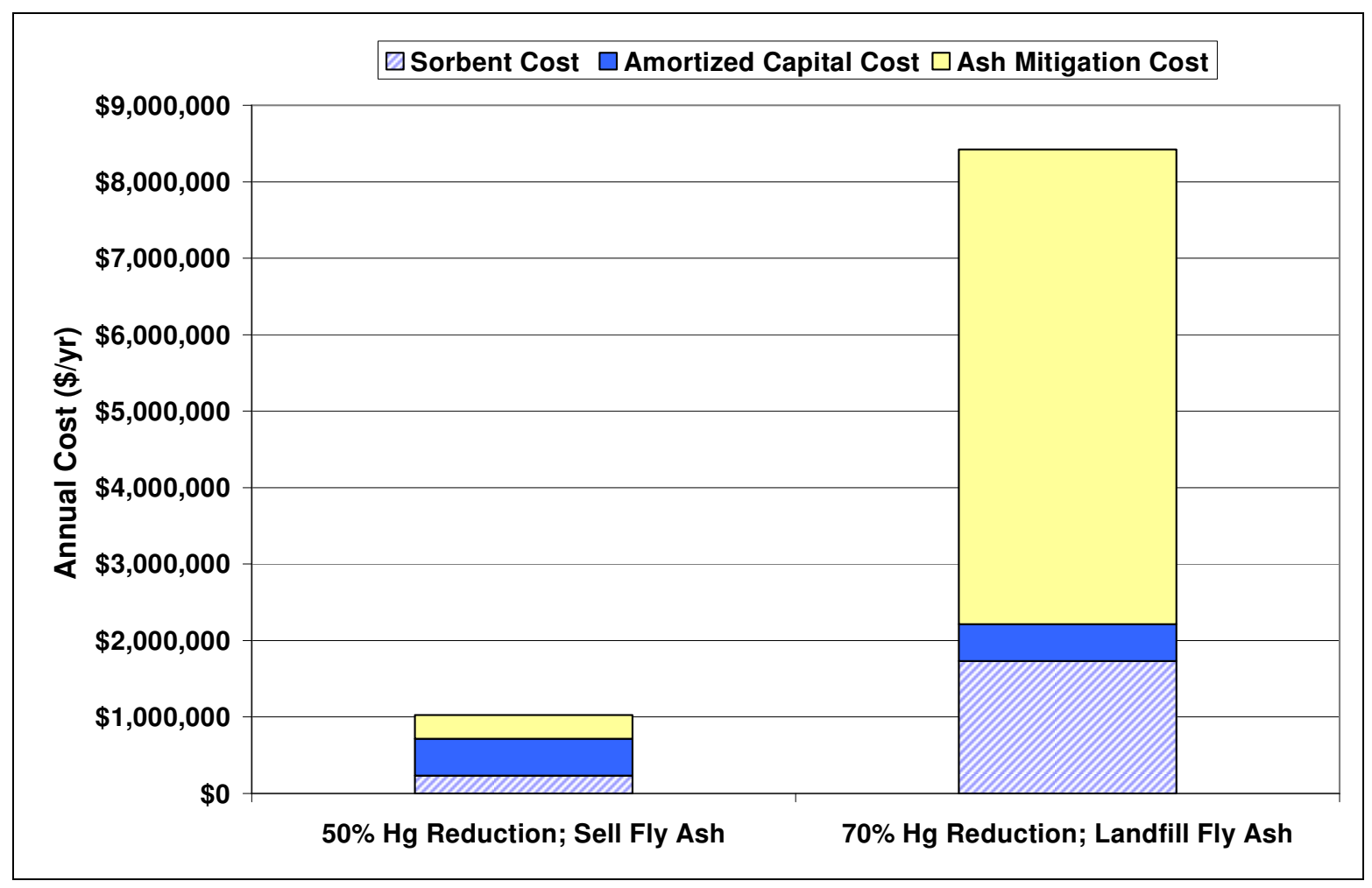

Note: Figure shows Sorbent Cost at $\$ 1.50 / \mathrm{lb}$ F.O.B.

Figure 4-27. Total Annual Cost of ACl for Two Different Levels of Hg Removal at the Stack

Table 4-53 presents the cost of ACI in units of $\$ / 1 b \mathrm{Hg}$ removed for removal across the ESP/FGD system. If the FGD system produced a salable gypsum byproduct, there would be concerns about possible carbon breakthrough from the ESP contaminating the gypsum product and resulting in lost sales. Testing at LMS did show visible signs of carbon breaking through the ESP; however, the testing was not on a scale to determine whether this would have an impact on the inert content and color of the FGD byproduct. The cost for mercury removal across the ESP/FGD systems ranged from $\$ 4,180 / \mathrm{lb}-\$ 4,374 / \mathrm{lb}$ for $50 \%$ reduction at the stack, to $\$ 24,115 / \mathrm{lb}-\$ 25,134 / \mathrm{lb}$ for $70 \%$ reduction at the stack.

Table 4-53. Cost of $\mathrm{ACl}$ in $\$ / \mathrm{lb} \mathrm{Hg}$ Removed

\begin{tabular}{||l|c|c|c||}
\hline \hline Targeted \% Hg Reduction at Stack & \% & $\mathbf{5 0 \%}$ & $\mathbf{7 0 \%}$ \\
\hline FGD Outlet Hg (BL) & $\mathrm{lb} / \mathrm{yr}$ & 480 & 480 \\
\hline Hg removed by ACI across ESP/FGD & $\mathrm{lb} / \mathrm{yr}$ & 240 & 336 \\
\hline FGD Outlet Hg (w/ ACI) & $\mathrm{lb} / \mathrm{yr}$ & 240 & 144 \\
\hline \$/lb Hg removed (ESP + FGD) & & $\mathbf{\$ 4 , 1 8 0 -}$ & $\mathbf{\$ 2 4 , 1 1 5 -}$ \\
$\mathbf{\$ 2 5 , 1 3 4}$
\end{tabular}




\section{Recommendations to potentially achieve $90 \%$ Hg Removal}

The mercury removal objectives of this analysis are met using $0.18 \mathrm{lb} / \mathrm{Macf}$ Darco $\mathrm{Hg}-\mathrm{LH}$ to achieve an overall system removal of 50\% while preserving fly ash integrity. With $1.3 \mathrm{lb} / \mathrm{Macf}$ Darco Hg-LH injection, system removals of $70 \%$ could be achieved (air heater inlet to stack, with $15 \%$ flue gas bypass), but ash integrity is compromised at injection rates above $0.5 \mathrm{lb} / \mathrm{Macf}$.

Results from this test program showed that $90 \%$ removal of mercury was not achievable using a carbon injection rate conducive for fly ash resale. In addition, parametric test results suggest that $90 \%$ removal may not be possible at LMS using only an ACI control process. It is probable that with a combination of technologies, LMS could possibly achieve $90 \% \mathrm{Hg}$ removal at the stack. An investigation of these options and their potential costs is presented below:

- Elimination of $15 \%$ FGD Bypass;

- Control FGD Hg Re-Emissions with Additives;

- $\mathrm{SO}_{3}$ Mitigation;

- Injection of Finely Ground Carbon; and

- Improved Sorbent Distribution.

\section{Elimination of FGD Bypass}

The LMS FGD system currently operates with, on average, a 10-15\% gas bypass. Flue gas characterization tests showed that $\sim 96 \%$ of oxidized mercury is captured across the scrubber. If all of the flue gas was flowed through the FGD (eliminate any bypass), LMS could expect to achieve $2-6 \%$ additional mercury removal (assuming that $96 \%$ of the oxidized mercury previously being bypassed is removed in the FGD).

The elimination of the FGD bypass would result in an expected increase in FGD reagent usage and disposal costs assuming the plant would elect to capture more $\mathrm{SO}_{2}$ (upon eliminating the bypass). There may be some positive impact on costs, however, such as reduced $\mathrm{SO}_{2}$ emissions and the associated value of emissions credits.

\section{Mercury Re-Emission Additives}

As mentioned previously, intermittent mercury re-emissions were observed throughout the test program. The addition of re-emission additives to the FGD system can be used in combination with sorbent injection to potentially increase overall system mercury removal. Mercury reemissions evolve from the liquor phase as previously scrubbed oxidized mercury is reduced to its elemental form. Re-emission additives work by precipitating oxidized mercury from the liquor phase before it is chemically reduced. Re-emission additives are ideal for increasing overall system mercury removal; however, their performance is highly dependent on the amount of oxidized mercury entering the FGD system as well as the chemical composition and operating conditions of the absorber. 
Direct costs associated with a re-emission additive system would include capital and operational costs. Indirect costs associated with the additive system would include the potentially negative impact on gypsum quality, although the theoretical plant does not sell its gypsum byproduct. Each of these cost estimates and the assumptions associated with the estimates are discussed in the following sections.

\section{Capital Costs}

In determining a reasonable capital cost estimate, a simple system design was completed. This design assumed that the FGD additive would be unloaded, stored, and pumped from a storage tank to the injection locations using two (2) additive feed pumps ( 1 operating, 1 spare). The additive would be injected into the recycle slurry pumps' suction on each of the five (5) operating absorbers. The additive would be metered based on the mercury concentration at the absorber inlet and the estimated effectiveness of the additive.

Other injection locations that were considered include the limestone slurry storage tank and the absorber slurry reagent tanks. These two locations would not be as ideal, as they both increase the liquid-phase residence time of the additive and its exposure to trace metals present in the slurry. Mercury re-emission additives not only precipitate mercury but are capable of precipitating other trace metals. Freshly ground limestone introduces a significant amount of trace metals into the slurry system. This competition between mercury and other trace metals would reduce the overall effectiveness of the additive and would therefore require an excess of additive to counter the presence of trace metals. It is important that the additive is introduced at the point where the residence time can be minimized, thus making the recycle pump suction an ideal location for addition.

The typical reagent flow rate for a chemical additive was calculated to be 0.3 gallons per hour (gph), with a maximum addition rate of $3 \mathrm{gph}$, depending on what additive is selected. For the purposes of the capital cost estimate, the flow rate did not significantly impact the economic analysis.

The following capital equipment was assumed in researching and developing the cost estimate:

- Small storage tank with required heaters and instrumentation;

- Two (2) additive feed pumps (one operating, one spare);

- Flow meters and flow control valves for each absorber ( to meter the flow based on absorber operating status, inlet mercury, etc.); and

- Necessary piping and instrumentation to control the process.

Based on the scope and based on other similar chemical injection projects, the total capital cost would be expected to be between $\$ 1 \mathrm{M}-\$ 3 \mathrm{M}$. A more detailed estimate would need to be completed to determine the cost with greater accuracy.

\section{Operating Costs}

Operating costs for an additive injection system include reagent and maintenance costs. The actual reagent costs will depend on the additive selected and the resulting usage rate of that 
additive. For purposes of this cost estimate, a range of expected additive costs were obtained and are presented in Table 4-54.

Table 4-54. Estimated Range of Costs for Annual Additive Consumption

\begin{tabular}{||l|c|c|c||}
\hline & Low & Average & High \\
\hline Additive Cost, per lb & $\$ 2$ & $\$ 5$ & $\$ 7$ \\
\hline Dosage Range, gram additive to gram oxidized Hg & 4 & 102 & 200 \\
\hline Annual Cost with 50\% Hg Removal Upstream of FGD & $\$ 8,300$ & $\$ 107,500$ & $\$ 206,700$ \\
\hline Annual Cost with 70\% Hg Removal Upstream of FGD & $\$ 4,900$ & $\$ 64,100$ & $\$ 123,300$ \\
\hline
\end{tabular}

The labor required to monitor the operation of the additive injection system, coordinate additive shipments, and provide routine maintenance was estimated to be two hours per week. At a loaded labor rate of $\$ 50 / \mathrm{hr}$, a total yearly cost for labor would be $\$ 5,200$. A spare parts budget of $\$ 1,000 / y r$ would be sufficient. With these assumptions, the total maintenance cost would be: $\$ 6,200$.

Therefore, the total operating costs would range from $\$ 10,200$ to $\$ 172,900$ depending on the removal rate achieved upstream of the FGD and the additive selected. A more accurate estimate of reagent costs would require further investigation to determine the optimal additive and dosage rate.

\section{$\mathrm{SO}_{3}$ Mitigation}

Mercury removal rates are directly affected by the $\mathrm{SO}_{3}$ concentration in the flue gas. Vaporous $\mathrm{SO}_{3}$ is formed during the combustion process as sulfur in the fuel is oxidized. Typically 1 to $2 \%$ of the sulfur is oxidized to $\mathrm{SO}_{3}$ in the boiler; however, the amount of $\mathrm{SO}_{3}$ formed can vary based on the coal fuel/oxygen stoichiometry, combustion temperature, and the presence of catalyst such as nickel and vanadium. As flue gas passes through the selective catalytic reduction (SCR) system, additional $\mathrm{SO}_{3}$ is formed as a portion of the sulfur dioxide $\left(\mathrm{SO}_{2}\right)$ is converted to $\mathrm{SO}_{3}$ as it passes through the catalyst. Normally, $0.5 \%$ to $2 \%$ of the $\mathrm{SO}_{2}$ entering the $\mathrm{SCR}$ is converted to $\mathrm{SO}_{3}$.

$\mathrm{SO}_{3}$ directly competes with mercury for adsorption on unburned carbon and/or injected carbon. By implementing an $\mathrm{SO}_{3}$ mitigation technology, LMS could expect to achieve higher mercury removal. Figure 4-28 below illustrates the effect of $\mathrm{SO}_{3}$, and provides indication of how mercury capture in fly ash greatly improves as $\mathrm{SO}_{3}$ concentrations decrease to very low values. 


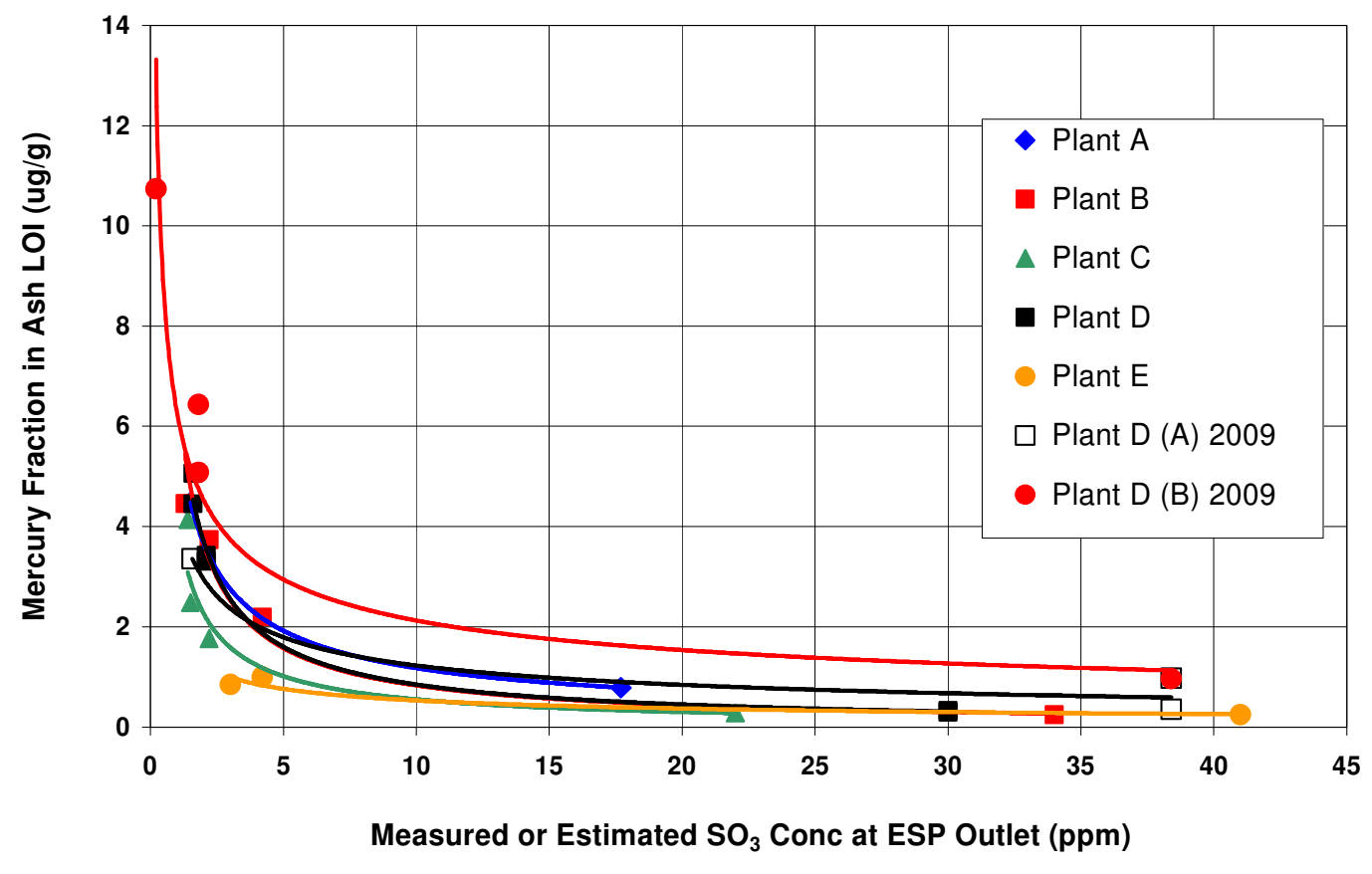

Figure 4-28. Impact of $\mathrm{SO}_{3}$ on $\mathrm{Hg}$ Capture in Ash

There are two main categories of $\mathrm{SO}_{3}$ mitigation processes, dry-injection and wet-injection. In a dry injection process, solid reagent is pneumatically conveyed to the injection location where it is blown into the flue gas ducts, much like the ACI process. The wet injection process dissolves the reagent and delivers it to the flue gas as a clear liquid. The liquid is sprayed into the duct using dual-fluid, air-atomizing nozzles designed to produce very fine droplets. The injected droplets dry quickly and form extremely small solid reagent particles with a large overall surface area for improved reaction. The advantages of wet injection are better distribution within the duct and higher $\mathrm{SO}_{3}$ removals, allowing a utility to achieve $\mathrm{SO}_{3}$ levels of $<5 \mathrm{ppm}$.

A typical dry sorbent injection system costs $\$ 4-5 \mathrm{M}$ for a single 500 to $800 \mathrm{MW}$ unit whereas a typical wet injection system costs around $\$ 6 \mathrm{M}$. Typical reagents costs for a theoretical $500 \mathrm{MW}$ plant burning 70/30 TxL/PRB blend would run $\$ 200,000$ - 300,000/year for a dry injection system depending on the dry reagent and around $\$ 250,000 /$ year for a wet injection system.

\section{Injection of Finely Ground Carbon}

The injection of smaller sorbent particles should improve sorbent-gas contact in the duct and, subsequently, improve mercury removal performance. Unfortunately, results from this program indicated challenges associated with the agglomeration of a finely-ground carbon sorbent during transport and feeding. Typically a $20-60 \%$ increase in sorbent cost would be expected for the decrease in particle size. Additional development is needed to determine cost-effective means to effectively transport and inject finely-ground carbon particles. 


\section{Improved Sorbent Injection}

Previous testing has shown improvements in mercury removal when locating the sorbent injection lances upstream of the air preheater and with the use of a lance design with more energetic lance nozzles. URS has developed a proprietary design for carbon injection lances which were implemented in the 2009 test program. The lances are designed to increase gas turbulence and recirculation downstream of the lance and to distribute carbon particles more evenly along the length of the lance. This test program represents the first time this lance design has been tested in a flue gas application.

At Limestone, the testing was somewhat inconclusive in that there were uncertainties associated with changes in the number of lances used and plugging of the solids dispersion lances.

However, CFD models presented in Figures 2-4 and 2-5 show the improvement in distribution expected to be achieved over the traditional simple pipe lance design delivery system. Figure 429 shows predicted mercury removal across the system utilizing several different sorbents through the solids dispersion lance assuming 95\% removal of oxidized mercury across the FGD.

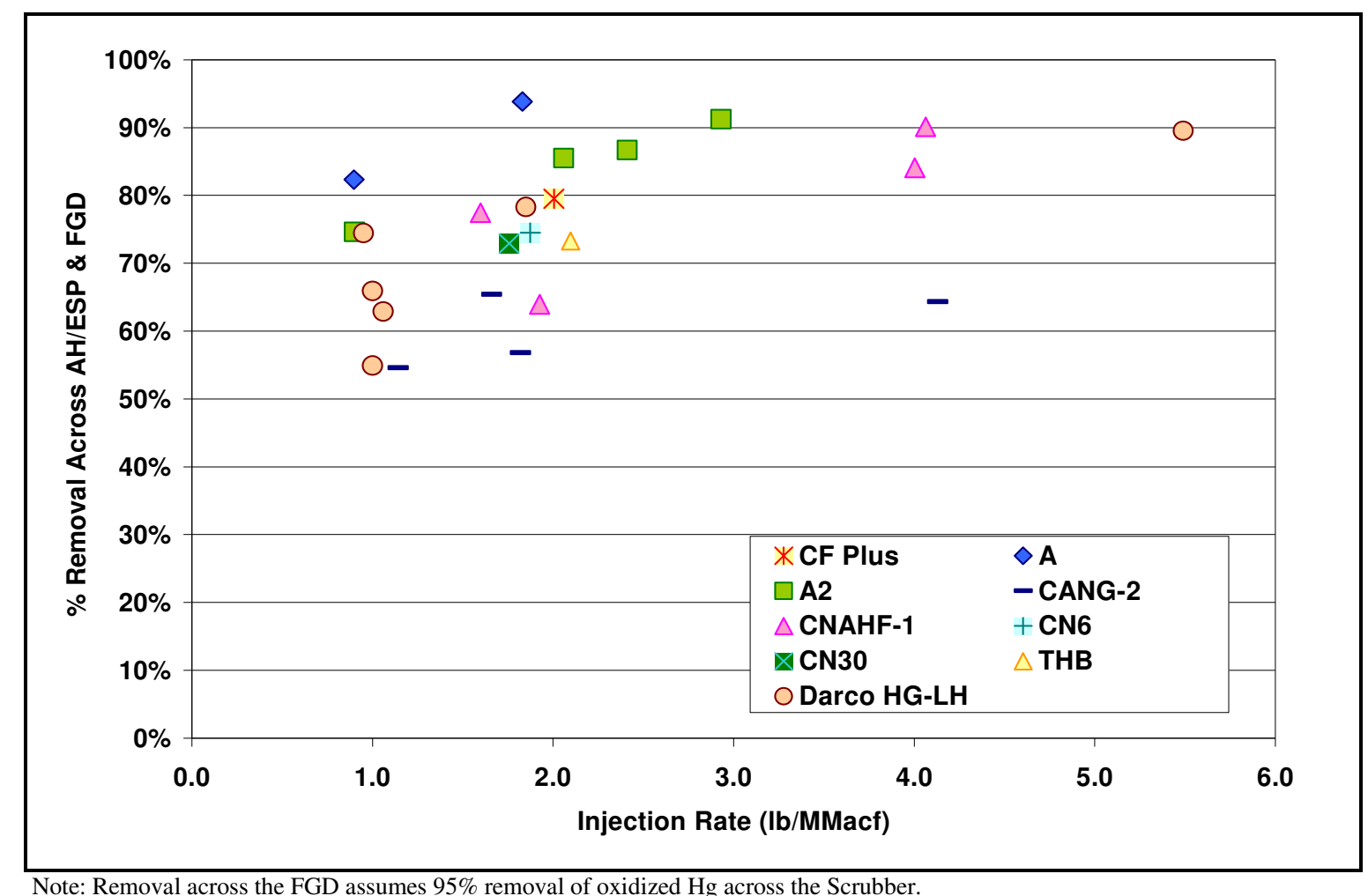

Note: Removal across the FGD assumes $95 \%$ removal of oxidized $\mathrm{Hg}$ across the Scrubber.

Figure 4-29. Predicted Hg Removal across the AH/ESP \& FGD, Solids Dispersion Lance 
As shown in Figure 4-29, there are several instances in which the solids dispersion lance achieved $>70 \%$ removal at injection rates $<1.3 \mathrm{lb} / \mathrm{Macf}$ using Darco $\mathrm{Hg}-\mathrm{LH}$ and other various sorbents (A2 and A). Additionally, the figure shows an instance in which the solids dispersion lance achieved $>90 \%$ mercury removal below $2.0 \mathrm{lb} /$ Macf sorbent injection. Based on these results, it seems that increased mercury removal is achievable with the use of a more energetic solids dispersion lance resulting in improved sorbent distribution. To determine the approximate cost for a full-scale installation, a more detailed review would need to be conducted of the plant requirements, duct dimensions, and final design options. 


\subsection{CONCLUSIONS AND RECOMMENDATIONS}

A multi-phase sorbent injection test program was conducted as part of Cooperative Agreement DE-FC26-06NT42779, "Mercury Control for Plants Firing Texas Lignite and Equipped with ESP-wet FGD." The project was primarily funded by the U.S. DOE National Energy Technology Laboratory. EPRI, NRG Texas, Luminant (formerly TXU), and AEP were project co-funders. URS Group was the prime contractor, and Apogee Scientific and ADA-ES were subcontractors.

The host site for this program was NRG Texas' Limestone Electric Generating Station (LMS) Units 1 and 2, located in Jewett, Texas. The 900-MW units typically fire a 70/30 wt\% blend of Texas lignite and Powder River Basin coal, and are equipped with cold-side ESPs and limestone forced oxidation FGD systems.

This program focused on the use of several sorbent injection technologies to reduce flue gas mercury emissions with special emphasis placed on the resulting impacts on fly ash quality. The LMS units generate high quality, low LOI fly ash that is used for cement replacement in concrete production, providing both an environmental benefit (e.g., landfill avoidance, $\mathrm{CO}_{2}$ emissions avoidance for the concrete manufacturer) and an economic benefit to the plant. The use of sorbent injection to control mercury emissions at LMS has the potential to jeopardize the beneficial re-use of the ash in concrete. Most sorbents are made of activated carbon and are injected upstream of the ESP. The carbon is captured along with the fly ash by the ESP. The presence of carbon in the ash is problematic for concrete production because of its impact on air entrainment in the concrete product. The natural air content of concrete is about $2 \%$; however an air content of $6 \%$ is generally required to prevent cracking during cold weather. Air entrainment in concrete is achieved by using surfactants called Air Entraining Agents (AEAs) to stabilize a well-distributed air void system in the concrete. Carbon in the fly ash has a strong tendency to adsorb these surfactants, thus making it more difficult to entrain air in the concrete. Fly ash with elevated carbon content requires additional AEA (i.e., have a higher AEA demand) to create the necessary air voids. While low AEA demand is desired, ashes with higher AEA demand may be acceptable in concrete so long as the demand is consistent over time. Consistency must be inherent within each batch of fly ash and from batch-to-batch because the ready-mix concrete manufacturer cannot easily adjust the AEA dosage to the AEA demand of each batch of fly ash received.

In this project, several approaches were evaluated for reducing the impact of sorbent injection on fly ash quality. These included use of more ash compatible sorbents (such as non-carbon mercury sorbents and passivation of activated carbon to reduce AEA demand), minimizing sorbent use (such as relocation of the injection location, use of finer sorbent size distribution, better sorbent distribution lances) to reduce the amount of sorbent in the ash, and the use of Toxecon $^{\mathrm{TM}}$ II technology (injection of activated carbon between ESP fields) to preserve quality of the fly ash in the ESP fields prior to carbon injection.

At the time when this project was awarded, pending federal legislation targeted $70 \%$ reduction in mercury emissions from the fleet of coal fired power plants. Accordingly, the objective of this project was to achieve $50-70 \%$ system mercury removal at LMS with sorbent injection while maintaining the integrity of fly ash for use in concrete. This project identified several technology 
options that should meet this goal. However, the power industry now faces a possible MACT standard that could require greater than $90 \%$ mercury removal for some coal-fired facilities. Therefore, the project team set an additional, informal goal of determining the highest possible mercury removal that can be achieved at LMS. The regulatory emissions target for LMS is still unknown, but the project team evaluated mercury control technologies for their ability to maintain stack mercury concentrations at less than $2 \mu \mathrm{g} / \mathrm{dNm}^{3}(1.35 \mathrm{lb} / \mathrm{TBTU})$ at $3 \% \mathrm{O}_{2}$ while preserving fly ash integrity. As will be discussed below, achieving this goal will be difficult for LMS as it currently operates, partly because of the variable nature of TxL coal with respect to mercury and chloride concentrations; it also possesses significantly higher mercury and sulfur concentrations than typical PRB coal. These factors combine to result in lower general performance and higher variability for mercury control options implemented in this flue gas, as compared to PRB-derived flue gas.

Baseline (i.e., 70/30 TxL/PRB coal blend, no mercury controls) mercury emissions for Units 1 and 2 were measured at several points in the test program. The baseline measurements indicated that less than $5 \%$ of the flue gas mercury was removed by the fly ash. Baseline ESP outlet mercury concentrations averaged $20 \mu \mathrm{g} / \mathrm{dNm}^{3}$ and ranged from $15-25 \mu \mathrm{g} / \mathrm{dNm}^{3}$. Mercury oxidation at the ESP outlet averaged $50 \%$, but could vary from $25-75 \%$. With $\sim 15 \%$ of the flue gas bypassing the FGD, mercury removal across the system averaged only $22 \%$, with FGD outlet concentrations ranging from $12-19 \mu \mathrm{g} / \mathrm{dNm}^{3}$. The data suggest there were intermittent mercury re-emissions from the FGD system; the percent of oxidized mercury at the ESP outlet that was re-emitted from the FGD ranged from $-27 \%$ to $17 \%$.

Various approaches for implementing sorbent injection while preserving fly ash integrity are described below. For each approach, mercury removal results are presented in terms of the official program goal of 50-70\% removal and in terms of the informal but more stringent goal of achieving $<2 \mu \mathrm{g} / \mathrm{dNm}^{3}$ stack $\mathrm{Hg}$ concentration. The impacts of each technology on fly ash integrity and other balance of plant effects are also discussed. Most of the technological approaches were evaluated in short-term parametric tests, with each test condition lasting between several hours and two days. Such tests work well for quickly screening technologies for their potential to remove and oxidize mercury. Continuous long-term tests of the most promising technologies are needed to quantify variability in mercury removal performance and fly ash integrity. One such long-term test was conducted as part of this project - the continuous injection of $2.0 \mathrm{lb} / \mathrm{Macf}$ Darco Hg-LH upstream of the ESP over a two-month period.

\section{Use of Non-Carbon Sorbents}

Perhaps the most obvious first approach to minimizing the effect of sorbent injection on fly ash integrity is the use of non-carbon sorbents that do not increase AEA demand of the fly ash; however, non-carbon sorbents have historically demonstrated lower mercury adsorption capacities than carbon sorbents. Only one non-carbon sorbent was identified in this program that was available in sufficient quantity and had sufficient historical test data to merit the expense of a field trial. This non-carbon sorbent was BASF's MS200, an enhanced molecular sieve material. In short-term parametric tests across Unit 1A ESP, BASF MS200 reached a plateau of 50\% mercury removal across the AH/ESP at $6 \mathrm{lb} / \mathrm{Macf}$. BASF conducted further studies on their own and determined that the non-carbon BASF MS200 have quite different physical characteristics compared to activated carbons and this may lead to non optimized feed and dispersion of the 
sorbent when used with activated carbon injection equipment. Further development of this sorbent is being conducted by BASF. Because several carbon based sorbents achieved higher mercury removal and higher ESP outlet oxidation at lower injection rates, no further tests were conducted with BASF MS200.

\section{Reduction of Carbon Injection Rate}

Several approaches were tested in an attempt to reduce the carbon injection rate while still achieving high levels of mercury removal, thus limiting the increase in AEA demand of the fly ash. These approaches included identification of the most reactive sorbents (thus requiring the lowest injection rate), sorbent grinding to increase effective surface area, use of enhancement additives (such as calcium bromide to the coal), and improvements to the distribution of the sorbent within the duct.

\section{Evaluation of Carbon Sorbents for Reactivity}

For LMS, the ideal carbon sorbent will have high reactivity associated with both the adsorption and oxidation of mercury so as to best leverage the FGD system's ability to remove oxidized mercury from the flue gas. Carbon sorbents from Norit Americas, Calgon Carbon, and Sorbent Technologies were evaluated for mercury removal across the AH/ESP, mercury oxidation at the ESP outlet, and mercury removal across the system (AH/ESP/FGD).

In parametric tests conducted in 2007 across the Unit 1A ESP, Norit's Darco Hg and Darco HgLH and Sorbent Technologies' B-PAC all achieved 70\% removal across the AH/ESP at injection rates of $1.5-2 \mathrm{lb} / \mathrm{Macf}$. At these injection rates, AEA demand tests indicated that some of these sorbents may result in ash suitable for concrete use. An injection rate of $\sim 4.0 \mathrm{lb} / \mathrm{Macf}$ Darco $\mathrm{Hg}$ LH or B-PAC was required to achieve $90 \%$ removal across the AH/ESP; however, this rate was too high to maintain the integrity of the fly ash. Because the rate of $2.0 \mathrm{lb} / \mathrm{Macf}$ Darco $\mathrm{Hg}-\mathrm{LH}$ met the project's removal objectives and had promise for maintaining fly ash integrity, a sixtyday test was conducted at this injection rate.

During the long-term test, mercury removal across the AH/ESP varied from 30 to $97 \%$, averaging $82 \%$ as measured by SCEM. Mercury removals calculated from the fly ash mercury concentrations showed a lower removal (66\%) while Ontario Hydro measurements made in another duct indicated only $40 \%$ removal. The poor agreement using different measurements is quite likely due to stratification and placement of the sampling probes. Still, the data illustrate the significant variability in mercury control effectiveness that can be expected at Limestone. Mercury oxidation averaged $80 \%$ at the ESP outlet during the two-month continuous injection test, as measured by both SCEM and Ontario Hydro. With injection of $2 \mathrm{lb} / \mathrm{Macf}$ Darco Hg-LH, the fly ash quality was diminished but was deemed just within specifications for use in concrete; however, at this injection rate, the ash marketer predicted it would be difficult for the plant to maintain ash consistency sufficient for the concrete market. These difficulties surfaced in followon tests conducted in 2009, when an injection rate of $0.5 \mathrm{lb} / \mathrm{Macf}$ Darco $\mathrm{Hg}-\mathrm{LH}$ was deemed suitable for fly ash integrity, but an injection rate of $2.0 \mathrm{lb} / \mathrm{Macf}$ exceeded the threshold AEA demand and could thus not be marketed for concrete use. From the cumulative set of data from this program, an injection rate of $0.5 \mathrm{lb} / \mathrm{Macf}$ Darco $\mathrm{Hg}-\mathrm{LH}$ was consistently suitable for ash integrity, with foam index similar to baseline ash. Higher injection rates and other carbon 
sorbents would require further full-scale testing to better define the maximum acceptable injection rate for ash integrity.

As observed in the sixty-day test with Darco Hg-LH and as well as with other carbon sorbents evaluated in the 2007 parametric tests, mercury oxidation at the ESP outlet ranged from $60 \%$ to greater than $80 \%$. The degree of mercury oxidation was independent of sorbent injection rate. The 2007 test program focused on measuring mercury removal across the AH/ESP because FGD outlet measurements were not possible with only $1 / 4$ of the unit being treated; however, theoretical mercury removal across the AH/ESP/FGD system were calculated assuming no mercury re-emissions and $100 \%$ of the flue gas is treated by the FGD. Based on the 2007 results, a rate of $0.5 \mathrm{lb} / \mathrm{Macf}$ Darco $\mathrm{Hg}-\mathrm{LH}$ was estimated to obtain $50 \%$ reduction in mercury at the ESP outlet; this subsequently translated to $90 \%$ removal across the AH/ESP/FGD, when considering mercury oxidation levels at the ESP outlet. However, as will be discussed below, repeat tests conducted on Unit 2 in 2009 indicated lower mercury removal; for example, $0.5 \mathrm{lb} / \mathrm{Macf}$ Darco $\mathrm{Hg}-\mathrm{LH}$ resulted in only $50 \%$ removal across the AH/ESP/FGD.

Follow-on testing was conducted on Unit 2 in 2009, this time with carbon injected over the entirety of Unit 2 rather than just the Unit 1A ESP as in 2007. By treating the entire unit, flue gas mercury measurements could be made across the FGD system; however, 10-15\% of the flue gas bypassed the FGD system, so measured AH-to-stack mercury removals were somewhat lower than what would be expected if there were no bypass.

In 2009, mercury removal performance of all sorbents was extremely variable across Unit 2, a phenomenon that was also observed in 2007's two-month injection test of Darco Hg-LH at 2.0 lb/Macf across Unit 1. However, measured mercury removals across Unit 2 were lower in 2009. As noted previously, in 2007 Darco Hg and Darco Hg-LH achieved 70\% reduction in mercury at the ESP outlet at injection rates of $1.5-2 \mathrm{lb} /$ Macf. In 2009, neither of these sorbents achieved greater than $60 \%$ removal across the AH/ESP at these rates. Likewise, mercury oxidation at the ESP outlet was lower during both baseline and sorbent injection for 2009 vs. 2007 tests. These results suggest a possible difference in operating conditions, boiler and gas cleanup configuration, flue gas mercury reactivity and/or a change in the coal characteristics between Unit 1 and 2. Despite the lower and more variable mercury removal performance, all tested sorbents met the program goals of 50-70\% AH-to-stack mercury removal. However, none of the sorbents exceeded $80 \%$ AH-to-stack removal, and none achieved less than $5 \mu \mathrm{g} / \mathrm{dNm}^{3}$ at the stack. By increasing the PRB content of the fuel blend from 70/30 to 55/45 TxL/PRB, stack mercury concentrations decreased from $\sim 6$ to nearly $3 \mu \mathrm{g} / \mathrm{dNm}^{3}$ with $1.8 \mathrm{lb} / \mathrm{Macf}$ Darco Hg-LH.

One new sorbent from Calgon Carbon (labeled A) was designed for sulfur tolerance and it did show improvement over other sorbents tested. In three separate tests, it achieved $80 \%$ mercury removal across AH/ESP at $1.8 \mathrm{lb} / \mathrm{Macf}$, as compared to $60 \%$ removal for Darco $\mathrm{Hg}-\mathrm{LH}$. However, tests with Calgon's A sorbent were very short in duration and mercury removal across the FGD was not measured because only $1 / 4$ of the unit was treated.

Results from the Phase 4 tests were used to conduct an economic analysis to project costs for controlling mercury to various degrees at a 500-MW plant configured and operated in a similar manner as LMS. Test results indicated that $50 \%$ system removal of mercury could be achieved 
with an ACI addition rate of $0.2 \mathrm{lb} / \mathrm{Macf}$; furthermore, this addition rate results in a saleable fly ash byproduct. Total projected first year costs for maintaining 50\% mercury removal range from $\$ 1.00 \mathrm{M}-\$ 1.05 \mathrm{M}$. To achieve $70 \%$ system removal, an ACI rate of $1.8 \mathrm{lb} / \mathrm{Macf}$ would be required. Test results indicated that carbon injection rates higher than $0.5 \mathrm{lb} / \mathrm{Macf}$ would result in the fly ash not being marketable for cement replacement in concrete production and would therefore require landfilling; this would thus apply to the $70 \%$ removal case. Therefore, the total projected first year cost for achieving $70 \%$ removal with ACI would range from $\$ 8.1 \mathrm{M}-\$ 8.4 \mathrm{M}$; here, approximately $75 \%$ of the total costs would be associated with the loss of fly ash sales and subsequent landfill requirements.

Results from the Phase 4 tests indicated that $90 \%$ mercury removal may not be attainable at LMS using activated carbon injection. It is therefore not possible to project costs for this level of control. It is likely that a combination of control technologies or process modification may be required to achieve $90 \%$ removal. Possible control scenarios could include elimination of the FGD bypass, control of mercury re-emissions from the FGD unit, flue gas $\mathrm{SO}_{3}$ mitigation, injection of finely-ground activated carbon, and improved sorbent distribution in the flue gas duct.

\section{Evaluation of Finely Ground Sorbent}

One way to increase the reactivity of a sorbent is to grind it to a smaller particle size so that there is more surface area available for reaction. This concept was tested with finely ground Darco $\mathrm{Hg}$-LH prepared off site and then shipped to Limestone in bulk bags. The finely ground carbon did not improve mercury removal across the ESP compared to normally supplied unground activated carbon. In-situ particle size measurements in the transport line showed agglomeration of the AC particles. Agglomeration was significant enough that at injection rates of $1 \mathrm{lb} / \mathrm{Macf}$ and higher the mean particle size for the finely ground carbon was greater than that for the standard carbon. It is uncertain if agglomeration occurred in the bulk bags during shipment or in the sorbent feed system. It is also uncertain if different sorbents have different agglomeration characteristics. Some AC suppliers utilize "on-site" grinding and other de-agglomeration techniques that appear to be more successful in enhancing ACI effectiveness. Thus, use of finer sorbent sizes to reduce the amount of sorbent needed is still not well understood and is being investigated further.

\section{Evaluation of Enhancement Additive - Calcium Bromide Addition to Coal}

Tests were conducted to evaluate the addition of calcium bromide to the coal in an attempt to improve mercury oxidation and enhance sorbent performance so as to lower the required sorbent injection rate. The addition of bromine to the coal up to a rate of $175 \mathrm{ppm}$ (as Br; dry basis) did not improve mercury removal across the AH/ESP in the absence of sorbent injection; it provided nominal improvement in mercury removal across the system, with stack mercury concentrations ranging from $7-12 \mu \mathrm{g} / \mathrm{dNm}^{3}$.

The combination of $0.5 \mathrm{lb} / \mathrm{Macf}$ Darco $\mathrm{Hg}$ carbon and $97 \mathrm{ppm} \mathrm{Br}$ resulted in stack mercury concentrations decreasing to $5.9 \mu \mathrm{g} / \mathrm{dNm}^{3}$, as compared to $11.0 \mu \mathrm{g} / \mathrm{dNm}^{3}$ with sorbent alone. The lowest stack mercury concentration achieved was $2.6 \mu \mathrm{g} / \mathrm{dNm}^{3}$ with the addition of $280 \mathrm{ppm} \mathrm{Br}$ and $1.6 \mathrm{lb} / \mathrm{Macf}$ finely ground Darco $\mathrm{Hg}-\mathrm{LH}$. 
While the combination of bromide addition and sorbent injection came closest of all tested technologies to reaching the informal, more stringent goal of $<2 \mu \mathrm{g} / \mathrm{dNm}^{3} \mathrm{Hg}$ at the stack, the required sorbent injection rate of $1.6 \mathrm{lb} / \mathrm{Macf}$ finely ground Darco $\mathrm{Hg}-\mathrm{LH}$ was high enough to potentially jeopardize the beneficial use of ash and the required bromide injection rate could adversely impact the scrubber system. Without changes in scrubber blowdown rates, high bromide addition rates will cause the steady-state FGD Br level to increase, which may possibly lead to corrosion problems in alloy-based scrubbers. The high bromide injection rates $(>200$ ppm by weight in coal) would also cost Limestone Units 1 and 2 more than $\$ 2$ million in annual chemical cost alone. Long-term testing would be required to better evaluate both of these possible negative impacts.

\section{Relocation of Sorbent Injection Lances}

The injection lances were moved from upstream of the ESP (2007 and 2009 test location) to upstream of the air heater (2009 test location) in an attempt to provide additional sorbent mixing and duct residence time. Injection of sorbent upstream of the air heater did not improve mercury removal as compared to injection upstream of the ESP. However, only eight injection lances were used upstream of the $\mathrm{AH}$, due to port constraints, compared to 16 lances used upstream of the ESP. Any gains in residence time from injecting upstream of the AH may have been offset by decreased lateral sorbent distribution caused by the reduced number of lances. Alternatively, mercury removal performance at LMS may have been reaction-limited rather than mass transferlimited, in which case improvements to sorbent distribution would not have resulted in increased mercury removal.

\section{Improvement of Sorbent Distribution within Duct}

The second approach was to improving sorbent distribution was to use solid dispersion lances designed to increase the contact between flue gas mercury and the sorbent. Modeling by computational fluid dynamics showed that the dispersion should improve sorbent coverage by a factor of $2-5$ (depending on distance from lance) compared to the traditional lances. Use of the alternate lance design did not result in increased mercury removal as compared to the traditional lances that were employed for most of the test program. However, at the conclusion of the tests, an inspection of the dispersion lances revealed that some plugging of the nozzles and inlet plenum occurred during injection (partly due to debris in the carbon). It is unknown how much of an effect the plugging had on the distribution of carbon in the duct and the resulting performance of the dispersion lances. Again, if the mercury removal at LMS was reactionlimited, rather than mass transfer-limited, then the dispersion lances would not have resulted in increased mercury removal. Further testing of the dispersion lances is warranted to address operational problems and evaluate the lances while operating at true design specifications.

\section{Use of Low Ash Impact Carbons}

Norit Americas, Sorbent Technologies, and Calgon Carbon all have developed low ash impact versions of their standard brominated activated carbons, labeled EXP-224, C-PAC, and CF Plus Ultra, respectively. One approach used by some of the suppliers is to passivate the carbon sorbent so that it is not as reactive with AEAs. In all cases these sorbents showed lower mercury removals than their standard counterparts; however, all passivated sorbents still met the 50 $70 \%$ system mercury removal target at an injection rate of $\sim 1 \mathrm{lb} / \mathrm{Macf}$. Concrete compatibility tests were limited with these sorbents, but initial results indicated that all sorbents would meet 
AEA demand requirements. Based on the system removal performance plateau observed with Darco Hg-LH, it appears unlikely that these sorbents would achieve higher mercury removal at higher injection rates.

\section{Toxecon $^{\mathrm{TM}}$ II}

EPRI's patented Toxecon ${ }^{\mathrm{TM}}$ II involves the injection of dry sorbent between the fields of an ESP, thus allowing for the untreated ash in the front fields to be segregated from the treated sorbent/ash mixture (pending a re-design of the ash handling system). Toxecon ${ }^{\mathrm{TM}}$ II therefore maintains the integrity of the bulk (>90\%) of the fly ash, which is an advantage to plants such as LMS that market their fly ash as a beneficial cement replacement in concrete. Alternatively, sorbent injection can be staged such that lances inject a small amount of sorbent upstream of the ESP and additional sorbent is injected downstream in the Toxecon ${ }^{\mathrm{TM}}$ II configuration to minimize sorbent effects on collected fly ash.

Based on initial parametric test results (for injection upstream of the ESP), Norit DARCO Hg and Norit DARCO Hg-LH were selected for further testing in the Toxecon ${ }^{\mathrm{TM}}$ II and staged configurations. Mercury reductions up to $60 \%$ were measured at the ESP outlet using the Toxecon $^{\text {TM }}$ II configuration. However, the Toxecon ${ }^{\text {TM }}$ II system could not achieve higher removals, even with a second injection grid design. Properly designing an injection grid that can uniformly cover the space between ESP fields remains a challenge. ADA-ES, designer of the Toxecon ${ }^{\text {TM }}$ II injection grid, is continuing to refine the distribution grid to optimize the coverage across the ESP face. The mercury oxidation at the Toxecon ${ }^{\mathrm{TM}}$ II outlet was 70 to $80 \%$. Thus, even at $60 \%$ removal, the total removal that can potentially be achieved across the combination of ESP and FGD could exceed $90 \%$.

Particulate filters collected during Toxecon ${ }^{\mathrm{TM}}$ II injection were considerably blackened, providing visual evidence of carbon penetration through the ESP; however, particulate emissions remained below regulatory limits. The small amounts of carbon not captured by the ESP would likely be captured by the FGD. EPRI is currently investigating the benefits of adding AC to the FGD as a means to reduce mercury in the scrubber liquor and possibly reduce mercury reemissions from the scrubber.

The staged injection arrangement did not offer any improvement in mercury removal over other injection configurations.

\section{Trace Metals}

EPRI funded measurements were made to determine the effect that mercury control systems have on trace element removal. Flue gas trace metals concentrations were measured by Method 29 on baseline, ACI (1.89 lb/Macf Darco Hg-LH), and ACI + Br (0.48 lb/Macf Darco Hg + 122 ppm Br to coal, dry basis) test days. Associated coal, ash, and FGD samples were also analyzed. In addition, flue gas trace metals were measured using an emerging alternate method, Cooper Environmental Services' X-Ray Filter Method (XFM); tests represented the first use of this method on coal fired flue gas. The XFM method showed promising potential as an alternative to EPA's Method 29, with the particular advantage of faster turn-around of analytical results. In general, measured trace metals were comparable for Method 29 and XFM, although no specific numerical criteria were established to characterize equivalency. 
Trace element removal across the ESP was very high (>98.5\%; most metals exceeding 99\%) for all metals except selenium and mercury. The FGD scrubber provided additional removal of all trace metals. Flue gas measurements showed no selenium removal across the ESP (although ash selenium concentrations indicated some removal); the FGD removed a significant amount of selenium $(78-85 \%)$. Selenium was most likely present in the flue gas as an acid gas $\left(\mathrm{SeO}_{2}\right)$ that was readily removed by the FGD.

Mercury was the only trace element that consistently showed increased removal with the application of ACI and ACI+Br. For the other elements, small increases or decreases in removal were experienced at the two $\mathrm{Hg}$ control test conditions when compared to baseline operation. No trends in trace metals removal should be extracted from these small changes because the obtained data set was small, measured flue gas concentrations were low, and the variability in trace metals concentrations was high.

Fly ash samples and their associated leachates were analyzed for trace metals content.

Most elements showed few significant differences in leaching behavior between baseline and mercury control test conditions. A significant difference occurred when the difference between the two results was greater than a factor of $2(>100 \%)$. By this criterion, $\mathrm{Hg}$ concentration in the leachate and percentage of $\mathrm{Hg}$ leached both decreased from baseline to the test conditions, indicating stabilization of mercury in the fly ash. Ba and $\mathrm{Zn}$ concentrations in the leachate and percentage of $\mathrm{Ba}$ and $\mathrm{Zn}$ leached both increased from baseline to the mercury control test conditions.

\section{Recommendations}

The mercury removal objectives of this program were met by most of the process configurations and conditions evaluated. At $0.5 \mathrm{lb} / \mathrm{Macf}$ Darco $\mathrm{Hg}-\mathrm{LH}$, an overall system removal of $50 \%$ was achieved with fly ash integrity was preserved. With $1-2 \mathrm{lb} / \mathrm{Macf}$ sorbent injection, system mercury removals (air heater inlet to stack, with $15 \%$ flue gas bypass) of $60-70 \%$ could be achieved but ash integrity was compromised. While this fly ash may not be suitable for the concrete market, it would likely be suitable for other markets requiring lower quality ash. A $60 \%$ mercury removal across the ESP could also be achieved with Toxecon ${ }^{\mathrm{TM}}$ II at higher injection rates ( 2 to $5 \mathrm{lbs} / \mathrm{MMacf}$ ) while preserving $90 \%$ of the beneficial use of ash.

Although test results showed that the program objectives could be achieved using a number of process configurations, sorbents, and injection rates, they also indicated that higher mercury removals at LMS may be challenging to maintain cost effectively, especially if there is a desire to preserve the beneficial use of ash. Besides trying to limit the amount of carbon in the fly ash, the variability in mercury emissions and removal with time will make maintaining a consistent ash to carbon ratio very difficult.

For all sorbents evaluated, mercury removal performance across the AH/ESP was extremely variable over time and across the ducts tested, which is one of the challenges associated with mercury removal in TxL flue gas. Additional removal would be expected by eliminating the 10$15 \%$ of FGD bypass. 
The cumulative results from four years of testing show that promising mercury control technologies will need to be rigorously tested at LMS for several months before the variability in mercury removal and ash integrity can be adequately assessed. It is probable that a combination of technologies will be necessary for LMS to achieve $<2 \mu \mathrm{g} / \mathrm{dNm}^{3} \mathrm{Hg}$ at the stack. To accomplish this goal while maintaining fly ash integrity, various combinations of the following approaches merit further investigation:

- Injection of finely ground carbons

The injection of smaller sorbent particles should improve sorbent-gas contact in the duct and, subsequently, improve mercury removal performance. Results from this program indicated challenges associated with the agglomeration of a finely-ground carbon sorbent during transport and feeding. Additional development work should focus on mechanical means to either prevent sorbent agglomeration or re-disperse the particles prior to injection as well as the development of fine-particle sorbents resistant to agglomeration.

- Improvements to the injection system

While the short tests at Limestone with locating the injection system upstream of the airheater and with improving the sorbent distribution with a modified injecting lance design did not appear to improve mercury control effectiveness, the testing was somewhat inclusive in that there were uncertainties associated with changes in the number of lances used and lance pluggage. Testing at other sites showed improvements in mercury removal when locating the sorbent injection lances upstream of the airheater and with the use of a lance design with more energetic lance nozzles. Thus, these options should be re-visited.

- Use of low ash impact (LAI) carbon and non-carbon sorbents

LAI carbons and non-carbon sorbents evaluated in this program demonstrated beneficial qualities related to the reuse properties of fly ash. Results also showed that these sorbents removed less mercury than the regularly supplied carbons and may be limited to the amount of removal achieved (i.e., performance plateau was observed relative to injection rate) in the TxL/PRB derived flue gas. Future work should focus on the development of LAI and non-carbon sorbents with better mercury capacities or removal properties in TxL flue gas.

\section{- Use of sulfur tolerant sorbent}

Calgon Carbon's sulfur tolerant sorbent showed promising results for mercury removal and oxidation, performing better than other sorbents at similar injection rates during a limited number of tests. These results suggest this sorbent, and possibly other sulfur-tolerant carbons, could be more effective than regular ACs in TxL/PRBderived flue gas. TxL/PRB-derived flue gas is expected to contain higher $\mathrm{SO}_{2}$ levels than a PRB (only)-derived flue gas. 
- Increase fraction of PRB fired at LMS

Increasing the fraction of PRB in the LMS fuel blend should improve the ability to achieve higher levels of system mercury removal, as demonstrated by limited testing in which the PRB fraction was increased from $30 \%$ to $45 \%$. Results showed that lower mercury emissions were observed at LMS, both during baseline operation and with sorbent injection, when the ratio of PRB/TxL fired was increased. Because only limited data were obtained at alternate fuel blends, additional tests should be considered to better characterize sorbent injection performance and variability at higher PRB/TxL combustion ratios.

However, with increased PRB fraction, the amount of ash in the flue gas will also decrease. Thus, the amount of AC that can be injected while still maintaining ash use acceptability may also decrease since the ash to carbon ratios will be lower for PRB than TxL coal.

- Combination of bromide addition to the coal with sorbent addition

The highest system mercury removal was achieved with $280 \mathrm{ppm} \mathrm{Br}$ and $1.6 \mathrm{lb} / \mathrm{Macf}$ finely ground Darco Hg-LH. While the combination of bromide addition and sorbent injection appears capable of reaching the team's informal, more stringent goal of $<2$ $\mu \mathrm{g} / \mathrm{dNm}^{3} \mathrm{Hg}$ at the stack, the required sorbent injection rate of $1.6 \mathrm{lb} / \mathrm{Macf}$ finely ground Darco Hg-LH was high enough to potentially jeopardize the beneficial use of ash, and the required bromide injection rate could adversely impact the scrubber system. The high bromide dosage needed will also increase the annual operating cost (for chemicals) quite significantly ( $>\$ 2$ million per yr for Limestone 1 and 2). Longer-term testing would be required to evaluate performance and fly ash property variability at these conditions as well as to evaluate any impact on FGD performance when operating at steady-state bromine conditions.

- Use of re-emissions additives

Results of the Phase IV testing indicated periods when mercury re-emissions from the FGD system were apparent. This phenomenon offsets some of the benefits associated with mercury oxidation across the AH/ESP, resulting in lower system removals. Additional mercury control testing at LMS should include evaluation of chemical FGD additives for controlling re-emissions.

\section{- Toxecon $^{\mathrm{TM}} \mathrm{II}$}

TOXECON II may still prove to be a viable option for Limestone if overall mercury emissions (coal to stack) needs to be maintained $>90 \%$ (or $<2 \mu \mathrm{g} / \mathrm{dNm}^{3} \mathrm{Hg}$ ) while still preserving most of the beneficial ash use. Even with the current non-optimized injection system and $\sim 60 \%$ mercury removal across the ESP, the overall removals could exceed $90 \%$ due to the high mercury oxidation observed at the ESP outlet. Further optimization of the injection grid and/or supplemental boiler bromide addition 
could achieve even higher removal effectiveness. The impact of capturing small amounts of activated carbon in the FGD needs to be assessed for its possible positive benefits (e.g., keep mercury on the solids, lower re-emissions capture other trace toxics) and negative benefits (hard to separate from gypsum). 


\subsection{REFERENCES}

(1) Sjostrom, S. et al. "Low-Cost Options for Moderate Levels of Mercury Control Final Report for MidAmerican's Louisa Generating Station, Council Bluffs Energy Center and Entergy's Independence Steam Electric Station.” DOE-NETL Quarterly Report 42307R16, August 2008.

(2) Sun et al. "The Effect of Coal Combustion Flue Gas Components on Low-Level Chlorine Speciation Using EPA Method 26A," J. Air \& Waste Manage. Assoc. 2000, 50, 936-940.

(3) Holmes, M. et al. "Enhancing Carbon Reactivity for Mercury Control in Coal-Fired Power Plants: Results from Leland Olds, Stanton, and Antelope Valley Stations”. DOE-NETL Mercury Control Technology Conference, 2006. http://www.netl.doe.gov/ publications/proceedings/06/mercury/presentations/Holmes_presentation_121106.pdf

(4) Paradis, J. et al. "The Effects of Activated Carbon Injection on the Important Properties of PRB Derived Fly Ash for Use in the Concrete Industry”. Western Fuels Conference, 2006.

(5) U.S. Environmental Protection Agency. Method 29 - Determination of Metals Emissions from Stationary Sources. http://www.epa.gov/ttn/emc/promgate/m-29.pdf. Last accessed 24 September 2009.

(6) Yanca, C.A.; Barth, D.C.; Petterson, K.A.; Nakanishi, M.P.; Johnsen, B.E.; Cooper, J.A.; Lambert, R.H.; Bivins, D.G. 2006. Validation of Three New Methods for Determination of Metal Emissions using a Modified EPA Method 301. J. Air \& Waste Manage. Assoc., 56, $1733-1742$.

(7) B. Nott, Flue Gas Mercury Measurements Methods Evaluation. Electric Power Research Institute Report: EPRI TR-105851, Dec. 1995.

(8) Landreth, Ronald, Nelson, Sid Jr., Liu, Xin, Tang, Zhong, Overholt, Arlen, Brickett, Lynn. Mercury Reduction Performance of Concrete-Friendly C-PAC Sorbent 2007 World of Coal Ash, Covington, KY USA May, 2007. 


\title{
Mercury Control for Plants Firing Texas Lignite and Equipped with ESP-wet FGD
}

\author{
Appendices \\ Prepared by: \\ Katherine Dombrowski \\ Carl Richardson \\ January 2010 \\ Cooperative Agreement No: DE-FC26-06NT42779 \\ URS Group, Inc. \\ 9400 Amberglen Boulevard \\ Austin, Texas 78729 \\ Prepared for: \\ Andrew O'Palko \\ National Energy Technology Laboratory \\ U.S. Department of Energy \\ P.O. Box 880 \\ Morgantown, WV 26508-0880
}




\section{List of Tables}

Table A-1. Quality Assurance Objectives for Critical Measurement Parameters .................... A-3

Table A-2. Quality Control Checks performed on the SCEMs ........................................... A-5

Table A-3. QC Samples for Critical Measurement Parameter ............................................ A-7

Table A-4. QA/QC Results for Mercury Analyses of Ontario Hydro Impinger Solutions -

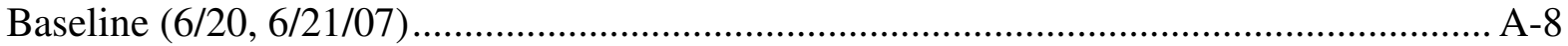

Table A-5. QA/QC Results for Mercury Analyses of Ontario Hydro Impinger Solutions Long-Term Trip \#1 $(7 / 10,7 / 11 / 07)$............................................................................. A-9

Table A-6. QA/QC Results for Mercury Analyses of Ontario Hydro Impinger Solutions -

Long-Term Trip \#2 (7/31, 8/1/07) .............................................................................. A-10

Table A-7. QA/QC Results for Mercury Analyses of Ontario Hydro Impinger Solutions Long-Term Trip \#3 (8/14, 8/15/07) .................................................................. A-11

Table A-8. QA/QC Results for Mercury Analyses of Coal Samples .................................... A-13

Table A-9. QA/QC Results for Mercury Analyses of Ash Samples..................................... A-15

Table A-10. QA/QC Results for Mercury Analyses of Ontario Hydro Impinger Solutions -

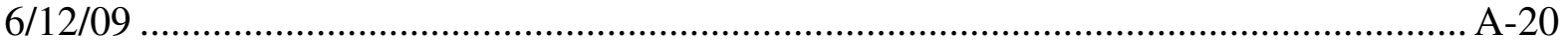

Table A-11. QA/QC Results for Mercury Analyses of Ontario Hydro Impinger Solutions $6 / 18 / 09$

Table A-12. QA/QC Results for Mercury Analyses of Ontario Hydro Impinger Solutions $7 / 9 / 09$

Table A-13. QA/QC Results for Mercury Analyses of Ontario Hydro Impinger Solutions $7 / 10 / 09$

Table A-14. QA/QC Results for Mercury Analyses of Ontario Hydro Impinger Solutions $7 / 11 / 09$

Table A-15. QA/QC Results for Mercury Analyses of Coal Samples

Table A-16. QA/QC Results for Mercury Analyses of Ash Samples. A-25

Table A-17. QA/QC Results for Mercury Analysis on ESP Outlet Appendix K Sorbent Tubes

Table A-18. QA/QC Results for Mercury Analysis on Stack Appendix K Sorbent Tube ....... A-31

Table C-1. Parametric Phase 1 Unit 1 Hourly Average Process Data C-2

Table C-2. Parametric Phase 2 Unit 1 Hourly Average Process Data

Table C-3. Parametric Phase 3 Unit 1 Hourly Average Process Data .................................... C-20

Table C-4. Long Term Unit 1 Hourly Average Process Data............................................... C-25

Table D-1. Inlet Delta P, Temperature, and Velocity Measurements (performed 11/29/06) ..... D-3

Table D-2. ACI Ports Delta P, Temperature, and Velocity Measurements (performed $11 / 28 / 06)$

Table D-3. Toxecon Delta P, Temperature, and Velocity Measurements (performed 4/30/07)

Table D-4. Duct 1A1 Delta P, Temperature, and Velocity Measurements (performed 4/26/07) D-6

Table D-5. Duct 1A2 Delta P, Temperature, and Velocity Measurements (performed $11 / 30 / 06)$ 
Table D-6. Duct 1B1 Delta P, Temperature, and Velocity Measurements (performed $11 / 30 / 06)$ D-8

Table D-7. Duct 1B2 Delta P, Temperature, and Velocity Measurements (performed $6 / 20 / 07)$ D-9

Table D-8. Velocity Traverse for ESP Inlet 2D1 Parametric Phase IV D-10 Table D-9. Velocity Travese for ESP Outlet 2D1 Parametric Phase IV D-11 Table D-10. Single Point Velocity Measurement for ESP Outlet 2C1 Parametric Phase IV ... D-12 Table D-11. Single Point Velocity Measurement at the Stack Parametric Phase IV D-13

Table E-1. Parametric Phase I Ash Hg and LOI Analysis - Baseline ....................................E-2 Table E-2. Ash Hg and LOI Analysis from Parametric Phase I .............................................. Table E-3. Parametric Phase II \& III Ash Hg and LOI Analysis - Baseline .............................E-4 Table E-4. Parametric Phase II \& III Ash Hg and LOI Analysis ...........................................E-5

Table E-5. Summary of Long Term Baseline Ash Hg \& LOI Analysis on Side A....................E-6 Table E-6. Summary of Long Term Baseline Ash Hg \& LOI Analysis on Side B ....................E-7 Table E-7. Summary of Long Term Ash Hg \& LOI Analysis on Side A Field 1 .....................E-8 Table E-8. Summary of Long Term Ash Hg \& LOI Analysis on Side A Field 2 ...................E-10 Table E-9. Summary of Long Term Ash Hg \& LOI Analysis on Side A Field 3 ....................E-11 Table E-10. Summary of Long Term Ash Hg \& LOI Analysis on Side A Fields 4\&5.............. 12 Table E-11. Summary of Long Term Ash Hg \& LOI Analysis on Side A Fields 5\&6.............E-13 Table E-12. Summary of Long Term Ash Hg \& LOI Analysis on Side B (Untreated ESP) ....E-13

Table F-1. ESP Parameters for Material Balance ..................................................................F-2

Table F-2. Mass Balance Results .......................................................................................F-3

Table H-1. Analyses of Texas Lignite Fired during Phase I Parametric Tests .......................... H-2 Table H-2. Analyses of PRB Fired during Phase I Parametric Tests ...................................... H-2 Table H-3. Analyses of TxL Fired during Phase II Parametric Tests...................................... H-3 Table H-4. Analyses of PRB Fired during Phase II Parametric Tests .................................... H-3 Table H-5. Analysis of TxL Fired during Long-Term Tests .................................................. H-4 Table H-6. Analysis of PRB Fired during Long Term Tests ........................................... H-8

Table I-1. Headwaters Concrete Results Using Ash from Long-Term Injection; Individual Cylinder 7-Day Compressive Strength ............................................................................... I-6 Table I-2. First Field Long Term Concrete Data Unit 1 A-Side (Treated Duct), from LMS Lab.I7

Table I-3. First Field Long Term Concrete LMS Data Unit 1 B-Side (Untreated Duct). ............I-8

Table I-4. Petrographic Analysis of Concrete Samples with ACI .............................................

Table J-1. Parametric Phase IV Unit 2 Hourly Average Process Data...................................... J-2

Table L-1. Summary of Method 29 ESP Outlet Data for TRI Metals (ug/Nm ${ }^{3}$, dry, $3 \% \mathrm{O}_{2}$ ).....L-2 Table L-2. Summary of Method 29 ESP Outlet Data for Mercury (ug/ $\mathrm{Nm}^{3}$, dry, 3\% $\mathrm{O}_{2}$ ) ...........2 Table L-3. Summary of Method 29 ESP Outlet Data for Other Metals (ug/Nm 3 , dry, 3\% $\mathrm{O}_{2}$ )..L-2 Table L-4. Summary of Method 29 Stack data for TRI metals ( $\mathrm{ug} / \mathrm{Nm}^{3}$, dry, $3 \% \mathrm{O}_{2}$ ) ............... Table L-5. Summary of Method 29 Stack data for Mercury (ug/ $\mathrm{Nm}^{3}$, dry, $3 \% \mathrm{O}_{2}$ ) ...................3 
Table L-6. Summary of Method 29 Stack data for other trace metals (ug/Nm ${ }^{3}$, dry, $3 \% \mathrm{O}_{2}$ ).....L-3 Table L-7. Comparison Summary of ESP Outlet XFM and Method 29 Results for TRI

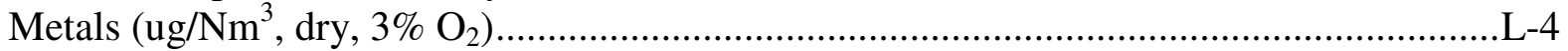

Table L-8. Comparison Summary of ESP Outlet XFM and Method 29 Results for Other Trace Metals (ug/ $\mathrm{Nm}^{3}$, dry, $3 \% \mathrm{O}_{2}$ )..............................................................................

Table L-9. Comparison Summary of Stack XFM and Method 29 Results for TRI Metals

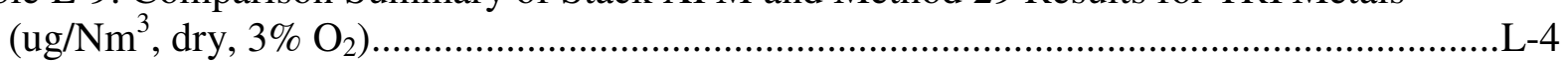

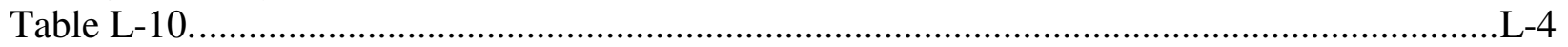

Table L-11Aluminum Comparison Summary for Br + ACI Conditions ...................................15

Table L-12. Aluminum Comparison Summary for Baseline Conditions ................................

Table L-13. Aluminum Comparison Summary for ACI Conditions ......................................15

Table L-14. Silver Comparison Summary for Br + ACI Conditions.....................................16

Table L-15. Silver Comparison Summary for Baseline Conditions ........................................16

Table L-16. Silver Comparison Summary for ACI Conditions .................................................16

Table L-17. Arsenic Comparison Summary for $\mathrm{Br}+$ ACI Conditions........................................17

Table L-18. Arsenic Comparison Summary for Baseline Conditions ....................................... 17

Table L-19. Arsenic Comparison Summary for ACI Conditions .............................................17

Table L-20. Barium Comparison Summary for Br + ACI Conditions ...................................... 18

Table L-21. Barium Comparison Summary for Baseline Conditions........................................18

Table L-22. Barium Comparison Summary for ACI Conditions .......................................... 18

Table L-23. Beryllium Comparison Summary for Br + ACI Conditions ................................. 19

Table L-24. Beryllium Comparison Summary for Baseline Conditions ..................................19

Table L-25. Beryllium Comparison Summary for ACI Conditions .........................................19

Table L-26. Cadmium Comparison Summary for $\mathrm{Br}+$ ACI Conditions ................................. 20

Table L-27. Cadmium Comparison Summary for Baseline Conditions ...................................2-20

Table L-28. Cadmium Comparison Summary for ACI Conditions..........................................20

Table L-29. Cobalt Comparison Summary for Br + ACI Conditions .......................................21

Table L-30. Cobalt Comparison Summary for Baseline Conditions .......................................L-21

Table L-31. Cobalt Comparison Summary for ACI Conditions ...............................................21

Table L-32. Chromium Comparison Summary for $\mathrm{Br}+$ ACI Conditions ................................ 22

Table L-33. Chromium Comparison Summary for Baseline Conditions ................................22

Table L-34. Chromium Comparison Summary for ACI Conditions ........................................L-22

Table L-35. Copper Comparison Summary for Br + ACI Conditions .......................................23

Table L-36. Copper Comparison Summary for Baseline Conditions ......................................23

Table L-37. Copper Comparison Summary for ACI Conditions...............................................23

Table L-38. Iron Comparison Summary for $\mathrm{Br}+$ ACI Conditions .......................................24

Table L-39. Iron Comparison Summary for Baseline Conditions ............................................24

Table L-40. Iron Comparison Summary for ACI Conditions .................................................. 24

Table L-41. Mercury Comparison Summary for Br + ACI Conditions ...................................25

Table L-42. Mercury Comparison Summary for Baseline Conditions ................................... 25

Table L-43. Mercury Comparison Summary for ACI Conditions.............................................25

Table L-44. Molybdenum Comparison Summary for Br + ACI Conditions.............................26

Table L-45. Molybdenum Comparison Summary for Baseline Conditions ..............................26

Table L-46. Molybdenum Comparison Summary for ACI Conditions .....................................26

Table L-47. Manganese Comparison Summary for Br + ACI Conditions ................................27

Table L-48. Manganese Comparison Summary for Baseline Conditions .................................L-27 
Table L-49. Manganese Comparison Summary for ACI Conditions ......................................27

Table L-50. Nickel Comparison Summary for Br + ACI Conditions ....................................2-28

Table L-51. Nickel Comparison Summary for Baseline Conditions ......................................L-28

Table L-52. Nickel Comparison Summary for ACI Conditions .............................................28

Table L-53. Lead Comparison Summary for Br + ACI Conditions ...........................................29

Table L-54. Lead Comparison Summary for Baseline Conditions............................................L-29

Table L-55. Lead Comparison Summary for ACI Conditions .................................................29

Table L-56. Antimony Comparison Summary for Br + ACI Conditions ..................................

Table L-57. Antimony Comparison Summary for Baseline Conditions ...................................-30

Table L-58. Antimony Comparison Summary for ACI Conditions .........................................-30

Table L-59. Selenium Comparison Summary for $\mathrm{Br}+$ ACI Conditions ...................................-31

Table L-60. Selenium Comparison Summary for Baseline Conditions ...................................-31

Table L-61. Selenium Comparison Summary for ACI Conditions ........................................... -31

Table L-62. Tin Comparison Summary for $\mathrm{Br}+$ ACI Conditions............................................. 32

Table L-63. Tin Comparison Summary for Baseline Conditions .............................................

Table L-64. Tin Comparison Summary for ACI Conditions ..................................................

Table L-65. Strontium Comparison Summary for $\mathrm{Br}+$ ACI Conditions .................................-33

Table L-66. Strontium Comparison Summary for Baseline Conditions...................................33

Table L-67. Strontium Comparison Summary for ACI Conditions .........................................-33

Table L-68. Titanium Comparison Summary for Br + ACI Conditions...................................34

Table L-69. Titanium Comparison Summary for Baseline Conditions ....................................

Table L-70. Titanium Comparison Summary for ACI Conditions ..........................................

Table L-71. Thallium Comparison Summary for Br + ACI Conditions...................................

Table L-72. Thallium Comparison Summary for Baseline Conditions ...................................-35

Table L-73. Thallium Comparison Summary for ACI Conditions ............................................35

Table L-74. Vandium Comparison Summary for $\mathrm{Br}+$ ACI Conditions ..................................-36

Table L-75. Vandium Comparison Summary for Baseline Conditions......................................36

Table L-76. Vandium Comparison Summary for ACI Conditions.............................................-36

Table L-77. Zinc Comparison Summary for Br + ACI Conditions ...........................................-37

Table L-78. Zinc Comparison Summary for Baseline Conditions .......................................... 37

Table L-79. Zinc Comparison Summary for ACI Conditions ............................................... 37

Table M-1. Fraction of Fly Ash Captured by Field ............................................................ M-2

Table M-2. Trace Element Concentration in the Fly Ash by ESP Field................................ M-2

Table M-3. Fly Ash Trace Element Concentrations ........................................................ M-3

Table O-1. Outlet Particulate Loading Measurements for $\mathrm{CaBr}_{2}$ Injection (Method 5)............ O-1

Table O-2. Baseline Outlet Particulate Loading Measurements (Method 5)........................... O-1

Table O-3. Outlet Particulate Loading Measurements for Sorbent Injected at $1.9 \mathrm{lb} / \mathrm{MMacf}$

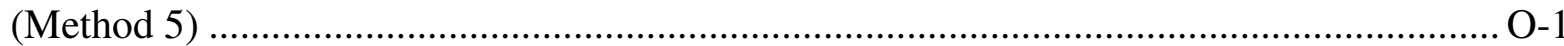

Table O-4. Comparison of Average Baseline and Sorbent Injection Particulate Loading

Measurements (Method 5) ....................................................................................... O-1

Table O-5. Comparison of Method 5 and Method 17 Average Particulate Loading

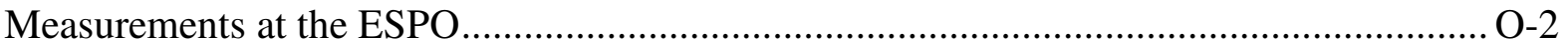

Table O-6. Baseline Particulate Loading Measurements at ESP Inlet................................... O-2 
Table O-7. Inlet Particulate Loading Measurements during Sorbent Injection Test at 0.5 lb/MMacf (Method 17) O-2

Table O-8. Outlet Particulate Loading Measurements for Sorbent Injection Test at $0.5 \mathrm{lb} / \mathrm{MMacf}$ O-3

Table O-9. Outlet Particulate Loading Measurements for Sorbent Injection Test at $1.0 \mathrm{lb} / \mathrm{MMacf}$ O-3

Table O-10. Outlet Particulate Loading Measurements for Sorbent Injection Test at 1.9 $\mathrm{lb} / \mathrm{MMacf}$. O-3

Table O-11. Comparison of Average Baseline and Sorbent Injection Particulate Loading Measurements (Method 17). O-4 


\section{List of Figures}

Figure G-1. IGS Filter Change on Treated Outlet June 20, 2007 ......................................... G-2

Figure G-2. IGS Filter Change on Treated Outlet June 28, 2007 ....................................... G-3

Figure G-3. IGS Filter Change on Treated Outlet July 11, 2007 ........................................ G-3

Figure K-1. Flue Gas Hg Concentrations for AH Inlet and ESP Outlet 6/11-6/13 ................. K-2

Figure K-2. Flue Gas Hg Concentrations for AH Inlet and Stack 6/11-6/13 .......................... K-2

Figure K-3. Flue Gas Hg Concentrations for ESP Outlet and Stack 6/11-6/13 _....................... K-3

Figure K-4. Flue Gas Hg Concentrations for AH Inlet and ESP Outlet 6/13-6/15 ................. K-3

Figure K-5. Flue Gas Hg Concentrations for AH Inlet and Stack 6/13-6/15 ......................... K-4

Figure K-6. Flue Gas Hg Concentrations for ESP Outlet and Stack 6/13-6/15 ....................... K-4

Figure K-7. Flue Gas Hg Concentrations for AH Inlet and ESP Outlet 6/15-6/17 ................... K-5

Figure K-8. Flue Gas Hg Concentrations for AH Inlet and Stack 6/15-6/17 ........................... K-5

Figure K-9. Flue Gas Hg Concentrations for ESP Outlet and Stack 6/15-6/17 ...................... K-6

Figure K-10. Flue Gas Hg Concentrations for AH Inlet and ESP Outlet 6/17-6/19 ................ K-6

Figure K-11. Flue Gas Hg Concentrations for AH Inlet and Stack 6/17-6/19 ....................... K-7

Figure K-12. Flue Gas Hg Concentrations for ESP Outlet and Stack 6/17-6/19 ...................... K-7

Figure K-13. Flue Gas Hg Concentrations for AH Inlet and ESP Outlet 6/19-6/21 ............... K-8

Figure K-14. Flue Gas Hg Concentrations for AH Inlet and Stack 6/19-6/21 ........................ K-8

Figure K-15. Flue Gas Hg Concentrations for ESP Outlet and Stack 6/19-6/21 ..................... K-9

Figure K-16. Flue Gas Hg Concentrations for AH Inlet and ESP Outlet 6/21-6/23 ............... K-9

Figure K-17. Flue Gas Hg Concentrations for AH Inlet and Stack 6/21-6/23 ..................... K-10

Figure K-18. Flue Gas Hg Concentrations for ESP Outlet and Stack 6/21-6/23 .................. K-10

Figure K-19. Flue Gas Hg Concentrations for AH Inlet and ESP Outlet 6/23-6/25 .............. K-11

Figure K-20. Flue Gas Hg Concentrations for AH Inlet and Stack 6/23-6/25 ..................... K-11

Figure K-21. Flue Gas Hg Concentrations for ESP Outlet and Stack 6/23-6/25 ................... K-12

Figure K-22. Flue Gas Hg Concentrations for AH Inlet and ESP Outlet 6/25-6/27 .............. K-12

Figure K-23. Flue Gas Hg Concentrations for AH Inlet and Stack 6/25-6/27 ..................... K-13

Figure K-24. Flue Gas Hg Concentrations for ESP Outlet and Stack 6/25-6/27 ................... K-13

Figure K-25. Flue Gas Hg Concentrations for AH Inlet and ESP Outlet 6/27-6/29 .............. K-14

Figure K-26. Flue Gas Hg Concentrations for AH Inlet and Stack 6/27-6/29 ..................... K-14

Figure K-27. Flue Gas Hg Concentrations for ESP Outlet and Stack 6/27-6/29................... K-15

Figure K-28. Flue Gas Hg Concentrations for AH Inlet and ESP Outlet 7/9-7/11 ................ K-15

Figure K-29. Flue Gas Hg Concentrations for AH Inlet and Stack 7/9-7/11 ....................... K-16

Figure K-30. Flue Gas Hg Concentrations for ESP Outlet and Stack 7/9-7/11 .................... K-16

Figure K-31. Flue Gas Hg Concentrations for AH Inlet and ESP Outlet 7/11-7/13 _.............. K-17

Figure K-32. Flue Gas Hg Concentrations for AH Inlet and Stack 7/11-7/13 ....................... K-17

Figure K-33. Flue Gas Hg Concentrations for ESP Outlet and Stack 7/11-7/13 ................... K-18

Figure K-34. Flue Gas Hg Concentrations for AH Inlet and ESP Outlet 7/13-7/15 .............. K-18

Figure K-35. Flue Gas Hg Concentrations for AH Inlet and Stack 7/13-7/15 ..................... K-19

Figure K-36. Flue Gas Hg Concentrations for ESP Outlet and Stack 7/13-7/15 ................... K-19

Figure K-37. Flue Gas Hg Concentrations for AH Inlet and ESP Outlet 7/15-7/17 .............. K-20

Figure K-38. Flue Gas Hg Concentrations for AH Inlet and Stack 7/15-7/17 ....................... K-20

Figure K-39. Flue Gas Hg Concentrations for ESP Outlet and Stack 7/15-7/17 ................... K-21

Figure K-40. Flue Gas Hg Concentrations for AH Inlet and ESP Outlet 7/17-7/19 .............. K-21 
Figure K-41. Flue Gas Hg Concentrations for AH Inlet and Stack 7/17-7/19 ...................... K-22

Figure K-42. Flue Gas Hg Concentrations for ESP Outlet and Stack 7/17-7/19 .................... K-22

Figure K-43. Flue Gas Hg Concentrations for AH Inlet and ESP Outlet 7/19-7/21 .............. K-23

Figure K-44. Flue Gas Hg Concentrations for AH Inlet and Stack 7/19-7/21 ..................... K-23

Figure K-45. Flue Gas Hg Concentrations for ESP Outlet and Stack 7/19-7/21 .................. K-24

Figure K-46. Flue Gas Hg Concentrations for AH Inlet and ESP Outlet 7/21-7/23 .............. K-24

Figure K-47. Flue Gas Hg Concentrations for AH Inlet and Stack 7/21-7/23 ..................... K-25

Figure K-48. Flue Gas Hg Concentrations for ESP Outlet and Stack 7/21-7/23 ................... K-25

Figure K-49. Baseline Flue Gas Hg Concentrations with FGD in Inhibited Oxidation Mode. K-26

Figure L-1. Method 29 ESP Outlet Metals Below Detection Limit ...........................................-5

Figure L-2. Method 29 Stack Metals Below Detection Limit ................................................5

Figure L-3. Method 29 ESP Outlet Metals Near Detection Limit ..............................................6

Figure L-4. Method 29 Stack Metals Near Detection Limit ...............................................6

Figure L-5. Method 29 ESP Outlet Metals Greater than Detection Limit.................................

Figure L-6. Method 29 Stack Metals Greater than Detection Limit........................................

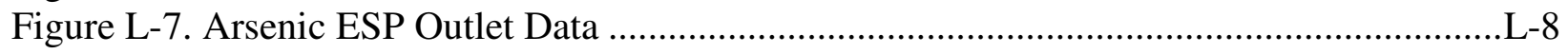

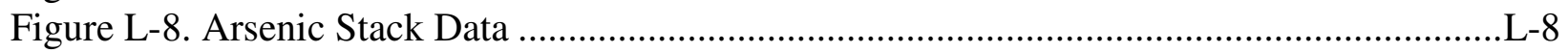

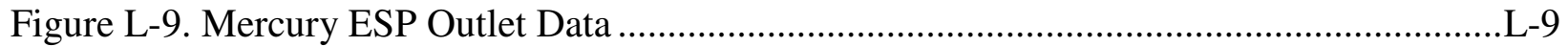

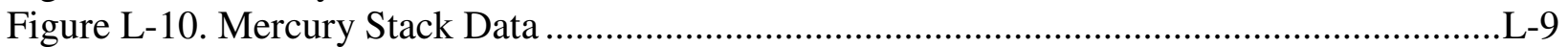

Figure L-11. Selenium ESP Outlet Data..........................................................................

Figure L-12. Selenium Stack Data.............................................................................L-10

Figure L-13. Comparison of Averages from XFM and M29 for ESP Outlet 7/12/09

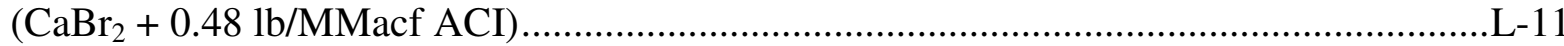

Figure L-14. Comparison of Averages from XFM and M29 for Stack 7/12/09

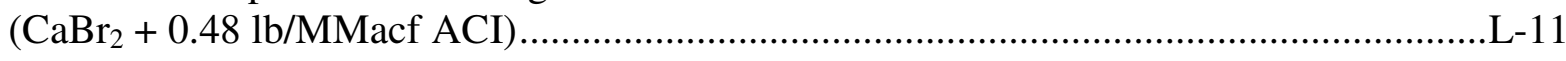

Figure L-15. Comparison of Averages from XFM and M29 for ESP Outlet 7/13/09

(Baseline Conditions)................................................................................................... 12

Figure L-16. Comparison of Averages from XFM and M29 for Stack 7/13/09 (Baseline

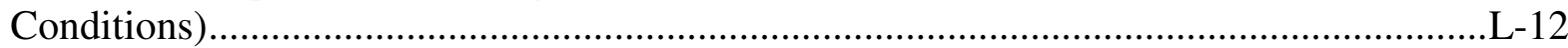

Figure L-17. Comparison of Averages from XFM and M29 for ESP Outlet 7/14/09

(1.9 lb/MMacf ACI) ..................................................................................................... 13

Figure L-18. Comparison of Averages from XFM and M29 for Stack 7/14/09

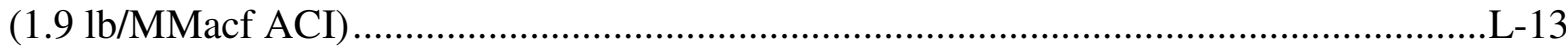

Figure L-19. Method 29 ESP Outlet Data for all Three Conditions ........................................ 14

Figure L-20. Method 29 Stack Data for all Three Conditions .............................................. 14

Figure N-1. XFM ESP Outlet Metals within Uncertainty .............................................. N-2

Figure N-2. XFM Stack Metals within Uncertainty ...................................................... N-2

Figure N-3. XFM ESP Outlet Metals near Uncertainty.................................................... N-3

Figure N-4. XFM Stack Metals near Uncertainty .......................................................... N-3

Figure N-5. XFM ESP Outlet Metals Greater than Uncertainty.......................................... N-4

Figure N-6. XFM Stack Metals Greater than Uncertainty ............................................. N-4 
APPENDIX A -QUALITY ASSURANCE/QUALITY CONTROL RESULTS AND DISCUSSION 
The quality assurance measures implemented for this project are summarized in this appendix. The QA/QC measures addressed the following critical measurement parameters: 1) total and speciated mercury in flue gas at the ESP inlet, and ESP outlet; and 2) mercury content in the coal and byproducts solids.

Specific quantitative data quality objectives established for the project, expressed as precision, accuracy and completeness are summarized in Table A-1.

\section{Source Sampling Equipment}

QA/QC measures conducted prior to and during the field test program included calibrations of the sorbent injection and sampling systems, as well as internal quality control checks related to analytical instruments and measurements. Each of these topics is discussed in the following sections.

\section{Calibration of Injection and Sampling Equipment}

The following calibration procedures were used for the sorbent injection and source sampling equipment during the course of the project. Records of all manufacturer calibration and field calibrations for all injection and sampling equipment are maintained in the URS and Apogee project files.

\section{Sorbent Injection System}

Before the testing program began on Unit 1, the sorbent injection system was calibrated over the range of expected sorbent injection rates to ensure accurate delivery of sorbent to the duct injection points. Prior to the start of each injection test the specific feed-rate desired was confirmed by timed catch and weigh of the sorbent at the eductor inlet location. This calibration was repeated at the completion of the test to determine if any significant shift in feed-rate may have occurred during the test period that was not evident from the loss-of weight system. Throughout the 60-day extended injection the unit was calibrated to ensure accurate delivery of the sorbent. 
Table A-55. Quality Assurance Objectives for Critical Measurement Parameters

\begin{tabular}{|c|c|c|c|c|}
\hline $\begin{array}{l}\text { Critical Parameter } \\
\text { (Method) }\end{array}$ & Sampling Method & $\begin{array}{c}\text { Experimental } \\
\text { Conditions }\end{array}$ & Precision & Accuracy \\
\hline $\begin{array}{l}\text { Mercury in Flue Gas } \\
\text { (Method } 7470 \text { Digestion; } \\
\text { CVAA Analysis) }\end{array}$ & $\begin{array}{l}\text { Ontario Hydro } \\
\text { Method }\end{array}$ & $\begin{array}{l}\text { Matrix Spike and } \\
\text { Duplicates }\end{array}$ & $\begin{array}{l}10 \% \text { Relative } \\
\text { Percent } \\
\text { Difference }\end{array}$ & $\begin{array}{l}85-115 \% \\
\text { Recovery }\end{array}$ \\
\hline $\begin{array}{l}\text { Mercury in Flue Gas } \\
\text { (KCl/SnCl } \text { Impingers, }_{2} \\
\text { CVAA Analysis) }\end{array}$ & $\begin{array}{l}\text { Semi-continuous } \\
\text { Gas Analyzer } \\
\text { (SCEM) }\end{array}$ & $\begin{array}{c}\text { Matrix Spike (Method } \\
\text { of Standard } \\
\text { Additions)/ Replicate } \\
\text { Assays/ Relative } \\
\text { Accuracy Testing }\end{array}$ & $\begin{array}{l}20 \% \text { Relative } \\
\text { Percent } \\
\text { Difference }\end{array}$ & $\begin{array}{l}80-120 \% \\
\text { Recovery }\end{array}$ \\
\hline \multirow[t]{2}{*}{$\begin{array}{l}\text { Mercury in Flue Gas (Dry } \\
\text { Sorbent Trap, CVAFS } \\
\text { Analysis) }\end{array}$} & \multirow[t]{2}{*}{$\begin{array}{c}\text { Modified } \\
\text { Appendix K }\end{array}$} & $\begin{array}{l}\text { Matrix Spike and } \\
\text { Duplicates }\end{array}$ & $\begin{array}{l}\text { 10\% Relative } \\
\text { Percent } \\
\text { Difference }\end{array}$ & $\begin{array}{l}85-115 \% \\
\text { Recovery }\end{array}$ \\
\hline & & Field Spikes & NA & $\begin{array}{l}80-120 \% \\
\text { Recovery }\end{array}$ \\
\hline \multirow[t]{2}{*}{$\begin{array}{l}\text { Mercury in Coal, (ASTM } \\
\text { 3684; HF Digestion; } \\
\text { CVAA Analysis) }^{1}\end{array}$} & \multirow[t]{2}{*}{$\begin{array}{l}\text { Grab Sample } \\
\text { Composites }\end{array}$} & $\begin{array}{l}\text { Matrix Spike and } \\
\text { Triplicates }\end{array}$ & $\begin{array}{l}\text { 25\% Relative } \\
\text { Percent } \\
\text { Difference }\end{array}$ & NA \\
\hline & & $\begin{array}{l}\text { Coal NIST Standard } \\
\text { Reference Materials }\end{array}$ & NA & $\begin{array}{l}80-120 \% \\
\text { Recovery }\end{array}$ \\
\hline \multirow[t]{2}{*}{$\begin{array}{l}\text { Mercury in ESP Fly Ash }{ }^{1} \\
\text { (HF Digestion CVAA } \\
\text { Analysis) }\end{array}$} & \multirow[t]{2}{*}{$\begin{array}{l}\text { Grab Sample } \\
\text { Composites }\end{array}$} & $\begin{array}{l}\text { Matrix Spike and } \\
\text { Duplicates }\end{array}$ & $\begin{array}{l}10 \% \text { Relative } \\
\text { Percent } \\
\text { Difference }\end{array}$ & $\begin{array}{c}85-115 \% \text { (Detected) } \\
75-125 \% \text { (Not Detected) } \\
\text { Recovery }\end{array}$ \\
\hline & & $\begin{array}{c}\text { Fly Ash NIST } \\
\text { Standard Reference } \\
\text { Materials }\end{array}$ & NA & $\begin{array}{l}85-115 \% \\
\text { Recovery }\end{array}$ \\
\hline
\end{tabular}

${ }^{1}$ All coal and ESP fly ash samples were to be analyzed in triplicate. 
The loss-of-weight load cell system was checked prior to the test by adding and then removing a calibration weight and the resulting step change in the system is noted. Additionally the static weight of the bulk bag containing the sorbent was recorded at the start and completion of each test. The accuracy and consistency of volumetric feeding of dry sorbents is susceptible to changes due to material density, moisture, and plugging. The combined method of a pre- and post-static weight of the sorbent loaded on the system gave a finite measure of the total amount of sorbent injected. The pre- and post-catch weigh calibration technique provided the known feed-rate at the beginning and end of each test. The real-time loss-of-weight load cell system gave the operators rapid indication of any significant change in feed-rate during the test period.

Various components of the source sampling equipment were calibrated prior to use in the field test program. These calibrations are summarized below:

Type S pitot tube calibration - design and construction of pitot tube according to EPA requirement, inspection according to EPA Method 2.

Sample nozzle calibration - clean, inspect and calibrate according to EPA Method 5

Temperature measuring devices - calibrate against a NIST-traceable mercury-in-glass thermometer, confirm linearity using a traceable precision voltage generator.

Dry gas meter and orifice - semi-annual calibration using traceable calibrated critical orifices.

\section{SCEM Analyzers}

The analyzers were calibrated for elemental mercury, and sample flow rate, following installation at the test sites and periodically throughout the testing program. The calibration of both the Au-CVAAS analyzer, which measures the mass of mercury desorbed, and the mass flow meter in the monitor, which measures the total sample volume through the analyzer, were checked daily during testing. The analyzer was calibrated by introducing a spike of vapor phase elemental mercury standard into the analyzer upstream of the gold wire or just upstream of the impinger solutions. These quality control samples are important for ensuring proper transport of mercury through the various flow lines. The mercury vapor for the spike was taken from the air space in a vial containing liquid elemental mercury. The mercury spike concentration is calculated from the vapor pressure of mercury and the temperature of the vial. The vial temperature was measured with a precision thermometer.

QA/QC results for SCEM analyzer measurements, met the acceptance criteria of $85-115 \%$ recovery. In most cases, when spike recoveries were outside the specification, the unit was recalibrated or other corrective action was taken.

The calibration of the mass flow meter was checked by connecting the operating meter in series with a pre-calibrated dry cal meter and verifying measured flow rates across the range expected during testing.

Documentation of analyzer calibration and any system maintenance was recorded in the project notebook. Verification of computerized analyzer calculations was conducted manually on a periodic basis. Any data collected during periods of suspect analyzer operation were flagged as questionable data. 
Table A-56. Quality Control Checks performed on the SCEMs

\begin{tabular}{|c|c|}
\hline \multicolumn{2}{|c|}{ The following QA/QC checks were performed on the mercury SCEMs: } \\
\hline Setup QC Parameter & Passing Criterion \\
\hline Leak Check & $<3 \%$ leak \\
\hline MFM Calibration Check & $97-103 \%$ \\
\hline Spike thru totals impingers and heated line & $85-115 \%$ \\
\hline Spike thru elementals impingers and heated line & $85-115 \%$ \\
\hline \multicolumn{2}{|l|}{ Each morning, the following $\mathrm{QA} / \mathrm{QC}$ checks were performed: } \\
\hline Morning QC Parameter & Passing Criterion \\
\hline Leak Check & $<3 \%$ leak \\
\hline MFM Check-single point & $97-103 \%$ \\
\hline 2 QC Spikes (upstream of gold, or in flue gas) & $\begin{array}{l}(85-115 \% \text { in flue gas }) \\
(90-110 \% \text { in air) }\end{array}$ \\
\hline \multicolumn{2}{|l|}{ Each day, these additional QA/QC checks were performed: } \\
\hline Daily QC Parameter & Passing Criterion \\
\hline QC Spikes in Flue Gas (at least twice/day) & $85-115 \%$ \\
\hline $\begin{array}{l}\text { QC spike thru totals impingers and heated line (every } \\
\text { other day) }\end{array}$ & $85-115 \%$ \\
\hline $\begin{array}{l}\text { QC spike thru elementals impingers and heated line (every } \\
\text { other day) }\end{array}$ & $85-115 \%$ \\
\hline
\end{tabular}

\section{Internal Quality Control Checks}

Quality control procedures were also included in this test program for both sampling and analytical activities. In most instances, strict adherence to prescribed method-defined procedures for each sampling and analytical effort is the most applicable QC check. However, in some cases specific QC samples were planned to assess overall measurement data quality. QC samples for the critical measurement parameters are summarized in Table A-3.

The QC analyses conducted during the testing program were designed to provide a quantitative assessment of the measurement system data. The two aspects of data quality that are of primary concern are precision and accuracy. Accuracy reflects the degree to which the measured value represents the actual or "true" value for a given parameter and includes elements of both bias and precision. Precision is a measure of the variability associated with the measurement system.

\section{Precision}


EPA defines precision as "a measure of mutual agreement among individual measurements of the same property, usually under prescribed similar conditions." For this project, precision estimates were based on conditions that encompass as many components of variability as are feasible, which includes variability in the sample matrix itself, as well as imprecision in sample collection, preparation, and analysis. Precision data were reported for analytical duplicate samples.

Where estimated from duplicate (two) results, precision was expressed in terms of relative percent difference (RPD) between results for analytical duplicates. RPD was calculated as follows:

$$
\mathrm{RPD}=\frac{\left|\mathrm{X}_{1}-\mathrm{X}_{2}\right|}{\text { Mean }} \times 100
$$

$\mathrm{RPD}$ is related to percent coefficient of variation $(\mathrm{CV})$ by $(\mathrm{RPD}=\mathrm{CV} \times \sqrt{2})$.

Where estimated from triplicate (three) results, precision was expressed in terms of relative standard deviation (RSD) between results for analytical replicates. RSD was calculated as follows:

$$
\mathrm{RSD}=\frac{\mid \text { Standard Deviation } \mid}{\text { Mean }} \times 100
$$

These terms are independent of the error (bias) of the analyses and reflect only the degree to which the measurements agree with one another, not the degree to which they agree with the "true" value for the parameter measured.

\section{Accuracy}

Accuracy, according to EPA's definition is "the degree of agreement of a measurement (or an average of measurements of the same thing), $\mathrm{X}$, with an accepted reference or true value, T." Accuracy includes components of both bias (systematic error) and imprecision (random error). Bias may be estimated from the average of a set of individual accuracy measurements.

For this project, accuracy objectives are expressed in terms of individual measurements. Individual measurements were compared with the objectives presented previously in Table A-3. In the final analysis, the average accuracy (i.e., bias), calculated as percent recovery, were reported and used to assess the impact on project objectives. Percent recovery was calculated as follows:

$$
\% \text { Recovery }=\frac{\text { Measured Value }}{\text { Reference Value }} \times 100
$$


In the case of matrix spiked samples, measured value in the above equation represents the difference between the spiked sample measurement result and the unspiked sample results. The reference value represents the amount of spike added to the sample.

Table A-57. QC Samples for Critical Measurement Parameter

\begin{tabular}{|c|c|c|c|c|c|}
\hline Parameter & $\begin{array}{c}\text { Field } \\
\text { Blank }^{2}\end{array}$ & $\begin{array}{c}\text { Trip } \\
\text { (reagent) } \\
\text { Blank }^{3}\end{array}$ & $\begin{array}{l}\text { Matrix } \\
\text { Spike }\end{array}$ & Replicates & $\begin{array}{c}\text { Standard } \\
\text { Material } \\
\text { Analysis }\end{array}$ \\
\hline $\begin{array}{l}\text { Mercury in Flue Gas } \\
\text { (Ontario Hydro method) }\end{array}$ & $\begin{array}{l}1 \text { per batch of } \\
\mathrm{KMnO}_{4} \\
\text { reagent }\end{array}$ & $\begin{array}{l}1 \text { per batch } \\
\text { of } \mathrm{KMnO}_{4} \\
\text { reagent }\end{array}$ & $\begin{array}{l}1 \text { per sample } \\
\text { location }\end{array}$ & $\begin{array}{c}\text { Duplicate, } \\
\text { every sample }\end{array}$ & - \\
\hline $\begin{array}{l}\text { Mercury in Flue Gas (semi- } \\
\text { continuous analyzer) }\end{array}$ & - & - & 1 per day & $\begin{array}{l}\text { Duplicate, } 1 \\
\text { per day }\end{array}$ & - \\
\hline $\begin{array}{l}\text { Mercury in Flue Gas } \\
\text { (Sorbent Traps) }\end{array}$ & $\begin{array}{c}1 \text { per sample } \\
\text { event }\end{array}$ & $\begin{array}{c}1 \text { per } \\
\text { analysis set } \\
\text { of } 20 \text { traps }\end{array}$ & 1 per 10 samples & $\begin{array}{c}\text { "B" trap } \\
\text { analysis on } \\
\text { every sample } \\
\text { pair for } \\
\text { breakthrough } \\
\text { All in } \\
\text { duplicate } \\
\end{array}$ & \\
\hline Mercury in Coal & NA & NA & 1 per 10 samples & $\begin{array}{l}\text { Triplicate all } \\
\text { samples }\end{array}$ & $\begin{array}{l}1 \text { per batch } \\
\text { prepared }\end{array}$ \\
\hline $\begin{array}{l}\text { Mercury ESP Fly Ash } \\
\text { Solids }{ }^{4}\end{array}$ & NA & NA & 1 per 10 samples & $\begin{array}{l}\text { Duplicate, } 1 \\
\text { per } 10 \\
\text { samples }\end{array}$ & $\begin{array}{l}1 \text { per batch } \\
\text { prepared }\end{array}$ \\
\hline
\end{tabular}

\section{Ontario Hydro}

Source sampling field data for the three Ontario Hydro verification tests conducted during baseline and long term test phases are summarized. Percent isokinetics, a measure of sample representativeness, were within acceptable limits for all test runs.

QA/QC results for reagent blanks, field blanks and laboratory analyses from the Ontario Hydro verification trips are provided in Table A-4. All results were within the data quality objectives of the test program and the results as a whole did not indicate a significant contamination or bias in the analytical results for the Ontario Hydro method.

QA/QC results for reagent blanks, field blanks, and laboratory analyses from the Ontario Hydro verification trips are provided in Tables A-5 through A-7. All results were within the data quality objectives of the test program and the results as whole did not indicate a significant contamination or bias in the analytical results for the Ontario Hydro method.

\footnotetext{
${ }^{2}$ Field blank impinger solutions are used to perform a matrix matched instrument calibration to compensate for possible background contribution in the blank sampling train and to compensate for matrix interference.

${ }^{3}$ Analysis of the reagent blank is not generally conducted unless appreciable amounts of target analyte are noted in the field blank.

${ }^{4}$ These samples were to be analyzed in triplicate.
} 
Table A-58. QA/QC Results for Mercury Analyses of Ontario Hydro Impinger Solutions - Baseline (6/20, 6/21/07)

\begin{tabular}{|c|c|c|c|c|c|c|c|c|}
\hline \multirow[b]{2}{*}{ QA Check } & \multirow[b]{2}{*}{ Sample } & \multirow{2}{*}{$\begin{array}{l}\text { Objective } \\
\text { (KMnO4 } \\
\text { and KCl) }\end{array}$} & \multirow{2}{*}{$\begin{array}{c}\text { Objective } \\
\text { (NI and } \\
\text { PNR) }\end{array}$} & \multicolumn{5}{|c|}{ Ontario Hydro Sample Fractions } \\
\hline & & & & KMnO4 & $\mathbf{K C l}$ & $\mathrm{H} 2 \mathrm{O} 2$ & Filter & PNR/Nitric Rinse \\
\hline DI Water Blank & All & $<\mathrm{DL}$ & $<\mathrm{DL}$ & $<\mathrm{DL}$ & $<\mathrm{DL}$ & $<\mathrm{DL}$ & $<\mathrm{DL}$ & $<\mathrm{DL}$ \\
\hline Reagent Blank & All & $<\mathrm{DL}$ & $<\mathrm{DL}$ & $<\mathrm{DL}$ & $<$ DL & $<\mathrm{DL}$ & $<\mathrm{DL}$ & $<\mathrm{DL}$ \\
\hline Field Blank & All & $<\mathrm{DL}$ & $<\mathrm{DL}$ & $<\mathrm{DL}$ & $<\mathrm{DL}$ & $<\mathrm{DL}$ & $<\mathrm{DL}$ & $<\mathrm{DL}$ \\
\hline $\begin{array}{c}\text { Lab QC Standard } \\
\text { Recovery } \\
\end{array}$ & $\begin{array}{c}\text { Treated and } \\
\text { Untreated }\end{array}$ & $90-110 \%$ & $85-115 \%$ & $98-101 \%$ & $97-99 \%$ & $101-101 \%$ & $97-99 \%$ & $97-114 \%$ \\
\hline Matrix Spike & Treated & $85-115 \%$ & $85-115 \%$ & $108 \%$ & $104 \%$ & $99-100 \%$ & NA & $111 \%$ \\
\hline $\begin{array}{c}\text { Replicate Analysis } \\
\text { RPD }\end{array}$ & Treated & $<10 \%$ & $<15 \%$ & $0.1-0.8 \%$ & $0.1-1 \%$ & $0.7-9 \%$ & $\mathrm{NC}$ & $\mathrm{NC}$ \\
\hline Matrix Spike & Untreated & $85-115 \%$ & $85-115 \%$ & $89-109 \%$ & $97-103 \%$ & $100-105 \%$ & $\mathrm{NA}$ & $106-111 \%$ \\
\hline $\begin{array}{c}\text { Replicate Analysis } \\
\text { RPD }\end{array}$ & Untreated & $<10 \%$ & $<15 \%$ & $0.1-0.3 \%$ & $0-0.6 \%$ & $0.1-0.8 \%$ & $\mathrm{NC}$ & $\mathrm{NC}$ \\
\hline
\end{tabular}


Table A-59. QA/QC Results for Mercury Analyses of Ontario Hydro Impinger Solutions - Long-Term Trip \#1 (7/10, 7/11/07)

\begin{tabular}{|c|c|c|c|c|c|c|c|c|}
\hline \multirow[b]{2}{*}{ QA Check } & \multirow[b]{2}{*}{ Sample } & \multirow{2}{*}{$\begin{array}{l}\text { Objective } \\
\text { (KMnO4 } \\
\text { and } \mathrm{KCl} \text { ) }\end{array}$} & \multirow{2}{*}{$\begin{array}{c}\text { Objective } \\
\text { (NI and } \\
\text { PNR) }\end{array}$} & \multicolumn{5}{|c|}{ Ontario Hydro Sample Fractions } \\
\hline & & & & KMnO4 & $\mathbf{K C l}$ & $\mathrm{H} 2 \mathrm{O} 2$ & Filter & PNR/Nitric Rinse \\
\hline DI Water Blank & All & $<\mathrm{DL}$ & $<\mathrm{DL}$ & $<\mathrm{DL}$ & $<\mathrm{DL}$ & $<\mathrm{DL}$ & $<\mathrm{DL}$ & $<\mathrm{DL}$ \\
\hline Reagent Blank & All & $<\mathrm{DL}$ & $<\mathrm{DL}$ & $<\mathrm{DL}$ & $<\mathrm{DL}$ & $<\mathrm{DL}$ & $<\mathrm{DL}$ & $<\mathrm{DL}$ \\
\hline Field Blank & All & $<\mathrm{DL}$ & $<\mathrm{DL}$ & $<\mathrm{DL}$ & $<\mathrm{DL}$ & $<\mathrm{DL}$ & $<\mathrm{DL}$ & $<\mathrm{DL}$ \\
\hline $\begin{array}{c}\text { Lab QC Standard } \\
\text { Recovery }\end{array}$ & $\begin{array}{c}\text { Treated and } \\
\text { Untreated } \\
\end{array}$ & $90-110 \%$ & $85-115 \%$ & $101-102 \%$ & $95-104 \%$ & $99-100 \%$ & $97-99 \%$ & $102-104 \%$ \\
\hline Matrix Spike & Treated & $85-115 \%$ & $85-115 \%$ & $104 \%$ & $100 \%$ & $100 \%$ & $98 \%$ & $110 \%$ \\
\hline $\begin{array}{c}\text { Replicate Analysis } \\
\text { RPD }\end{array}$ & Treated & $<10 \%$ & $<15 \%$ & $0.6-2 \%$ & $0.4-0.7 \%$ & $\mathrm{NC}$ & $\mathrm{NC}$ & $\mathrm{NC}$ \\
\hline Matrix Spike & Untreated & $85-115 \%$ & $85-115 \%$ & $104 \%$ & $114 \%$ & $90 \%$ & NA & $103 \%$ \\
\hline $\begin{array}{c}\text { Replicate Analysis } \\
\text { RPD } \\
\end{array}$ & Untreated & $<10 \%$ & $<15 \%$ & $0.6-2 \%$ & $0.1-2 \%$ & $0.2-3 \%$ & $\mathrm{NC}$ & $\mathrm{NC}$ \\
\hline
\end{tabular}


Table A-60. QA/QC Results for Mercury Analyses of Ontario Hydro Impinger Solutions - Long-Term Trip \#2 (7/31, 8/1/07)

\begin{tabular}{|c|c|c|c|c|c|c|c|c|}
\hline \multirow[b]{2}{*}{ QA Check } & \multirow[b]{2}{*}{ Sample } & \multirow{2}{*}{$\begin{array}{r}\text { Objective } \\
\text { (KMnO4 } \\
\text { and KCl) }\end{array}$} & \multirow{2}{*}{$\begin{array}{c}\text { Objective } \\
\text { (NI and } \\
\text { PNR) }\end{array}$} & \multicolumn{5}{|c|}{ Ontario Hydro Sample Fractions } \\
\hline & & & & KMnO4 & $\mathbf{K C l}$ & $\mathrm{H} 2 \mathrm{O} 2$ & Filter & $\begin{array}{c}\text { PNR/Nitric } \\
\text { Rinse }\end{array}$ \\
\hline DI Water Blank & All & $<\mathrm{DL}$ & $<\mathrm{DL}$ & $<\mathrm{DL}$ & $<\mathrm{DL}$ & $<\mathrm{DL}$ & $<\mathrm{DL}$ & $<\mathrm{DL}$ \\
\hline Reagent Blank & All & $<\mathrm{DL}$ & $<\mathrm{DL}$ & $<\mathrm{DL}$ & $<\mathrm{DL}$ & $<\mathrm{DL}$ & $<\mathrm{DL}$ & $<\mathrm{DL}$ \\
\hline Field Blank & All & $<\mathrm{DL}$ & $<\mathrm{DL}$ & $<\mathrm{DL}$ & $<\mathrm{DL}$ & $<\mathrm{DL}$ & $<\mathrm{DL}$ & $<\mathrm{DL}$ \\
\hline $\begin{array}{c}\text { Lab QC Standard } \\
\text { Recovery }\end{array}$ & $\begin{array}{c}\text { Treated and } \\
\text { Untreated }\end{array}$ & $90-110 \%$ & $85-115 \%$ & $99-100 \%$ & $99-110 \%$ & $96-105 \%$ & $100-102 \%$ & $100-102 \%$ \\
\hline Matrix Spike & Treated & $85-115 \%$ & $85-115 \%$ & $97-101 \%$ & $95-103 \%$ & $105 \%$ & $97 \%$ & $87-98 \%$ \\
\hline $\begin{array}{c}\text { Replicate Analysis } \\
\text { RPD }\end{array}$ & Treated & $<10 \%$ & $<15 \%$ & $0.24-0.78 \%$ & $0.1-0.56 \%$ & $\mathrm{NC}$ & $\mathrm{NC}$ & $\mathrm{NC}$ \\
\hline Matrix Spike & Untreated & $85-115 \%$ & $85-115 \%$ & $100 \%$ & $104 \%$ & $97 \%$ & $100 \%$ & $100 \%$ \\
\hline $\begin{array}{c}\text { Replicate Analysis } \\
\text { RPD } \\
\end{array}$ & Untreated & $<10 \%$ & $<15 \%$ & $0.4-1 \%$ & $0.2-2 \%$ & $0.5-2 \%$ & $\mathrm{NC}$ & $\mathrm{NC}$ \\
\hline
\end{tabular}


Table A-61. QA/QC Results for Mercury Analyses of Ontario Hydro Impinger Solutions - Long-Term Trip \#3 (8/14, 8/15/07)

\begin{tabular}{|c|c|c|c|c|c|c|c|c|}
\hline \multirow[b]{2}{*}{ QA Check } & \multirow[b]{2}{*}{ Sample } & \multirow{2}{*}{$\begin{array}{l}\text { Objective } \\
\text { (KMnO4 } \\
\text { and KCl) }\end{array}$} & \multirow{2}{*}{$\begin{array}{c}\text { Objective } \\
\text { (NI and } \\
\text { PNR) }\end{array}$} & \multicolumn{5}{|c|}{ Ontario Hydro Sample Fractions } \\
\hline & & & & KMnO4 & $\mathrm{KCl}$ & $\mathrm{H} 2 \mathrm{O2}$ & Filter & PNR/Nitric Rinse \\
\hline DI Water Blank & All & $<\mathrm{DL}$ & $<\mathrm{DL}$ & $<\mathrm{DL}$ & $<\mathrm{DL}$ & $<\mathrm{DL}$ & $<\mathrm{DL}$ & $<\mathrm{DL}$ \\
\hline Reagent Blank & All & $<\mathrm{DL}$ & $<\mathrm{DL}$ & $<\mathrm{DL}$ & $<\mathrm{DL}$ & $<\mathrm{DL}$ & $<\mathrm{DL}$ & $<\mathrm{DL}$ \\
\hline Field Blank & All & $<\mathrm{DL}$ & $<\mathrm{DL}$ & $<\mathrm{DL}$ & $<\mathrm{DL}$ & $<\mathrm{DL}$ & $<\mathrm{DL}$ & $<\mathrm{DL}$ \\
\hline $\begin{array}{c}\text { Lab QC Standard } \\
\text { Recovery }\end{array}$ & $\begin{array}{c}\text { Treated and } \\
\text { Untreated }\end{array}$ & $90-110 \%$ & $85-115 \%$ & $101-102 \%$ & $100-104 \%$ & $98.00 \%$ & $100-102 \%$ & $98-99 \%$ \\
\hline Matrix Spike & Treated & $85-115 \%$ & $85-115 \%$ & $101-106 \%$ & $94-95 \%$ & $102 \%$ & $97 \%$ & $102 \%$ \\
\hline $\begin{array}{l}\text { Replicate Analysis } \\
\text { RPD }\end{array}$ & Treated & $<10 \%$ & $<15 \%$ & $0.3-0.9 \%$ & $0.1-1 \%$ & $\mathrm{NC}$ & $\mathrm{NC}$ & $\mathrm{NC}$ \\
\hline Matrix Spike & Untreated & $85-115 \%$ & $85-115 \%$ & $100 \%$ & $94 \%$ & $98-101 \%$ & $100 \%$ & $97 \%$ \\
\hline $\begin{array}{l}\text { Replicate Analysis } \\
\text { RPD }\end{array}$ & Untreated & $<10 \%$ & $<15 \%$ & $0.4-0.6 \%$ & $0.2-1 \%$ & $1.0 \%$ & $\mathrm{NC}$ & $\mathrm{NC}$ \\
\hline
\end{tabular}




\section{Mercury in Coal and Ash}

Results for mercury in coal were determined by Consol Energy Laboratories (Consol) using Method ASTM D6722 "Determination of Mercury in Coal, Coke, and Solid Residues from Combustion of Coal and Coke by High Temperature Combustion Atomic Absorption Spectrometry." In this method the test specimen is heated in a tube furnace in a stream of oxygen. The gas stream containing the mercury vapor passes through a pre-packed portion of the combustion train where ash, moisture, halogens, and minerals are removed. The purified gas stream containing the mercury vapor then passes through an amalgamator tube containing goldplated ceramic beads, which collect the mercury. When all the mercury has been collected, the amalgamator is heated, releasing the mercury vapor which is then transported through a cuvette positioned in the path length of an atomic absorption spectrometer.

Consol performed a duplicate analysis for each coal sample. Results for the coal QA/QC are presented in Table A-8. The criteria used to determine if the duplicate passes was an ASTM reproducibility limit $[0.008+(0.06 *$ (average $\mathrm{Hg}$ results $))]$. If the absolute difference between the two mercury results was less than the calculated ASTM reproducibility limit then the precision was considered passing. Consol also analyzed a standard reference material (SRM) every 10 samples. The laboratory used the SRM as a continuing calibration verification (CCV) and bracketed their data with it.

The relative percent difference (RPD) of coal sample 7/3/07 Mill H and 7/29/2007 Mill J were $52 \%$ and $34 \%$, respectively. This is greater than the $25 \%$ acceptance criteria. Also the ASTM reproducibility of several coal samples failed. This is not atypical of coal precision. This is due to the difficulty to digest a completely homogenized coal sample.

Results for mercury in ash were determined by URS Corporation. Ash samples were digested using a general hydrofluoric acid and aqua regia digestion and analyzed for mercury by cold vapor atomic absorption (CVAA).

To verify the quality of the fly ash mercury data, URS used analytical method blanks, matrix spikes, post digestion spikes, duplicates, SRMs, and CCVs. Results for the ash QA/QC are presented in Table A-9. Matrix spikes (MSs) are a known volume of mercury that has been added to the ash sample before it has been digested, recovered, and analyzed for mercury. The purpose is to ensure mercury has not been lost during the analytical process. Because these spikes are prepared before the sample has been analyzed, the amount added is an educated guess based on typical mercury levels in ash samples. If the unspiked ash sample is greater than four times the spiked amount, then the spike is deemed inappropriate and a post digestion spike (PDS) is performed or the sample is simple re-digested and re-spiked with the appropriate amount of spike. With a few exceptions, results were within the data quality objectives of the test program and the results as a whole do not indicate a significant bias in the analytical results for the ash samples.

The MS on ash sample from Baseline 6/22/07 field 6\&7F2A recovered at $84 \%$ due to digested spike amount being inappropriate. A PDS was performed on this sample and recovered at $97.0 \%$. The MS on ash sample from Long Term 6/29/07 field 3F2A recovered at 27.3\% due to digested 
spike amount being inappropriate. A PDS was performed on this sample and recovered at $98.5 \%$. The MS on ash sample from Long Term 6/29/07 field 4\&5F1A recovered at $118.4 \%$ due to digested spike amount being inappropriate. A PDS was performed on this sample and recovered at $96.3 \%$. The MS on ash sample from Long Term 7/21/07 field 3F3A recovered at 51.9\% due to digested spike amount being inappropriate. Two PDSs were performed on this sample and recovered at $99.4 \%$ and $101.5 \%$. The spike was not added to MS on ash sample Baseline 6/20/07 field 1F1A due to analyst error. A PDS was performed on this sample and recovered at $96.7 \%$. Because all PDSs passed criteria data quality was not impacted due to failing MSs.

The RPD for an ash sample that is detected below two times the reporting limit (RL) does not affect the quality of the data. The results for ash sample Long Term 8/3/07 field 1F3B were detected less than two times the RL; therefore, the RPD of $20.0 \%$ does not affect the quality of the data.

Table A-62. QA/QC Results for Mercury Analyses of Coal Samples

\begin{tabular}{|c|c|c|c|c|c|c|c|}
\hline Description & $\begin{array}{l}\text { Coal } \\
\text { type }\end{array}$ & $\begin{array}{c}\mathrm{Hg} \\
(\mathrm{ppm})\end{array}$ & $\begin{array}{c}\mathbf{H g} \\
(\mathrm{ppm})\end{array}$ & $\%$ RPD & $\begin{array}{c}\text { ASTM } \\
\begin{array}{c}\text { Reproducibility } \\
\text { Limit }\end{array} \\
\end{array}$ & $\begin{array}{c}\text { Absolute } \\
\text { Difference }\end{array}$ & Fail? \\
\hline \multicolumn{4}{|c|}{ Objective $\rightarrow$} & $<25 \%$ & & & Pass \\
\hline 6/21/2007 Mill H & Lignite & 0.198 & 0.191 & 4 & 0.020 & 0.007 & pass \\
\hline 6/21/2007 Mill J & PRB & 0.212 & 0.218 & 3 & 0.021 & 0.007 & pass \\
\hline 6/21/2007 Mill K & Lignite & 0.079 & 0.071 & 11 & 0.013 & 0.008 & pass \\
\hline 6/25/2007 Mill J & PRB & 0.217 & 0.227 & 4 & 0.021 & 0.010 & pass \\
\hline 6/25/2007 Mill K & Lignite & 0.150 & 0.156 & 4 & 0.017 & 0.006 & pass \\
\hline 6/27/2007 Mill H & Lignite & 0.068 & 0.066 & 2 & 0.012 & 0.001 & pass \\
\hline 6/29/2007 Mill H & Lignite & 0.105 & 0.105 & 0 & 0.014 & 0.000 & pass \\
\hline 6/29/2007 Mill K & PRB & 0.120 & 0.140 & 16 & 0.016 & 0.021 & fail \\
\hline 6/29/2007 Mill F & Lignite & 0.217 & 0.202 & 7 & 0.021 & 0.015 & pass \\
\hline 7/3/2007 Mill H & Lignite & 0.170 & 0.100 & 52 & 0.016 & 0.070 & fail \\
\hline 7/3/2007 Mill K & PRB & 0.082 & 0.083 & 1 & 0.013 & 0.001 & pass \\
\hline 7/5/2007 Mill H & Lignite & 0.217 & 0.176 & 21 & 0.020 & 0.041 & fail \\
\hline 7/5/2007 Mill J & Lignite & 0.284 & 0.270 & 5 & 0.025 & 0.015 & pass \\
\hline 7/5/2007 Mill K & PRB & 0.083 & 0.080 & 3 & 0.013 & 0.003 & pass \\
\hline 7/8/2007 Mill J & Lignite & 0.095 & 0.097 & 3 & 0.014 & 0.002 & pass \\
\hline 7/8/2007 Mill K & PRB & 0.210 & 0.204 & 3 & 0.020 & 0.006 & pass \\
\hline 7/9/2007 Mill H & Lignite & 0.114 & 0.109 & 4 & 0.015 & 0.005 & pass \\
\hline 7/9/2007 Mill J & Lignite & 0.292 & 0.284 & 3 & 0.025 & 0.008 & pass \\
\hline 7/9/2007 Mill K & PRB & 0.169 & 0.179 & 5 & 0.018 & 0.009 & pass \\
\hline 7/19/2007 Mill J & PRB & 0.091 & 0.088 & 4 & 0.013 & 0.004 & pass \\
\hline 7/19/2007 Mill F & Lignite & 0.172 & 0.185 & 7 & 0.019 & 0.013 & pass \\
\hline 7/22/2007 Mill H & Lignite & 0.194 & 0.198 & 2 & 0.020 & 0.004 & pass \\
\hline 7/22/2007 Mill G & Lignite & 0.164 & 0.146 & 12 & 0.017 & 0.018 & fail \\
\hline $7 / 22 / 2007$ Mill J & PRB & 0.093 & 0.115 & 21 & 0.014 & 0.022 & fail \\
\hline $7 / 25 / 2007$ Mill J & PRB & 0.099 & 0.095 & 4 & 0.014 & 0.004 & pass \\
\hline 7/25/2007 Mill H & Lignite & 0.162 & 0.145 & 11 & 0.017 & 0.017 & pass \\
\hline 7/27/2007 Mill J & PRB & 0.091 & 0.113 & 21 & 0.014 & 0.022 & fail \\
\hline
\end{tabular}




\begin{tabular}{|c|c|c|c|c|c|c|c|}
\hline Description & $\begin{array}{l}\text { Coal } \\
\text { type }\end{array}$ & $\begin{array}{c}\mathrm{Hg} \\
(\mathrm{ppm})\end{array}$ & $\begin{array}{c}\mathrm{Hg} \\
(\mathrm{ppm})\end{array}$ & $\%$ RPD & \begin{tabular}{|c|} 
ASTM \\
$\begin{array}{c}\text { Reproducibility } \\
\text { Limit }\end{array}$ \\
\end{tabular} & $\begin{array}{c}\text { Absolute } \\
\text { Difference }\end{array}$ & Fail? \\
\hline Objective $\rightarrow$ & & & & $<25 \%$ & & & Pass \\
\hline 7/27/2007 Mill H & Lignite & 0.209 & 0.233 & 11 & 0.021 & 0.023 & fail \\
\hline 7/27/2007 Mill K & Lignite & 0.181 & 0.216 & 17 & 0.020 & 0.035 & fail \\
\hline 7/29/2007 Mill H & Lignite & 0.138 & 0.136 & 2 & 0.016 & 0.003 & pass \\
\hline 7/29/2007 Mill J & PRB & 0.084 & 0.060 & 34 & 0.012 & 0.024 & fail \\
\hline 7/29/2007 Mill K & Lignite & 0.257 & 0.247 & 4 & 0.023 & 0.010 & pass \\
\hline 8/7/2007 Mill J & PRB & 0.101 & 0.094 & 7 & 0.014 & 0.007 & pass \\
\hline 8/7/2007 Mill K & Lignite & 0.166 & 0.171 & 3 & 0.018 & 0.005 & pass \\
\hline 8/9/2007 Mill H & Lignite & 0.195 & 0.190 & 3 & 0.020 & 0.005 & pass \\
\hline 8/9/2007 Mill J & PRB & 0.062 & 0.071 & 13 & 0.012 & 0.009 & pass \\
\hline 8/9/2007 Mill K & Lignite & 0.639 & 0.590 & 8 & 0.045 & 0.049 & fail \\
\hline 8/15/2007 Mill K & Lignite & 0.144 & 0.153 & 6 & 0.017 & 0.009 & pass \\
\hline 8/15/2007 Mill H & Lignite & 0.204 & 0.217 & 6 & 0.021 & 0.013 & pass \\
\hline 8/17/2007 Mill J & PRB & 0.223 & 0.207 & 8 & 0.021 & 0.017 & pass \\
\hline 8/17/2007 Mill K & Lignite & 0.181 & 0.206 & 13 & 0.020 & 0.025 & fail \\
\hline 8/17/2007 Mill H & Lignite & 0.079 & 0.094 & 17 & 0.013 & 0.015 & fail \\
\hline 8/19/2007 Mill J & PRB & 0.089 & 0.100 & 11 & 0.014 & 0.011 & pass \\
\hline 8/19/2007 Mill H & Lignite & 0.186 & 0.170 & 9 & 0.019 & 0.016 & pass \\
\hline 8/19/2007 Mill K & Lignite & 0.224 & 0.225 & 1 & 0.021 & 0.001 & pass \\
\hline 8/21/2007 Mill H & Lignite & 0.225 & 0.223 & 1 & 0.021 & 0.002 & pass \\
\hline 8/21/2007 Mill J & PRB & 0.123 & 0.144 & 15 & 0.016 & 0.021 & fail \\
\hline 6/20/2007 Mill H & Lignite & 0.122 & 0.140 & 14 & 0.016 & 0.018 & fail \\
\hline 6/20/2007 Mill J & PRB & 0.0928 & 0.100 & 8 & 0.014 & 0.008 & pass \\
\hline 6/20/2007 Mill K & Lignite & 0.241 & 0.239 & 1 & 0.022 & 0.002 & pass \\
\hline 7/11/2007 Mill H & Lignite & 0.300 & 0.300 & 0 & 0.026 & 0.000 & pass \\
\hline 7/11/2007 Mill J & Lignite & 0.258 & 0.281 & 9 & 0.024 & 0.024 & pass \\
\hline 7/11/2007 Mill K & PRB & 0.0544 & 0.0640 & 16 & 0.012 & 0.010 & pass \\
\hline
\end{tabular}


Table A-63. QA/QC Results for Mercury Analyses of Ash Samples

\begin{tabular}{|c|c|c|c|c|c|c|}
\hline \multirow{2}{*}{$\begin{array}{l}\text { Sample Analysis } \\
\text { Batch Date }\end{array}$} & Sample & $\begin{array}{c}\text { Method } \\
\text { Blank }\end{array}$ & MS Recovery & RPD $^{5}$ & $\begin{array}{c}\text { Reference } \\
\text { Ash } \\
\text { Recovery }\end{array}$ & $\mathrm{CCV}^{6}$ \\
\hline & Objective $\rightarrow$ & $<\mathrm{DL}$ & $\begin{array}{c}85-115 \% \text {-detect } \\
75-125 \% \text {-non-detect }\end{array}$ & $<10 \%$ & $85-115 \%$ & $85-115 \%$ \\
\hline \multirow{7}{*}{$\begin{array}{l}\text { Analysis on } 8 / 10 / 07 \\
\text { Samples from } \\
6 / 20 / 07 \text { and } 6 / 22 / 07\end{array}$} & DI Water Blank & $<\mathrm{DL}$ & $\begin{array}{l}-- \\
\end{array}$ & $\begin{array}{l}- \\
\end{array}$ & $\begin{array}{l}- \\
\end{array}$ & $\begin{array}{l}- \\
\end{array}$ \\
\hline & Blank & $<\mathrm{DL}$ & 105.0 & -- & -- & -- \\
\hline & NIST Ash $1633 b^{7,8}$ & -- & -- & -- & 114.2 & -- \\
\hline & Calibration verification & -- & -- & -- & - & $98.4-102.0$ \\
\hline & Replicate Analysis Range & -- & -- & $2.53-4.65$ & -- & -- \\
\hline & $\begin{array}{c}\text { Matrix Spike }{ }^{9} \text { Ranges } \\
\text { (Ash from BL 6/20/07 } \\
\text { 1F2B, 6/22/07 1F1A, and } \\
6 / 22 / 072 \mathrm{~F} 3 \mathrm{~A} \text { ) } \\
\end{array}$ & -- & $102.0-107.3$ & -- & -- & -- \\
\hline & PDS ${ }^{10}$ Ranges & -- & -- & -- & -- & -- \\
\hline \multirow{7}{*}{$\begin{array}{c}\text { Analysis on } 8 / 15 / 07 \\
\text { Samples from } \\
6 / 22 / 07\end{array}$} & DI Water Blank & $<\mathrm{DL}$ & & & & \\
\hline & Blank & $<\mathrm{DL}$ & 95.0 & -- & -- & -- \\
\hline & NIST Ash 1633b & -- & -- & -- & 107.8 & -- \\
\hline & Calibration verification & -- & -- & -- & -- & $97.0-104.3$ \\
\hline & Replicate Analysis Range & -- & -- & $0.00-4.58$ & -- & -- \\
\hline & $\begin{array}{c}\text { Matrix Spike Ranges } \\
\text { (Ash from BL 6/22/07 } \\
4 \& 5 \mathrm{~F} 3 \mathrm{~A}, 6 / 22 / 076 \& 7 \mathrm{~F} 2 \mathrm{~A} \\
\text { and } 6 / 22 / 073 \mathrm{~F} 2 \mathrm{~A})\end{array}$ & -- & 83.9-102.8 & -- & -- & -- \\
\hline & $\begin{array}{c}\text { PDS Ranges (Ash from BL } \\
6 / 22 / 076 \& 7 \mathrm{~F} 2 \mathrm{~A})\end{array}$ & -- & 97.0 & -- & -- & -- \\
\hline \multirow{7}{*}{$\begin{array}{c}\text { Analysis on } 8 / 16 / 07 \\
\text { Samples from } \\
6 / 28 / 07 \text { and } 6 / 29 / 07\end{array}$} & DI Water Blank & $<\mathrm{DL}$ & -- & -- & -- & -- \\
\hline & Blank & $<\mathrm{DL}$ & 101.0 & -- & -- & -- \\
\hline & NIST Ash 1633b & -- & -- & -- & 102.8 & -- \\
\hline & Calibration verification & -- & -- & -- & - & $90.3-102.3$ \\
\hline & Replicate Analysis Range & -- & -- & $1.13-4.05$ & -- & -- \\
\hline & $\begin{array}{c}\text { Matrix Spike Ranges } \\
\text { (Ash LT 6/28/07 1F2A, } \\
\text { 6/29/08 2F3A, and 6/29/07 } \\
\text { 3F2A) } \\
\end{array}$ & -- & $27.3-102.4$ & -- & -- & -- \\
\hline & $\begin{array}{c}\text { PDS Ranges (Ash from LT } \\
6 / 29 / 07 \text { 3F2A) }\end{array}$ & -- & 89.4 & -- & -- & -- \\
\hline \multirow{7}{*}{$\begin{array}{l}\text { Analysis on } 8 / 16 / 07 \\
\text { Samples from } 7 / 5 / 07\end{array}$} & DI Water Blank & $<\mathrm{DL}$ & -- & -- & -- & -- \\
\hline & Blank & $<\mathrm{DL}$ & 94.0 & -- & -- & -- \\
\hline & NIST Ash 1633b & -- & -- & -- & 94.3 & -- \\
\hline & Calibration verification & -- & -- & -- & - & $95.7-98.5$ \\
\hline & Replicate Analysis Range & -- & -- & $0.03-2.24$ & -- & --- \\
\hline & $\begin{array}{c}\text { Matrix Spike Ranges } \\
\text { (Ash from LT 7/5/07 3F2A, } \\
\text { 7/5/07 4\&5F1A, and 7/5/07 } \\
6 \& 7 \mathrm{~F} 3 \mathrm{~A} \text { ) }\end{array}$ & -- & $33.2-97.3$ & -- & -- & -- \\
\hline & $\begin{array}{c}\text { PDS Ranges (Ash from LT } \\
7 / 5 / 076 \& 7 \mathrm{~F} 3 \mathrm{~A})\end{array}$ & -- & 98.5 & -- & -- & -- \\
\hline
\end{tabular}

${ }^{5} \mathrm{RPD}=$ Relative Percent Deviation.

${ }^{6} \mathrm{CCV}=$ Continuing calibration verification

${ }^{7}$ NIST $=$ National Institute of Standards and Technology.

${ }^{8}$ NIST Ash $1633 \mathrm{~b}$ has an uncertified mercury value of $0.141 \mu \mathrm{g} / \mathrm{g}$.

${ }^{9}$ Matrix spikes, spikes that have been digested along with the sample.

${ }^{10}$ PDS $=$ Post Digestion Spike. 


\begin{tabular}{|c|c|c|c|c|c|c|}
\hline \multirow{2}{*}{$\begin{array}{l}\text { Sample Analysis } \\
\text { Batch Date }\end{array}$} & Sample & $\begin{array}{l}\text { Method } \\
\text { Blank }\end{array}$ & MS Recovery & RPD 11 & $\begin{array}{c}\text { Reference } \\
\text { Ash } \\
\text { Recovery } \\
\end{array}$ & CCV 12 \\
\hline & Objective $\rightarrow$ & $<\mathrm{DL}$ & $\begin{array}{c}85-115 \% \text {-detect } \\
75-125 \% \text {-non-detect }\end{array}$ & $<10 \%$ & $85-115 \%$ & $85-115 \%$ \\
\hline \multirow{7}{*}{$\begin{array}{l}\text { Analysis on } 8 / 29 / 07 \\
\text { Samples from } \\
6 / 29 / 07 \text { and } 7 / 5 / 07\end{array}$} & DI Water Blank & $<\mathrm{DL}$ & $\begin{array}{l}-- \\
\end{array}$ & -- & $\begin{array}{c}-- \\
\end{array}$ & $\begin{array}{c}- \\
\end{array}$ \\
\hline & Blank & $<\mathrm{DL}$ & 99.0 & -- & -- & -- \\
\hline & NIST Ash 1633b & -- & -- & -- & $102.8-104.3$ & -- \\
\hline & Calibration verification & -- & -- & -- & - & 100.1-101.9 \\
\hline & Replicate Analysis Range & -- & -- & $1.66-2.82$ & -- & -- \\
\hline & $\begin{array}{c}\text { Matrix Spike Ranges } \\
\text { (Ash from LT 6/29/07 } \\
\text { 4\&5F1A, 7/5/07 1F2A, and } \\
7 / 5 / 07 \text { 2F3A) }\end{array}$ & -- & $102.3-\mathbf{1 1 8 . 4}$ & -- & -- & -- \\
\hline & $\begin{array}{c}\text { PDS Ranges (Ash from LT } \\
6 / 29 / 074 \& 5 \mathrm{~F} 1 \mathrm{~A})\end{array}$ & -- & 96.3 & -- & -- & -- \\
\hline \multirow{7}{*}{$\begin{array}{l}\text { Analysis on } 9 / 7 / 07 \\
\text { Samples from } \\
7 / 9 / 07,7 / 10 / 07, \\
7 / 21 / 07 \text {, and } 8 / 18 / 07\end{array}$} & DI Water Blank & $<\mathrm{DL}$ & -- & -- & -- & -- \\
\hline & Blank & $<\mathrm{DL}$ & 99.0 & -- & -- & -- \\
\hline & NIST Ash $1633 \mathrm{~b}$ & -- & 98.9 & -- & $100.7-105.7$ & -- \\
\hline & Calibration verification & -- & -- & -- & - & $97.4-103.7$ \\
\hline & Replicate Analysis Range & -- & -- & $0.00-2.45$ & -- & -- \\
\hline & $\begin{array}{c}\text { Matrix Spike Ranges } \\
\text { (Ash from LT 6/29/07 } \\
\text { 4\&5F1A, 7/5/07 1F2A, and } \\
7 / 5 / 07 \text { 2F3A) }\end{array}$ & -- & $98.2-109.1$ & -- & -- & -- \\
\hline & PDS Ranges & -- & -- & -- & -- & -- \\
\hline \multirow{7}{*}{$\begin{array}{l}\text { Analysis on } 10 / 3 / 07 \\
\text { Samples from } \\
7 / 21 / 07,7 / 28 / 07 \\
8 / 3 / 07 \text { and } 8 / 18 / 07\end{array}$} & DI Water Blank & $<\mathrm{DL}$ & -- & -- & -- & -- \\
\hline & Blank & $<\mathrm{DL}$ & 99.0 & -- & -- & -- \\
\hline & NIST Ash $1633 b$ & -- & -- & -- & $102.8-104.3$ & -- \\
\hline & Calibration verification & -- & -- & -- & - & $100.1-101.9$ \\
\hline & Replicate Analysis Range & -- & -- & $0.58-20$ & -- & -- \\
\hline & $\begin{array}{c}\text { Matrix Spike Ranges } \\
\text { (Ash from LT 7/21/07 } \\
\text { 3F3A, 7/28/07 1F1A, 8/3/07 } \\
\text { 1F3B, and 8/18/07 3F3A) }\end{array}$ & -- & 51.9-104.2 & -- & -- & -- \\
\hline & $\begin{array}{c}\text { PDS Ranges (Ash from LT } \\
7 / 21 / 073 \mathrm{~F} 3 \mathrm{~A})\end{array}$ & -- & $99.4-101.5$ & -- & -- & -- \\
\hline \multirow{7}{*}{$\begin{array}{l}\text { Analysis on } 10 / 3 / 07 \\
\text { Samples from } \\
7 / 21 / 07,8 / 11 / 07 \\
\text { and } 8 / 17 / 07\end{array}$} & DI Water Blank & $<\mathrm{DL}$ & -- & -- & -- & -- \\
\hline & Blank & $<\mathrm{DL}$ & 104.0 & -- & -- & -- \\
\hline & NIST Ash 1633b & -- & -- & -- & 103.5 & -- \\
\hline & Calibration verification & -- & -- & -- & - & $98.9-104.5$ \\
\hline & Replicate Analysis Range & -- & -- & $0.41-3.76$ & -- & -- \\
\hline & $\begin{array}{l}\text { Matrix Spike Ranges } \\
\text { (Ash from LT 8/11/07 } \\
\text { 1F1A, 8/17/07 1F1B) }\end{array}$ & -- & $103-115$ & -- & -- & -- \\
\hline & $\begin{array}{c}\text { PDS Ranges (Ash from LT } \\
7 / 21 / 074 \& 5 \mathrm{~F} 1 \mathrm{~A}, 7 / 21 / 07 \\
6 \& 7 \mathrm{~F} 1 \mathrm{~A} \text {, and } 8 / 17 / 071 \mathrm{~F} 1 \mathrm{~B})\end{array}$ & -- & 101.9-104.8 & -- & -- & -- \\
\hline
\end{tabular}

${ }^{11} \mathrm{RPD}=$ Relative Percent Deviation.

${ }^{12} \mathrm{CCV}=$ Continuing calibration verification 


\begin{tabular}{|c|c|c|c|c|c|c|}
\hline \multirow{2}{*}{$\begin{array}{l}\text { Sample Analysis } \\
\text { Batch Date }\end{array}$} & Sample & $\begin{array}{c}\text { Method } \\
\text { Blank }\end{array}$ & MS Recovery & RPD 13 & $\begin{array}{c}\text { Reference } \\
\text { Ash } \\
\text { Recovery }\end{array}$ & CCV 14 \\
\hline & Objective $\rightarrow$ & $<$ DL & $\begin{array}{c}85-115 \% \text {-detect } \\
75-125 \% \text {-non-detect }\end{array}$ & $<10 \%$ & $85-115 \%$ & $85-115 \%$ \\
\hline \multirow{7}{*}{$\begin{array}{c}\text { Analysis on } 10 / 5 / 07 \\
\text { Samples from } \\
8 / 18 / 07\end{array}$} & DI Water Blank & $<\mathrm{DL}$ & $\begin{array}{l}-- \\
\end{array}$ & -- & 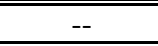 & $\begin{array}{l}-- \\
\end{array}$ \\
\hline & Blank & $<\mathrm{DL}$ & 98.0 & -- & -- & -- \\
\hline & NIST Ash 1633b & -- & -- & -- & 100.0 & -- \\
\hline & Calibration verification & -- & -- & -- & - & $99.2-101.7$ \\
\hline & Replicate Analysis Range & -- & -- & 2.05 & -- & -- \\
\hline & $\begin{array}{c}\text { Matrix Spike Ranges } \\
\text { (Ash from LT 8/18/07 } \\
\text { 1F1A, 8/18/07 4\&5F1A, and } \\
\text { 8/18/07 6\&7F1A) }\end{array}$ & -- & 102.4 & -- & -- & -- \\
\hline & $\begin{array}{c}\text { PDS Ranges (Ash from LT } \\
8 / 18 / 074 \& 5 \mathrm{~F} 1 \mathrm{~A})\end{array}$ & -- & 97.7 & -- & -- & -- \\
\hline \multirow{7}{*}{$\begin{array}{c}\text { Analysis on } \\
\text { 10/24/07 Reanalysis } \\
\text { of samples from } \\
8 / 18 / 07\end{array}$} & DI Water Blank & $<\mathrm{DL}$ & -- & -- & -- & -- \\
\hline & Blank & $<\mathrm{DL}$ & 106.0 & -- & -- & -- \\
\hline & NIST Ash 1633b & -- & -- & -- & 106.4 & -- \\
\hline & Calibration verification & -- & -- & -- & - & $98.3-101.9$ \\
\hline & Replicate Analysis Range & -- & -- & $0.08-2.37$ & -- & -- \\
\hline & $\begin{array}{c}\text { Matrix Spike Ranges } \\
\text { (Ash from LT 8/18/07 } \\
\text { 4\&5F1A and LT 8/18/07 } \\
\text { 6\&7F1A ) }\end{array}$ & -- & $90.0-101.6$ & -- & -- & -- \\
\hline & $\begin{array}{c}\text { PDS Ranges (Ash from LT } \\
8 / 18 / 074 \& 5 \mathrm{~F} 1 \mathrm{~A})\end{array}$ & -- & 101.6 & -- & -- & -- \\
\hline \multirow{7}{*}{$\begin{array}{c}\text { Analysis on } \\
\text { 12/28/07 Reanalysis } \\
\text { of samples from } \\
7 / 5 / 07 \text { and } 8 / 18 / 07\end{array}$} & DI Water Blank & $<\mathrm{DL}$ & -- & -- & -- & -- \\
\hline & Blank & $<\mathrm{DL}$ & 102.0 & -- & -- & -- \\
\hline & NIST Ash $1633 \mathrm{~b}$ & -- & -- & -- & 102.1 & -- \\
\hline & Calibration verification & -- & -- & -- & - & $99.3-103.0$ \\
\hline & Replicate Analysis Range & -- & -- & $0.78-4.34$ & -- & -- \\
\hline & Matrix Spike Ranges & -- & -- & -- & -- & -- \\
\hline & PDS Ranges & -- & -- & -- & -- & -- \\
\hline \multirow{7}{*}{$\begin{array}{c}\text { Analysis on } 1 / 19 / 08 \\
\text { Samples from } \\
7 / 3 / 07,7 / 19 / 07 \\
7 / 22 / 07,7 / 25 / 07 \\
7 / 27 / 07,7 / 29 / 07 \\
8 / 9 / 07,8 / 15 / 07 \text {, and } \\
8 / 19 / 07\end{array}$} & DI Water Blank & $<\mathrm{DL}$ & -- & -- & -- & -- \\
\hline & Blank & $<\mathrm{DL}$ & 99.0 & -- & -- & -- \\
\hline & NIST Ash 1633b & -- & -- & -- & 96.5 & -- \\
\hline & Calibration verification & -- & -- & -- & - & $99.3-101.9$ \\
\hline & Replicate Analysis Range & -- & -- & 0.53 & -- & -- \\
\hline & $\begin{array}{c}\text { Matrix Spike Ranges } \\
\text { (Ash from LT 7/3/07 1F1A) }\end{array}$ & -- & 91.0 & -- & -- & -- \\
\hline & PDS Ranges & -- & -- & -- & -- & -- \\
\hline \multirow{7}{*}{$\begin{array}{c}\text { Analysis on } 1 / 23 / 08 \\
\text { Samples from } \\
\text { 6/20/07, 6/29/07, } \\
\text { 7/8/07, and } 8 / 13 / 07\end{array}$} & DI Water Blank & $<\mathrm{DL}$ & -- & -- & -- & -- \\
\hline & Blank & $<\mathrm{DL}$ & 104.0 & -- & -- & -- \\
\hline & NIST Ash $1633 \mathrm{~b}$ & -- & -- & -- & 102.1 & -- \\
\hline & Calibration verification & -- & -- & -- & - & $99.3-103.0$ \\
\hline & Replicate Analysis Range & -- & -- & $0.97-1.06$ & -- & -- \\
\hline & $\begin{array}{c}\text { Matrix Spike Ranges } \\
\text { (Ash from BL 6/20/07 } \\
\text { 1F1A, LT 6/29/07 1F3A, } \\
\text { and LT 8/13/07 1F1A) }\end{array}$ & -- & 0.00-101.9 & -- & -- & -- \\
\hline & $\begin{array}{c}\text { PDS Ranges (Ash from BL } \\
6 / 20 / 071 \mathrm{~F} 1 \mathrm{~A})\end{array}$ & -- & 96.7 & -- & -- & -- \\
\hline
\end{tabular}

${ }^{13} \mathrm{RPD}=$ Relative Percent Deviation.

${ }^{14} \mathrm{CCV}=$ Continuing calibration verification 


\begin{tabular}{|c|c|c|c|c|c|c|}
\hline \multirow{2}{*}{$\begin{array}{l}\text { Sample Analysis } \\
\text { Batch Date }\end{array}$} & Sample & $\begin{array}{l}\text { Method } \\
\text { Blank }\end{array}$ & MS Recovery & RPD 15 & $\begin{array}{c}\text { Reference } \\
\text { Ash } \\
\text { Recovery }\end{array}$ & CCV 16 \\
\hline & Objective $\rightarrow$ & $<\mathrm{DL}$ & $\begin{array}{c}85-115 \% \text {-detect } \\
75-125 \% \text {-non-detect }\end{array}$ & $<10 \%$ & $85-115 \%$ & $85-115 \%$ \\
\hline \multirow{7}{*}{$\begin{array}{l}\text { Analysis on } 1 / 23 / 08 \\
\text { Samples from } \\
7 / 4 / 07,7 / 10 / 07 \\
7 / 11 / 07 \text {, and } 8 / 18 / 07\end{array}$} & DI Water Blank & $<\mathrm{DL}$ & -- & -- & -- & -- \\
\hline & Blank & $<\mathrm{DL}$ & 112.0 & -- & -- & -- \\
\hline & NIST Ash 1633b & -- & -- & -- & 107.8 & -- \\
\hline & Calibration verification & -- & -- & -- & - & 98.4-104.7 \\
\hline & Replicate Analysis Range & -- & -- & $3.08-3.15$ & -- & -- \\
\hline & $\begin{array}{c}\text { Matrix Spike Ranges } \\
\text { (Ash from LT 7/4/07 1F1A, } \\
\text { 7/10/07 1F2A, and 7/11/07 } \\
1 \mathrm{~F} 3 \mathrm{~A} \text { ) } \\
\end{array}$ & -- & $88.8-108.8$ & -- & -- & -- \\
\hline & PDS Ranges & -- & -- & -- & -- & -- \\
\hline \multirow{7}{*}{$\begin{array}{c}\text { Analysis on } 1 / 24 / 08 \\
\text { Samples from } \\
7 / 28 / 07,7 / 31 / 07 \\
\text { and } 8 / 1 / 07\end{array}$} & DI Water Blank & $<\mathrm{DL}$ & -- & -- & -- & -- \\
\hline & Blank & $<\mathrm{DL}$ & 103.0 & -- & -- & -- \\
\hline & NIST Ash 1633b & -- & -- & -- & 105.7 & -- \\
\hline & Calibration verification & -- & -- & -- & - & $97.7-105.5$ \\
\hline & Replicate Analysis Range & -- & -- & $0.86-3.38$ & -- & -- \\
\hline & $\begin{array}{c}\text { Matrix Spike Ranges } \\
\text { (Ash from LT 7/28/07 } \\
4 \& 5 \mathrm{~F} 1 \mathrm{~A}, 7 / 31 / 071 \mathrm{~F} 2 \mathrm{~A} \text {, and } \\
8 / 1 / 071 \mathrm{~F} 3 \mathrm{~A}) \\
\end{array}$ & -- & $90.3-96.8$ & -- & -- & -- \\
\hline & PDS Ranges & -- & -- & -- & -- & -- \\
\hline \multirow{7}{*}{$\begin{array}{l}\text { Analysis on } 1 / 31 / 08 \\
\text { Sample Reanalysis } \\
\text { from } 7 / 11 / 07, \\
7 / 28 / 07 \text {, and } 8 / 18 / 07\end{array}$} & DI Water Blank & $<\mathrm{DL}$ & -- & -- & -- & -- \\
\hline & Blank & $<\mathrm{DL}$ & 103.0 & -- & -- & -- \\
\hline & NIST Ash 1633b & -- & -- & -- & 105.7 & -- \\
\hline & Calibration verification & -- & -- & -- & - & $97.7-105.5$ \\
\hline & Replicate Analysis Range & -- & -- & $2.33-3.10$ & -- & -- \\
\hline & $\begin{array}{c}\text { Matrix Spike Ranges } \\
\text { (Ash from LT-7/11/07- } \\
\text { 1F3A, LT-7/28/07-6\&7F3A, } \\
\text { \& LT-8/18/07-4\&5F1A) }\end{array}$ & -- & $102.5-106.8$ & -- & -- & -- \\
\hline & PDS Ranges & -- & -- & -- & -- & -- \\
\hline \multirow{7}{*}{$\begin{array}{l}\text { Analysis on } 1 / 31 / 08 \\
\text { Samples from } 8 / 5 / 07\end{array}$} & DI Water Blank & $<\mathrm{DL}$ & -- & -- & -- & -- \\
\hline & Blank & $<\mathrm{DL}$ & 99.0 & -- & -- & -- \\
\hline & NIST Ash 1633b & -- & -- & -- & 103.5 & -- \\
\hline & Calibration verification & -- & -- & -- & - & 97.9-105.9 \\
\hline & Replicate Analysis Range & -- & -- & $0.17-1.52$ & -- & -- \\
\hline & $\begin{array}{c}\text { Matrix Spike Ranges } \\
\text { (Ash from LT-8/5/07-1F1A) }\end{array}$ & -- & 102.5 & -- & -- & -- \\
\hline & $\begin{array}{c}\text { PDS Ranges (Ash from LT- } \\
8 / 5 / 07-4 \& 5 \mathrm{~F} 1 \mathrm{~A}) \\
\end{array}$ & -- & 107.0 & -- & -- & -- \\
\hline
\end{tabular}

${ }^{15} \mathrm{RPD}=$ Relative Percent Deviation.

${ }^{16} \mathrm{CCV}=$ Continuing calibration verification 


\begin{tabular}{|c|c|c|c|c|c|c|}
\hline \multirow{2}{*}{$\begin{array}{l}\text { Sample Analysis } \\
\text { Batch Date }\end{array}$} & Sample & $\begin{array}{l}\text { Method } \\
\text { Blank }\end{array}$ & MS Recovery & RPD 17 & $\begin{array}{c}\text { Reference } \\
\text { Ash } \\
\text { Recovery }\end{array}$ & CCV 18 \\
\hline & Objective $\rightarrow$ & $<\mathrm{DL}$ & $\begin{array}{c}85-115 \% \text {-detect } \\
75-125 \% \text {-non-detect }\end{array}$ & $<10 \%$ & $85-115 \%$ & $85-115 \%$ \\
\hline \multirow{7}{*}{$\begin{array}{c}\text { Analysis on } 2 / 5 / 08 \\
\text { Samples from } \\
6 / 18 / 07,7 / 9 / 07 \text {, and } \\
7 / 28 / 07\end{array}$} & DI Water Blank & $<\mathrm{DL}$ & $\begin{array}{c}-- \\
\end{array}$ & $-\overline{--}$ & $\begin{array}{c}-- \\
\end{array}$ & 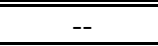 \\
\hline & Blank & $<\mathrm{DL}$ & 101.0 & -- & -- & -- \\
\hline & NIST Ash $1633 \mathrm{~b}$ & -- & -- & -- & 102.8 & -- \\
\hline & Calibration verification & -- & -- & -- & - & $100.6-102.8$ \\
\hline & Replicate Analysis Range & -- & -- & $2.41-5.12$ & -- & -- \\
\hline & $\begin{array}{c}\text { Matrix Spike Ranges } \\
\text { (Ash from BL 6/18/07 } \\
\text { 1F2B, BL 6/18/07 1F3A, LT } \\
\text { 7/9/07 1F1A, and LT } \\
\text { 7/28/07 2F2A) }\end{array}$ & -- & 106.1-117.1 ${ }^{19}$ & -- & -- & -- \\
\hline & PDS Ranges & -- & -- & -- & -- & -- \\
\hline \multirow{7}{*}{$\begin{array}{c}\text { Analysis on } 2 / 11 / 08 \\
\text { Samples from } \\
7 / 28 / 07 \text { and } 8 / 5 / 07\end{array}$} & DI Water Blank & $<\mathrm{DL}$ & -- & -- & -- & -- \\
\hline & Blank & $<\mathrm{DL}$ & 102.0 & -- & -- & -- \\
\hline & NIST Ash 1633b & -- & -- & -- & $105.7-110.6$ & -- \\
\hline & Calibration verification & -- & -- & -- & - & $97.9-101.2$ \\
\hline & Replicate Analysis Range & -- & -- & $1.39-3.94$ & -- & -- \\
\hline & $\begin{array}{c}\text { Matrix Spike Ranges } \\
\text { (Ash from LT-7/28/07- } \\
\text { 3F1A, LT-8/5/07-2F2A, LT- } \\
\text { 8/5/07-3F3A, and LT- } \\
\text { 8/5/07-6\&7F2A) } \\
\end{array}$ & -- & $105.6-112.2$ & -- & -- & -- \\
\hline & PDS Ranges & -- & 98.5 & -- & -- & -- \\
\hline
\end{tabular}

${ }^{17} \mathrm{RPD}=$ Relative Percent Deviation.

${ }^{18} \mathrm{CCV}=$ Continuing calibration verification

${ }^{19}$ Parent sample to spike was not detected; therefore, acceptable criteria is $\pm 25 \%$. 
QA/QC Results for 2009 Testing

Table A-64. QA/QC Results for Mercury Analyses of Ontario Hydro Impinger Solutions $6 / 12 / 09$

\begin{tabular}{|c|c|c|c|c|c|c|c|c|}
\hline \multirow[b]{2}{*}{$\begin{array}{c}\text { QA } \\
\text { Check }\end{array}$} & \multirow[b]{2}{*}{ Sample } & \multirow{2}{*}{$\begin{array}{l}\text { Objective } \\
\text { (KMnO4 } \\
\text { and KCl) }\end{array}$} & \multirow{2}{*}{$\begin{array}{c}\text { Objective } \\
\text { (NI and } \\
\text { PNR) }\end{array}$} & \multicolumn{5}{|c|}{ Ontario Hydro Sample Fractions } \\
\hline & & & & KMnO4 & KCl & $\mathrm{H} 2 \mathrm{O} 2$ & Filter & $\begin{array}{c}\text { PNR/Nitric } \\
\text { Rinse }\end{array}$ \\
\hline $\begin{array}{c}\text { DI Water } \\
\text { Blank } \\
\end{array}$ & All & $<\mathrm{DL}$ & $<\mathrm{DL}$ & $<\mathrm{DL}$ & $<\mathrm{DL}$ & $<\mathrm{DL}$ & $<\mathrm{DL}$ & $<\mathrm{DL}$ \\
\hline $\begin{array}{c}\text { Reagent } \\
\text { Blank }\end{array}$ & All & $<\mathrm{DL}$ & $<\mathrm{DL}$ & $<\mathrm{DL}$ & $<\mathrm{DL}$ & $<\mathrm{DL}$ & $<\mathrm{DL}$ & $<\mathrm{DL}$ \\
\hline $\begin{array}{l}\text { Field } \\
\text { Blank } \\
\end{array}$ & All & $<\mathrm{DL}$ & $<\mathrm{DL}$ & $<\mathrm{DL}$ & $<\mathrm{DL}$ & $<\mathrm{DL}$ & $<\mathrm{DL}$ & $<\mathrm{DL}$ \\
\hline $\begin{array}{c}\text { Lab QC } \\
\text { Standard } \\
\text { Recovery }\end{array}$ & $\begin{array}{c}\text { Treated } \\
\text { and } \\
\text { Untreated }\end{array}$ & $90-110 \%$ & $85-115 \%$ & $98-101 \%$ & $97-99 \%$ & $101-101 \%$ & $97-99 \%$ & $97-114 \%$ \\
\hline $\begin{array}{l}\text { Matrix } \\
\text { Spike }\end{array}$ & Treated & $85-115 \%$ & $85-115 \%$ & $108 \%$ & $104 \%$ & $99-100 \%$ & NA & $111 \%$ \\
\hline $\begin{array}{c}\text { Replicate } \\
\text { Analysis } \\
\text { RPD }\end{array}$ & Treated & $<10 \%$ & $<15 \%$ & $0.1-0.8 \%$ & $0.1-1 \%$ & $0.7-9 \%$ & $\mathrm{NC}$ & $\mathrm{NC}$ \\
\hline $\begin{array}{l}\text { Matrix } \\
\text { Spike }\end{array}$ & Untreated & $85-115 \%$ & $85-115 \%$ & $89-109 \%$ & $97-103 \%$ & $100-105 \%$ & NA & $106-111 \%$ \\
\hline $\begin{array}{c}\text { Replicate } \\
\text { Analysis } \\
\text { RPD }\end{array}$ & Untreated & $<10 \%$ & $<15 \%$ & $0.1-0.3 \%$ & $0-0.6 \%$ & $0.1-0.8 \%$ & $\mathrm{NC}$ & $\mathrm{NC}$ \\
\hline
\end{tabular}


Table A-65. QA/QC Results for Mercury Analyses of Ontario Hydro Impinger Solutions $6 / 18 / 09$

\begin{tabular}{|c|c|c|c|c|c|c|c|c|}
\hline \multirow[b]{2}{*}{$\begin{array}{c}\text { QA } \\
\text { Check }\end{array}$} & \multirow[b]{2}{*}{ Sample } & \multirow{2}{*}{$\begin{array}{l}\text { Objective } \\
\text { (KMnO4 } \\
\text { and } \mathrm{KCl} \text { ) }\end{array}$} & \multirow{2}{*}{$\begin{array}{c}\text { Objective } \\
\text { (NI and } \\
\text { PNR) }\end{array}$} & \multicolumn{5}{|c|}{ Ontario Hydro Sample Fractions } \\
\hline & & & & KMnO4 & $\mathrm{KCl}$ & H2O2 & Filter & $\begin{array}{l}\text { PNR/Nitric } \\
\text { Rinse }\end{array}$ \\
\hline $\begin{array}{c}\text { DI Water } \\
\text { Blank }\end{array}$ & All & $<\mathrm{DL}$ & $<\mathrm{DL}$ & $<\mathrm{DL}$ & $<\mathrm{DL}$ & $<\mathrm{DL}$ & $<\mathrm{DL}$ & $<\mathrm{DL}$ \\
\hline $\begin{array}{c}\text { Reagent } \\
\text { Blank }\end{array}$ & All & $<\mathrm{DL}$ & $<\mathrm{DL}$ & $<\mathrm{DL}$ & $<\mathrm{DL}$ & $<\mathrm{DL}$ & $<\mathrm{DL}$ & $<\mathrm{DL}$ \\
\hline $\begin{array}{l}\text { Field } \\
\text { Blank }\end{array}$ & All & $<\mathrm{DL}$ & $<\mathrm{DL}$ & $<\mathrm{DL}$ & $<\mathrm{DL}$ & $<\mathrm{DL}$ & $<\mathrm{DL}$ & $<\mathrm{DL}$ \\
\hline $\begin{array}{c}\text { Lab QC } \\
\text { Standard } \\
\text { Recovery }\end{array}$ & $\begin{array}{c}\text { Treated } \\
\text { and } \\
\text { Untreated }\end{array}$ & $90-110 \%$ & $85-115 \%$ & $98-101 \%$ & $97-99 \%$ & $101-101 \%$ & $97-99 \%$ & $97-114 \%$ \\
\hline $\begin{array}{l}\text { Matrix } \\
\text { Spike }\end{array}$ & Treated & $85-115 \%$ & $85-115 \%$ & $108 \%$ & $104 \%$ & $99-100 \%$ & NA & $111 \%$ \\
\hline $\begin{array}{c}\text { Replicate } \\
\text { Analysis } \\
\text { RPD }\end{array}$ & Treated & $<10 \%$ & $<15 \%$ & $0.1-0.8 \%$ & $0.1-1 \%$ & $0.7-9 \%$ & $\mathrm{NC}$ & $\mathrm{NC}$ \\
\hline $\begin{array}{c}\text { Matrix } \\
\text { Spike }\end{array}$ & Untreated & $85-115 \%$ & $85-115 \%$ & $89-109 \%$ & $97-103 \%$ & $100-105 \%$ & NA & $106-111 \%$ \\
\hline $\begin{array}{c}\text { Replicate } \\
\text { Analysis } \\
\text { RPD }\end{array}$ & Untreated & $<10 \%$ & $<15 \%$ & $0.1-0.3 \%$ & $0-0.6 \%$ & $0.1-0.8 \%$ & $\mathrm{NC}$ & $\mathrm{NC}$ \\
\hline
\end{tabular}


Table A-66. QA/QC Results for Mercury Analyses of Ontario Hydro Impinger Solutions 7/9/09

\begin{tabular}{|c|c|c|c|c|c|c|c|c|}
\hline \multirow[b]{2}{*}{$\begin{array}{c}\text { QA } \\
\text { Check }\end{array}$} & \multirow[b]{2}{*}{ Sample } & \multirow{2}{*}{$\begin{array}{l}\text { Objective } \\
\text { (KMnO4 } \\
\text { and } \mathrm{KCl} \text { ) }\end{array}$} & \multirow{2}{*}{$\begin{array}{c}\text { Objective } \\
\text { (NI and } \\
\text { PNR) }\end{array}$} & \multicolumn{5}{|c|}{ Ontario Hydro Sample Fractions } \\
\hline & & & & KMnO4 & KCl & $\mathrm{H} 2 \mathrm{O2}$ & Filter & $\begin{array}{l}\text { PNR/Nitric } \\
\text { Rinse }\end{array}$ \\
\hline $\begin{array}{c}\text { DI Water } \\
\text { Blank }\end{array}$ & All & $<\mathrm{DL}$ & $<\mathrm{DL}$ & $<\mathrm{DL}$ & $<\mathrm{DL}$ & $<\mathrm{DL}$ & $<\mathrm{DL}$ & $<\mathrm{DL}$ \\
\hline $\begin{array}{c}\text { Reagent } \\
\text { Blank }\end{array}$ & All & $<\mathrm{DL}$ & $<\mathrm{DL}$ & $<\mathrm{DL}$ & $<\mathrm{DL}$ & $<\mathrm{DL}$ & $<\mathrm{DL}$ & $<\mathrm{DL}$ \\
\hline $\begin{array}{l}\text { Field } \\
\text { Blank }\end{array}$ & All & $<\mathrm{DL}$ & $<\mathrm{DL}$ & $<\mathrm{DL}$ & $<\mathrm{DL}$ & $<\mathrm{DL}$ & $<\mathrm{DL}$ & $<\mathrm{DL}$ \\
\hline $\begin{array}{c}\text { Lab QC } \\
\text { Standard } \\
\text { Recovery }\end{array}$ & $\begin{array}{c}\text { Treated } \\
\text { and } \\
\text { Untreated }\end{array}$ & $90-110 \%$ & $85-115 \%$ & $98-101 \%$ & $97-99 \%$ & $101-101 \%$ & $97-99 \%$ & $97-114 \%$ \\
\hline $\begin{array}{l}\text { Matrix } \\
\text { Spike }\end{array}$ & Treated & $85-115 \%$ & $85-115 \%$ & $108 \%$ & $104 \%$ & $99-100 \%$ & NA & $111 \%$ \\
\hline $\begin{array}{c}\text { Replicate } \\
\text { Analysis } \\
\text { RPD }\end{array}$ & Treated & $<10 \%$ & $<15 \%$ & $0.1-0.8 \%$ & $0.1-1 \%$ & $0.7-9 \%$ & $\mathrm{NC}$ & $\mathrm{NC}$ \\
\hline $\begin{array}{c}\text { Matrix } \\
\text { Spike }\end{array}$ & Untreated & $85-115 \%$ & $85-115 \%$ & $89-109 \%$ & $97-103 \%$ & $100-105 \%$ & NA & $106-111 \%$ \\
\hline $\begin{array}{c}\text { Replicate } \\
\text { Analysis } \\
\text { RPD }\end{array}$ & Untreated & $<10 \%$ & $<15 \%$ & $0.1-0.3 \%$ & $0-0.6 \%$ & $0.1-0.8 \%$ & $\mathrm{NC}$ & $\mathrm{NC}$ \\
\hline
\end{tabular}


Table A-67. QA/QC Results for Mercury Analyses of Ontario Hydro Impinger Solutions 7/10/09

\begin{tabular}{|c|c|c|c|c|c|c|c|c|}
\hline \multirow[b]{2}{*}{$\begin{array}{c}\text { QA } \\
\text { Check }\end{array}$} & \multirow[b]{2}{*}{ Sample } & \multirow{2}{*}{$\begin{array}{l}\text { Objective } \\
\text { (KMnO4 } \\
\text { and } \mathrm{KCl} \text { ) }\end{array}$} & \multirow{2}{*}{$\begin{array}{c}\text { Objective } \\
\text { (NI and } \\
\text { PNR) }\end{array}$} & \multicolumn{5}{|c|}{ Ontario Hydro Sample Fractions } \\
\hline & & & & KMnO4 & $\mathrm{KCl}$ & H2O2 & Filter & $\begin{array}{c}\text { PNR/Nitric } \\
\text { Rinse }\end{array}$ \\
\hline $\begin{array}{c}\text { DI Water } \\
\text { Blank }\end{array}$ & All & $<\mathrm{DL}$ & $<\mathrm{DL}$ & $<\mathrm{DL}$ & $<\mathrm{DL}$ & $<\mathrm{DL}$ & $<\mathrm{DL}$ & $<\mathrm{DL}$ \\
\hline $\begin{array}{c}\text { Reagent } \\
\text { Blank }\end{array}$ & All & $<\mathrm{DL}$ & $<\mathrm{DL}$ & $<\mathrm{DL}$ & $<\mathrm{DL}$ & $<\mathrm{DL}$ & $<\mathrm{DL}$ & $<\mathrm{DL}$ \\
\hline $\begin{array}{l}\text { Field } \\
\text { Blank }\end{array}$ & All & $<\mathrm{DL}$ & $<\mathrm{DL}$ & $<\mathrm{DL}$ & $<\mathrm{DL}$ & $<\mathrm{DL}$ & $<\mathrm{DL}$ & $<\mathrm{DL}$ \\
\hline $\begin{array}{l}\text { Lab QC } \\
\text { Standard } \\
\text { Recovery }\end{array}$ & $\begin{array}{c}\text { Treated } \\
\text { and } \\
\text { Untreated }\end{array}$ & $90-110 \%$ & $85-115 \%$ & $98-101 \%$ & $97-99 \%$ & $101-101 \%$ & $97-99 \%$ & $97-114 \%$ \\
\hline $\begin{array}{l}\text { Matrix } \\
\text { Spike }\end{array}$ & Treated & $85-115 \%$ & $85-115 \%$ & $108 \%$ & $104 \%$ & $99-100 \%$ & NA & $111 \%$ \\
\hline $\begin{array}{c}\text { Replicate } \\
\text { Analysis } \\
\text { RPD }\end{array}$ & Treated & $<10 \%$ & $<15 \%$ & $0.1-0.8 \%$ & $0.1-1 \%$ & $0.7-9 \%$ & $\mathrm{NC}$ & $\mathrm{NC}$ \\
\hline $\begin{array}{c}\text { Matrix } \\
\text { Spike }\end{array}$ & Untreated & $85-115 \%$ & $85-115 \%$ & $89-109 \%$ & $97-103 \%$ & $100-105 \%$ & NA & $106-111 \%$ \\
\hline $\begin{array}{c}\text { Replicate } \\
\text { Analysis } \\
\text { RPD }\end{array}$ & Untreated & $<10 \%$ & $<15 \%$ & $0.1-0.3 \%$ & $0-0.6 \%$ & $0.1-0.8 \%$ & $\mathrm{NC}$ & $\mathrm{NC}$ \\
\hline
\end{tabular}


Table A-68. QA/QC Results for Mercury Analyses of Ontario Hydro Impinger Solutions $7 / 11 / 09$

\begin{tabular}{|c|c|c|c|c|c|c|c|c|}
\hline \multirow[b]{2}{*}{$\begin{array}{c}\text { QA } \\
\text { Check }\end{array}$} & \multirow[b]{2}{*}{ Sample } & \multirow{2}{*}{$\begin{array}{l}\text { Objective } \\
\text { (KMnO4 } \\
\text { and } \mathrm{KCl} \text { ) }\end{array}$} & \multirow{2}{*}{$\begin{array}{c}\text { Objective } \\
\text { (NI and } \\
\text { PNR) }\end{array}$} & \multicolumn{5}{|c|}{ Ontario Hydro Sample Fractions } \\
\hline & & & & KMnO4 & $\mathrm{KCl}$ & H2O2 & Filter & $\begin{array}{l}\text { PNR/Nitric } \\
\text { Rinse }\end{array}$ \\
\hline $\begin{array}{c}\text { DI Water } \\
\text { Blank }\end{array}$ & All & $<\mathrm{DL}$ & $<\mathrm{DL}$ & $<\mathrm{DL}$ & $<\mathrm{DL}$ & $<\mathrm{DL}$ & $<\mathrm{DL}$ & $<\mathrm{DL}$ \\
\hline $\begin{array}{c}\text { Reagent } \\
\text { Blank }\end{array}$ & All & $<\mathrm{DL}$ & $<\mathrm{DL}$ & $<\mathrm{DL}$ & $<\mathrm{DL}$ & $<\mathrm{DL}$ & $<\mathrm{DL}$ & $<\mathrm{DL}$ \\
\hline $\begin{array}{l}\text { Field } \\
\text { Blank }\end{array}$ & All & $<\mathrm{DL}$ & $<\mathrm{DL}$ & $<\mathrm{DL}$ & $<\mathrm{DL}$ & $<\mathrm{DL}$ & $<\mathrm{DL}$ & $<\mathrm{DL}$ \\
\hline $\begin{array}{c}\text { Lab QC } \\
\text { Standard } \\
\text { Recovery }\end{array}$ & $\begin{array}{c}\text { Treated } \\
\text { and } \\
\text { Untreated }\end{array}$ & $90-110 \%$ & $85-115 \%$ & $98-101 \%$ & $97-99 \%$ & $101-101 \%$ & $97-99 \%$ & $97-114 \%$ \\
\hline $\begin{array}{l}\text { Matrix } \\
\text { Spike }\end{array}$ & Treated & $85-115 \%$ & $85-115 \%$ & $108 \%$ & $104 \%$ & $99-100 \%$ & NA & $111 \%$ \\
\hline $\begin{array}{c}\text { Replicate } \\
\text { Analysis } \\
\text { RPD }\end{array}$ & Treated & $<10 \%$ & $<15 \%$ & $0.1-0.8 \%$ & $0.1-1 \%$ & $0.7-9 \%$ & $\mathrm{NC}$ & $\mathrm{NC}$ \\
\hline $\begin{array}{c}\text { Matrix } \\
\text { Spike }\end{array}$ & Untreated & $85-115 \%$ & $85-115 \%$ & $89-109 \%$ & $97-103 \%$ & $100-105 \%$ & NA & $106-111 \%$ \\
\hline $\begin{array}{c}\text { Replicate } \\
\text { Analysis } \\
\text { RPD }\end{array}$ & Untreated & $<10 \%$ & $<15 \%$ & $0.1-0.3 \%$ & $0-0.6 \%$ & $0.1-0.8 \%$ & $\mathrm{NC}$ & $\mathrm{NC}$ \\
\hline
\end{tabular}


Table A-69. QA/QC Results for Mercury Analyses of Coal Samples

\begin{tabular}{|c|c|c|c|c|c|c|c|}
\hline Description & $\begin{array}{l}\text { Coal } \\
\text { type }\end{array}$ & $\begin{array}{c}\mathrm{Hg} \\
(\mathrm{ppm})\end{array}$ & $\begin{array}{c}\mathbf{H g} \\
(\mathrm{ppm})\end{array}$ & $\%$ RPD & $\begin{array}{c}\text { ASTM } \\
\text { Reproducibility } \\
\text { Limit }\end{array}$ & $\begin{array}{c}\text { Absolute } \\
\text { Difference }\end{array}$ & Fail? \\
\hline \multicolumn{4}{|c|}{ Objective $\rightarrow$} & $<25 \%$ & & & Pass \\
\hline $6 / 12 / 2009$ & PRB & 0.170 & 0.178 & 4.62 & 0.0184 & 0.0080 & Pass \\
\hline $6 / 12 / 2009$ & Lignite & 0.184 & 0.194 & 4.98 & 0.0193 & 0.0094 & Pass \\
\hline $6 / 15 / 2009$ & Lignite & 0.146 & 0.157 & 7.02 & 0.0171 & 0.0106 & Pass \\
\hline $6 / 15 / 2009$ & PRB & 0.165 & 0.171 & 3.69 & 0.0181 & 0.0062 & Pass \\
\hline $6 / 18 / 2009$ & Lignite & 0.435 & 0.406 & 6.94 & 0.0332 & 0.0292 & Pass \\
\hline $6 / 18 / 2009$ & PRB & 0.123 & 0.135 & 9.23 & 0.0158 & 0.0119 & Pass \\
\hline $6 / 25 / 2009$ & PRB & 0.255 & 0.266 & 4.29 & 0.0236 & 0.0112 & Pass \\
\hline $6 / 25 / 2009$ & Lignite & 0.722 & 0.695 & 3.85 & 0.0505 & 0.0273 & Pass \\
\hline $6 / 28 / 2009$ & PRB & 0.835 & 0.861 & 3.00 & 0.0589 & 0.0255 & Pass \\
\hline $6 / 28 / 2009$ & Lignite & 0.201 & 0.199 & 0.66 & 0.0200 & 0.0013 & Pass \\
\hline $7 / 10 / 2009$ & PRB & 0.090 & 0.095 & 5.13 & 0.0135 & 0.0047 & Pass \\
\hline $7 / 10 / 2009$ & Lignite & 0.287 & 0.284 & 0.95 & 0.0251 & 0.0027 & Pass \\
\hline $7 / 12 / 2009$ & PRB & 0.068 & 0.058 & 14.74 & 0.0118 & 0.0093 & Pass \\
\hline $7 / 12 / 2009$ & Lignite & 0.247 & 0.254 & 2.62 & 0.0230 & 0.0066 & Pass \\
\hline $7 / 13 / 2009$ & Lignite & 0.359 & 0.342 & 4.95 & 0.0290 & 0.0173 & Pass \\
\hline $7 / 13 / 2009$ & PRB & 0.105 & 0.104 & 1.26 & 0.0143 & 0.0013 & Pass \\
\hline $7 / 14 / 2009$ & Lignite & 0.313 & 0.332 & 5.96 & 0.0274 & 0.0192 & Pass \\
\hline $7 / 14 / 2009$ & PRB & 0.076 & 0.067 & 13.08 & 0.0123 & 0.0093 & Pass \\
\hline $7 / 16 / 2009$ & Lignite & 0.572 & 0.598 & 4.48 & 0.0431 & 0.0262 & Pass \\
\hline $7 / 16 / 2009$ & PRB & 0.073 & 0.068 & 7.55 & 0.0122 & 0.0053 & Pass \\
\hline $7 / 18 / 2009$ & Lignite & 0.253 & 0.247 & 2.68 & 0.0230 & 0.0067 & Pass \\
\hline $7 / 18 / 2009$ & PRB & 0.083 & 0.091 & 9.23 & 0.0132 & 0.0080 & Pass \\
\hline
\end{tabular}

Table A-70. QA/QC Results for Mercury Analyses of Ash Samples 


\begin{tabular}{|c|c|c|c|c|c|c|}
\hline \multirow{2}{*}{$\begin{array}{l}\text { Sample Analysis } \\
\text { Batch Date }\end{array}$} & Sample & $\begin{array}{l}\text { Method } \\
\text { Blank }\end{array}$ & MS Recovery & RPD $^{20}$ & $\begin{array}{l}\text { Reference } \\
\text { Ash } \\
\text { Recovery }\end{array}$ & $\mathrm{CCV}^{21}$ \\
\hline & Objective $\rightarrow$ & $<\mathrm{DL}$ & $\begin{array}{c}85-115 \% \text {-detect } \\
75-125 \% \text {-non-detect }\end{array}$ & $<10 \%$ & $85-115 \%$ & $85-115 \%$ \\
\hline \multirow{7}{*}{$\begin{array}{c}\text { Analysis on } \\
7 / 31 / 09 ; \text { samples } \\
\text { from } 6 / 11-6 / 14 / 09\end{array}$} & DI Water Blank & $<\mathrm{DL}$ & 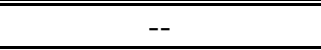 & 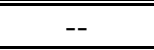 & $\overline{-1-}$ & $-\overline{--}$ \\
\hline & Blank & $<\mathrm{DL}$ & 106 & -- & -- & -- \\
\hline & NIST Ash $1633 b^{22,23}$ & -- & -- & -- & 122 & -- \\
\hline & Calibration verification & -- & -- & -- & -- & $100.5-102.5$ \\
\hline & Replicate Analysis Range & -- & -- & $0-5.5$ & -- & -- \\
\hline & $\begin{array}{c}\text { Matrix Spike }{ }^{24} \text { Ranges } \\
\text { (Ash from 6/11/09 2F2C, } \\
\text { 6/13/09 2F11D, and } \\
\text { 6/14/09 2F11D) } \\
\end{array}$ & -- & 103-109 & -- & -- & -- \\
\hline & PDS ${ }^{25}$ Ranges & -- & -- & -- & -- & -- \\
\hline \multirow{7}{*}{$\begin{array}{c}\text { Analysis on } \\
8 / 5 / 09 ; \text { samples } \\
\text { from } 6 / 15 / 09 \text { and } \\
6 / 16 / 09\end{array}$} & DI Water Blank & $<\mathrm{DL}$ & -- & -- & -- & -- \\
\hline & Blank & $<\mathrm{DL}$ & 104 & -- & -- & -- \\
\hline & NIST Ash 1633b & -- & -- & -- & 107 & -- \\
\hline & Calibration verification & -- & -- & -- & -- & $99.1-100.9$ \\
\hline & Replicate Analysis Range & -- & -- & $0.68-0.69$ & -- & -- \\
\hline & $\begin{array}{c}\text { Matrix Spike Ranges } \\
\text { (Ash from 6/15/09 2F3D } \\
\text { and 6/16/09 2F11D) }\end{array}$ & -- & $91.6-95.8$ & -- & -- & -- \\
\hline & PDS Ranges & -- & -- & -- & -- & -- \\
\hline \multirow{7}{*}{$\begin{array}{c}\text { Analysis on } \\
8 / 5 / 09 ; \text { samples } \\
\text { from } 6 / 21-6 / 25 / 09 \\
\text { and } 6 / 28 / 09\end{array}$} & DI Water Blank & $<\mathrm{DL}$ & -- & -- & -- & -- \\
\hline & Blank & $<\mathrm{DL}$ & 101 & -- & -- & -- \\
\hline & NIST Ash 1633b & -- & -- & -- & 106 & -- \\
\hline & Calibration verification & -- & -- & -- & -- & $99.6-101.2$ \\
\hline & Replicate Analysis Range & -- & -- & $0-2.7$ & -- & -- \\
\hline & $\begin{array}{c}\text { Matrix Spike Ranges } \\
\text { (Ash 6/21/09 2F14C, } \\
\text { 6/22/09 2F11C, 6/23/09 } \\
\text { 2F2C, 6/24/09 2F11C; } \\
\text { 6/25/09 2F2C; 6/28/09 } \\
\text { 2F14C) } \\
\end{array}$ & -- & $96-104.9$ & -- & -- & -- \\
\hline & PDS Ranges & -- & -- & -- & -- & -- \\
\hline \multirow{6}{*}{$\begin{array}{c}\text { Analyzed } 8 / 6 / 09 ; \\
\text { samples from } \\
6 / 15 / 09 \text { and } 7 / 8- \\
7 / 12 / 09\end{array}$} & DI Water Blank & $<\mathrm{DL}$ & -- & -- & -- & -- \\
\hline & Blank & $<\mathrm{DL}$ & 102 & -- & -- & -- \\
\hline & NIST Ash 1633b & -- & -- & -- & 109 & -- \\
\hline & Calibration verification & -- & -- & -- & -- & $99.3-101.2$ \\
\hline & Replicate Analysis Range & -- & -- & $0.27-4.41$ & -- & -- \\
\hline & $\begin{array}{c}\text { Matrix Spike Ranges } \\
\text { (Ash from 7/8/09 2F2C, } \\
\text { 7/9/09 2F2C, 7/10/09 } \\
\text { 2F11C, and 7/12/09 } \\
\text { 2F2C) }\end{array}$ & -- & $94.7-107.8$ & -- & -- & -- \\
\hline
\end{tabular}

${ }^{20} \mathrm{RPD}=$ Relative Percent Deviation.

${ }^{21} \mathrm{CCV}=$ Continuing calibration verification

${ }^{22}$ NIST $=$ National Institute of Standards and Technology.

${ }^{23}$ NIST Ash $1633 \mathrm{~b}$ has an uncertified mercury value of $0.141 \mu \mathrm{g} / \mathrm{g}$.

${ }^{24}$ Matrix spikes, spikes that have been digested along with the sample.

${ }^{25}$ PDS $=$ Post Digestion Spike. 


\begin{tabular}{|c|c|c|c|c|c|c|}
\hline \multirow{3}{*}{$\begin{array}{l}\text { Sample Analysis } \\
\text { Batch Date }\end{array}$} & Sample & $\begin{array}{l}\text { Method } \\
\text { Blank }\end{array}$ & MS Recovery & RPD $^{20}$ & $\begin{array}{c}\text { Reference } \\
\text { Ash } \\
\text { Recovery }\end{array}$ & $\mathrm{CCV}^{21}$ \\
\hline & Objective $\rightarrow$ & $<$ DL & $\begin{array}{c}85-115 \% \text {-detect } \\
75-125 \% \text {-non-detect }\end{array}$ & $<10 \%$ & $85-115 \%$ & $85-115 \%$ \\
\hline & $\begin{array}{l}\text { PDS Ranges (Ash from } \\
6 / 15 / 09 \quad 2 \mathrm{~F} 11 \mathrm{C})\end{array}$ & -- & 92.8 & -- & -- & -- \\
\hline \multirow{7}{*}{$\begin{array}{c}\text { Analyzed 8/12/09; } \\
\text { samples from } \\
6 / 17-6 / 18 / 09 \text { and } \\
7 / 8 / 09\end{array}$} & DI Water Blank & $<\mathrm{DL}$ & -- & -- & -- & -- \\
\hline & Blank & $<\mathrm{DL}$ & 98 & -- & -- & -- \\
\hline & NIST Ash 1633b & -- & -- & -- & 105 & -- \\
\hline & Calibration verification & -- & -- & -- & -- & $95.7-97.2$ \\
\hline & Replicate Analysis Range & -- & -- & $0.15-0.84$ & -- & -- \\
\hline & $\begin{array}{c}\text { Matrix Spike Ranges } \\
\text { (Ash from 6/17/09 2F2D, } \\
6 / 17 / 09 \text { 2F11C, 6/18/09 } \\
\text { 2F3D, and 7/8/09 2F2C) }\end{array}$ & -- & $93.1-97.4$ & -- & -- & -- \\
\hline & PDS Ranges & -- & -- & -- & -- & -- \\
\hline \multirow{7}{*}{$\begin{array}{c}\text { Analyzed } 8 / 19 / 09 ; \\
\text { samples from } \\
7 / 12 / 09,7 / 14- \\
7 / 15 / 09 \text {, and } 7 / 22- \\
7 / 23 / 09\end{array}$} & DI Water Blank & $<\mathrm{DL}$ & -- & -- & -- & -- \\
\hline & Blank & $<\mathrm{DL}$ & 102 & -- & -- & -- \\
\hline & NIST Ash 1633b & -- & -- & -- & 106 & -- \\
\hline & Calibration verification & -- & -- & -- & -- & $99-100.1$ \\
\hline & Replicate Analysis Range & -- & -- & $0.19-1.58$ & -- & -- \\
\hline & $\begin{array}{c}\text { Matrix Spike Ranges } \\
\text { (Ash from 7/12/09 } \\
\text { 2F11C, 7/14/09 2F14C, } \\
\text { 7/15/09 2F2C, and } \\
\text { 7/23/09 2F1C) } \\
\end{array}$ & -- & $93.2-98.3$ & -- & -- & -- \\
\hline & PDS Ranges & -- & -- & -- & -- & -- \\
\hline
\end{tabular}


Table A-71. QA/QC Results for Mercury Analysis on ESP Outlet Appendix K Sorbent Tubes

\begin{tabular}{|c|c|c|c|c|c|}
\hline Date & Start Time & Stop Time & $\begin{array}{c}\text { Spiked Bed } \\
\text { Recovery (\%) }\end{array}$ & $\begin{array}{c}\text { Breakthrough } \\
\text { to Bed } 2 \\
(\%)\end{array}$ & $\begin{array}{c}\text { Relative } \\
\text { Deviation } \\
\text { Between } \\
\text { Tubes (\%) }\end{array}$ \\
\hline $6 / 11 / 2009$ & $9: 16: 44$ & $17: 16: 55$ & N/A & 0.5 & N/A \\
\hline $6 / 11 / 2009$ & $17: 42: 59$ & $01: 43: 13$ & $123.3 \%$ & 0.2 & N/A \\
\hline $6 / 12 / 2009$ & $8: 55: 20$ & $16: 55: 39$ & N/A & 0.5 & N/A \\
\hline $6 / 12 / 2009$ & $17: 24: 32$ & $01: 24: 54$ & N/A & 0.4 & N/A \\
\hline $6 / 13 / 2009$ & $10: 52: 52$ & $16: 53: 43$ & N/A & 1.6 & \multirow{2}{*}{$2.2 \%$} \\
\hline $6 / 13 / 2009$ & $10: 52: 52$ & $16: 53: 43$ & $109.3 \%$ & 0.5 & \\
\hline $6 / 13 / 2009$ & $17: 21: 45$ & 01:22:01 & N/A & 1.0 & \multirow{2}{*}{$2.3 \%$} \\
\hline $6 / 13 / 2009$ & $17: 21: 45$ & 01:22:01 & $114.6 \%$ & 0.0 & \\
\hline $6 / 14 / 2009$ & $7: 57: 26$ & $15: 07: 03$ & N/A & 1.0 & N/A \\
\hline $6 / 14 / 2009$ & $15: 25: 43$ & $23: 26: 03$ & $103.9 \%$ & 0.0 & N/A \\
\hline $6 / 15 / 2009$ & 8:53:37 & $16: 53: 54$ & N/A & 0.4 & N/A \\
\hline $6 / 15 / 2009$ & $18: 00: 52$ & 02:01:12 & N/A & 0.6 & N/A \\
\hline $6 / 16 / 2009$ & $7: 53: 55$ & $15: 54: 17$ & $119.5 \%$ & 0.0 & N/A \\
\hline $6 / 16 / 2009$ & $17: 58: 30$ & $22: 58: 42$ & N/A & 0.5 & N/A \\
\hline $6 / 17 / 2009$ & $7: 52: 52$ & $15: 45: 48$ & N/A & 0.8 & N/A \\
\hline $6 / 17 / 2009$ & $16: 15: 00$ & $00: 15: 23$ & $115.3 \%$ & 0.0 & N/A \\
\hline $6 / 18 / 2009$ & 7:53:38 & $15: 54: 00$ & N/A & 1.2 & N/A \\
\hline $6 / 21 / 2009$ & $8: 42: 27$ & $16: 42: 44$ & $112.6 \%$ & 0.2 & N/A \\
\hline $6 / 21 / 2009$ & $17: 31: 21$ & 01:31:42 & N/A & 0.4 & N/A \\
\hline $6 / 22 / 2009$ & 11:57:05 & $14: 57: 14$ & $95.9 \%$ & 0.0 & N/A \\
\hline $6 / 22 / 2009$ & $15: 44: 08$ & $19: 44: 20$ & N/A & 1.3 & N/A \\
\hline $6 / 23 / 2009$ & 11:15:03 & $15: 15: 11$ & $85.3 \%$ & 0.9 & N/A \\
\hline
\end{tabular}




\begin{tabular}{|c|c|c|c|c|c|}
\hline Date & Start Time & Stop Time & $\begin{array}{c}\text { Spiked Bed } \\
\text { Recovery (\%) }\end{array}$ & $\begin{array}{c}\text { Breakthrough } \\
\text { to Bed } 2 \\
\text { (\%) }\end{array}$ & $\begin{array}{c}\text { Relative } \\
\text { Deviation } \\
\text { Between } \\
\text { Tubes (\%) }\end{array}$ \\
\hline $6 / 23 / 2009$ & 15:59:11 & $19: 59: 23$ & N/A & 1.0 & N/A \\
\hline $6 / 24 / 2009$ & $10: 42: 02$ & $13: 42: 12$ & N/A & 1.7 & N/A \\
\hline $6 / 24 / 2009$ & $14: 18: 00$ & 16:18:05 & N/A & 4.4 & N/A \\
\hline $6 / 26 / 2009$ & 9:42:00 & $12: 42: 06$ & N/A & 1.7 & N/A \\
\hline $6 / 26 / 2009$ & $13: 58: 20$ & $18: 58: 29$ & $118.2 \%$ & 0.0 & N/A \\
\hline $6 / 27 / 2009$ & 11:58:47 & 16:29:01 & N/A & 1.9 & N/A \\
\hline $6 / 27 / 2009$ & 17:11:08 & $20: 11: 14$ & $89.7 \%$ & 0.0 & N/A \\
\hline $6 / 28 / 2009$ & 9:59:34 & $12: 59: 40$ & N/A & 9.4 & N/A \\
\hline $6 / 28 / 2009$ & $13: 24: 50$ & $15: 54: 55$ & $115.7 \%$ & 0.0 & N/A \\
\hline $7 / 8 / 2009$ & 11:30:03 & 14:30:07 & $121.7 \%$ & 0.4 & N/A \\
\hline 7/8/2009 & $16: 15: 15$ & 17:09:48 & N/A & 17.5 & N/A \\
\hline 7/9/2009 & $11: 55: 22$ & $14: 55: 29$ & $114.5 \%$ & 0.0 & N/A \\
\hline 7/10/2009 & 8:49:08 & $11: 49: 14$ & $112.8 \%$ & 0.0 & N/A \\
\hline 7/10/2009 & $14: 20: 19$ & $16: 40: 16$ & N/A & 4.5 & N/A \\
\hline $7 / 11 / 2009$ & 9:10:02 & $11: 35: 39$ & $123.7 \%$ & 1.1 & N/A \\
\hline $7 / 11 / 2009$ & 14:00:44 & $16: 03: 32$ & N/A & 4.3 & N/A \\
\hline $7 / 12 / 2009$ & 8:14:59 & $11: 15: 07$ & $108.2 \%$ & 0.0 & N/A \\
\hline $7 / 12 / 2009$ & $12: 56: 12$ & $15: 36: 20$ & N/A & 2.6 & N/A \\
\hline $7 / 13 / 2009$ & 7:55:05 & $10: 55: 14$ & $109.7 \%$ & 0.0 & N/A \\
\hline $7 / 14 / 2009$ & $7: 37: 16$ & $10: 37: 25$ & $109.3 \%$ & 0.0 & N/A \\
\hline $7 / 14 / 2009$ & $13: 33: 54$ & $16: 34: 03$ & N/A & 2.5 & N/A \\
\hline $7 / 15 / 2009$ & 9:48:06 & $12: 48: 15$ & $114.8 \%$ & 1.2 & N/A \\
\hline $7 / 15 / 2009$ & $13: 26: 39$ & $16: 24: 55$ & N/A & 2.5 & N/A \\
\hline $7 / 16 / 2009$ & 9:50:00 & $12: 50: 10$ & $105.3 \%$ & 1.2 & N/A \\
\hline
\end{tabular}




\begin{tabular}{|c|c|c|c|c|c|}
\hline Date & Start Time & Stop Time & $\begin{array}{l}\text { Spiked Bed } \\
\text { Recovery (\%) }\end{array}$ & $\begin{array}{c}\text { Breakthrough } \\
\text { to Bed } 2 \\
(\%)\end{array}$ & $\begin{array}{c}\text { Relative } \\
\text { Deviation } \\
\text { Between } \\
\text { Tubes (\%) }\end{array}$ \\
\hline $7 / 16 / 2009$ & $13: 18: 32$ & $16: 18: 43$ & N/A & 0.0 & N/A \\
\hline $7 / 21 / 2009$ & $11: 29: 44$ & 13:09:03 & N/A & 1.9 & $-3.9 \%$ \\
\hline $7 / 21 / 2009$ & 14:10:02 & $15: 49: 17$ & $106.1 \%$ & 0.0 & \multirow{2}{*}{$1.4 \%$} \\
\hline $7 / 21 / 2009$ & 14:10:02 & $15: 49: 17$ & N/A & 3.0 & \\
\hline $7 / 22 / 2009$ & 10:54:06 & $12: 36: 06$ & N/A & 0.0 & \multirow{2}{*}{$-0.1 \%$} \\
\hline $7 / 22 / 2009$ & 10:54:06 & 12:36:06 & $104.7 \%$ & 3.3 & \\
\hline $7 / 22 / 2009$ & $13: 15: 08$ & $14: 53: 05$ & N/A & 0.0 & \multirow{2}{*}{$0.1 \%$} \\
\hline $7 / 22 / 2009$ & $13: 15: 08$ & $14: 53: 05$ & $106.7 \%$ & 0.0 & \\
\hline $7 / 22 / 2009$ & $15: 31: 59$ & 17:09:03 & N/A & 0.0 & \multirow{2}{*}{$1.0 \%$} \\
\hline $7 / 22 / 2009$ & $15: 31: 59$ & 17:09:03 & $106.4 \%$ & 1.9 & \\
\hline $7 / 23 / 2009$ & $11: 23: 56$ & $12: 58: 15$ & $119.4 \%$ & 0.0 & \multirow{2}{*}{$-1.6 \%$} \\
\hline $7 / 23 / 2009$ & $11: 23: 56$ & $12: 58: 15$ & N/A & 1.4 & \\
\hline $7 / 23 / 2009$ & $13: 40: 06$ & $15: 14: 03$ & $110.8 \%$ & 0.0 & \multirow{2}{*}{$1.7 \%$} \\
\hline $7 / 23 / 2009$ & 13:40:06 & $15: 14: 03$ & N/A & 1.9 & \\
\hline $7 / 23 / 2009$ & $15: 58: 56$ & $17: 33: 02$ & N/A & 2.5 & \multirow{2}{*}{$0.0 \%$} \\
\hline $7 / 23 / 2009$ & 15:58:56 & $17: 33: 02$ & N/A & 2.2 & \\
\hline
\end{tabular}


Table A-72. QA/QC Results for Mercury Analysis on Stack Appendix K Sorbent Tube

\begin{tabular}{|c|c|c|c|c|c|}
\hline Date & Start Time & Stop Time & $\begin{array}{c}\text { Spiked Bed } \\
\text { Recovery (\%) }\end{array}$ & $\begin{array}{l}\text { Breakthrough } \\
\text { to Bed 2(\%) }\end{array}$ & $\begin{array}{c}\text { Relative } \\
\text { Deviation } \\
\text { Between } \\
\text { Tubes (\%) }\end{array}$ \\
\hline $6 / 11 / 2009$ & 9:16:02 & $17: 16: 25$ & N/A & 0.7 & N/A \\
\hline $6 / 11 / 2009$ & $17: 31: 16$ & $01: 31: 40$ & $116.0 \%$ & 0.6 & N/A \\
\hline $6 / 12 / 2009$ & $8: 10: 39$ & $16: 04: 38$ & N/A & 0.4 & N/A \\
\hline $6 / 12 / 2009$ & $16: 22: 06$ & $00: 22: 32$ & $112.4 \%$ & 0.0 & N/A \\
\hline $6 / 13 / 2009$ & $11: 39: 37$ & $17: 47: 16$ & N/A & 1.5 & \multirow{2}{*}{$0.8 \%$} \\
\hline $6 / 13 / 2009$ & $11: 39: 37$ & $17: 47: 16$ & $115.6 \%$ & 0.0 & \\
\hline $6 / 13 / 2009$ & 18:00:12 & 02:00:36 & N/A & 2.1 & \multirow{2}{*}{$0.2 \%$} \\
\hline $6 / 13 / 2009$ & 18:00:12 & 02:00:36 & $116.4 \%$ & 0.0 & \\
\hline $6 / 14 / 2009$ & $8: 57: 20$ & $16: 01: 52$ & N/A & 2.0 & N/A \\
\hline $6 / 14 / 2009$ & $16: 20: 04$ & 00:20:29 & N/A & 0.9 & \multirow{2}{*}{$0.5 \%$} \\
\hline $6 / 14 / 2009$ & $16: 20: 04$ & $00: 20: 29$ & $114.3 \%$ & 0.0 & \\
\hline $6 / 15 / 2009$ & $10: 21: 19$ & $16: 30: 22$ & N/A & 1.4 & N/A \\
\hline $6 / 15 / 2009$ & $17: 23: 57$ & $01: 24: 23$ & $106.0 \%$ & 0.0 & N/A \\
\hline $6 / 16 / 2009$ & 9:12:50 & $17: 13: 17$ & N/A & 0.6 & N/A \\
\hline $6 / 16 / 2009$ & 19:01:46 & 00:02:03 & N/A & 0.6 & N/A \\
\hline $6 / 17 / 2009$ & 9:17:09 & $17: 17: 35$ & N/A & 2.3 & N/A \\
\hline $6 / 17 / 2009$ & 18:06:56 & 02:07:22 & $106.7 \%$ & 0.0 & N/A \\
\hline $6 / 18 / 2009$ & $8: 55: 17$ & $16: 55: 43$ & N/A & 0.8 & N/A \\
\hline $6 / 21 / 2009$ & 9:48:00 & $17: 48: 27$ & $105.1 \%$ & 0.0 & N/A \\
\hline $6 / 21 / 2009$ & $18: 52: 33$ & 02:53:00 & N/A & 0.9 & N/A \\
\hline $6 / 22 / 2009$ & $11: 56: 32$ & $14: 56: 41$ & $88.3 \%$ & 0.0 & N/A \\
\hline $6 / 22 / 2009$ & $15: 44: 24$ & $19: 42: 40$ & N/A & 1.6 & N/A \\
\hline
\end{tabular}




\begin{tabular}{|c|c|c|c|c|c|}
\hline Date & Start Time & Stop Time & $\begin{array}{c}\text { Spiked Bed } \\
\text { Recovery (\%) }\end{array}$ & $\begin{array}{l}\text { Breakthrough } \\
\text { to Bed 2(\%) }\end{array}$ & $\begin{array}{c}\text { Relative } \\
\text { Deviation } \\
\text { Between } \\
\text { Tubes (\%) }\end{array}$ \\
\hline $6 / 23 / 2009$ & $11: 15: 12$ & $15: 15: 26$ & $78.6 \%$ & 0.0 & N/A \\
\hline $6 / 23 / 2009$ & $15: 57: 27$ & $19: 57: 42$ & N/A & 0.0 & N/A \\
\hline $6 / 24 / 2009$ & $10: 40: 16$ & $13: 40: 28$ & $104.9 \%$ & 0.0 & N/A \\
\hline $6 / 24 / 2009$ & $14: 13: 40$ & $15: 43: 17$ & N/A & 5.7 & N/A \\
\hline $6 / 26 / 2009$ & 9:30:02 & 13:00:16 & N/A & 1.5 & N/A \\
\hline $6 / 26 / 2009$ & $13: 52: 50$ & 18:53:10 & $124.8 \%$ & 0.0 & N/A \\
\hline $6 / 27 / 2009$ & $12: 00: 28$ & $16: 30: 46$ & N/A & 3.9 & N/A \\
\hline $6 / 27 / 2009$ & $16: 57: 40$ & $19: 57: 52$ & $102.2 \%$ & 25.8 & N/A \\
\hline $6 / 28 / 2009$ & 10:00:10 & $13: 00: 23$ & N/A & 5.3 & N/A \\
\hline $6 / 28 / 2009$ & $13: 21: 23$ & $15: 51: 34$ & $111.2 \%$ & 0.0 & N/A \\
\hline 7/8/2009 & $11: 25: 22$ & $14: 25: 32$ & $112.4 \%$ & 0.0 & N/A \\
\hline 7/8/2009 & $16: 15: 10$ & $17: 10: 05$ & N/A & 9.7 & N/A \\
\hline $7 / 9 / 2009$ & 11:55:06 & $14: 55: 17$ & $107.5 \%$ & 0.0 & N/A \\
\hline $7 / 10 / 2009$ & 8:30:44 & $11: 30: 57$ & $113.0 \%$ & 0.0 & N/A \\
\hline $7 / 10 / 2009$ & 14:20:06 & $16: 56: 32$ & N/A & 3.8 & N/A \\
\hline $7 / 11 / 2009$ & 9:10:20 & $12: 10: 33$ & $113.1 \%$ & 0.9 & N/A \\
\hline $7 / 11 / 2009$ & 14:00:15 & 16:09:04 & N/A & 5.3 & N/A \\
\hline $7 / 12 / 2009$ & 8:23:00 & $11: 23: 14$ & $110.2 \%$ & 1.7 & N/A \\
\hline $7 / 12 / 2009$ & $12: 30: 39$ & $15: 30: 52$ & N/A & 2.3 & N/A \\
\hline $7 / 13 / 2009$ & $7: 51: 23$ & $10: 51: 35$ & $104.1 \%$ & 0.9 & N/A \\
\hline $7 / 13 / 2009$ & $12: 53: 22$ & $15: 53: 35$ & N/A & 3.1 & N/A \\
\hline $7 / 14 / 2009$ & $7: 35: 50$ & 10:36:04 & $105.4 \%$ & 1.1 & N/A \\
\hline $7 / 14 / 2009$ & $13: 30: 54$ & $16: 31: 08$ & N/A & 3.8 & N/A \\
\hline
\end{tabular}




\begin{tabular}{|c|c|c|c|c|c|}
\hline Date & Start Time & Stop Time & $\begin{array}{c}\text { Spiked Bed } \\
\text { Recovery (\%) }\end{array}$ & $\begin{array}{c}\text { Relative } \\
\text { Breakthrough } \\
\text { to Bed 2(\%) }\end{array}$ & $\begin{array}{c}\text { Deviation } \\
\text { Between } \\
\text { Tubes (\%) }\end{array}$ \\
\hline $7 / 15 / 2009$ & $9: 47: 32$ & $12: 47: 48$ & $103.2 \%$ & 0.7 & N/A \\
\hline $7 / 15 / 2009$ & $13: 25: 30$ & $16: 22: 35$ & N/A & 2.5 & N/A \\
\hline $7 / 16 / 2009$ & $9: 48: 07$ & $12: 48: 23$ & $101.8 \%$ & 0.0 & N/A \\
\hline $7 / 16 / 2009$ & $13: 18: 35$ & $16: 18: 52$ & N/A & 0.0 & N/A \\
\hline
\end{tabular}


APPENDIX B - MERCURY SCEM CALCULATIONS 


\section{Methodology for Generating Mercury Concentrations in units of $\mu \mathrm{g} / \mathrm{dNm}^{3}$ at $3 \% \mathrm{O}_{2}$}

This section explains how vapor-phase mercury concentrations are obtained from the mercury SCEMs.

The mercury SCEMs use a gold amalgamation column coupled with a CVAA. The flue gas is conditioned to remove the acid gas constituents (which can harm the gold's ability to adsorb mercury). It is also conditioned to either convert all the mercury to the elemental phase or to remove the oxidized mercury, leaving just the elemental phase. The CVAA can only detect the elemental form of mercury.

A measured flow rate of conditioned flue gas is passed over the gold amalgamation column for a fixed period of time. The flow rate is measured by a mass flow meter. The flow meter is calibrated to generate flow rates in the units of normal cubic meters $\left(\mathrm{Nm}^{3}\right)$, where normal means the gas flow has been corrected to $32^{\circ} \mathrm{F}$.

As the flue gas passes over the gold, the mercury in the flue gas adsorbs to the gold. Once a measured quantity of flue gas has passed over the gold, the gold is heated to desorb the mercury. This desorbed mercury is detected by the CVAA. The size of the peak generated by the CVAA correlates to a mass of mercury, as determined by a calibration curve. To produce the mercury concentration in $\mu \mathrm{g} / \mathrm{dNm}^{3}$, the mass of mercury is divided by the volume of flue gas sampled.

These mercury measurements are initially calculated at the actual $\mathrm{O}_{2}$ concentration in the duct. For each mercury concentration, an oxygen concentration is measured. The mercury data are corrected to a $3 \% \mathrm{O}_{2}$ basis in order to account for dilution effects from location to location. The calculation for conversion to $3 \% \mathrm{O}_{2}$ is:

$\mathrm{Hg}\left[\mu \mathrm{g} / \mathrm{dNm}^{3}\right.$ at $\left.3 \% \mathrm{O}_{2}\right]=\mathrm{Hg}\left[\mu \mathrm{g} / \mathrm{dNm}^{3}\right.$ at $\left.\mathrm{x} \% \mathrm{O}_{2}\right] *(20.9-3) /(20.9-\mathrm{x})$

where $\mathrm{x}$ represents the actual $\mathrm{O}_{2}$ concentration measured.

Each mercury SCEM produces a datum point every three to seven minutes, depending on the sample time needed to collect a detectable amount of mercury on the gold. The sample time increases as the flue gas mercury concentration decreases.

\section{Methodology for Data Analysis of Parametric Results}

This appendix explains how the raw data gathered by the mercury SCEMs are manipulated to produce the vapor phase mercury removal results for the parametric test conditions. A parametric test condition consists of a carbon type and carbon injection rate.

Mercury SCEMs were employed at the ESP inlet and ESP outlet locations. An average mercury concentration was calculated for each location at each test condition. Each test condition lasted from two to three hours. During each test period, flue gas mercury concentrations were measured by the SCEMs. The test period was run long enough for the mercury concentrations to reach a steady state. At each location the steady-state data were averaged to generate an average mercury 
concentration for the test condition. Mercury removals across the ESP were calculated for each injection rate using these average mercury concentrations.

\section{Methodology for Data Analysis of Long-Term Results}

The long-term carbon injection test was run for a one-month period. Over this time period, mercury SCEM data were collected every three to seven minutes at the ESP inlet and ESP outlet locations. Because of the huge volume of data, the mercury concentrations were reduced to onehour averages. These one-hour averages were used for the plots in this report and for calculations of percent removal across the ESP. 


\section{APPENDIX C - PLANT DATA TABLE}


Table C-1. Parametric Phase 1 Unit 1 Hourly Average Process Data

\begin{tabular}{|c|c|c|c|c|c|c|c|c|c|c|c|c|c|c|c|c|}
\hline Date and & $\begin{array}{c}\text { Gross } \\
\text { Gen }\end{array}$ & $\begin{array}{l}\text { Steam } \\
\text { Flow }\end{array}$ & $\begin{array}{c}\text { Gross } \\
\text { HR } \\
\end{array}$ & $\begin{array}{l}\text { Total } \\
\text { Fuel }\end{array}$ & $\begin{array}{c}\text { Total } \\
\text { Lignite }\end{array}$ & $\begin{array}{l}\text { Total } \\
\text { PRB }\end{array}$ & $\begin{array}{l}\text { Total } \\
\text { PRB }\end{array}$ & Btu Gain & Econ O2 & $\begin{array}{c}\text { Temp A } \\
\text { APH } \\
\text { Out } \\
\end{array}$ & $\begin{array}{c}\text { Temp B } \\
\text { APH } \\
\text { Out } \\
\end{array}$ & $\begin{array}{l}\text { Stack } \\
\text { Flow }\end{array}$ & Opacity & SO2 In & SO2 Out & $\begin{array}{l}\text { NOx } \\
\text { Out }\end{array}$ \\
\hline and Time & MW & $\begin{array}{c}\text { KLB/ } \\
\text { HR }\end{array}$ & $\begin{array}{c}\text { Btu/kW } \\
\mathbf{h r}\end{array}$ & $\begin{array}{c}\text { TON/ } \\
\text { HR }\end{array}$ & $\begin{array}{c}\text { TON/ } \\
\text { HR } \\
\end{array}$ & $\begin{array}{c}\text { TON/ } \\
\text { HR }\end{array}$ & $\begin{array}{c}\% \\
\text { Weight }\end{array}$ & & $\%$ & DEGF & DEGF & KSCF & $\%$ & $\begin{array}{c}\mathrm{lb} / \mathbf{M M} \\
\text { Btu }\end{array}$ & \begin{tabular}{|c|}
$\mathbf{l b} / \mathbf{M M}$ \\
Btu \\
\end{tabular} & $\begin{array}{l}\text { lb/M } \\
\text { MBtu }\end{array}$ \\
\hline 12/3/06 1:00 & 878 & 6042 & 9685 & 580.2 & 444.3 & 135.9 & 23.4 & 1.17 & 3.1 & 288 & 288 & 2368 & 7.9 & 1.4 & 0.1 & \#N/A \\
\hline 12/3/06 2:00 & 880 & 6082 & 9685 & 580.7 & 445.0 & 135.7 & 23.4 & 1.17 & 3.1 & 289 & 287 & 2364 & 7.7 & 1.4 & 0.1 & \#N/A \\
\hline 12/3/06 3:00 & 886 & 6104 & 9685 & 562.6 & 433.0 & 129.6 & 23.0 & 1.18 & 3.1 & 290 & 285 & 2361 & 7.5 & 1.2 & 0.1 & \#N/A \\
\hline 12/3/06 4:00 & 876 & 6033 & 9685 & 557.6 & 429.8 & 127.8 & 22.9 & 1.20 & 3.2 & 288 & 284 & 2362 & 7.3 & 1.2 & 0.1 & \#N/A \\
\hline 12/3/06 5:00 & 877 & 6019 & 9685 & 572.3 & 439.6 & 132.7 & 23.2 & 1.19 & 3.1 & 287 & 285 & 2362 & 7.5 & 1.3 & 0.1 & \#N/A \\
\hline 12/3/06 6:00 & 879 & 6044 & 9685 & 585.4 & 448.4 & 137.0 & 23.4 & 1.17 & 3.1 & 287 & 285 & 2372 & 6.2 & 1.6 & 0.2 & \#N/A \\
\hline 12/3/06 7:00 & 882 & 6076 & 9685 & 594.6 & 454.5 & 140.1 & 23.6 & 1.16 & 3.1 & 285 & 285 & 2394 & 6.9 & 1.7 & 0.2 & \#N/A \\
\hline 12/3/06 8:00 & 882 & 6087 & 9685 & 600.1 & 456.9 & 143.2 & 23.9 & 1.14 & 3.1 & 285 & 284 & 2397 & 10.9 & 1.7 & 0.2 & \#N/A \\
\hline 12/3/06 9:00 & 882 & 6077 & 9685 & 600.9 & 455.4 & 145.4 & 24.2 & 1.14 & 3.1 & 286 & 285 & 2387 & 6.9 & 1.7 & 0.2 & \#N/A \\
\hline 12/3/06 10:00 & 885 & 6081 & 9685 & 595.3 & 447.8 & 147.5 & 24.8 & 1.13 & 3.1 & 288 & 287 & 2385 & 6.6 & 1.6 & 0.2 & \#N/A \\
\hline 12/3/06 11:00 & 882 & 6066 & 9685 & 585.8 & 428.0 & 157.8 & 26.9 & 1.15 & 3.1 & 288 & 287 & 2383 & 6.7 & 1.5 & 0.2 & \#N/A \\
\hline 12/3/06 12:00 & 879 & 6071 & 9685 & 581.9 & 424.8 & 157.1 & 27.0 & 1.16 & 3.1 & 284 & 285 & 2361 & 6.9 & 1.5 & 0.2 & \#N/A \\
\hline 12/3/06 13:00 & 878 & 6058 & 9685 & 587.6 & 427.9 & 159.7 & 27.2 & 1.16 & 3.0 & 285 & 286 & 2375 & 7.0 & 1.5 & 0.2 & \#N/A \\
\hline 12/3/06 14:00 & 881 & 6102 & 9685 & 589.5 & 429.0 & 160.5 & 27.2 & 1.16 & 3.0 & 285 & 286 & 2364 & 6.9 & 1.5 & 0.2 & \#N/A \\
\hline 12/3/06 15:00 & 884 & 6084 & 9685 & 583.3 & 425.3 & 158.0 & 27.1 & 1.16 & 3.0 & 287 & 288 & 2341 & 6.7 & 1.5 & 0.1 & \#N/A \\
\hline 12/3/06 16:00 & 882 & 6093 & 9685 & 575.2 & 420.4 & 154.8 & 26.9 & 1.17 & 3.0 & 289 & 289 & 2339 & 6.8 & 1.4 & 0.1 & \#N/A \\
\hline 12/3/06 17:00 & 881 & 6067 & 9685 & 568.4 & 416.4 & 152.0 & 26.7 & 1.18 & 3.1 & 289 & 290 & 2352 & 7.0 & 1.3 & 0.1 & \#N/A \\
\hline 12/3/06 18:00 & 883 & 6092 & 9685 & 568.6 & 416.5 & 152.1 & 26.8 & 1.19 & 3.1 & 289 & 291 & 2392 & 7.7 & 1.3 & 0.1 & \#N/A \\
\hline 12/3/06 19:00 & 889 & 6125 & 9685 & 572.4 & 418.8 & 153.6 & 26.8 & 1.19 & 3.0 & 290 & 291 & 2386 & 7.8 & 1.3 & 0.1 & \#N/A \\
\hline 12/3/06 20:00 & 889 & 6131 & 9685 & 573.9 & 419.7 & 154.2 & 26.9 & 1.19 & 3.1 & 291 & 292 & 2387 & 7.9 & 1.3 & 0.1 & \#N/A \\
\hline 12/3/06 21:00 & 889 & 6123 & 9685 & 577.9 & 422.1 & 155.8 & 27.0 & 1.19 & 3.1 & 290 & 291 & 2383 & 7.8 & 1.3 & 0.1 & \#N/A \\
\hline 12/3/06 22:00 & 891 & 6159 & 9685 & 579.4 & 423.0 & 156.4 & 27.0 & 1.19 & 3.0 & 290 & 290 & 2389 & 7.9 & 1.3 & 0.1 & \#N/A \\
\hline 12/3/06 23:00 & 893 & 6160 & 9685 & 575.2 & 420.5 & 154.7 & 26.9 & 1.19 & 3.0 & 290 & 288 & 2373 & 7.9 & 1.3 & 0.1 & \#N/A \\
\hline 12/4/06 0:00 & 891 & 6161 & 9685 & 567.0 & 415.6 & 151.4 & 26.7 & 1.20 & 3.0 & 286 & 285 & 2387 & 7.5 & 1.3 & 0.1 & \#N/A \\
\hline 12/4/06 1:00 & 886 & 6121 & 9685 & 571.5 & 418.3 & 153.2 & 26.8 & 1.20 & 3.1 & 286 & 285 & 2386 & 7.5 & 1.3 & 0.1 & \#N/A \\
\hline 12/4/06 2:00 & 890 & 6131 & 9685 & 576.9 & 421.6 & 155.3 & 26.9 & 1.19 & 3.0 & 285 & 285 & 2383 & 7.7 & 1.4 & 0.1 & \#N/A \\
\hline 12/4/06 3:00 & 892 & 6156 & 9685 & 574.9 & 420.4 & 154.6 & 26.9 & 1.19 & 3.0 & 284 & 284 & 2377 & 7.7 & 1.3 & 0.1 & \#N/A \\
\hline 12/4/06 4:00 & 891 & 6134 & 9685 & 573.1 & 419.2 & 153.8 & 26.8 & 1.19 & 3.0 & 284 & 284 & 2392 & 8.0 & 1.2 & 0.1 & \#N/A \\
\hline 12/4/06 5:00 & 888 & 6101 & 9685 & 574.8 & 420.0 & 154.8 & 26.9 & 1.19 & 3.1 & 285 & 285 & 2391 & 8.0 & 1.3 & 0.1 & \#N/A \\
\hline 12/4/06 6:00 & 890 & 6131 & 9685 & 577.2 & 420.9 & 156.3 & 27.1 & 1.19 & 3.0 & 286 & 286 & 2389 & 8.7 & 1.4 & 0.1 & \#N/A \\
\hline 12/4/06 7:00 & 888 & 6103 & 9685 & 582.3 & 424.0 & 158.3 & 27.2 & 1.18 & 3.0 & 287 & 286 & 2393 & 8.9 & 1.5 & 0.1 & \#N/A \\
\hline 12/4/06 8:00 & 890 & 6132 & 9685 & 590.9 & 430.1 & 160.8 & 27.2 & 1.17 & 3.0 & 288 & 286 & 2379 & 8.6 & 1.6 & 0.2 & \#N/A \\
\hline 12/4/06 9:00 & 892 & 6148 & 9685 & 584.4 & 427.3 & 157.1 & 26.9 & 1.17 & 3.0 & 289 & 288 & 2373 & 7.7 & 1.5 & 0.2 & \#N/A \\
\hline 12/4/06 10:00 & 886 & 6094 & 9685 & 576.3 & 421.2 & 155.2 & 26.9 & 1.17 & 3.1 & 291 & 291 & 2367 & 7.8 & 1.4 & 0.1 & \#N/A \\
\hline
\end{tabular}




\begin{tabular}{|c|c|c|c|c|c|c|c|c|c|c|c|c|c|c|c|c|}
\hline Date and & $\begin{array}{c}\text { Gross } \\
\text { Gen }\end{array}$ & $\begin{array}{c}\text { Steam } \\
\text { Flow }\end{array}$ & $\begin{array}{c}\text { Gross } \\
\text { HR }\end{array}$ & $\begin{array}{l}\text { Total } \\
\text { Fuel }\end{array}$ & $\begin{array}{c}\text { Total } \\
\text { Lignite }\end{array}$ & $\begin{array}{l}\text { Total } \\
\text { PRB }\end{array}$ & $\begin{array}{l}\text { Total } \\
\text { PRB }\end{array}$ & Btu Gain & Econ O2 & $\begin{array}{c}\text { Temp A } \\
\text { APH } \\
\text { Out }\end{array}$ & $\begin{array}{c}\text { Temp B } \\
\text { APH } \\
\text { Out }\end{array}$ & $\begin{array}{l}\text { Stack } \\
\text { Flow }\end{array}$ & Opacity & SO2 In & SO2 Out & $\begin{array}{c}\text { NOx } \\
\text { Out }\end{array}$ \\
\hline and Time & MW & $\begin{array}{c}\text { KLB/ } \\
\text { HR }\end{array}$ & \begin{tabular}{|c} 
Btu/kW \\
hr
\end{tabular} & $\begin{array}{c}\text { TON/ } \\
\text { HR }\end{array}$ & $\begin{array}{c}\text { TON/ } \\
\text { HR }\end{array}$ & $\begin{array}{c}\text { TON/ } \\
\text { HR }\end{array}$ & $\begin{array}{c}\% \\
\text { Weight }\end{array}$ & & $\%$ & DEGF & DEGF & KSCF & $\%$ & $\begin{array}{c}\mathrm{lb} / \mathrm{MM} \\
\text { Btu }\end{array}$ & $\begin{array}{c}\mathrm{lb} / \mathrm{MM} \\
\text { Btu }\end{array}$ & $\begin{array}{l}\text { lb/M } \\
\text { MBtu }\end{array}$ \\
\hline $12 / 4 / 0611: 00$ & 882 & 6051 & 9685 & 581.6 & 424.3 & 157.3 & 27.0 & 1.17 & 3.1 & 293 & 292 & 2367 & 8.1 & 1.5 & 0.1 & \#N/A \\
\hline 12/4/06 12:00 & 885 & 6121 & 9685 & 584.5 & 426.3 & 158.2 & 27.1 & 1.17 & 3.0 & 294 & 292 & 2372 & 8.3 & 1.5 & 0.1 & \#N/A \\
\hline 12/4/06 13:00 & 886 & 6098 & 9685 & 582.6 & 424.9 & 157.6 & 27.1 & 1.17 & 3.1 & 291 & 292 & 2350 & 8.3 & 1.4 & 0.1 & \#N/A \\
\hline 12/4/06 14:00 & 887 & 6103 & 9685 & 576.3 & 420.7 & 155.6 & 27.0 & 1.17 & 3.0 & 289 & 290 & 2339 & 7.9 & 1.4 & 0.1 & \#N/A \\
\hline $12 / 4 / 0615: 00$ & 884 & 6097 & 9685 & 572.6 & 418.4 & 154.2 & 26.9 & 1.18 & 3.1 & 289 & 288 & 2336 & 7.8 & 1.3 & 0.1 & \#N/A \\
\hline 12/4/06 16:00 & 882 & 6118 & 9685 & 574.7 & 419.7 & 155.0 & 27.0 & 1.18 & 3.1 & 289 & 289 & 2338 & 7.5 & 1.3 & 0.1 & \#N/A \\
\hline 12/4/06 17:00 & 885 & 6091 & 9685 & 575.9 & 420.5 & 155.3 & 27.0 & 1.18 & 3.0 & 289 & 290 & 2332 & 7.3 & 1.3 & 0.1 & \#N/A \\
\hline $12 / 4 / 0618: 00$ & 883 & 6082 & 9685 & 579.5 & 422.9 & 156.6 & 27.0 & 1.18 & 3.1 & 290 & 290 & 2354 & 7.5 & 1.4 & 0.1 & \#N/A \\
\hline 12/4/06 19:00 & 885 & 6092 & 9685 & 587.1 & 428.0 & 159.1 & 27.1 & 1.17 & 3.0 & 289 & 290 & 2357 & 7.7 & 1.4 & 0.2 & \#N/A \\
\hline $12 / 4 / 0620: 00$ & 886 & 6106 & 9685 & 588.3 & 428.8 & 159.5 & 27.1 & 1.16 & 3.0 & 287 & 288 & 2363 & 7.8 & 1.5 & 0.2 & \#N/A \\
\hline 12/4/06 21:00 & 885 & 6098 & 9685 & 589.5 & 429.6 & 159.9 & 27.1 & 1.16 & 3.0 & 287 & 287 & 2354 & 7.7 & 1.5 & 0.2 & \#N/A \\
\hline 12/4/06 22:00 & 887 & 6119 & 9685 & 588.6 & 429.0 & 159.6 & 27.1 & 1.16 & 3.0 & 288 & 287 & 2368 & 7.9 & 1.5 & 0.2 & \#N/A \\
\hline 12/4/06 23:00 & 885 & 6120 & 9685 & 586.0 & 427.3 & 158.7 & 27.1 & 1.16 & 3.1 & 289 & 288 & 2372 & 8.0 & 1.6 & 0.2 & \#N/A \\
\hline 12/5/06 0:00 & 885 & 6099 & 9685 & 586.1 & 427.4 & 158.7 & 27.1 & 1.16 & 3.0 & 291 & 288 & 2369 & 8.2 & 1.6 & 0.2 & \#N/A \\
\hline 12/5/06 1:00 & 885 & 6097 & 9685 & 583.7 & 425.8 & 157.9 & 27.1 & 1.17 & 3.0 & 290 & 288 & 2370 & 8.2 & 1.5 & 0.2 & \#N/A \\
\hline 12/5/06 2:00 & 885 & 6105 & 9685 & 583.6 & 425.7 & 157.9 & 27.1 & 1.17 & 3.0 & 288 & 287 & 2364 & 7.9 & 1.5 & 0.2 & \#N/A \\
\hline 12/5/06 3:00 & 885 & 6091 & 9685 & 581.8 & 424.5 & 157.3 & 27.0 & 1.17 & 3.0 & 288 & 287 & 2370 & 7.8 & 1.5 & 0.2 & \#N/A \\
\hline 12/5/06 4:00 & 886 & 6092 & 9685 & 578.1 & 422.0 & 156.1 & 27.0 & 1.17 & 3.0 & 289 & 288 & 2374 & 7.9 & 1.4 & 0.1 & \#N/A \\
\hline 12/5/06 5:00 & 877 & 6041 & 9685 & 568.3 & 407.8 & 160.4 & 28.2 & 1.18 & 3.0 & 296 & 291 & 2347 & 8.1 & 1.4 & 0.1 & \#N/A \\
\hline $12 / 5 / 066: 00$ & 876 & 6053 & 9685 & 568.9 & 397.0 & 171.9 & 30.2 & 1.18 & 3.1 & 292 & 288 & 2352 & 8.2 & 1.4 & 0.1 & \#N/A \\
\hline $12 / 5 / 067: 00$ & 883 & 6088 & 9685 & 575.1 & 401.5 & 173.6 & 30.2 & 1.18 & 3.0 & 290 & 287 & 2351 & 8.1 & 1.4 & 0.2 & \#N/A \\
\hline 12/5/06 8:00 & 886 & 6103 & 9685 & 574.0 & 401.0 & 173.0 & 30.1 & 1.19 & 3.0 & 289 & 287 & 2362 & 8.1 & 1.4 & 0.2 & \#N/A \\
\hline 12/5/06 9:00 & 885 & 6088 & 9685 & 572.0 & 399.7 & 172.3 & 30.1 & 1.19 & 3.0 & 288 & 287 & 2354 & 8.0 & 1.4 & 0.1 & \#N/A \\
\hline 12/5/06 10:00 & 867 & 5982 & 9685 & 556.3 & 389.2 & 167.1 & 30.0 & 1.19 & 3.0 & 291 & 288 & 2339 & 8.0 & 1.4 & 0.1 & \#N/A \\
\hline 12/5/06 11:00 & 881 & 6083 & 9685 & 564.5 & 394.7 & 169.8 & 30.1 & 1.20 & 3.1 & 293 & 290 & 2355 & 8.4 & 1.4 & 0.1 & \#N/A \\
\hline 12/5/06 12:00 & 881 & 6090 & 9685 & 566.5 & 396.0 & 170.5 & 30.1 & 1.20 & 3.0 & 297 & 293 & 2343 & 8.6 & 1.4 & 0.1 & \#N/A \\
\hline 12/5/06 13:00 & 882 & 6069 & 9670 & 566.7 & 396.2 & 170.6 & 30.1 & 1.20 & 3.1 & 297 & 294 & 2341 & 8.7 & 1.4 & 0.2 & \#N/A \\
\hline $12 / 5 / 0614: 00$ & 882 & 6067 & 9695 & 568.5 & 397.4 & 171.2 & 30.1 & 1.19 & 3.0 & 294 & 291 & 2342 & 8.3 & 1.4 & 0.2 & \#N/A \\
\hline 12/5/06 15:00 & 879 & 6082 & 9744 & 571.8 & 399.5 & 172.3 & 30.1 & 1.19 & 3.1 & 295 & 293 & 2355 & 8.3 & 1.4 & 0.2 & \#N/A \\
\hline $12 / 5 / 0616: 00$ & 881 & 6106 & 9819 & 576.6 & 402.8 & 173.9 & 30.2 & 1.19 & 3.0 & 297 & 295 & 2352 & 8.4 & 1.4 & 0.2 & \#N/A \\
\hline 12/5/06 17:00 & 881 & 6092 & 9775 & 576.6 & 402.7 & 173.9 & 30.2 & 1.18 & 3.0 & 297 & 294 & 2348 & 8.2 & 1.4 & 0.2 & \#N/A \\
\hline 12/5/06 18:00 & 883 & 6100 & 9723 & 576.1 & 402.4 & 173.7 & 30.2 & 1.18 & 3.0 & 296 & 292 & 2359 & 8.1 & 1.4 & 0.1 & \#N/A \\
\hline 12/5/06 19:00 & 879 & 6071 & 9718 & 574.1 & 401.1 & 173.1 & 30.1 & 1.18 & 3.1 & 296 & 292 & 2363 & 8.1 & 1.4 & 0.1 & \#N/A \\
\hline 12/5/06 20:00 & 880 & 6091 & 9750 & 581.6 & 406.1 & 175.6 & 30.2 & 1.17 & 3.0 & 295 & 290 & 2360 & 8.1 & 1.4 & 0.1 & \#N/A \\
\hline 12/5/06 21:00 & 883 & 6087 & 9724 & 579.8 & 404.9 & 174.9 & 30.2 & 1.18 & 3.0 & 292 & 287 & 2358 & 7.7 & 1.4 & 0.1 & \#N/A \\
\hline 12/5/06 22:00 & 883 & 6079 & 9628 & 571.5 & 399.4 & 172.2 & 30.1 & 1.18 & 3.0 & 291 & 287 & 2363 & 7.6 & 1.4 & 0.1 & \#N/A \\
\hline $12 / 5 / 0623: 00$ & 875 & 6012 & 9674 & 570.3 & 401.1 & 169.2 & 29.7 & 1.18 & 3.1 & 295 & 292 & 2343 & 7.6 & 1.4 & 0.1 & \#N/A \\
\hline
\end{tabular}




\begin{tabular}{|c|c|c|c|c|c|c|c|c|c|c|c|c|c|c|c|c|}
\hline Date and & $\begin{array}{c}\text { Gross } \\
\text { Gen }\end{array}$ & $\begin{array}{c}\text { Steam } \\
\text { Flow }\end{array}$ & $\begin{array}{c}\text { Gross } \\
\text { HR }\end{array}$ & $\begin{array}{l}\text { Total } \\
\text { Fuel }\end{array}$ & $\begin{array}{c}\text { Total } \\
\text { Lignite }\end{array}$ & $\begin{array}{l}\text { Total } \\
\text { PRB }\end{array}$ & $\begin{array}{l}\text { Total } \\
\text { PRB }\end{array}$ & Btu Gain & Econ O2 & $\begin{array}{c}\text { Temp A } \\
\text { APH } \\
\text { Out }\end{array}$ & $\begin{array}{c}\text { Temp B } \\
\text { APH } \\
\text { Out }\end{array}$ & $\begin{array}{l}\text { Stack } \\
\text { Flow }\end{array}$ & Opacity & SO2 In & SO2 Out & $\begin{array}{c}\text { NOx } \\
\text { Out }\end{array}$ \\
\hline and Time & MW & $\begin{array}{c}\text { KLB/ } \\
\text { HR }\end{array}$ & \begin{tabular}{|c} 
Btu/kW \\
hr
\end{tabular} & $\begin{array}{c}\text { TON/ } \\
\text { HR }\end{array}$ & $\begin{array}{c}\text { TON/ } \\
\text { HR }\end{array}$ & $\begin{array}{c}\text { TON/ } \\
\text { HR }\end{array}$ & $\begin{array}{c}\% \\
\text { Weight }\end{array}$ & & $\%$ & DEGF & DEGF & KSCF & $\%$ & $\begin{array}{c}\mathrm{lb} / \mathrm{MM} \\
\text { Btu }\end{array}$ & $\begin{array}{c}\mathrm{lb} / \mathrm{MM} \\
\text { Btu }\end{array}$ & $\begin{array}{l}\text { lb/M } \\
\text { MBtu }\end{array}$ \\
\hline $12 / 6 / 060: 00$ & 838 & 5792 & 9749 & 555.4 & 388.2 & 167.2 & 30.1 & 1.17 & 3.1 & 293 & 291 & 2291 & 7.3 & 1.4 & 0.1 & \#N/A \\
\hline 12/6/06 1:00 & 889 & 6157 & 9782 & 589.5 & 412.6 & 176.9 & 30.0 & 1.17 & 3.0 & 289 & 284 & 2373 & 7.6 & 1.4 & 0.1 & \#N/A \\
\hline 12/6/06 2:00 & 894 & 6094 & 9583 & 588.3 & 411.7 & 176.6 & 30.0 & 1.16 & 3.0 & 288 & 284 & 2373 & 7.5 & 1.4 & 0.2 & \#N/A \\
\hline 12/6/06 3:00 & 893 & 6110 & 9547 & 581.1 & 406.6 & 174.5 & 30.0 & 1.17 & 3.0 & 288 & 285 & 2375 & 7.6 & 1.4 & 0.1 & \#N/A \\
\hline 12/6/06 4:00 & 889 & 6077 & 9564 & 574.9 & 402.2 & 172.7 & 30.0 & 1.17 & 3.0 & 290 & 286 & 2372 & 7.6 & 1.3 & 0.1 & \#N/A \\
\hline 12/6/06 5:00 & 886 & 6054 & 9647 & 582.9 & 407.9 & 175.0 & 30.0 & 1.17 & 3.1 & 290 & 287 & 2385 & 6.9 & 1.3 & 0.1 & \#N/A \\
\hline 12/6/06 6:00 & 888 & 6074 & 9701 & 591.4 & 413.9 & 177.4 & 30.0 & 1.16 & 3.0 & 291 & 288 & 2394 & 7.4 & 1.4 & 0.2 & \#N/A \\
\hline 12/6/06 7:00 & 890 & 6118 & 9724 & 593.4 & 415.4 & 178.0 & 30.0 & 1.15 & 3.0 & 292 & 289 & 2380 & 7.4 & 1.4 & 0.2 & \#N/A \\
\hline 12/6/06 8:00 & 890 & 6107 & 9664 & 594.9 & 416.4 & 178.5 & 30.0 & 1.15 & 3.0 & 292 & 290 & 2382 & 7.5 & 1.4 & 0.2 & \#N/A \\
\hline 12/6/06 9:00 & 891 & 6118 & 9577 & 591.8 & 414.2 & 177.5 & 30.0 & 1.15 & 3.0 & 292 & 289 & 2391 & 7.5 & 1.4 & 0.1 & \#N/A \\
\hline 12/6/06 10:00 & 890 & 6110 & 9649 & 588.8 & 411.5 & 177.3 & 30.1 & 1.16 & 3.0 & 294 & 291 & 2387 & 7.6 & 1.3 & 0.1 & \#N/A \\
\hline 12/6/06 11:00 & 888 & 6114 & 9627 & 587.2 & 410.4 & 176.8 & 30.1 & 1.16 & 3.0 & 297 & 292 & 2380 & 7.5 & 1.3 & 0.1 & \#N/A \\
\hline $12 / 6 / 0612: 00$ & 865 & 5945 & 9717 & 575.1 & 402.2 & 172.9 & 30.1 & 1.16 & 3.1 & 301 & 297 & 2341 & 7.7 & 1.4 & 0.1 & \#N/A \\
\hline 12/6/06 13:00 & 847 & 5838 & 9831 & 572.0 & 405.0 & 167.0 & 29.2 & 1.15 & 3.0 & 301 & 301 & 2329 & 7.9 & 1.4 & 0.2 & \#N/A \\
\hline 12/6/06 14:00 & 874 & 6026 & 9644 & 578.4 & 414.9 & 163.6 & 28.3 & 1.16 & 3.0 & 301 & 299 & 2369 & 8.5 & 1.4 & 0.1 & \#N/A \\
\hline 12/6/06 15:00 & 873 & 6006 & 9628 & 573.3 & 411.2 & 162.1 & 28.3 & 1.16 & 3.0 & 302 & 300 & 2388 & 8.9 & 1.4 & 0.2 & \#N/A \\
\hline 12/6/06 16:00 & 884 & 6095 & 9679 & 581.3 & 417.0 & 164.4 & 28.3 & 1.17 & 8.0 & 304 & 301 & 2427 & 8.9 & 1.4 & 0.1 & \#N/A \\
\hline $12 / 6 / 0617: 00$ & 884 & 6104 & 9706 & 582.0 & 417.5 & 164.6 & 28.3 & 1.17 & 3.1 & 301 & 299 & 2423 & 9.1 & 1.4 & 0.1 & \#N/A \\
\hline 12/6/06 18:00 & 884 & 6094 & 9708 & 585.8 & 420.2 & 165.6 & 28.3 & 1.16 & 3.1 & 299 & 298 & 2407 & 9.0 & 1.4 & 0.2 & \#N/A \\
\hline 12/6/06 19:00 & 884 & 6106 & 9777 & 591.6 & 424.3 & 167.3 & 28.3 & 1.16 & 3.0 & 298 & 298 & 2408 & 9.6 & 1.5 & 0.2 & \#N/A \\
\hline $12 / 6 / 0620: 00$ & 886 & 6121 & 9695 & 592.8 & 425.1 & 167.7 & 28.3 & 1.15 & 3.0 & 296 & 298 & 2412 & 9.6 & 1.5 & 0.1 & \#N/A \\
\hline 12/6/06 21:00 & 888 & 6107 & 9657 & 589.6 & 422.8 & 166.8 & 28.3 & 1.16 & 3.0 & 296 & 298 & 2418 & 9.0 & 1.4 & 0.1 & \#N/A \\
\hline 12/6/06 22:00 & 885 & 6117 & 9688 & 586.6 & 420.7 & 165.9 & 28.3 & 1.16 & 3.1 & 294 & 297 & 2430 & 8.8 & 1.4 & 0.1 & \#N/A \\
\hline 12/6/06 23:00 & 884 & 6112 & 9620 & 583.5 & 418.5 & 165.0 & 28.3 & 1.16 & 3.1 & 293 & 296 & 2400 & 8.9 & 1.4 & 0.1 & \#N/A \\
\hline $12 / 7 / 060: 00$ & 866 & 6000 & 9711 & 571.6 & 410.1 & 161.6 & 28.3 & 1.17 & 3.1 & 293 & 293 & 2380 & 8.4 & 1.4 & 0.1 & \#N/A \\
\hline 12/7/06 1:00 & 883 & 6117 & 9702 & 580.3 & 416.2 & 164.0 & 28.3 & 1.17 & 3.0 & 293 & 292 & 2386 & 8.4 & 1.4 & 0.1 & \#N/A \\
\hline 12/7/06 2:00 & 884 & 6095 & 9586 & 573.0 & 411.0 & 162.0 & 28.3 & 1.18 & 3.0 & 292 & 291 & 2383 & 8.1 & 1.3 & 0.1 & \#N/A \\
\hline 12/7/06 3:00 & 882 & 6065 & 9664 & 571.5 & 409.9 & 161.6 & 28.3 & 1.18 & 3.0 & 291 & 289 & 2366 & 7.9 & 1.3 & 0.1 & \#N/A \\
\hline 12/7/06 4:00 & 883 & 6092 & 9659 & 568.3 & 407.7 & 160.6 & 28.3 & 1.19 & 3.0 & 293 & 289 & 2372 & 7.9 & 1.3 & 0.1 & \#N/A \\
\hline 12/7/06 5:00 & 882 & 6054 & 9707 & 567.6 & 407.1 & 160.4 & 28.3 & 1.19 & 3.0 & 293 & 290 & 2375 & 7.4 & 1.3 & 0.1 & \#N/A \\
\hline 12/7/06 6:00 & 880 & 6070 & 9737 & 573.0 & 411.0 & 161.9 & 28.3 & 1.19 & 3.0 & 293 & 290 & 2396 & 8.3 & 1.3 & 0.1 & \#N/A \\
\hline 12/7/06 7:00 & 883 & 6073 & 9791 & 578.0 & 414.6 & 163.4 & 28.3 & 1.18 & 3.0 & 296 & 292 & 2417 & 8.6 & 1.3 & 0.1 & \#N/A \\
\hline 12/7/06 8:00 & 881 & 6085 & 9685 & 573.1 & 411.1 & 162.0 & 28.3 & 1.18 & 3.0 & 297 & 294 & 2407 & 8.8 & 1.3 & 0.1 & \#N/A \\
\hline 12/7/06 9:00 & 882 & 6100 & 9630 & 571.8 & 410.2 & 161.6 & 28.3 & 1.19 & 3.0 & 299 & 295 & 2403 & 8.7 & 1.3 & 0.1 & \#N/A \\
\hline 12/7/06 10:00 & 881 & 6093 & 9678 & 568.8 & 407.8 & 161.0 & 28.3 & 1.19 & 3.0 & 300 & 296 & 2401 & 8.9 & 1.2 & 0.1 & \#N/A \\
\hline 12/7/06 11:00 & 881 & 6091 & 9707 & 568.5 & 406.9 & 161.6 & 28.4 & 1.19 & 3.0 & 300 & 296 & 2395 & 9.0 & 1.2 & 0.1 & \#N/A \\
\hline $12 / 7 / 0612: 00$ & 880 & 6093 & 9778 & 571.2 & 408.6 & 162.6 & 28.5 & 1.19 & 3.0 & 302 & 299 & 2385 & 9.1 & 1.3 & 0.1 & \#N/A \\
\hline
\end{tabular}




\begin{tabular}{|c|c|c|c|c|c|c|c|c|c|c|c|c|c|c|c|c|}
\hline Date and & $\begin{array}{c}\text { Gross } \\
\text { Gen }\end{array}$ & $\begin{array}{c}\text { Steam } \\
\text { Flow }\end{array}$ & $\begin{array}{c}\text { Gross } \\
\text { HR }\end{array}$ & $\begin{array}{l}\text { Total } \\
\text { Fuel } \\
\end{array}$ & $\begin{array}{c}\text { Total } \\
\text { Lignite }\end{array}$ & $\begin{array}{l}\text { Total } \\
\text { PRB }\end{array}$ & $\begin{array}{l}\text { Total } \\
\text { PRB }\end{array}$ & Btu Gain & Econ O2 & $\begin{array}{c}\text { Temp A } \\
\text { APH } \\
\text { Out } \\
\end{array}$ & $\begin{array}{c}\text { Temp B } \\
\text { APH } \\
\text { Out } \\
\end{array}$ & $\begin{array}{l}\text { Stack } \\
\text { Flow }\end{array}$ & Opacity & SO2 In & SO2 Out & $\begin{array}{c}\text { NOx } \\
\text { Out }\end{array}$ \\
\hline and Time & MW & $\begin{array}{c}\text { KLB/ } \\
\text { HR }\end{array}$ & \begin{tabular}{|c|} 
Btu/kW \\
hr
\end{tabular} & $\begin{array}{c}\text { TON/ } \\
\text { HR }\end{array}$ & $\begin{array}{c}\text { TON/ } \\
\text { HR }\end{array}$ & $\begin{array}{c}\text { TON/ } \\
\text { HR }\end{array}$ & $\begin{array}{c}\% \\
\text { Weight }\end{array}$ & & $\%$ & DEGF & DEGF & KSCF & $\%$ & $\begin{array}{c}\mathrm{lb} / \mathrm{MM} \\
\text { Btu }\end{array}$ & \begin{tabular}{|c|} 
Ib/MM \\
Btu
\end{tabular} & \begin{tabular}{|l|} 
lb/M \\
MBtu \\
\end{tabular} \\
\hline 12/7/06 13:00 & 881 & 6086 & 9781 & 574.9 & 410.8 & 164.2 & 28.6 & 1.19 & 3.0 & 302 & 299 & 2400 & 9.1 & 1.4 & 0.1 & \#N/A \\
\hline 12/7/06 14:00 & 882 & 6100 & 9776 & 578.3 & 412.8 & 165.5 & 28.6 & 1.18 & 3.0 & 297 & 295 & 2397 & 8.8 & 1.4 & 0.1 & \#N/A \\
\hline $12 / 7 / 06$ 15:00 & 882 & 6099 & 9776 & 577.3 & 412.2 & 165.0 & 28.6 & 1.18 & 3.0 & 297 & 295 & 2390 & 8.7 & 1.3 & 0.1 & \#N/A \\
\hline 12/7/06 16:00 & 881 & 6110 & 9776 & 579.9 & 413.8 & 166.1 & 28.6 & 1.18 & 3.0 & 297 & 295 & 2394 & 8.5 & 1.4 & 0.1 & \#N/A \\
\hline $12 / 7 / 06$ 17:00 & 883 & 6112 & 9776 & 580.0 & 413.8 & 166.2 & 28.7 & 1.18 & 3.0 & 295 & 294 & 2385 & 8.2 & 1.4 & 0.2 & \#N/A \\
\hline 12/7/06 18:00 & 882 & 6126 & 9776 & 576.9 & 411.9 & 164.9 & 28.6 & 1.18 & 3.0 & 294 & 293 & 2411 & 8.6 & 1.4 & 0.2 & \#N/A \\
\hline 12/7/06 19:00 & 879 & 6104 & 9776 & 578.6 & 413.0 & 165.7 & 28.6 & 1.18 & 3.1 & 291 & 290 & 2410 & 8.5 & 1.5 & 0.2 & \#N/A \\
\hline 12/7/06 20:00 & 882 & 6103 & 9776 & 584.5 & 416.5 & 168.0 & 28.7 & 1.17 & 3.0 & 288 & 287 & 2404 & 8.1 & 1.5 & 0.2 & \#N/A \\
\hline 12/7/06 21:00 & 882 & 6127 & 9776 & 586.1 & 417.5 & 168.6 & 28.8 & 1.17 & 3.0 & 286 & 285 & 2401 & 7.9 & 1.6 & 0.2 & \#N/A \\
\hline 12/7/06 22:00 & 883 & 6091 & 9776 & 585.2 & 416.4 & 168.8 & 28.8 & 1.17 & 3.0 & 285 & 282 & 2395 & 7.7 & 1.6 & 0.2 & \#N/A \\
\hline $12 / 7 / 0623: 00$ & 880 & 6092 & 9776 & 589.0 & 419.1 & 169.9 & 28.8 & 1.16 & 3.0 & 284 & 282 & 2410 & 7.6 & 1.6 & 0.2 & \#N/A \\
\hline 12/8/06 0:00 & 882 & 6081 & 9776 & 595.3 & 423.6 & 171.7 & 28.8 & 1.15 & 3.0 & 285 & 281 & 2401 & 7.7 & 1.6 & 0.2 & \#N/A \\
\hline 12/8/06 1:00 & 881 & 6077 & 9776 & 602.2 & 429.8 & 172.3 & 28.6 & 1.14 & 3.1 & 286 & 280 & 2410 & 7.9 & 1.6 & 0.2 & \#N/A \\
\hline 12/8/06 2:00 & 887 & 6090 & 9776 & 603.0 & 432.4 & 170.6 & 28.3 & 1.13 & 3.0 & 283 & 278 & 2418 & 8.8 & 1.7 & 0.2 & \#N/A \\
\hline 12/8/06 3:00 & 882 & 6063 & 9776 & 597.0 & 428.1 & 168.8 & 28.3 & 1.13 & 3.1 & 281 & 277 & 2420 & 10.4 & 1.6 & 0.2 & \#N/A \\
\hline 12/8/06 4:00 & 882 & 6040 & 9776 & 599.6 & 430.0 & 169.6 & 28.3 & 1.13 & 3.0 & 281 & 277 & 2414 & 11.6 & 1.7 & 0.2 & \#N/A \\
\hline 12/8/06 5:00 & 881 & 6068 & 9776 & 595.6 & 427.2 & 168.5 & 28.3 & 1.13 & 3.1 & 278 & 275 & 2413 & 11.0 & 1.8 & 0.3 & \#N/A \\
\hline 12/8/06 6:00 & 885 & 6083 & 9776 & 603.7 & 434.0 & 169.7 & 28.1 & 1.13 & 3.0 & 278 & 274 & 2421 & 11.4 & 1.9 & 0.3 & \#N/A \\
\hline $12 / 8 / 067: 00$ & 888 & 6123 & 9776 & 612.5 & 440.6 & 171.8 & 28.1 & 1.12 & 3.0 & 280 & 275 & 2436 & 11.4 & 2.0 & 0.3 & \#N/A \\
\hline 12/8/06 8:00 & 891 & 6120 & 9776 & 615.7 & 442.9 & 172.7 & 28.1 & 1.12 & 3.0 & 279 & 275 & 2441 & 12.4 & 1.9 & 0.3 & \#N/A \\
\hline 12/8/06 9:00 & 892 & 6141 & 9776 & 600.4 & 432.0 & 168.4 & 28.0 & 1.12 & 3.0 & 278 & 274 & 2419 & 8.4 & 1.8 & 0.3 & \#N/A \\
\hline 12/8/06 10:00 & 884 & 6058 & 9776 & 593.3 & 427.0 & 166.3 & 28.0 & 1.14 & 3.1 & 278 & 277 & 2384 & 7.4 & 1.7 & 0.3 & \#N/A \\
\hline 12/8/06 11:00 & 885 & 6084 & 9776 & 591.1 & 425.4 & 165.7 & 28.0 & 1.14 & 3.1 & 280 & 278 & 2388 & 7.5 & 1.7 & 0.3 & \#N/A \\
\hline 12/8/06 12:00 & 885 & 6070 & 9776 & 590.8 & 425.2 & 165.7 & 28.0 & 1.15 & 3.0 & 281 & 279 & 2404 & 7.5 & 1.7 & 0.3 & \#N/A \\
\hline 12/8/06 13:00 & 889 & 6096 & 9776 & 592.2 & 426.2 & 166.1 & 28.0 & 1.15 & 3.0 & 283 & 281 & 2392 & 7.7 & 1.7 & 0.3 & \#N/A \\
\hline 12/8/06 14:00 & 890 & 6113 & 9776 & 590.2 & 424.7 & 165.5 & 28.0 & 1.15 & 3.1 & 286 & 284 & 2367 & 8.0 & 1.7 & 0.3 & \#N/A \\
\hline 12/8/06 15:00 & 892 & 6122 & 9776 & 584.1 & 420.4 & 163.7 & 28.0 & 1.16 & 3.0 & 287 & 286 & 2343 & 8.1 & 1.7 & 0.3 & \#N/A \\
\hline $12 / 8 / 0616: 00$ & 888 & 6131 & 9776 & 581.6 & 418.6 & 163.0 & 28.0 & 1.17 & 3.1 & 288 & 286 & 2345 & 8.2 & 1.6 & 0.3 & \#N/A \\
\hline 12/8/06 17:00 & 883 & 6073 & 9776 & 579.7 & 417.2 & 162.4 & 28.0 & 1.17 & 3.0 & 286 & 284 & 2330 & 7.5 & 1.7 & 0.3 & \#N/A \\
\hline 12/8/06 18:00 & 881 & 6060 & 9776 & 579.3 & 417.0 & 162.3 & 28.0 & 1.17 & 3.0 & 286 & 284 & 2347 & 7.6 & 1.7 & 0.3 & \#N/A \\
\hline 12/8/06 19:00 & 880 & 6080 & 9776 & 581.6 & 418.6 & 163.0 & 28.0 & 1.17 & 3.1 & 287 & 284 & 2357 & 7.7 & 1.7 & 0.3 & \#N/A \\
\hline 12/8/06 20:00 & 882 & 6083 & 9776 & 579.1 & 416.8 & 162.3 & 28.0 & 1.17 & 3.0 & 285 & 284 & 2365 & 7.6 & 1.7 & 0.3 & \#N/A \\
\hline 12/8/06 21:00 & 881 & 6059 & 9776 & 576.4 & 414.9 & 161.5 & 28.0 & 1.17 & 3.0 & 286 & 284 & 2358 & 7.6 & 1.6 & 0.3 & \#N/A \\
\hline 12/8/06 22:00 & 881 & 6038 & 9776 & 575.8 & 414.5 & 161.3 & 28.0 & 1.17 & 3.1 & 283 & 281 & 2356 & 7.6 & 1.6 & 0.3 & \#N/A \\
\hline 12/8/06 23:00 & 878 & 6019 & 9776 & 575.4 & 414.1 & 161.3 & 28.0 & 1.17 & 3.0 & 284 & 282 & 2353 & 7.8 & 1.6 & 0.3 & \#N/A \\
\hline 12/9/06 0:00 & 881 & 6055 & 9776 & 577.2 & 415.4 & 161.8 & 28.0 & 1.17 & 3.0 & 285 & 284 & 2367 & 7.8 & 1.6 & 0.2 & \#N/A \\
\hline 12/9/06 1:00 & 881 & 6075 & 9776 & 576.4 & 414.9 & 161.6 & 28.0 & 1.17 & 3.1 & 285 & 285 & 2365 & 8.0 & 1.6 & 0.3 & \#N/A \\
\hline
\end{tabular}




\begin{tabular}{|c|c|c|c|c|c|c|c|c|c|c|c|c|c|c|c|c|}
\hline Date and & $\begin{array}{c}\text { Gross } \\
\text { Gen }\end{array}$ & $\begin{array}{l}\text { Steam } \\
\text { Flow }\end{array}$ & $\begin{array}{c}\text { Gross } \\
\text { HR }\end{array}$ & $\begin{array}{l}\text { Total } \\
\text { Fuel }\end{array}$ & $\begin{array}{c}\text { Total } \\
\text { Lignite }\end{array}$ & $\begin{array}{l}\text { Total } \\
\text { PRB }\end{array}$ & $\begin{array}{l}\text { Total } \\
\text { PRB }\end{array}$ & Btu Gain & Econ 02 & $\begin{array}{c}\text { Temp A } \\
\text { APH } \\
\text { Out }\end{array}$ & $\begin{array}{c}\text { Temp B } \\
\text { APH } \\
\text { Out }\end{array}$ & $\begin{array}{l}\text { Stack } \\
\text { Flow }\end{array}$ & Opacity & SO2 In & SO2 Out & $\begin{array}{c}\text { NOx } \\
\text { Out }\end{array}$ \\
\hline and Time & MW & $\begin{array}{c}\text { KLB/ } \\
\text { HR }\end{array}$ & \begin{tabular}{|c} 
Btu/kW \\
hr
\end{tabular} & $\begin{array}{c}\text { TON/ } \\
\text { HR }\end{array}$ & $\begin{array}{c}\text { TON/ } \\
\text { HR }\end{array}$ & $\begin{array}{c}\text { TON/ } \\
\text { HR }\end{array}$ & $\begin{array}{c}\% \\
\text { Weight }\end{array}$ & & $\%$ & DEGF & DEGF & KSCF & $\%$ & $\begin{array}{c}\mathrm{lb} / \mathrm{MM} \\
\text { Btu }\end{array}$ & $\begin{array}{c}\mathrm{lb} / \mathrm{MM} \\
\text { Btu }\end{array}$ & $\begin{array}{l}\text { lb/M } \\
\text { MBtu }\end{array}$ \\
\hline $12 / 9 / 062: 00$ & 880 & 6030 & 9776 & 581.3 & 418.4 & 163.0 & 28.0 & 1.17 & 3.0 & 287 & 286 & 2359 & 7.8 & 1.6 & 0.3 & \#N/A \\
\hline 12/9/06 3:00 & 880 & 6063 & 9776 & 583.5 & 419.9 & 163.5 & 28.0 & 1.16 & 3.1 & 286 & 285 & 2341 & 8.1 & 1.7 & 0.3 & \#N/A \\
\hline 12/9/06 4:00 & 881 & 6080 & 9776 & 584.2 & 420.5 & 163.7 & 28.0 & 1.16 & 3.0 & 285 & 284 & 2342 & 7.9 & 1.6 & 0.3 & \#N/A \\
\hline 12/9/06 5:00 & 882 & 6037 & 9776 & 582.9 & 419.5 & 163.4 & 28.0 & 1.16 & 3.0 & 283 & 282 & 2345 & 9.4 & 1.6 & 0.2 & \#N/A \\
\hline 12/9/06 6:00 & 879 & 6030 & 9776 & 589.0 & 423.9 & 165.1 & 28.0 & 1.15 & 3.1 & 284 & 281 & 2337 & 7.7 & 1.5 & 0.2 & \#N/A \\
\hline 12/9/06 7:00 & 879 & 6020 & 9776 & 596.8 & 429.5 & 167.3 & 28.0 & 1.14 & 3.0 & 285 & 282 & 2340 & 7.9 & 1.5 & 0.2 & \#N/A \\
\hline 12/9/06 8:00 & 885 & 6107 & 9776 & 597.9 & 430.3 & 167.6 & 28.0 & 1.13 & 3.0 & 284 & 282 & 2344 & 8.2 & 1.5 & 0.2 & \#N/A \\
\hline 12/9/06 9:00 & 881 & 6029 & 9776 & 601.4 & 432.7 & 168.7 & 28.0 & 1.13 & 3.0 & 282 & 280 & 2339 & 8.0 & 1.6 & 0.3 & \#N/A \\
\hline 12/9/06 10:00 & 883 & 6064 & 9776 & 600.9 & 432.5 & 168.5 & 28.0 & 1.13 & 3.0 & 283 & 281 & 2343 & 7.8 & 1.7 & 0.3 & \#N/A \\
\hline 12/9/06 11:00 & 884 & 6067 & 9776 & 597.5 & 430.0 & 167.6 & 28.0 & 1.13 & 3.0 & 284 & 282 & 2370 & 7.9 & 1.6 & 0.3 & \#N/A \\
\hline 12/9/06 12:00 & 881 & 6061 & 9776 & 602.9 & 434.1 & 168.8 & 28.0 & 1.13 & 3.0 & 286 & 285 & 2364 & 8.2 & 1.7 & 0.3 & \#N/A \\
\hline 12/9/06 13:00 & 884 & 6080 & 9776 & 604.5 & 436.9 & 167.6 & 27.7 & 1.12 & 3.0 & 288 & 286 & 2393 & 8.4 & 1.6 & 0.3 & \#N/A \\
\hline $12 / 9 / 0614: 00$ & 880 & 6044 & 9776 & 600.1 & 433.8 & 166.3 & 27.7 & 1.12 & 3.0 & 290 & 288 & 2371 & 8.4 & 1.6 & 0.3 & \#N/A \\
\hline 12/9/06 15:00 & 881 & 6035 & 9776 & 600.9 & 434.4 & 166.5 & 27.7 & 1.12 & 3.1 & 292 & 290 & 2345 & 8.5 & 1.6 & 0.3 & \#N/A \\
\hline $12 / 9 / 0616: 00$ & 881 & 6067 & 9776 & 605.2 & 438.3 & 166.9 & 27.6 & 1.12 & 3.0 & 293 & 291 & 2347 & 8.7 & 1.7 & 0.3 & \#N/A \\
\hline 12/9/06 17:00 & 885 & 6080 & 9776 & 594.4 & 430.9 & 163.5 & 27.5 & 1.13 & 3.0 & 293 & 292 & 2355 & 8.4 & 1.6 & 0.3 & \#N/A \\
\hline 12/9/06 18:00 & 882 & 6042 & 9776 & 586.6 & 425.5 & 161.1 & 27.5 & 1.14 & 3.1 & 292 & 291 & 2358 & 8.6 & 1.5 & 0.2 & \#N/A \\
\hline 12/9/06 19:00 & 879 & 6045 & 9776 & 583.3 & 425.1 & 158.2 & 27.1 & 1.15 & 3.1 & 291 & 291 & 2369 & 8.6 & 1.5 & 0.2 & \#N/A \\
\hline 12/9/06 20:00 & 878 & 6019 & 9776 & 587.2 & 428.4 & 158.8 & 27.1 & 1.15 & 3.1 & 291 & 291 & 2379 & 8.5 & 1.5 & 0.2 & \#N/A \\
\hline 12/9/06 21:00 & 882 & 6014 & 9776 & 593.1 & 433.3 & 159.8 & 26.9 & 1.14 & 3.0 & 291 & 290 & 2395 & 8.4 & 1.5 & 0.2 & \#N/A \\
\hline 12/9/06 22:00 & 884 & 6053 & 9776 & 587.3 & 428.4 & 158.9 & 27.1 & 1.14 & 3.0 & 290 & 290 & 2404 & 8.5 & 1.5 & 0.2 & \#N/A \\
\hline 12/9/06 23:00 & 881 & 6039 & 9776 & 585.6 & 427.0 & 158.6 & 27.1 & 1.15 & 3.0 & 291 & 291 & 2388 & 8.6 & 1.5 & 0.2 & \#N/A \\
\hline 12/10/06 0:00 & 874 & 5981 & 9776 & 595.8 & 435.5 & 160.3 & 26.9 & 1.14 & 3.1 & 292 & 293 & 2375 & 8.8 & 1.6 & 0.2 & \#N/A \\
\hline 12/10/06 1:00 & 883 & 6095 & 9776 & 613.4 & 450.2 & 163.2 & 26.6 & 1.12 & 3.0 & 290 & 292 & 2383 & 8.8 & 1.7 & 0.3 & \#N/A \\
\hline $12 / 10 / 062: 00$ & 890 & 6078 & 9776 & 588.4 & 429.4 & 159.0 & 27.0 & 1.13 & 3.0 & 288 & 289 & 2393 & 8.4 & 1.5 & 0.2 & \#N/A \\
\hline 12/10/06 3:00 & 879 & 6003 & 9776 & 581.1 & 423.2 & 157.8 & 27.2 & 1.14 & 3.1 & 288 & 288 & 2382 & 8.5 & 1.5 & 0.2 & \#N/A \\
\hline 12/10/06 4:00 & 878 & 6010 & 9776 & 588.4 & 429.4 & 159.1 & 27.0 & 1.14 & 3.1 & 289 & 288 & 2365 & 8.4 & 1.5 & 0.2 & \#N/A \\
\hline 12/10/06 5:00 & 881 & 6051 & 9776 & 585.6 & 427.7 & 157.9 & 27.0 & 1.15 & 3.0 & 289 & 289 & 2371 & 8.2 & 1.5 & 0.2 & \#N/A \\
\hline $12 / 10 / 06$ 6:00 & 879 & 6017 & 9776 & 583.4 & 426.5 & 156.9 & 26.9 & 1.15 & 3.1 & 289 & 290 & 2384 & 8.5 & 1.5 & 0.2 & \#N/A \\
\hline $12 / 10 / 067: 00$ & 878 & 6022 & 9776 & 590.0 & 431.1 & 158.9 & 26.9 & 1.15 & 3.1 & 290 & 289 & 2394 & 8.7 & 1.5 & 0.2 & \#N/A \\
\hline 12/10/06 8:00 & 882 & 6103 & 9776 & 596.1 & 435.7 & 160.4 & 26.9 & 1.14 & 3.0 & 289 & 288 & 2399 & 8.3 & 1.6 & 0.3 & \#N/A \\
\hline $12 / 10 / 06$ 9:00 & 880 & 6072 & 9776 & 604.9 & 442.3 & 162.6 & 26.9 & 1.13 & 3.0 & 288 & 287 & 2398 & 8.5 & 1.6 & 0.3 & \#N/A \\
\hline 12/10/06 10:00 & 887 & 6106 & 9776 & 598.7 & 434.9 & 163.8 & 27.4 & 1.13 & 3.0 & 286 & 286 & 2402 & 8.4 & 1.6 & 0.3 & \#N/A \\
\hline 12/10/06 11:00 & 884 & 6072 & 9776 & 583.1 & 422.0 & 161.1 & 27.6 & 1.15 & 3.0 & 287 & 286 & 2400 & 8.3 & 1.4 & 0.2 & \#N/A \\
\hline 12/10/06 12:00 & 878 & 6068 & 9776 & 584.3 & 423.2 & 161.1 & 27.6 & 1.16 & 3.1 & 287 & 285 & 2404 & 8.4 & 1.5 & 0.2 & \#N/A \\
\hline 12/10/06 13:00 & 881 & 6080 & 9776 & 585.6 & 425.4 & 160.2 & 27.4 & 1.16 & 3.0 & 289 & 289 & 2407 & 8.5 & 1.5 & 0.2 & \#N/A \\
\hline $12 / 10 / 06$ 14:00 & 881 & 6079 & 9776 & 589.1 & 429.4 & 159.7 & 27.1 & 1.15 & 3.0 & 290 & 291 & 2395 & 8.6 & 1.5 & 0.2 & \#N/A \\
\hline
\end{tabular}




\begin{tabular}{|c|c|c|c|c|c|c|c|c|c|c|c|c|c|c|c|c|}
\hline Date and & $\begin{array}{c}\text { Gross } \\
\text { Gen }\end{array}$ & $\begin{array}{l}\text { Steam } \\
\text { Flow }\end{array}$ & $\begin{array}{c}\text { Gross } \\
\text { HR }\end{array}$ & $\begin{array}{l}\text { Total } \\
\text { Fuel }\end{array}$ & $\begin{array}{c}\text { Total } \\
\text { Lignite }\end{array}$ & $\begin{array}{l}\text { Total } \\
\text { PRB }\end{array}$ & $\begin{array}{l}\text { Total } \\
\text { PRB }\end{array}$ & Btu Gain & Econ 02 & $\begin{array}{c}\text { Temp A } \\
\text { APH } \\
\text { Out }\end{array}$ & $\begin{array}{c}\text { Temp B } \\
\text { APH } \\
\text { Out }\end{array}$ & $\begin{array}{l}\text { Stack } \\
\text { Flow }\end{array}$ & Opacity & SO2 In & SO2 Out & $\begin{array}{l}\text { NOx } \\
\text { Out }\end{array}$ \\
\hline and Time & MW & $\begin{array}{c}\text { KLB/ } \\
\text { HR }\end{array}$ & $\begin{array}{c}\text { Btu/kW } \\
\text { hr }\end{array}$ & $\begin{array}{c}\text { TON/ } \\
\text { HR }\end{array}$ & $\begin{array}{c}\text { TON/ } \\
\text { HR }\end{array}$ & $\begin{array}{c}\text { TON/ } \\
\text { HR }\end{array}$ & $\begin{array}{c}\% \\
\text { Weight }\end{array}$ & & $\%$ & DEGF & DEGF & KSCF & $\%$ & $\begin{array}{c}\mathrm{lb} / \mathbf{M M} \\
\text { Btu }\end{array}$ & $\begin{array}{c}\text { lb/MM } \\
\text { Btu }\end{array}$ & $\begin{array}{l}\text { lb/M } \\
\text { MBtu }\end{array}$ \\
\hline 12/10/06 15:00 & 882 & 6122 & 9776 & 587.0 & 427.3 & 159.7 & 27.2 & 1.16 & 3.0 & 291 & 290 & 2392 & 8.7 & 1.4 & 0.2 & \#N/A \\
\hline 12/10/06 16:00 & 880 & 6081 & 9776 & 586.5 & 426.8 & 159.7 & 27.2 & 1.16 & 3.0 & 291 & 290 & 2400 & 8.6 & 1.4 & 0.2 & \#N/A \\
\hline 12/10/06 17:00 & 882 & 6075 & 9776 & 585.7 & 426.0 & 159.7 & 27.3 & 1.16 & 3.0 & 292 & 291 & 2397 & 8.6 & 1.4 & 0.2 & \#N/A \\
\hline 12/10/06 18:00 & 879 & 6065 & 9776 & 585.7 & 426.0 & 159.7 & 27.3 & 1.16 & 3.0 & 292 & 291 & 2393 & 9.1 & 1.4 & 0.2 & \#N/A \\
\hline 12/10/06 19:00 & 881 & 6065 & 9776 & 586.8 & 427.2 & 159.7 & 27.2 & 1.15 & 3.0 & 292 & 288 & 2391 & 8.4 & 1.5 & 0.2 & \#N/A \\
\hline 12/10/06 20:00 & 878 & 6064 & 9776 & 595.1 & 435.4 & 159.7 & 26.8 & 1.15 & 3.0 & 292 & 292 & 2387 & 8.6 & 1.6 & 0.3 & \#N/A \\
\hline 12/10/06 21:00 & 879 & 6064 & 9776 & 604.5 & 444.9 & 159.6 & 26.4 & 1.14 & 3.0 & 294 & 293 & 2395 & 9.0 & 1.7 & 0.3 & \#N/A \\
\hline $12 / 10 / 0622: 00$ & 887 & 6124 & 9776 & 596.0 & 436.4 & 159.6 & 26.8 & 1.13 & 3.0 & 294 & 294 & 2420 & 9.0 & 1.7 & 0.3 & \#N/A \\
\hline 12/10/06 23:00 & 882 & 6076 & 9776 & 583.1 & 423.4 & 159.7 & 27.4 & 1.15 & 3.1 & 295 & 294 & 2401 & 9.1 & 1.6 & 0.3 & \#N/A \\
\hline
\end{tabular}


Table C-2. Parametric Phase 2 Unit 1 Hourly Average Process Data

\begin{tabular}{|c|c|c|c|c|c|c|c|c|c|c|c|c|c|c|c|c|}
\hline Date and & $\begin{array}{c}\text { Gross } \\
\text { Gen } \\
\end{array}$ & $\begin{array}{l}\text { Steam } \\
\text { Flow }\end{array}$ & Gross HR & $\begin{array}{l}\text { Total } \\
\text { Fuel } \\
\end{array}$ & \begin{tabular}{|c} 
Total \\
Lignite \\
\end{tabular} & $\begin{array}{l}\text { Total } \\
\text { PRB }\end{array}$ & $\begin{array}{l}\text { Total } \\
\text { PRB } \\
\end{array}$ & $\begin{array}{l}\text { Btu } \\
\text { Gain }\end{array}$ & $\begin{array}{c}\text { Econ } \\
\text { O2 } \\
\end{array}$ & $\begin{array}{c}\text { Temp } \\
\text { A APH } \\
\text { Out }\end{array}$ & \begin{tabular}{|c|} 
Temp \\
B APH \\
Out \\
\end{tabular} & $\begin{array}{l}\text { Stack } \\
\text { Flow } \\
\end{array}$ & Opacity & SO2 In & SO2 Out & NOx Out \\
\hline \begin{tabular}{|c|} 
Start Date and \\
Time \\
\end{tabular} & MW & KLB/HR & Btu/kWhr & TON/HR & TON/HR & TON/HR & \begin{tabular}{c|}
$\%$ \\
Weight \\
\end{tabular} & & $\%$ & DEGF & DEGF & KSCF & $\%$ & lb/MMBtu & lb/MMBtu & lb/MMBtu \\
\hline 4/20/07 1:00 & 874 & 6050 & 9872 & 612.4 & 453.6 & 158.8 & 25.9 & 1.12 & 3.2 & 299 & 297 & 2300 & 10.0 & 1.8 & 0.2 & 0.2 \\
\hline 4/20/07 2:00 & 878 & 6043 & 9872 & 636.7 & 474.5 & 162.3 & 25.5 & 1.09 & 3.1 & 299 & 294 & 2296 & 9.0 & 2.0 & 0.2 & 0.2 \\
\hline 4/20/07 3:00 & 884 & 6108 & 9872 & 624.0 & 463.6 & 160.5 & 25.7 & 1.09 & 3.1 & 298 & 294 & 2303 & 9.2 & 1.8 & 0.2 & 0.2 \\
\hline 4/20/07 4:00 & 870 & 5979 & 9872 & 604.6 & 446.9 & 157.6 & 26.1 & 1.09 & 3.2 & 298 & 293 & 2273 & 9.2 & 1.7 & 0.2 & 0.2 \\
\hline 4/20/07 5:00 & 885 & 6069 & 9872 & 627.4 & 466.5 & 160.9 & 25.6 & 1.09 & 3.1 & 298 & 294 & 2307 & 9.5 & 1.8 & 0.2 & 0.2 \\
\hline 4/20/07 6:00 & 890 & 6087 & 9872 & 631.4 & 469.9 & 161.5 & 25.6 & 1.08 & 3.1 & 297 & 296 & 2315 & 10.0 & 1.8 & 0.2 & 0.2 \\
\hline 4/20/07 7:00 & 889 & 6121 & 9872 & 631.2 & 468.8 & 162.4 & 25.7 & 1.08 & 3.1 & 296 & 296 & 2318 & 9.2 & 1.8 & 0.2 & 0.2 \\
\hline 4/20/07 8:00 & 888 & 6124 & 9872 & 627.7 & 465.2 & 162.5 & 25.9 & 1.09 & 3.1 & 295 & 295 & 2316 & 9.2 & 1.8 & 0.2 & 0.2 \\
\hline 4/20/07 9:00 & 888 & 6128 & 9872 & 613.2 & 452.8 & 160.4 & 26.2 & 1.10 & 3.1 & 294 & 293 & 2320 & 9.2 & 1.6 & 0.2 & 0.2 \\
\hline 4/20/07 10:00 & 883 & 6069 & 9872 & 608.4 & 448.7 & 159.7 & 26.2 & 1.11 & 3.2 & 294 & 294 & 2326 & 9.2 & 1.6 & 0.1 & 0.2 \\
\hline 4/20/07 11:00 & 886 & 6093 & 9872 & 601.9 & 443.1 & 158.8 & 26.4 & 1.12 & 3.1 & 298 & 297 & 2326 & 10.4 & 1.5 & 0.1 & 0.2 \\
\hline 4/20/07 12:00 & 880 & 6055 & 9872 & 604.7 & 445.6 & 159.2 & 26.3 & 1.12 & 3.2 & 298 & 299 & 2316 & 10.2 & 1.5 & 0.1 & 0.2 \\
\hline 4/20/07 13:00 & 883 & 6090 & 9872 & 613.2 & 452.8 & 160.4 & 26.2 & 1.12 & 3.1 & 300 & 300 & 2323 & 10.2 & 1.5 & 0.1 & 0.2 \\
\hline 4/20/07 14:00 & 887 & 6107 & 9872 & 612.0 & 451.8 & 160.2 & 26.2 & 1.11 & 3.1 & 302 & 300 & 2324 & 10.3 & 1.5 & 0.1 & 0.2 \\
\hline 4/20/07 15:00 & 887 & 6087 & 9872 & 602.9 & 443.9 & 158.9 & 26.4 & 1.12 & 3.1 & 303 & 302 & 2325 & 10.4 & 1.4 & 0.1 & 0.2 \\
\hline 4/20/07 16:00 & 885 & 6081 & 9872 & 598.0 & 439.7 & 158.3 & 26.5 & 1.13 & 3.1 & 304 & 303 & 2321 & 10.5 & 1.4 & 0.1 & 0.2 \\
\hline 4/20/07 17:00 & 884 & 6093 & 9872 & 596.8 & 438.7 & 158.1 & 26.5 & 1.14 & 3.1 & 306 & 303 & 2330 & 10.3 & 1.4 & 0.1 & 0.2 \\
\hline 4/20/07 18:00 & 888 & 6112 & 9872 & 602.2 & 442.3 & 159.9 & 26.6 & 1.14 & 3.1 & 305 & 303 & 2329 & 10.4 & 1.4 & 0.1 & 0.2 \\
\hline 4/20/07 19:00 & 888 & 6150 & 9872 & 605.1 & 443.7 & 161.3 & 26.7 & 1.14 & 3.1 & 302 & 302 & 2337 & 10.7 & 1.4 & 0.1 & 0.2 \\
\hline 4/20/07 20:00 & 889 & 6146 & 9872 & 603.8 & 442.6 & 161.1 & 26.7 & 1.14 & 3.1 & 303 & 301 & 2341 & 10.6 & 1.5 & 0.1 & 0.2 \\
\hline 4/20/07 21:00 & 891 & 6128 & 9872 & 603.8 & 442.6 & 161.2 & 26.7 & 1.14 & 3.1 & 302 & 300 & 2336 & 10.4 & 1.4 & 0.1 & 0.2 \\
\hline 4/20/07 22:00 & 889 & 6149 & 9872 & 600.5 & 439.8 & 160.7 & 26.8 & 1.14 & 3.1 & 301 & 300 & 2334 & 10.5 & 1.4 & 0.1 & 0.2 \\
\hline 4/20/07 23:00 & 887 & 6081 & 9872 & 596.4 & 436.3 & 160.1 & 26.8 & 1.14 & 3.1 & 299 & 299 & 2324 & 10.4 & 1.4 & 0.1 & 0.2 \\
\hline 4/21/07 0:00 & 887 & 6087 & 9872 & 593.0 & 433.4 & 159.6 & 26.9 & 1.14 & 3.1 & 298 & 298 & 2305 & 10.4 & 1.4 & 0.1 & 0.2 \\
\hline 4/21/07 1:00 & 851 & 5891 & 9872 & 562.8 & 409.9 & 152.9 & 27.2 & 1.15 & 3.2 & 297 & 295 & 2249 & 10.1 & 1.3 & 0.1 & 0.2 \\
\hline 4/21/07 2:00 & 719 & 4924 & 9872 & 487.9 & 368.8 & 119.2 & 24.4 & 1.15 & 3.2 & 300 & 292 & 2000 & 9.2 & 1.4 & 0.1 & 0.2 \\
\hline 4/21/07 3:00 & 824 & 5637 & 9872 & 558.8 & 436.6 & 122.1 & 21.9 & 1.14 & 3.2 & 294 & 292 & 2149 & 9.9 & 1.4 & 0.1 & 0.2 \\
\hline 4/21/07 4:00 & 864 & 5923 & 9872 & 581.8 & 438.3 & 143.5 & 24.7 & 1.14 & 3.1 & 296 & 293 & 2257 & 10.3 & 1.4 & 0.1 & 0.2 \\
\hline 4/21/07 5:00 & 845 & 5766 & 9872 & 563.4 & 417.1 & 146.3 & 26.0 & 1.14 & 3.1 & 293 & 293 & 2194 & 10.0 & 1.3 & 0.1 & 0.2 \\
\hline
\end{tabular}




\begin{tabular}{|c|c|c|c|c|c|c|c|c|c|c|c|c|c|c|c|c|}
\hline Date and & $\begin{array}{c}\text { Gross } \\
\text { Gen }\end{array}$ & $\begin{array}{l}\text { Steam } \\
\text { Flow }\end{array}$ & Gross HR & $\begin{array}{l}\text { Total } \\
\text { Fuel } \\
\end{array}$ & $\begin{array}{c}\text { Total } \\
\text { Lignite }\end{array}$ & $\begin{array}{l}\text { Total } \\
\text { PRB }\end{array}$ & $\begin{array}{l}\text { Total } \\
\text { PRB }\end{array}$ & $\begin{array}{c}\text { Btu } \\
\text { Gain }\end{array}$ & $\begin{array}{c}\text { Econ } \\
\text { O2 }\end{array}$ & $\begin{array}{c}\text { Temp } \\
\text { A APH } \\
\text { Out }\end{array}$ & $\begin{array}{c}\text { Temp } \\
\text { B APH } \\
\text { Out } \\
\end{array}$ & $\begin{array}{l}\text { Stack } \\
\text { Flow }\end{array}$ & Opacity & SO2 In & SO2 Out & NOx Out \\
\hline $\begin{array}{c}\text { Start Date and } \\
\text { Time }\end{array}$ & MW & KLB/HR & Btu/kWhr & TON/HR & TON/HR & TON/HR & \begin{tabular}{|c|}
$\%$ \\
Weight
\end{tabular} & & $\%$ & DEGF & DEGF & KSCF & $\%$ & lb/MMBtu & Ib/MMBtu & Ib/MMBtu \\
\hline $4 / 21 / 076: 00$ & 883 & 6121 & 9872 & 592.6 & 431.6 & 161.0 & 27.2 & 1.14 & 3.2 & 296 & 293 & 2294 & 11.1 & 1.4 & 0.1 & 0.2 \\
\hline $4 / 21 / 07$ 7:00 & 884 & 6110 & 9872 & 587.8 & 431.3 & 156.4 & 26.6 & 1.15 & 3.1 & 293 & 291 & 2286 & 10.5 & 1.4 & 0.1 & 0.2 \\
\hline 4/21/07 8:00 & 886 & 6061 & 9872 & 572.5 & 420.8 & 151.7 & 26.5 & 1.17 & 3.1 & 291 & 289 & 2287 & 10.5 & 1.4 & 0.1 & 0.2 \\
\hline 4/21/07 9:00 & 881 & 6081 & 9872 & 572.1 & 420.2 & 152.0 & 26.6 & 1.18 & 3.2 & 293 & 290 & 2294 & 10.6 & 1.4 & 0.1 & 0.2 \\
\hline $4 / 21 / 07$ 10:00 & 883 & 6069 & 9872 & 582.0 & 426.9 & 155.1 & 26.7 & 1.17 & 3.1 & 295 & 292 & 2302 & 10.6 & 1.4 & 0.1 & 0.2 \\
\hline $4 / 21 / 07$ 11:00 & 886 & 6090 & 9872 & 589.5 & 432.3 & 157.2 & 26.7 & 1.16 & 3.1 & 297 & 294 & 2309 & 10.6 & 1.4 & 0.1 & 0.2 \\
\hline $4 / 21 / 07$ 12:00 & 888 & 6131 & 9872 & 591.6 & 436.1 & 155.5 & 26.3 & 1.16 & 3.1 & 300 & 297 & 2318 & 10.8 & 1.4 & 0.1 & 0.2 \\
\hline 4/21/07 13:00 & 888 & 6088 & 9872 & 590.2 & 435.0 & 155.1 & 26.3 & 1.15 & 3.1 & 302 & 299 & 2316 & 10.8 & 1.4 & 0.1 & 0.2 \\
\hline $4 / 21 / 0714: 00$ & 888 & 6113 & 9872 & 588.7 & 434.0 & 154.7 & 26.3 & 1.16 & 3.1 & 303 & 299 & 2313 & 10.6 & 1.4 & 0.1 & 0.2 \\
\hline $4 / 21 / 07$ 15:00 & 886 & 6105 & 9872 & 581.8 & 429.0 & 152.7 & 26.3 & 1.16 & 3.1 & 304 & 301 & 2327 & 10.6 & 1.4 & 0.1 & 0.2 \\
\hline 4/21/07 16:00 & 888 & 6090 & 9872 & 585.7 & 431.9 & 153.9 & 26.3 & 1.16 & 3.1 & 304 & 303 & 2329 & 10.5 & 1.4 & 0.1 & 0.2 \\
\hline $4 / 21 / 07$ 17:00 & 888 & 6106 & 9872 & 591.0 & 435.7 & 155.4 & 26.3 & 1.16 & 3.1 & 304 & 304 & 2340 & 10.6 & 1.4 & 0.1 & 0.2 \\
\hline $4 / 21 / 07$ 18:00 & 887 & 6100 & 9872 & 596.1 & 439.3 & 156.8 & 26.3 & 1.15 & 3.1 & 307 & 305 & 2335 & 10.3 & 1.4 & 0.1 & 0.2 \\
\hline 4/21/07 19:00 & 885 & 6094 & 9872 & 592.6 & 436.7 & 155.8 & 26.3 & 1.15 & 3.1 & 305 & 304 & 2314 & 10.6 & 1.4 & 0.1 & 0.2 \\
\hline $4 / 21 / 0720: 00$ & 881 & 6055 & 9872 & 586.1 & 432.1 & 154.0 & 26.3 & 1.15 & 3.1 & 302 & 302 & 2304 & 10.5 & 1.4 & 0.1 & 0.2 \\
\hline $4 / 21 / 0721: 00$ & 881 & 6070 & 9872 & 587.3 & 433.0 & 154.3 & 26.3 & 1.15 & 3.1 & 301 & 301 & 2293 & 10.7 & 1.4 & 0.1 & 0.2 \\
\hline $4 / 21 / 0722: 00$ & 879 & 6060 & 9872 & 583.2 & 430.1 & 153.1 & 26.3 & 1.15 & 3.1 & 300 & 298 & 2289 & 10.6 & 1.4 & 0.1 & 0.2 \\
\hline $4 / 21 / 0723: 00$ & 877 & 6041 & 9872 & 584.0 & 430.6 & 153.4 & 26.3 & 1.16 & 3.1 & 297 & 295 & 2282 & 10.7 & 1.4 & 0.1 & 0.2 \\
\hline 4/22/07 0:00 & 877 & 6064 & 9872 & 581.1 & 428.6 & 152.5 & 26.2 & 1.16 & 3.1 & 296 & 292 & 2285 & 10.6 & 1.4 & 0.1 & 0.2 \\
\hline 4/22/07 1:00 & 882 & 6028 & 9872 & 578.3 & 426.5 & 151.7 & 26.2 & 1.16 & 3.1 & 294 & 291 & 2280 & 10.5 & 1.4 & 0.1 & 0.2 \\
\hline 4/22/07 2:00 & 879 & 6006 & 9872 & 570.7 & 421.1 & 149.6 & 26.2 & 1.17 & 3.2 & 294 & 292 & 2281 & 10.7 & 1.4 & 0.1 & 0.2 \\
\hline 4/22/07 3:00 & 876 & 5979 & 9872 & 578.1 & 426.4 & 151.7 & 26.2 & 1.16 & 3.2 & 295 & 292 & 2271 & 10.6 & 1.4 & 0.1 & 0.2 \\
\hline 4/22/07 4:00 & 879 & 6046 & 9872 & 577.6 & 426.0 & 151.5 & 26.2 & 1.17 & 3.1 & 297 & 293 & 2285 & 10.7 & 1.4 & 0.1 & 0.2 \\
\hline 4/22/07 5:00 & 879 & 6026 & 9872 & 571.7 & 421.8 & 149.9 & 26.2 & 1.17 & 3.1 & 298 & 294 & 2293 & 10.7 & 1.4 & 0.1 & 0.2 \\
\hline 4/22/07 6:00 & 878 & 6021 & 9872 & 571.2 & 421.4 & 149.7 & 26.2 & 1.17 & 3.2 & 299 & 295 & 2292 & 10.6 & 1.4 & 0.1 & 0.2 \\
\hline 4/22/07 7:00 & 861 & 5933 & 9872 & 568.0 & 421.5 & 146.5 & 25.8 & 1.18 & 3.2 & 298 & 295 & 2256 & 10.8 & 1.4 & 0.1 & 0.2 \\
\hline 4/22/07 8:00 & 884 & 6067 & 9872 & 587.1 & 431.7 & 155.4 & 26.5 & 1.16 & 3.1 & 296 & 294 & 2310 & 10.9 & 1.4 & 0.1 & 0.2 \\
\hline 4/22/07 9:00 & 885 & 6106 & 9872 & 587.8 & 432.1 & 155.7 & 26.5 & 1.16 & 3.1 & 297 & 294 & 2307 & 10.7 & 1.5 & 0.1 & 0.2 \\
\hline 4/22/07 10:00 & 885 & 6110 & 9872 & 584.6 & 429.8 & 154.8 & 26.5 & 1.16 & 3.1 & 297 & 293 & 2297 & 10.8 & 1.5 & 0.1 & 0.2 \\
\hline 4/22/07 11:00 & 886 & 6051 & 9872 & 580.1 & 426.6 & 153.5 & 26.5 & 1.16 & 3.1 & 299 & 294 & 2288 & 10.9 & 1.4 & 0.1 & 0.2 \\
\hline $4 / 22 / 07$ 12:00 & 882 & 6043 & 9872 & 585.6 & 430.6 & 155.0 & 26.5 & 1.16 & 3.1 & 300 & 296 & 2311 & 10.8 & 1.4 & 0.1 & 0.2 \\
\hline
\end{tabular}




\begin{tabular}{|c|c|c|c|c|c|c|c|c|c|c|c|c|c|c|c|c|}
\hline Date and & $\begin{array}{c}\text { Gross } \\
\text { Gen }\end{array}$ & $\begin{array}{l}\text { Steam } \\
\text { Flow }\end{array}$ & Gross HR & $\begin{array}{l}\text { Total } \\
\text { Fuel } \\
\end{array}$ & \begin{tabular}{|c|} 
Total \\
Lignite \\
\end{tabular} & $\begin{array}{l}\text { Total } \\
\text { PRB }\end{array}$ & $\begin{array}{l}\text { Total } \\
\text { PRB }\end{array}$ & $\begin{array}{l}\text { Btu } \\
\text { Gain }\end{array}$ & $\begin{array}{c}\text { Econ } \\
\text { O2 }\end{array}$ & $\begin{array}{c}\text { Temp } \\
\text { A APH } \\
\text { Out }\end{array}$ & \begin{tabular}{|c|} 
Temp \\
B APH \\
Out \\
\end{tabular} & $\begin{array}{l}\text { Stack } \\
\text { Flow } \\
\end{array}$ & Opacity & SO2 In & SO2 Out & NOx Out \\
\hline $\begin{array}{c}\text { Start Date and } \\
\text { Time } \\
\end{array}$ & MW & KLB/HR & Btu/kWhr & TON/HR & TON/HR| & TON/HR & \begin{tabular}{c|}
$\%$ \\
Weight
\end{tabular} & & $\%$ & DEGF & DEGF & KSCF & $\%$ & lb/MMBtu & lb/MMBtu & lb/MMBtu \\
\hline 4/22/07 13:00 & 882 & 6070 & 9872 & 595.8 & 438.7 & 157.0 & 26.4 & 1.15 & 3.1 & 302 & 299 & 2328 & 11.0 & 1.4 & 0.1 & 0.2 \\
\hline 4/22/07 14:00 & 887 & 6082 & 9872 & 594.7 & 438.3 & 156.4 & 26.3 & 1.14 & 3.1 & 303 & 301 & 2323 & 10.8 & 1.4 & 0.1 & 0.2 \\
\hline $4 / 22 / 07$ 15:00 & 885 & 6066 & 9872 & 593.7 & 437.6 & 156.1 & 26.3 & 1.14 & 3.1 & 304 & 301 & 2324 & 10.7 & 1.4 & 0.1 & 0.2 \\
\hline 4/22/07 16:00 & 885 & 6100 & 9872 & 589.2 & 434.3 & 154.8 & 26.3 & 1.15 & 3.1 & 304 & 301 & 2326 & 10.7 & 1.4 & 0.1 & 0.2 \\
\hline 4/22/07 17:00 & 883 & 6051 & 9872 & 587.3 & 433.0 & 154.3 & 26.3 & 1.15 & 3.1 & 305 & 302 & 2320 & 10.8 & 1.4 & 0.1 & 0.2 \\
\hline 4/22/07 18:00 & 884 & 6049 & 9872 & 590.6 & 435.4 & 155.2 & 26.3 & 1.15 & 3.1 & 306 & 302 & 2317 & 10.8 & 1.4 & 0.1 & 0.2 \\
\hline 4/22/07 19:00 & 885 & 6075 & 9872 & 590.1 & 435.0 & 155.1 & 26.3 & 1.15 & 3.1 & 306 & 303 & 2327 & 10.9 & 1.4 & 0.1 & 0.2 \\
\hline 4/22/07 20:00 & 884 & 6070 & 9872 & 589.5 & 434.6 & 154.9 & 26.3 & 1.15 & 3.1 & 305 & 304 & 2328 & 11.0 & 1.4 & 0.1 & 0.2 \\
\hline 4/22/07 21:00 & 885 & 6111 & 9872 & 584.1 & 430.7 & 153.4 & 26.3 & 1.16 & 3.2 & 303 & 302 & 2328 & 10.8 & 1.4 & 0.1 & 0.2 \\
\hline $4 / 22 / 07$ 22:00 & 883 & 6067 & 9872 & 585.6 & 431.9 & 153.7 & 26.2 & 1.16 & 3.2 & 300 & 298 & 2330 & 10.7 & 1.4 & 0.1 & 0.2 \\
\hline 4/22/07 23:00 & 885 & 6088 & 9872 & 581.6 & 429.0 & 152.7 & 26.2 & 1.16 & 3.1 & 301 & 298 & 2317 & 10.8 & 1.4 & 0.1 & 0.2 \\
\hline 4/23/07 0:00 & 885 & 6108 & 9872 & 577.2 & 425.8 & 151.3 & 26.2 & 1.17 & 3.1 & 300 & 299 & 2321 & 10.8 & 1.4 & 0.1 & 0.2 \\
\hline 4/23/07 1:00 & 882 & 6051 & 9872 & 578.2 & 426.5 & 151.7 & 26.2 & 1.17 & 3.2 & 299 & 297 & 2306 & 10.7 & 1.4 & 0.1 & 0.2 \\
\hline 4/23/07 2:00 & 881 & 6062 & 9872 & 588.0 & 433.5 & 154.5 & 26.3 & 1.16 & 3.1 & 299 & 296 & 2310 & 10.7 & 1.5 & 0.1 & 0.2 \\
\hline 4/23/07 3:00 & 882 & 6054 & 9872 & 599.9 & 442.0 & 157.9 & 26.3 & 1.15 & 3.1 & 300 & 296 & 2322 & 10.7 & 1.5 & 0.1 & 0.2 \\
\hline $4 / 23 / 074: 00$ & 887 & 6109 & 9872 & 605.2 & 445.8 & 159.4 & 26.3 & 1.13 & 3.1 & 299 & 297 & 2318 & 10.8 & 1.6 & 0.1 & 0.2 \\
\hline $4 / 23 / 07$ 5:00 & 887 & 6099 & 9872 & 601.4 & 443.0 & 158.3 & 26.3 & 1.13 & 3.1 & 300 & 297 & 2322 & 10.8 & 1.5 & 0.1 & 0.2 \\
\hline 4/23/07 6:00 & 886 & 6067 & 9872 & 598.1 & 440.6 & 157.4 & 26.3 & 1.13 & 3.1 & 302 & 296 & 2320 & 11.3 & 1.5 & 0.1 & 0.2 \\
\hline $4 / 23 / 07$ 7:00 & 886 & 6056 & 9872 & 594.0 & 437.8 & 156.2 & 26.3 & 1.13 & 3.1 & 303 & 297 & 2326 & 10.8 & 1.5 & 0.1 & 0.2 \\
\hline $4 / 23 / 078: 00$ & 883 & 6097 & 9872 & 592.2 & 436.5 & 155.7 & 26.3 & 1.14 & 3.1 & 303 & 298 & 2346 & 10.9 & 1.5 & 0.1 & 0.2 \\
\hline 4/23/07 9:00 & 883 & 6072 & 9872 & 593.4 & 437.4 & 156.1 & 26.3 & 1.14 & 3.1 & 300 & 297 & 2348 & 9.7 & 1.5 & 0.1 & 0.2 \\
\hline 4/23/07 10:00 & 883 & 6070 & 9872 & 597.2 & 440.1 & 157.1 & 26.3 & 1.14 & 3.2 & 298 & 297 & 2334 & 9.7 & 1.6 & 0.1 & 0.2 \\
\hline \begin{tabular}{|l|}
$4 / 23 / 07$ 11:00 \\
\end{tabular} & 886 & 6146 & 9872 & 597.6 & 440.3 & 157.3 & 26.3 & 1.15 & 3.1 & 298 & 297 & 2344 & 9.7 & 1.5 & 0.1 & 0.2 \\
\hline 4/23/07 12:00 & 887 & 6113 & 9872 & 592.0 & 436.4 & 155.6 & 26.3 & 1.15 & 3.1 & 299 & 297 & 2397 & 9.5 & 1.5 & 0.1 & 0.2 \\
\hline 4/23/07 13:00 & 885 & 6102 & 9872 & 595.4 & 438.8 & 156.6 & 26.3 & 1.15 & 3.1 & 300 & 299 & 2419 & 9.4 & 1.5 & 0.1 & 0.2 \\
\hline 4/23/07 14:00 & 887 & 6092 & 9872 & 601.2 & 442.9 & 158.3 & 26.3 & 1.14 & 3.1 & 302 & 302 & 2345 & 9.5 & 1.5 & 0.1 & 0.2 \\
\hline 4/23/07 15:00 & 888 & 6101 & 9872 & 599.9 & 442.0 & 157.9 & 26.3 & 1.14 & 3.1 & 303 & 302 & 2336 & 9.3 & 1.5 & 0.1 & 0.2 \\
\hline 4/23/07 16:00 & 886 & 6102 & 9872 & 600.1 & 442.2 & 157.9 & 26.3 & 1.14 & 3.1 & 303 & 302 & 2345 & 9.1 & 1.5 & 0.1 & 0.2 \\
\hline 4/23/07 17:00 & 885 & 6097 & 9872 & 603.8 & 444.8 & 159.0 & 26.3 & 1.13 & 3.1 & 302 & 302 & 2339 & 9.6 & 1.5 & 0.1 & 0.2 \\
\hline 4/23/07 18:00 & 885 & 6112 & 9872 & 610.1 & 449.3 & 160.8 & 26.4 & 1.12 & 3.1 & 302 & 302 & 2332 & 9.5 & 1.5 & 0.1 & 0.2 \\
\hline 4/23/07 19:00 & 887 & 6091 & 9872 & 617.9 & 454.8 & 163.0 & 26.4 & 1.11 & 3.1 & 302 & 302 & 2340 & 9.5 & 1.5 & 0.1 & 0.2 \\
\hline
\end{tabular}




\begin{tabular}{|c|c|c|c|c|c|c|c|c|c|c|c|c|c|c|c|c|}
\hline Date and & $\begin{array}{c}\text { Gross } \\
\text { Gen }\end{array}$ & $\begin{array}{l}\text { Steam } \\
\text { Flow }\end{array}$ & Gross HR & $\begin{array}{l}\text { Total } \\
\text { Fuel } \\
\end{array}$ & $\begin{array}{c}\text { Total } \\
\text { Lignite }\end{array}$ & $\begin{array}{l}\text { Total } \\
\text { PRB }\end{array}$ & $\begin{array}{l}\text { Total } \\
\text { PRB }\end{array}$ & $\begin{array}{l}\text { Btu } \\
\text { Gain }\end{array}$ & $\begin{array}{c}\text { Econ } \\
\text { O2 }\end{array}$ & \begin{tabular}{|c|} 
Temp \\
A APH \\
Out \\
\end{tabular} & $\begin{array}{c}\text { Temp } \\
\text { B APH } \\
\text { Out }\end{array}$ & $\begin{array}{l}\text { Stack } \\
\text { Flow }\end{array}$ & Opacity & SO2 In & SO2 Out & NOx Out \\
\hline $\begin{array}{c}\text { Start Date and } \\
\text { Time }\end{array}$ & MW & KLB/HR & Btu/kWhr & TON/HR & TON/HR & TON/HR & \begin{tabular}{|c|}
$\%$ \\
Weight
\end{tabular} & & $\%$ & DEGF & DEGF & KSCF & $\%$ & lb/MMBtu & Ib/MMBtu & Ib/MMBtu \\
\hline $4 / 23 / 07$ 20:00 & 884 & 6121 & 9872 & 625.7 & 460.4 & 165.3 & 26.4 & 1.10 & 3.1 & 301 & 301 & 2328 & 9.7 & 1.6 & 0.1 & 0.2 \\
\hline 4/23/07 21:00 & 885 & 6143 & 9872 & 636.6 & 471.7 & 165.0 & 25.9 & 1.09 & 3.1 & 301 & 300 & 2340 & 9.3 & 1.6 & 0.1 & 0.2 \\
\hline $4 / 23 / 0722: 00$ & 889 & 6119 & 9872 & 641.9 & 475.5 & 166.4 & 25.9 & 1.08 & 3.1 & 301 & 300 & 2344 & 9.1 & 1.7 & 0.1 & 0.2 \\
\hline $4 / 23 / 07$ 23:00 & 890 & 6097 & 9872 & 642.9 & 476.2 & 166.7 & 25.9 & 1.07 & 3.1 & 303 & 301 & 2326 & 9.2 & 1.7 & 0.2 & 0.2 \\
\hline 4/24/07 0:00 & 889 & 6122 & 9872 & 632.7 & 468.9 & 163.8 & 25.9 & 1.07 & 3.1 & 300 & 298 & 2318 & 9.2 & 1.6 & 0.1 & 0.2 \\
\hline 4/24/07 1:00 & 888 & 6084 & 9872 & 630.1 & 467.0 & 163.0 & 25.9 & 1.07 & 3.1 & 301 & 297 & 2327 & 9.3 & 1.6 & 0.1 & 0.2 \\
\hline 4/24/07 2:00 & 882 & 6045 & 9872 & 638.1 & 472.7 & 165.3 & 25.9 & 1.07 & 3.2 & 301 & 297 & 2314 & 9.0 & 1.6 & 0.1 & 0.2 \\
\hline 4/24/07 3:00 & 886 & 6099 & 9872 & 643.8 & 476.8 & 167.0 & 25.9 & 1.06 & 3.1 & 299 & 297 & 2309 & 8.8 & 1.6 & 0.1 & 0.2 \\
\hline 4/24/07 4:00 & 888 & 6144 & 9872 & 636.3 & 471.5 & 164.8 & 25.9 & 1.07 & 3.1 & 300 & 296 & 2320 & 8.6 & 1.6 & 0.1 & 0.2 \\
\hline $4 / 24 / 07$ 5:00 & 891 & 6127 & 9872 & 620.1 & 458.5 & 161.6 & 26.1 & 1.08 & 3.1 & 299 & 296 & 2329 & 8.6 & 1.5 & 0.1 & 0.2 \\
\hline 4/24/07 6:00 & 886 & 6088 & 9872 & 607.0 & 447.9 & 159.0 & 26.2 & 1.10 & 3.1 & 298 & 295 & 2317 & 8.6 & 1.4 & 0.1 & 0.2 \\
\hline $4 / 24 / 07$ 7:00 & 884 & 6069 & 9872 & 605.0 & 446.5 & 158.5 & 26.2 & 1.11 & 3.2 & 298 & 295 & 2316 & 9.0 & 1.4 & 0.1 & 0.2 \\
\hline 4/24/07 8:00 & 885 & 6102 & 9872 & 605.6 & 447.0 & 158.6 & 26.2 & 1.12 & 3.1 & 300 & 296 & 2326 & 8.9 & 1.4 & 0.1 & 0.2 \\
\hline 4/24/07 9:00 & 885 & 6131 & 9872 & 604.0 & 445.8 & 158.2 & 26.2 & 1.13 & 3.2 & 300 & 297 & 2315 & 9.2 & 1.4 & 0.1 & 0.2 \\
\hline $4 / 24 / 07$ 10:00 & 885 & 6131 & 9872 & 603.3 & 445.3 & 158.0 & 26.2 & 1.13 & 3.1 & 301 & 296 & 2324 & 8.9 & 1.4 & 0.1 & 0.2 \\
\hline $4 / 24 / 07$ 11:00 & 884 & 6148 & 9872 & 604.9 & 446.5 & 158.4 & 26.2 & 1.13 & 3.1 & 301 & 296 & 2317 & 8.9 & 1.3 & 0.1 & 0.2 \\
\hline $4 / 24 / 07$ 12:00 & 889 & 6116 & 9872 & 603.8 & 445.7 & 158.1 & 26.2 & 1.13 & 3.1 & 299 & 296 & 2317 & 8.9 & 1.3 & 0.1 & 0.2 \\
\hline $4 / 24 / 07$ 13:00 & 886 & 6110 & 9872 & 605.2 & 446.7 & 158.5 & 26.2 & 1.13 & 3.1 & 301 & 297 & 2321 & 13.2 & 1.3 & 0.1 & 0.2 \\
\hline $4 / 24 / 07$ 14:00 & 886 & 6110 & 9872 & 606.3 & 447.5 & 158.8 & 26.2 & 1.13 & 3.1 & 304 & 297 & 2319 & 8.4 & 1.3 & 0.1 & 0.2 \\
\hline $4 / 24 / 07$ 15:00 & 888 & 6111 & 9872 & 604.6 & 446.3 & 158.3 & 26.2 & 1.13 & 3.1 & 302 & 299 & 2331 & 8.5 & 1.4 & 0.1 & 0.2 \\
\hline 4/24/07 16:00 & 888 & 6127 & 9872 & 598.0 & 441.5 & 156.5 & 26.2 & 1.14 & 3.1 & 299 & 298 & 2331 & 9.5 & 1.4 & 0.1 & 0.2 \\
\hline 4/24/07 17:00 & 889 & 6154 & 9872 & 584.8 & 432.1 & 152.7 & 26.1 & 1.15 & 3.1 & 299 & 298 & 2329 & 9.6 & 1.3 & 0.1 & 0.2 \\
\hline 4/24/07 18:00 & 885 & 6106 & 9872 & 574.2 & 422.4 & 151.8 & 26.4 & 1.17 & 3.2 & 299 & 297 & 2331 & 9.5 & 1.3 & 0.1 & 0.2 \\
\hline $4 / 24 / 07$ 19:00 & 879 & 6077 & 9872 & 586.3 & 430.4 & 155.8 & 26.6 & 1.17 & 3.2 & 298 & 297 & 2300 & 9.8 & 1.4 & 0.1 & 0.2 \\
\hline $4 / 24 / 0720: 00$ & 882 & 6111 & 9872 & 605.2 & 445.8 & 159.4 & 26.3 & 1.15 & 3.1 & 297 & 295 & 2302 & 9.8 & 1.5 & 0.1 & 0.2 \\
\hline $4 / 24 / 07$ 21:00 & 888 & 6140 & 9872 & 614.0 & 454.3 & 159.7 & 26.0 & 1.13 & 3.1 & 298 & 295 & 2309 & 9.4 & 1.6 & 0.1 & 0.2 \\
\hline $4 / 24 / 0722: 00$ & 889 & 6139 & 9872 & 612.9 & 453.6 & 159.3 & 26.0 & 1.12 & 3.1 & 300 & 295 & 2311 & 9.3 & 1.6 & 0.1 & 0.2 \\
\hline $4 / 24 / 07$ 23:00 & 892 & 6104 & 9872 & 604.7 & 447.4 & 157.3 & 26.0 & 1.13 & 3.1 & 300 & 296 & 2315 & 9.4 & 1.6 & 0.1 & 0.2 \\
\hline $4 / 25 / 07$ 0:00 & 889 & 6106 & 9872 & 596.1 & 441.0 & 155.1 & 26.0 & 1.13 & 3.1 & 299 & 297 & 2324 & 9.8 & 1.5 & 0.1 & 0.2 \\
\hline 4/25/07 1:00 & 885 & 6100 & 9872 & 592.7 & 438.4 & 154.3 & 26.0 & 1.14 & 3.1 & 299 & 295 & 2317 & 10.0 & 1.5 & 0.1 & 0.2 \\
\hline $4 / 25 / 07$ 2:00 & 887 & 6103 & 9872 & 588.3 & 435.1 & 153.2 & 26.0 & 1.15 & 3.1 & 298 & 278 & 2297 & 8.9 & 1.5 & 0.1 & 0.2 \\
\hline
\end{tabular}

C-11 


\begin{tabular}{|c|c|c|c|c|c|c|c|c|c|c|c|c|c|c|c|c|}
\hline Date and & $\begin{array}{c}\text { Gross } \\
\text { Gen }\end{array}$ & $\begin{array}{l}\text { Steam } \\
\text { Flow }\end{array}$ & Gross HR & $\begin{array}{l}\text { Total } \\
\text { Fuel } \\
\end{array}$ & $\begin{array}{c}\text { Total } \\
\text { Lignite }\end{array}$ & $\begin{array}{l}\text { Total } \\
\text { PRB }\end{array}$ & $\begin{array}{l}\text { Total } \\
\text { PRB }\end{array}$ & $\begin{array}{c}\text { Btu } \\
\text { Gain }\end{array}$ & $\begin{array}{c}\text { Econ } \\
\text { O2 }\end{array}$ & $\begin{array}{c}\text { Temp } \\
\text { A APH } \\
\text { Out }\end{array}$ & $\begin{array}{c}\text { Temp } \\
\text { B APH } \\
\text { Out } \\
\end{array}$ & $\begin{array}{l}\text { Stack } \\
\text { Flow }\end{array}$ & Opacity & SO2 In & SO2 Out & NOx Out \\
\hline $\begin{array}{c}\text { Start Date and } \\
\text { Time }\end{array}$ & MW & KLB/HR & Btu/kWhr & TON/HR & TON/HR & TON/HR & \begin{tabular}{|c|}
$\%$ \\
Weight
\end{tabular} & & $\%$ & DEGF & DEGF & KSCF & $\%$ & lb/MMBtu & Ib/MMBtu & Ib/MMBtu \\
\hline $4 / 25 / 07$ 3:00 & 887 & 6085 & 9872 & 581.5 & 430.0 & 151.5 & 26.1 & 1.16 & 3.2 & 297 & 282 & 2308 & 8.9 & 1.5 & 0.1 & 0.2 \\
\hline $4 / 25 / 074: 00$ & 883 & 6108 & 9872 & 582.7 & 430.9 & 151.8 & 26.1 & 1.16 & 3.2 & 298 & 285 & 2294 & 9.7 & 1.6 & 0.1 & 0.2 \\
\hline $4 / 25 / 07$ 5:00 & 885 & 6118 & 9872 & 585.0 & 432.7 & 152.4 & 26.0 & 1.17 & 3.1 & 295 & 284 & 2301 & 9.4 & 1.6 & 0.1 & 0.2 \\
\hline 4/25/07 6:00 & 885 & 6110 & 9872 & 587.2 & 434.2 & 152.9 & 26.0 & 1.16 & 3.1 & 295 & 286 & 2301 & 9.4 & 1.6 & 0.1 & 0.2 \\
\hline 4/25/07 7:00 & 887 & 6052 & 9872 & 592.8 & 438.5 & 154.3 & 26.0 & 1.16 & 3.1 & 294 & 289 & 2290 & 9.2 & 1.6 & 0.1 & 0.2 \\
\hline 4/25/07 8:00 & 886 & 6105 & 9872 & 597.3 & 441.8 & 155.4 & 26.0 & 1.15 & 3.1 & 293 & 289 & 2304 & 9.1 & 1.6 & 0.1 & 0.2 \\
\hline 4/25/07 9:00 & 889 & 6087 & 9872 & 595.8 & 440.7 & 155.0 & 26.0 & 1.14 & 3.1 & 295 & 289 & 2286 & 8.8 & 1.6 & 0.1 & 0.2 \\
\hline $4 / 25 / 07$ 10:00 & 887 & 6069 & 9872 & 596.3 & 441.1 & 155.2 & 26.0 & 1.14 & 3.2 & 296 & 291 & 2285 & 8.4 & 1.6 & 0.1 & 0.2 \\
\hline $4 / 25 / 07$ 11:00 & 886 & 6101 & 9872 & 598.1 & 442.5 & 155.6 & 26.0 & 1.14 & 3.1 & 299 & 294 & 2303 & 8.2 & 1.6 & 0.1 & 0.2 \\
\hline $4 / 25 / 07$ 12:00 & 886 & 6076 & 9872 & 600.0 & 443.9 & 156.1 & 26.0 & 1.13 & 3.2 & 298 & 294 & 2303 & 8.9 & 1.6 & 0.1 & 0.2 \\
\hline 4/25/07 13:00 & 886 & 6061 & 9872 & 602.7 & 445.9 & 156.8 & 26.0 & 1.13 & 3.1 & 296 & 296 & 2315 & 9.2 & 1.5 & 0.1 & 0.2 \\
\hline $4 / 25 / 0714: 00$ & 884 & 6054 & 9872 & 609.4 & 450.9 & 158.4 & 26.0 & 1.12 & 3.1 & 298 & 298 & 2315 & 8.3 & 1.5 & 0.1 & 0.2 \\
\hline $4 / 25 / 07$ 15:00 & 886 & 6083 & 9872 & 618.3 & 457.6 & 160.7 & 26.0 & 1.11 & 3.1 & 300 & 300 & 2325 & 9.0 & 1.5 & 0.1 & 0.2 \\
\hline 4/25/07 16:00 & 888 & 6105 & 9872 & 614.8 & 455.0 & 159.8 & 26.0 & 1.11 & 3.1 & 297 & 298 & 2322 & 9.3 & 1.4 & 0.1 & 0.2 \\
\hline 4/25/07 17:00 & 887 & 6103 & 9872 & 614.4 & 454.7 & 159.7 & 26.0 & 1.11 & 3.1 & 298 & 298 & 2321 & 9.2 & 1.4 & 0.1 & 0.2 \\
\hline $4 / 25 / 07$ 18:00 & 889 & 6097 & 9872 & 609.0 & 450.7 & 158.3 & 26.0 & 1.11 & 3.1 & 299 & 299 & 2318 & 9.6 & 1.5 & 0.1 & 0.2 \\
\hline 4/25/07 19:00 & 890 & 6112 & 9872 & 590.6 & 436.8 & 153.8 & 26.0 & 1.13 & 3.1 & 298 & 299 & 2319 & 9.0 & 1.4 & 0.1 & 0.2 \\
\hline $4 / 25 / 0720: 00$ & 882 & 6083 & 9872 & 590.4 & 436.7 & 153.7 & 26.0 & 1.15 & 3.2 & 294 & 295 & 2304 & 9.4 & 1.5 & 0.1 & 0.2 \\
\hline $4 / 25 / 07$ 21:00 & 886 & 6060 & 9872 & 600.3 & 447.0 & 153.3 & 25.5 & 1.14 & 3.2 & 294 & 294 & 2298 & 9.2 & 1.7 & 0.2 & 0.2 \\
\hline $4 / 25 / 0722: 00$ & 885 & 6094 & 9872 & 609.5 & 452.6 & 157.0 & 25.8 & 1.13 & 3.1 & 291 & 293 & 2291 & 8.8 & 1.9 & 0.2 & 0.2 \\
\hline $4 / 25 / 0723: 00$ & 885 & 6080 & 9872 & 607.7 & 449.3 & 158.5 & 26.1 & 1.12 & 3.1 & 291 & 292 & 2290 & 8.5 & 2.1 & 0.2 & 0.2 \\
\hline $4 / 26 / 07$ 0:00 & 884 & 6016 & 9872 & 600.0 & 443.5 & 156.5 & 26.1 & 1.12 & 3.1 & 290 & 289 & 2279 & 7.9 & 2.1 & 0.2 & 0.2 \\
\hline 4/26/07 1:00 & 885 & 6041 & 9872 & 597.3 & 441.4 & 155.9 & 26.1 & 1.12 & 3.1 & 288 & 289 & 2300 & 7.5 & 2.2 & 0.2 & 0.2 \\
\hline 4/26/07 2:00 & 886 & 6041 & 9872 & 595.1 & 439.8 & 155.3 & 26.1 & 1.13 & 3.1 & 289 & 289 & 2298 & 7.4 & 2.4 & 0.2 & 0.2 \\
\hline 4/26/07 3:00 & 885 & 6033 & 9872 & 593.7 & 438.7 & 155.0 & 26.1 & 1.13 & 3.2 & 290 & 289 & 2292 & 7.3 & 2.3 & 0.2 & 0.2 \\
\hline 4/26/07 4:00 & 884 & 6017 & 9872 & 600.7 & 444.0 & 156.7 & 26.1 & 1.13 & 3.1 & 291 & 289 & 2279 & 7.3 & 2.2 & 0.2 & 0.2 \\
\hline 4/26/07 5:00 & 885 & 6042 & 9872 & 608.6 & 449.9 & 158.7 & 26.1 & 1.12 & 3.1 & 291 & 288 & 2287 & 7.2 & 1.9 & 0.2 & 0.2 \\
\hline 4/26/07 6:00 & 886 & 6099 & 9872 & 611.1 & 455.6 & 155.5 & 25.4 & 1.12 & 3.1 & 289 & 286 & 2286 & 7.8 & 1.9 & 0.2 & 0.2 \\
\hline 4/26/07 7:00 & 889 & 6127 & 9872 & 601.3 & 450.1 & 151.2 & 25.1 & 1.12 & 3.1 & 288 & 286 & 2290 & 7.3 & 1.7 & 0.2 & 0.2 \\
\hline 4/26/07 8:00 & 888 & 6063 & 9872 & 590.7 & 442.1 & 148.5 & 25.1 & 1.14 & 3.1 & 286 & 284 & 2270 & 7.3 & 1.6 & 0.1 & 0.2 \\
\hline 4/26/07 9:00 & 886 & 6078 & 9872 & 585.1 & 438.0 & 147.2 & 25.2 & 1.15 & 3.1 & 288 & 287 & 2271 & 7.5 & 1.5 & 0.1 & 0.2 \\
\hline
\end{tabular}

C-12 


\begin{tabular}{|c|c|c|c|c|c|c|c|c|c|c|c|c|c|c|c|c|}
\hline Date and & $\begin{array}{c}\text { Gross } \\
\text { Gen }\end{array}$ & $\begin{array}{l}\text { Steam } \\
\text { Flow }\end{array}$ & Gross HR & $\begin{array}{l}\text { Total } \\
\text { Fuel } \\
\end{array}$ & \begin{tabular}{|c|} 
Total \\
Lignite \\
\end{tabular} & $\begin{array}{l}\text { Total } \\
\text { PRB }\end{array}$ & $\begin{array}{l}\text { Total } \\
\text { PRB }\end{array}$ & $\begin{array}{l}\text { Btu } \\
\text { Gain }\end{array}$ & $\begin{array}{c}\text { Econ } \\
\text { O2 }\end{array}$ & $\begin{array}{c}\text { Temp } \\
\text { A APH } \\
\text { Out }\end{array}$ & \begin{tabular}{|c|} 
Temp \\
B APH \\
Out \\
\end{tabular} & $\begin{array}{l}\text { Stack } \\
\text { Flow } \\
\end{array}$ & Opacity & SO2 In & SO2 Out & NOx Out \\
\hline $\begin{array}{c}\text { Start Date and } \\
\text { Time } \\
\end{array}$ & MW & KLB/HR & Btu/kWhr & TON/HR & TON/HR| & TON/HR & \begin{tabular}{c|}
$\%$ \\
Weight
\end{tabular} & & $\%$ & DEGF & DEGF & KSCF & $\%$ & lb/MMBtu & lb/MMBtu & lb/MMBtu \\
\hline 4/26/07 10:00 & 885 & 6048 & 9872 & 581.5 & 434.8 & 146.7 & 25.2 & 1.15 & 3.2 & 291 & 289 & 2257 & 7.8 & 1.5 & 0.1 & 0.2 \\
\hline 4/26/07 11:00 & 884 & 6066 & 9872 & 582.8 & 428.8 & 154.0 & 26.4 & 1.16 & 3.1 & 294 & 291 & 2256 & 8.6 & 1.4 & 0.1 & 0.2 \\
\hline $4 / 26 / 07$ 12:00 & 883 & 6065 & 9872 & 588.5 & 432.7 & 155.9 & 26.5 & 1.15 & 3.1 & 297 & 293 & 2266 & 8.9 & 1.4 & 0.1 & 0.2 \\
\hline 4/26/07 13:00 & 885 & 6089 & 9872 & 596.3 & 438.5 & 157.8 & 26.5 & 1.15 & 3.1 & 299 & 296 & 2267 & 9.3 & 1.5 & 0.1 & 0.2 \\
\hline 4/26/07 14:00 & 886 & 6088 & 9872 & 605.5 & 445.4 & 160.1 & 26.4 & 1.14 & 3.1 & 301 & 298 & 2275 & 9.5 & 1.6 & 0.1 & 0.2 \\
\hline 4/26/07 15:00 & 889 & 6100 & 9872 & 604.1 & 444.4 & 159.8 & 26.4 & 1.13 & 3.1 & 303 & 300 & 2296 & 9.4 & 1.6 & 0.1 & 0.2 \\
\hline 4/26/07 16:00 & 887 & 6104 & 9872 & 599.6 & 441.0 & 158.6 & 26.5 & 1.13 & 3.1 & 304 & 301 & 2304 & 8.8 & 1.6 & 0.1 & 0.2 \\
\hline 4/26/07 17:00 & 886 & 6075 & 9872 & 598.5 & 440.1 & 158.3 & 26.5 & 1.13 & 3.1 & 303 & 300 & 2307 & 8.8 & 1.6 & 0.2 & 0.2 \\
\hline 4/26/07 18:00 & 889 & 6088 & 9872 & 593.5 & 436.4 & 157.1 & 26.5 & 1.14 & 3.1 & 301 & 301 & 2329 & 8.3 & 1.6 & 0.2 & 0.2 \\
\hline 4/26/07 19:00 & 884 & 6044 & 9872 & 594.3 & 437.0 & 157.3 & 26.5 & 1.14 & 3.1 & 301 & 301 & 2310 & 8.4 & 1.6 & 0.2 & 0.2 \\
\hline 4/26/07 20:00 & 883 & 6073 & 9872 & 600.9 & 442.0 & 158.9 & 26.4 & 1.13 & 3.2 & 301 & 302 & 2312 & 8.3 & 1.6 & 0.2 & 0.2 \\
\hline 4/26/07 21:00 & 887 & 6088 & 9872 & 607.8 & 447.1 & 160.7 & 26.4 & 1.13 & 3.1 & 301 & 301 & 2305 & 8.3 & 1.6 & 0.2 & 0.2 \\
\hline $4 / 26 / 07$ 22:00 & 888 & 6137 & 9872 & 598.7 & 440.3 & 158.4 & 26.5 & 1.13 & 3.1 & 296 & 297 & 2313 & 8.9 & 1.5 & 0.1 & 0.2 \\
\hline 4/26/07 23:00 & 889 & 6098 & 9872 & 590.2 & 433.9 & 156.3 & 26.5 & 1.14 & 3.1 & 296 & 296 & 2311 & 8.8 & 1.5 & 0.1 & 0.2 \\
\hline 4/27/07 0:00 & 886 & 6078 & 9872 & 581.9 & 427.6 & 154.2 & 26.5 & 1.15 & 3.2 & 297 & 296 & 2303 & 9.0 & 1.4 & 0.1 & 0.2 \\
\hline $4 / 27 / 07$ 1:00 & 884 & 6063 & 9872 & 581.2 & 424.2 & 157.0 & 27.0 & 1.16 & 3.1 & 298 & 297 & 2301 & 8.9 & 1.3 & 0.1 & 0.2 \\
\hline $4 / 27 / 07$ 2:00 & 884 & 6051 & 9872 & 586.7 & 428.0 & 158.6 & 27.0 & 1.16 & 3.1 & 299 & 298 & 2300 & 8.9 & 1.3 & 0.1 & 0.2 \\
\hline 4/27/07 3:00 & 885 & 6076 & 9872 & 590.5 & 430.8 & 159.7 & 27.0 & 1.15 & 3.1 & 299 & 298 & 2298 & 9.2 & 1.3 & 0.1 & 0.2 \\
\hline 4/27/07 4:00 & 886 & 6116 & 9872 & 590.8 & 431.0 & 159.8 & 27.1 & 1.15 & 3.1 & 299 & 298 & 2297 & 9.6 & 1.3 & 0.1 & 0.2 \\
\hline $4 / 27 / 075: 00$ & 886 & 6116 & 9872 & 592.9 & 432.5 & 160.4 & 27.1 & 1.15 & 3.1 & 296 & 295 & 2315 & 9.3 & 1.4 & 0.1 & 0.2 \\
\hline 4/27/07 6:00 & 888 & 6068 & 9872 & 590.3 & 430.6 & 159.7 & 27.1 & 1.15 & 3.1 & 294 & 293 & 2312 & 9.1 & 1.3 & 0.1 & 0.2 \\
\hline 4/27/07 7:00 & 887 & 6077 & 9872 & 587.0 & 428.3 & 158.8 & 27.0 & 1.15 & 3.1 & 293 & 293 & 2298 & 9.1 & 1.3 & 0.1 & 0.2 \\
\hline 4/27/07 8:00 & 887 & 6086 & 9872 & 582.4 & 425.0 & 157.4 & 27.0 & 1.16 & 3.1 & 295 & 293 & 2292 & 9.3 & 1.3 & 0.1 & 0.2 \\
\hline 4/27/07 9:00 & 886 & 6091 & 9872 & 580.8 & 423.8 & 157.0 & 27.0 & 1.16 & 3.1 & 297 & 295 & 2291 & 9.6 & 1.3 & 0.1 & 0.2 \\
\hline 4/27/07 10:00 & 885 & 6090 & 9872 & 579.0 & 422.6 & 156.5 & 27.0 & 1.17 & 3.1 & 298 & 298 & 2296 & 9.8 & 1.3 & 0.1 & 0.2 \\
\hline 4/27/07 11:00 & 886 & 6092 & 9872 & 580.0 & 423.2 & 156.8 & 27.0 & 1.17 & 3.1 & 299 & 299 & 2291 & 9.8 & 1.3 & 0.1 & 0.2 \\
\hline 4/27/07 12:00 & 885 & 6101 & 9872 & 579.9 & 423.2 & 156.7 & 27.0 & 1.17 & 3.2 & 301 & 300 & 2301 & 9.7 & 1.3 & 0.1 & 0.2 \\
\hline 4/27/07 13:00 & 886 & 6155 & 9872 & 577.0 & 421.1 & 155.9 & 27.0 & 1.18 & 3.1 & 300 & 301 & 2314 & 9.8 & 1.3 & 0.1 & 0.2 \\
\hline 4/27/07 14:00 & 889 & 6112 & 9872 & 571.7 & 417.3 & 154.3 & 27.0 & 1.19 & 3.1 & 302 & 301 & 2324 & 9.9 & 1.2 & 0.1 & 0.2 \\
\hline 4/27/07 15:00 & 885 & 6102 & 9872 & 566.6 & 413.6 & 152.9 & 27.0 & 1.19 & 3.2 & 303 & 301 & 2324 & 9.2 & 1.2 & 0.1 & 0.2 \\
\hline 4/27/07 16:00 & 884 & 6083 & 9872 & 569.3 & 415.6 & 153.7 & 27.0 & 1.19 & 3.1 & 304 & 303 & 2317 & 8.7 & 1.2 & 0.1 & 0.2 \\
\hline
\end{tabular}

C-13 


\begin{tabular}{|c|c|c|c|c|c|c|c|c|c|c|c|c|c|c|c|c|}
\hline Date and & $\begin{array}{c}\text { Gross } \\
\text { Gen }\end{array}$ & $\begin{array}{l}\text { Steam } \\
\text { Flow }\end{array}$ & Gross HR & $\begin{array}{l}\text { Total } \\
\text { Fuel } \\
\end{array}$ & $\begin{array}{c}\text { Total } \\
\text { Lignite }\end{array}$ & $\begin{array}{l}\text { Total } \\
\text { PRB }\end{array}$ & $\begin{array}{l}\text { Total } \\
\text { PRB }\end{array}$ & $\begin{array}{l}\text { Btu } \\
\text { Gain }\end{array}$ & $\begin{array}{c}\text { Econ } \\
\text { O2 }\end{array}$ & $\begin{array}{c}\text { Temp } \\
\text { A APH } \\
\text { Out }\end{array}$ & $\begin{array}{c}\text { Temp } \\
\text { B APH } \\
\text { Out } \\
\end{array}$ & $\begin{array}{l}\text { Stack } \\
\text { Flow }\end{array}$ & Opacity & SO2 In & SO2 Out & NOx Out \\
\hline $\begin{array}{c}\text { Start Date and } \\
\text { Time }\end{array}$ & MW & KLB/HR & Btu/kWhr & TON/HR & TON/HR & TON/HR & \begin{tabular}{|c|}
$\%$ \\
Weight
\end{tabular} & & $\%$ & DEGF & DEGF & KSCF & $\%$ & lb/MMBtu & Ib/MMBtu & Ib/MMBtu \\
\hline $4 / 27 / 07$ 17:00 & 884 & 6128 & 9872 & 575.6 & 420.1 & 155.5 & 27.0 & 1.19 & 3.1 & 305 & 304 & 2325 & 9.1 & 1.3 & 0.1 & 0.2 \\
\hline 4/27/07 18:00 & 890 & 6118 & 9872 & 573.4 & 418.6 & 154.8 & 27.0 & 1.19 & 3.1 & 303 & 301 & 2327 & 9.3 & 1.3 & 0.1 & 0.2 \\
\hline $4 / 27 / 07$ 19:00 & 889 & 6090 & 9872 & 563.0 & 411.1 & 151.9 & 27.0 & 1.20 & 3.1 & 301 & 300 & 2307 & 9.4 & 1.2 & 0.1 & 0.2 \\
\hline $4 / 27 / 0720: 00$ & 884 & 6064 & 9872 & 565.2 & 412.7 & 152.5 & 27.0 & 1.20 & 3.1 & 301 & 299 & 2307 & 9.6 & 1.2 & 0.1 & 0.2 \\
\hline $4 / 27 / 07$ 21:00 & 881 & 6042 & 9872 & 581.5 & 424.3 & 157.1 & 27.0 & 1.19 & 3.1 & 300 & 298 & 2298 & 9.5 & 1.3 & 0.1 & 0.2 \\
\hline $4 / 27 / 0722: 00$ & 886 & 6064 & 9872 & 596.4 & 434.9 & 161.4 & 27.1 & 1.16 & 3.1 & 298 & 298 & 2303 & 9.8 & 1.4 & 0.1 & 0.2 \\
\hline 4/27/07 23:00 & 891 & 6148 & 9872 & 597.2 & 435.5 & 161.7 & 27.1 & 1.15 & 3.1 & 298 & 297 & 2310 & 9.9 & 1.4 & 0.1 & 0.2 \\
\hline 4/28/07 0:00 & 889 & 6138 & 9872 & 586.8 & 428.1 & 158.7 & 27.1 & 1.16 & 3.1 & 298 & 297 & 2314 & 9.7 & 1.4 & 0.1 & 0.2 \\
\hline 4/28/07 1:00 & 886 & 6081 & 9872 & 581.8 & 424.6 & 157.2 & 27.0 & 1.16 & 3.1 & 298 & 296 & 2318 & 9.8 & 1.4 & 0.1 & 0.2 \\
\hline 4/28/07 2:00 & 884 & 6094 & 9872 & 583.7 & 425.8 & 157.9 & 27.0 & 1.17 & 3.1 & 297 & 295 & 2321 & 9.7 & 1.4 & 0.1 & 0.2 \\
\hline 4/28/07 3:00 & 887 & 6057 & 9872 & 585.8 & 427.4 & 158.4 & 27.0 & 1.16 & 3.1 & 298 & 295 & 2312 & 9.6 & 1.4 & 0.1 & 0.2 \\
\hline 4/28/07 4:00 & 887 & 6064 & 9872 & 585.9 & 427.5 & 158.5 & 27.0 & 1.16 & 3.1 & 299 & 296 & 2302 & 9.6 & 1.4 & 0.1 & 0.2 \\
\hline 4/28/07 5:00 & 885 & 6076 & 9872 & 589.2 & 429.8 & 159.4 & 27.1 & 1.15 & 3.1 & 300 & 296 & 2305 & 9.4 & 1.4 & 0.1 & 0.2 \\
\hline 4/28/07 6:00 & 885 & 6065 & 9872 & 592.5 & 432.2 & 160.3 & 27.1 & 1.15 & 3.1 & 301 & 296 & 2310 & 9.5 & 1.5 & 0.1 & 0.2 \\
\hline 4/28/07 7:00 & 879 & 6077 & 9872 & 606.5 & 442.2 & 164.3 & 27.1 & 1.14 & 3.2 & 299 & 297 & 2315 & 10.1 & 1.5 & 0.1 & 0.2 \\
\hline 4/28/07 8:00 & 889 & 6138 & 9872 & 614.9 & 448.2 & 166.7 & 27.1 & 1.12 & 3.0 & 298 & 297 & 2334 & 10.0 & 1.6 & 0.1 & 0.2 \\
\hline $4 / 28 / 07$ 9:00 & 892 & 6119 & 9872 & 604.2 & 440.6 & 163.7 & 27.1 & 1.12 & 3.1 & 299 & 295 & 2331 & 10.0 & 1.5 & 0.1 & 0.2 \\
\hline $4 / 28 / 07$ 10:00 & 888 & 6066 & 9872 & 597.5 & 435.7 & 161.8 & 27.1 & 1.13 & 3.1 & 297 & 295 & 2312 & 9.6 & 1.5 & 0.1 & 0.2 \\
\hline $4 / 28 / 07$ 11:00 & 888 & 6076 & 9872 & 591.7 & 431.7 & 160.1 & 27.1 & 1.14 & 3.1 & 298 & 296 & 2311 & 9.5 & 1.4 & 0.1 & 0.2 \\
\hline $4 / 28 / 07$ 12:00 & 889 & 6074 & 9872 & 577.8 & 421.7 & 156.1 & 27.0 & 1.15 & 3.2 & 300 & 299 & 2307 & 9.5 & 1.4 & 0.1 & 0.2 \\
\hline $4 / 28 / 07$ 13:00 & 880 & 6027 & 9872 & 580.8 & 423.8 & 157.0 & 27.0 & 1.16 & 3.2 & 302 & 302 & 2303 & 9.9 & 1.4 & 0.1 & 0.2 \\
\hline $4 / 28 / 07$ 14:00 & 884 & 6110 & 9872 & 589.0 & 429.7 & 159.3 & 27.1 & 1.16 & 3.1 & 303 & 304 & 2311 & 10.0 & 1.4 & 0.1 & 0.2 \\
\hline 4/28/07 15:00 & 887 & 6098 & 9872 & 587.1 & 428.3 & 158.8 & 27.0 & 1.16 & 3.1 & 303 & 304 & 2313 & 10.1 & 1.4 & 0.1 & 0.2 \\
\hline $4 / 28 / 07$ 16:00 & 888 & 6078 & 9872 & 585.1 & 426.9 & 158.2 & 27.0 & 1.16 & 3.1 & 306 & 305 & 2319 & 9.7 & 1.4 & 0.1 & 0.2 \\
\hline $4 / 28 / 07$ 17:00 & 885 & 6071 & 9872 & 585.6 & 427.2 & 158.4 & 27.0 & 1.16 & 3.1 & 306 & 305 & 2321 & 9.9 & 1.4 & 0.1 & 0.2 \\
\hline $4 / 28 / 07$ 18:00 & 883 & 6082 & 9872 & 590.9 & 431.0 & 159.9 & 27.1 & 1.16 & 3.2 & 305 & 305 & 2322 & 9.7 & 1.4 & 0.1 & 0.2 \\
\hline 4/28/07 19:00 & 890 & 6088 & 9872 & 588.4 & 429.3 & 159.1 & 27.0 & 1.15 & 3.1 & 304 & 304 & 2320 & 9.2 & 1.4 & 0.1 & 0.2 \\
\hline $4 / 28 / 0720: 00$ & 887 & 6106 & 9872 & 581.3 & 424.2 & 157.2 & 27.0 & 1.16 & 3.1 & 305 & 303 & 2321 & 9.8 & 1.4 & 0.1 & 0.2 \\
\hline 4/28/07 21:00 & 889 & 6113 & 9872 & 580.1 & 423.3 & 156.8 & 27.0 & 1.17 & 3.2 & 304 & 303 & 2316 & 9.8 & 1.4 & 0.1 & 0.2 \\
\hline $4 / 28 / 0722: 00$ & 890 & 6114 & 9872 & 577.5 & 421.5 & 156.1 & 27.0 & 1.18 & 3.1 & 302 & 303 & 2315 & 9.8 & 1.4 & 0.1 & 0.2 \\
\hline $4 / 28 / 0723: 00$ & 890 & 6117 & 9872 & 575.0 & 419.7 & 155.3 & 27.0 & 1.18 & 3.1 & 301 & 303 & 2314 & 9.8 & 1.4 & 0.1 & 0.2 \\
\hline
\end{tabular}

C-14 


\begin{tabular}{|c|c|c|c|c|c|c|c|c|c|c|c|c|c|c|c|c|}
\hline Date and & $\begin{array}{c}\text { Gross } \\
\text { Gen }\end{array}$ & $\begin{array}{l}\text { Steam } \\
\text { Flow }\end{array}$ & Gross HR & $\begin{array}{l}\text { Total } \\
\text { Fuel } \\
\end{array}$ & $\begin{array}{c}\text { Total } \\
\text { Lignite }\end{array}$ & $\begin{array}{l}\text { Total } \\
\text { PRB }\end{array}$ & $\begin{array}{l}\text { Total } \\
\text { PRB }\end{array}$ & $\begin{array}{c}\text { Btu } \\
\text { Gain }\end{array}$ & $\begin{array}{c}\text { Econ } \\
\text { O2 }\end{array}$ & $\begin{array}{c}\text { Temp } \\
\text { A APH } \\
\text { Out }\end{array}$ & $\begin{array}{c}\text { Temp } \\
\text { B APH } \\
\text { Out } \\
\end{array}$ & $\begin{array}{l}\text { Stack } \\
\text { Flow }\end{array}$ & Opacity & SO2 In & SO2 Out & NOx Out \\
\hline $\begin{array}{c}\text { Start Date and } \\
\text { Time }\end{array}$ & MW & KLB/HR & Btu/kWhr & TON/HR & TON/HR & TON/HR & \begin{tabular}{|c|}
$\%$ \\
Weight
\end{tabular} & & $\%$ & DEGF & DEGF & KSCF & $\%$ & lb/MMBtu & Ib/MMBtu & Ib/MMBtu \\
\hline 4/29/07 0:00 & 892 & 6105 & 9872 & 569.5 & 415.7 & 153.8 & 27.0 & 1.19 & 3.1 & 302 & 301 & 2322 & 10.0 & 1.5 & 0.1 & 0.2 \\
\hline $4 / 29 / 07$ 1:00 & 889 & 6103 & 9872 & 565.3 & 412.8 & 152.5 & 27.0 & 1.20 & 3.1 & 304 & 301 & 2318 & 10.2 & 1.5 & 0.1 & 0.2 \\
\hline $4 / 29 / 072: 00$ & 886 & 6139 & 9872 & 567.3 & 414.2 & 153.1 & 27.0 & 1.20 & 3.2 & 302 & 300 & 2307 & 10.1 & 1.6 & 0.1 & 0.2 \\
\hline 4/29/07 3:00 & 891 & 6104 & 9872 & 569.1 & 415.5 & 153.6 & 27.0 & 1.20 & 3.1 & 299 & 299 & 2306 & 10.2 & 1.6 & 0.1 & 0.2 \\
\hline 4/29/07 4:00 & 888 & 6161 & 9872 & 564.8 & 412.4 & 152.4 & 27.0 & 1.21 & 3.2 & 300 & 301 & 2325 & 10.0 & 1.5 & 0.1 & 0.2 \\
\hline 4/29/07 5:00 & 894 & 6086 & 9872 & 560.9 & 409.6 & 151.3 & 27.0 & 1.21 & 3.1 & 301 & 298 & 2320 & 9.8 & 1.5 & 0.1 & 0.2 \\
\hline 4/29/07 6:00 & 888 & 6129 & 9872 & 557.3 & 407.0 & 150.3 & 27.0 & 1.22 & 3.2 & 301 & 297 & 2310 & 10.3 & 1.4 & 0.1 & 0.2 \\
\hline 4/29/07 7:00 & 889 & 6120 & 9872 & 556.8 & 406.7 & 150.1 & 27.0 & 1.22 & 3.1 & 298 & 295 & 2313 & 9.8 & 1.4 & 0.1 & 0.2 \\
\hline 4/29/07 8:00 & 887 & 6068 & 9872 & 565.7 & 413.0 & 152.7 & 27.0 & 1.22 & 3.1 & 297 & 295 & 2319 & 9.9 & 1.5 & 0.1 & 0.2 \\
\hline 4/29/07 9:00 & 889 & 6086 & 9872 & 576.9 & 421.0 & 155.9 & 27.0 & 1.20 & 3.1 & 301 & 296 & 2327 & 10.1 & 1.6 & 0.1 & 0.2 \\
\hline 4/29/07 10:00 & 891 & 6120 & 9872 & 580.9 & 423.9 & 157.0 & 27.0 & 1.18 & 3.1 & 303 & 297 & 2329 & 10.0 & 1.6 & 0.2 & 0.2 \\
\hline $4 / 29 / 07$ 11:00 & 890 & 6151 & 9872 & 583.6 & 425.8 & 157.8 & 27.0 & 1.18 & 3.1 & 303 & 298 & 2328 & 10.0 & 1.6 & 0.2 & 0.2 \\
\hline $4 / 29 / 07$ 12:00 & 891 & 6141 & 9872 & 583.6 & 425.8 & 157.8 & 27.0 & 1.18 & 3.1 & 305 & 300 & 2337 & 9.9 & 1.6 & 0.1 & 0.2 \\
\hline 4/29/07 13:00 & 889 & 6172 & 9872 & 579.6 & 423.0 & 156.6 & 27.0 & 1.18 & 3.1 & 306 & 301 & 2327 & 9.9 & 1.6 & 0.1 & 0.2 \\
\hline $4 / 29 / 07$ 14:00 & 892 & 6137 & 9872 & 576.1 & 420.4 & 155.7 & 27.0 & 1.19 & 3.1 & 307 & 303 & 2331 & 9.9 & 1.6 & 0.1 & 0.2 \\
\hline $4 / 29 / 07$ 15:00 & 892 & 6121 & 9872 & 571.3 & 417.0 & 154.2 & 27.0 & 1.19 & 3.1 & 308 & 305 & 2328 & 9.5 & 1.5 & 0.1 & 0.2 \\
\hline 4/29/07 16:00 & 889 & 6118 & 9872 & 570.1 & 416.1 & 153.9 & 27.0 & 1.19 & 3.1 & 308 & 306 & 2333 & 9.6 & 1.6 & 0.1 & 0.2 \\
\hline 4/29/07 17:00 & 888 & 6146 & 9872 & 568.8 & 415.3 & 153.5 & 27.0 & 1.20 & 3.1 & 309 & 307 & 2336 & 9.9 & 1.6 & 0.1 & 0.2 \\
\hline $4 / 29 / 07$ 18:00 & 885 & 6157 & 9872 & 571.9 & 417.5 & 154.4 & 27.0 & 1.20 & 3.2 & 306 & 305 & 2321 & 9.8 & 1.6 & 0.1 & 0.2 \\
\hline 4/29/07 19:00 & 890 & 6100 & 9872 & 581.4 & 424.2 & 157.1 & 27.0 & 1.19 & 3.1 & 305 & 305 & 2340 & 9.9 & 1.7 & 0.2 & 0.2 \\
\hline $4 / 29 / 0720: 00$ & 893 & 6128 & 9872 & 580.9 & 423.9 & 157.0 & 27.0 & 1.18 & 3.1 & 305 & 306 & 2330 & 10.0 & 1.7 & 0.2 & 0.2 \\
\hline $4 / 29 / 0721: 00$ & 891 & 6143 & 9872 & 577.4 & 421.3 & 156.1 & 27.0 & 1.19 & 3.1 & 305 & 306 & 2343 & 9.6 & 1.6 & 0.2 & 0.2 \\
\hline 4/29/07 22:00 & 875 & 6073 & 9872 & 567.2 & 439.7 & 127.5 & 22.5 & 1.19 & 3.2 & 307 & 310 & 2323 & 9.8 & 1.7 & 0.2 & 0.2 \\
\hline $4 / 29 / 0723: 00$ & 877 & 5986 & 9872 & 574.6 & 450.3 & 124.3 & 21.6 & 1.18 & 3.1 & 305 & 308 & 2310 & 9.7 & 1.7 & 0.2 & 0.2 \\
\hline 4/30/07 0:00 & 883 & 6039 & 9872 & 567.1 & 417.7 & 149.4 & 26.3 & 1.18 & 3.2 & 305 & 303 & 2316 & 10.0 & 1.6 & 0.1 & 0.2 \\
\hline 4/30/07 1:00 & 880 & 6034 & 9872 & 567.1 & 415.3 & 151.8 & 26.8 & 1.19 & 3.1 & 305 & 301 & 2311 & 10.2 & 1.6 & 0.1 & 0.2 \\
\hline 4/30/07 2:00 & 877 & 6049 & 9872 & 579.2 & 422.4 & 156.8 & 27.1 & 1.18 & 3.2 & 303 & 299 & 2310 & 10.2 & 1.7 & 0.2 & 0.2 \\
\hline 4/30/07 3:00 & 893 & 6063 & 9872 & 594.0 & 432.8 & 161.1 & 27.1 & 1.16 & 3.1 & 302 & 298 & 2308 & 10.3 & 1.8 & 0.2 & 0.2 \\
\hline 4/30/07 4:00 & 896 & 6108 & 9872 & 582.6 & 424.7 & 157.9 & 27.1 & 1.16 & 3.1 & 302 & 298 & 2310 & 10.2 & 1.6 & 0.1 & 0.2 \\
\hline 4/30/07 5:00 & 891 & 6086 & 9872 & 571.1 & 416.5 & 154.6 & 27.1 & 1.17 & 3.1 & 302 & 298 & 2307 & 9.8 & 1.5 & 0.1 & 0.2 \\
\hline 4/30/07 6:00 & 887 & 6038 & 9872 & 573.2 & 418.0 & 155.2 & 27.1 & 1.18 & 3.2 & 301 & 298 & 2308 & 10.4 & 1.5 & 0.1 & 0.2 \\
\hline
\end{tabular}

C-15 


\begin{tabular}{|c|c|c|c|c|c|c|c|c|c|c|c|c|c|c|c|c|}
\hline Date and & $\begin{array}{c}\text { Gross } \\
\text { Gen }\end{array}$ & $\begin{array}{l}\text { Steam } \\
\text { Flow }\end{array}$ & Gross HR & $\begin{array}{l}\text { Total } \\
\text { Fuel } \\
\end{array}$ & $\begin{array}{c}\text { Total } \\
\text { Lignite }\end{array}$ & $\begin{array}{l}\text { Total } \\
\text { PRB }\end{array}$ & $\begin{array}{l}\text { Total } \\
\text { PRB }\end{array}$ & $\begin{array}{l}\text { Btu } \\
\text { Gain }\end{array}$ & $\begin{array}{c}\text { Econ } \\
\text { O2 }\end{array}$ & \begin{tabular}{|c|} 
Temp \\
A APH \\
Out \\
\end{tabular} & $\begin{array}{c}\text { Temp } \\
\text { B APH } \\
\text { Out }\end{array}$ & $\begin{array}{l}\text { Stack } \\
\text { Flow }\end{array}$ & Opacity & SO2 In & SO2 Out & NOx Out \\
\hline $\begin{array}{c}\text { Start Date and } \\
\text { Time }\end{array}$ & MW & KLB/HR & Btu/kWhr & TON/HR & TON/HR & TON/HR & \begin{tabular}{|c|}
$\%$ \\
Weight
\end{tabular} & & $\%$ & DEGF & DEGF & KSCF & $\%$ & lb/MMBtu & Ib/MMBtu & Ib/MMBtu \\
\hline $4 / 30 / 07$ 7:00 & 887 & 6041 & 9872 & 581.6 & 424.0 & 157.6 & 27.1 & 1.17 & 3.1 & 301 & 298 & 2312 & 10.3 & 1.7 & 0.2 & 0.2 \\
\hline 4/30/07 8:00 & 891 & 6109 & 9872 & 583.8 & 425.4 & 158.4 & 27.1 & 1.17 & 3.1 & 306 & 299 & 2315 & 10.5 & 1.7 & 0.2 & 0.2 \\
\hline 4/30/07 9:00 & 892 & 6096 & 9872 & 578.8 & 419.5 & 159.3 & 27.5 & 1.17 & 3.1 & 308 & 302 & 2320 & 10.2 & 1.6 & 0.2 & 0.2 \\
\hline 4/30/07 10:00 & 888 & 6113 & 9872 & 575.4 & 417.1 & 158.4 & 27.5 & 1.18 & 3.2 & 306 & 301 & 2317 & 9.4 & 1.6 & 0.1 & 0.2 \\
\hline 4/30/07 11:00 & 889 & 6066 & 9872 & 579.7 & 420.1 & 159.6 & 27.5 & 1.18 & 3.2 & 305 & 300 & 2315 & 9.6 & 1.6 & 0.2 & 0.2 \\
\hline $4 / 30 / 07$ 12:00 & 890 & 6091 & 9872 & 582.4 & 422.0 & 160.3 & 27.5 & 1.17 & 3.1 & 308 & 303 & 2320 & 9.6 & 1.6 & 0.1 & 0.2 \\
\hline 4/30/07 13:00 & 890 & 6092 & 9872 & 584.6 & 423.6 & 161.0 & 27.5 & 1.17 & 3.1 & 308 & 305 & 2324 & 9.5 & 1.6 & 0.1 & 0.2 \\
\hline 4/30/07 14:00 & 888 & 6155 & 9859 & 584.7 & 423.7 & 161.0 & 27.5 & 1.17 & 3.1 & 306 & 303 & 2339 & 9.6 & 1.6 & 0.2 & 0.2 \\
\hline $4 / 30 / 07$ 15:00 & 893 & 6114 & 9723 & 584.5 & 423.6 & 160.9 & 27.5 & 1.17 & 3.1 & 304 & 300 & 2306 & 9.3 & 1.7 & 0.2 & 0.2 \\
\hline 4/30/07 16:00 & 891 & 6107 & 9687 & 579.9 & 420.3 & 159.6 & 27.5 & 1.17 & 3.1 & 305 & 301 & 2322 & 9.3 & 1.6 & 0.2 & 0.2 \\
\hline 4/30/07 17:00 & 890 & 6103 & 9679 & 578.5 & 419.2 & 159.2 & 27.5 & 1.17 & 3.1 & 305 & 302 & 2330 & 9.4 & 1.6 & 0.2 & 0.2 \\
\hline 4/30/07 18:00 & 890 & 6082 & 9678 & 578.1 & 419.0 & 159.2 & 27.5 & 1.18 & 3.1 & 303 & 301 & 2319 & 9.4 & 1.6 & 0.2 & 0.2 \\
\hline 4/30/07 19:00 & 888 & 6114 & 9598 & 576.3 & 417.6 & 158.6 & 27.5 & 1.18 & 3.2 & 300 & 299 & 2324 & 9.1 & 1.6 & 0.2 & 0.2 \\
\hline 4/30/07 20:00 & 891 & 6111 & 9690 & 576.8 & 418.1 & 158.8 & 27.5 & 1.18 & 3.1 & 300 & 297 & 2316 & 8.8 & 1.6 & 0.1 & 0.2 \\
\hline 4/30/07 21:00 & 891 & 6071 & 9732 & 580.9 & 421.0 & 159.9 & 27.5 & 1.18 & 3.1 & 297 & 297 & 2300 & 9.0 & 1.6 & 0.2 & 0.2 \\
\hline $4 / 30 / 0722: 00$ & 892 & 6070 & 9621 & 580.4 & 420.6 & 159.8 & 27.5 & 1.17 & 3.1 & 299 & 297 & 2296 & 9.0 & 1.6 & 0.2 & 0.2 \\
\hline 4/30/07 23:00 & 890 & 6075 & 9631 & 580.9 & 421.0 & 159.9 & 27.5 & 1.17 & 3.1 & 299 & 296 & 2295 & 8.8 & 1.6 & 0.1 & 0.2 \\
\hline 5/1/07 0:00 & 891 & 6070 & 9601 & 579.9 & 422.0 & 157.9 & 27.2 & 1.17 & 3.1 & 300 & 295 & 2306 & 8.9 & 1.6 & 0.1 & 0.2 \\
\hline 5/1/07 1:00 & 886 & 6051 & 9676 & 581.9 & 424.9 & 157.0 & 27.0 & 1.16 & 3.2 & 301 & 296 & 2299 & 9.1 & 1.7 & 0.2 & 0.2 \\
\hline 5/1/07 2:00 & 889 & 6095 & 9754 & 590.7 & 432.3 & 158.4 & 26.8 & 1.16 & 3.1 & 300 & 296 & 2296 & 9.1 & 1.9 & 0.2 & 0.2 \\
\hline 5/1/07 3:00 & 896 & 6103 & 9574 & 578.6 & 423.7 & 155.0 & 26.8 & 1.16 & 3.1 & 300 & 296 & 2304 & 8.9 & 1.8 & 0.2 & 0.2 \\
\hline 5/1/07 4:00 & 888 & 6067 & 9544 & 575.1 & 418.6 & 156.4 & 27.2 & 1.17 & 3.2 & 300 & 296 & 2303 & 8.9 & 1.9 & 0.2 & 0.2 \\
\hline 5/1/07 5:00 & 885 & 6097 & 9754 & 581.6 & 422.9 & 158.6 & 27.3 & 1.17 & 3.2 & 297 & 295 & 2310 & 8.6 & 2.1 & 0.2 & 0.2 \\
\hline 5/1/07 6:00 & 889 & 6090 & 9801 & 591.0 & 429.7 & 161.4 & 27.3 & 1.16 & 3.1 & 297 & 294 & 2317 & 8.5 & 2.4 & 0.3 & 0.2 \\
\hline 5/1/07 7:00 & 894 & 6144 & 9638 & 583.8 & 424.5 & 159.3 & 27.3 & 1.17 & 3.1 & 298 & 294 & 2323 & 8.0 & 2.4 & 0.2 & 0.2 \\
\hline 5/1/07 8:00 & 889 & 6124 & 9632 & 576.6 & 422.1 & 154.5 & 26.8 & 1.17 & 3.2 & 298 & 293 & 2301 & 7.9 & 2.3 & 0.2 & 0.2 \\
\hline 5/1/07 9:00 & 892 & 6076 & 9667 & 574.6 & 419.6 & 155.0 & 27.0 & 1.18 & 3.1 & 297 & 287 & 2312 & 7.6 & 2.3 & 0.2 & 0.2 \\
\hline 5/1/07 10:00 & 891 & 6057 & 9639 & 571.9 & 418.4 & 153.4 & 26.8 & 1.18 & 3.2 & 297 & 285 & 2303 & 7.7 & 2.2 & 0.2 & 0.2 \\
\hline 5/1/07 11:00 & 887 & 6037 & 9606 & 568.2 & 416.7 & 151.5 & 26.7 & 1.18 & 3.1 & 297 & 286 & 2283 & 7.9 & 2.1 & 0.2 & 0.2 \\
\hline 5/1/07 12:00 & 884 & 6056 & 9732 & 573.3 & 419.8 & 153.5 & 26.8 & 1.18 & 3.1 & 297 & 285 & 2285 & 8.6 & 2.0 & 0.2 & 0.2 \\
\hline 5/1/07 13:00 & 890 & 6049 & 9669 & 578.1 & 422.6 & 155.5 & 26.9 & 1.18 & 3.1 & 294 & 287 & 2304 & 8.3 & 2.0 & 0.2 & 0.2 \\
\hline
\end{tabular}

C-16 


\begin{tabular}{|c|c|c|c|c|c|c|c|c|c|c|c|c|c|c|c|c|}
\hline Date and & $\begin{array}{c}\text { Gross } \\
\text { Gen }\end{array}$ & $\begin{array}{l}\text { Steam } \\
\text { Flow }\end{array}$ & Gross HR & $\begin{array}{l}\text { Total } \\
\text { Fuel } \\
\end{array}$ & $\begin{array}{c}\text { Total } \\
\text { Lignite }\end{array}$ & $\begin{array}{l}\text { Total } \\
\text { PRB }\end{array}$ & $\begin{array}{l}\text { Total } \\
\text { PRB }\end{array}$ & $\begin{array}{c}\text { Btu } \\
\text { Gain }\end{array}$ & $\begin{array}{c}\text { Econ } \\
\text { O2 } \\
\end{array}$ & $\begin{array}{c}\text { Temp } \\
\text { A APH } \\
\text { Out }\end{array}$ & $\begin{array}{c}\text { Temp } \\
\text { B APH } \\
\text { Out } \\
\end{array}$ & $\begin{array}{l}\text { Stack } \\
\text { Flow }\end{array}$ & Opacity & SO2 In & SO2 Out & NOx Out \\
\hline $\begin{array}{c}\text { Start Date and } \\
\text { Time }\end{array}$ & MW & KLB/HR & Btu/kWhr & TON/HR & TON/HR & TON/HR & \begin{tabular}{|c|}
$\%$ \\
Weight
\end{tabular} & & $\%$ & DEGF & DEGF & KSCF & $\%$ & lb/MMBtu & Ib/MMBtu & Ib/MMBtu \\
\hline 5/1/07 14:00 & 892 & 6086 & 9602 & 576.4 & 421.6 & 154.8 & 26.9 & 1.18 & 3.1 & 294 & 290 & 2301 & 8.1 & 2.0 & 0.2 & 0.2 \\
\hline 5/1/07 15:00 & 891 & 6085 & 9569 & 570.6 & 418.1 & 152.5 & 26.7 & 1.18 & 3.2 & 292 & 262 & 2281 & 8.4 & 1.9 & 0.2 & 0.2 \\
\hline 5/1/07 16:00 & 887 & 6073 & 9657 & 572.3 & 419.2 & 153.1 & 26.8 & 1.18 & 4.3 & 292 & 279 & 2292 & 8.3 & 1.9 & 0.2 & 0.2 \\
\hline 5/1/07 17:00 & 889 & 6103 & 9670 & 577.3 & 422.2 & 155.1 & 26.9 & 1.18 & 3.3 & 293 & 287 & 2316 & 8.2 & 2.0 & 0.2 & 0.2 \\
\hline 5/1/07 18:00 & 889 & 6091 & 9733 & 582.7 & 425.4 & 157.2 & 27.0 & 1.18 & 3.3 & 295 & 291 & 2329 & 8.0 & 2.0 & 0.2 & 0.2 \\
\hline 5/1/07 19:00 & 890 & 6099 & 9734 & 586.6 & 425.5 & 161.2 & 27.5 & 1.17 & 3.3 & 296 & 290 & 2326 & 7.9 & 1.9 & 0.2 & 0.2 \\
\hline 5/1/07 20:00 & 892 & 6097 & 9647 & 586.3 & 423.2 & 163.1 & 27.8 & 1.16 & 3.2 & 297 & 288 & 2313 & 7.8 & 1.8 & 0.2 & 0.2 \\
\hline 5/1/07 21:00 & 890 & 6109 & 9716 & 588.1 & 426.2 & 161.9 & 27.5 & 1.16 & 3.2 & 299 & 292 & 2326 & 8.2 & 1.7 & 0.1 & 0.2 \\
\hline 5/1/07 22:00 & 892 & 6089 & 9703 & 588.6 & 426.5 & 162.1 & 27.5 & 1.16 & 3.2 & 301 & 294 & 2329 & 8.4 & 1.6 & 0.1 & 0.2 \\
\hline 5/1/07 23:00 & 890 & 6082 & 9661 & 589.9 & 427.4 & 162.5 & 27.5 & 1.15 & 3.2 & 302 & 298 & 2316 & 8.9 & 1.6 & 0.1 & 0.2 \\
\hline 5/2/07 0:00 & 889 & 6089 & 9636 & 589.1 & 426.8 & 162.2 & 27.5 & 1.15 & 3.2 & 301 & 295 & 2312 & 8.6 & 1.6 & 0.1 & 0.2 \\
\hline 5/2/07 1:00 & 889 & 6102 & 9717 & 591.3 & 428.5 & 162.9 & 27.5 & 1.15 & 3.2 & 302 & 295 & 2308 & 8.8 & 1.6 & 0.1 & 0.2 \\
\hline 5/2/07 2:00 & 890 & 6092 & 9705 & 591.8 & 428.8 & 163.0 & 27.5 & 1.15 & 3.2 & 303 & 298 & 2309 & 8.7 & 1.6 & 0.1 & 0.2 \\
\hline 5/2/07 3:00 & 890 & 6071 & 9710 & 594.9 & 431.0 & 163.9 & 27.5 & 1.15 & 3.2 & 305 & 299 & 2315 & 9.1 & 1.6 & 0.1 & 0.2 \\
\hline 5/2/07 4:00 & 891 & 6121 & 9681 & 595.4 & 431.4 & 164.0 & 27.5 & 1.15 & 3.1 & 306 & 301 & 2322 & 9.3 & 1.6 & 0.1 & 0.2 \\
\hline 5/2/07 5:00 & 892 & 6083 & 9651 & 591.9 & 429.1 & 162.9 & 27.5 & 1.15 & 3.0 & 306 & 300 & 2324 & 9.0 & 1.6 & 0.1 & 0.2 \\
\hline 5/2/07 6:00 & 877 & 6010 & 9743 & 593.9 & 437.8 & 156.0 & 26.3 & 1.14 & 3.0 & 314 & 304 & 2302 & 9.4 & 1.6 & 0.1 & 0.2 \\
\hline 5/2/07 7:00 & 885 & 6139 & 9809 & 602.2 & 442.9 & 159.2 & 26.4 & 1.14 & 3.1 & 300 & 296 & 2346 & 9.0 & 1.6 & 0.1 & 0.2 \\
\hline 5/2/07 8:00 & 894 & 6116 & 9622 & 598.3 & 440.0 & 158.3 & 26.5 & 1.14 & 2.9 & 297 & 293 & 2332 & 8.6 & 1.5 & 0.1 & 0.2 \\
\hline 5/2/07 9:00 & 889 & 6092 & 9685 & 596.2 & 438.4 & 157.8 & 26.5 & 1.14 & 3.1 & 298 & 294 & 2330 & 8.6 & 1.5 & 0.1 & 0.2 \\
\hline 5/2/07 10:00 & 891 & 6130 & 9662 & 592.0 & 435.3 & 156.7 & 26.5 & 1.15 & 3.0 & 300 & 294 & 2298 & 8.6 & 1.5 & 0.1 & 0.2 \\
\hline 5/2/07 11:00 & 889 & 6097 & 9703 & 590.4 & 434.1 & 156.3 & 26.5 & 1.15 & 3.1 & 298 & 294 & 2309 & 8.6 & 1.5 & 0.1 & 0.2 \\
\hline 5/2/07 12:00 & 886 & 6085 & 9577 & 580.5 & 426.2 & 154.3 & 26.6 & 1.16 & 3.1 & 301 & 295 & 2299 & 8.6 & 1.5 & 0.1 & 0.2 \\
\hline 5/2/07 13:00 & 880 & 6075 & 9772 & 587.7 & 432.2 & 155.5 & 26.5 & 1.16 & 3.3 & 301 & 302 & 2328 & 8.7 & 1.6 & 0.1 & 0.2 \\
\hline 5/2/07 14:00 & 889 & 6089 & 9710 & 590.1 & 433.9 & 156.2 & 26.5 & 1.15 & 3.3 & 301 & 301 & 2340 & 8.4 & 1.6 & 0.1 & 0.2 \\
\hline $5 / 2 / 07$ 15:00 & 886 & 6073 & 9702 & 588.0 & 432.3 & 155.7 & 26.5 & 1.15 & 3.2 & 300 & 302 & 2320 & 7.9 & 1.6 & 0.1 & 0.2 \\
\hline 5/2/07 16:00 & 887 & 6081 & 9753 & 595.1 & 437.6 & 157.4 & 26.5 & 1.15 & 3.4 & 298 & 300 & 2336 & 8.0 & 1.5 & 0.1 & 0.2 \\
\hline 5/2/07 17:00 & 887 & 6087 & 9779 & 601.2 & 442.2 & 159.0 & 26.5 & 1.14 & 3.1 & 301 & 302 & 2312 & 8.4 & 1.5 & 0.1 & 0.2 \\
\hline 5/2/07 18:00 & 886 & 6078 & 9776 & 603.2 & 443.7 & 159.5 & 26.4 & 1.13 & 3.1 & 301 & 303 & 2320 & 8.8 & 1.6 & 0.1 & 0.2 \\
\hline 5/2/07 19:00 & 884 & 6108 & 9758 & 601.4 & 442.3 & 159.0 & 26.4 & 1.13 & 3.1 & 302 & 303 & 2316 & 8.8 & 1.5 & 0.1 & 0.2 \\
\hline 5/2/07 20:00 & 884 & 6080 & 9650 & 595.7 & 438.1 & 157.6 & 26.5 & 1.13 & 3.1 & 299 & 301 & 2327 & 8.5 & 1.5 & 0.1 & 0.2 \\
\hline
\end{tabular}




\begin{tabular}{|c|c|c|c|c|c|c|c|c|c|c|c|c|c|c|c|c|}
\hline Date and & $\begin{array}{c}\text { Gross } \\
\text { Gen } \\
\end{array}$ & $\begin{array}{l}\text { Steam } \\
\text { Flow }\end{array}$ & Gross HR & $\begin{array}{l}\text { Total } \\
\text { Fuel } \\
\end{array}$ & \begin{tabular}{|c|} 
Total \\
Lignite \\
\end{tabular} & $\begin{array}{l}\text { Total } \\
\text { PRB }\end{array}$ & $\begin{array}{l}\text { Total } \\
\text { PRB }\end{array}$ & $\begin{array}{l}\text { Btu } \\
\text { Gain }\end{array}$ & $\begin{array}{c}\text { Econ } \\
\text { O2 }\end{array}$ & $\begin{array}{c}\text { Temp } \\
\text { A APH } \\
\text { Out }\end{array}$ & \begin{tabular}{|c|} 
Temp \\
B APH \\
Out \\
\end{tabular} & $\begin{array}{l}\text { Stack } \\
\text { Flow } \\
\end{array}$ & Opacity & SO2 In & SO2 Out & NOx Out \\
\hline $\begin{array}{c}\text { Start Date and } \\
\text { Time } \\
\end{array}$ & MW & KLB/HR & Btu/kWhr & TON/HR & TON/HR & TON/HR & \begin{tabular}{c|}
$\%$ \\
Weight
\end{tabular} & & $\%$ & DEGF & DEGF & KSCF & $\%$ & lb/MMBtu & lb/MMBtu & lb/MMBtu \\
\hline 5/2/07 21:00 & 887 & 6044 & 9643 & 592.6 & 435.8 & 156.8 & 26.5 & 1.14 & 3.1 & 296 & 272 & 2302 & 8.3 & 1.5 & 0.1 & 0.2 \\
\hline 5/2/07 22:00 & 887 & 6051 & 9621 & 593.6 & 436.5 & 157.1 & 26.5 & 1.14 & 3.2 & 296 & 262 & 2281 & 8.0 & 1.5 & 0.1 & 0.2 \\
\hline 5/2/07 23:00 & 887 & 6047 & 9602 & 591.3 & 434.7 & 156.6 & 26.5 & 1.14 & 3.1 & 296 & 266 & 2278 & 8.0 & 1.5 & 0.1 & 0.2 \\
\hline 5/3/07 0:00 & 886 & 6019 & 9639 & 596.0 & 438.3 & 157.8 & 26.5 & 1.14 & 3.1 & 297 & 277 & 2285 & 8.0 & 1.5 & 0.1 & 0.2 \\
\hline 5/3/07 1:00 & 886 & 6057 & 9680 & 596.0 & 438.3 & 157.7 & 26.5 & 1.13 & 3.3 & 297 & 286 & 2283 & 7.9 & 1.6 & 0.1 & 0.2 \\
\hline 5/3/07 2:00 & 889 & 6078 & 9661 & 593.6 & 436.5 & 157.1 & 26.5 & 1.14 & 3.0 & 297 & 291 & 2285 & 8.2 & 1.6 & 0.1 & 0.2 \\
\hline 5/3/07 3:00 & 890 & 6057 & 9542 & 584.3 & 429.5 & 154.8 & 26.5 & 1.15 & 2.9 & 297 & 293 & 2264 & 8.2 & 1.6 & 0.1 & 0.2 \\
\hline 5/3/07 4:00 & 894 & 6140 & 9308 & 555.7 & 409.1 & 146.6 & 26.4 & 1.18 & 2.6 & 298 & 292 & 2209 & 8.1 & 1.3 & 0.1 & 0.2 \\
\hline 5/3/07 5:00 & 888 & 6059 & 9308 & 532.1 & 399.1 & 133.0 & 25.0 & 1.22 & 2.7 & 300 & 292 & 2235 & 8.5 & 1.0 & 0.1 & 0.2 \\
\hline 5/3/07 6:00 & 875 & 5972 & 9348 & 512.7 & 386.9 & 125.8 & 24.5 & 1.26 & 3.0 & 298 & 292 & 2211 & 9.6 & 0.9 & 0.1 & 0.2 \\
\hline 5/3/07 7:00 & 840 & 5756 & 9596 & 501.2 & 429.6 & 71.6 & 14.3 & 1.28 & 3.1 & 298 & 299 & 2181 & 9.1 & 0.9 & 0.1 & 0.2 \\
\hline 5/3/07 8:00 & 886 & 6039 & 9656 & 529.7 & 452.8 & 76.9 & 14.5 & 1.28 & 3.4 & 295 & 291 & 2301 & 9.8 & 0.8 & 0.1 & 0.2 \\
\hline 5/3/07 9:00 & 887 & 6069 & 9742 & 535.8 & 458.8 & 76.9 & 14.4 & 1.27 & 3.5 & 296 & 292 & 2311 & 10.1 & 0.8 & 0.1 & 0.2 \\
\hline 5/3/07 10:00 & 887 & 6095 & 9759 & 538.8 & 461.4 & 77.4 & 14.4 & 1.27 & 3.5 & 295 & 291 & 2341 & 9.9 & 0.8 & 0.1 & 0.2 \\
\hline 5/3/07 11:00 & 857 & 5839 & 9724 & 520.9 & 446.0 & 75.0 & 14.4 & 1.26 & 3.5 & 289 & 289 & 2275 & 9.3 & 0.8 & 0.1 & 0.2 \\
\hline 5/3/07 12:00 & 886 & 6070 & 9705 & 538.8 & 461.8 & 77.0 & 14.3 & 1.26 & 3.4 & 291 & 283 & 2311 & 9.6 & 0.8 & 0.1 & 0.2 \\
\hline 5/3/07 13:00 & 886 & 6077 & 9593 & 535.9 & 459.3 & 76.6 & 14.3 & 1.26 & 3.4 & 294 & 287 & 2294 & 9.7 & 0.8 & 0.1 & 0.2 \\
\hline 5/3/07 14:00 & 849 & 5873 & 9689 & 511.2 & 436.5 & 74.7 & 14.6 & 1.27 & 3.5 & 295 & 289 & 2268 & 9.5 & 0.8 & 0.1 & 0.2 \\
\hline 5/3/07 15:00 & 629 & 4328 & 9672 & 377.9 & 304.6 & 73.3 & 19.4 & 1.27 & 3.9 & 298 & 293 & 1905 & 7.8 & 0.8 & 0.1 & 0.1 \\
\hline 5/3/07 16:00 & 595 & 4036 & 9747 & 362.3 & 289.9 & 72.4 & 20.0 & 1.26 & 10.3 & 283 & 284 & 1865 & 7.2 & 0.8 & 0.1 & 0.1 \\
\hline 5/3/07 17:00 & 587 & 3989 & 9714 & 361.3 & 289.8 & 71.6 & 19.8 & 1.25 & 3.9 & 283 & 283 & 1855 & 7.2 & 0.8 & 0.1 & 0.1 \\
\hline 5/3/07 18:00 & 588 & 3977 & 9656 & 360.8 & 295.3 & 65.5 & 18.1 & 1.24 & 4.0 & 281 & 275 & 1858 & 7.2 & 0.8 & 0.1 & 0.1 \\
\hline 5/3/07 19:00 & 588 & 3986 & 9599 & 358.0 & 293.1 & 64.9 & 18.1 & 1.24 & 4.0 & 280 & 272 & 1860 & 7.0 & 0.8 & 0.1 & 0.1 \\
\hline 5/3/07 20:00 & 602 & 4109 & 9686 & 370.6 & 303.2 & 67.4 & 18.2 & 1.24 & 3.9 & 281 & 274 & 1878 & 7.2 & 0.8 & 0.1 & 0.1 \\
\hline 5/3/07 21:00 & 671 & 4560 & 9690 & 414.0 & 339.8 & 74.2 & 17.9 & 1.24 & 3.6 & 284 & 276 & 1975 & 7.4 & 0.8 & 0.1 & 0.1 \\
\hline 5/3/07 22:00 & 701 & 4751 & 9678 & 432.4 & 362.1 & 70.3 & 16.3 & 1.24 & 3.4 & 287 & 282 & 2029 & 7.6 & 0.8 & 0.1 & 0.1 \\
\hline 5/3/07 23:00 & 864 & 5968 & 9666 & 532.7 & 427.2 & 105.5 & 19.8 & 1.24 & 3.3 & 297 & 292 & 2269 & 8.9 & 0.8 & 0.1 & 0.2 \\
\hline 5/4/07 0:00 & 890 & 6099 & 9657 & 545.0 & 416.7 & 128.3 & 23.5 & 1.25 & 3.3 & 303 & 298 & 2333 & 9.5 & 0.8 & 0.1 & 0.2 \\
\hline 5/4/07 1:00 & 889 & 6113 & 9744 & 545.7 & 405.6 & 140.1 & 25.7 & 1.25 & 3.2 & 302 & 298 & 2329 & 9.5 & 0.8 & 0.1 & 0.2 \\
\hline $5 / 4 / 072: 00$ & 891 & 6112 & 9719 & 544.6 & 404.7 & 139.8 & 25.7 & 1.25 & 3.2 & 304 & 299 & 2315 & 9.6 & 0.8 & 0.1 & 0.2 \\
\hline 5/4/07 3:00 & 889 & 6130 & 9714 & 544.0 & 404.3 & 139.7 & 25.7 & 1.25 & 3.2 & 304 & 301 & 2298 & 9.9 & 0.8 & 0.1 & 0.2 \\
\hline
\end{tabular}

C-18 


\begin{tabular}{|c|c|c|c|c|c|c|c|c|c|c|c|c|c|c|c|c|}
\hline Date and & $\begin{array}{c}\text { Gross } \\
\text { Gen }\end{array}$ & $\begin{array}{l}\text { Steam } \\
\text { Flow } \\
\end{array}$ & Gross HR & $\begin{array}{l}\text { Total } \\
\text { Fuel } \\
\end{array}$ & $\begin{array}{c}\text { Total } \\
\text { Lignite } \\
\end{array}$ & $\begin{array}{l}\text { Total } \\
\text { PRB } \\
\end{array}$ & $\begin{array}{l}\text { Total } \\
\text { PRB }\end{array}$ & $\begin{array}{c}\text { Btu } \\
\text { Gain }\end{array}$ & $\begin{array}{c}\text { Econ } \\
\mathrm{O2} \\
\end{array}$ & \begin{tabular}{|c|} 
Temp \\
A APH \\
Out \\
\end{tabular} & $\begin{array}{c}\text { Temp } \\
\text { B APH } \\
\text { Out } \\
\end{array}$ & $\begin{array}{l}\text { Stack } \\
\text { Flow }\end{array}$ & Opacity & SO2 In & SO2 Out & NOx Out \\
\hline $\begin{array}{c}\text { Start Date and } \\
\text { Time }\end{array}$ & MW & KLB/HR & Btu/kWhr & TON/HR & TON/HR & TON/HR & \begin{tabular}{|c|}
$\%$ \\
Weight
\end{tabular} & & $\%$ & DEGF & DEGF & KSCF & $\%$ & lb/MMBtu & Ib/MMBtu & Ib/MMBtu \\
\hline 5/4/07 4:00 & 889 & 6128 & 9742 & 545.0 & 405.1 & 139.9 & 25.7 & 1.26 & 3.2 & 304 & 303 & 2314 & 10.1 & 0.8 & 0.1 & 0.2 \\
\hline 5/4/07 5:00 & 890 & 6142 & 9748 & 545.9 & 405.7 & 140.2 & 25.7 & 1.26 & 3.2 & 306 & 303 & 2321 & 10.2 & 0.8 & 0.1 & 0.2 \\
\hline 5/4/07 6:00 & 890 & 6143 & 9722 & 543.0 & 403.6 & 139.4 & 25.7 & 1.26 & 3.2 & 306 & 303 & 2317 & 10.8 & 0.8 & 0.1 & 0.2 \\
\hline 5/4/07 7:00 & 850 & 5886 & 9694 & 515.5 & 372.7 & 142.8 & 27.7 & 1.26 & 3.3 & 307 & 302 & 2262 & 10.5 & 0.8 & 0.1 & 0.1 \\
\hline 5/4/07 8:00 & 827 & 5684 & 9771 & 496.9 & 351.6 & 145.3 & 29.2 & 1.27 & 3.2 & 312 & 305 & 2208 & 10.3 & 0.8 & 0.1 & 0.2 \\
\hline 5/4/07 9:00 & 804 & 5562 & 9510 & 468.5 & 330.2 & 138.3 & 29.5 & 1.29 & 3.3 & 301 & 300 & 2159 & 10.0 & 0.7 & 0.1 & 0.1 \\
\hline 5/4/07 10:00 & 744 & 5185 & 9490 & 425.4 & 311.6 & 113.8 & 26.7 & 1.32 & 3.3 & 304 & 300 & 2059 & 9.5 & 0.7 & 0.1 & 0.1 \\
\hline 5/4/07 11:00 & 726 & 4984 & 9586 & 410.7 & 302.4 & 108.3 & 26.4 & 1.33 & 3.4 & 305 & 297 & 2028 & 9.4 & 0.7 & 0.1 & 0.2 \\
\hline 5/4/07 12:00 & 677 & 4598 & 9752 & 389.3 & 276.8 & 112.5 & 28.9 & 1.34 & 3.6 & 302 & 294 & 1982 & 9.3 & 0.7 & 0.1 & 0.2 \\
\hline 5/4/07 13:00 & 712 & 4831 & 9647 & 409.0 & 284.4 & 124.5 & 30.4 & 1.33 & 3.4 & 303 & 293 & 2067 & 9.8 & 0.7 & 0.1 & 0.2 \\
\hline 5/4/07 14:00 & 752 & 5105 & 9712 & 436.3 & 295.0 & 141.3 & 32.4 & 1.32 & 3.3 & 305 & 298 & 2125 & 10.3 & 0.8 & 0.1 & 0.2 \\
\hline 5/4/07 15:00 & 851 & 5881 & 9744 & 497.8 & 347.2 & 150.7 & 30.3 & 1.32 & 3.2 & 308 & 302 & 2259 & 10.9 & 0.8 & 0.1 & 0.2 \\
\hline 5/4/07 16:00 & 891 & 6122 & 9708 & 513.4 & 370.9 & 142.5 & 27.8 & 1.33 & 3.2 & 310 & 306 & 2310 & 11.2 & 0.8 & 0.1 & 0.2 \\
\hline 5/4/07 17:00 & 893 & 6109 & 9684 & 510.0 & 369.9 & 140.1 & 27.5 & 1.33 & 3.2 & 311 & 308 & 2300 & 11.1 & 0.7 & 0.1 & 0.2 \\
\hline 5/4/07 18:00 & 805 & 5524 & 9643 & 457.7 & 336.8 & 120.9 & 26.4 & 1.34 & 3.2 & 310 & 308 & 2169 & 10.2 & 0.7 & 0.1 & 0.2 \\
\hline 5/4/07 19:00 & 766 & 5258 & 9727 & 442.8 & 326.9 & 115.9 & 26.2 & 1.33 & 3.4 & 307 & 305 & 2087 & 9.9 & 0.8 & 0.1 & 0.1 \\
\hline 5/4/07 20:00 & 730 & 4994 & 9968 & 439.6 & 323.3 & 116.2 & 26.4 & 1.32 & 3.3 & 303 & 301 & 2041 & 9.5 & 1.2 & 0.1 & 0.2 \\
\hline 5/4/07 21:00 & 706 & 4810 & 9888 & 429.3 & 304.3 & 125.0 & 29.1 & 1.29 & 3.3 & 302 & 296 & 1980 & 8.9 & 1.5 & 0.1 & 0.2 \\
\hline 5/4/07 22:00 & 774 & 5271 & 9684 & 460.7 & 335.2 & 125.5 & 27.2 & 1.28 & 3.2 & 300 & 296 & 2074 & 9.4 & 1.3 & 0.1 & 0.2 \\
\hline 5/4/07 23:00 & 878 & 6030 & 9614 & 517.6 & 388.1 & 129.5 & 25.0 & 1.29 & 3.3 & 303 & 301 & 2293 & 10.6 & 1.1 & 0.1 & 0.2 \\
\hline
\end{tabular}


Table C-3. Parametric Phase 3 Unit 1 Hourly Average Process Data

\begin{tabular}{|c|c|c|c|c|c|c|c|c|c|c|c|c|c|c|c|c|}
\hline Date and & $\begin{array}{c}\text { Gross } \\
\text { Gen }\end{array}$ & $\begin{array}{c}\text { Steam } \\
\text { Flow }\end{array}$ & Gross HR & $\begin{array}{l}\text { Total } \\
\text { Fuel } \\
\end{array}$ & $\begin{array}{c}\text { Total } \\
\text { Lignite } \\
\end{array}$ & $\begin{array}{l}\text { Total } \\
\text { PRB }\end{array}$ & $\begin{array}{l}\text { Total } \\
\text { PRB } \\
\end{array}$ & $\begin{array}{c}\text { Btu } \\
\text { Gain }\end{array}$ & $\begin{array}{c}\text { Econ } \\
\text { O2 } \\
\end{array}$ & $\begin{array}{c}\text { Temp } \\
\text { A APH } \\
\text { Out }\end{array}$ & \begin{tabular}{|c|} 
Temp \\
B APH \\
Out \\
\end{tabular} & $\begin{array}{l}\text { Stack } \\
\text { Flow }\end{array}$ & Opacity & SO2 In & SO2 Out & NOx Out \\
\hline $\begin{array}{l}\text { Start Date } \\
\text { and Time }\end{array}$ & MW & KLB/HR & Btu/kWhr & TON/HR & TON/HR & TON/HR & \begin{tabular}{|c|}
$\%$ \\
Weight \\
\end{tabular} & & $\%$ & DEGF & DEGF & KSCF & $\%$ & lb/MMBtu & lb/MMBtu & lb/MMBtu \\
\hline 5/22/07 1:00 & 887 & 6122 & 9774 & 602.0 & 443.0 & 158.9 & 26.4 & 1.14 & 3.1 & 303 & 300 & 2346 & 9.9 & 1.8 & 0.2 & 0.2 \\
\hline 5/22/07 2:00 & 889 & 6133 & 9774 & 602.5 & 443.5 & 159.0 & 26.4 & 1.14 & 3.1 & 300 & 299 & 2349 & 9.8 & 1.8 & 0.2 & 0.2 \\
\hline 5/22/07 3:00 & 892 & 6107 & 9774 & 605.0 & 445.3 & 159.8 & 26.4 & 1.13 & 3.1 & 301 & 299 & 2347 & 9.8 & 1.8 & 0.2 & 0.2 \\
\hline 5/22/07 4:00 & 891 & 6118 & 9774 & 608.1 & 447.5 & 160.7 & 26.4 & 1.13 & 3.1 & 301 & 299 & 2345 & 10.1 & 1.9 & 0.2 & 0.2 \\
\hline 5/22/07 5:00 & 890 & 6176 & 9774 & 600.1 & 441.8 & 158.3 & 26.4 & 1.13 & 3.2 & 299 & 298 & 2336 & 9.6 & 1.8 & 0.2 & 0.2 \\
\hline 5/22/07 6:00 & 894 & 6137 & 9774 & 591.3 & 435.5 & 155.9 & 26.4 & 1.15 & 3.2 & 297 & 281 & 2314 & 10.3 & 1.8 & 0.2 & 0.2 \\
\hline 5/22/07 7:00 & 889 & 6108 & 9774 & 587.1 & 432.4 & 154.7 & 26.3 & 1.16 & 3.2 & 298 & 285 & 2321 & 9.6 & 1.7 & 0.1 & 0.2 \\
\hline 5/22/07 8:00 & 889 & 6114 & 9774 & 592.2 & 436.1 & 156.1 & 26.4 & 1.16 & 3.2 & 298 & 286 & 2295 & 9.7 & 1.8 & 0.1 & 0.2 \\
\hline 5/22/07 9:00 & 889 & 6116 & 9774 & 589.3 & 434.0 & 155.3 & 26.3 & 1.16 & 3.2 & 298 & 289 & 2295 & 9.5 & 1.7 & 0.1 & 0.2 \\
\hline $5 / 22 / 07$ 10:00 & 891 & 6107 & 9774 & 583.5 & 429.9 & 153.6 & 26.3 & 1.16 & 3.2 & 298 & 293 & 2304 & 9.6 & 1.7 & 0.2 & 0.2 \\
\hline 5/22/07 11:00 & 889 & 6093 & 9774 & 585.8 & 431.5 & 154.3 & 26.3 & 1.16 & 3.1 & 300 & 295 & 2291 & 9.7 & 1.8 & 0.2 & 0.2 \\
\hline 5/22/07 12:00 & 876 & 6025 & 9774 & 579.7 & 427.2 & 152.6 & 26.3 & 1.16 & 3.2 & 300 & 296 & 2292 & 9.5 & 1.8 & 0.2 & 0.2 \\
\hline 5/22/07 13:00 & 882 & 6096 & 9774 & 580.3 & 427.6 & 152.7 & 26.3 & 1.17 & 3.1 & 301 & 296 & 2316 & 9.7 & 1.8 & 0.2 & 0.2 \\
\hline 5/22/07 14:00 & 872 & 6051 & 9774 & 574.4 & 423.4 & 151.0 & 26.3 & 1.17 & 3.2 & 303 & 296 & 2292 & 9.7 & 1.9 & 0.2 & 0.2 \\
\hline 5/22/07 15:00 & 797 & 5444 & 9774 & 518.0 & 381.2 & 136.8 & 26.4 & 1.17 & 3.2 & 297 & 293 & 1951 & 9.0 & 1.9 & 0.2 & 0.2 \\
\hline 5/22/07 16:00 & 649 & 4450 & 9774 & 435.2 & 311.1 & 124.1 & 28.5 & 1.17 & 3.5 & 295 & 288 & 1946 & 8.3 & 1.9 & 0.2 & 0.2 \\
\hline 5/22/07 17:00 & 650 & 4438 & 9774 & 438.2 & 310.9 & 127.3 & 29.1 & 1.15 & 3.5 & 295 & 286 & 1966 & 8.1 & 1.8 & 0.1 & 0.2 \\
\hline 5/22/07 18:00 & 588 & 4014 & 9774 & 399.6 & 267.6 & 132.0 & 33.0 & 1.14 & 3.9 & 293 & 284 & 1899 & 8.0 & 1.8 & 0.1 & 0.2 \\
\hline 5/22/07 19:00 & 644 & 4370 & 9774 & 441.5 & 296.4 & 145.0 & 32.8 & 1.12 & 3.5 & 289 & 278 & 1950 & 7.9 & 1.8 & 0.1 & 0.2 \\
\hline 5/22/07 20:00 & 724 & 4915 & 9774 & 497.4 & 347.5 & 149.9 & 30.1 & 1.12 & 3.3 & 291 & 283 & 2066 & 8.1 & 1.8 & 0.2 & 0.2 \\
\hline 5/22/07 21:00 & 768 & 5301 & 9774 & 523.6 & 377.2 & 146.4 & 28.0 & 1.12 & 3.2 & 294 & 291 & 2093 & 8.0 & 1.8 & 0.2 & 0.2 \\
\hline 5/22/07 22:00 & 710 & 4836 & 9774 & 486.6 & 343.2 & 143.4 & 29.5 & 1.12 & 3.3 & 295 & 292 & 1991 & 7.7 & 1.8 & 0.1 & 0.2 \\
\hline 5/22/07 23:00 & 795 & 5430 & 9774 & 540.0 & 385.7 & 154.2 & 28.6 & 1.12 & 3.1 & 296 & 292 & 2140 & 8.0 & 1.8 & 0.1 & 0.2 \\
\hline 5/23/07 0:00 & 876 & 6065 & 9774 & 599.1 & 444.8 & 154.3 & 25.8 & 1.13 & 3.2 & 299 & 295 & 2284 & 9.0 & 1.8 & 0.1 & 0.2 \\
\hline 5/23/07 1:00 & 888 & 6115 & 9774 & 604.0 & 450.4 & 153.6 & 25.4 & 1.13 & 3.1 & 299 & 295 & 2321 & 8.9 & 1.8 & 0.2 & 0.2 \\
\hline 5/23/07 2:00 & 888 & 6104 & 9774 & 602.6 & 449.4 & 153.3 & 25.4 & 1.13 & 3.1 & 298 & 293 & 2309 & 8.8 & 1.8 & 0.2 & 0.2 \\
\hline 5/23/07 3:00 & 891 & 6070 & 9774 & 600.0 & 447.4 & 152.6 & 25.4 & 1.13 & 3.1 & 298 & 292 & 2299 & 8.8 & 1.8 & 0.2 & 0.2 \\
\hline 5/23/07 4:00 & 886 & 6049 & 9774 & 593.0 & 449.8 & 143.2 & 24.1 & 1.13 & 3.1 & 297 & 292 & 2299 & 8.6 & 1.8 & 0.2 & 0.2 \\
\hline $5 / 23 / 075: 00$ & 884 & 6068 & 9774 & 595.6 & 454.6 & 141.0 & 23.7 & 1.14 & 3.1 & 298 & 293 & 2306 & 8.7 & 1.8 & 0.2 & 0.2 \\
\hline
\end{tabular}




\begin{tabular}{|c|c|c|c|c|c|c|c|c|c|c|c|c|c|c|c|c|}
\hline Date and & $\begin{array}{c}\text { Gross } \\
\text { Gen }\end{array}$ & $\begin{array}{l}\text { Steam } \\
\text { Flow }\end{array}$ & Gross HR & $\begin{array}{l}\text { Total } \\
\text { Fuel }\end{array}$ & $\begin{array}{c}\text { Total } \\
\text { Lignite }\end{array}$ & $\begin{array}{l}\text { Total } \\
\text { PRB }\end{array}$ & $\begin{array}{l}\text { Total } \\
\text { PRB }\end{array}$ & $\begin{array}{c}\text { Btu } \\
\text { Gain }\end{array}$ & $\begin{array}{c}\text { Econ } \\
\mathrm{O} 2 \\
\end{array}$ & $\begin{array}{c}\text { Temp } \\
\text { A APH } \\
\text { Out }\end{array}$ & \begin{tabular}{|c|} 
Temp \\
B APH \\
Out \\
\end{tabular} & $\begin{array}{l}\text { Stack } \\
\text { Flow }\end{array}$ & Opacity & SO2 In & SO2 Out & NOx Out \\
\hline $\begin{array}{l}\text { Start Date } \\
\text { and Time }\end{array}$ & MW & KLB/HR & Btu/kWhr & TON/HR & TON/HR & TON/HR & $\begin{array}{c}\% \\
\text { Weight }\end{array}$ & & $\%$ & DEGF & DEGF & KSCF & $\%$ & lb/MMBtu & lb/MMBtu & lb/MMBtu \\
\hline $5 / 23 / 076: 00$ & 850 & 5893 & 9774 & 567.8 & 435.1 & 132.7 & 23.4 & 1.14 & 3.1 & 297 & 292 & 2250 & 9.1 & 1.9 & 0.2 & 0.2 \\
\hline \begin{tabular}{|l|}
$5 / 23 / 07 ~ 7: 00$ \\
\end{tabular} & 715 & 4893 & 9774 & 492.3 & 400.3 & 92.1 & 18.7 & 1.14 & 3.1 & 294 & 288 & 2020 & 7.7 & 2.0 & 0.2 & 0.2 \\
\hline 5/23/07 8:00 & 795 & 5436 & 9774 & 550.3 & 444.0 & 106.3 & 19.3 & 1.12 & 3.1 & 296 & 290 & 2134 & 8.3 & 2.0 & 0.2 & 0.2 \\
\hline 5/23/07 9:00 & 803 & 5608 & 9774 & 540.3 & 418.0 & 122.4 & 22.6 & 1.13 & 3.2 & 297 & 290 & 2207 & 8.1 & 2.0 & 0.2 & 0.2 \\
\hline 5/23/07 10:00 & 668 & 4586 & 9774 & 450.3 & 366.4 & 83.9 & 18.6 & 1.13 & 3.5 & 291 & 286 & 1952 & 7.5 & 2.1 & 0.2 & 0.2 \\
\hline 5/23/07 11:00 & 540 & 3724 & 9774 & 371.7 & 306.4 & 65.3 & 17.6 & 1.12 & 4.1 & 295 & 284 & 1816 & 7.8 & 2.0 & 0.2 & 0.2 \\
\hline 5/23/07 12:00 & 610 & 4138 & 9774 & 436.4 & 362.6 & 73.7 & 16.9 & 1.10 & 3.4 & 300 & 284 & 1880 & 7.8 & 2.0 & 0.2 & 0.2 \\
\hline 5/23/07 13:00 & 590 & 4055 & 9774 & 405.7 & 341.2 & 64.6 & 15.9 & 1.10 & 3.9 & 291 & 282 & 1884 & 7.8 & 1.9 & 0.2 & 0.2 \\
\hline 5/23/07 14:00 & 551 & 3749 & 9774 & 382.0 & 319.9 & 62.1 & 16.3 & 1.10 & 4.0 & 288 & 279 & 1807 & 7.7 & 1.8 & 0.1 & 0.2 \\
\hline 5/23/07 15:00 & 570 & 3872 & 9774 & 397.1 & 332.0 & 65.1 & 16.4 & 1.10 & 3.9 & 290 & 282 & 1836 & 7.7 & 1.7 & 0.1 & 0.2 \\
\hline 5/23/07 16:00 & 660 & 4500 & 9774 & 461.3 & 387.8 & 73.5 & 15.9 & 1.09 & 3.5 & 295 & 286 & 1981 & 7.8 & 1.7 & 0.1 & 0.2 \\
\hline 5/23/07 17:00 & 722 & 4923 & 9774 & 500.3 & 425.9 & 74.3 & 14.9 & 1.10 & 3.2 & 295 & 289 & 2079 & 7.9 & 1.7 & 0.1 & 0.2 \\
\hline 5/23/07 18:00 & 723 & 4933 & 9774 & 503.2 & 428.7 & 74.5 & 14.8 & 1.10 & 3.2 & 295 & 290 & 2088 & 7.9 & 1.8 & 0.1 & 0.2 \\
\hline 5/23/07 19:00 & 699 & 4789 & 9774 & 488.2 & 413.1 & 75.1 & 15.4 & 1.10 & 3.3 & 294 & 288 & 2043 & 7.6 & 1.9 & 0.1 & 0.2 \\
\hline 5/23/07 20:00 & 626 & 4300 & 9774 & 436.0 & 362.3 & 73.7 & 16.9 & 1.10 & 3.7 & 297 & 287 & 1947 & 7.4 & 1.8 & 0.2 & 0.2 \\
\hline 5/23/07 21:00 & 641 & 4366 & 9774 & 448.0 & 372.8 & 75.2 & 16.8 & 1.09 & 3.5 & 295 & 286 & 1940 & 7.6 & 1.8 & 0.2 & 0.2 \\
\hline 5/23/07 22:00 & 600 & 4094 & 9774 & 418.9 & 345.7 & 73.2 & 17.5 & 1.10 & 3.8 & 294 & 284 & 1898 & 7.5 & 1.8 & 0.2 & 0.2 \\
\hline 5/23/07 23:00 & 791 & 5386 & 9774 & 555.0 & 455.7 & 99.2 & 17.9 & 1.09 & 3.1 & 300 & 293 & 2174 & 8.4 & 1.8 & 0.2 & 0.2 \\
\hline 5/24/07 0:00 & 884 & 6089 & 9774 & 607.5 & 464.1 & 143.4 & 23.6 & 1.10 & 3.2 & 305 & 298 & 2353 & 8.7 & 1.8 & 0.2 & 0.2 \\
\hline 5/24/07 1:00 & 883 & 6105 & 9774 & 608.1 & 464.5 & 143.5 & 23.6 & 1.11 & 3.1 & 306 & 299 & 2342 & 8.7 & 1.9 & 0.2 & 0.2 \\
\hline 5/24/07 2:00 & 886 & 6123 & 9774 & 605.9 & 462.7 & 143.2 & 23.6 & 1.12 & 3.1 & 304 & 299 & 2351 & 8.7 & 1.8 & 0.2 & 0.2 \\
\hline 5/24/07 3:00 & 886 & 6102 & 9774 & 603.4 & 460.5 & 142.9 & 23.7 & 1.13 & 3.1 & 302 & 298 & 2341 & 8.5 & 1.8 & 0.2 & 0.2 \\
\hline 5/24/07 4:00 & 886 & 6102 & 9774 & 602.1 & 452.9 & 149.2 & 24.8 & 1.13 & 3.1 & 303 & 299 & 2355 & 8.6 & 1.7 & 0.2 & 0.2 \\
\hline 5/24/07 5:00 & 887 & 6115 & 9774 & 600.4 & 450.3 & 150.1 & 25.0 & 1.13 & 3.1 & 305 & 300 & 2348 & 8.7 & 1.7 & 0.2 & 0.2 \\
\hline 5/24/07 6:00 & 878 & 6055 & 9774 & 596.4 & 446.6 & 149.9 & 25.1 & 1.13 & 3.1 & 305 & 300 & 2325 & 8.6 & 1.7 & 0.1 & 0.2 \\
\hline 5/24/07 7:00 & 858 & 5860 & 9774 & 584.6 & 432.9 & 151.7 & 25.9 & 1.13 & 3.1 & 305 & 300 & 2284 & 8.6 & 1.7 & 0.1 & 0.2 \\
\hline 5/24/07 8:00 & 883 & 6044 & 9774 & 600.9 & 446.6 & 154.3 & 25.7 & 1.13 & 3.1 & 306 & 302 & 2329 & 8.9 & 1.6 & 0.1 & 0.2 \\
\hline 5/24/07 9:00 & 882 & 6067 & 9774 & 599.3 & 445.7 & 153.6 & 25.6 & 1.13 & 3.1 & 310 & 304 & 2342 & 9.2 & 1.4 & 0.1 & 0.2 \\
\hline 5/24/07 10:00 & 883 & 6073 & 9774 & 596.2 & 447.0 & 149.2 & 25.0 & 1.13 & 3.1 & 309 & 302 & 2382 & 9.2 & 1.3 & 0.1 & 0.2 \\
\hline 5/24/07 11:00 & 882 & 6117 & 9774 & 593.7 & 445.3 & 148.4 & 25.0 & 1.14 & 3.1 & 309 & 301 & 2293 & 9.5 & 1.3 & 0.1 & 0.2 \\
\hline 5/24/07 12:00 & 886 & 6089 & 9774 & 592.5 & 444.4 & 148.1 & 25.0 & 1.15 & 3.1 & 309 & 302 & 2294 & 9.5 & 1.3 & 0.1 & 0.2 \\
\hline
\end{tabular}




\begin{tabular}{|c|c|c|c|c|c|c|c|c|c|c|c|c|c|c|c|c|}
\hline Date and & $\begin{array}{c}\text { Gross } \\
\text { Gen }\end{array}$ & $\begin{array}{l}\text { Steam } \\
\text { Flow }\end{array}$ & Gross HR & $\begin{array}{l}\text { Total } \\
\text { Fuel }\end{array}$ & $\begin{array}{c}\text { Total } \\
\text { Lignite }\end{array}$ & $\begin{array}{l}\text { Total } \\
\text { PRB }\end{array}$ & $\begin{array}{l}\text { Total } \\
\text { PRB }\end{array}$ & $\begin{array}{c}\text { Btu } \\
\text { Gain }\end{array}$ & $\begin{array}{c}\text { Econ } \\
\mathrm{O} 2 \\
\end{array}$ & $\begin{array}{c}\text { Temp } \\
\text { A APH } \\
\text { Out }\end{array}$ & \begin{tabular}{|c|} 
Temp \\
B APH \\
Out \\
\end{tabular} & $\begin{array}{l}\text { Stack } \\
\text { Flow }\end{array}$ & Opacity & SO2 In & SO2 Out & NOx Out \\
\hline $\begin{array}{l}\text { Start Date } \\
\text { and Time }\end{array}$ & MW & KLB/HR & Btu/kWhr & TON/HR & TON/HR & TON/HR & $\begin{array}{c}\% \\
\text { Weight } \\
\end{array}$ & & $\%$ & DEGF & DEGF & KSCF & $\%$ & Ib/MMBtu & lb/MMBtu & lb/MMBtu \\
\hline 5/24/07 13:00 & 883 & 6109 & 9774 & 595.1 & 446.3 & 148.8 & 25.0 & 1.15 & 3.1 & 308 & 301 & 2298 & 9.6 & 1.4 & 0.1 & 0.2 \\
\hline $5 / 24 / 07$ 14:00 & 884 & 6097 & 9774 & 598.9 & 449.2 & 149.7 & 25.0 & 1.14 & 3.1 & 308 & 302 & 2295 & 9.6 & 1.4 & 0.1 & 0.2 \\
\hline 5/24/07 15:00 & 887 & 6123 & 9774 & 595.2 & 446.4 & 148.8 & 25.0 & 1.14 & 3.1 & 311 & 305 & 2298 & 9.7 & 1.4 & 0.1 & 0.2 \\
\hline 5/24/07 16:00 & 883 & 6115 & 9774 & 593.8 & 445.3 & 148.5 & 25.0 & 1.15 & 3.1 & 313 & 307 & 2308 & 9.8 & 1.4 & 0.1 & 0.2 \\
\hline 5/24/07 17:00 & 840 & 5857 & 9774 & 559.8 & 413.8 & 146.0 & 26.1 & 1.15 & 3.2 & 312 & 308 & 2248 & 9.5 & 1.5 & 0.1 & 0.2 \\
\hline 5/24/07 18:00 & 694 & 4759 & 9774 & 472.8 & 338.8 & 134.0 & 28.3 & 1.15 & 3.3 & 316 & 306 & 1935 & 8.1 & 1.5 & 0.1 & 0.2 \\
\hline 5/24/07 19:00 & 594 & 4128 & 9774 & 415.4 & 329.4 & 86.0 & 20.7 & 1.14 & 3.8 & 312 & 309 & 1831 & 8.1 & 1.6 & 0.1 & 0.2 \\
\hline 5/24/07 20:00 & 634 & 4265 & 9774 & 460.0 & 383.0 & 77.0 & 16.7 & 1.10 & 3.4 & 298 & 277 & 1856 & 8.0 & 1.6 & 0.1 & 0.2 \\
\hline 5/24/07 21:00 & 855 & 5920 & 9774 & 591.8 & 468.6 & 123.2 & 20.8 & 1.09 & 3.1 & 298 & 258 & 2232 & 9.4 & 1.6 & 0.1 & 0.2 \\
\hline 5/24/07 22:00 & 822 & 5608 & 9774 & 572.7 & 459.0 & 113.7 & 19.8 & 1.10 & 3.2 & 297 & 273 & 2158 & 8.7 & 1.6 & 0.1 & 0.2 \\
\hline 5/24/07 23:00 & 874 & 6017 & 9774 & 608.5 & 470.0 & 138.5 & 22.8 & 1.10 & 3.2 & 301 & 277 & 2235 & 9.2 & 1.6 & 0.1 & 0.2 \\
\hline 5/25/07 0:00 & 888 & 6108 & 9774 & 618.4 & 466.3 & 152.1 & 24.6 & 1.10 & 3.1 & 303 & 273 & 2256 & 9.3 & 1.6 & 0.1 & 0.2 \\
\hline 5/25/07 1:00 & 887 & 6116 & 9774 & 622.9 & 467.2 & 155.7 & 25.0 & 1.10 & 3.1 & 304 & 266 & 2251 & 9.3 & 1.6 & 0.1 & 0.2 \\
\hline $5 / 25 / 072: 00$ & 890 & 6180 & 9774 & 618.3 & 463.7 & 154.5 & 25.0 & 1.11 & 3.1 & 302 & 282 & 2271 & 9.4 & 1.6 & 0.1 & 0.2 \\
\hline 5/25/07 3:00 & 894 & 6154 & 9774 & 602.5 & 451.9 & 150.6 & 25.0 & 1.12 & 3.1 & 300 & 289 & 2287 & 9.2 & 1.5 & 0.1 & 0.2 \\
\hline \begin{tabular}{|l|}
$5 / 25 / 074: 00$ \\
\end{tabular} & 888 & 6106 & 9774 & 597.9 & 448.5 & 149.4 & 25.0 & 1.13 & 3.1 & 302 & 293 & 2281 & 9.2 & 1.4 & 0.1 & 0.2 \\
\hline 5/25/07 5:00 & 887 & 6110 & 9774 & 599.5 & 449.6 & 149.8 & 25.0 & 1.14 & 3.1 & 304 & 296 & 2290 & 9.1 & 1.4 & 0.1 & 0.2 \\
\hline 5/25/07 6:00 & 891 & 6160 & 9774 & 594.8 & 446.2 & 148.7 & 25.0 & 1.14 & 3.1 & 307 & 297 & 2286 & 9.3 & 1.4 & 0.1 & 0.2 \\
\hline 5/25/07 7:00 & 892 & 6191 & 9774 & 572.6 & 428.6 & 144.1 & 25.2 & 1.17 & 3.1 & 308 & 297 & 2289 & 9.3 & 1.2 & 0.1 & 0.2 \\
\hline 5/25/07 8:00 & 889 & 6151 & 9774 & 549.2 & 409.0 & 140.2 & 25.5 & 1.21 & 3.2 & 307 & 297 & 2292 & 9.2 & 1.0 & 0.1 & 0.2 \\
\hline 5/25/07 9:00 & 881 & 6087 & 9774 & 544.1 & 405.2 & 138.9 & 25.5 & 1.23 & 3.2 & 306 & 297 & 2293 & 9.0 & 0.9 & 0.1 & 0.2 \\
\hline 5/25/07 10:00 & 882 & 6082 & 9774 & 551.0 & 410.4 & 140.6 & 25.5 & 1.24 & 3.1 & 309 & 298 & 2294 & 9.1 & 0.9 & 0.1 & 0.2 \\
\hline 5/25/07 11:00 & 884 & 6119 & 9774 & 554.0 & 412.6 & 141.4 & 25.5 & 1.24 & 3.1 & 310 & 300 & 2284 & 9.5 & 0.9 & 0.1 & 0.2 \\
\hline 5/25/07 12:00 & 808 & 5651 & 9774 & 502.1 & 370.8 & 131.3 & 26.2 & 1.24 & 3.2 & 308 & 303 & 2152 & 9.1 & 0.9 & 0.1 & 0.2 \\
\hline 5/25/07 13:00 & 641 & 4358 & 9774 & 401.2 & 328.8 & 72.5 & 18.1 & 1.24 & 3.6 & 296 & 296 & 1882 & 8.2 & 0.9 & 0.1 & 0.1 \\
\hline 5/25/07 14:00 & 846 & 5837 & 9774 & 528.7 & 382.3 & 146.4 & 27.7 & 1.23 & 3.1 & 301 & 295 & 2185 & 9.1 & 0.9 & 0.1 & 0.2 \\
\hline $5 / 25 / 07$ 15:00 & 887 & 6118 & 9774 & 545.1 & 389.4 & 155.7 & 28.6 & 1.24 & 3.1 & 309 & 303 & 2267 & 9.6 & 0.9 & 0.1 & 0.2 \\
\hline 5/25/07 16:00 & 883 & 6094 & 9774 & 544.3 & 388.8 & 155.5 & 28.6 & 1.25 & 3.1 & 308 & 303 & 2268 & 9.2 & 0.9 & 0.1 & 0.2 \\
\hline 5/25/07 17:00 & 885 & 6122 & 9774 & 544.8 & 389.2 & 155.6 & 28.6 & 1.25 & 3.1 & 306 & 303 & 2266 & 9.3 & 0.9 & 0.1 & 0.2 \\
\hline 5/25/07 18:00 & 885 & 6115 & 9774 & 543.5 & 388.2 & 155.3 & 28.6 & 1.25 & 3.1 & 306 & 304 & 2272 & 9.3 & 0.9 & 0.1 & 0.2 \\
\hline 5/25/07 19:00 & 886 & 6109 & 9774 & 542.8 & 387.7 & 155.1 & 28.6 & 1.26 & 3.1 & 307 & 305 & 2273 & 9.3 & 0.9 & 0.1 & 0.2 \\
\hline
\end{tabular}




\begin{tabular}{|c|c|c|c|c|c|c|c|c|c|c|c|c|c|c|c|c|}
\hline Date and & $\begin{array}{c}\text { Gross } \\
\text { Gen }\end{array}$ & $\begin{array}{c}\text { Steam } \\
\text { Flow }\end{array}$ & Gross HR & $\begin{array}{l}\text { Total } \\
\text { Fuel }\end{array}$ & $\begin{array}{c}\text { Total } \\
\text { Lignite }\end{array}$ & $\begin{array}{l}\text { Total } \\
\text { PRB }\end{array}$ & $\begin{array}{l}\text { Total } \\
\text { PRB }\end{array}$ & $\begin{array}{c}\text { Btu } \\
\text { Gain }\end{array}$ & $\begin{array}{c}\text { Econ } \\
\text { O2 } \\
\end{array}$ & $\begin{array}{c}\text { Temp } \\
\text { A APH } \\
\text { Out }\end{array}$ & $\begin{array}{c}\text { Temp } \\
\text { B APH } \\
\text { Out }\end{array}$ & $\begin{array}{l}\text { Stack } \\
\text { Flow } \\
\end{array}$ & Opacity & SO2 In & SO2 Out & NOx Out \\
\hline $\begin{array}{l}\text { Start Date } \\
\text { and Time }\end{array}$ & MW & KLB/HR & Btu/kWhr & TON/HR & TON/HR & TON/HR & $\begin{array}{c}\% \\
\text { Weight }\end{array}$ & & $\%$ & DEGF & DEGF & KSCF & $\%$ & |lb/MMBtu & lb/MMBtu & lb/MMBtu \\
\hline $5 / 25 / 0720: 00$ & 885 & 6097 & 9774 & 541.7 & 387.0 & 154.7 & 28.6 & 1.25 & 3.1 & 308 & 306 & 2274 & 9.5 & 0.9 & 0.1 & 0.2 \\
\hline 5/25/07 21:00 & 884 & 6084 & 9774 & 546.1 & 390.1 & 156.0 & 28.6 & 1.25 & 3.1 & 308 & 307 & 2267 & 9.5 & 0.9 & 0.1 & 0.2 \\
\hline 5/25/07 22:00 & 886 & 6125 & 9774 & 547.4 & 391.1 & 156.4 & 28.6 & 1.25 & 3.1 & 306 & 304 & 2271 & 9.6 & 0.9 & 0.1 & 0.2 \\
\hline 5/25/07 23:00 & 888 & 6084 & 9774 & 546.8 & 390.6 & 156.2 & 28.6 & 1.24 & 3.1 & 305 & 301 & 2268 & 9.1 & 0.9 & 0.1 & 0.2 \\
\hline $5 / 26 / 07$ 0:00 & 887 & 6094 & 9774 & 544.6 & 389.0 & 155.6 & 28.6 & 1.25 & 3.1 & 306 & 302 & 2276 & 9.1 & 0.9 & 0.1 & 0.2 \\
\hline 5/26/07 1:00 & 886 & 6112 & 9774 & 540.4 & 386.0 & 154.4 & 28.6 & 1.25 & 3.1 & 307 & 304 & 2274 & 9.4 & 0.9 & 0.1 & 0.2 \\
\hline $5 / 26 / 07$ 2:00 & 884 & 6081 & 9774 & 539.9 & 385.6 & 154.3 & 28.6 & 1.26 & 3.1 & 309 & 305 & 2266 & 9.4 & 0.9 & 0.1 & 0.2 \\
\hline 5/26/07 3:00 & 884 & 6075 & 9774 & 544.5 & 389.0 & 155.5 & 28.6 & 1.25 & 3.1 & 310 & 306 & 2269 & 9.3 & 0.9 & 0.1 & 0.2 \\
\hline 5/26/07 4:00 & 884 & 6083 & 9774 & 548.9 & 392.1 & 156.8 & 28.6 & 1.24 & 3.1 & 309 & 305 & 2258 & 9.6 & 0.9 & 0.1 & 0.2 \\
\hline 5/26/07 5:00 & 879 & 6035 & 9774 & 568.7 & 412.1 & 156.6 & 27.5 & 1.23 & 3.2 & 309 & 307 & 2249 & 9.5 & 1.1 & 0.1 & 0.2 \\
\hline 5/26/07 6:00 & 884 & 6023 & 9774 & 596.2 & 444.2 & 152.0 & 25.5 & 1.18 & 3.1 & 307 & 304 & 2274 & 9.8 & 1.3 & 0.1 & 0.2 \\
\hline 5/26/07 7:00 & 886 & 6124 & 9774 & 614.8 & 455.4 & 159.4 & 25.9 & 1.14 & 3.1 & 307 & 302 & 2297 & 9.6 & 1.4 & 0.1 & 0.2 \\
\hline 5/26/07 8:00 & 887 & 6107 & 9774 & 630.4 & 466.3 & 164.1 & 26.0 & 1.11 & 3.1 & 306 & 301 & 2297 & 9.8 & 1.6 & 0.2 & 0.2 \\
\hline 5/26/07 9:00 & 889 & 6158 & 9774 & 637.1 & 471.1 & 166.0 & 26.1 & 1.09 & 3.1 & 305 & 300 & 2311 & 9.9 & 1.7 & 0.2 & 0.2 \\
\hline 5/26/07 10:00 & 893 & 6137 & 9774 & 623.3 & 461.2 & 162.1 & 26.0 & 1.09 & 3.1 & 304 & 299 & 2317 & 9.7 & 1.6 & 0.2 & 0.2 \\
\hline 5/26/07 11:00 & 888 & 6091 & 9774 & 613.7 & 454.4 & 159.3 & 26.0 & 1.10 & 3.1 & 304 & 299 & 2307 & 9.7 & 1.6 & 0.2 & 0.2 \\
\hline 5/26/07 12:00 & 884 & 6060 & 9774 & 610.5 & 452.1 & 158.4 & 25.9 & 1.11 & 3.1 & 304 & 297 & 2299 & 9.5 & 1.6 & 0.2 & 0.2 \\
\hline 5/26/07 13:00 & 884 & 6067 & 9774 & 613.8 & 454.4 & 159.4 & 26.0 & 1.11 & 3.1 & 305 & 298 & 2280 & 9.6 & 1.6 & 0.2 & 0.2 \\
\hline 5/26/07 14:00 & 886 & 6075 & 9774 & 615.0 & 455.3 & 159.7 & 26.0 & 1.10 & 3.1 & 305 & 299 & 2288 & 9.6 & 1.7 & 0.2 & 0.2 \\
\hline 5/26/07 15:00 & 885 & 6063 & 9774 & 616.9 & 460.7 & 156.2 & 25.3 & 1.10 & 3.1 & 307 & 300 & 2290 & 9.6 & 1.7 & 0.2 & 0.2 \\
\hline 5/26/07 16:00 & 886 & 6074 & 9774 & 618.1 & 462.4 & 155.6 & 25.2 & 1.10 & 3.1 & 308 & 301 & 2292 & 9.7 & 1.7 & 0.2 & 0.2 \\
\hline 5/26/07 17:00 & 887 & 6104 & 9774 & 615.1 & 460.2 & 154.9 & 25.2 & 1.10 & 3.1 & 309 & 301 & 2290 & 10.7 & 1.7 & 0.2 & 0.2 \\
\hline 5/26/07 18:00 & 890 & 6158 & 9774 & 595.1 & 445.2 & 149.9 & 25.2 & 1.12 & 3.1 & 308 & 300 & 2275 & 10.0 & 1.5 & 0.2 & 0.2 \\
\hline 5/26/07 19:00 & 883 & 6071 & 9774 & 583.2 & 436.2 & 146.9 & 25.2 & 1.15 & 3.2 & 304 & 297 & 2260 & 9.6 & 1.3 & 0.1 & 0.2 \\
\hline 5/26/07 20:00 & 880 & 6016 & 9774 & 597.5 & 447.0 & 150.5 & 25.2 & 1.14 & 3.2 & 305 & 297 & 2264 & 9.6 & 1.4 & 0.2 & 0.2 \\
\hline 5/26/07 21:00 & 885 & 6040 & 9774 & 610.7 & 456.9 & 153.8 & 25.2 & 1.13 & 3.1 & 306 & 298 & 2278 & 9.4 & 1.6 & 0.2 & 0.2 \\
\hline 5/26/07 22:00 & 888 & 6076 & 9774 & 614.2 & 459.5 & 154.7 & 25.2 & 1.11 & 3.1 & 306 & 300 & 2274 & 9.5 & 1.6 & 0.2 & 0.2 \\
\hline 5/26/07 23:00 & 888 & 6086 & 9774 & 609.5 & 455.9 & 153.6 & 25.2 & 1.11 & 3.1 & 306 & 300 & 2272 & 9.6 & 1.6 & 0.2 & 0.2 \\
\hline 5/27/07 0:00 & 886 & 6073 & 9774 & 604.2 & 452.0 & 152.2 & 25.2 & 1.12 & 3.1 & 308 & 300 & 2267 & 9.8 & 1.6 & 0.2 & 0.2 \\
\hline 5/27/07 1:00 & 880 & 6073 & 9774 & 612.0 & 457.8 & 154.1 & 25.2 & 1.11 & 3.2 & 306 & 299 & 2280 & 9.9 & 1.8 & 0.2 & 0.2 \\
\hline 5/27/07 2:00 & 887 & 6046 & 9774 & 621.3 & 464.8 & 156.5 & 25.2 & 1.10 & 3.1 & 303 & 299 & 2274 & 9.5 & 1.9 & 0.2 & 0.2 \\
\hline
\end{tabular}




\begin{tabular}{|c|c|c|c|c|c|c|c|c|c|c|c|c|c|c|c|c|}
\hline Date and & $\begin{array}{c}\text { Gross } \\
\text { Gen } \\
\end{array}$ & $\begin{array}{l}\text { Steam } \\
\text { Flow }\end{array}$ & Gross HR & $\begin{array}{l}\text { Total } \\
\text { Fuel }\end{array}$ & $\begin{array}{c}\text { Total } \\
\text { Lignite } \\
\end{array}$ & $\begin{array}{l}\text { Total } \\
\text { PRB }\end{array}$ & $\begin{array}{l}\text { Total } \\
\text { PRB }\end{array}$ & $\begin{array}{c}\text { Btu } \\
\text { Gain }\end{array}$ & $\begin{array}{c}\text { Econ } \\
\text { O2 } \\
\end{array}$ & \begin{tabular}{|c} 
Temp \\
A APH \\
Out \\
\end{tabular} & \begin{tabular}{|c|} 
Temp \\
B APH \\
Out
\end{tabular} & $\begin{array}{l}\text { Stack } \\
\text { Flow }\end{array}$ & Opacity & SO2 In & SO2 Out & NOx Out \\
\hline $\begin{array}{l}\text { Start Date } \\
\text { and Time }\end{array}$ & MW & KLB/HR & Btu/kWhr & TON/HR & TON/HR & TON/HR & $\begin{array}{c}\% \\
\text { Weight } \\
\end{array}$ & & $\%$ & DEGF & DEGF & KSCF & $\%$ & lb/MMBtu & lb/MMBtu & lb/MMBtu \\
\hline 5/27/07 3:00 & 887 & 6060 & 9774 & 624.7 & 467.3 & 157.4 & 25.2 & 1.09 & 3.1 & 307 & 296 & 2280 & 9.1 & 2.0 & 0.2 & 0.2 \\
\hline 5/27/07 4:00 & 887 & 6049 & 9774 & 625.1 & 467.6 & 157.4 & 25.2 & 1.09 & 3.1 & 306 & 296 & 2286 & 9.1 & 2.0 & 0.2 & 0.2 \\
\hline 5/27/07 5:00 & 886 & 6060 & 9774 & 626.3 & 468.6 & 157.7 & 25.2 & 1.08 & 3.1 & 307 & 296 & 2273 & 9.0 & 2.0 & 0.2 & 0.2 \\
\hline 5/27/07 6:00 & 876 & 6012 & 9774 & 615.5 & 460.5 & 155.0 & 25.2 & 1.09 & 3.1 & 305 & 297 & 2249 & 9.4 & 1.9 & 0.2 & 0.2 \\
\hline 5/27/07 7:00 & 815 & 5601 & 9774 & 575.9 & 425.0 & 150.8 & 26.2 & 1.09 & 3.2 & 303 & 293 & 2145 & 8.5 & 1.9 & 0.2 & 0.2 \\
\hline 5/27/07 8:00 & 882 & 6024 & 9774 & 617.1 & 462.8 & 154.2 & 25.0 & 1.09 & 3.1 & 306 & 296 & 2288 & 9.0 & 1.8 & 0.2 & 0.2 \\
\hline 5/27/07 9:00 & 883 & 6020 & 9774 & 616.2 & 462.2 & 154.0 & 25.0 & 1.09 & 3.1 & 305 & 298 & 2294 & 9.0 & 1.8 & 0.2 & 0.2 \\
\hline 5/27/07 10:00 & 881 & 6008 & 9774 & 611.4 & 458.6 & 152.8 & 25.0 & 1.09 & 3.1 & 304 & 299 & 2292 & 9.1 & 1.8 & 0.2 & 0.2 \\
\hline 5/27/07 11:00 & 883 & 6045 & 9774 & 604.4 & 453.3 & 151.1 & 25.0 & 1.10 & 3.1 & 306 & 301 & 2296 & 9.3 & 1.7 & 0.2 & 0.2 \\
\hline 5/27/07 12:00 & 882 & 6060 & 9774 & 582.2 & 436.7 & 145.5 & 25.0 & 1.13 & 3.1 & 306 & 301 & 2302 & 9.6 & 1.6 & 0.2 & 0.2 \\
\hline 5/27/07 13:00 & 883 & 6107 & 9774 & 558.3 & 417.4 & 140.9 & 25.2 & 1.17 & 3.1 & 304 & 299 & 2278 & 9.4 & 1.3 & 0.1 & 0.2 \\
\hline 5/27/07 14:00 & 882 & 6049 & 9774 & 547.4 & 398.9 & 148.6 & 27.1 & 1.20 & 3.2 & 302 & 298 & 2266 & 9.4 & 1.2 & 0.1 & 0.2 \\
\hline 5/27/07 15:00 & 882 & 6048 & 9774 & 542.4 & 395.5 & 146.8 & 27.1 & 1.23 & 3.2 & 302 & 297 & 2264 & 9.3 & 1.1 & 0.1 & 0.2 \\
\hline 5/27/07 16:00 & 883 & 6058 & 9774 & 536.1 & 391.4 & 144.8 & 27.0 & 1.24 & 3.1 & 302 & 296 & 2262 & 9.4 & 1.1 & 0.1 & 0.2 \\
\hline 5/27/07 17:00 & 882 & 6048 & 9774 & 533.8 & 388.7 & 145.0 & 27.2 & 1.26 & 3.1 & 302 & 296 & 2231 & 9.4 & 1.1 & 0.1 & 0.2 \\
\hline 5/27/07 18:00 & 883 & 6061 & 9774 & 533.9 & 388.2 & 145.7 & 27.3 & 1.26 & 3.1 & 304 & 299 & 2241 & 9.5 & 1.0 & 0.1 & 0.2 \\
\hline 5/27/07 19:00 & 882 & 6049 & 9774 & 532.7 & 387.4 & 145.3 & 27.3 & 1.26 & 3.1 & 306 & 301 & 2245 & 9.4 & 1.0 & 0.1 & 0.2 \\
\hline 5/27/07 20:00 & 883 & 6060 & 9774 & 535.6 & 389.3 & 146.3 & 27.3 & 1.26 & 3.1 & 308 & 303 & 2253 & 9.4 & 1.0 & 0.1 & 0.2 \\
\hline 5/27/07 21:00 & 883 & 6074 & 9774 & 539.1 & 391.7 & 147.4 & 27.4 & 1.26 & 3.1 & 311 & 302 & 2266 & 9.4 & 1.0 & 0.1 & 0.2 \\
\hline 5/27/07 22:00 & 883 & 6048 & 9774 & 538.4 & 391.2 & 147.2 & 27.3 & 1.26 & 3.1 & 307 & 301 & 2266 & 9.4 & 1.0 & 0.1 & 0.2 \\
\hline 5/27/07 23:00 & 883 & 6022 & 9774 & 537.7 & 390.7 & 147.0 & 27.3 & 1.26 & 3.1 & 305 & 299 & 2259 & 9.2 & 0.9 & 0.1 & 0.2 \\
\hline
\end{tabular}


Table C-4. Long Term Unit 1 Hourly Average Process Data

\begin{tabular}{|c|c|c|c|c|c|c|c|c|c|c|c|c|c|c|c|c|}
\hline Date and & $\begin{array}{c}\text { Gross } \\
\text { Gen }\end{array}$ & $\begin{array}{c}\text { Steam } \\
\text { Flow }\end{array}$ & Gross HR & Total Fuel & $\begin{array}{c}\text { Total } \\
\text { Lignite }\end{array}$ & Total PRB & $\begin{array}{l}\text { Total } \\
\text { PRB }\end{array}$ & $\begin{array}{c}\text { Btu } \\
\text { Gain }\end{array}$ & $\begin{array}{c}\text { Econ } \\
\text { O2 }\end{array}$ & $\begin{array}{c}\text { Temp } \\
\text { A APH } \\
\text { Out }\end{array}$ & $\begin{array}{c}\text { Temp } \\
\text { B APH } \\
\text { Out }\end{array}$ & $\begin{array}{l}\text { Stack } \\
\text { Flow }\end{array}$ & Opacity & SO2 In & $\begin{array}{l}\text { SO2 } \\
\text { Out }\end{array}$ & NOx \\
\hline $\begin{array}{l}\text { Start Date } \\
\text { and Time }\end{array}$ & MW & $\begin{array}{c}\text { KLB/ } \\
\text { HR }\end{array}$ & Btu/kWhr & TON/HR & TON/HR & TON/HR & $\begin{array}{c}\% \\
\text { Weight } \\
\end{array}$ & & $\%$ & DEGF & DEGF & KSCF & $\%$ & $\begin{array}{c}\text { Ib/MM } \\
\text { Btu }\end{array}$ & $\begin{array}{c}\text { Ib/MM } \\
\text { Btu }\end{array}$ & $\begin{array}{l}\text { lb/M } \\
\text { MBtu } \\
\end{array}$ \\
\hline 6/19/07 1:00 & 886 & 6141 & 9790 & 577.6 & 429.7 & 147.9 & 25.6 & 1.18 & 2.1 & 307 & 302 & 2198 & 10.1 & 2.4 & 0.2 & 0.2 \\
\hline 6/19/07 2:00 & 889 & 6093 & 9773 & 578.5 & 430.4 & 148.1 & 25.6 & 1.18 & 2.0 & 304 & 300 & 2216 & 10.0 & 2.4 & 0.2 & 0.2 \\
\hline $6 / 19 / 07$ 3:00 & 887 & 6124 & 9753 & 580.6 & 431.9 & 148.6 & 25.6 & 1.18 & 2.1 & 304 & 299 & 2215 & 10.1 & 2.4 & 0.2 & 0.2 \\
\hline $6 / 19 / 074: 00$ & 886 & 6148 & 9803 & 582.9 & 433.7 & 149.2 & 25.6 & 1.18 & 2.1 & 303 & 299 & 2209 & 10.0 & 2.3 & 0.2 & 0.2 \\
\hline 6/19/07 5:00 & 889 & 6151 & 9762 & 578.0 & 426.5 & 151.5 & 26.2 & 1.18 & 2.1 & 305 & 298 & 2202 & 9.9 & 2.2 & 0.2 & 0.2 \\
\hline 6/19/07 6:00 & 888 & 6115 & 9673 & 569.0 & 402.4 & 166.7 & 29.3 & 1.19 & 2.1 & 305 & 299 & 2201 & 10.5 & 2.2 & 0.2 & 0.2 \\
\hline 6/19/07 7:00 & 883 & 6069 & 9724 & 567.7 & 400.3 & 167.5 & 29.5 & 1.19 & 2.1 & 304 & 300 & 2190 & 10.3 & 2.2 & 0.2 & 0.2 \\
\hline 6/19/07 8:00 & 884 & 6077 & 9721 & 569.0 & 399.9 & 169.0 & 29.7 & 1.19 & 2.1 & 306 & 302 & 2190 & 10.3 & 2.1 & 0.2 & 0.2 \\
\hline 6/19/07 9:00 & 882 & 6096 & 9760 & 570.5 & 401.1 & 169.4 & 29.7 & 1.19 & 2.1 & 309 & 304 & 2215 & 10.5 & 2.1 & 0.2 & 0.2 \\
\hline 6/19/07 10:00 & 881 & 6058 & 9689 & 567.5 & 394.8 & 172.8 & 30.4 & 1.19 & 2.1 & 309 & 307 & 2194 & 10.5 & 2.2 & 0.2 & 0.2 \\
\hline 6/19/07 11:00 & 857 & 5993 & 9748 & 552.5 & 382.6 & 169.9 & 30.8 & 1.20 & 2.1 & 310 & 307 & 2146 & 10.3 & 2.1 & 0.2 & 0.2 \\
\hline 6/19/07 12:00 & 871 & 5973 & 9897 & 566.5 & 399.8 & 166.7 & 29.4 & 1.20 & 2.3 & 307 & 305 & 2185 & 10.4 & 2.0 & 0.2 & 0.2 \\
\hline 6/19/07 13:00 & 889 & 6116 & 9767 & 580.7 & 412.6 & 168.1 & 29.0 & 1.19 & 2.4 & 306 & 308 & 2229 & 10.6 & 2.1 & 0.2 & 0.2 \\
\hline 6/19/07 14:00 & 882 & 6095 & 9777 & 576.4 & 410.6 & 165.8 & 28.8 & 1.18 & 2.4 & 307 & 307 & 2230 & 10.6 & 2.1 & 0.2 & 0.2 \\
\hline 6/19/07 15:00 & 874 & 6041 & 9810 & 566.8 & 403.7 & 163.1 & 28.8 & 1.18 & 2.4 & 306 & 307 & 2244 & 10.5 & 2.2 & 0.2 & 0.2 \\
\hline 6/19/07 16:00 & 881 & 6052 & 9762 & 569.8 & 405.9 & 164.0 & 28.8 & 1.18 & 2.4 & 309 & 309 & 2241 & 10.5 & 2.2 & 0.2 & 0.2 \\
\hline 6/19/07 17:00 & 882 & 6098 & 9725 & 576.7 & 407.6 & 169.1 & 29.3 & 1.18 & 2.4 & 311 & 314 & 2241 & 10.6 & 2.3 & 0.2 & 0.2 \\
\hline 6/19/07 18:00 & 857 & 5944 & 9823 & 563.0 & 392.2 & 170.7 & 30.3 & 1.18 & 2.4 & 315 & 322 & 2202 & 10.4 & 2.4 & 0.2 & 0.2 \\
\hline 6/19/07 19:00 & 876 & 6084 & 9794 & 573.0 & 408.9 & 164.1 & 28.6 & 1.18 & 2.4 & 314 & 321 & 2235 & 10.7 & 2.1 & 0.2 & 0.2 \\
\hline 6/19/07 20:00 & 878 & 6093 & 9798 & 571.7 & 411.3 & 160.5 & 28.1 & 1.19 & 2.4 & 316 & 325 & 2246 & 10.7 & 2.0 & 0.2 & 0.2 \\
\hline 6/19/07 21:00 & 885 & 6120 & 9773 & 571.4 & 411.6 & 159.7 & 28.0 & 1.19 & 2.4 & 315 & 324 & 2272 & 10.7 & 2.0 & 0.2 & 0.2 \\
\hline 6/19/07 22:00 & 884 & 6123 & 9807 & 569.5 & 410.4 & 159.2 & 27.9 & 1.19 & 2.4 & 309 & 316 & 2270 & 10.5 & 2.1 & 0.2 & 0.2 \\
\hline 6/19/07 23:00 & 885 & 6111 & 9788 & 572.4 & 412.3 & 160.1 & 28.0 & 1.19 & 2.4 & 308 & 313 & 2263 & 10.6 & 2.1 & 0.2 & 0.2 \\
\hline 6/20/07 0:00 & 883 & 6140 & 9819 & 571.1 & 411.4 & 159.6 & 28.0 & 1.20 & 2.4 & 305 & 309 & 2240 & 10.6 & 2.1 & 0.2 & 0.2 \\
\hline 6/20/07 1:00 & 886 & 6106 & 9808 & 571.7 & 411.8 & 159.9 & 28.0 & 1.20 & 2.3 & 303 & 306 & 2237 & 10.6 & 2.2 & 0.2 & 0.2 \\
\hline 6/20/07 2:00 & 886 & 6102 & 9724 & 570.8 & 411.3 & 159.5 & 27.9 & 1.19 & 2.4 & 304 & 306 & 2235 & 10.7 & 2.2 & 0.2 & 0.2 \\
\hline 6/20/07 3:00 & 884 & 6092 & 9768 & 573.1 & 412.8 & 160.3 & 28.0 & 1.19 & 2.4 & 304 & 306 & 2233 & 10.4 & 2.2 & 0.2 & 0.2 \\
\hline 6/20/07 4:00 & 885 & 6101 & 9796 & 575.4 & 414.3 & 161.1 & 28.0 & 1.19 & 2.4 & 304 & 306 & 2234 & 10.5 & 2.2 & 0.2 & 0.2 \\
\hline $6 / 20 / 07$ 5:00 & 885 & 6094 & 9761 & 576.7 & 415.1 & 161.5 & 28.0 & 1.18 & 2.4 & 305 & 305 & 2236 & 10.2 & 2.2 & 0.2 & 0.2 \\
\hline
\end{tabular}




\begin{tabular}{|c|c|c|c|c|c|c|c|c|c|c|c|c|c|c|c|c|}
\hline Date and & $\begin{array}{c}\text { Gross } \\
\text { Gen }\end{array}$ & $\begin{array}{c}\text { Steam } \\
\text { Flow }\end{array}$ & Gross HR & Total Fuel & $\begin{array}{c}\text { Total } \\
\text { Lignite }\end{array}$ & Total PRB & $\begin{array}{l}\text { Total } \\
\text { PRB }\end{array}$ & $\begin{array}{c}\text { Btu } \\
\text { Gain }\end{array}$ & $\begin{array}{c}\text { Econ } \\
\text { O2 }\end{array}$ & $\begin{array}{c}\text { Temp } \\
\text { A APH } \\
\text { Out }\end{array}$ & $\begin{array}{c}\text { Temp } \\
\text { B APH } \\
\text { Out }\end{array}$ & $\begin{array}{l}\text { Stack } \\
\text { Flow }\end{array}$ & Opacity & SO2 In & $\begin{array}{l}\text { SO2 } \\
\text { Out }\end{array}$ & NOx \\
\hline $\begin{array}{l}\text { Start Date } \\
\text { and Time }\end{array}$ & MW & $\begin{array}{c}\text { KLB/ } \\
\text { HR }\end{array}$ & Btu/kWhr & TON/HR & TON/HR & TON/HR & $\begin{array}{c}\% \\
\text { Weight }\end{array}$ & & $\%$ & DEGF & DEGF & KSCF & $\%$ & $\begin{array}{c}\text { Ib/MM } \\
\text { Btu }\end{array}$ & $\begin{array}{c}\text { Ib/MM } \\
\text { Btu }\end{array}$ & $\begin{array}{l}\mathbf{l b} / \mathbf{M} \\
\text { MBtu }\end{array}$ \\
\hline 6/20/07 6:00 & 884 & 6102 & 9783 & 579.6 & 417.1 & 162.5 & 28.0 & 1.18 & 2.4 & 305 & 304 & 2236 & 10.7 & 2.2 & 0.2 & 0.2 \\
\hline 6/20/07 7:00 & 885 & 6093 & 9749 & 579.8 & 417.9 & 161.9 & 27.9 & 1.18 & 2.4 & 304 & 303 & 2231 & 10.4 & 2.2 & 0.2 & 0.2 \\
\hline $6 / 20 / 078: 00$ & 884 & 6088 & 9759 & 581.7 & 419.3 & 162.4 & 27.9 & 1.17 & 2.4 & 304 & 303 & 2220 & 9.9 & 2.0 & 0.2 & 0.2 \\
\hline $6 / 20 / 07$ 9:00 & 882 & 6111 & 9751 & 579.0 & 417.5 & 161.5 & 27.9 & 1.17 & 2.4 & 306 & 304 & 2216 & 8.1 & 2.0 & 0.2 & 0.2 \\
\hline $6 / 20 / 07$ 10:00 & 878 & 6099 & 9794 & 576.3 & 415.5 & 160.7 & 27.9 & 1.18 & 2.4 & 307 & 303 & 2225 & 7.7 & 2.0 & 0.2 & 0.2 \\
\hline $6 / 20 / 07$ 11:00 & 870 & 6010 & 9937 & 575.1 & 414.8 & 160.4 & 27.9 & 1.18 & 2.4 & 309 & 308 & 2222 & 8.1 & 2.1 & 0.2 & 0.2 \\
\hline $6 / 20 / 07$ 12:00 & 872 & 6018 & 9741 & 576.0 & 415.7 & 160.3 & 27.8 & 1.17 & 2.4 & 310 & 307 & 2224 & 8.0 & 2.2 & 0.2 & 0.2 \\
\hline $6 / 20 / 07$ 13:00 & 876 & 6031 & 9739 & 573.8 & 414.9 & 158.9 & 27.7 & 1.17 & 2.4 & 307 & 307 & 2217 & 8.3 & 2.2 & 0.2 & 0.2 \\
\hline $6 / 20 / 07$ 14:00 & 868 & 5958 & 9711 & 569.6 & 422.4 & 147.3 & 25.9 & 1.17 & 2.4 & 309 & 308 & 2206 & 7.9 & 2.2 & 0.2 & 0.2 \\
\hline $6 / 20 / 07$ 15:00 & 866 & 5929 & 9939 & 589.5 & 498.6 & 90.9 & 15.4 & 1.16 & 2.4 & 314 & 306 & 2218 & 7.9 & 2.4 & 0.2 & 0.2 \\
\hline $6 / 20 / 07$ 16:00 & 882 & 6089 & 9915 & 607.6 & 527.3 & 80.2 & 13.2 & 1.13 & 2.4 & 312 & 302 & 2233 & 8.0 & 2.4 & 0.2 & 0.2 \\
\hline $6 / 20 / 07$ 17:00 & 888 & 6105 & 9905 & 615.1 & 533.4 & 81.8 & 13.3 & 1.12 & 2.4 & 313 & 303 & 2258 & 8.1 & 2.4 & 0.2 & 0.2 \\
\hline 6/20/07 18:00 & 889 & 6115 & 9801 & 611.1 & 529.8 & 81.3 & 13.3 & 1.12 & 2.4 & 312 & 304 & 2254 & 7.9 & 2.4 & 0.2 & 0.2 \\
\hline 6/20/07 19:00 & 888 & 6129 & 9736 & 605.0 & 524.5 & 80.5 & 13.3 & 1.12 & 2.4 & 314 & 305 & 2241 & 8.1 & 2.5 & 0.2 & 0.2 \\
\hline $6 / 20 / 07$ 20:00 & 887 & 6094 & 9689 & 602.9 & 522.4 & 80.5 & 13.3 & 1.13 & 2.4 & 311 & 303 & 2235 & 7.9 & 2.5 & 0.2 & 0.2 \\
\hline 6/20/07 21:00 & 887 & 6084 & 9710 & 601.0 & 520.3 & 80.7 & 13.4 & 1.13 & 2.4 & 310 & 301 & 2235 & 7.9 & 2.4 & 0.2 & 0.2 \\
\hline $6 / 20 / 0722: 00$ & 884 & 6097 & 9727 & 601.0 & 520.3 & 80.7 & 13.4 & 1.13 & 2.4 & 309 & 301 & 2212 & 7.8 & 2.2 & 0.2 & 0.2 \\
\hline $6 / 20 / 07$ 23:00 & 885 & 6086 & 9750 & 604.7 & 523.5 & 81.2 & 13.4 & 1.13 & 2.4 & 306 & 300 & 2233 & 7.6 & 2.3 & 0.2 & 0.2 \\
\hline 6/21/07 0:00 & 880 & 6109 & 9655 & 590.2 & 474.2 & 116.1 & 19.7 & 1.14 & 2.3 & 311 & 308 & 2226 & 7.6 & 2.4 & 0.2 & 0.2 \\
\hline 6/21/07 1:00 & 884 & 6111 & 9549 & 572.6 & 416.6 & 156.0 & 27.2 & 1.16 & 2.5 & 307 & 308 & 2232 & 7.8 & 2.2 & 0.2 & 0.2 \\
\hline $6 / 21 / 072: 00$ & 880 & 6055 & 9643 & 564.2 & 410.5 & 153.7 & 27.2 & 1.18 & 2.5 & 301 & 303 & 2217 & 7.3 & 2.1 & 0.2 & 0.2 \\
\hline 6/21/07 3:00 & 877 & 6023 & 9725 & 566.0 & 413.4 & 152.7 & 27.0 & 1.19 & 2.4 & 300 & 302 & 2207 & 7.3 & 2.1 & 0.2 & 0.2 \\
\hline $6 / 21 / 074: 00$ & 878 & 6048 & 9750 & 572.4 & 417.9 & 154.5 & 27.0 & 1.18 & 2.4 & 299 & 303 & 2207 & 7.4 & 2.1 & 0.2 & 0.2 \\
\hline $6 / 21 / 075: 00$ & 880 & 6089 & 9823 & 576.6 & 420.9 & 155.7 & 27.0 & 1.18 & 2.4 & 299 & 302 & 2203 & 7.3 & 2.0 & 0.2 & 0.2 \\
\hline 6/21/07 6:00 & 882 & 6081 & 9837 & 577.8 & 421.7 & 156.1 & 27.0 & 1.18 & 2.3 & 300 & 302 & 2191 & 7.7 & 2.1 & 0.2 & 0.2 \\
\hline 6/21/07 7:00 & 882 & 6074 & 9752 & 577.4 & 421.5 & 155.9 & 27.0 & 1.17 & 2.3 & 299 & 301 & 2189 & 7.6 & 2.1 & 0.2 & 0.2 \\
\hline $6 / 21 / 078: 00$ & 886 & 6111 & 9742 & 577.9 & 419.9 & 158.0 & 27.3 & 1.18 & 2.3 & 300 & 301 & 2220 & 7.6 & 2.0 & 0.2 & 0.2 \\
\hline $6 / 21 / 07$ 9:00 & 888 & 6129 & 9749 & 576.8 & 416.7 & 160.1 & 27.7 & 1.18 & 2.3 & 303 & 302 & 2232 & 8.0 & 2.0 & 0.2 & 0.2 \\
\hline $6 / 21 / 07$ 10:00 & 887 & 6131 & 9780 & 574.1 & 412.0 & 162.1 & 28.2 & 1.19 & 2.4 & 301 & 302 & 2234 & 7.9 & 2.0 & 0.2 & 0.2 \\
\hline $6 / 21 / 07$ 11:00 & 888 & 6122 & 9741 & 571.5 & 409.5 & 162.0 & 28.4 & 1.19 & 2.4 & 303 & 303 & 2224 & 7.9 & 2.0 & 0.2 & 0.2 \\
\hline $6 / 21 / 07$ 12:00 & 886 & 6104 & 9747 & 570.7 & 408.9 & 161.8 & 28.4 & 1.20 & 2.3 & 304 & 303 & 2227 & 8.0 & 2.0 & 0.2 & 0.2 \\
\hline
\end{tabular}




\begin{tabular}{|c|c|c|c|c|c|c|c|c|c|c|c|c|c|c|c|c|}
\hline Date and & $\begin{array}{c}\text { Gross } \\
\text { Gen }\end{array}$ & $\begin{array}{c}\text { Steam } \\
\text { Flow }\end{array}$ & Gross HR & Total Fuel & $\begin{array}{c}\text { Total } \\
\text { Lignite } \\
\end{array}$ & Total PRB & $\begin{array}{l}\text { Total } \\
\text { PRB } \\
\end{array}$ & $\begin{array}{c}\text { Btu } \\
\text { Gain }\end{array}$ & $\begin{array}{c}\text { Econ } \\
\text { O2 }\end{array}$ & $\begin{array}{c}\text { Temp } \\
\text { A APH } \\
\text { Out }\end{array}$ & $\begin{array}{c}\text { Temp } \\
\text { B APH } \\
\text { Out }\end{array}$ & $\begin{array}{l}\text { Stack } \\
\text { Flow }\end{array}$ & Opacity & SO2 In & $\begin{array}{l}\text { SO2 } \\
\text { Out }\end{array}$ & NOx \\
\hline $\begin{array}{l}\text { Start Date } \\
\text { and Time }\end{array}$ & MW & $\begin{array}{c}\text { KLB/ } \\
\text { HR }\end{array}$ & Btu/kWhr & TON/HR & TON/HR & TON/HR & $\begin{array}{c}\% \\
\text { Weight }\end{array}$ & & $\%$ & DEGF & DEGF & KSCF & $\%$ & $\begin{array}{c}\text { Ib/MM } \\
\text { Btu }\end{array}$ & $\begin{array}{c}\text { Ib/MM } \\
\text { Btu }\end{array}$ & $\begin{array}{l}\text { Ib/M } \\
\text { MBtu }\end{array}$ \\
\hline $6 / 21 / 07$ 13:00 & 887 & 6131 & 9714 & 565.2 & 405.0 & 160.2 & 28.3 & 1.20 & 2.4 & 301 & 288 & 2220 & 7.2 & 2.1 & 0.2 & 0.2 \\
\hline 6/21/07 14:00 & 884 & 6121 & 9773 & 563.7 & 403.9 & 159.8 & 28.3 & 1.21 & 2.3 & 299 & 299 & 2209 & 7.5 & 2.1 & 0.2 & 0.2 \\
\hline $6 / 21 / 07$ 15:00 & 883 & 6135 & 9859 & 566.7 & 406.0 & 160.7 & 28.4 & 1.21 & 2.4 & 300 & 301 & 2212 & 7.6 & 2.1 & 0.2 & 0.2 \\
\hline 6/21/07 16:00 & 886 & 6119 & 9812 & 569.8 & 408.3 & 161.6 & 28.4 & 1.20 & 4.4 & 302 & 302 & 2219 & 7.5 & 2.1 & 0.2 & 0.2 \\
\hline 6/21/07 17:00 & 884 & 6163 & 9800 & 571.7 & 411.9 & 159.7 & 27.9 & 1.20 & 2.3 & 301 & 302 & 2211 & 7.3 & 2.1 & 0.2 & 0.2 \\
\hline $6 / 21 / 07$ 18:00 & 888 & 6131 & 9835 & 569.6 & 413.2 & 156.5 & 27.5 & 1.20 & 2.3 & 300 & 300 & 2208 & 7.4 & 2.2 & 0.2 & 0.2 \\
\hline 6/21/07 19:00 & 886 & 6106 & 9801 & 570.9 & 413.5 & 157.4 & 27.6 & 1.20 & 2.3 & 301 & 301 & 2222 & 7.5 & 2.2 & 0.2 & 0.2 \\
\hline $6 / 21 / 07$ 20:00 & 883 & 6124 & 9796 & 573.5 & 417.4 & 156.1 & 27.2 & 1.19 & 2.3 & 300 & 302 & 2216 & 7.4 & 2.3 & 0.2 & 0.2 \\
\hline $6 / 21 / 07$ 21:00 & 888 & 6103 & 9840 & 577.8 & 421.3 & 156.5 & 27.1 & 1.19 & 2.3 & 299 & 300 & 2214 & 7.4 & 2.3 & 0.2 & 0.2 \\
\hline $6 / 21 / 07$ 22:00 & 887 & 6126 & 9800 & 576.2 & 419.6 & 156.6 & 27.2 & 1.19 & 2.3 & 298 & 297 & 2214 & 7.3 & 2.3 & 0.2 & 0.2 \\
\hline 6/21/07 23:00 & 888 & 6077 & 9734 & 578.2 & 419.1 & 159.1 & 27.5 & 1.18 & 2.3 & 297 & 297 & 2215 & 7.1 & 2.2 & 0.2 & 0.2 \\
\hline $6 / 22 / 07$ 0:00 & 885 & 6116 & 9801 & 579.1 & 420.7 & 158.4 & 27.4 & 1.18 & 2.3 & 298 & 297 & 2229 & 7.2 & 2.2 & 0.2 & 0.2 \\
\hline 6/22/07 1:00 & 888 & 6082 & 9754 & 577.8 & 421.0 & 156.8 & 27.1 & 1.18 & 2.3 & 298 & 298 & 2227 & 7.2 & 2.2 & 0.2 & 0.2 \\
\hline 6/22/07 2:00 & 886 & 6072 & 9797 & 580.9 & 422.7 & 158.2 & 27.2 & 1.18 & 2.3 & 299 & 299 & 2215 & 7.3 & 2.2 & 0.2 & 0.2 \\
\hline 6/22/07 3:00 & 889 & 6104 & 9741 & 578.5 & 421.8 & 156.6 & 27.1 & 1.17 & 2.3 & 299 & 298 & 2220 & 7.3 & 2.1 & 0.2 & 0.2 \\
\hline 6/22/07 4:00 & 887 & 6073 & 9661 & 571.7 & 415.4 & 156.3 & 27.3 & 1.18 & 2.3 & 298 & 298 & 2210 & 7.3 & 2.1 & 0.2 & 0.2 \\
\hline 6/22/07 5:00 & 883 & 6081 & 9712 & 573.8 & 417.9 & 155.9 & 27.2 & 1.18 & 2.3 & 300 & 300 & 2198 & 7.3 & 2.1 & 0.2 & 0.2 \\
\hline 6/22/07 6:00 & 887 & 6119 & 9695 & 572.7 & 417.8 & 154.9 & 27.1 & 1.19 & 2.3 & 299 & 298 & 2209 & 7.6 & 2.1 & 0.2 & 0.2 \\
\hline 6/22/07 7:00 & 891 & 6120 & 9713 & 573.1 & 418.0 & 155.0 & 27.1 & 1.19 & 2.3 & 297 & 297 & 2216 & 7.3 & 2.0 & 0.2 & 0.2 \\
\hline 6/22/07 8:00 & 888 & 6152 & 9732 & 571.3 & 416.8 & 154.5 & 27.0 & 1.19 & 2.3 & 298 & 297 & 2210 & 7.2 & 2.0 & 0.2 & 0.2 \\
\hline 6/22/07 9:00 & 889 & 6133 & 9778 & 571.0 & 416.6 & 154.4 & 27.0 & 1.20 & 2.3 & 297 & 297 & 2216 & 7.2 & 1.9 & 0.2 & 0.2 \\
\hline $6 / 22 / 07$ 10:00 & 892 & 6116 & 9785 & 571.3 & 416.7 & 154.6 & 27.1 & 1.20 & 2.3 & 299 & 299 & 2219 & 7.3 & 1.9 & 0.2 & 0.2 \\
\hline 6/22/07 11:00 & 891 & 6110 & 9785 & 572.6 & 417.6 & 154.9 & 27.1 & 1.19 & 2.5 & 301 & 301 & 2227 & 7.4 & 1.9 & 0.2 & 0.2 \\
\hline 6/22/07 12:00 & 889 & 6119 & 9760 & 575.6 & 419.8 & 155.8 & 27.1 & 1.19 & 2.5 & 304 & 304 & 2227 & 7.7 & 1.9 & 0.2 & 0.2 \\
\hline 6/22/07 13:00 & 890 & 6139 & 9771 & 577.5 & 421.1 & 156.3 & 27.1 & 1.19 & 2.4 & 306 & 307 & 2227 & 7.9 & 1.9 & 0.2 & 0.2 \\
\hline 6/22/07 14:00 & 890 & 6145 & 9799 & 577.4 & 421.1 & 156.3 & 27.1 & 1.19 & 2.5 & 308 & 308 & 2232 & 8.0 & 1.9 & 0.2 & 0.2 \\
\hline 6/22/07 15:00 & 890 & 6140 & 9798 & 579.1 & 422.3 & 156.8 & 27.1 & 1.19 & 2.5 & 308 & 309 & 2250 & 8.1 & 1.9 & 0.2 & 0.2 \\
\hline 6/22/07 16:00 & 891 & 6150 & 9747 & 577.5 & 421.2 & 156.3 & 27.1 & 1.18 & 2.5 & 308 & 309 & 2247 & 8.1 & 1.9 & 0.2 & 0.2 \\
\hline 6/22/07 17:00 & 884 & 6104 & 9856 & 582.4 & 426.2 & 156.2 & 26.8 & 1.18 & 2.5 & 308 & 309 & 2234 & 8.3 & 2.0 & 0.2 & 0.2 \\
\hline 6/22/07 18:00 & 882 & 6081 & 10078 & 607.2 & 448.7 & 158.5 & 26.1 & 1.15 & 2.5 & 304 & 305 & 2245 & 7.9 & 2.4 & 0.2 & 0.2 \\
\hline $6 / 22 / 07$ 19:00 & 891 & 6172 & 9794 & 600.8 & 445.3 & 155.6 & 25.9 & 1.14 & 2.4 & 304 & 303 & 2252 & 7.9 & 2.4 & 0.2 & 0.2 \\
\hline
\end{tabular}




\begin{tabular}{|c|c|c|c|c|c|c|c|c|c|c|c|c|c|c|c|c|}
\hline Date and & $\begin{array}{c}\text { Gross } \\
\text { Gen }\end{array}$ & $\begin{array}{c}\text { Steam } \\
\text { Flow }\end{array}$ & Gross HR & Total Fuel & $\begin{array}{c}\text { Total } \\
\text { Lignite }\end{array}$ & Total PRB & $\begin{array}{l}\text { Total } \\
\text { PRB } \\
\end{array}$ & $\begin{array}{c}\text { Btu } \\
\text { Gain }\end{array}$ & $\begin{array}{c}\text { Econ } \\
\text { O2 }\end{array}$ & $\begin{array}{c}\text { Temp } \\
\text { A APH } \\
\text { Out }\end{array}$ & $\begin{array}{c}\text { Temp } \\
\text { B APH } \\
\text { Out }\end{array}$ & $\begin{array}{l}\text { Stack } \\
\text { Flow }\end{array}$ & Opacity & SO2 In & $\begin{array}{l}\text { SO2 } \\
\text { Out }\end{array}$ & NOx \\
\hline $\begin{array}{l}\text { Start Date } \\
\text { and Time }\end{array}$ & MW & $\begin{array}{c}\text { KLB/ } \\
\text { HR }\end{array}$ & Btu/kWhr & TON/HR & TON/HR & TON/HR & $\begin{array}{c}\% \\
\text { Weight }\end{array}$ & & $\%$ & DEGF & DEGF & KSCF & $\%$ & $\begin{array}{c}\text { Ib/MM } \\
\text { Btu }\end{array}$ & $\begin{array}{c}\text { Ib/MM } \\
\text { Btu }\end{array}$ & $\begin{array}{l}\text { Ib/M } \\
\text { MBtu }\end{array}$ \\
\hline 6/22/07 20:00 & 891 & 6150 & 9516 & 577.0 & 424.0 & 152.9 & 26.5 & 1.16 & 2.5 & 302 & 303 & 2245 & 7.7 & 2.1 & 0.2 & 0.2 \\
\hline 6/22/07 21:00 & 884 & 6104 & 9626 & 566.7 & 414.8 & 151.9 & 26.8 & 1.18 & 2.5 & 301 & 300 & 2238 & 7.4 & 2.0 & 0.2 & 0.2 \\
\hline 6/22/07 22:00 & 884 & 6085 & 9700 & 564.0 & 412.4 & 151.6 & 26.9 & 1.20 & 2.4 & 301 & 301 & 2228 & 7.4 & 1.9 & 0.2 & 0.2 \\
\hline $6 / 22 / 07$ 23:00 & 884 & 6091 & 9719 & 562.7 & 410.7 & 152.0 & 27.0 & 1.20 & 2.4 & 301 & 299 & 2210 & 7.5 & 1.9 & 0.2 & 0.2 \\
\hline $6 / 23 / 07$ 0:00 & 881 & 6084 & 9839 & 567.7 & 414.7 & 153.0 & 27.0 & 1.20 & 2.4 & 302 & 299 & 2205 & 7.7 & 2.1 & 0.2 & 0.2 \\
\hline 6/23/07 1:00 & 883 & 6124 & 9843 & 570.6 & 417.0 & 153.6 & 26.9 & 1.20 & 2.4 & 301 & 300 & 2201 & 7.6 & 2.2 & 0.2 & 0.2 \\
\hline $6 / 23 / 072: 00$ & 888 & 6078 & 9777 & 569.8 & 416.3 & 153.5 & 26.9 & 1.20 & 2.3 & 300 & 298 & 2204 & 7.4 & 2.2 & 0.2 & 0.2 \\
\hline 6/23/07 3:00 & 886 & 6096 & 9693 & 567.5 & 414.5 & 153.1 & 27.0 & 1.20 & 2.4 & 302 & 298 & 2193 & 7.5 & 2.3 & 0.2 & 0.2 \\
\hline 6/23/07 4:00 & 887 & 6094 & 9716 & 564.7 & 412.3 & 152.4 & 27.0 & 1.20 & 2.4 & 301 & 296 & 2183 & 7.3 & 2.3 & 0.2 & 0.2 \\
\hline $6 / 23 / 07$ 5:00 & 884 & 6051 & 9651 & 565.3 & 412.7 & 152.5 & 27.0 & 1.20 & 2.4 & 301 & 297 & 2187 & 7.0 & 2.3 & 0.2 & 0.2 \\
\hline $6 / 23 / 076: 00$ & 882 & 6090 & 9745 & 571.0 & 417.3 & 153.7 & 26.9 & 1.20 & 2.4 & 301 & 298 & 2196 & 7.3 & 2.3 & 0.2 & 0.2 \\
\hline $6 / 23 / 07$ 7:00 & 888 & 6091 & 9727 & 568.4 & 415.2 & 153.1 & 26.9 & 1.20 & 2.4 & 299 & 297 & 2204 & 7.1 & 2.2 & 0.2 & 0.2 \\
\hline 6/23/07 8:00 & 884 & 6059 & 9683 & 566.8 & 414.0 & 152.9 & 27.0 & 1.19 & 2.4 & 299 & 298 & 2204 & 7.0 & 2.2 & 0.2 & 0.2 \\
\hline $6 / 23 / 07$ 9:00 & 883 & 6063 & 9753 & 571.8 & 418.0 & 153.8 & 26.9 & 1.19 & 2.4 & 300 & 298 & 2198 & 7.2 & 2.2 & 0.2 & 0.2 \\
\hline $6 / 23 / 07$ 10:00 & 884 & 6074 & 9738 & 574.4 & 420.1 & 154.3 & 26.9 & 1.18 & 2.4 & 301 & 299 & 2205 & 7.1 & 2.2 & 0.2 & 0.2 \\
\hline $6 / 23 / 07$ 11:00 & 882 & 6056 & 9847 & 585.4 & 428.8 & 156.6 & 26.7 & 1.17 & 2.4 & 303 & 301 & 2219 & 7.2 & 2.3 & 0.2 & 0.2 \\
\hline $6 / 23 / 07$ 12:00 & 887 & 6106 & 9867 & 588.1 & 431.0 & 157.1 & 26.7 & 1.16 & 2.4 & 304 & 302 & 2233 & 7.4 & 2.2 & 0.2 & 0.2 \\
\hline $6 / 23 / 07$ 13:00 & 889 & 6120 & 9692 & 578.8 & 423.6 & 155.2 & 26.8 & 1.17 & 2.4 & 306 & 304 & 2227 & 7.5 & 2.0 & 0.2 & 0.2 \\
\hline $6 / 23 / 07$ 14:00 & 887 & 6104 & 9597 & 567.1 & 414.2 & 152.9 & 27.0 & 1.18 & 2.4 & 306 & 305 & 2219 & 7.5 & 1.9 & 0.2 & 0.2 \\
\hline $6 / 23 / 07$ 15:00 & 882 & 6083 & 9662 & 566.6 & 413.8 & 152.8 & 27.0 & 1.19 & 2.4 & 308 & 306 & 2227 & 7.6 & 2.0 & 0.2 & 0.2 \\
\hline $6 / 23 / 07$ 16:00 & 884 & 6096 & 9712 & 567.8 & 414.7 & 153.1 & 27.0 & 1.20 & 2.4 & 310 & 308 & 2221 & 7.6 & 2.1 & 0.2 & 0.2 \\
\hline $6 / 23 / 07$ 17:00 & 881 & 6056 & 9845 & 577.5 & 422.5 & 155.0 & 26.8 & 1.19 & 2.4 & 311 & 309 & 2215 & 7.7 & 2.2 & 0.2 & 0.2 \\
\hline $6 / 23 / 07$ 18:00 & 886 & 6093 & 9827 & 585.4 & 428.8 & 156.6 & 26.8 & 1.17 & 2.3 & 311 & 310 & 2229 & 7.7 & 2.4 & 0.2 & 0.2 \\
\hline 6/23/07 19:00 & 884 & 6132 & 9798 & 584.9 & 428.4 & 156.5 & 26.8 & 1.17 & 2.4 & 307 & 304 & 2219 & 7.4 & 2.4 & 0.2 & 0.2 \\
\hline 6/23/07 20:00 & 884 & 6135 & 9765 & 588.1 & 430.9 & 157.1 & 26.7 & 1.17 & 2.4 & 301 & 299 & 2228 & 7.1 & 2.4 & 0.2 & 0.2 \\
\hline $6 / 23 / 07$ 21:00 & 889 & 6121 & 9707 & 581.4 & 425.5 & 155.8 & 26.8 & 1.17 & 2.4 & 298 & 296 & 2227 & 7.0 & 2.3 & 0.2 & 0.2 \\
\hline $6 / 23 / 07$ 22:00 & 888 & 6096 & 9592 & 569.0 & 415.2 & 153.8 & 27.0 & 1.18 & 2.4 & 296 & 294 & 2211 & 6.9 & 2.2 & 0.2 & 0.2 \\
\hline $6 / 23 / 07$ 23:00 & 881 & 6065 & 9690 & 568.8 & 414.8 & 154.0 & 27.1 & 1.19 & 2.4 & 296 & 294 & 2195 & 6.8 & 2.2 & 0.2 & 0.2 \\
\hline $6 / 24 / 07$ 0:00 & 879 & 6068 & 9911 & 583.4 & 427.0 & 156.5 & 26.8 & 1.18 & 2.3 & 295 & 294 & 2189 & 6.8 & 2.4 & 0.2 & 0.2 \\
\hline $6 / 24 / 07$ 1:00 & 884 & 6094 & 9892 & 597.1 & 438.0 & 159.1 & 26.7 & 1.16 & 2.4 & 298 & 296 & 2198 & 7.1 & 2.6 & 0.2 & 0.2 \\
\hline $6 / 24 / 07$ 2:00 & 888 & 6157 & 9849 & 596.1 & 437.2 & 158.9 & 26.7 & 1.15 & 2.4 & 298 & 296 & 2209 & 7.3 & 2.7 & 0.2 & 0.2 \\
\hline
\end{tabular}




\begin{tabular}{|c|c|c|c|c|c|c|c|c|c|c|c|c|c|c|c|c|}
\hline Date and & $\begin{array}{c}\text { Gross } \\
\text { Gen }\end{array}$ & $\begin{array}{c}\text { Steam } \\
\text { Flow }\end{array}$ & Gross HR & Total Fuel & $\begin{array}{c}\text { Total } \\
\text { Lignite }\end{array}$ & Total PRB & $\begin{array}{l}\text { Total } \\
\text { PRB }\end{array}$ & $\begin{array}{c}\text { Btu } \\
\text { Gain }\end{array}$ & $\begin{array}{c}\text { Econ } \\
\text { O2 }\end{array}$ & $\begin{array}{c}\text { Temp } \\
\text { A APH } \\
\text { Out }\end{array}$ & $\begin{array}{c}\text { Temp } \\
\text { B APH } \\
\text { Out }\end{array}$ & $\begin{array}{l}\text { Stack } \\
\text { Flow }\end{array}$ & Opacity & SO2 In & $\begin{array}{l}\text { SO2 } \\
\text { Out }\end{array}$ & NOx \\
\hline $\begin{array}{l}\text { Start Date } \\
\text { and Time }\end{array}$ & MW & $\begin{array}{c}\text { KLB/ } \\
\text { HR }\end{array}$ & Btu/kWhr & TON/HR & TON/HR & TON/HR & $\begin{array}{c}\% \\
\text { Weight }\end{array}$ & & $\%$ & DEGF & DEGF & KSCF & $\%$ & $\begin{array}{c}\text { Ib/MM } \\
\text { Btu }\end{array}$ & $\begin{array}{c}\text { Ib/MM } \\
\text { Btu }\end{array}$ & $\begin{array}{l}\mathbf{l b} / \mathbf{M} \\
\text { MBtu }\end{array}$ \\
\hline 6/24/07 3:00 & 883 & 6171 & 9882 & 594.6 & 435.9 & 158.7 & 26.7 & 1.15 & 2.4 & 299 & 294 & 2209 & 7.2 & 2.6 & 0.2 & 0.2 \\
\hline 6/24/07 4:00 & 886 & 6152 & 9873 & 596.3 & 437.3 & 159.0 & 26.7 & 1.15 & 2.4 & 299 & 292 & 2218 & 7.3 & 2.5 & 0.2 & 0.2 \\
\hline $6 / 24 / 07$ 5:00 & 888 & 6097 & 9803 & 597.3 & 438.2 & 159.2 & 26.6 & 1.15 & 2.4 & 298 & 294 & 2222 & 7.3 & 2.5 & 0.2 & 0.2 \\
\hline $6 / 24 / 076: 00$ & 885 & 6104 & 9806 & 599.1 & 440.3 & 158.7 & 26.5 & 1.14 & 2.4 & 298 & 295 & 2222 & 7.7 & 2.4 & 0.2 & 0.2 \\
\hline $6 / 24 / 07$ 7:00 & 885 & 6073 & 9809 & 601.3 & 442.7 & 158.6 & 26.4 & 1.14 & 2.4 & 298 & 296 & 2217 & 7.2 & 2.2 & 0.2 & 0.2 \\
\hline 6/24/07 8:00 & 885 & 6090 & 9820 & 605.8 & 447.1 & 158.7 & 26.2 & 1.13 & 2.4 & 299 & 297 & 2224 & 7.2 & 2.1 & 0.2 & 0.2 \\
\hline 6/24/07 9:00 & 884 & 6085 & 9821 & 609.5 & 450.6 & 158.9 & 26.1 & 1.12 & 2.5 & 300 & 298 & 2228 & 7.3 & 2.0 & 0.2 & 0.2 \\
\hline $6 / 24 / 07$ 10:00 & 887 & 6106 & 9743 & 608.4 & 450.0 & 158.3 & 26.0 & 1.12 & 2.4 & 301 & 299 & 2230 & 7.3 & 2.0 & 0.2 & 0.2 \\
\hline 6/24/07 11:00 & 885 & 6106 & 9792 & 606.4 & 449.0 & 157.4 & 26.0 & 1.12 & 2.5 & 301 & 300 & 2240 & 7.3 & 2.0 & 0.2 & 0.2 \\
\hline $6 / 24 / 07$ 12:00 & 885 & 6095 & 9743 & 605.5 & 448.3 & 157.2 & 26.0 & 1.13 & 2.5 & 303 & 303 & 2246 & 7.5 & 2.0 & 0.2 & 0.2 \\
\hline $6 / 24 / 07$ 13:00 & 886 & 6135 & 9681 & 596.5 & 440.3 & 156.2 & 26.2 & 1.13 & 2.4 & 306 & 305 & 2248 & 7.8 & 2.0 & 0.2 & 0.2 \\
\hline $6 / 24 / 07$ 14:00 & 887 & 6132 & 9635 & 583.6 & 429.3 & 154.3 & 26.4 & 1.15 & 2.5 & 307 & 306 & 2247 & 8.3 & 1.9 & 0.2 & 0.2 \\
\hline $6 / 24 / 07$ 15:00 & 883 & 6093 & 9656 & 579.3 & 425.0 & 154.3 & 26.6 & 1.16 & 2.5 & 309 & 307 & 2240 & 8.6 & 1.8 & 0.1 & 0.2 \\
\hline $6 / 24 / 07$ 16:00 & 881 & 6098 & 9802 & 584.5 & 428.7 & 155.8 & 26.7 & 1.17 & 2.5 & 311 & 309 & 2239 & 8.3 & 1.8 & 0.2 & 0.2 \\
\hline 6/24/07 17:00 & 880 & 6107 & 9956 & 595.9 & 438.2 & 157.7 & 26.5 & 1.16 & 2.5 & 311 & 311 & 2250 & 8.2 & 1.9 & 0.2 & 0.2 \\
\hline 6/24/07 18:00 & 883 & 6129 & 9976 & 605.5 & 446.9 & 158.6 & 26.2 & 1.15 & 2.4 & 308 & 309 & 2263 & 7.9 & 2.0 & 0.2 & 0.2 \\
\hline $6 / 24 / 07$ 19:00 & 887 & 6144 & 9866 & 607.5 & 449.9 & 157.5 & 25.9 & 1.14 & 2.4 & 307 & 307 & 2275 & 7.9 & 2.0 & 0.2 & 0.2 \\
\hline $6 / 24 / 07$ 20:00 & 885 & 6159 & 9846 & 605.1 & 449.2 & 155.9 & 25.8 & 1.13 & 2.5 & 305 & 305 & 2254 & 7.9 & 2.0 & 0.2 & 0.2 \\
\hline $6 / 24 / 07$ 21:00 & 886 & 6124 & 9882 & 605.9 & 450.7 & 155.3 & 25.6 & 1.13 & 2.5 & 302 & 303 & 2261 & 7.7 & 1.9 & 0.2 & 0.2 \\
\hline 6/24/07 22:00 & 885 & 6143 & 9828 & 604.4 & 449.3 & 155.1 & 25.7 & 1.13 & 2.5 & 302 & 303 & 2263 & 7.8 & 1.9 & 0.2 & 0.2 \\
\hline $6 / 24 / 07$ 23:00 & 887 & 6134 & 9727 & 598.5 & 444.5 & 154.1 & 25.7 & 1.14 & 2.4 & 302 & 303 & 2262 & 7.8 & 1.8 & 0.2 & 0.2 \\
\hline $6 / 25 / 07$ 0:00 & 885 & 6130 & 9730 & 595.0 & 440.6 & 154.4 & 25.9 & 1.14 & 2.5 & 303 & 302 & 2258 & 7.8 & 1.8 & 0.1 & 0.2 \\
\hline $6 / 25 / 07$ 1:00 & 885 & 6144 & 9773 & 590.6 & 436.8 & 153.8 & 26.0 & 1.15 & 2.5 & 303 & 302 & 2261 & 8.1 & 1.7 & 0.1 & 0.2 \\
\hline $6 / 25 / 072: 00$ & 883 & 6118 & 9842 & 592.2 & 438.2 & 154.0 & 26.0 & 1.16 & 2.5 & 302 & 301 & 2260 & 8.0 & 1.7 & 0.1 & 0.2 \\
\hline 6/25/07 3:00 & 885 & 6087 & 9759 & 596.8 & 442.0 & 154.8 & 25.9 & 1.15 & 2.4 & 301 & 300 & 2260 & 7.8 & 1.7 & 0.1 & 0.2 \\
\hline 6/25/07 4:00 & 885 & 6110 & 9784 & 597.4 & 442.5 & 154.9 & 25.9 & 1.14 & 2.5 & 301 & 301 & 2253 & 8.2 & 1.7 & 0.1 & 0.2 \\
\hline $6 / 25 / 07$ 5:00 & 883 & 6132 & 9804 & 600.4 & 445.0 & 155.4 & 25.9 & 1.14 & 2.4 & 302 & 302 & 2248 & 8.1 & 1.8 & 0.1 & 0.2 \\
\hline $6 / 25 / 076: 00$ & 883 & 6206 & 9778 & 593.5 & 439.6 & 153.9 & 25.9 & 1.15 & 2.2 & 302 & 302 & 2227 & 7.6 & 1.7 & 0.1 & 0.2 \\
\hline $6 / 25 / 07$ 7:00 & 885 & 6161 & 9814 & 586.4 & 434.3 & 152.1 & 25.9 & 1.16 & 2.1 & 300 & 300 & 2203 & 7.8 & 1.6 & 0.1 & 0.2 \\
\hline $6 / 25 / 078: 00$ & 878 & 6196 & 9868 & 581.6 & 430.7 & 150.9 & 25.9 & 1.18 & 2.0 & 300 & 300 & 2198 & 7.8 & 1.6 & 0.1 & 0.2 \\
\hline $6 / 25 / 07$ 9:00 & 872 & 6268 & 10091 & 584.3 & 432.2 & 152.0 & 26.0 & 1.19 & 1.9 & 300 & 301 & 2195 & 7.8 & 1.7 & 0.1 & 0.2 \\
\hline
\end{tabular}




\begin{tabular}{|c|c|c|c|c|c|c|c|c|c|c|c|c|c|c|c|c|}
\hline Date and & $\begin{array}{c}\text { Gross } \\
\text { Gen }\end{array}$ & $\begin{array}{c}\text { Steam } \\
\text { Flow }\end{array}$ & Gross HR & Total Fuel & $\begin{array}{c}\text { Total } \\
\text { Lignite }\end{array}$ & Total PRB & $\begin{array}{l}\text { Total } \\
\text { PRB } \\
\end{array}$ & $\begin{array}{c}\text { Btu } \\
\text { Gain }\end{array}$ & $\begin{array}{c}\text { Econ } \\
\text { O2 }\end{array}$ & $\begin{array}{c}\text { Temp } \\
\text { A APH } \\
\text { Out }\end{array}$ & $\begin{array}{c}\text { Temp } \\
\text { B APH } \\
\text { Out }\end{array}$ & $\begin{array}{l}\text { Stack } \\
\text { Flow }\end{array}$ & Opacity & SO2 In & $\begin{array}{l}\text { SO2 } \\
\text { Out }\end{array}$ & NOx \\
\hline $\begin{array}{l}\text { Start Date } \\
\text { and Time }\end{array}$ & MW & $\begin{array}{c}\text { KLB/ } \\
\text { HR }\end{array}$ & Btu/kWhr & TON/HR & TON/HR & TON/HR & $\begin{array}{c}\% \\
\text { Weight }\end{array}$ & & $\%$ & DEGF & DEGF & KSCF & $\%$ & $\begin{array}{c}\text { Ib/MM } \\
\text { Btu }\end{array}$ & $\begin{array}{c}\text { Ib/MM } \\
\text { Btu }\end{array}$ & $\begin{array}{l}\text { Ib/M } \\
\text { MBtu }\end{array}$ \\
\hline 6/25/07 10:00 & 874 & 6238 & 10121 & 585.1 & 432.7 & 152.4 & 26.0 & 1.19 & 2.1 & 300 & 300 & 2209 & 7.9 & 1.7 & 0.1 & 0.2 \\
\hline 6/25/07 11:00 & 874 & 6198 & 10102 & 582.4 & 430.7 & 151.7 & 26.0 & 1.19 & 2.2 & 300 & 300 & 2226 & 8.0 & 1.6 & 0.1 & 0.2 \\
\hline $6 / 25 / 07$ 12:00 & 872 & 6185 & 9957 & 579.3 & 428.4 & 150.9 & 26.1 & 1.19 & 2.3 & 299 & 295 & 2224 & 8.0 & 1.5 & 0.1 & 0.2 \\
\hline $6 / 25 / 07$ 13:00 & 878 & 6227 & 9997 & 583.2 & 431.2 & 151.9 & 26.0 & 1.19 & 2.3 & 301 & 295 & 2229 & 7.8 & 1.6 & 0.1 & 0.2 \\
\hline $6 / 25 / 07$ 14:00 & 881 & 6233 & 10048 & 588.0 & 434.9 & 153.0 & 26.0 & 1.19 & 2.3 & 302 & 298 & 2229 & 8.1 & 1.6 & 0.1 & 0.2 \\
\hline $6 / 25 / 07$ 15:00 & 881 & 6241 & 10114 & 591.3 & 437.4 & 153.9 & 26.0 & 1.18 & 2.2 & 304 & 300 & 2221 & 8.3 & 1.6 & 0.1 & 0.2 \\
\hline $6 / 25 / 07$ 16:00 & 882 & 6250 & 10100 & 594.3 & 439.7 & 154.7 & 26.0 & 1.18 & 2.3 & 305 & 301 & 2244 & 8.6 & 1.6 & 0.1 & 0.2 \\
\hline $6 / 25 / 07$ 17:00 & 883 & 6265 & 10095 & 595.5 & 440.6 & 154.9 & 26.0 & 1.18 & 2.2 & 306 & 302 & 2246 & 8.7 & 1.6 & 0.1 & 0.2 \\
\hline $6 / 25 / 07$ 18:00 & 882 & 6248 & 10018 & 592.2 & 438.1 & 154.1 & 26.0 & 1.18 & 2.2 & 306 & 304 & 2245 & 8.5 & 1.6 & 0.1 & 0.2 \\
\hline $6 / 25 / 07$ 19:00 & 882 & 6134 & 9898 & 585.8 & 433.3 & 152.5 & 26.0 & 1.17 & 2.2 & 306 & 305 & 2231 & 8.3 & 1.6 & 0.1 & 0.2 \\
\hline $6 / 25 / 0720: 00$ & 880 & 6114 & 9835 & 584.9 & 432.6 & 152.3 & 26.0 & 1.17 & 2.3 & 307 & 307 & 2223 & 8.2 & 1.6 & 0.1 & 0.2 \\
\hline $6 / 25 / 07$ 21:00 & 879 & 6140 & 9865 & 588.3 & 435.2 & 153.2 & 26.0 & 1.17 & 2.3 & 307 & 306 & 2224 & 8.5 & 1.6 & 0.1 & 0.2 \\
\hline 6/25/07 22:00 & 880 & 6171 & 9965 & 594.7 & 439.9 & 154.7 & 26.0 & 1.16 & 2.3 & 306 & 306 & 2236 & 8.5 & 1.7 & 0.1 & 0.2 \\
\hline $6 / 25 / 07$ 23:00 & 884 & 6239 & 10048 & 605.2 & 447.8 & 157.4 & 26.0 & 1.16 & 2.3 & 304 & 305 & 2252 & 8.3 & 1.8 & 0.1 & 0.2 \\
\hline 6/26/07 0:00 & 886 & 6176 & 9937 & 605.0 & 447.7 & 157.4 & 26.0 & 1.15 & 2.2 & 303 & 302 & 2251 & 8.0 & 1.9 & 0.2 & 0.2 \\
\hline $6 / 26 / 07$ 1:00 & 886 & 6156 & 9903 & 603.1 & 446.3 & 156.9 & 26.0 & 1.15 & 2.2 & 304 & 302 & 2241 & 8.1 & 1.9 & 0.2 & 0.2 \\
\hline $6 / 26 / 072: 00$ & 884 & 6134 & 9800 & 598.6 & 442.8 & 155.8 & 26.0 & 1.14 & 2.2 & 304 & 301 & 2232 & 8.0 & 1.9 & 0.2 & 0.2 \\
\hline $6 / 26 / 07$ 3:00 & 881 & 6108 & 9817 & 597.1 & 441.8 & 155.4 & 26.0 & 1.14 & 2.2 & 304 & 301 & 2217 & 8.1 & 1.9 & 0.2 & 0.2 \\
\hline $6 / 26 / 074: 00$ & 882 & 6102 & 9783 & 596.0 & 440.9 & 155.1 & 26.0 & 1.14 & 2.3 & 303 & 301 & 2229 & 8.2 & 1.9 & 0.2 & 0.2 \\
\hline $6 / 26 / 07$ 5:00 & 876 & 6161 & 9806 & 589.3 & 433.1 & 156.3 & 26.5 & 1.15 & 2.3 & 305 & 303 & 2229 & 8.2 & 1.9 & 0.2 & 0.2 \\
\hline $6 / 26 / 076: 00$ & 870 & 6125 & 10071 & 598.7 & 442.7 & 156.0 & 26.1 & 1.15 & 2.2 & 306 & 299 & 2213 & 8.0 & 2.0 & 0.2 & 0.2 \\
\hline $6 / 26 / 07$ 7:00 & 880 & 6120 & 10060 & 614.6 & 454.8 & 159.8 & 26.0 & 1.13 & 2.1 & 304 & 298 & 2209 & 8.1 & 2.1 & 0.2 & 0.2 \\
\hline $6 / 26 / 07$ 8:00 & 883 & 6189 & 9842 & 606.4 & 448.6 & 157.7 & 26.0 & 1.13 & 6.6 & 303 & 298 & 2222 & 8.1 & 2.0 & 0.2 & 0.2 \\
\hline $6 / 26 / 07$ 9:00 & 880 & 6183 & 9864 & 599.3 & 443.3 & 155.9 & 26.0 & 1.14 & 4.7 & 304 & 300 & 2225 & 8.3 & 1.8 & 0.2 & 0.2 \\
\hline $6 / 26 / 07$ 10:00 & 882 & 6154 & 9900 & 595.2 & 440.4 & 154.8 & 26.0 & 1.15 & 2.0 & 303 & 299 & 2204 & 8.3 & 1.7 & 0.1 & 0.2 \\
\hline $6 / 26 / 07$ 11:00 & 881 & 6140 & 9775 & 589.5 & 435.8 & 153.7 & 26.1 & 1.15 & 2.0 & 304 & 300 & 2201 & 8.4 & 1.7 & 0.1 & 0.2 \\
\hline $6 / 26 / 07$ 12:00 & 880 & 6140 & 9828 & 589.2 & 435.0 & 154.2 & 26.2 & 1.16 & 2.0 & 305 & 301 & 2220 & 8.7 & 1.6 & 0.1 & 0.2 \\
\hline $6 / 26 / 07$ 13:00 & 883 & 6149 & 9832 & 589.1 & 435.7 & 153.4 & 26.0 & 1.16 & 2.0 & 309 & 304 & 2223 & 9.2 & 1.6 & 0.1 & 0.2 \\
\hline $6 / 26 / 07$ 14:00 & 884 & 6145 & 9828 & 588.6 & 435.3 & 153.2 & 26.0 & 1.17 & 2.0 & 308 & 305 & 2210 & 9.7 & 1.5 & 0.1 & 0.2 \\
\hline $6 / 26 / 07$ 15:00 & 884 & 6168 & 9800 & 585.0 & 432.6 & 152.3 & 26.0 & 1.17 & 1.9 & 309 & 297 & 2214 & 8.5 & 1.5 & 0.1 & 0.2 \\
\hline $6 / 26 / 07$ 16:00 & 883 & 6133 & 9879 & 583.8 & 431.8 & 152.1 & 26.0 & 1.17 & 1.9 & 309 & 296 & 2210 & 8.1 & 1.5 & 0.1 & 0.2 \\
\hline
\end{tabular}




\begin{tabular}{|c|c|c|c|c|c|c|c|c|c|c|c|c|c|c|c|c|}
\hline Date and & $\begin{array}{c}\text { Gross } \\
\text { Gen }\end{array}$ & $\begin{array}{c}\text { Steam } \\
\text { Flow }\end{array}$ & Gross HR & Total Fuel & $\begin{array}{c}\text { Total } \\
\text { Lignite }\end{array}$ & Total PRB & $\begin{array}{l}\text { Total } \\
\text { PRB } \\
\end{array}$ & $\begin{array}{c}\text { Btu } \\
\text { Gain }\end{array}$ & $\begin{array}{c}\text { Econ } \\
\text { O2 }\end{array}$ & $\begin{array}{c}\text { Temp } \\
\text { A APH } \\
\text { Out }\end{array}$ & $\begin{array}{c}\text { Temp } \\
\text { B APH } \\
\text { Out }\end{array}$ & $\begin{array}{l}\text { Stack } \\
\text { Flow }\end{array}$ & Opacity & SO2 In & $\begin{array}{l}\text { SO2 } \\
\text { Out }\end{array}$ & NOx \\
\hline $\begin{array}{l}\text { Start Date } \\
\text { and Time }\end{array}$ & MW & $\begin{array}{c}\text { KLB/ } \\
\text { HR }\end{array}$ & Btu/kWhr & TON/HR & TON/HR & TON/HR & $\begin{array}{c}\% \\
\text { Weight }\end{array}$ & & $\%$ & DEGF & DEGF & KSCF & $\%$ & $\begin{array}{c}\text { Ib/MM } \\
\text { Btu }\end{array}$ & $\begin{array}{c}\text { Ib/MM } \\
\text { Btu }\end{array}$ & $\begin{array}{l}\text { Ib/M } \\
\text { MBtu }\end{array}$ \\
\hline 6/26/07 17:00 & 879 & 6162 & 9925 & 588.0 & 434.9 & 153.1 & 26.0 & 1.17 & 1.9 & 308 & 297 & 2201 & 8.4 & 1.5 & 0.1 & 0.2 \\
\hline 6/26/07 18:00 & 881 & 6173 & 10054 & 599.4 & 443.5 & 155.9 & 26.0 & 1.16 & 1.8 & 308 & 298 & 2191 & 8.9 & 1.5 & 0.1 & 0.2 \\
\hline $6 / 26 / 07$ 19:00 & 882 & 6127 & 9972 & 600.1 & 444.7 & 155.4 & 25.9 & 1.15 & 1.8 & 312 & 302 & 2188 & 9.1 & 1.5 & 0.1 & 0.2 \\
\hline $6 / 26 / 0720: 00$ & 879 & 6109 & 9791 & 587.1 & 433.9 & 153.1 & 26.1 & 1.15 & 2.1 & 316 & 304 & 2204 & 9.3 & 1.5 & 0.1 & 0.2 \\
\hline $6 / 26 / 0721: 00$ & 879 & 6163 & 9879 & 586.4 & 433.5 & 152.9 & 26.1 & 1.16 & 2.2 & 311 & 301 & 2232 & 9.6 & 1.5 & 0.1 & 0.2 \\
\hline 6/26/07 22:00 & 883 & 6163 & 9831 & 584.1 & 431.8 & 152.2 & 26.1 & 1.17 & 2.3 & 305 & 292 & 2213 & 9.0 & 1.6 & 0.1 & 0.2 \\
\hline $6 / 26 / 07$ 23:00 & 886 & 6130 & 9707 & 575.5 & 425.7 & 149.8 & 26.0 & 1.18 & 2.2 & 299 & 272 & 2192 & 7.9 & 1.5 & 0.1 & 0.2 \\
\hline 6/27/07 0:00 & 885 & 6136 & 9633 & 564.4 & 418.3 & 146.1 & 25.9 & 1.19 & 2.2 & 299 & 275 & 2187 & 8.1 & 1.4 & 0.1 & 0.2 \\
\hline 6/27/07 1:00 & 882 & 6094 & 9633 & 555.9 & 415.8 & 140.0 & 25.2 & 1.21 & 2.1 & 301 & 278 & 2175 & 8.0 & 1.2 & 0.1 & 0.2 \\
\hline $6 / 27 / 072: 00$ & 884 & 6081 & 9583 & 547.9 & 411.3 & 136.7 & 24.9 & 1.22 & 2.1 & 302 & 290 & 2175 & 9.0 & 1.1 & 0.1 & 0.2 \\
\hline $6 / 27 / 073: 00$ & 882 & 6077 & 9607 & 541.1 & 406.4 & 134.7 & 24.9 & 1.24 & 2.1 & 302 & 293 & 2176 & 9.3 & 1.0 & 0.1 & 0.1 \\
\hline $6 / 27 / 074: 00$ & 881 & 6040 & 9676 & 539.2 & 405.1 & 134.1 & 24.9 & 1.25 & 2.1 & 303 & 295 & 2176 & 9.6 & 0.9 & 0.1 & 0.1 \\
\hline $6 / 27 / 07$ 5:00 & 873 & 6184 & 9765 & 534.9 & 401.6 & 133.3 & 24.9 & 1.26 & 2.1 & 302 & 294 & 2171 & 9.3 & 0.9 & 0.1 & 0.1 \\
\hline $6 / 27 / 076: 00$ & 876 & 6187 & 9957 & 537.5 & 403.1 & 134.4 & 25.0 & 1.28 & 2.1 & 303 & 294 & 2200 & 9.8 & 0.8 & 0.1 & 0.1 \\
\hline $6 / 27 / 07$ 7:00 & 882 & 6173 & 9940 & 541.4 & 404.0 & 137.4 & 25.4 & 1.28 & 2.1 & 306 & 297 & 2210 & 9.8 & 0.8 & 0.1 & 0.1 \\
\hline $6 / 27 / 07$ 8:00 & 883 & 6218 & 10034 & 544.9 & 403.6 & 141.3 & 25.9 & 1.27 & 2.1 & 309 & 299 & 2224 & 9.4 & 0.8 & 0.1 & 0.2 \\
\hline $6 / 27 / 07$ 9:00 & 881 & 6236 & 10082 & 550.5 & 420.6 & 129.9 & 23.6 & 1.27 & 2.1 & 310 & 300 & 2227 & 9.6 & 0.8 & 0.1 & 0.2 \\
\hline $6 / 27 / 07$ 10:00 & 886 & 6218 & 10007 & 552.0 & 423.5 & 128.6 & 23.3 & 1.27 & 2.0 & 311 & 300 & 2233 & 9.1 & 0.8 & 0.1 & 0.2 \\
\hline $6 / 27 / 07$ 11:00 & 887 & 6192 & 9978 & 552.9 & 424.5 & 128.4 & 23.2 & 1.26 & 2.0 & 314 & 302 & 2234 & 9.1 & 0.8 & 0.1 & 0.2 \\
\hline $6 / 27 / 07$ 12:00 & 884 & 6123 & 9922 & 553.0 & 445.2 & 107.9 & 19.5 & 1.25 & 2.0 & 324 & 309 & 2205 & 9.2 & 0.8 & 0.1 & 0.2 \\
\hline $6 / 27 / 07$ 13:00 & 878 & 6141 & 9951 & 555.8 & 476.1 & 79.7 & 14.3 & 1.24 & 2.0 & 333 & 318 & 2197 & 9.5 & 0.9 & 0.1 & 0.2 \\
\hline $6 / 27 / 07$ 14:00 & 886 & 6242 & 10011 & 562.8 & 489.4 & 73.4 & 13.0 & 1.24 & 2.1 & 321 & 313 & 2222 & 9.6 & 0.8 & 0.1 & 0.2 \\
\hline $6 / 27 / 07$ 15:00 & 888 & 6247 & 9904 & 561.3 & 489.9 & 71.4 & 12.7 & 1.24 & 2.1 & 315 & 308 & 2227 & 9.6 & 0.9 & 0.1 & 0.2 \\
\hline $6 / 27 / 07$ 16:00 & 890 & 6247 & 9944 & 561.6 & 490.2 & 71.3 & 12.7 & 1.24 & 2.1 & 313 & 306 & 2236 & 9.7 & 0.9 & 0.1 & 0.2 \\
\hline 6/27/07 17:00 & 894 & 6192 & 9905 & 562.6 & 491.1 & 71.5 & 12.7 & 1.24 & 2.0 & 316 & 308 & 2242 & 9.7 & 0.9 & 0.1 & 0.2 \\
\hline $6 / 27 / 07$ 18:00 & 894 & 6165 & 9875 & 559.8 & 488.7 & 71.2 & 12.7 & 1.23 & 2.0 & 318 & 310 & 2234 & 9.8 & 0.9 & 0.1 & 0.2 \\
\hline 6/27/07 19:00 & 881 & 6050 & 9717 & 547.2 & 455.7 & 91.5 & 16.7 & 1.23 & 2.1 & 322 & 319 & 2205 & 10.2 & 0.9 & 0.1 & 0.2 \\
\hline 6/27/07 20:00 & 874 & 6134 & 9811 & 542.5 & 409.4 & 133.2 & 24.5 & 1.24 & 2.1 & 311 & 319 & 2189 & 10.1 & 0.8 & 0.1 & 0.1 \\
\hline $6 / 27 / 07$ 21:00 & 880 & 6128 & 9854 & 539.0 & 404.2 & 134.7 & 25.0 & 1.26 & 2.1 & 302 & 305 & 2206 & 10.1 & 0.8 & 0.1 & 0.1 \\
\hline $6 / 27 / 0722: 00$ & 880 & 6095 & 9762 & 536.2 & 402.1 & 134.0 & 25.0 & 1.26 & 2.2 & 302 & 299 & 2194 & 9.9 & 0.7 & 0.1 & 0.2 \\
\hline $6 / 27 / 07$ 23:00 & 880 & 6105 & 9780 & 533.3 & 400.0 & 133.3 & 25.0 & 1.27 & 2.2 & 306 & 303 & 2196 & 10.1 & 0.7 & 0.1 & 0.2 \\
\hline
\end{tabular}




\begin{tabular}{|c|c|c|c|c|c|c|c|c|c|c|c|c|c|c|c|c|}
\hline Date and & $\begin{array}{c}\text { Gross } \\
\text { Gen }\end{array}$ & $\begin{array}{c}\text { Steam } \\
\text { Flow }\end{array}$ & Gross HR & Total Fuel & $\begin{array}{c}\text { Total } \\
\text { Lignite }\end{array}$ & Total PRB & $\begin{array}{l}\text { Total } \\
\text { PRB }\end{array}$ & $\begin{array}{c}\text { Btu } \\
\text { Gain }\end{array}$ & $\begin{array}{c}\text { Econ } \\
\text { O2 }\end{array}$ & $\begin{array}{c}\text { Temp } \\
\text { A APH } \\
\text { Out }\end{array}$ & $\begin{array}{c}\text { Temp } \\
\text { B APH } \\
\text { Out }\end{array}$ & $\begin{array}{l}\text { Stack } \\
\text { Flow }\end{array}$ & Opacity & SO2 In & $\begin{array}{l}\text { SO2 } \\
\text { Out }\end{array}$ & NOx \\
\hline $\begin{array}{l}\text { Start Date } \\
\text { and Time }\end{array}$ & MW & $\begin{array}{c}\text { KLB/ } \\
\text { HR }\end{array}$ & Btu/kWhr & TON/HR & TON/HR & TON/HR & $\begin{array}{c}\% \\
\text { Weight }\end{array}$ & & $\%$ & DEGF & DEGF & KSCF & $\%$ & $\begin{array}{c}\text { Ib/MM } \\
\text { Btu }\end{array}$ & $\begin{array}{c}\text { Ib/MM } \\
\text { Btu }\end{array}$ & $\begin{array}{l}\mathbf{l b} / \mathbf{M} \\
\text { MBtu }\end{array}$ \\
\hline 6/28/07 0:00 & 880 & 6103 & 9797 & 530.8 & 398.1 & 132.7 & 25.0 & 1.28 & 2.2 & 306 & 304 & 2197 & 10.3 & 0.8 & 0.1 & 0.2 \\
\hline 6/28/07 1:00 & 879 & 6074 & 9798 & 531.3 & 398.6 & 132.8 & 25.0 & 1.28 & 2.2 & 308 & 304 & 2200 & 10.5 & 0.8 & 0.1 & 0.2 \\
\hline $6 / 28 / 072: 00$ & 880 & 6073 & 9842 & 532.5 & 399.4 & 133.1 & 25.0 & 1.28 & 2.2 & 307 & 305 & 2203 & 10.4 & 0.8 & 0.1 & 0.2 \\
\hline $6 / 28 / 07$ 3:00 & 881 & 6071 & 9778 & 533.4 & 400.1 & 133.3 & 25.0 & 1.27 & 2.2 & 308 & 306 & 2198 & 10.7 & 0.8 & 0.1 & 0.2 \\
\hline $6 / 28 / 074: 00$ & 880 & 6066 & 9735 & 533.4 & 400.1 & 133.3 & 25.0 & 1.27 & 2.2 & 307 & 305 & 2193 & 10.5 & 0.8 & 0.1 & 0.2 \\
\hline $6 / 28 / 075: 00$ & 876 & 6169 & 9820 & 533.5 & 400.1 & 133.4 & 25.0 & 1.28 & 2.2 & 307 & 306 & 2197 & 10.1 & 0.8 & 0.1 & 0.2 \\
\hline 6/28/07 6:00 & 881 & 6254 & 9933 & 539.4 & 404.0 & 135.4 & 25.1 & 1.29 & 2.2 & 305 & 302 & 2210 & 11.3 & 0.8 & 0.1 & 0.2 \\
\hline 6/28/07 7:00 & 883 & 6249 & 10028 & 540.8 & 390.2 & 150.7 & 27.9 & 1.29 & 2.2 & 308 & 308 & 2200 & 11.2 & 0.8 & 0.1 & 0.2 \\
\hline 6/28/07 8:00 & 873 & 6152 & 10089 & 538.0 & 384.3 & 153.7 & 28.6 & 1.29 & 2.5 & 302 & 303 & 2202 & 11.2 & 0.8 & 0.1 & 0.2 \\
\hline $6 / 28 / 07$ 9:00 & 878 & 6160 & 10068 & 543.7 & 388.4 & 155.2 & 28.6 & 1.28 & 2.4 & 305 & 304 & 2214 & 11.1 & 0.9 & 0.1 & 0.2 \\
\hline $6 / 28 / 07$ 10:00 & 884 & 6160 & 9909 & 543.5 & 398.4 & 145.1 & 26.7 & 1.27 & 2.4 & 311 & 308 & 2216 & 10.8 & 0.9 & 0.1 & 0.2 \\
\hline $6 / 28 / 07$ 11:00 & 884 & 6176 & 9886 & 544.4 & 402.0 & 142.4 & 26.2 & 1.27 & 2.4 & 314 & 308 & 2230 & 10.8 & 0.9 & 0.1 & 0.2 \\
\hline 6/28/07 12:00 & 885 & 6161 & 9927 & 546.1 & 404.6 & 141.5 & 25.9 & 1.26 & 2.3 & 312 & 309 & 2222 & 11.0 & 0.9 & 0.1 & 0.2 \\
\hline 6/28/07 13:00 & 884 & 6105 & 9941 & 554.4 & 412.6 & 141.8 & 25.6 & 1.25 & 2.2 & 314 & 310 & 2218 & 11.3 & 0.9 & 0.1 & 0.2 \\
\hline $6 / 28 / 07$ 14:00 & 881 & 6047 & 10068 & 574.4 & 430.1 & 144.4 & 25.1 & 1.22 & 2.2 & 317 & 312 & 2207 & 11.2 & 1.1 & 0.1 & 0.2 \\
\hline $6 / 28 / 07$ 15:00 & 884 & 6070 & 10062 & 596.3 & 447.3 & 149.1 & 25.0 & 1.18 & 2.0 & 314 & 311 & 2206 & 11.1 & 1.4 & 0.1 & 0.2 \\
\hline $6 / 28 / 07$ 16:00 & 885 & 6128 & 10072 & 620.5 & 468.3 & 152.2 & 24.5 & 1.15 & 2.1 & 312 & 310 & 2213 & 11.0 & 1.6 & 0.2 & 0.2 \\
\hline $6 / 28 / 07$ 17:00 & 885 & 6168 & 10001 & 623.7 & 469.0 & 154.7 & 24.8 & 1.13 & 2.1 & 311 & 308 & 2217 & 10.8 & 1.8 & 0.2 & 0.2 \\
\hline 6/28/07 18:00 & 884 & 6202 & 9984 & 622.8 & 467.1 & 155.7 & 25.0 & 1.12 & 2.1 & 311 & 307 & 2228 & 10.7 & 1.8 & 0.2 & 0.2 \\
\hline 6/28/07 19:00 & 883 & 6232 & 9987 & 625.2 & 468.9 & 156.3 & 25.0 & 1.12 & 2.1 & 308 & 306 & 2234 & 10.3 & 1.8 & 0.2 & 0.2 \\
\hline $6 / 28 / 0720: 00$ & 876 & 6197 & 9991 & 620.4 & 470.2 & 150.2 & 24.2 & 1.11 & 2.1 & 309 & 306 & 2217 & 10.2 & 1.8 & 0.2 & 0.2 \\
\hline $6 / 28 / 07$ 21:00 & 870 & 6172 & 10030 & 620.0 & 465.0 & 154.9 & 25.0 & 1.11 & 2.1 & 307 & 305 & 2225 & 10.3 & 1.8 & 0.2 & 0.2 \\
\hline $6 / 28 / 0722: 00$ & 871 & 6201 & 10039 & 617.5 & 463.2 & 154.3 & 25.0 & 1.11 & 2.1 & 304 & 301 & 2219 & 9.8 & 1.8 & 0.2 & 0.2 \\
\hline $6 / 28 / 07$ 23:00 & 874 & 6183 & 10064 & 619.1 & 464.3 & 154.7 & 25.0 & 1.12 & 2.1 & 301 & 299 & 2219 & 9.7 & 1.8 & 0.2 & 0.2 \\
\hline 6/29/07 0:00 & 877 & 6328 & 10004 & 615.8 & 464.7 & 151.1 & 24.5 & 1.13 & 2.1 & 303 & 301 & 2232 & 9.8 & 1.8 & 0.2 & 0.2 \\
\hline 6/29/07 1:00 & 875 & 6374 & 10100 & 607.4 & 462.4 & 145.0 & 23.9 & 1.15 & 2.1 & 310 & 310 & 2237 & 9.8 & 1.6 & 0.2 & 0.2 \\
\hline 6/29/07 2:00 & 878 & 6376 & 10148 & 605.5 & 469.0 & 136.5 & 22.5 & 1.17 & 2.2 & 311 & 312 & 2235 & 10.0 & 1.5 & 0.1 & 0.2 \\
\hline 6/29/07 3:00 & 895 & 6275 & 10172 & 613.3 & 468.2 & 145.0 & 23.7 & 1.16 & 2.2 & 308 & 307 & 2238 & 10.1 & 1.5 & 0.1 & 0.2 \\
\hline $6 / 29 / 074: 00$ & 895 & 6146 & 9723 & 597.1 & 447.8 & 149.2 & 25.0 & 1.15 & 2.2 & 303 & 301 & 2233 & 10.1 & 1.4 & 0.1 & 0.2 \\
\hline $6 / 29 / 075: 00$ & 884 & 6068 & 9702 & 589.0 & 441.8 & 147.2 & 25.0 & 1.15 & 2.2 & 301 & 299 & 2198 & 9.7 & 1.4 & 0.1 & 0.2 \\
\hline $6 / 29 / 076: 00$ & 876 & 6101 & 9796 & 590.9 & 443.2 & 147.7 & 25.0 & 1.15 & 2.3 & 301 & 298 & 2209 & 10.5 & 1.5 & 0.1 & 0.2 \\
\hline
\end{tabular}




\begin{tabular}{|c|c|c|c|c|c|c|c|c|c|c|c|c|c|c|c|c|}
\hline Date and & $\begin{array}{c}\text { Gross } \\
\text { Gen }\end{array}$ & $\begin{array}{c}\text { Steam } \\
\text { Flow }\end{array}$ & Gross HR & Total Fuel & $\begin{array}{c}\text { Total } \\
\text { Lignite }\end{array}$ & Total PRB & $\begin{array}{l}\text { Total } \\
\text { PRB }\end{array}$ & $\begin{array}{c}\text { Btu } \\
\text { Gain }\end{array}$ & $\begin{array}{c}\text { Econ } \\
\text { O2 }\end{array}$ & $\begin{array}{c}\text { Temp } \\
\text { A APH } \\
\text { Out }\end{array}$ & $\begin{array}{c}\text { Temp } \\
\text { B APH } \\
\text { Out }\end{array}$ & $\begin{array}{l}\text { Stack } \\
\text { Flow }\end{array}$ & Opacity & SO2 In & $\begin{array}{l}\text { SO2 } \\
\text { Out }\end{array}$ & NOx \\
\hline $\begin{array}{l}\text { Start Date } \\
\text { and Time }\end{array}$ & MW & $\begin{array}{c}\text { KLB/ } \\
\text { HR }\end{array}$ & Btu/kWhr & TON/HR & TON/HR & TON/HR & $\begin{array}{c}\% \\
\text { Weight }\end{array}$ & & $\%$ & DEGF & DEGF & KSCF & $\%$ & $\begin{array}{c}\text { Ib/MM } \\
\text { Btu }\end{array}$ & $\begin{array}{c}\text { Ib/MM } \\
\text { Btu }\end{array}$ & $\begin{array}{l}\mathbf{l b} / \mathbf{M} \\
\text { MBtu }\end{array}$ \\
\hline 6/29/07 7:00 & 880 & 6077 & 9907 & 594.5 & 445.8 & 148.6 & 25.0 & 1.15 & 2.2 & 299 & 298 & 2223 & 10.0 & 1.5 & 0.1 & 0.2 \\
\hline 6/29/07 8:00 & 877 & 6039 & 9908 & 602.5 & 451.9 & 150.6 & 25.0 & 1.14 & 2.2 & 301 & 298 & 2218 & 10.0 & 1.6 & 0.2 & 0.2 \\
\hline $6 / 29 / 07$ 9:00 & 883 & 6149 & 9987 & 621.4 & 466.1 & 155.3 & 25.0 & 1.12 & 2.2 & 302 & 300 & 2225 & 10.0 & 1.6 & 0.2 & 0.2 \\
\hline $6 / 29 / 07$ 10:00 & 890 & 6198 & 9943 & 623.3 & 467.5 & 155.8 & 25.0 & 1.11 & 2.2 & 304 & 303 & 2242 & 9.8 & 1.6 & 0.2 & 0.2 \\
\hline $6 / 29 / 07$ 11:00 & 879 & 6123 & 9720 & 603.9 & 477.3 & 126.7 & 21.0 & 1.12 & 2.3 & 309 & 308 & 2232 & 9.9 & 1.6 & 0.2 & 0.2 \\
\hline $6 / 29 / 07$ 12:00 & 871 & 6118 & 9967 & 611.0 & 530.5 & 80.5 & 13.2 & 1.12 & 2.2 & 315 & 319 & 2234 & 9.9 & 1.6 & 0.2 & 0.2 \\
\hline 6/29/07 13:00 & 885 & 6159 & 9929 & 620.2 & 541.8 & 78.4 & 12.6 & 1.12 & 2.2 & 312 & 313 & 2241 & 9.8 & 1.7 & 0.2 & 0.2 \\
\hline 6/29/07 14:00 & 884 & 6160 & 9900 & 623.5 & 544.6 & 78.9 & 12.7 & 1.11 & 2.2 & 309 & 309 & 2214 & 9.9 & 1.7 & 0.2 & 0.2 \\
\hline $6 / 29 / 07$ 15:00 & 884 & 6190 & 9922 & 623.8 & 544.9 & 78.9 & 12.7 & 1.11 & 2.3 & 309 & 310 & 2239 & 9.8 & 1.7 & 0.2 & 0.1 \\
\hline $6 / 29 / 07$ 16:00 & 887 & 6160 & 9931 & 623.6 & 545.5 & 78.1 & 12.5 & 1.11 & 2.4 & 313 & 311 & 2264 & 9.8 & 1.7 & 0.2 & 0.1 \\
\hline $6 / 29 / 07$ 17:00 & 889 & 6120 & 9805 & 620.0 & 542.5 & 77.5 & 12.5 & 1.10 & 2.3 & 312 & 311 & 2276 & 9.7 & 1.7 & 0.2 & 0.2 \\
\hline $6 / 29 / 07$ 18:00 & 884 & 6130 & 9786 & 618.3 & 541.0 & 77.3 & 12.5 & 1.10 & 2.3 & 310 & 310 & 2267 & 9.6 & 1.7 & 0.2 & 0.2 \\
\hline 6/29/07 19:00 & 885 & 6150 & 9869 & 620.3 & 542.8 & 77.5 & 12.5 & 1.11 & 2.3 & 309 & 310 & 2252 & 9.5 & 1.8 & 0.2 & 0.2 \\
\hline 6/29/07 20:00 & 884 & 6194 & 9801 & 612.6 & 536.0 & 76.6 & 12.5 & 1.12 & 2.3 & 308 & 308 & 2248 & 9.5 & 1.7 & 0.2 & 0.2 \\
\hline 6/29/07 21:00 & 888 & 6129 & 9791 & 608.9 & 532.8 & 76.1 & 12.5 & 1.12 & 2.2 & 306 & 307 & 2249 & 9.5 & 1.7 & 0.2 & 0.2 \\
\hline 6/29/07 22:00 & 885 & 6127 & 9785 & 607.2 & 531.3 & 75.9 & 12.5 & 1.13 & 2.3 & 305 & 307 & 2252 & 9.2 & 1.7 & 0.2 & 0.2 \\
\hline $6 / 29 / 07$ 23:00 & 882 & 6133 & 9837 & 605.4 & 529.7 & 75.7 & 12.5 & 1.13 & 2.3 & 306 & 307 & 2247 & 9.4 & 1.7 & 0.2 & 0.2 \\
\hline 6/30/07 0:00 & 880 & 6101 & 9857 & 604.6 & 529.0 & 75.5 & 12.5 & 1.13 & 2.3 & 307 & 307 & 2242 & 9.6 & 1.7 & 0.2 & 0.2 \\
\hline 6/30/07 1:00 & 879 & 6091 & 9844 & 608.7 & 532.6 & 76.1 & 12.5 & 1.12 & 2.3 & 307 & 307 & 2238 & 9.6 & 1.7 & 0.2 & 0.2 \\
\hline 6/30/07 2:00 & 880 & 6130 & 9883 & 608.6 & 532.5 & 76.1 & 12.5 & 1.12 & 2.2 & 304 & 305 & 2243 & 9.7 & 1.8 & 0.2 & 0.2 \\
\hline 6/30/07 3:00 & 881 & 6082 & 9777 & 606.8 & 531.0 & 75.8 & 12.5 & 1.12 & 2.2 & 303 & 303 & 2227 & 9.6 & 1.9 & 0.2 & 0.2 \\
\hline 6/30/07 4:00 & 880 & 6077 & 9805 & 605.6 & 529.9 & 75.7 & 12.5 & 1.12 & 2.3 & 302 & 303 & 2220 & 9.6 & 1.9 & 0.2 & 0.2 \\
\hline $6 / 30 / 07$ 5:00 & 879 & 6074 & 9805 & 607.5 & 531.6 & 75.9 & 12.5 & 1.12 & 2.3 & 303 & 304 & 2225 & 9.4 & 2.0 & 0.2 & 0.2 \\
\hline 6/30/07 6:00 & 879 & 6056 & 9833 & 612.8 & 536.2 & 76.6 & 12.5 & 1.11 & 2.3 & 303 & 302 & 2221 & 9.3 & 2.0 & 0.2 & 0.2 \\
\hline 6/30/07 7:00 & 879 & 6077 & 9893 & 622.4 & 544.6 & 77.8 & 12.5 & 1.10 & 2.2 & 304 & 302 & 2225 & 9.3 & 2.0 & 0.2 & 0.2 \\
\hline 6/30/07 8:00 & 883 & 6120 & 9802 & 620.5 & 542.9 & 77.6 & 12.5 & 1.10 & 2.2 & 304 & 302 & 2231 & 9.4 & 1.9 & 0.2 & 0.2 \\
\hline 6/30/07 9:00 & 878 & 6142 & 9801 & 618.9 & 541.5 & 77.4 & 12.5 & 1.10 & 2.3 & 304 & 302 & 2232 & 9.4 & 1.9 & 0.2 & 0.2 \\
\hline 6/30/07 10:00 & 876 & 6167 & 9949 & 621.4 & 543.3 & 78.1 & 12.6 & 1.11 & 2.2 & 304 & 301 & 2229 & 9.4 & 1.9 & 0.2 & 0.2 \\
\hline 6/30/07 11:00 & 884 & 6142 & 9783 & 612.0 & 530.3 & 81.7 & 13.3 & 1.11 & 2.2 & 305 & 302 & 2219 & 9.6 & 1.8 & 0.2 & 0.2 \\
\hline $6 / 30 / 07$ 12:00 & 884 & 6142 & 9755 & 607.8 & 525.8 & 82.0 & 13.5 & 1.12 & 2.3 & 308 & 305 & 2224 & 9.6 & 1.7 & 0.2 & 0.2 \\
\hline $6 / 30 / 07$ 13:00 & 879 & 6124 & 9819 & 604.1 & 515.4 & 88.7 & 14.7 & 1.13 & 2.3 & 311 & 309 & 2227 & 9.8 & 1.7 & 0.2 & 0.2 \\
\hline
\end{tabular}




\begin{tabular}{|c|c|c|c|c|c|c|c|c|c|c|c|c|c|c|c|c|}
\hline Date and & $\begin{array}{c}\text { Gross } \\
\text { Gen }\end{array}$ & $\begin{array}{c}\text { Steam } \\
\text { Flow }\end{array}$ & Gross HR & Total Fuel & $\begin{array}{c}\text { Total } \\
\text { Lignite }\end{array}$ & Total PRB & $\begin{array}{l}\text { Total } \\
\text { PRB }\end{array}$ & $\begin{array}{c}\text { Btu } \\
\text { Gain }\end{array}$ & $\begin{array}{c}\text { Econ } \\
\text { O2 }\end{array}$ & $\begin{array}{c}\text { Temp } \\
\text { A APH } \\
\text { Out }\end{array}$ & $\begin{array}{c}\text { Temp } \\
\text { B APH } \\
\text { Out }\end{array}$ & $\begin{array}{l}\text { Stack } \\
\text { Flow }\end{array}$ & Opacity & SO2 In & $\begin{array}{l}\text { SO2 } \\
\text { Out }\end{array}$ & NOx \\
\hline $\begin{array}{l}\text { Start Date } \\
\text { and Time }\end{array}$ & MW & $\begin{array}{c}\text { KLB/ } \\
\text { HR }\end{array}$ & Btu/kWhr & TON/HR & TON/HR & TON/HR & $\begin{array}{c}\% \\
\text { Weight }\end{array}$ & & $\%$ & DEGF & DEGF & KSCF & $\%$ & $\begin{array}{c}\text { Ib/MM } \\
\text { Btu }\end{array}$ & $\begin{array}{c}\text { Ib/MM } \\
\text { Btu }\end{array}$ & $\begin{array}{l}\mathbf{l b} / \mathbf{M} \\
\text { MBtu }\end{array}$ \\
\hline $6 / 30 / 07$ 14:00 & 879 & 6101 & 9865 & 603.8 & 491.4 & 112.4 & 18.6 & 1.13 & 2.2 & 314 & 310 & 2221 & 9.8 & 1.8 & 0.2 & 0.2 \\
\hline 6/30/07 15:00 & 880 & 6162 & 9850 & 599.2 & 521.0 & 78.1 & 13.0 & 1.14 & 2.3 & 317 & 317 & 2224 & 9.5 & 1.7 & 0.2 & 0.2 \\
\hline $6 / 30 / 07$ 16:00 & 880 & 6113 & 9852 & 596.7 & 520.4 & 76.3 & 12.8 & 1.14 & 2.3 & 314 & 313 & 2230 & 9.7 & 1.6 & 0.2 & 0.2 \\
\hline $6 / 30 / 07$ 17:00 & 879 & 6090 & 9833 & 599.4 & 522.8 & 76.7 & 12.8 & 1.14 & 2.3 & 315 & 313 & 2207 & 9.9 & 1.6 & 0.2 & 0.2 \\
\hline 6/30/07 18:00 & 879 & 6089 & 9887 & 606.0 & 528.5 & 77.5 & 12.8 & 1.13 & 2.2 & 314 & 313 & 2214 & 9.9 & 1.6 & 0.2 & 0.2 \\
\hline $6 / 30 / 07$ 19:00 & 881 & 6108 & 9882 & 607.7 & 530.0 & 77.7 & 12.8 & 1.13 & 2.2 & 313 & 312 & 2215 & 9.7 & 1.6 & 0.2 & 0.2 \\
\hline 6/30/07 20:00 & 881 & 6123 & 9784 & 605.9 & 528.4 & 77.5 & 12.8 & 1.13 & 2.2 & 311 & 310 & 2216 & 9.7 & 1.6 & 0.2 & 0.2 \\
\hline 6/30/07 21:00 & 880 & 6142 & 9814 & 601.3 & 524.4 & 76.9 & 12.8 & 1.13 & 2.2 & 309 & 308 & 2221 & 9.4 & 1.5 & 0.1 & 0.2 \\
\hline 6/30/07 22:00 & 880 & 6123 & 9775 & 596.9 & 520.6 & 76.4 & 12.8 & 1.14 & 2.3 & 305 & 305 & 2208 & 9.6 & 1.5 & 0.1 & 0.2 \\
\hline 6/30/07 23:00 & 880 & 6096 & 9777 & 595.9 & 519.7 & 76.2 & 12.8 & 1.14 & 2.3 & 306 & 305 & 2205 & 9.6 & 1.5 & 0.1 & 0.2 \\
\hline 7/1/07 0:00 & 878 & 6112 & 9814 & 596.9 & 520.6 & 76.4 & 12.8 & 1.14 & 2.3 & 308 & 305 & 2226 & 9.6 & 1.5 & 0.1 & 0.2 \\
\hline 7/1/07 1:00 & 879 & 6131 & 9902 & 596.2 & 519.9 & 76.3 & 12.8 & 1.15 & 2.2 & 308 & 304 & 2223 & 9.7 & 1.4 & 0.1 & 0.2 \\
\hline 7/1/07 2:00 & 874 & 6021 & 9827 & 590.8 & 515.2 & 75.6 & 12.8 & 1.14 & 2.3 & 307 & 304 & 2186 & 9.4 & 1.5 & 0.1 & 0.2 \\
\hline 7/1/07 3:00 & 876 & 6060 & 9829 & 597.1 & 520.7 & 76.4 & 12.8 & 1.14 & 2.3 & 307 & 304 & 2202 & 9.5 & 1.5 & 0.1 & 0.2 \\
\hline 7/1/07 4:00 & 883 & 6119 & 9848 & 605.5 & 528.1 & 77.4 & 12.8 & 1.13 & 2.3 & 308 & 305 & 2223 & 9.6 & 1.6 & 0.1 & 0.2 \\
\hline 7/1/07 5:00 & 880 & 6116 & 9853 & 604.3 & 525.8 & 78.5 & 13.0 & 1.13 & 2.2 & 308 & 305 & 2221 & 9.5 & 1.6 & 0.1 & 0.2 \\
\hline $7 / 1 / 076: 00$ & 881 & 6141 & 9882 & 608.5 & 529.3 & 79.3 & 13.0 & 1.13 & 2.3 & 306 & 304 & 2227 & 9.7 & 1.5 & 0.1 & 0.2 \\
\hline 7/1/07 7:00 & 883 & 6179 & 9792 & 607.3 & 527.1 & 80.2 & 13.2 & 1.13 & 2.3 & 306 & 302 & 2230 & 10.4 & 1.5 & 0.1 & 0.2 \\
\hline 7/1/07 8:00 & 876 & 6150 & 9874 & 606.7 & 480.1 & 126.6 & 20.9 & 1.13 & 2.2 & 311 & 304 & 2225 & 9.8 & 1.5 & 0.1 & 0.2 \\
\hline 7/1/07 9:00 & 884 & 6125 & 9835 & 610.0 & 455.5 & 154.4 & 25.3 & 1.13 & 2.2 & 308 & 300 & 2242 & 9.8 & 1.5 & 0.1 & 0.2 \\
\hline 7/1/07 10:00 & 885 & 6138 & 9765 & 603.6 & 451.5 & 152.1 & 25.2 & 1.13 & 2.2 & 309 & 301 & 2241 & 9.8 & 1.5 & 0.1 & 0.2 \\
\hline 7/1/07 11:00 & 884 & 6134 & 9869 & 609.3 & 455.7 & 153.5 & 25.2 & 1.13 & 2.3 & 311 & 303 & 2258 & 10.0 & 1.5 & 0.1 & 0.2 \\
\hline $7 / 1 / 07$ 12:00 & 884 & 6180 & 9933 & 612.2 & 458.0 & 154.2 & 25.2 & 1.13 & 2.2 & 311 & 304 & 2256 & 10.1 & 1.5 & 0.1 & 0.2 \\
\hline 7/1/07 13:00 & 884 & 6146 & 9832 & 606.7 & 453.9 & 152.8 & 25.2 & 1.13 & 2.2 & 312 & 305 & 2256 & 10.0 & 1.5 & 0.1 & 0.2 \\
\hline 7/1/07 14:00 & 883 & 6152 & 9814 & 605.5 & 452.9 & 152.6 & 25.2 & 1.13 & 2.3 & 313 & 306 & 2249 & 10.1 & 1.5 & 0.1 & 0.2 \\
\hline 7/1/07 15:00 & 883 & 6127 & 9779 & 598.3 & 447.5 & 150.7 & 25.2 & 1.14 & 2.2 & 312 & 304 & 2256 & 10.0 & 1.5 & 0.1 & 0.2 \\
\hline 7/1/07 16:00 & 876 & 6079 & 9767 & 590.9 & 442.0 & 148.9 & 25.2 & 1.14 & 2.3 & 311 & 303 & 2236 & 10.0 & 1.4 & 0.1 & 0.2 \\
\hline $7 / 1 / 07$ 17:00 & 880 & 6116 & 9820 & 595.7 & 445.6 & 150.1 & 25.2 & 1.15 & 2.3 & 312 & 304 & 2240 & 10.2 & 1.5 & 0.1 & 0.2 \\
\hline $7 / 1 / 07$ 18:00 & 883 & 6136 & 9856 & 599.0 & 448.1 & 150.9 & 25.2 & 1.15 & 2.3 & 313 & 306 & 2250 & 10.2 & 1.5 & 0.1 & 0.2 \\
\hline 7/1/07 19:00 & 885 & 6133 & 9897 & 606.1 & 453.4 & 152.6 & 25.2 & 1.14 & 2.2 & 315 & 307 & 2263 & 10.2 & 1.6 & 0.2 & 0.2 \\
\hline $7 / 1 / 07$ 20:00 & 884 & 6202 & 9898 & 600.8 & 449.5 & 151.4 & 25.2 & 1.14 & 2.3 & 315 & 306 & 2261 & 10.1 & 1.5 & 0.1 & 0.2 \\
\hline
\end{tabular}




\begin{tabular}{|c|c|c|c|c|c|c|c|c|c|c|c|c|c|c|c|c|}
\hline Date and & $\begin{array}{c}\text { Gross } \\
\text { Gen }\end{array}$ & $\begin{array}{c}\text { Steam } \\
\text { Flow }\end{array}$ & Gross HR & Total Fuel & $\begin{array}{c}\text { Total } \\
\text { Lignite }\end{array}$ & Total PRB & $\begin{array}{l}\text { Total } \\
\text { PRB }\end{array}$ & $\begin{array}{c}\text { Btu } \\
\text { Gain }\end{array}$ & $\begin{array}{c}\text { Econ } \\
\text { O2 }\end{array}$ & $\begin{array}{c}\text { Temp } \\
\text { A APH } \\
\text { Out }\end{array}$ & $\begin{array}{c}\text { Temp } \\
\text { B APH } \\
\text { Out }\end{array}$ & $\begin{array}{l}\text { Stack } \\
\text { Flow }\end{array}$ & Opacity & SO2 In & $\begin{array}{l}\text { SO2 } \\
\text { Out }\end{array}$ & NOx \\
\hline $\begin{array}{c}\text { Start Date } \\
\text { and Time }\end{array}$ & MW & $\begin{array}{c}\text { KLB/ } \\
\text { HR }\end{array}$ & Btu/kWhr & TON/HR & TON/HR & TON/HR & $\begin{array}{c}\% \\
\text { Weight }\end{array}$ & & $\%$ & DEGF & DEGF & KSCF & $\%$ & $\begin{array}{c}\text { Ib/MM } \\
\text { Btu }\end{array}$ & $\begin{array}{c}\text { Ib/MM } \\
\text { Btu }\end{array}$ & $\begin{array}{l}\mathbf{l b} / \mathbf{M} \\
\text { MBtu }\end{array}$ \\
\hline 7/1/07 21:00 & 886 & 6169 & 9824 & 600.4 & 449.1 & 151.3 & 25.2 & 1.15 & 2.3 & 311 & 302 & 2257 & 10.1 & 1.5 & 0.1 & 0.2 \\
\hline 7/1/07 22:00 & 885 & 6148 & 9883 & 603.4 & 451.4 & 152.0 & 25.2 & 1.14 & 2.2 & 311 & 302 & 2259 & 10.2 & 1.5 & 0.1 & 0.2 \\
\hline 7/1/07 23:00 & 887 & 6147 & 9857 & 604.0 & 451.9 & 152.2 & 25.2 & 1.14 & 2.2 & 312 & 303 & 2255 & 10.2 & 1.5 & 0.1 & 0.2 \\
\hline 7/2/07 0:00 & 886 & 6146 & 9804 & 602.5 & 450.7 & 151.8 & 25.2 & 1.14 & 2.3 & 313 & 304 & 2248 & 10.2 & 1.4 & 0.1 & 0.2 \\
\hline $7 / 2 / 07$ 1:00 & 885 & 6159 & 9859 & 603.3 & 451.3 & 152.0 & 25.2 & 1.14 & 2.3 & 313 & 304 & 2257 & 10.1 & 1.4 & 0.1 & 0.2 \\
\hline $7 / 2 / 072: 00$ & 886 & 6136 & 9841 & 603.5 & 451.5 & 152.0 & 25.2 & 1.14 & 2.3 & 310 & 302 & 2261 & 10.2 & 1.4 & 0.1 & 0.2 \\
\hline 7/2/07 3:00 & 885 & 6094 & 9826 & 605.7 & 453.1 & 152.6 & 25.2 & 1.13 & 2.3 & 309 & 302 & 2259 & 10.3 & 1.5 & 0.1 & 0.2 \\
\hline 7/2/07 4:00 & 884 & 6110 & 9838 & 611.3 & 457.4 & 154.0 & 25.2 & 1.12 & 2.2 & 307 & 300 & 2255 & 10.3 & 1.5 & 0.1 & 0.2 \\
\hline 7/2/07 5:00 & 884 & 6169 & 9799 & 613.1 & 458.7 & 154.4 & 25.2 & 1.12 & 2.2 & 306 & 299 & 2254 & 9.9 & 1.5 & 0.1 & 0.2 \\
\hline 7/2/07 6:00 & 882 & 6179 & 9953 & 614.8 & 459.9 & 154.9 & 25.2 & 1.12 & 2.2 & 305 & 299 & 2259 & 9.8 & 1.5 & 0.1 & 0.2 \\
\hline $7 / 2 / 07$ 7:00 & 885 & 6150 & 9899 & 618.3 & 462.6 & 155.7 & 25.2 & 1.11 & 2.2 & 304 & 298 & 2257 & 10.3 & 1.5 & 0.1 & 0.2 \\
\hline 7/2/07 8:00 & 886 & 6172 & 9876 & 618.4 & 462.7 & 155.8 & 25.2 & 1.11 & 2.2 & 305 & 299 & 2253 & 10.1 & 1.6 & 0.2 & 0.2 \\
\hline 7/2/07 9:00 & 887 & 6161 & 9801 & 615.5 & 460.5 & 155.0 & 25.2 & 1.11 & 2.2 & 306 & 298 & 2253 & 10.0 & 1.6 & 0.2 & 0.2 \\
\hline 7/2/07 10:00 & 886 & 6121 & 9750 & 612.7 & 458.4 & 154.3 & 25.2 & 1.12 & 2.2 & 304 & 297 & 2249 & 9.9 & 1.5 & 0.1 & 0.2 \\
\hline 7/2/07 11:00 & 885 & 6118 & 9801 & 613.9 & 459.3 & 154.7 & 25.2 & 1.12 & 2.2 & 305 & 297 & 2242 & 9.9 & 1.6 & 0.2 & 0.2 \\
\hline 7/2/07 12:00 & 886 & 6140 & 9825 & 610.9 & 457.0 & 153.9 & 25.2 & 1.12 & 2.1 & 307 & 299 & 2232 & 10.1 & 1.6 & 0.2 & 0.2 \\
\hline 7/2/07 13:00 & 888 & 6138 & 9691 & 599.9 & 448.8 & 151.1 & 25.2 & 1.13 & 2.1 & 310 & 302 & 2225 & 10.0 & 1.5 & 0.2 & 0.2 \\
\hline 7/2/07 14:00 & 883 & 6112 & 9738 & 597.5 & 446.9 & 150.6 & 25.2 & 1.14 & 2.1 & 310 & 303 & 2227 & 10.1 & 1.6 & 0.2 & 0.2 \\
\hline 7/2/07 15:00 & 885 & 6130 & 9788 & 597.9 & 447.3 & 150.6 & 25.2 & 1.14 & 2.1 & 310 & 303 & 2228 & 10.1 & 1.6 & 0.2 & 0.2 \\
\hline 7/2/07 16:00 & 885 & 6156 & 9739 & 591.5 & 442.5 & 149.0 & 25.2 & 1.15 & 2.1 & 309 & 303 & 2232 & 10.1 & 1.6 & 0.2 & 0.2 \\
\hline 7/2/07 17:00 & 884 & 6099 & 9796 & 593.7 & 444.1 & 149.6 & 25.2 & 1.15 & 2.1 & 309 & 304 & 2233 & 10.2 & 1.6 & 0.2 & 0.2 \\
\hline 7/2/07 18:00 & 886 & 6102 & 9746 & 593.9 & 444.3 & 149.6 & 25.2 & 1.15 & 2.1 & 310 & 305 & 2224 & 10.2 & 1.6 & 0.2 & 0.2 \\
\hline $7 / 2 / 07$ 19:00 & 884 & 6079 & 9792 & 596.8 & 446.4 & 150.3 & 25.2 & 1.14 & 2.1 & 310 & 305 & 2220 & 10.2 & 1.5 & 0.1 & 0.2 \\
\hline $7 / 2 / 0720: 00$ & 274 & 2173 & 9811 & 187.7 & 140.4 & 47.3 & 25.2 & 1.04 & 13.7 & 282 & 276 & 2218 & 39.0 & 1.5 & 0.1 & 0.1 \\
\hline 7/2/07 21:00 & 0 & 623 & 9814 & 0.0 & 0.0 & 0.0 & \#N/A & 1.00 & 19.2 & 227 & 216 & 1622 & 60.0 & 0.5 & 0.0 & 0.0 \\
\hline 7/2/07 22:00 & 5 & 316 & 9814 & 0.0 & 0.0 & 0.0 & \#N/A & 1.00 & 17.6 & 210 & 196 & 1451 & 23.2 & 0.0 & 0.0 & 0.0 \\
\hline 7/2/07 23:00 & 12 & 441 & 9814 & 0.2 & 0.0 & 0.2 & 100.0 & 1.00 & 18.3 & 206 & 193 & 1439 & 28.8 & 0.0 & 0.0 & 0.0 \\
\hline 7/3/07 0:00 & 6 & 265 & 9814 & 7.1 & 7.1 & 0.0 & 0.0 & 1.00 & 18.3 & 199 & 187 & 1475 & 28.2 & 0.1 & 0.0 & 0.0 \\
\hline 7/3/07 1:00 & 71 & 892 & 9814 & 71.3 & 66.4 & 4.9 & 6.8 & 1.00 & 14.7 & 214 & 196 & 1500 & 11.3 & 0.9 & 0.2 & 0.3 \\
\hline $7 / 3 / 072: 00$ & 153 & 1398 & 9814 & 127.4 & 115.4 & 11.9 & 9.4 & 1.00 & 12.4 & 223 & 208 & 1431 & 10.1 & 1.3 & 0.3 & 0.7 \\
\hline 7/3/07 3:00 & 245 & 2002 & 9814 & 168.5 & 166.3 & 2.2 & 1.3 & 1.00 & 9.5 & 242 & 232 & 1320 & 9.6 & 1.5 & 0.4 & 0.7 \\
\hline
\end{tabular}




\begin{tabular}{|c|c|c|c|c|c|c|c|c|c|c|c|c|c|c|c|c|}
\hline Date and & $\begin{array}{c}\text { Gross } \\
\text { Gen }\end{array}$ & $\begin{array}{l}\text { Steam } \\
\text { Flow }\end{array}$ & Gross HR & Total Fuel & $\begin{array}{c}\text { Total } \\
\text { Lignite }\end{array}$ & Total PRB & $\begin{array}{l}\text { Total } \\
\text { PRB }\end{array}$ & $\begin{array}{c}\text { Btu } \\
\text { Gain }\end{array}$ & $\begin{array}{c}\text { Econ } \\
\text { O2 }\end{array}$ & $\begin{array}{c}\text { Temp } \\
\text { A APH } \\
\text { Out }\end{array}$ & $\begin{array}{c}\text { Temp } \\
\text { B APH } \\
\text { Out }\end{array}$ & $\begin{array}{l}\text { Stack } \\
\text { Flow }\end{array}$ & Opacity & SO2 In & $\begin{array}{l}\text { SO2 } \\
\text { Out }\end{array}$ & NOx \\
\hline $\begin{array}{c}\text { Start Date } \\
\text { and Time }\end{array}$ & MW & $\begin{array}{c}\text { KLB/ } \\
\text { HR }\end{array}$ & Btu/kWhr & TON/HR & TON/HR & TON/HR & $\begin{array}{c}\% \\
\text { Weight }\end{array}$ & & $\%$ & DEGF & DEGF & KSCF & $\%$ & $\begin{array}{c}\text { Ib/MM } \\
\text { Btu }\end{array}$ & $\begin{array}{c}\text { Ib/MM } \\
\text { Btu }\end{array}$ & $\begin{array}{l}\mathbf{l b} / \mathbf{M} \\
\text { MBtu }\end{array}$ \\
\hline 7/3/07 4:00 & 407 & 3042 & 9715 & 279.7 & 227.7 & 52.0 & 18.6 & 1.01 & 5.5 & 253 & 253 & 1393 & 10.4 & 1.4 & 0.2 & 0.3 \\
\hline 7/3/07 5:00 & 597 & 4181 & 9478 & 430.2 & 352.6 & 77.6 & 18.0 & 1.03 & 3.5 & 275 & 277 & 1666 & 13.0 & 1.5 & 0.1 & 0.2 \\
\hline 7/3/07 6:00 & 692 & 4764 & 9582 & 494.7 & 378.9 & 115.7 & 23.4 & 1.05 & 3.1 & 294 & 291 & 1842 & 13.0 & 1.6 & 0.1 & 0.2 \\
\hline 7/3/07 7:00 & 808 & 5656 & 9613 & 563.8 & 420.5 & 143.3 & 25.4 & 1.08 & 3.0 & 298 & 293 & 2116 & 11.2 & 1.6 & 0.2 & 0.2 \\
\hline 7/3/07 8:00 & 840 & 5755 & 9644 & 581.1 & 435.9 & 145.2 & 25.0 & 1.10 & 3.0 & 301 & 297 & 2234 & 10.5 & 1.5 & 0.1 & 0.2 \\
\hline 7/3/07 9:00 & 864 & 5951 & 9767 & 594.7 & 446.1 & 148.7 & 25.0 & 1.11 & 3.0 & 304 & 301 & 2275 & 10.5 & 1.5 & 0.1 & 0.2 \\
\hline 7/3/07 10:00 & 864 & 5936 & 9700 & 595.5 & 446.7 & 148.8 & 25.0 & 1.11 & 3.0 & 305 & 302 & 2282 & 10.4 & 1.6 & 0.2 & 0.2 \\
\hline 7/3/07 11:00 & 850 & 5877 & 9743 & 585.2 & 439.0 & 146.3 & 25.0 & 1.12 & 3.0 & 306 & 300 & 2260 & 10.5 & 1.6 & 0.2 & 0.2 \\
\hline 7/3/07 12:00 & 794 & 5405 & 9755 & 549.6 & 412.2 & 137.4 & 25.0 & 1.11 & 3.0 & 304 & 296 & 2148 & 10.1 & 1.6 & 0.2 & 0.2 \\
\hline 7/3/07 13:00 & 858 & 5925 & 9765 & 594.9 & 446.2 & 148.7 & 25.0 & 1.11 & 3.0 & 306 & 297 & 2246 & 10.2 & 1.6 & 0.2 & 0.2 \\
\hline $7 / 3 / 07$ 14:00 & 880 & 6090 & 9764 & 607.0 & 455.3 & 151.8 & 25.0 & 1.12 & 2.9 & 312 & 307 & 2301 & 10.7 & 1.5 & 0.1 & 0.2 \\
\hline 7/3/07 15:00 & 881 & 6150 & 9811 & 603.7 & 452.9 & 150.9 & 25.0 & 1.12 & 2.8 & 309 & 299 & 2309 & 10.0 & 1.5 & 0.1 & 0.2 \\
\hline 7/3/07 16:00 & 869 & 6040 & 9823 & 596.7 & 441.8 & 155.0 & 26.0 & 1.13 & 2.9 & 311 & 297 & 2274 & 8.8 & 1.4 & 0.1 & 0.2 \\
\hline 7/3/07 17:00 & 880 & 6110 & 9901 & 605.9 & 454.4 & 151.5 & 25.0 & 1.13 & 2.8 & 308 & 298 & 2299 & 10.0 & 1.5 & 0.1 & 0.2 \\
\hline 7/3/07 18:00 & 883 & 6104 & 9776 & 600.0 & 450.0 & 150.0 & 25.0 & 1.13 & 2.8 & 307 & 299 & 2294 & 10.5 & 1.5 & 0.1 & 0.2 \\
\hline 7/3/07 19:00 & 879 & 6071 & 9790 & 599.5 & 449.7 & 149.9 & 25.0 & 1.13 & 2.9 & 308 & 300 & 2297 & 10.3 & 1.5 & 0.1 & 0.2 \\
\hline $7 / 3 / 0720: 00$ & 879 & 6107 & 9814 & 602.3 & 451.7 & 150.6 & 25.0 & 1.13 & 2.9 & 306 & 284 & 2282 & 9.3 & 1.6 & 0.1 & 0.2 \\
\hline $7 / 3 / 0721: 00$ & 886 & 6186 & 9700 & 584.0 & 437.8 & 146.2 & 25.0 & 1.15 & 2.8 & 304 & 280 & 2287 & 8.9 & 1.4 & 0.1 & 0.2 \\
\hline 7/3/07 22:00 & 885 & 6126 & 9441 & 556.2 & 412.9 & 143.3 & 25.8 & 1.19 & 2.8 & 303 & 290 & 2267 & 9.7 & 1.2 & 0.1 & 0.2 \\
\hline 7/3/07 23:00 & 869 & 6061 & 9466 & 530.4 & 383.5 & 146.9 & 27.7 & 1.23 & 2.9 & 311 & 299 & 2241 & 10.3 & 1.0 & 0.1 & 0.2 \\
\hline 7/4/07 0:00 & 881 & 6075 & 9587 & 527.4 & 376.7 & 150.7 & 28.6 & 1.26 & 2.9 & 308 & 296 & 2240 & 10.5 & 0.9 & 0.1 & 0.2 \\
\hline 7/4/07 1:00 & 884 & 6107 & 9700 & 529.4 & 378.1 & 151.3 & 28.6 & 1.28 & 2.8 & 310 & 297 & 2255 & 10.4 & 0.9 & 0.1 & 0.2 \\
\hline $7 / 4 / 07$ 2:00 & 884 & 6129 & 9675 & 524.5 & 374.0 & 150.4 & 28.7 & 1.29 & 2.8 & 313 & 299 & 2252 & 10.7 & 0.8 & 0.1 & 0.2 \\
\hline 7/4/07 3:00 & 885 & 6136 & 9719 & 524.1 & 372.6 & 151.5 & 28.9 & 1.30 & 2.8 & 316 & 301 & 2250 & 10.5 & 0.8 & 0.1 & 0.2 \\
\hline 7/4/07 4:00 & 886 & 6129 & 9759 & 524.3 & 373.6 & 150.7 & 28.7 & 1.30 & 2.8 & 317 & 302 & 2259 & 10.8 & 0.8 & 0.1 & 0.2 \\
\hline $7 / 4 / 07$ 5:00 & 888 & 6157 & 9794 & 525.5 & 375.2 & 150.3 & 28.6 & 1.31 & 2.8 & 318 & 303 & 2257 & 10.5 & 0.8 & 0.1 & 0.2 \\
\hline 7/4/07 6:00 & 887 & 6151 & 9804 & 529.0 & 376.1 & 152.9 & 28.9 & 1.30 & 2.8 & 319 & 305 & 2264 & 10.6 & 0.8 & 0.1 & 0.2 \\
\hline 7/4/07 7:00 & 885 & 6149 & 9940 & 532.7 & 378.8 & 153.9 & 28.9 & 1.30 & 2.8 & 320 & 303 & 2263 & 10.9 & 0.9 & 0.1 & 0.2 \\
\hline 7/4/07 8:00 & 887 & 6102 & 9891 & 533.2 & 378.6 & 154.6 & 29.0 & 1.29 & 2.7 & 313 & 300 & 2240 & 10.6 & 0.9 & 0.1 & 0.2 \\
\hline 7/4/07 9:00 & 884 & 6102 & 9871 & 535.3 & 378.9 & 156.3 & 29.2 & 1.28 & 2.6 & 312 & 299 & 2238 & 10.7 & 0.9 & 0.1 & 0.2 \\
\hline 7/4/07 10:00 & 886 & 6069 & 9817 & 535.6 & 379.2 & 156.4 & 29.2 & 1.27 & 2.6 & 313 & 300 & 2244 & 10.7 & 1.0 & 0.1 & 0.2 \\
\hline
\end{tabular}




\begin{tabular}{|c|c|c|c|c|c|c|c|c|c|c|c|c|c|c|c|c|}
\hline Date and & $\begin{array}{c}\text { Gross } \\
\text { Gen }\end{array}$ & $\begin{array}{c}\text { Steam } \\
\text { Flow }\end{array}$ & Gross HR & Total Fuel & $\begin{array}{c}\text { Total } \\
\text { Lignite }\end{array}$ & Total PRB & $\begin{array}{l}\text { Total } \\
\text { PRB }\end{array}$ & $\begin{array}{c}\text { Btu } \\
\text { Gain }\end{array}$ & $\begin{array}{c}\text { Econ } \\
\text { O2 }\end{array}$ & $\begin{array}{c}\text { Temp } \\
\text { A APH } \\
\text { Out }\end{array}$ & $\begin{array}{c}\text { Temp } \\
\text { B APH } \\
\text { Out }\end{array}$ & $\begin{array}{l}\text { Stack } \\
\text { Flow }\end{array}$ & Opacity & SO2 In & $\begin{array}{l}\text { SO2 } \\
\text { Out }\end{array}$ & NOx \\
\hline $\begin{array}{c}\text { Start Date } \\
\text { and Time }\end{array}$ & MW & $\begin{array}{c}\text { KLB/ } \\
\text { HR }\end{array}$ & Btu/kWhr & TON/HR & TON/HR & TON/HR & $\begin{array}{c}\% \\
\text { Weight }\end{array}$ & & $\%$ & DEGF & DEGF & KSCF & $\%$ & $\begin{array}{c}\text { Ib/MM } \\
\text { Btu }\end{array}$ & $\begin{array}{c}\text { Ib/MM } \\
\text { Btu }\end{array}$ & $\begin{array}{l}\mathbf{l b} / \mathbf{M} \\
\text { MBtu }\end{array}$ \\
\hline 7/4/07 11:00 & 885 & 6071 & 9755 & 535.5 & 379.1 & 156.4 & 29.2 & 1.27 & 2.6 & 314 & 300 & 2227 & 10.7 & 1.0 & 0.1 & 0.2 \\
\hline 7/4/07 12:00 & 883 & 6112 & 9740 & 536.4 & 379.7 & 156.6 & 29.2 & 1.27 & 2.7 & 316 & 298 & 2235 & 10.7 & 1.0 & 0.1 & 0.2 \\
\hline 7/4/07 13:00 & 883 & 6120 & 9785 & 536.1 & 379.6 & 156.5 & 29.2 & 1.27 & 2.6 & 313 & 300 & 2241 & 10.7 & 0.9 & 0.1 & 0.2 \\
\hline 7/4/07 14:00 & 884 & 6099 & 9778 & 536.4 & 379.8 & 156.6 & 29.2 & 1.27 & 2.6 & 314 & 302 & 2235 & 10.8 & 0.9 & 0.1 & 0.2 \\
\hline $7 / 4 / 07$ 15:00 & 885 & 6090 & 9742 & 535.4 & 379.1 & 156.4 & 29.2 & 1.27 & 2.6 & 316 & 304 & 2226 & 10.8 & 0.9 & 0.1 & 0.2 \\
\hline $7 / 4 / 07$ 16:00 & 884 & 6090 & 9807 & 535.4 & 379.1 & 156.3 & 29.2 & 1.27 & 2.6 & 317 & 306 & 2232 & 10.7 & 0.9 & 0.1 & 0.2 \\
\hline 7/4/07 17:00 & 885 & 6088 & 9750 & 534.6 & 378.5 & 156.1 & 29.2 & 1.27 & 2.6 & 320 & 307 & 2243 & 11.0 & 0.9 & 0.1 & 0.2 \\
\hline 7/4/07 18:00 & 886 & 6095 & 9633 & 528.0 & 373.7 & 154.3 & 29.2 & 1.28 & 2.6 & 320 & 307 & 2235 & 10.6 & 0.9 & 0.1 & 0.2 \\
\hline 7/4/07 19:00 & 885 & 6099 & 9624 & 519.7 & 367.9 & 151.9 & 29.2 & 1.29 & 2.7 & 319 & 307 & 2217 & 10.7 & 0.9 & 0.1 & 0.2 \\
\hline $7 / 4 / 0720: 00$ & 883 & 6087 & 9703 & 514.5 & 368.5 & 146.0 & 28.4 & 1.31 & 2.6 & 316 & 305 & 2211 & 10.4 & 0.9 & 0.1 & 0.2 \\
\hline $7 / 4 / 0721: 00$ & 875 & 6049 & 9685 & 507.4 & 377.7 & 129.6 & 25.6 & 1.32 & 2.6 & 318 & 306 & 2189 & 10.5 & 0.9 & 0.1 & 0.2 \\
\hline $7 / 4 / 0722: 00$ & 865 & 6036 & 9884 & 510.1 & 423.3 & 86.9 & 17.0 & 1.32 & 2.7 & 317 & 311 & 2186 & 10.0 & 0.9 & 0.1 & 0.1 \\
\hline 7/4/07 23:00 & 876 & 6102 & 9840 & 516.3 & 426.4 & 89.9 & 17.4 & 1.32 & 2.6 & 317 & 308 & 2211 & 10.1 & 0.9 & 0.1 & 0.2 \\
\hline $7 / 5 / 07$ 0:00 & 870 & 6053 & 9841 & 514.5 & 388.6 & 125.9 & 24.5 & 1.32 & 2.7 & 323 & 309 & 2205 & 10.2 & 0.9 & 0.1 & 0.2 \\
\hline $7 / 5 / 07$ 1:00 & 881 & 6102 & 9907 & 525.1 & 374.7 & 150.4 & 28.6 & 1.31 & 2.7 & 316 & 304 & 2223 & 10.3 & 0.9 & 0.1 & 0.2 \\
\hline $7 / 5 / 072: 00$ & 884 & 6042 & 9869 & 529.7 & 376.2 & 153.5 & 29.0 & 1.30 & 2.6 & 313 & 302 & 2211 & 10.5 & 0.9 & 0.1 & 0.2 \\
\hline $7 / 5 / 07$ 3:00 & 879 & 5985 & 9884 & 541.6 & 386.8 & 154.7 & 28.6 & 1.27 & 2.7 & 314 & 301 & 2220 & 10.6 & 1.0 & 0.1 & 0.2 \\
\hline $7 / 5 / 074: 00$ & 878 & 5988 & 10119 & 571.1 & 407.9 & 163.2 & 28.6 & 1.23 & 2.7 & 315 & 303 & 2232 & 10.6 & 1.3 & 0.1 & 0.2 \\
\hline 7/5/07 5:00 & 882 & 6069 & 10156 & 598.4 & 432.1 & 166.4 & 27.8 & 1.18 & 2.5 & 314 & 303 & 2240 & 10.2 & 1.6 & 0.2 & 0.2 \\
\hline $7 / 5 / 076: 00$ & 886 & 6144 & 9988 & 604.5 & 448.9 & 155.6 & 25.7 & 1.15 & 2.6 & 310 & 303 & 2258 & 10.6 & 1.5 & 0.2 & 0.2 \\
\hline 7/5/07 7:00 & 889 & 6129 & 9886 & 605.3 & 449.8 & 155.4 & 25.7 & 1.14 & 2.6 & 310 & 304 & 2281 & 10.9 & 1.5 & 0.2 & 0.2 \\
\hline 7/5/07 8:00 & 887 & 6120 & 9837 & 602.8 & 448.0 & 154.8 & 25.7 & 1.13 & 2.6 & 312 & 305 & 2276 & 10.7 & 1.5 & 0.2 & 0.2 \\
\hline 7/5/07 9:00 & 886 & 6108 & 9752 & 600.1 & 446.1 & 154.0 & 25.7 & 1.14 & 2.6 & 313 & 304 & 2279 & 10.6 & 1.5 & 0.2 & 0.2 \\
\hline $7 / 5 / 07$ 10:00 & 883 & 6125 & 9798 & 600.9 & 446.7 & 154.3 & 25.7 & 1.14 & 2.5 & 313 & 302 & 2264 & 9.5 & 1.5 & 0.1 & 0.2 \\
\hline 7/5/07 11:00 & 884 & 6131 & 9808 & 601.0 & 446.7 & 154.3 & 25.7 & 1.14 & 2.5 & 313 & 302 & 2255 & 10.2 & 1.5 & 0.1 & 0.2 \\
\hline 7/5/07 12:00 & 886 & 6128 & 9835 & 600.7 & 446.5 & 154.2 & 25.7 & 1.14 & 2.5 & 312 & 302 & 2248 & 10.4 & 1.5 & 0.1 & 0.2 \\
\hline 7/5/07 13:00 & 882 & 6117 & 9768 & 598.5 & 447.8 & 150.7 & 25.2 & 1.14 & 2.4 & 313 & 305 & 2248 & 10.5 & 1.5 & 0.2 & 0.2 \\
\hline $7 / 5 / 07$ 14:00 & 882 & 6126 & 9758 & 593.0 & 443.0 & 150.0 & 25.3 & 1.14 & 2.5 & 315 & 309 & 2244 & 10.4 & 1.5 & 0.1 & 0.2 \\
\hline $7 / 5 / 07$ 15:00 & 881 & 6080 & 9854 & 597.2 & 444.0 & 153.2 & 25.6 & 1.14 & 7.2 & 311 & 306 & 2242 & 10.6 & 1.4 & 0.1 & 0.2 \\
\hline $7 / 5 / 07$ 16:00 & 882 & 6070 & 9854 & 601.6 & 447.1 & 154.4 & 25.7 & 1.14 & 2.5 & 311 & 305 & 2237 & 10.2 & 1.5 & 0.2 & 0.2 \\
\hline 7/5/07 17:00 & 882 & 6097 & 9900 & 605.1 & 449.7 & 155.4 & 25.7 & 1.13 & 2.4 & 311 & 305 & 2241 & 10.4 & 1.5 & 0.2 & 0.2 \\
\hline
\end{tabular}




\begin{tabular}{|c|c|c|c|c|c|c|c|c|c|c|c|c|c|c|c|c|}
\hline Date and & $\begin{array}{c}\text { Gross } \\
\text { Gen }\end{array}$ & $\begin{array}{c}\text { Steam } \\
\text { Flow }\end{array}$ & Gross HR & Total Fuel & $\begin{array}{c}\text { Total } \\
\text { Lignite }\end{array}$ & Total PRB & $\begin{array}{l}\text { Total } \\
\text { PRB }\end{array}$ & $\begin{array}{c}\text { Btu } \\
\text { Gain }\end{array}$ & $\begin{array}{c}\text { Econ } \\
\text { O2 }\end{array}$ & $\begin{array}{c}\text { Temp } \\
\text { A APH } \\
\text { Out }\end{array}$ & $\begin{array}{c}\text { Temp } \\
\text { B APH } \\
\text { Out }\end{array}$ & $\begin{array}{l}\text { Stack } \\
\text { Flow }\end{array}$ & Opacity & SO2 In & $\begin{array}{l}\text { SO2 } \\
\text { Out }\end{array}$ & NOx \\
\hline $\begin{array}{c}\text { Start Date } \\
\text { and Time }\end{array}$ & MW & $\begin{array}{c}\text { KLB/ } \\
\text { HR }\end{array}$ & Btu/kWhr & TON/HR & TON/HR & TON/HR & $\begin{array}{c}\% \\
\text { Weight }\end{array}$ & & $\%$ & DEGF & DEGF & KSCF & $\%$ & $\begin{array}{c}\text { Ib/MM } \\
\text { Btu }\end{array}$ & $\begin{array}{c}\text { Ib/MM } \\
\text { Btu }\end{array}$ & $\begin{array}{l}\mathbf{l b} / \mathbf{M} \\
\text { MBtu }\end{array}$ \\
\hline 7/5/07 18:00 & 882 & 6107 & 9796 & 605.3 & 449.8 & 155.5 & 25.7 & 1.13 & 2.4 & 313 & 307 & 2244 & 10.6 & 1.5 & 0.2 & 0.2 \\
\hline 7/5/07 19:00 & 883 & 6137 & 9798 & 600.8 & 446.6 & 154.2 & 25.7 & 1.13 & 2.5 & 314 & 309 & 2242 & 10.4 & 1.4 & 0.1 & 0.2 \\
\hline $7 / 5 / 0720: 00$ & 887 & 6192 & 9620 & 579.3 & 431.1 & 148.2 & 25.6 & 1.16 & 2.4 & 314 & 309 & 2238 & 10.5 & 1.3 & 0.1 & 0.2 \\
\hline 7/5/07 21:00 & 886 & 6182 & 9453 & 550.1 & 400.7 & 149.3 & 27.1 & 1.20 & 2.5 & 319 & 310 & 2240 & 10.2 & 1.0 & 0.1 & 0.2 \\
\hline $7 / 5 / 0722: 00$ & 882 & 6138 & 9563 & 532.6 & 380.5 & 152.2 & 28.6 & 1.24 & 2.5 & 314 & 301 & 2231 & 9.6 & 0.8 & 0.1 & 0.2 \\
\hline 7/5/07 23:00 & 884 & 6146 & 9717 & 534.4 & 381.7 & 152.7 & 28.6 & 1.27 & 2.5 & 312 & 301 & 2221 & 10.0 & 0.8 & 0.1 & 0.2 \\
\hline 7/6/07 0:00 & 885 & 6157 & 9764 & 537.5 & 383.9 & 153.6 & 28.6 & 1.28 & 2.5 & 315 & 304 & 2224 & 10.7 & 0.8 & 0.1 & 0.2 \\
\hline $7 / 6 / 07$ 1:00 & 887 & 6151 & 9904 & 543.8 & 388.4 & 155.4 & 28.6 & 1.27 & 2.5 & 315 & 304 & 2216 & 10.7 & 0.8 & 0.1 & 0.2 \\
\hline $7 / 6 / 07$ 2:00 & 891 & 6149 & 9927 & 549.9 & 392.8 & 157.1 & 28.6 & 1.26 & 2.4 & 316 & 305 & 2214 & 10.7 & 0.8 & 0.1 & 0.2 \\
\hline 7/6/07 3:00 & 891 & 6142 & 9902 & 552.7 & 394.8 & 158.0 & 28.6 & 1.25 & 2.5 & 318 & 306 & 2232 & 10.9 & 0.9 & 0.1 & 0.2 \\
\hline 7/6/07 4:00 & 891 & 6173 & 9856 & 553.1 & 395.0 & 158.0 & 28.6 & 1.25 & 2.4 & 316 & 307 & 2237 & 11.0 & 0.9 & 0.1 & 0.2 \\
\hline 7/6/07 5:00 & 892 & 6173 & 9873 & 550.5 & 393.2 & 157.3 & 28.6 & 1.25 & 2.4 & 316 & 305 & 2232 & 10.9 & 0.8 & 0.1 & 0.2 \\
\hline 7/6/07 6:00 & 891 & 6155 & 9835 & 547.2 & 390.9 & 156.3 & 28.6 & 1.25 & 2.5 & 316 & 304 & 2228 & 10.7 & 0.8 & 0.1 & 0.2 \\
\hline 7/6/07 7:00 & 891 & 6150 & 9797 & 543.3 & 388.0 & 155.2 & 28.6 & 1.26 & 2.5 & 313 & 304 & 2215 & 11.0 & 0.8 & 0.1 & 0.2 \\
\hline 7/6/07 8:00 & 889 & 6160 & 9775 & 543.1 & 387.9 & 155.2 & 28.6 & 1.26 & 2.5 & 310 & 302 & 2194 & 10.6 & 0.8 & 0.1 & 0.2 \\
\hline 7/6/07 9:00 & 890 & 6175 & 9782 & 543.4 & 388.1 & 155.3 & 28.6 & 1.27 & 2.4 & 311 & 301 & 2204 & 10.8 & 0.7 & 0.1 & 0.2 \\
\hline $7 / 6 / 07$ 10:00 & 892 & 6155 & 9762 & 540.3 & 385.9 & 154.4 & 28.6 & 1.27 & 2.4 & 313 & 304 & 2205 & 10.7 & 0.7 & 0.1 & 0.2 \\
\hline $7 / 6 / 07$ 11:00 & 891 & 6139 & 9798 & 538.9 & 384.9 & 154.0 & 28.6 & 1.27 & 2.5 & 315 & 306 & 2202 & 10.7 & 0.7 & 0.1 & 0.2 \\
\hline 7/6/07 12:00 & 889 & 6133 & 9816 & 541.1 & 386.5 & 154.6 & 28.6 & 1.27 & 2.5 & 318 & 310 & 2208 & 10.8 & 0.7 & 0.1 & 0.2 \\
\hline 7/6/07 13:00 & 883 & 6101 & 9777 & 538.3 & 381.1 & 157.1 & 29.2 & 1.27 & 2.4 & 319 & 311 & 2204 & 10.8 & 0.8 & 0.1 & 0.2 \\
\hline 7/6/07 14:00 & 867 & 5978 & 9856 & 534.6 & 381.3 & 153.3 & 28.7 & 1.26 & 2.4 & 320 & 313 & 2188 & 10.7 & 0.8 & 0.1 & 0.2 \\
\hline 7/6/07 15:00 & 760 & 5279 & 9839 & 464.6 & 329.7 & 134.9 & 29.0 & 1.25 & 2.5 & 326 & 317 & 2034 & 10.2 & 0.9 & 0.1 & 0.1 \\
\hline $7 / 6 / 07$ 16:00 & 688 & 4698 & 9676 & 421.5 & 289.5 & 132.0 & 31.3 & 1.24 & 2.6 & 316 & 306 & 1862 & 10.3 & 0.9 & 0.1 & 0.1 \\
\hline $7 / 6 / 07$ 17:00 & 801 & 5535 & 9726 & 498.0 & 356.9 & 141.0 & 28.3 & 1.23 & 2.5 & 314 & 305 & 2038 & 10.3 & 0.9 & 0.1 & 0.1 \\
\hline 7/6/07 18:00 & 854 & 5919 & 9796 & 532.6 & 380.4 & 152.2 & 28.6 & 1.24 & 2.5 & 314 & 303 & 2151 & 10.5 & 0.9 & 0.1 & 0.2 \\
\hline 7/6/07 19:00 & 880 & 6118 & 9770 & 547.0 & 390.7 & 156.3 & 28.6 & 1.24 & 2.5 & 317 & 307 & 2190 & 10.9 & 0.9 & 0.1 & 0.2 \\
\hline 7/6/07 20:00 & 884 & 6203 & 9821 & 545.7 & 389.7 & 155.9 & 28.6 & 1.25 & 2.5 & 318 & 308 & 2207 & 10.9 & 0.9 & 0.1 & 0.2 \\
\hline 7/6/07 21:00 & 888 & 6164 & 9842 & 541.3 & 386.6 & 154.6 & 28.6 & 1.26 & 2.6 & 318 & 309 & 2225 & 11.0 & 0.9 & 0.1 & 0.2 \\
\hline $7 / 6 / 0722: 00$ & 886 & 6169 & 9760 & 538.5 & 384.6 & 153.8 & 28.6 & 1.27 & 2.6 & 319 & 310 & 2229 & 11.3 & 0.9 & 0.1 & 0.2 \\
\hline $7 / 6 / 0723: 00$ & 886 & 6178 & 9808 & 534.3 & 381.7 & 152.7 & 28.6 & 1.28 & 2.6 & 321 & 312 & 2231 & 11.2 & 0.8 & 0.1 & 0.2 \\
\hline 7/7/07 0:00 & 884 & 6137 & 9844 & 537.2 & 383.7 & 153.5 & 28.6 & 1.28 & 2.6 & 318 & 314 & 2227 & 11.2 & 0.8 & 0.1 & 0.2 \\
\hline
\end{tabular}




\begin{tabular}{|c|c|c|c|c|c|c|c|c|c|c|c|c|c|c|c|c|}
\hline Date and & $\begin{array}{c}\text { Gross } \\
\text { Gen }\end{array}$ & $\begin{array}{l}\text { Steam } \\
\text { Flow }\end{array}$ & Gross HR & Total Fuel & $\begin{array}{c}\text { Total } \\
\text { Lignite }\end{array}$ & Total PRB & $\begin{array}{l}\text { Total } \\
\text { PRB }\end{array}$ & $\begin{array}{c}\text { Btu } \\
\text { Gain }\end{array}$ & $\begin{array}{c}\text { Econ } \\
\text { O2 }\end{array}$ & $\begin{array}{c}\text { Temp } \\
\text { A APH } \\
\text { Out }\end{array}$ & $\begin{array}{c}\text { Temp } \\
\text { B APH } \\
\text { Out }\end{array}$ & $\begin{array}{l}\text { Stack } \\
\text { Flow }\end{array}$ & Opacity & SO2 In & $\begin{array}{l}\text { SO2 } \\
\text { Out }\end{array}$ & NOx \\
\hline $\begin{array}{c}\text { Start Date } \\
\text { and Time }\end{array}$ & MW & $\begin{array}{c}\text { KLB/ } \\
\text { HR }\end{array}$ & Btu/kWhr & TON/HR & TON/HR & TON/HR & $\begin{array}{c}\% \\
\text { Weight }\end{array}$ & & $\%$ & DEGF & DEGF & KSCF & $\%$ & $\begin{array}{c}\text { Ib/MM } \\
\text { Btu }\end{array}$ & $\begin{array}{c}\text { Ib/MM } \\
\text { Btu }\end{array}$ & $\begin{array}{l}\mathbf{l b} / \mathbf{M} \\
\text { MBtu }\end{array}$ \\
\hline 7/7/07 1:00 & 885 & 6165 & 9932 & 541.7 & 387.0 & 154.8 & 28.6 & 1.28 & 2.6 & 318 & 314 & 2227 & 11.4 & 0.8 & 0.1 & 0.2 \\
\hline 7/7/07 2:00 & 888 & 6193 & 9824 & 537.5 & 384.0 & 153.6 & 28.6 & 1.28 & 2.6 & 318 & 316 & 2228 & 11.4 & 0.8 & 0.1 & 0.1 \\
\hline 7/7/07 3:00 & 885 & 6154 & 9822 & 539.2 & 385.2 & 154.1 & 28.6 & 1.28 & 2.6 & 318 & 315 & 2231 & 11.1 & 0.8 & 0.1 & 0.1 \\
\hline 7/7/07 4:00 & 884 & 6106 & 9984 & 549.9 & 392.8 & 157.1 & 28.6 & 1.27 & 2.6 & 318 & 315 & 2228 & 11.2 & 0.9 & 0.1 & 0.2 \\
\hline 7/7/07 5:00 & 881 & 6083 & 10011 & 559.0 & 401.4 & 157.5 & 28.2 & 1.24 & 2.6 & 321 & 316 & 2220 & 11.0 & 1.1 & 0.1 & 0.2 \\
\hline 7/7/07 6:00 & 884 & 6069 & 10148 & 577.2 & 424.8 & 152.4 & 26.4 & 1.21 & 2.6 & 318 & 317 & 2230 & 11.2 & 1.3 & 0.1 & 0.2 \\
\hline 7/7/07 7:00 & 890 & 6072 & 10057 & 585.3 & 430.4 & 154.9 & 26.5 & 1.18 & 2.7 & 313 & 314 & 2250 & 11.3 & 1.4 & 0.1 & 0.2 \\
\hline 7/7/07 8:00 & 884 & 6161 & 9885 & 581.7 & 425.9 & 155.8 & 26.8 & 1.17 & 2.7 & 313 & 309 & 2252 & 11.3 & 1.4 & 0.1 & 0.2 \\
\hline 7/7/07 9:00 & 883 & 6157 & 9875 & 580.9 & 424.7 & 156.2 & 26.9 & 1.18 & 2.7 & 312 & 310 & 2243 & 11.2 & 1.4 & 0.1 & 0.2 \\
\hline 7/7/07 10:00 & 883 & 6118 & 9837 & 582.0 & 424.4 & 157.6 & 27.1 & 1.18 & 2.7 & 313 & 313 & 2231 & 11.1 & 1.4 & 0.1 & 0.2 \\
\hline $7 / 7 / 07$ 11:00 & 880 & 6160 & 10028 & 594.2 & 435.4 & 158.8 & 26.7 & 1.17 & 2.7 & 313 & 313 & 2253 & 11.1 & 1.5 & 0.2 & 0.2 \\
\hline 7/7/07 12:00 & 884 & 6175 & 9960 & 595.0 & 437.0 & 158.0 & 26.6 & 1.16 & 2.7 & 312 & 315 & 2260 & 11.2 & 1.4 & 0.1 & 0.2 \\
\hline 7/7/07 13:00 & 873 & 6066 & 9851 & 583.8 & 431.5 & 152.3 & 26.1 & 1.16 & 2.7 & 316 & 320 & 2254 & 11.2 & 1.4 & 0.1 & 0.2 \\
\hline 7/7/07 14:00 & 883 & 6160 & 9725 & 581.0 & 432.9 & 148.1 & 25.5 & 1.17 & 2.7 & 319 & 322 & 2266 & 11.4 & 1.3 & 0.1 & 0.2 \\
\hline 7/7/07 15:00 & 877 & 6155 & 9901 & 585.6 & 431.8 & 153.8 & 26.3 & 1.18 & 2.8 & 316 & 320 & 2257 & 11.4 & 1.4 & 0.1 & 0.2 \\
\hline 7/7/07 16:00 & 881 & 6137 & 9980 & 595.8 & 439.9 & 155.9 & 26.2 & 1.16 & 2.7 & 314 & 318 & 2258 & 11.2 & 1.4 & 0.1 & 0.2 \\
\hline 7/7/07 17:00 & 883 & 6174 & 9966 & 595.4 & 440.0 & 155.4 & 26.1 & 1.16 & 2.7 & 315 & 317 & 2284 & 11.0 & 1.4 & 0.1 & 0.2 \\
\hline 7/7/07 18:00 & 884 & 6191 & 9927 & 592.1 & 437.6 & 154.4 & 26.1 & 1.16 & 2.7 & 314 & 315 & 2287 & 11.2 & 1.4 & 0.1 & 0.2 \\
\hline 7/7/07 19:00 & 883 & 6207 & 9854 & 588.1 & 434.8 & 153.3 & 26.1 & 1.17 & 2.7 & 311 & 314 & 2270 & 11.2 & 1.4 & 0.1 & 0.2 \\
\hline 7/7/07 20:00 & 884 & 6182 & 9868 & 585.8 & 433.2 & 152.6 & 26.1 & 1.17 & 2.7 & 311 & 312 & 2277 & 11.1 & 1.4 & 0.1 & 0.2 \\
\hline 7/7/07 21:00 & 883 & 6148 & 9950 & 588.1 & 434.8 & 153.3 & 26.1 & 1.17 & 2.7 & 311 & 313 & 2267 & 10.9 & 1.4 & 0.1 & 0.2 \\
\hline 7/7/07 22:00 & 884 & 6137 & 9890 & 591.3 & 437.1 & 154.2 & 26.1 & 1.17 & 2.7 & 311 & 313 & 2254 & 10.8 & 1.4 & 0.1 & 0.2 \\
\hline 7/7/07 23:00 & 884 & 6140 & 9870 & 593.0 & 438.3 & 154.7 & 26.1 & 1.16 & 2.7 & 311 & 312 & 2258 & 10.8 & 1.4 & 0.1 & 0.2 \\
\hline 7/8/07 0:00 & 883 & 6146 & 9907 & 596.2 & 440.6 & 155.7 & 26.1 & 1.15 & 2.7 & 311 & 312 & 2266 & 10.9 & 1.4 & 0.2 & 0.2 \\
\hline 7/8/07 1:00 & 854 & 5950 & 9919 & 577.4 & 427.2 & 150.2 & 26.0 & 1.15 & 2.7 & 309 & 310 & 2217 & 10.8 & 1.4 & 0.2 & 0.2 \\
\hline 7/8/07 2:00 & 873 & 6083 & 9852 & 588.7 & 435.2 & 153.5 & 26.1 & 1.16 & 2.7 & 310 & 310 & 2241 & 11.0 & 1.4 & 0.2 & 0.2 \\
\hline 7/8/07 3:00 & 885 & 6210 & 9858 & 595.0 & 439.7 & 155.3 & 26.1 & 1.16 & 2.7 & 310 & 310 & 2274 & 11.0 & 1.4 & 0.2 & 0.2 \\
\hline 7/8/07 4:00 & 887 & 6184 & 9859 & 594.9 & 439.6 & 155.3 & 26.1 & 1.16 & 2.7 & 312 & 311 & 2270 & 11.1 & 1.4 & 0.1 & 0.2 \\
\hline 7/8/07 5:00 & 886 & 6183 & 9875 & 598.1 & 441.9 & 156.2 & 26.1 & 1.16 & 2.7 & 312 & 312 & 2267 & 11.0 & 1.4 & 0.1 & 0.2 \\
\hline 7/8/07 6:00 & 886 & 6174 & 9948 & 603.0 & 445.4 & 157.6 & 26.1 & 1.15 & 2.7 & 313 & 312 & 2268 & 10.5 & 1.5 & 0.2 & 0.2 \\
\hline 7/8/07 7:00 & 886 & 6169 & 9932 & 607.3 & 448.5 & 158.8 & 26.2 & 1.14 & 2.7 & 311 & 310 & 2261 & 11.2 & 1.5 & 0.2 & 0.2 \\
\hline
\end{tabular}




\begin{tabular}{|c|c|c|c|c|c|c|c|c|c|c|c|c|c|c|c|c|}
\hline Date and & $\begin{array}{c}\text { Gross } \\
\text { Gen }\end{array}$ & $\begin{array}{c}\text { Steam } \\
\text { Flow }\end{array}$ & Gross HR & Total Fuel & $\begin{array}{c}\text { Total } \\
\text { Lignite }\end{array}$ & Total PRB & $\begin{array}{l}\text { Total } \\
\text { PRB }\end{array}$ & $\begin{array}{c}\text { Btu } \\
\text { Gain }\end{array}$ & $\begin{array}{c}\text { Econ } \\
\text { O2 }\end{array}$ & $\begin{array}{c}\text { Temp } \\
\text { A APH } \\
\text { Out }\end{array}$ & $\begin{array}{c}\text { Temp } \\
\text { B APH } \\
\text { Out }\end{array}$ & $\begin{array}{l}\text { Stack } \\
\text { Flow }\end{array}$ & Opacity & SO2 In & $\begin{array}{l}\text { SO2 } \\
\text { Out }\end{array}$ & NOx \\
\hline $\begin{array}{c}\text { Start Date } \\
\text { and Time }\end{array}$ & MW & $\begin{array}{c}\text { KLB/ } \\
\text { HR }\end{array}$ & Btu/kWhr & TON/HR & TON/HR & TON/HR & $\begin{array}{c}\% \\
\text { Weight }\end{array}$ & & $\%$ & DEGF & DEGF & KSCF & $\%$ & $\begin{array}{c}\text { Ib/MM } \\
\text { Btu }\end{array}$ & $\begin{array}{c}\text { Ib/MM } \\
\text { Btu }\end{array}$ & $\begin{array}{l}\mathbf{l b} / \mathbf{M} \\
\text { MBtu }\end{array}$ \\
\hline 7/8/07 8:00 & 882 & 6171 & 9938 & 599.7 & 442.6 & 157.1 & 26.2 & 1.14 & 2.7 & 311 & 307 & 2259 & 10.7 & 1.5 & 0.2 & 0.2 \\
\hline 7/8/07 9:00 & 883 & 6159 & 9875 & 598.9 & 442.4 & 156.5 & 26.1 & 1.15 & 2.7 & 312 & 307 & 2260 & 10.8 & 1.5 & 0.2 & 0.2 \\
\hline 7/8/07 10:00 & 880 & 6137 & 9937 & 600.4 & 443.5 & 156.9 & 26.1 & 1.14 & 2.7 & 308 & 308 & 2266 & 10.7 & 1.5 & 0.2 & 0.2 \\
\hline 7/8/07 11:00 & 881 & 6152 & 9915 & 603.0 & 445.3 & 157.7 & 26.2 & 1.14 & 2.7 & 309 & 309 & 2271 & 10.8 & 1.5 & 0.2 & 0.2 \\
\hline $7 / 8 / 07$ 12:00 & 882 & 6166 & 9860 & 600.2 & 443.8 & 156.5 & 26.1 & 1.14 & 2.7 & 312 & 310 & 2263 & 10.9 & 1.6 & 0.2 & 0.2 \\
\hline 7/8/07 13:00 & 882 & 6173 & 9839 & 593.5 & 438.5 & 155.0 & 26.1 & 1.15 & 2.7 & 313 & 312 & 2255 & 10.8 & 1.5 & 0.2 & 0.2 \\
\hline 7/8/07 14:00 & 881 & 6146 & 9842 & 589.5 & 435.7 & 153.8 & 26.1 & 1.16 & 2.6 & 314 & 314 & 2266 & 10.7 & 1.5 & 0.2 & 0.2 \\
\hline 7/8/07 15:00 & 879 & 6137 & 9868 & 590.1 & 436.2 & 154.0 & 26.1 & 1.16 & 2.6 & 314 & 315 & 2266 & 10.2 & 1.5 & 0.2 & 0.2 \\
\hline $7 / 8 / 07$ 16:00 & 878 & 6136 & 9906 & 590.7 & 436.5 & 154.1 & 26.1 & 1.16 & 2.6 & 316 & 316 & 2256 & 10.3 & 1.6 & 0.2 & 0.2 \\
\hline 7/8/07 17:00 & 878 & 6131 & 9916 & 594.8 & 439.5 & 155.3 & 26.1 & 1.16 & 2.5 & 318 & 316 & 2254 & 10.5 & 1.6 & 0.2 & 0.2 \\
\hline 7/8/07 18:00 & 879 & 6140 & 9905 & 596.4 & 440.6 & 155.8 & 26.1 & 1.15 & 2.3 & 315 & 315 & 2235 & 10.5 & 1.6 & 0.2 & 0.2 \\
\hline 7/8/07 19:00 & 877 & 6156 & 9921 & 597.4 & 441.3 & 156.0 & 26.1 & 1.15 & 2.2 & 314 & 314 & 2213 & 10.6 & 1.6 & 0.2 & 0.2 \\
\hline 7/8/07 20:00 & 869 & 6126 & 9942 & 594.3 & 443.5 & 150.8 & 25.4 & 1.15 & 2.2 & 316 & 318 & 2217 & 10.4 & 1.6 & 0.2 & 0.2 \\
\hline 7/8/07 21:00 & 865 & 6218 & 10145 & 596.9 & 444.4 & 152.6 & 25.6 & 1.16 & 2.2 & 312 & 313 & 2228 & 10.3 & 1.6 & 0.2 & 0.2 \\
\hline 7/8/07 22:00 & 869 & 6241 & 10088 & 591.9 & 440.8 & 151.1 & 25.5 & 1.17 & 2.1 & 307 & 305 & 2209 & 10.4 & 1.5 & 0.2 & 0.2 \\
\hline 7/8/07 23:00 & 871 & 6197 & 10181 & 594.7 & 442.8 & 151.9 & 25.5 & 1.17 & 2.2 & 307 & 305 & 2206 & 10.3 & 1.5 & 0.2 & 0.2 \\
\hline 7/9/07 0:00 & 873 & 6174 & 10117 & 595.6 & 443.4 & 152.2 & 25.6 & 1.16 & 2.2 & 308 & 306 & 2204 & 10.4 & 1.6 & 0.2 & 0.2 \\
\hline 7/9/07 1:00 & 874 & 6191 & 10086 & 596.5 & 444.0 & 152.4 & 25.6 & 1.16 & 2.2 & 308 & 306 & 2204 & 10.3 & 1.6 & 0.2 & 0.2 \\
\hline 7/9/07 2:00 & 875 & 6202 & 10050 & 594.9 & 442.9 & 152.0 & 25.5 & 1.16 & 2.2 & 305 & 305 & 2210 & 10.3 & 1.7 & 0.2 & 0.2 \\
\hline 7/9/07 3:00 & 876 & 6215 & 9949 & 586.5 & 437.0 & 149.6 & 25.5 & 1.17 & 2.2 & 305 & 302 & 2220 & 10.5 & 1.7 & 0.2 & 0.2 \\
\hline 7/9/07 4:00 & 876 & 6183 & 9937 & 580.3 & 432.5 & 147.8 & 25.5 & 1.18 & 2.2 & 305 & 302 & 2200 & 10.4 & 1.5 & 0.2 & 0.2 \\
\hline 7/9/07 5:00 & 874 & 6143 & 9945 & 581.2 & 433.2 & 148.1 & 25.5 & 1.18 & 2.2 & 306 & 303 & 2207 & 10.2 & 1.5 & 0.2 & 0.2 \\
\hline $7 / 9 / 07$ 6:00 & 874 & 6136 & 10005 & 587.3 & 437.5 & 149.8 & 25.5 & 1.18 & 2.2 & 308 & 304 & 2218 & 10.2 & 1.6 & 0.2 & 0.2 \\
\hline 7/9/07 7:00 & 875 & 6150 & 9990 & 588.6 & 438.5 & 150.2 & 25.5 & 1.17 & 2.2 & 309 & 305 & 2212 & 10.3 & 1.5 & 0.2 & 0.2 \\
\hline 7/9/07 8:00 & 874 & 6171 & 10025 & 590.0 & 439.5 & 150.6 & 25.5 & 1.17 & 2.2 & 309 & 306 & 2210 & 10.3 & 1.5 & 0.2 & 0.2 \\
\hline 7/9/07 9:00 & 875 & 6210 & 10036 & 587.0 & 437.3 & 149.7 & 25.5 & 1.18 & 2.2 & 306 & 306 & 2217 & 10.5 & 1.5 & 0.2 & 0.2 \\
\hline 7/9/07 10:00 & 875 & 6229 & 9949 & 577.2 & 430.3 & 146.9 & 25.5 & 1.19 & 2.2 & 306 & 304 & 2206 & 10.4 & 1.4 & 0.1 & 0.2 \\
\hline 7/9/07 11:00 & 874 & 6193 & 9822 & 573.4 & 427.5 & 145.8 & 25.4 & 1.20 & 2.2 & 309 & 305 & 2192 & 10.5 & 1.4 & 0.1 & 0.2 \\
\hline $7 / 9 / 07$ 12:00 & 875 & 6145 & 9821 & 578.2 & 431.0 & 147.2 & 25.5 & 1.20 & 2.2 & 311 & 306 & 2201 & 10.6 & 1.5 & 0.2 & 0.2 \\
\hline 7/9/07 13:00 & 874 & 6162 & 10021 & 582.6 & 434.2 & 148.4 & 25.5 & 1.19 & 2.2 & 311 & 307 & 2201 & 10.5 & 1.5 & 0.2 & 0.2 \\
\hline 7/9/07 14:00 & 871 & 6247 & 10089 & 580.5 & 432.6 & 147.8 & 25.5 & 1.19 & 2.2 & 308 & 306 & 2206 & 10.4 & 1.6 & 0.2 & 0.2 \\
\hline
\end{tabular}




\begin{tabular}{|c|c|c|c|c|c|c|c|c|c|c|c|c|c|c|c|c|}
\hline Date and & $\begin{array}{c}\text { Gross } \\
\text { Gen }\end{array}$ & $\begin{array}{c}\text { Steam } \\
\text { Flow }\end{array}$ & Gross HR & Total Fuel & $\begin{array}{c}\text { Total } \\
\text { Lignite }\end{array}$ & Total PRB & $\begin{array}{l}\text { Total } \\
\text { PRB }\end{array}$ & $\begin{array}{c}\text { Btu } \\
\text { Gain }\end{array}$ & $\begin{array}{c}\text { Econ } \\
\text { O2 }\end{array}$ & $\begin{array}{c}\text { Temp } \\
\text { A APH } \\
\text { Out }\end{array}$ & $\begin{array}{c}\text { Temp } \\
\text { B APH } \\
\text { Out }\end{array}$ & $\begin{array}{l}\text { Stack } \\
\text { Flow }\end{array}$ & Opacity & SO2 In & $\begin{array}{l}\text { SO2 } \\
\text { Out }\end{array}$ & NOx \\
\hline $\begin{array}{l}\text { Start Date } \\
\text { and Time }\end{array}$ & MW & $\begin{array}{c}\text { KLB/ } \\
\text { HR }\end{array}$ & Btu/kWhr & TON/HR & TON/HR & TON/HR & $\begin{array}{c}\% \\
\text { Weight }\end{array}$ & & $\%$ & DEGF & DEGF & KSCF & $\%$ & $\begin{array}{c}\text { Ib/MM } \\
\text { Btu }\end{array}$ & $\begin{array}{c}\text { Ib/MM } \\
\text { Btu }\end{array}$ & $\begin{array}{l}\mathbf{l b} / \mathbf{M} \\
\text { MBtu }\end{array}$ \\
\hline 7/9/07 15:00 & 877 & 6213 & 10190 & 589.6 & 439.1 & 150.4 & 25.5 & 1.19 & 2.2 & 307 & 306 & 2231 & 10.4 & 1.6 & 0.2 & 0.2 \\
\hline 7/9/07 16:00 & 880 & 6210 & 10141 & 591.7 & 442.1 & 149.6 & 25.3 & 1.18 & 2.2 & 310 & 308 & 2218 & 10.3 & 1.6 & 0.2 & 0.2 \\
\hline 7/9/07 17:00 & 877 & 6232 & 10010 & 588.3 & 441.2 & 147.1 & 25.0 & 1.18 & 2.3 & 312 & 310 & 2220 & 10.7 & 1.6 & 0.2 & 0.2 \\
\hline 7/9/07 18:00 & 875 & 6220 & 10120 & 590.7 & 443.0 & 147.7 & 25.0 & 1.18 & 2.2 & 310 & 309 & 2240 & 10.5 & 1.7 & 0.2 & 0.2 \\
\hline 7/9/07 19:00 & 877 & 6207 & 10074 & 595.1 & 446.3 & 148.8 & 25.0 & 1.17 & 2.2 & 310 & 308 & 2227 & 10.5 & 1.7 & 0.2 & 0.2 \\
\hline 7/9/07 20:00 & 877 & 6165 & 10060 & 597.8 & 448.4 & 149.5 & 25.0 & 1.16 & 2.2 & 309 & 308 & 2218 & 10.5 & 1.7 & 0.2 & 0.2 \\
\hline 7/9/07 21:00 & 875 & 6150 & 10141 & 608.1 & 456.0 & 152.0 & 25.0 & 1.15 & 2.2 & 309 & 308 & 2220 & 10.2 & 1.8 & 0.2 & 0.2 \\
\hline 7/9/07 22:00 & 873 & 6197 & 10158 & 617.0 & 462.8 & 154.2 & 25.0 & 1.13 & 2.2 & 308 & 307 & 2226 & 10.3 & 1.8 & 0.2 & 0.2 \\
\hline 7/9/07 23:00 & 868 & 6308 & 10233 & 621.9 & 466.4 & 155.5 & 25.0 & 1.13 & 2.3 & 307 & 305 & 2229 & 10.2 & 1.7 & 0.2 & 0.2 \\
\hline $7 / 10 / 07$ 0:00 & 866 & 6428 & 10434 & 625.6 & 469.2 & 156.4 & 25.0 & 1.14 & 2.3 & 306 & 305 & 2252 & 10.1 & 1.7 & 0.2 & 0.2 \\
\hline 7/10/07 1:00 & 871 & 6454 & 10537 & 634.2 & 475.6 & 158.5 & 25.0 & 1.14 & 2.3 & 304 & 304 & 2255 & 10.0 & 1.7 & 0.2 & 0.2 \\
\hline $7 / 10 / 072: 00$ & 875 & 6479 & 10479 & 632.1 & 474.1 & 158.0 & 25.0 & 1.14 & 2.3 & 304 & 302 & 2257 & 9.9 & 1.7 & 0.2 & 0.2 \\
\hline 7/10/07 3:00 & 881 & 6351 & 10463 & 638.9 & 479.2 & 159.7 & 25.0 & 1.13 & 2.2 & 305 & 302 & 2254 & 10.1 & 1.7 & 0.2 & 0.2 \\
\hline 7/10/07 4:00 & 878 & 6381 & 10357 & 638.4 & 478.8 & 159.6 & 25.0 & 1.12 & 2.3 & 308 & 303 & 2252 & 10.2 & 1.6 & 0.1 & 0.2 \\
\hline 7/10/07 5:00 & 879 & 6288 & 10304 & 640.7 & 480.5 & 160.2 & 25.0 & 1.11 & 2.5 & 309 & 303 & 2274 & 9.9 & 1.6 & 0.1 & 0.2 \\
\hline 7/10/07 6:00 & 882 & 6132 & 9996 & 631.0 & 473.3 & 157.7 & 25.0 & 1.09 & 2.5 & 309 & 304 & 2267 & 10.4 & 1.6 & 0.1 & 0.2 \\
\hline 7/10/07 7:00 & 877 & 6104 & 9952 & 630.7 & 473.0 & 157.7 & 25.0 & 1.09 & 2.5 & 309 & 303 & 2266 & 10.8 & 1.7 & 0.2 & 0.2 \\
\hline 7/10/07 8:00 & 885 & 6114 & 9843 & 630.3 & 472.7 & 157.6 & 25.0 & 1.08 & 2.5 & 310 & 303 & 2266 & 10.3 & 1.7 & 0.2 & 0.2 \\
\hline 7/10/07 9:00 & 881 & 6138 & 9771 & 622.0 & 466.5 & 155.5 & 25.0 & 1.09 & 2.5 & 311 & 303 & 2269 & 10.4 & 1.6 & 0.1 & 0.2 \\
\hline 7/10/07 10:00 & 882 & 6125 & 9753 & 610.0 & 457.5 & 152.5 & 25.0 & 1.10 & 2.5 & 309 & 302 & 2259 & 10.3 & 1.5 & 0.1 & 0.2 \\
\hline 7/10/07 11:00 & 880 & 6084 & 9622 & 590.2 & 442.6 & 147.6 & 25.0 & 1.12 & 2.5 & 309 & 303 & 2250 & 10.3 & 1.4 & 0.1 & 0.2 \\
\hline 7/10/07 12:00 & 874 & 6044 & 9694 & 579.6 & 434.7 & 144.9 & 25.0 & 1.15 & 2.6 & 310 & 304 & 2248 & 10.3 & 1.3 & 0.1 & 0.2 \\
\hline 7/10/07 13:00 & 869 & 5985 & 9840 & 587.8 & 440.7 & 147.1 & 25.0 & 1.15 & 2.6 & 310 & 306 & 2240 & 10.4 & 1.4 & 0.1 & 0.2 \\
\hline 7/10/07 14:00 & 869 & 5996 & 10066 & 615.2 & 460.7 & 154.5 & 25.1 & 1.13 & 2.5 & 309 & 308 & 2240 & 10.4 & 1.5 & 0.1 & 0.2 \\
\hline 7/10/07 15:00 & 876 & 6138 & 10038 & 627.9 & 469.5 & 158.4 & 25.2 & 1.10 & 2.5 & 311 & 309 & 2250 & 10.3 & 1.6 & 0.1 & 0.2 \\
\hline 7/10/07 16:00 & 879 & 6186 & 9914 & 618.0 & 462.3 & 155.6 & 25.2 & 1.11 & 2.4 & 310 & 309 & 2252 & 10.3 & 1.5 & 0.1 & 0.2 \\
\hline 7/10/07 17:00 & 880 & 6109 & 9795 & 606.9 & 454.0 & 152.9 & 25.2 & 1.12 & 2.4 & 312 & 309 & 2244 & 10.6 & 1.5 & 0.1 & 0.2 \\
\hline 7/10/07 18:00 & 877 & 6051 & 9787 & 605.4 & 452.9 & 152.5 & 25.2 & 1.12 & 2.4 & 312 & 310 & 2242 & 10.4 & 1.5 & 0.1 & 0.2 \\
\hline 7/10/07 19:00 & 881 & 6090 & 9860 & 616.6 & 461.3 & 155.3 & 25.2 & 1.11 & 2.4 & 314 & 311 & 2255 & 10.4 & 1.6 & 0.1 & 0.2 \\
\hline 7/10/07 20:00 & 883 & 6120 & 9844 & 613.8 & 459.2 & 154.6 & 25.2 & 1.11 & 2.4 & 311 & 311 & 2257 & 10.4 & 1.6 & 0.1 & 0.2 \\
\hline $7 / 10 / 07$ 21:00 & 879 & 6088 & 9888 & 617.7 & 462.1 & 155.6 & 25.2 & 1.11 & 2.4 & 311 & 310 & 2256 & 10.5 & 1.6 & 0.1 & 0.2 \\
\hline
\end{tabular}




\begin{tabular}{|c|c|c|c|c|c|c|c|c|c|c|c|c|c|c|c|c|}
\hline Date and & $\begin{array}{c}\text { Gross } \\
\text { Gen }\end{array}$ & $\begin{array}{c}\text { Steam } \\
\text { Flow }\end{array}$ & Gross HR & Total Fuel & $\begin{array}{c}\text { Total } \\
\text { Lignite }\end{array}$ & Total PRB & $\begin{array}{l}\text { Total } \\
\text { PRB }\end{array}$ & $\begin{array}{c}\text { Btu } \\
\text { Gain }\end{array}$ & $\begin{array}{c}\text { Econ } \\
\text { O2 }\end{array}$ & $\begin{array}{c}\text { Temp } \\
\text { A APH } \\
\text { Out }\end{array}$ & $\begin{array}{c}\text { Temp } \\
\text { B APH } \\
\text { Out }\end{array}$ & $\begin{array}{l}\text { Stack } \\
\text { Flow }\end{array}$ & Opacity & SO2 In & $\begin{array}{l}\text { SO2 } \\
\text { Out }\end{array}$ & NOx \\
\hline $\begin{array}{l}\text { Start Date } \\
\text { and Time }\end{array}$ & MW & $\begin{array}{c}\text { KLB/ } \\
\text { HR }\end{array}$ & Btu/kWhr & TON/HR & TON/HR & TON/HR & $\begin{array}{c}\% \\
\text { Weight }\end{array}$ & & $\%$ & DEGF & DEGF & KSCF & $\%$ & $\begin{array}{c}\text { Ib/MM } \\
\text { Btu }\end{array}$ & $\begin{array}{c}\text { Ib/MM } \\
\text { Btu }\end{array}$ & $\begin{array}{l}\mathbf{l b} / \mathbf{M} \\
\text { MBtu }\end{array}$ \\
\hline 7/10/07 22:00 & 878 & 6087 & 9934 & 627.8 & 469.7 & 158.1 & 25.2 & 1.10 & 2.4 & 310 & 309 & 2257 & 10.4 & 1.7 & 0.2 & 0.2 \\
\hline 7/10/07 23:00 & 885 & 6116 & 9791 & 622.1 & 465.0 & 157.2 & 25.3 & 1.09 & 2.4 & 310 & 307 & 2252 & 10.3 & 1.7 & 0.2 & 0.2 \\
\hline 7/11/07 0:00 & 880 & 6082 & 9732 & 615.0 & 459.6 & 155.5 & 25.3 & 1.10 & 2.4 & 308 & 305 & 2252 & 10.3 & 1.6 & 0.1 & 0.2 \\
\hline 7/11/07 1:00 & 880 & 6097 & 9765 & 611.2 & 456.8 & 154.4 & 25.3 & 1.11 & 2.4 & 309 & 304 & 2249 & 10.3 & 1.6 & 0.1 & 0.2 \\
\hline $7 / 11 / 072: 00$ & 877 & 6032 & 9725 & 605.7 & 452.5 & 153.2 & 25.3 & 1.11 & 2.4 & 310 & 302 & 2214 & 10.3 & 1.6 & 0.1 & 0.2 \\
\hline 7/11/07 3:00 & 870 & 5978 & 9802 & 606.9 & 454.3 & 152.6 & 25.1 & 1.11 & 2.4 & 315 & 304 & 2212 & 10.5 & 1.6 & 0.1 & 0.2 \\
\hline 7/11/07 4:00 & 884 & 6105 & 9766 & 609.8 & 455.8 & 153.9 & 25.2 & 1.11 & 2.4 & 311 & 300 & 2234 & 10.3 & 1.6 & 0.1 & 0.2 \\
\hline 7/11/07 5:00 & 882 & 6077 & 9760 & 608.1 & 454.3 & 153.8 & 25.3 & 1.12 & 2.4 & 310 & 299 & 2238 & 10.2 & 1.6 & 0.1 & 0.2 \\
\hline $7 / 11 / 076: 00$ & 783 & 5425 & 9830 & 547.2 & 380.7 & 166.5 & 30.4 & 1.12 & 2.7 & 308 & 303 & 2074 & 9.6 & 1.7 & 0.1 & 0.2 \\
\hline $7 / 11 / 07$ 7:00 & 765 & 5255 & 9880 & 535.0 & 375.2 & 159.8 & 29.9 & 1.11 & 2.3 & 308 & 305 & 2013 & 10.1 & 1.6 & 0.2 & 0.2 \\
\hline $7 / 11 / 078: 00$ & 872 & 5982 & 9756 & 600.5 & 446.4 & 154.0 & 25.7 & 1.11 & 2.4 & 308 & 299 & 2196 & 9.7 & 1.5 & 0.2 & 0.2 \\
\hline 7/11/07 9:00 & 877 & 6040 & 9736 & 601.4 & 450.2 & 151.2 & 25.1 & 1.12 & 4.8 & 308 & 299 & 2209 & 9.8 & 1.6 & 0.2 & 0.2 \\
\hline 7/11/07 10:00 & 879 & 6063 & 9753 & 600.3 & 449.5 & 150.9 & 25.1 & 1.12 & 2.4 & 309 & 299 & 2211 & 9.4 & 1.6 & 0.2 & 0.2 \\
\hline 7/11/07 11:00 & 881 & 6065 & 9685 & 597.4 & 447.4 & 150.0 & 25.1 & 1.13 & 2.4 & 310 & 301 & 2224 & 9.5 & 1.6 & 0.2 & 0.2 \\
\hline 7/11/07 12:00 & 878 & 6056 & 9745 & 596.5 & 446.4 & 150.1 & 25.2 & 1.13 & 2.4 & 312 & 302 & 2217 & 9.3 & 1.5 & 0.2 & 0.2 \\
\hline 7/11/07 13:00 & 878 & 6097 & 9878 & 601.1 & 448.9 & 152.3 & 25.3 & 1.13 & 2.4 & 314 & 304 & 2205 & 9.5 & 1.5 & 0.2 & 0.2 \\
\hline $7 / 11 / 07$ 14:00 & 879 & 6107 & 9840 & 602.5 & 451.1 & 151.5 & 25.1 & 1.13 & 2.3 & 313 & 304 & 2201 & 9.3 & 1.6 & 0.2 & 0.2 \\
\hline $7 / 11 / 07$ 15:00 & 885 & 6121 & 9839 & 604.2 & 452.2 & 151.9 & 25.1 & 1.13 & 2.2 & 314 & 304 & 2209 & 9.5 & 1.6 & 0.3 & 0.2 \\
\hline 7/11/07 16:00 & 887 & 6122 & 9667 & 597.6 & 447.5 & 150.0 & 25.1 & 1.14 & 2.2 & 315 & 306 & 2210 & 9.6 & 1.5 & 0.2 & 0.2 \\
\hline 7/11/07 17:00 & 882 & 6073 & 9685 & 589.4 & 441.6 & 147.8 & 25.1 & 1.14 & 2.2 & 314 & 307 & 2201 & 9.7 & 1.5 & 0.2 & 0.2 \\
\hline 7/11/07 18:00 & 880 & 6076 & 9747 & 586.5 & 439.4 & 147.0 & 25.1 & 1.15 & 2.2 & 315 & 307 & 2197 & 9.7 & 1.5 & 0.2 & 0.2 \\
\hline 7/11/07 19:00 & 881 & 6077 & 9723 & 582.2 & 436.1 & 146.0 & 25.1 & 1.16 & 2.3 & 316 & 308 & 2204 & 9.7 & 1.4 & 0.2 & 0.2 \\
\hline $7 / 11 / 07$ 20:00 & 880 & 6079 & 9785 & 582.5 & 436.6 & 145.9 & 25.0 & 1.16 & 2.3 & 314 & 308 & 2207 & 9.8 & 1.5 & 0.2 & 0.2 \\
\hline $7 / 11 / 07$ 21:00 & 877 & 6052 & 9688 & 574.3 & 431.3 & 143.0 & 24.9 & 1.17 & 2.3 & 312 & 308 & 2197 & 10.0 & 1.4 & 0.2 & 0.2 \\
\hline 7/11/07 22:00 & 873 & 6000 & 9752 & 573.9 & 430.8 & 143.1 & 24.9 & 1.17 & 2.3 & 312 & 308 & 2192 & 9.9 & 1.5 & 0.2 & 0.2 \\
\hline 7/11/07 23:00 & 874 & 5982 & 9848 & 584.9 & 438.6 & 146.2 & 25.0 & 1.16 & 2.3 & 312 & 307 & 2199 & 9.6 & 1.6 & 0.3 & 0.2 \\
\hline 7/12/07 0:00 & 879 & 6037 & 9739 & 583.6 & 437.1 & 146.5 & 25.1 & 1.15 & 2.3 & 311 & 305 & 2205 & 9.9 & 1.6 & 0.3 & 0.2 \\
\hline 7/12/07 1:00 & 874 & 6038 & 9725 & 581.6 & 431.5 & 150.1 & 25.8 & 1.16 & 2.4 & 312 & 304 & 2197 & 10.0 & 1.6 & 0.2 & 0.2 \\
\hline $7 / 12 / 072: 00$ & 870 & 6009 & 9789 & 580.6 & 427.3 & 153.3 & 26.4 & 1.16 & 2.4 & 312 & 303 & 2193 & 9.5 & 1.6 & 0.3 & 0.2 \\
\hline 7/12/07 3:00 & 866 & 5910 & 9820 & 583.8 & 429.6 & 154.1 & 26.4 & 1.15 & 2.3 & 318 & 305 & 2187 & 9.6 & 1.6 & 0.3 & 0.2 \\
\hline 7/12/07 4:00 & 879 & 6070 & 9828 & 596.3 & 444.7 & 151.6 & 25.4 & 1.14 & 2.4 & 313 & 303 & 2213 & 9.3 & 1.6 & 0.3 & 0.2 \\
\hline
\end{tabular}




\begin{tabular}{|c|c|c|c|c|c|c|c|c|c|c|c|c|c|c|c|c|}
\hline Date and & $\begin{array}{c}\text { Gross } \\
\text { Gen }\end{array}$ & $\begin{array}{c}\text { Steam } \\
\text { Flow }\end{array}$ & Gross HR & Total Fuel & $\begin{array}{c}\text { Total } \\
\text { Lignite }\end{array}$ & Total PRB & $\begin{array}{l}\text { Total } \\
\text { PRB } \\
\end{array}$ & $\begin{array}{c}\text { Btu } \\
\text { Gain }\end{array}$ & $\begin{array}{c}\text { Econ } \\
\text { O2 }\end{array}$ & $\begin{array}{c}\text { Temp } \\
\text { A APH } \\
\text { Out }\end{array}$ & $\begin{array}{c}\text { Temp } \\
\text { B APH } \\
\text { Out }\end{array}$ & $\begin{array}{l}\text { Stack } \\
\text { Flow }\end{array}$ & Opacity & SO2 In & $\begin{array}{l}\text { SO2 } \\
\text { Out }\end{array}$ & NOx \\
\hline $\begin{array}{l}\text { Start Date } \\
\text { and Time }\end{array}$ & MW & $\begin{array}{c}\text { KLB/ } \\
\text { HR }\end{array}$ & Btu/kWhr & TON/HR & TON/HR & TON/HR & $\begin{array}{c}\% \\
\text { Weight }\end{array}$ & & $\%$ & DEGF & DEGF & KSCF & $\%$ & $\begin{array}{c}\text { Ib/MM } \\
\text { Btu }\end{array}$ & $\begin{array}{c}\text { Ib/MM } \\
\text { Btu }\end{array}$ & $\begin{array}{l}\text { Ib/M } \\
\text { MBtu }\end{array}$ \\
\hline 7/12/07 5:00 & 883 & 6089 & 9774 & 596.2 & 443.6 & 152.6 & 25.6 & 1.14 & 2.3 & 313 & 301 & 2222 & 9.7 & 1.6 & 0.3 & 0.2 \\
\hline 7/12/07 6:00 & 883 & 6046 & 9740 & 597.3 & 444.2 & 153.1 & 25.6 & 1.13 & 2.3 & 312 & 301 & 2220 & 10.1 & 1.6 & 0.3 & 0.2 \\
\hline 7/12/07 7:00 & 883 & 6049 & 9778 & 596.2 & 443.3 & 152.8 & 25.6 & 1.13 & 2.4 & 311 & 300 & 2214 & 10.6 & 1.6 & 0.3 & 0.2 \\
\hline 7/12/07 8:00 & 882 & 6051 & 9692 & 593.5 & 441.5 & 152.1 & 25.6 & 1.14 & 2.4 & 312 & 300 & 2219 & 10.3 & 1.6 & 0.3 & 0.2 \\
\hline 7/12/07 9:00 & 879 & 6078 & 9704 & 592.1 & 440.4 & 151.6 & 25.6 & 1.14 & 2.4 & 311 & 300 & 2232 & 10.3 & 1.6 & 0.2 & 0.2 \\
\hline $7 / 12 / 07$ 10:00 & 884 & 6055 & 9666 & 588.7 & 438.0 & 150.7 & 25.6 & 1.15 & 2.3 & 311 & 300 & 2217 & 10.4 & 1.5 & 0.2 & 0.2 \\
\hline $7 / 12 / 07$ 11:00 & 882 & 6065 & 9684 & 581.8 & 433.1 & 148.7 & 25.6 & 1.15 & 2.3 & 313 & 301 & 2202 & 10.8 & 1.5 & 0.2 & 0.2 \\
\hline $7 / 12 / 07$ 12:00 & 880 & 6019 & 9697 & 583.3 & 434.1 & 149.2 & 25.6 & 1.16 & 2.3 & 316 & 304 & 2211 & 11.0 & 1.5 & 0.2 & 0.2 \\
\hline 7/12/07 13:00 & 878 & 6062 & 9715 & 585.3 & 435.5 & 149.7 & 25.6 & 1.15 & 2.3 & 316 & 306 & 2215 & 11.0 & 1.5 & 0.2 & 0.2 \\
\hline $7 / 12 / 07$ 14:00 & 882 & 6026 & 9771 & 588.9 & 438.2 & 150.7 & 25.6 & 1.15 & 2.2 & 317 & 305 & 2208 & 10.9 & 1.5 & 0.2 & 0.2 \\
\hline $7 / 12 / 07$ 15:00 & 880 & 6079 & 9740 & 587.6 & 437.2 & 150.4 & 25.6 & 1.15 & 2.2 & 317 & 308 & 2196 & 10.8 & 1.5 & 0.2 & 0.2 \\
\hline $7 / 12 / 07$ 16:00 & 884 & 6047 & 9728 & 582.8 & 433.8 & 149.0 & 25.6 & 1.16 & 2.2 & 319 & 307 & 2201 & 10.8 & 1.3 & 0.2 & 0.2 \\
\hline 7/12/07 17:00 & 884 & 6073 & 9702 & 580.7 & 432.3 & 148.4 & 25.6 & 1.16 & 2.2 & 320 & 310 & 2214 & 10.9 & 1.2 & 0.2 & 0.2 \\
\hline $7 / 12 / 07$ 18:00 & 886 & 6087 & 9743 & 587.8 & 437.4 & 150.4 & 25.6 & 1.16 & 2.2 & 319 & 311 & 2224 & 10.9 & 1.2 & 0.2 & 0.2 \\
\hline 7/12/07 19:00 & 879 & 6136 & 10031 & 603.8 & 448.8 & 155.0 & 25.7 & 1.15 & 2.2 & 325 & 315 & 2248 & 11.0 & 1.2 & 0.2 & 0.2 \\
\hline $7 / 12 / 07$ 20:00 & 876 & 6135 & 10117 & 614.0 & 456.1 & 157.9 & 25.7 & 1.13 & 2.2 & 327 & 320 & 2274 & 11.2 & 1.3 & 0.2 & 0.2 \\
\hline $7 / 12 / 07$ 21:00 & 871 & 6153 & 10150 & 621.3 & 461.7 & 159.6 & 25.7 & 1.12 & 2.2 & 326 & 319 & 2281 & 11.2 & 1.4 & 0.2 & 0.2 \\
\hline $7 / 12 / 07$ 22:00 & 862 & 6148 & 10108 & 614.0 & 457.0 & 157.0 & 25.6 & 1.11 & 2.2 & 327 & 318 & 2293 & 11.0 & 1.4 & 0.2 & 0.2 \\
\hline $7 / 12 / 07$ 23:00 & 855 & 6069 & 10025 & 603.5 & 450.0 & 153.5 & 25.4 & 1.12 & 2.3 & 326 & 316 & 2287 & 10.7 & 1.4 & 0.2 & 0.2 \\
\hline 7/13/07 0:00 & 850 & 6076 & 9983 & 591.4 & 439.7 & 151.7 & 25.7 & 1.13 & 2.3 & 326 & 317 & 2273 & 10.6 & 1.4 & 0.2 & 0.2 \\
\hline 7/13/07 1:00 & 656 & 4882 & 9961 & 439.5 & 340.8 & 98.7 & 22.5 & 1.15 & 3.0 & 322 & 316 & 2011 & 10.5 & 1.3 & 0.2 & 0.2 \\
\hline 7/13/07 2:00 & 391 & 3298 & 9167 & 230.0 & 177.0 & 53.0 & 23.1 & 1.13 & 6.3 & 295 & 287 & 1700 & 9.9 & 1.2 & 0.2 & 0.2 \\
\hline 7/13/07 3:00 & 91 & 1032 & 9002 & 43.1 & 42.8 & 0.3 & 0.7 & 1.00 & 13.8 & 267 & 252 & 1393 & 23.9 & 0.8 & 0.2 & 0.2 \\
\hline 7/13/07 4:00 & 0 & 121 & 9002 & 0.0 & 0.0 & 0.0 & \#N/A & 1.00 & 19.6 & 200 & 232 & 1394 & 91.9 & 0.0 & 0.0 & 0.0 \\
\hline 7/13/07 5:00 & 0 & 0 & 9002 & 0.0 & 0.0 & 0.0 & $\# N / A$ & 1.00 & 20.1 & 197 & 232 & 1394 & 93.5 & 0.0 & 0.0 & 0.0 \\
\hline $7 / 13 / 07$ 6:00 & 0 & 0 & 9002 & 0.0 & 0.0 & 0.0 & \#N/A & 1.00 & 20.3 & 211 & 217 & 1395 & 34.5 & 0.0 & 0.0 & 0.0 \\
\hline 7/13/07 7:00 & 0 & 0 & 9002 & 0.0 & 0.0 & 0.0 & $\# N / A$ & 1.00 & 20.4 & 159 & 163 & 1395 & 16.8 & 0.0 & 0.0 & 0.0 \\
\hline 7/13/07 8:00 & 0 & 0 & 9002 & 0.0 & 0.0 & 0.0 & $\# N / A$ & 1.00 & 20.5 & 135 & 134 & 1395 & 11.8 & 0.0 & 0.0 & 0.0 \\
\hline 7/13/07 9:00 & 0 & 0 & 9002 & 0.0 & 0.0 & 0.0 & \#N/A & 1.00 & 20.4 & 120 & 118 & 1394 & 13.8 & 0.0 & 0.0 & 0.0 \\
\hline $7 / 13 / 07$ 10:00 & 0 & 0 & 9002 & 0.0 & 0.0 & 0.0 & \#N/A & 1.00 & 20.1 & 110 & 108 & 1394 & 11.2 & 0.0 & 0.0 & 0.0 \\
\hline 7/13/07 11:00 & 0 & 0 & 9002 & 0.0 & 0.0 & 0.0 & \#N/A & 1.00 & 20.3 & 104 & 103 & 1394 & 9.9 & 0.0 & 0.0 & 0.0 \\
\hline
\end{tabular}




\begin{tabular}{|c|c|c|c|c|c|c|c|c|c|c|c|c|c|c|c|c|}
\hline Date and & $\begin{array}{c}\text { Gross } \\
\text { Gen }\end{array}$ & $\begin{array}{c}\text { Steam } \\
\text { Flow }\end{array}$ & Gross HR & Total Fuel & $\begin{array}{c}\text { Total } \\
\text { Lignite }\end{array}$ & Total PRB & $\begin{array}{l}\text { Total } \\
\text { PRB }\end{array}$ & $\begin{array}{c}\text { Btu } \\
\text { Gain }\end{array}$ & $\begin{array}{c}\text { Econ } \\
\text { O2 }\end{array}$ & $\begin{array}{c}\text { Temp } \\
\text { A APH } \\
\text { Out }\end{array}$ & $\begin{array}{c}\text { Temp } \\
\text { B APH } \\
\text { Out }\end{array}$ & $\begin{array}{l}\text { Stack } \\
\text { Flow }\end{array}$ & Opacity & SO2 In & $\begin{array}{l}\text { SO2 } \\
\text { Out }\end{array}$ & NOx \\
\hline $\begin{array}{l}\text { Start Date } \\
\text { and Time }\end{array}$ & MW & $\begin{array}{c}\text { KLB/ } \\
\text { HR }\end{array}$ & Btu/kWhr & TON/HR & TON/HR & TON/HR & $\begin{array}{c}\% \\
\text { Weight }\end{array}$ & & $\%$ & DEGF & DEGF & KSCF & $\%$ & $\begin{array}{c}\text { Ib/MM } \\
\text { Btu }\end{array}$ & $\begin{array}{c}\text { Ib/MM } \\
\text { Btu }\end{array}$ & $\begin{array}{l}\mathbf{l b} / \mathbf{M} \\
\text { MBtu }\end{array}$ \\
\hline 7/13/07 12:00 & 0 & 0 & 9002 & 0.0 & 0.0 & 0.0 & \#N/A & 1.00 & 20.1 & 100 & 99 & 1394 & 9.0 & 0.0 & 0.0 & 0.0 \\
\hline 7/13/07 13:00 & 0 & 0 & 9002 & 0.0 & 0.0 & 0.0 & \#N/A & 1.00 & 20.2 & 98 & 97 & 1394 & 9.0 & 0.0 & 0.0 & 0.0 \\
\hline 7/13/07 14:00 & 0 & 0 & 9002 & 0.0 & 0.0 & 0.0 & \#N/A & 1.00 & 20.3 & 97 & 96 & 1394 & 9.1 & 0.0 & 0.0 & 0.0 \\
\hline 7/13/07 15:00 & 0 & 0 & 9002 & 0.0 & 0.0 & 0.0 & \#N/A & 1.00 & 20.4 & 96 & 96 & 1394 & 15.4 & 0.0 & 0.0 & 0.0 \\
\hline $7 / 13 / 07$ 16:00 & 0 & 0 & 9002 & 0.0 & 0.0 & 0.0 & \#N/A & 1.00 & 20.3 & 98 & 96 & 1394 & 28.5 & 0.0 & 0.0 & 0.0 \\
\hline 7/13/07 17:00 & 0 & 0 & 9002 & 0.0 & 0.0 & 0.0 & \#N/A & 1.00 & 20.3 & 99 & 98 & 1394 & 25.4 & 0.0 & 0.0 & 0.0 \\
\hline 7/13/07 18:00 & 0 & 0 & 9002 & 0.0 & 0.0 & 0.0 & \#N/A & 1.00 & 20.1 & 100 & 99 & 1394 & 22.9 & 0.0 & 0.0 & 0.0 \\
\hline 7/13/07 19:00 & 0 & 0 & 9002 & 0.0 & 0.0 & 0.0 & \#N/A & 1.00 & 20.2 & 101 & 100 & 1394 & 19.8 & 0.0 & 0.0 & 0.0 \\
\hline 7/13/07 20:00 & 0 & 0 & 9002 & 0.0 & 0.0 & 0.0 & \#N/A & 1.00 & 20.4 & 99 & 98 & 1394 & 20.6 & 0.0 & 0.0 & 0.0 \\
\hline 7/13/07 21:00 & 0 & 0 & 9002 & 0.0 & 0.0 & 0.0 & \#N/A & 1.00 & 20.5 & 97 & 96 & 1394 & 18.5 & 0.0 & 0.0 & 0.0 \\
\hline 7/13/07 22:00 & 0 & 0 & 9002 & 0.0 & 0.0 & 0.0 & \#N/A & 1.00 & 20.5 & 96 & 95 & 1394 & 30.6 & 0.0 & 0.0 & 0.0 \\
\hline 7/13/07 23:00 & 0 & 0 & 9002 & 0.0 & 0.0 & 0.0 & \#N/A & 1.00 & 20.9 & 94 & 94 & 1394 & 20.8 & 0.0 & 0.0 & 0.0 \\
\hline 7/14/07 0:00 & 0 & 0 & 9002 & 0.0 & 0.0 & 0.0 & \#N/A & 1.00 & 20.5 & 92 & 91 & 1394 & 17.5 & 0.0 & 0.0 & 0.0 \\
\hline 7/14/07 1:00 & 0 & 0 & 9002 & 0.0 & 0.0 & 0.0 & \#N/A & 1.00 & 20.5 & 91 & 90 & 1394 & 16.8 & 0.0 & 0.0 & 0.0 \\
\hline 7/14/07 2:00 & 0 & 0 & 9002 & 0.0 & 0.0 & 0.0 & \#N/A & 1.00 & 20.5 & 90 & 88 & 1394 & 15.7 & 0.0 & 0.0 & 0.0 \\
\hline $7 / 14 / 07$ 3:00 & 0 & 0 & 9002 & 0.0 & 0.0 & 0.0 & \#N/A & 1.00 & 20.5 & 89 & 87 & 1394 & 14.8 & 0.0 & 0.0 & 0.0 \\
\hline $7 / 14 / 07$ 4:00 & 0 & 0 & 9002 & 0.0 & 0.0 & 0.0 & \#N/A & 1.00 & 20.5 & 87 & 86 & 1394 & 14.2 & 0.0 & 0.0 & 0.0 \\
\hline $7 / 14 / 07$ 5:00 & 0 & 0 & 9002 & 0.0 & 0.0 & 0.0 & \#N/A & 1.00 & 20.5 & 86 & 85 & 1394 & 14.1 & 0.0 & 0.0 & 0.0 \\
\hline 7/14/07 6:00 & 0 & 0 & 9002 & 0.0 & 0.0 & 0.0 & \#N/A & 1.00 & 20.5 & 85 & 84 & 1393 & 14.7 & 0.0 & 0.0 & 0.0 \\
\hline 7/14/07 7:00 & 0 & 0 & 9002 & 0.0 & 0.0 & 0.0 & \#N/A & 1.00 & 20.5 & 84 & 83 & 1394 & 13.6 & 0.0 & 0.0 & 0.0 \\
\hline 7/14/07 8:00 & 0 & 0 & 9002 & 0.0 & 0.0 & 0.0 & \#N/A & 1.00 & 20.5 & 83 & 82 & 1394 & 13.5 & 0.0 & 0.0 & 0.0 \\
\hline 7/14/07 9:00 & 0 & 0 & 9002 & 0.0 & 0.0 & 0.0 & \#N/A & 1.00 & 20.5 & 83 & 82 & 1394 & 12.9 & 0.0 & 0.0 & 0.0 \\
\hline 7/14/07 10:00 & 0 & 0 & 9002 & 0.0 & 0.0 & 0.0 & \#N/A & 1.00 & 20.5 & 82 & 80 & 1394 & 12.0 & 0.0 & 0.0 & 0.0 \\
\hline 7/14/07 11:00 & 0 & 0 & 9002 & 0.0 & 0.0 & 0.0 & \#N/A & 1.00 & 20.6 & 81 & 80 & 1394 & 12.0 & 0.0 & 0.0 & 0.0 \\
\hline 7/14/07 12:00 & 0 & 0 & 9002 & 0.0 & 0.0 & 0.0 & \#N/A & 1.00 & 20.5 & 81 & 80 & 1394 & 12.2 & 0.0 & 0.0 & 0.0 \\
\hline 7/14/07 13:00 & 0 & 0 & 9002 & 0.0 & 0.0 & 0.0 & \#N/A & 1.00 & 20.5 & 81 & 80 & 1394 & 12.7 & 0.0 & 0.0 & 0.0 \\
\hline 7/14/07 14:00 & 0 & 0 & 9002 & 0.0 & 0.0 & 0.0 & $\# \mathrm{~N} / \mathrm{A}$ & 1.00 & 20.4 & 81 & 80 & 1395 & 12.0 & 0.0 & 0.0 & 0.0 \\
\hline 7/14/07 15:00 & 0 & 0 & 9002 & 0.0 & 0.0 & 0.0 & \#N/A & 1.00 & 20.4 & 81 & 80 & 1395 & 11.8 & 0.0 & 0.0 & 0.0 \\
\hline 7/14/07 16:00 & 0 & 0 & 9002 & 0.0 & 0.0 & 0.0 & \#N/A & 1.00 & 20.4 & 82 & 81 & 1394 & 11.8 & 0.0 & 0.0 & 0.0 \\
\hline 7/14/07 17:00 & 0 & 0 & 9002 & 0.0 & 0.0 & 0.0 & \#N/A & 1.00 & 20.4 & 82 & 81 & 1394 & 11.0 & 0.0 & 0.0 & 0.0 \\
\hline $7 / 14 / 07$ 18:00 & 0 & 0 & 9002 & 0.0 & 0.0 & 0.0 & \#N/A & 1.00 & 20.5 & 81 & 81 & 1394 & 10.8 & 0.0 & 0.0 & 0.0 \\
\hline
\end{tabular}




\begin{tabular}{|c|c|c|c|c|c|c|c|c|c|c|c|c|c|c|c|c|}
\hline Date and & $\begin{array}{c}\text { Gross } \\
\text { Gen }\end{array}$ & $\begin{array}{c}\text { Steam } \\
\text { Flow }\end{array}$ & Gross HR & Total Fuel & $\begin{array}{c}\text { Total } \\
\text { Lignite }\end{array}$ & Total PRB & $\begin{array}{l}\text { Total } \\
\text { PRB } \\
\end{array}$ & $\begin{array}{c}\text { Btu } \\
\text { Gain }\end{array}$ & $\begin{array}{c}\text { Econ } \\
\text { O2 }\end{array}$ & $\begin{array}{c}\text { Temp } \\
\text { A APH } \\
\text { Out }\end{array}$ & $\begin{array}{c}\text { Temp } \\
\text { B APH } \\
\text { Out }\end{array}$ & $\begin{array}{l}\text { Stack } \\
\text { Flow }\end{array}$ & Opacity & SO2 In & $\begin{array}{l}\text { SO2 } \\
\text { Out }\end{array}$ & NOx \\
\hline $\begin{array}{l}\text { Start Date } \\
\text { and Time }\end{array}$ & MW & $\begin{array}{c}\text { KLB/ } \\
\text { HR }\end{array}$ & Btu/kWhr & TON/HR & TON/HR & TON/HR & $\begin{array}{c}\% \\
\text { Weight }\end{array}$ & & $\%$ & DEGF & DEGF & KSCF & $\%$ & $\begin{array}{c}\text { Ib/MM } \\
\text { Btu }\end{array}$ & $\begin{array}{c}\text { Ib/MM } \\
\text { Btu }\end{array}$ & $\begin{array}{l}\text { Ib/M } \\
\text { MBtu }\end{array}$ \\
\hline 7/14/07 19:00 & 0 & 0 & 9002 & 0.0 & 0.0 & 0.0 & $\# N / A$ & 1.00 & 20.5 & 82 & 81 & 1394 & 10.6 & 0.0 & 0.0 & 0.0 \\
\hline 7/14/07 20:00 & 0 & 0 & 9002 & 0.0 & 0.0 & 0.0 & $\# N / A$ & 1.00 & 20.4 & 81 & 81 & 1394 & 10.6 & 0.0 & 0.0 & 0.0 \\
\hline $7 / 14 / 07$ 21:00 & 0 & 0 & 9002 & 0.0 & 0.0 & 0.0 & \#N/A & 1.00 & 20.4 & 82 & 82 & 1394 & 10.7 & 0.0 & 0.0 & 0.0 \\
\hline $7 / 14 / 07$ 22:00 & 0 & 0 & 9002 & 0.0 & 0.0 & 0.0 & $\# N / A$ & 1.00 & 20.4 & 82 & 82 & 1394 & 10.3 & 0.0 & 0.0 & 0.0 \\
\hline $7 / 14 / 07$ 23:00 & 0 & 0 & 9002 & 0.0 & 0.0 & 0.0 & \#N/A & 1.00 & 20.5 & 83 & 82 & 1394 & 10.3 & 0.0 & 0.0 & 0.0 \\
\hline 7/15/07 0:00 & 0 & 0 & 9002 & 0.0 & 0.0 & 0.0 & $\# N / A$ & 1.00 & 20.8 & 83 & 82 & 1394 & 9.8 & 0.0 & 0.0 & 0.0 \\
\hline 7/15/07 1:00 & 0 & 0 & 9002 & 0.0 & 0.0 & 0.0 & \#N/A & 1.00 & 21.2 & 83 & 82 & 1394 & 9.5 & 0.0 & 0.0 & 0.0 \\
\hline 7/15/07 2:00 & 0 & 0 & 9002 & 0.0 & 0.0 & 0.0 & \#N/A & 1.00 & 20.8 & 82 & 82 & 1395 & 9.2 & 0.0 & 0.0 & 0.0 \\
\hline 7/15/07 3:00 & 0 & 0 & 9002 & 0.0 & 0.0 & 0.0 & \#N/A & 1.00 & 20.8 & 82 & 82 & 1394 & 9.2 & 0.0 & 0.0 & 0.0 \\
\hline 7/15/07 4:00 & 0 & 0 & 9002 & 0.0 & 0.0 & 0.0 & $\# N / A$ & 1.00 & 20.8 & 82 & 82 & 1394 & 9.4 & 0.0 & 0.0 & 0.0 \\
\hline $7 / 15 / 07$ 5:00 & 0 & 0 & 9002 & 0.0 & 0.0 & 0.0 & \#N/A & 1.00 & 20.8 & 82 & 81 & 1394 & 9.4 & 0.0 & 0.0 & 0.0 \\
\hline 7/15/07 6:00 & 0 & 0 & 9002 & 0.0 & 0.0 & 0.0 & $\# \mathrm{~N} / \mathrm{A}$ & 1.00 & 20.8 & 82 & 81 & 1394 & 9.3 & 0.0 & 0.0 & 0.0 \\
\hline 7/15/07 7:00 & 0 & 0 & 9002 & 0.0 & 0.0 & 0.0 & $\# N / A$ & 1.00 & 20.8 & 81 & 81 & 1394 & 9.5 & 0.0 & 0.0 & 0.0 \\
\hline 7/15/07 8:00 & 0 & 0 & 9002 & 0.0 & 0.0 & 0.0 & \#N/A & 1.00 & 20.8 & 81 & 80 & 1394 & 9.0 & 0.0 & 0.0 & 0.0 \\
\hline 7/15/07 9:00 & 0 & 0 & 9002 & 0.0 & 0.0 & 0.0 & $\# N / A$ & 1.00 & 20.8 & 81 & 80 & 1395 & 9.1 & 0.0 & 0.0 & 0.0 \\
\hline $7 / 15 / 07$ 10:00 & 0 & 0 & 9002 & 0.0 & 0.0 & 0.0 & $\# N / A$ & 1.00 & 20.8 & 81 & 80 & 1394 & 9.0 & 0.0 & 0.0 & 0.0 \\
\hline $7 / 15 / 07$ 11:00 & 0 & 0 & 9002 & 0.0 & 0.0 & 0.0 & $\# \mathrm{~N} / \mathrm{A}$ & 1.00 & 20.8 & 80 & 80 & 1394 & 9.2 & 0.0 & 0.0 & 0.0 \\
\hline $7 / 15 / 07$ 12:00 & 0 & 0 & 9002 & 0.0 & 0.0 & 0.0 & \#N/A & 1.00 & 20.8 & 80 & 80 & 1394 & 9.3 & 0.0 & 0.0 & 0.0 \\
\hline $7 / 15 / 07$ 13:00 & 0 & 0 & 9002 & 0.0 & 0.0 & 0.0 & $\# N / A$ & 1.00 & 20.8 & 80 & 80 & 1394 & 9.3 & 0.0 & 0.0 & 0.0 \\
\hline $7 / 15 / 07$ 14:00 & 0 & 0 & 9002 & 0.0 & 0.0 & 0.0 & \#N/A & 1.00 & 20.8 & 80 & 80 & 1394 & 9.3 & 0.0 & 0.0 & 0.0 \\
\hline $7 / 15 / 07$ 15:00 & 0 & 0 & 9002 & 0.0 & 0.0 & 0.0 & $\# N / A$ & 1.00 & 20.8 & 81 & 80 & 1394 & 9.2 & 0.0 & 0.0 & 0.0 \\
\hline $7 / 15 / 07$ 16:00 & 0 & 0 & 9002 & 0.0 & 0.0 & 0.0 & $\# N / A$ & 1.00 & 20.8 & 81 & 81 & 1394 & 9.0 & 0.0 & 0.0 & 0.0 \\
\hline $7 / 15 / 07$ 17:00 & 0 & 0 & 9002 & 0.0 & 0.0 & 0.0 & \#N/A & 1.00 & 20.8 & 82 & 81 & 1394 & 8.9 & 0.0 & 0.0 & 0.0 \\
\hline $7 / 15 / 07$ 18:00 & 0 & 0 & 9002 & 0.0 & 0.0 & 0.0 & \#N/A & 1.00 & 20.8 & 81 & 81 & 1394 & 9.0 & 0.0 & 0.0 & 0.0 \\
\hline 7/15/07 19:00 & 0 & 0 & 9002 & 0.0 & 0.0 & 0.0 & $\# N / A$ & 1.00 & 20.8 & 82 & 82 & 1394 & 9.1 & 0.0 & 0.0 & 0.0 \\
\hline $7 / 15 / 07$ 20:00 & 0 & 0 & 9002 & 0.0 & 0.0 & 0.0 & \#N/A & 1.00 & 20.8 & 82 & 82 & 1394 & 9.0 & 0.0 & 0.0 & 0.0 \\
\hline $7 / 15 / 07$ 21:00 & 0 & 0 & 9002 & 0.0 & 0.0 & 0.0 & $\# N / A$ & 1.00 & 20.8 & 83 & 83 & 1394 & 9.0 & 0.0 & 0.0 & 0.0 \\
\hline $7 / 15 / 07$ 22:00 & 0 & 0 & 9002 & 0.0 & 0.0 & 0.0 & \#N/A & 1.00 & 20.8 & 83 & 83 & 1394 & 9.1 & 0.0 & 0.0 & 0.0 \\
\hline 7/15/07 23:00 & 0 & 0 & 9002 & 0.0 & 0.0 & 0.0 & \#N/A & 1.00 & 20.8 & 83 & 83 & 1394 & 9.1 & 0.0 & 0.0 & 0.0 \\
\hline 7/16/07 0:00 & 0 & 0 & 9002 & 0.0 & 0.0 & 0.0 & \#N/A & 1.00 & 20.8 & 84 & 83 & 1394 & 8.8 & 0.0 & 0.0 & 0.0 \\
\hline $7 / 16 / 07$ 1:00 & 0 & 6 & 9002 & 0.0 & 0.0 & 0.0 & \#N/A & 1.00 & 20.8 & 83 & 82 & 1394 & 8.8 & 0.0 & 0.0 & 0.0 \\
\hline
\end{tabular}




\begin{tabular}{|c|c|c|c|c|c|c|c|c|c|c|c|c|c|c|c|c|}
\hline Date and & $\begin{array}{c}\text { Gross } \\
\text { Gen }\end{array}$ & $\begin{array}{c}\text { Steam } \\
\text { Flow }\end{array}$ & Gross HR & Total Fuel & $\begin{array}{c}\text { Total } \\
\text { Lignite }\end{array}$ & Total PRB & $\begin{array}{l}\text { Total } \\
\text { PRB }\end{array}$ & $\begin{array}{c}\text { Btu } \\
\text { Gain }\end{array}$ & $\begin{array}{c}\text { Econ } \\
\text { O2 }\end{array}$ & $\begin{array}{c}\text { Temp } \\
\text { A APH } \\
\text { Out }\end{array}$ & $\begin{array}{c}\text { Temp } \\
\text { B APH } \\
\text { Out }\end{array}$ & $\begin{array}{l}\text { Stack } \\
\text { Flow }\end{array}$ & Opacity & SO2 In & $\begin{array}{l}\text { SO2 } \\
\text { Out }\end{array}$ & NOx \\
\hline $\begin{array}{l}\text { Start Date } \\
\text { and Time }\end{array}$ & MW & $\begin{array}{c}\text { KLB/ } \\
\text { HR }\end{array}$ & Btu/kWhr & TON/HR & TON/HR & TON/HR & $\begin{array}{c}\% \\
\text { Weight }\end{array}$ & & $\%$ & DEGF & DEGF & KSCF & $\%$ & $\begin{array}{c}\text { Ib/MM } \\
\text { Btu }\end{array}$ & $\begin{array}{c}\text { Ib/MM } \\
\text { Btu }\end{array}$ & $\begin{array}{l}\mathbf{l b} / \mathbf{M} \\
\text { MBtu }\end{array}$ \\
\hline 7/16/07 2:00 & 0 & 0 & 9002 & 0.0 & 0.0 & 0.0 & \#N/A & 1.00 & 20.8 & 83 & 82 & 1394 & 8.9 & 0.0 & 0.0 & 0.0 \\
\hline 7/16/07 3:00 & 0 & 0 & 9002 & 0.0 & 0.0 & 0.0 & \#N/A & 1.00 & 20.8 & 84 & 82 & 1394 & 9.1 & 0.0 & 0.0 & 0.0 \\
\hline $7 / 16 / 074: 00$ & 0 & 0 & 9002 & 0.0 & 0.0 & 0.0 & \#N/A & 1.00 & 20.8 & 83 & 82 & 1394 & 9.2 & 0.0 & 0.0 & 0.0 \\
\hline $7 / 16 / 07$ 5:00 & 0 & 0 & 9002 & 0.0 & 0.0 & 0.0 & \#N/A & 1.00 & 20.7 & 83 & 82 & 1394 & 9.2 & 0.0 & 0.0 & 0.0 \\
\hline $7 / 16 / 076: 00$ & 0 & 0 & 9002 & 0.0 & 0.0 & 0.0 & \#N/A & 1.00 & 20.7 & 83 & 83 & 1330 & 22.4 & 0.0 & 0.0 & 0.0 \\
\hline $7 / 16 / 07$ 7:00 & 0 & 0 & 9002 & 0.0 & 0.0 & 0.0 & \#N/A & 1.00 & 20.6 & 85 & 89 & 1104 & 18.6 & 0.0 & 0.0 & 0.0 \\
\hline 7/16/07 8:00 & 0 & 0 & 9002 & 0.0 & 0.0 & 0.0 & \#N/A & 1.00 & 18.5 & 97 & 97 & 1066 & 24.1 & 0.0 & 0.0 & 0.0 \\
\hline 7/16/07 9:00 & 0 & 5 & 9002 & 0.0 & 0.0 & 0.0 & \#N/A & 1.00 & 18.4 & 128 & 114 & 1054 & 25.4 & 0.0 & 0.0 & 0.0 \\
\hline 7/16/07 10:00 & 0 & 1 & 9002 & 0.0 & 0.0 & 0.0 & \#N/A & 1.00 & 19.4 & 152 & 128 & 1021 & 20.6 & 0.0 & 0.0 & 0.0 \\
\hline 7/16/07 11:00 & 0 & 0 & 9002 & 0.0 & 0.0 & 0.0 & \#N/A & 1.00 & 19.2 & 164 & 136 & 1007 & 18.2 & 0.0 & 0.0 & 0.0 \\
\hline 7/16/07 12:00 & 0 & 0 & 9002 & 0.0 & 0.0 & 0.0 & \#N/A & 1.00 & 19.0 & 182 & 148 & 1035 & 20.3 & 0.1 & 0.0 & 0.0 \\
\hline 7/16/07 13:00 & 0 & 0 & 9002 & 0.0 & 0.0 & 0.0 & \#N/A & 1.00 & 19.0 & 195 & 158 & 1050 & 21.8 & 0.0 & 0.0 & 0.0 \\
\hline 7/16/07 14:00 & 0 & 29 & 9002 & 0.0 & 0.0 & 0.0 & \#N/A & 1.00 & 18.7 & 205 & 165 & 1044 & 21.2 & 0.0 & 0.0 & 0.0 \\
\hline 7/16/07 15:00 & 0 & 241 & 9002 & 0.0 & 0.0 & 0.0 & \#N/A & 1.00 & 18.2 & 218 & 173 & 1066 & 22.1 & 0.1 & 0.0 & 0.0 \\
\hline 7/16/07 16:00 & 8 & 491 & 9002 & 11.7 & 11.7 & 0.0 & 0.0 & 1.00 & 17.1 & 220 & 189 & 1069 & 25.1 & 0.2 & 0.0 & 0.1 \\
\hline 7/16/07 17:00 & 40 & 583 & 9002 & 47.4 & 47.4 & 0.0 & 0.0 & 1.00 & 15.0 & 213 & 201 & 1076 & 10.4 & 0.9 & 0.2 & 0.3 \\
\hline 7/16/07 18:00 & 63 & 710 & 9002 & 55.7 & 55.7 & 0.0 & 0.0 & 1.00 & 14.5 & 214 & 205 & 1091 & 9.9 & 0.9 & 0.2 & 0.3 \\
\hline 7/16/07 19:00 & 113 & 1100 & 9002 & 73.7 & 52.8 & 20.9 & 28.4 & 1.00 & 12.6 & 217 & 210 & 1188 & 10.9 & 0.8 & 0.2 & 0.5 \\
\hline 7/16/07 20:00 & 143 & 1307 & 9002 & 91.4 & 54.7 & 36.7 & 40.1 & 1.00 & 11.5 & 220 & 215 & 1245 & 10.6 & 0.8 & 0.2 & 0.7 \\
\hline 7/16/07 21:00 & 224 & 1929 & 9002 & 135.0 & 93.4 & 41.7 & 30.9 & 1.00 & 9.9 & 235 & 228 & 1368 & 10.1 & 0.9 & 0.2 & 0.6 \\
\hline $7 / 16 / 07$ 22:00 & 379 & 3136 & 9002 & 233.2 & 172.6 & 60.6 & 26.0 & 1.03 & 6.3 & 248 & 240 & 1544 & 9.5 & 1.0 & 0.2 & 0.3 \\
\hline 7/16/07 23:00 & 453 & 3640 & 9002 & 286.2 & 214.7 & 71.5 & 25.0 & 1.10 & 4.9 & 257 & 248 & 1630 & 9.6 & 1.1 & 0.1 & 0.1 \\
\hline 7/17/07 0:00 & 643 & 4652 & 9392 & 434.1 & 340.5 & 93.6 & 21.6 & 1.12 & 3.5 & 276 & 267 & 1894 & 11.1 & 1.3 & 0.1 & 0.2 \\
\hline $7 / 17 / 07$ 1:00 & 841 & 5949 & 9852 & 587.0 & 439.6 & 147.5 & 25.1 & 1.12 & 2.9 & 301 & 288 & 2241 & 11.8 & 1.4 & 0.1 & 0.2 \\
\hline 7/17/07 2:00 & 878 & 6191 & 9927 & 608.0 & 456.0 & 152.0 & 25.0 & 1.13 & 2.9 & 309 & 292 & 2308 & 11.2 & 1.5 & 0.1 & 0.2 \\
\hline 7/17/07 3:00 & 890 & 6170 & 9884 & 611.8 & 458.8 & 153.0 & 25.0 & 1.13 & 2.9 & 311 & 295 & 2314 & 11.0 & 1.5 & 0.1 & 0.2 \\
\hline 7/17/07 4:00 & 891 & 6120 & 9743 & 606.0 & 448.4 & 157.6 & 26.0 & 1.13 & 2.8 & 312 & 296 & 2300 & 11.0 & 1.4 & 0.1 & 0.2 \\
\hline 7/17/07 5:00 & 887 & 6062 & 9706 & 601.2 & 442.4 & 158.8 & 26.4 & 1.13 & 2.8 & 312 & 297 & 2291 & 11.0 & 1.4 & 0.1 & 0.2 \\
\hline $7 / 17 / 076: 00$ & 888 & 6087 & 9623 & 593.6 & 436.5 & 157.1 & 26.5 & 1.13 & 2.8 & 312 & 298 & 2282 & 11.0 & 1.4 & 0.1 & 0.2 \\
\hline 7/17/07 7:00 & 886 & 6078 & 9565 & 580.5 & 426.7 & 153.8 & 26.5 & 1.15 & 2.9 & 314 & 297 & 2275 & 11.2 & 1.3 & 0.1 & 0.2 \\
\hline 7/17/07 8:00 & 883 & 6035 & 9673 & 584.3 & 429.5 & 154.8 & 26.5 & 1.16 & 2.9 & 307 & 297 & 2249 & 11.0 & 1.3 & 0.2 & 0.2 \\
\hline
\end{tabular}




\begin{tabular}{|c|c|c|c|c|c|c|c|c|c|c|c|c|c|c|c|c|}
\hline Date and & $\begin{array}{c}\text { Gross } \\
\text { Gen }\end{array}$ & $\begin{array}{c}\text { Steam } \\
\text { Flow }\end{array}$ & Gross HR & Total Fuel & $\begin{array}{c}\text { Total } \\
\text { Lignite }\end{array}$ & Total PRB & $\begin{array}{l}\text { Total } \\
\text { PRB }\end{array}$ & $\begin{array}{c}\text { Btu } \\
\text { Gain }\end{array}$ & $\begin{array}{c}\text { Econ } \\
\text { O2 }\end{array}$ & $\begin{array}{c}\text { Temp } \\
\text { A APH } \\
\text { Out }\end{array}$ & $\begin{array}{c}\text { Temp } \\
\text { B APH } \\
\text { Out }\end{array}$ & $\begin{array}{l}\text { Stack } \\
\text { Flow }\end{array}$ & Opacity & SO2 In & $\begin{array}{l}\text { SO2 } \\
\text { Out }\end{array}$ & NOx \\
\hline $\begin{array}{l}\text { Start Date } \\
\text { and Time }\end{array}$ & MW & $\begin{array}{c}\text { KLB/ } \\
\text { HR }\end{array}$ & Btu/kWhr & TON/HR & TON/HR & TON/HR & $\begin{array}{c}\% \\
\text { Weight }\end{array}$ & & $\%$ & DEGF & DEGF & KSCF & $\%$ & $\begin{array}{c}\text { Ib/MM } \\
\text { Btu }\end{array}$ & $\begin{array}{c}\text { Ib/MM } \\
\text { Btu }\end{array}$ & $\begin{array}{l}\mathbf{l b} / \mathbf{M} \\
\text { MBtu }\end{array}$ \\
\hline 7/17/07 9:00 & 889 & 6106 & 9763 & 592.6 & 435.7 & 156.9 & 26.5 & 1.15 & 2.8 & 310 & 296 & 2262 & 11.0 & 1.3 & 0.2 & 0.2 \\
\hline 7/17/07 10:00 & 890 & 6102 & 9776 & 593.1 & 436.1 & 157.0 & 26.5 & 1.15 & 2.8 & 314 & 298 & 2268 & 10.9 & 1.4 & 0.2 & 0.2 \\
\hline 7/17/07 11:00 & 889 & 6122 & 9764 & 594.9 & 437.5 & 157.4 & 26.5 & 1.15 & 2.8 & 316 & 300 & 2261 & 10.7 & 1.5 & 0.3 & 0.2 \\
\hline 7/17/07 12:00 & 890 & 6098 & 9715 & 598.0 & 439.8 & 158.2 & 26.5 & 1.15 & 2.8 & 317 & 302 & 2265 & 10.9 & 1.5 & 0.3 & 0.2 \\
\hline 7/17/07 13:00 & 889 & 6121 & 9795 & 601.3 & 442.3 & 159.0 & 26.4 & 1.14 & 2.8 & 313 & 299 & 2279 & 10.9 & 1.5 & 0.3 & 0.2 \\
\hline 7/17/07 14:00 & 876 & 6039 & 9757 & 595.3 & 437.8 & 157.6 & 26.5 & 1.14 & 2.9 & 309 & 297 & 2250 & 10.9 & 1.4 & 0.2 & 0.2 \\
\hline 7/17/07 15:00 & 882 & 6045 & 9770 & 599.0 & 440.5 & 158.5 & 26.5 & 1.13 & 2.8 & 309 & 301 & 2241 & 10.9 & 1.4 & 0.2 & 0.2 \\
\hline 7/17/07 16:00 & 768 & 5438 & 9717 & 505.7 & 371.3 & 134.4 & 26.6 & 1.11 & 5.2 & 308 & 302 & 1999 & 15.8 & 1.4 & 0.2 & 0.2 \\
\hline 7/17/07 17:00 & 35 & 872 & 9679 & 1.1 & 0.8 & 0.3 & 30.4 & 1.00 & 17.3 & 272 & 257 & 1372 & 36.5 & 0.4 & 0.1 & 0.1 \\
\hline 7/17/07 18:00 & 52 & 692 & 9679 & 26.9 & 26.9 & 0.0 & 0.0 & 1.00 & 15.9 & 251 & 211 & 1451 & 37.1 & 0.4 & 0.1 & 0.1 \\
\hline 7/17/07 19:00 & 122 & 1167 & 9679 & 80.8 & 80.8 & 0.0 & 0.0 & 1.00 & 12.6 & 240 & 200 & 1504 & 14.1 & 0.9 & 0.2 & 0.4 \\
\hline 7/17/07 20:00 & 215 & 1688 & 9679 & 132.3 & 132.3 & 0.0 & 0.0 & 1.00 & 10.5 & 249 & 215 & 1530 & 10.8 & 1.1 & 0.3 & 0.6 \\
\hline 7/17/07 21:00 & 296 & 2210 & 9679 & 183.1 & 183.1 & 0.0 & 0.0 & 1.00 & 7.3 & 261 & 226 & 1463 & 10.2 & 1.3 & 0.3 & 0.4 \\
\hline 7/17/07 22:00 & 427 & 3003 & 9236 & 270.3 & 268.1 & 2.2 & 0.8 & 1.00 & 5.4 & 279 & 240 & 1568 & 10.9 & 1.4 & 0.3 & 0.2 \\
\hline 7/17/07 23:00 & 608 & 4213 & 8261 & 388.9 & 340.2 & 48.7 & 12.5 & 1.02 & 3.6 & 298 & 254 & 1805 & 12.9 & 1.4 & 0.2 & 0.1 \\
\hline 7/18/07 0:00 & 700 & 4881 & 8726 & 456.5 & 343.4 & 113.1 & 24.8 & 1.06 & 3.3 & 312 & 268 & 2019 & 11.7 & 1.4 & 0.2 & 0.2 \\
\hline 7/18/07 1:00 & 701 & 4781 & 9342 & 472.6 & 341.9 & 130.8 & 27.7 & 1.08 & 3.3 & 310 & 267 & 1972 & 11.5 & 1.3 & 0.2 & 0.2 \\
\hline $7 / 18 / 072: 00$ & 716 & 4859 & 9582 & 484.7 & 350.4 & 134.3 & 27.7 & 1.10 & 3.3 & 310 & 266 & 1973 & 11.2 & 1.3 & 0.2 & 0.2 \\
\hline 7/18/07 3:00 & 752 & 5091 & 9535 & 501.8 & 364.4 & 137.4 & 27.4 & 1.12 & 3.1 & 312 & 267 & 2007 & 12.2 & 1.3 & 0.2 & 0.2 \\
\hline 7/18/07 4:00 & 769 & 5301 & 9691 & 513.3 & 368.3 & 145.0 & 28.3 & 1.13 & 3.1 & 306 & 272 & 2050 & 12.8 & 1.3 & 0.2 & 0.2 \\
\hline 7/18/07 5:00 & 774 & 5259 & 9737 & 515.1 & 366.2 & 148.8 & 28.9 & 1.14 & 3.1 & 297 & 286 & 2067 & 10.7 & 1.3 & 0.2 & 0.2 \\
\hline $7 / 18 / 07$ 6:00 & 787 & 5314 & 9685 & 521.7 & 370.9 & 150.7 & 28.9 & 1.14 & 3.1 & 298 & 288 & 2083 & 10.9 & 1.3 & 0.2 & 0.2 \\
\hline 7/18/07 7:00 & 799 & 5436 & 9730 & 536.0 & 381.2 & 154.8 & 28.9 & 1.14 & 3.1 & 298 & 289 & 2102 & 10.5 & 1.3 & 0.2 & 0.2 \\
\hline 7/18/07 8:00 & 799 & 5449 & 9712 & 537.6 & 382.4 & 155.3 & 28.9 & 1.13 & 3.1 & 296 & 290 & 2099 & 10.8 & 1.3 & 0.2 & 0.2 \\
\hline 7/18/07 9:00 & 800 & 5439 & 9712 & 539.7 & 383.8 & 155.9 & 28.9 & 1.13 & 3.1 & 297 & 291 & 2112 & 10.7 & 1.3 & 0.2 & 0.2 \\
\hline 7/18/07 10:00 & 800 & 5466 & 9680 & 539.0 & 383.4 & 155.7 & 28.9 & 1.13 & 5.0 & 300 & 292 & 2111 & 10.7 & 1.3 & 0.2 & 0.2 \\
\hline 7/18/07 11:00 & 802 & 5453 & 9646 & 534.1 & 379.8 & 154.3 & 28.9 & 1.14 & 3.3 & 301 & 292 & 2111 & 10.9 & 1.3 & 0.2 & 0.2 \\
\hline 7/18/07 12:00 & 800 & 5453 & 9603 & 529.4 & 376.4 & 153.0 & 28.9 & 1.14 & 3.1 & 301 & 293 & 2109 & 10.6 & 1.4 & 0.2 & 0.2 \\
\hline 7/18/07 13:00 & 797 & 5449 & 9676 & 531.0 & 377.6 & 153.4 & 28.9 & 1.14 & 3.1 & 303 & 293 & 2110 & 10.7 & 1.5 & 0.3 & 0.2 \\
\hline 7/18/07 14:00 & 798 & 5431 & 9760 & 537.4 & 382.1 & 155.2 & 28.9 & 1.14 & 3.1 & 303 & 294 & 2106 & 9.3 & 1.5 & 0.3 & 0.2 \\
\hline $7 / 18 / 07$ 15:00 & 801 & 5443 & 9740 & 540.1 & 384.1 & 156.0 & 28.9 & 1.13 & 3.1 & 303 & 295 & 2112 & 8.4 & 1.6 & 0.3 & 0.2 \\
\hline
\end{tabular}




\begin{tabular}{|c|c|c|c|c|c|c|c|c|c|c|c|c|c|c|c|c|}
\hline Date and & $\begin{array}{c}\text { Gross } \\
\text { Gen }\end{array}$ & $\begin{array}{c}\text { Steam } \\
\text { Flow }\end{array}$ & Gross HR & Total Fuel & $\begin{array}{c}\text { Total } \\
\text { Lignite }\end{array}$ & Total PRB & $\begin{array}{l}\text { Total } \\
\text { PRB }\end{array}$ & $\begin{array}{c}\text { Btu } \\
\text { Gain }\end{array}$ & $\begin{array}{c}\text { Econ } \\
\text { O2 }\end{array}$ & $\begin{array}{c}\text { Temp } \\
\text { A APH } \\
\text { Out }\end{array}$ & $\begin{array}{c}\text { Temp } \\
\text { B APH } \\
\text { Out }\end{array}$ & $\begin{array}{l}\text { Stack } \\
\text { Flow }\end{array}$ & Opacity & SO2 In & $\begin{array}{l}\text { SO2 } \\
\text { Out }\end{array}$ & NOx \\
\hline $\begin{array}{l}\text { Start Date } \\
\text { and Time }\end{array}$ & MW & $\begin{array}{c}\text { KLB/ } \\
\text { HR }\end{array}$ & Btu/kWhr & TON/HR & TON/HR & TON/HR & $\begin{array}{c}\% \\
\text { Weight }\end{array}$ & & $\%$ & DEGF & DEGF & KSCF & $\%$ & $\begin{array}{c}\text { Ib/MM } \\
\text { Btu }\end{array}$ & $\begin{array}{c}\text { Ib/MM } \\
\text { Btu }\end{array}$ & $\begin{array}{l}\mathbf{l b} / \mathbf{M} \\
\text { MBtu }\end{array}$ \\
\hline 7/18/07 16:00 & 801 & 5457 & 9603 & 537.4 & 382.2 & 155.2 & 28.9 & 1.13 & 3.1 & 303 & 295 & 2122 & 8.4 & 1.6 & 0.3 & 0.2 \\
\hline 7/18/07 17:00 & 800 & 5437 & 9645 & 536.9 & 381.9 & 155.1 & 28.9 & 1.13 & 3.1 & 303 & 295 & 2125 & 8.6 & 1.5 & 0.3 & 0.2 \\
\hline 7/18/07 18:00 & 800 & 5426 & 9632 & 535.3 & 380.6 & 154.6 & 28.9 & 1.13 & 3.0 & 303 & 296 & 2110 & 8.4 & 1.4 & 0.3 & 0.2 \\
\hline 7/18/07 19:00 & 800 & 5457 & 9663 & 532.2 & 378.5 & 153.7 & 28.9 & 1.14 & 3.0 & 305 & 296 & 2090 & 8.4 & 1.4 & 0.3 & 0.2 \\
\hline $7 / 18 / 07$ 20:00 & 799 & 5457 & 9676 & 528.6 & 375.9 & 152.7 & 28.9 & 1.14 & 3.0 & 301 & 293 & 2090 & 8.2 & 1.4 & 0.2 & 0.2 \\
\hline 7/18/07 21:00 & 798 & 5470 & 9651 & 526.7 & 374.5 & 152.2 & 28.9 & 1.15 & 2.9 & 301 & 288 & 2106 & 8.2 & 1.4 & 0.2 & 0.2 \\
\hline 7/18/07 22:00 & 797 & 5472 & 9759 & 529.8 & 377.1 & 152.8 & 28.8 & 1.15 & 2.9 & 300 & 289 & 2105 & 8.0 & 1.4 & 0.2 & 0.2 \\
\hline 7/18/07 23:00 & 801 & 5426 & 9645 & 530.3 & 379.5 & 150.8 & 28.4 & 1.15 & 2.9 & 300 & 290 & 2094 & 8.4 & 1.4 & 0.2 & 0.2 \\
\hline 7/19/07 0:00 & 801 & 5423 & 9592 & 527.2 & 376.8 & 150.4 & 28.5 & 1.15 & 2.9 & 301 & 292 & 2091 & 8.3 & 1.4 & 0.2 & 0.2 \\
\hline 7/19/07 1:00 & 798 & 5425 & 9646 & 530.7 & 376.6 & 154.2 & 29.0 & 1.14 & 3.0 & 302 & 291 & 2088 & 8.8 & 1.4 & 0.2 & 0.2 \\
\hline $7 / 19 / 072: 00$ & 798 & 5412 & 9669 & 537.1 & 381.1 & 156.0 & 29.0 & 1.14 & 2.9 & 301 & 291 & 2103 & 8.8 & 1.5 & 0.2 & 0.2 \\
\hline 7/19/07 3:00 & 803 & 5453 & 9610 & 532.9 & 378.1 & 154.8 & 29.0 & 1.14 & 2.9 & 300 & 291 & 2103 & 9.0 & 1.5 & 0.2 & 0.2 \\
\hline 7/19/07 4:00 & 799 & 5444 & 9562 & 528.3 & 373.9 & 154.3 & 29.2 & 1.14 & 3.0 & 300 & 290 & 2092 & 9.2 & 1.5 & 0.2 & 0.2 \\
\hline 7/19/07 5:00 & 799 & 5431 & 9637 & 530.4 & 373.8 & 156.6 & 29.5 & 1.15 & 2.9 & 298 & 289 & 2082 & 8.7 & 1.5 & 0.2 & 0.2 \\
\hline 7/19/07 6:00 & 801 & 5435 & 9503 & 525.3 & 370.2 & 155.1 & 29.5 & 1.15 & 2.9 & 298 & 288 & 2082 & 8.8 & 1.5 & 0.2 & 0.2 \\
\hline 7/19/07 7:00 & 798 & 5414 & 9589 & 526.1 & 370.7 & 155.4 & 29.5 & 1.15 & 2.9 & 298 & 289 & 2077 & 9.1 & 1.5 & 0.2 & 0.2 \\
\hline 7/19/07 8:00 & 798 & 5408 & 9642 & 533.8 & 376.2 & 157.6 & 29.5 & 1.14 & 2.9 & 299 & 290 & 2097 & 9.4 & 1.6 & 0.3 & 0.2 \\
\hline 7/19/07 9:00 & 800 & 5442 & 9657 & 536.3 & 378.0 & 158.3 & 29.5 & 1.14 & 2.9 & 300 & 292 & 2111 & 9.5 & 1.7 & 0.3 & 0.2 \\
\hline 7/19/07 10:00 & 799 & 5445 & 9616 & 534.6 & 376.8 & 157.8 & 29.5 & 1.14 & 2.9 & 301 & 293 & 2097 & 9.3 & 1.6 & 0.3 & 0.2 \\
\hline 7/19/07 11:00 & 800 & 5430 & 9642 & 535.4 & 377.4 & 158.0 & 29.5 & 1.13 & 2.9 & 302 & 294 & 2097 & 9.3 & 1.6 & 0.3 & 0.2 \\
\hline 7/19/07 12:00 & 799 & 5437 & 9693 & 538.4 & 379.5 & 158.9 & 29.5 & 1.13 & 2.9 & 305 & 295 & 2100 & 9.4 & 1.6 & 0.3 & 0.2 \\
\hline 7/19/07 13:00 & 800 & 5462 & 9677 & 538.8 & 379.8 & 159.0 & 29.5 & 1.13 & 2.9 & 305 & 296 & 2104 & 10.0 & 1.6 & 0.3 & 0.2 \\
\hline 7/19/07 14:00 & 801 & 5467 & 9616 & 534.2 & 376.5 & 157.7 & 29.5 & 1.14 & 3.0 & 301 & 293 & 2112 & 9.0 & 1.6 & 0.3 & 0.2 \\
\hline 7/19/07 15:00 & 801 & 5465 & 9590 & 528.9 & 372.8 & 156.2 & 29.5 & 1.14 & 2.9 & 299 & 286 & 2096 & 8.7 & 1.5 & 0.2 & 0.2 \\
\hline 7/19/07 16:00 & 799 & 5453 & 9614 & 525.2 & 370.0 & 155.1 & 29.5 & 1.15 & 2.8 & 298 & 285 & 2071 & 8.6 & 1.5 & 0.2 & 0.2 \\
\hline 7/19/07 17:00 & 797 & 5421 & 9650 & 530.8 & 374.0 & 156.7 & 29.5 & 1.15 & 2.8 & 298 & 288 & 2066 & 8.9 & 1.6 & 0.3 & 0.2 \\
\hline 7/19/07 18:00 & 801 & 5435 & 9664 & 533.9 & 377.0 & 156.9 & 29.4 & 1.14 & 2.7 & 300 & 289 & 2073 & 9.1 & 1.6 & 0.3 & 0.2 \\
\hline 7/19/07 19:00 & 803 & 5487 & 9600 & 525.2 & 373.4 & 151.7 & 28.9 & 1.15 & 2.7 & 300 & 289 & 2081 & 9.2 & 1.5 & 0.2 & 0.2 \\
\hline 7/19/07 20:00 & 799 & 5434 & 9583 & 520.8 & 370.3 & 150.5 & 28.9 & 1.16 & 2.7 & 300 & 288 & 2081 & 8.7 & 1.4 & 0.2 & 0.2 \\
\hline 7/19/07 21:00 & 798 & 5414 & 9619 & 525.8 & 373.9 & 151.9 & 28.9 & 1.16 & 2.7 & 300 & 289 & 2073 & 8.5 & 1.5 & 0.2 & 0.2 \\
\hline $7 / 19 / 07$ 22:00 & 798 & 5479 & 9670 & 528.5 & 375.8 & 152.7 & 28.9 & 1.15 & 2.7 & 301 & 289 & 2078 & 8.3 & 1.5 & 0.2 & 0.2 \\
\hline
\end{tabular}




\begin{tabular}{|c|c|c|c|c|c|c|c|c|c|c|c|c|c|c|c|c|}
\hline Date and & $\begin{array}{c}\text { Gross } \\
\text { Gen }\end{array}$ & $\begin{array}{c}\text { Steam } \\
\text { Flow }\end{array}$ & Gross HR & Total Fuel & $\begin{array}{c}\text { Total } \\
\text { Lignite }\end{array}$ & Total PRB & $\begin{array}{l}\text { Total } \\
\text { PRB }\end{array}$ & $\begin{array}{c}\text { Btu } \\
\text { Gain }\end{array}$ & $\begin{array}{c}\text { Econ } \\
\text { O2 }\end{array}$ & $\begin{array}{c}\text { Temp } \\
\text { A APH } \\
\text { Out }\end{array}$ & $\begin{array}{c}\text { Temp } \\
\text { B APH } \\
\text { Out }\end{array}$ & $\begin{array}{l}\text { Stack } \\
\text { Flow }\end{array}$ & Opacity & SO2 In & $\begin{array}{l}\text { SO2 } \\
\text { Out }\end{array}$ & NOx \\
\hline $\begin{array}{l}\text { Start Date } \\
\text { and Time }\end{array}$ & MW & $\begin{array}{c}\text { KLB/ } \\
\text { HR }\end{array}$ & Btu/kWhr & TON/HR & TON/HR & TON/HR & $\begin{array}{c}\% \\
\text { Weight }\end{array}$ & & $\%$ & DEGF & DEGF & KSCF & $\%$ & $\begin{array}{c}\text { Ib/MM } \\
\text { Btu }\end{array}$ & $\begin{array}{c}\text { Ib/MM } \\
\text { Btu }\end{array}$ & $\begin{array}{l}\mathbf{l b} / \mathbf{M} \\
\text { MBtu }\end{array}$ \\
\hline 7/19/07 23:00 & 800 & 5475 & 9689 & 529.4 & 376.5 & 152.9 & 28.9 & 1.15 & 2.7 & 298 & 288 & 2081 & 8.7 & 1.6 & 0.3 & 0.2 \\
\hline 7/20/07 0:00 & 799 & 5423 & 9654 & 530.7 & 377.3 & 153.4 & 28.9 & 1.15 & 2.7 & 298 & 288 & 2074 & 8.8 & 1.7 & 0.3 & 0.2 \\
\hline $7 / 20 / 07$ 1:00 & 800 & 5436 & 9722 & 539.5 & 382.1 & 157.4 & 29.2 & 1.14 & 2.7 & 300 & 289 & 2076 & 9.2 & 1.7 & 0.3 & 0.2 \\
\hline $7 / 20 / 07$ 2:00 & 805 & 5497 & 9621 & 532.8 & 377.2 & 155.6 & 29.2 & 1.14 & 2.6 & 299 & 289 & 2077 & 9.1 & 1.6 & 0.3 & 0.2 \\
\hline $7 / 20 / 07$ 3:00 & 802 & 5467 & 9591 & 524.1 & 371.0 & 153.1 & 29.2 & 1.15 & 2.7 & 297 & 289 & 2069 & 8.9 & 1.5 & 0.3 & 0.2 \\
\hline $7 / 20 / 074: 00$ & 801 & 5424 & 9558 & 520.5 & 368.4 & 152.1 & 29.2 & 1.16 & 2.7 & 298 & 290 & 2062 & 8.9 & 1.4 & 0.2 & 0.2 \\
\hline $7 / 20 / 075: 00$ & 801 & 5428 & 9569 & 518.5 & 366.9 & 151.5 & 29.2 & 1.16 & 2.7 & 300 & 291 & 2059 & 8.6 & 1.3 & 0.2 & 0.2 \\
\hline 7/20/07 6:00 & 801 & 5420 & 9554 & 519.2 & 367.5 & 151.7 & 29.2 & 1.16 & 2.7 & 300 & 292 & 2064 & 8.5 & 1.4 & 0.2 & 0.2 \\
\hline 7/20/07 7:00 & 800 & 5415 & 9609 & 521.8 & 369.4 & 152.5 & 29.2 & 1.16 & 2.7 & 301 & 292 & 2060 & 8.9 & 1.5 & 0.2 & 0.2 \\
\hline $7 / 20 / 078: 00$ & 801 & 5432 & 9628 & 523.8 & 370.7 & 153.0 & 29.2 & 1.16 & 2.7 & 301 & 293 & 2069 & 8.9 & 1.6 & 0.3 & 0.2 \\
\hline 7/20/07 9:00 & 802 & 5454 & 9619 & 520.7 & 368.6 & 152.2 & 29.2 & 1.16 & 2.6 & 302 & 295 & 2084 & 9.0 & 1.6 & 0.3 & 0.2 \\
\hline 7/20/07 10:00 & 801 & 5440 & 9602 & 518.9 & 367.2 & 151.7 & 29.2 & 1.17 & 2.7 & 303 & 296 & 2085 & 9.0 & 1.6 & 0.3 & 0.2 \\
\hline 7/20/07 11:00 & 800 & 5462 & 9614 & 519.4 & 367.6 & 151.8 & 29.2 & 1.17 & 2.7 & 303 & 296 & 2093 & 8.8 & 1.6 & 0.3 & 0.2 \\
\hline 7/20/07 12:00 & 801 & 5458 & 9649 & 518.9 & 367.3 & 151.6 & 29.2 & 1.17 & 2.7 & 299 & 281 & 2072 & 6.6 & 1.5 & 0.2 & 0.2 \\
\hline 7/20/07 13:00 & 799 & 5485 & 9684 & 521.1 & 368.9 & 152.3 & 29.2 & 1.17 & 2.7 & 298 & 283 & 2070 & 7.3 & 1.6 & 0.3 & 0.2 \\
\hline 7/20/07 14:00 & 803 & 5486 & 9734 & 521.2 & 368.9 & 152.3 & 29.2 & 1.17 & 2.7 & 297 & 285 & 2079 & 7.9 & 1.7 & 0.3 & 0.2 \\
\hline 7/20/07 15:00 & 804 & 5447 & 9645 & 517.4 & 366.2 & 151.2 & 29.2 & 1.18 & 2.7 & 297 & 287 & 2074 & 8.1 & 1.7 & 0.3 & 0.2 \\
\hline $7 / 20 / 07$ 16:00 & 801 & 5445 & 9631 & 516.4 & 365.4 & 150.9 & 29.2 & 1.18 & 2.6 & 298 & 288 & 2077 & 8.3 & 1.7 & 0.3 & 0.2 \\
\hline 7/20/07 17:00 & 803 & 5471 & 9619 & 515.0 & 364.5 & 150.5 & 29.2 & 1.18 & 2.7 & 300 & 289 & 2085 & 8.8 & 1.6 & 0.3 & 0.2 \\
\hline 7/20/07 18:00 & 801 & 5448 & 9646 & 513.2 & 363.2 & 150.0 & 29.2 & 1.18 & 2.7 & 299 & 289 & 2092 & 8.5 & 1.5 & 0.2 & 0.2 \\
\hline 7/20/07 19:00 & 799 & 5412 & 9685 & 522.5 & 369.8 & 152.7 & 29.2 & 1.18 & 2.7 & 300 & 290 & 2092 & 9.0 & 1.6 & 0.3 & 0.2 \\
\hline $7 / 20 / 07$ 20:00 & 803 & 5445 & 9684 & 528.4 & 374.1 & 154.4 & 29.2 & 1.16 & 2.6 & 301 & 292 & 2090 & 8.9 & 1.6 & 0.3 & 0.2 \\
\hline 7/20/07 21:00 & 805 & 5478 & 9634 & 521.9 & 369.4 & 152.5 & 29.2 & 1.16 & 2.6 & 302 & 293 & 2082 & 8.9 & 1.5 & 0.2 & 0.2 \\
\hline $7 / 20 / 07$ 22:00 & 805 & 5490 & 9488 & 507.5 & 359.2 & 148.4 & 29.2 & 1.18 & 2.6 & 300 & 292 & 2074 & 8.2 & 1.3 & 0.2 & 0.2 \\
\hline 7/20/07 23:00 & 799 & 5424 & 9524 & 502.7 & 355.7 & 147.0 & 29.2 & 1.19 & 2.6 & 298 & 289 & 2065 & 8.3 & 1.2 & 0.2 & 0.2 \\
\hline 7/21/07 0:00 & 799 & 5411 & 9567 & 503.4 & 356.2 & 147.2 & 29.2 & 1.20 & 2.6 & 300 & 289 & 2056 & 8.5 & 1.2 & 0.2 & 0.2 \\
\hline $7 / 21 / 07$ 1:00 & 797 & 5433 & 9701 & 512.3 & 362.5 & 149.8 & 29.2 & 1.19 & 2.6 & 301 & 289 & 2060 & 8.7 & 1.3 & 0.2 & 0.2 \\
\hline $7 / 21 / 072: 00$ & 801 & 5465 & 9769 & 522.0 & 369.5 & 152.5 & 29.2 & 1.19 & 2.5 & 298 & 289 & 2071 & 8.7 & 1.4 & 0.2 & 0.2 \\
\hline $7 / 21 / 073: 00$ & 805 & 5456 & 9722 & 523.2 & 370.3 & 152.8 & 29.2 & 1.17 & 2.5 & 299 & 289 & 2073 & 8.7 & 1.4 & 0.2 & 0.2 \\
\hline $7 / 21 / 074: 00$ & 804 & 5445 & 9653 & 521.2 & 368.9 & 152.3 & 29.2 & 1.17 & 2.5 & 300 & 290 & 2073 & 8.7 & 1.4 & 0.2 & 0.2 \\
\hline $7 / 21 / 075: 00$ & 804 & 5436 & 9579 & 516.4 & 365.5 & 150.9 & 29.2 & 1.17 & 2.5 & 300 & 291 & 2074 & 8.3 & 1.3 & 0.2 & 0.2 \\
\hline
\end{tabular}




\begin{tabular}{|c|c|c|c|c|c|c|c|c|c|c|c|c|c|c|c|c|}
\hline Date and & $\begin{array}{c}\text { Gross } \\
\text { Gen }\end{array}$ & $\begin{array}{l}\text { Steam } \\
\text { Flow }\end{array}$ & Gross HR & Total Fuel & $\begin{array}{c}\text { Total } \\
\text { Lignite }\end{array}$ & Total PRB & $\begin{array}{l}\text { Total } \\
\text { PRB }\end{array}$ & $\begin{array}{c}\text { Btu } \\
\text { Gain }\end{array}$ & $\begin{array}{c}\text { Econ } \\
\text { O2 }\end{array}$ & $\begin{array}{c}\text { Temp } \\
\text { A APH } \\
\text { Out }\end{array}$ & $\begin{array}{c}\text { Temp } \\
\text { B APH } \\
\text { Out }\end{array}$ & $\begin{array}{l}\text { Stack } \\
\text { Flow }\end{array}$ & Opacity & SO2 In & $\begin{array}{l}\text { SO2 } \\
\text { Out }\end{array}$ & NOx \\
\hline $\begin{array}{l}\text { Start Date } \\
\text { and Time }\end{array}$ & MW & $\begin{array}{c}\text { KLB/ } \\
\text { HR }\end{array}$ & Btu/kWhr & TON/HR & TON/HR & TON/HR & $\begin{array}{c}\% \\
\text { Weight }\end{array}$ & & $\%$ & DEGF & DEGF & KSCF & $\%$ & $\begin{array}{c}\text { Ib/MM } \\
\text { Btu }\end{array}$ & $\begin{array}{c}\text { Ib/MM } \\
\text { Btu }\end{array}$ & $\begin{array}{l}\mathbf{l b} / \mathbf{M} \\
\text { MBtu }\end{array}$ \\
\hline 7/21/07 6:00 & 799 & 5394 & 9607 & 519.9 & 368.0 & 151.9 & 29.2 & 1.17 & 2.6 & 301 & 292 & 2072 & 8.6 & 1.4 & 0.2 & 0.2 \\
\hline 7/21/07 7:00 & 799 & 5406 & 9743 & 533.1 & 377.4 & 155.7 & 29.2 & 1.16 & 2.5 & 301 & 292 & 2074 & 9.1 & 1.6 & 0.3 & 0.2 \\
\hline $7 / 21 / 078: 00$ & 803 & 5453 & 9666 & 539.3 & 381.9 & 157.5 & 29.2 & 1.14 & 2.5 & 301 & 293 & 2084 & 8.9 & 1.6 & 0.3 & 0.2 \\
\hline $7 / 21 / 07$ 9:00 & 804 & 5477 & 9754 & 539.9 & 382.3 & 157.6 & 29.2 & 1.14 & 2.5 & 301 & 294 & 2091 & 8.7 & 1.5 & 0.2 & 0.2 \\
\hline $7 / 21 / 07$ 10:00 & 804 & 5476 & 9613 & 536.9 & 380.1 & 156.8 & 29.2 & 1.14 & 2.5 & 301 & 296 & 2097 & 8.8 & 1.5 & 0.2 & 0.2 \\
\hline 7/21/07 11:00 & 802 & 5491 & 9662 & 536.0 & 379.5 & 156.5 & 29.2 & 1.14 & 2.6 & 301 & 295 & 2103 & 9.0 & 1.5 & 0.3 & 0.2 \\
\hline 7/21/07 12:00 & 803 & 5500 & 9684 & 532.5 & 377.0 & 155.5 & 29.2 & 1.15 & 2.5 & 300 & 295 & 2100 & 9.0 & 1.5 & 0.3 & 0.2 \\
\hline 7/21/07 13:00 & 802 & 5493 & 9678 & 530.5 & 375.6 & 154.9 & 29.2 & 1.15 & 2.6 & 301 & 295 & 2091 & 9.1 & 1.5 & 0.2 & 0.2 \\
\hline $7 / 21 / 07$ 14:00 & 803 & 5473 & 9646 & 530.8 & 375.8 & 155.0 & 29.2 & 1.15 & 2.6 & 301 & 296 & 2096 & 9.4 & 1.5 & 0.3 & 0.2 \\
\hline $7 / 21 / 07$ 15:00 & 804 & 5494 & 9608 & 527.2 & 373.2 & 154.0 & 29.2 & 1.16 & 2.6 & 303 & 296 & 2102 & 9.7 & 1.5 & 0.2 & 0.2 \\
\hline $7 / 21 / 07$ 16:00 & 803 & 5485 & 9527 & 520.6 & 368.5 & 152.1 & 29.2 & 1.16 & 2.5 & 304 & 297 & 2096 & 9.5 & 1.4 & 0.2 & 0.2 \\
\hline 7/21/07 17:00 & 800 & 5473 & 9630 & 519.2 & 367.5 & 151.7 & 29.2 & 1.17 & 2.6 & 304 & 298 & 2084 & 9.4 & 1.4 & 0.2 & 0.2 \\
\hline 7/21/07 18:00 & 799 & 5445 & 9675 & 524.7 & 371.5 & 153.3 & 29.2 & 1.17 & 2.5 & 302 & 296 & 2080 & 9.1 & 1.5 & 0.3 & 0.2 \\
\hline 7/21/07 19:00 & 801 & 5451 & 9765 & 533.8 & 378.0 & 155.8 & 29.2 & 1.16 & 2.5 & 307 & 295 & 2083 & 9.6 & 1.6 & 0.3 & 0.2 \\
\hline 7/21/07 20:00 & 803 & 5508 & 9749 & 536.3 & 379.7 & 156.6 & 29.2 & 1.15 & 2.6 & 303 & 295 & 2079 & 9.8 & 1.6 & 0.3 & 0.2 \\
\hline 7/21/07 21:00 & 807 & 5485 & 9648 & 530.0 & 375.2 & 154.8 & 29.2 & 1.15 & 2.5 & 300 & 294 & 2073 & 9.5 & 1.5 & 0.3 & 0.2 \\
\hline $7 / 21 / 0722: 00$ & 803 & 5448 & 9606 & 525.6 & 372.0 & 153.6 & 29.2 & 1.15 & 2.5 & 302 & 294 & 2080 & 9.2 & 1.4 & 0.2 & 0.2 \\
\hline $7 / 21 / 07$ 23:00 & 803 & 5458 & 9608 & 525.2 & 371.8 & 153.4 & 29.2 & 1.16 & 2.5 & 303 & 295 & 2078 & 9.4 & 1.4 & 0.2 & 0.2 \\
\hline 7/22/07 0:00 & 805 & 5474 & 9594 & 523.1 & 370.3 & 152.8 & 29.2 & 1.16 & 2.6 & 305 & 297 & 2092 & 9.2 & 1.4 & 0.2 & 0.2 \\
\hline 7/22/07 1:00 & 857 & 5925 & 9912 & 578.8 & 421.5 & 157.3 & 27.2 & 1.16 & 2.5 & 310 & 302 & 2194 & 9.9 & 1.4 & 0.2 & 0.2 \\
\hline $7 / 22 / 07$ 2:00 & 888 & 6103 & 9865 & 602.3 & 444.6 & 157.7 & 26.2 & 1.15 & 2.5 & 309 & 301 & 2254 & 10.1 & 1.6 & 0.3 & 0.2 \\
\hline 7/22/07 3:00 & 887 & 6099 & 9715 & 595.3 & 438.7 & 156.6 & 26.3 & 1.14 & 2.4 & 310 & 301 & 2229 & 10.0 & 1.6 & 0.3 & 0.2 \\
\hline $7 / 22 / 074: 00$ & 886 & 6073 & 9657 & 589.4 & 433.8 & 155.6 & 26.4 & 1.15 & 2.4 & 312 & 303 & 2222 & 10.4 & 1.6 & 0.3 & 0.2 \\
\hline $7 / 22 / 075: 00$ & 888 & 6094 & 9704 & 585.9 & 431.0 & 155.0 & 26.4 & 1.15 & 2.4 & 313 & 303 & 2239 & 9.7 & 1.5 & 0.3 & 0.2 \\
\hline 7/22/07 6:00 & 889 & 6088 & 9696 & 586.2 & 431.2 & 155.0 & 26.4 & 1.16 & 2.4 & 314 & 304 & 2241 & 9.8 & 1.5 & 0.3 & 0.2 \\
\hline 7/22/07 7:00 & 889 & 6113 & 9711 & 586.8 & 431.6 & 155.1 & 26.4 & 1.16 & 2.4 & 316 & 307 & 2239 & 9.6 & 1.5 & 0.3 & 0.2 \\
\hline $7 / 22 / 07$ 8:00 & 888 & 6127 & 9740 & 590.3 & 434.5 & 155.7 & 26.4 & 1.16 & 2.4 & 314 & 305 & 2234 & 9.9 & 1.5 & 0.2 & 0.2 \\
\hline 7/22/07 9:00 & 888 & 6134 & 9801 & 595.9 & 439.3 & 156.6 & 26.3 & 1.15 & 2.3 & 311 & 303 & 2245 & 9.9 & 1.6 & 0.3 & 0.2 \\
\hline 7/22/07 10:00 & 890 & 6110 & 9816 & 600.4 & 443.0 & 157.4 & 26.2 & 1.15 & 2.4 & 312 & 302 & 2243 & 9.8 & 1.7 & 0.3 & 0.2 \\
\hline $7 / 22 / 07$ 11:00 & 891 & 6135 & 9760 & 599.5 & 442.3 & 157.2 & 26.2 & 1.14 & 2.3 & 316 & 304 & 2252 & 10.0 & 1.7 & 0.3 & 0.2 \\
\hline $7 / 22 / 07$ 12:00 & 891 & 6151 & 9741 & 594.0 & 437.7 & 156.3 & 26.3 & 1.15 & 2.4 & 315 & 307 & 2252 & 10.0 & 1.6 & 0.3 & 0.2 \\
\hline
\end{tabular}




\begin{tabular}{|c|c|c|c|c|c|c|c|c|c|c|c|c|c|c|c|c|}
\hline Date and & $\begin{array}{c}\text { Gross } \\
\text { Gen }\end{array}$ & $\begin{array}{c}\text { Steam } \\
\text { Flow }\end{array}$ & Gross HR & Total Fuel & $\begin{array}{c}\text { Total } \\
\text { Lignite }\end{array}$ & Total PRB & $\begin{array}{l}\text { Total } \\
\text { PRB }\end{array}$ & $\begin{array}{c}\text { Btu } \\
\text { Gain }\end{array}$ & $\begin{array}{c}\text { Econ } \\
\text { O2 }\end{array}$ & $\begin{array}{c}\text { Temp } \\
\text { A APH } \\
\text { Out }\end{array}$ & $\begin{array}{c}\text { Temp } \\
\text { B APH } \\
\text { Out }\end{array}$ & $\begin{array}{l}\text { Stack } \\
\text { Flow }\end{array}$ & Opacity & SO2 In & $\begin{array}{l}\text { SO2 } \\
\text { Out }\end{array}$ & NOx \\
\hline $\begin{array}{l}\text { Start Date } \\
\text { and Time }\end{array}$ & MW & $\begin{array}{c}\text { KLB/ } \\
\text { HR }\end{array}$ & Btu/kWhr & TON/HR & TON/HR & TON/HR & $\begin{array}{c}\% \\
\text { Weight }\end{array}$ & & $\%$ & DEGF & DEGF & KSCF & $\%$ & $\begin{array}{c}\text { Ib/MM } \\
\text { Btu }\end{array}$ & $\begin{array}{c}\text { Ib/MM } \\
\text { Btu }\end{array}$ & $\begin{array}{l}\mathbf{l b} / \mathbf{M} \\
\text { MBtu }\end{array}$ \\
\hline $7 / 22 / 07$ 13:00 & 882 & 6083 & 9737 & 588.5 & 433.2 & 155.3 & 26.4 & 1.15 & 2.4 & 315 & 307 & 2230 & 10.1 & 1.6 & 0.3 & 0.2 \\
\hline 7/22/07 14:00 & 880 & 6044 & 9818 & 595.7 & 439.0 & 156.7 & 26.3 & 1.14 & 2.4 & 319 & 309 & 2228 & 9.9 & 1.6 & 0.3 & 0.2 \\
\hline $7 / 22 / 07$ 15:00 & 888 & 6141 & 9809 & 605.3 & 446.7 & 158.7 & 26.2 & 1.14 & 2.3 & 321 & 311 & 2253 & 9.8 & 1.6 & 0.3 & 0.2 \\
\hline $7 / 22 / 07$ 16:00 & 890 & 6145 & 9782 & 601.9 & 443.9 & 158.0 & 26.2 & 1.14 & 2.3 & 318 & 311 & 2264 & 10.2 & 1.6 & 0.3 & 0.2 \\
\hline $7 / 22 / 07$ 17:00 & 886 & 6118 & 9772 & 599.7 & 442.2 & 157.5 & 26.3 & 1.14 & 2.4 & 317 & 309 & 2267 & 9.9 & 1.6 & 0.3 & 0.2 \\
\hline 7/22/07 18:00 & 881 & 6040 & 9807 & 601.1 & 443.3 & 157.8 & 26.2 & 1.13 & 2.3 & 317 & 311 & 2239 & 9.9 & 1.7 & 0.3 & 0.2 \\
\hline 7/22/07 19:00 & 886 & 6094 & 9746 & 601.2 & 444.8 & 156.4 & 26.0 & 1.13 & 2.3 & 320 & 311 & 2235 & 9.9 & 1.7 & 0.3 & 0.2 \\
\hline 7/22/07 20:00 & 885 & 6128 & 9656 & 588.7 & 435.5 & 153.2 & 26.0 & 1.14 & 2.3 & 321 & 310 & 2239 & 9.8 & 1.6 & 0.3 & 0.2 \\
\hline 7/22/07 21:00 & 880 & 6094 & 9724 & 582.2 & 429.7 & 152.6 & 26.2 & 1.16 & 2.3 & 319 & 310 & 2225 & 9.8 & 1.5 & 0.3 & 0.2 \\
\hline $7 / 22 / 0722: 00$ & 879 & 6055 & 9787 & 584.4 & 431.4 & 153.0 & 26.2 & 1.16 & 2.3 & 315 & 307 & 2221 & 9.8 & 1.6 & 0.3 & 0.2 \\
\hline $7 / 22 / 07$ 23:00 & 881 & 6030 & 9835 & 590.8 & 436.9 & 153.9 & 26.0 & 1.15 & 2.3 & 313 & 304 & 2233 & 10.2 & 1.6 & 0.3 & 0.2 \\
\hline 7/23/07 0:00 & 884 & 6046 & 9690 & 590.5 & 436.7 & 153.8 & 26.1 & 1.15 & 2.3 & 312 & 303 & 2234 & 10.0 & 1.7 & 0.3 & 0.2 \\
\hline 7/23/07 1:00 & 885 & 6075 & 9644 & 582.1 & 429.5 & 152.6 & 26.2 & 1.15 & 2.3 & 311 & 303 & 2233 & 9.9 & 1.6 & 0.2 & 0.2 \\
\hline 7/23/07 2:00 & 879 & 6020 & 9676 & 578.6 & 426.5 & 152.1 & 26.3 & 1.16 & 2.3 & 311 & 303 & 2227 & 9.9 & 1.5 & 0.2 & 0.2 \\
\hline 7/23/07 3:00 & 878 & 6017 & 9840 & 593.3 & 439.1 & 154.2 & 26.0 & 1.15 & 2.2 & 311 & 304 & 2229 & 10.2 & 1.7 & 0.3 & 0.2 \\
\hline 7/23/07 4:00 & 882 & 6098 & 9753 & 596.5 & 441.9 & 154.6 & 25.9 & 1.14 & 2.2 & 311 & 304 & 2236 & 10.1 & 1.8 & 0.3 & 0.2 \\
\hline $7 / 23 / 07$ 5:00 & 884 & 6070 & 9711 & 594.0 & 439.7 & 154.3 & 26.0 & 1.14 & 2.2 & 312 & 304 & 2231 & 9.6 & 1.8 & 0.3 & 0.2 \\
\hline $7 / 23 / 076: 00$ & 883 & 6069 & 9711 & 591.9 & 437.9 & 154.0 & 26.0 & 1.14 & 2.2 & 312 & 302 & 2215 & 9.3 & 1.8 & 0.3 & 0.2 \\
\hline 7/23/07 7:00 & 888 & 6125 & 9712 & 594.7 & 440.3 & 154.4 & 26.0 & 1.14 & 2.1 & 311 & 300 & 2212 & 9.4 & 1.8 & 0.3 & 0.2 \\
\hline 7/23/07 8:00 & 888 & 6092 & 9746 & 600.2 & 445.0 & 155.2 & 25.9 & 1.14 & 2.0 & 310 & 300 & 2209 & 10.0 & 1.8 & 0.3 & 0.2 \\
\hline 7/23/07 9:00 & 889 & 6097 & 9841 & 609.8 & 453.3 & 156.5 & 25.7 & 1.13 & 2.0 & 313 & 301 & 2212 & 9.7 & 2.0 & 0.4 & 0.2 \\
\hline 7/23/07 10:00 & 892 & 6137 & 9744 & 607.2 & 451.0 & 156.2 & 25.7 & 1.13 & 2.0 & 312 & 302 & 2211 & 10.1 & 1.9 & 0.3 & 0.2 \\
\hline 7/23/07 11:00 & 892 & 6126 & 9756 & 604.1 & 448.4 & 155.7 & 25.8 & 1.13 & 2.0 & 314 & 304 & 2214 & 10.0 & 1.9 & 0.3 & 0.2 \\
\hline $7 / 23 / 07$ 12:00 & 891 & 6106 & 9731 & 602.6 & 447.1 & 155.5 & 25.8 & 1.13 & 2.0 & 317 & 306 & 2216 & 10.0 & 1.9 & 0.3 & 0.2 \\
\hline 7/23/07 13:00 & 891 & 6114 & 9718 & 600.4 & 445.2 & 155.2 & 25.9 & 1.13 & 2.0 & 318 & 308 & 2206 & 9.9 & 1.9 & 0.4 & 0.2 \\
\hline 7/23/07 14:00 & 889 & 6123 & 9768 & 598.6 & 443.6 & 155.0 & 25.9 & 1.14 & 2.0 & 315 & 306 & 2203 & 9.3 & 1.8 & 0.3 & 0.2 \\
\hline 7/23/07 15:00 & 891 & 6104 & 9718 & 595.1 & 440.6 & 154.5 & 26.0 & 1.14 & 2.0 & 316 & 307 & 2202 & 9.4 & 1.8 & 0.3 & 0.2 \\
\hline 7/23/07 16:00 & 889 & 6106 & 9727 & 593.9 & 443.1 & 150.9 & 25.4 & 1.14 & 2.0 & 317 & 307 & 2214 & 9.7 & 1.7 & 0.3 & 0.2 \\
\hline 7/23/07 17:00 & 885 & 6144 & 9801 & 593.7 & 445.2 & 148.4 & 25.0 & 1.15 & 2.0 & 315 & 308 & 2207 & 9.7 & 1.7 & 0.3 & 0.2 \\
\hline 7/23/07 18:00 & 880 & 6063 & 9812 & 589.1 & 441.8 & 147.3 & 25.0 & 1.15 & 2.0 & 314 & 306 & 2199 & 9.4 & 1.7 & 0.3 & 0.2 \\
\hline $7 / 23 / 07$ 19:00 & 878 & 6086 & 9819 & 591.0 & 443.3 & 147.7 & 25.0 & 1.15 & 2.0 & 315 & 304 & 2194 & 9.4 & 1.7 & 0.3 & 0.2 \\
\hline
\end{tabular}




\begin{tabular}{|c|c|c|c|c|c|c|c|c|c|c|c|c|c|c|c|c|}
\hline Date and & $\begin{array}{c}\text { Gross } \\
\text { Gen }\end{array}$ & $\begin{array}{c}\text { Steam } \\
\text { Flow }\end{array}$ & Gross HR & Total Fuel & $\begin{array}{c}\text { Total } \\
\text { Lignite }\end{array}$ & Total PRB & $\begin{array}{l}\text { Total } \\
\text { PRB }\end{array}$ & $\begin{array}{c}\text { Btu } \\
\text { Gain }\end{array}$ & $\begin{array}{c}\text { Econ } \\
\text { O2 }\end{array}$ & $\begin{array}{c}\text { Temp } \\
\text { A APH } \\
\text { Out }\end{array}$ & $\begin{array}{c}\text { Temp } \\
\text { B APH } \\
\text { Out }\end{array}$ & $\begin{array}{l}\text { Stack } \\
\text { Flow }\end{array}$ & Opacity & SO2 In & $\begin{array}{l}\text { SO2 } \\
\text { Out }\end{array}$ & NOx \\
\hline $\begin{array}{l}\text { Start Date } \\
\text { and Time }\end{array}$ & MW & $\begin{array}{c}\text { KLB/ } \\
\text { HR }\end{array}$ & Btu/kWhr & TON/HR & TON/HR & TON/HR & $\begin{array}{c}\% \\
\text { Weight }\end{array}$ & & $\%$ & DEGF & DEGF & KSCF & $\%$ & $\begin{array}{c}\text { Ib/MM } \\
\text { Btu }\end{array}$ & $\begin{array}{c}\text { Ib/MM } \\
\text { Btu }\end{array}$ & $\begin{array}{l}\mathbf{l b} / \mathbf{M} \\
\text { MBtu }\end{array}$ \\
\hline $7 / 23 / 07$ 20:00 & 882 & 6031 & 9746 & 590.1 & 442.6 & 147.5 & 25.0 & 1.15 & 2.0 & 313 & 304 & 2179 & 9.4 & 1.8 & 0.3 & 0.2 \\
\hline 7/23/07 21:00 & 880 & 6038 & 9670 & 582.4 & 436.8 & 145.6 & 25.0 & 1.15 & 2.0 & 313 & 303 & 2180 & 9.2 & 1.8 & 0.3 & 0.2 \\
\hline $7 / 23 / 07$ 22:00 & 878 & 6013 & 9634 & 581.7 & 436.2 & 145.4 & 25.0 & 1.15 & 2.0 & 311 & 302 & 2180 & 8.9 & 1.9 & 0.4 & 0.2 \\
\hline 7/23/07 23:00 & 879 & 6009 & 9723 & 589.0 & 441.7 & 147.3 & 25.0 & 1.15 & 2.0 & 307 & 301 & 2182 & 9.6 & 2.1 & 0.4 & 0.2 \\
\hline $7 / 24 / 07$ 0:00 & 885 & 6057 & 9700 & 591.7 & 443.8 & 147.9 & 25.0 & 1.14 & 2.0 & 307 & 300 & 2189 & 9.6 & 2.2 & 0.4 & 0.2 \\
\hline $7 / 24 / 07$ 1:00 & 883 & 6060 & 9649 & 582.3 & 436.7 & 145.6 & 25.0 & 1.15 & 2.0 & 307 & 299 & 2187 & 9.7 & 2.2 & 0.4 & 0.2 \\
\hline 7/24/07 2:00 & 880 & 6024 & 9611 & 571.6 & 428.7 & 142.9 & 25.0 & 1.16 & 2.0 & 308 & 298 & 2179 & 9.8 & 2.0 & 0.4 & 0.2 \\
\hline 7/24/07 3:00 & 880 & 5991 & 9602 & 568.9 & 426.7 & 142.2 & 25.0 & 1.17 & 2.0 & 309 & 298 & 2166 & 9.5 & 1.8 & 0.3 & 0.2 \\
\hline $7 / 24 / 074: 00$ & 882 & 6007 & 9610 & 570.1 & 427.6 & 142.5 & 25.0 & 1.17 & 2.0 & 311 & 298 & 2173 & 9.3 & 1.8 & 0.3 & 0.2 \\
\hline $7 / 24 / 07$ 5:00 & 881 & 6016 & 9685 & 577.6 & 433.2 & 144.4 & 25.0 & 1.17 & 2.0 & 308 & 297 & 2177 & 8.6 & 1.9 & 0.3 & 0.2 \\
\hline $7 / 24 / 076: 00$ & 885 & 6082 & 9790 & 589.7 & 442.3 & 147.4 & 25.0 & 1.16 & 2.0 & 303 & 296 & 2190 & 8.3 & 2.1 & 0.4 & 0.2 \\
\hline $7 / 24 / 07$ 7:00 & 890 & 6072 & 9796 & 599.1 & 448.4 & 150.7 & 25.2 & 1.15 & 2.0 & 303 & 296 & 2188 & 8.2 & 2.2 & 0.4 & 0.2 \\
\hline 7/24/07 8:00 & 894 & 6068 & 9730 & 601.6 & 446.8 & 154.8 & 25.7 & 1.13 & 2.0 & 304 & 297 & 2195 & 8.2 & 2.1 & 0.4 & 0.2 \\
\hline 7/24/07 9:00 & 892 & 6099 & 9617 & 594.6 & 441.6 & 153.0 & 25.7 & 1.14 & 2.0 & 304 & 298 & 2203 & 8.1 & 1.9 & 0.3 & 0.2 \\
\hline 7/24/07 10:00 & 890 & 6059 & 9663 & 594.7 & 441.7 & 153.0 & 25.7 & 1.14 & 2.0 & 306 & 298 & 2199 & 7.7 & 1.8 & 0.3 & 0.2 \\
\hline 7/24/07 11:00 & 890 & 6079 & 9657 & 596.0 & 442.7 & 153.3 & 25.7 & 1.14 & 2.0 & 307 & 300 & 2184 & 8.1 & 1.7 & 0.3 & 0.2 \\
\hline 7/24/07 12:00 & 583 & 4211 & 7562 & 384.1 & 274.8 & 109.3 & 28.5 & 1.09 & 5.5 & 264 & 308 & 1871 & 11.1 & 1.6 & 0.2 & 0.3 \\
\hline $7 / 24 / 07$ 13:00 & 450 & 3120 & 7131 & 323.4 & 241.9 & 81.4 & 25.2 & 1.07 & 4.8 & 251 & 303 & 1634 & 7.4 & 1.6 & 0.2 & 0.2 \\
\hline 7/24/07 14:00 & 738 & 5007 & 9381 & 510.8 & 394.5 & 116.2 & 22.8 & 1.07 & 3.2 & 299 & 295 & 2040 & 7.5 & 1.8 & 0.3 & 0.2 \\
\hline 7/24/07 15:00 & 873 & 6097 & 9500 & 593.2 & 444.8 & 148.3 & 25.0 & 1.11 & 2.9 & 307 & 298 & 2259 & 8.0 & 2.0 & 0.4 & 0.2 \\
\hline $7 / 24 / 07$ 16:00 & 881 & 6047 & 9568 & 584.7 & 438.5 & 146.2 & 25.0 & 1.13 & 2.5 & 309 & 302 & 2233 & 7.6 & 2.1 & 0.4 & 0.2 \\
\hline 7/24/07 17:00 & 881 & 5997 & 9462 & 570.2 & 427.6 & 142.5 & 25.0 & 1.15 & 2.5 & 310 & 303 & 2224 & 8.1 & 2.1 & 0.4 & 0.2 \\
\hline 7/24/07 18:00 & 879 & 5965 & 9549 & 565.1 & 423.8 & 141.3 & 25.0 & 1.17 & 2.5 & 309 & 302 & 2208 & 8.4 & 2.1 & 0.4 & 0.2 \\
\hline 7/24/07 19:00 & 877 & 5946 & 9636 & 566.4 & 424.8 & 141.6 & 25.0 & 1.17 & 2.5 & 311 & 303 & 2199 & 8.4 & 2.1 & 0.4 & 0.2 \\
\hline 7/24/07 20:00 & 877 & 5949 & 9670 & 576.0 & 432.0 & 144.0 & 25.0 & 1.17 & 2.5 & 311 & 303 & 2213 & 8.8 & 2.1 & 0.4 & 0.2 \\
\hline 7/24/07 21:00 & 880 & 5983 & 9670 & 580.0 & 435.0 & 145.0 & 25.0 & 1.16 & 2.5 & 311 & 304 & 2218 & 8.5 & 2.0 & 0.4 & 0.2 \\
\hline 7/24/07 22:00 & 881 & 5987 & 9610 & 579.5 & 434.7 & 144.9 & 25.0 & 1.15 & 2.4 & 311 & 305 & 2224 & 8.3 & 1.8 & 0.3 & 0.2 \\
\hline $7 / 24 / 07$ 23:00 & 880 & 5978 & 9683 & 580.1 & 435.0 & 145.0 & 25.0 & 1.15 & 2.5 & 310 & 304 & 2217 & 8.8 & 1.9 & 0.3 & 0.2 \\
\hline $7 / 25 / 07$ 0:00 & 880 & 6001 & 9658 & 579.5 & 434.6 & 144.8 & 25.0 & 1.16 & 2.5 & 312 & 302 & 2222 & 8.8 & 2.1 & 0.4 & 0.2 \\
\hline $7 / 25 / 07$ 1:00 & 879 & 6016 & 9690 & 578.3 & 433.8 & 144.5 & 25.0 & 1.16 & 2.5 & 310 & 301 & 2223 & 9.6 & 2.2 & 0.4 & 0.2 \\
\hline $7 / 25 / 072: 00$ & 882 & 5983 & 9601 & 571.9 & 429.0 & 143.0 & 25.0 & 1.16 & 2.4 & 308 & 298 & 2213 & 9.7 & 2.2 & 0.4 & 0.2 \\
\hline
\end{tabular}




\begin{tabular}{|c|c|c|c|c|c|c|c|c|c|c|c|c|c|c|c|c|}
\hline Date and & $\begin{array}{c}\text { Gross } \\
\text { Gen }\end{array}$ & $\begin{array}{c}\text { Steam } \\
\text { Flow }\end{array}$ & Gross HR & Total Fuel & $\begin{array}{c}\text { Total } \\
\text { Lignite }\end{array}$ & Total PRB & $\begin{array}{l}\text { Total } \\
\text { PRB }\end{array}$ & $\begin{array}{c}\text { Btu } \\
\text { Gain }\end{array}$ & $\begin{array}{c}\text { Econ } \\
\text { O2 }\end{array}$ & $\begin{array}{c}\text { Temp } \\
\text { A APH } \\
\text { Out }\end{array}$ & $\begin{array}{c}\text { Temp } \\
\text { B APH } \\
\text { Out }\end{array}$ & $\begin{array}{l}\text { Stack } \\
\text { Flow }\end{array}$ & Opacity & SO2 In & $\begin{array}{l}\text { SO2 } \\
\text { Out }\end{array}$ & NOx \\
\hline $\begin{array}{l}\text { Start Date } \\
\text { and Time }\end{array}$ & MW & $\begin{array}{c}\text { KLB/ } \\
\text { HR }\end{array}$ & Btu/kWhr & TON/HR & TON/HR & TON/HR & $\begin{array}{c}\% \\
\text { Weight }\end{array}$ & & $\%$ & DEGF & DEGF & KSCF & $\%$ & $\begin{array}{c}\text { Ib/MM } \\
\text { Btu }\end{array}$ & $\begin{array}{c}\text { Ib/MM } \\
\text { Btu }\end{array}$ & $\begin{array}{l}\mathbf{l b} / \mathbf{M} \\
\text { MBtu }\end{array}$ \\
\hline 7/25/07 3:00 & 879 & 5956 & 9569 & 568.8 & 426.7 & 142.2 & 25.0 & 1.17 & 2.4 & 307 & 298 & 2210 & 9.8 & 2.1 & 0.4 & 0.2 \\
\hline 7/25/07 4:00 & 879 & 5961 & 9596 & 568.7 & 426.6 & 142.2 & 25.0 & 1.17 & 2.4 & 308 & 298 & 2210 & 10.0 & 2.1 & 0.4 & 0.2 \\
\hline $7 / 25 / 07$ 5:00 & 880 & 6019 & 9579 & 565.2 & 423.9 & 141.3 & 25.0 & 1.18 & 2.4 & 309 & 297 & 2209 & 9.7 & 2.1 & 0.4 & 0.2 \\
\hline $7 / 25 / 076: 00$ & 880 & 6004 & 9688 & 565.9 & 424.5 & 141.5 & 25.0 & 1.18 & 2.2 & 306 & 296 & 2186 & 10.0 & 2.0 & 0.4 & 0.2 \\
\hline $7 / 25 / 07$ 7:00 & 889 & 6025 & 9715 & 574.6 & 430.9 & 143.6 & 25.0 & 1.18 & 2.1 & 307 & 295 & 2186 & 10.6 & 2.1 & 0.4 & 0.2 \\
\hline $7 / 25 / 078: 00$ & 890 & 6031 & 9670 & 579.1 & 434.3 & 144.7 & 25.0 & 1.17 & 2.1 & 307 & 295 & 2177 & 10.1 & 2.2 & 0.4 & 0.2 \\
\hline 7/25/07 9:00 & 889 & 6052 & 9707 & 584.7 & 438.6 & 146.2 & 25.0 & 1.16 & 2.2 & 307 & 295 & 2200 & 9.7 & 2.3 & 0.4 & 0.2 \\
\hline 7/25/07 10:00 & 890 & 6085 & 9745 & 586.8 & 440.0 & 146.8 & 25.0 & 1.16 & 2.2 & 310 & 297 & 2196 & 9.7 & 2.2 & 0.4 & 0.2 \\
\hline 7/25/07 11:00 & 880 & 6087 & 9712 & 580.2 & 433.5 & 146.8 & 25.3 & 1.16 & 2.2 & 315 & 303 & 2201 & 9.9 & 2.0 & 0.4 & 0.2 \\
\hline 7/25/07 12:00 & 887 & 6070 & 9713 & 583.6 & 437.5 & 146.2 & 25.0 & 1.16 & 2.2 & 313 & 301 & 2204 & 9.8 & 2.0 & 0.4 & 0.2 \\
\hline $7 / 25 / 07$ 13:00 & 891 & 6096 & 9674 & 581.6 & 436.2 & 145.4 & 25.0 & 1.17 & 2.2 & 314 & 302 & 2194 & 10.0 & 2.0 & 0.4 & 0.2 \\
\hline 7/25/07 14:00 & 889 & 6105 & 9660 & 574.3 & 430.8 & 143.6 & 25.0 & 1.18 & 2.2 & 313 & 301 & 2199 & 10.1 & 1.9 & 0.4 & 0.2 \\
\hline 7/25/07 15:00 & 887 & 6081 & 9709 & 577.3 & 433.0 & 144.3 & 25.0 & 1.18 & 2.3 & 312 & 301 & 2201 & 9.9 & 1.9 & 0.4 & 0.2 \\
\hline 7/25/07 16:00 & 888 & 6084 & 9725 & 583.3 & 437.4 & 145.8 & 25.0 & 1.17 & 2.2 & 313 & 302 & 2204 & 10.0 & 1.9 & 0.4 & 0.2 \\
\hline 7/25/07 17:00 & 888 & 6129 & 9794 & 587.6 & 440.6 & 146.9 & 25.0 & 1.17 & 2.2 & 314 & 303 & 2215 & 10.1 & 1.9 & 0.4 & 0.2 \\
\hline 7/25/07 18:00 & 891 & 6110 & 9797 & 590.7 & 443.0 & 147.6 & 25.0 & 1.16 & 2.2 & 313 & 303 & 2217 & 10.2 & 1.9 & 0.4 & 0.2 \\
\hline 7/25/07 19:00 & 891 & 6091 & 9757 & 589.8 & 442.4 & 147.5 & 25.0 & 1.16 & 2.2 & 313 & 303 & 2216 & 10.2 & 2.0 & 0.4 & 0.2 \\
\hline $7 / 25 / 0720: 00$ & 890 & 6100 & 9732 & 591.0 & 443.2 & 147.8 & 25.0 & 1.15 & 2.2 & 313 & 303 & 2222 & 10.1 & 2.0 & 0.4 & 0.2 \\
\hline 7/25/07 21:00 & 890 & 6131 & 9761 & 589.6 & 442.2 & 147.4 & 25.0 & 1.16 & 2.2 & 311 & 299 & 2220 & 9.8 & 2.0 & 0.4 & 0.2 \\
\hline 7/25/07 22:00 & 891 & 6095 & 9699 & 590.2 & 442.7 & 147.6 & 25.0 & 1.15 & 2.2 & 310 & 297 & 2200 & 9.7 & 2.0 & 0.4 & 0.2 \\
\hline $7 / 25 / 07$ 23:00 & 889 & 6088 & 9785 & 597.3 & 448.0 & 149.3 & 25.0 & 1.15 & 2.2 & 309 & 295 & 2199 & 10.0 & 2.0 & 0.4 & 0.2 \\
\hline 7/26/07 0:00 & 885 & 6105 & 9943 & 607.6 & 455.7 & 151.9 & 25.0 & 1.14 & 2.2 & 307 & 294 & 2206 & 10.0 & 2.0 & 0.4 & 0.2 \\
\hline $7 / 26 / 07$ 1:00 & 886 & 6017 & 9853 & 615.7 & 461.8 & 153.9 & 25.0 & 1.12 & 2.2 & 307 & 295 & 2201 & 9.7 & 2.1 & 0.4 & 0.2 \\
\hline $7 / 26 / 072: 00$ & 886 & 6029 & 9736 & 615.7 & 461.8 & 153.9 & 25.0 & 1.10 & 2.2 & 307 & 295 & 2202 & 9.9 & 2.2 & 0.4 & 0.2 \\
\hline 7/26/07 3:00 & 885 & 6020 & 9548 & 601.3 & 451.0 & 150.3 & 25.0 & 1.11 & 2.2 & 307 & 295 & 2200 & 9.9 & 2.0 & 0.4 & 0.2 \\
\hline 7/26/07 4:00 & 885 & 6002 & 9594 & 599.9 & 449.9 & 150.0 & 25.0 & 1.11 & 2.2 & 308 & 296 & 2207 & 10.3 & 2.0 & 0.4 & 0.2 \\
\hline $7 / 26 / 075: 00$ & 885 & 6065 & 9636 & 603.7 & 452.8 & 150.9 & 25.0 & 1.12 & 2.2 & 310 & 297 & 2205 & 9.6 & 2.1 & 0.4 & 0.2 \\
\hline $7 / 26 / 076: 00$ & 885 & 6027 & 9674 & 601.3 & 451.0 & 150.3 & 25.0 & 1.12 & 2.1 & 307 & 295 & 2189 & 9.9 & 2.3 & 0.4 & 0.2 \\
\hline $7 / 26 / 07$ 7:00 & 886 & 6043 & 9695 & 606.7 & 455.0 & 151.7 & 25.0 & 1.11 & 2.1 & 306 & 295 & 2188 & 9.6 & 2.3 & 0.4 & 0.2 \\
\hline $7 / 26 / 078: 00$ & 887 & 6065 & 9722 & 614.4 & 460.8 & 153.6 & 25.0 & 1.11 & 2.1 & 305 & 294 & 2184 & 9.7 & 2.2 & 0.3 & 0.2 \\
\hline $7 / 26 / 07$ 9:00 & 890 & 6111 & 9714 & 613.7 & 460.2 & 153.4 & 25.0 & 1.11 & 2.0 & 306 & 295 & 2195 & 9.4 & 2.1 & 0.3 & 0.2 \\
\hline
\end{tabular}




\begin{tabular}{|c|c|c|c|c|c|c|c|c|c|c|c|c|c|c|c|c|}
\hline Date and & $\begin{array}{c}\text { Gross } \\
\text { Gen }\end{array}$ & $\begin{array}{c}\text { Steam } \\
\text { Flow }\end{array}$ & Gross HR & Total Fuel & $\begin{array}{c}\text { Total } \\
\text { Lignite }\end{array}$ & Total PRB & $\begin{array}{l}\text { Total } \\
\text { PRB } \\
\end{array}$ & $\begin{array}{c}\text { Btu } \\
\text { Gain }\end{array}$ & $\begin{array}{c}\text { Econ } \\
\text { O2 }\end{array}$ & $\begin{array}{c}\text { Temp } \\
\text { A APH } \\
\text { Out }\end{array}$ & $\begin{array}{c}\text { Temp } \\
\text { B APH } \\
\text { Out }\end{array}$ & $\begin{array}{l}\text { Stack } \\
\text { Flow }\end{array}$ & Opacity & SO2 In & $\begin{array}{l}\text { SO2 } \\
\text { Out }\end{array}$ & NOx \\
\hline $\begin{array}{l}\text { Start Date } \\
\text { and Time }\end{array}$ & MW & $\begin{array}{c}\text { KLB/ } \\
\text { HR }\end{array}$ & Btu/kWhr & TON/HR & TON/HR & TON/HR & $\begin{array}{c}\% \\
\text { Weight }\end{array}$ & & $\%$ & DEGF & DEGF & KSCF & $\%$ & $\begin{array}{c}\text { Ib/MM } \\
\text { Btu }\end{array}$ & $\begin{array}{c}\text { Ib/MM } \\
\text { Btu }\end{array}$ & $\begin{array}{l}\text { Ib/M } \\
\text { MBtu }\end{array}$ \\
\hline 7/26/07 10:00 & 884 & 6046 & 9633 & 600.4 & 450.1 & 150.3 & 25.0 & 1.12 & 2.1 & 307 & 296 & 2198 & 9.4 & 2.1 & 0.2 & 0.2 \\
\hline 7/26/07 11:00 & 880 & 5999 & 9696 & 599.3 & 448.9 & 150.4 & 25.1 & 1.12 & 2.1 & 309 & 298 & 2201 & 9.9 & 2.1 & 0.3 & 0.2 \\
\hline $7 / 26 / 07$ 12:00 & 886 & 6082 & 9716 & 607.5 & 455.4 & 152.0 & 25.0 & 1.12 & 2.1 & 310 & 299 & 2220 & 10.1 & 2.3 & 0.3 & 0.2 \\
\hline $7 / 26 / 07$ 13:00 & 886 & 6082 & 9832 & 620.5 & 465.8 & 154.7 & 24.9 & 1.11 & 2.1 & 311 & 301 & 2237 & 10.0 & 2.4 & 0.3 & 0.2 \\
\hline $7 / 26 / 07$ 14:00 & 889 & 6102 & 9860 & 625.3 & 469.7 & 155.6 & 24.9 & 1.10 & 2.1 & 311 & 302 & 2235 & 9.7 & 2.5 & 0.3 & 0.2 \\
\hline $7 / 26 / 07$ 15:00 & 886 & 6064 & 9740 & 619.6 & 465.1 & 154.4 & 24.9 & 1.09 & 2.1 & 311 & 301 & 2236 & 9.6 & 2.6 & 0.3 & 0.2 \\
\hline 7/26/07 16:00 & 886 & 6076 & 9711 & 620.6 & 466.0 & 154.6 & 24.9 & 1.09 & 2.1 & 308 & 297 & 2247 & 8.5 & 2.5 & 0.3 & 0.2 \\
\hline $7 / 26 / 07$ 17:00 & 885 & 6066 & 9697 & 620.9 & 466.2 & 154.7 & 24.9 & 1.09 & 2.1 & 306 & 289 & 2239 & 8.6 & 2.4 & 0.3 & 0.2 \\
\hline 7/26/07 18:00 & 891 & 6098 & 9664 & 618.2 & 464.0 & 154.2 & 24.9 & 1.10 & 2.0 & 307 & 291 & 2238 & 9.1 & 2.3 & 0.3 & 0.2 \\
\hline 7/26/07 19:00 & 890 & 6079 & 9609 & 614.5 & 461.1 & 153.4 & 25.0 & 1.10 & 2.1 & 305 & 281 & 2241 & 7.7 & 2.1 & 0.2 & 0.2 \\
\hline $7 / 26 / 07$ 20:00 & 890 & 6086 & 9658 & 611.2 & 458.5 & 152.8 & 25.0 & 1.11 & 2.1 & 304 & 286 & 2229 & 8.0 & 2.0 & 0.2 & 0.2 \\
\hline $7 / 26 / 07$ 21:00 & 889 & 6073 & 9638 & 610.4 & 457.8 & 152.6 & 25.0 & 1.11 & 2.0 & 304 & 288 & 2220 & 7.2 & 1.9 & 0.2 & 0.2 \\
\hline $7 / 26 / 07$ 22:00 & 889 & 6078 & 9710 & 610.3 & 457.7 & 152.6 & 25.0 & 1.11 & 2.1 & 305 & 291 & 2207 & 9.0 & 1.9 & 0.2 & 0.2 \\
\hline $7 / 26 / 07$ 23:00 & 890 & 6081 & 9684 & 609.3 & 456.9 & 152.4 & 25.0 & 1.11 & 2.1 & 307 & 294 & 2217 & 9.4 & 2.0 & 0.2 & 0.2 \\
\hline 7/27/07 0:00 & 889 & 6083 & 9657 & 606.5 & 454.7 & 151.8 & 25.0 & 1.12 & 2.1 & 309 & 297 & 2228 & 9.6 & 2.0 & 0.2 & 0.2 \\
\hline 7/27/07 1:00 & 886 & 6142 & 9676 & 605.1 & 453.6 & 151.5 & 25.0 & 1.12 & 2.1 & 309 & 296 & 2231 & 9.7 & 2.0 & 0.2 & 0.2 \\
\hline $7 / 27 / 072: 00$ & 890 & 6090 & 9777 & 607.0 & 455.1 & 151.9 & 25.0 & 1.13 & 2.1 & 307 & 295 & 2240 & 9.6 & 2.0 & 0.2 & 0.2 \\
\hline 7/27/07 3:00 & 892 & 6072 & 9633 & 607.3 & 455.3 & 151.9 & 25.0 & 1.12 & 2.2 & 307 & 296 & 2245 & 9.9 & 2.0 & 0.2 & 0.2 \\
\hline 7/27/07 4:00 & 888 & 6102 & 9687 & 606.2 & 454.5 & 151.7 & 25.0 & 1.12 & 2.2 & 309 & 296 & 2228 & 10.1 & 2.0 & 0.2 & 0.2 \\
\hline 7/27/07 5:00 & 891 & 6076 & 9742 & 607.4 & 455.5 & 152.0 & 25.0 & 1.12 & 2.1 & 308 & 296 & 2230 & 9.4 & 2.0 & 0.2 & 0.2 \\
\hline 7/27/07 6:00 & 891 & 6077 & 9692 & 606.5 & 454.7 & 151.8 & 25.0 & 1.12 & 2.1 & 310 & 297 & 2225 & 9.6 & 2.0 & 0.2 & 0.2 \\
\hline 7/27/07 7:00 & 889 & 6106 & 9693 & 604.8 & 453.4 & 151.5 & 25.0 & 1.12 & 2.2 & 308 & 297 & 2241 & 10.0 & 1.9 & 0.2 & 0.2 \\
\hline $7 / 27 / 07$ 8:00 & 889 & 6087 & 9688 & 606.6 & 454.8 & 151.8 & 25.0 & 1.12 & 2.2 & 304 & 296 & 2236 & 9.8 & 1.9 & 0.2 & 0.2 \\
\hline 7/27/07 9:00 & 889 & 6100 & 9702 & 610.5 & 457.9 & 152.6 & 25.0 & 1.12 & 2.1 & 305 & 297 & 2239 & 10.2 & 2.0 & 0.2 & 0.2 \\
\hline 7/27/07 10:00 & 892 & 6107 & 9728 & 609.1 & 456.8 & 152.3 & 25.0 & 1.12 & 2.1 & 307 & 298 & 2252 & 10.2 & 2.0 & 0.2 & 0.2 \\
\hline $7 / 27 / 07$ 11:00 & 891 & 6112 & 9668 & 605.7 & 454.0 & 151.7 & 25.0 & 1.12 & 2.2 & 307 & 301 & 2265 & 10.1 & 1.9 & 0.2 & 0.2 \\
\hline $7 / 27 / 07$ 12:00 & 888 & 6095 & 9739 & 607.6 & 455.6 & 152.0 & 25.0 & 1.12 & 2.1 & 310 & 303 & 2260 & 10.3 & 1.9 & 0.2 & 0.2 \\
\hline 7/27/07 13:00 & 888 & 6119 & 9830 & 612.3 & 459.5 & 152.9 & 25.0 & 1.12 & 2.2 & 312 & 305 & 2258 & 9.6 & 2.0 & 0.2 & 0.2 \\
\hline $7 / 27 / 07$ 14:00 & 889 & 6123 & 9823 & 614.2 & 461.1 & 153.1 & 24.9 & 1.11 & 2.1 & 312 & 306 & 2268 & 10.0 & 2.0 & 0.2 & 0.2 \\
\hline $7 / 27 / 07$ 15:00 & 845 & 5844 & 9881 & 589.6 & 497.8 & 91.8 & 15.6 & 1.11 & 2.3 & 319 & 309 & 2212 & 9.8 & 2.1 & 0.2 & 0.2 \\
\hline $7 / 27 / 07$ 16:00 & 801 & 5562 & 9928 & 565.3 & 565.3 & 0.0 & 0.0 & 1.10 & 2.5 & 317 & 312 & 2136 & 9.1 & 2.3 & 0.3 & 0.2 \\
\hline
\end{tabular}




\begin{tabular}{|c|c|c|c|c|c|c|c|c|c|c|c|c|c|c|c|c|}
\hline Date and & $\begin{array}{c}\text { Gross } \\
\text { Gen }\end{array}$ & $\begin{array}{c}\text { Steam } \\
\text { Flow }\end{array}$ & Gross HR & Total Fuel & $\begin{array}{c}\text { Total } \\
\text { Lignite }\end{array}$ & Total PRB & $\begin{array}{l}\text { Total } \\
\text { PRB }\end{array}$ & $\begin{array}{c}\text { Btu } \\
\text { Gain }\end{array}$ & $\begin{array}{c}\text { Econ } \\
\text { O2 }\end{array}$ & $\begin{array}{c}\text { Temp } \\
\text { A APH } \\
\text { Out }\end{array}$ & $\begin{array}{c}\text { Temp } \\
\text { B APH } \\
\text { Out }\end{array}$ & $\begin{array}{l}\text { Stack } \\
\text { Flow }\end{array}$ & Opacity & SO2 In & $\begin{array}{l}\text { SO2 } \\
\text { Out }\end{array}$ & NOx \\
\hline $\begin{array}{l}\text { Start Date } \\
\text { and Time }\end{array}$ & MW & $\begin{array}{c}\text { KLB/ } \\
\text { HR }\end{array}$ & Btu/kWhr & TON/HR & TON/HR & TON/HR & $\begin{array}{c}\% \\
\text { Weight }\end{array}$ & & $\%$ & DEGF & DEGF & KSCF & $\%$ & $\begin{array}{c}\text { Ib/MM } \\
\text { Btu }\end{array}$ & $\begin{array}{c}\text { Ib/MM } \\
\text { Btu }\end{array}$ & $\begin{array}{l}\mathbf{l b} / \mathbf{M} \\
\text { MBtu }\end{array}$ \\
\hline 7/27/07 17:00 & 802 & 5459 & 9728 & 564.8 & 564.8 & 0.0 & 0.0 & 1.09 & 2.5 & 304 & 291 & 2115 & 7.9 & 2.2 & 0.3 & 0.2 \\
\hline 7/27/07 18:00 & 802 & 5450 & 9660 & 557.9 & 557.9 & 0.0 & 0.0 & 1.09 & 2.5 & 307 & 296 & 2105 & 9.0 & 2.1 & 0.2 & 0.2 \\
\hline 7/27/07 19:00 & 785 & 5343 & 10078 & 588.1 & 550.5 & 37.6 & 6.4 & 1.07 & 2.6 & 311 & 303 & 2093 & 9.1 & 2.1 & 0.2 & 0.2 \\
\hline 7/27/07 20:00 & 800 & 5438 & 10051 & 615.2 & 567.2 & 47.9 & 7.8 & 1.01 & 2.2 & 314 & 307 & 2091 & 9.2 & 2.2 & 0.3 & 0.2 \\
\hline $7 / 27 / 0721: 00$ & 788 & 5407 & 9160 & 560.5 & 560.5 & 0.0 & 0.0 & 1.03 & 2.5 & 308 & 298 & 2079 & 8.9 & 2.1 & 0.2 & 0.2 \\
\hline $7 / 27 / 0722: 00$ & 795 & 5418 & 9554 & 574.3 & 545.3 & 29.0 & 5.1 & 1.05 & 2.6 & 308 & 298 & 2086 & 8.2 & 2.1 & 0.2 & 0.2 \\
\hline $7 / 27 / 07$ 23:00 & 879 & 5960 & 9618 & 630.6 & 552.3 & 78.2 & 12.4 & 1.05 & 2.5 & 307 & 301 & 2243 & 9.2 & 2.0 & 0.2 & 0.2 \\
\hline 7/28/07 0:00 & 888 & 6062 & 9639 & 632.1 & 553.1 & 79.0 & 12.5 & 1.06 & 2.5 & 305 & 301 & 2269 & 9.8 & 1.9 & 0.2 & 0.2 \\
\hline 7/28/07 1:00 & 887 & 6054 & 9681 & 636.1 & 556.6 & 79.5 & 12.5 & 1.06 & 2.5 & 303 & 300 & 2275 & 9.6 & 1.9 & 0.2 & 0.2 \\
\hline $7 / 28 / 07$ 2:00 & 848 & 5847 & 9783 & 618.9 & 566.3 & 52.6 & 8.5 & 1.06 & 2.5 & 307 & 299 & 2216 & 9.4 & 1.9 & 0.2 & 0.2 \\
\hline $7 / 28 / 07$ 3:00 & 786 & 5370 & 9859 & 586.9 & 586.9 & 0.0 & 0.0 & 1.05 & 2.5 & 301 & 294 & 2069 & 8.4 & 2.0 & 0.2 & 0.2 \\
\hline $7 / 28 / 074: 00$ & 795 & 5414 & 9751 & 595.4 & 592.5 & 2.9 & 0.5 & 1.03 & 2.5 & 308 & 299 & 2094 & 8.4 & 2.1 & 0.2 & 0.2 \\
\hline 7/28/07 5:00 & 863 & 5860 & 9623 & 634.1 & 575.5 & 58.6 & 9.2 & 1.03 & 2.4 & 306 & 299 & 2204 & 8.9 & 1.9 & 0.2 & 0.2 \\
\hline 7/28/07 6:00 & 885 & 6032 & 9486 & 634.5 & 563.2 & 71.4 & 11.2 & 1.04 & 2.5 & 305 & 298 & 2251 & 9.4 & 1.9 & 0.2 & 0.2 \\
\hline $7 / 28 / 07$ 7:00 & 886 & 6039 & 9599 & 632.2 & 568.7 & 63.5 & 10.0 & 1.06 & 2.5 & 305 & 297 & 2260 & 10.0 & 1.9 & 0.2 & 0.2 \\
\hline 7/28/07 8:00 & 888 & 6093 & 9568 & 628.4 & 567.2 & 61.1 & 9.7 & 1.07 & 2.5 & 305 & 296 & 2283 & 9.7 & 1.8 & 0.2 & 0.2 \\
\hline 7/28/07 9:00 & 866 & 5966 & 9623 & 610.5 & 557.8 & 52.7 & 8.6 & 1.08 & 2.5 & 310 & 301 & 2259 & 9.8 & 1.8 & 0.2 & 0.2 \\
\hline $7 / 28 / 07$ 10:00 & 887 & 6080 & 9654 & 621.6 & 570.7 & 50.9 & 8.2 & 1.09 & 2.5 & 306 & 305 & 2277 & 9.7 & 1.8 & 0.2 & 0.2 \\
\hline 7/28/07 11:00 & 889 & 6066 & 9663 & 623.3 & 572.4 & 50.9 & 8.2 & 1.09 & 2.5 & 307 & 304 & 2272 & 9.9 & 1.8 & 0.2 & 0.2 \\
\hline 7/28/07 12:00 & 888 & 6085 & 9766 & 630.2 & 579.3 & 50.9 & 8.1 & 1.08 & 2.5 & 309 & 306 & 2270 & 10.1 & 1.7 & 0.2 & 0.2 \\
\hline 7/28/07 13:00 & 891 & 6104 & 9677 & 628.3 & 577.3 & 50.9 & 8.1 & 1.08 & 2.5 & 311 & 306 & 2269 & 10.3 & 1.6 & 0.2 & 0.2 \\
\hline 7/28/07 14:00 & 889 & 6103 & 9683 & 625.8 & 574.9 & 51.0 & 8.1 & 1.09 & 2.5 & 313 & 307 & 2262 & 10.2 & 1.6 & 0.2 & 0.2 \\
\hline $7 / 28 / 07$ 15:00 & 889 & 6107 & 9711 & 627.6 & 576.7 & 50.9 & 8.1 & 1.08 & 2.5 & 315 & 309 & 2259 & 9.9 & 1.6 & 0.2 & 0.2 \\
\hline $7 / 28 / 07$ 16:00 & 847 & 5847 & 9821 & 607.5 & 576.4 & 31.2 & 5.1 & 1.08 & 2.4 & 318 & 309 & 2214 & 9.8 & 1.6 & 0.2 & 0.2 \\
\hline 7/28/07 17:00 & 889 & 6163 & 9766 & 626.4 & 575.6 & 50.8 & 8.1 & 1.08 & 2.5 & 317 & 307 & 2305 & 9.9 & 1.6 & 0.2 & 0.2 \\
\hline 7/28/07 18:00 & 891 & 6121 & 9597 & 615.1 & 564.3 & 50.8 & 8.3 & 1.10 & 2.5 & 317 & 308 & 2292 & 9.9 & 1.5 & 0.2 & 0.2 \\
\hline 7/28/07 19:00 & 890 & 6136 & 9580 & 600.7 & 534.1 & 66.6 & 11.1 & 1.12 & 2.5 & 317 & 311 & 2288 & 9.8 & 1.4 & 0.2 & 0.2 \\
\hline 7/28/07 20:00 & 884 & 6073 & 9693 & 598.5 & 496.8 & 101.8 & 17.0 & 1.13 & 2.5 & 318 & 312 & 2296 & 9.5 & 1.4 & 0.2 & 0.2 \\
\hline 7/28/07 21:00 & 883 & 6116 & 9817 & 605.0 & 503.2 & 101.8 & 16.8 & 1.13 & 2.5 & 317 & 310 & 2280 & 9.8 & 1.4 & 0.2 & 0.2 \\
\hline $7 / 28 / 0722: 00$ & 891 & 6101 & 9763 & 604.6 & 502.8 & 101.8 & 16.8 & 1.13 & 2.5 & 314 & 308 & 2282 & 9.8 & 1.4 & 0.2 & 0.2 \\
\hline $7 / 28 / 07$ 23:00 & 882 & 6070 & 9800 & 607.8 & 531.6 & 76.2 & 12.5 & 1.12 & 2.6 & 316 & 311 & 2277 & 10.1 & 1.5 & 0.2 & 0.2 \\
\hline
\end{tabular}




\begin{tabular}{|c|c|c|c|c|c|c|c|c|c|c|c|c|c|c|c|c|}
\hline Date and & $\begin{array}{c}\text { Gross } \\
\text { Gen }\end{array}$ & $\begin{array}{c}\text { Steam } \\
\text { Flow }\end{array}$ & Gross HR & Total Fuel & $\begin{array}{c}\text { Total } \\
\text { Lignite }\end{array}$ & Total PRB & $\begin{array}{l}\text { Total } \\
\text { PRB }\end{array}$ & $\begin{array}{c}\text { Btu } \\
\text { Gain }\end{array}$ & $\begin{array}{c}\text { Econ } \\
\text { O2 }\end{array}$ & $\begin{array}{c}\text { Temp } \\
\text { A APH } \\
\text { Out }\end{array}$ & $\begin{array}{c}\text { Temp } \\
\text { B APH } \\
\text { Out }\end{array}$ & $\begin{array}{l}\text { Stack } \\
\text { Flow }\end{array}$ & Opacity & SO2 In & $\begin{array}{l}\text { SO2 } \\
\text { Out }\end{array}$ & NOx \\
\hline $\begin{array}{l}\text { Start Date } \\
\text { and Time }\end{array}$ & MW & $\begin{array}{c}\text { KLB/ } \\
\text { HR }\end{array}$ & Btu/kWhr & TON/HR & TON/HR & TON/HR & $\begin{array}{c}\% \\
\text { Weight }\end{array}$ & & $\%$ & DEGF & DEGF & KSCF & $\%$ & $\begin{array}{c}\text { Ib/MM } \\
\text { Btu }\end{array}$ & $\begin{array}{c}\text { Ib/MM } \\
\text { Btu }\end{array}$ & $\begin{array}{l}\mathbf{l b} / \mathbf{M} \\
\text { MBtu }\end{array}$ \\
\hline 7/29/07 0:00 & 886 & 6086 & 9949 & 625.0 & 550.2 & 74.8 & 12.0 & 1.11 & 2.4 & 314 & 313 & 2276 & 10.0 & 1.5 & 0.2 & 0.2 \\
\hline 7/29/07 1:00 & 868 & 5962 & 9717 & 601.4 & 476.3 & 125.1 & 20.8 & 1.10 & 2.4 & 312 & 310 & 2247 & 9.7 & 1.5 & 0.2 & 0.2 \\
\hline $7 / 29 / 07$ 2:00 & 885 & 6100 & 9774 & 614.1 & 473.6 & 140.5 & 22.9 & 1.11 & 2.5 & 310 & 308 & 2282 & 9.9 & 1.5 & 0.2 & 0.2 \\
\hline $7 / 29 / 07$ 3:00 & 888 & 6039 & 9712 & 614.3 & 471.4 & 142.9 & 23.3 & 1.10 & 2.5 & 308 & 306 & 2268 & 10.3 & 1.5 & 0.2 & 0.2 \\
\hline $7 / 29 / 074: 00$ & 885 & 6038 & 9681 & 616.3 & 473.0 & 143.3 & 23.3 & 1.10 & 2.5 & 308 & 305 & 2271 & 10.3 & 1.5 & 0.2 & 0.2 \\
\hline $7 / 29 / 075: 00$ & 885 & 6056 & 9779 & 619.6 & 475.6 & 144.0 & 23.2 & 1.09 & 2.5 & 309 & 304 & 2265 & 9.8 & 1.5 & 0.2 & 0.2 \\
\hline 7/29/07 6:00 & 886 & 6037 & 9727 & 619.4 & 477.8 & 141.6 & 22.9 & 1.09 & 2.5 & 311 & 305 & 2273 & 9.9 & 1.5 & 0.2 & 0.2 \\
\hline 7/29/07 7:00 & 881 & 6049 & 9770 & 629.3 & 542.0 & 87.2 & 13.9 & 1.08 & 2.5 & 315 & 305 & 2260 & 9.5 & 1.5 & 0.2 & 0.2 \\
\hline $7 / 29 / 078: 00$ & 886 & 6071 & 9785 & 632.2 & 557.9 & 74.3 & 11.8 & 1.07 & 2.5 & 313 & 300 & 2278 & 9.9 & 1.6 & 0.2 & 0.2 \\
\hline 7/29/07 9:00 & 884 & 6088 & 9787 & 633.7 & 556.9 & 76.8 & 12.1 & 1.07 & 2.5 & 320 & 307 & 2288 & 9.7 & 1.6 & 0.2 & 0.2 \\
\hline $7 / 29 / 07$ 10:00 & 889 & 6088 & 9752 & 631.8 & 538.3 & 93.4 & 14.8 & 1.08 & 2.4 & 315 & 308 & 2285 & 9.9 & 1.6 & 0.2 & 0.2 \\
\hline 7/29/07 11:00 & 886 & 6105 & 9661 & 622.8 & 516.3 & 106.5 & 17.1 & 1.08 & 2.5 & 313 & 306 & 2272 & 10.3 & 1.5 & 0.2 & 0.2 \\
\hline 7/29/07 12:00 & 884 & 6080 & 9809 & 627.2 & 510.9 & 116.3 & 18.5 & 1.08 & 2.5 & 311 & 306 & 2274 & 10.0 & 1.6 & 0.2 & 0.2 \\
\hline 7/29/07 13:00 & 888 & 6114 & 9682 & 624.9 & 488.9 & 136.0 & 21.8 & 1.08 & 2.5 & 312 & 308 & 2276 & 10.1 & 1.6 & 0.2 & 0.2 \\
\hline 7/29/07 14:00 & 887 & 6050 & 9607 & 618.6 & 473.9 & 144.7 & 23.4 & 1.09 & 2.5 & 313 & 309 & 2275 & 9.9 & 1.5 & 0.2 & 0.2 \\
\hline 7/29/07 15:00 & 887 & 6069 & 9599 & 612.0 & 467.9 & 144.1 & 23.5 & 1.10 & 2.4 & 313 & 310 & 2275 & 9.6 & 1.5 & 0.2 & 0.2 \\
\hline 7/29/07 16:00 & 886 & 6063 & 9603 & 604.8 & 462.5 & 142.3 & 23.5 & 1.11 & 2.5 & 312 & 311 & 2287 & 9.9 & 1.5 & 0.2 & 0.2 \\
\hline 7/29/07 17:00 & 884 & 6101 & 9754 & 613.6 & 477.7 & 135.9 & 22.1 & 1.11 & 2.5 & 317 & 311 & 2299 & 10.1 & 1.5 & 0.2 & 0.2 \\
\hline 7/29/07 18:00 & 885 & 6120 & 9968 & 632.3 & 550.7 & 81.7 & 12.9 & 1.10 & 2.5 & 319 & 316 & 2302 & 9.8 & 1.6 & 0.2 & 0.2 \\
\hline 7/29/07 19:00 & 892 & 6135 & 9722 & 621.8 & 492.9 & 128.9 & 20.7 & 1.10 & 2.4 & 319 & 316 & 2296 & 9.5 & 1.5 & 0.2 & 0.2 \\
\hline 7/29/07 20:00 & 884 & 6073 & 9633 & 606.8 & 444.6 & 162.1 & 26.7 & 1.11 & 2.5 & 315 & 311 & 2294 & 9.6 & 1.5 & 0.2 & 0.2 \\
\hline 7/29/07 21:00 & 883 & 6059 & 9645 & 606.7 & 444.6 & 162.2 & 26.7 & 1.11 & 2.5 & 313 & 310 & 2286 & 9.8 & 1.6 & 0.2 & 0.2 \\
\hline 7/29/07 22:00 & 888 & 6132 & 9748 & 607.7 & 445.3 & 162.4 & 26.7 & 1.12 & 2.5 & 315 & 309 & 2274 & 9.6 & 1.6 & 0.2 & 0.2 \\
\hline $7 / 29 / 07$ 23:00 & 890 & 6144 & 9665 & 599.4 & 439.0 & 160.3 & 26.7 & 1.13 & 2.5 & 315 & 309 & 2282 & 10.1 & 1.5 & 0.2 & 0.2 \\
\hline 7/30/07 0:00 & 891 & 6108 & 9626 & 596.0 & 436.5 & 159.5 & 26.8 & 1.14 & 2.5 & 312 & 306 & 2288 & 10.2 & 1.5 & 0.2 & 0.2 \\
\hline 7/30/07 1:00 & 888 & 6089 & 9742 & 601.7 & 440.8 & 160.9 & 26.7 & 1.14 & 2.5 & 310 & 303 & 2290 & 10.1 & 1.6 & 0.2 & 0.2 \\
\hline 7/30/07 2:00 & 889 & 6125 & 9741 & 603.2 & 441.9 & 161.3 & 26.7 & 1.13 & 2.5 & 308 & 303 & 2270 & 10.1 & 1.6 & 0.2 & 0.2 \\
\hline 7/30/07 3:00 & 889 & 6118 & 9801 & 605.7 & 443.8 & 161.9 & 26.7 & 1.13 & 2.5 & 309 & 303 & 2281 & 10.1 & 1.6 & 0.2 & 0.2 \\
\hline $7 / 30 / 074: 00$ & 891 & 6107 & 9801 & 606.3 & 444.2 & 162.0 & 26.7 & 1.13 & 2.5 & 308 & 302 & 2280 & 10.2 & 1.6 & 0.2 & 0.2 \\
\hline 7/30/07 5:00 & 889 & 6102 & 9798 & 607.5 & 445.7 & 161.8 & 26.6 & 1.13 & 2.5 & 309 & 303 & 2275 & 10.0 & 1.6 & 0.2 & 0.2 \\
\hline $7 / 30 / 076: 00$ & 886 & 6112 & 9793 & 607.5 & 446.9 & 160.6 & 26.4 & 1.12 & 2.5 & 308 & 302 & 2263 & 10.1 & 1.7 & 0.2 & 0.2 \\
\hline
\end{tabular}




\begin{tabular}{|c|c|c|c|c|c|c|c|c|c|c|c|c|c|c|c|c|}
\hline Date and & $\begin{array}{c}\text { Gross } \\
\text { Gen }\end{array}$ & $\begin{array}{c}\text { Steam } \\
\text { Flow }\end{array}$ & Gross HR & Total Fuel & $\begin{array}{c}\text { Total } \\
\text { Lignite }\end{array}$ & Total PRB & $\begin{array}{l}\text { Total } \\
\text { PRB }\end{array}$ & $\begin{array}{c}\text { Btu } \\
\text { Gain }\end{array}$ & $\begin{array}{c}\text { Econ } \\
\text { O2 }\end{array}$ & $\begin{array}{c}\text { Temp } \\
\text { A APH } \\
\text { Out }\end{array}$ & $\begin{array}{c}\text { Temp } \\
\text { B APH } \\
\text { Out }\end{array}$ & $\begin{array}{l}\text { Stack } \\
\text { Flow }\end{array}$ & Opacity & SO2 In & $\begin{array}{l}\text { SO2 } \\
\text { Out }\end{array}$ & NOx \\
\hline $\begin{array}{l}\text { Start Date } \\
\text { and Time }\end{array}$ & MW & $\begin{array}{c}\text { KLB/ } \\
\text { HR }\end{array}$ & Btu/kWhr & TON/HR & TON/HR & TON/HR & $\begin{array}{c}\% \\
\text { Weight }\end{array}$ & & $\%$ & DEGF & DEGF & KSCF & $\%$ & $\begin{array}{c}\text { Ib/MM } \\
\text { Btu }\end{array}$ & $\begin{array}{c}\text { Ib/MM } \\
\text { Btu }\end{array}$ & $\begin{array}{l}\mathbf{l b} / \mathbf{M} \\
\text { MBtu }\end{array}$ \\
\hline 7/30/07 7:00 & 885 & 6057 & 9761 & 605.5 & 445.4 & 160.1 & 26.4 & 1.12 & 2.5 & 306 & 299 & 2266 & 10.6 & 1.7 & 0.2 & 0.2 \\
\hline 7/30/07 8:00 & 884 & 6086 & 9767 & 608.4 & 447.5 & 160.8 & 26.4 & 1.12 & 2.5 & 307 & 300 & 2263 & 10.1 & 1.7 & 0.2 & 0.2 \\
\hline 7/30/07 9:00 & 887 & 6089 & 9747 & 605.9 & 445.8 & 160.2 & 26.4 & 1.12 & 2.5 & 309 & 302 & 2285 & 10.1 & 1.8 & 0.2 & 0.2 \\
\hline 7/30/07 10:00 & 887 & 6072 & 9674 & 599.7 & 441.1 & 158.6 & 26.5 & 1.13 & 5.1 & 309 & 302 & 2282 & 10.2 & 1.8 & 0.2 & 0.2 \\
\hline 7/30/07 11:00 & 885 & 6076 & 9663 & 595.7 & 438.0 & 157.6 & 26.5 & 1.13 & 2.5 & 310 & 303 & 2270 & 10.0 & 1.7 & 0.2 & 0.2 \\
\hline $7 / 30 / 07$ 12:00 & 883 & 6124 & 9749 & 596.8 & 438.9 & 157.9 & 26.5 & 1.14 & 2.5 & 314 & 304 & 2264 & 10.3 & 1.6 & 0.2 & 0.2 \\
\hline 7/30/07 13:00 & 892 & 6095 & 9704 & 597.3 & 439.3 & 158.1 & 26.5 & 1.14 & 2.6 & 315 & 305 & 2289 & 10.0 & 1.6 & 0.2 & 0.2 \\
\hline 7/30/07 14:00 & 888 & 6088 & 9798 & 606.4 & 446.0 & 160.3 & 26.4 & 1.13 & 2.7 & 314 & 306 & 2294 & 10.2 & 1.6 & 0.2 & 0.2 \\
\hline $7 / 30 / 07$ 15:00 & 889 & 6098 & 9797 & 615.0 & 452.5 & 162.5 & 26.4 & 1.12 & 2.7 & 315 & 308 & 2297 & 10.1 & 1.6 & 0.2 & 0.2 \\
\hline 7/30/07 16:00 & 891 & 6098 & 9810 & 620.8 & 457.0 & 163.9 & 26.4 & 1.11 & 2.7 & 318 & 310 & 2302 & 10.1 & 1.6 & 0.2 & 0.2 \\
\hline 7/30/07 17:00 & 892 & 6138 & 9736 & 618.9 & 455.5 & 163.4 & 26.4 & 1.10 & 2.6 & 319 & 311 & 2317 & 9.9 & 1.6 & 0.2 & 0.2 \\
\hline 7/30/07 18:00 & 890 & 6102 & 9725 & 620.7 & 456.8 & 163.9 & 26.4 & 1.10 & 2.7 & 319 & 311 & 2315 & 9.9 & 1.6 & 0.2 & 0.2 \\
\hline 7/30/07 19:00 & 889 & 6108 & 9752 & 623.1 & 458.6 & 164.5 & 26.4 & 1.10 & 2.6 & 317 & 310 & 2312 & 10.1 & 1.6 & 0.2 & 0.2 \\
\hline 7/30/07 20:00 & 890 & 6093 & 9771 & 630.1 & 463.8 & 166.2 & 26.4 & 1.09 & 2.6 & 318 & 310 & 2324 & 10.1 & 1.7 & 0.2 & 0.2 \\
\hline 7/30/07 21:00 & 889 & 6132 & 9783 & 632.2 & 465.4 & 166.8 & 26.4 & 1.09 & 2.7 & 320 & 311 & 2312 & 9.9 & 1.7 & 0.2 & 0.2 \\
\hline 7/30/07 22:00 & 895 & 6131 & 9653 & 621.8 & 457.6 & 164.2 & 26.4 & 1.09 & 2.6 & 315 & 309 & 2309 & 9.7 & 1.7 & 0.2 & 0.2 \\
\hline 7/30/07 23:00 & 891 & 6102 & 9592 & 614.0 & 451.8 & 162.2 & 26.4 & 1.10 & 2.7 & 313 & 306 & 2311 & 9.9 & 1.7 & 0.2 & 0.2 \\
\hline $7 / 31 / 07$ 0:00 & 891 & 6089 & 9590 & 609.3 & 448.2 & 161.0 & 26.4 & 1.11 & 2.7 & 312 & 306 & 2303 & 10.2 & 1.7 & 0.2 & 0.2 \\
\hline 7/31/07 1:00 & 890 & 6115 & 9651 & 604.0 & 444.2 & 159.7 & 26.4 & 1.12 & 2.7 & 313 & 305 & 2308 & 9.8 & 1.7 & 0.2 & 0.2 \\
\hline 7/31/07 2:00 & 891 & 6084 & 9660 & 599.1 & 440.7 & 158.5 & 26.5 & 1.13 & 2.7 & 313 & 304 & 2316 & 9.8 & 1.6 & 0.2 & 0.2 \\
\hline $7 / 31 / 073: 00$ & 890 & 6086 & 9641 & 597.6 & 439.5 & 158.1 & 26.5 & 1.13 & 2.7 & 312 & 303 & 2308 & 10.1 & 1.6 & 0.2 & 0.2 \\
\hline $7 / 31 / 074: 00$ & 890 & 6089 & 9661 & 595.3 & 437.7 & 157.5 & 26.5 & 1.14 & 2.7 & 313 & 304 & 2316 & 10.0 & 1.6 & 0.2 & 0.2 \\
\hline $7 / 31 / 07$ 5:00 & 889 & 6088 & 9730 & 595.9 & 438.2 & 157.7 & 26.5 & 1.14 & 2.7 & 314 & 305 & 2311 & 9.7 & 1.5 & 0.2 & 0.2 \\
\hline $7 / 31 / 076: 00$ & 888 & 6108 & 9722 & 596.1 & 438.4 & 157.8 & 26.5 & 1.14 & 2.6 & 314 & 306 & 2301 & 10.1 & 1.6 & 0.2 & 0.2 \\
\hline 7/31/07 7:00 & 886 & 6121 & 9710 & 591.8 & 435.2 & 156.7 & 26.5 & 1.15 & 2.6 & 313 & 305 & 2300 & 10.7 & 1.6 & 0.2 & 0.2 \\
\hline 7/31/07 8:00 & 884 & 6093 & 9808 & 593.8 & 436.7 & 157.2 & 26.5 & 1.15 & 2.5 & 309 & 302 & 2299 & 10.2 & 1.6 & 0.2 & 0.2 \\
\hline 7/31/07 9:00 & 886 & 6103 & 9765 & 595.5 & 437.9 & 157.6 & 26.5 & 1.15 & 2.5 & 310 & 303 & 2291 & 10.2 & 1.5 & 0.2 & 0.2 \\
\hline 7/31/07 10:00 & 886 & 6116 & 9750 & 593.0 & 436.0 & 157.0 & 26.5 & 1.15 & 2.5 & 311 & 304 & 2288 & 10.2 & 1.5 & 0.2 & 0.2 \\
\hline 7/31/07 11:00 & 885 & 6116 & 9744 & 589.6 & 433.5 & 156.2 & 26.5 & 1.15 & 2.5 & 311 & 304 & 2289 & 10.4 & 1.4 & 0.2 & 0.2 \\
\hline 7/31/07 12:00 & 885 & 6096 & 9776 & 588.1 & 432.4 & 155.7 & 26.5 & 1.16 & 2.5 & 311 & 303 & 2294 & 10.5 & 1.5 & 0.2 & 0.2 \\
\hline $7 / 31 / 07$ 13:00 & 884 & 6067 & 9805 & 593.0 & 436.0 & 157.0 & 26.5 & 1.15 & 2.5 & 313 & 304 & 2306 & 10.5 & 1.5 & 0.2 & 0.2 \\
\hline
\end{tabular}




\begin{tabular}{|c|c|c|c|c|c|c|c|c|c|c|c|c|c|c|c|c|}
\hline Date and & $\begin{array}{c}\text { Gross } \\
\text { Gen }\end{array}$ & $\begin{array}{c}\text { Steam } \\
\text { Flow }\end{array}$ & Gross HR & Total Fuel & $\begin{array}{c}\text { Total } \\
\text { Lignite }\end{array}$ & Total PRB & $\begin{array}{l}\text { Total } \\
\text { PRB }\end{array}$ & $\begin{array}{c}\text { Btu } \\
\text { Gain }\end{array}$ & $\begin{array}{c}\text { Econ } \\
\text { O2 }\end{array}$ & $\begin{array}{c}\text { Temp } \\
\text { A APH } \\
\text { Out }\end{array}$ & $\begin{array}{c}\text { Temp } \\
\text { B APH } \\
\text { Out }\end{array}$ & $\begin{array}{l}\text { Stack } \\
\text { Flow }\end{array}$ & Opacity & SO2 In & $\begin{array}{l}\text { SO2 } \\
\text { Out }\end{array}$ & NOx \\
\hline $\begin{array}{l}\text { Start Date } \\
\text { and Time }\end{array}$ & MW & $\begin{array}{c}\text { KLB/ } \\
\text { HR }\end{array}$ & Btu/kWhr & TON/HR & TON/HR & TON/HR & $\begin{array}{c}\% \\
\text { Weight }\end{array}$ & & $\%$ & DEGF & DEGF & KSCF & $\%$ & $\begin{array}{c}\text { Ib/MM } \\
\text { Btu }\end{array}$ & $\begin{array}{c}\text { Ib/MM } \\
\text { Btu }\end{array}$ & $\begin{array}{l}\mathbf{l b} / \mathbf{M} \\
\text { MBtu }\end{array}$ \\
\hline $7 / 31 / 07$ 14:00 & 885 & 6086 & 9742 & 594.5 & 437.1 & 157.4 & 26.5 & 1.15 & 2.5 & 314 & 305 & 2304 & 10.5 & 1.5 & 0.2 & 0.2 \\
\hline 7/31/07 15:00 & 887 & 6057 & 9777 & 596.5 & 438.7 & 157.9 & 26.5 & 1.14 & 2.5 & 314 & 307 & 2300 & 10.4 & 1.4 & 0.2 & 0.2 \\
\hline $7 / 31 / 07$ 16:00 & 885 & 6057 & 9763 & 601.6 & 442.5 & 159.1 & 26.4 & 1.13 & 2.5 & 316 & 309 & 2302 & 10.4 & 1.5 & 0.2 & 0.2 \\
\hline 7/31/07 17:00 & 883 & 6090 & 9803 & 609.8 & 448.6 & 161.2 & 26.4 & 1.12 & 2.5 & 319 & 310 & 2294 & 10.4 & 1.5 & 0.2 & 0.2 \\
\hline 7/31/07 18:00 & 886 & 6086 & 9842 & 613.9 & 451.7 & 162.2 & 26.4 & 1.12 & 2.5 & 318 & 310 & 2292 & 10.5 & 1.5 & 0.2 & 0.2 \\
\hline 7/31/07 19:00 & 889 & 6108 & 9722 & 607.5 & 446.9 & 160.6 & 26.4 & 1.12 & 2.5 & 317 & 309 & 2295 & 10.5 & 1.6 & 0.2 & 0.2 \\
\hline 7/31/07 20:00 & 890 & 6114 & 9616 & 592.1 & 435.4 & 156.8 & 26.5 & 1.13 & 2.4 & 316 & 308 & 2290 & 10.2 & 1.6 & 0.2 & 0.2 \\
\hline 7/31/07 21:00 & 883 & 6085 & 9680 & 587.2 & 431.7 & 155.5 & 26.5 & 1.15 & 2.4 & 315 & 308 & 2273 & 10.4 & 1.7 & 0.2 & 0.2 \\
\hline 7/31/07 22:00 & 883 & 6068 & 9826 & 599.8 & 441.1 & 158.7 & 26.5 & 1.14 & 2.4 & 313 & 307 & 2280 & 10.2 & 2.0 & 0.2 & 0.2 \\
\hline 7/31/07 23:00 & 885 & 6131 & 9885 & 606.7 & 446.3 & 160.4 & 26.4 & 1.14 & 2.4 & 309 & 304 & 2288 & 10.1 & 2.3 & 0.3 & 0.2 \\
\hline $8 / 1 / 07$ 0:00 & 891 & 6137 & 9809 & 603.9 & 444.2 & 159.7 & 26.4 & 1.13 & 2.4 & 308 & 303 & 2301 & 10.0 & 2.2 & 0.2 & 0.2 \\
\hline $8 / 1 / 07$ 1:00 & 887 & 6136 & 9717 & 599.8 & 441.1 & 158.7 & 26.5 & 1.14 & 2.4 & 308 & 304 & 2286 & 10.2 & 2.1 & 0.2 & 0.2 \\
\hline $8 / 1 / 07$ 2:00 & 886 & 6060 & 9789 & 599.2 & 440.7 & 158.5 & 26.5 & 1.14 & 2.4 & 308 & 303 & 2274 & 10.2 & 2.0 & 0.2 & 0.2 \\
\hline 8/1/07 3:00 & 889 & 6102 & 9694 & 599.2 & 440.7 & 158.5 & 26.5 & 1.14 & 2.4 & 307 & 302 & 2282 & 10.0 & 2.0 & 0.2 & 0.2 \\
\hline 8/1/07 4:00 & 889 & 6088 & 9697 & 598.3 & 440.0 & 158.3 & 26.5 & 1.14 & 2.3 & 306 & 302 & 2283 & 10.2 & 1.8 & 0.2 & 0.2 \\
\hline $8 / 1 / 07$ 5:00 & 888 & 6101 & 9699 & 597.6 & 439.5 & 158.1 & 26.5 & 1.14 & 2.3 & 308 & 303 & 2271 & 9.7 & 1.8 & 0.2 & 0.2 \\
\hline $8 / 1 / 076: 00$ & 886 & 6069 & 9806 & 605.1 & 445.2 & 160.0 & 26.4 & 1.13 & 2.3 & 310 & 304 & 2264 & 9.9 & 1.9 & 0.2 & 0.2 \\
\hline $8 / 1 / 07$ 7:00 & 885 & 6118 & 9896 & 616.0 & 453.2 & 162.7 & 26.4 & 1.12 & 2.3 & 310 & 304 & 2269 & 9.8 & 2.0 & 0.2 & 0.2 \\
\hline 8/1/07 8:00 & 890 & 6138 & 9815 & 616.8 & 453.9 & 163.0 & 26.4 & 1.11 & 2.2 & 310 & 302 & 2268 & 10.0 & 2.0 & 0.2 & 0.2 \\
\hline 8/1/07 9:00 & 889 & 6123 & 9760 & 614.0 & 451.8 & 162.2 & 26.4 & 1.11 & 2.3 & 310 & 302 & 2260 & 10.2 & 2.0 & 0.2 & 0.2 \\
\hline $8 / 1 / 07$ 10:00 & 889 & 6109 & 9665 & 606.6 & 446.2 & 160.4 & 26.4 & 1.12 & 2.3 & 308 & 303 & 2265 & 10.2 & 1.9 & 0.2 & 0.2 \\
\hline 8/1/07 11:00 & 887 & 6092 & 9698 & 602.3 & 443.0 & 159.3 & 26.4 & 1.12 & 2.3 & 307 & 304 & 2262 & 10.1 & 1.8 & 0.2 & 0.2 \\
\hline $8 / 1 / 07$ 12:00 & 886 & 6098 & 9750 & 602.7 & 443.3 & 159.4 & 26.4 & 1.13 & 2.3 & 309 & 306 & 2247 & 10.2 & 1.8 & 0.2 & 0.2 \\
\hline $8 / 1 / 07$ 13:00 & 881 & 6046 & 9768 & 599.9 & 465.0 & 134.9 & 22.5 & 1.13 & 2.3 & 316 & 310 & 2241 & 10.2 & 1.8 & 0.2 & 0.2 \\
\hline $8 / 1 / 07$ 14:00 & 877 & 6047 & 9843 & 612.3 & 530.4 & 81.9 & 13.4 & 1.11 & 2.2 & 318 & 304 & 2225 & 9.3 & 1.9 & 0.2 & 0.2 \\
\hline 8/1/07 15:00 & 885 & 6084 & 9729 & 610.2 & 528.9 & 81.4 & 13.3 & 1.11 & 2.3 & 310 & 289 & 2260 & 7.8 & 1.9 & 0.2 & 0.2 \\
\hline 8/1/07 16:00 & 881 & 6030 & 9706 & 610.1 & 528.7 & 81.3 & 13.3 & 1.11 & 2.3 & 310 & 296 & 2260 & 7.4 & 1.9 & 0.2 & 0.2 \\
\hline $8 / 1 / 07$ 17:00 & 880 & 6041 & 9776 & 613.5 & 531.7 & 81.8 & 13.3 & 1.10 & 2.3 & 311 & 295 & 2247 & 8.0 & 2.0 & 0.2 & 0.2 \\
\hline $8 / 1 / 07$ 18:00 & 881 & 6042 & 9762 & 616.5 & 534.3 & 82.1 & 13.3 & 1.10 & 2.3 & 310 & 293 & 2242 & 8.3 & 2.0 & 0.3 & 0.2 \\
\hline $8 / 1 / 07$ 19:00 & 883 & 6038 & 9732 & 614.9 & 532.9 & 81.9 & 13.3 & 1.10 & 2.3 & 310 & 296 & 2238 & 8.8 & 2.0 & 0.3 & 0.2 \\
\hline $8 / 1 / 07$ 20:00 & 882 & 6078 & 9752 & 618.6 & 536.2 & 82.4 & 13.3 & 1.10 & 2.3 & 310 & 297 & 2229 & 9.1 & 2.0 & 0.3 & 0.2 \\
\hline
\end{tabular}




\begin{tabular}{|c|c|c|c|c|c|c|c|c|c|c|c|c|c|c|c|c|}
\hline Date and & $\begin{array}{c}\text { Gross } \\
\text { Gen }\end{array}$ & $\begin{array}{c}\text { Steam } \\
\text { Flow }\end{array}$ & Gross HR & Total Fuel & $\begin{array}{c}\text { Total } \\
\text { Lignite }\end{array}$ & Total PRB & $\begin{array}{l}\text { Total } \\
\text { PRB } \\
\end{array}$ & $\begin{array}{c}\text { Btu } \\
\text { Gain }\end{array}$ & $\begin{array}{c}\text { Econ } \\
\text { O2 }\end{array}$ & $\begin{array}{c}\text { Temp } \\
\text { A APH } \\
\text { Out }\end{array}$ & $\begin{array}{c}\text { Temp } \\
\text { B APH } \\
\text { Out }\end{array}$ & $\begin{array}{l}\text { Stack } \\
\text { Flow }\end{array}$ & Opacity & SO2 In & $\begin{array}{l}\text { SO2 } \\
\text { Out }\end{array}$ & NOx \\
\hline $\begin{array}{l}\text { Start Date } \\
\text { and Time }\end{array}$ & MW & $\begin{array}{c}\text { KLB/ } \\
\text { HR }\end{array}$ & Btu/kWhr & TON/HR & TON/HR & TON/HR & $\begin{array}{c}\% \\
\text { Weight }\end{array}$ & & $\%$ & DEGF & DEGF & KSCF & $\%$ & $\begin{array}{c}\text { Ib/MM } \\
\text { Btu }\end{array}$ & $\begin{array}{c}\text { Ib/MM } \\
\text { Btu }\end{array}$ & $\begin{array}{l}\text { Ib/M } \\
\text { MBtu }\end{array}$ \\
\hline 8/1/07 21:00 & 884 & 6070 & 9779 & 620.7 & 538.0 & 82.7 & 13.3 & 1.09 & 2.3 & 309 & 296 & 2231 & 9.2 & 2.1 & 0.4 & 0.2 \\
\hline 8/1/07 22:00 & 885 & 6047 & 9671 & 614.8 & 532.9 & 81.9 & 13.3 & 1.10 & 2.3 & 308 & 296 & 2224 & 9.2 & 2.0 & 0.4 & 0.2 \\
\hline 8/1/07 23:00 & 885 & 6093 & 9650 & 612.3 & 530.7 & 81.6 & 13.3 & 1.10 & 2.3 & 309 & 297 & 2228 & 9.5 & 2.0 & 0.3 & 0.2 \\
\hline $8 / 2 / 07$ 0:00 & 885 & 6106 & 9697 & 607.7 & 526.6 & 81.0 & 13.3 & 1.11 & 2.3 & 308 & 297 & 2242 & 9.4 & 1.9 & 0.3 & 0.2 \\
\hline $8 / 2 / 07$ 1:00 & 886 & 6121 & 9698 & 604.6 & 523.9 & 80.6 & 13.3 & 1.12 & 2.3 & 309 & 298 & 2230 & 9.8 & 1.8 & 0.3 & 0.2 \\
\hline $8 / 2 / 072: 00$ & 882 & 6123 & 9727 & 596.9 & 517.2 & 79.7 & 13.3 & 1.13 & 2.3 & 308 & 298 & 2224 & 9.3 & 1.7 & 0.3 & 0.2 \\
\hline $8 / 2 / 07$ 3:00 & 884 & 6019 & 9681 & 589.5 & 510.8 & 78.8 & 13.4 & 1.14 & 2.3 & 308 & 297 & 2214 & 9.4 & 1.5 & 0.3 & 0.2 \\
\hline $8 / 2 / 074: 00$ & 884 & 6054 & 9632 & 589.9 & 511.1 & 78.8 & 13.4 & 1.14 & 2.3 & 309 & 299 & 2210 & 9.5 & 1.5 & 0.2 & 0.2 \\
\hline $8 / 2 / 075: 00$ & 885 & 6087 & 9757 & 598.6 & 519.3 & 79.3 & 13.2 & 1.14 & 2.3 & 311 & 300 & 2214 & 9.3 & 1.5 & 0.2 & 0.2 \\
\hline $8 / 2 / 076: 00$ & 880 & 6129 & 10006 & 613.3 & 552.2 & 61.2 & 10.0 & 1.13 & 2.3 & 312 & 302 & 2224 & 9.7 & 1.6 & 0.3 & 0.2 \\
\hline $8 / 2 / 07$ 7:00 & 869 & 6090 & 10039 & 612.0 & 544.1 & 67.9 & 11.1 & 1.12 & 2.2 & 313 & 304 & 2199 & 10.0 & 1.7 & 0.3 & 0.2 \\
\hline $8 / 2 / 078: 00$ & 885 & 6185 & 10001 & 628.0 & 536.8 & 91.2 & 14.5 & 1.11 & 2.3 & 313 & 303 & 2235 & 9.8 & 1.7 & 0.3 & 0.2 \\
\hline 8/2/07 9:00 & 889 & 6142 & 9896 & 629.2 & 523.1 & 106.1 & 16.9 & 1.10 & 2.2 & 313 & 303 & 2236 & 9.7 & 1.7 & 0.3 & 0.2 \\
\hline $8 / 2 / 07$ 10:00 & 887 & 6115 & 9627 & 606.0 & 497.6 & 108.4 & 17.9 & 1.11 & 2.2 & 310 & 303 & 2233 & 9.6 & 1.6 & 0.3 & 0.2 \\
\hline 8/2/07 11:00 & 885 & 6098 & 9594 & 594.7 & 483.7 & 111.0 & 18.7 & 1.13 & 2.3 & 310 & 305 & 2219 & 9.6 & 1.5 & 0.2 & 0.2 \\
\hline $8 / 2 / 0712: 00$ & 889 & 6153 & 9606 & 586.6 & 477.7 & 108.9 & 18.6 & 1.15 & 2.3 & 311 & 308 & 2220 & 9.7 & 1.4 & 0.2 & 0.2 \\
\hline 8/2/07 13:00 & 890 & 6159 & 9581 & 575.1 & 470.5 & 104.6 & 18.2 & 1.17 & 2.3 & 314 & 309 & 2224 & 9.7 & 1.3 & 0.2 & 0.2 \\
\hline $8 / 2 / 07$ 14:00 & 891 & 6171 & 9559 & 560.3 & 470.2 & 90.1 & 16.1 & 1.20 & 2.3 & 318 & 311 & 2222 & 9.8 & 1.1 & 0.2 & 0.2 \\
\hline $8 / 2 / 07$ 15:00 & 888 & 6165 & 9447 & 539.2 & 471.7 & 67.5 & 12.5 & 1.23 & 2.3 & 321 & 311 & 2205 & 9.4 & 0.9 & 0.1 & 0.2 \\
\hline $8 / 2 / 07$ 16:00 & 882 & 6101 & 9581 & 526.2 & 460.7 & 65.5 & 12.4 & 1.26 & 2.2 & 315 & 308 & 2179 & 9.3 & 0.8 & 0.1 & 0.2 \\
\hline 8/2/07 17:00 & 881 & 6099 & 9601 & 519.5 & 456.5 & 63.0 & 12.1 & 1.29 & 2.2 & 316 & 307 & 2187 & 9.6 & 0.8 & 0.1 & 0.2 \\
\hline 8/2/07 18:00 & 879 & 6081 & 9727 & 518.3 & 460.1 & 58.1 & 11.2 & 1.30 & 2.2 & 317 & 308 & 2187 & 9.5 & 0.7 & 0.1 & 0.1 \\
\hline $8 / 2 / 07$ 19:00 & 878 & 6077 & 9790 & 521.2 & 463.2 & 58.1 & 11.1 & 1.30 & 2.2 & 317 & 307 & 2181 & 9.3 & 0.7 & 0.1 & 0.2 \\
\hline $8 / 2 / 0720: 00$ & 879 & 6127 & 9784 & 520.9 & 462.9 & 58.0 & 11.1 & 1.31 & 2.2 & 312 & 303 & 2177 & 9.6 & 0.7 & 0.1 & 0.2 \\
\hline 8/2/07 21:00 & 882 & 6088 & 9825 & 521.0 & 463.0 & 58.0 & 11.1 & 1.31 & 2.2 & 311 & 302 & 2178 & 9.5 & 0.7 & 0.1 & 0.2 \\
\hline $8 / 2 / 07$ 22:00 & 883 & 6090 & 9848 & 520.2 & 462.2 & 58.0 & 11.1 & 1.31 & 2.1 & 313 & 303 & 2186 & 10.4 & 0.7 & 0.1 & 0.2 \\
\hline 8/2/07 23:00 & 882 & 6077 & 9822 & 519.6 & 461.6 & 58.0 & 11.2 & 1.31 & 2.2 & 315 & 305 & 2179 & 10.8 & 0.7 & 0.1 & 0.2 \\
\hline $8 / 3 / 07$ 0:00 & 882 & 6080 & 9791 & 521.1 & 463.1 & 58.0 & 11.1 & 1.30 & 2.2 & 317 & 307 & 2186 & 10.9 & 0.7 & 0.1 & 0.2 \\
\hline $8 / 3 / 07$ 1:00 & 882 & 6084 & 9793 & 522.4 & 464.4 & 58.0 & 11.1 & 1.30 & 2.2 & 318 & 308 & 2190 & 11.1 & 0.7 & 0.1 & 0.2 \\
\hline $8 / 3 / 072: 00$ & 883 & 6060 & 9761 & 520.2 & 462.2 & 58.0 & 11.1 & 1.30 & 2.2 & 316 & 307 & 2182 & 11.1 & 0.7 & 0.1 & 0.1 \\
\hline $8 / 3 / 07$ 3:00 & 881 & 6065 & 9755 & 521.6 & 463.6 & 58.0 & 11.1 & 1.30 & 2.2 & 314 & 306 & 2185 & 10.8 & 0.7 & 0.1 & 0.1 \\
\hline
\end{tabular}




\begin{tabular}{|c|c|c|c|c|c|c|c|c|c|c|c|c|c|c|c|c|}
\hline Date and & $\begin{array}{c}\text { Gross } \\
\text { Gen }\end{array}$ & $\begin{array}{c}\text { Steam } \\
\text { Flow }\end{array}$ & Gross HR & Total Fuel & $\begin{array}{c}\text { Total } \\
\text { Lignite }\end{array}$ & Total PRB & $\begin{array}{l}\text { Total } \\
\text { PRB }\end{array}$ & $\begin{array}{c}\text { Btu } \\
\text { Gain }\end{array}$ & $\begin{array}{c}\text { Econ } \\
\text { O2 }\end{array}$ & $\begin{array}{c}\text { Temp } \\
\text { A APH } \\
\text { Out }\end{array}$ & $\begin{array}{c}\text { Temp } \\
\text { B APH } \\
\text { Out }\end{array}$ & $\begin{array}{l}\text { Stack } \\
\text { Flow }\end{array}$ & Opacity & SO2 In & $\begin{array}{l}\text { SO2 } \\
\text { Out }\end{array}$ & NOx \\
\hline $\begin{array}{c}\text { Start Date } \\
\text { and Time }\end{array}$ & MW & $\begin{array}{c}\text { KLB/ } \\
\text { HR }\end{array}$ & Btu/kWhr & TON/HR & TON/HR & TON/HR & $\begin{array}{c}\% \\
\text { Weight }\end{array}$ & & $\%$ & DEGF & DEGF & KSCF & $\%$ & $\begin{array}{c}\text { Ib/MM } \\
\text { Btu }\end{array}$ & $\begin{array}{c}\text { Ib/MM } \\
\text { Btu }\end{array}$ & $\begin{array}{l}\mathbf{l b} / \mathbf{M} \\
\text { MBtu }\end{array}$ \\
\hline 8/3/07 4:00 & 882 & 6056 & 9738 & 522.7 & 464.7 & 58.0 & 11.1 & 1.30 & 2.2 & 312 & 305 & 2175 & 10.7 & 0.7 & 0.1 & 0.2 \\
\hline 8/3/07 5:00 & 882 & 6047 & 9740 & 524.5 & 466.5 & 58.0 & 11.1 & 1.29 & 2.1 & 316 & 306 & 2165 & 10.6 & 0.7 & 0.1 & 0.1 \\
\hline 8/3/07 6:00 & 883 & 6036 & 9716 & 525.4 & 467.4 & 58.0 & 11.0 & 1.29 & 2.2 & 317 & 307 & 2169 & 10.8 & 0.8 & 0.1 & 0.1 \\
\hline $8 / 3 / 07$ 7:00 & 881 & 6035 & 9728 & 526.0 & 468.0 & 58.0 & 11.0 & 1.28 & 2.2 & 317 & 304 & 2167 & 11.8 & 0.8 & 0.1 & 0.1 \\
\hline 8/3/07 8:00 & 880 & 6016 & 9860 & 540.2 & 482.2 & 58.0 & 10.7 & 1.27 & 2.2 & 313 & 302 & 2188 & 11.0 & 0.9 & 0.1 & 0.2 \\
\hline 8/3/07 9:00 & 887 & 6008 & 10013 & 567.7 & 509.8 & 57.9 & 10.2 & 1.23 & 2.1 & 314 & 303 & 2203 & 11.0 & 1.2 & 0.2 & 0.2 \\
\hline $8 / 3 / 07$ 10:00 & 891 & 6016 & 9933 & 589.2 & 531.2 & 58.0 & 9.8 & 1.19 & 2.1 & 316 & 305 & 2200 & 11.0 & 1.4 & 0.3 & 0.2 \\
\hline $8 / 3 / 07$ 11:00 & 886 & 6102 & 9995 & 607.5 & 531.7 & 75.9 & 12.5 & 1.15 & 2.2 & 316 & 305 & 2204 & 10.9 & 1.6 & 0.3 & 0.2 \\
\hline $8 / 3 / 07$ 12:00 & 884 & 6143 & 10019 & 621.3 & 539.1 & 82.2 & 13.2 & 1.13 & 2.2 & 317 & 306 & 2216 & 10.9 & 1.8 & 0.3 & 0.2 \\
\hline $8 / 3 / 07$ 13:00 & 887 & 6154 & 9917 & 622.7 & 541.0 & 81.7 & 13.1 & 1.11 & 2.1 & 317 & 308 & 2216 & 11.0 & 1.8 & 0.3 & 0.2 \\
\hline $8 / 3 / 07$ 14:00 & 883 & 6137 & 9793 & 613.9 & 532.9 & 81.0 & 13.2 & 1.11 & 2.2 & 317 & 309 & 2223 & 10.9 & 1.7 & 0.3 & 0.2 \\
\hline $8 / 3 / 07$ 15:00 & 883 & 6098 & 9746 & 605.5 & 524.7 & 80.8 & 13.3 & 1.12 & 2.2 & 317 & 308 & 2215 & 10.7 & 1.6 & 0.3 & 0.2 \\
\hline $8 / 3 / 07$ 16:00 & 880 & 6077 & 9758 & 600.9 & 520.4 & 80.5 & 13.4 & 1.12 & 2.2 & 317 & 309 & 2204 & 10.8 & 1.6 & 0.3 & 0.2 \\
\hline $8 / 3 / 07$ 17:00 & 881 & 6139 & 9814 & 604.2 & 523.1 & 81.1 & 13.4 & 1.13 & 2.2 & 319 & 309 & 2206 & 10.6 & 1.6 & 0.3 & 0.2 \\
\hline $8 / 3 / 07$ 18:00 & 885 & 6166 & 9824 & 605.7 & 524.1 & 81.6 & 13.5 & 1.13 & 2.2 & 320 & 309 & 2207 & 10.5 & 1.6 & 0.3 & 0.2 \\
\hline $8 / 3 / 07$ 19:00 & 885 & 6114 & 9844 & 604.7 & 522.6 & 82.1 & 13.6 & 1.14 & 2.2 & 316 & 308 & 2213 & 10.2 & 1.6 & 0.3 & 0.2 \\
\hline $8 / 3 / 0720: 00$ & 883 & 6129 & 9738 & 598.2 & 517.5 & 80.7 & 13.5 & 1.14 & 2.2 & 314 & 305 & 2210 & 10.1 & 1.6 & 0.3 & 0.2 \\
\hline $8 / 3 / 0721: 00$ & 882 & 6132 & 9781 & 591.3 & 511.6 & 79.7 & 13.5 & 1.15 & 2.2 & 314 & 304 & 2208 & 10.2 & 1.5 & 0.3 & 0.2 \\
\hline $8 / 3 / 07$ 22:00 & 882 & 6103 & 9775 & 589.6 & 510.2 & 79.5 & 13.5 & 1.15 & 2.2 & 314 & 302 & 2203 & 10.0 & 1.4 & 0.3 & 0.2 \\
\hline 8/3/07 23:00 & 880 & 6113 & 9784 & 590.9 & 509.8 & 81.1 & 13.7 & 1.15 & 2.2 & 312 & 301 & 2212 & 10.0 & 1.4 & 0.2 & 0.2 \\
\hline $8 / 4 / 07$ 0:00 & 881 & 6072 & 9851 & 600.6 & 517.0 & 83.6 & 13.9 & 1.15 & 2.3 & 312 & 300 & 2212 & 10.0 & 1.5 & 0.3 & 0.2 \\
\hline $8 / 4 / 07$ 1:00 & 881 & 6145 & 9860 & 601.5 & 518.6 & 83.0 & 13.8 & 1.14 & 2.3 & 313 & 299 & 2220 & 10.2 & 1.5 & 0.3 & 0.2 \\
\hline $8 / 4 / 07$ 2:00 & 886 & 6073 & 9757 & 597.4 & 515.1 & 82.3 & 13.8 & 1.14 & 2.3 & 310 & 298 & 2214 & 10.0 & 1.5 & 0.3 & 0.2 \\
\hline $8 / 4 / 07$ 3:00 & 883 & 6045 & 9751 & 598.0 & 515.6 & 82.4 & 13.8 & 1.13 & 2.3 & 311 & 297 & 2210 & 10.1 & 1.4 & 0.3 & 0.2 \\
\hline 8/4/07 4:00 & 882 & 6057 & 9753 & 598.6 & 515.8 & 82.8 & 13.8 & 1.13 & 2.3 & 311 & 298 & 2215 & 9.9 & 1.4 & 0.2 & 0.2 \\
\hline 8/4/07 5:00 & 882 & 6065 & 9721 & 597.2 & 514.3 & 82.9 & 13.9 & 1.13 & 2.3 & 310 & 298 & 2215 & 9.4 & 1.4 & 0.2 & 0.2 \\
\hline 8/4/07 6:00 & 883 & 6045 & 9695 & 593.6 & 511.1 & 82.4 & 13.9 & 1.14 & 2.3 & 310 & 298 & 2212 & 9.9 & 1.4 & 0.3 & 0.2 \\
\hline $8 / 4 / 07$ 7:00 & 880 & 6041 & 9624 & 588.5 & 506.8 & 81.7 & 13.9 & 1.14 & 2.3 & 309 & 298 & 2208 & 10.3 & 1.4 & 0.3 & 0.2 \\
\hline 8/4/07 8:00 & 882 & 6069 & 9637 & 584.0 & 503.0 & 81.1 & 13.9 & 1.15 & 2.3 & 309 & 297 & 2216 & 9.9 & 1.4 & 0.3 & 0.2 \\
\hline 8/4/07 9:00 & 880 & 6087 & 9716 & 583.3 & 502.4 & 81.0 & 13.9 & 1.16 & 2.3 & 310 & 298 & 2224 & 9.8 & 1.4 & 0.2 & 0.2 \\
\hline $8 / 4 / 07$ 10:00 & 884 & 6062 & 9757 & 587.6 & 506.0 & 81.6 & 13.9 & 1.16 & 2.3 & 312 & 300 & 2225 & 9.4 & 1.4 & 0.3 & 0.2 \\
\hline
\end{tabular}




\begin{tabular}{|c|c|c|c|c|c|c|c|c|c|c|c|c|c|c|c|c|}
\hline Date and & $\begin{array}{c}\text { Gross } \\
\text { Gen }\end{array}$ & $\begin{array}{c}\text { Steam } \\
\text { Flow }\end{array}$ & Gross HR & Total Fuel & $\begin{array}{c}\text { Total } \\
\text { Lignite }\end{array}$ & Total PRB & $\begin{array}{l}\text { Total } \\
\text { PRB }\end{array}$ & $\begin{array}{c}\text { Btu } \\
\text { Gain }\end{array}$ & $\begin{array}{c}\text { Econ } \\
\text { O2 }\end{array}$ & $\begin{array}{c}\text { Temp } \\
\text { A APH } \\
\text { Out }\end{array}$ & $\begin{array}{c}\text { Temp } \\
\text { B APH } \\
\text { Out }\end{array}$ & $\begin{array}{l}\text { Stack } \\
\text { Flow }\end{array}$ & Opacity & SO2 In & $\begin{array}{l}\text { SO2 } \\
\text { Out }\end{array}$ & NOx \\
\hline $\begin{array}{c}\text { Start Date } \\
\text { and Time }\end{array}$ & MW & $\begin{array}{c}\text { KLB/ } \\
\text { HR }\end{array}$ & Btu/kWhr & TON/HR & TON/HR & TON/HR & $\begin{array}{c}\% \\
\text { Weight }\end{array}$ & & $\%$ & DEGF & DEGF & KSCF & $\%$ & $\begin{array}{c}\text { Ib/MM } \\
\text { Btu }\end{array}$ & $\begin{array}{c}\text { Ib/MM } \\
\text { Btu }\end{array}$ & $\begin{array}{l}\mathbf{l b} / \mathbf{M} \\
\text { MBtu }\end{array}$ \\
\hline 8/4/07 11:00 & 883 & 6123 & 9744 & 587.2 & 505.7 & 81.5 & 13.9 & 1.16 & 2.3 & 310 & 302 & 2224 & 9.5 & 1.4 & 0.2 & 0.2 \\
\hline 8/4/07 12:00 & 885 & 6111 & 9834 & 588.3 & 506.6 & 81.7 & 13.9 & 1.16 & 2.3 & 312 & 304 & 2210 & 9.0 & 1.4 & 0.2 & 0.2 \\
\hline $8 / 4 / 07$ 13:00 & 886 & 6107 & 9850 & 590.3 & 508.3 & 82.0 & 13.9 & 1.16 & 2.3 & 311 & 306 & 2210 & 9.6 & 1.4 & 0.2 & 0.2 \\
\hline $8 / 4 / 07$ 14:00 & 886 & 6089 & 9818 & 590.5 & 508.5 & 82.0 & 13.9 & 1.16 & 2.3 & 311 & 306 & 2217 & 9.9 & 1.5 & 0.3 & 0.2 \\
\hline $8 / 4 / 07$ 15:00 & 885 & 6107 & 9785 & 591.5 & 509.4 & 82.1 & 13.9 & 1.15 & 2.3 & 312 & 307 & 2233 & 9.8 & 1.5 & 0.3 & 0.2 \\
\hline $8 / 4 / 07$ 16:00 & 885 & 6098 & 9795 & 593.1 & 511.4 & 81.7 & 13.8 & 1.15 & 2.3 & 313 & 307 & 2237 & 10.0 & 1.5 & 0.3 & 0.2 \\
\hline $8 / 4 / 07$ 17:00 & 885 & 6111 & 9778 & 595.0 & 513.0 & 81.9 & 13.8 & 1.15 & 2.3 & 314 & 308 & 2231 & 10.1 & 1.5 & 0.3 & 0.2 \\
\hline 8/4/07 18:00 & 885 & 6140 & 9818 & 594.4 & 512.5 & 81.9 & 13.8 & 1.15 & 2.3 & 315 & 308 & 2239 & 10.0 & 1.5 & 0.3 & 0.2 \\
\hline $8 / 4 / 07$ 19:00 & 887 & 6111 & 9738 & 592.2 & 510.6 & 81.5 & 13.8 & 1.15 & 2.3 & 313 & 307 & 2234 & 10.0 & 1.4 & 0.3 & 0.2 \\
\hline $8 / 4 / 0720: 00$ & 884 & 6131 & 9763 & 592.2 & 510.7 & 81.5 & 13.8 & 1.15 & 2.3 & 311 & 306 & 2238 & 10.1 & 1.4 & 0.3 & 0.2 \\
\hline $8 / 4 / 0721: 00$ & 885 & 6149 & 9865 & 590.2 & 508.9 & 81.2 & 13.8 & 1.16 & 2.3 & 310 & 304 & 2247 & 10.0 & 1.4 & 0.2 & 0.2 \\
\hline $8 / 4 / 0722: 00$ & 885 & 6139 & 9780 & 581.0 & 501.1 & 79.9 & 13.8 & 1.17 & 2.3 & 308 & 301 & 2235 & 10.1 & 1.3 & 0.2 & 0.2 \\
\hline 8/4/07 23:00 & 883 & 6077 & 9745 & 577.7 & 498.2 & 79.4 & 13.8 & 1.17 & 2.3 & 308 & 301 & 2216 & 10.1 & 1.3 & 0.2 & 0.2 \\
\hline 8/5/07 0:00 & 879 & 6087 & 9807 & 578.8 & 499.2 & 79.6 & 13.8 & 1.17 & 2.3 & 309 & 300 & 2212 & 9.7 & 1.3 & 0.2 & 0.2 \\
\hline 8/5/07 1:00 & 880 & 6088 & 9873 & 582.6 & 502.5 & 80.1 & 13.8 & 1.17 & 2.3 & 308 & 298 & 2220 & 9.9 & 1.4 & 0.2 & 0.2 \\
\hline 8/5/07 2:00 & 886 & 6079 & 9747 & 577.1 & 497.8 & 79.4 & 13.8 & 1.17 & 2.2 & 307 & 298 & 2206 & 9.6 & 1.4 & 0.2 & 0.2 \\
\hline $8 / 5 / 07$ 3:00 & 884 & 6082 & 9640 & 564.4 & 486.9 & 77.6 & 13.7 & 1.18 & 2.3 & 305 & 295 & 2193 & 9.5 & 1.3 & 0.2 & 0.2 \\
\hline $8 / 5 / 074: 00$ & 882 & 6042 & 9604 & 556.7 & 479.9 & 76.8 & 13.8 & 1.20 & 2.3 & 307 & 294 & 2188 & 9.9 & 1.2 & 0.2 & 0.2 \\
\hline $8 / 5 / 07$ 5:00 & 878 & 6038 & 9728 & 562.2 & 483.4 & 78.8 & 14.0 & 1.20 & 2.3 & 309 & 295 & 2199 & 9.9 & 1.2 & 0.2 & 0.2 \\
\hline 8/5/07 6:00 & 881 & 6083 & 9822 & 572.4 & 492.2 & 80.3 & 14.0 & 1.20 & 2.3 & 310 & 296 & 2203 & 10.1 & 1.3 & 0.2 & 0.2 \\
\hline $8 / 5 / 07$ 7:00 & 886 & 6077 & 9848 & 578.2 & 497.2 & 81.1 & 14.0 & 1.19 & 2.3 & 308 & 295 & 2198 & 10.2 & 1.3 & 0.2 & 0.2 \\
\hline 8/5/07 8:00 & 885 & 6093 & 9779 & 582.9 & 501.2 & 81.7 & 14.0 & 1.18 & 2.3 & 308 & 296 & 2209 & 10.2 & 1.3 & 0.3 & 0.2 \\
\hline $8 / 5 / 07$ 9:00 & 884 & 6130 & 9797 & 584.4 & 502.5 & 82.0 & 14.0 & 1.17 & 2.3 & 310 & 296 & 2213 & 10.2 & 1.3 & 0.3 & 0.2 \\
\hline $8 / 5 / 07$ 10:00 & 883 & 6164 & 9805 & 583.3 & 501.5 & 81.8 & 14.0 & 1.17 & 2.3 & 311 & 297 & 2204 & 10.3 & 1.3 & 0.3 & 0.2 \\
\hline $8 / 5 / 07$ 11:00 & 888 & 6155 & 9802 & 581.3 & 499.8 & 81.5 & 14.0 & 1.18 & 2.3 & 310 & 297 & 2208 & 10.3 & 1.3 & 0.2 & 0.2 \\
\hline $8 / 5 / 07$ 12:00 & 885 & 6145 & 9772 & 576.7 & 495.8 & 80.9 & 14.0 & 1.18 & 2.3 & 311 & 298 & 2206 & 10.2 & 1.3 & 0.2 & 0.2 \\
\hline 8/5/07 13:00 & 885 & 6088 & 9706 & 572.6 & 492.3 & 80.3 & 14.0 & 1.18 & 2.3 & 312 & 300 & 2194 & 10.1 & 1.3 & 0.2 & 0.2 \\
\hline $8 / 5 / 07$ 14:00 & 881 & 6064 & 9784 & 574.6 & 494.0 & 80.6 & 14.0 & 1.18 & 2.3 & 313 & 301 & 2197 & 10.3 & 1.3 & 0.2 & 0.2 \\
\hline $8 / 5 / 07$ 15:00 & 881 & 6073 & 9827 & 578.0 & 497.2 & 80.8 & 14.0 & 1.18 & 2.3 & 315 & 302 & 2210 & 10.2 & 1.4 & 0.2 & 0.2 \\
\hline $8 / 5 / 07$ 16:00 & 879 & 6097 & 9856 & 583.6 & 502.8 & 80.8 & 13.8 & 1.17 & 2.3 & 318 & 304 & 2228 & 10.4 & 1.4 & 0.2 & 0.2 \\
\hline $8 / 5 / 07$ 17:00 & 880 & 6105 & 9875 & 588.9 & 507.5 & 81.4 & 13.8 & 1.17 & 2.3 & 316 & 304 & 2236 & 10.3 & 1.4 & 0.2 & 0.2 \\
\hline
\end{tabular}




\begin{tabular}{|c|c|c|c|c|c|c|c|c|c|c|c|c|c|c|c|c|}
\hline Date and & $\begin{array}{c}\text { Gross } \\
\text { Gen }\end{array}$ & $\begin{array}{c}\text { Steam } \\
\text { Flow }\end{array}$ & Gross HR & Total Fuel & $\begin{array}{c}\text { Total } \\
\text { Lignite }\end{array}$ & Total PRB & $\begin{array}{l}\text { Total } \\
\text { PRB }\end{array}$ & $\begin{array}{c}\text { Btu } \\
\text { Gain }\end{array}$ & $\begin{array}{c}\text { Econ } \\
\text { O2 }\end{array}$ & $\begin{array}{c}\text { Temp } \\
\text { A APH } \\
\text { Out }\end{array}$ & $\begin{array}{c}\text { Temp } \\
\text { B APH } \\
\text { Out }\end{array}$ & $\begin{array}{l}\text { Stack } \\
\text { Flow }\end{array}$ & Opacity & SO2 In & $\begin{array}{l}\text { SO2 } \\
\text { Out }\end{array}$ & NOx \\
\hline $\begin{array}{c}\text { Start Date } \\
\text { and Time }\end{array}$ & MW & $\begin{array}{c}\text { KLB/ } \\
\text { HR }\end{array}$ & Btu/kWhr & TON/HR & TON/HR & TON/HR & $\begin{array}{c}\% \\
\text { Weight }\end{array}$ & & $\%$ & DEGF & DEGF & KSCF & $\%$ & $\begin{array}{c}\text { Ib/MM } \\
\text { Btu }\end{array}$ & $\begin{array}{c}\text { Ib/MM } \\
\text { Btu }\end{array}$ & $\begin{array}{l}\mathbf{l b} / \mathbf{M} \\
\text { MBtu }\end{array}$ \\
\hline 8/5/07 18:00 & 884 & 6088 & 9755 & 588.6 & 507.2 & 81.4 & 13.8 & 1.16 & 2.2 & 314 & 304 & 2236 & 10.4 & 1.4 & 0.2 & 0.2 \\
\hline $8 / 5 / 07$ 19:00 & 882 & 6060 & 9743 & 590.0 & 508.4 & 81.6 & 13.8 & 1.15 & 2.3 & 314 & 305 & 2230 & 10.4 & 1.5 & 0.2 & 0.2 \\
\hline $8 / 5 / 0720: 00$ & 880 & 6058 & 9866 & 598.0 & 515.3 & 82.7 & 13.8 & 1.14 & 2.3 & 315 & 306 & 2232 & 10.6 & 1.6 & 0.2 & 0.2 \\
\hline $8 / 5 / 0721: 00$ & 879 & 6133 & 9881 & 599.9 & 516.9 & 83.0 & 13.8 & 1.14 & 2.3 & 314 & 305 & 2253 & 10.5 & 1.6 & 0.2 & 0.2 \\
\hline $8 / 5 / 0722: 00$ & 887 & 6119 & 9813 & 596.0 & 513.6 & 82.5 & 13.8 & 1.14 & 2.2 & 310 & 302 & 2263 & 10.4 & 1.5 & 0.2 & 0.2 \\
\hline $8 / 5 / 07$ 23:00 & 887 & 6111 & 9735 & 592.0 & 510.2 & 81.9 & 13.8 & 1.14 & 2.3 & 310 & 302 & 2251 & 10.5 & 1.6 & 0.2 & 0.2 \\
\hline 8/6/07 0:00 & 882 & 6078 & 9854 & 597.9 & 515.2 & 82.7 & 13.8 & 1.14 & 2.3 & 308 & 301 & 2248 & 10.3 & 1.7 & 0.2 & 0.2 \\
\hline 8/6/07 1:00 & 884 & 6128 & 9868 & 599.5 & 516.5 & 82.9 & 13.8 & 1.14 & 2.2 & 307 & 299 & 2249 & 10.1 & 1.8 & 0.2 & 0.2 \\
\hline $8 / 6 / 07$ 2:00 & 889 & 6125 & 9689 & 591.2 & 509.5 & 81.7 & 13.8 & 1.15 & 2.3 & 306 & 297 & 2243 & 10.4 & 1.7 & 0.2 & 0.2 \\
\hline 8/6/07 3:00 & 887 & 6100 & 9695 & 583.8 & 503.1 & 80.7 & 13.8 & 1.16 & 2.3 & 306 & 295 & 2237 & 10.5 & 1.7 & 0.2 & 0.2 \\
\hline 8/6/07 4:00 & 886 & 6091 & 9685 & 580.1 & 499.9 & 80.2 & 13.8 & 1.16 & 2.3 & 307 & 295 & 2233 & 10.3 & 1.7 & 0.2 & 0.2 \\
\hline 8/6/07 5:00 & 883 & 6078 & 9677 & 582.2 & 501.7 & 80.5 & 13.8 & 1.17 & 2.3 & 307 & 295 & 2231 & 10.0 & 1.7 & 0.2 & 0.2 \\
\hline 8/6/07 6:00 & 880 & 6082 & 9900 & 593.9 & 512.1 & 81.8 & 13.8 & 1.16 & 2.3 & 308 & 296 & 2230 & 10.0 & 1.8 & 0.2 & 0.2 \\
\hline 8/6/07 7:00 & 886 & 6121 & 9893 & 597.5 & 515.6 & 81.9 & 13.7 & 1.15 & 2.2 & 308 & 295 & 2245 & 10.2 & 1.9 & 0.2 & 0.2 \\
\hline 8/6/07 8:00 & 888 & 6139 & 9740 & 591.5 & 510.4 & 81.1 & 13.7 & 1.15 & 2.2 & 308 & 295 & 2245 & 10.1 & 1.9 & 0.3 & 0.2 \\
\hline 8/6/07 9:00 & 887 & 6119 & 9688 & 582.7 & 502.9 & 79.9 & 13.7 & 1.16 & 2.3 & 309 & 296 & 2237 & 10.1 & 2.0 & 0.3 & 0.2 \\
\hline $8 / 6 / 07$ 10:00 & 882 & 6070 & 9697 & 579.7 & 500.3 & 79.4 & 13.7 & 1.17 & 6.6 & 309 & 297 & 2226 & 9.8 & 2.0 & 0.3 & 0.2 \\
\hline $8 / 6 / 07$ 11:00 & 881 & 6055 & 9795 & 584.0 & 504.0 & 80.0 & 13.7 & 1.16 & 2.7 & 311 & 299 & 2225 & 9.9 & 2.0 & 0.3 & 0.2 \\
\hline $8 / 6 / 07$ 12:00 & 879 & 6064 & 9865 & 591.8 & 510.7 & 81.1 & 13.7 & 1.16 & 2.3 & 313 & 300 & 2237 & 10.0 & 2.0 & 0.3 & 0.2 \\
\hline 8/6/07 13:00 & 881 & 6136 & 9800 & 588.5 & 507.8 & 80.7 & 13.7 & 1.16 & 2.3 & 314 & 300 & 2236 & 9.9 & 2.0 & 0.3 & 0.2 \\
\hline $8 / 6 / 07$ 14:00 & 880 & 6114 & 9674 & 575.1 & 496.3 & 78.7 & 13.7 & 1.17 & 2.3 & 313 & 301 & 2223 & 9.9 & 1.7 & 0.2 & 0.2 \\
\hline $8 / 6 / 07$ 15:00 & 880 & 6051 & 9686 & 571.1 & 493.0 & 78.2 & 13.7 & 1.18 & 2.3 & 315 & 302 & 2213 & 10.0 & 1.7 & 0.2 & 0.2 \\
\hline $8 / 6 / 07$ 16:00 & 879 & 6040 & 9816 & 578.3 & 499.1 & 79.2 & 13.7 & 1.18 & 2.3 & 316 & 304 & 2230 & 9.8 & 1.9 & 0.2 & 0.2 \\
\hline $8 / 6 / 07$ 17:00 & 875 & 6040 & 9960 & 588.1 & 507.5 & 80.6 & 13.7 & 1.17 & 2.3 & 314 & 305 & 2242 & 9.8 & 2.1 & 0.2 & 0.2 \\
\hline 8/6/07 18:00 & 879 & 6062 & 9917 & 599.3 & 517.1 & 82.2 & 13.7 & 1.15 & 2.2 & 313 & 306 & 2248 & 9.4 & 2.1 & 0.3 & 0.2 \\
\hline $8 / 6 / 07$ 19:00 & 884 & 6082 & 9802 & 600.7 & 518.3 & 82.4 & 13.7 & 1.14 & 2.2 & 316 & 306 & 2258 & 9.4 & 2.0 & 0.2 & 0.2 \\
\hline 8/6/07 20:00 & 882 & 6057 & 9751 & 602.7 & 520.0 & 82.7 & 13.7 & 1.13 & 2.3 & 316 & 306 & 2264 & 9.5 & 1.9 & 0.2 & 0.2 \\
\hline $8 / 6 / 07$ 21:00 & 880 & 6083 & 9860 & 608.2 & 524.7 & 83.4 & 13.7 & 1.12 & 2.3 & 315 & 306 & 2262 & 9.6 & 1.9 & 0.2 & 0.2 \\
\hline $8 / 6 / 0722: 00$ & 882 & 6133 & 9826 & 602.2 & 519.6 & 82.6 & 13.7 & 1.13 & 2.3 & 312 & 303 & 2266 & 9.4 & 1.8 & 0.2 & 0.2 \\
\hline $8 / 6 / 0723: 00$ & 886 & 6104 & 9646 & 588.4 & 507.8 & 80.6 & 13.7 & 1.14 & 2.3 & 313 & 301 & 2259 & 9.6 & 1.6 & 0.2 & 0.2 \\
\hline 8/7/07 0:00 & 878 & 6078 & 9732 & 585.6 & 505.4 & 80.3 & 13.7 & 1.15 & 2.3 & 311 & 298 & 2251 & 9.4 & 1.6 & 0.2 & 0.2 \\
\hline
\end{tabular}




\begin{tabular}{|c|c|c|c|c|c|c|c|c|c|c|c|c|c|c|c|c|}
\hline Date and & $\begin{array}{c}\text { Gross } \\
\text { Gen }\end{array}$ & $\begin{array}{c}\text { Steam } \\
\text { Flow }\end{array}$ & Gross HR & Total Fuel & $\begin{array}{c}\text { Total } \\
\text { Lignite }\end{array}$ & Total PRB & $\begin{array}{l}\text { Total } \\
\text { PRB }\end{array}$ & $\begin{array}{c}\text { Btu } \\
\text { Gain }\end{array}$ & $\begin{array}{c}\text { Econ } \\
\text { O2 }\end{array}$ & $\begin{array}{c}\text { Temp } \\
\text { A APH } \\
\text { Out }\end{array}$ & $\begin{array}{c}\text { Temp } \\
\text { B APH } \\
\text { Out }\end{array}$ & $\begin{array}{l}\text { Stack } \\
\text { Flow }\end{array}$ & Opacity & SO2 In & $\begin{array}{l}\text { SO2 } \\
\text { Out }\end{array}$ & NOx \\
\hline $\begin{array}{c}\text { Start Date } \\
\text { and Time }\end{array}$ & MW & $\begin{array}{c}\text { KLB/ } \\
\text { HR }\end{array}$ & Btu/kWhr & TON/HR & TON/HR & TON/HR & $\begin{array}{c}\% \\
\text { Weight }\end{array}$ & & $\%$ & DEGF & DEGF & KSCF & $\%$ & $\begin{array}{c}\text { Ib/MM } \\
\text { Btu }\end{array}$ & $\begin{array}{c}\text { Ib/MM } \\
\text { Btu }\end{array}$ & $\begin{array}{l}\mathbf{l b} / \mathbf{M} \\
\text { MBtu }\end{array}$ \\
\hline 8/7/07 1:00 & 879 & 6048 & 9879 & 595.7 & 514.1 & 81.7 & 13.7 & 1.15 & 2.3 & 309 & 298 & 2261 & 9.9 & 1.6 & 0.2 & 0.2 \\
\hline 8/7/07 2:00 & 882 & 6086 & 9877 & 599.6 & 517.4 & 82.2 & 13.7 & 1.14 & 2.2 & 308 & 297 & 2272 & 9.2 & 1.7 & 0.2 & 0.2 \\
\hline 8/7/07 3:00 & 884 & 6065 & 9774 & 599.1 & 517.0 & 82.2 & 13.7 & 1.14 & 2.2 & 307 & 296 & 2260 & 9.4 & 1.6 & 0.2 & 0.2 \\
\hline 8/7/07 4:00 & 883 & 6061 & 9758 & 597.8 & 515.8 & 82.0 & 13.7 & 1.13 & 2.3 & 307 & 297 & 2257 & 9.2 & 1.6 & 0.2 & 0.2 \\
\hline $8 / 7 / 07$ 5:00 & 883 & 6055 & 9712 & 595.9 & 514.2 & 81.7 & 13.7 & 1.13 & 2.3 & 308 & 296 & 2256 & 9.1 & 1.6 & 0.2 & 0.2 \\
\hline $8 / 7 / 076: 00$ & 884 & 6072 & 9584 & 584.6 & 504.5 & 80.1 & 13.7 & 1.14 & 2.3 & 306 & 296 & 2244 & 9.6 & 1.5 & 0.2 & 0.2 \\
\hline 8/7/07 7:00 & 879 & 6027 & 9707 & 583.2 & 503.3 & 79.9 & 13.7 & 1.15 & 2.2 & 305 & 294 & 2235 & 9.7 & 1.5 & 0.2 & 0.2 \\
\hline 8/7/07 8:00 & 876 & 6034 & 9826 & 591.9 & 510.7 & 81.1 & 13.7 & 1.15 & 2.2 & 307 & 295 & 2235 & 9.7 & 1.6 & 0.2 & 0.2 \\
\hline 8/7/07 9:00 & 880 & 6147 & 9821 & 591.1 & 510.1 & 81.0 & 13.7 & 1.15 & 2.2 & 308 & 296 & 2244 & 9.7 & 1.6 & 0.2 & 0.2 \\
\hline $8 / 7 / 07$ 10:00 & 884 & 6097 & 9779 & 585.0 & 504.8 & 80.1 & 13.7 & 1.16 & 2.2 & 308 & 298 & 2235 & 9.6 & 1.5 & 0.2 & 0.2 \\
\hline $8 / 7 / 07$ 11:00 & 880 & 6123 & 9828 & 581.8 & 502.2 & 79.7 & 13.7 & 1.16 & 2.2 & 310 & 299 & 2234 & 9.6 & 1.5 & 0.2 & 0.2 \\
\hline $8 / 7 / 07$ 12:00 & 877 & 6056 & 9951 & 593.6 & 512.3 & 81.4 & 13.7 & 1.16 & 2.2 & 313 & 302 & 2247 & 9.6 & 1.6 & 0.2 & 0.2 \\
\hline 8/7/07 13:00 & 879 & 6085 & 10089 & 611.1 & 528.1 & 83.0 & 13.6 & 1.14 & 2.2 & 317 & 304 & 2254 & 9.8 & 1.8 & 0.2 & 0.2 \\
\hline 8/7/07 14:00 & 884 & 6116 & 9931 & 610.5 & 529.7 & 80.8 & 13.2 & 1.13 & 2.2 & 318 & 305 & 2256 & 9.8 & 1.8 & 0.2 & 0.2 \\
\hline $8 / 7 / 07$ 15:00 & 884 & 6160 & 9751 & 599.0 & 519.6 & 79.4 & 13.3 & 1.13 & 2.2 & 318 & 306 & 2251 & 9.5 & 1.7 & 0.2 & 0.2 \\
\hline 8/7/07 16:00 & 883 & 6083 & 9740 & 592.5 & 514.0 & 78.6 & 13.3 & 1.14 & 2.2 & 320 & 308 & 2245 & 9.5 & 1.6 & 0.2 & 0.2 \\
\hline $8 / 7 / 07$ 17:00 & 877 & 6050 & 9865 & 603.9 & 523.9 & 80.0 & 13.2 & 1.13 & 2.2 & 321 & 309 & 2248 & 9.6 & 1.8 & 0.2 & 0.2 \\
\hline $8 / 7 / 07$ 18:00 & 881 & 6090 & 9841 & 607.1 & 526.7 & 80.4 & 13.2 & 1.12 & 2.2 & 319 & 308 & 2262 & 9.4 & 1.8 & 0.2 & 0.2 \\
\hline 8/7/07 19:00 & 881 & 6083 & 9844 & 611.1 & 530.2 & 80.9 & 13.2 & 1.12 & 2.2 & 320 & 309 & 2262 & 9.6 & 1.8 & 0.2 & 0.2 \\
\hline 8/7/07 20:00 & 873 & 6066 & 9795 & 600.4 & 522.8 & 77.6 & 12.9 & 1.12 & 2.2 & 319 & 306 & 2238 & 9.6 & 1.8 & 0.2 & 0.2 \\
\hline $8 / 7 / 07$ 21:00 & 875 & 6059 & 9781 & 599.0 & 522.9 & 76.2 & 12.7 & 1.13 & 2.2 & 316 & 304 & 2246 & 9.8 & 1.7 & 0.2 & 0.2 \\
\hline 8/7/07 22:00 & 879 & 6031 & 9786 & 603.3 & 525.4 & 77.9 & 12.9 & 1.12 & 2.3 & 315 & 303 & 2244 & 9.7 & 1.7 & 0.2 & 0.2 \\
\hline $8 / 7 / 0723: 00$ & 878 & 6077 & 9835 & 608.7 & 530.1 & 78.5 & 12.9 & 1.12 & 2.3 & 312 & 301 & 2247 & 9.9 & 1.8 & 0.2 & 0.2 \\
\hline $8 / 8 / 07$ 0:00 & 882 & 6063 & 9835 & 615.0 & 535.6 & 79.3 & 12.9 & 1.11 & 2.3 & 311 & 301 & 2257 & 9.9 & 1.8 & 0.2 & 0.2 \\
\hline $8 / 8 / 07$ 1:00 & 881 & 6076 & 9888 & 622.4 & 542.1 & 80.3 & 12.9 & 1.10 & 2.3 & 313 & 301 & 2265 & 9.9 & 1.9 & 0.2 & 0.2 \\
\hline 8/8/07 2:00 & 881 & 6074 & 9891 & 630.3 & 549.1 & 81.2 & 12.9 & 1.09 & 2.3 & 313 & 300 & 2257 & 9.7 & 1.9 & 0.2 & 0.2 \\
\hline 8/8/07 3:00 & 882 & 6104 & 9866 & 635.1 & 553.4 & 81.7 & 12.9 & 1.08 & 2.2 & 312 & 299 & 2248 & 9.6 & 1.9 & 0.2 & 0.2 \\
\hline 8/8/07 4:00 & 883 & 6115 & 9770 & 629.6 & 548.7 & 80.9 & 12.8 & 1.08 & 2.3 & 311 & 298 & 2252 & 9.8 & 1.9 & 0.2 & 0.2 \\
\hline $8 / 8 / 07$ 5:00 & 882 & 6086 & 9781 & 625.9 & 545.5 & 80.4 & 12.8 & 1.09 & 2.4 & 305 & 297 & 2260 & 9.4 & 1.8 & 0.2 & 0.2 \\
\hline $8 / 8 / 076: 00$ & 884 & 6070 & 9712 & 619.5 & 539.8 & 79.6 & 12.9 & 1.09 & 2.3 & 306 & 297 & 2258 & 9.5 & 1.8 & 0.2 & 0.2 \\
\hline $8 / 8 / 07$ 7:00 & 882 & 6068 & 9669 & 611.6 & 532.9 & 78.6 & 12.9 & 1.10 & 2.4 & 307 & 297 & 2253 & 9.7 & 1.7 & 0.2 & 0.2 \\
\hline
\end{tabular}




\begin{tabular}{|c|c|c|c|c|c|c|c|c|c|c|c|c|c|c|c|c|}
\hline Date and & $\begin{array}{c}\text { Gross } \\
\text { Gen }\end{array}$ & $\begin{array}{c}\text { Steam } \\
\text { Flow }\end{array}$ & Gross HR & Total Fuel & $\begin{array}{c}\text { Total } \\
\text { Lignite }\end{array}$ & Total PRB & $\begin{array}{l}\text { Total } \\
\text { PRB }\end{array}$ & $\begin{array}{c}\text { Btu } \\
\text { Gain }\end{array}$ & $\begin{array}{c}\text { Econ } \\
\text { O2 }\end{array}$ & $\begin{array}{c}\text { Temp } \\
\text { A APH } \\
\text { Out }\end{array}$ & $\begin{array}{c}\text { Temp } \\
\text { B APH } \\
\text { Out }\end{array}$ & $\begin{array}{l}\text { Stack } \\
\text { Flow }\end{array}$ & Opacity & SO2 In & $\begin{array}{l}\text { SO2 } \\
\text { Out }\end{array}$ & NOx \\
\hline $\begin{array}{c}\text { Start Date } \\
\text { and Time }\end{array}$ & MW & $\begin{array}{c}\text { KLB/ } \\
\text { HR }\end{array}$ & Btu/kWhr & TON/HR & TON/HR & TON/HR & $\begin{array}{c}\% \\
\text { Weight }\end{array}$ & & $\%$ & DEGF & DEGF & KSCF & $\%$ & $\begin{array}{c}\text { Ib/MM } \\
\text { Btu }\end{array}$ & $\begin{array}{c}\text { Ib/MM } \\
\text { Btu }\end{array}$ & $\begin{array}{l}\mathbf{l b} / \mathbf{M} \\
\text { MBtu }\end{array}$ \\
\hline 8/8/07 8:00 & 880 & 6085 & 9753 & 611.0 & 532.5 & 78.5 & 12.9 & 1.10 & 2.3 & 310 & 298 & 2248 & 9.8 & 1.7 & 0.2 & 0.2 \\
\hline 8/8/07 9:00 & 880 & 6076 & 9819 & 611.1 & 532.5 & 78.6 & 12.9 & 1.11 & 2.3 & 310 & 299 & 2243 & 9.9 & 1.6 & 0.2 & 0.2 \\
\hline $8 / 8 / 07$ 10:00 & 878 & 6040 & 9897 & 621.5 & 541.7 & 79.9 & 12.8 & 1.10 & 2.3 & 308 & 300 & 2252 & 9.6 & 1.8 & 0.2 & 0.2 \\
\hline $8 / 8 / 07$ 11:00 & 879 & 6075 & 9921 & 634.1 & 552.7 & 81.4 & 12.8 & 1.08 & 2.2 & 310 & 300 & 2257 & 9.8 & 1.9 & 0.2 & 0.2 \\
\hline $8 / 8 / 07$ 12:00 & 883 & 6107 & 9847 & 634.5 & 553.1 & 81.5 & 12.8 & 1.08 & 2.2 & 313 & 302 & 2249 & 9.8 & 1.9 & 0.2 & 0.2 \\
\hline $8 / 8 / 07$ 13:00 & 884 & 6126 & 9729 & 622.9 & 542.9 & 80.0 & 12.9 & 1.09 & 2.2 & 313 & 303 & 2248 & 9.7 & 1.8 & 0.2 & 0.2 \\
\hline $8 / 8 / 07$ 14:00 & 884 & 6057 & 9741 & 619.6 & 540.0 & 79.6 & 12.8 & 1.09 & 2.2 & 312 & 304 & 2246 & 9.4 & 1.8 & 0.2 & 0.2 \\
\hline $8 / 8 / 07$ 15:00 & 879 & 6079 & 9739 & 617.3 & 537.9 & 79.4 & 12.9 & 1.10 & 2.3 & 313 & 303 & 2244 & 9.5 & 1.8 & 0.2 & 0.2 \\
\hline $8 / 8 / 07$ 16:00 & 883 & 6047 & 9745 & 617.8 & 538.4 & 79.4 & 12.9 & 1.10 & 2.2 & 314 & 305 & 2247 & 9.5 & 1.8 & 0.2 & 0.2 \\
\hline $8 / 8 / 07$ 17:00 & 881 & 6082 & 9725 & 608.2 & 530.0 & 78.2 & 12.9 & 1.10 & 2.3 & 314 & 306 & 2252 & 9.7 & 1.7 & 0.2 & 0.2 \\
\hline $8 / 8 / 07$ 18:00 & 879 & 6045 & 9726 & 602.0 & 524.6 & 77.4 & 12.9 & 1.11 & 2.3 & 314 & 306 & 2254 & 9.6 & 1.7 & 0.1 & 0.2 \\
\hline $8 / 8 / 07$ 19:00 & 876 & 6045 & 9779 & 603.1 & 525.5 & 77.6 & 12.9 & 1.12 & 2.3 & 313 & 305 & 2251 & 9.7 & 1.7 & 0.2 & 0.2 \\
\hline 8/8/07 20:00 & 826 & 5681 & 9937 & 582.6 & 500.8 & 81.8 & 14.0 & 1.11 & 2.3 & 320 & 309 & 2173 & 9.3 & 1.8 & 0.2 & 0.2 \\
\hline 8/8/07 21:00 & 815 & 5580 & 9943 & 589.4 & 503.3 & 86.0 & 14.6 & 1.08 & 2.3 & 335 & 314 & 2143 & 9.1 & 1.9 & 0.2 & 0.2 \\
\hline 8/8/07 22:00 & 820 & 5666 & 9863 & 599.5 & 511.6 & 87.9 & 14.7 & 1.06 & 2.3 & 331 & 310 & 2160 & 9.1 & 1.9 & 0.2 & 0.2 \\
\hline 8/8/07 23:00 & 814 & 5598 & 9896 & 601.2 & 513.0 & 88.2 & 14.7 & 1.05 & 2.4 & 321 & 303 & 2149 & 9.0 & 2.0 & 0.2 & 0.2 \\
\hline $8 / 9 / 07$ 0:00 & 830 & 5682 & 9741 & 604.5 & 517.2 & 87.4 & 14.5 & 1.05 & 2.3 & 317 & 303 & 2149 & 9.3 & 2.0 & 0.2 & 0.2 \\
\hline $8 / 9 / 07$ 1:00 & 881 & 6083 & 9579 & 622.2 & 539.4 & 82.8 & 13.3 & 1.06 & 2.4 & 311 & 301 & 2246 & 9.6 & 1.8 & 0.2 & 0.2 \\
\hline 8/9/07 2:00 & 878 & 6006 & 9568 & 609.4 & 530.2 & 79.2 & 13.0 & 1.08 & 2.4 & 310 & 299 & 2245 & 9.6 & 1.8 & 0.2 & 0.2 \\
\hline 8/9/07 3:00 & 876 & 6022 & 9631 & 605.9 & 526.9 & 79.0 & 13.0 & 1.10 & 2.4 & 310 & 296 & 2242 & 9.8 & 1.8 & 0.2 & 0.2 \\
\hline 8/9/07 4:00 & 879 & 6017 & 9669 & 602.0 & 523.5 & 78.5 & 13.0 & 1.11 & 2.4 & 310 & 295 & 2247 & 9.8 & 1.8 & 0.2 & 0.2 \\
\hline 8/9/07 5:00 & 879 & 6045 & 9650 & 593.8 & 516.7 & 77.1 & 13.0 & 1.12 & 2.5 & 309 & 295 & 2252 & 9.5 & 2.0 & 0.2 & 0.2 \\
\hline $8 / 9 / 07$ 6:00 & 877 & 6036 & 9672 & 587.6 & 511.5 & 76.1 & 13.0 & 1.14 & 2.5 & 309 & 296 & 2248 & 9.6 & 2.1 & 0.2 & 0.2 \\
\hline $8 / 9 / 07$ 7:00 & 879 & 6023 & 9726 & 591.8 & 515.1 & 76.7 & 13.0 & 1.14 & 2.5 & 310 & 296 & 2257 & 9.4 & 2.2 & 0.2 & 0.2 \\
\hline 8/9/07 8:00 & 880 & 6099 & 9780 & 595.5 & 518.4 & 77.2 & 13.0 & 1.14 & 2.4 & 309 & 294 & 2261 & 9.9 & 2.3 & 0.2 & 0.2 \\
\hline 8/9/07 9:00 & 887 & 6103 & 9744 & 594.0 & 516.9 & 77.0 & 13.0 & 1.14 & 2.4 & 309 & 295 & 2252 & 9.8 & 2.3 & 0.2 & 0.2 \\
\hline 8/9/07 10:00 & 887 & 6105 & 9713 & 587.8 & 511.6 & 76.2 & 13.0 & 1.15 & 2.4 & 311 & 297 & 2254 & 9.6 & 2.2 & 0.2 & 0.2 \\
\hline 8/9/07 11:00 & 884 & 6121 & 9717 & 582.0 & 506.7 & 75.3 & 12.9 & 1.16 & 2.4 & 313 & 299 & 2267 & 9.6 & 2.0 & 0.2 & 0.2 \\
\hline $8 / 9 / 07$ 12:00 & 883 & 6081 & 9843 & 588.8 & 512.5 & 76.3 & 13.0 & 1.16 & 2.4 & 315 & 303 & 2268 & 9.7 & 2.0 & 0.2 & 0.2 \\
\hline $8 / 9 / 07$ 13:00 & 885 & 6100 & 9850 & 593.5 & 516.6 & 77.0 & 13.0 & 1.15 & 2.4 & 318 & 306 & 2260 & 9.2 & 2.1 & 0.2 & 0.2 \\
\hline $8 / 9 / 07$ 14:00 & 885 & 6108 & 9795 & 593.1 & 516.2 & 76.9 & 13.0 & 1.15 & 2.4 & 319 & 308 & 2263 & 9.3 & 2.2 & 0.2 & 0.2 \\
\hline
\end{tabular}




\begin{tabular}{|c|c|c|c|c|c|c|c|c|c|c|c|c|c|c|c|c|}
\hline Date and & $\begin{array}{c}\text { Gross } \\
\text { Gen }\end{array}$ & $\begin{array}{c}\text { Steam } \\
\text { Flow }\end{array}$ & Gross HR & Total Fuel & $\begin{array}{c}\text { Total } \\
\text { Lignite }\end{array}$ & Total PRB & $\begin{array}{l}\text { Total } \\
\text { PRB }\end{array}$ & $\begin{array}{c}\text { Btu } \\
\text { Gain }\end{array}$ & $\begin{array}{c}\text { Econ } \\
\text { O2 }\end{array}$ & $\begin{array}{c}\text { Temp } \\
\text { A APH } \\
\text { Out }\end{array}$ & $\begin{array}{c}\text { Temp } \\
\text { B APH } \\
\text { Out }\end{array}$ & $\begin{array}{l}\text { Stack } \\
\text { Flow }\end{array}$ & Opacity & SO2 In & $\begin{array}{l}\text { SO2 } \\
\text { Out }\end{array}$ & NOx \\
\hline $\begin{array}{l}\text { Start Date } \\
\text { and Time }\end{array}$ & MW & $\begin{array}{c}\text { KLB/ } \\
\text { HR }\end{array}$ & Btu/kWhr & TON/HR & TON/HR & TON/HR & $\begin{array}{c}\% \\
\text { Weight }\end{array}$ & & $\%$ & DEGF & DEGF & KSCF & $\%$ & $\begin{array}{c}\text { Ib/MM } \\
\text { Btu }\end{array}$ & $\begin{array}{c}\text { Ib/MM } \\
\text { Btu }\end{array}$ & $\begin{array}{l}\mathbf{l b} / \mathbf{M} \\
\text { MBtu }\end{array}$ \\
\hline 8/9/07 15:00 & 887 & 6118 & 9810 & 595.5 & 518.2 & 77.3 & 13.0 & 1.15 & 2.3 & 320 & 309 & 2267 & 9.2 & 2.5 & 0.2 & 0.2 \\
\hline 8/9/07 16:00 & 884 & 6119 & 9805 & 588.6 & 512.3 & 76.3 & 13.0 & 1.15 & 2.3 & 322 & 311 & 2259 & 9.4 & 2.6 & 0.3 & 0.2 \\
\hline $8 / 9 / 07$ 17:00 & 879 & 6062 & 9818 & 588.1 & 511.9 & 76.2 & 13.0 & 1.15 & 2.3 & 320 & 309 & 2254 & 9.6 & 2.6 & 0.3 & 0.2 \\
\hline 8/9/07 18:00 & 881 & 6047 & 9759 & 588.8 & 512.5 & 76.3 & 13.0 & 1.15 & 2.2 & 318 & 308 & 2250 & 9.4 & 2.8 & 0.3 & 0.2 \\
\hline 8/9/07 19:00 & 880 & 6025 & 9766 & 590.6 & 514.0 & 76.6 & 13.0 & 1.15 & 2.2 & 314 & 308 & 2246 & 9.3 & 2.8 & 0.3 & 0.2 \\
\hline $8 / 9 / 0720: 00$ & 881 & 6060 & 9741 & 594.2 & 517.2 & 77.0 & 13.0 & 1.14 & 2.2 & 314 & 308 & 2255 & 9.3 & 2.7 & 0.3 & 0.2 \\
\hline 8/9/07 21:00 & 881 & 6112 & 9746 & 587.4 & 511.3 & 76.1 & 13.0 & 1.15 & 2.3 & 313 & 306 & 2260 & 9.3 & 2.5 & 0.2 & 0.2 \\
\hline 8/9/07 22:00 & 881 & 6080 & 9776 & 583.8 & 508.3 & 75.6 & 12.9 & 1.16 & 2.3 & 310 & 305 & 2254 & 9.4 & 2.2 & 0.2 & 0.2 \\
\hline 8/9/07 23:00 & 883 & 6084 & 9748 & 581.1 & 505.9 & 75.2 & 12.9 & 1.16 & 2.2 & 312 & 304 & 2253 & 9.5 & 2.0 & 0.2 & 0.2 \\
\hline $8 / 10 / 07$ 0:00 & 879 & 6076 & 9761 & 579.0 & 504.2 & 74.9 & 12.9 & 1.17 & 2.3 & 315 & 306 & 2246 & 9.9 & 1.9 & 0.2 & 0.2 \\
\hline $8 / 10 / 07$ 1:00 & 877 & 6097 & 9832 & 581.9 & 506.6 & 75.3 & 12.9 & 1.17 & 2.3 & 313 & 307 & 2239 & 10.0 & 2.1 & 0.2 & 0.2 \\
\hline $8 / 10 / 072: 00$ & 873 & 6028 & 9858 & 580.5 & 502.3 & 78.2 & 13.5 & 1.17 & 2.2 & 316 & 306 & 2234 & 10.0 & 2.1 & 0.2 & 0.2 \\
\hline 8/10/07 3:00 & 878 & 6044 & 9734 & 578.0 & 482.2 & 95.8 & 16.6 & 1.17 & 2.2 & 319 & 311 & 2234 & 9.9 & 2.0 & 0.2 & 0.2 \\
\hline 8/10/07 4:00 & 877 & 6059 & 9780 & 577.6 & 478.5 & 99.1 & 17.2 & 1.17 & 2.2 & 319 & 311 & 2241 & 9.4 & 2.0 & 0.2 & 0.2 \\
\hline 8/10/07 5:00 & 878 & 6071 & 9839 & 578.6 & 479.9 & 98.7 & 17.1 & 1.17 & 2.2 & 320 & 309 & 2244 & 9.1 & 2.3 & 0.2 & 0.2 \\
\hline 8/10/07 6:00 & 878 & 6058 & 9839 & 582.2 & 484.4 & 97.8 & 16.8 & 1.17 & 2.3 & 317 & 305 & 2244 & 9.6 & 2.2 & 0.2 & 0.2 \\
\hline $8 / 10 / 07$ 7:00 & 881 & 6051 & 9750 & 582.0 & 484.8 & 97.2 & 16.7 & 1.16 & 2.3 & 316 & 305 & 2233 & 9.6 & 2.0 & 0.2 & 0.2 \\
\hline $8 / 10 / 078: 00$ & 879 & 6063 & 9765 & 585.8 & 488.0 & 97.8 & 16.7 & 1.16 & 2.3 & 316 & 305 & 2232 & 10.0 & 2.0 & 0.2 & 0.2 \\
\hline 8/10/07 9:00 & 882 & 6079 & 9837 & 593.2 & 491.9 & 101.3 & 17.1 & 1.15 & 2.2 & 318 & 307 & 2248 & 10.2 & 2.1 & 0.2 & 0.2 \\
\hline $8 / 10 / 07$ 10:00 & 882 & 6060 & 9792 & 592.4 & 490.2 & 102.3 & 17.3 & 1.15 & 2.2 & 320 & 310 & 2251 & 10.1 & 2.0 & 0.2 & 0.2 \\
\hline $8 / 10 / 07$ 11:00 & 881 & 6061 & 9797 & 593.0 & 489.9 & 103.1 & 17.4 & 1.15 & 2.3 & 321 & 313 & 2250 & 10.0 & 1.9 & 0.2 & 0.2 \\
\hline $8 / 10 / 07$ 12:00 & 881 & 6089 & 9734 & 588.8 & 488.5 & 100.3 & 17.0 & 1.15 & 2.3 & 322 & 314 & 2262 & 10.0 & 1.7 & 0.2 & 0.2 \\
\hline 8/10/07 13:00 & 880 & 6055 & 9812 & 587.5 & 493.5 & 94.0 & 16.0 & 1.15 & 2.3 & 322 & 314 & 2267 & 10.1 & 1.8 & 0.2 & 0.2 \\
\hline $8 / 10 / 07$ 14:00 & 880 & 6046 & 9779 & 588.9 & 494.8 & 94.1 & 16.0 & 1.15 & 2.3 & 318 & 315 & 2259 & 9.9 & 2.0 & 0.2 & 0.2 \\
\hline 8/10/07 15:00 & 879 & 6047 & 9843 & 595.6 & 500.0 & 95.5 & 16.0 & 1.14 & 2.3 & 318 & 315 & 2248 & 10.0 & 2.2 & 0.2 & 0.2 \\
\hline 8/10/07 16:00 & 882 & 6069 & 9798 & 598.0 & 496.9 & 101.1 & 16.9 & 1.14 & 2.2 & 316 & 314 & 2241 & 10.0 & 2.2 & 0.2 & 0.2 \\
\hline 8/10/07 17:00 & 881 & 6121 & 9779 & 591.9 & 487.4 & 104.5 & 17.7 & 1.14 & 2.3 & 316 & 315 & 2243 & 10.0 & 2.1 & 0.2 & 0.2 \\
\hline 8/10/07 18:00 & 880 & 6058 & 9850 & 596.2 & 488.5 & 107.7 & 18.1 & 1.14 & 2.3 & 316 & 315 & 2252 & 9.8 & 2.0 & 0.2 & 0.2 \\
\hline 8/10/07 19:00 & 877 & 6040 & 9984 & 614.5 & 506.8 & 107.7 & 17.5 & 1.13 & 2.3 & 316 & 315 & 2256 & 9.8 & 2.0 & 0.2 & 0.2 \\
\hline $8 / 10 / 07$ 20:00 & 876 & 6071 & 10101 & 634.7 & 545.4 & 89.3 & 14.1 & 1.09 & 2.2 & 321 & 318 & 2269 & 9.6 & 2.0 & 0.2 & 0.2 \\
\hline $8 / 10 / 07$ 21:00 & 883 & 6153 & 9857 & 626.8 & 548.4 & 78.4 & 12.5 & 1.09 & 2.2 & 319 & 312 & 2262 & 9.6 & 2.0 & 0.2 & 0.2 \\
\hline
\end{tabular}




\begin{tabular}{|c|c|c|c|c|c|c|c|c|c|c|c|c|c|c|c|c|}
\hline Date and & $\begin{array}{c}\text { Gross } \\
\text { Gen }\end{array}$ & $\begin{array}{c}\text { Steam } \\
\text { Flow }\end{array}$ & Gross HR & Total Fuel & $\begin{array}{c}\text { Total } \\
\text { Lignite }\end{array}$ & Total PRB & $\begin{array}{l}\text { Total } \\
\text { PRB }\end{array}$ & $\begin{array}{c}\text { Btu } \\
\text { Gain }\end{array}$ & $\begin{array}{c}\text { Econ } \\
\text { O2 }\end{array}$ & $\begin{array}{c}\text { Temp } \\
\text { A APH } \\
\text { Out }\end{array}$ & $\begin{array}{c}\text { Temp } \\
\text { B APH } \\
\text { Out }\end{array}$ & $\begin{array}{l}\text { Stack } \\
\text { Flow }\end{array}$ & Opacity & SO2 In & $\begin{array}{l}\text { SO2 } \\
\text { Out }\end{array}$ & NOx \\
\hline $\begin{array}{l}\text { Start Date } \\
\text { and Time }\end{array}$ & MW & $\begin{array}{c}\text { KLB/ } \\
\text { HR }\end{array}$ & Btu/kWhr & TON/HR & TON/HR & TON/HR & $\begin{array}{c}\% \\
\text { Weight }\end{array}$ & & $\%$ & DEGF & DEGF & KSCF & $\%$ & $\begin{array}{c}\text { Ib/MM } \\
\text { Btu }\end{array}$ & $\begin{array}{c}\text { Ib/MM } \\
\text { Btu }\end{array}$ & $\begin{array}{l}\mathbf{l b} / \mathbf{M} \\
\text { MBtu }\end{array}$ \\
\hline 8/10/07 22:00 & 888 & 6094 & 9714 & 616.3 & 539.2 & 77.0 & 12.5 & 1.10 & 2.2 & 314 & 307 & 2262 & 9.8 & 2.0 & 0.2 & 0.2 \\
\hline 8/10/07 23:00 & 881 & 6063 & 9707 & 615.6 & 538.7 & 76.9 & 12.5 & 1.10 & 2.3 & 311 & 306 & 2264 & 10.0 & 2.1 & 0.2 & 0.2 \\
\hline $8 / 11 / 07$ 0:00 & 875 & 6035 & 9831 & 620.5 & 542.9 & 77.6 & 12.5 & 1.09 & 2.2 & 311 & 307 & 2267 & 9.7 & 2.2 & 0.2 & 0.2 \\
\hline $8 / 11 / 07$ 1:00 & 860 & 5960 & 9768 & 606.1 & 528.0 & 78.0 & 12.9 & 1.09 & 2.2 & 319 & 312 & 2235 & 9.3 & 2.4 & 0.2 & 0.2 \\
\hline $8 / 11 / 072: 00$ & 876 & 5993 & 9670 & 607.3 & 530.0 & 77.3 & 12.7 & 1.10 & 2.3 & 311 & 306 & 2234 & 9.3 & 2.6 & 0.3 & 0.2 \\
\hline $8 / 11 / 073: 00$ & 877 & 5978 & 9606 & 599.8 & 523.6 & 76.2 & 12.7 & 1.10 & 2.2 & 309 & 303 & 2227 & 9.6 & 2.6 & 0.3 & 0.2 \\
\hline 8/11/07 4:00 & 875 & 5957 & 9633 & 596.5 & 520.8 & 75.8 & 12.7 & 1.11 & 2.3 & 308 & 302 & 2231 & 9.7 & 2.6 & 0.3 & 0.2 \\
\hline 8/11/07 5:00 & 866 & 5897 & 9643 & 587.7 & 512.9 & 74.8 & 12.7 & 1.12 & 2.3 & 312 & 305 & 2221 & 9.5 & 2.6 & 0.3 & 0.2 \\
\hline $8 / 11 / 076: 00$ & 868 & 5932 & 9615 & 589.3 & 507.1 & 82.2 & 14.0 & 1.12 & 2.2 & 320 & 309 & 2231 & 9.4 & 2.6 & 0.3 & 0.2 \\
\hline $8 / 11 / 07$ 7:00 & 875 & 6023 & 9712 & 597.4 & 520.9 & 76.5 & 12.8 & 1.12 & 2.3 & 312 & 303 & 2239 & 9.3 & 2.6 & 0.3 & 0.2 \\
\hline $8 / 11 / 078: 00$ & 880 & 6017 & 9702 & 599.1 & 523.4 & 75.8 & 12.6 & 1.12 & 2.3 & 309 & 303 & 2251 & 9.6 & 2.8 & 0.3 & 0.2 \\
\hline 8/11/07 9:00 & 881 & 6011 & 9719 & 597.2 & 522.5 & 74.6 & 12.5 & 1.12 & 2.2 & 308 & 302 & 2251 & 9.5 & 2.7 & 0.3 & 0.2 \\
\hline 8/11/07 10:00 & 877 & 6047 & 9739 & 599.3 & 524.3 & 75.0 & 12.5 & 1.12 & 2.3 & 309 & 302 & 2251 & 9.5 & 2.8 & 0.3 & 0.2 \\
\hline 8/11/07 11:00 & 879 & 6040 & 9869 & 610.8 & 534.3 & 76.5 & 12.5 & 1.12 & 2.3 & 310 & 304 & 2244 & 9.5 & 2.8 & 0.3 & 0.2 \\
\hline 8/11/07 12:00 & 882 & 6066 & 9797 & 614.0 & 536.7 & 77.3 & 12.6 & 1.11 & 2.2 & 313 & 306 & 2259 & 9.6 & 2.8 & 0.3 & 0.2 \\
\hline 8/11/07 13:00 & 883 & 6073 & 9794 & 614.0 & 536.5 & 77.5 & 12.6 & 1.11 & 2.2 & 314 & 307 & 2268 & 9.6 & 2.7 & 0.3 & 0.2 \\
\hline $8 / 11 / 07$ 14:00 & 884 & 6071 & 9730 & 613.6 & 536.2 & 77.4 & 12.6 & 1.11 & 2.3 & 315 & 308 & 2262 & 9.6 & 2.6 & 0.3 & 0.2 \\
\hline $8 / 11 / 07$ 15:00 & 882 & 6075 & 9748 & 609.9 & 532.9 & 77.0 & 12.6 & 1.11 & 2.3 & 317 & 309 & 2252 & 9.3 & 2.4 & 0.2 & 0.2 \\
\hline 8/11/07 16:00 & 882 & 6065 & 9774 & 611.9 & 534.6 & 77.2 & 12.6 & 1.11 & 2.2 & 317 & 311 & 2245 & 9.3 & 2.2 & 0.2 & 0.2 \\
\hline 8/11/07 17:00 & 881 & 6084 & 9822 & 614.4 & 536.9 & 77.5 & 12.6 & 1.11 & 2.2 & 318 & 312 & 2246 & 9.3 & 2.0 & 0.2 & 0.2 \\
\hline 8/11/07 18:00 & 883 & 6088 & 9770 & 612.4 & 535.1 & 77.3 & 12.6 & 1.11 & 2.2 & 318 & 312 & 2243 & 8.9 & 2.0 & 0.2 & 0.2 \\
\hline $8 / 11 / 07$ 19:00 & 884 & 6074 & 9736 & 607.1 & 530.5 & 76.6 & 12.6 & 1.11 & 2.2 & 318 & 312 & 2253 & 8.9 & 2.0 & 0.2 & 0.2 \\
\hline 8/11/07 20:00 & 882 & 6098 & 9682 & 602.8 & 526.7 & 76.1 & 12.6 & 1.12 & 2.3 & 316 & 311 & 2256 & 9.0 & 1.9 & 0.2 & 0.2 \\
\hline $8 / 11 / 07$ 21:00 & 883 & 6075 & 9742 & 599.5 & 523.9 & 75.7 & 12.6 & 1.13 & 2.3 & 315 & 310 & 2249 & 9.3 & 1.8 & 0.2 & 0.2 \\
\hline 8/11/07 22:00 & 882 & 6079 & 9691 & 595.8 & 521.2 & 74.6 & 12.5 & 1.13 & 2.3 & 315 & 309 & 2261 & 9.5 & 1.7 & 0.2 & 0.2 \\
\hline 8/11/07 23:00 & 881 & 6073 & 9790 & 596.0 & 521.5 & 74.5 & 12.5 & 1.14 & 2.2 & 314 & 308 & 2266 & 9.6 & 1.6 & 0.1 & 0.2 \\
\hline 8/12/07 0:00 & 879 & 6107 & 9854 & 598.0 & 523.3 & 74.7 & 12.5 & 1.14 & 2.3 & 312 & 306 & 2275 & 9.6 & 1.6 & 0.1 & 0.2 \\
\hline $8 / 12 / 07$ 1:00 & 882 & 6107 & 9932 & 600.6 & 525.5 & 75.1 & 12.5 & 1.14 & 2.2 & 310 & 304 & 2260 & 9.6 & 1.6 & 0.1 & 0.2 \\
\hline $8 / 12 / 072: 00$ & 885 & 6089 & 9742 & 595.3 & 520.9 & 74.4 & 12.5 & 1.14 & 2.2 & 311 & 305 & 2261 & 9.7 & 1.5 & 0.1 & 0.2 \\
\hline $8 / 12 / 073: 00$ & 883 & 6085 & 9751 & 593.0 & 518.8 & 74.1 & 12.5 & 1.14 & 2.3 & 309 & 304 & 2261 & 10.1 & 1.4 & 0.1 & 0.2 \\
\hline $8 / 12 / 074: 00$ & 882 & 6064 & 9768 & 597.1 & 522.5 & 74.7 & 12.5 & 1.14 & 2.2 & 308 & 303 & 2252 & 10.5 & 1.5 & 0.1 & 0.2 \\
\hline
\end{tabular}




\begin{tabular}{|c|c|c|c|c|c|c|c|c|c|c|c|c|c|c|c|c|}
\hline Date and & $\begin{array}{c}\text { Gross } \\
\text { Gen }\end{array}$ & $\begin{array}{c}\text { Steam } \\
\text { Flow }\end{array}$ & Gross HR & Total Fuel & $\begin{array}{c}\text { Total } \\
\text { Lignite }\end{array}$ & Total PRB & $\begin{array}{l}\text { Total } \\
\text { PRB } \\
\end{array}$ & $\begin{array}{c}\text { Btu } \\
\text { Gain }\end{array}$ & $\begin{array}{c}\text { Econ } \\
\text { O2 }\end{array}$ & $\begin{array}{c}\text { Temp } \\
\text { A APH } \\
\text { Out }\end{array}$ & $\begin{array}{c}\text { Temp } \\
\text { B APH } \\
\text { Out }\end{array}$ & $\begin{array}{l}\text { Stack } \\
\text { Flow }\end{array}$ & Opacity & SO2 In & $\begin{array}{l}\text { SO2 } \\
\text { Out }\end{array}$ & NOx \\
\hline $\begin{array}{l}\text { Start Date } \\
\text { and Time }\end{array}$ & MW & $\begin{array}{c}\text { KLB/ } \\
\text { HR }\end{array}$ & Btu/kWhr & TON/HR & TON/HR & TON/HR & $\begin{array}{c}\% \\
\text { Weight }\end{array}$ & & $\%$ & DEGF & DEGF & KSCF & $\%$ & $\begin{array}{c}\text { Ib/MM } \\
\text { Btu }\end{array}$ & $\begin{array}{c}\text { Ib/MM } \\
\text { Btu }\end{array}$ & $\begin{array}{l}\text { Ib/M } \\
\text { MBtu }\end{array}$ \\
\hline 8/12/07 5:00 & 882 & 6075 & 9835 & 598.6 & 523.8 & 74.8 & 12.5 & 1.14 & 2.2 & 309 & 303 & 2255 & 10.1 & 1.6 & 0.1 & 0.2 \\
\hline 8/12/07 6:00 & 882 & 6089 & 9788 & 599.6 & 524.7 & 74.9 & 12.5 & 1.13 & 2.3 & 309 & 302 & 2267 & 10.0 & 1.6 & 0.2 & 0.2 \\
\hline $8 / 12 / 07$ 7:00 & 883 & 6079 & 9796 & 600.6 & 525.5 & 75.1 & 12.5 & 1.13 & 2.3 & 308 & 302 & 2260 & 10.7 & 1.6 & 0.2 & 0.2 \\
\hline $8 / 12 / 07$ 8:00 & 883 & 6066 & 9798 & 602.3 & 527.0 & 75.3 & 12.5 & 1.13 & 2.2 & 310 & 304 & 2255 & 10.2 & 1.7 & 0.2 & 0.2 \\
\hline $8 / 12 / 07$ 9:00 & 880 & 6100 & 9827 & 604.2 & 528.7 & 75.5 & 12.5 & 1.13 & 2.3 & 310 & 304 & 2267 & 10.3 & 1.7 & 0.2 & 0.2 \\
\hline $8 / 12 / 07$ 10:00 & 881 & 6107 & 9826 & 605.6 & 529.9 & 75.7 & 12.5 & 1.13 & 2.2 & 311 & 304 & 2268 & 10.4 & 1.7 & 0.2 & 0.2 \\
\hline $8 / 12 / 07$ 11:00 & 884 & 6111 & 9728 & 598.7 & 523.9 & 74.8 & 12.5 & 1.13 & 2.2 & 311 & 306 & 2249 & 10.3 & 1.7 & 0.2 & 0.2 \\
\hline $8 / 12 / 07$ 12:00 & 882 & 6093 & 9723 & 595.7 & 520.9 & 74.9 & 12.6 & 1.14 & 2.3 & 313 & 308 & 2264 & 10.2 & 1.6 & 0.2 & 0.2 \\
\hline 8/12/07 13:00 & 881 & 6078 & 9806 & 597.7 & 522.2 & 75.5 & 12.6 & 1.14 & 2.2 & 315 & 311 & 2262 & 10.2 & 1.6 & 0.2 & 0.2 \\
\hline $8 / 12 / 07$ 14:00 & 882 & 6099 & 9837 & 597.8 & 522.1 & 75.7 & 12.7 & 1.14 & 2.2 & 317 & 312 & 2247 & 10.1 & 1.7 & 0.2 & 0.2 \\
\hline $8 / 12 / 07$ 15:00 & 882 & 6126 & 9738 & 592.5 & 517.4 & 75.2 & 12.7 & 1.15 & 2.2 & 318 & 312 & 2242 & 10.0 & 1.7 & 0.2 & 0.2 \\
\hline 8/12/07 16:00 & 883 & 6092 & 9777 & 588.0 & 513.5 & 74.5 & 12.7 & 1.15 & 2.3 & 319 & 314 & 2244 & 10.0 & 1.8 & 0.2 & 0.2 \\
\hline $8 / 12 / 07$ 17:00 & 881 & 6078 & 9812 & 587.8 & 513.3 & 74.5 & 12.7 & 1.15 & 2.3 & 321 & 315 & 2248 & 10.1 & 1.9 & 0.2 & 0.2 \\
\hline $8 / 12 / 07$ 18:00 & 880 & 6082 & 9871 & 591.9 & 516.8 & 75.1 & 12.7 & 1.15 & 2.2 & 320 & 314 & 2245 & 10.1 & 2.0 & 0.2 & 0.2 \\
\hline $8 / 12 / 07$ 19:00 & 883 & 6095 & 9797 & 590.2 & 515.3 & 74.9 & 12.7 & 1.15 & 2.2 & 319 & 314 & 2253 & 9.9 & 2.0 & 0.2 & 0.2 \\
\hline $8 / 12 / 0720: 00$ & 882 & 6055 & 9777 & 591.4 & 516.3 & 75.0 & 12.7 & 1.15 & 2.3 & 319 & 313 & 2252 & 9.9 & 2.0 & 0.2 & 0.2 \\
\hline $8 / 12 / 07$ 21:00 & 881 & 6083 & 9810 & 592.1 & 516.9 & 75.1 & 12.7 & 1.15 & 2.2 & 318 & 313 & 2272 & 10.1 & 2.0 & 0.2 & 0.2 \\
\hline $8 / 12 / 0722: 00$ & 881 & 6109 & 9796 & 588.2 & 513.7 & 74.6 & 12.7 & 1.15 & 2.3 & 317 & 311 & 2271 & 10.4 & 1.9 & 0.2 & 0.2 \\
\hline $8 / 12 / 07$ 23:00 & 881 & 6064 & 9793 & 590.4 & 515.5 & 74.9 & 12.7 & 1.15 & 2.3 & 315 & 309 & 2260 & 10.5 & 1.8 & 0.2 & 0.2 \\
\hline $8 / 13 / 07$ 0:00 & 877 & 6101 & 9891 & 599.3 & 523.1 & 76.2 & 12.7 & 1.14 & 2.2 & 314 & 309 & 2266 & 10.5 & 1.8 & 0.2 & 0.2 \\
\hline $8 / 13 / 07$ 1:00 & 882 & 6093 & 9949 & 607.4 & 530.1 & 77.3 & 12.7 & 1.13 & 2.3 & 315 & 308 & 2276 & 10.4 & 1.8 & 0.2 & 0.2 \\
\hline $8 / 13 / 072: 00$ & 883 & 6074 & 9927 & 616.0 & 537.4 & 78.5 & 12.8 & 1.12 & 2.2 & 314 & 309 & 2271 & 10.6 & 1.8 & 0.2 & 0.2 \\
\hline $8 / 13 / 07$ 3:00 & 882 & 6144 & 9898 & 613.1 & 534.9 & 78.1 & 12.7 & 1.11 & 2.2 & 314 & 308 & 2270 & 10.4 & 1.8 & 0.2 & 0.2 \\
\hline $8 / 13 / 074: 00$ & 884 & 6149 & 9774 & 603.3 & 526.5 & 76.7 & 12.7 & 1.12 & 2.3 & 314 & 305 & 2248 & 10.5 & 1.7 & 0.2 & 0.2 \\
\hline $8 / 13 / 07$ 5:00 & 879 & 6021 & 9686 & 593.4 & 518.1 & 75.3 & 12.7 & 1.13 & 2.2 & 312 & 304 & 2234 & 10.4 & 1.7 & 0.2 & 0.2 \\
\hline $8 / 13 / 076: 00$ & 880 & 6018 & 9744 & 597.4 & 521.6 & 75.9 & 12.7 & 1.13 & 2.2 & 311 & 303 & 2262 & 10.2 & 1.9 & 0.2 & 0.2 \\
\hline $8 / 13 / 07$ 7:00 & 881 & 6023 & 9712 & 597.3 & 521.5 & 75.9 & 12.7 & 1.13 & 2.2 & 310 & 303 & 2261 & 10.1 & 2.0 & 0.2 & 0.2 \\
\hline 8/13/07 8:00 & 881 & 6045 & 9701 & 593.0 & 517.7 & 75.2 & 12.7 & 1.13 & 2.2 & 311 & 303 & 2255 & 10.4 & 1.9 & 0.2 & 0.2 \\
\hline $8 / 13 / 07$ 9:00 & 879 & 6042 & 9705 & 590.3 & 515.4 & 74.9 & 12.7 & 1.14 & 2.3 & 312 & 303 & 2247 & 10.3 & 2.0 & 0.2 & 0.2 \\
\hline $8 / 13 / 07$ 10:00 & 879 & 6052 & 9760 & 591.0 & 516.0 & 75.0 & 12.7 & 1.14 & 2.3 & 312 & 305 & 2250 & 10.1 & 2.1 & 0.2 & 0.2 \\
\hline 8/13/07 11:00 & 881 & 6074 & 9670 & 586.3 & 512.0 & 74.3 & 12.7 & 1.15 & 2.3 & 313 & 307 & 2247 & 10.3 & 2.1 & 0.2 & 0.2 \\
\hline
\end{tabular}




\begin{tabular}{|c|c|c|c|c|c|c|c|c|c|c|c|c|c|c|c|c|}
\hline Date and & $\begin{array}{c}\text { Gross } \\
\text { Gen }\end{array}$ & $\begin{array}{c}\text { Steam } \\
\text { Flow }\end{array}$ & Gross HR & Total Fuel & $\begin{array}{c}\text { Total } \\
\text { Lignite }\end{array}$ & Total PRB & $\begin{array}{l}\text { Total } \\
\text { PRB } \\
\end{array}$ & $\begin{array}{c}\text { Btu } \\
\text { Gain }\end{array}$ & $\begin{array}{c}\text { Econ } \\
\text { O2 }\end{array}$ & $\begin{array}{c}\text { Temp } \\
\text { A APH } \\
\text { Out }\end{array}$ & $\begin{array}{c}\text { Temp } \\
\text { B APH } \\
\text { Out }\end{array}$ & $\begin{array}{l}\text { Stack } \\
\text { Flow }\end{array}$ & Opacity & SO2 In & $\begin{array}{l}\text { SO2 } \\
\text { Out }\end{array}$ & NOx \\
\hline $\begin{array}{l}\text { Start Date } \\
\text { and Time }\end{array}$ & MW & $\begin{array}{c}\text { KLB/ } \\
\text { HR }\end{array}$ & Btu/kWhr & TON/HR & TON/HR & TON/HR & $\begin{array}{c}\% \\
\text { Weight }\end{array}$ & & $\%$ & DEGF & DEGF & KSCF & $\%$ & $\begin{array}{c}\text { Ib/MM } \\
\text { Btu }\end{array}$ & $\begin{array}{c}\text { Ib/MM } \\
\text { Btu }\end{array}$ & $\begin{array}{l}\text { Ib/M } \\
\text { MBtu }\end{array}$ \\
\hline 8/13/07 12:00 & 881 & 6050 & 9704 & 582.2 & 508.5 & 73.7 & 12.7 & 1.15 & 2.2 & 315 & 310 & 2244 & 10.1 & 2.1 & 0.2 & 0.2 \\
\hline 8/13/07 13:00 & 881 & 6044 & 9679 & 577.2 & 504.2 & 73.0 & 12.7 & 1.16 & 2.3 & 314 & 311 & 2241 & 10.1 & 2.1 & 0.2 & 0.2 \\
\hline $8 / 13 / 07$ 14:00 & 876 & 6061 & 9731 & 577.9 & 504.8 & 73.1 & 12.6 & 1.17 & 2.3 & 316 & 311 & 2247 & 10.0 & 2.3 & 0.2 & 0.2 \\
\hline $8 / 13 / 07$ 15:00 & 883 & 6050 & 9762 & 577.8 & 504.7 & 73.1 & 12.7 & 1.17 & 2.2 & 315 & 311 & 2230 & 10.0 & 2.3 & 0.2 & 0.2 \\
\hline $8 / 13 / 07$ 16:00 & 882 & 6065 & 9749 & 574.1 & 501.5 & 72.5 & 12.6 & 1.18 & 2.2 & 316 & 311 & 2213 & 9.7 & 2.3 & 0.2 & 0.2 \\
\hline $8 / 13 / 07$ 17:00 & 883 & 6063 & 9711 & 570.4 & 498.4 & 72.0 & 12.6 & 1.18 & 2.2 & 318 & 312 & 2218 & 9.9 & 2.2 & 0.2 & 0.2 \\
\hline $8 / 13 / 07$ 18:00 & 880 & 6016 & 9714 & 571.0 & 498.9 & 72.1 & 12.6 & 1.18 & 2.3 & 318 & 312 & 2228 & 9.6 & 2.2 & 0.2 & 0.2 \\
\hline 8/13/07 19:00 & 878 & 5995 & 9842 & 584.1 & 510.1 & 74.0 & 12.7 & 1.17 & 2.3 & 319 & 312 & 2253 & 9.9 & 2.2 & 0.2 & 0.2 \\
\hline 8/13/07 20:00 & 880 & 6057 & 9861 & 594.8 & 519.3 & 75.5 & 12.7 & 1.15 & 2.2 & 318 & 311 & 2261 & 10.1 & 2.2 & 0.2 & 0.2 \\
\hline $8 / 13 / 07$ 21:00 & 881 & 6094 & 9840 & 597.9 & 521.9 & 75.9 & 12.7 & 1.14 & 2.2 & 316 & 310 & 2261 & 9.9 & 2.0 & 0.2 & 0.2 \\
\hline $8 / 13 / 07$ 22:00 & 884 & 6058 & 9753 & 598.2 & 522.2 & 76.0 & 12.7 & 1.14 & 2.2 & 315 & 310 & 2261 & 10.2 & 1.9 & 0.2 & 0.2 \\
\hline $8 / 13 / 07$ 23:00 & 882 & 6040 & 9759 & 603.6 & 526.8 & 76.8 & 12.7 & 1.13 & 2.3 & 316 & 310 & 2257 & 10.2 & 1.8 & 0.2 & 0.2 \\
\hline 8/14/07 0:00 & 874 & 6072 & 9884 & 610.3 & 532.5 & 77.7 & 12.7 & 1.12 & 2.3 & 316 & 312 & 2246 & 10.2 & 1.9 & 0.2 & 0.2 \\
\hline $8 / 14 / 07$ 1:00 & 860 & 5942 & 9958 & 606.5 & 524.8 & 81.7 & 13.5 & 1.11 & 2.2 & 325 & 316 & 2239 & 10.0 & 2.0 & 0.2 & 0.2 \\
\hline $8 / 14 / 072: 00$ & 859 & 5900 & 9975 & 622.9 & 539.5 & 83.4 & 13.4 & 1.08 & 2.2 & 325 & 317 & 2225 & 9.3 & 2.1 & 0.2 & 0.2 \\
\hline 8/14/07 3:00 & 864 & 5888 & 9922 & 637.0 & 552.1 & 84.8 & 13.3 & 1.06 & 2.2 & 321 & 313 & 2219 & 9.2 & 2.3 & 0.2 & 0.2 \\
\hline $8 / 14 / 074: 00$ & 875 & 5991 & 9690 & 634.4 & 546.7 & 87.7 & 13.8 & 1.05 & 2.2 & 320 & 313 & 2242 & 9.2 & 2.2 & 0.2 & 0.2 \\
\hline $8 / 14 / 07$ 5:00 & 880 & 6018 & 9513 & 621.1 & 533.0 & 88.2 & 14.2 & 1.06 & 2.3 & 318 & 311 & 2263 & 9.3 & 2.1 & 0.2 & 0.2 \\
\hline $8 / 14 / 076: 00$ & 878 & 5984 & 9634 & 623.1 & 534.6 & 88.5 & 14.2 & 1.07 & 2.3 & 318 & 310 & 2253 & 9.7 & 2.2 & 0.2 & 0.2 \\
\hline $8 / 14 / 07$ 7:00 & 880 & 6021 & 9632 & 621.7 & 519.0 & 102.7 & 16.5 & 1.08 & 2.3 & 319 & 313 & 2261 & 9.7 & 2.2 & 0.2 & 0.2 \\
\hline $8 / 14 / 07$ 8:00 & 877 & 6043 & 9797 & 627.4 & 483.8 & 143.6 & 22.9 & 1.08 & 2.3 & 318 & 318 & 2252 & 9.6 & 2.2 & 0.2 & 0.2 \\
\hline 8/14/07 9:00 & 883 & 6033 & 9726 & 627.9 & 474.9 & 153.0 & 24.4 & 1.08 & 2.2 & 313 & 311 & 2262 & 9.6 & 2.1 & 0.3 & 0.2 \\
\hline $8 / 14 / 07$ 10:00 & 880 & 6062 & 9692 & 623.4 & 473.0 & 150.4 & 24.1 & 1.08 & 2.5 & 312 & 309 & 2282 & 9.7 & 2.0 & 0.3 & 0.2 \\
\hline $8 / 14 / 07$ 11:00 & 879 & 6038 & 9735 & 619.4 & 472.2 & 147.2 & 23.8 & 1.08 & 2.5 & 314 & 311 & 2261 & 9.8 & 2.0 & 0.3 & 0.2 \\
\hline 8/14/07 12:00 & 873 & 6019 & 9726 & 620.9 & 479.1 & 141.8 & 22.8 & 1.09 & 2.5 & 319 & 315 & 2261 & 9.6 & 1.9 & 0.3 & 0.2 \\
\hline $8 / 14 / 07$ 13:00 & 870 & 6026 & 10027 & 639.0 & 552.0 & 87.0 & 13.6 & 1.07 & 2.5 & 330 & 320 & 2262 & 9.3 & 2.0 & 0.3 & 0.2 \\
\hline $8 / 14 / 07$ 14:00 & 884 & 6110 & 9933 & 651.2 & 568.7 & 82.5 & 12.7 & 1.06 & 2.5 & 320 & 313 & 2262 & 9.5 & 2.0 & 0.3 & 0.2 \\
\hline $8 / 14 / 07$ 15:00 & 887 & 6110 & 9839 & 654.3 & 571.7 & 82.6 & 12.6 & 1.05 & 2.4 & 318 & 312 & 2248 & 9.4 & 2.0 & 0.3 & 0.2 \\
\hline $8 / 14 / 07$ 16:00 & 885 & 6069 & 9714 & 643.4 & 562.2 & 81.2 & 12.6 & 1.05 & 2.4 & 320 & 313 & 2237 & 9.1 & 2.0 & 0.3 & 0.2 \\
\hline $8 / 14 / 07$ 17:00 & 882 & 6054 & 9713 & 637.6 & 557.4 & 80.2 & 12.6 & 1.06 & 2.4 & 321 & 313 & 2225 & 9.1 & 2.0 & 0.3 & 0.2 \\
\hline 8/14/07 18:00 & 882 & 6094 & 9603 & 622.5 & 544.5 & 78.0 & 12.5 & 1.07 & 2.4 & 320 & 312 & 2225 & 9.1 & 1.9 & 0.3 & 0.2 \\
\hline
\end{tabular}




\begin{tabular}{|c|c|c|c|c|c|c|c|c|c|c|c|c|c|c|c|c|}
\hline Date and & $\begin{array}{c}\text { Gross } \\
\text { Gen }\end{array}$ & $\begin{array}{c}\text { Steam } \\
\text { Flow }\end{array}$ & Gross HR & Total Fuel & $\begin{array}{c}\text { Total } \\
\text { Lignite }\end{array}$ & Total PRB & $\begin{array}{l}\text { Total } \\
\text { PRB }\end{array}$ & $\begin{array}{c}\text { Btu } \\
\text { Gain }\end{array}$ & $\begin{array}{c}\text { Econ } \\
\text { O2 }\end{array}$ & $\begin{array}{c}\text { Temp } \\
\text { A APH } \\
\text { Out }\end{array}$ & $\begin{array}{c}\text { Temp } \\
\text { B APH } \\
\text { Out }\end{array}$ & $\begin{array}{l}\text { Stack } \\
\text { Flow }\end{array}$ & Opacity & SO2 In & $\begin{array}{l}\text { SO2 } \\
\text { Out }\end{array}$ & NOx \\
\hline $\begin{array}{l}\text { Start Date } \\
\text { and Time }\end{array}$ & MW & $\begin{array}{c}\text { KLB/ } \\
\text { HR }\end{array}$ & Btu/kWhr & TON/HR & TON/HR & TON/HR & $\begin{array}{c}\% \\
\text { Weight }\end{array}$ & & $\%$ & DEGF & DEGF & KSCF & $\%$ & $\begin{array}{c}\text { Ib/MM } \\
\text { Btu }\end{array}$ & $\begin{array}{c}\text { Ib/MM } \\
\text { Btu }\end{array}$ & $\begin{array}{l}\mathbf{l b} / \mathbf{M} \\
\text { MBtu }\end{array}$ \\
\hline 8/14/07 19:00 & 881 & 6066 & 9567 & 607.1 & 531.3 & 75.8 & 12.5 & 1.09 & 2.4 & 319 & 310 & 2219 & 9.2 & 1.7 & 0.2 & 0.2 \\
\hline 8/14/07 20:00 & 878 & 6039 & 9740 & 610.9 & 534.6 & 76.3 & 12.5 & 1.10 & 2.4 & 317 & 309 & 2232 & 9.2 & 1.6 & 0.2 & 0.2 \\
\hline $8 / 14 / 07$ 21:00 & 879 & 6069 & 9893 & 625.5 & 547.1 & 78.4 & 12.5 & 1.09 & 2.4 & 316 & 308 & 2244 & 9.3 & 1.7 & 0.2 & 0.2 \\
\hline 8/14/07 22:00 & 886 & 6119 & 9857 & 629.4 & 550.4 & 79.0 & 12.5 & 1.09 & 2.4 & 315 & 306 & 2244 & 9.0 & 1.8 & 0.3 & 0.2 \\
\hline $8 / 14 / 07$ 23:00 & 888 & 6083 & 9655 & 614.9 & 538.0 & 76.9 & 12.5 & 1.09 & 2.4 & 314 & 306 & 2249 & 9.1 & 1.7 & 0.3 & 0.2 \\
\hline $8 / 15 / 07$ 0:00 & 881 & 6033 & 9705 & 612.2 & 535.5 & 76.8 & 12.5 & 1.10 & 2.4 & 313 & 305 & 2221 & 9.3 & 1.7 & 0.3 & 0.2 \\
\hline 8/15/07 1:00 & 880 & 6065 & 9792 & 613.2 & 535.6 & 77.6 & 12.7 & 1.10 & 2.4 & 313 & 305 & 2225 & 9.3 & 1.6 & 0.3 & 0.2 \\
\hline 8/15/07 2:00 & 879 & 6072 & 9794 & 611.5 & 534.3 & 77.2 & 12.6 & 1.11 & 2.4 & 313 & 304 & 2233 & 9.1 & 1.6 & 0.3 & 0.2 \\
\hline $8 / 15 / 07$ 3:00 & 881 & 6061 & 9790 & 614.2 & 537.2 & 76.9 & 12.5 & 1.11 & 2.4 & 311 & 303 & 2231 & 9.2 & 1.5 & 0.3 & 0.2 \\
\hline $8 / 15 / 074: 00$ & 883 & 6084 & 9648 & 605.7 & 530.1 & 75.6 & 12.5 & 1.11 & 2.3 & 311 & 302 & 2233 & 9.4 & 1.4 & 0.3 & 0.2 \\
\hline $8 / 15 / 075: 00$ & 869 & 5952 & 9681 & 594.3 & 500.5 & 93.9 & 15.8 & 1.12 & 2.5 & 315 & 306 & 2226 & 9.4 & 1.4 & 0.3 & 0.2 \\
\hline $8 / 15 / 076: 00$ & 876 & 6017 & 9914 & 613.7 & 482.5 & 131.2 & 21.4 & 1.11 & 2.5 & 317 & 308 & 2248 & 10.2 & 1.5 & 0.3 & 0.2 \\
\hline 8/15/07 7:00 & 882 & 6067 & 9884 & 624.6 & 479.8 & 144.8 & 23.2 & 1.09 & 2.5 & 311 & 304 & 2261 & 10.1 & 1.5 & 0.3 & 0.2 \\
\hline 8/15/07 8:00 & 884 & 6050 & 9851 & 634.0 & 486.7 & 147.3 & 23.2 & 1.08 & 6.2 & 311 & 304 & 2246 & 10.3 & 1.5 & 0.3 & 0.2 \\
\hline 8/15/07 9:00 & 885 & 6112 & 9770 & 636.5 & 488.9 & 147.6 & 23.2 & 1.07 & 2.3 & 312 & 305 & 2238 & 10.4 & 1.5 & 0.3 & 0.2 \\
\hline 8/15/07 10:00 & 884 & 6096 & 9583 & 614.7 & 470.2 & 144.5 & 23.5 & 1.09 & 2.3 & 312 & 306 & 2246 & 10.3 & 1.4 & 0.2 & 0.2 \\
\hline $8 / 15 / 07$ 11:00 & 880 & 6039 & 9646 & 611.7 & 464.2 & 147.5 & 24.1 & 1.10 & 2.3 & 312 & 307 & 2248 & 10.3 & 1.4 & 0.2 & 0.2 \\
\hline $8 / 15 / 07$ 12:00 & 880 & 6066 & 9869 & 628.5 & 477.7 & 150.9 & 24.0 & 1.09 & 2.3 & 314 & 307 & 2251 & 10.4 & 1.4 & 0.2 & 0.2 \\
\hline 8/15/07 13:00 & 881 & 6153 & 10013 & 643.8 & 489.2 & 154.6 & 24.0 & 1.08 & 2.3 & 315 & 311 & 2250 & 11.1 & 1.5 & 0.3 & 0.2 \\
\hline 8/15/07 14:00 & 884 & 6059 & 9739 & 626.5 & 471.6 & 154.9 & 24.7 & 1.08 & 2.2 & 317 & 311 & 2226 & 10.8 & 1.5 & 0.3 & 0.2 \\
\hline $8 / 15 / 07$ 15:00 & 883 & 6101 & 9577 & 609.8 & 457.3 & 152.6 & 25.0 & 1.09 & 2.3 & 318 & 313 & 2231 & 11.0 & 1.5 & 0.2 & 0.2 \\
\hline $8 / 15 / 07$ 16:00 & 879 & 6038 & 9670 & 602.6 & 451.1 & 151.5 & 25.1 & 1.11 & 2.3 & 318 & 313 & 2233 & 10.5 & 1.5 & 0.2 & 0.2 \\
\hline $8 / 15 / 07$ 17:00 & 874 & 6004 & 9850 & 615.6 & 462.3 & 153.4 & 24.9 & 1.10 & 2.4 & 319 & 312 & 2245 & 9.7 & 1.7 & 0.3 & 0.2 \\
\hline $8 / 15 / 07$ 18:00 & 879 & 6032 & 9925 & 631.6 & 475.9 & 155.7 & 24.6 & 1.09 & 2.3 & 317 & 311 & 2254 & 9.4 & 2.0 & 0.3 & 0.2 \\
\hline 8/15/07 19:00 & 882 & 6108 & 9813 & 632.0 & 476.2 & 155.7 & 24.6 & 1.08 & 2.3 & 316 & 311 & 2264 & 9.3 & 1.9 & 0.3 & 0.2 \\
\hline 8/15/07 20:00 & 885 & 6101 & 9784 & 628.9 & 473.6 & 155.3 & 24.7 & 1.08 & 2.3 & 315 & 310 & 2272 & 10.3 & 2.0 & 0.3 & 0.2 \\
\hline 8/15/07 21:00 & 883 & 6153 & 9734 & 617.5 & 463.8 & 153.7 & 24.9 & 1.09 & 2.3 & 314 & 308 & 2265 & 10.7 & 1.9 & 0.3 & 0.2 \\
\hline 8/15/07 22:00 & 887 & 6111 & 9647 & 605.5 & 453.5 & 152.0 & 25.1 & 1.11 & 2.3 & 313 & 306 & 2267 & 10.7 & 1.9 & 0.3 & 0.2 \\
\hline 8/15/07 23:00 & 885 & 6083 & 9592 & 593.5 & 443.3 & 150.2 & 25.3 & 1.13 & 2.3 & 311 & 304 & 2261 & 10.8 & 1.8 & 0.3 & 0.2 \\
\hline $8 / 16 / 07$ 0:00 & 879 & 6041 & 9700 & 596.3 & 445.7 & 150.7 & 25.3 & 1.13 & 2.3 & 312 & 304 & 2243 & 10.7 & 1.7 & 0.3 & 0.2 \\
\hline $8 / 16 / 07$ 1:00 & 877 & 6053 & 9807 & 603.6 & 451.9 & 151.7 & 25.1 & 1.13 & 2.3 & 312 & 304 & 2240 & 9.8 & 1.7 & 0.3 & 0.2 \\
\hline
\end{tabular}




\begin{tabular}{|c|c|c|c|c|c|c|c|c|c|c|c|c|c|c|c|c|}
\hline Date and & $\begin{array}{c}\text { Gross } \\
\text { Gen }\end{array}$ & $\begin{array}{c}\text { Steam } \\
\text { Flow }\end{array}$ & Gross HR & Total Fuel & $\begin{array}{c}\text { Total } \\
\text { Lignite }\end{array}$ & Total PRB & $\begin{array}{l}\text { Total } \\
\text { PRB }\end{array}$ & $\begin{array}{c}\text { Btu } \\
\text { Gain }\end{array}$ & $\begin{array}{c}\text { Econ } \\
\text { O2 }\end{array}$ & $\begin{array}{c}\text { Temp } \\
\text { A APH } \\
\text { Out }\end{array}$ & $\begin{array}{c}\text { Temp } \\
\text { B APH } \\
\text { Out }\end{array}$ & $\begin{array}{l}\text { Stack } \\
\text { Flow }\end{array}$ & Opacity & SO2 In & $\begin{array}{l}\text { SO2 } \\
\text { Out }\end{array}$ & NOx \\
\hline $\begin{array}{l}\text { Start Date } \\
\text { and Time }\end{array}$ & MW & $\begin{array}{c}\text { KLB/ } \\
\text { HR }\end{array}$ & Btu/kWhr & TON/HR & TON/HR & TON/HR & $\begin{array}{c}\% \\
\text { Weight }\end{array}$ & & $\%$ & DEGF & DEGF & KSCF & $\%$ & $\begin{array}{c}\text { Ib/MM } \\
\text { Btu }\end{array}$ & $\begin{array}{c}\text { Ib/MM } \\
\text { Btu }\end{array}$ & $\begin{array}{l}\mathbf{l b} / \mathbf{M} \\
\text { MBtu }\end{array}$ \\
\hline 8/16/07 2:00 & 881 & 6051 & 9789 & 607.3 & 455.2 & 152.2 & 25.1 & 1.12 & 2.3 & 313 & 304 & 2246 & 9.6 & 1.7 & 0.3 & 0.2 \\
\hline 8/16/07 3:00 & 882 & 6085 & 9721 & 601.8 & 450.4 & 151.4 & 25.2 & 1.12 & 2.3 & 313 & 304 & 2242 & 9.4 & 1.8 & 0.3 & 0.2 \\
\hline 8/16/07 4:00 & 882 & 6075 & 9720 & 595.1 & 444.7 & 150.4 & 25.3 & 1.13 & 2.3 & 312 & 304 & 2245 & 10.0 & 1.7 & 0.3 & 0.2 \\
\hline $8 / 16 / 07$ 5:00 & 880 & 6030 & 9746 & 593.4 & 443.2 & 150.2 & 25.3 & 1.13 & 2.3 & 312 & 304 & 2243 & 10.6 & 1.7 & 0.3 & 0.2 \\
\hline $8 / 16 / 076: 00$ & 881 & 6059 & 9736 & 591.1 & 441.2 & 149.9 & 25.4 & 1.14 & 2.3 & 312 & 304 & 2229 & 10.6 & 1.7 & 0.3 & 0.2 \\
\hline $8 / 16 / 07$ 7:00 & 881 & 6054 & 9635 & 587.0 & 437.7 & 149.3 & 25.4 & 1.14 & 2.3 & 313 & 304 & 2227 & 10.8 & 1.7 & 0.3 & 0.2 \\
\hline 8/16/07 8:00 & 880 & 6041 & 9720 & 585.7 & 436.6 & 149.1 & 25.5 & 1.15 & 2.3 & 313 & 305 & 2240 & 10.7 & 1.7 & 0.3 & 0.2 \\
\hline 8/16/07 9:00 & 880 & 6055 & 9698 & 583.2 & 434.4 & 148.8 & 25.5 & 1.15 & 2.3 & 315 & 307 & 2237 & 10.7 & 1.8 & 0.3 & 0.2 \\
\hline $8 / 16 / 07$ 10:00 & 879 & 6055 & 9737 & 584.4 & 435.5 & 148.9 & 25.5 & 1.16 & 2.3 & 315 & 308 & 2232 & 10.7 & 1.7 & 0.3 & 0.2 \\
\hline $8 / 16 / 07$ 11:00 & 880 & 6091 & 9837 & 586.2 & 437.0 & 149.2 & 25.4 & 1.16 & 2.3 & 315 & 310 & 2241 & 10.8 & 1.8 & 0.3 & 0.2 \\
\hline $8 / 16 / 07$ 12:00 & 880 & 6118 & 9700 & 576.8 & 428.9 & 147.8 & 25.6 & 1.17 & 2.3 & 315 & 310 & 2242 & 10.9 & 1.8 & 0.3 & 0.2 \\
\hline $8 / 16 / 07$ 13:00 & 879 & 6094 & 9700 & 568.9 & 422.2 & 146.7 & 25.8 & 1.18 & 2.3 & 316 & 311 & 2243 & 10.8 & 1.9 & 0.3 & 0.2 \\
\hline $8 / 16 / 07$ 14:00 & 877 & 6049 & 9809 & 575.2 & 427.6 & 147.6 & 25.7 & 1.18 & 2.4 & 317 & 310 & 2239 & 10.7 & 2.0 & 0.4 & 0.2 \\
\hline $8 / 16 / 07$ 15:00 & 878 & 6085 & 9893 & 583.0 & 434.2 & 148.7 & 25.5 & 1.17 & 2.3 & 315 & 309 & 2245 & 10.8 & 2.2 & 0.4 & 0.2 \\
\hline $8 / 16 / 07$ 16:00 & 881 & 6104 & 9810 & 580.6 & 432.2 & 148.4 & 25.6 & 1.17 & 2.3 & 312 & 307 & 2263 & 11.0 & 2.2 & 0.4 & 0.2 \\
\hline $8 / 16 / 07$ 17:00 & 878 & 6108 & 9816 & 582.1 & 433.5 & 148.6 & 25.5 & 1.17 & 2.3 & 312 & 306 & 2265 & 11.1 & 2.2 & 0.4 & 0.2 \\
\hline $8 / 16 / 07$ 18:00 & 879 & 6081 & 9932 & 588.5 & 439.0 & 149.5 & 25.4 & 1.17 & 2.3 & 311 & 303 & 2259 & 11.0 & 2.2 & 0.4 & 0.2 \\
\hline $8 / 16 / 07$ 19:00 & 880 & 6089 & 9882 & 590.8 & 441.0 & 149.8 & 25.4 & 1.16 & 2.3 & 310 & 304 & 2255 & 11.2 & 2.3 & 0.4 & 0.2 \\
\hline $8 / 16 / 07$ 20:00 & 880 & 6114 & 9866 & 592.5 & 442.4 & 150.1 & 25.3 & 1.15 & 2.3 & 310 & 304 & 2259 & 11.2 & 2.5 & 0.5 & 0.2 \\
\hline $8 / 16 / 07$ 21:00 & 879 & 6126 & 9884 & 591.6 & 441.6 & 150.0 & 25.4 & 1.15 & 2.3 & 309 & 301 & 2241 & 11.3 & 2.5 & 0.5 & 0.2 \\
\hline $8 / 16 / 07$ 22:00 & 882 & 6079 & 9854 & 594.2 & 443.9 & 150.3 & 25.3 & 1.15 & 2.3 & 308 & 300 & 2236 & 11.2 & 2.3 & 0.4 & 0.2 \\
\hline $8 / 16 / 07$ 23:00 & 882 & 6090 & 9826 & 593.3 & 443.1 & 150.2 & 25.3 & 1.15 & 2.3 & 309 & 300 & 2235 & 11.2 & 2.2 & 0.4 & 0.2 \\
\hline $8 / 17 / 07$ 0:00 & 882 & 6071 & 9701 & 582.2 & 433.6 & 148.6 & 25.5 & 1.15 & 2.3 & 310 & 300 & 2238 & 10.9 & 2.2 & 0.4 & 0.2 \\
\hline $8 / 17 / 07$ 1:00 & 880 & 6064 & 9666 & 578.9 & 430.8 & 148.1 & 25.6 & 1.16 & 2.3 & 312 & 301 & 2232 & 10.8 & 2.3 & 0.4 & 0.2 \\
\hline 8/17/07 2:00 & 878 & 6008 & 9746 & 584.4 & 435.5 & 148.9 & 25.5 & 1.16 & 2.3 & 312 & 301 & 2229 & 10.7 & 2.3 & 0.4 & 0.2 \\
\hline 8/17/07 3:00 & 881 & 6055 & 9738 & 585.2 & 436.2 & 149.0 & 25.5 & 1.16 & 2.3 & 313 & 302 & 2228 & 10.7 & 2.1 & 0.4 & 0.2 \\
\hline 8/17/07 4:00 & 880 & 6076 & 9689 & 581.0 & 432.6 & 148.4 & 25.5 & 1.16 & 2.3 & 311 & 303 & 2239 & 11.1 & 2.0 & 0.3 & 0.2 \\
\hline 8/17/07 5:00 & 880 & 6046 & 9756 & 583.6 & 434.8 & 148.8 & 25.5 & 1.16 & 2.3 & 314 & 304 & 2247 & 11.5 & 2.2 & 0.4 & 0.2 \\
\hline $8 / 17 / 076: 00$ & 880 & 6030 & 9790 & 589.8 & 440.1 & 149.7 & 25.4 & 1.15 & 2.3 & 313 & 304 & 2237 & 11.5 & 2.5 & 0.5 & 0.2 \\
\hline $8 / 17 / 07$ 7:00 & 881 & 6074 & 9770 & 589.7 & 440.1 & 149.6 & 25.4 & 1.15 & 2.3 & 311 & 303 & 2246 & 11.8 & 2.4 & 0.5 & 0.2 \\
\hline 8/17/07 8:00 & 883 & 6067 & 9730 & 587.5 & 438.2 & 149.3 & 25.4 & 1.15 & 2.3 & 311 & 302 & 2256 & 11.4 & 2.2 & 0.4 & 0.2 \\
\hline
\end{tabular}




\begin{tabular}{|c|c|c|c|c|c|c|c|c|c|c|c|c|c|c|c|c|}
\hline Date and & $\begin{array}{c}\text { Gross } \\
\text { Gen }\end{array}$ & $\begin{array}{c}\text { Steam } \\
\text { Flow }\end{array}$ & Gross HR & Total Fuel & $\begin{array}{c}\text { Total } \\
\text { Lignite }\end{array}$ & Total PRB & $\begin{array}{l}\text { Total } \\
\text { PRB } \\
\end{array}$ & $\begin{array}{c}\text { Btu } \\
\text { Gain }\end{array}$ & $\begin{array}{c}\text { Econ } \\
\text { O2 }\end{array}$ & $\begin{array}{c}\text { Temp } \\
\text { A APH } \\
\text { Out }\end{array}$ & $\begin{array}{c}\text { Temp } \\
\text { B APH } \\
\text { Out }\end{array}$ & $\begin{array}{l}\text { Stack } \\
\text { Flow }\end{array}$ & Opacity & SO2 In & $\begin{array}{l}\text { SO2 } \\
\text { Out }\end{array}$ & NOx \\
\hline $\begin{array}{l}\text { Start Date } \\
\text { and Time }\end{array}$ & MW & $\begin{array}{c}\text { KLB/ } \\
\text { HR }\end{array}$ & Btu/kWhr & TON/HR & TON/HR & TON/HR & $\begin{array}{c}\% \\
\text { Weight }\end{array}$ & & $\%$ & DEGF & DEGF & KSCF & $\%$ & $\begin{array}{c}\text { Ib/MM } \\
\text { Btu }\end{array}$ & $\begin{array}{c}\text { Ib/MM } \\
\text { Btu }\end{array}$ & $\begin{array}{l}\text { Ib/M } \\
\text { MBtu }\end{array}$ \\
\hline 8/17/07 9:00 & 882 & 6057 & 9670 & 582.3 & 433.7 & 148.6 & 25.5 & 1.16 & 2.3 & 312 & 302 & 2252 & 11.2 & 2.1 & 0.4 & 0.2 \\
\hline 8/17/07 10:00 & 878 & 6079 & 9698 & 579.9 & 431.6 & 148.3 & 25.6 & 1.16 & 2.3 & 311 & 303 & 2237 & 11.3 & 2.2 & 0.4 & 0.2 \\
\hline $8 / 17 / 07$ 11:00 & 884 & 6076 & 9761 & 581.8 & 433.2 & 148.6 & 25.5 & 1.17 & 2.3 & 311 & 302 & 2236 & 11.1 & 2.3 & 0.4 & 0.2 \\
\hline $8 / 17 / 07$ 12:00 & 885 & 6088 & 9731 & 580.3 & 432.0 & 148.4 & 25.6 & 1.17 & 2.3 & 313 & 304 & 2247 & 11.1 & 2.2 & 0.4 & 0.2 \\
\hline $8 / 17 / 07$ 13:00 & 884 & 6105 & 9752 & 579.9 & 431.6 & 148.3 & 25.6 & 1.17 & 2.3 & 315 & 308 & 2254 & 11.2 & 2.2 & 0.4 & 0.2 \\
\hline $8 / 17 / 07$ 14:00 & 885 & 6120 & 9731 & 575.4 & 427.8 & 147.7 & 25.7 & 1.18 & 2.3 & 317 & 309 & 2244 & 11.2 & 2.2 & 0.4 & 0.2 \\
\hline $8 / 17 / 07$ 15:00 & 884 & 6073 & 9749 & 580.1 & 431.7 & 148.4 & 25.6 & 1.18 & 2.3 & 318 & 307 & 2246 & 11.1 & 2.2 & 0.4 & 0.2 \\
\hline $8 / 17 / 07$ 16:00 & 886 & 6071 & 9829 & 584.9 & 435.8 & 149.0 & 25.5 & 1.17 & 2.3 & 315 & 306 & 2258 & 11.0 & 2.2 & 0.4 & 0.2 \\
\hline 8/17/07 17:00 & 873 & 6044 & 9700 & 569.9 & 412.2 & 157.7 & 27.7 & 1.17 & 2.3 & 324 & 308 & 2228 & 11.1 & 2.1 & 0.4 & 0.2 \\
\hline $8 / 17 / 07$ 18:00 & 867 & 6019 & 9351 & 537.8 & 392.2 & 145.6 & 27.1 & 1.19 & 2.3 & 323 & 307 & 2206 & 10.9 & 1.9 & 0.5 & 0.2 \\
\hline $8 / 17 / 07$ 19:00 & 881 & 6047 & 9635 & 565.0 & 423.7 & 141.3 & 25.0 & 1.19 & 2.3 & 312 & 302 & 2216 & 10.8 & 1.9 & 0.5 & 0.2 \\
\hline $8 / 17 / 0720: 00$ & 881 & 6059 & 9774 & 569.0 & 424.7 & 144.3 & 25.4 & 1.19 & 2.2 & 310 & 301 & 2217 & 11.0 & 1.9 & 0.5 & 0.2 \\
\hline $8 / 17 / 0721: 00$ & 882 & 6088 & 9768 & 563.6 & 419.0 & 144.6 & 25.7 & 1.20 & 2.2 & 310 & 299 & 2208 & 11.3 & 1.9 & 0.4 & 0.2 \\
\hline $8 / 17 / 07$ 22:00 & 881 & 6079 & 9696 & 562.9 & 420.3 & 142.6 & 25.3 & 1.20 & 2.2 & 312 & 299 & 2197 & 11.2 & 1.9 & 0.4 & 0.2 \\
\hline $8 / 17 / 07$ 23:00 & 882 & 6059 & 9826 & 564.3 & 423.2 & 141.1 & 25.0 & 1.20 & 2.1 & 312 & 300 & 2197 & 11.3 & 2.0 & 0.4 & 0.2 \\
\hline $8 / 18 / 07$ 0:00 & 880 & 6077 & 9754 & 564.1 & 423.1 & 141.0 & 25.0 & 1.20 & 2.2 & 311 & 298 & 2191 & 11.1 & 1.9 & 0.4 & 0.2 \\
\hline $8 / 18 / 07$ 1:00 & 881 & 6122 & 9865 & 567.7 & 425.8 & 141.9 & 25.0 & 1.20 & 2.1 & 310 & 298 & 2202 & 11.3 & 1.9 & 0.4 & 0.2 \\
\hline $8 / 18 / 07$ 2:00 & 887 & 6089 & 9765 & 568.2 & 426.2 & 142.0 & 25.0 & 1.20 & 2.2 & 311 & 299 & 2213 & 11.4 & 1.7 & 0.4 & 0.2 \\
\hline 8/18/07 3:00 & 884 & 6062 & 9856 & 579.6 & 434.7 & 144.9 & 25.0 & 1.19 & 2.2 & 313 & 301 & 2209 & 11.8 & 1.9 & 0.4 & 0.2 \\
\hline $8 / 18 / 074: 00$ & 884 & 6094 & 9912 & 589.4 & 442.1 & 147.3 & 25.0 & 1.17 & 2.3 & 314 & 300 & 2205 & 12.3 & 2.1 & 0.5 & 0.2 \\
\hline $8 / 18 / 07$ 5:00 & 888 & 6100 & 9773 & 589.8 & 442.3 & 147.4 & 25.0 & 1.16 & 2.3 & 313 & 299 & 2223 & 11.7 & 2.1 & 0.5 & 0.2 \\
\hline $8 / 18 / 076: 00$ & 885 & 6117 & 9750 & 587.2 & 440.4 & 146.8 & 25.0 & 1.16 & 2.3 & 312 & 298 & 2233 & 11.6 & 2.1 & 0.5 & 0.2 \\
\hline $8 / 18 / 07$ 7:00 & 885 & 6120 & 9777 & 587.1 & 440.3 & 146.8 & 25.0 & 1.16 & 2.3 & 311 & 298 & 2230 & 11.2 & 2.2 & 0.5 & 0.2 \\
\hline 8/18/07 8:00 & 887 & 6111 & 9750 & 583.5 & 437.6 & 145.8 & 25.0 & 1.16 & 2.3 & 313 & 300 & 2229 & 11.0 & 2.2 & 0.5 & 0.2 \\
\hline 8/18/07 9:00 & 886 & 6092 & 9777 & 581.7 & 436.3 & 145.4 & 25.0 & 1.17 & 2.4 & 314 & 302 & 2233 & 11.2 & 2.2 & 0.5 & 0.2 \\
\hline $8 / 18 / 07$ 10:00 & 884 & 6102 & 9783 & 584.2 & 438.1 & 146.0 & 25.0 & 1.17 & 2.4 & 315 & 304 & 2232 & 11.1 & 2.2 & 0.5 & 0.2 \\
\hline $8 / 18 / 07$ 11:00 & 884 & 6118 & 9792 & 586.1 & 439.6 & 146.5 & 25.0 & 1.17 & 2.3 & 313 & 304 & 2248 & 10.8 & 2.3 & 0.5 & 0.2 \\
\hline 8/18/07 12:00 & 883 & 6134 & 9830 & 586.8 & 440.1 & 146.7 & 25.0 & 1.17 & 2.3 & 313 & 305 & 2257 & 10.8 & 2.2 & 0.5 & 0.2 \\
\hline $8 / 18 / 07$ 13:00 & 885 & 6113 & 9800 & 585.5 & 439.1 & 146.4 & 25.0 & 1.17 & 2.3 & 315 & 306 & 2263 & 10.9 & 2.2 & 0.5 & 0.2 \\
\hline $8 / 18 / 07$ 14:00 & 885 & 6088 & 9690 & 577.9 & 433.5 & 144.5 & 25.0 & 1.17 & 2.3 & 319 & 307 & 2248 & 11.0 & 2.1 & 0.4 & 0.2 \\
\hline $8 / 18 / 07$ 15:00 & 882 & 6060 & 9739 & 573.9 & 430.4 & 143.5 & 25.0 & 1.17 & 2.4 & 318 & 308 & 2252 & 10.8 & 2.1 & 0.4 & 0.2 \\
\hline
\end{tabular}




\begin{tabular}{|c|c|c|c|c|c|c|c|c|c|c|c|c|c|c|c|c|}
\hline Date and & $\begin{array}{c}\text { Gross } \\
\text { Gen }\end{array}$ & $\begin{array}{c}\text { Steam } \\
\text { Flow }\end{array}$ & Gross HR & Total Fuel & $\begin{array}{c}\text { Total } \\
\text { Lignite }\end{array}$ & Total PRB & $\begin{array}{l}\text { Total } \\
\text { PRB }\end{array}$ & $\begin{array}{c}\text { Btu } \\
\text { Gain }\end{array}$ & $\begin{array}{c}\text { Econ } \\
\text { O2 }\end{array}$ & $\begin{array}{c}\text { Temp } \\
\text { A APH } \\
\text { Out }\end{array}$ & $\begin{array}{c}\text { Temp } \\
\text { B APH } \\
\text { Out }\end{array}$ & $\begin{array}{l}\text { Stack } \\
\text { Flow }\end{array}$ & Opacity & SO2 In & $\begin{array}{l}\text { SO2 } \\
\text { Out }\end{array}$ & NOx \\
\hline $\begin{array}{l}\text { Start Date } \\
\text { and Time }\end{array}$ & MW & $\begin{array}{c}\text { KLB/ } \\
\text { HR }\end{array}$ & Btu/kWhr & TON/HR & TON/HR & TON/HR & $\begin{array}{c}\% \\
\text { Weight }\end{array}$ & & $\%$ & DEGF & DEGF & KSCF & $\%$ & $\begin{array}{c}\text { Ib/MM } \\
\text { Btu }\end{array}$ & $\begin{array}{c}\text { Ib/MM } \\
\text { Btu }\end{array}$ & $\begin{array}{l}\mathbf{l b} / \mathbf{M} \\
\text { MBtu }\end{array}$ \\
\hline 8/18/07 16:00 & 881 & 6061 & 9736 & 575.4 & 431.6 & 143.9 & 25.0 & 1.18 & 2.4 & 319 & 310 & 2231 & 10.9 & 2.2 & 0.4 & 0.2 \\
\hline 8/18/07 17:00 & 881 & 6101 & 9768 & 579.9 & 434.9 & 145.0 & 25.0 & 1.18 & 2.3 & 322 & 312 & 2242 & 11.1 & 2.2 & 0.4 & 0.2 \\
\hline $8 / 18 / 07$ 18:00 & 884 & 6107 & 9850 & 580.6 & 435.5 & 145.1 & 25.0 & 1.18 & 2.3 & 320 & 309 & 2254 & 10.9 & 2.2 & 0.4 & 0.2 \\
\hline 8/18/07 19:00 & 880 & 6100 & 9828 & 577.6 & 433.2 & 144.4 & 25.0 & 1.18 & 2.3 & 315 & 307 & 2257 & 10.7 & 2.2 & 0.4 & 0.2 \\
\hline $8 / 18 / 07$ 20:00 & 878 & 6055 & 9843 & 576.9 & 432.7 & 144.2 & 25.0 & 1.18 & 2.2 & 315 & 306 & 2242 & 10.7 & 2.2 & 0.4 & 0.2 \\
\hline 8/18/07 21:00 & 881 & 6081 & 9791 & 574.8 & 431.1 & 143.7 & 25.0 & 1.18 & 2.2 & 316 & 307 & 2235 & 11.1 & 2.0 & 0.4 & 0.2 \\
\hline 8/18/07 22:00 & 882 & 6064 & 9734 & 570.0 & 427.5 & 142.5 & 25.0 & 1.18 & 2.2 & 318 & 307 & 2234 & 11.3 & 1.9 & 0.4 & 0.2 \\
\hline 8/18/07 23:00 & 880 & 6017 & 9735 & 570.9 & 428.2 & 142.7 & 25.0 & 1.18 & 2.1 & 316 & 306 & 2222 & 11.3 & 1.9 & 0.4 & 0.2 \\
\hline 8/19/07 0:00 & 879 & 6001 & 9788 & 579.0 & 434.3 & 144.7 & 25.0 & 1.17 & 2.1 & 314 & 306 & 2201 & 11.3 & 2.1 & 0.4 & 0.2 \\
\hline $8 / 19 / 07$ 1:00 & 881 & 6057 & 9702 & 577.9 & 433.4 & 144.5 & 25.0 & 1.17 & 2.1 & 316 & 306 & 2199 & 11.5 & 2.1 & 0.4 & 0.2 \\
\hline $8 / 19 / 072: 00$ & 884 & 6061 & 9670 & 574.4 & 430.8 & 143.6 & 25.0 & 1.17 & 2.1 & 314 & 304 & 2208 & 11.7 & 2.1 & 0.4 & 0.2 \\
\hline $8 / 19 / 07$ 3:00 & 884 & 6082 & 9708 & 575.4 & 431.5 & 143.8 & 25.0 & 1.18 & 2.1 & 313 & 301 & 2208 & 11.6 & 2.1 & 0.4 & 0.2 \\
\hline 8/19/07 4:00 & 881 & 6070 & 9685 & 570.4 & 427.8 & 142.6 & 25.0 & 1.18 & 2.1 & 313 & 301 & 2201 & 11.8 & 2.1 & 0.4 & 0.2 \\
\hline 8/19/07 5:00 & 879 & 6033 & 9766 & 568.4 & 426.3 & 142.1 & 25.0 & 1.18 & 2.1 & 311 & 299 & 2196 & 12.0 & 2.0 & 0.4 & 0.2 \\
\hline 8/19/07 6:00 & 879 & 5982 & 9749 & 574.7 & 431.0 & 143.6 & 25.0 & 1.18 & 2.1 & 312 & 300 & 2191 & 12.2 & 1.9 & 0.4 & 0.2 \\
\hline 8/19/07 7:00 & 882 & 5991 & 9681 & 576.8 & 432.6 & 144.2 & 25.0 & 1.17 & 2.1 & 314 & 301 & 2187 & 11.6 & 1.9 & 0.4 & 0.2 \\
\hline 8/19/07 8:00 & 883 & 6019 & 9642 & 577.9 & 433.4 & 144.5 & 25.0 & 1.17 & 2.1 & 316 & 303 & 2202 & 11.6 & 1.8 & 0.3 & 0.2 \\
\hline $8 / 19 / 07$ 9:00 & 884 & 6063 & 9649 & 579.5 & 434.6 & 144.8 & 25.0 & 1.17 & 2.1 & 316 & 302 & 2208 & 11.6 & 1.8 & 0.3 & 0.2 \\
\hline 8/19/07 10:00 & 884 & 6035 & 9744 & 584.3 & 438.2 & 146.1 & 25.0 & 1.16 & 2.1 & 315 & 302 & 2203 & 11.4 & 1.9 & 0.4 & 0.2 \\
\hline 8/19/07 11:00 & 886 & 6053 & 9721 & 587.4 & 440.5 & 146.9 & 25.0 & 1.16 & 2.0 & 317 & 304 & 2201 & 11.4 & 1.9 & 0.3 & 0.2 \\
\hline $8 / 19 / 07$ 12:00 & 885 & 6064 & 9694 & 586.3 & 439.7 & 146.6 & 25.0 & 1.16 & 2.1 & 319 & 306 & 2211 & 11.4 & 1.6 & 0.3 & 0.2 \\
\hline $8 / 19 / 07$ 13:00 & 886 & 6105 & 9652 & 579.2 & 434.4 & 144.8 & 25.0 & 1.16 & 2.1 & 320 & 308 & 2213 & 11.4 & 1.4 & 0.2 & 0.2 \\
\hline $8 / 19 / 07$ 14:00 & 880 & 6077 & 9654 & 572.7 & 429.5 & 143.2 & 25.0 & 1.17 & 2.1 & 319 & 308 & 2207 & 11.5 & 1.3 & 0.2 & 0.2 \\
\hline $8 / 19 / 07$ 15:00 & 883 & 6027 & 9713 & 579.6 & 434.7 & 144.8 & 25.0 & 1.17 & 2.1 & 321 & 309 & 2211 & 11.5 & 1.3 & 0.2 & 0.2 \\
\hline 8/19/07 16:00 & 882 & 6067 & 9775 & 583.7 & 437.8 & 145.9 & 25.0 & 1.16 & 2.1 & 324 & 309 & 2218 & 11.7 & 1.3 & 0.2 & 0.2 \\
\hline 8/19/07 17:00 & 887 & 6072 & 9789 & 587.4 & 440.6 & 146.8 & 25.0 & 1.16 & 2.0 & 324 & 311 & 2228 & 11.6 & 1.3 & 0.2 & 0.2 \\
\hline 8/19/07 18:00 & 886 & 6057 & 9752 & 588.9 & 441.7 & 147.2 & 25.0 & 1.16 & 2.1 & 324 & 312 & 2228 & 11.7 & 1.4 & 0.2 & 0.2 \\
\hline 8/19/07 19:00 & 883 & 6085 & 9816 & 591.6 & 443.7 & 147.9 & 25.0 & 1.15 & 2.1 & 321 & 311 & 2228 & 11.5 & 1.5 & 0.3 & 0.2 \\
\hline 8/19/07 20:00 & 885 & 6101 & 9818 & 593.7 & 445.3 & 148.4 & 25.0 & 1.15 & 2.0 & 321 & 309 & 2228 & 11.4 & 1.6 & 0.3 & 0.2 \\
\hline $8 / 19 / 0721: 00$ & 884 & 6112 & 9816 & 594.5 & 445.9 & 148.6 & 25.0 & 1.15 & 2.1 & 320 & 308 & 2227 & 11.5 & 1.7 & 0.3 & 0.2 \\
\hline $8 / 19 / 07$ 22:00 & 885 & 6115 & 9780 & 594.1 & 445.6 & 148.5 & 25.0 & 1.15 & 2.0 & 320 & 308 & 2235 & 11.5 & 1.7 & 0.3 & 0.2 \\
\hline
\end{tabular}




\begin{tabular}{|c|c|c|c|c|c|c|c|c|c|c|c|c|c|c|c|c|}
\hline Date and & $\begin{array}{c}\text { Gross } \\
\text { Gen }\end{array}$ & $\begin{array}{c}\text { Steam } \\
\text { Flow }\end{array}$ & Gross HR & Total Fuel & $\begin{array}{c}\text { Total } \\
\text { Lignite }\end{array}$ & Total PRB & $\begin{array}{l}\text { Total } \\
\text { PRB }\end{array}$ & $\begin{array}{c}\text { Btu } \\
\text { Gain }\end{array}$ & $\begin{array}{c}\text { Econ } \\
\text { O2 }\end{array}$ & $\begin{array}{c}\text { Temp } \\
\text { A APH } \\
\text { Out }\end{array}$ & $\begin{array}{c}\text { Temp } \\
\text { B APH } \\
\text { Out }\end{array}$ & $\begin{array}{l}\text { Stack } \\
\text { Flow }\end{array}$ & Opacity & SO2 In & $\begin{array}{l}\text { SO2 } \\
\text { Out }\end{array}$ & NOx \\
\hline $\begin{array}{l}\text { Start Date } \\
\text { and Time }\end{array}$ & MW & $\begin{array}{c}\text { KLB/ } \\
\text { HR }\end{array}$ & Btu/kWhr & TON/HR & TON/HR & TON/HR & $\begin{array}{c}\% \\
\text { Weight }\end{array}$ & & $\%$ & DEGF & DEGF & KSCF & $\%$ & $\begin{array}{c}\text { Ib/MM } \\
\text { Btu }\end{array}$ & $\begin{array}{c}\text { Ib/MM } \\
\text { Btu }\end{array}$ & $\begin{array}{l}\mathbf{l b} / \mathbf{M} \\
\text { MBtu }\end{array}$ \\
\hline 8/19/07 23:00 & 886 & 6111 & 9791 & 589.5 & 442.1 & 147.3 & 25.0 & 1.15 & 2.1 & 320 & 307 & 2231 & 11.5 & 1.5 & 0.3 & 0.2 \\
\hline 8/20/07 0:00 & 881 & 6128 & 9731 & 587.0 & 440.3 & 146.7 & 25.0 & 1.16 & 2.1 & 319 & 308 & 2219 & 11.6 & 1.5 & 0.3 & 0.2 \\
\hline $8 / 20 / 07$ 1:00 & 882 & 6105 & 9823 & 589.8 & 442.4 & 147.4 & 25.0 & 1.16 & 2.0 & 317 & 305 & 2215 & 11.6 & 1.5 & 0.3 & 0.2 \\
\hline $8 / 20 / 072: 00$ & 885 & 6095 & 9762 & 586.0 & 439.5 & 146.5 & 25.0 & 1.16 & 2.1 & 313 & 303 & 2211 & 11.7 & 1.6 & 0.3 & 0.2 \\
\hline $8 / 20 / 073: 00$ & 884 & 6058 & 9758 & 586.1 & 439.6 & 146.5 & 25.0 & 1.16 & 2.0 & 313 & 301 & 2220 & 12.0 & 1.6 & 0.3 & 0.2 \\
\hline $8 / 20 / 074: 00$ & 880 & 6103 & 9773 & 587.6 & 440.7 & 146.9 & 25.0 & 1.16 & 2.1 & 312 & 300 & 2220 & 12.4 & 1.7 & 0.3 & 0.2 \\
\hline 8/20/07 5:00 & 884 & 6100 & 9745 & 585.3 & 439.0 & 146.3 & 25.0 & 1.16 & 2.1 & 312 & 300 & 2223 & 12.8 & 1.6 & 0.3 & 0.2 \\
\hline 8/20/07 6:00 & 882 & 6078 & 9781 & 586.7 & 435.4 & 151.3 & 25.8 & 1.16 & 2.2 & 313 & 300 & 2238 & 12.8 & 1.5 & 0.3 & 0.2 \\
\hline $8 / 20 / 07$ 7:00 & 883 & 6131 & 9782 & 581.5 & 430.4 & 151.2 & 26.0 & 1.16 & 2.2 & 312 & 299 & 2236 & 13.1 & 1.5 & 0.3 & 0.2 \\
\hline 8/20/07 8:00 & 881 & 6134 & 9722 & 573.3 & 425.0 & 148.4 & 25.9 & 1.18 & 2.2 & 310 & 297 & 2238 & 9.6 & 1.4 & 0.2 & 0.2 \\
\hline 8/20/07 9:00 & 881 & 6082 & 9787 & 573.5 & 428.8 & 144.8 & 25.2 & 1.18 & 2.2 & 312 & 299 & 2224 & 7.2 & 1.4 & 0.2 & 0.2 \\
\hline $8 / 20 / 07$ 10:00 & 879 & 6078 & 9847 & 579.5 & 433.8 & 145.8 & 25.1 & 1.18 & 2.2 & 312 & 300 & 2220 & 10.5 & 1.5 & 0.3 & 0.2 \\
\hline 8/20/07 11:00 & 883 & 6052 & 9877 & 590.8 & 442.6 & 148.3 & 25.1 & 1.16 & 2.2 & 313 & 301 & 2218 & 7.3 & 1.5 & 0.3 & 0.2 \\
\hline 8/20/07 12:00 & 883 & 6102 & 9897 & 595.1 & 446.3 & 148.8 & 25.0 & 1.15 & 2.2 & 315 & 303 & 2224 & 8.6 & 1.5 & 0.3 & 0.2 \\
\hline 8/20/07 13:00 & 883 & 6126 & 9861 & 592.0 & 444.0 & 148.0 & 25.0 & 1.15 & 2.2 & 318 & 305 & 2241 & 8.6 & 1.5 & 0.3 & 0.2 \\
\hline $8 / 20 / 07$ 14:00 & 883 & 6109 & 9720 & 582.3 & 436.7 & 145.6 & 25.0 & 1.16 & 2.3 & 317 & 306 & 2239 & 8.5 & 1.4 & 0.2 & 0.2 \\
\hline $8 / 20 / 07$ 15:00 & 881 & 6063 & 9762 & 581.5 & 436.1 & 145.4 & 25.0 & 1.16 & 2.4 & 321 & 308 & 2256 & 18.6 & 1.4 & 0.2 & 0.2 \\
\hline $8 / 20 / 07$ 16:00 & 881 & 6055 & 9761 & 583.7 & 437.8 & 145.9 & 25.0 & 1.16 & 2.3 & 322 & 310 & 2233 & 23.0 & 1.4 & 0.2 & 0.2 \\
\hline $8 / 20 / 07$ 17:00 & 880 & 6087 & 9809 & 583.9 & 437.9 & 145.9 & 25.0 & 1.16 & 2.3 & 321 & 311 & 2233 & 8.7 & 1.4 & 0.2 & 0.2 \\
\hline 8/20/07 18:00 & 880 & 6080 & 9892 & 590.8 & 443.1 & 147.6 & 25.0 & 1.16 & 2.3 & 322 & 311 & 2239 & 9.1 & 1.4 & 0.2 & 0.2 \\
\hline $8 / 20 / 07$ 19:00 & 883 & 6086 & 9877 & 595.5 & 446.7 & 148.9 & 25.0 & 1.15 & 2.2 & 322 & 311 & 2243 & 9.1 & 1.5 & 0.3 & 0.2 \\
\hline $8 / 20 / 0720: 00$ & 882 & 6086 & 9877 & 601.0 & 450.7 & 150.2 & 25.0 & 1.14 & 2.2 & 322 & 311 & 2242 & 9.2 & 1.5 & 0.3 & 0.2 \\
\hline 8/20/07 21:00 & 878 & 6144 & 9973 & 605.7 & 454.3 & 151.4 & 25.0 & 1.14 & 2.3 & 319 & 307 & 2244 & 9.2 & 1.5 & 0.3 & 0.2 \\
\hline $8 / 20 / 0722: 00$ & 887 & 6071 & 9809 & 608.2 & 456.1 & 152.0 & 25.0 & 1.13 & 2.2 & 316 & 305 & 2241 & 9.0 & 1.5 & 0.3 & 0.2 \\
\hline 8/20/07 23:00 & 885 & 6078 & 9741 & 606.5 & 454.8 & 151.6 & 25.0 & 1.12 & 2.2 & 316 & 305 & 2228 & 9.2 & 1.5 & 0.3 & 0.2 \\
\hline 8/21/07 0:00 & 883 & 6110 & 9727 & 602.0 & 451.5 & 150.5 & 25.0 & 1.13 & 2.2 & 314 & 302 & 2223 & 9.3 & 1.5 & 0.3 & 0.2 \\
\hline 8/21/07 1:00 & 883 & 6054 & 9798 & 604.3 & 453.2 & 151.0 & 25.0 & 1.12 & 2.2 & 314 & 301 & 2226 & 9.2 & 1.5 & 0.2 & 0.2 \\
\hline $8 / 21 / 072: 00$ & 880 & 6037 & 9875 & 613.6 & 460.2 & 153.4 & 25.0 & 1.11 & 2.2 & 313 & 300 & 2224 & 9.1 & 1.5 & 0.3 & 0.2 \\
\hline $8 / 21 / 073: 00$ & 883 & 6082 & 9801 & 617.3 & 463.0 & 154.3 & 25.0 & 1.10 & 2.2 & 313 & 300 & 2221 & 9.1 & 1.5 & 0.3 & 0.2 \\
\hline $8 / 21 / 074: 00$ & 885 & 6087 & 9750 & 613.0 & 459.8 & 153.2 & 25.0 & 1.11 & 2.2 & 314 & 302 & 2223 & 8.8 & 1.5 & 0.2 & 0.2 \\
\hline $8 / 21 / 075: 00$ & 884 & 6078 & 9677 & 607.5 & 455.6 & 151.9 & 25.0 & 1.11 & 2.3 & 314 & 301 & 2217 & 8.6 & 1.4 & 0.2 & 0.2 \\
\hline
\end{tabular}




\begin{tabular}{|c|c|c|c|c|c|c|c|c|c|c|c|c|c|c|c|c|}
\hline Date and & $\begin{array}{c}\text { Gross } \\
\text { Gen }\end{array}$ & $\begin{array}{c}\text { Steam } \\
\text { Flow }\end{array}$ & Gross HR & Total Fuel & $\begin{array}{c}\text { Total } \\
\text { Lignite }\end{array}$ & Total PRB & $\begin{array}{l}\text { Total } \\
\text { PRB } \\
\end{array}$ & $\begin{array}{c}\text { Btu } \\
\text { Gain }\end{array}$ & $\begin{array}{c}\text { Econ } \\
\text { O2 }\end{array}$ & $\begin{array}{c}\text { Temp } \\
\text { A APH } \\
\text { Out }\end{array}$ & $\begin{array}{c}\text { Temp } \\
\text { B APH } \\
\text { Out }\end{array}$ & $\begin{array}{l}\text { Stack } \\
\text { Flow }\end{array}$ & Opacity & SO2 In & $\begin{array}{l}\text { SO2 } \\
\text { Out }\end{array}$ & NOx \\
\hline $\begin{array}{l}\text { Start Date } \\
\text { and Time }\end{array}$ & MW & $\begin{array}{c}\text { KLB/ } \\
\text { HR }\end{array}$ & Btu/kWhr & TON/HR & TON/HR & TON/HR & $\begin{array}{c}\% \\
\text { Weight }\end{array}$ & & $\%$ & DEGF & DEGF & KSCF & $\%$ & $\begin{array}{c}\text { Ib/MM } \\
\text { Btu }\end{array}$ & $\begin{array}{c}\text { Ib/MM } \\
\text { Btu }\end{array}$ & $\begin{array}{l}\text { Ib/M } \\
\text { MBtu }\end{array}$ \\
\hline 8/21/07 6:00 & 883 & 6065 & 9678 & 602.7 & 452.0 & 150.7 & 25.0 & 1.12 & 2.3 & 311 & 300 & 2224 & 8.7 & 1.5 & 0.2 & 0.2 \\
\hline 8/21/07 7:00 & 883 & 6064 & 9707 & 599.8 & 449.9 & 149.9 & 25.0 & 1.12 & 2.2 & 312 & 300 & 2229 & 8.9 & 1.5 & 0.2 & 0.2 \\
\hline $8 / 21 / 078: 00$ & 880 & 6079 & 9743 & 597.7 & 448.3 & 149.4 & 25.0 & 1.13 & 2.3 & 310 & 299 & 2228 & 9.4 & 1.5 & 0.2 & 0.2 \\
\hline 8/21/07 9:00 & 883 & 6082 & 9727 & 597.0 & 447.8 & 149.2 & 25.0 & 1.14 & 2.2 & 310 & 300 & 2245 & 9.4 & 1.5 & 0.2 & 0.2 \\
\hline $8 / 21 / 07$ 10:00 & 882 & 6096 & 9785 & 592.8 & 444.6 & 148.2 & 25.0 & 1.14 & 2.3 & 311 & 300 & 2250 & 9.0 & 1.4 & 0.2 & 0.2 \\
\hline $8 / 21 / 07$ 11:00 & 881 & 6067 & 9786 & 596.4 & 447.3 & 149.1 & 25.0 & 1.14 & 2.2 & 314 & 301 & 2245 & 8.9 & 1.5 & 0.2 & 0.2 \\
\hline $8 / 21 / 07$ 12:00 & 881 & 6088 & 9784 & 597.3 & 448.0 & 149.3 & 25.0 & 1.14 & 2.2 & 316 & 303 & 2252 & 9.0 & 1.5 & 0.2 & 0.2 \\
\hline $8 / 21 / 07$ 13:00 & 884 & 6073 & 9738 & 598.1 & 448.6 & 149.5 & 25.0 & 1.14 & 2.2 & 318 & 305 & 2266 & 9.2 & 1.5 & 0.2 & 0.2 \\
\hline $8 / 21 / 07$ 14:00 & 881 & 6094 & 9783 & 594.5 & 445.9 & 148.6 & 25.0 & 1.14 & 2.2 & 319 & 307 & 2269 & 8.9 & 1.5 & 0.2 & 0.2 \\
\hline $8 / 21 / 07$ 15:00 & 879 & 6080 & 9782 & 591.0 & 443.3 & 147.8 & 25.0 & 1.15 & 2.2 & 318 & 307 & 2255 & 8.8 & 1.6 & 0.2 & 0.2 \\
\hline $8 / 21 / 07$ 16:00 & 881 & 6038 & 9795 & 590.7 & 443.0 & 147.7 & 25.0 & 1.14 & 2.2 & 317 & 307 & 2233 & 8.8 & 1.8 & 0.3 & 0.2 \\
\hline $8 / 21 / 07$ 17:00 & 866 & 6003 & 9767 & 585.1 & 461.5 & 123.6 & 21.1 & 1.14 & 2.2 & 320 & 313 & 2201 & 8.5 & 2.0 & 0.4 & 0.2 \\
\hline 8/21/07 18:00 & 868 & 6026 & 9946 & 598.8 & 523.9 & 74.9 & 12.5 & 1.13 & 2.3 & 318 & 316 & 2210 & 7.9 & 2.3 & 0.4 & 0.2 \\
\hline $8 / 21 / 07$ 19:00 & 885 & 6084 & 9778 & 604.9 & 529.3 & 75.6 & 12.5 & 1.13 & 2.2 & 315 & 312 & 2241 & 7.8 & 2.3 & 0.5 & 0.2 \\
\hline $8 / 21 / 0720: 00$ & 884 & 6090 & 9768 & 602.1 & 526.9 & 75.3 & 12.5 & 1.13 & 2.2 & 315 & 312 & 2244 & 7.3 & 2.5 & 0.5 & 0.2 \\
\hline $8 / 21 / 07$ 21:00 & 883 & 6089 & 9784 & 601.1 & 525.9 & 75.1 & 12.5 & 1.13 & 2.3 & 314 & 310 & 2234 & 7.5 & 2.6 & 0.5 & 0.2 \\
\hline $8 / 21 / 07$ 22:00 & 884 & 6074 & 9756 & 598.1 & 523.3 & 74.8 & 12.5 & 1.13 & 2.3 & 313 & 309 & 2232 & 7.7 & 2.6 & 0.5 & 0.2 \\
\hline $8 / 21 / 07$ 23:00 & 883 & 6061 & 9739 & 597.5 & 522.8 & 74.7 & 12.5 & 1.13 & 2.2 & 311 & 309 & 2229 & 7.5 & 2.5 & 0.5 & 0.2 \\
\hline $8 / 22 / 07$ 0:00 & 881 & 6097 & 9724 & 592.9 & 518.8 & 74.1 & 12.5 & 1.14 & 2.2 & 310 & 310 & 2227 & 7.7 & 2.2 & 0.4 & 0.2 \\
\hline $8 / 22 / 07$ 1:00 & 881 & 6079 & 9750 & 589.0 & 515.4 & 73.6 & 12.5 & 1.15 & 2.4 & 311 & 306 & 2222 & 8.0 & 2.1 & 0.4 & 0.2 \\
\hline $8 / 22 / 07$ 2:00 & 879 & 6023 & 9750 & 588.0 & 514.5 & 73.5 & 12.5 & 1.15 & 2.3 & 308 & 305 & 2212 & 7.7 & 2.0 & 0.4 & 0.2 \\
\hline 8/22/07 3:00 & 880 & 6057 & 9772 & 591.2 & 517.3 & 73.9 & 12.5 & 1.14 & 2.2 & 307 & 303 & 2211 & 8.0 & 1.9 & 0.3 & 0.2 \\
\hline $8 / 22 / 074: 00$ & 882 & 6066 & 9745 & 593.0 & 518.9 & 74.1 & 12.5 & 1.14 & 2.3 & 307 & 303 & 2218 & 7.7 & 1.7 & 0.3 & 0.2 \\
\hline $8 / 22 / 075: 00$ & 882 & 6051 & 9793 & 600.0 & 525.0 & 75.0 & 12.5 & 1.14 & 2.2 & 308 & 304 & 2231 & 7.2 & 1.6 & 0.3 & 0.2 \\
\hline $8 / 22 / 076: 00$ & 880 & 6095 & 9866 & 606.6 & 530.8 & 75.8 & 12.5 & 1.13 & 2.2 & 307 & 303 & 2235 & 8.2 & 1.6 & 0.3 & 0.2 \\
\hline $8 / 22 / 07$ 7:00 & 881 & 6085 & 9900 & 613.7 & 535.9 & 77.8 & 12.7 & 1.12 & 2.3 & 307 & 303 & 2225 & 8.2 & 1.5 & 0.3 & 0.2 \\
\hline $8 / 22 / 078: 00$ & 860 & 5952 & 9852 & 603.6 & 523.7 & 80.0 & 13.3 & 1.11 & 2.2 & 309 & 307 & 2201 & 8.4 & 1.5 & 0.2 & 0.2 \\
\hline $8 / 22 / 07$ 9:00 & 877 & 6077 & 9779 & 609.6 & 534.2 & 75.4 & 12.4 & 1.11 & 2.2 & 315 & 312 & 2231 & 8.9 & 1.5 & 0.2 & 0.2 \\
\hline $8 / 22 / 07$ 10:00 & 864 & 6054 & 9858 & 605.4 & 529.4 & 75.9 & 12.5 & 1.11 & 2.3 & 315 & 308 & 2240 & 8.7 & 1.5 & 0.2 & 0.2 \\
\hline $8 / 22 / 07$ 11:00 & 873 & 6032 & 9865 & 615.2 & 537.5 & 77.7 & 12.6 & 1.10 & 2.3 & 319 & 311 & 2246 & 8.9 & 1.5 & 0.2 & 0.2 \\
\hline $8 / 22 / 07$ 12:00 & 884 & 6107 & 9822 & 618.1 & 540.9 & 77.3 & 12.5 & 1.10 & 2.6 & 313 & 309 & 2281 & 9.3 & 1.4 & 0.2 & 0.2 \\
\hline
\end{tabular}




\begin{tabular}{|c|c|c|c|c|c|c|c|c|c|c|c|c|c|c|c|c|}
\hline Date and & $\begin{array}{c}\text { Gross } \\
\text { Gen }\end{array}$ & $\begin{array}{c}\text { Steam } \\
\text { Flow }\end{array}$ & Gross HR & Total Fuel & $\begin{array}{c}\text { Total } \\
\text { Lignite }\end{array}$ & Total PRB & $\begin{array}{l}\text { Total } \\
\text { PRB }\end{array}$ & $\begin{array}{l}\text { Btu } \\
\text { Gain }\end{array}$ & $\begin{array}{c}\text { Econ } \\
\text { O2 }\end{array}$ & $\begin{array}{c}\text { Temp } \\
\text { A APH } \\
\text { Out }\end{array}$ & $\begin{array}{c}\text { Temp } \\
\text { B APH } \\
\text { Out }\end{array}$ & $\begin{array}{l}\text { Stack } \\
\text { Flow }\end{array}$ & Opacity & SO2 In & $\begin{array}{l}\text { SO2 } \\
\text { Out }\end{array}$ & NOx \\
\hline $\begin{array}{l}\text { Start Date } \\
\text { and Time }\end{array}$ & MW & $\begin{array}{c}\text { KLB/ } \\
\text { HR }\end{array}$ & Btu/kWhr & TON/HR & TON/HR & TON/HR & $\begin{array}{c}\% \\
\text { Weight }\end{array}$ & & $\%$ & DEGF & DEGF & KSCF & $\%$ & $\begin{array}{c}\text { Ib/MM } \\
\text { Btu }\end{array}$ & $\begin{array}{c}\text { lb/MM } \\
\text { Btu }\end{array}$ & $\begin{array}{l}\text { Ib/M } \\
\text { MBtu }\end{array}$ \\
\hline 8/22/07 13:00 & 884 & 6130 & 9732 & 608.9 & 532.8 & 76.1 & 12.5 & 1.11 & 8.0 & 313 & 308 & 2282 & 9.5 & 1.4 & 0.2 & 0.2 \\
\hline 8/22/07 14:00 & 881 & 6089 & 9784 & 608.2 & 532.2 & 76.0 & 12.5 & 1.12 & 3.0 & 312 & 308 & 2284 & 9.5 & 1.4 & 0.2 & 0.2 \\
\hline 8/22/07 15:00 & 881 & 6092 & 9859 & 609.9 & 533.6 & 76.2 & 12.5 & 1.12 & 2.6 & 311 & 307 & 2273 & 9.6 & 1.4 & 0.2 & 0.2 \\
\hline 8/22/07 16:00 & 883 & 6101 & 9831 & 609.5 & 533.3 & 76.2 & 12.5 & 1.12 & 2.6 & 314 & 309 & 2259 & 10.0 & 1.5 & 0.2 & 0.2 \\
\hline $8 / 22 / 07$ 17:00 & 880 & 6096 & 9732 & 598.7 & 500.9 & 97.8 & 16.3 & 1.13 & 2.6 & 312 & 309 & 2262 & 9.4 & 1.6 & 0.3 & 0.2 \\
\hline 8/22/07 18:00 & 877 & 6044 & 9739 & 592.1 & 445.8 & 146.3 & 24.7 & 1.14 & 2.6 & 316 & 318 & 2275 & 9.3 & 1.7 & 0.3 & 0.2 \\
\hline 8/22/07 19:00 & 879 & 6079 & 9751 & 591.7 & 443.8 & 147.9 & 25.0 & 1.14 & 2.6 & 310 & 312 & 2268 & 9.5 & 1.7 & 0.3 & 0.2 \\
\hline 8/22/07 20:00 & 879 & 6101 & 9823 & 593.1 & 444.8 & 148.3 & 25.0 & 1.15 & 2.5 & 311 & 310 & 2266 & 9.8 & 1.7 & 0.3 & 0.2 \\
\hline 8/22/07 21:00 & 880 & 6107 & 9873 & 595.2 & 446.3 & 148.8 & 25.0 & 1.15 & 2.5 & 309 & 308 & 2270 & 9.7 & 1.7 & 0.3 & 0.2 \\
\hline 8/22/07 22:00 & 884 & 6094 & 9813 & 595.0 & 446.3 & 148.7 & 25.0 & 1.15 & 2.5 & 306 & 305 & 2264 & 9.7 & 1.7 & 0.3 & 0.2 \\
\hline 8/22/07 23:00 & 882 & 6084 & 9823 & 597.5 & 448.2 & 149.4 & 25.0 & 1.14 & 2.6 & 305 & 304 & 2273 & 10.0 & 1.6 & 0.3 & 0.2 \\
\hline
\end{tabular}




\section{APPENDIX D - DUCT VELOCITY RESULTS}


For all runs, port A was on the far right, when facing downstream the direction of flue gas flow and additional ports ran the width of the duct alphabetically. 
Table D-1. Inlet Delta P, Temperature, and Velocity Measurements (performed 11/29/06)

\begin{tabular}{|r|c|}
\hline date & $11 / 29 / 06$ \\
\hline time & $1700-1740$ \\
\hline moisture & 13.5 \\
\hline O2 & 5 \\
\hline CO2 & 16 \\
\hline static & -11 \\
\hline barometric & 29.32 \\
\hline gas m.w. & 29.04 \\
\hline pitot correction factor & 0.84 \\
\hline absolute stack pressure & 28.51 \\
\hline
\end{tabular}

\begin{tabular}{|c|c|c|c|c|c|c|c|c|c|}
\hline \multirow[b]{2}{*}{$\begin{array}{l}\text { Port Depth } \\
\text { (in.) }\end{array}$} & \multicolumn{3}{|c|}{$\overline{\bar{B}}$} & \multicolumn{3}{|c|}{$\overline{\overline{\mathbf{E}}}$} & \multicolumn{3}{|c|}{$\overline{\mathbf{H}}$} \\
\hline & $\begin{array}{c}\text { Delta P } \\
\left.\text { (in. } \mathbf{H}_{2} \mathbf{0}\right)\end{array}$ & $\begin{array}{c}\mathbf{T} \\
\left({ }^{\mathbf{0}} \mathbf{F}\right)\end{array}$ & $\begin{array}{c}\text { Velocity } \\
\text { (ft/sec) }\end{array}$ & $\begin{array}{c}\text { Delta P } \\
\left(\text { in. } \mathbf{H}_{2} \mathbf{0}\right)\end{array}$ & $\begin{array}{c}\mathbf{T} \\
\left({ }^{\mathbf{0}} \mathbf{F}\right)\end{array}$ & $\begin{array}{c}\text { Velocity } \\
\text { (ft/sec) }\end{array}$ & $\begin{array}{c}\text { Delta P } \\
\left(\text { in. } \mathbf{H}_{2} \mathbf{0}\right)\end{array}$ & $\begin{array}{c}\mathbf{T} \\
\left({ }^{\mathbf{0}} \mathbf{F}\right)\end{array}$ & $\begin{array}{c}\text { Velocity } \\
\text { (ft/sec) }\end{array}$ \\
\hline 32.675 & $\bar{~} 1.15$ & 329 & $\overline{75.18}$ & $\overline{0.47}$ & 311 & $\overline{447.51}$ & $\overline{0.8}$ & $\overline{319}$ & $\overline{62.30}$ \\
\hline 62.525 & 0.96 & 328 & 68.64 & 0.43 & 318 & 45.65 & 0.77 & 323 & 61.28 \\
\hline 92.375 & 0.69 & 328 & 58.20 & 0.44 & 317 & 46.15 & 0.63 & 321 & 55.36 \\
\hline 122.225 & 0.83 & 328 & 63.83 & 0.74 & 330 & 60.34 & 1.2 & 336 & 77.14 \\
\hline 152.095 & 1.1 & 321 & 73.15 & 0.81 & 324 & 62.89 & 1.4 & 335 & 83.26 \\
\hline
\end{tabular}

\begin{tabular}{|c|c|c|c|c|c|c|c|c|c|}
\hline \multirow[b]{2}{*}{$\begin{array}{l}\text { Port Depth } \\
\text { (in.) }\end{array}$} & \multicolumn{3}{|c|}{$\mathbf{L}$} & \multicolumn{3}{|c|}{$\mathbf{M}$} & \multicolumn{3}{|c|}{$\mathbf{O}$} \\
\hline & $\begin{array}{c}\text { Delta P } \\
\left.\text { (in. } \mathrm{H}_{2} \mathbf{0}\right) \\
\end{array}$ & $\begin{array}{c}\mathbf{T} \\
\left({ }^{0} \mathbf{F}\right) \\
\end{array}$ & $\begin{array}{c}\text { Velocity } \\
\text { (ft/sec) }\end{array}$ & \begin{tabular}{|c|} 
Delta P \\
(in. $\left.\mathrm{H}_{2} \mathbf{0}\right)$
\end{tabular} & $\begin{array}{c}\mathbf{T} \\
\left({ }^{\mathbf{0}} \mathbf{F}\right) \\
\end{array}$ & $\begin{array}{c}\text { Velocity } \\
\text { (ft/sec) }\end{array}$ & $\begin{array}{c}\text { Delta P } \\
\left.\text { (in. } \mathrm{H}_{2} \mathbf{0}\right) \\
\end{array}$ & $\begin{array}{c}\mathbf{T} \\
\left({ }^{0} \mathbf{F}\right) \\
\end{array}$ & $\begin{array}{c}\text { Velocity } \\
\text { (ft/sec) }\end{array}$ \\
\hline 32.675 & 0.77 & 311 & 60.81 & 0.68 & 304 & 56.89 & 0.94 & 311 & 67.19 \\
\hline 62.525 & 0.79 & 310 & 61.56 & 0.49 & 301 & 48.19 & 0.91 & 313 & 66.19 \\
\hline 92.375 & 0.56 & 309 & 51.79 & 0.43 & 296 & 45.00 & 0.55 & 313 & 51.46 \\
\hline 122.225 & 0.84 & 315 & 63.68 & 0.62 & 302 & 54.25 & 0.7 & 310 & 57.94 \\
\hline 152.095 & 0.66 & 307 & 56.15 & 0.54 & 305 & 50.73 & 0.85 & 300 & 63.43 \\
\hline
\end{tabular}

Data compiled from single velocity traverse, performed 11/29/06. Moisture is average of nlet runs from 11/30/06. 
Table D-2. ACI Ports Delta P, Temperature, and Velocity Measurements (performed 11/28/06)

\begin{tabular}{|r|c|}
\hline date & $11 / 28 / 06$ \\
\hline time & $1450-1502$ \\
\hline moisture & 13.5 \\
\hline $\mathbf{O 2}$ & 5 \\
\hline CO2 & 16 \\
\hline static & -11 \\
\hline barometric & 29.32 \\
\hline gas m.w. & 29.04 \\
\hline pitot correction factor & 0.84 \\
\hline absolute stack pressure & 28.51 \\
\hline
\end{tabular}

\begin{tabular}{|c|c|c|c|c|c|c|c|c|}
\hline \multirow[b]{2}{*}{$\begin{array}{l}\text { Port Depth } \\
\text { (in.) }\end{array}$} & \multicolumn{3}{|c|}{$\overline{\mathbf{A}}$} & \multicolumn{3}{|c|}{$\overline{\mathrm{C}}$} & \multicolumn{2}{|r|}{$\bar{E}$} \\
\hline & $\begin{array}{c}\text { Delta P } \\
\left(\text { in. } \mathrm{H}_{2} \mathbf{0}\right)\end{array}$ & $\begin{array}{c}\mathrm{T} \\
\left({ }^{\mathbf{0}} \mathbf{F}\right)\end{array}$ & $\begin{array}{c}\text { Velocity } \\
\text { (ft/sec) }\end{array}$ & $\begin{array}{c}\text { Delta P } \\
\left.\text { (in. } \mathrm{H}_{2} \mathbf{0}\right)\end{array}$ & $\begin{array}{c}\mathbf{T} \\
\left({ }^{\mathbf{0}} \mathbf{F}\right)\end{array}$ & $\begin{array}{c}\text { Velocity } \\
\text { (ft/sec) }\end{array}$ & \begin{tabular}{|c|} 
Delta P \\
$\left(\right.$ in. $\left.\mathrm{H}_{2} \mathbf{0}\right)$ \\
\end{tabular} & $\begin{array}{c}\mathrm{T} \\
\left({ }^{0} \mathbf{F}\right)\end{array}$ \\
\hline 17.625 & 0.86 & 300 & 63.81 & 0.77 & 302 & 60.45 & 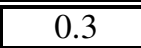 & 324 \\
\hline 52.875 & 0.92 & 333 & 67.41 & 0.65 & 322 & 56.27 & 0.25 & 324 \\
\hline 88.125 & 0.66 & 331 & 57.03 & 0.65 & 326 & 56.41 & 0.27 & 327 \\
\hline 123.375 & 0.72 & 330 & 59.52 & 0.85 & 326 & 64.51 & 0.31 & 328 \\
\hline
\end{tabular}

\begin{tabular}{|c|c|c|c|c|c|c|}
\hline \multirow[b]{2}{*}{$\begin{array}{l}\text { Port Depth } \\
\text { (in.) }\end{array}$} & \multicolumn{3}{|c|}{$\mathbf{G}$} & \multicolumn{3}{|c|}{$\mathbf{I}$} \\
\hline & $\begin{array}{c}\text { Delta P } \\
\left(\text { in. } \mathbf{H}_{2} \mathbf{0}\right) \\
\end{array}$ & $\begin{array}{c}\mathbf{T} \\
\left({ }^{\mathbf{0}} \mathbf{F}\right)\end{array}$ & $\begin{array}{c}\text { Velocity } \\
\text { (ft/sec) }\end{array}$ & $\begin{array}{r}\text { Delta P } \\
\left.\text { (in. } \mathrm{H}_{2} \mathbf{0}\right) \\
\end{array}$ & $\begin{array}{c}\mathbf{T} \\
\left({ }^{\mathbf{0}} \mathbf{F}\right)\end{array}$ & $\begin{array}{c}\text { Velocity } \\
\text { (ft/sec) }\end{array}$ \\
\hline 17.625 & 0.85 & 330 & 64.67 & 0.75 & 325 & 60.56 \\
\hline 52.875 & 0.77 & 332 & 61.63 & 0.7 & 327 & 58.58 \\
\hline 88.125 & 0.63 & 333 & 55.78 & 0.63 & 326 & 55.54 \\
\hline 123.375 & 0.9 & 332 & 66.63 & 0.64 & 325 & 55.94 \\
\hline
\end{tabular}

Data compiled from single velocity traverse, performed 11/28/06. Moisture and O2/CO2 compiled from inlet runs performed 11/30/06. 
Table D-3. Toxecon Delta P, Temperature, and Velocity Measurements (performed 4/30/07)

\begin{tabular}{|r|c|}
\hline date & $4 / 30 / 07$ \\
\hline time & $1031-1256$ \\
\hline moisture & 12 \\
\hline O2 & 7.6 \\
\hline CO2 & 12 \\
\hline static & -12 \\
\hline barometric & 29.78 \\
\hline gas m.w. & 28.76 \\
\hline pitot correction factor & 0.84 \\
\hline absolute stack pressure & 28.90 \\
\hline \hline
\end{tabular}

\begin{tabular}{|c|c|c|c|c|c|c|c|c|c|c|c|c|}
\hline \multirow[b]{2}{*}{$\begin{array}{l}\text { Port Depth } \\
\text { (in.) }\end{array}$} & \multicolumn{3}{|c|}{ B } & \multicolumn{3}{|c|}{$\overline{\bar{C} \mathbf{C}}$} & \multicolumn{3}{|c|}{$\bar{D}$} & \multicolumn{3}{|c|}{$\overline{\mathbf{E}}$} \\
\hline & \begin{tabular}{|c|} 
Delta P \\
(in. $\left.\mathrm{H}_{2} \mathbf{0}\right)$ \\
\end{tabular} & $\begin{array}{c}\mathrm{T} \\
\left({ }^{0} \mathbf{F}\right)\end{array}$ & $\begin{array}{c}\text { Velocity } \\
(\mathrm{ft} / \mathrm{sec})\end{array}$ & \begin{tabular}{|c|} 
Delta P \\
(in. $\left.\mathbf{H}_{2} \mathbf{0}\right)$ \\
\end{tabular} & $\begin{array}{c}\mathrm{T} \\
\left({ }^{0} \mathbf{F}\right)\end{array}$ & $\begin{array}{c}\begin{array}{c}\text { Velocity } \\
\text { (ft/sec) }\end{array} \\
\end{array}$ & \begin{tabular}{|l|} 
Delta P \\
(in. $\mathbf{H}_{2} \mathbf{0}$ ) \\
\end{tabular} & $\begin{array}{c}\mathrm{T} \\
\left({ }^{0} \mathbf{F}\right)\end{array}$ & $\begin{array}{c}\begin{array}{c}\text { Velocity } \\
\text { (ft/sec) }\end{array} \\
\end{array}$ & $\begin{array}{r}\text { Delta P } \\
\left.\text { (in. } \mathrm{H}_{2} \mathbf{0}\right) \\
\end{array}$ & $\begin{array}{c}\mathbf{T} \\
\left({ }^{0} \mathbf{F}\right)\end{array}$ & $\begin{array}{r}\text { Velocity } \\
\text { (ft/sec) }\end{array}$ \\
\hline 10 & 0.005 & 257 & 4.72 & 0.005 & 336 & 4.97 & 0.008 & 242 & 5.90 & 0.008 & 243 & 5.91 \\
\hline 31 & 0.019 & 337 & 9.69 & 0.014 & 335 & 8.31 & 0.008 & 334 & 6.28 & 0.01 & 332 & 7.01 \\
\hline 42 & 0.02 & 338 & 9.95 & 0.014 & 337 & 8.32 & 0.01 & 334 & 7.02 & 0.012 & 333 & 7.68 \\
\hline 63 & 0.019 & 337 & 9.69 & 0.016 & 336 & 8.89 & 0.01 & 335 & 7.02 & 0.008 & 334 & 6.28 \\
\hline 84 & 0.021 & 335 & 10.18 & 0.02 & 334 & 9.93 & 0.014 & 334 & 8.31 & 0.013 & 332 & 7.99 \\
\hline 105 & 0.021 & 300 & 9.95 & 0.023 & 323 & 10.57 & 0.017 & 332 & 9.14 & 0.019 & 326 & 9.63 \\
\hline
\end{tabular}

Data compiled from single M17 run, 4/30/07 
Table D-4. Duct 1A1 Delta P, Temperature, and Velocity Measurements (performed 4/26/07)

\begin{tabular}{|r|c|}
\hline date & $4 / 26 / 07$ \\
\hline time & $1046-1226$ \\
\hline moisture & 12 \\
\hline O2 & 7.6 \\
\hline CO2 & 12 \\
\hline static & -13.5 \\
\hline barometric & 29.6 \\
\hline gas m.w. & 28.76 \\
\hline pitot correction factor & 0.84 \\
\hline absolute stack pressure & 28.61 \\
\hline
\end{tabular}

\begin{tabular}{|c|c|c|c|c|c|c|c|c|c|}
\hline \multirow[b]{2}{*}{$\begin{array}{c}\text { Port Depth } \\
\text { (in.) }\end{array}$} & \multicolumn{3}{|c|}{$\bar{F}$} & \multicolumn{3}{|c|}{$\overline{\mathbf{G}}$} & \multicolumn{3}{|c|}{$\overline{\mathbf{H}}$} \\
\hline & \begin{tabular}{|c|} 
Delta P \\
$\left(\right.$ in. $\left.\mathbf{H}_{2} \mathbf{0}\right)$ \\
\end{tabular} & $\begin{array}{c}\mathbf{T} \\
\left({ }^{0} \mathbf{F}\right)\end{array}$ & $\begin{array}{c}\text { Velocity } \\
\text { (ft/sec) }\end{array}$ & \begin{tabular}{|c|} 
Delta P \\
$\left(\right.$ in. $\left.\mathrm{H}_{2} \mathbf{0}\right)$ \\
\end{tabular} & $\begin{array}{c}\mathbf{T} \\
\left({ }^{\mathbf{0}} \mathbf{F}\right)\end{array}$ & $\begin{array}{c}\text { Velocity } \\
\text { (ft/sec) }\end{array}$ & $\begin{array}{c}\text { Delta P } \\
\left(\text { in. } \mathrm{H}_{2} \mathbf{0}\right) \\
\end{array}$ & $\begin{array}{c}\mathbf{T} \\
\left({ }^{0} \mathbf{F}\right)\end{array}$ & $\begin{array}{c}\text { Velocity } \\
\text { (ft/sec) }\end{array}$ \\
\hline 24 & 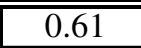 & 324 & 54.75 & 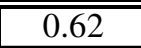 & 323 & 55.16 & 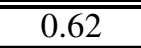 & 322 & 55.13 \\
\hline 38.5 & 0.71 & 325 & 59.11 & 0.68 & 324 & 57.81 & 0.66 & 322 & 56.88 \\
\hline 53 & 0.97 & 322 & 68.96 & 0.99 & 324 & 69.75 & 0.89 & 322 & 66.05 \\
\hline 67.5 & 0.62 & 320 & 55.06 & 0.55 & 323 & 51.96 & 0.53 & 322 & 50.97 \\
\hline 82 & 0.65 & 320 & 56.38 & 0.4 & 323 & 44.31 & 0.48 & 321 & 48.48 \\
\hline 96.5 & 0.52 & 322 & 50.49 & 0.4 & 323 & 44.31 & 0.42 & 322 & 45.37 \\
\hline 111 & 0.57 & 318 & 52.72 & 0.62 & 321 & 55.09 & 0.56 & 321 & 52.36 \\
\hline 126 & 1.3 & 318 & 79.62 & 1.3 & 318 & 79.62 & 1.4 & 317 & 82.58 \\
\hline
\end{tabular}

Data compiled from single M17 run, performed 4/26/07. 
Table D-5. Duct 1 A2 Delta P, Temperature, and Velocity Measurements (performed 11/30/06)

\begin{tabular}{|r|c|}
\hline date & $11 / 30 / 06$ \\
\hline time & -- \\
\hline moisture & 14.4 \\
\hline O2 & 6.85 \\
\hline CO2 & 13.67 \\
\hline static & -12 \\
\hline barometric & 29.44 \\
\hline gas m.w. & 28.67 \\
\hline pitot correction factor & 0.84 \\
\hline absolute stack pressure & 28.56 \\
\hline
\end{tabular}

\begin{tabular}{|c|c|c|c|c|c|c|c|c|c|}
\hline \multirow[b]{2}{*}{$\begin{array}{c}\text { Port Depth } \\
\text { (in.) }\end{array}$} & \multicolumn{3}{|c|}{$\overline{\mathrm{A}}$} & \multicolumn{3}{|c|}{$\overline{\text { B }}$} & \multicolumn{3}{|c|}{$\overline{\overline{C C}}$} \\
\hline & $\begin{array}{c}\text { delta P } \\
\left(\text { in. } \mathrm{H}_{2} \mathbf{0}\right)\end{array}$ & $\begin{array}{c}\mathbf{T} \\
\left({ }^{0} \mathbf{F}\right)\end{array}$ & $\begin{array}{c}\text { Velocity } \\
\text { (ft/sec) }\end{array}$ & $\begin{array}{c}\text { Delta P } \\
\left(\text { in. } \mathrm{H}_{2} \mathbf{0}\right)\end{array}$ & $\begin{array}{c}\mathbf{T} \\
\left({ }^{0} \mathbf{F}\right)\end{array}$ & $\begin{array}{c}\text { Velocity } \\
\text { (ft/sec) }\end{array}$ & $\begin{array}{c}\text { Delta P } \\
\left.\text { (in. } \mathrm{H}_{2} \mathbf{0}\right)\end{array}$ & $\begin{array}{c}\mathbf{T} \\
\left({ }^{0} \mathbf{F}\right)\end{array}$ & $\begin{array}{c}\text { Velocity } \\
\text { (ft/sec) }\end{array}$ \\
\hline 5.777 & 0.42 & 333 & 45.80 & 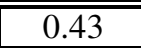 & 333 & 46.35 & 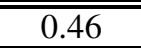 & 333 & 477.94 \\
\hline 17.33 & 0.49 & 333 & 49.47 & 0.49 & 333 & 49.47 & 0.5 & 333 & 49.98 \\
\hline 28.88 & 0.53 & 333 & 51.45 & 0.53 & 333 & 51.45 & 0.53 & 333 & 51.45 \\
\hline 40.43 & 0.63 & 333 & 56.10 & 0.77 & 333 & 62.02 & 0.76 & 333 & 61.62 \\
\hline 51.98 & 0.61 & 333 & 55.20 & 0.7 & 333 & 59.13 & 0.73 & 333 & 60.39 \\
\hline 63.53 & 0.47 & 333 & 48.45 & 0.41 & 333 & 45.26 & 0.45 & 333 & 47.41 \\
\hline 75.08 & 0.44 & 333 & 46.88 & 0.3 & 333 & 38.71 & 0.45 & 333 & 47.41 \\
\hline 86.63 & 0.39 & 333 & 44.14 & 0.32 & 333 & 39.98 & 0.38 & 333 & 43.57 \\
\hline 98.18 & 0.34 & 333 & 41.21 & 0.26 & 333 & 36.04 & 0.29 & 333 & 38.06 \\
\hline
\end{tabular}

Data compiled from single velocity traverse, performed 11/30/06. Data sheet only included

delta Ps. Barometric pressure taken from inlet runs 11/30/06. Moisture, O2/CO2, static pressure and average stack temperature compiled from 1a1 runs performed 6/20/07 and $6 / 21 / 07$. 
Table D-6. Duct 1B1 Delta P, Temperature, and Velocity Measurements (performed 11/30/06)

\begin{tabular}{|r|c|}
\hline date & $11 / 30 / 06$ \\
\hline time & -- \\
\hline moisture & 14.8 \\
\hline O2 & 5.9 \\
\hline CO2 & 14 \\
\hline static & -12 \\
\hline barometric & 29.44 \\
\hline gas m.w. & 28.63 \\
\hline pitot correction factor & 0.84 \\
\hline absolute stack pressure & 28.56 \\
\hline
\end{tabular}

\begin{tabular}{|c|c|c|c|c|c|c|}
\hline \multirow[b]{2}{*}{$\begin{array}{c}\text { Port Depth } \\
\text { (in.) }\end{array}$} & \multicolumn{3}{|c|}{$\overline{\bar{A}}$} & \multicolumn{3}{|c|}{$\overline{\overline{\mathbf{B}}}$} \\
\hline & $\begin{array}{c}\text { Delta P } \\
\left(\text { in. } \mathrm{H}_{2} \mathbf{0}\right)\end{array}$ & $\begin{array}{c}\mathbf{T} \\
\left({ }^{0} \mathbf{F}\right)\end{array}$ & $\begin{array}{l}\text { Velocity } \\
\text { (ft/sec) }\end{array}$ & $\begin{array}{c}\text { Delta P } \\
\left.\text { (in. } \mathrm{H}_{2} \mathbf{0}\right)\end{array}$ & $\begin{array}{c}\mathbf{T} \\
\left({ }^{0} \mathrm{~F}\right)\end{array}$ & $\begin{array}{l}\text { Velocity } \\
\text { (ft/sec) }\end{array}$ \\
\hline 5.777 & 0.56 & 284 & 51.26 & 0.98 & 284 & 67.81 \\
\hline 17.33 & 0.76 & 284 & 59.72 & 0.91 & 284 & 65.35 \\
\hline 28.88 & 0.72 & 284 & 58.13 & 0.74 & 284 & 58.93 \\
\hline 40.43 & 0.68 & 284 & 56.49 & 0.75 & 284 & 59.33 \\
\hline 51.98 & 0.69 & 284 & 56.90 & 0.75 & 284 & 59.33 \\
\hline 63.53 & 0.68 & 284 & 56.49 & 0.76 & 284 & 59.72 \\
\hline 75.08 & 0.77 & 284 & 60.11 & 0.8 & 284 & 61.27 \\
\hline 86.63 & 0.92 & 284 & 65.71 & 0.9 & 284 & 64.99 \\
\hline 98.18 & 0.33 & 284 & 39.35 & 0.72 & 284 & 58.13 \\
\hline
\end{tabular}

\footnotetext{
Data compiled from single velocity traverse, performed 11/30/06. Data sheet only included delta Ps. Barometric pressure taken from inlet runs 11/30/06. Moisture, O2/CO2, static pressure and average stack temperature compiled from 1 b2 runs performed 6/20/07 and 6/21/07.
} 
Table D-7. Duct 1B2 Delta P, Temperature, and Velocity Measurements (performed 6/20/07)

\begin{tabular}{|r|c|}
\hline date & $6 / 20 / 07$ \\
\hline time & $1010-1224$ \\
\hline moisture & 15 \\
\hline O2 & 5.8 \\
\hline CO2 & 14 \\
\hline static & -12 \\
\hline barometric & 29.72 \\
\hline gas m.w. & 28.60 \\
\hline pitot correction factor & 0.84 \\
\hline absolute stack pressure & 28.84 \\
\hline
\end{tabular}

\begin{tabular}{|c|c|c|c|c|c|c|c|c|c|}
\hline \multirow[b]{2}{*}{$\begin{array}{c}\text { Port Depth } \\
\text { (in.) }\end{array}$} & \multicolumn{3}{|c|}{$\bar{F}$} & \multicolumn{3}{|c|}{$\overline{\mathbf{G}}$} & \multicolumn{3}{|c|}{$\overline{\mathbf{H}}$} \\
\hline & \begin{tabular}{|c|} 
Delta P \\
$\left(\right.$ in. $\left.\mathbf{H}_{2} \mathbf{0}\right)$ \\
\end{tabular} & $\begin{array}{c}\mathbf{T} \\
\left({ }^{0} \mathbf{F}\right)\end{array}$ & $\begin{array}{c}\text { Velocity } \\
\text { (ft/sec) }\end{array}$ & \begin{tabular}{|c|} 
Delta P \\
$\left(\right.$ in. $\left.\mathrm{H}_{2} \mathbf{0}\right)$ \\
\end{tabular} & $\begin{array}{c}\mathbf{T} \\
\left({ }^{\mathbf{0}} \mathbf{F}\right)\end{array}$ & $\begin{array}{c}\text { Velocity } \\
\text { (ft/sec) }\end{array}$ & $\begin{array}{c}\text { Delta P } \\
\left(\text { in. } \mathrm{H}_{2} \mathbf{0}\right) \\
\end{array}$ & $\begin{array}{c}\mathbf{T} \\
\left({ }^{0} \mathbf{F}\right)\end{array}$ & $\begin{array}{c}\text { Velocity } \\
\text { (ft/sec) }\end{array}$ \\
\hline 24 & 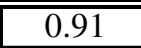 & 283 & 65.02 & 0.83 & 286 & 62.22 & 0.89 & 287 & 64.47 \\
\hline 38.5 & 0.91 & 282 & 64.97 & 0.95 & 287 & 66.61 & 0.98 & 288 & 67.70 \\
\hline 53 & 0.64 & 282 & 54.49 & 0.97 & 288 & 67.35 & 0.85 & 291 & 63.18 \\
\hline 67.5 & 0.94 & 282 & 66.04 & 0.78 & 286 & 60.32 & 0.92 & 288 & 65.59 \\
\hline 82 & 0.96 & 278 & 66.56 & 0.74 & 286 & 58.75 & 0.9 & 287 & 64.83 \\
\hline 96.5 & 0.78 & 279 & 60.03 & 0.75 & 284 & 59.07 & 0.55 & 286 & 50.65 \\
\hline 111 & 0.80 & 279 & 60.80 & 0.84 & 284 & 62.51 & 0.64 & 286 & 54.64 \\
\hline 126 & 0.86 & 278 & 62.99 & 0.83 & 283 & 62.09 & 0.65 & 286 & 55.06 \\
\hline
\end{tabular}

Data compiled from single M5/OH run, performed 6/20/07. 
Table D-8. Velocity Traverse for ESP Inlet 2D1 Parametric Phase IV

\begin{tabular}{|r|r|}
\hline date & $6 / 10 / 2009$ \\
\hline time & $908-1736$ \\
\hline moisture & 14.03 \\
\hline $\mathbf{O}_{2}$ & 5.55 \\
\hline $\mathbf{C O}_{2}$ & 12.67 \\
\hline static & -12.50 \\
\hline barometric & 29.36 \\
\hline gas m.w. & 28.53 \\
\hline $\begin{array}{r}\text { pitot correction } \\
\text { factor }\end{array}$ & 0.84 \\
\hline $\begin{array}{r}\text { absolute stack } \\
\text { pressure }\end{array}$ & 28.44 \\
\hline |
\end{tabular}

\begin{tabular}{|c|c|c|c|c|c|c|c|c|c|c|c|c|}
\hline & & D1 & & & D2 & & & D3 & & & D4 & \\
\hline Port Depth (in.) & $\begin{array}{c}\text { Delta P } \\
\left(\text { in. } \mathrm{H}_{2} \mathrm{O}\right)\end{array}$ & $\begin{array}{c}\mathbf{T} \\
\left({ }^{\mathbf{0}} \mathbf{F}\right)\end{array}$ & $\begin{array}{c}\text { Velocity } \\
\text { (ft/sec) }\end{array}$ & $\begin{array}{c}\text { Delta P } \\
\text { (in. } \\
\left.\mathrm{H}_{2} \mathrm{O}\right)\end{array}$ & $\begin{array}{c}\mathbf{T} \\
\left({ }^{\mathbf{0}} \mathbf{F}\right)\end{array}$ & $\begin{array}{c}\text { Velocity } \\
\text { (ft/sec) }\end{array}$ & $\begin{array}{c}\text { Delta P } \\
\text { (in. } \\
\left.\mathrm{H}_{2} \mathrm{O}\right)\end{array}$ & $\begin{array}{c}\mathbf{T} \\
\left({ }^{\mathbf{0}} \mathbf{F}\right) \\
\end{array}$ & $\begin{array}{c}\text { Velocity } \\
\text { (ft/sec) }\end{array}$ & $\begin{array}{c}\text { Delta P } \\
\text { (in. } \\
\left.\mathrm{H}_{2} \mathrm{O}\right)\end{array}$ & $\begin{array}{c}\mathbf{T} \\
\left({ }^{\mathbf{0}} \mathbf{F}\right) \\
\end{array}$ & $\begin{array}{c}\text { Velocity } \\
\text { (ft/sec) }\end{array}$ \\
\hline 24 & 0.76 & 335 & 62.0 & 1.45 & 345 & 86.1 & 1.35 & 334 & 82.5 & 0.93 & 329 & 67.1 \\
\hline 48 & 1.10 & 343 & 74.9 & 1.35 & 346 & 83.1 & 0.92 & 340 & 68.4 & 1.03 & 337 & 71.4 \\
\hline 72 & 0.96 & 346 & 70.1 & 0.74 & 345 & 61.5 & 0.70 & 339 & 59.6 & 0.92 & 337 & 67.4 \\
\hline 96 & 1.15 & 346 & 76.7 & 0.96 & 344 & 70.0 & 0.84 & 337 & 65.2 & 1.05 & 337 & 72.3 \\
\hline 120 & 1.10 & 335 & 74.6 & 0.92 & 345 & 68.6 & 0.90 & 334 & 67.2 & 1.10 & 329 & 73.2 \\
\hline
\end{tabular}

Data compiled from Method 17 Runs performed on ESP Inlet Duct 2D-1 on 6-10-09. Velocity data is the average of two separate runs at each port, moisture data is the average of two separate moisture trains--one performed in conjunction with the 4 morning samples, one performed with the 4 afternoon samples. Ports are named from left to right facing downstream (facing the ESP). 
Table D-9. Velocity Travese for ESP Outlet 2D1 Parametric Phase IV

\begin{tabular}{|r|r|}
\hline date & $6 / 10 / 2009$ \\
\hline time & $905-1744$ \\
\hline moisture & 14.57 \\
\hline $\mathbf{O}_{\mathbf{2}}$ & 4.92 \\
$\mathbf{C O}_{\mathbf{2}}$ & 12.67 \\
static & -13.00 \\
\hline barometric & 29.42 \\
\hline gas m.w. & 28.44 \\
\hline $\begin{array}{r}\text { pitot correction } \\
\text { factor }\end{array}$ & 0.84 \\
\hline $\begin{array}{r}\text { absolute stack } \\
\text { pressure }\end{array}$ & 28.40 \\
\hline
\end{tabular}

\begin{tabular}{|c|c|c|c|c|c|c|c|c|c|}
\hline \multirow[b]{2}{*}{ Port Depth (in.) } & \multirow[b]{2}{*}{$\begin{array}{c}\text { Delta P } \\
\left(\text { in. } \mathrm{H}_{2} \mathrm{O}\right)\end{array}$} & \multicolumn{3}{|l|}{$\overline{\mathbf{A}}$} & \multicolumn{2}{|l|}{ B } & \multicolumn{2}{|r|}{$\mathbf{C}$} & \multirow[b]{2}{*}{$\begin{array}{c}\text { Velocity } \\
(\mathrm{ft} / \mathrm{sec})\end{array}$} \\
\hline & & $\begin{array}{c}\mathbf{T} \\
\left({ }^{\mathbf{0}} \mathbf{F}\right)\end{array}$ & $\begin{array}{l}\text { Velocity } \\
\text { (ft/sec) }\end{array}$ & $\begin{array}{c}\text { Delta P } \\
\text { (in. } \\
\left.\mathbf{H}_{2} \mathbf{O}\right)\end{array}$ & $\begin{array}{c}\mathbf{T} \\
\left({ }^{\mathbf{0}} \mathbf{F}\right)\end{array}$ & $\begin{array}{l}\text { Velocity } \\
\text { (ft/sec) }\end{array}$ & $\begin{array}{c}\text { Delta P } \\
\text { (in. } \\
\mathbf{H}_{2} \mathbf{O} \text { ) }\end{array}$ & $\begin{array}{c}\mathbf{T} \\
\left({ }^{\mathbf{0}} \mathbf{F}\right)\end{array}$ & \\
\hline 12 & 0.67 & 336 & 58.1 & 0.72 & 323 & 59.8 & 0.81 & 324 & 63.5 \\
\hline 24 & 0.77 & 335 & 62.5 & 0.76 & 337 & 62.0 & 0.82 & 327 & 64.0 \\
\hline 36 & 0.67 & 336 & 58.3 & 0.57 & 337 & 53.9 & 0.64 & 329 & 56.5 \\
\hline 48 & 1.30 & 336 & 81.2 & 1.20 & 336 & 78.1 & 1.40 & 328 & 83.9 \\
\hline 60 & 1.20 & 331 & 77.8 & 1.10 & 336 & 74.7 & 0.87 & 330 & 66.2 \\
\hline 72 & 0.65 & 335 & 57.2 & 0.85 & 334 & 65.6 & 0.80 & 333 & 63.4 \\
\hline 84 & 0.66 & 338 & 58.0 & 0.75 & 339 & 61.6 & 0.74 & 336 & 61.1 \\
\hline 96 & 0.78 & 340 & 62.9 & 0.79 & 339 & 63.3 & 0.63 & 338 & 56.4 \\
\hline 108 & 0.82 & 341 & 64.6 & 0.77 & 340 & 62.7 & 0.70 & 336 & 59.4 \\
\hline 120 & 0.97 & 340 & 70.4 & 0.98 & 340 & 70.7 & 1.00 & 334 & 71.2 \\
\hline
\end{tabular}

Data compiled from Method 17 Runs performed on ESP Outlet Duct 2D-1 on 6-10-09. Velocity data is the average of two separate readings at each port depth, moisture data is the average of two separate moisture trains--one performed in conjunction with the morning sample (taken from the points on the bottom half of the duct), one performed with the afternoon sample (taken from the top half of the duct). Ports are named from left to right facing upstream (facing the ESP). 
Table D-10. Single Point Velocity Measurement for ESP Outlet 2C1 Parametric Phase IV

\begin{tabular}{|r|c|}
\hline date & \multicolumn{1}{|c|}{$6 / 11 / 2009$} \\
\hline time & \multicolumn{1}{|c|}{$1109-$} \\
\hline moisture & 1717 \\
\hline $\mathbf{O}_{\mathbf{2}}$ & 5.60 \\
\hline $\mathbf{C O}_{2}$ & 13.83 \\
\hline static & -13.00 \\
\hline barometric & 29.32 \\
\hline gas m.w. & 28.72 \\
\hline $\begin{array}{r}\text { pitot correction } \\
\text { factor }\end{array}$ & 0.84 \\
\hline $\begin{array}{r}\text { absolute stack } \\
\text { pressure }\end{array}$ & 28.40 \\
\hline
\end{tabular}

\begin{tabular}{||r|c|c|c||}
\hline & & B & \\
\hline & $\begin{array}{c}\text { Delta } \mathbf{P} \\
\left.\text { (in. } \mathbf{H}_{\mathbf{2}} \mathbf{O}\right)\end{array}$ & $\begin{array}{c}\mathbf{T} \\
\left({ }^{\mathbf{}} \mathbf{F}\right)\end{array}$ & $\begin{array}{c}\text { Velocity } \\
\text { (ft/sec) }\end{array}$ \\
\hline 84 & 0.72 & 323 & 59.5 \\
\hline
\end{tabular}

$\mathrm{dP}$, stack temperature, and $\mathrm{O} 2$ data compiled from single Appendix $\mathrm{K}$ run on 6-11-09. Moisture, $\mathrm{CO} 2$, and static pressure data taken from corresponding Method 17 Run performed on Outlet 2D1 on the afternoon of 6-11-09. 
Table D-11. Single Point Velocity Measurement at the Stack Parametric Phase IV

\begin{tabular}{|r|r|}
\hline date & $7 / 12 / 2009$ \\
\hline time & $802-1537$ \\
\hline moisture & 18.81 \\
\hline $\mathbf{O}_{\mathbf{2}}$ & 5.60 \\
\hline $\mathbf{C O}_{\mathbf{2}}$ & 14.00 \\
static & 0.30 \\
\hline barometric & 29.26 \\
\hline gas m.w. & 28.12 \\
\hline $\begin{array}{r}\text { pitot correction } \\
\text { factor }\end{array}$ & 0.84 \\
\hline $\begin{array}{r}\text { absolute stack } \\
\text { pressure }\end{array}$ & 29.28 \\
\hline
\end{tabular}

\begin{tabular}{||r|c|c|c||}
\hline & & & \\
\hline & $\begin{array}{c}\text { Delta } \mathbf{P} \\
\left.\text { (in. } \mathbf{H}_{\mathbf{2}} \mathbf{O}\right)\end{array}$ & $\begin{array}{c}\mathbf{T} \\
\left({ }^{\mathbf{0}} \mathbf{F}\right)\end{array}$ & $\begin{array}{c}\text { Velocity } \\
\text { (ft/sec) }\end{array}$ \\
\hline 84 & 1.58 & 162 & 78.6 \\
\hline
\end{tabular}

Data compiled from 3 Method 29 runs performed on 7/12/09. All runs performed in a single port at a single port depth. 


\section{APPENDIX E - ASH ANALYTICAL RESULTS}


Table E-1. Parametric Phase I Ash Hg and LOI Analysis - Baseline

\begin{tabular}{|c|c|c|c|c|c|}
\hline Condition & $\begin{array}{l}\text { Date of } \\
\text { Sample }\end{array}$ & Time of Sample & $\begin{array}{l}\text { Field \& } \\
\text { Hopper }\end{array}$ & $\begin{array}{c}\text { Ash Hg } \\
\text { Content } \\
\text { (ug/g) }\end{array}$ & $\begin{array}{c}\text { Ash LOI } \\
\text { Content } \\
(\%)\end{array}$ \\
\hline Baseline & $12 / 1 / 2006$ & $9: 45$ & $1 \mathrm{~F} 1 \mathrm{~A}$ & & 0.21 \\
\hline Baseline & $12 / 1 / 2006$ & $9: 45$ & $1 \mathrm{~F} 2 \mathrm{~A}$ & & 0.20 \\
\hline Baseline & $12 / 1 / 2006$ & $9: 45$ & $1 \mathrm{~F} 3 \mathrm{~A}$ & & 0.19 \\
\hline Baseline & $12 / 1 / 2006$ & $16: 30$ & $1 \mathrm{~F} 1 \mathrm{~A}$ & $<0.025$ & 0.17 \\
\hline Baseline & $12 / 1 / 2006$ & $16: 30$ & $1 \mathrm{~F} 2 \mathrm{~A}$ & $<0.025$ & 0.12 \\
\hline Baseline & $12 / 1 / 2006$ & $16: 30$ & 1F3A & $<0.025$ & 0.12 \\
\hline Baseline & $12 / 2 / 2006$ & $10: 40$ & $1 \mathrm{~F} 1 \mathrm{~A}$ & & 0.17 \\
\hline Baseline & $12 / 2 / 2006$ & $10: 40$ & $1 \mathrm{~F} 2 \mathrm{~A}$ & & 0.15 \\
\hline Baseline & $12 / 2 / 2006$ & $10: 40$ & $1 \mathrm{~F} 3 \mathrm{~A}$ & & 0.15 \\
\hline Baseline & $12 / 2 / 2006$ & $13: 15$ & $1 \mathrm{~F} 1 \mathrm{~A}$ & & 0.15 \\
\hline Baseline & $12 / 2 / 2006$ & $13: 15$ & $1 \mathrm{~F} 2 \mathrm{~A}$ & & 0.13 \\
\hline Baseline & $12 / 2 / 2006$ & $13: 15$ & $1 \mathrm{~F} 3 \mathrm{~A}$ & & 0.12 \\
\hline Baseline & $12 / 2 / 2006$ & $16: 00$ & 1F1A & $<0.025$ & 0.10 \\
\hline Baseline & $12 / 2 / 2006$ & $16: 00$ & $1 \mathrm{~F} 2 \mathrm{~A}$ & $<0.025$ & 0.12 \\
\hline Baseline & $12 / 2 / 2006$ & $16: 00$ & $1 \mathrm{~F} 3 \mathrm{~A}$ & $<0.025$ & 0.08 \\
\hline $\begin{array}{l}\text { Baseline Average } \\
\text { Phase I - Field 1 }\end{array}$ & & & & $<0.025$ & 0.15 \\
\hline
\end{tabular}


Table E-2. Ash Hg and LOI Analysis from Parametric Phase I

\begin{tabular}{|c|c|c|c|c|c|}
\hline Condition & $\begin{array}{l}\text { Date of } \\
\text { Sample }\end{array}$ & Time of Sample & $\begin{array}{l}\text { Field \& } \\
\text { Hopper }\end{array}$ & $\begin{array}{c}\text { Ash Hg } \\
\text { Content } \\
\text { (ug/g) }\end{array}$ & $\begin{array}{c}\text { Ash LOI } \\
\text { Content } \\
(\%)\end{array}$ \\
\hline Darco at $0.5 \mathrm{lb} / \mathrm{Macf} *$ & $12 / 2 / 2006$ & 16:00 & $1 \mathrm{~F} 1 \mathrm{~A}$ & & 0.23 \\
\hline Darco at $0.5 \mathrm{lb} / \mathrm{Macf} *$ & $12 / 2 / 2006$ & 16:00 & $1 \mathrm{~F} 2 \mathrm{~A}$ & & 0.18 \\
\hline Darco at $0.5 \mathrm{lb} / \mathrm{Macf} *$ & $12 / 2 / 2006$ & 16:00 & $1 \mathrm{~F} 3 \mathrm{~A}$ & & 0.20 \\
\hline Darco at 1lb/Macf* & $12 / 2 / 2006$ & 16:00 & $1 \mathrm{~F} 1 \mathrm{~A}$ & & 0.31 \\
\hline Darco at $11 \mathrm{~b} / \mathrm{Macf} *$ & $12 / 2 / 2006$ & 16:00 & $1 \mathrm{~F} 2 \mathrm{~A}$ & & 0.29 \\
\hline Darco at $11 \mathrm{~b} / \mathrm{Macf} *$ & $12 / 2 / 2006$ & 16:00 & $1 \mathrm{~F} 3 \mathrm{~A}$ & & 0.26 \\
\hline Darco at $1.5 \mathrm{lb} / \mathrm{Macf} *$ & $12 / 2 / 2006$ & 16:00 & $1 \mathrm{~F} 1 \mathrm{~A}$ & & 0.33 \\
\hline Darco at $1.5 \mathrm{lb} / \mathrm{Macf} *$ & $12 / 2 / 2006$ & 16:00 & $1 \mathrm{~F} 2 \mathrm{~A}$ & & 0.35 \\
\hline Darco at $1.51 \mathrm{~b} / \mathrm{Macf} *$ & $12 / 2 / 2006$ & 16:00 & $1 \mathrm{~F} 3 \mathrm{~A}$ & & 0.32 \\
\hline Darco at 2lb/Macf* & $12 / 2 / 2006$ & 16:00 & 1F1A & & 0.42 \\
\hline Darco at 2lb/Macf* & $12 / 2 / 2006$ & 16:00 & $1 \mathrm{~F} 2 \mathrm{~A}$ & & 0.40 \\
\hline Darco at $2 \mathrm{lb} / \mathrm{Macf} *$ & $12 / 2 / 2006$ & $16: 00$ & $1 \mathrm{~F} 3 \mathrm{~A}$ & & 0.40 \\
\hline Darco at $0.5 \mathrm{lb} / \mathrm{Macf} *$ & $12 / 2 / 2006$ & $16: 00$ & $1 \mathrm{~F} 1 \mathrm{~A}$ & & 0.19 \\
\hline Darco at $0.51 \mathrm{~b} / \mathrm{Macf} *$ & $12 / 2 / 2006$ & 16:00 & $1 \mathrm{~F} 2 \mathrm{~A}$ & & 0.19 \\
\hline Darco at $0.5 \mathrm{lb} / \mathrm{Macf} *$ & $12 / 2 / 2006$ & 16:00 & $1 \mathrm{~F} 3 \mathrm{~A}$ & & 0.19 \\
\hline Darco at $0.6 \mathrm{lb} / \mathrm{Macf}$ & $12 / 9 / 2006$ & $12: 20$ & $1 \mathrm{~F} 1 \mathrm{~A}$ & & 0.28 \\
\hline Darco at $0.6 \mathrm{lb} / \mathrm{Macf}$ & $12 / 9 / 2006$ & $12: 20$ & $1 \mathrm{~F} 2 \mathrm{~A}$ & & 0.25 \\
\hline Darco at $0.6 \mathrm{lb} / \mathrm{Macf}$ & $12 / 9 / 2006$ & 12:20 & $1 \mathrm{~F} 3 \mathrm{~A}$ & & 0.24 \\
\hline Darco at $0.6 \mathrm{lb} / \mathrm{Macf}$ & $12 / 9 / 2006$ & $14: 45$ & $1 \mathrm{~F} 1 \mathrm{~A}$ & & 0.32 \\
\hline Darco at $0.6 \mathrm{lb} / \mathrm{Macf}$ & $12 / 9 / 2006$ & $14: 45$ & $1 \mathrm{~F} 2 \mathrm{~A}$ & & 0.29 \\
\hline Darco at $0.6 \mathrm{lb} / \mathrm{Macf}$ & $12 / 9 / 2006$ & $14: 45$ & $1 \mathrm{~F} 3 \mathrm{~A}$ & & 0.23 \\
\hline Darco at $0.6 \mathrm{lb} / \mathrm{Macf}$ & $12 / 9 / 2006$ & $17: 05$ & $1 \mathrm{~F} 1 \mathrm{~A}$ & 0.478 & 0.17 \\
\hline Darco at $0.6 \mathrm{lb} / \mathrm{Macf}$ & $12 / 9 / 2006$ & 17:05 & $1 \mathrm{~F} 2 \mathrm{~A}$ & 0.538 & 0.12 \\
\hline Darco at $0.6 \mathrm{lb} / \mathrm{Macf}$ & $12 / 9 / 2006$ & $17: 05$ & $1 \mathrm{~F} 3 \mathrm{~A}$ & 0.467 & 0.09 \\
\hline Darco Composite ${ }^{* *}$ & $12 / 9 / 2006$ & $12: 20,14: 45,17: 05$ & $1 \mathrm{~F} 1 \mathrm{~A}$ & & 0.16 \\
\hline Darco Composite** & $12 / 9 / 2006$ & $12: 20,14: 45,17: 05$ & $1 \mathrm{~F} 2 \mathrm{~A}$ & & 0.15 \\
\hline Darco Composite** & $12 / 9 / 2006$ & $12: 20,14: 45,17: 05$ & $1 \mathrm{~F} 3 \mathrm{~A}$ & & 0.12 \\
\hline
\end{tabular}

*Simulated blends of Darco Hg and baseline ash collected on 12/2/06.

**Composite of ash from 12:20, 14:45, and 17:05 
Table E-3. Parametric Phase II \& III Ash Hg and LOI Analysis - Baseline

\begin{tabular}{||l|c|c|c|c|c||}
\hline \multicolumn{1}{|c|}{ Condition } & $\begin{array}{c}\text { Date of } \\
\text { Sample }\end{array}$ & $\begin{array}{c}\text { Time of } \\
\text { Sample }\end{array}$ & $\begin{array}{c}\text { Field \& } \\
\text { Hopper }\end{array}$ & $\begin{array}{c}\text { Ash Hg } \\
\text { Content } \\
\text { (ug/g) }\end{array}$ & $\begin{array}{c}\text { Ash LOI } \\
\text { Content } \\
\text { (\%) }\end{array}$ \\
\hline \hline Baseline & $4 / 19 / 2007$ & $12: 15$ & 1F1A & $<0.025$ & 0.10 \\
\hline Baseline & $4 / 19 / 2007$ & $12: 15$ & 1F2A & $<0.025$ & 0.17 \\
\hline Baseline & $4 / 19 / 2007$ & $12: 15$ & 1F3A & $<0.025$ & 0.09 \\
\hline Baseline & $4 / 20 / 2007$ & $14: 30$ & 1F1A & $<0.025$ & 0.09 \\
\hline Baseline & $4 / 20 / 2007$ & $14: 30$ & 1F2A & $<0.025$ & 0.06 \\
\hline Baseline & $4 / 20 / 2007$ & $14: 30$ & 1F3A & $<0.025$ & 0.04 \\
\hline Baseline & $4 / 27 / 2007$ & $15: 10$ & 1F1A & 0.036 & 0.09 \\
\hline Baseline & $4 / 27 / 2007$ & $15: 10$ & 1F2A & 0.158 & 0.11 \\
\hline Baseline & $4 / 27 / 2007$ & $15: 10$ & 1F3A & 0.171 & 0.08 \\
\hline Baseline & $4 / 27 / 2007$ & $15: 20$ & 6\&7F1A & 0.348 & 0.59 \\
\hline Baseline & $4 / 27 / 2007$ & $15: 20$ & 6\&7F2A & 0.497 & 0.52 \\
\hline Baseline & $4 / 27 / 2007$ & $15: 20$ & 6\&7F3A & 0.900 & 0.34 \\
\hline Baseline & $4 / 28 / 2007$ & $12: 20$ & 1F1A & 0.029 & 0.10 \\
\hline Baseline & $4 / 28 / 2007$ & $12: 20$ & 1F2A & $<0.025$ & 0.05 \\
\hline Baseline & $4 / 28 / 2007$ & $12: 20$ & 1F3A & 0.036 & 0.01 \\
\hline Baseline & $4 / 28 / 2007$ & $12: 40$ & 6\&7F1A & 0.153 & 0.73 \\
\hline Baseline & $4 / 28 / 2007$ & $12: 40$ & 6\&7F2A & 0.244 & 0.65 \\
\hline Baseline & $4 / 28 / 2007$ & $12: 40$ & 6\&7F3A & 0.455 & 0.36 \\
\hline Baseline & $4 / 29 / 2007$ & $14: 20$ & 1F1A & $<0.025$ & 0.06 \\
\hline Baseline & $4 / 29 / 2007$ & $14: 20$ & 1F2A & $<0.025$ & 0.06 \\
\hline Baseline & $4 / 29 / 2007$ & $14: 20$ & 1F3A & $<0.025$ & 0.04 \\
\hline Baseline & $4 / 29 / 2007$ & $14: 20$ & 6\&7F1A & 0.089 & 0.73 \\
\hline Baseline & $4 / 29 / 2007$ & $14: 20$ & 6\&7F2A & 0.120 & 0.51 \\
\hline Baseline & $4 / 29 / 2007$ & $14: 20$ & 6\&7F3A & 0.152 & 0.26 \\
\hline Baseline & $4 / 29 / 2007$ & $15: 30$ & 5FEF & 0.284 & 0.50 \\
\hline $\begin{array}{l}\text { Baseline Average } \\
\text { Phase II - Field 1 }\end{array}$ & & & & \\
\hline Baseline Average \\
Phase II - Field 5 & & & & $\mathbf{0 . 0 4 5}$ & $\mathbf{0 . 0 8}$ \\
\hline Baseline Average \\
Phase II - Field 6\&7 & & & & $\mathbf{0 . 2 8 4}$ & $\mathbf{0 . 5 0}$ \\
\hline & & & & $\mathbf{0 . 3 2 9}$ & $\mathbf{0 . 5 2}$ \\
\hline
\end{tabular}


Table E-4. Parametric Phase II \& III Ash Hg and LOI Analysis

\begin{tabular}{|c|c|c|c|c|c|}
\hline Condition & $\begin{array}{l}\text { Date of } \\
\text { Sample }\end{array}$ & $\begin{array}{l}\text { Time of } \\
\text { Sample }\end{array}$ & $\begin{array}{l}\text { Field \& } \\
\text { Hopper }\end{array}$ & $\begin{array}{c}\text { Ash Hg } \\
\text { Content } \\
\text { (ug/g) }\end{array}$ & $\begin{array}{c}\text { Ash LOI } \\
\text { Content } \\
(\%)\end{array}$ \\
\hline BASF MS200 at 12lb/Macf & $4 / 22 / 2007$ & $16: 30$ & $1 \mathrm{~F} 1 \mathrm{~A}$ & 0.423 & 0.99 \\
\hline BASF MS200 at $12 \mathrm{lb} / \mathrm{Macf}$ & $4 / 22 / 2007$ & $16: 30$ & $1 \mathrm{~F} 2 \mathrm{~A}$ & 0.442 & 0.56 \\
\hline BASF MS200 at 12lb/Macf & $4 / 22 / 2007$ & $16: 30$ & $1 \mathrm{~F} 3 \mathrm{~A}$ & 0.314 & 0.15 \\
\hline C-PAC at $1.5 \mathrm{lb} / \mathrm{Macf}$ & $4 / 23 / 2007$ & $16: 55$ & $1 \mathrm{~F} 1 \mathrm{~A}$ & 0.351 & 0.20 \\
\hline C-PAC at $1.5 \mathrm{lb} / \mathrm{Macf}$ & $4 / 23 / 2007$ & $16: 55$ & $1 \mathrm{~F} 2 \mathrm{~A}$ & 0.579 & 0.39 \\
\hline C-PAC at $1.5 \mathrm{lb} / \mathrm{Macf}$ & $4 / 23 / 2007$ & $16: 55$ & $1 \mathrm{~F} 3 \mathrm{~A}$ & 0.533 & 0.40 \\
\hline Darco Hg at 1lb/Macf & $4 / 24 / 2007$ & $13: 25$ & $1 \mathrm{~F} 1 \mathrm{~A}$ & 0.357 & 0.08 \\
\hline Darco Hg at 1lb/Macf & $4 / 24 / 2007$ & $13: 25$ & 1F2A & 0.410 & 0.12 \\
\hline Darco Hg at $1 \mathrm{lb} / \mathrm{Macf}$ & $4 / 24 / 2007$ & $13: 25$ & $1 \mathrm{~F} 3 \mathrm{~A}$ & 0.398 & 0.14 \\
\hline Darco Hg at 2lb/Macf & $4 / 24 / 2007$ & $16: 20$ & $1 \mathrm{~F} 1 \mathrm{~A}$ & 0.522 & 0.19 \\
\hline Darco Hg at 2lb/Macf & $4 / 24 / 2007$ & $16: 20$ & 1F2A & 0.609 & 0.24 \\
\hline Darco Hg at 2lb/Macf & $4 / 24 / 2007$ & $16: 20$ & $1 \mathrm{~F} 3 \mathrm{~A}$ & 0.543 & 0.32 \\
\hline Cal HGR-LH at 2lb/Macf & $4 / 25 / 2007$ & $16: 35$ & $1 \mathrm{~F} 1 \mathrm{~A}$ & 0.397 & 0.22 \\
\hline Cal HGR-LH at 2lb/Macf & $4 / 25 / 2007$ & $16: 35$ & $1 \mathrm{~F} 2 \mathrm{~A}$ & 0.478 & 0.32 \\
\hline Cal HGR-LH at 2lb/Macf & $4 / 25 / 2007$ & $16: 35$ & $1 \mathrm{~F} 3 \mathrm{~A}$ & 0.282 & 0.22 \\
\hline Toxecon II at 2lb/Macf & $4 / 30 / 2007$ & $12: 00$ & $6 \& 7 \mathrm{~F} 1 \mathrm{~A}$ & 0.124 & 0.73 \\
\hline Toxecon II at 2lb/Macf & $4 / 30 / 2007$ & $12: 00$ & $6 \& 7 \mathrm{~F} 2 \mathrm{~A}$ & 0.161 & 0.72 \\
\hline Toxecon II at 2lb/Macf & $4 / 30 / 2007$ & $12: 00$ & $6 \& 7 \mathrm{~F} 3 \mathrm{~A}$ & 0.259 & 0.41 \\
\hline Toxecon II at 2lb/Macf & $4 / 30 / 2007$ & 13:00 & $5 \mathrm{~F} 3 \mathrm{~A}$ & $0.079 *$ & 0.33 \\
\hline Toxecon II at 2lb/Macf & $4 / 30 / 2007$ & $12: 30$ & $5 \mathrm{~F} 1 \mathrm{~A}$ & 0.368 & 0.56 \\
\hline Toxecon II at 5lb/Macf & $4 / 30 / 2007$ & $17: 00$ & $6 \& 7 \mathrm{~F} 1 \mathrm{~A}$ & 1.063 & 0.82 \\
\hline Toxecon II at 5lb/Macf & $4 / 30 / 2007$ & $17: 00$ & $6 \& 7 \mathrm{~F} 2 \mathrm{~A}$ & 0.363 & 0.74 \\
\hline Toxecon II at 5lb/Macf & $4 / 30 / 2007$ & $17: 00$ & $6 \& 7 \mathrm{~F} 3 \mathrm{~A}$ & 0.206 & 0.42 \\
\hline Toxecon II at 5lb/Macf & $4 / 30 / 2007$ & $17: 20$ & $5 \mathrm{~F} 1 \mathrm{~A}$ & 4.63 & 10.9 \\
\hline Darco Hg@3lbs/Macf & $5 / 2 / 2007$ & $16: 20$ & $1 \mathrm{~F} 1 \mathrm{~A}$ & 0.401 & 0.215 \\
\hline Darco Hg@3lbs/Macf & $5 / 2 / 2007$ & $16: 20$ & $1 \mathrm{~F} 2 \mathrm{~A}$ & 0.247 & 0.090 \\
\hline Darco Hg@3lbs/Macf & $5 / 2 / 2007$ & $16: 20$ & $1 \mathrm{~F} 3 \mathrm{~A}$ & 0.551 & 0.265 \\
\hline Toxecon II @ 6lb/Macf* & $5 / 23 / 2007$ & $16: 50$ & $5 \mathrm{~F} 3 \mathrm{~A}$ & 2.86 & 8.602 \\
\hline
\end{tabular}


Table E-5. Summary of Long Term Baseline Ash Hg \& LOI Analysis on Side A

\begin{tabular}{|c|c|c|c|c|c|}
\hline Condition & $\begin{array}{l}\text { Date of } \\
\text { Sample }\end{array}$ & $\begin{array}{l}\text { Time of } \\
\text { Sample }\end{array}$ & $\begin{array}{l}\text { Field \& } \\
\text { Hopper }\end{array}$ & $\begin{array}{c}\text { Ash Hg } \\
\text { Content } \\
\text { (ug/g) }\end{array}$ & $\begin{array}{c}\text { Ash } \\
\text { LOI } \\
\text { Content } \\
(\%) \\
\end{array}$ \\
\hline Baseline & $6 / 18 / 2007$ & $16: 39$ & $1 \mathrm{~F} 1 \mathrm{~A}$ & $<0.025$ & 0.34 \\
\hline Baseline & $6 / 18 / 2007$ & $16: 34$ & $1 \mathrm{~F} 2 \mathrm{~A}$ & $<0.025$ & 0.25 \\
\hline Baseline & $6 / 18 / 2007$ & $16: 30$ & $1 \mathrm{~F} 3 \mathrm{~A}$ & 0.029 & 0.18 \\
\hline Baseline & $6 / 20 / 2007$ & $11: 15$ & 1F1A & $<0.025$ & 0.16 \\
\hline Baseline & $6 / 20 / 2007$ & $11: 15$ & $1 \mathrm{~F} 2 \mathrm{~A}$ & $<0.024$ & 0.18 \\
\hline Baseline & $6 / 20 / 2007$ & $11: 15$ & $1 \mathrm{~F} 3 \mathrm{~A}$ & $<0.023$ & 0.14 \\
\hline Baseline & $6 / 22 / 2007$ & 12:10 & $1 \mathrm{~F} 1 \mathrm{~A}$ & 0.043 & 0.03 \\
\hline Baseline & $6 / 22 / 2007$ & $10: 45$ & $1 \mathrm{~F} 2 \mathrm{~A}$ & 0.035 & 0.03 \\
\hline Baseline & $6 / 22 / 2007$ & $10: 30$ & $1 \mathrm{~F} 3 \mathrm{~A}$ & 0.034 & 0.04 \\
\hline $\begin{array}{l}\text { Baseline Average } \\
\text { LT - Field } 1 \text { Side A }\end{array}$ & & & & 0.029 & 0.15 \\
\hline Baseline & $6 / 22 / 2007$ & $10: 20$ & $2 \mathrm{~F} 1 \mathrm{~A}$ & $<0.025$ & 0.23 \\
\hline Baseline & $6 / 22 / 2007$ & $10: 20$ & $2 \mathrm{~F} 2 \mathrm{~A}$ & $<0.024$ & 0.15 \\
\hline Baseline & $6 / 22 / 2007$ & $10: 20$ & $2 \mathrm{~F} 3 \mathrm{~A}$ & 0.040 & 0.11 \\
\hline $\begin{array}{l}\text { Baseline Average } \\
\text { LT - Field } 2 \text { Side A } \\
\end{array}$ & & & & 0.030 & 0.16 \\
\hline Baseline & $6 / 22 / 2007$ & $11: 30$ & $3 \mathrm{~F} 1 \mathrm{~A}$ & $<0.025$ & 0.36 \\
\hline Baseline & $6 / 22 / 2007$ & $11: 30$ & $3 \mathrm{~F} 2 \mathrm{~A}$ & $<0.025$ & 0.31 \\
\hline Baseline & $6 / 22 / 2007$ & $11: 30$ & $3 \mathrm{~F} 3 \mathrm{~A}$ & $<0.025$ & 0.27 \\
\hline $\begin{array}{l}\text { Baseline Average } \\
\text { LT - Field } 3 \text { Side A }\end{array}$ & & & & 0.025 & 0.31 \\
\hline Baseline & $6 / 22 / 2007$ & $11: 35$ & $4 \& 5 \mathrm{~F} 1 \mathrm{~A}$ & 2.060 & 2.71 \\
\hline Baseline & $6 / 22 / 2007$ & 11:40 & $4 \& 5 \mathrm{~F} 2 \mathrm{~A}$ & 0.674 & 0.88 \\
\hline Baseline & $6 / 22 / 2007$ & $11: 35$ & $4 \& 5 \mathrm{~F} 3 \mathrm{~A}$ & $<0.025$ & 0.47 \\
\hline $\begin{array}{l}\text { Baseline Average } \\
\text { LT - Field 4\&5 Side } \\
\text { A }\end{array}$ & & & & 0.920 & 1.36 \\
\hline Baseline & $6 / 22 / 2007$ & $11: 50$ & $6 \& 7 \mathrm{~F} 1 \mathrm{~A}$ & 0.759 & 4.30 \\
\hline Baseline & $6 / 22 / 2007$ & 11:05 & $6 \& 7 \mathrm{~F} 2 \mathrm{~A}$ & 1.460 & 2.55 \\
\hline Baseline & $6 / 22 / 2007$ & $11: 50$ & $6 \& 7 \mathrm{~F} 3 \mathrm{~A}$ & 0.128 & 0.89 \\
\hline $\begin{array}{l}\text { Baseline Average } \\
\text { LT - Field 6\&7 Side } \\
\text { A }\end{array}$ & & & & $\mathbf{0 . 7 8 2}$ & 2.58 \\
\hline
\end{tabular}


Table E-6. Summary of Long Term Baseline Ash Hg \& LOI Analysis on Side B

\begin{tabular}{||l|c|c|c|c|c||}
\hline \multicolumn{1}{|c|}{ Condition } & $\begin{array}{c}\text { Date of } \\
\text { Sample }\end{array}$ & $\begin{array}{c}\text { Time of } \\
\text { Sample }\end{array}$ & $\begin{array}{c}\text { Field \& } \\
\text { Hopper }\end{array}$ & $\begin{array}{c}\text { Ash Hg } \\
\text { Content } \\
(\mathbf{u g} / \mathbf{g})\end{array}$ & $\begin{array}{c}\text { Ash } \\
\text { LOI } \\
\text { Content } \\
(\boldsymbol{\%})\end{array}$ \\
\hline \hline Baseline & $6 / 18 / 2007$ & $16: 25$ & $1 \mathrm{~F} 1 \mathrm{~B}$ & 0.048 & 0.59 \\
\hline Baseline & $6 / 18 / 2007$ & $16: 22$ & $1 \mathrm{~F} 2 \mathrm{~B}$ & 0.042 & 0.49 \\
\hline Baseline & $6 / 18 / 2007$ & $16: 19$ & $1 \mathrm{~F} 3 \mathrm{~B}$ & 0.028 & 0.22 \\
\hline Baseline & $6 / 20 / 2007$ & $13: 40$ & $1 \mathrm{~F} 1 \mathrm{~B}$ & 0.053 & 0.03 \\
\hline Baseline & $6 / 20 / 2007$ & $13: 40$ & $1 \mathrm{~F} 2 \mathrm{~B}$ & 0.051 & 0.03 \\
\hline Baseline & $6 / 20 / 2007$ & $13: 40$ & $1 \mathrm{~F} 3 \mathrm{~B}$ & 0.042 & 0.01 \\
\hline $\begin{array}{l}\text { Baseline Average } \\
\text { LT - Field 1 Side B }\end{array}$ & & & & & \\
\hline
\end{tabular}


Table E-7. Summary of Long Term Ash Hg \& LOI Analysis on Side A Field 1

\begin{tabular}{|c|c|c|c|c|c|}
\hline Condition & $\begin{array}{l}\text { Date of } \\
\text { Sample }\end{array}$ & $\begin{array}{l}\text { Time of } \\
\text { Sample }\end{array}$ & $\begin{array}{l}\text { Field \& } \\
\text { Hopper }\end{array}$ & $\begin{array}{c}\text { Ash Hg } \\
\text { Content } \\
\text { (ug/g) }\end{array}$ & $\begin{array}{c}\text { Ash } \\
\text { LOI } \\
\text { Content } \\
(\%)\end{array}$ \\
\hline LT Darco Hg-LH @ 2.0lb/Macf & $6 / 28 / 2007$ & 14:00 & $1 \mathrm{~F} 1 \mathrm{~A}$ & 0.394 & 0.40 \\
\hline LT Darco Hg-LH @ 2.0lb/Macf & $6 / 28 / 2007$ & $14: 00$ & $1 \mathrm{~F} 2 \mathrm{~A}$ & 0.569 & 0.53 \\
\hline LT Darco Hg-LH @ 2.0lb/Macf & $6 / 28 / 2007$ & $14: 00$ & $1 \mathrm{~F} 3 \mathrm{~A}$ & 0.371 & 0.30 \\
\hline LT Darco Hg-LH @ 2.0lb/Macf & $6 / 29 / 2007$ & 13:00 & $1 \mathrm{~F} 1 \mathrm{~A}$ & 0.711 & 0.54 \\
\hline LT Darco Hg-LH @ 2.0lb/Macf & $6 / 29 / 2007$ & 13:00 & $1 \mathrm{~F} 2 \mathrm{~A}$ & 0.920 & 0.88 \\
\hline LT Darco Hg-LH @ 2.0lb/Macf & $6 / 29 / 2007$ & 13:00 & $1 \mathrm{~F} 3 \mathrm{~A}$ & 0.720 & 0.50 \\
\hline LT Darco Hg-LH @ 2.0lb/Macf & $7 / 3 / 2007$ & $11: 30$ & $1 \mathrm{~F} 1 \mathrm{~A}$ & 0.570 & 0.54 \\
\hline LT Darco Hg-LH @ 2.0lb/Macf & $7 / 3 / 2007$ & $11: 30$ & $1 \mathrm{~F} 2 \mathrm{~A}$ & 0.715 & 0.67 \\
\hline LT Darco Hg-LH @ 2.0lb/Macf & $7 / 3 / 2007$ & $11: 30$ & $1 \mathrm{~F} 3 \mathrm{~A}$ & 0.384 & 0.58 \\
\hline LT Darco Hg-LH @ 2.0lb/Macf & $7 / 4 / 2007$ & $14: 40$ & $1 \mathrm{~F} 1 \mathrm{~A}$ & 0.650 & 0.60 \\
\hline LT Darco Hg-LH @ 2.0lb/Macf & $7 / 4 / 2007$ & $14: 40$ & $1 \mathrm{~F} 2 \mathrm{~A}$ & 0.756 & 0.58 \\
\hline LT Darco Hg-LH @ 2.0lb/Macf & $7 / 4 / 2007$ & $14: 40$ & $1 \mathrm{~F} 3 \mathrm{~A}$ & 1.060 & 0.89 \\
\hline LT Darco Hg-LH @ 2.0lb/Macf & $7 / 5 / 2007$ & $14: 10$ & $1 \mathrm{~F} 1 \mathrm{~A}$ & 0.633 & 0.63 \\
\hline LT Darco Hg-LH @ 2.0lb/Macf & $7 / 5 / 2007$ & $14: 10$ & $1 \mathrm{~F} 2 \mathrm{~A}$ & 0.722 & 0.60 \\
\hline LT Darco Hg-LH @ 2.0lb/Macf & $7 / 5 / 2007$ & $14: 10$ & $1 \mathrm{~F} 3 \mathrm{~A}^{*}$ & 0.300 & 0.67 \\
\hline LT Darco Hg-LH @ 2.0lb/Macf & $7 / 8 / 2007$ & $11: 20$ & $1 \mathrm{~F} 1 \mathrm{~A}$ & 0.889 & 0.59 \\
\hline LT Darco Hg-LH @ 2.0lb/Macf & $7 / 8 / 2007$ & $11: 20$ & $1 \mathrm{~F} 2 \mathrm{~A}$ & 1.099 & 0.94 \\
\hline LT Darco Hg-LH @ 2.0lb/Macf & $7 / 8 / 2007$ & $11: 20$ & $1 \mathrm{~F} 3 \mathrm{~A}^{*}$ & 0.244 & 0.40 \\
\hline LT Darco Hg-LH @ 2.0lb/Macf & $7 / 9 / 2007$ & $14: 30$ & $1 \mathrm{~F} 1 \mathrm{~A}$ & 0.888 & 0.47 \\
\hline LT Darco Hg-LH @ 2.0lb/Macf & $7 / 9 / 2007$ & $14: 30$ & $1 \mathrm{~F} 2 \mathrm{~A}$ & 0.986 & 0.54 \\
\hline LT Darco Hg-LH @ 2.0lb/Macf & $7 / 9 / 2007$ & $14: 30$ & $1 \mathrm{~F} 3 \mathrm{~A}^{*}$ & 0.132 & 0.17 \\
\hline LT Darco Hg-LH @ 2.0lb/Macf & $7 / 10 / 2007$ & $11: 20$ & $1 \mathrm{~F} 1 \mathrm{~A}$ & 0.561 & 0.43 \\
\hline LT Darco Hg-LH @ 2.0lb/Macf & $7 / 10 / 2007$ & $11: 20$ & $1 \mathrm{~F} 2 \mathrm{~A}$ & 0.86 & 0.39 \\
\hline LT Darco Hg-LH @ 2.0lb/Macf & $7 / 10 / 2007$ & $11: 20$ & $1 \mathrm{~F} 3 \mathrm{~A}^{*}$ & 0.128 & 0.22 \\
\hline LT Darco Hg-LH @ 2.0lb/Macf & $7 / 11 / 2007$ & 15:07 & $1 \mathrm{~F} 1 \mathrm{~A}$ & 0.613 & 0.46 \\
\hline LT Darco Hg-LH @ 2.0lb/Macf & $7 / 11 / 2007$ & 15:07 & $1 \mathrm{~F} 2 \mathrm{~A}$ & 0.688 & 0.45 \\
\hline LT Darco Hg-LH @ 2.0lb/Macf & $7 / 11 / 2007$ & 15:07 & $1 \mathrm{~F} 3 \mathrm{~A}^{*}$ & 0.164 & 0.30 \\
\hline LT Darco Hg-LH @ 2.0lb/Macf & $7 / 19 / 2007$ & $17: 40$ & $1 \mathrm{~F} 1 \mathrm{~A}$ & 0.626 & 0.48 \\
\hline LT Darco Hg-LH @ 2.0lb/Macf & $7 / 19 / 2007$ & $17: 40$ & $1 \mathrm{~F} 2 \mathrm{~A}$ & 0.723 & 0.47 \\
\hline LT Darco Hg-LH @ 2.0lb/Macf & $7 / 21 / 2007$ & 12:11 & $1 \mathrm{~F} 1 \mathrm{~A}$ & 0.957 & 0.56 \\
\hline LT Darco Hg-LH @ 2.0lb/Macf & $7 / 21 / 2007$ & $12: 12$ & $1 \mathrm{~F} 2 \mathrm{~A}$ & 1.080 & 0.53 \\
\hline LT Darco Hg-LH @ 2.0lb/Macf & $7 / 21 / 2007$ & $12: 17$ & $1 \mathrm{~F} 3 \mathrm{~A}^{*}$ & 0.161 & 0.24 \\
\hline LT Darco Hg-LH @ 2.0lb/Macf & $7 / 22 / 2007$ & $14: 30$ & $1 \mathrm{~F} 1 \mathrm{~A}$ & 0.749 & 0.49 \\
\hline LT Darco Hg-LH @ 2.0lb/Macf & $7 / 22 / 2007$ & $14: 30$ & $1 \mathrm{~F} 2 \mathrm{~A}$ & 1.126 & 0.48 \\
\hline LT Darco Hg-LH @ 2.0lb/Macf & $7 / 25 / 2007$ & $12: 25$ & $1 \mathrm{~F} 1 \mathrm{~A}$ & 0.998 & 0.60 \\
\hline LT Darco Hg-LH @ 2.0lb/Macf & $7 / 25 / 2007$ & $12: 25$ & $1 \mathrm{~F} 2 \mathrm{~A}$ & 1.094 & 0.57 \\
\hline LT Darco Hg-LH @ 2.0lb/Macf & $7 / 25 / 2007$ & $12: 25$ & $1 \mathrm{~F} 3 \mathrm{~A}^{*}$ & 0.776 & 0.60 \\
\hline LT Darco Hg-LH @ 2.0lb/Macf & $7 / 27 / 2007$ & $15: 13$ & $1 \mathrm{~F} 1 \mathrm{~A}$ & 0.638 & 0.60 \\
\hline LT Darco Hg-LH @ 2.0lb/Macf & $7 / 27 / 2007$ & 15:13 & $1 \mathrm{~F} 2 \mathrm{~A}$ & 0.770 & 0.49 \\
\hline LT Darco Hg-LH @ 2.0lb/Macf & $7 / 27 / 2007$ & 15:13 & $1 \mathrm{~F} 3 \mathrm{~A}^{*}$ & 0.372 & 0.36 \\
\hline
\end{tabular}




\begin{tabular}{|c|c|c|c|c|c|}
\hline$\overline{\text { Condition }}$ & $\begin{array}{l}\text { Date of } \\
\text { Sample }\end{array}$ & $\begin{array}{l}\text { Time of } \\
\text { Sample }\end{array}$ & $\begin{array}{l}\text { Field \& } \\
\text { Hopper }\end{array}$ & $\begin{array}{c}\text { Ash Hg } \\
\text { Content } \\
\text { (ug/g) }\end{array}$ & $\begin{array}{c}\text { Ash } \\
\text { LOI } \\
\text { Content } \\
(\%)\end{array}$ \\
\hline LT Darco Hg-LH @ 2.0lb/Macf & $7 / 28 / 2007$ & $14: 55$ & $1 \mathrm{~F} 1 \mathrm{~A}$ & 0.510 & 0.38 \\
\hline LT Darco Hg-LH @ 2.0lb/Macf & $7 / 28 / 2007$ & 14:55 & $1 \mathrm{~F} 2 \mathrm{~A}$ & 0.643 & 0.40 \\
\hline LT Darco Hg-LH @ 2.0lb/Macf & $7 / 28 / 2007$ & $14: 55$ & $1 \mathrm{~F} 3 \mathrm{~A}^{*}$ & 0.525 & 0.47 \\
\hline LT Darco Hg-LH @ 2.0lb/Macf & $7 / 29 / 2007$ & $18: 15$ & $1 \mathrm{~F} 1 \mathrm{~A}$ & 0.440 & 0.43 \\
\hline LT Darco Hg-LH @ 2.0lb/Macf & $7 / 29 / 2007$ & $18: 15$ & $1 \mathrm{~F} 2 \mathrm{~A}$ & 0.494 & 0.41 \\
\hline LT Darco Hg-LH @ 2.0lb/Macf & $7 / 29 / 2007$ & $18: 15$ & $1 \mathrm{~F} 3 \mathrm{~A}^{*}$ & 0.474 & 0.38 \\
\hline LT Darco Hg-LH @ 2.0lb/Macf & $7 / 31 / 2007$ & $14: 50$ & $1 \mathrm{~F} 1 \mathrm{~A}$ & 0.740 & 0.66 \\
\hline LT Darco Hg-LH @ 2.0lb/Macf & $7 / 31 / 2007$ & $14: 50$ & $1 \mathrm{~F} 2 \mathrm{~A}$ & 0.700 & 0.47 \\
\hline LT Darco Hg-LH @ 2.0lb/Macf & $7 / 31 / 2007$ & $14: 50$ & $1 \mathrm{~F} 3 \mathrm{~A}^{*}$ & 0.424 & 0.34 \\
\hline LT Darco Hg-LH @ 2.0lb/Macf & $8 / 1 / 2007$ & $12: 15$ & $1 \mathrm{~F} 1 \mathrm{~A}$ & 0.463 & 0.41 \\
\hline LT Darco Hg-LH @ 2.0lb/Macf & $8 / 1 / 2007$ & $12: 15$ & $1 \mathrm{~F} 2 \mathrm{~A}$ & 0.571 & 0.44 \\
\hline LT Darco Hg-LH @ 2.0lb/Macf & $8 / 1 / 2007$ & $12: 15$ & $1 \mathrm{~F} 3 \mathrm{~A}^{*}$ & 0.440 & 0.24 \\
\hline LT Darco Hg-LH @ 2.0lb/Macf & $8 / 3 / 2007$ & $8: 00$ & $1 \mathrm{~F} 1 \mathrm{~A}$ & 0.604 & 1.31 \\
\hline LT Darco Hg-LH @ 2.0lb/Macf & $8 / 3 / 2007$ & $8: 00$ & $1 \mathrm{~F} 2 \mathrm{~A}$ & 0.671 & 1.15 \\
\hline LT Darco Hg-LH @ 2.0lb/Macf & $8 / 3 / 2007$ & $8: 00$ & $1 \mathrm{~F} 3 \mathrm{~A}^{*}$ & 0.420 & 0.93 \\
\hline LT Darco Hg-LH @ 2.0lb/Macf & $8 / 5 / 2007$ & $15: 30$ & $1 \mathrm{~F} 1 \mathrm{~A}$ & 0.722 & 0.68 \\
\hline LT Darco Hg-LH @ 2.0lb/Macf & $8 / 5 / 2007$ & $15: 30$ & $1 \mathrm{~F} 2 \mathrm{~A}$ & 0.807 & 0.61 \\
\hline LT Darco Hg-LH @ 2.0lb/Macf & $8 / 5 / 2007$ & $15: 30$ & $1 \mathrm{~F} 3 \mathrm{~A}^{*}$ & 0.562 & 0.64 \\
\hline LT Darco Hg-LH @ 2.0lb/Macf & $8 / 9 / 2007$ & $21: 00$ & $1 \mathrm{~F} 1 \mathrm{~A}$ & 0.361 & 0.37 \\
\hline LT Darco Hg-LH @ 2.0lb/Macf & $8 / 9 / 2007$ & 21:00 & $1 \mathrm{~F} 2 \mathrm{~A}$ & 0.512 & 0.42 \\
\hline LT Darco Hg-LH @ 2.0lb/Macf & $8 / 9 / 2007$ & 21:00 & $1 \mathrm{~F} 3 \mathrm{~A}^{*}$ & 0.512 & 0.21 \\
\hline LT Darco Hg-LH @ 2.0lb/Macf & $8 / 11 / 2007$ & 18:00 & $1 \mathrm{~F} 1 \mathrm{~A}$ & 0.492 & 0.41 \\
\hline LT Darco Hg-LH @ 2.0lb/Macf & $8 / 11 / 2007$ & 18:00 & $1 \mathrm{~F} 2 \mathrm{~A}$ & 0.563 & 0.38 \\
\hline LT Darco Hg-LH @ 2.0lb/Macf & $8 / 11 / 2007$ & 18:00 & $1 \mathrm{~F} 3 \mathrm{~A}^{*}$ & 0.626 & 0.23 \\
\hline LT Darco Hg-LH @ 2.0lb/Macf & $8 / 13 / 2007$ & 11:00 & $1 \mathrm{~F} 1 \mathrm{~A}$ & 0.470 & 0.56 \\
\hline LT Darco Hg-LH @ 2.0lb/Macf & $8 / 13 / 2007$ & 11:00 & $1 \mathrm{~F} 2 \mathrm{~A}$ & 0.586 & 0.64 \\
\hline LT Darco Hg-LH @ 2.0lb/Macf & $8 / 13 / 2007$ & 11:00 & $1 \mathrm{~F} 3 \mathrm{~A}^{*}$ & 0.474 & 0.32 \\
\hline LT Darco Hg-LH @ 2.0lb/Macf & $8 / 15 / 2007$ & 11:00 & $1 \mathrm{~F} 1 \mathrm{~A}$ & 0.392 & 0.50 \\
\hline LT Darco Hg-LH @ 2.0lb/Macf & $8 / 15 / 2007$ & 11:00 & $1 \mathrm{~F} 2 \mathrm{~A}$ & 0.318 & 0.44 \\
\hline LT Darco Hg-LH @ 2.0lb/Macf & $8 / 15 / 2007$ & 11:00 & $1 \mathrm{~F} 3 \mathrm{~A}^{*}$ & 0.403 & 0.64 \\
\hline LT Darco Hg-LH @ 2.0lb/Macf & $8 / 18 / 2007$ & $13: 00$ & $1 \mathrm{~F} 1 \mathrm{~A}$ & 0.584 & 0.26 \\
\hline LT Darco Hg-LH @ 2.0lb/Macf & $8 / 18 / 2007$ & 13:00 & $1 \mathrm{~F} 2 \mathrm{~A}$ & 0.744 & 0.55 \\
\hline LT Darco Hg-LH @ 2.0lb/Macf & $8 / 18 / 2007$ & 13:00 & $1 \mathrm{~F} 3 \mathrm{~A}^{*}$ & 0.580 & 0.46 \\
\hline LT Darco Hg-LH @ 2.0lb/Macf & $8 / 19 / 2007$ & $14: 00$ & $1 \mathrm{~F} 1 \mathrm{~A}$ & 0.731 & 0.73 \\
\hline LT Darco Hg-LH @ 2.0lb/Macf & $8 / 19 / 2007$ & $14: 00$ & $1 \mathrm{~F} 2 \mathrm{~A}$ & 0.794 & 0.57 \\
\hline LT Darco Hg-LH @ 2.0lb/Macf & $8 / 19 / 2007$ & 14:00 & $1 \mathrm{~F} 3 \mathrm{~A}^{*}$ & 0.743 & 0.48 \\
\hline
\end{tabular}

* Hopper 3A ash was contaminated with economizer ash for all periods after 7/4/2007. Hg and LOI content of the ash are reported as an average of hoppers $1 \mathrm{~A}$ and $2 \mathrm{~A}$ for each field in report. 
Table E-8. Summary of Long Term Ash Hg \& LOI Analysis on Side A Field 2

\begin{tabular}{|l|c|c|c|c|c||}
\hline \multicolumn{1}{|c|}{ Condition } & $\begin{array}{c}\text { Date of } \\
\text { Sample }\end{array}$ & $\begin{array}{c}\text { Time of } \\
\text { Sample }\end{array}$ & $\begin{array}{c}\text { Field \& } \\
\text { Hopper }\end{array}$ & $\begin{array}{c}\text { Ash Hg } \\
\text { Content } \\
\text { ug/g) }\end{array}$ & $\begin{array}{c}\text { Ash } \\
\text { LOI } \\
\text { Content } \\
(\boldsymbol{\%})\end{array}$ \\
\hline \hline LT Darco Hg-LH @ 2.0lb/Macf & $6 / 29 / 2007$ & $13: 00$ & 2F1A & 1.440 & 0.53 \\
\hline LT Darco Hg-LH @ 2.0lb/Macf & $6 / 29 / 2007$ & $13: 00$ & 2F2A & 2.060 & 0.61 \\
\hline LT Darco Hg-LH @ 2.0lb/Macf & $6 / 29 / 2007$ & $13: 00$ & 2F3A & 1.270 & 0.49 \\
\hline LT Darco Hg-LH @ 2.0lb/Macf & $7 / 5 / 2007$ & $14: 10$ & 2F1A & 1.700 & 1.00 \\
\hline LT Darco Hg-LH @ 2.0lb/Macf & $7 / 5 / 2007$ & $14: 10$ & 2F2A & 1.930 & 1.14 \\
\hline LT Darco Hg-LH @ 2.0lb/Macf & $7 / 5 / 2007$ & $14: 10$ & 2F3A* & 0.967 & 0.73 \\
\hline LT Darco Hg-LH @ 2.0lb/Macf & $7 / 21 / 2007$ & $12: 27$ & 2F1A & 2.330 & 0.87 \\
\hline LT Darco Hg-LH @ 2.0lb/Macf & $7 / 21 / 2007$ & $12: 25$ & 2F2A & 2.640 & 0.71 \\
\hline LT Darco Hg-LH @ 2.0lb/Macf & $7 / 28 / 2007$ & $15: 00$ & 2F1A & 1.896 & 0.70 \\
\hline LT Darco Hg-LH @ 2.0lb/Macf & $7 / 28 / 2007$ & $15: 00$ & 2F2A & 1.662 & 0.56 \\
\hline LT Darco Hg-LH @ 2.0lb/Macf & $7 / 28 / 2007$ & $15: 00$ & 2F3A* & 1.047 & 0.52 \\
\hline LT Darco Hg-LH @ 2.0lb/Macf & $7 / 21 / 2007$ & $12: 23$ & 2F3A & 0.978 & 0.47 \\
\hline LT Darco Hg-LH @ 2.0lb/Macf & $8 / 5 / 2007$ & $15: 30$ & 2F1A & 1.937 & 0.89 \\
\hline LT Darco Hg-LH @ 2.0lb/Macf & $8 / 5 / 2007$ & $15: 30$ & 2F2A & 2.390 & 0.97 \\
\hline LT Darco Hg-LH @ 2.0lb/Macf & $8 / 5 / 2007$ & $15: 30$ & 2F3A* & 1.277 & 0.72 \\
\hline LT Darco Hg-LH @ 2.0lb/Macf & $8 / 18 / 2007$ & $13: 00$ & 2F1A & 1.500 & 0.66 \\
\hline LT Darco Hg-LH @ 2.0lb/Macf & $8 / 18 / 2007$ & $13: 00$ & 2F2A & 1.810 & 0.60 \\
\hline LT Darco Hg-LH @ 2.0lb/Macf & $8 / 18 / 2007$ & $13: 00$ & 2F3A* & 1.630 & 0.59 \\
\hline \hline
\end{tabular}

* Hopper 3A ash was contaminated with economizer ash for all periods after 7/4/2007. Hg and LOI content of the ash are reported as an average of hoppers $1 \mathrm{~A}$ and $2 \mathrm{~A}$ for each field in report. 
Table E-9. Summary of Long Term Ash Hg \& LOI Analysis on Side A Field 3

\begin{tabular}{|c|c|c|c|c|c|}
\hline Condition & $\begin{array}{l}\text { Date of } \\
\text { Sample }\end{array}$ & $\begin{array}{l}\text { Time of } \\
\text { Sample }\end{array}$ & $\begin{array}{l}\text { Field \& } \\
\text { Hopper }\end{array}$ & $\begin{array}{c}\text { Ash Hg } \\
\text { Content } \\
\text { (ug/g) }\end{array}$ & $\begin{array}{c}\text { Ash } \\
\text { LOI } \\
\text { Content } \\
(\%) \\
\end{array}$ \\
\hline LT Darco Hg-LH @ 2.0lb/Macf & $6 / 29 / 2007$ & 13:00 & $3 \mathrm{~F} 1 \mathrm{~A}$ & 3.470 & 0.65 \\
\hline LT Darco Hg-LH @ 2.0lb/Macf & $6 / 29 / 2007$ & 13:00 & $3 \mathrm{~F} 2 \mathrm{~A}$ & 3.210 & 0.85 \\
\hline LT Darco Hg-LH @ 2.0lb/Macf & $6 / 29 / 2007$ & 13:00 & $3 \mathrm{~F} 3 \mathrm{~A}$ & 2.290 & 0.63 \\
\hline LT Darco Hg-LH @ 2.0lb/Macf & $7 / 5 / 2007$ & $14: 10$ & $3 \mathrm{~F} 1 \mathrm{~A}$ & 2.930 & 1.05 \\
\hline LT Darco Hg-LH @ 2.0lb/Macf & $7 / 5 / 2007$ & $14: 10$ & $3 \mathrm{~F} 2 \mathrm{~A}$ & 3.300 & 1.49 \\
\hline LT Darco Hg-LH @ 2.0lb/Macf & $7 / 5 / 2007$ & 14:10 & $3 \mathrm{~F} 3 \mathrm{~A}^{*}$ & 1.760 & 0.96 \\
\hline LT Darco Hg-LH @ 2.0lb/Macf & $7 / 21 / 2007$ & $12: 38$ & $3 \mathrm{~F} 1 \mathrm{~A}$ & 2.730 & 1.01 \\
\hline LT Darco Hg-LH @ 2.0lb/Macf & $7 / 21 / 2007$ & 13:00 & $3 \mathrm{~F} 2 \mathrm{~A}$ & 4.750 & 1.29 \\
\hline LT Darco Hg-LH @ 2.0lb/Macf & $7 / 21 / 2007$ & $12: 31$ & $3 \mathrm{~F} 3 \mathrm{~A}^{*}$ & 2.240 & 0.87 \\
\hline LT Darco Hg-LH @ 2.0lb/Macf & $7 / 28 / 2007$ & $15: 10$ & $3 \mathrm{~F} 1 \mathrm{~A}$ & 3.940 & 0.84 \\
\hline LT Darco Hg-LH @ 2.0lb/Macf & $7 / 28 / 2007$ & $15: 10$ & $3 \mathrm{~F} 2 \mathrm{~A}$ & 3.381 & 0.87 \\
\hline LT Darco Hg-LH @ 2.0lb/Macf & $7 / 28 / 2007$ & $15: 10$ & $3 \mathrm{~F} 3 \mathrm{~A}^{*}$ & 2.003 & 0.68 \\
\hline LT Darco Hg-LH @ 2.0lb/Macf & $8 / 5 / 2007$ & $15: 30$ & $3 \mathrm{~F} 1 \mathrm{~A}$ & 3.566 & 0.71 \\
\hline LT Darco Hg-LH @ 2.0lb/Macf & $8 / 5 / 2007$ & $15: 30$ & $3 \mathrm{~F} 2 \mathrm{~A}$ & 2.878 & 0.77 \\
\hline LT Darco Hg-LH @ 2.0lb/Macf & $8 / 5 / 2007$ & $15: 30$ & $3 \mathrm{~F} 3 \mathrm{~A}^{*}$ & 2.000 & 0.46 \\
\hline LT Darco Hg-LH @ 2.0lb/Macf & $8 / 18 / 2007$ & 13:00 & $3 \mathrm{~F} 1 \mathrm{~A}$ & 2.700 & 0.78 \\
\hline LT Darco Hg-LH @ 2.0lb/Macf & $8 / 18 / 2007$ & 13:00 & $3 \mathrm{~F} 2 \mathrm{~A}$ & 2.800 & 1.01 \\
\hline LT Darco Hg-LH @ 2.0lb/Macf & $8 / 18 / 2007$ & 13:00 & $3 \mathrm{~F} 3 \mathrm{~A}^{*}$ & 2.180 & 0.80 \\
\hline
\end{tabular}

* Hopper 3A ash was contaminated with economizer ash for all periods after 7/4/2007. $\mathrm{Hg}$ and LOI content of the ash are reported as an average of hoppers $1 \mathrm{~A}$ and $2 \mathrm{~A}$ for each field in report. 
Table E-10. Summary of Long Term Ash Hg \& LOI Analysis on Side A Fields 4\&5

\begin{tabular}{|c|c|c|c|c|c|}
\hline Condition & $\begin{array}{l}\text { Date of } \\
\text { Sample }\end{array}$ & $\begin{array}{l}\text { Time of } \\
\text { Sample }\end{array}$ & $\begin{array}{l}\text { Field \& } \\
\text { Hopper }\end{array}$ & $\begin{array}{c}\text { Ash Hg } \\
\text { Content } \\
\text { (ug/g) }\end{array}$ & $\begin{array}{c}\text { Ash } \\
\text { LOI } \\
\text { Content } \\
(\%)\end{array}$ \\
\hline LT Darco Hg-LH @ 2.0lb/Macf & $6 / 29 / 2007$ & 13:00 & $4 \& 5 \mathrm{~F} 1 \mathrm{~A}$ & 3.870 & 0.80 \\
\hline LT Darco Hg-LH @ 2.0lb/Macf & $6 / 29 / 2007$ & $13: 00$ & $4 \& 5 \mathrm{~F} 2 \mathrm{~A}$ & 3.660 & 0.90 \\
\hline LT Darco Hg-LH @ 2.0lb/Macf & $6 / 29 / 2007$ & $13: 00$ & $4 \& 5 \mathrm{~F} 3 \mathrm{~A}$ & 3.250 & 0.73 \\
\hline LT Darco Hg-LH @ 2.0lb/Macf & $7 / 5 / 2007$ & $14: 10$ & $4 \& 5 \mathrm{~F} 1 \mathrm{~A}$ & 3.480 & 0.98 \\
\hline LT Darco Hg-LH @ 2.0lb/Macf & $7 / 5 / 2007$ & $14: 10$ & $4 \& 5 \mathrm{~F} 2 \mathrm{~A}$ & 4.150 & 1.74 \\
\hline LT Darco Hg-LH @ 2.0lb/Macf & $7 / 5 / 2007$ & $14: 10$ & $4 \& 5 \mathrm{~F} 3 \mathrm{~A}^{*}$ & 3.270 & 0.79 \\
\hline LT Darco Hg-LH @ 2.0lb/Macf & $7 / 21 / 2007$ & $12: 41$ & $4 \& 5 \mathrm{~F} 1 \mathrm{~A}$ & 3.230 & 1.31 \\
\hline LT Darco Hg-LH @ 2.0lb/Macf & $7 / 21 / 2007$ & $12: 42$ & $4 \& 5 \mathrm{~F} 2 \mathrm{~A}$ & 3.450 & 1.48 \\
\hline LT Darco Hg-LH @ 2.0lb/Macf & $7 / 21 / 2007$ & $12: 49$ & $4 \& 5 \mathrm{~F} 3 \mathrm{~A}^{*}$ & 0.796 & 0.81 \\
\hline LT Darco Hg-LH @ 2.0lb/Macf & $7 / 28 / 2007$ & $15: 10$ & $4 \& 5 \mathrm{~F} 1 \mathrm{~A}$ & 2.870 & 1.45 \\
\hline LT Darco Hg-LH @ 2.0lb/Macf & $7 / 28 / 2007$ & $15: 10$ & $4 \& 5 \mathrm{~F} 2 \mathrm{~A}$ & 4.916 & 1.42 \\
\hline LT Darco Hg-LH @ 2.0lb/Macf & $7 / 28 / 2007$ & $15: 10$ & $4 \& 5 \mathrm{~F} 3 \mathrm{~A}^{*}$ & 3.871 & 0.79 \\
\hline LT Darco Hg-LH @ 2.0lb/Macf & $8 / 5 / 2007$ & $15: 30$ & $4 \& 5 \mathrm{~F} 1 \mathrm{~A}$ & 4.060 & 0.80 \\
\hline LT Darco Hg-LH @ 2.0lb/Macf & $8 / 5 / 2007$ & $15: 30$ & $4 \& 5 \mathrm{~F} 2 \mathrm{~A}$ & 3.710 & 0.94 \\
\hline LT Darco Hg-LH @ 2.0lb/Macf & $8 / 5 / 2007$ & $15: 30$ & $4 \& 5 \mathrm{~F} 3 \mathrm{~A}^{*}$ & 3.533 & 0.96 \\
\hline LT Darco Hg-LH @ 2.0lb/Macf & $8 / 18 / 2007$ & 13:00 & $4 \& 5 \mathrm{~F} 1 \mathrm{~A}$ & 1.900 & 0.84 \\
\hline LT Darco Hg-LH @ 2.0lb/Macf & $8 / 18 / 2007$ & 13:00 & $4 \& 5 \mathrm{~F} 2 \mathrm{~A}$ & 2.350 & 1.17 \\
\hline LT Darco Hg-LH @ 2.0lb/Macf & $8 / 18 / 2007$ & 13:00 & $4 \& 5 \mathrm{~F} 3 \mathrm{~A}^{*}$ & 3.290 & 1.00 \\
\hline
\end{tabular}

* Hopper 3A ash was contaminated with economizer ash for all periods after 7/4/2007. $\mathrm{Hg}$ and

LOI content of the ash are reported as an average of hoppers $1 \mathrm{~A}$ and $2 \mathrm{~A}$ for each field in report. 
Table E-11. Summary of Long Term Ash Hg \& LOI Analysis on Side A Fields $5 \& 6$

\begin{tabular}{||l|c|c|c|c|c||}
\hline \hline \multicolumn{1}{|c|}{ Condition } & $\begin{array}{c}\text { Date of } \\
\text { Sample }\end{array}$ & $\begin{array}{c}\text { Time of } \\
\text { Sample }\end{array}$ & $\begin{array}{c}\text { Field \& } \\
\text { Hopper }\end{array}$ & $\begin{array}{c}\text { Ash Hg } \\
\text { Content } \\
\mathbf{u g} / \mathbf{g})\end{array}$ & $\begin{array}{c}\text { Ash } \\
\text { LOI } \\
\text { Content } \\
(\%)\end{array}$ \\
\hline \hline LT Darco Hg-LH @ 2.0lb/Macf & $7 / 5 / 2007$ & $14: 10$ & $6 \& 7 \mathrm{~F} 1 \mathrm{~A}$ & 2.870 & 1.76 \\
\hline LT Darco Hg-LH @ 2.0lb/Macf & $7 / 5 / 2007$ & $14: 10$ & $6 \& 7 \mathrm{~F} 2 \mathrm{~A}$ & 1.020 & 1.49 \\
\hline LT Darco Hg-LH @ 2.0lb/Macf & $7 / 5 / 2007$ & $14: 10$ & $6 \& 7 \mathrm{~F} 3 \mathrm{~A}^{*}$ & 3.450 & 1.12 \\
\hline LT Darco Hg-LH @ 2.0lb/Macf & $7 / 21 / 2007$ & $12: 56$ & $6 \& 7 \mathrm{~F} 1 \mathrm{~A}$ & 2.610 & 1.70 \\
\hline LT Darco Hg-LH @ 2.0lb/Macf & $7 / 21 / 2007$ & $12: 52$ & $6 \& 7 \mathrm{~F} 2 \mathrm{~A}$ & 1.140 & 1.81 \\
\hline LT Darco Hg-LH @ 2.0lb/Macf & $7 / 21 / 2007$ & $12: 50$ & $6 \& 7 \mathrm{~F} 3 \mathrm{~A}^{*}$ & 6.600 & 1.03 \\
\hline LT Darco Hg-LH @ 2.0lb/Macf & $7 / 28 / 2007$ & $15: 20$ & $6 \& 7 \mathrm{~F} 1 \mathrm{~A}$ & 2.092 & 2.59 \\
\hline LT Darco Hg-LH @ 2.0lb/Macf & $7 / 28 / 2007$ & $15: 20$ & $6 \& 7 \mathrm{~F} 2 \mathrm{~A}$ & 3.366 & 1.71 \\
\hline LT Darco Hg-LH @ 2.0lb/Macf & $7 / 28 / 2007$ & $15: 20$ & $6 \& 7 \mathrm{~F} 3 \mathrm{~A}^{*}$ & 4.470 & 0.99 \\
\hline LT Darco Hg-LH @ 2.0lb/Macf & $8 / 5 / 2007$ & $15: 30$ & $6 \& 7 \mathrm{~F} 1 \mathrm{~A}$ & 1.225 & 1.35 \\
\hline LT Darco Hg-LH @ 2.0lb/Macf & $8 / 5 / 2007$ & $15: 30$ & $6 \& 7 \mathrm{~F} 2 \mathrm{~A}$ & 1.390 & 1.37 \\
\hline LT Darco Hg-LH @ 2.0lb/Macf & $8 / 5 / 2007$ & $15: 30$ & $6 \& 7 \mathrm{~F} 3 \mathrm{~A} *$ & 3.831 & 0.93 \\
\hline LT Darco Hg-LH @ 2.0lb/Macf & $8 / 18 / 2007$ & $13: 00$ & $6 \& 7 \mathrm{~F} 1 \mathrm{~A}$ & 1.303 & 1.19 \\
\hline LT Darco Hg-LH @ 2.0lb/Macf & $8 / 18 / 2007$ & $13: 00$ & $6 \& 7 \mathrm{~F} 2 \mathrm{~A}$ & 0.973 & 1.58 \\
\hline LT Darco Hg-LH @ 2.0lb/Macf & $8 / 18 / 2007$ & $13: 00$ & $6 \& 7 \mathrm{~F} 3 \mathrm{~A} *$ & 2.863 & 1.02 \\
\hline \hline
\end{tabular}

* Hopper 3A ash was contaminated with economizer ash for all periods after 7/4/2007. $\mathrm{Hg}$ and

LOI content of the ash are reported as an average of hoppers $1 \mathrm{~A}$ and $2 \mathrm{~A}$ for each field in report.

Table E-12. Summary of Long Term Ash Hg \& LOI Analysis on Side B (Untreated ESP)

\begin{tabular}{|l|c|c|c|c|c||}
\hline \multicolumn{1}{|c|}{ Condition } & $\begin{array}{c}\text { Date of } \\
\text { Sample }\end{array}$ & $\begin{array}{c}\text { Time of } \\
\text { Sample }\end{array}$ & $\begin{array}{c}\text { Field \& } \\
\text { Hopper }\end{array}$ & $\begin{array}{c}\text { Ash Hg } \\
\text { Content } \\
\mathbf{u g} / \mathbf{g})\end{array}$ & $\begin{array}{c}\text { Ash } \\
\text { LOI } \\
\text { Content } \\
(\boldsymbol{\%})\end{array}$ \\
\hline \hline LT Darco Hg-LH @ 2.0lb/Macf & $7 / 9 / 2007$ & $14: 30$ & $1 \mathrm{~F} 1 \mathrm{~B}$ & 0.094 & 0.25 \\
\hline LT Darco Hg-LH @ 2.0lb/Macf & $7 / 9 / 2007$ & $14: 30$ & $1 \mathrm{~F} 3 \mathrm{~B}$ & 0.085 & 0.09 \\
\hline LT Darco Hg-LH @ 2.0lb/Macf & $7 / 9 / 2007$ & $11: 40$ & $1 \mathrm{~F} 2 \mathrm{~B}$ & 0.054 & 0.11 \\
\hline LT Darco Hg-LH @ 2.0lb/Macf & $8 / 3 / 2007$ & $14: 55$ & $1 \mathrm{~F} 1 \mathrm{~B}$ & 0.064 & 0.21 \\
\hline LT Darco Hg-LH @ 2.0lb/Macf & $8 / 3 / 2007$ & $14: 55$ & $1 \mathrm{~F} 2 \mathrm{~B}$ & 0.070 & 0.35 \\
\hline LT Darco Hg-LH @ 2.0lb/Macf & $8 / 3 / 2007$ & $14: 55$ & $1 \mathrm{~F} 3 \mathrm{~B}$ & 0.050 & 0.14 \\
\hline LT Darco Hg-LH @ 2.0lb/Macf & $8 / 17 / 2007$ & $11: 30$ & $1 \mathrm{~F} 1 \mathrm{~B}$ & $<0.025$ & 0.25 \\
\hline LT Darco Hg-LH @ 2.0lb/Macf & $8 / 17 / 2007$ & $11: 30$ & $1 \mathrm{~F} 2 \mathrm{~B}$ & $<0.024$ & 0.14 \\
\hline LT Darco Hg-LH @ 2.0lb/Macf & $8 / 17 / 2007$ & $11: 30$ & $1 \mathrm{~F} 3 \mathrm{~B}$ & $<0.025$ & 0.13 \\
\hline $\begin{array}{l}\text { Average } \\
\text { LT - Field 1 Side B }\end{array}$ & & & & $\mathbf{0 . 0 5 5}$ & $\mathbf{0 . 1 9}$ \\
\hline
\end{tabular}




\section{APPENDIX F - MASS BALANCE METHODOLOGY AND RESULTS}




\section{Table F-1. ESP Parameters for Material Balance}

\begin{tabular}{|c|c|c|}
\hline fraction coal ash reporting as fly as $h$ & 0.85 & \\
\hline fraction fly ash captured in ESP & 0.9995 & \\
\hline & $\begin{array}{c}\text { fraction fly ash captured } \\
\text { per field (per LMS) }\end{array}$ & $\begin{array}{l}\text { treated ash Hg } \\
\text { content (average } \\
\text { of fields } 1 \mathrm{~A} \& \\
2 \mathrm{~A})(\mathrm{ppm})\end{array}$ \\
\hline ESP field 1 & 0.94 & used daily value \\
\hline ESP field 2 & 0.042 & 1.915 \\
\hline ESP field 3 & 0.01 & 3.246 \\
\hline ESP field $4 \& 5$ & 0.004 & 3.705 \\
\hline ESP field $6 \& 7$ & 0.002 & 1.964 \\
\hline
\end{tabular}

For baseline ash, only field 1 data were used. All

downstream fields had mercury concentrations similar

to field 1

During long-term injection, the first field ash mercury

concentrations come from the daily analyzed value.

For downstream fields, used an average of data

collected in each field, as it was reasonably consistent

from week to week of the test. 
Table F-2. Mass Balance Results

\begin{tabular}{|c|c|c|c|c|c|c|c|}
\hline Date & & $12 / 2 / 2006$ & $12 / 9 / 2006$ & $6 / 18 / 2007$ & $6 / 20 / 2007$ & \begin{tabular}{|l|}
$6 / 20 / 2007$ \\
\end{tabular} & $6 / 21 / 2007$ \\
\hline Condition & & $\begin{array}{c}\text { Parametric } \\
\text { Baseline }\end{array}$ & $\begin{array}{l}\text { Darco Hg - } \\
0.6 \mathrm{lb} / \mathrm{Macf}\end{array}$ & $\begin{array}{c}\text { Long-term } \\
\text { Baseline }\end{array}$ & $\begin{array}{c}\text { Long-term } \\
\text { Baseline }\end{array}$ & $\begin{array}{c}\text { Long-term } \\
\text { Baseline }\end{array}$ & $\begin{array}{l}\text { Long-term } \\
\text { Baseline }\end{array}$ \\
\hline Inputs: & Units & & & & & & \\
\hline Time Coal Sampled & & $10: 30$ & $10: 30$ & Ave & Ave & Ave & Ave \\
\hline Time Coal should hit Furnace & & $10: 30$ & $10: 30$ & $16: 34$ & $22: 00$ & $22: 00$ & $13: 00$ \\
\hline Load, Gross at time Coal hit Furnace & MW (gross) & 883 & 884 & 886 & 886 & 886 & 890 \\
\hline Btu Ratio & Btu blend/6399 Btu & & & 1.16 & 1.13 & 1.13 & 1.2 \\
\hline$\%$ Coal 2 (PRB) & & & & 25.57 & 13.45 & 13.45 & 28.35 \\
\hline Time Ash Sampled & & $16: 00$ & 17:05 & $16: 34$ & $11: 15$ & $10: 45$ & $13: 00$ \\
\hline Load, Gross at time Ash Sampled & MW (gross) & 881 & 883 & 886 & 876 & 876 & 890 \\
\hline Gross Heat Rate & Btu/kW-h & 9685 & 9776 & 9703 & 9773 & 9773 & 9727 \\
\hline Fraction Coal 1 by Wt. & wt. Fraction & 0.731 & 0.72 & 0.7443 & 0.8655 & 0.8655 & 0.7165 \\
\hline Coal $1 \mathrm{Hg}(\mathrm{TxL})$ & $\mu \mathrm{g} / \mathrm{g}, \mathrm{dry}$ & 0.199 & 0.139 & 0.198 & 0.185 & 0.185 & 0.198 \\
\hline Coal 1 Ash $(T x L)$ & wt $\%$, dry & 22.28 & 15.08 & 21.22 & 22.55 & 22.55 & 21.22 \\
\hline Coal 1 Moisture $(\mathrm{TxL})$ & wt $\%$ & 31.19 & 31.34 & 32.49 & 33.10 & 33.10 & 32.49 \\
\hline Coal 1 Heating Value (TxL) & Btu/lb, dry & 10149 & 10962 & 9946 & 9514 & 9514 & 9946 \\
\hline Coal 1 F-factor $(\mathrm{TxL})$ & dry scf/Mbtu, $0 \% \mathrm{O} 2$ & 9486 & 9644 & 10248 & 10248 & 10248 & 10248 \\
\hline $\mathrm{Coal} 2 \mathrm{Hg}$ (PRB) & $\mu \mathrm{g} / \mathrm{g}, \mathrm{dry}$ & 0.116 & 0.143 & 0.096 & 0.097 & 0.097 & 0.096 \\
\hline Coal 2 Ash (PRB) & wt\%, dry & 7.16 & 9.12 & 8.09 & 7.06 & 7.06 & 8.09 \\
\hline Coal 2 Moisture (PRB) & $w t \%$ & 31.16 & 29.71 & 32.93 & 30.57 & 30.57 & 32.93 \\
\hline Coal 2 Heating Value (PRB) & Btu/lb, dry & 11901 & 11667 & 11645 & 11718 & 11718 & 11645 \\
\hline Coal 2 F-factor (PRB) & dry scf/Mbtu, $0 \% \mathrm{O} 2$ & 9583 & 9651 & 10228 & 10033 & 10033 & 10228 \\
\hline Date Ash Sampled & & & & $6 / 18 / 2007$ & $6 / 20 / 2007$ & $6 / 22 / 2007$ & Ave \\
\hline Time Ash Sampled & & & & $16: 34$ & $11: 15$ & $10: 45$ & \\
\hline Treated Ash $\mathrm{Hg}$ (from URS lab) - first field only & $\mu \mathrm{g} / \mathrm{g}$ & 0.025 & 0.494 & 0.029 & 0.025 & 0.025 & 0.030 \\
\hline Treated Ash $\mathrm{Hg}$ (from URS lab) - weighted for all fields & $\mu \mathrm{g} / \mathrm{g}$ & 0.025 & 0.494 & 0.029 & 0.025 & 0.025 & 0.030 \\
\hline Untreated Ash $\mathrm{Hg}$ (from URS lab) & $\mu \mathrm{g} / \mathrm{q}$ & & & 0.039 & 0.049 & 0.049 & 0.053 \\
\hline SCEM start time & & & & $14: 30$ & $10: 00$ & $13: 50$ & $11: 00$ \\
\hline SCEM end time & & & & $18: 30$ & $12: 24$ & $16: 15$ & $15: 30$ \\
\hline SCEM ESP Inlet & $\mu \mathrm{g} / \mathrm{dry} \mathrm{Nm3} @ 3 \% \mathrm{O} 2$ & 26.13 & 23.19 & & 26.62 & 22.71 & \\
\hline SCEM ESP Outlet Treated & $\mu \mathrm{g} / \mathrm{dry}$ Nm3 @ 3\% O2 & 15.57 & 11.66 & & 18.49 & \#N/A & 21.11 \\
\hline SCEM ESP Outlet Untreated & $\mu \mathrm{g} / \mathrm{dry} \mathrm{Nm3} @ 3 \% \mathrm{O} 2$ & 22.78 & 18.87 & & 24.14 & 26.57 & \\
\hline $\mathrm{OH}$ start time & & & & & $10: 10$ & $13: 50$ & $11: 01$ \\
\hline $\mathrm{OH}$ end time & & & & & $12: 25$ & $16: 04$ & $15: 32$ \\
\hline OH ESP Outlet Treated & $\mu \mathrm{g} / \mathrm{dry}$ Nm3 @ 3\% O2 & & & & 28.75 & 22.88 & 26.47 \\
\hline OH ESP Outlet Untreated & $\mu \mathrm{g} / \mathrm{dry} \mathrm{Nm3} @ 3 \% \mathrm{O} 2$ & & & & 22.65 & 28.54 & 20.89 \\
\hline \multicolumn{8}{|l|}{ Calculated Values: } \\
\hline Fraction Coal 1 by Btu & Btu Fraction & 0.70 & 0.70 & 0.71 & 0.83 & 0.83 & 0.68 \\
\hline Composite F-factor & dscf/MMBtu at 3\% O2 & 11110 & 11263 & 11959 & 11924 & 11924 & 11958 \\
\hline Gas flow rate & dscfm at $3 \% \mathrm{O} 2$ & 1582951 & 1622706 & 1714491 & 1720128 & 1720128 & 1725107 \\
\hline Gas flow rate & dry Nm3/min & 41785 & 42835 & 45258 & 45406 & 45406 & 45538 \\
\hline Coal feed rate & ton/hr (dry) & 402 & 387 & 414 & 441 & 441 & 415 \\
\hline Mercury Rate in Coal & $g / h$ & 64.5 & 49.2 & 64.7 & 69.5 & 69.5 & 63.7 \\
\hline Mercury Rate in Coal & $\mathrm{lb} / \mathrm{Tb} \mathrm{Tu}$ & 16.6 & 12.6 & 16.6 & 17.7 & 17.7 & 16.2 \\
\hline $\mathrm{Hg}$ Concentration from Coal & $\mu \mathrm{g} / \mathrm{dNm} 3$ at $3 \% \mathrm{O} 2$ & 25.7 & 19.2 & 23.8 & 25.5 & 25.5 & 23.3 \\
\hline Mercury Rate in Ash Treated, weighted & $g / h$ & 1.4 & 19.8 & 1.7 & 1.7 & 1.7 & 1.7 \\
\hline Mercury Rate in Ash Untreated & $\mathrm{g} / \mathrm{h}$ & & & 2.2 & 3.4 & 3.4 & 3.0 \\
\hline SCEM Mercury Rate ESP Inlet & $g / h$ & 65.5 & 59.6 & & 72.5 & 61.9 & \\
\hline SCEM Mercury Rate ESP Outlet Treated & $\mathrm{g} / \mathrm{h}$ & 39.0 & 30.0 & & 50.4 & & 57.7 \\
\hline SCEM Mercury Rate ESP Outlet Untreated & $\mathrm{g} / \mathrm{h}$ & 57.1 & 48.5 & & 65.8 & 72.4 & \\
\hline OH Mercury Rate ESP Outlet Treated & $\mathrm{g} / \mathrm{h}$ & & & & 78.3 & 62.3 & 72.3 \\
\hline OH Mercury Rate ESP Outlet Untreated & $g / h$ & & & & 61.7 & 77.8 & 57.1 \\
\hline \multicolumn{8}{|l|}{\begin{tabular}{|l} 
Weighted Average Coal Values: \\
\end{tabular}} \\
\hline wtd $\mathrm{Hg}$ & ug/g, dry & 0.177 & 0.140 & 0.172 & 0.174 & 0.174 & 0.169 \\
\hline wtd ash & wt $\%$, as recd & 12.53 & 9.25 & 12.05 & 13.72 & 13.72 & 11.80 \\
\hline wtd moisture & wt $\%$ & 31.2 & 30.9 & 32.6 & 32.8 & 32.8 & 32.6 \\
\hline wtd Btu & Btu/lb, as recd & 7309 & 7715 & 6995 & 6603 & 6603 & 7025 \\
\hline \multicolumn{8}{|l|}{ SCEM vs Coal Hq Ratios: } \\
\hline SCEM inlet $\mathrm{Hg} / \mathrm{Coal} \mathrm{Hg}$ & & $102 \%$ & $121 \%$ & & $104 \%$ & $89 \%$ & \\
\hline SCEM ESP outlet untreated $\mathrm{Hg} / \mathrm{Coal} \mathrm{Hg}$ & & $89 \%$ & $99 \%$ & & $95 \%$ & $104 \%$ & \\
\hline \multicolumn{8}{|l|}{ Percent Removal: } \\
\hline treated ash $\mathrm{Hg} / \mathrm{Coal} \mathrm{Hg}$ & & $2 \%$ & $40 \%$ & $3 \%$ & $2 \%$ & $2 \%$ & $3 \%$ \\
\hline treated SCEM Hg/Coal Hg & & $39 \%$ & $39 \%$ & & $27 \%$ & & $9 \%$ \\
\hline treated $\mathrm{OH} \mathrm{Hg} / \mathrm{Coal} \mathrm{Hg}$ & & & & & $-13 \%$ & $10 \%$ & $-14 \%$ \\
\hline treated ash $\mathrm{Hg}$ /inlet ESP Hg & & & & & & & \\
\hline treated SCEM Hg/inlet ESP Hg & & & & & & & \\
\hline treated $\mathrm{OH} \mathrm{Hg} /$ inlet ESP Hg & & & & & $-8 \%$ & $-1 \%$ & \\
\hline untreated ash $\mathrm{Hg}$ /inlet ESP Hg & & & & & $5 \%$ & $5 \%$ & \\
\hline untreated SCEM Hg/inlet ESP Hg & & $13 \%$ & $19 \%$ & & $9 \%$ & $-17 \%$ & \\
\hline untreated $\mathrm{OH} \mathrm{Hg}$ /inlet ESP Hg & & & & & $15 \%$ & $-26 \%$ & \\
\hline Hg Mass Balance Ratio: & & & & & & & \\
\hline (Coal In/SCEM Out) Treated & & 1.59 & 0.99 & & 1.33 & & 1.07 \\
\hline (Coal In/OH Out) Treated & & & & & 0.87 & 1.08 & 0.86 \\
\hline (SCEM In/SCEM Out) Treated & & 1.62 & 1.20 & & 1.39 & & \\
\hline (SCEM $\ln / \mathrm{OH}$ Out) Treated & & & & & 0.91 & 0.97 & \\
\hline (Coal In/SCEM Out) Untreated & & & & & 1.00 & 0.92 & \\
\hline (Coal In/OH Out) Untreated & & & & & 1.07 & 0.86 & 1.06 \\
\hline (SCEM In/SCEM Out) Untreated & & & & & 1.05 & 0.82 & \\
\hline (SCEM $\ln / \mathrm{OH}$ Out) Untreated & & & & & 1.11 & 0.76 & \\
\hline $\begin{array}{l}\text { Overall Removal - assuming } 95 \% \text { oxidized } \mathrm{Hg} \\
\text { removed bV FGD: }\end{array}$ & & & & & & & \\
\hline SCEM/coal basis (assuming $74 \%$ ox) & & $57 \%$ & $57 \%$ & & $49 \%$ & & \\
\hline $\mathrm{OH} /$ coal basis (assuming $69 \%$ ox) & & & & & $26 \%$ & $41 \%$ & \\
\hline
\end{tabular}




\begin{tabular}{|c|c|c|c|c|c|c|c|}
\hline Date & & $6 / 22 / 2007$ & Average & $6 / 25 / 2007$ & $6 / 28 / 2007$ & \begin{tabular}{|l|l|}
$6 / 29 / 2007$ \\
\end{tabular} & $7 / 3 / 2007$ \\
\hline Condition & & $\begin{array}{l}\text { Long-term } \\
\text { Baseline }\end{array}$ & Baseline & $\begin{array}{c}\text { Darco HG- } \\
\text { LH } \\
2.0 \mathrm{lb} / \text { Macf } \\
\end{array}$ & \begin{tabular}{|c|} 
Darco HG- \\
LH \\
$2.0 \mathrm{lb} / \mathrm{Macf}$ \\
\end{tabular} & \begin{tabular}{|c|} 
Darco HG- \\
LH \\
$2.0 \mathrm{lb} /$ Macf
\end{tabular} & $\begin{array}{c}\text { Darco HG- } \\
\text { LH } \\
2.0 \mathrm{lb} / \mathrm{Macf}\end{array}$ \\
\hline Inputs: & Units & & & & & & \\
\hline Time Coal Sampled & & Ave & & $22: 30$ & Ave & $21: 00$ & $16: 30$ \\
\hline Time Coal should hit Furnace & & $10: 45$ & & $22: 30$ & $14: 00$ & $21: 00$ & $16: 30$ \\
\hline Load, Gross at time Coal hit Furnace & MW (gross) & 890 & 887 & 882 & 879 & 889 & 878 \\
\hline Btu Ratio & Btu blend/6399 Btu & 1.19 & 1.16 & 1.16 & 1.21 & 1.12 & 1.13 \\
\hline$\%$ Coal 2 (PRB) & & 28.48 & 21.86 & 27.53 & 100 & 24.98 & 25 \\
\hline Time Ash Sampled & & $10: 45$ & & $0: 00$ & $14: 00$ & $13: 00$ & $11: 30$ \\
\hline Load, Gross at time Ash Sampled & MW (gross) & 890 & 884 & 881 & 879 & 888 & 795 \\
\hline Gross Heat Rate & Btu/kW-h & 9783 & 9752 & 10010 & 10032 & 9689 & 9934 \\
\hline Fraction Coal 1 by Wt. & wt. Fraction & 0.7152 & 0.78 & 0.7247 & 0 & 0.7502 & 0.75 \\
\hline Coal $1 \mathrm{Hg}(\mathrm{TxL})$ & $\mu \mathrm{g} / \mathrm{g}, \mathrm{dry}$ & 0.198 & 0.198 & 0.222 & 0.198 & 0.210 & 0.135 \\
\hline Coal 1 Ash $(\mathrm{TxL})$ & wt $\%$, dry & 21.22 & 21.22 & 20.76 & 21.22 & 23.25 & 24.25 \\
\hline Coal 1 Moisture (TxL) & $w t \%$ & 32.49 & 32.49 & 33.67 & 32.49 & 32.30 & 33.08 \\
\hline Coal 1 Heating Value $(T x L)$ & Btu/lb, dry & 9946 & 9946 & 10040 & 9946 & 9392 & 9380 \\
\hline Coal 1 F-factor $(T x L)$ & dry scf/Mbtu, $0 \% \mathrm{O} 2$ & 10248 & 10248 & 10287 & 10248 & 10248 & 10256 \\
\hline Coal $2 \mathrm{Hg}$ (PRB) & $\mu \mathrm{g} / \mathrm{g}, \mathrm{dry}$ & 0.096 & 0.096 & 0.153 & 0.096 & 0.118 & 0.083 \\
\hline Coal 2 Ash (PRB) & wt $\%$, dry & 8.09 & 8.09 & 7.63 & 8.09 & 9.54 & 9.72 \\
\hline Coal 2 Moisture (PRB) & $w t \%$ & 32.93 & 32.93 & 33.39 & 32.93 & 33.19 & 33.08 \\
\hline Coal 2 Heating Value (PRB) & Btu/lb, dry & 11645 & 11645 & 11718 & 11645 & 11471 & 11572 \\
\hline Coal 2 F-factor (PRB) & dry scf/Mbtu, $0 \% \mathrm{O} 2$ & 10228 & 10228 & 10033 & 10228 & 10228 & 9772 \\
\hline Date Ash Sampled & & $6 / 22 / 2007$ & & Ave & $6 / 28 / 2007$ & $6 / 29 / 2007$ & $7 / 3 / 2007$ \\
\hline Time Ash Sampled & & $10: 45$ & & & $14: 00$ & $13: 00$ & $11: 30$ \\
\hline Treated Ash $\mathrm{Hg}$ (from URS lab) - first field only & $\mu \mathrm{g} / \mathrm{g}$ & 0.037 & 0.030 & 0.665 & 0.445 & 0.784 & 0.556 \\
\hline Treated Ash Hg (from URS lab) - weighted for all fields & $\mu \mathrm{g} / \mathrm{g}$ & 0.037 & 0.030 & 0.757 & 0.550 & 0.868 & 0.655 \\
\hline Untreated Ash Hg (from URS lab) & $\mu \mathrm{g} / \mathrm{g}$ & & 0.053 & & & & \\
\hline SCEM start time & & $8: 45$ & & 19:00 & $12: 00$ & 19:00 & $14: 30$ \\
\hline SCEM end time & & $12: 45$ & & $23: 59$ & $16: 00$ & $23: 00$ & $18: 30$ \\
\hline SCEM ESP Inlet & ug/dry Nm3 @ 3\% O2 & 23.73 & 24.35 & 14.89 & & 27.04 & 31.67 \\
\hline SCEM ESP Outlet Treated & $\mu \mathrm{g} / \mathrm{dry}$ Nm3 @ 3\% O2 & 21.85 & $\# \mathrm{~N} / \mathrm{A}$ & 4.93 & 1.63 & 4.93 & 4.37 \\
\hline SCEM ESP Outlet Untreated & $\mu \mathrm{g} / \mathrm{dry}$ Nm3 @ 3\% O2 & 25.39 & 25.37 & 21.92 & 9.43 & 17.97 & 16.19 \\
\hline \multicolumn{8}{|l|}{$\mathrm{OH}$ start time } \\
\hline \multicolumn{8}{|l|}{$\mathrm{OH}$ end time } \\
\hline OH ESP Outlet Treated & $\mu \mathrm{g} / \mathrm{dry} \mathrm{Nm3} @$ @ 3\% O2 & & 26.03 & & & & \\
\hline OH ESP Outlet Untreated & $\mu \mathrm{g} / \mathrm{dry}$ Nm3 @ 3\% O2 & & 24.03 & & & & \\
\hline \multicolumn{8}{|l|}{ Calculated Values: } \\
\hline Fraction Coal 1 by Btu & Btu Fraction & 0.68 & 0.75 & 0.69 & 0.00 & 0.71 & 0.71 \\
\hline Composite F-factor & dscf/MMBtu at 3\% O2 & 11958 & 11945 & 11920 & 11942 & 11959 & 11810 \\
\hline Gas flow rate & dscfm at $3 \% \mathrm{O} 2$ & 1734680 & 1722907 & 1753585 & 1755207 & 1715985 & 1716449 \\
\hline Gas flow rate & dry Nm3/min & 45791 & 45480 & 46290 & 46332 & 45297 & 45309 \\
\hline Coal feed rate & ton/hr (dry) & 417 & 426 & 420 & 379 & 434 & 439 \\
\hline Mercury Rate in Coal & $g / h$ & 64.0 & 66.2 & 77.4 & 33.0 & 73.5 & 48.5 \\
\hline Mercury Rate in Coal & $\mathrm{lb} / \mathrm{Tbtu}$ & 16.2 & 16.9 & 19.3 & 8.2 & 18.8 & 12.3 \\
\hline $\mathrm{Hg}$ Concentration from Coal & $\mu \mathrm{g} / \mathrm{dNm} 3$ at $3 \% \mathrm{O} 2$ & 23.3 & 24.3 & 27.9 & 11.9 & 27.1 & 17.8 \\
\hline Mercury Rate in Ash Treated, weighted & $g / h$ & 2.1 & 1.8 & 42.0 & 13.0 & 57.8 & 45.7 \\
\hline Mercury Rate in Ash Untreated & $\mathrm{g} / \mathrm{h}$ & & 3.0 & & & & \\
\hline SCEM Mercury Rate ESP Inlet & $\mathrm{g} / \mathrm{h}$ & 65.2 & 66.5 & 41.4 & & 73.5 & 86.1 \\
\hline SCEM Mercury Rate ESP Outlet Treated & $\mathrm{g} / \mathrm{h}$ & 60.0 & 56.0 & 13.7 & 4.5 & 13.4 & 11.9 \\
\hline SCEM Mercury Rate ESP Outlet Untreated & $\mathrm{g} / \mathrm{h}$ & 69.8 & 69.3 & 60.9 & 26.2 & 48.8 & 44.0 \\
\hline OH Mercury Rate ESP Outlet Treated & $\mathrm{g} / \mathrm{h}$ & & 71.0 & & & & \\
\hline OH Mercury Rate ESP Outlet Untreated & $\mathrm{g} / \mathrm{h}$ & & 65.5 & & & & \\
\hline \multicolumn{8}{|l|}{ Weighted Average Coal Values: } \\
\hline wtd $\mathrm{Hg}$ & ug/g, dry & 0.169 & 0.171 & 0.203 & 0.096 & 0.187 & 0.122 \\
\hline wtd ash & wt $\%$, as recd & 11.79 & 12.61 & 11.38 & 5.43 & 13.40 & 13.80 \\
\hline wtd moisture & wt\% & 32.6 & 32.7 & 33.6 & 32.9 & 32.5 & 33.1 \\
\hline wtd Btu & Btu/lb, as recd & 7027 & 6850 & 6975 & 7810 & 6684 & 6644 \\
\hline SCEM vs Coal Hg Ratios: & & & & & & & \\
\hline SCEM inlet $\mathrm{Hg} / \mathrm{Coal} \mathrm{Hg}$ & & $102 \%$ & $98 \%$ & $53 \%$ & & $100 \%$ & $177 \%$ \\
\hline SCEM ESP outlet untreated $\mathrm{Hg} / \mathrm{Coal} \mathrm{Hg}$ & & $109 \%$ & $103 \%$ & $79 \%$ & $80 \%$ & $66 \%$ & $91 \%$ \\
\hline Percent Removal: & & & & & & & \\
\hline treated ash $\mathrm{Hg} / \mathrm{Coal} \mathrm{Hg}$ & & $3 \%$ & $3 \%$ & $54 \%$ & $39 \%$ & $79 \%$ & $94 \%$ \\
\hline treated SCEM Hg/Coal $\mathrm{Hg}$ & & $6 \%$ & $14 \%$ & $82 \%$ & $86 \%$ & $82 \%$ & $76 \%$ \\
\hline treated $\mathrm{OH} \mathrm{Hg} / \mathrm{Coal} \mathrm{Hg}$ & & & $-5 \%$ & & & & \\
\hline treated ash $\mathrm{Hg}$ /inlet ESP Hg & & & & $102 \%$ & & $79 \%$ & $53 \%$ \\
\hline treated SCEM Hg/inlet ESP Hq & & & & $67 \%$ & & $82 \%$ & $86 \%$ \\
\hline treated $\mathrm{OH} \mathrm{Hg}$ /inlet ESP Hg & & & $-7 \%$ & & & & \\
\hline untreated ash $\mathrm{Hg} /$ inlet ESP Hg & & & $5 \%$ & & & & \\
\hline untreated SCEM Ha/inlet ESP Hq & & $-7 \%$ & $-4 \%$ & $-47 \%$ & & $34 \%$ & $49 \%$ \\
\hline untreated $\mathrm{OH} \mathrm{Hg}$ /inlet $\mathrm{ESP} \mathrm{Hg}$ & & & $2 \%$ & & & & \\
\hline Hg Mass Balance Ratio: & & & & & & & \\
\hline (Coal In/SCEM Out) Treated & & 1.03 & 1.14 & 1.39 & 1.88 & 1.03 & 0.84 \\
\hline (Coal In/OH Out) Treated & & & 0.94 & & & & \\
\hline (SCEM In/SCEM Out) Treated & & 1.05 & 1.22 & 0.74 & & 1.03 & 1.49 \\
\hline (SCEM In/OH Out) Treated & & & 0.94 & & & & \\
\hline (Coal In/SCEM Out) Untreated & & & 0.96 & & & & \\
\hline (Coal In/OH Out) Untreated & & & 0.99 & & & & \\
\hline (SCEM In/SCEM Out) Untreated & & & 0.93 & & & & \\
\hline (SCEM $\ln / \mathrm{OH}$ Out) Untreated & & & 0.94 & & & & \\
\hline $\begin{array}{l}\text { Overall Removal - assuming } 95 \% \text { oxidized } \mathrm{Hg} \\
\text { removed by FGD: }\end{array}$ & & & & & & & \\
\hline SCEM/coal basis (assuming $74 \%$ ox) & & & $49 \%$ & $88 \%$ & $90 \%$ & $87 \%$ & $83 \%$ \\
\hline $\mathrm{OH} /$ coal basis (assuming $69 \%$ ox) & & & $34 \%$ & & & & \\
\hline
\end{tabular}




\begin{tabular}{|c|c|c|c|c|c|c|c|}
\hline Date & & $7 / 4 / 2007$ & $7 / 5 / 2007$ & $7 / 8 / 2007$ & $7 / 9 / 2007$ & $7 / 10 / 2007$ & $7 / 10 / 2007$ \\
\hline Condition & & \begin{tabular}{|c|} 
Darco HG- \\
LH \\
$2.0 \mathrm{lb} / \mathrm{Macf}$ \\
\end{tabular} & \begin{tabular}{|c|} 
Darco HG- \\
LH \\
$2.0 \mathrm{lb} / \mathrm{Macf}$ \\
\end{tabular} & \begin{tabular}{|c|} 
Darco HG- \\
LH \\
$2.0 \mathrm{lb} / \mathrm{Macf}$ \\
\end{tabular} & \begin{tabular}{|c|} 
Darco HG- \\
LH \\
$2.0 \mathrm{lb} / \mathrm{Macf}$
\end{tabular} & \begin{tabular}{|c|} 
Darco HG- \\
LH \\
$2.0 \mathrm{lb} / \mathrm{Macf}$ \\
\end{tabular} & $\begin{array}{c}\text { Darco HG- } \\
\text { LH } \\
2.0 \mathrm{lb} / \mathrm{Macf}\end{array}$ \\
\hline Inputs: & Units & & & & & & \\
\hline Time Coal Sampled & & Ave & $16: 41$ & $0: 30$ & $16: 12$ & Ave & Ave \\
\hline Time Coal should hit Furnace & & $14: 40$ & $16: 41$ & $0: 30$ & $16: 12$ & $14: 00$ & $14: 00$ \\
\hline Load, Gross at time Coal hit Furnace & MW (gross) & 887 & 882 & 881 & 881 & 869 & 869 \\
\hline Btu Ratio & Btu blend/6399 Btu & 1.27 & 1.13 & 1.15 & 1.18 & 1.12 & 1.12 \\
\hline$\%$ Coal 2 (PRB) & & 100 & 38.53 & 26.14 & 24.99 & 25.2 & 25.2 \\
\hline Time Ash Sampled & & $14: 40$ & $14: 10$ & $11: 20$ & $14: 30$ & $11: 20$ & $11: 20$ \\
\hline Load, Gross at time Ash Sampled & MW (gross) & 887 & 879 & 882 & 875 & 875 & 875 \\
\hline Gross Heat Rate & Btu/kW-h & 9735 & 9922 & 10003 & 10127 & 10039 & 10039 \\
\hline Fraction Coal 1 by Wt. & wt. Fraction & 0 & 0.6147 & 0.7386 & 0.7501 & 0.748 & 0.748 \\
\hline Coal $1 \mathrm{Hg}(\mathrm{TxL})$ & $\mu \mathrm{g} / \mathrm{g}, \mathrm{dry}$ & 0.198 & 0.237 & 0.207 & 0.231 & 0.198 & 0.198 \\
\hline Coal 1 Ash (TxL) & wt $\%$, dry & 21.22 & 22.50 & 15.70 & 24.53 & 21.22 & 21.22 \\
\hline Coal 1 Moisture $(\mathrm{TxL})$ & $w t \%$ & 32.49 & 33.66 & 33.72 & 29.99 & 32.49 & 32.49 \\
\hline Coal 1 Heating Value $(T x L)$ & Btu/lb, dry & 9946 & 9614 & 10635 & 10898 & 9946 & 9946 \\
\hline Coal $1 \mathrm{~F}$-factor (TxL) & dry scf/Mbtu, $0 \% \mathrm{O} 2$ & 10248 & 10248 & 10115 & 10248 & 10248 & 10248 \\
\hline Coal $2 \mathrm{Hg}$ (PRB) & $\mu \mathrm{g} / \mathrm{g}, \mathrm{dry}$ & 0.096 & 0.081 & 0.096 & 0.111 & 0.096 & 0.096 \\
\hline Coal 2 Ash (PRB) & wt $\%$, dry & 8.09 & 9.00 & 9.66 & 8.84 & 8.09 & 8.09 \\
\hline Coal 2 Moisture (PRB) & wt\% & 32.93 & 32.96 & 30.17 & 31.78 & 32.93 & 32.93 \\
\hline Coal 2 Heating Value (PRB) & Btu/lb, dry & 11645 & 11559 & 11458 & 11602 & 11645 & 11645 \\
\hline Coal 2 F-factor (PRB) & dry scf/Mbtu, $0 \% \mathrm{O} 2$ & 10228 & 10228 & 10086 & 10228 & 10228 & 10228 \\
\hline Date Ash Sampled & & $7 / 4 / 2007$ & $7 / 5 / 2007$ & $7 / 8 / 2007$ & $7 / 9 / 2007$ & $7 / 10 / 2007$ & $7 / 10 / 2007$ \\
\hline Time Ash Sampled & & $14: 40$ & $14: 10$ & $11: 20$ & $14: 30$ & $11: 20$ & $11: 20$ \\
\hline Treated Ash $\mathrm{Hg}$ (from URS lab) - first field only & $\mu \mathrm{g} / \mathrm{g}$ & 0.822 & 0.678 & 0.994 & 0.937 & 0.711 & 0.711 \\
\hline Treated Ash $\mathrm{Hg}$ (from URS lab) - weighted for all fields & $\mu \mathrm{g} / \mathrm{g}$ & 0.904 & 0.769 & 1.066 & 1.012 & 0.800 & 0.800 \\
\hline Untreated Ash Hg (from URS lab) & $\mu \mathrm{g} / \mathrm{g}$ & & & & 0.078 & & \\
\hline SCEM start time & & $12: 40$ & $14: 40$ & $0: 00$ & $14: 15$ & $12: 10$ & $15: 20$ \\
\hline SCEM end time & & $16: 40$ & $18: 40$ & $4: 00$ & $18: 15$ & $14: 30$ & $17: 35$ \\
\hline SCEM ESP Inlet & $\mu \mathrm{g} / \mathrm{dry}$ Nm3 @ 3\% O2 & 10.32 & 35.19 & 37.12 & 34.14 & 26.69 & 32.88 \\
\hline SCEM ESP Outlet Treated & $\mu \mathrm{g} / \mathrm{dry} \mathrm{Nm} 3 @ 3 \% \mathrm{O} 2$ & 0.93 & 3.19 & 3.62 & 5.54 & 4.47 & 6.00 \\
\hline SCEM ESP Outlet Untreated & $\mu \mathrm{g} / \mathrm{dry} \mathrm{Nm} 3 @ 3 \%$ O2 & 9.94 & 22.49 & 22.65 & 22.42 & 20.85 & 20.87 \\
\hline $\mathrm{OH}$ start time & & & & & & $12: 10$ & $15: 20$ \\
\hline $\mathrm{OH}$ end time & & & & & & $14: 24$ & $17: 35$ \\
\hline OH ESP Outlet Treated & $\mu \mathrm{g} / \mathrm{dry} \mathrm{Nm3} @ \mathrm{Q} 3 \% \mathrm{O} 2$ & & & & & 14.89 & 19.98 \\
\hline OH ESP Outlet Untreated & $\mu \mathrm{g} / \mathrm{dry}$ Nm3 @ 3\% O2 & & & & & 35.54 & 38.71 \\
\hline \multicolumn{8}{|l|}{ Calculated Values: } \\
\hline Fraction Coal 1 by Btu & Btu Fraction & 0.00 & 0.57 & 0.71 & 0.74 & 0.72 & 0.72 \\
\hline Composite F-factor & dscf/MMBtu at $3 \% 02$ & 11942 & 11955 & 11800 & 11959 & 11959 & 11959 \\
\hline Gas flow rate & dscfm at $3 \%$ O2 & 1719341 & 1744579 & 1732933 & 1778373 & 1739597 & 1739597 \\
\hline Gas flow rate & dry $\mathrm{Nm} 3 / \mathrm{min}$ & 45386 & 46052 & 45744 & 46944 & 45920 & 45920 \\
\hline Coal feed rate & ton/hr (dry) & 371 & 422 & 406 & 403 & 421 & 421 \\
\hline Mercury Rate in Coal & $\mathrm{g} / \mathrm{h}$ & 32.3 & 67.8 & 65.6 & 73.5 & 65.8 & 65.8 \\
\hline Mercury Rate in Coal & $\mathrm{lb} / \mathrm{Tb} t \mathrm{u}$ & 8.2 & 17.1 & 16.4 & 18.2 & 16.6 & 16.6 \\
\hline $\mathrm{Hg}$ Concentration from Coal & $\mu \mathrm{g} / \mathrm{dNm} 3$ at $3 \% \mathrm{O} 2$ & 11.9 & 24.5 & 23.9 & 26.1 & 23.9 & 23.9 \\
\hline Mercury Rate in Ash Treated, weighted & $\mathrm{g} / \mathrm{h}$ & 20.9 & 43.3 & 46.9 & 65.1 & 46.5 & 46.5 \\
\hline Mercury Rate in Ash Untreated & $\mathrm{g} / \mathrm{h}$ & & & & 5.0 & & \\
\hline SCEM Mercury Rate ESP Inlet & $\mathrm{g} / \mathrm{h}$ & 28.1 & 97.2 & 101.9 & 96.1 & 73.5 & 90.6 \\
\hline SCEM Mercury Rate ESP Outlet Treated & $\mathrm{g} / \mathrm{h}$ & 2.5 & 8.8 & 9.9 & 15.6 & 12.3 & 16.5 \\
\hline SCEM Mercury Rate ESP Outlet Untreated & $\mathrm{g} / \mathrm{h}$ & 27.1 & 62.1 & 62.2 & 63.1 & 57.4 & 57.5 \\
\hline OH Mercury Rate ESP Outlet Treated & $\mathrm{g} / \mathrm{h}$ & & & & & 41.0 & 55.0 \\
\hline $\mathrm{OH}$ Mercury Rate ESP Outlet Untreated & $g / h$ & & & & & 97.9 & 106.7 \\
\hline \multicolumn{8}{|l|}{ Weighted Average Coal Values: } \\
\hline wtd $\mathrm{Hg}$ & ug/g. dry & 0.096 & 0.177 & 0.178 & 0.201 & 0.172 & 0.172 \\
\hline wtd ash & wt $\%$, as recd & 5.43 & 11.50 & 9.45 & 14.39 & 12.08 & 12.08 \\
\hline wtd moisture & wt $\%$ & 32.9 & 33.4 & 32.8 & 30.4 & 32.6 & 32.6 \\
\hline wtd Btu & Btu/lb, as recd & 7810 & 6906 & 7298 & 7701 & 6991 & 6991 \\
\hline \multicolumn{8}{|l|}{ SCEM vs Coal Hg Ratios: } \\
\hline SCEM inlet $\mathrm{Hg} / \mathrm{Coal} \mathrm{Hg}$ & & $87 \%$ & $143 \%$ & $155 \%$ & $131 \%$ & $112 \%$ & $138 \%$ \\
\hline SCEM ESP outlet untreated $\mathrm{Hg} / \mathrm{Coal} \mathrm{Hg}$ & & $84 \%$ & $92 \%$ & $95 \%$ & $86 \%$ & $87 \%$ & $87 \%$ \\
\hline \multicolumn{8}{|l|}{ Percent Removal: } \\
\hline treated ash $\mathrm{Hg} / \mathrm{Coal} \mathrm{Ha}$ & & $65 \%$ & $64 \%$ & $72 \%$ & $88 \%$ & $71 \%$ & $71 \%$ \\
\hline treated SCEM Hg/Coal Hg & & $92 \%$ & $87 \%$ & $85 \%$ & $79 \%$ & $81 \%$ & $75 \%$ \\
\hline treated $\mathrm{OH} \mathrm{Hg} / \mathrm{Coal} \mathrm{Hg}$ & & & & & & $38 \%$ & $16 \%$ \\
\hline treated ash $\mathrm{Hg} /$ inlet ESP Hg & & $74 \%$ & $44 \%$ & $46 \%$ & $68 \%$ & $63 \%$ & $51 \%$ \\
\hline treated SCEM Hg/inlet ESP Hg & & $91 \%$ & $91 \%$ & $90 \%$ & $84 \%$ & $83 \%$ & $82 \%$ \\
\hline treated $\mathrm{OH} \mathrm{Hg} /$ inlet ESP Hg & & & & & & $44 \%$ & $39 \%$ \\
\hline untreated ash $\mathrm{Ha} /$ inlet ESP $\mathrm{Ha}$ & & & & & $5 \%$ & & \\
\hline untreated SCEM Ha/inlet ESP Hq & & $4 \%$ & $36 \%$ & $39 \%$ & $34 \%$ & $22 \%$ & $37 \%$ \\
\hline untreated $\mathrm{OH} \mathrm{Hg}$ /inlet ESP Hq & & & & & & $-33 \%$ & $-18 \%$ \\
\hline Hg Mass Balance Ratio: & & & & & & & \\
\hline (Coal In/SCEM Out) Treated & & 1.38 & 1.30 & 1.15 & 0.91 & 1.12 & 1.04 \\
\hline (Coal $\ln / \mathrm{OH}$ Out) Treated & & & & & & 0.75 & 0.65 \\
\hline (SCEM In/SCEM Out) Treated & & 1.20 & 1.87 & 1.79 & 1.19 & 1.25 & 1.44 \\
\hline (SCEM In/OH Out) Treated & & & & & & 0.84 & 0.89 \\
\hline (Coal In/SCEM Out) Untreated & & & & & 1.08 & & \\
\hline (Coal $\ln / \mathrm{OH}$ Out) Untreated & & & & & & & \\
\hline (SCEM In/SCEM Out) Untreated & & & & & 1.41 & & \\
\hline (SCEM $\ln / \mathrm{OH}$ Out) Untreated & & & & & & & \\
\hline $\begin{array}{l}\text { Overall Removal - assuming 95\% oxidized } \mathrm{Hg} \\
\text { removed bV FGD: }\end{array}$ & & & & & & & \\
\hline SCEM/coal basis (assuming $74 \%$ ox) & & $95 \%$ & $91 \%$ & $89 \%$ & $85 \%$ & $87 \%$ & $82 \%$ \\
\hline $\mathrm{OH} / \mathrm{coal}$ basis (assuming $69 \%$ ox) & & & & & & $59 \%$ & $45 \%$ \\
\hline
\end{tabular}




\begin{tabular}{|c|c|c|c|c|c|c|c|}
\hline Date & & $7 / 11 / 2007$ & $7 / 19 / 2007$ & $7 / 21 / 2007$ & \begin{tabular}{|l|}
$7 / 22 / 2007$ \\
\end{tabular} & \begin{tabular}{|l|}
$7 / 25 / 2007$ \\
\end{tabular} & $7 / 27 / 2007$ \\
\hline Condition & & \begin{tabular}{|c|} 
Darco HG- \\
LH \\
$2.0 \mathrm{lb} / \mathrm{Macf}$ \\
\end{tabular} & \begin{tabular}{|c|} 
Darco HG- \\
LH \\
$2.0 \mathrm{lb} / \mathrm{Macf}$ \\
\end{tabular} & \begin{tabular}{|c|} 
Darco HG- \\
$\mathrm{LH}$ \\
$2.0 \mathrm{lb} / \mathrm{Macf}$ \\
\end{tabular} & \begin{tabular}{|c|} 
Darco HG- \\
LH \\
$2.0 \mathrm{lb} / \mathrm{Macf}$ \\
\end{tabular} & \begin{tabular}{|c|} 
Darco HG- \\
LH \\
$2.0 \mathrm{lb} / \mathrm{Macf}$
\end{tabular} & $\begin{array}{c}\text { Darco HG- } \\
\text { LH } \\
2.0 \mathrm{lb} / \mathrm{Macf}\end{array}$ \\
\hline Inputs: & Units & & & & & & \\
\hline Time Coal Sampled & & Ave & $8: 20$ & Ave & $0: 05$ & $15: 56$ & $22: 00$ \\
\hline Time Coal should hit Furnace & & $16: 15$ & $8: 20$ & $12: 12$ & $0: 05$ & $15: 56$ & $22: 00$ \\
\hline Load, Gross at time Coal hit Furnace & MW (gross) & 881 & 799 & 803 & 806 & 888 & 792 \\
\hline Btu Ratio & Btu blend/6399 Btu & 1.14 & 1.14 & 1.15 & 1.17 & 1.17 & 1.05 \\
\hline$\%$ Coal 2 (PRB) & & 25.49 & 29.52 & 29.21 & 29.23 & 25.01 & 8.6 \\
\hline Time Ash Sampled & & $15: 07$ & $15: 01$ & $12: 12$ & $14: 30$ & $12: 25$ & $15: 13$ \\
\hline Load, Gross at time Ash Sampled & MW (gross) & 891 & 801 & 803 & 890 & 892 & 820 \\
\hline Gross Heat Rate & Btu/kW-h & 9627 & 9621 & 9730 & 9599 & 9822 & 9573 \\
\hline Fraction Coal 1 by Wt. & wt. Fraction & 0.7451 & 0.7048 & 0.7079 & 0.7077 & 0.7499 & 0.914 \\
\hline Coal $1 \mathrm{Hg}(\mathrm{TxL})$ & $\mu \mathrm{g} / \mathrm{g}, \mathrm{dry}$ & 0.285 & 0.179 & 0.198 & 0.175 & 0.154 & 0.210 \\
\hline Coal 1 Ash (TxL) & wt $\%$, dry & 19.51 & 19.47 & 21.22 & 17.19 & 20.31 & 23.04 \\
\hline Coal 1 Moisture $(T x L)$ & $w \%$ & 32.71 & 32.95 & 32.49 & 36.14 & 31.86 & 33.76 \\
\hline Coal 1 Heating Value $(\mathrm{TxL})$ & Btu/lb, dry & 10008 & 10184 & 9946 & 10417 & 10097 & 9667 \\
\hline Coal 1 F-factor $(\mathrm{TxL})$ & dry scf/Mbtu, $0 \% \mathrm{O} 2$ & 10248 & 10336 & 10248 & 10248 & 10302 & 10248 \\
\hline Coal $2 \mathrm{Hg}$ (PRB) & $\mu \mathrm{g} / \mathrm{g}, \mathrm{dry}$ & 0.059 & 0.090 & 0.096 & 0.104 & 0.097 & 0.102 \\
\hline Coal 2 Ash (PRB) & wt $\%$, dry & 6.39 & 7.42 & 8.09 & 8.65 & 7.36 & 7.70 \\
\hline Coal 2 Moisture (PRB) & wt $\%$ & 30.27 & 32.65 & 32.93 & 32.68 & 31.76 & 34.80 \\
\hline Coal 2 Heating Value (PRB) & Btu/lb, dry & 11770 & 11794 & 11645 & 12326 & 10257 & 11748 \\
\hline Coal 2 F-factor (PRB) & dry scf/Mbtu, $0 \% \mathrm{O} 2$ & 10228 & 10049 & 10228 & 10228 & 11570 & 10228 \\
\hline Date Ash Sampled & & $7 / 11 / 2007$ & $7 / 19 / 2007^{\star \star}$ & $7 / 21 / 2007$ & $7 / 22 / 2007^{\star \star}$ & $7 / 25 / 2007$ & $7 / 27 / 2007$ \\
\hline Time Ash Sampled & & $15: 07$ & $15: 01$ & $12: 12$ & $14: 30$ & $12: 25$ & $15: 13$ \\
\hline Treated Ash $\mathrm{Hg}$ (from URS lab) - first field only & $\mu \mathrm{g} / \mathrm{g}$ & 0.651 & 0.675 & 1.020 & 0.938 & 1.046 & 0.704 \\
\hline Treated Ash $\mathrm{Hg}$ (from URS lab) - weighted for all fields & $\mu \mathrm{g} / \mathrm{g}$ & 0.744 & 0.766 & 1.090 & 1.013 & 1.115 & 0.793 \\
\hline Untreated Ash Hg (from URS lab) & $\mu \mathrm{g} / \mathrm{g}$ & & & & & & \\
\hline SCEM start time & & $9: 30$ & $6: 20$ & $10: 10$ & $0: 00$ & $11: 00$ & $21: 30$ \\
\hline SCEM end time & & $11: 45$ & $10: 20$ & $14: 10$ & $4: 00$ & $17: 00$ & $23: 59$ \\
\hline SCEM ESP Inlet & $\mu \mathrm{g} / \mathrm{dry} \mathrm{Nm} 3$ @ 3\% O2 & 32.04 & 17.29 & 24.43 & 29.31 & 24.86 & 19.24 \\
\hline SCEM ESP Outlet Treated & $\mu \mathrm{g} / \mathrm{dry} \mathrm{Nm} 3 @ 3 \%$ O2 & 8.39 & 2.73 & 1.28 & 0.43 & 3.93 & 6.31 \\
\hline SCEM ESP Outlet Untreated & $\mu \mathrm{g} / \mathrm{dry}$ Nm3 @ 3\% O2 & 27.00 & 18.92 & 17.19 & 14.07 & 19.91 & 19.16 \\
\hline $\mathrm{OH}$ start time & & $9: 32$ & & & & & \\
\hline $\mathrm{OH}$ end time & & $11: 45$ & & & & & \\
\hline OH ESP Outlet Treated & $\mu \mathrm{g} / \mathrm{dry}$ Nm3 @ 3\% O2 & 18.52 & & & & & \\
\hline OH ESP Outlet Untreated & $\mu \mathrm{g} / \mathrm{dry}$ Nm3 @ 3\% O2 & 41.68 & & & & & \\
\hline \multicolumn{8}{|l|}{ Calculated Values: } \\
\hline Fraction Coal 1 by Btu & Btu Fraction & 0.71 & 0.67 & 0.68 & 0.66 & 0.75 & 0.90 \\
\hline Composite F-factor & dscf/MMBtu at $3 \% 02$ & 11959 & 11959 & 11958 & 11958 & 12404 & 11963 \\
\hline Gas flow rate & dscfm at $3 \%$ O2 & 1689645 & 1532962 & 1558051 & 1542810 & 1802104 & 1511331 \\
\hline Gas flow rate & dry Nm3/min & 44602 & 40466 & 41128 & 40726 & 47570 & 39895 \\
\hline Coal feed rate & ton/hr (dry) & 405 & 361 & 374 & 353 & 430 & 385 \\
\hline Mercury Rate in Coal & $g / h$ & 83.5 & 49.8 & 57.1 & 49.4 & 54.4 & 70.1 \\
\hline Mercury Rate in Coal & $\mathrm{lb} / \mathrm{Tbtu}$ & 21.7 & 14.3 & 16.1 & 14.1 & 13.8 & 20.4 \\
\hline $\mathrm{Hg}$ Concentration from Coal & $\mu \mathrm{g} / \mathrm{dNm} 3$ at $3 \% \mathrm{O} 2$ & 31.2 & 20.5 & 23.2 & 20.2 & 19.1 & 29.3 \\
\hline Mercury Rate in Ash Treated, weighted & $\mathrm{g} / \mathrm{h}$ & 37.4 & 33.9 & 54.8 & 40.2 & 63.1 & 51.2 \\
\hline Mercury Rate in Ash Untreated & $g / h$ & & & & & & \\
\hline SCEM Mercury Rate ESP Inlet & $\mathrm{g} / \mathrm{h}$ & 85.7 & 42.0 & 60.3 & 71.6 & 71.0 & 46.1 \\
\hline SCEM Mercury Rate ESP Outlet Treated & $\mathrm{g} / \mathrm{h}$ & 22.4 & 6.6 & 3.2 & 1.1 & 11.2 & 15.1 \\
\hline SCEM Mercury Rate ESP Outlet Untreated & $\mathrm{g} / \mathrm{h}$ & 72.2 & 45.9 & 42.4 & 34.4 & 56.8 & 45.9 \\
\hline OH Mercury Rate ESP Outlet Treated & $\mathrm{g} / \mathrm{h}$ & 49.6 & & & & & \\
\hline $\mathrm{OH}$ Mercury Rate ESP Outlet Untreated & $\mathrm{g} / \mathrm{h}$ & 111.5 & & & & & \\
\hline \multicolumn{8}{|l|}{ Weighted Average Coal Values: } \\
\hline wtd $\mathrm{Hg}$ & ug/g, dry & 0.227 & 0.152 & 0.168 & 0.154 & 0.139 & 0.201 \\
\hline wtd ash & wt $\%$, as recd & 10.92 & 10.68 & 11.73 & 9.47 & 11.63 & 14.38 \\
\hline wtd moisture & wt $\%$ & 32.1 & 32.9 & 32.6 & 35.1 & 31.8 & 33.8 \\
\hline wtd Btu & Btu/lb, as recd & 7110 & 7157 & 7035 & 7133 & 6910 & 6511 \\
\hline \multicolumn{8}{|l|}{ SCEM vs Coal Hg Ratios: } \\
\hline SCEM inlet $\mathrm{Hg} / \mathrm{Coal} \mathrm{Hg}$ & & $103 \%$ & $84 \%$ & $105 \%$ & $145 \%$ & $130 \%$ & $66 \%$ \\
\hline SCEM ESP outlet untreated $\mathrm{Hg} / \mathrm{Coal} \mathrm{Hg}$ & & $86 \%$ & $92 \%$ & $74 \%$ & $70 \%$ & $104 \%$ & $65 \%$ \\
\hline \multicolumn{8}{|l|}{ Percent Removal: } \\
\hline treated ash $\mathrm{Hg} / \mathrm{Coal} \mathrm{Hg}$ & & $45 \%$ & $68 \%$ & $96 \%$ & $81 \%$ & $116 \%$ & $73 \%$ \\
\hline treated SCEM Hg/Coal $\mathrm{Hg}$ & & $73 \%$ & $87 \%$ & $94 \%$ & $98 \%$ & $79 \%$ & $78 \%$ \\
\hline treated $\mathrm{OH} \mathrm{Hg} / \mathrm{Coal} \mathrm{Hg}$ & & $41 \%$ & & & & & \\
\hline treated ash $\mathrm{Hg}$ /inlet ESP Hg & & $44 \%$ & $81 \%$ & $91 \%$ & $56 \%$ & $89 \%$ & $111 \%$ \\
\hline treated SCEM Hg/inlet ESP Hg & & $74 \%$ & $84 \%$ & $95 \%$ & $99 \%$ & $84 \%$ & $67 \%$ \\
\hline treated $\mathrm{OH} \mathrm{Hg}$ /inlet ESP Hg & & $42 \%$ & & & & & \\
\hline untreated ash $\mathrm{Hg}$ /inlet ESP Hg & & & & & & & \\
\hline untreated SCEM Hg/inlet ESP Hg & & $16 \%$ & $-9 \%$ & $30 \%$ & $52 \%$ & $20 \%$ & $0 \%$ \\
\hline untreated $\mathrm{OH} \mathrm{Hg}$ /inlet ESP Hg & & $-30 \%$ & & & & & \\
\hline Hg Mass Balance Ratio: & & & & & & & \\
\hline (Coal In/SCEM Out) Treated & & 1.40 & 1.23 & 0.99 & 1.20 & 0.73 & 1.06 \\
\hline (Coal In/OH Out) Treated & & 0.96 & & & & & \\
\hline (SCEM In/SCEM Out) Treated & & 1.43 & 1.04 & 1.04 & 1.73 & 0.95 & 0.69 \\
\hline (SCEM In/OH Out) Treated & & 0.99 & & & & & \\
\hline (Coal In/SCEM Out) Untreated & & & & & & & \\
\hline (Coal In/OH Out) Untreated & & & & & & & \\
\hline (SCEM In/SCEM Out) Untreated & & & & & & & \\
\hline (SCEM In/OH Out) Untreated & & & & & & & \\
\hline $\begin{array}{l}\text { Overall Removal - assuming } 95 \% \text { oxidized } \mathrm{Hg} \\
\text { removed bV FGD: }\end{array}$ & & & & & & & \\
\hline SCEM/coal basis (assuming $74 \%$ ox) & & $81 \%$ & $91 \%$ & $96 \%$ & $98 \%$ & $86 \%$ & $85 \%$ \\
\hline $\mathrm{OH} / \mathrm{coal}$ basis (assuming $69 \%$ ox) & & $61 \%$ & & & & & \\
\hline
\end{tabular}




\begin{tabular}{|c|c|c|c|c|c|c|c|}
\hline Date & & \begin{tabular}{|l|l|}
$7 / 28 / 2007$ \\
\end{tabular} & $7 / 29 / 2007$ & 7/31/2007 & 7/31/2007 & $8 / 1 / 2007$ & $8 / 3 / 2007$ \\
\hline Condition & & \begin{tabular}{|c|} 
Darco HG- \\
LH \\
$2.0 \mathrm{lb} /$ Macf \\
\end{tabular} & \begin{tabular}{|c|} 
Darco HG- \\
LH \\
$2.0 \mathrm{lb} /$ Macf \\
\end{tabular} & $\begin{array}{c}\text { Darco HG- } \\
\text { LH } \\
2.0 \mathrm{lb} / \mathrm{Macf}\end{array}$ & $\begin{array}{c}\text { Darco HG- } \\
\text { LH } \\
2.0 \mathrm{lb} / \mathrm{Macf}\end{array}$ & \begin{tabular}{|c|} 
Darco HG- \\
LH \\
$2.0 \mathrm{lb} /$ Macf \\
\end{tabular} & \begin{tabular}{|c|} 
Darco HG- \\
LH \\
$2.0 \mathrm{lb} / \mathrm{Macf}$ \\
\end{tabular} \\
\hline Inputs: & Units & & & & & & \\
\hline Time Coal Sampled & & Ave & $22: 00$ & Ave & Ave & Ave & Ave \\
\hline Time Coal should hit Furnace & & $14: 55$ & $22: 00$ & $14: 50$ & $14: 50$ & $12: 15$ & $8: 00$ \\
\hline Load, Gross at time Coal hit Furnace & MW (gross) & 890 & 886 & 889 & 889 & 884 & 876 \\
\hline Btu Ratio & Btu blend/6399 Btu & 1.08 & 1.12 & 1.14 & 1.14 & 1.13 & 1.27 \\
\hline$\%$ Coal 2 (PRB) & & 8.1 & 26.7 & 26.46 & 26.46 & 26.45 & 100 \\
\hline Time Ash Sampled & & $14: 55$ & $18: 15$ & $14: 50$ & $14: 50$ & $12: 15$ & $8: 00$ \\
\hline Load, Gross at time Ash Sampled & MW (gross) & 890 & 893 & 889 & 889 & 884 & 876 \\
\hline Gross Heat Rate & Btu/kW-h & 9723 & 9703 & 9738 & 9738 & 9755 & 9953 \\
\hline Fraction Coal 1 by Wt. & wt. Fraction & 0.919 & 0.733 & 0.7354 & 0.7354 & 0.7355 & 0 \\
\hline Coal $1 \mathrm{Hg}(\mathrm{TxL})$ & $\mu \mathrm{g} / \mathrm{q}, \mathrm{dry}$ & 0.198 & 0.195 & 0.198 & 0.198 & 0.198 & 0.198 \\
\hline Coal 1 Ash $(T x L)$ & wt $\%$, dry & 21.22 & 21.22 & 21.22 & 21.22 & 21.22 & 21.22 \\
\hline Coal 1 Moisture $(\mathrm{TxL})$ & $w t \%$ & 32.49 & 30.67 & 32.49 & 32.49 & 32.49 & 32.49 \\
\hline Coal 1 Heating Value $(T x L)$ & Btu/lb, dry & 9946 & 9878 & 9946 & 9946 & 9946 & 9946 \\
\hline Coal 1 F-factor $(\mathrm{TxL})$ & dry scf/Mbtu, $0 \%$ O2 & 10248 & 10248 & 10248 & 10248 & 10248 & 10248 \\
\hline Coal $2 \mathrm{Hg}$ (PRB) & $\mu \mathrm{g} / \mathrm{g}, \mathrm{dry}$ & 0.096 & 0.072 & 0.096 & 0.096 & 0.096 & 0.096 \\
\hline Coal 2 Ash (PRB) & wt $\%$, dry & 8.09 & 6.59 & 8.09 & 8.09 & 8.09 & 8.09 \\
\hline Coal 2 Moisture (PRB) & $\mathrm{wt} \%$ & 32.93 & 30.87 & 32.93 & 32.93 & 32.93 & 32.93 \\
\hline Coal 2 Heating Value (PRB) & Btu/lb, dry & 11645 & 11880 & 11645 & 11645 & 11645 & 11645 \\
\hline Coal 2 F-factor (PRB) & dry scf/Mbtu, $0 \% \mathrm{O} 2$ & 10228 & 10228 & 10228 & 10228 & 10228 & 10228 \\
\hline Date Ash Sampled & & $7 / 28 / 2007$ & $7 / 29 / 2007$ & $7 / 31 / 2007$ & $8 / 1 / 2007$ & $8 / 1 / 2007$ & $8 / 3 / 2007$ \\
\hline Time Ash Sampled & & $14: 55$ & $18: 15$ & $14: 50$ & $14: 50$ & $12: 15$ & $8: 00$ \\
\hline Treated Ash $\mathrm{Hg}$ (from URS lab) - first field only & $\mu \mathrm{g} / \mathrm{g}$ & 0.577 & 0.467 & 0.720 & 0.720 & 0.517 & 0.638 \\
\hline Treated Ash $\mathrm{Hg}$ (from URS lab) - weighted for all fields & $\mu \mathrm{g} / \mathrm{g}$ & 0.674 & 0.571 & 0.808 & 0.808 & 0.618 & 0.731 \\
\hline Untreated Ash Hg (from URS lab) & $\mu \mathrm{g} / \mathrm{g}$ & & & & & & 0.061 \\
\hline SCEM start time & & $11: 00$ & $20: 00$ & $10: 00$ & $14: 01$ & $9: 20$ & $4: 00$ \\
\hline SCEM end time & & $17: 00$ & $23: 59$ & $12: 45$ & $16: 13$ & $11: 36$ & $8: 00$ \\
\hline SCEM ESP Inlet & $\mu \mathrm{g} / \mathrm{dry}$ Nm3 @ 3\% O2 & 22.08 & 23.66 & 23.56 & 25.56 & 27.84 & 12.85 \\
\hline SCEM ESP Outlet Treated & $\mu \mathrm{g} / \mathrm{dry}$ Nm3 @ 3\% O2 & 4.14 & 3.50 & 4.04 & 3.21 & 6.02 & 0.40 \\
\hline SCEM ESP Outlet Untreated & $\mu \mathrm{g} / \mathrm{dry} \mathrm{Nm3} @ 3 \% \mathrm{O}$ & 17.29 & 15.51 & 16.11 & 19.45 & 17.73 & 7.08 \\
\hline $\mathrm{OH}$ start time & & & & $10: 00$ & $14: 01$ & $9: 20$ & \\
\hline $\mathrm{OH}$ end time & & & & $12: 45$ & $16: 13$ & $11: 36$ & \\
\hline OH ESP Outlet Treated & $\mu \mathrm{g} / \mathrm{dry}$ Nm3 @ 3\% O2 & & & 9.63 & 9.34 & 17.05 & \\
\hline OH ESP Outlet Untreated & $\mu \mathrm{g} / \mathrm{dry}$ Nm3 @ 3\% O2 & & & 30.83 & 31.84 & 26.48 & \\
\hline \multicolumn{8}{|l|}{ Calculated Values: } \\
\hline Fraction Coal 1 by Btu & Btu Fraction & 0.91 & 0.70 & 0.70 & 0.70 & 0.71 & 0.00 \\
\hline Composite F-factor & dscf/MMBtu at 3\% O2 & 11963 & 11958 & 11959 & 11959 & 11959 & 11942 \\
\hline Gas flow rate & dscfm at $3 \%$ O2 & 1726337 & 1712524 & 1725661 & 1725661 & 1718413 & 1736163 \\
\hline Gas flow rate & dry Nm3/min & 45570 & 45206 & 45552 & 45552 & 45361 & 45830 \\
\hline Coal feed rate & ton/hr (dry) & 429 & 413 & 416 & 416 & 415 & 375 \\
\hline Mercury Rate in Coal & $\mathrm{g} / \mathrm{h}$ & 73.9 & 60.6 & 64.6 & 64.6 & 64.4 & 32.6 \\
\hline Mercury Rate in Coal & $\mathrm{lb} / \mathrm{Tbtu}$ & 18.8 & 15.5 & 16.5 & 16.5 & 16.5 & 8.2 \\
\hline $\mathrm{Hg}$ Concentration from Coal & $\mu \mathrm{g} / \mathrm{dNm} 3$ at $3 \%$ O2 & 27.0 & 22.3 & 23.7 & 23.7 & 23.7 & 11.9 \\
\hline Mercury Rate in Ash Treated, weighted & $\mathrm{g} / \mathrm{h}$ & 45.0 & 31.5 & 46.1 & 46.1 & 35.1 & 17.1 \\
\hline Mercury Rate in Ash Untreated & $\mathrm{g} / \mathrm{h}$ & & & & & & 1.4 \\
\hline SCEM Mercury Rate ESP Inlet & $g / h$ & 60.4 & 64.2 & 64.4 & 69.9 & 75.8 & 35.3 \\
\hline SCEM Mercury Rate ESP Outlet Treated & $g / h$ & 11.3 & 9.5 & 11.0 & 8.8 & 16.4 & 1.1 \\
\hline SCEM Mercury Rate ESP Outlet Untreated & $\mathrm{g} / \mathrm{h}$ & 47.3 & 42.1 & 44.0 & 53.2 & 48.3 & 19.5 \\
\hline $\mathrm{OH}$ Mercury Rate ESP Outlet Treated & $\mathrm{g} / \mathrm{h}$ & & & 26.3 & 25.5 & 46.4 & \\
\hline OH Mercury Rate ESP Outlet Untreated & $\mathrm{g} / \mathrm{h}$ & & & 84.3 & 87.0 & 72.1 & \\
\hline \multicolumn{8}{|l|}{ Weighted Average Coal Values: } \\
\hline wtd $\mathrm{Hg}$ & ug/g, dry & 0.190 & 0.162 & 0.171 & 0.171 & 0.171 & 0.096 \\
\hline wtd ash & wt $\%$, as recd & 13.60 & 12.00 & 11.97 & 11.97 & 11.97 & 5.43 \\
\hline wtd moisture & wt $\%$ & 32.5 & 30.7 & 32.6 & 32.6 & 32.6 & 32.9 \\
\hline wtd Btu & Btu/lb, as recd & 6803 & 7212 & 7004 & 7004 & 7004 & 7810 \\
\hline \multicolumn{8}{|l|}{ SCEM vs Coal Hg Ratios: } \\
\hline SCEM inlet $\mathrm{Hg} / \mathrm{Coal} \mathrm{Hg}$ & & $82 \%$ & $106 \%$ & $100 \%$ & $108 \%$ & $118 \%$ & $108 \%$ \\
\hline SCEM ESP outlet untreated $\mathrm{Hg} / \mathrm{Coal} \mathrm{Hg}$ & & $64 \%$ & $69 \%$ & $68 \%$ & $82 \%$ & $75 \%$ & $60 \%$ \\
\hline \multicolumn{8}{|l|}{ Percent Removal: } \\
\hline treated ash $\mathrm{Hg} / \mathrm{Coal} \mathrm{Hg}$ & & $61 \%$ & $52 \%$ & $71 \%$ & $71 \%$ & $55 \%$ & $52 \%$ \\
\hline treated SCEM Hg/Coal $\mathrm{Hg}$ & & $85 \%$ & $84 \%$ & $83 \%$ & $86 \%$ & $75 \%$ & $97 \%$ \\
\hline treated $\mathrm{OH} \mathrm{Ha} / \mathrm{Coal} \mathrm{Hq}$ & & & & $59 \%$ & $61 \%$ & $28 \%$ & \\
\hline treated ash $\mathrm{Hg}$ /inlet ESP Hg & & $74 \%$ & $49 \%$ & $72 \%$ & $66 \%$ & $46 \%$ & $48 \%$ \\
\hline treated SCEM Hg/inlet ESP Hg & & $81 \%$ & $85 \%$ & $83 \%$ & $87 \%$ & $78 \%$ & $97 \%$ \\
\hline treated $\mathrm{OH} \mathrm{Hg} /$ inlet ESP Hg & & & & $59 \%$ & $63 \%$ & $39 \%$ & \\
\hline untreated ash $\mathrm{Hg} /$ inlet ESP Hg & & & & & & & $4 \%$ \\
\hline untreated SCEM Hg/inlet ESP Hg & & $22 \%$ & $34 \%$ & $32 \%$ & $24 \%$ & $36 \%$ & $45 \%$ \\
\hline untreated $\mathrm{OH} \mathrm{Hg} /$ inlet ESP Hg & & & & $-31 \%$ & $-25 \%$ & $5 \%$ & \\
\hline Hg Mass Balance Ratio: & & & & & & & \\
\hline (Coal In/SCEM Out) Treated & & 1.31 & 1.48 & 1.13 & 1.18 & 1.25 & 1.79 \\
\hline (Coal In/OH Out) Treated & & & & 0.89 & 0.90 & 0.79 & \\
\hline (SCEM In/SCEM Out) Treated & & 1.07 & 1.57 & 1.13 & 1.27 & 1.47 & 1.94 \\
\hline (SCEM In/OH Out) Treated & & & & 0.89 & 0.97 & 0.93 & \\
\hline (Coal In/SCEM Out) Untreated & & & & & & & 1.56 \\
\hline (Coal In/OH Out) Untreated & & & & & & & \\
\hline (SCEM In/SCEM Out) Untreated & & & & & & & 1.69 \\
\hline (SCEM In/OH Out) Untreated & & & & & & & \\
\hline $\begin{array}{l}\text { Overall Removal - assuming } 95 \% \text { oxidized } \mathrm{Hg} \\
\text { removed bv FGD: }\end{array}$ & & & & & & & \\
\hline SCEM/coal basis (assuming $74 \%$ ox) & & $89 \%$ & $89 \%$ & $88 \%$ & $90 \%$ & $82 \%$ & $98 \%$ \\
\hline $\mathrm{OH} / \mathrm{coal}$ basis (assuming $69 \%$ ox) & & & & $73 \%$ & $74 \%$ & $53 \%$ & \\
\hline
\end{tabular}




\begin{tabular}{|c|c|c|c|c|c|c|c|}
\hline Date & & $8 / 5 / 2007$ & $8 / 7 / 2007$ & $8 / 9 / 2007$ & $8 / 11 / 2007$ & $8 / 13 / 2007$ & $8 / 14 / 2007$ \\
\hline Condition & & \begin{tabular}{|c|} 
Darco HG- \\
LH \\
$2.0 \mathrm{lb} /$ Macf \\
\end{tabular} & $\begin{array}{c}\text { Darco HG- } \\
\text { LH } \\
2.0 \mathrm{lb} / \mathrm{Macf}\end{array}$ & \begin{tabular}{|c|} 
Darco HG- \\
LH \\
$2.0 \mathrm{lb} / \mathrm{Macf}$ \\
\end{tabular} & \begin{tabular}{|c|} 
Darco HG- \\
LH \\
$2.0 \mathrm{lb} /$ Macf
\end{tabular} & \begin{tabular}{|c|} 
Darco HG- \\
LH \\
$2.0 \mathrm{lb} / \mathrm{Macf}$ \\
\end{tabular} & $\begin{array}{c}\text { Darco HG- } \\
\mathrm{LH} \\
2.0 \mathrm{lb} / \mathrm{Macf}\end{array}$ \\
\hline Inputs: & Units & & & & & & \\
\hline Time Coal Sampled & & Ave & $8: 05$ & 7:52/Ave & Ave & Ave & Ave \\
\hline Time Coal should hit Furnace & & $15: 30$ & $8: 05$ & $7: 52$ & $18: 00$ & $11: 00$ & $14: 30$ \\
\hline Load, Gross at time Coal hit Furnace & MW (gross) & 878 & 875 & 881 & 885 & 881 & 884 \\
\hline Btu Ratio & Btu blend/6399 Btu & 1.17 & 1.14 & 1.14 & 1.11 & 1.15 & 1.05 \\
\hline$\%$ Coal 2 (PRB) & & 25.82 & 25.62 & 23.66 & 12.62 & 25.35 & 12.64 \\
\hline Time Ash Sampled & & $15: 30$ & $8: 05$ & $21: 00$ & $18: 00$ & $11: 00$ & $14: 30$ \\
\hline Load, Gross at time Ash Sampled & MW (gross) & 878 & 875 & 879 & 885 & 881 & 884 \\
\hline Gross Heat Rate & Btu/kW-h & 9837 & 9836 & 9785 & 9746 & 9670 & 9818 \\
\hline Fraction Coal 1 by Wt. & wt. Fraction & 0.7418 & 0.7438 & 0.7634 & 0.8738 & 0.7465 & 0.8736 \\
\hline Coal $1 \mathrm{Hg}(\mathrm{TxL})$ & $\mu \mathrm{g} / \mathrm{g}, \mathrm{dry}$ & 0.198 & 0.193 & 0.180 & 0.198 & 0.198 & 0.198 \\
\hline Coal 1 Ash $(\mathrm{TxL})$ & wt $\%$, dry & 21.22 & 19.94 & 25.54 & 21.22 & 21.22 & 21.22 \\
\hline Coal 1 Moisture $(\mathrm{TxL})$ & $w t \%$ & 32.49 & 32.49 & 31.75 & 32.49 & 32.49 & 32.49 \\
\hline Coal 1 Heating Value $(T x L)$ & Btu/lb, dry & 9946 & 10178 & 9234 & 9946 & 9946 & 9946 \\
\hline Coal 1 F-factor $(T x L)$ & dry scf/Mbtu, $0 \% \mathrm{O} 2$ & 10248 & 10248 & 10300 & 10248 & 10248 & 10248 \\
\hline Coal $2 \mathrm{Hg}$ (PRB) & $\mu \mathrm{g} / \mathrm{g}, \mathrm{dry}$ & 0.096 & 0.067 & 0.096 & 0.096 & 0.096 & 0.096 \\
\hline Coal 2 Ash (PRB) & wt $\%$, dry & 8.09 & 8.29 & 8.09 & 8.09 & 8.09 & 8.09 \\
\hline Coal 2 Moisture (PRB) & wt $\%$ & 32.93 & 32.35 & 32.93 & 32.93 & 32.93 & 32.93 \\
\hline Coal 2 Heating Value (PRB) & Btu/lb, dry & 11645 & 11581 & 11645 & 11645 & 11645 & 11645 \\
\hline Coal 2 F-factor (PRB) & dry scf/Mbtu, $0 \%$ O2 & 10228 & 10228 & 10228 & 10228 & 10228 & 10228 \\
\hline Date Ash Sampled & & $8 / 5 / 2007$ & Ave & $8 / 9 / 2007$ & \begin{tabular}{|l|}
$8 / 11 / 2007$ \\
\end{tabular} & \begin{tabular}{|l|}
$8 / 13 / 2007$ \\
\end{tabular} & Ave \\
\hline Time Ash Sampled & & $15: 30$ & & $21: 00$ & $18: 00$ & $11: 00$ & \\
\hline Treated Ash $\mathrm{Hg}$ (from URS lab) - first field only & $\mu \mathrm{g} / \mathrm{g}$ & 0.765 & 0.665 & 0.462 & 0.560 & 0.510 & 0.665 \\
\hline Treated Ash Hg (from URS lab) - weighted for all fields & $\mu \mathrm{g} / \mathrm{g}$ & 0.851 & 0.757 & 0.566 & 0.658 & 0.611 & 0.757 \\
\hline Untreated Ash Hg (from URS lab) & $\mu \mathrm{g} / \mathrm{g}$ & & 0.053 & & & & 0.053 \\
\hline SCEM start time & & $13: 30$ & $6: 00$ & $6: 00$ & $16: 00$ & $7: 00$ & $11: 30$ \\
\hline SCEM end time & & $17: 30$ & $10: 00$ & 9:00 & $20: 00$ & $13: 00$ & $13: 45$ \\
\hline SCEM ESP Inlet & $\mu \mathrm{g} / \mathrm{dry} \mathrm{Nm3} @ 3 \%$ O2 & 29.00 & 17.93 & 17.49 & 25.48 & 26.25 & 25.84 \\
\hline SCEM ESP Outlet Treated & $\mu \mathrm{g} / \mathrm{dry}$ Nm3 @ 3\% O2 & 3.14 & 3.22 & 5.32 & 6.51 & 5.47 & 7.65 \\
\hline SCEM ESP Outlet Untreated & $\mu \mathrm{g} / \mathrm{dry} \mathrm{Nm3} @ 3 \% \mathrm{O} 2$ & 16.55 & 15.35 & 16.64 & 16.04 & 23.87 & 16.56 \\
\hline $\mathrm{OH}$ start time & & & & & & & $11: 30$ \\
\hline $\mathrm{OH}$ end time & & & & & & & $13: 45$ \\
\hline OH ESP Outlet Treated & $\mu \mathrm{g} / \mathrm{dry}$ Nm3 @ 3\% O2 & & & & & & 21.91 \\
\hline OH ESP Outlet Untreated & $\mu \mathrm{g} / \mathrm{dry}$ Nm3 @ 3\% O2 & & & & & & 33.39 \\
\hline \multicolumn{8}{|l|}{ Calculated Values: } \\
\hline Fraction Coal 1 by Btu & Btu Fraction & 0.71 & 0.72 & 0.72 & 0.86 & 0.72 & 0.86 \\
\hline Composite F-factor & dscf/MMBtu at 3\% O2 & 11959 & 11959 & 12003 & 11962 & 11959 & 11962 \\
\hline Gas flow rate & dscfm at $3 \%$ O2 & 1721317 & 1715867 & 1724307 & 1720174 & 1698114 & 1730912 \\
\hline Gas flow rate & dry $\mathrm{Nm} 3 / \mathrm{min}$ & 45438 & 45294 & 45517 & 45408 & 44825 & 45691 \\
\hline Coal feed rate & ton $/ \mathrm{hr}(\mathrm{dry})$ & 416 & 408 & 440 & 425 & 411 & 427 \\
\hline Mercury Rate in Coal & $\mathrm{g} / \mathrm{h}$ & 64.8 & 59.5 & 63.7 & 71.4 & 64.1 & 71.8 \\
\hline Mercury Rate in Coal & $\mathrm{lb} / \mathrm{Tbtu}$ & 16.5 & 15.2 & 16.3 & 18.2 & 16.6 & 18.2 \\
\hline $\mathrm{Hg}$ Concentration from Coal & $\mu \mathrm{g} / \mathrm{dNm} 3$ at $3 \% \mathrm{O} 2$ & 23.8 & 21.9 & 23.3 & 26.2 & 23.8 & 26.2 \\
\hline Mercury Rate in Ash Treated, weighted & $\mathrm{g} / \mathrm{h}$ & 48.7 & 40.4 & 41.2 & 42.2 & 34.6 & 48.8 \\
\hline Mercury Rate in Ash Untreated & $\mathrm{g} / \mathrm{h}$ & & 2.8 & & & & 3.4 \\
\hline SCEM Mercury Rate ESP Inlet & $\mathrm{g} / \mathrm{h}$ & 79.1 & 48.7 & 47.8 & 69.4 & 70.6 & 70.8 \\
\hline SCEM Mercury Rate ESP Outlet Treated & $\mathrm{g} / \mathrm{h}$ & 8.6 & 8.7 & 14.5 & 17.7 & 14.7 & 21.0 \\
\hline SCEM Mercury Rate ESP Outlet Untreated & $\mathrm{g} / \mathrm{h}$ & 45.1 & 41.7 & 45.4 & 43.7 & 64.2 & 45.4 \\
\hline OH Mercury Rate ESP Outlet Treated & $\mathrm{g} / \mathrm{h}$ & & & & & & 60.1 \\
\hline OH Mercury Rate ESP Outlet Untreated & $\mathrm{g} / \mathrm{h}$ & & & & & & 91.5 \\
\hline \multicolumn{8}{|l|}{ Weighted Average Coal Values: } \\
\hline wtd $\mathrm{Hg}$ & ug/g, dry & 0.172 & 0.160 & 0.160 & 0.185 & 0.172 & 0.185 \\
\hline wtd ash & wt $\%$, as recd & 12.03 & 11.45 & 14.59 & 13.20 & 12.07 & 13.20 \\
\hline wtd moisture & wt $\%$ & 32.6 & 32.5 & 32.0 & 32.5 & 32.6 & 32.5 \\
\hline wtd Btu & Btu/lb, as recd & 6997 & 7118 & 6659 & 6853 & 6992 & 6853 \\
\hline \multicolumn{8}{|l|}{ SCEM vs Coal Hg Ratios: } \\
\hline SCEM inlet $\mathrm{Hg} / \mathrm{Coal} \mathrm{Hg}$ & & $122 \%$ & $82 \%$ & $75 \%$ & $97 \%$ & $110 \%$ & $99 \%$ \\
\hline SCEM ESP outlet untreated $\mathrm{Hg} / \mathrm{Coal} \mathrm{Hg}$ & & $70 \%$ & $70 \%$ & $71 \%$ & $61 \%$ & $100 \%$ & $63 \%$ \\
\hline \multicolumn{8}{|l|}{ Percent Removal: } \\
\hline treated ash $\mathrm{Hg} / \mathrm{Coal} \mathrm{Hg}$ & & $75 \%$ & $68 \%$ & $65 \%$ & $59 \%$ & $54 \%$ & $68 \%$ \\
\hline treated SCEM Hg/Coal Hg & & $87 \%$ & $85 \%$ & $77 \%$ & $75 \%$ & $77 \%$ & $71 \%$ \\
\hline treated $\mathrm{OH} \mathrm{Ha} / \mathrm{Coal} \mathrm{Hg}$ & & & & & & & $16 \%$ \\
\hline treated ash $\mathrm{Hg} /$ inlet ESP $\mathrm{Hg}$ & & $62 \%$ & $83 \%$ & $86 \%$ & $61 \%$ & $49 \%$ & $69 \%$ \\
\hline treated SCEM Hg/inlet ESP Hg & & $89 \%$ & $82 \%$ & $70 \%$ & $74 \%$ & $79 \%$ & $70 \%$ \\
\hline treated $\mathrm{OH} \mathrm{Hg}$ /inlet ESP Hg & & & & & & & $15 \%$ \\
\hline untreated ash $\mathrm{Hg}$ /inlet ESP Hg & & & $6 \%$ & & & & $5 \%$ \\
\hline untreated SCEM Hg/inlet ESP Hg & & $43 \%$ & $14 \%$ & $5 \%$ & $37 \%$ & $9 \%$ & $36 \%$ \\
\hline untreated $\mathrm{OH} \mathrm{Hg} /$ inlet ESP Hg & & & & & & & $-29 \%$ \\
\hline Hg Mass Balance Ratio: & & & & & & & \\
\hline (Coal In/SCEM Out) Treated & & 1.13 & 1.21 & 1.14 & 1.19 & 1.30 & 1.03 \\
\hline (Coal In/OH Out) Treated & & & & & & & 0.66 \\
\hline (SCEM In/SCEM Out) Treated & & 1.38 & 0.99 & 0.86 & 1.16 & 1.43 & 1.01 \\
\hline (SCEM In/OH Out) Treated & & & & & & & 0.65 \\
\hline (Coal In/SCEM Out) Untreated & & & 1.33 & & & & 1.47 \\
\hline (Coal In/OH Out) Untreated & & & & & & & 0.76 \\
\hline (SCEM In/SCEM Out) Untreated & & & 1.09 & & & & 1.45 \\
\hline (SCEM In/OH Out) Untreated & & & & & & & 0.75 \\
\hline $\begin{array}{l}\text { Overall Removal - assuming } 95 \% \text { oxidized } \mathrm{Hg} \\
\text { removed by FGD: }\end{array}$ & & & & & & & \\
\hline SCEM/coal basis (assuming $74 \%$ ox) & & $91 \%$ & $90 \%$ & $84 \%$ & $83 \%$ & $84 \%$ & $79 \%$ \\
\hline $\mathrm{OH} /$ coal basis (assuming $69 \%$ ox) & & & & & & & $45 \%$ \\
\hline
\end{tabular}




\begin{tabular}{|c|c|c|c|c|c|c|c|c|}
\hline Date & & $8 / 14 / 2007$ & $8 / 15 / 2007$ & $8 / 17 / 2007$ & $8 / 18 / 2007$ & $8 / 19 / 2007$ & $8 / 21 / 2007$ & \begin{tabular}{|l|} 
Averages \\
\end{tabular} \\
\hline Condition & & \begin{tabular}{|c|} 
Darco HG- \\
LH \\
$2.0 \mathrm{lb} / \mathrm{Macf}$ \\
\end{tabular} & $\begin{array}{c}\text { Darco HG- } \\
\text { LH } \\
2.0 \mathrm{lb} / \mathrm{Macf}\end{array}$ & \begin{tabular}{|c|} 
Darco HG- \\
LH \\
$2.0 \mathrm{lb} / \mathrm{Macf}$ \\
\end{tabular} & $\begin{array}{c}\text { Darco HG- } \\
\text { LH } \\
2.0 \mathrm{lb} / \mathrm{Macf}\end{array}$ & $\begin{array}{c}\text { Darco HG- } \\
\text { LH } \\
2.0 \mathrm{lb} / \mathrm{Macf}\end{array}$ & $\begin{array}{c}\text { Darco HG- } \\
\text { LH } \\
2.0 \mathrm{lb} / \mathrm{Macf}\end{array}$ & $\begin{array}{l}\text { Long Term } \\
\text { Injection }\end{array}$ \\
\hline Inputs: & Units & & & & & & & \\
\hline Time Coal Sampled & & Ave & $7: 52$ & $22: 30$ & Ave & $21: 30$ & $7: 10$ & \\
\hline Time Coal should hit Furnace & & $14: 30$ & $7: 52$ & $22: 30$ & $13: 00$ & $21: 30$ & $7: 10$ & \\
\hline Load, Gross at time Coal hit Furnace & MW (gross) & 884 & 886 & 881 & 891 & 885 & 885 & 873 \\
\hline Btu Ratio & Btu blend/6399 Btu & 1.05 & 1.08 & 1.2 & 1.17 & 1.15 & 1.13 & 1.14 \\
\hline$\%$ Coal 2 (PRB) & & 12.64 & 23.28 & 24.98 & 25 & 25 & 24.99 & 30.60 \\
\hline Time Ash Sampled & & $14: 30$ & $11: 00$ & $11: 30$ & $13: 00$ & $14: 00$ & $7: 10$ & \\
\hline Load, Gross at time Ash Sampled & MW (gross) & 884 & 876 & 887 & 891 & 886 & 885 & 874 \\
\hline Gross Heat Rate & Btu/kW-h & 9818 & 9851 & 9881 & 9817 & 9781 & 9631 & 9811 \\
\hline Fraction Coal 1 by Wt. & wt. Fraction & 0.8736 & 0.7672 & 0.7502 & 0.75 & 0.75 & 0.7501 & 0.69 \\
\hline Coal $1 \mathrm{Hg}(\mathrm{T} x \mathrm{~L})$ & $\mu \mathrm{g} / \mathrm{g}, \mathrm{dry}$ & 0.198 & 0.180 & 0.204 & 0.198 & 0.201 & 0.224 & 0.198 \\
\hline Coal 1 Ash $(T x L)$ & wt $\%$, dry & 21.22 & 25.54 & 16.50 & 21.22 & 18.43 & 18.95 & 21.22 \\
\hline Coal 1 Moisture (TxL) & wt\% & 32.49 & 31.75 & 33.28 & 32.49 & 28.66 & 32.83 & 32.49 \\
\hline Coal 1 Heating Value $(T x L)$ & Btu/lb, dry & 9946 & 9234 & 10695 & 9946 & 10303 & 10293 & 9946 \\
\hline Coal 1 F-factor (TxL) & dry scf/Mbtu, $0 \%$ O2 & 10248 & 10300 & 10248 & 10248 & 10248 & 10264 & 10248 \\
\hline Coal $2 \mathrm{Hg}$ (PRB) & $\mu \mathrm{g} / \mathrm{g}, \mathrm{dry}$ & 0.096 & 0.096 & 0.087 & 0.096 & 0.095 & 0.134 & 0.096 \\
\hline Coal 2 Ash (PRB) & wt $\%$, dry & 8.09 & 8.09 & 8.69 & 8.09 & 7.23 & 9.41 & 8.09 \\
\hline Coal 2 Moisture (PRB) & wt $\%$ & 32.93 & 32.93 & 49.60 & 32.93 & 31.85 & 30.87 & 32.93 \\
\hline Coal 2 Heating Value (PRB) & Btu/lb, dry & 11645 & 11645 & 11793 & 11645 & 11771 & 11557 & 11645 \\
\hline Coal 2 F-factor (PRB) & dry scf/Mbtu, $0 \%$ O2 & 10228 & 10228 & 10228 & 10228 & 10228 & 10119 & 10228 \\
\hline Date Ash Sampled & & Ave & $8 / 15 / 2007$ & \begin{tabular}{|l|}
$8 / 17 / 2007$ \\
\end{tabular} & $8 / 18 / 2007$ & $8 / 19 / 2007$ & Ave & \\
\hline Time Ash Sampled & & & $11: 00$ & $11: 30$ & $13: 00$ & $14: 00$ & & \\
\hline Treated Ash $\mathrm{Hg}$ (from URS lab) - first field only & $\mu \mathrm{g} / \mathrm{g}$ & 0.665 & 0.371 & & 0.636 & 0.756 & 0.665 & 0.665 \\
\hline Treated Ash $\mathrm{Hg}$ (from URS lab) - weighted for all fields & $\mu \mathrm{g} / \mathrm{g}$ & 0.757 & 0.480 & & 0.729 & 0.842 & 0.757 & 0.780 \\
\hline Untreated Ash $\mathrm{Hg}$ (from URS lab) & $\mu \mathrm{g} / \mathrm{g}$ & 0.053 & & 0.025 & & & 0.053 & 0.053 \\
\hline SCEM start time & & $15: 00$ & $9: 30$ & $20: 00$ & $11: 00$ & $17: 30$ & $7: 30$ & \\
\hline SCEM end time & & $17: 10$ & $11: 38$ & $23: 59$ & $15: 00$ & $21: 30$ & $10: 30$ & \\
\hline SCEM ESP Inlet & $\mu \mathrm{g} / \mathrm{dry} \mathrm{Nm3} @ 3 \% \mathrm{O} 2$ & 21.61 & 26.83 & 19.83 & 26.80 & 29.38 & & 24.97 \\
\hline SCEM ESP Outlet Treated & $\mu \mathrm{g} / \mathrm{dry}$ Nm3 @ 3\% O2 & 7.73 & 2.42 & 4.02 & 6.72 & 4.52 & 3.07 & 4.23 \\
\hline SCEM ESP Outlet Untreated & $\mu \mathrm{g} / \mathrm{dry}$ Nm3 @ 3\% O2 & 16.40 & 15.17 & 16.65 & 15.87 & 18.64 & 18.17 & 17.65 \\
\hline $\mathrm{OH}$ start time & & $15: 00$ & $9: 30$ & & & & & \\
\hline $\mathrm{OH}$ end time & & $17: 10$ & $11: 38$ & & & & & \\
\hline OH ESP Outlet Treated & $\mu \mathrm{g} / \mathrm{dry}$ Nm3 @ 3\% O2 & 22.37 & 10.77 & & & & & 16.05 \\
\hline $\mathrm{OH}$ ESP Outlet Untreated & $\mu \mathrm{g} / \mathrm{dry}$ Nm3 @ 3\% O2 & 30.58 & 26.51 & & & & & 32.84 \\
\hline \multicolumn{9}{|l|}{ Calculated Values: } \\
\hline Fraction Coal 1 by Btu & Btu Fraction & 0.86 & 0.73 & 0.78 & 0.72 & 0.73 & 0.72 & 0.66 \\
\hline Composite F-factor & dscf/MMBtu at $3 \% \mathrm{O} 2$ & 11962 & 12003 & 11960 & 11959 & 11959 & 11937 & 11958 \\
\hline Gas flow rate & dscfm at $3 \% 02$ & 1730912 & 1746890 & 1735258 & 1743535 & 1725327 & 1695946 & 1706819 \\
\hline Gas flow rate & dry $\mathrm{Nm} 3 / \mathrm{min}$ & 45691 & 46113 & 45806 & 46024 & 45544 & 44768 & 45055 \\
\hline Coal feed rate & ton $/ \mathrm{hr}$ (dry) & 427 & 446 & 397 & 422 & 406 & 402 & 409 \\
\hline Mercury Rate in Coal & $g / h$ & 71.8 & 64.8 & 62.9 & 66.0 & 64.3 & 73.4 & 61.9 \\
\hline Mercury Rate in Coal & $\mathrm{lb} / \mathrm{Tbtu}$ & 18.2 & 16.3 & 15.9 & 16.6 & 16.4 & 19.0 & 15.9 \\
\hline $\mathrm{Hg}$ Concentration from Coal & $\mu \mathrm{g} / \mathrm{dNm} 3$ at $3 \% \mathrm{O} 2$ & 26.2 & 23.4 & 22.9 & 23.9 & 23.5 & 27.3 & 22.9 \\
\hline Mercury Rate in Ash Treated, weighted & $g / h$ & 48.8 & 35.6 & & 42.6 & 41.4 & 38.7 & 42.4 \\
\hline Mercury Rate in Ash Untreated & $\mathrm{g} / \mathrm{h}$ & 3.4 & & 1.1 & & & 2.7 & 2.9 \\
\hline SCEM Mercury Rate ESP Inlet & $\mathrm{g} / \mathrm{h}$ & 59.2 & 74.2 & 54.5 & 74.0 & 80.3 & & 67.5 \\
\hline SCEM Mercury Rate ESP Outlet Treated & $\mathrm{g} / \mathrm{h}$ & 21.2 & 6.7 & 11.0 & 18.6 & 12.4 & 8.2 & 11.4 \\
\hline SCEM Mercury Rate ESP Outlet Untreated & $g / h$ & 45.0 & 42.0 & 45.8 & 43.8 & 50.9 & 48.8 & 47.7 \\
\hline OH Mercury Rate ESP Outlet Treated & $\mathrm{g} / \mathrm{h}$ & 61.3 & 29.8 & & & & & 43.4 \\
\hline OH Mercury Rate ESP Outlet Untreated & $\mathrm{g} / \mathrm{h}$ & 83.8 & 73.3 & & & & & 88.8 \\
\hline \multicolumn{9}{|l|}{ Weighted Average Coal Values: } \\
\hline wtd $\mathrm{Hg}$ & ug/g, dry & 0.185 & 0.160 & 0.175 & 0.173 & 0.175 & 0.201 & 0.167 \\
\hline wtd ash & $\mathrm{wt} \%$, as recd & 13.20 & 14.63 & 9.35 & 12.10 & 11.09 & 11.17 & 11.60 \\
\hline wtd moisture & wt\% & 32.5 & 32.0 & 37.4 & 32.6 & 29.5 & 32.3 & 32.6 \\
\hline wtd Btu & Btu/lb, as recd & 6853 & 6653 & 6838 & 6988 & 7518 & 7183 & 7050 \\
\hline \multicolumn{9}{|l|}{ SCEM vs Coal Hg Ratios: } \\
\hline SCEM inlet $\mathrm{Hg} / \mathrm{Coal} \mathrm{Hg}$ & & $83 \%$ & $115 \%$ & $87 \%$ & $112 \%$ & $125 \%$ & & $109 \%$ \\
\hline SCEM ESP outlet untreated $\mathrm{Hq} / \mathrm{Coal} \mathrm{Hg}$ & & $63 \%$ & $65 \%$ & $73 \%$ & $66 \%$ & $79 \%$ & $66 \%$ & $77 \%$ \\
\hline \multicolumn{9}{|l|}{ Percent Removal: } \\
\hline treated ash $\mathrm{Hg} / \mathrm{Coal} \mathrm{Hg}$ & & $68 \%$ & $55 \%$ & & $65 \%$ & $64 \%$ & $53 \%$ & $68 \%$ \\
\hline treated SCEM Hg/Coal Hg & & $70 \%$ & $90 \%$ & $82 \%$ & $72 \%$ & $81 \%$ & $89 \%$ & $82 \%$ \\
\hline treated $\mathrm{OH} \mathrm{Hg} / \mathrm{Coal} \mathrm{Hg}$ & & $15 \%$ & $54 \%$ & & & & & $30 \%$ \\
\hline treated ash $\mathrm{Hg} /$ inlet ESP Hg & & $82 \%$ & $48 \%$ & & $58 \%$ & $52 \%$ & & $66 \%$ \\
\hline treated SCEM Hg/inlet ESP Hg & & $64 \%$ & $91 \%$ & $80 \%$ & $75 \%$ & $85 \%$ & & $82 \%$ \\
\hline treated $\mathrm{OH} \mathrm{Hg} /$ inlet ESP Hg & & $-4 \%$ & $60 \%$ & & & & & $40 \%$ \\
\hline untreated ash $\mathrm{Hg} /$ inlet ESP Hg & & $6 \%$ & & $2 \%$ & & & & $5 \%$ \\
\hline untreated SCEM Hg/inlet ESP Hg & & $24 \%$ & $43 \%$ & $16 \%$ & $41 \%$ & $37 \%$ & & $23 \%$ \\
\hline untreated $\mathrm{OH} \mathrm{Hg}$ /inlet ESP Hg & & $-42 \%$ & $1 \%$ & & & & & $-43 \%$ \\
\hline Hg Mass Balance Ratio: & & & & & & & & \\
\hline (Coal In/SCEM Out) Treated & & 1.03 & 1.53 & & 1.08 & 1.20 & 1.56 & 1.15 \\
\hline (Coal In/OH Out) Treated & & 0.65 & 0.99 & & & & & 0.72 \\
\hline (SCEM In/SCEM Out) Treated & & 0.85 & 1.76 & & 1.21 & 1.49 & & 1.25 \\
\hline (SCEM In/OH Out) Treated & & 0.54 & 1.14 & & & & & 0.79 \\
\hline (Coal In/SCEM Out) Untreated & & 1.48 & & 1.34 & & & 1.43 & 1.22 \\
\hline (Coal In/OH Out) Untreated & & 0.82 & & & & & & 0.68 \\
\hline (SCEM In/SCEM Out) Untreated & & 1.22 & & 1.16 & & & & 1.33 \\
\hline (SCEM In/OH Out) Untreated & & 0.68 & & & & & & 0.74 \\
\hline $\begin{array}{l}\text { Overall Removal - assuming 95\% oxidized } \mathrm{Hg} \\
\text { removed bV FGD: }\end{array}$ & & & & & & & & \\
\hline SCEM/coal basis (assuming $74 \%$ ox & & $79 \%$ & $93 \%$ & $88 \%$ & $80 \%$ & $86 \%$ & $92 \%$ & $87 \%$ \\
\hline $\mathrm{OH} / \mathrm{coal}$ basis (assuming $69 \%$ ox) & & $44 \%$ & $70 \%$ & & & & & $54 \%$ \\
\hline
\end{tabular}




\section{APPENDIX G - ESP OUTLET SCEM IGS FILTER CHANGES}


The IGS filter on the treated ESP outlet was changed three different times during long-term testing. The first change occurred 6/20/07 during baseline testing. The second change occurred 6/28/07 during long-term injection. The third change occurred on 7/11/07 during long-term injection.

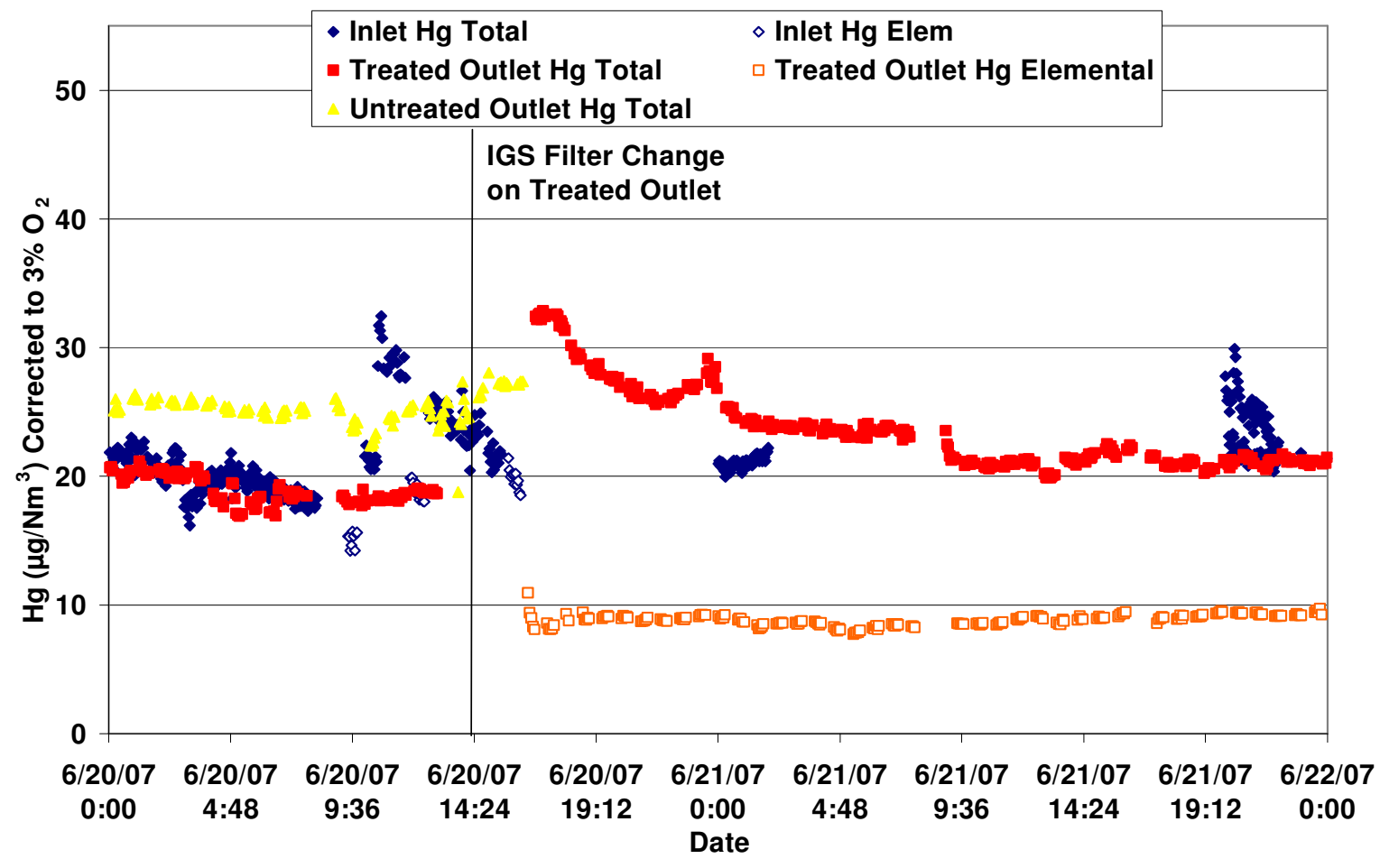

Figure G-1. IGS Filter Change on Treated Outlet June 20, 2007 


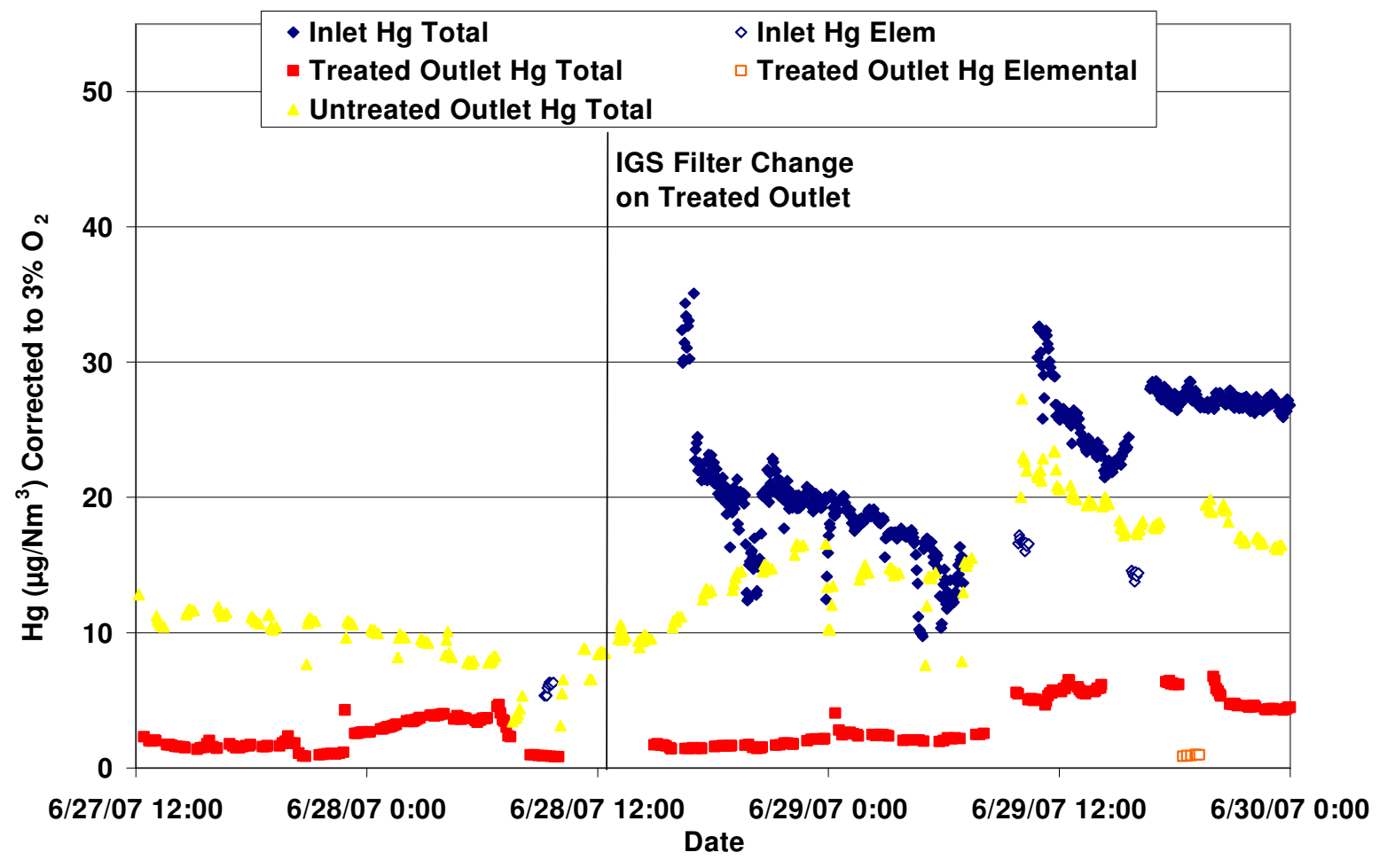

Figure G-2. IGS Filter Change on Treated Outlet June 28, 2007

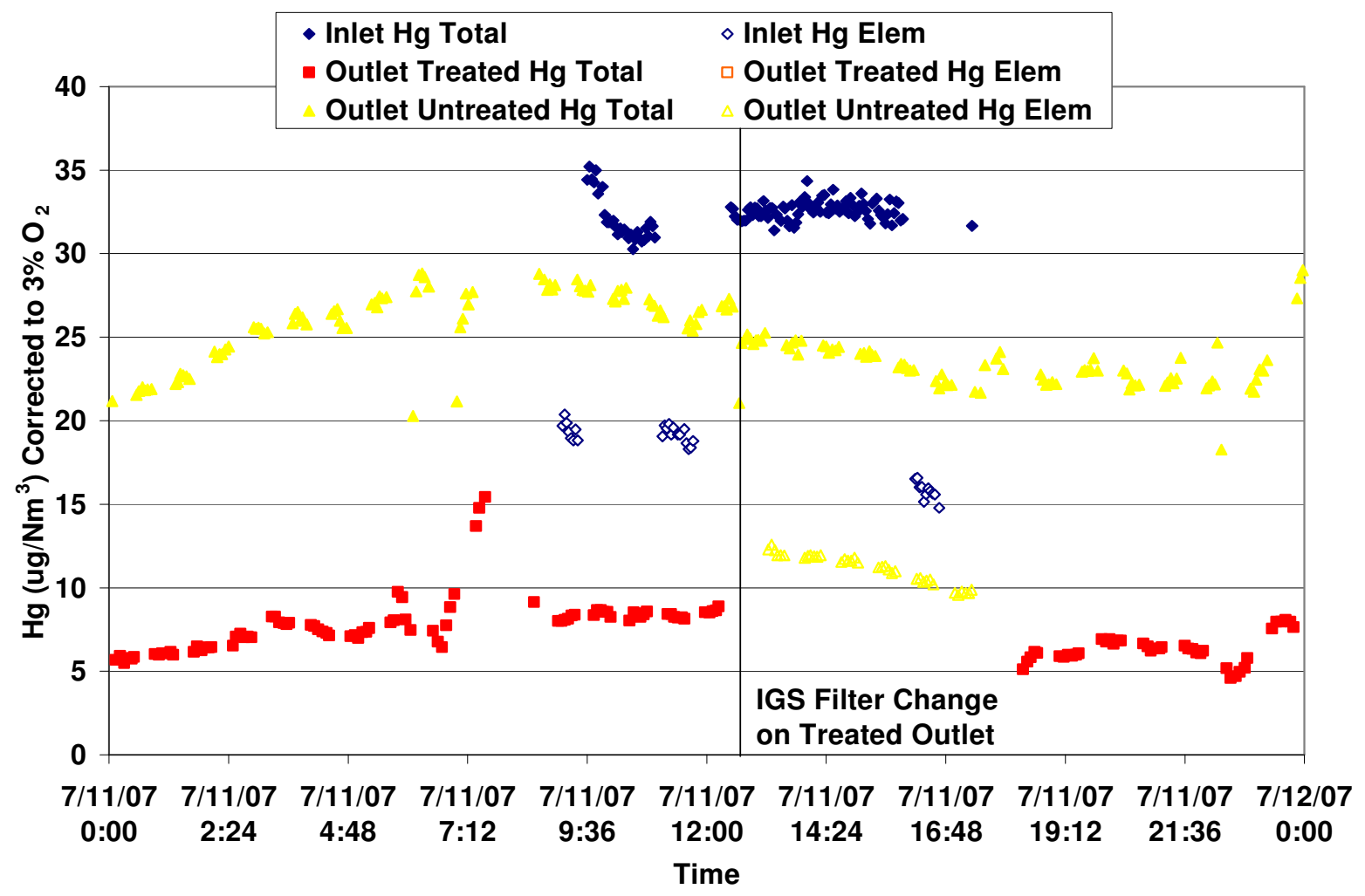

Figure G-3. IGS Filter Change on Treated Outlet July 11, 2007 


\section{APPENDIX H - COAL ANALYTICAL RESULTS}


Table H-1. Analyses of Texas Lignite Fired during Phase I Parametric Tests

\begin{tabular}{||l|c|c|c|c|c|c|c|c||}
\hline Coal Type & TxL & TxL & TxL & TxL & TxL & TxL & Average & St Dev \\
\hline \hline Date & $12 / 1 / 2006$ & $12 / 1 / 2006$ & $12 / 2 / 2006$ & $12 / 2 / 2006$ & $12 / 9 / 2006$ & $12 / 9 / 2006$ & & \\
\hline Time & $10: 15$ & $10: 15$ & $10: 30$ & $10: 30$ & $10: 30$ & $10: 40$ & & \\
\hline \% Moisture & 32.74 & 32.22 & 31.19 & 31.48 & 31.34 & 32.49 & 31.91 & 0.66 \\
\hline Dry Basis: & & & & & & & & \\
\hline Btu/lb & - & - & 10149 & - & 10962 & 10823 & 10645 & 434.85 \\
\hline \% Carbon & - & - & 57.18 & - & 62.93 & - & 60.06 & 4.07 \\
\hline \% Hydrogen & - & - & 4.06 & - & 4.43 & - & 4.25 & 0.26 \\
\hline \% Nitrogen & - & - & 0.86 & - & 0.88 & - & 0.87 & 0.01 \\
\hline \% Sulfur & - & - & 1.07 & - & 0.84 & 0.73 & 0.88 & 0.17 \\
\hline \% Ash & - & - & 22.28 & 19.63 & 15.08 & 16.15 & 18.29 & 3.30 \\
\hline \% Oxygen & - & - & 14.59 & - & 15.84 & - & 15.22 & 0.88 \\
\hline Hg (ppm) & 0.184 & 0.21 & 0.199 & 0.243 & 0.119 & 0.159 & 0.186 & 0.04 \\
\hline Cl (ppm) & 7.75 & 34.9 & 32.8 & 38.4 & 50.9 & 34.3 & 33.2 & 14.09 \\
\hline Br (ppm) & 9.63 & 9.8 & 9.74 & 9.1 & 10.3 & 10.4 & 9.8 & 0.47 \\
\hline F (ppm) & 35.8 & 49 & 92.1 & 74 & 57.2 & 39.9 & 58 & 21.54 \\
\hline \hline
\end{tabular}

Table H-2. Analyses of PRB Fired during Phase I Parametric Tests

\begin{tabular}{|l|c|c|c|c|c||}
\hline \multicolumn{1}{|c|}{ Coal Type } & PRB & PRB & PRB & Average & St Dev \\
\hline \hline Date & $12 / 1 / 2006$ & $12 / 2 / 2006$ & $12 / 9 / 2006$ & & \\
\hline Time & $10: 15$ & $10: 30$ & $10: 50$ & & \\
\hline \% Moisture & 30.38 & 31.16 & 29.71 & 30.42 & 0.73 \\
\hline Dry Basis: & & & & & \\
\hline Btu/lb & - & 11901 & 11667 & 11784 & 165 \\
\hline \% Carbon & - & 69.06 & 67.86 & 68.46 & 0.85 \\
\hline \% Hydrogen & - & 4.50 & 4.44 & 4.47 & 0.04 \\
\hline \% Nitrogen & - & 0.71 & 0.78 & 0.75 & 0.05 \\
\hline \% Sulfur & - & 0.42 & 0.67 & 0.55 & 0.18 \\
\hline \% Ash & - & 7.16 & 9.12 & 8.14 & 1.39 \\
\hline \% Oxygen & - & 18.15 & 17.13 & 17.64 & 0.72 \\
\hline Hg (ppm) & 0.104 & 0.116 & 0.143 & 0.121 & 0.020 \\
\hline Cl (ppm) & 12.1 & 20.2 & NR & 16.2 & 5.7 \\
\hline Br (ppm) & $<1$ & $<1$ & $<1$ & $<1$ & 0 \\
\hline F (ppm) & 61.8 & 70.5 & 68.6 & 67.0 & 4.6 \\
\hline \multicolumn{2}{|c|}{$\mathrm{NR}$ Not repted }
\end{tabular}

$\mathrm{NR}=$ Not reported, value measured was $138 \mathrm{ppm} \mathrm{Cl}$, which is an order of magnitude higher than any other known $\mathrm{Cl}$ value for $\mathrm{PRB}$ coal for this plant. 
Table H-3. Analyses of TxL Fired during Phase II Parametric Tests

\begin{tabular}{||l|c|c|c|c|c|c||}
\hline \hline Coal Type & TxL & TxL & TxL & TxL & Average & St Dev \\
\hline \hline Date & $4 / 19 / 2007$ & $4 / 19 / 2007$ & $4 / 20 / 2007$ & $4 / 20 / 2007$ & & \\
\hline Time & $14: 20$ & $14: 30$ & $13: 00$ & $13: 00$ & & \\
\hline \% Moisture & 33.16 & 32.47 & 32.34 & 32.63 & 32.65 & 0.36 \\
\hline Dry Basis: & & & & & & \\
\hline Btu/lb & 9965 & 10803 & 9105 & 10042 & 9979 & 695 \\
\hline \% Sulfur & 1 & 0.78 & 0.78 & 0.87 & 0.858 & 0.104 \\
\hline \% Ash & 19.74 & 13.8 & 27.24 & 20.33 & 20.278 & 5.499 \\
\hline Hg (ppm) & 0.156 & 0.132 & 0.175 & 0.237 & 0.175 & 0.045 \\
\hline Cl (ppm) & 36 & - & 47 & - & 40 & 10 \\
\hline Br (ppm) & 5.81 & - & 5.8 & - & 5.805 & 0.007 \\
\hline F (ppm) & 77 & - & 89.5 & - & 83.250 & 8.839 \\
\hline \hline
\end{tabular}

Table H-4. Analyses of PRB Fired during Phase II Parametric Tests

\begin{tabular}{|c|c|c|c|c||}
\hline Coal Type & PRB & PRB & Average & St Dev \\
\hline \hline Date & $4 / 19 / 2007$ & $4 / 20 / 2007$ & & \\
\hline Time & $14: 25$ & $13: 00$ & & \\
\hline \% Moisture & 31.89 & 31.47 & 31.68 & 0.30 \\
\hline Dry Basis: & & & & \\
\hline Btu/lb & 11301 & 11268 & 11285 & 23 \\
\hline \% Sulfur & 0.58 & 0.56 & 0.570 & 0.014 \\
\hline$\%$ Ash & 10.45 & 10.49 & 10.470 & 0.028 \\
\hline $\mathrm{Hg}(\mathrm{ppm})$ & 0.166 & 0.12 & 0.143 & 0.033 \\
\hline $\mathrm{Cl}(\mathrm{ppm})$ & 12 & 37 & 25 & 18 \\
\hline $\mathrm{Br}(\mathrm{ppm})$ & 4.99 & 4.64 & 4.815 & 0.247 \\
\hline $\mathrm{F}(\mathrm{ppm})$ & 77.9 & 43.2 & 60.550 & 24.537 \\
\hline
\end{tabular}


Table H-5. Analysis of TxL Fired during Long-Term Tests

\begin{tabular}{|c|c|c|c|c|c|c|c|c|c|c|}
\hline Coal Type & TxL & TxL & TxL & TxL & TxL & TxL & TxL & TxL & TxL & TxL \\
\hline Date & $6 / 20 / 2007$ & $6 / 20 / 2007$ & $6 / 21 / 2007$ & $6 / 21 / 2007$ & $6 / 25 / 2007$ & $6 / 29 / 2007$ & $7 / 3 / 2007$ & $7 / 5 / 2007$ & $7 / 5 / 2007$ & $7 / 8 / 2007$ \\
\hline Time & $22: 00$ & $22: 00$ & $22: 30$ & $22: 30$ & $22: 30$ & $21: 00$ & $16: 30$ & $16: 38$ & $16: 44$ & $0: 30$ \\
\hline$\%$ Moisture & 33.40 & 32.80 & 33.16 & 34.33 & 33.67 & 32.30 & 33.08 & 34.39 & 32.93 & 33.72 \\
\hline \multicolumn{11}{|l|}{ Dry Basis: } \\
\hline Heating Value, Dry Btu/lb & 9447 & 9580 & 9989 & 10003 & 10040 & 9392 & 9380 & 9859 & 9368 & 10635 \\
\hline$\%$ Carbon & - & - & - & - & 58.86 & - & 55.37 & - & - & 62.14 \\
\hline$\%$ Hydrogen & - & - & - & - & 5.05 & - & 4.73 & - & - & 5.19 \\
\hline$\%$ Nitrogen & - & - & - & - & 0.88 & - & 0.82 & - & - & 0.86 \\
\hline$\%$ Sulfur & 1.00 & 1.52 & 1.57 & 1.35 & 1.33 & 1.14 & 0.95 & 0.91 & 0.93 & 0.86 \\
\hline$\%$ Ash & 22.67 & 22.43 & 21.25 & 21.06 & 20.76 & 23.25 & 24.25 & 21.15 & 23.85 & 15.70 \\
\hline$\%$ Oxygen & - & - & - & - & 13.12 & - & 13.88 & - & - & 15.24 \\
\hline $\mathrm{Hg}(\mathrm{ppm})$ & 0.131 & 0.240 & 0.195 & 0.215 & 0.222 & 0.210 & 0.135 & 0.197 & 0.277 & 0.207 \\
\hline $\mathrm{Cl}(\mathrm{ppm})$ & - & - & - & - & $<5$ & - & $<5$ & - & - & 52 \\
\hline $\mathrm{Br}(\mathrm{ppm})$ & - & - & - & - & $<1.0$ & - & $<1.0$ & - & - & $<1.0$ \\
\hline $\begin{array}{l}\text { F-factor - dry scf/Mbtu, } \\
0 \% \mathrm{O} 2\end{array}$ & - & - & - & - & 10287 & - & 10256 & - & - & 10115 \\
\hline
\end{tabular}




\begin{tabular}{|c|c|c|c|c|c|c|c|c|c|c|}
\hline Coal Type & TxL & TxL & TxL & TxL & TxL & TxL & TxL & TxL & TxL & TxL \\
\hline Date & $7 / 9 / 2007$ & $7 / 9 / 2007$ & $7 / 11 / 2007$ & $7 / 11 / 2007$ & $7 / 19 / 2007$ & $7 / 22 / 2007$ & $7 / 22 / 2007$ & $7 / 25 / 2007$ & $7 / 27 / 2007$ & $7 / 27 / 2007$ \\
\hline Time & $16: 15$ & $16: 10$ & $16: 15$ & $16: 10$ & $8: 20$ & $0: 05$ & $0: 05$ & $15: 56$ & $22: 00$ & $22: 00$ \\
\hline$\%$ Moisture & 29.98 & 30.00 & 32.42 & 33.00 & 32.95 & 42.74 & 29.54 & 31.86 & 34.13 & 33.39 \\
\hline \multicolumn{11}{|l|}{ Dry Basis: } \\
\hline Heating Value, Dry Btu/lb & 11794 & 10001 & 10235 & 9780 & 10184 & 10422 & 10411 & 10097 & 9690 & 9643 \\
\hline$\%$ Carbon & - & - & - & - & 60.25 & - & - & 59.39 & - & - \\
\hline \% Hydrogen & - & - & - & - & 5.07 & - & - & 5.05 & - & - \\
\hline$\%$ Nitrogen & - & - & - & - & 0.92 & - & - & 0.84 & - & - \\
\hline$\%$ Sulfur & 0.89 & 1.18 & 1.23 & 0.94 & 1.04 & 0.97 & 0.92 & 1.24 & 1.15 & 1.11 \\
\hline$\%$ Ash & 27.85 & 21.21 & 18.80 & 20.22 & 19.47 & 17.43 & 16.94 & 20.31 & 22.73 & 23.35 \\
\hline$\%$ Oxygen & - & - & - & - & 13.25 & - & - & 13.16 & - & - \\
\hline $\mathrm{Hg}(\mathrm{ppm})$ & 0.174 & 0.288 & 0.300 & 0.270 & 0.179 & 0.196 & 0.155 & 0.154 & 0.221 & 0.199 \\
\hline $\mathrm{Cl}$ (ppm) & - & - & - & - & $<5$ & - & - & 37 & - & - \\
\hline $\mathrm{Br}(\mathrm{ppm})$ & - & - & - & - & $<1.0$ & - & - & $<1.0$ & - & - \\
\hline $\begin{array}{l}\text { F-factor - dry scf/Mbtu, } \\
0 \% \mathrm{O} 2\end{array}$ & - & - & - & - & 10336 & - & - & 10302 & - & - \\
\hline
\end{tabular}




\begin{tabular}{|c|c|c|c|c|c|c|c|c|c|}
\hline Coal Type & TxL & TxL & TxL & TxL & TxL & TxL & TxL & TxL & TxL \\
\hline Date & $7 / 29 / 2007$ & $7 / 29 / 2007$ & $8 / 7 / 2007$ & $8 / 9 / 2007$ & $8 / 9 / 2007$ & $8 / 15 / 2007$ & $8 / 15 / 2007$ & $8 / 17 / 2007$ & $8 / 17 / 2007$ \\
\hline Time & $22: 00$ & $22: 00$ & $7: 45$ & $8: 05$ & $8: 15$ & $7: 50$ & $7: 55$ & $22: 30$ & $22: 30$ \\
\hline$\%$ Moisture & 32.24 & 29.10 & 30.85 & 32.49 & 31.58 & 31.30 & 32.20 & 33.03 & 33.52 \\
\hline \multicolumn{10}{|l|}{ Dry Basis: } \\
\hline Heating Value, Dry Btu/lb & 9858 & 9897 & 9916 & 10178 & 9672 & 8808 & 9660 & 10814 & 10576 \\
\hline$\%$ Carbon & - & - & 57.48 & - & - & 51.82 & 57.20 & - & - \\
\hline$\%$ Hydrogen & - & - & 4.82 & - & - & 4.55 & 5.04 & - & - \\
\hline$\%$ Nitrogen & - & - & 0.85 & - & - & 0.73 & 0.82 & - & - \\
\hline$\%$ Sulfur & 0.94 & 0.95 & 1.04 & 1.41 & $5.79 *$ & 0.71 & 0.80 & 1.39 & 1.72 \\
\hline$\%$ Ash & 21.46 & 20.97 & 20.95 & 19.94 & 23.29 & 28.77 & 22.30 & 15.79 & 17.20 \\
\hline$\%$ Oxygen & - & - & 14.85 & - & - & 13.40 & 13.82 & - & - \\
\hline $\mathrm{Hg}(\mathrm{ppm})$ & 0.137 & 0.252 & 0.168 & 0.193 & 0.615 & 0.148 & 0.211 & 0.193 & 0.215 \\
\hline $\mathrm{Cl}(\mathrm{ppm})$ & - & - & 58 & - & - & 177 & 160 & - & - \\
\hline $\mathrm{Br}(\mathrm{ppm})$ & - & - & $<1.0$ & - & - & $<1.0$ & $<1.0$ & - & - \\
\hline $\begin{array}{l}\text { F-factor - dry scf/Mbtu, } \\
0 \% \mathrm{O} 2\end{array}$ & - & - & 10021 & - & - & 10239 & 10360 & - & - \\
\hline
\end{tabular}

* Value is not typical, and was disregarded in calculations. 


\begin{tabular}{||l|c|c|c|c|c||}
\hline \hline Coal Type & TxL & TxL & TxL & & \\
\hline \hline Date & $8 / 19 / 2007$ & $8 / 19 / 2007$ & $8 / 21 / 2007$ & Average & St Dev \\
\hline Time & $21: 30$ & $21: 30$ & $7: 10$ & & \\
\hline \% Moisture & 21.95 & 35.37 & 32.83 & $\mathbf{3 2 . 5 1}$ & $\mathbf{3 . 1 0}$ \\
\hline Dry Basis: & & & & & \\
\hline Heating Value, Dry Btu/lb & 10391 & 10214 & 10293 & $\mathbf{1 0 0 0 7}$ & $\mathbf{5 4 0}$ \\
\hline \% Carbon & - & - & 60.54 & $\mathbf{5 8 . 1 2}$ & $\mathbf{3 . 1 1}$ \\
\hline \% Hydrogen & - & - & 5.11 & $\mathbf{4 . 9 6}$ & $\mathbf{0 . 2 1}$ \\
\hline \% Nitrogen & - & - & 0.88 & $\mathbf{0 . 8 4}$ & $\mathbf{0 . 0 5}$ \\
\hline \% Sulfur & 1.02 & 0.99 & 0.94 & $\mathbf{1 . 2 5}$ & $\mathbf{0 . 8 9}$ \\
\hline \% Ash & 17.93 & 18.92 & 18.95 & $\mathbf{2 0 . 9 7}$ & $\mathbf{3 . 0 7}$ \\
\hline \% Oxygen & - & - & 13.57 & $\mathbf{1 3 . 8 1}$ & $\mathbf{0 . 7 6}$ \\
\hline Hg (ppm) & 0.178 & 0.225 & 0.224 & $\mathbf{0 . 2 2}$ & $\mathbf{0 . 0 9}$ \\
\hline Cl (ppm) & - & - & 36 & $\mathbf{5 9}$ & $\mathbf{6 5}$ \\
\hline Br (ppm) & - & - & $<1.0$ & $\mathbf{1}$ & $\mathbf{0}$ \\
\hline $\begin{array}{l}\text { F-factor }- \text { dry scf/Mbtu, } \\
\text { 0\% O2 }\end{array}$ & - & - & 10264 & $\mathbf{1 0 2 4 2}$ & $\mathbf{1 0 8}$ \\
\hline \hline
\end{tabular}


Table H-6. Analysis of PRB Fired during Long Term Tests

\begin{tabular}{|c|c|c|c|c|c|c|c|c|c|c|}
\hline Coal Type & PRB & PRB & PRB & PRB & PRB & PRB & PRB & PRB & PRB & PRB \\
\hline Date & $6 / 20 / 2007$ & $6 / 21 / 2007$ & $6 / 25 / 2007$ & $6 / 27 / 2007$ & $6 / 29 / 2007$ & $6 / 29 / 2007$ & $7 / 3 / 2007$ & $7 / 5 / 2007$ & $7 / 8 / 2007$ & $7 / 9 / 2007$ \\
\hline Time & $22: 00$ & $22: 30$ & $22: 30$ & $15: 55$ & $21: 00$ & $21: 00$ & $16: 40$ & $16: 46$ & $0: 30$ & $16: 05$ \\
\hline$\%$ Moisture & 30.57 & 31.11 & 33.39 & 32.91 & 34.18 & 32.20 & 33.08 & 32.96 & 30.17 & 31.78 \\
\hline \multicolumn{11}{|l|}{ Dry Basis: } \\
\hline Btu/lb & 11653 & 11816 & 11718 & 11792 & 11209 & 11732 & 11572 & 11559 & 11458 & 11602 \\
\hline$\%$ Carbon & - & - & 68.59 & - & - & - & 67.39 & - & 67.16 & - \\
\hline$\%$ Hydrogen & - & - & 5.49 & - & - & - & 4.75 & - & 5.47 & - \\
\hline$\%$ Nitrogen & - & - & 0.72 & - & - & - & 0.82 & - & 0.74 & - \\
\hline$\%$ Sulfur & 0.70 & 0.58 & 0.61 & 0.53 & 0.74 & 0.50 & 0.53 & 0.60 & 0.59 & 0.54 \\
\hline$\%$ Ash & 7.06 & 7.02 & 7.63 & 7.44 & 10.97 & 8.10 & 9.72 & 9.00 & 9.66 & 8.84 \\
\hline$\%$ Oxygen & - & - & 16.96 & - & - & - & 16.79 & - & 16.38 & - \\
\hline $\mathrm{Hg}(\mathrm{ppm})$ & 0.097 & 0.075 & 0.153 & 0.067 & 0.105 & 0.130 & 0.083 & 0.081 & 0.096 & 0.111 \\
\hline $\mathrm{Cl}(\mathrm{ppm})$ & - & - & 6 & - & - & - & $<5$ & - & $<5$ & - \\
\hline $\mathrm{Br}(\mathrm{ppm})$ & - & - & $<1.0$ & - & - & - & $<1.0$ & - & $<1.0$ & - \\
\hline $\begin{array}{l}\text { F-factor - dry scf/Mbtu, } \\
0 \% \mathrm{O} 2\end{array}$ & - & - & 10033 & - & - & - & 9772 & - & 10086 & - \\
\hline
\end{tabular}




\begin{tabular}{|c|c|c|c|c|c|c|c|c|c|c|}
\hline Coal Type & PRB & PRB & PRB & PRB & PRB & PRB & PRB & PRB & PRB & PRB \\
\hline Date & $7 / 11 / 2007$ & $7 / 19 / 2007$ & $7 / 22 / 2007$ & $7 / 25 / 2007$ & $7 / 27 / 2007$ & $7 / 29 / 2007$ & $8 / 7 / 2007$ & $8 / 9 / 2007$ & $8 / 17 / 2007$ & $8 / 19 / 2007$ \\
\hline Time & $16: 18$ & $8: 10$ & $0: 05$ & $15: 51$ & $22: 00$ & $22: 00$ & $7: 40$ & $8: 10$ & $22: 30$ & $21: 30$ \\
\hline$\%$ Moisture & 30.27 & 32.65 & 32.68 & 31.76 & 34.80 & 30.87 & 29.10 & 32.35 & 49.60 & 31.85 \\
\hline \multicolumn{11}{|l|}{ Dry Basis: } \\
\hline Btu/lb & 11770 & 11794 & 12326 & 10257 & 11748 & 11880 & 11906 & 11581 & 11793 & 11771 \\
\hline$\%$ Carbon & - & 69.14 & - & 69.08 & - & - & 69.52 & - & - & - \\
\hline$\%$ Hydrogen & - & 5.50 & - & 5.56 & - & - & 5.47 & - & - & - \\
\hline$\%$ Nitrogen & - & 0.71 & - & 0.72 & - & - & 0.71 & - & - & - \\
\hline$\%$ Sulfur & 0.48 & 0.53 & 0.53 & 0.57 & 0.50 & 0.52 & 0.45 & 0.60 & 0.54 & 0.58 \\
\hline$\%$ Ash & 6.39 & 7.42 & 8.65 & 7.36 & 7.70 & 6.59 & 6.45 & 8.29 & 8.69 & 7.23 \\
\hline$\%$ Oxygen & - & 16.70 & - & 16.70 & - & - & 17.39 & - & - & - \\
\hline $\mathrm{Hg}(\mathrm{ppm})$ & 0.059 & 0.090 & 0.104 & 0.097 & 0.102 & 0.072 & 0.098 & 0.067 & 0.087 & 0.095 \\
\hline $\mathrm{Cl}(\mathrm{ppm})$ & - & $<5$ & - & 84 & - & - & 44 & - & - & - \\
\hline $\mathrm{Br}(\mathrm{ppm})$ & - & $<1.0$ & - & $<1.0$ & - & - & $<1.0$ & - & - & - \\
\hline $\begin{array}{l}\text { F-factor - dry scf/Mbtu, } \\
0 \% \mathrm{O} 2\end{array}$ & - & 10049 & - & 11570 & - & - & 9964 & - & - & - \\
\hline
\end{tabular}




\begin{tabular}{||l|c|c|c||}
\hline Coal Type & PRB & PRB & PRB \\
\hline \hline Date & $8 / 21 / 2007$ & Average & St Dev \\
\hline Time & $7: 15$ & & \\
\hline \% Moisture & 30.87 & $\mathbf{3 2 . 8 2}$ & $\mathbf{4 . 2 5}$ \\
\hline Dry Basis: & & & \\
\hline Btu/lb & 11557 & $\mathbf{1 1 6 4 3}$ & $\mathbf{4 0 0}$ \\
\hline \% Carbon & 67.72 & $\mathbf{6 8 . 3 7}$ & $\mathbf{0 . 9 4}$ \\
\hline \% Hydrogen & 5.56 & $\mathbf{5 . 4 0}$ & $\mathbf{0 . 2 9}$ \\
\hline \% Nitrogen & 0.79 & $\mathbf{0 . 7 4}$ & $\mathbf{0 . 0 4}$ \\
\hline \% Sulfur & 0.57 & $\mathbf{0 . 5 6}$ & $\mathbf{0 . 0 6}$ \\
\hline \% Ash & 9.41 & $\mathbf{8 . 0 8}$ & $\mathbf{1 . 2 3}$ \\
\hline \% Oxygen & 15.95 & $\mathbf{1 6 . 7 0}$ & $\mathbf{0 . 4 5}$ \\
\hline Hg (ppm) & 0.134 & $\mathbf{0 . 1 0}$ & $\mathbf{0 . 0 2}$ \\
\hline Cl (ppm) & $<5$ & $\mathbf{2 2}$ & $\mathbf{3 1}$ \\
\hline Br (ppm) & $<1.0$ & $<1.0$ & $\mathbf{0 . 0}$ \\
\hline F-factor - dry scf/Mbtu, 0\% O2 & 10119 & $\mathbf{1 0 2 2 8}$ & $\mathbf{6 0 3}$ \\
\hline \hline
\end{tabular}


APPENDIX I - CONCRETE ANALYTICAL RESULTS 
The following paragraphs describe and procedures for the foam index testing conduscted by URS.

The foam index test is a titration used to indicate the air entrainment additive (AEA) adsorptive capacity of carbon present in the fly ash. In this test, a fly ash samples are titrated to a stable foam point using air entrainment additive (AEA). URS uses Grace Construction Product's Daravair 1000 diluted to a $1 \%$ solids concentration for titrating. There are two types of foam index tests that URS performs. The first type is "full-scale" and uses fly ash that was collected at field sites during activated carbon injection testing. The second type is "bench-scale" and uses baseline fly ash and activated carbon that is mixed in appropriate amounts to simulate activated carbon injection rates.

\section{Materials and Apparatus}

- De-ionized water

- 1\% solids vinsol rosin solution made fresh daily from Daravair 1000 (see below)

- Auto pipettor (calibrated to deliver $25 \mu \mathrm{L}$ drops - see below)

- Portland cement

- Fly ash sample

- Powdered activated carbon (if performing bench-scale addition tests)

\section{Health and Safety}

- Vinsol rosin is a skin irritant. Prolonged skin contact can result in burns.

-Will cause eye burns if eye contact occurs

- Nitrile gloves required

- Safety glasses required (goggles recommended)

- Lab coat or long sleeves required

- All waste and rinses containing vinsol rosin, Portland cement, or vinsol rosin must be disposed of in approved 55-gallon drum located in lab D-119.

- Notify lab manager when 55 -gallon drum is $3 / 4$ full.

\section{Quality Control and Verification}

- Pipettor will be calibrated daily to achieve a $25 \mu \mathrm{L}$ drop.

- $1 \%$ solids vinsol resin solution will be replaced once per week as needed.

- Jars/lids will be kept clean and free of cracks or will be replaced.

-Each new batch of $1 \%$ vinsol solution should produce the following results with Baldwin baseline fly ash (average of three trials): $4 \pm 1$ drops. 


\section{Notes and Helpful Suggestions}

- All tests should be completed in triplicate.

- It is easiest to weigh out all fly ash/carbon/cement for a batch of tests first and then start the titrations.

- Record all times, drops and data on the foam index data sheets.

- Waste from all tests should be disposed of in 55-gallon drum labeled for foam index waste. All jars/graduated cylinders/flasks should be rinsed thoroughly and rinses be added to the 55-gallon drum.

\section{How to make a 1\% Vinsol Rosin solution}

1. Use a glass graduated cylinder to measure $9.5 \pm 0.1 \mathrm{~mL}$ of Daravair 1000 .

2. Pour the $9.5 \pm 0.1 \mathrm{~mL}$ of Daravair 1000 into a $50 \mathrm{~mL}$ volumetric flask.

3. Use DI $\mathrm{H}_{2} \mathrm{O}$ to rinse the graduated cylinder three times and pour into the flask with the Daravair 1000. Fill the volumetric flask to the $50 \mathrm{~mL}$ line.

4. Shake flask to mix well.

5. Rinse the graduated cylinder with vinsol rosin at least three more time with DI $\mathrm{H}_{2} \mathrm{O}$ and pour into the 55-gallon drum labeled for foam index waste.

\section{Procedure 1 - Full-scale Foam Index Test:}

1. Place $6 \mathrm{~g} \pm 0.1 \mathrm{~g}$ fly ash in a clean dry jar.

2. Place $24 \mathrm{~g} \pm 0.1 \mathrm{~g}$ Portland cement into jar.

3. Add $70 \mathrm{~g} \pm 0.1 \mathrm{~g}$ DI water to the fly ash/cement mixture. Immediately close the cap tightly and shake the mixture for 20 second with a firm, consistent motion.

4. Record time when step 5 is started on jar.

5. Remove cap and add 1 drop of $1 \%$ vinsol solution to the fly ash/cement/water mixture. Immediately close cap and tightly and shake the mixture for 20 seconds with a firm and consistent motion.

6. Remove the cap and observe the surface of the mixture for foam. If there is no foam, repeat step 6 using 1 drop increments. Continue to repeat step 5 until foam covers entire surface of mixture and is stable for 30 seconds. It is very important to keep track of the number of drops added to the mixture.

7. When foam covers the entire surface of the mixture and is stable for 30 seconds, shake the mixture for an additional 20 seconds. If the foam remains stable and covers the entire surface after 60 seconds, the endpoint has been achieved. If foam is not stable, repeat step 5 until foam is stable for 60 seconds.

8. Record time and total number of drops used.

Step 9 - Optional Modified Step

9. Let glass jar sit until foam is no longer stable. Record time when foam is no longer stable. 


\section{Procedure 2 - Bench-scale Foam Index Test:}

1. Place $\mathrm{X} \mathrm{g} \pm 0.1 \mathrm{~g}$ baseline fly ash in a clean dry jar. $\mathrm{X}$ is determined from foam index test matrix.

2. Place $\mathrm{Xg} \pm 0.1 \mathrm{~g}$ designated activated carbon into jar. $\mathrm{X}$ is determine from foam index test matrix.

3. Place $24 \mathrm{~g} \pm 0.1 \mathrm{~g}$ Portland cement into jar.

4. Add $70 \mathrm{~g} \pm 0.1 \mathrm{~g}$ DI water to the fly ash/cement mixture. Immediately close the cap tightly and shake the mixture for 20 second with a firm, consistent motion.

5. Record time when step 6 is started on jar.

6. Remove cap and add 1 drop of $1 \%$ vinsol solution to the fly ash/cement/water mixture. Immediately close cap and tightly and shake the mixture for 20 seconds with a firm and consistent motion.

7. Remove the cap and observe the surface of the mixture for foam. If there is no foam, repeat step 6 using 1 drop increments. Continue to repeat step 6 until foam covers entire surface of mixture and is stable for 30 seconds. It is very important to keep track of the number of drops added to the mixture.

8. When foam covers the entire surface of the mixture and is stable for 30 seconds, shake the mixture for an additional 20 seconds. If the foam remains stable and covers the entire surface after 60 seconds, the endpoint has been achieved. If foam is not stable, repeat step 6 until foam is stable for 60 seconds.

9. Record time on jar and total number of drops used in book.

Step 10 - Optional Modified Step

10. Let glass jar sit until foam is no longer stable. Record time when foam is no longer stable.

The following paragraphs detail the foam index testing procedure used by Headwaters.

\section{Purpose}

The following specification is set forth to maintain consistency and guidelines for performing the aforementioned test. This procedure is not drawn from a published ASTM procedure and is the standard operating procedure for this facility. The Area Q.C. Coordinators will determine frequency of testing.

\section{Equipment}

MB-VR air entraining agent (AEA)

Type I or Type II water as defined by ASTM

D1193, 11.01

Hamilton Beach Blender, 10 speed with glass canister

Disposable 10cc slip tip syringes, Fisher catalog \#14-826-13

\section{Procedure}

1. All samples should be dried prior to analysis.
$250 \mathrm{~mL}$ graduated

cylinder

$100 \mathrm{~mL}$ graduated

cylinder

Scale reading to $0.1 \mathrm{~g}$

Stopwatch 
2. Make a 1:4 dilution** of MB-VR by diluting $20 \mathrm{~mL}$ of AEA with $80 \mathrm{~mL}$ of water.

3. Place $200 \mathrm{~mL}$ of water into Hamilton Beach Blender. Add $80.0 \mathrm{~g}$ of Class F fly ash to be tested. For Class C fly ash, use $40.0 \mathrm{~g}$.

4. Mix the solution for 10 seconds on the "Blend" speed. (Blender will have the "HI" button depressed. Then, pushing the "Blend" button to turn on the blender.) Turn off the blender.

5. Remove the blender lid. Ensure that there are no air pockets between the tip of the dropper and the AEA. Add drops of diluted AEA. The starting point for the drops should be at least one drop less than the anticipated number of drops. If stable foam is obtained with the first amount, of AEA added, repeat the test using less AEA.

6. Replace the blender lid and mix on the "Blend" speed for 10 seconds. Remove the lid and view the stability of the foam.

7. Repeat steps 5 and 6 until enough AEA is present to produce a solid layer of air bubbles on top of the solution. This means that no windows appear from bubbles that have popped. There is no time limit for the layer to remain intact.

8. When stable foam has been achieved, replace the blender lid and mix for an additional 10 seconds.

9. If the foam remains stable, record the amount of AEA required to produce the layer of bubbles. If any windows appear, repeat steps 5 through 7 until the foam remains stable after step 8 . 
Table I-1. Headwaters Concrete Results Using Ash from Long-Term Injection; Individual Cylinder 7-Day Compressive Strength

\begin{tabular}{||c|c|c|c||}
\hline \multirow{2}{*}{} & \multicolumn{3}{|c||}{$\begin{array}{c}\text { 7-Day Compressive Strength } \\
\text { (psi of unconfined compressive strength) }\end{array}$} \\
\cline { 2 - 4 } & $\begin{array}{c}\text { Control with } \\
\text { Portland Cement } \\
\text { (no ash) }\end{array}$ & $\begin{array}{c}\text { Untreated Ash } \\
\text { Truck Sample }\end{array}$ & Multi-Field Blend* \\
\cline { 2 - 4 } & $10 / 30 / 2007$ & $6 / 26 / 2007$ & $7 / 9 / 07 \& 8 / 2 / 07$ \\
\hline \hline Cylinder 1 & 3938 & 3745 & 3526 \\
\hline Cylinder 2 & 3948 & 3660 & 3729 \\
\hline Cylinder 3 & 4162 & 3734 & 3734 \\
\hline Average & 4016 & 3713 & 3663 \\
\hline \hline
\end{tabular}

* Blended sample made by blending 50:50 first field samples from hoppers 1A and 2A collected on 7/9/07. Ash from hopper 1F3A on 7/9/07 was not used due to its coarseness. This 50:50 blend was then mixed 80:20 with Field 3F3A from 8/2/07 to give a final blend of hoppers used to prepare concrete mixes. No first field ash from 8/2/07 was used because plant went to all PRB before it could be collected.

** Reported average of three individual cylinders. See Appendix for the individual cylinder results. 
Table I-2. First Field Long Term Concrete Data Unit 1 A-Side (Treated Duct), from LMS Lab

\begin{tabular}{|c|c|c|c|c|c|c|c|c|c|}
\hline \multirow[b]{2}{*}{ Date } & \multicolumn{3}{|c|}{ 1F1A } & \multicolumn{3}{|c|}{ 1F2A } & \multicolumn{3}{|c|}{ 1F3A } \\
\hline & $\begin{array}{c}\text { Foam } \\
\text { Index } \\
\text { (Drops } \\
\text { AEA) } \\
\end{array}$ & $\begin{array}{l}\text { LOI } \\
(\%) \\
\end{array}$ & $\begin{array}{c}\geq 325 \\
\text { Mesh } \\
(\%) \\
\end{array}$ & $\begin{array}{c}\text { Foam } \\
\text { Index } \\
\text { (Drops } \\
\text { AEA) } \\
\end{array}$ & $\begin{array}{l}\text { LOI } \\
(\%) \\
\end{array}$ & $\begin{array}{c}\geq 325 \\
\text { Mesh } \\
(\%) \\
\end{array}$ & $\begin{array}{l}\text { Foam } \\
\text { Index } \\
\text { (Drops } \\
\text { AEA) } \\
\end{array}$ & $\begin{array}{l}\text { LOI } \\
(\%) \\
\end{array}$ & $\begin{array}{c}325 \\
\text { Mesh } \\
(\%) \\
\end{array}$ \\
\hline \multicolumn{10}{|l|}{ Baseline } \\
\hline $6 / 18 / 2007$ & 4 & 0.10 & 23.4 & 4 & 0.11 & 18.42 & 4 & 0.14 & 20.9 \\
\hline $6 / 22 / 2007$ & 5 & - & - & 5 & - & - & 4 & - & - \\
\hline \multicolumn{10}{|c|}{ Long Term } \\
\hline $6 / 25 / 2007$ & 14 & 0.66 & 25.9 & 12 & 0.46 & 25.45 & 13 & 0.74 & 33.1 \\
\hline $7 / 9 / 2007$ & 12 & 0.42 & 29.9 & 11 & 0.37 & 26.17 & 15 & 0.21 & 83.7 \\
\hline $7 / 20 / 2007$ & 8 & 0.25 & 27.0 & 12 & 0.36 & 19.12 & - & - & - \\
\hline $7 / 25 / 2007$ & 14 & 0.47 & 23.8 & 13 & 0.46 & 24.54 & 7 & 0.19 & 52.9 \\
\hline $7 / 27 / 2007$ & 10 & 0.44 & 29.3 & 11 & 0.41 & 26.43 & - & - & - \\
\hline $7 / 31 / 2007$ & 9 & 0.24 & 34.3 & 10 & 0.28 & 30.67 & - & - & - \\
\hline $8 / 3 / 2007$ & 19 & 1.03 & 20.9 & 19 & 0.85 & 19.92 & 10 & 0.77 & 33.0 \\
\hline $8 / 7 / 2007$ & 11 & 0.47 & 32.8 & 9 & 0.44 & 26.38 & 8 & 0.43 & 36.8 \\
\hline $8 / 10 / 2007$ & 15 & 0.41 & 27.0 & 14 & 0.47 & 26.75 & 10 & 0.36 & 42.7 \\
\hline $8 / 13 / 2007$ & 10 & 0.37 & 43.8 & 10 & 0.43 & 37.39 & 12 & 0.50 & 38.9 \\
\hline $8 / 17 / 2007$ & 12 & 0.40 & 21.5 & 12 & 0.59 & 24.72 & 8 & 0.37 & 48.1 \\
\hline
\end{tabular}


Table I-3. First Field Long Term Concrete LMS Data Unit 1 B-Side (Untreated Duct).

\begin{tabular}{|c|c|c|c|c|c|c|c|c|c|}
\hline \multirow[b]{2}{*}{ Date } & \multicolumn{3}{|c|}{ 1F1B } & \multicolumn{3}{|c|}{ 1F2B } & \multicolumn{3}{|c|}{ 1F3B } \\
\hline & $\begin{array}{c}\text { Foam } \\
\text { Index } \\
\text { (Drops } \\
\text { AEA) }\end{array}$ & $\begin{array}{c}\text { LOI } \\
(\%)\end{array}$ & $\begin{array}{c}325 \\
\text { Mesh } \\
(\%) \\
\end{array}$ & $\begin{array}{c}\text { Foam } \\
\text { Index } \\
\text { (Drops } \\
\text { AEA) }\end{array}$ & $\begin{array}{c}\text { LOI } \\
(\%)\end{array}$ & $\begin{array}{c}\mathbf{3 2 5} \\
\text { Mesh } \\
\\
(\%) \\
\end{array}$ & $\begin{array}{c}\text { Foam } \\
\text { Index } \\
\text { (Drops } \\
\text { AEA) }\end{array}$ & $\begin{array}{c}\text { LOI } \\
(\%)\end{array}$ & $\begin{array}{c}\mathbf{3 2 5} \\
\text { Mesh } \\
\\
(\%) \\
\end{array}$ \\
\hline \multicolumn{10}{|c|}{ Long Term } \\
\hline $7 / 2 / 2007$ & 4 & 0.27 & 28.12 & 4 & 0.21 & 22.12 & 4 & 0.23 & 30.35 \\
\hline $7 / 9 / 2007$ & 4 & 0.19 & 30.93 & 4 & 0.18 & 30.86 & 3 & 0.12 & 27.26 \\
\hline $7 / 20 / 2007$ & 4 & 0.05 & 21.13 & 4 & 0.07 & 19.16 & 3 & 0.09 & 19.45 \\
\hline $7 / 27 / 2007$ & 4 & 0.12 & 25.54 & 5 & 0.18 & 21.8 & 4 & 0.08 & 21.99 \\
\hline $8 / 3 / 2007$ & 6 & 0.31 & 26.15 & 7 & 0.27 & 19.13 & 6 & 0.1 & 21.08 \\
\hline $8 / 10 / 2007$ & 4 & 0.15 & 21.8 & 4 & 0.15 & 19.6 & 4 & 0.1 & 24.64 \\
\hline $8 / 17 / 2007$ & 5 & 0.09 & 21.71 & 4 & 0.15 & 21.5 & 4 & 0.16 & 19.62 \\
\hline
\end{tabular}

\section{Petrographic Analysis Report}

Per agreement with the subcontractor, Domnion Consulting, the entire report from the sub-contractor is included below. URS has included the note the sample 1493LS represents $1.89 \mathrm{lb} / \mathrm{Macf}, 1495 \mathrm{LS}$ represents $0.99 \mathrm{lb} / \mathrm{Macf}$, and 1496LS represents 1.00 lb/Macf.

We received three longitudinally sawn pieces of 4 by 8 inch concrete cylinders from you on February 2, 2010 identified as 1493LS, 1495LS and 1496LS. Cylinders were fabricated on November 4, 2009. Parameters of the air-void system requested are listed in the table below:

Table I-4. Petrographic Analysis of Concrete Samples with ACI

\begin{tabular}{|c|c|c|c|c|c|c|c|}
\hline Sample & $\begin{array}{c}\text { Length of } \\
\text { Traverse } \\
\text { inches (mm) }\end{array}$ & $\begin{array}{c}\text { Area } \\
\text { Traversed } \\
\text { sq in (sq cm) }\end{array}$ & $\begin{array}{c}\text { Total } \\
\text { Stops }\end{array}$ & $\begin{array}{c}\text { Paste-Air } \\
\text { Ratio } \\
\mathrm{p} / \mathrm{A}\end{array}$ & $\begin{array}{c}\text { Specific } \\
\text { Surface } \\
\alpha \text { in }^{-1}\left(\mathrm{~mm}^{-1}\right)\end{array}$ & $\begin{array}{c}\text { Spacing } \\
\text { Factor } \\
\text { L in (mm) }\end{array}$ & $\begin{array}{c}\text { Air } \\
\text { Voids } \\
(\%)\end{array}$ \\
\hline 1493LS & $105(2667)$ & $26(168)$ & 1750 & 2.20 & $595(23)$ & $0.004(0.094)$ & $\mathbf{1 0 . 8 6}$ \\
\hline 1495LS & $105(2667)$ & $26(168)$ & 1750 & 3.13 & $623(24)$ & $0.005(0.127)$ & $\mathbf{9 . 7 2}$ \\
\hline 1496LS & $105(2667)$ & $26(168)$ & 1750 & 3.45 & $658(25)$ & $0.005(0.127)$ & $\mathbf{9 . 0 8}$ \\
\hline
\end{tabular}

*1493LS- 1.89 lb/MAcf, 1495LS 0.99 lb/Macf, 1496LS 1.00 lb/Macf

The original sawed surface of each sample was lapped, placed on a two-way stage, and moved through a pre-determined grid pattern noting the presence of aggregate, paste or air-voids at each calibrated stop. The Modified Point-Count (Method B) was used to perform this examination at a magnification of $50 \mathrm{X}$.

The above observations and comments specifically apply to the samples as received for examination and analysis. Samples will be retained in our storage facility for three months than discarded unless other arrangements have been made. This report may be copied only in its entirety without prior written approval from this office. Please call or email us if you have any questions concerning this report or need additional information. 
APPENDIX J PROCESS PARAMETERS FOR UNIT 2 
Table J-1. Parametric Phase IV Unit 2 Hourly Average Process Data

\begin{tabular}{|c|c|c|c|c|c|c|c|c|c|c|c|c|c|c|c|c|c|c|}
\hline $\begin{array}{l}\text { Start } \\
\text { Date/ } \\
\text { Time }\end{array}$ & $\begin{array}{l}\text { End } \\
\text { Date/ } \\
\text { Time }\end{array}$ & $\begin{array}{l}\text { Gross } \\
\text { Load }\end{array}$ & $\begin{array}{c}\text { Gross } \\
\text { HR }\end{array}$ & $\begin{array}{c}\text { A } \\
\text { Econ } \\
\text { O2 }\end{array}$ & $\begin{array}{c}\text { B } \\
\text { Econ } \\
\text { O2 }\end{array}$ & $\begin{array}{l}\text { Fuel } \\
\text { Flow }\end{array}$ & $\begin{array}{l}\text { BTU } \\
\text { Gain }\end{array}$ & $\begin{array}{c}\text { A } \\
\text { APH } \\
\text { In }\end{array}$ & $\begin{array}{c}\text { B } \\
\text { APH } \\
\text { In }\end{array}$ & $\begin{array}{c}\text { A } \\
\text { APH } \\
\text { Out }\end{array}$ & $\begin{array}{c}\text { B } \\
\text { APH } \\
\text { Out }\end{array}$ & $\begin{array}{l}\text { Stack } \\
\text { Flow }\end{array}$ & Opacity & SO2 In & $\begin{array}{l}\text { SO2 } \\
\text { Out }\end{array}$ & $\mathrm{CO}$ & $\begin{array}{c}\text { Stack } \\
\text { SCEM } \\
\text { Elemental } \\
\mathrm{Hg} \\
\end{array}$ & $\begin{array}{c}\text { Stack } \\
\text { SCEM } \\
\text { Total Hg }\end{array}$ \\
\hline & & MW & Btu/kWh & $\%$ & $\%$ & Ton/hr & & DEGF & DEGF & DEGF & DEGF & KSCF & $\%$ & Ib/MMB & $\mathrm{Ib} / \mathrm{MMb}$ & PPM & $\begin{array}{c}(\mu \mathrm{g} / \mathrm{dNm} 3) \\
@ 3 \% 02\end{array}$ & $\begin{array}{c}(\mu \mathrm{g} / \mathrm{dNm} 3) \\
@ 3 \% 02\end{array}$ \\
\hline $\begin{array}{r}6 / 11 / 2009 \\
0: 00\end{array}$ & $\begin{array}{r}/ 11 / 2009 \\
1: 00\end{array}$ & 879.7 & 8080.5 & 3.0 & 2.2 & 592.2 & 1.1 & 766.1 & 757.4 & 312.9 & 307.8 & 2280.2 & 10.4 & 1.5 & 0.4 & 28.4 & 11.0 & 12.7 \\
\hline $\begin{array}{r}6 / 11 / 2009 \\
1: 00 \\
\end{array}$ & $\begin{array}{r}6 / 11 / 2009 \\
2: 00 \\
\end{array}$ & 820.9 & 8056.6 & 3.0 & 2.3 & 550.5 & 1.1 & 748.2 & 740.3 & 311.9 & 307.7 & 2145.2 & 9.7 & 1.6 & 0.4 & 25.4 & 10.6 & 12.3 \\
\hline $\begin{array}{r}6 / 11 / 2009 \\
2: 00\end{array}$ & $\begin{array}{r}6 / 11 / 2009 \\
3: 00\end{array}$ & 790.3 & 8061.5 & 3.0 & 2.4 & 534.5 & 1.1 & 730.7 & 722.4 & 302.3 & 299.1 & 2067.6 & 8.7 & 1.5 & 0.4 & 13.4 & 10.2 & 11.8 \\
\hline $\begin{array}{r}6 / 11 / 2009 \\
3: 00\end{array}$ & $\begin{array}{r}6 / 11 / 2009 \\
4: 00\end{array}$ & 788.9 & 8066.6 & 2.9 & 2.3 & 537.6 & 1.1 & 733.5 & 726.0 & 299.0 & 295.7 & 2055.0 & 8.7 & 1.5 & 0.4 & 10.8 & 10.2 & 11.8 \\
\hline $\begin{array}{r}6 / 11 / 2009 \\
4: 00\end{array}$ & $\begin{array}{r}6 / 11 / 2009 \\
5: 00\end{array}$ & 782.7 & 8069.1 & 2.9 & 2.4 & 530.3 & 1.1 & 735.9 & 727.7 & 299.0 & 295.8 & 2030.1 & 8.6 & 1.5 & 0.4 & 10.4 & \#N/A & \#N/A \\
\hline $\begin{array}{r}6 / 11 / 2009 \\
5: 00 \\
\end{array}$ & $\begin{array}{r}6 / 11 / 2009 \\
6: 00 \\
\end{array}$ & 764.5 & 8069.1 & 3.0 & 2.4 & 524.8 & 1.1 & 732.1 & 722.8 & 297.9 & 293.6 & 2072.2 & 7.6 & 1.5 & 0.4 & 7.3 & $\# \mathrm{~N} / \mathrm{A}$ & \#N/A \\
\hline $\begin{array}{r}6 / 11 / 2009 \\
6: 00\end{array}$ & $\begin{array}{r}6 / 11 / 2009 \\
7: 00\end{array}$ & 875.2 & 8069.1 & 3.0 & 2.4 & 590.7 & 1.1 & 764.0 & 754.2 & 294.8 & 293.4 & 2332.8 & 8.7 & 1.5 & 0.4 & 23.4 & $\# \mathrm{~N} / \mathrm{A}$ & $\# N / A$ \\
\hline $\begin{array}{r}6 / 11 / 2009 \\
7: 00 \\
\end{array}$ & $\begin{array}{r}6 / 11 / 2009 \\
8: 00 \\
\end{array}$ & 905.3 & 8069.1 & 2.9 & 2.4 & 613.0 & 1.1 & 779.6 & 765.9 & 300.1 & 300.2 & 2376.7 & 8.7 & 1.5 & 0.4 & 30.8 & 11.6 & 13.2 \\
\hline $\begin{array}{r}6 / 11 / 2009 \\
8: 00 \\
\end{array}$ & $\begin{array}{r}6 / 11 / 2009 \\
9: 00 \\
\end{array}$ & 869.2 & 8069.1 & 2.9 & 2.3 & 589.7 & 1.1 & 776.9 & 763.5 & 305.7 & 304.2 & 2112.3 & 8.1 & 1.5 & 0.4 & 28.6 & 11.9 & 13.4 \\
\hline $\begin{array}{r}6 / 11 / 2009 \\
9: 00\end{array}$ & $\begin{array}{r}6 / 11 / 2009 \\
10: 00\end{array}$ & 786.0 & 8069.1 & 2.9 & 2.3 & 534.3 & 1.1 & 754.8 & 739.8 & 312.8 & 310.8 & 2051.7 & 7.2 & 1.5 & 0.4 & 11.8 & 11.9 & 14.1 \\
\hline $\begin{array}{r}6 / 11 / 2009 \\
10: 00\end{array}$ & $\begin{array}{r}6 / 11 / 2009 \\
11: 00\end{array}$ & 751.6 & 8069.1 & 3.0 & 2.3 & 509.1 & 1.1 & 743.4 & 727.6 & 309.2 & 305.7 & 2017.8 & 6.9 & 1.5 & 0.5 & 7.8 & 9.7 & 13.4 \\
\hline $\begin{array}{r}6 / 11 / 2009 \\
11: 00\end{array}$ & $\begin{array}{r}6 / 11 / 2009 \\
12: 00\end{array}$ & 690.2 & 8069.1 & 3.2 & 2.5 & 470.2 & 1.1 & 727.5 & 713.2 & 305.7 & 296.9 & 1918.9 & 6.8 & 1.5 & 0.4 & 5.1 & 9.5 & 12.7 \\
\hline $\begin{array}{r}6 / 11 / 2009 \\
12: 00 \\
\end{array}$ & $\begin{array}{r}6 / 11 / 2009 \\
13: 00 \\
\end{array}$ & 722.8 & 8069.1 & 3.1 & 2.3 & 503.1 & 1.1 & 726.6 & 718.6 & 307.2 & 299.3 & 2001.4 & 7.2 & 1.5 & 0.4 & 6.4 & 9.9 & 12.4 \\
\hline $\begin{array}{r}6 / 11 / 2009 \\
13: 00 \\
\end{array}$ & $\begin{array}{r}6 / 11 / 2009 \\
14: 00 \\
\end{array}$ & 644.4 & 8069.1 & 3.7 & 3.0 & 429.7 & 1.1 & 699.8 & 693.6 & 302.5 & 297.5 & 1855.0 & 6.5 & 1.5 & 0.4 & 6.1 & 9.0 & 11.6 \\
\hline $\begin{array}{r}6 / 11 / 2009 \\
14: 00\end{array}$ & $\begin{array}{r}6 / 11 / 2009 \\
15: 00\end{array}$ & 545.4 & 8069.1 & 3.8 & 3.1 & 386.8 & 1.1 & 659.2 & 651.2 & 296.4 & 295.1 & 1626.4 & 6.0 & 1.5 & 0.4 & 6.0 & 7.9 & 10.9 \\
\hline $\begin{array}{r}6 / 11 / 2009 \\
15: 00 \\
\end{array}$ & $\begin{array}{r}6 / 11 / 2009 \\
16: 00 \\
\end{array}$ & 627.4 & 8069.1 & 3.5 & 2.5 & 436.9 & 1.1 & 687.7 & 686.2 & 293.6 & 290.3 & 1775.3 & 6.3 & 1.5 & 0.4 & 5.4 & 8.4 & 11.3 \\
\hline $\begin{array}{r}6 / 11 / 2009 \\
16: 00 \\
\end{array}$ & $\begin{array}{r}6 / 11 / 2009 \\
17: 00 \\
\end{array}$ & 591.3 & 8069.1 & 3.7 & 2.7 & 418.5 & 1.1 & 676.7 & 677.7 & 292.5 & 287.3 & 1722.9 & 6.0 & 1.5 & 0.4 & 4.7 & 8.8 & 11.5 \\
\hline $\begin{array}{r}6 / 11 / 2009 \\
17: 00 \\
\end{array}$ & $\begin{array}{r}6 / 11 / 2009 \\
18: 00 \\
\end{array}$ & 687.2 & 8069.1 & 3.4 & 2.1 & 479.1 & 1.1 & 707.2 & 709.7 & 295.8 & 293.7 & 1902.6 & 6.9 & 1.5 & 0.4 & 5.4 & 10.6 & 12.8 \\
\hline
\end{tabular}




\begin{tabular}{|c|c|c|c|c|c|c|c|c|c|c|c|c|c|c|c|c|c|c|}
\hline \multirow[t]{2}{*}{$\begin{array}{l}\text { Start } \\
\text { Date/ } \\
\text { Time }\end{array}$} & \multirow[t]{2}{*}{$\begin{array}{l}\text { End } \\
\text { Date/ } \\
\text { Time }\end{array}$} & $\begin{array}{l}\text { Gross } \\
\text { Load }\end{array}$ & $\begin{array}{c}\text { Gross } \\
\text { HR }\end{array}$ & $\begin{array}{c}\text { A } \\
\text { Econ } \\
\text { O2 }\end{array}$ & $\begin{array}{c}\text { B } \\
\text { Econ } \\
\text { O2 }\end{array}$ & $\begin{array}{l}\text { Fuel } \\
\text { Flow }\end{array}$ & $\begin{array}{l}\text { BTU } \\
\text { Gain }\end{array}$ & $\begin{array}{c}\text { A } \\
\text { APH } \\
\text { In }\end{array}$ & $\begin{array}{c}\text { B } \\
\text { APH } \\
\text { In }\end{array}$ & $\begin{array}{c}\text { A } \\
\text { APH } \\
\text { Out }\end{array}$ & $\begin{array}{c}\text { B } \\
\text { APH } \\
\text { Out }\end{array}$ & $\begin{array}{l}\text { Stack } \\
\text { Flow }\end{array}$ & Opacity & SO2 In & $\begin{array}{l}\text { SO2 } \\
\text { Out }\end{array}$ & $\mathrm{CO}$ & $\begin{array}{c}\text { Stack } \\
\text { SCEM } \\
\text { Elemental } \\
\mathrm{Hg}\end{array}$ & $\begin{array}{c}\text { Stack } \\
\text { SCEM } \\
\text { Total Hg }\end{array}$ \\
\hline & & MW & Btu/kWh & $\%$ & $\%$ & Ton/hr & & DEGF & DEGF & DEGF & DEGF & KSCF & $\%$ & Ib/MMB & $\mathrm{Ib} / \mathrm{MMb}$ & PPM & $\begin{array}{c}(\mu \mathrm{g} / \mathrm{dNm} 3) \\
@ 3 \% 02\end{array}$ & $\begin{array}{c}(\mu \mathrm{g} / \mathrm{dNm} 3) \\
@ 3 \% 02\end{array}$ \\
\hline $\begin{array}{r}/ 11 / 2009 \\
18: 00\end{array}$ & $\begin{array}{r}6 / 11 / 2009 \\
19: 00\end{array}$ & 574.1 & 8069.1 & 4.0 & 3.0 & 390.8 & 1.1 & 684.1 & 681.9 & 294.2 & 290.5 & 1697.5 & 6.6 & 1.5 & 0.4 & 4.2 & 9.8 & 11.7 \\
\hline $\begin{array}{r}6 / 11 / 2009 \\
19: 00\end{array}$ & $\begin{array}{r}6 / 11 / 2009 \\
20: 00\end{array}$ & 546.0 & 8069.1 & 3.8 & 3.0 & 378.6 & 1.1 & 669.4 & 665.7 & 288.6 & 282.6 & 1617.2 & 6.5 & 1.5 & 0.4 & 4.1 & 8.9 & 11.3 \\
\hline $\begin{array}{r}6 / 11 / 2009 \\
20: 00\end{array}$ & $\begin{array}{r}6 / 11 / 2009 \\
21: 00\end{array}$ & 528.2 & 8069.1 & 4.0 & 3.3 & 368.4 & 1.1 & 665.4 & 661.8 & 289.3 & 283.0 & 1589.9 & 6.5 & 1.4 & 0.4 & 4.6 & 8.3 & 11.0 \\
\hline $\begin{array}{r}6 / 11 / 2009 \\
21: 00\end{array}$ & $\begin{array}{r}\text { 6/11/2009 } \\
22: 00\end{array}$ & 541.0 & 8069.1 & 3.7 & 3.1 & 384.5 & 1.1 & 657.7 & 651.1 & 285.7 & 278.6 & 1598.3 & 6.4 & 1.4 & 0.4 & 4.7 & 7.9 & 10.7 \\
\hline $\begin{array}{r}6 / 11 / 2009 \\
22: 00\end{array}$ & $\begin{array}{r}6 / 11 / 2009 \\
23: 00\end{array}$ & 677.4 & 8069.1 & 3.3 & 2.3 & 468.7 & 1.1 & 705.9 & 694.6 & 291.8 & 285.4 & 1884.2 & 7.2 & 1.4 & 0.4 & 5.7 & 9.6 & 12.0 \\
\hline $\begin{array}{r}6 / 11 / 2009 \\
23: 00\end{array}$ & $\begin{array}{r}6 / 12 / 2009 \\
0: 00\end{array}$ & 742.9 & 8069.1 & 3.3 & 2.3 & 510.2 & 1.1 & 739.1 & 727.7 & 302.8 & 294.9 & 2044.6 & 7.5 & 1.4 & 0.4 & 6.5 & 10.9 & 12.8 \\
\hline $\begin{array}{r}6 / 12 / 2009 \\
0: 00\end{array}$ & $\begin{array}{r}6 / 12 / 2009 \\
1: 00\end{array}$ & 773.0 & 8069.1 & 3.2 & 2.3 & 525.2 & 1.1 & 744.3 & 732.1 & 308.3 & 301.1 & 2071.4 & 7.7 & 1.5 & 0.4 & 7.4 & 11.7 & 13.5 \\
\hline $\begin{array}{r}6 / 12 / 2009 \\
1: 00\end{array}$ & $\begin{array}{r}6 / 12 / 2009 \\
2: 00\end{array}$ & 619.7 & 8069.1 & 3.8 & 2.9 & 419.5 & 1.1 & 701.1 & 689.8 & 301.2 & 293.4 & 1775.5 & 7.1 & 1.5 & 0.4 & 4.8 & 10.5 & 12.2 \\
\hline $\begin{array}{r}6 / 12 / 2009 \\
2: 00\end{array}$ & $\begin{array}{r}6 / 12 / 2009 \\
3: 00\end{array}$ & 571.3 & 8069.1 & 3.6 & 3.0 & 397.7 & 1.1 & 683.7 & 672.8 & 300.9 & 286.6 & 1678.6 & 6.6 & 1.5 & 0.4 & 5.0 & 10.0 & 11.6 \\
\hline $\begin{array}{r}6 / 12 / 2009 \\
3: 00 \\
\end{array}$ & $\begin{array}{r}6 / 12 / 2009 \\
4: 00 \\
\end{array}$ & 613.2 & 8069.1 & 3.4 & 2.8 & 431.6 & 1.1 & 695.8 & 685.7 & 300.0 & 284.9 & 1760.8 & 6.9 & 1.5 & 0.4 & 4.8 & 10.4 & 12.1 \\
\hline $\begin{array}{r}6 / 12 / 2009 \\
4: 00\end{array}$ & $\begin{array}{r}6 / 12 / 2009 \\
5: 00\end{array}$ & 703.5 & 8069.1 & 3.2 & 2.4 & 492.2 & 1.1 & 728.3 & 722.5 & 304.3 & 292.2 & 1953.2 & 7.5 & 1.6 & 0.4 & 4.8 & 11.7 & 13.4 \\
\hline $\begin{array}{r}6 / 12 / 2009 \\
5: 00\end{array}$ & $\begin{array}{r}6 / 12 / 2009 \\
6: 00\end{array}$ & 721.4 & 8069.1 & 3.2 & 2.4 & 505.4 & 1.1 & 726.8 & 722.2 & 306.7 & 294.8 & 2005.3 & 8.2 & 1.7 & 0.4 & 5.4 & \#N/A & $\# \mathrm{~N} / \mathrm{A}$ \\
\hline $\begin{array}{r}6 / 12 / 2009 \\
6: 00\end{array}$ & $\begin{array}{r}6 / 12 / 2009 \\
7: 00\end{array}$ & 837.3 & 8069.1 & 3.1 & 2.4 & 583.0 & 1.1 & 757.1 & 747.7 & 308.3 & 299.6 & 2249.6 & 9.2 & 1.7 & 0.4 & 10.5 & $\# \mathrm{~N} / \mathrm{A}$ & $\# \mathrm{~N} / \mathrm{A}$ \\
\hline $\begin{array}{r}6 / 12 / 2009 \\
7: 00\end{array}$ & $\begin{array}{r}6 / 12 / 2009 \\
8: 00\end{array}$ & 909.2 & 8069.1 & 2.9 & 2.4 & 626.7 & 1.1 & 783.4 & 772.9 & 314.4 & 309.8 & 2376.4 & 9.6 & 1.7 & 0.4 & 11.2 & 14.4 & 15.6 \\
\hline $\begin{array}{r}6 / 12 / 2009 \\
8: 00 \\
\end{array}$ & $\begin{array}{r}6 / 12 / 2009 \\
9: 00 \\
\end{array}$ & 909.0 & 8069.1 & 3.0 & 2.3 & 624.6 & 1.1 & 779.2 & 769.3 & 316.4 & 311.9 & 2375.9 & 9.7 & 1.7 & 0.4 & 9.8 & 14.6 & 15.7 \\
\hline $\begin{array}{r}6 / 12 / 2009 \\
9: 00 \\
\end{array}$ & $\begin{array}{r}6 / 12 / 2009 \\
10: 00 \\
\end{array}$ & 910.8 & 8069.1 & 2.9 & 2.4 & 625.6 & 1.1 & 775.3 & 762.9 & 316.0 & 310.5 & 2370.5 & 9.2 & 1.8 & 0.4 & 11.1 & 14.7 & 15.8 \\
\hline $\begin{array}{r}6 / 12 / 2009 \\
10: 00 \\
\end{array}$ & $\begin{array}{r}6 / 12 / 2009 \\
11: 00 \\
\end{array}$ & 911.3 & 8069.1 & 2.9 & 2.3 & 620.3 & 1.1 & 777.1 & 777.7 & 315.4 & 310.4 & 2370.2 & 9.0 & 1.8 & 0.5 & 9.9 & 14.7 & 15.9 \\
\hline $\begin{array}{r}6 / 12 / 2009 \\
11: 00\end{array}$ & $\begin{array}{r}6 / 12 / 2009 \\
12: 00\end{array}$ & 909.1 & 8069.1 & 2.9 & 2.3 & 617.9 & 1.1 & 780.8 & 785.9 & 317.7 & 312.9 & 2352.7 & 9.0 & 1.8 & 0.4 & 9.2 & 14.7 & 16.0 \\
\hline $\begin{array}{r}6 / 12 / 2009 \\
12: 00\end{array}$ & $\begin{array}{r}6 / 12 / 2009 \\
13: 00\end{array}$ & 910.1 & 8069.1 & 2.9 & 2.3 & 617.8 & 1.1 & 786.8 & 791.4 & 322.1 & 317.2 & 2354.3 & 9.2 & 1.8 & 0.5 & 12.0 & 14.8 & 16.1 \\
\hline $6 / 12 / 2009$ & $6 / 12 / 2009$ & 909.0 & 8069.1 & 3.0 & 2.3 & 617.2 & 1.1 & 780.8 & 787.0 & 323.4 & 318.9 & 2357.1 & 9.2 & 1.8 & 0.5 & 12.3 & 14.6 & 16.0 \\
\hline
\end{tabular}




\begin{tabular}{|c|c|c|c|c|c|c|c|c|c|c|c|c|c|c|c|c|c|c|}
\hline \multirow[t]{2}{*}{$\begin{array}{l}\text { Start } \\
\text { Date/ } \\
\text { Time }\end{array}$} & \multirow[t]{2}{*}{$\begin{array}{l}\text { End } \\
\text { Date/ } \\
\text { Time }\end{array}$} & $\begin{array}{l}\text { Gross } \\
\text { Load }\end{array}$ & $\begin{array}{c}\text { Gross } \\
\text { HR }\end{array}$ & $\begin{array}{c}\text { A } \\
\text { Econ } \\
\text { O2 }\end{array}$ & $\begin{array}{c}\text { B } \\
\text { Econ } \\
\text { O2 }\end{array}$ & $\begin{array}{l}\text { Fuel } \\
\text { Flow }\end{array}$ & $\begin{array}{l}\text { BTU } \\
\text { Gain }\end{array}$ & $\begin{array}{c}\text { A } \\
\text { APH } \\
\text { In }\end{array}$ & $\begin{array}{c}\text { B } \\
\text { APH } \\
\text { In }\end{array}$ & $\begin{array}{c}\text { A } \\
\text { APH } \\
\text { Out }\end{array}$ & $\begin{array}{c}\text { B } \\
\text { APH } \\
\text { Out }\end{array}$ & $\begin{array}{l}\text { Stack } \\
\text { Flow }\end{array}$ & Opacity & SO2 In & $\begin{array}{l}\text { SO2 } \\
\text { Out }\end{array}$ & $\mathrm{CO}$ & $\begin{array}{c}\text { Stack } \\
\text { SCEM } \\
\text { Elemental } \\
\mathrm{Hg}\end{array}$ & $\begin{array}{c}\text { Stack } \\
\text { SCEM } \\
\text { Total Hg }\end{array}$ \\
\hline & & MW & Btu/kWh & $\%$ & $\%$ & Ton/hr & & DEGF & DEGF & DEGF & DEGF & KSCF & $\%$ & $\mathrm{Ib} / \mathrm{MMB}$ & $\mathrm{lb} / \mathrm{MMb}$ & PPM & $\begin{array}{c}(\mu \mathrm{g} / \mathrm{dNm} 3) \\
@ 3 \% 02\end{array}$ & $\begin{array}{c}(\mu \mathrm{g} / \mathrm{dNm} 3) \\
\text { @ 3\%O2 }\end{array}$ \\
\hline $13: 00$ & $14: 00$ & & & & & & & & & & & & & & & & & \\
\hline $\begin{array}{r}6 / 12 / 2009 \\
14: 00\end{array}$ & $\begin{array}{r}6 / 12 / 2009 \\
15: 00\end{array}$ & 909.7 & 8069.1 & 2.9 & 2.3 & 618.7 & 1.1 & 778.7 & 783.2 & 323.7 & 318.9 & 2355.7 & 8.8 & 1.8 & 0.5 & 8.5 & 14.6 & 16.4 \\
\hline $\begin{array}{r}6 / 12 / 2009 \\
15: 00\end{array}$ & $\begin{array}{r}6 / 12 / 2009 \\
16: 00\end{array}$ & 910.6 & 8069.1 & 2.9 & 2.3 & 619.0 & 1.1 & 777.0 & 782.9 & 323.2 & 318.7 & 2365.0 & 8.7 & 1.7 & 0.5 & 9.6 & 14.6 & 16.5 \\
\hline $\begin{array}{r}6 / 12 / 2009 \\
16: 00 \\
\end{array}$ & $\begin{array}{r}6 / 12 / 2009 \\
17: 00 \\
\end{array}$ & 909.5 & 8069.1 & 2.8 & 2.4 & 617.9 & 1.1 & 773.9 & 783.2 & 323.5 & 319.1 & 2353.9 & 8.5 & 1.7 & 0.5 & 9.0 & 14.5 & 16.8 \\
\hline $\begin{array}{r}6 / 12 / 2009 \\
17: 00\end{array}$ & $\begin{array}{r}6 / 12 / 2009 \\
18: 00\end{array}$ & 911.6 & 8069.1 & 2.7 & 2.4 & 616.1 & 1.1 & 779.2 & 786.2 & 324.5 & 319.2 & 2346.4 & 8.5 & 1.7 & 0.5 & 10.7 & 13.7 & 16.5 \\
\hline $\begin{array}{r}6 / 12 / 2009 \\
18: 00\end{array}$ & $\begin{array}{r}6 / 12 / 2009 \\
19: 00\end{array}$ & 912.1 & 8069.1 & 2.7 & 2.4 & 610.8 & 1.1 & 780.1 & 786.9 & 325.8 & 320.5 & 2343.8 & 8.5 & 1.6 & 0.4 & 9.0 & 14.3 & 16.4 \\
\hline $\begin{array}{r}6 / 12 / 2009 \\
19: 00\end{array}$ & $\begin{array}{r}6 / 12 / 2009 \\
20: 00\end{array}$ & 911.5 & 8069.1 & 2.7 & 2.4 & 605.3 & 1.1 & 780.6 & 788.6 & 325.0 & 320.1 & 2312.7 & 8.5 & 1.5 & 0.4 & 9.1 & 14.4 & 16.3 \\
\hline $\begin{array}{r}6 / 12 / 2009 \\
20: 00\end{array}$ & $\begin{array}{r}6 / 12 / 2009 \\
21: 00\end{array}$ & 909.4 & 8069.1 & 2.7 & 2.5 & 604.5 & 1.1 & 778.2 & 784.1 & 324.6 & 319.6 & 2323.9 & 9.0 & 1.5 & 0.4 & 8.3 & 14.0 & 16.0 \\
\hline $\begin{array}{r}6 / 12 / 2009 \\
21: 00\end{array}$ & $\begin{array}{r}6 / 12 / 2009 \\
22: 00\end{array}$ & 908.7 & 8069.1 & 2.7 & 2.4 & 604.8 & 1.1 & 778.9 & 784.2 & 322.7 & 317.9 & 2307.7 & 10.3 & 1.5 & 0.4 & 8.5 & 13.7 & 15.9 \\
\hline $\begin{array}{r}6 / 12 / 2009 \\
22: 00 \\
\end{array}$ & $\begin{array}{r}6 / 12 / 2009 \\
23: 00 \\
\end{array}$ & 907.8 & 8069.1 & 2.7 & 2.4 & 608.7 & 1.1 & 779.1 & 785.1 & 322.3 & 317.3 & 2330.6 & 10.5 & 1.5 & 0.4 & 9.3 & 13.6 & 15.9 \\
\hline $\begin{array}{r}6 / 12 / 2009 \\
23: 00\end{array}$ & $\begin{array}{r}6 / 13 / 2009 \\
0: 00\end{array}$ & 911.4 & 8069.1 & 2.7 & 2.4 & 613.6 & 1.1 & 782.4 & 787.9 & 322.6 & 317.1 & 2336.9 & 10.3 & 1.6 & 0.4 & 12.7 & 13.7 & 15.9 \\
\hline $\begin{array}{r}6 / 13 / 2009 \\
0: 00\end{array}$ & $\begin{array}{r}6 / 13 / 2009 \\
1: 00\end{array}$ & 910.3 & 8069.1 & 2.7 & 2.4 & 615.4 & 1.1 & 784.6 & 789.7 & 321.7 & 315.8 & 2349.7 & 10.6 & 1.6 & 0.4 & 19.7 & 13.8 & 15.6 \\
\hline $\begin{array}{r}6 / 13 / 2009 \\
1: 00\end{array}$ & $\begin{array}{r}6 / 13 / 2009 \\
2: 00\end{array}$ & 898.4 & 8069.1 & 2.7 & 2.4 & 601.1 & 1.1 & 786.1 & 787.2 & 320.8 & 314.1 & 2314.8 & 10.9 & 1.6 & 0.4 & 16.7 & $\# \mathrm{~N} / \mathrm{A}$ & $\# \mathrm{~N} / \mathrm{A}$ \\
\hline $\begin{array}{r}6 / 13 / 2009 \\
2: 00\end{array}$ & $\begin{array}{r}6 / 13 / 2009 \\
3: 00\end{array}$ & 837.6 & 8069.1 & 2.9 & 2.1 & 559.9 & 1.1 & 772.0 & 764.3 & 317.6 & 307.5 & 2176.3 & 10.3 & 1.6 & 0.4 & 7.7 & $\# \mathrm{~N} / \mathrm{A}$ & $\# \mathrm{~N} / \mathrm{A}$ \\
\hline $\begin{array}{r}6 / 13 / 2009 \\
3: 00 \\
\end{array}$ & $\begin{array}{r}6 / 13 / 2009 \\
4: 00 \\
\end{array}$ & 749.5 & 8069.1 & 3.1 & 2.1 & 505.5 & 1.1 & 748.4 & 745.7 & 311.7 & 302.5 & 2022.5 & 9.3 & 1.6 & 0.4 & 6.2 & 13.1 & 15.1 \\
\hline $\begin{array}{r}6 / 13 / 2009 \\
4: 00 \\
\end{array}$ & $\begin{array}{r}6 / 13 / 2009 \\
5: 00 \\
\end{array}$ & 710.8 & 8069.1 & 3.1 & 2.4 & 482.8 & 1.1 & 733.2 & 731.4 & 306.7 & 297.5 & 1976.8 & 8.9 & 1.6 & 0.4 & 5.5 & $\# \mathrm{~N} / \mathrm{A}$ & $\# \mathrm{~N} / \mathrm{A}$ \\
\hline $\begin{array}{r}6 / 13 / 2009 \\
5: 00 \\
\end{array}$ & $\begin{array}{r}6 / 13 / 2009 \\
6: 00 \\
\end{array}$ & 710.2 & 8069.1 & 3.2 & 2.4 & 484.8 & 1.1 & 718.4 & 723.3 & 302.5 & 293.7 & 1995.7 & 8.2 & 1.6 & 0.4 & 5.4 & $\# \mathrm{~N} / \mathrm{A}$ & $\# \mathrm{~N} / \mathrm{A}$ \\
\hline $\begin{array}{r}6 / 13 / 2009 \\
6: 00 \\
\end{array}$ & $\begin{array}{r}6 / 13 / 2009 \\
7: 00 \\
\end{array}$ & 762.2 & 8069.1 & 3.1 & 2.4 & 526.4 & 1.1 & 721.6 & 727.6 & 300.0 & 292.7 & 2125.0 & 8.5 & 1.7 & 0.4 & 7.1 & $\# \mathrm{~N} / \mathrm{A}$ & $\# \mathrm{~N} / \mathrm{A}$ \\
\hline $\begin{array}{r}6 / 13 / 2009 \\
7: 00\end{array}$ & $\begin{array}{r}6 / 13 / 2009 \\
8: 00\end{array}$ & 899.6 & 8069.1 & 2.9 & 2.4 & 615.3 & 1.1 & 762.3 & 767.8 & 304.7 & 298.6 & 2369.3 & 8.8 & 1.8 & 0.4 & 9.9 & 15.0 & 16.5 \\
\hline $\begin{array}{r}6 / 13 / 2009 \\
8: 00\end{array}$ & $\begin{array}{r}6 / 13 / 2009 \\
9: 00\end{array}$ & 911.0 & 8069.1 & 2.9 & 2.3 & 621.6 & 1.1 & 773.8 & 784.1 & 310.5 & 304.4 & 2375.2 & 9.2 & 1.8 & 0.4 & 13.0 & 16.2 & 17.5 \\
\hline
\end{tabular}




\begin{tabular}{|c|c|c|c|c|c|c|c|c|c|c|c|c|c|c|c|c|c|c|}
\hline \multirow[t]{2}{*}{$\begin{array}{l}\text { Start } \\
\text { Date/ } \\
\text { Time }\end{array}$} & \multirow[t]{2}{*}{$\begin{array}{l}\text { End } \\
\text { Date/ } \\
\text { Time }\end{array}$} & $\begin{array}{l}\text { Gross } \\
\text { Load }\end{array}$ & $\begin{array}{c}\text { Gross } \\
\text { HR }\end{array}$ & $\begin{array}{c}\text { A } \\
\text { Econ } \\
\text { O2 }\end{array}$ & $\begin{array}{c}\text { B } \\
\text { Econ } \\
\text { O2 }\end{array}$ & $\begin{array}{l}\text { Fuel } \\
\text { Flow }\end{array}$ & $\begin{array}{l}\text { BTU } \\
\text { Gain }\end{array}$ & $\begin{array}{c}\text { A } \\
\text { APH } \\
\text { In }\end{array}$ & $\begin{array}{c}\text { B } \\
\text { APH } \\
\text { In }\end{array}$ & $\begin{array}{c}\text { A } \\
\text { APH } \\
\text { Out }\end{array}$ & $\begin{array}{c}\text { B } \\
\text { APH } \\
\text { Out }\end{array}$ & $\begin{array}{l}\text { Stack } \\
\text { Flow }\end{array}$ & Opacity & SO2 In & $\begin{array}{l}\text { SO2 } \\
\text { Out }\end{array}$ & $\mathrm{CO}$ & $\begin{array}{c}\text { Stack } \\
\text { SCEM } \\
\text { Elemental } \\
\mathrm{Hg}\end{array}$ & $\begin{array}{c}\text { Stack } \\
\text { SCEM } \\
\text { Total Hg }\end{array}$ \\
\hline & & MW & Btu/kWh & $\%$ & $\%$ & Ton/hr & & DEGF & DEGF & DEGF & DEGF & KSCF & $\%$ & $\mathrm{Ib} / \mathrm{MMB}$ & $\mathrm{Ib} / \mathrm{MMb}$ & PPM & $\begin{array}{c}\text { ( } \mu \mathrm{g} / \mathrm{dNm} \text { ) } \\
@ 3 \% 02\end{array}$ & $\begin{array}{c}(\mu \mathrm{g} / \mathrm{dNm} 3) \\
@ 3 \% 02\end{array}$ \\
\hline $\begin{array}{r}6 / 13 / 2009 \\
9: 00\end{array}$ & $\begin{array}{r}/ 13 / 2009 \\
10: 00\end{array}$ & 911.1 & 8069.1 & 2.9 & 2.4 & 622.9 & 1.1 & 773.0 & 783.2 & 313.9 & 307.3 & 2365.5 & 9.0 & 1.9 & 0.5 & 15.5 & 16.1 & 17.5 \\
\hline $\begin{array}{r}6 / 13 / 2009 \\
10: 00\end{array}$ & $\begin{array}{r}6 / 13 / 2009 \\
11: 00\end{array}$ & 913.0 & 8069.1 & 2.9 & 2.3 & 625.8 & 1.1 & 773.4 & 781.3 & 314.8 & 308.4 & 2348.2 & 8.9 & 2.0 & 0.5 & 15.5 & 9.5 & 10.9 \\
\hline $\begin{array}{r}6 / 13 / 2009 \\
11: 00\end{array}$ & $\begin{array}{r}6 / 13 / 2009 \\
12: 00\end{array}$ & 914.0 & 8069.1 & 2.9 & 2.3 & 626.6 & 1.1 & 769.9 & 779.2 & 316.0 & 310.1 & 2344.6 & 9.2 & 2.1 & 0.5 & 14.3 & 6.4 & 7.3 \\
\hline $\begin{array}{r}6 / 13 / 2009 \\
12: 00\end{array}$ & $\begin{array}{r}6 / 13 / 2009 \\
13: 00\end{array}$ & 913.4 & 8069.1 & 2.9 & 2.3 & 626.1 & 1.1 & 769.4 & 780.2 & 317.0 & 312.1 & 2354.6 & 8.9 & 2.2 & 0.6 & 12.7 & 6.6 & 7.5 \\
\hline $\begin{array}{r}6 / 13 / 2009 \\
13: 00\end{array}$ & $\begin{array}{r}6 / 13 / 2009 \\
14: 00\end{array}$ & 911.7 & 8069.1 & 3.0 & 2.2 & 630.4 & 1.1 & 766.8 & 778.5 & 317.9 & 313.5 & 2363.5 & 8.7 & 2.2 & 0.6 & 14.9 & 6.1 & 7.0 \\
\hline $\begin{array}{r}6 / 13 / 2009 \\
14: 00\end{array}$ & $\begin{array}{r}6 / 13 / 2009 \\
15: 00\end{array}$ & 913.7 & 8069.1 & 2.9 & 2.2 & 631.5 & 1.1 & 765.4 & 778.1 & 318.9 & 314.6 & 2349.3 & 8.6 & 2.2 & 0.6 & 15.7 & 5.5 & 6.3 \\
\hline $\begin{array}{r}6 / 13 / 2009 \\
15: 00\end{array}$ & $\begin{array}{r}6 / 13 / 2009 \\
16: 00\end{array}$ & 912.7 & 8069.1 & 2.8 & 2.3 & 626.0 & 1.1 & 763.6 & 778.3 & 320.7 & 316.7 & 2346.0 & 8.8 & 2.3 & 0.6 & 17.6 & 5.1 & 5.9 \\
\hline $\begin{array}{r}6 / 13 / 2009 \\
16: 00\end{array}$ & $\begin{array}{r}6 / 13 / 2009 \\
17: 00\end{array}$ & 910.4 & 8069.1 & 2.7 & 2.4 & 627.1 & 1.1 & 760.6 & 778.2 & 319.9 & 317.2 & 2349.5 & 8.8 & 2.3 & 0.6 & 13.8 & 5.2 & 6.0 \\
\hline $\begin{array}{r}6 / 13 / 2009 \\
17: 00\end{array}$ & $\begin{array}{r}6 / 13 / 2009 \\
18: 00\end{array}$ & 911.2 & 8069.1 & 2.8 & 2.4 & 630.3 & 1.1 & 764.7 & 779.2 & 320.7 & 317.3 & 2361.1 & 9.2 & 2.4 & 0.6 & 12.5 & 5.4 & 6.3 \\
\hline $\begin{array}{r}6 / 13 / 2009 \\
18: 00 \\
\end{array}$ & $\begin{array}{r}6 / 13 / 2009 \\
19: 00 \\
\end{array}$ & 910.4 & 8069.1 & 2.8 & 2.4 & 632.0 & 1.1 & 766.8 & 779.8 & 320.6 & 316.9 & 2335.4 & 9.7 & 2.4 & 0.6 & 11.1 & 5.8 & 6.6 \\
\hline $\begin{array}{r}6 / 13 / 2009 \\
19: 00\end{array}$ & $\begin{array}{r}6 / 13 / 2009 \\
20: 00\end{array}$ & 910.9 & 8069.1 & 2.8 & 2.3 & 633.7 & 1.1 & 768.7 & 781.0 & 320.3 & 316.3 & 2346.0 & 9.6 & 2.4 & 0.6 & 11.9 & 5.5 & 6.3 \\
\hline $\begin{array}{r}6 / 13 / 2009 \\
20: 00\end{array}$ & $\begin{array}{r}6 / 13 / 2009 \\
21: 00\end{array}$ & 911.0 & 8069.1 & 2.9 & 2.3 & 634.4 & 1.1 & 770.1 & 781.7 & 320.3 & 316.4 & 2337.7 & 9.8 & 2.4 & 0.6 & 11.7 & 5.5 & 6.3 \\
\hline $\begin{array}{r}6 / 13 / 2009 \\
21: 00\end{array}$ & $\begin{array}{r}6 / 13 / 2009 \\
22: 00\end{array}$ & 898.0 & 8069.1 & 2.9 & 2.2 & 623.8 & 1.1 & 768.5 & 777.8 & 320.0 & 314.8 & 2321.4 & 11.0 & 2.5 & 0.6 & 10.1 & 5.5 & 6.2 \\
\hline $\begin{array}{r}6 / 13 / 2009 \\
22: 00\end{array}$ & $\begin{array}{r}6 / 13 / 2009 \\
23: 00\end{array}$ & 903.6 & 8069.1 & 2.8 & 2.3 & 624.5 & 1.1 & 772.3 & 779.4 & 319.2 & 313.4 & 2340.4 & 11.7 & 2.4 & 0.6 & 11.0 & 5.4 & 6.0 \\
\hline $\begin{array}{r}/ 13 / 2009 \\
23: 00 \\
\end{array}$ & $\begin{array}{r}6 / 14 / 2009 \\
0: 00 \\
\end{array}$ & 904.3 & 8069.1 & 2.8 & 2.4 & 618.5 & 1.1 & 775.1 & 780.6 & 319.1 & 312.9 & 2337.1 & 12.2 & 2.5 & 0.5 & 11.9 & 5.2 & 5.7 \\
\hline $\begin{array}{r}6 / 14 / 2009 \\
0: 00 \\
\end{array}$ & $\begin{array}{r}6 / 14 / 2009 \\
1: 00 \\
\end{array}$ & 904.8 & 8069.1 & 2.8 & 2.4 & 614.3 & 1.1 & 771.4 & 777.5 & 319.1 & 312.3 & 2340.6 & 10.2 & 2.4 & 0.6 & 10.9 & 5.2 & 5.9 \\
\hline $\begin{array}{r}6 / 14 / 2009 \\
1: 00\end{array}$ & $\begin{array}{r}6 / 14 / 2009 \\
2: 00\end{array}$ & 902.0 & 8069.1 & 2.8 & 2.3 & 605.3 & 1.1 & 766.3 & 776.9 & 315.3 & 309.5 & 2318.9 & 10.1 & 2.3 & 0.6 & 9.7 & $\# \mathrm{~N} / \mathrm{A}$ & 6.0 \\
\hline $\begin{array}{r}6 / 14 / 2009 \\
2: 00\end{array}$ & $\begin{array}{r}6 / 14 / 2009 \\
3: 00\end{array}$ & 874.6 & 8069.1 & 2.9 & 2.2 & 582.0 & 1.1 & 760.5 & 772.5 & 313.1 & 307.2 & 2259.6 & 9.9 & 2.2 & 0.6 & 9.5 & $\# \mathrm{~N} / \mathrm{A}$ & $\# \mathrm{~N} / \mathrm{A}$ \\
\hline $\begin{array}{r}6 / 14 / 2009 \\
3: 00\end{array}$ & $\begin{array}{r}6 / 14 / 2009 \\
4: 00\end{array}$ & 807.7 & 8069.1 & 3.0 & 2.2 & 535.8 & 1.1 & 746.3 & 759.8 & 309.5 & 302.2 & 2098.7 & 8.8 & 2.1 & 0.6 & 7.0 & $\# \mathrm{~N} / \mathrm{A}$ & 4.3 \\
\hline $6 / 14 / 2009$ & $6 / 14 / 2009$ & 740.6 & 8069.1 & 3.1 & 2.3 & 494.4 & 1.1 & 727.8 & 739.8 & 310.5 & 297.5 & 1991.1 & 7.7 & 2.0 & 0.6 & 10.1 & 2.8 & 3.5 \\
\hline
\end{tabular}




\begin{tabular}{|c|c|c|c|c|c|c|c|c|c|c|c|c|c|c|c|c|c|c|}
\hline $\begin{array}{l}\text { Start } \\
\text { Date/ } \\
\text { Time }\end{array}$ & $\begin{array}{l}\text { End } \\
\text { Date/ } \\
\text { Time }\end{array}$ & $\begin{array}{l}\text { Gross } \\
\text { Load }\end{array}$ & $\begin{array}{c}\text { Gross } \\
\text { HR }\end{array}$ & $\begin{array}{c}\text { A } \\
\text { Econ } \\
\text { O2 }\end{array}$ & $\begin{array}{c}\text { B } \\
\text { Econ } \\
\text { O2 }\end{array}$ & $\begin{array}{l}\text { Fuel } \\
\text { Flow }\end{array}$ & $\begin{array}{l}\text { BTU } \\
\text { Gain }\end{array}$ & $\begin{array}{c}\text { A } \\
\text { APH } \\
\text { In }\end{array}$ & $\begin{array}{l}\text { B } \\
\text { APH } \\
\text { In }\end{array}$ & $\begin{array}{c}\text { A } \\
\text { APH } \\
\text { Out }\end{array}$ & $\begin{array}{c}\text { B } \\
\text { APH } \\
\text { Out }\end{array}$ & $\begin{array}{l}\text { Stack } \\
\text { Flow }\end{array}$ & Opacity & SO2 In & $\begin{array}{l}\text { SO2 } \\
\text { Out }\end{array}$ & $\mathrm{CO}$ & $\begin{array}{c}\text { Stack } \\
\text { SCEM } \\
\text { Elemental } \\
\mathrm{Hg}\end{array}$ & $\begin{array}{c}\text { Stack } \\
\text { SCEM } \\
\text { Total Hg }\end{array}$ \\
\hline & & MW & Btu/kWh & $\%$ & $\%$ & Ton/hr & & DEGF & DEGF & DEGF & DEGF & KSCF & $\%$ & $\mathrm{Ib} / \mathrm{MMB}$ & $\mathrm{Ib} / \mathrm{MMb}$ & PPM & $\begin{array}{c}\text { ( } \mu \mathrm{g} / \mathrm{dNm}) \\
@ 3 \% 02\end{array}$ & $\begin{array}{c}(\mu \mathrm{g} / \mathrm{dNm} 3) \\
\text { @ 3\%O2 }\end{array}$ \\
\hline $4: 00$ & $5: 00$ & & & & & & & & & & & & & & & & & \\
\hline $\begin{array}{r}6 / 14 / 2009 \\
5: 00 \\
\end{array}$ & $\begin{array}{r}6 / 14 / 2009 \\
6: 00 \\
\end{array}$ & 773.3 & 8069.1 & 3.0 & 2.4 & 522.5 & 1.1 & 736.2 & 746.1 & 304.7 & 293.8 & 2088.5 & 7.4 & 1.9 & 0.6 & 12.3 & $\# \mathrm{~N} / \mathrm{A}$ & $\# \mathrm{~N} / \mathrm{A}$ \\
\hline $\begin{array}{r}6 / 14 / 2009 \\
6: 00\end{array}$ & $\begin{array}{r}6 / 14 / 2009 \\
7: 00\end{array}$ & 896.0 & 8069.1 & 2.9 & 2.3 & 599.9 & 1.1 & 774.7 & 786.5 & 311.5 & 305.7 & 2318.3 & 10.3 & 1.8 & 0.4 & 16.0 & \#N/A & $\# \mathrm{~N} / \mathrm{A}$ \\
\hline $\begin{array}{r}6 / 14 / 2009 \\
7: 00\end{array}$ & $\begin{array}{r}6 / 14 / 2009 \\
8: 00\end{array}$ & 913.5 & 8069.1 & 2.9 & 2.2 & 609.9 & 1.1 & 784.3 & 798.1 & 317.3 & 312.4 & 2349.0 & 9.8 & 1.9 & 0.4 & 12.6 & 3.4 & 4.0 \\
\hline $\begin{array}{r}6 / 14 / 2009 \\
8: 00\end{array}$ & $\begin{array}{r}6 / 14 / 2009 \\
9: 00\end{array}$ & 911.2 & 8069.1 & 2.9 & 2.3 & 610.1 & 1.1 & 774.0 & 788.4 & 316.1 & 310.8 & 2363.6 & 8.1 & 1.9 & 0.5 & 14.5 & 3.6 & 4.2 \\
\hline $\begin{array}{r}6 / 14 / 2009 \\
9: 00\end{array}$ & $\begin{array}{r}6 / 14 / 2009 \\
10: 00\end{array}$ & 912.5 & 8069.1 & 2.8 & 2.3 & 609.7 & 1.1 & 775.1 & 788.6 & 314.9 & 309.7 & 2354.0 & 8.6 & 2.1 & 0.5 & 13.3 & 3.6 & 4.2 \\
\hline $\begin{array}{r}6 / 14 / 2009 \\
10: 00\end{array}$ & $\begin{array}{r}6 / 14 / 2009 \\
11: 00\end{array}$ & 911.6 & 8069.1 & 2.8 & 2.4 & 616.2 & 1.1 & 776.9 & 791.4 & 315.3 & 310.8 & 2353.5 & 10.0 & 2.2 & 0.5 & 11.0 & 3.8 & 4.3 \\
\hline $\begin{array}{r}6 / 14 / 2009 \\
11: 00\end{array}$ & $\begin{array}{r}6 / 14 / 2009 \\
12: 00\end{array}$ & 913.9 & 8069.1 & 2.7 & 2.4 & 618.8 & 1.1 & 770.4 & 781.9 & 316.2 & 311.6 & 2358.8 & 10.2 & 2.3 & 0.5 & 11.9 & 3.9 & 4.4 \\
\hline $\begin{array}{r}6 / 14 / 2009 \\
12: 00\end{array}$ & $\begin{array}{r}6 / 14 / 2009 \\
13: 00\end{array}$ & 913.0 & 8069.1 & 2.7 & 2.4 & 618.9 & 1.1 & 771.8 & 780.6 & 316.3 & 311.6 & 2329.9 & 10.5 & 2.4 & 0.6 & 13.4 & 4.1 & 4.5 \\
\hline $\begin{array}{r}6 / 14 / 2009 \\
13: 00\end{array}$ & $\begin{array}{r}6 / 14 / 2009 \\
14: 00\end{array}$ & 912.4 & 8069.1 & 2.7 & 2.4 & 621.5 & 1.1 & 771.8 & 778.7 & 318.7 & 314.1 & 2334.4 & 10.8 & 2.4 & 0.5 & 15.7 & 4.3 & 4.8 \\
\hline $\begin{array}{r}6 / 14 / 2009 \\
14: 00 \\
\end{array}$ & $\begin{array}{r}6 / 14 / 2009 \\
15: 00 \\
\end{array}$ & 914.2 & 8069.1 & 2.7 & 2.5 & 619.4 & 1.1 & 769.5 & 774.1 & 319.5 & 314.1 & 2326.6 & 10.4 & 2.3 & 0.5 & 17.1 & 4.4 & 4.9 \\
\hline $\begin{array}{r}6 / 14 / 2009 \\
15: 00\end{array}$ & $\begin{array}{r}6 / 14 / 2009 \\
16: 00\end{array}$ & 911.4 & 8069.1 & 2.7 & 2.5 & 620.9 & 1.1 & 770.1 & 775.7 & 320.5 & 315.6 & 2326.6 & 9.6 & 2.2 & 0.5 & 18.5 & 4.3 & 4.9 \\
\hline $\begin{array}{r}6 / 14 / 2009 \\
16: 00\end{array}$ & $\begin{array}{r}6 / 14 / 2009 \\
17: 00\end{array}$ & 910.0 & 8069.1 & 2.7 & 2.5 & 623.0 & 1.1 & 772.3 & 777.7 & 322.5 & 317.4 & 2324.2 & 9.0 & 2.2 & 0.5 & 17.9 & 4.4 & 5.1 \\
\hline $\begin{array}{r}6 / 14 / 2009 \\
17: 00\end{array}$ & $\begin{array}{r}6 / 14 / 2009 \\
18: 00\end{array}$ & 911.0 & 8069.1 & 2.7 & 2.4 & 625.3 & 1.1 & 776.5 & 782.7 & 323.9 & 319.3 & 2325.9 & 9.0 & 2.2 & 0.6 & 17.8 & 4.5 & 5.1 \\
\hline $\begin{array}{r}6 / 14 / 2009 \\
18: 00\end{array}$ & $\begin{array}{r}6 / 14 / 2009 \\
19: 00\end{array}$ & 912.3 & 8069.1 & 2.7 & 2.4 & 633.8 & 1.1 & 780.2 & 786.2 & 325.3 & 320.8 & 2337.5 & 9.1 & 2.2 & 0.5 & 13.4 & 4.5 & 5.2 \\
\hline $\begin{array}{r}6 / 14 / 2009 \\
19: 00\end{array}$ & $\begin{array}{r}6 / 14 / 2009 \\
20: 00\end{array}$ & 911.6 & 8069.1 & 2.7 & 2.4 & 638.6 & 1.1 & 778.6 & 785.5 & 325.5 & 320.5 & 2344.9 & 9.0 & 2.2 & 0.5 & 15.7 & 4.7 & 5.3 \\
\hline $\begin{array}{r}6 / 14 / 2009 \\
20: 00 \\
\end{array}$ & $\begin{array}{r}6 / 14 / 2009 \\
21: 00 \\
\end{array}$ & 913.6 & 8069.1 & 2.7 & 2.4 & 639.4 & 1.1 & 777.5 & 783.7 & 324.0 & 319.9 & 2344.3 & 9.3 & 2.2 & 0.6 & 16.1 & 4.8 & 5.5 \\
\hline $\begin{array}{r}6 / 14 / 2009 \\
21: 00 \\
\end{array}$ & $\begin{array}{r}6 / 14 / 2009 \\
22: 00 \\
\end{array}$ & 912.6 & 8069.1 & 2.7 & 2.4 & 640.5 & 1.1 & 771.9 & 779.0 & 321.9 & 318.2 & 2339.0 & 10.4 & 2.2 & 0.6 & 11.8 & 4.7 & 5.5 \\
\hline $\begin{array}{r}6 / 14 / 2009 \\
22: 00\end{array}$ & $\begin{array}{r}6 / 14 / 2009 \\
23: 00\end{array}$ & 914.2 & 8069.1 & 2.8 & 2.3 & 641.5 & 1.1 & 771.2 & 780.0 & 319.1 & 315.6 & 2341.5 & 10.7 & 2.2 & 0.6 & 12.2 & 4.8 & 5.6 \\
\hline $\begin{array}{r}6 / 14 / 2009 \\
23: 00\end{array}$ & $\begin{array}{r}6 / 15 / 2009 \\
0: 00\end{array}$ & 913.7 & 8069.1 & 2.8 & 2.4 & 639.7 & 1.1 & 774.9 & 783.6 & 318.3 & 314.6 & 2351.5 & 10.6 & 2.2 & 0.5 & 11.5 & 4.6 & 5.3 \\
\hline
\end{tabular}




\begin{tabular}{|c|c|c|c|c|c|c|c|c|c|c|c|c|c|c|c|c|c|c|}
\hline \multirow[t]{2}{*}{$\begin{array}{l}\text { Start } \\
\text { Date/ } \\
\text { Time }\end{array}$} & \multirow[t]{2}{*}{$\begin{array}{l}\text { End } \\
\text { Date/ } \\
\text { Time }\end{array}$} & $\begin{array}{l}\text { Gross } \\
\text { Load }\end{array}$ & $\begin{array}{c}\text { Gross } \\
\text { HR }\end{array}$ & $\begin{array}{c}\text { A } \\
\text { Econ } \\
\text { O2 }\end{array}$ & $\begin{array}{c}\text { B } \\
\text { Econ } \\
\text { O2 }\end{array}$ & $\begin{array}{l}\text { Fuel } \\
\text { Flow }\end{array}$ & $\begin{array}{l}\text { BTU } \\
\text { Gain }\end{array}$ & $\begin{array}{c}\text { A } \\
\text { APH } \\
\text { In }\end{array}$ & $\begin{array}{c}\text { B } \\
\text { APH } \\
\text { In }\end{array}$ & $\begin{array}{c}\text { A } \\
\text { APH } \\
\text { Out }\end{array}$ & $\begin{array}{c}\text { B } \\
\text { APH } \\
\text { Out }\end{array}$ & $\begin{array}{l}\text { Stack } \\
\text { Flow }\end{array}$ & Opacity & SO2 In & $\begin{array}{l}\text { SO2 } \\
\text { Out }\end{array}$ & $\mathrm{CO}$ & $\begin{array}{c}\text { Stack } \\
\text { SCEM } \\
\text { Elemental } \\
\mathrm{Hg}\end{array}$ & $\begin{array}{c}\text { Stack } \\
\text { SCEM } \\
\text { Total Hg }\end{array}$ \\
\hline & & MW & Btu/kWh & $\%$ & $\%$ & Ton/hr & & DEGF & DEGF & DEGF & DEGF & KSCF & $\%$ & $\mathrm{Ib} / \mathrm{MMB}$ & $\mathrm{Ib} / \mathrm{MMb}$ & PPM & $\begin{array}{c}\text { ( } \mu \mathrm{g} / \mathrm{dNm} \text { ) } \\
@ 3 \% 02\end{array}$ & $\begin{array}{c}(\mu \mathrm{g} / \mathrm{dNm} 3) \\
@ 3 \% 02\end{array}$ \\
\hline $\begin{array}{r}6 / 15 / 2009 \\
0: 00\end{array}$ & $\begin{array}{r}/ 15 / 2009 \\
1: 00\end{array}$ & 909.8 & 8069.1 & 2.8 & 2.4 & 647.2 & 1.1 & 775.9 & 783.8 & 318.1 & 313.6 & 2358.6 & 10.3 & 2.1 & 0.5 & 10.8 & 4.6 & 5.3 \\
\hline $\begin{array}{r}6 / 15 / 2009 \\
1: 00\end{array}$ & $\begin{array}{r}6 / 15 / 2009 \\
2: 00\end{array}$ & 914.1 & 8069.1 & 2.8 & 2.3 & 647.7 & 1.1 & 775.3 & 781.9 & 318.2 & 312.8 & 2363.8 & 10.2 & 2.1 & 0.6 & 11.5 & 4.9 & 5.7 \\
\hline $\begin{array}{r}6 / 15 / 2009 \\
2: 00\end{array}$ & $\begin{array}{r}6 / 15 / 2009 \\
3: 00\end{array}$ & 903.0 & 8069.1 & 2.8 & 2.4 & 630.5 & 1.1 & 762.8 & 768.1 & 314.3 & 307.2 & 2350.3 & 9.9 & 2.2 & 0.5 & 10.9 & 5.4 & 6.4 \\
\hline $\begin{array}{r}6 / 15 / 2009 \\
3: 00\end{array}$ & $\begin{array}{r}6 / 15 / 2009 \\
4: 00\end{array}$ & 878.0 & 8069.1 & 2.9 & 2.4 & 611.8 & 1.1 & 758.2 & 762.0 & 308.6 & 301.3 & 2293.4 & 9.7 & 2.2 & 0.6 & 9.7 & 5.5 & 6.6 \\
\hline $\begin{array}{r}6 / 15 / 2009 \\
4: 00\end{array}$ & $\begin{array}{r}6 / 15 / 2009 \\
5: 00\end{array}$ & 835.7 & 8069.1 & 3.0 & 2.4 & 587.7 & 1.1 & 749.5 & 753.9 & 306.5 & 297.5 & 2215.0 & 9.7 & 2.2 & 0.5 & 8.8 & $\# \mathrm{~N} / \mathrm{A}$ & $\# \mathrm{~N} / \mathrm{A}$ \\
\hline $\begin{array}{r}6 / 15 / 2009 \\
5: 00\end{array}$ & $\begin{array}{r}6 / 15 / 2009 \\
6: 00\end{array}$ & 896.9 & 8069.1 & 3.0 & 2.5 & 627.2 & 1.1 & 761.8 & 767.0 & 306.9 & 300.7 & 2348.8 & 8.9 & 2.2 & 0.6 & 9.4 & $\# \mathrm{~N} / \mathrm{A}$ & $\# \mathrm{~N} / \mathrm{A}$ \\
\hline $\begin{array}{r}6 / 15 / 2009 \\
6: 00\end{array}$ & $\begin{array}{r}6 / 15 / 2009 \\
7: 00\end{array}$ & 902.0 & 8069.1 & 2.9 & 2.4 & 634.0 & 1.1 & 764.9 & 766.1 & 308.1 & 300.7 & 2358.2 & 8.9 & 2.2 & 0.6 & 10.1 & $\# \mathrm{~N} / \mathrm{A}$ & $\# \mathrm{~N} / \mathrm{A}$ \\
\hline $\begin{array}{r}6 / 15 / 2009 \\
7: 00\end{array}$ & $\begin{array}{r}6 / 15 / 2009 \\
8: 00\end{array}$ & 903.7 & 8029.9 & 2.9 & 2.5 & 640.5 & 1.1 & 766.4 & 767.2 & 308.7 & 301.1 & 2366.5 & 9.0 & 2.2 & 0.6 & 10.5 & 6.1 & 7.3 \\
\hline $\begin{array}{r}6 / 15 / 2009 \\
8: 00\end{array}$ & $\begin{array}{r}6 / 15 / 2009 \\
9: 00\end{array}$ & 908.7 & 8038.2 & 2.8 & 2.5 & 640.3 & 1.1 & 771.0 & 770.0 & 310.5 & 302.8 & 2370.9 & 8.9 & 2.2 & 0.6 & 10.2 & 6.2 & 7.3 \\
\hline $\begin{array}{r}6 / 15 / 2009 \\
9: 00\end{array}$ & $\begin{array}{r}6 / 15 / 2009 \\
10: 00\end{array}$ & 908.0 & 8051.1 & 2.7 & 2.6 & 634.5 & 1.1 & 773.2 & 766.7 & 313.1 & 304.0 & 2366.0 & 9.7 & 2.4 & 0.6 & 11.0 & 6.6 & 7.7 \\
\hline $\begin{array}{r}6 / 15 / 2009 \\
10: 00\end{array}$ & $\begin{array}{r}6 / 15 / 2009 \\
11: 00\end{array}$ & 906.5 & 8015.7 & 2.7 & 2.6 & 629.9 & 1.1 & 773.2 & 762.9 & 314.3 & 303.6 & 2365.2 & 11.6 & 2.6 & 0.6 & 11.2 & 7.0 & 7.9 \\
\hline $\begin{array}{r}6 / 15 / 2009 \\
11: 00\end{array}$ & $\begin{array}{r}6 / 15 / 2009 \\
12: 00\end{array}$ & 906.1 & 8003.5 & 2.7 & 2.6 & 631.8 & 1.1 & 772.5 & 763.3 & 315.5 & 305.4 & 2360.4 & 12.1 & 2.8 & 0.6 & 10.8 & 7.4 & 8.2 \\
\hline $\begin{array}{r}6 / 15 / 2009 \\
12: 00\end{array}$ & $\begin{array}{r}6 / 15 / 2009 \\
13: 00\end{array}$ & 907.2 & 8003.5 & 3.0 & 2.4 & 633.4 & 1.1 & 771.9 & 763.0 & 316.4 & 308.0 & 2429.1 & 13.0 & 2.9 & 0.6 & 11.9 & 7.6 & 8.3 \\
\hline $\begin{array}{r}6 / 15 / 2009 \\
13: 00\end{array}$ & $\begin{array}{r}6 / 15 / 2009 \\
14: 00\end{array}$ & 910.4 & 8003.5 & 3.1 & 2.3 & 637.0 & 1.1 & 769.3 & 751.4 & 318.1 & 311.6 & 2588.0 & 12.7 & 2.8 & 0.6 & 11.3 & 7.1 & 7.8 \\
\hline $\begin{array}{r}6 / 15 / 2009 \\
14: 00\end{array}$ & $\begin{array}{r}6 / 15 / 2009 \\
15: 00\end{array}$ & 911.7 & 8003.5 & 3.0 & 2.3 & 638.0 & 1.1 & 771.8 & 755.5 & 318.6 & 312.2 & 2598.7 & 9.5 & 2.7 & 0.6 & 11.1 & 7.1 & 7.9 \\
\hline $\begin{array}{r}6 / 15 / 2009 \\
15: 00 \\
\end{array}$ & $\begin{array}{r}6 / 15 / 2009 \\
16: 00 \\
\end{array}$ & 911.4 & 8003.5 & 3.0 & 2.3 & 640.2 & 1.1 & 774.1 & 760.6 & 320.8 & 314.7 & 2568.3 & 8.2 & 2.5 & 0.5 & 11.8 & 7.0 & 7.8 \\
\hline $\begin{array}{r}6 / 15 / 2009 \\
16: 00\end{array}$ & $\begin{array}{r}6 / 15 / 2009 \\
17: 00\end{array}$ & 911.2 & 8023.9 & 3.0 & 2.3 & 641.2 & 1.1 & 771.0 & 758.9 & 322.7 & 317.0 & 2392.3 & 7.1 & 2.3 & 0.5 & 12.6 & 7.3 & 8.3 \\
\hline $\begin{array}{r}6 / 15 / 2009 \\
17: 00\end{array}$ & $\begin{array}{r}6 / 15 / 2009 \\
18: 00\end{array}$ & 910.3 & 8026.5 & 3.0 & 2.3 & 646.3 & 1.1 & 773.7 & 760.3 & 322.3 & 316.5 & 2366.7 & 6.0 & 2.0 & 0.5 & 11.4 & 7.2 & 8.5 \\
\hline $\begin{array}{r}6 / 15 / 2009 \\
18: 00\end{array}$ & $\begin{array}{r}6 / 15 / 2009 \\
19: 00\end{array}$ & 910.1 & 8078.5 & 3.0 & 2.3 & 651.5 & 1.1 & 771.0 & 758.6 & 322.4 & 317.2 & 2363.9 & 5.2 & 2.0 & 0.6 & 11.0 & 7.2 & 8.8 \\
\hline $6 / 15 / 2009$ & $6 / 15 / 2009$ & 914.7 & 8030.0 & 2.9 & 2.3 & 647.2 & 1.1 & 772.3 & 758.4 & 320.7 & 315.1 & 2358.1 & 5.0 & 1.9 & 0.6 & 13.7 & 7.0 & 8.8 \\
\hline
\end{tabular}




\begin{tabular}{|c|c|c|c|c|c|c|c|c|c|c|c|c|c|c|c|c|c|c|}
\hline $\begin{array}{l}\text { Start } \\
\text { Date/ } \\
\text { Time }\end{array}$ & $\begin{array}{l}\text { End } \\
\text { Date/ } \\
\text { Time }\end{array}$ & $\begin{array}{l}\text { Gross } \\
\text { Load }\end{array}$ & $\begin{array}{c}\text { Gross } \\
\text { HR }\end{array}$ & $\begin{array}{c}\text { A } \\
\text { Econ } \\
\text { O2 }\end{array}$ & $\begin{array}{c}\text { B } \\
\text { Econ } \\
\text { O2 }\end{array}$ & $\begin{array}{l}\text { Fuel } \\
\text { Flow }\end{array}$ & $\begin{array}{l}\text { BTU } \\
\text { Gain }\end{array}$ & $\begin{array}{c}\text { A } \\
\text { APH } \\
\text { In }\end{array}$ & $\begin{array}{c}\text { B } \\
\text { APH } \\
\text { In }\end{array}$ & $\begin{array}{c}\text { A } \\
\text { APH } \\
\text { Out }\end{array}$ & $\begin{array}{c}\text { B } \\
\text { APH } \\
\text { Out }\end{array}$ & $\begin{array}{l}\text { Stack } \\
\text { Flow }\end{array}$ & Opacity & SO2 In & $\begin{array}{l}\text { SO2 } \\
\text { Out }\end{array}$ & $\mathrm{CO}$ & $\begin{array}{c}\text { Stack } \\
\text { SCEM } \\
\text { Elemental } \\
\mathrm{Hg}\end{array}$ & $\begin{array}{c}\text { Stack } \\
\text { SCEM } \\
\text { Total Hg }\end{array}$ \\
\hline & & MW & Btu/kWh & $\%$ & $\%$ & Ton/hr & & DEGF & DEGF & DEGF & DEGF & KSCF & $\%$ & Ib/MMB & $\mathrm{Ib} / \mathrm{MMb}$ & PPM & $\begin{array}{c}\text { ( } \mu \mathrm{g} / \mathrm{dNm}) \\
@ 3 \% 02\end{array}$ & $\begin{array}{c}(\mu \mathrm{g} / \mathrm{dNm} 3) \\
\text { @ 3\%O2 }\end{array}$ \\
\hline $19: 00$ & $20: 00$ & & & & & & & & & & & & & & & & & \\
\hline $\begin{array}{r}6 / 15 / 2009 \\
20: 00 \\
\end{array}$ & $\begin{array}{r}6 / 15 / 2009 \\
21: 00 \\
\end{array}$ & 912.1 & 8035.2 & 3.0 & 2.3 & 645.5 & 1.1 & 774.2 & 761.6 & 320.1 & 315.0 & 2360.9 & 4.9 & 1.9 & 0.5 & 10.3 & 6.9 & 8.6 \\
\hline $\begin{array}{r}6 / 15 / 2009 \\
21: 00\end{array}$ & $\begin{array}{r}6 / 15 / 2009 \\
22: 00\end{array}$ & 912.1 & 8031.0 & 3.0 & 2.3 & 640.7 & 1.1 & 776.3 & 763.7 & 319.5 & 314.2 & 2362.3 & 5.0 & 2.0 & 0.5 & 10.4 & 6.8 & 8.5 \\
\hline $\begin{array}{r}6 / 15 / 2009 \\
22: 00\end{array}$ & $\begin{array}{r}6 / 15 / 2009 \\
23: 00 \\
\end{array}$ & 911.2 & 8012.4 & 2.9 & 2.4 & 639.7 & 1.1 & 776.9 & 763.7 & 318.9 & 312.9 & 2360.3 & 5.5 & 2.0 & 0.5 & 11.4 & 6.9 & 8.5 \\
\hline $\begin{array}{r}6 / 15 / 2009 \\
23: 00\end{array}$ & $\begin{array}{r}6 / 16 / 2009 \\
0: 00\end{array}$ & 912.1 & 7999.6 & 2.9 & 2.4 & 642.4 & 1.1 & 778.5 & 765.4 & 318.3 & 311.7 & 2361.8 & 5.4 & 2.0 & 0.5 & 11.7 & 6.8 & 8.2 \\
\hline $\begin{array}{r}6 / 16 / 2009 \\
0: 00\end{array}$ & $\begin{array}{r}6 / 16 / 2009 \\
1: 00\end{array}$ & 906.6 & 8052.3 & 2.9 & 2.5 & 634.0 & 1.1 & 769.1 & 757.2 & 317.2 & 310.9 & 2359.9 & 5.4 & 2.0 & 0.5 & 12.0 & 6.6 & 7.9 \\
\hline $\begin{array}{r}6 / 16 / 2009 \\
1: 00\end{array}$ & $\begin{array}{r}6 / 16 / 2009 \\
2: 00\end{array}$ & 902.1 & 8011.1 & 2.8 & 2.5 & 623.8 & 1.1 & 765.9 & 752.9 & 313.2 & 306.1 & 2363.6 & 5.8 & 2.1 & 0.5 & 14.8 & 6.5 & 7.7 \\
\hline $\begin{array}{r}6 / 16 / 2009 \\
2: 00\end{array}$ & $\begin{array}{r}6 / 16 / 2009 \\
3: 00 \\
\end{array}$ & 901.6 & 7965.2 & 2.9 & 2.5 & 616.0 & 1.1 & 770.8 & 753.9 & 312.9 & 305.1 & 2335.4 & 6.4 & 2.1 & 0.5 & 14.5 & 6.5 & 7.6 \\
\hline $\begin{array}{r}6 / 16 / 2009 \\
3: 00\end{array}$ & $\begin{array}{r}6 / 16 / 2009 \\
4: 00 \\
\end{array}$ & 901.9 & 7933.5 & 2.9 & 2.4 & 619.9 & 1.1 & 774.3 & 758.9 & 313.5 & 305.5 & 2322.0 & 6.3 & 2.1 & 0.5 & 13.4 & 6.4 & 7.6 \\
\hline $\begin{array}{r}6 / 16 / 2009 \\
4: 00\end{array}$ & $\begin{array}{r}6 / 16 / 2009 \\
5: 00 \\
\end{array}$ & 893.1 & 7965.0 & 2.9 & 2.4 & 616.6 & 1.1 & 774.6 & 759.8 & 313.9 & 306.1 & 2311.2 & 5.6 & 2.0 & 0.5 & 11.6 & 6.4 & 7.7 \\
\hline $\begin{array}{r}6 / 16 / 2009 \\
5: 00 \\
\end{array}$ & $\begin{array}{r}6 / 16 / 2009 \\
6: 00 \\
\end{array}$ & 893.2 & 7958.3 & 2.9 & 2.4 & 622.5 & 1.1 & 776.1 & 762.4 & 314.0 & 305.6 & 2326.1 & 4.9 & 2.0 & 0.5 & 10.2 & \#N/A & $\# \mathrm{~N} / \mathrm{A}$ \\
\hline $\begin{array}{r}6 / 16 / 2009 \\
6: 00\end{array}$ & $\begin{array}{r}6 / 16 / 2009 \\
7: 00\end{array}$ & 901.8 & 7960.2 & 2.9 & 2.4 & 625.0 & 1.1 & 780.3 & 767.0 & 314.4 & 307.5 & 2352.9 & 4.9 & 1.9 & 0.5 & 13.8 & $\# \mathrm{~N} / \mathrm{A}$ & $\# \mathrm{~N} / \mathrm{A}$ \\
\hline $\begin{array}{r}6 / 16 / 2009 \\
7: 00\end{array}$ & $\begin{array}{r}6 / 16 / 2009 \\
8: 00\end{array}$ & 905.8 & 8005.0 & 2.9 & 2.5 & 628.6 & 1.1 & 781.1 & 767.7 & 316.4 & 309.1 & 2364.1 & 4.6 & 1.8 & 0.5 & 11.1 & 5.9 & 7.6 \\
\hline $\begin{array}{r}6 / 16 / 2009 \\
8: 00\end{array}$ & $\begin{array}{r}6 / 16 / 2009 \\
9: 00\end{array}$ & 909.8 & 8026.6 & 2.9 & 2.5 & 635.7 & 1.1 & 772.1 & 759.6 & 315.3 & 308.2 & 2370.2 & 4.6 & 1.7 & 0.5 & 11.8 & 5.2 & 7.4 \\
\hline $\begin{array}{r}6 / 16 / 2009 \\
9: 00\end{array}$ & $\begin{array}{r}6 / 16 / 2009 \\
10: 00 \\
\end{array}$ & 912.1 & 7984.7 & 2.9 & 2.4 & 634.5 & 1.1 & 776.7 & 762.7 & 314.3 & 307.4 & 2363.1 & 4.7 & 1.7 & 0.5 & 13.3 & 5.0 & 7.1 \\
\hline $\begin{array}{r}6 / 16 / 2009 \\
10: 00\end{array}$ & $\begin{array}{r}6 / 16 / 2009 \\
11: 00\end{array}$ & 912.2 & 8015.0 & 2.8 & 2.4 & 628.9 & 1.1 & 772.8 & 760.4 & 317.1 & 309.9 & 2366.0 & 5.1 & 1.6 & 0.4 & 12.0 & 5.3 & 6.6 \\
\hline $\begin{array}{r}6 / 16 / 2009 \\
11: 00 \\
\end{array}$ & $\begin{array}{r}6 / 16 / 2009 \\
12: 00\end{array}$ & 909.8 & 8017.2 & 2.8 & 2.5 & 624.4 & 1.1 & 767.5 & 756.8 & 316.9 & 310.3 & 2367.5 & 5.3 & 1.7 & 0.4 & 10.6 & 5.2 & 6.3 \\
\hline $\begin{array}{r}6 / 16 / 2009 \\
12: 00 \\
\end{array}$ & $\begin{array}{r}6 / 16 / 2009 \\
13: 00 \\
\end{array}$ & 911.0 & 8014.9 & 2.8 & 2.5 & 628.8 & 1.1 & 773.0 & 763.1 & 319.0 & 313.5 & 2365.0 & 5.8 & 1.8 & 0.4 & 12.3 & 5.5 & 6.5 \\
\hline $\begin{array}{r}6 / 16 / 2009 \\
13: 00\end{array}$ & $\begin{array}{r}6 / 16 / 2009 \\
14: 00\end{array}$ & 911.5 & 8004.4 & 2.8 & 2.5 & 628.5 & 1.1 & 777.0 & 767.5 & 322.3 & 316.6 & 2342.0 & 6.3 & 1.8 & 0.4 & 11.9 & 5.5 & 6.5 \\
\hline $\begin{array}{r}6 / 16 / 2009 \\
14: 00\end{array}$ & $\begin{array}{r}6 / 16 / 2009 \\
15: 00 \\
\end{array}$ & 910.4 & 8026.8 & 2.9 & 2.4 & 631.8 & 1.1 & 775.4 & 766.4 & 321.3 & 316.7 & 2338.1 & 5.9 & 1.8 & 0.4 & 9.6 & 5.3 & 6.3 \\
\hline
\end{tabular}




\begin{tabular}{|c|c|c|c|c|c|c|c|c|c|c|c|c|c|c|c|c|c|c|}
\hline \multirow[t]{2}{*}{$\begin{array}{l}\text { Start } \\
\text { Date/ } \\
\text { Time }\end{array}$} & \multirow[t]{2}{*}{$\begin{array}{l}\text { End } \\
\text { Date/ } \\
\text { Time }\end{array}$} & $\begin{array}{l}\text { Gross } \\
\text { Load }\end{array}$ & $\begin{array}{c}\text { Gross } \\
\text { HR }\end{array}$ & $\begin{array}{c}\text { A } \\
\text { Econ } \\
\text { O2 }\end{array}$ & $\begin{array}{c}\text { B } \\
\text { Econ } \\
\text { O2 }\end{array}$ & $\begin{array}{l}\text { Fuel } \\
\text { Flow }\end{array}$ & $\begin{array}{l}\text { BTU } \\
\text { Gain }\end{array}$ & $\begin{array}{c}\text { A } \\
\text { APH } \\
\text { In }\end{array}$ & $\begin{array}{c}\text { B } \\
\text { APH } \\
\text { In }\end{array}$ & $\begin{array}{c}\text { A } \\
\text { APH } \\
\text { Out }\end{array}$ & $\begin{array}{c}\text { B } \\
\text { APH } \\
\text { Out }\end{array}$ & $\begin{array}{l}\text { Stack } \\
\text { Flow }\end{array}$ & Opacity & SO2 In & $\begin{array}{l}\text { SO2 } \\
\text { Out }\end{array}$ & $\mathrm{CO}$ & $\begin{array}{c}\text { Stack } \\
\text { SCEM } \\
\text { Elemental } \\
\mathrm{Hg}\end{array}$ & $\begin{array}{c}\text { Stack } \\
\text { SCEM } \\
\text { Total Hg }\end{array}$ \\
\hline & & MW & Btu/kWh & $\%$ & $\%$ & Ton/hr & & DEGF & DEGF & DEGF & DEGF & KSCF & $\%$ & $\mathrm{Ib} / \mathrm{MMB}$ & $\mathrm{Ib} / \mathrm{MMb}$ & PPM & $\begin{array}{c}\text { ( } \mu \mathrm{g} / \mathrm{dNm} \text { ) } \\
@ 3 \% 02\end{array}$ & $\begin{array}{c}(\mu \mathrm{g} / \mathrm{dNm} 3) \\
@ 3 \% 02\end{array}$ \\
\hline $\begin{array}{r}6 / 16 / 2009 \\
15: 00\end{array}$ & $\begin{array}{r}6 / 16 / 2009 \\
16: 00\end{array}$ & 913.7 & 7994.3 & 2.9 & 2.3 & 630.6 & 1.1 & 768.0 & 760.0 & 322.8 & 319.8 & 2336.9 & 5.8 & 1.9 & 0.4 & 9.2 & 5.4 & 6.3 \\
\hline $\begin{array}{r}6 / 16 / 2009 \\
16: 00\end{array}$ & $\begin{array}{r}6 / 16 / 2009 \\
17: 00\end{array}$ & 890.9 & 8070.5 & 2.9 & 2.2 & 619.5 & 1.1 & 763.2 & 756.9 & 324.4 & 321.4 & 2290.5 & 5.3 & 1.9 & 0.4 & 25.4 & 5.3 & 6.3 \\
\hline $\begin{array}{r}6 / 16 / 2009 \\
17: 00\end{array}$ & $\begin{array}{r}6 / 16 / 2009 \\
18: 00\end{array}$ & 845.0 & 8033.1 & 2.8 & 2.2 & 591.2 & 1.1 & 750.2 & 742.5 & 322.7 & 318.2 & 2179.1 & 5.0 & 1.8 & 0.4 & 20.8 & 5.0 & 6.0 \\
\hline $\begin{array}{r}6 / 16 / 2009 \\
18: 00\end{array}$ & $\begin{array}{r}6 / 16 / 2009 \\
19: 00\end{array}$ & 890.8 & 8008.4 & 2.9 & 2.4 & 630.2 & 1.1 & 763.0 & 754.3 & 319.3 & 313.7 & 2297.3 & 5.0 & 1.8 & 0.4 & 13.4 & 5.1 & 6.2 \\
\hline $\begin{array}{r}6 / 16 / 2009 \\
19: 00\end{array}$ & $\begin{array}{r}6 / 16 / 2009 \\
20: 00\end{array}$ & 911.9 & 8001.9 & 2.9 & 2.3 & 650.5 & 1.1 & 776.4 & 768.6 & 321.6 & 317.0 & 2347.9 & 4.9 & 1.8 & 0.5 & 9.1 & 5.3 & 6.7 \\
\hline $\begin{array}{r}6 / 16 / 2009 \\
20: 00\end{array}$ & $\begin{array}{r}6 / 16 / 2009 \\
21: 00\end{array}$ & 913.0 & 8013.3 & 2.9 & 2.3 & 652.1 & 1.0 & 778.2 & 770.1 & 322.8 & 318.0 & 2355.3 & 5.8 & 1.8 & 0.5 & 9.1 & 5.5 & 7.0 \\
\hline $\begin{array}{r}6 / 16 / 2009 \\
21: 00\end{array}$ & $\begin{array}{r}6 / 16 / 2009 \\
22: 00\end{array}$ & 915.2 & 8012.8 & 2.8 & 2.3 & 653.2 & 1.0 & 773.7 & 766.1 & 322.0 & 317.3 & 2368.2 & 8.2 & 1.9 & 0.5 & 10.6 & 5.7 & 7.1 \\
\hline $\begin{array}{r}6 / 16 / 2009 \\
22: 00\end{array}$ & $\begin{array}{r}6 / 16 / 2009 \\
23: 00\end{array}$ & 913.4 & 8028.9 & 2.8 & 2.4 & 643.6 & 1.0 & 767.6 & 758.6 & 318.5 & 313.6 & 2343.1 & 7.8 & 1.9 & 0.5 & 10.4 & 5.6 & 7.0 \\
\hline $\begin{array}{r}6 / 16 / 2009 \\
23: 00\end{array}$ & $\begin{array}{r}6 / 17 / 2009 \\
0: 00\end{array}$ & 910.8 & 8016.2 & 2.9 & 2.3 & 634.2 & 1.1 & 773.4 & 765.4 & 317.3 & 312.8 & 2325.1 & 8.0 & 1.8 & 0.5 & 9.9 & 5.3 & 6.7 \\
\hline $\begin{array}{r}6 / 17 / 2009 \\
0: 00 \\
\end{array}$ & $\begin{array}{r}6 / 17 / 2009 \\
1: 00 \\
\end{array}$ & 909.4 & 8020.1 & 2.9 & 2.3 & 632.4 & 1.1 & 777.6 & 768.1 & 317.8 & 313.0 & 2346.0 & 8.4 & 1.8 & 0.5 & 9.1 & 4.4 & 5.8 \\
\hline $\begin{array}{r}6 / 17 / 2009 \\
1: 00\end{array}$ & $\begin{array}{r}6 / 17 / 2009 \\
2: 00\end{array}$ & 892.9 & 8047.8 & 2.8 & 2.2 & 611.3 & 1.1 & 771.0 & 760.5 & 316.8 & 310.7 & 2302.3 & 8.1 & 1.7 & 0.5 & 10.3 & 3.9 & 5.2 \\
\hline $\begin{array}{r}6 / 17 / 2009 \\
2: 00\end{array}$ & $\begin{array}{r}6 / 17 / 2009 \\
3: 00\end{array}$ & 823.7 & 7971.5 & 2.9 & 2.1 & 553.9 & 1.1 & 749.8 & 740.3 & 311.1 & 301.6 & 2132.1 & 6.7 & 1.8 & 0.5 & 9.9 & 3.4 & 4.6 \\
\hline $\begin{array}{r}6 / 17 / 2009 \\
3: 00\end{array}$ & $\begin{array}{r}6 / 17 / 2009 \\
4: 00\end{array}$ & 767.6 & 7967.2 & 2.9 & 2.2 & 525.9 & 1.1 & 723.4 & 715.2 & 304.3 & 294.0 & 2060.2 & 5.8 & 1.9 & 0.5 & 8.3 & 3.4 & 4.5 \\
\hline $\begin{array}{r}6 / 17 / 2009 \\
4: 00\end{array}$ & $\begin{array}{r}6 / 17 / 2009 \\
5: 00\end{array}$ & 776.5 & 7826.3 & 2.7 & 2.2 & 531.1 & 1.1 & 729.1 & 718.7 & 300.2 & 289.4 & 2075.9 & 5.7 & 1.9 & 0.5 & 9.0 & $\# \mathrm{~N} / \mathrm{A}$ & $\# \mathrm{~N} / \mathrm{A}$ \\
\hline $\begin{array}{r}6 / 17 / 2009 \\
5: 00 \\
\end{array}$ & $\begin{array}{r}6 / 17 / 2009 \\
6: 00 \\
\end{array}$ & 801.7 & 7861.6 & 2.8 & 2.2 & 550.0 & 1.1 & 739.0 & 728.7 & 299.7 & 293.6 & 2168.3 & 7.9 & 1.9 & 0.5 & 11.4 & $\# \mathrm{~N} / \mathrm{A}$ & $\# \mathrm{~N} / \mathrm{A}$ \\
\hline $\begin{array}{r}6 / 17 / 2009 \\
6: 00 \\
\end{array}$ & $\begin{array}{r}6 / 17 / 2009 \\
7: 00 \\
\end{array}$ & 811.8 & 7906.8 & 2.7 & 2.1 & 544.7 & 1.1 & 750.6 & 740.7 & 302.3 & 300.3 & 2116.9 & 6.5 & 1.9 & 0.5 & 12.5 & $\# \mathrm{~N} / \mathrm{A}$ & $\# \mathrm{~N} / \mathrm{A}$ \\
\hline $\begin{array}{r}6 / 17 / 2009 \\
7: 00\end{array}$ & $\begin{array}{r}6 / 17 / 2009 \\
8: 00\end{array}$ & 801.3 & 7879.4 & 2.9 & 2.1 & 536.4 & 1.1 & 750.1 & 740.2 & 304.6 & 301.6 & 2093.4 & 6.8 & 1.7 & 0.5 & 9.1 & 3.1 & 4.7 \\
\hline $\begin{array}{r}6 / 17 / 2009 \\
8: 00\end{array}$ & $\begin{array}{r}6 / 17 / 2009 \\
9: 00\end{array}$ & 812.4 & 7905.6 & 2.9 & 2.1 & 550.5 & 1.1 & 755.4 & 744.9 & 309.2 & 303.4 & 2126.2 & 4.4 & 1.6 & 0.5 & 8.9 & 2.8 & 4.4 \\
\hline $\begin{array}{r}6 / 17 / 2009 \\
9: 00\end{array}$ & $\begin{array}{r}6 / 17 / 2009 \\
10: 00\end{array}$ & 874.4 & 7962.4 & 2.8 & 2.3 & 593.6 & 1.1 & 762.8 & 751.2 & 313.2 & 306.6 & 2255.6 & 5.8 & 1.7 & 0.5 & 14.1 & 3.6 & 5.1 \\
\hline $6 / 17 / 2009$ & $6 / 17 / 2009$ & 900.9 & 7943.0 & 2.6 & 2.3 & 601.3 & 1.1 & 764.9 & 751.5 & 311.1 & 304.3 & 2304.5 & 6.2 & 1.8 & 0.5 & 22.0 & 4.0 & 5.1 \\
\hline
\end{tabular}




\begin{tabular}{|c|c|c|c|c|c|c|c|c|c|c|c|c|c|c|c|c|c|c|}
\hline \multirow[t]{2}{*}{$\begin{array}{l}\text { Start } \\
\text { Date/ } \\
\text { Time }\end{array}$} & \multirow[t]{2}{*}{$\begin{array}{l}\text { End } \\
\text { Date/ } \\
\text { Time }\end{array}$} & $\begin{array}{l}\text { Gross } \\
\text { Load }\end{array}$ & $\begin{array}{c}\text { Gross } \\
\text { HR }\end{array}$ & $\begin{array}{c}\text { A } \\
\text { Econ } \\
\text { O2 }\end{array}$ & $\begin{array}{c}\text { B } \\
\text { Econ } \\
\text { O2 }\end{array}$ & $\begin{array}{l}\text { Fuel } \\
\text { Flow }\end{array}$ & $\begin{array}{l}\text { BTU } \\
\text { Gain }\end{array}$ & $\begin{array}{c}\text { A } \\
\text { APH } \\
\text { In }\end{array}$ & $\begin{array}{c}\text { B } \\
\text { APH } \\
\text { In }\end{array}$ & $\begin{array}{c}\text { A } \\
\text { APH } \\
\text { Out }\end{array}$ & $\begin{array}{c}\text { B } \\
\text { APH } \\
\text { Out }\end{array}$ & $\begin{array}{l}\text { Stack } \\
\text { Flow }\end{array}$ & Opacity & SO2 In & $\begin{array}{l}\text { SO2 } \\
\text { Out }\end{array}$ & $\mathrm{CO}$ & $\begin{array}{c}\text { Stack } \\
\text { SCEM } \\
\text { Elemental } \\
\mathrm{Hg}\end{array}$ & $\begin{array}{c}\text { Stack } \\
\text { SCEM } \\
\text { Total Hg }\end{array}$ \\
\hline & & MW & Btu/kWh & $\%$ & $\%$ & Ton/hr & & DEGF & DEGF & DEGF & DEGF & KSCF & $\%$ & $\mathrm{Ib} / \mathrm{MMB}$ & $\mathrm{lb} / \mathrm{MMb}$ & PPM & $\begin{array}{c}(\mu \mathrm{g} / \mathrm{dNm} 3) \\
@ 3 \% 02\end{array}$ & $\begin{array}{c}(\mu \mathrm{g} / \mathrm{dNm} 3) \\
\text { @ 3\%O2 }\end{array}$ \\
\hline $10: 00$ & $11: 00$ & & & & & & & & & & & & & & & & & \\
\hline $\begin{array}{r}6 / 17 / 2009 \\
11: 00\end{array}$ & $\begin{array}{r}6 / 17 / 2009 \\
12: 00\end{array}$ & 903.3 & 7949.6 & 2.6 & 2.4 & 598.6 & 1.1 & 763.0 & 751.9 & 307.4 & 301.2 & 2304.0 & 6.0 & 1.7 & 0.5 & 16.1 & 3.8 & 4.8 \\
\hline $\begin{array}{r}6 / 17 / 2009 \\
12: 00\end{array}$ & $\begin{array}{r}6 / 17 / 2009 \\
13: 00\end{array}$ & 893.1 & 8016.0 & 2.7 & 2.3 & 593.8 & 1.1 & 763.1 & 752.3 & 307.9 & 302.5 & 2282.7 & 6.1 & 1.8 & 0.5 & 11.9 & 4.1 & 5.1 \\
\hline $\begin{array}{r}6 / 17 / 2009 \\
13: 00 \\
\end{array}$ & $\begin{array}{r}6 / 17 / 2009 \\
14: 00 \\
\end{array}$ & 909.1 & 8023.3 & 2.7 & 2.2 & 609.8 & 1.1 & 767.2 & 756.6 & 310.9 & 306.2 & 2304.7 & 6.6 & 1.9 & 0.5 & 14.0 & 4.4 & 5.2 \\
\hline $\begin{array}{r}6 / 17 / 2009 \\
14: 00\end{array}$ & $\begin{array}{r}6 / 17 / 2009 \\
15: 00\end{array}$ & 912.6 & 7986.0 & 2.8 & 2.1 & 608.7 & 1.1 & 772.1 & 759.2 & 314.5 & 310.3 & 2300.8 & 6.9 & 1.9 & 0.5 & 15.5 & 4.6 & 5.4 \\
\hline $\begin{array}{r}6 / 17 / 2009 \\
15: 00\end{array}$ & $\begin{array}{r}6 / 17 / 2009 \\
16: 00\end{array}$ & 914.6 & 7992.8 & 2.8 & 2.1 & 603.6 & 1.1 & 774.5 & 760.9 & 317.4 & 312.9 & 2305.4 & 6.5 & 1.8 & 0.5 & 18.2 & 4.3 & 5.1 \\
\hline $\begin{array}{r}6 / 17 / 2009 \\
16: 00\end{array}$ & $\begin{array}{r}6 / 17 / 2009 \\
17: 00\end{array}$ & 912.2 & 8035.3 & 2.8 & 2.1 & 601.3 & 1.1 & 773.9 & 763.8 & 319.7 & 315.3 & 2307.8 & 6.0 & 1.8 & 0.5 & 14.6 & 4.0 & 4.8 \\
\hline $\begin{array}{r}6 / 17 / 2009 \\
17: 00\end{array}$ & $\begin{array}{r}6 / 17 / 2009 \\
18: 00\end{array}$ & 910.8 & 8018.3 & 2.8 & 2.1 & 601.1 & 1.1 & 761.3 & 760.1 & 317.1 & 314.0 & 2302.6 & 5.6 & 1.7 & 0.5 & 13.6 & 3.8 & 4.7 \\
\hline $\begin{array}{r}6 / 17 / 2009 \\
18: 00\end{array}$ & $\begin{array}{r}6 / 17 / 2009 \\
19: 00\end{array}$ & 910.7 & 7984.9 & 2.8 & 2.1 & 606.5 & 1.1 & 766.9 & 763.4 & 315.8 & 313.4 & 2317.7 & 5.5 & 1.8 & 0.5 & 14.7 & 4.2 & 5.0 \\
\hline $\begin{array}{r}6 / 17 / 2009 \\
19: 00 \\
\end{array}$ & $\begin{array}{r}6 / 17 / 2009 \\
20: 00 \\
\end{array}$ & 913.8 & 7996.8 & 2.8 & 2.1 & 605.7 & 1.1 & 770.8 & 767.4 & 316.7 & 314.0 & 2309.5 & 5.9 & 1.9 & 0.5 & 13.4 & 4.5 & 5.3 \\
\hline $\begin{array}{r}/ 17 / 2009 \\
20: 00 \\
\end{array}$ & $\begin{array}{r}6 / 17 / 2009 \\
21: 00 \\
\end{array}$ & 915.3 & 8004.8 & 2.8 & 2.0 & 601.6 & 1.1 & 774.0 & 770.5 & 317.3 & 314.3 & 2299.9 & 5.8 & 1.9 & 0.5 & 13.3 & 4.4 & 5.1 \\
\hline $\begin{array}{r}6 / 17 / 2009 \\
21: 00\end{array}$ & $\begin{array}{r}6 / 17 / 2009 \\
22: 00\end{array}$ & 914.4 & 7984.9 & 2.7 & 2.1 & 596.6 & 1.1 & 774.3 & 770.0 & 317.7 & 314.5 & 2301.8 & 5.3 & 1.8 & 0.5 & 12.3 & 4.1 & 4.8 \\
\hline $\begin{array}{r}6 / 17 / 2009 \\
22: 00\end{array}$ & $\begin{array}{r}6 / 17 / 2009 \\
23: 00\end{array}$ & 911.7 & 7939.5 & 2.7 & 2.1 & 590.1 & 1.1 & 763.4 & 760.0 & 313.6 & 310.5 & 2283.5 & 5.1 & 1.7 & 0.5 & 12.1 & 3.7 & 4.6 \\
\hline $\begin{array}{r}6 / 17 / 2009 \\
23: 00\end{array}$ & $\begin{array}{r}6 / 18 / 2009 \\
0: 00\end{array}$ & 906.0 & 8014.2 & 2.7 & 2.1 & 589.5 & 1.1 & 759.1 & 756.2 & 310.3 & 306.9 & 2268.9 & 5.2 & 1.7 & 0.4 & 14.2 & 3.7 & 4.6 \\
\hline $\begin{array}{r}6 / 18 / 2009 \\
0: 00 \\
\end{array}$ & $\begin{array}{r}6 / 18 / 2009 \\
1: 00 \\
\end{array}$ & 909.9 & 8001.4 & 2.7 & 2.1 & 602.7 & 1.1 & 764.7 & 759.5 & 309.4 & 306.0 & 2277.6 & 4.9 & 1.7 & 0.4 & 22.8 & 3.8 & 4.7 \\
\hline $\begin{array}{r}6 / 18 / 2009 \\
1: 00 \\
\end{array}$ & $\begin{array}{r}6 / 18 / 2009 \\
2: 00 \\
\end{array}$ & 911.2 & 8009.4 & 2.7 & 2.0 & 606.6 & 1.1 & 770.2 & 763.4 & 310.2 & 306.7 & 2297.2 & 5.0 & 1.8 & 0.5 & 23.6 & 4.2 & 5.0 \\
\hline $\begin{array}{r}6 / 18 / 2009 \\
2: 00 \\
\end{array}$ & $\begin{array}{r}6 / 18 / 2009 \\
3: 00 \\
\end{array}$ & 911.3 & 8000.5 & 2.7 & 2.0 & 603.4 & 1.1 & 772.6 & 767.0 & 310.3 & 306.6 & 2290.8 & 5.2 & 1.9 & 0.5 & 23.5 & 4.6 & 5.4 \\
\hline $\begin{array}{r}6 / 18 / 2009 \\
3: 00 \\
\end{array}$ & $\begin{array}{r}6 / 18 / 2009 \\
4: 00 \\
\end{array}$ & 823.3 & 7983.1 & 2.7 & 2.0 & 543.9 & 1.1 & 753.5 & 750.0 & 308.2 & 302.7 & 2098.7 & 5.0 & 1.8 & 0.5 & 16.7 & 3.9 & 4.7 \\
\hline $\begin{array}{r}6 / 18 / 2009 \\
4: 00\end{array}$ & $\begin{array}{r}6 / 18 / 2009 \\
5: 00\end{array}$ & 735.8 & 7981.0 & 2.9 & 2.1 & 502.0 & 1.1 & 715.6 & 709.9 & 299.4 & 292.4 & 1997.1 & 4.6 & 1.9 & 0.5 & 8.5 & 3.5 & 4.4 \\
\hline $\begin{array}{r}6 / 18 / 2009 \\
5: 00\end{array}$ & $\begin{array}{r}6 / 18 / 2009 \\
6: 00\end{array}$ & 869.9 & 7751.3 & 2.7 & 2.1 & 596.7 & 1.1 & 753.6 & 744.7 & 301.4 & 295.8 & 2297.7 & 5.3 & 1.8 & 0.5 & 17.1 & $\# \mathrm{~N} / \mathrm{A}$ & $\# \mathrm{~N} / \mathrm{A}$ \\
\hline
\end{tabular}




\begin{tabular}{|c|c|c|c|c|c|c|c|c|c|c|c|c|c|c|c|c|c|c|}
\hline \multirow[t]{2}{*}{$\begin{array}{l}\text { Start } \\
\text { Date/ } \\
\text { Time }\end{array}$} & \multirow[t]{2}{*}{$\begin{array}{l}\text { End } \\
\text { Date/ } \\
\text { Time }\end{array}$} & $\begin{array}{l}\text { Gross } \\
\text { Load }\end{array}$ & $\begin{array}{c}\text { Gross } \\
\text { HR }\end{array}$ & $\begin{array}{c}\text { A } \\
\text { Econ } \\
\text { O2 }\end{array}$ & $\begin{array}{c}\text { B } \\
\text { Econ } \\
\text { O2 }\end{array}$ & $\begin{array}{l}\text { Fuel } \\
\text { Flow }\end{array}$ & $\begin{array}{l}\text { BTU } \\
\text { Gain }\end{array}$ & $\begin{array}{c}\text { A } \\
\text { APH } \\
\text { In }\end{array}$ & $\begin{array}{c}\text { B } \\
\text { APH } \\
\text { In }\end{array}$ & $\begin{array}{c}\text { A } \\
\text { APH } \\
\text { Out }\end{array}$ & $\begin{array}{c}\text { B } \\
\text { APH } \\
\text { Out }\end{array}$ & $\begin{array}{l}\text { Stack } \\
\text { Flow }\end{array}$ & Opacity & SO2 In & $\begin{array}{l}\text { SO2 } \\
\text { Out }\end{array}$ & $\mathrm{CO}$ & $\begin{array}{c}\text { Stack } \\
\text { SCEM } \\
\text { Elemental } \\
\mathrm{Hg}\end{array}$ & $\begin{array}{c}\text { Stack } \\
\text { SCEM } \\
\text { Total Hg }\end{array}$ \\
\hline & & MW & Btu/kWh & $\%$ & $\%$ & Ton/hr & & DEGF & DEGF & DEGF & DEGF & KSCF & $\%$ & $\mathrm{Ib} / \mathrm{MMB}$ & $\mathrm{Ib} / \mathrm{MMb}$ & PPM & $\begin{array}{c}\text { ( } \mu \mathrm{g} / \mathrm{dNm} \text { ) } \\
@ 3 \% 02\end{array}$ & $\begin{array}{c}(\mu \mathrm{g} / \mathrm{dNm} 3) \\
@ 3 \% 02\end{array}$ \\
\hline $\begin{array}{r}6 / 18 / 2009 \\
6: 00\end{array}$ & $\begin{array}{r}6 / 18 / 2009 \\
7: 00\end{array}$ & 909.6 & 7883.9 & 2.6 & 2.2 & 617.9 & 1.1 & 762.4 & 754.1 & 306.1 & 300.8 & 2332.4 & 6.9 & 1.8 & 0.5 & 12.8 & $\# \mathrm{~N} / \mathrm{A}$ & $\# \mathrm{~N} / \mathrm{A}$ \\
\hline $\begin{array}{r}6 / 18 / 2009 \\
7: 00\end{array}$ & $\begin{array}{r}6 / 18 / 2009 \\
8: 00\end{array}$ & 913.4 & 7978.9 & 4.1 & 3.8 & 619.5 & 1.1 & 761.2 & 755.9 & 305.2 & 301.2 & 2345.7 & 7.0 & 1.9 & 0.5 & 13.9 & 4.9 & 6.0 \\
\hline $\begin{array}{r}6 / 18 / 2009 \\
8: 00\end{array}$ & $\begin{array}{r}6 / 18 / 2009 \\
9: 00\end{array}$ & 911.5 & 8011.9 & 2.8 & 2.1 & 618.8 & 1.1 & 752.6 & 755.9 & 304.0 & 301.4 & 2340.8 & 7.4 & 1.8 & 0.5 & 14.9 & 5.0 & 6.0 \\
\hline $\begin{array}{r}6 / 18 / 2009 \\
9: 00\end{array}$ & $\begin{array}{r}6 / 18 / 2009 \\
10: 00\end{array}$ & 913.5 & 8020.3 & 2.6 & 2.1 & 619.5 & 1.1 & 754.7 & 755.3 & 304.4 & 302.0 & 2319.9 & 7.5 & 1.9 & 0.5 & 13.6 & 4.7 & 5.9 \\
\hline $\begin{array}{r}6 / 18 / 2009 \\
10: 00\end{array}$ & $\begin{array}{r}6 / 18 / 2009 \\
11: 00\end{array}$ & 912.5 & 8020.8 & 2.6 & 2.1 & 619.2 & 1.1 & 757.2 & 755.2 & 305.3 & 301.9 & 2303.4 & 7.2 & 2.3 & 0.5 & 15.7 & 4.6 & 5.6 \\
\hline $\begin{array}{r}6 / 18 / 2009 \\
11: 00\end{array}$ & $\begin{array}{r}6 / 18 / 2009 \\
12: 00\end{array}$ & 912.7 & 7994.9 & 2.6 & 2.0 & 620.6 & 1.1 & 761.7 & 759.9 & 308.2 & 305.0 & 2312.0 & 7.3 & 2.0 & 0.5 & 19.5 & 4.7 & 5.7 \\
\hline $\begin{array}{r}6 / 18 / 2009 \\
12: 00\end{array}$ & $\begin{array}{r}6 / 18 / 2009 \\
13: 00\end{array}$ & 912.8 & 8016.5 & 2.6 & 2.1 & 623.7 & 1.1 & 766.2 & 762.9 & 312.0 & 309.3 & 2302.0 & 6.7 & 1.7 & 0.5 & 17.3 & 4.6 & 5.7 \\
\hline $\begin{array}{r}6 / 18 / 2009 \\
13: 00\end{array}$ & $\begin{array}{r}6 / 18 / 2009 \\
14: 00\end{array}$ & 911.5 & 8049.8 & 2.5 & 2.2 & 625.6 & 1.1 & 769.3 & 753.8 & 314.9 & 309.5 & 2293.8 & 6.4 & 1.7 & 0.5 & 16.6 & 4.7 & 6.0 \\
\hline $\begin{array}{r}6 / 18 / 2009 \\
14: 00\end{array}$ & $\begin{array}{r}6 / 18 / 2009 \\
15: 00\end{array}$ & 914.3 & 8025.3 & 2.5 & 2.1 & 626.3 & 1.1 & 770.7 & 752.2 & 316.3 & 309.7 & 2307.0 & 6.3 & 1.7 & 0.5 & 15.3 & 5.0 & 6.3 \\
\hline $\begin{array}{r}6 / 18 / 2009 \\
15: 00 \\
\end{array}$ & $\begin{array}{r}6 / 18 / 2009 \\
16: 00 \\
\end{array}$ & 914.9 & 8000.4 & 2.5 & 2.1 & 626.4 & 1.1 & 773.4 & 752.6 & 317.9 & 310.4 & 2296.4 & 5.9 & 1.7 & 0.5 & 14.4 & 5.0 & 6.4 \\
\hline $\begin{array}{r}6 / 18 / 2009 \\
16: 00\end{array}$ & $\begin{array}{r}6 / 18 / 2009 \\
17: 00\end{array}$ & 913.4 & 8029.9 & 2.4 & 2.2 & 624.4 & 1.1 & 773.8 & 751.9 & 320.1 & 311.9 & 2294.6 & 6.4 & 1.7 & 0.5 & 15.4 & 4.9 & 6.5 \\
\hline $\begin{array}{r}6 / 18 / 2009 \\
17: 00\end{array}$ & $\begin{array}{r}6 / 18 / 2009 \\
18: 00\end{array}$ & 914.1 & 8017.1 & 2.5 & 2.2 & 623.5 & 1.1 & 774.8 & 755.9 & 321.2 & 313.4 & 2302.1 & 6.5 & 1.6 & 0.4 & 15.7 & 5.1 & 6.4 \\
\hline $\begin{array}{r}6 / 18 / 2009 \\
18: 00\end{array}$ & $\begin{array}{r}6 / 18 / 2009 \\
19: 00\end{array}$ & 914.3 & 8026.2 & 2.5 & 2.2 & 619.8 & 1.1 & 778.2 & 762.2 & 322.4 & 315.3 & 2302.3 & 6.2 & 1.6 & 0.4 & 15.9 & 5.1 & 6.3 \\
\hline $\begin{array}{r}6 / 18 / 2009 \\
19: 00\end{array}$ & $\begin{array}{r}6 / 18 / 2009 \\
20: 00\end{array}$ & 913.2 & 8001.9 & 2.4 & 2.2 & 614.9 & 1.1 & 779.7 & 766.9 & 323.1 & 316.4 & 2291.5 & 5.9 & 1.5 & 0.4 & 16.2 & 4.7 & 6.0 \\
\hline $\begin{array}{r}/ 18 / 2009 \\
20: 00 \\
\end{array}$ & $\begin{array}{r}6 / 18 / 2009 \\
21: 00 \\
\end{array}$ & 913.8 & 8030.1 & 2.5 & 2.1 & 615.5 & 1.1 & 765.4 & 759.9 & 319.4 & 315.0 & 2288.6 & 5.7 & 1.5 & 0.4 & 17.0 & 4.5 & 5.9 \\
\hline $\begin{array}{r}6 / 18 / 2009 \\
21: 00\end{array}$ & $\begin{array}{r}6 / 18 / 2009 \\
22: 00\end{array}$ & 915.5 & 8014.4 & 2.3 & 2.2 & 609.1 & 1.1 & 764.7 & 758.2 & 315.7 & 311.4 & 2276.2 & 5.5 & 1.5 & 0.4 & 26.0 & 3.9 & 5.4 \\
\hline $\begin{array}{r}6 / 18 / 2009 \\
22: 00 \\
\end{array}$ & $\begin{array}{r}6 / 18 / 2009 \\
23: 00 \\
\end{array}$ & 912.1 & 8039.8 & 2.3 & 2.1 & 605.1 & 1.1 & 757.7 & 754.3 & 313.4 & 309.1 & 2290.9 & 5.8 & 1.5 & 0.4 & 20.3 & 5.4 & 7.2 \\
\hline $\begin{array}{r}6 / 18 / 2009 \\
23: 00\end{array}$ & $\begin{array}{r}6 / 19 / 2009 \\
0: 00\end{array}$ & 915.1 & 7994.0 & 2.3 & 2.2 & 607.5 & 1.1 & 761.3 & 758.4 & 311.4 & 306.9 & 2274.1 & 5.9 & 1.4 & 0.4 & 25.1 & 6.4 & 8.7 \\
\hline $\begin{array}{r}6 / 19 / 2009 \\
0: 00\end{array}$ & $\begin{array}{r}6 / 19 / 2009 \\
1: 00\end{array}$ & 901.9 & 8022.0 & 2.3 & 2.3 & 599.5 & 1.1 & 764.7 & 759.3 & 311.7 & 305.6 & 2272.5 & 6.2 & 1.5 & 0.4 & 43.5 & 6.9 & 9.2 \\
\hline $6 / 19 / 2009$ & $6 / 19 / 2009$ & 906.0 & 8036.1 & 2.3 & 2.3 & 601.9 & 1.1 & 771.2 & 764.7 & 312.2 & 305.9 & 2282.3 & 6.3 & 1.5 & 0.4 & 33.2 & 7.4 & 9.5 \\
\hline
\end{tabular}




\begin{tabular}{|c|c|c|c|c|c|c|c|c|c|c|c|c|c|c|c|c|c|c|}
\hline $\begin{array}{l}\text { Start } \\
\text { Date/ } \\
\text { Time }\end{array}$ & $\begin{array}{l}\text { End } \\
\text { Date/ } \\
\text { Time }\end{array}$ & $\begin{array}{l}\text { Gross } \\
\text { Load }\end{array}$ & $\begin{array}{c}\text { Gross } \\
\text { HR }\end{array}$ & $\begin{array}{c}\text { A } \\
\text { Econ } \\
\text { O2 }\end{array}$ & $\begin{array}{c}\text { B } \\
\text { Econ } \\
\text { O2 }\end{array}$ & $\begin{array}{l}\text { Fuel } \\
\text { Flow }\end{array}$ & $\begin{array}{l}\text { BTU } \\
\text { Gain }\end{array}$ & $\begin{array}{c}\text { A } \\
\text { APH } \\
\text { In }\end{array}$ & $\begin{array}{l}\text { B } \\
\text { APH } \\
\text { In }\end{array}$ & $\begin{array}{c}\text { A } \\
\text { APH } \\
\text { Out }\end{array}$ & $\begin{array}{c}\text { B } \\
\text { APH } \\
\text { Out }\end{array}$ & $\begin{array}{l}\text { Stack } \\
\text { Flow }\end{array}$ & Opacity & SO2 In & $\begin{array}{l}\text { SO2 } \\
\text { Out }\end{array}$ & $\mathrm{CO}$ & $\begin{array}{c}\text { Stack } \\
\text { SCEM } \\
\text { Elemental } \\
\mathrm{Hg}\end{array}$ & $\begin{array}{c}\text { Stack } \\
\text { SCEM } \\
\text { Total Hg }\end{array}$ \\
\hline & & MW & Btu/kWh & $\%$ & $\%$ & Ton/hr & & DEGF & DEGF & DEGF & DEGF & KSCF & $\%$ & $\mathrm{Ib} / \mathrm{MMB}$ & $\mathrm{Ib} / \mathrm{MMb}$ & PPM & $\begin{array}{c}(\mu \mathrm{g} / \mathrm{dNm} 3) \\
@ 3 \% 02\end{array}$ & $\begin{array}{c}(\mu \mathrm{g} / \mathrm{dNm} 3) \\
\text { @ 3\%O2 }\end{array}$ \\
\hline $1: 00$ & $2: 00$ & & & & & & & & & & & & & & & & & \\
\hline $\begin{array}{r}6 / 19 / 2009 \\
2: 00 \\
\end{array}$ & $\begin{array}{r}6 / 19 / 2009 \\
3: 00 \\
\end{array}$ & 912.3 & 8034.1 & 2.4 & 2.2 & 606.5 & 1.1 & 769.6 & 759.9 & 312.1 & 305.3 & 2304.9 & 6.6 & 1.5 & 0.4 & 19.1 & 7.7 & 9.8 \\
\hline $\begin{array}{r}6 / 19 / 2009 \\
3: 00\end{array}$ & $\begin{array}{r}6 / 19 / 2009 \\
4: 00\end{array}$ & 915.3 & 7938.5 & 2.6 & 2.0 & 602.3 & 1.1 & 770.2 & 766.6 & 308.8 & 304.3 & 2307.3 & 6.7 & 1.5 & 0.4 & 15.5 & 7.6 & 9.7 \\
\hline $\begin{array}{r}6 / 19 / 2009 \\
4: 00\end{array}$ & $\begin{array}{r}6 / 19 / 2009 \\
5: 00\end{array}$ & 913.5 & 7998.6 & 2.6 & 1.9 & 598.5 & 1.1 & 774.1 & 771.8 & 310.3 & 306.0 & 2283.6 & 6.8 & 1.5 & 0.4 & 16.7 & $\# \mathrm{~N} / \mathrm{A}$ & $\# \mathrm{~N} / \mathrm{A}$ \\
\hline $\begin{array}{r}6 / 19 / 2009 \\
5: 00\end{array}$ & $\begin{array}{r}6 / 19 / 2009 \\
6: 00\end{array}$ & 911.4 & 8009.3 & 2.6 & 1.9 & 599.7 & 1.1 & 775.8 & 773.1 & 311.6 & 306.9 & 2292.6 & 7.1 & 1.5 & 0.4 & 17.8 & $\# \mathrm{~N} / \mathrm{A}$ & $\# \mathrm{~N} / \mathrm{A}$ \\
\hline $\begin{array}{r}6 / 19 / 2009 \\
6: 00\end{array}$ & $\begin{array}{r}6 / 19 / 2009 \\
7: 00\end{array}$ & 910.0 & 7987.1 & 2.6 & 2.1 & 609.5 & 1.1 & 775.0 & 770.4 & 311.1 & 305.2 & 2320.2 & 7.9 & 1.5 & 0.4 & 16.7 & $\# \mathrm{~N} / \mathrm{A}$ & $\# \mathrm{~N} / \mathrm{A}$ \\
\hline $\begin{array}{r}6 / 19 / 2009 \\
7: 00\end{array}$ & $\begin{array}{r}6 / 19 / 2009 \\
8: 00\end{array}$ & 904.2 & 8003.6 & 2.7 & 2.4 & 614.1 & 1.1 & 778.8 & 773.1 & 309.1 & 303.2 & 2347.6 & 9.4 & 1.6 & 0.4 & 10.8 & 7.1 & 8.6 \\
\hline $\begin{array}{r}6 / 19 / 2009 \\
8: 00\end{array}$ & $\begin{array}{r}6 / 19 / 2009 \\
9: 00\end{array}$ & 902.1 & 7986.9 & 2.8 & 2.3 & 619.8 & 1.1 & 781.0 & 775.5 & 309.9 & 304.3 & 2344.3 & 9.1 & 1.6 & 0.4 & 9.5 & 8.2 & 9.7 \\
\hline $\begin{array}{r}6 / 19 / 2009 \\
9: 00\end{array}$ & $\begin{array}{r}6 / 19 / 2009 \\
10: 00\end{array}$ & 905.8 & 8037.7 & 2.7 & 2.4 & 623.6 & 1.1 & 781.0 & 775.2 & 312.0 & 306.1 & 2351.4 & 8.4 & 1.6 & 0.4 & 8.7 & 9.2 & 11.0 \\
\hline $\begin{array}{r}6 / 19 / 2009 \\
10: 00 \\
\end{array}$ & $\begin{array}{r}6 / 19 / 2009 \\
11: 00 \\
\end{array}$ & 905.3 & 8043.3 & 2.8 & 2.4 & 615.8 & 1.1 & 772.0 & 765.1 & 310.6 & 305.0 & 2337.5 & 8.0 & 1.6 & 0.4 & 8.8 & 9.7 & 11.7 \\
\hline $\begin{array}{r}6 / 19 / 2009 \\
11: 00\end{array}$ & $\begin{array}{r}6 / 19 / 2009 \\
12: 00\end{array}$ & 901.6 & 8007.7 & 2.8 & 2.4 & 616.2 & 1.1 & 774.1 & 768.5 & 310.9 & 305.6 & 2336.1 & 8.0 & 1.6 & 0.4 & 8.0 & 9.9 & 12.1 \\
\hline $\begin{array}{r}6 / 19 / 2009 \\
12: 00\end{array}$ & $\begin{array}{r}6 / 19 / 2009 \\
13: 00\end{array}$ & 901.9 & 8029.4 & 2.8 & 2.4 & 625.5 & 1.1 & 776.4 & 771.2 & 313.6 & 308.9 & 2333.5 & 8.0 & 1.6 & 0.4 & 8.5 & 10.3 & 12.6 \\
\hline $\begin{array}{r}6 / 19 / 2009 \\
13: 00\end{array}$ & $\begin{array}{r}6 / 19 / 2009 \\
14: 00\end{array}$ & 905.0 & 8046.4 & 2.8 & 2.4 & 618.1 & 1.1 & 777.0 & 771.0 & 317.0 & 311.6 & 2334.5 & 7.5 & 1.6 & 0.4 & 8.9 & 10.5 & 12.8 \\
\hline $\begin{array}{r}6 / 19 / 2009 \\
14: 00\end{array}$ & $\begin{array}{r}6 / 19 / 2009 \\
15: 00\end{array}$ & 901.9 & 8040.6 & 2.7 & 2.5 & 620.1 & 1.1 & 765.4 & 760.1 & 316.2 & 310.7 & 2335.2 & 7.2 & 1.6 & 0.4 & 9.1 & 10.4 & 12.6 \\
\hline $\begin{array}{r}6 / 19 / 2009 \\
15: 00\end{array}$ & $\begin{array}{r}6 / 19 / 2009 \\
16: 00\end{array}$ & 903.2 & 7960.4 & 2.7 & 2.6 & 622.1 & 1.1 & 771.6 & 764.6 & 316.3 & 310.6 & 2338.2 & 7.2 & 1.6 & 0.4 & 9.4 & 10.6 & 12.7 \\
\hline $\begin{array}{r}6 / 19 / 2009 \\
16: 00\end{array}$ & $\begin{array}{r}6 / 19 / 2009 \\
17: 00\end{array}$ & 901.9 & 8017.3 & 2.7 & 2.5 & 623.0 & 1.1 & 774.3 & 767.3 & 318.4 & 312.6 & 2339.7 & 7.3 & 1.7 & 0.4 & 8.3 & 11.3 & 13.2 \\
\hline $\begin{array}{r}6 / 19 / 2009 \\
17: 00 \\
\end{array}$ & $\begin{array}{r}6 / 19 / 2009 \\
18: 00 \\
\end{array}$ & 904.3 & 8018.8 & 2.7 & 2.5 & 623.5 & 1.1 & 776.8 & 767.6 & 319.2 & 312.9 & 2314.9 & 7.5 & 1.7 & 0.4 & 8.1 & 11.8 & 13.7 \\
\hline $\begin{array}{r}6 / 19 / 2009 \\
18: 00 \\
\end{array}$ & $\begin{array}{r}6 / 19 / 2009 \\
19: 00 \\
\end{array}$ & 905.0 & 8015.0 & 2.7 & 2.5 & 624.2 & 1.1 & 779.3 & 768.1 & 319.5 & 313.0 & 2328.3 & 7.3 & 1.8 & 0.4 & 8.3 & 12.1 & 13.8 \\
\hline $\begin{array}{r}6 / 19 / 2009 \\
19: 00\end{array}$ & $\begin{array}{r}6 / 19 / 2009 \\
20: 00\end{array}$ & 904.3 & 8023.3 & 2.7 & 2.4 & 617.0 & 1.1 & 781.4 & 769.5 & 319.2 & 312.9 & 2314.0 & 7.2 & 1.8 & 0.4 & 9.0 & 12.0 & 13.7 \\
\hline $\begin{array}{r}6 / 19 / 2009 \\
20: 00\end{array}$ & $\begin{array}{r}6 / 19 / 2009 \\
21: 00\end{array}$ & 890.7 & 7988.3 & 2.7 & 2.5 & 607.0 & 1.1 & 779.9 & 767.1 & 318.8 & 312.0 & 2291.8 & 8.0 & 1.8 & 0.4 & 8.9 & 11.7 & 13.5 \\
\hline
\end{tabular}




\begin{tabular}{|c|c|c|c|c|c|c|c|c|c|c|c|c|c|c|c|c|c|c|}
\hline \multirow[t]{2}{*}{$\begin{array}{l}\text { Start } \\
\text { Date/ } \\
\text { Time }\end{array}$} & \multirow[t]{2}{*}{$\begin{array}{l}\text { End } \\
\text { Date/ } \\
\text { Time }\end{array}$} & $\begin{array}{l}\text { Gross } \\
\text { Load }\end{array}$ & $\begin{array}{c}\text { Gross } \\
\text { HR }\end{array}$ & $\begin{array}{c}\text { A } \\
\text { Econ } \\
\text { O2 }\end{array}$ & $\begin{array}{c}\text { B } \\
\text { Econ } \\
\text { O2 }\end{array}$ & $\begin{array}{l}\text { Fuel } \\
\text { Flow }\end{array}$ & $\begin{array}{l}\text { BTU } \\
\text { Gain }\end{array}$ & $\begin{array}{c}\text { A } \\
\text { APH } \\
\text { In }\end{array}$ & $\begin{array}{c}\text { B } \\
\text { APH } \\
\text { In }\end{array}$ & $\begin{array}{c}\text { A } \\
\text { APH } \\
\text { Out }\end{array}$ & $\begin{array}{c}\text { B } \\
\text { APH } \\
\text { Out }\end{array}$ & $\begin{array}{l}\text { Stack } \\
\text { Flow }\end{array}$ & Opacity & SO2 In & $\begin{array}{l}\text { SO2 } \\
\text { Out }\end{array}$ & $\mathrm{CO}$ & $\begin{array}{c}\text { Stack } \\
\text { SCEM } \\
\text { Elemental } \\
\mathrm{Hg}\end{array}$ & $\begin{array}{c}\text { Stack } \\
\text { SCEM } \\
\text { Total Hg }\end{array}$ \\
\hline & & MW & Btu/kWh & $\%$ & $\%$ & Ton/hr & & DEGF & DEGF & DEGF & DEGF & KSCF & $\%$ & $\mathrm{Ib} / \mathrm{MMB}$ & $\mathrm{Ib} / \mathrm{MMb}$ & PPM & $\begin{array}{c}\text { ( } \mu \mathrm{g} / \mathrm{dNm} \text { ) } \\
@ 3 \% 02\end{array}$ & $\begin{array}{c}(\mu \mathrm{g} / \mathrm{dNm} 3) \\
@ 3 \% 02\end{array}$ \\
\hline $\begin{array}{r}6 / 19 / 2009 \\
21: 00\end{array}$ & $\begin{array}{r}6 / 19 / 2009 \\
22: 00\end{array}$ & 891.2 & 8027.8 & 2.7 & 2.5 & 601.9 & 1.1 & 767.1 & 757.5 & 316.3 & 309.8 & 2295.4 & 10.1 & 1.8 & 0.4 & 8.5 & 11.3 & 13.1 \\
\hline $\begin{array}{r}6 / 19 / 2009 \\
22: 00\end{array}$ & $\begin{array}{r}\text { 6/19/2009 } \\
23: 00\end{array}$ & 881.3 & 8026.1 & 2.8 & 2.4 & 590.7 & 1.1 & 758.8 & 751.0 & 310.3 & 303.8 & 2268.6 & 9.4 & 1.7 & 0.4 & 8.3 & 10.8 & 12.6 \\
\hline $\begin{array}{r}6 / 19 / 2009 \\
23: 00\end{array}$ & $\begin{array}{r}6 / 20 / 2009 \\
0: 00\end{array}$ & 899.1 & 8030.2 & 2.8 & 2.4 & 603.7 & 1.1 & 769.0 & 762.0 & 309.7 & 304.6 & 2313.0 & 9.8 & 1.7 & 0.4 & 9.1 & 11.0 & 12.6 \\
\hline $\begin{array}{r}6 / 20 / 2009 \\
0: 00\end{array}$ & $\begin{array}{r}6 / 20 / 2009 \\
1: 00\end{array}$ & 832.1 & 7976.2 & 2.9 & 2.2 & 559.4 & 1.1 & 758.5 & 751.6 & 309.0 & 302.0 & 2161.8 & 8.8 & 1.7 & 0.4 & 9.1 & 10.5 & 12.5 \\
\hline $\begin{array}{r}6 / 20 / 2009 \\
1: 00\end{array}$ & $\begin{array}{r}6 / 20 / 2009 \\
2: 00\end{array}$ & 784.8 & 7936.3 & 3.0 & 2.3 & 535.3 & 1.1 & 741.5 & 736.2 & 304.6 & 296.1 & 2060.7 & 8.0 & 1.7 & 0.4 & 10.2 & $\# \mathrm{~N} / \mathrm{A}$ & $\# \mathrm{~N} / \mathrm{A}$ \\
\hline $\begin{array}{r}6 / 20 / 2009 \\
2: 00\end{array}$ & $\begin{array}{r}6 / 20 / 2009 \\
3: 00\end{array}$ & 878.7 & 7965.3 & 2.8 & 2.5 & 595.6 & 1.1 & 769.8 & 762.0 & 306.0 & 299.9 & 2271.1 & 9.2 & 1.6 & 0.4 & 11.0 & $\# \mathrm{~N} / \mathrm{A}$ & $\# \mathrm{~N} / \mathrm{A}$ \\
\hline $\begin{array}{r}6 / 20 / 2009 \\
3: 00\end{array}$ & $\begin{array}{r}6 / 20 / 2009 \\
4: 00\end{array}$ & 857.0 & 7963.1 & 2.8 & 2.3 & 573.5 & 1.1 & 773.8 & 764.8 & 307.8 & 300.9 & 2212.1 & 9.2 & 1.6 & 0.4 & 10.6 & 9.9 & 12.5 \\
\hline $\begin{array}{r}6 / 20 / 2009 \\
4: 00\end{array}$ & $\begin{array}{r}6 / 20 / 2009 \\
5: 00\end{array}$ & 786.7 & 7968.9 & 3.0 & 2.2 & 531.3 & 1.1 & 753.7 & 747.8 & 304.6 & 296.5 & 2063.5 & 7.9 & 1.5 & 0.4 & 8.4 & 8.9 & 11.7 \\
\hline $\begin{array}{r}6 / 20 / 2009 \\
5: 00\end{array}$ & $\begin{array}{r}6 / 20 / 2009 \\
6: 00\end{array}$ & 786.8 & 7919.8 & 3.0 & 2.3 & 531.8 & 1.1 & 751.9 & 745.5 & 302.2 & 293.9 & 2099.2 & 7.8 & 1.5 & 0.4 & 8.8 & $\# \mathrm{~N} / \mathrm{A}$ & $\# \mathrm{~N} / \mathrm{A}$ \\
\hline $\begin{array}{r}6 / 20 / 2009 \\
6: 00\end{array}$ & $\begin{array}{r}6 / 20 / 2009 \\
7: 00\end{array}$ & 843.7 & 7905.9 & 2.9 & 2.5 & 569.2 & 1.1 & 772.7 & 763.9 & 305.3 & 297.9 & 2193.1 & 8.2 & 1.4 & 0.4 & 10.4 & $\# \mathrm{~N} / \mathrm{A}$ & $\# \mathrm{~N} / \mathrm{A}$ \\
\hline $\begin{array}{r}6 / 20 / 2009 \\
7: 00\end{array}$ & $\begin{array}{r}6 / 20 / 2009 \\
8: 00\end{array}$ & 885.4 & 7955.1 & 2.9 & 2.4 & 606.4 & 1.1 & 787.8 & 780.7 & 309.5 & 304.0 & 2296.2 & 7.4 & 1.4 & 0.4 & 9.1 & 9.5 & 12.3 \\
\hline $\begin{array}{r}6 / 20 / 2009 \\
8: 00\end{array}$ & $\begin{array}{r}6 / 20 / 2009 \\
9: 00\end{array}$ & 896.6 & 8023.6 & 2.8 & 2.4 & 625.2 & 1.1 & 785.1 & 778.3 & 312.9 & 307.4 & 2331.5 & 6.6 & 1.4 & 0.4 & 9.6 & 10.3 & 13.1 \\
\hline $\begin{array}{r}6 / 20 / 2009 \\
9: 00\end{array}$ & $\begin{array}{r}6 / 20 / 2009 \\
10: 00\end{array}$ & 894.3 & 7985.1 & 2.8 & 2.4 & 627.7 & 1.1 & 781.1 & 770.4 & 310.9 & 304.3 & 2323.6 & 6.4 & 1.5 & 0.4 & 13.3 & 10.7 & 13.4 \\
\hline $\begin{array}{r}6 / 20 / 2009 \\
10: 00\end{array}$ & $\begin{array}{r}6 / 20 / 2009 \\
11: 00\end{array}$ & 883.7 & 7981.1 & 2.8 & 2.4 & 620.1 & 1.1 & 781.1 & 767.7 & 311.0 & 303.6 & 2295.2 & 6.4 & 1.5 & 0.4 & 12.9 & 10.8 & 13.4 \\
\hline $\begin{array}{r}6 / 20 / 2009 \\
11: 00\end{array}$ & $\begin{array}{r}6 / 20 / 2009 \\
12: 00\end{array}$ & 900.3 & 8016.9 & 2.7 & 2.5 & 640.7 & 1.1 & 784.8 & 771.4 & 314.2 & 307.6 & 2323.5 & 6.5 & 1.5 & 0.4 & 10.3 & 11.3 & 14.0 \\
\hline $\begin{array}{r}6 / 20 / 2009 \\
12: 00 \\
\end{array}$ & $\begin{array}{r}6 / 20 / 2009 \\
13: 00 \\
\end{array}$ & 905.0 & 8073.7 & 2.7 & 2.6 & 640.3 & 1.1 & 781.6 & 767.4 & 316.7 & 309.7 & 2339.9 & 6.7 & 1.5 & 0.4 & 11.4 & 11.3 & 13.9 \\
\hline $\begin{array}{r}6 / 20 / 2009 \\
13: 00 \\
\end{array}$ & $\begin{array}{r}6 / 20 / 2009 \\
14: 00 \\
\end{array}$ & 905.4 & 8052.2 & 2.6 & 2.7 & 639.3 & 1.1 & 775.7 & 759.8 & 315.3 & 308.5 & 2336.7 & 6.5 & 1.5 & 0.4 & 15.5 & 10.9 & 13.6 \\
\hline $\begin{array}{r}6 / 20 / 2009 \\
14: 00\end{array}$ & $\begin{array}{r}6 / 20 / 2009 \\
15: 00\end{array}$ & 906.1 & 8043.0 & 2.6 & 2.7 & 632.4 & 1.1 & 776.4 & 754.8 & 318.0 & 310.1 & 2331.6 & 6.6 & 1.5 & 0.4 & 18.7 & 11.0 & 13.6 \\
\hline $\begin{array}{r}6 / 20 / 2009 \\
15: 00\end{array}$ & $\begin{array}{r}6 / 20 / 2009 \\
16: 00\end{array}$ & 907.3 & 8038.5 & 2.7 & 2.6 & 621.6 & 1.1 & 777.9 & 751.6 & 317.5 & 307.9 & 2340.3 & 6.4 & 1.5 & 0.4 & 17.8 & 10.9 & 13.6 \\
\hline $6 / 20 / 2009$ & $6 / 20 / 2009$ & 905.2 & 8095.0 & 2.9 & 2.4 & 612.5 & 1.1 & 775.8 & 755.2 & 318.3 & 310.7 & 2341.7 & 6.4 & 1.4 & 0.4 & 13.8 & 10.7 & 13.3 \\
\hline
\end{tabular}




\begin{tabular}{|c|c|c|c|c|c|c|c|c|c|c|c|c|c|c|c|c|c|c|}
\hline $\begin{array}{l}\text { Start } \\
\text { Date/ } \\
\text { Time }\end{array}$ & $\begin{array}{l}\text { End } \\
\text { Date/ } \\
\text { Time }\end{array}$ & $\begin{array}{l}\text { Gross } \\
\text { Load }\end{array}$ & $\begin{array}{c}\text { Gross } \\
\text { HR }\end{array}$ & $\begin{array}{c}\text { A } \\
\text { Econ } \\
\text { O2 }\end{array}$ & $\begin{array}{c}\text { B } \\
\text { Econ } \\
\text { O2 }\end{array}$ & $\begin{array}{l}\text { Fuel } \\
\text { Flow }\end{array}$ & $\begin{array}{l}\text { BTU } \\
\text { Gain }\end{array}$ & $\begin{array}{c}\text { A } \\
\text { APH } \\
\text { In }\end{array}$ & $\begin{array}{l}\text { B } \\
\text { APH } \\
\text { In }\end{array}$ & $\begin{array}{c}\text { A } \\
\text { APH } \\
\text { Out }\end{array}$ & $\begin{array}{c}\text { B } \\
\text { APH } \\
\text { Out }\end{array}$ & $\begin{array}{l}\text { Stack } \\
\text { Flow }\end{array}$ & Opacity & SO2 In & $\begin{array}{l}\text { SO2 } \\
\text { Out }\end{array}$ & $\mathrm{CO}$ & $\begin{array}{c}\text { Stack } \\
\text { SCEM } \\
\text { Elemental } \\
\mathrm{Hg}\end{array}$ & $\begin{array}{c}\text { Stack } \\
\text { SCEM } \\
\text { Total Hg }\end{array}$ \\
\hline & & MW & Btu/kWh & $\%$ & $\%$ & Ton/hr & & DEGF & DEGF & DEGF & DEGF & KSCF & $\%$ & $\mathrm{Ib} / \mathrm{MMB}$ & $\mathrm{Ib} / \mathrm{MMb}$ & PPM & $\begin{array}{c}(\mu \mathrm{g} / \mathrm{dNm} 3) \\
@ 3 \% 02\end{array}$ & $\begin{array}{c}(\mu \mathrm{g} / \mathrm{dNm} 3) \\
\text { @ 3\%O2 }\end{array}$ \\
\hline $16: 00$ & $17: 00$ & & & & & & & & & & & & & & & & & \\
\hline $\begin{array}{r}6 / 20 / 2009 \\
17: 00 \\
\end{array}$ & $\begin{array}{r}6 / 20 / 2009 \\
18: 00 \\
\end{array}$ & 905.2 & 8053.7 & 2.9 & 2.4 & 602.7 & 1.1 & 777.5 & 757.9 & 317.9 & 310.3 & 2311.0 & 6.6 & 1.4 & 0.4 & 14.7 & 10.3 & 13.1 \\
\hline $\begin{array}{r}6 / 20 / 2009 \\
18: 00\end{array}$ & $\begin{array}{r}6 / 20 / 2009 \\
19: 00\end{array}$ & 903.6 & 8001.8 & 2.7 & 2.6 & 600.8 & 1.1 & 785.0 & 765.1 & 319.9 & 312.1 & 2313.9 & 6.7 & 1.4 & 0.4 & 14.7 & 10.3 & 13.2 \\
\hline $\begin{array}{r}6 / 20 / 2009 \\
19: 00 \\
\end{array}$ & $\begin{array}{r}6 / 20 / 2009 \\
20: 00 \\
\end{array}$ & 904.4 & 8026.4 & 2.6 & 2.7 & 602.3 & 1.1 & 789.3 & 769.3 & 321.5 & 312.9 & 2320.7 & 6.8 & 1.4 & 0.4 & 12.8 & 10.2 & 13.2 \\
\hline $\begin{array}{r}6 / 20 / 2009 \\
20: 00\end{array}$ & $\begin{array}{r}6 / 20 / 2009 \\
21: 00\end{array}$ & 906.3 & 8033.5 & 2.7 & 2.6 & 597.6 & 1.1 & 777.0 & 761.9 & 318.4 & 312.1 & 2330.1 & 7.9 & 1.4 & 0.4 & 9.8 & 10.2 & 13.0 \\
\hline $\begin{array}{r}6 / 20 / 2009 \\
21: 00\end{array}$ & $\begin{array}{r}6 / 20 / 2009 \\
22: 00\end{array}$ & 905.9 & 8026.0 & 2.8 & 2.5 & 596.1 & 1.1 & 774.7 & 763.3 & 313.4 & 308.5 & 2318.5 & 10.2 & 1.4 & 0.4 & 8.6 & 10.2 & 13.0 \\
\hline $\begin{array}{r}6 / 20 / 2009 \\
22: 00\end{array}$ & $\begin{array}{r}6 / 20 / 2009 \\
23: 00\end{array}$ & 900.1 & 8032.8 & 2.7 & 2.6 & 584.6 & 1.1 & 783.3 & 764.5 & 314.2 & 307.6 & 2299.6 & 9.9 & 1.4 & 0.4 & 9.8 & 9.9 & 12.9 \\
\hline $\begin{array}{r}6 / 20 / 2009 \\
23: 00\end{array}$ & $\begin{array}{r}6 / 21 / 2009 \\
0: 00\end{array}$ & 881.9 & 8013.6 & 2.8 & 2.5 & 574.6 & 1.1 & 781.7 & 766.2 & 313.6 & 306.4 & 2257.0 & 10.3 & 1.4 & 0.4 & 8.9 & 9.7 & 12.7 \\
\hline $\begin{array}{r}6 / 21 / 2009 \\
0: 00\end{array}$ & $\begin{array}{r}6 / 21 / 2009 \\
1: 00\end{array}$ & 900.1 & 8014.4 & 2.8 & 2.5 & 595.9 & 1.1 & 788.6 & 775.3 & 314.5 & 308.8 & 2320.2 & 10.9 & 1.4 & 0.4 & 8.6 & 10.1 & 13.1 \\
\hline $\begin{array}{r}6 / 21 / 2009 \\
1: 00\end{array}$ & $\begin{array}{r}6 / 21 / 2009 \\
2: 00\end{array}$ & 904.5 & 8047.2 & 2.7 & 2.6 & 599.0 & 1.1 & 793.8 & 780.1 & 315.0 & 309.6 & 2333.5 & 10.5 & 1.4 & 0.4 & 9.2 & $\# \mathrm{~N} / \mathrm{A}$ & 13.4 \\
\hline $\begin{array}{r}6 / 21 / 2009 \\
2: 00 \\
\end{array}$ & $\begin{array}{r}6 / 21 / 2009 \\
3: 00 \\
\end{array}$ & 892.1 & 8029.1 & 2.7 & 2.5 & 586.6 & 1.1 & 793.9 & 780.0 & 314.3 & 308.5 & 2306.4 & 10.6 & 1.4 & 0.4 & 9.2 & \#N/A & $\# \mathrm{~N} / \mathrm{A}$ \\
\hline $\begin{array}{r}6 / 21 / 2009 \\
3: 00\end{array}$ & $\begin{array}{r}6 / 21 / 2009 \\
4: 00\end{array}$ & 815.7 & 8008.7 & 2.9 & 2.4 & 544.5 & 1.1 & 774.0 & 761.3 & 310.6 & 303.5 & 2142.1 & 9.1 & 1.5 & 0.4 & 8.5 & $\# \mathrm{~N} / \mathrm{A}$ & 13.2 \\
\hline $\begin{array}{r}6 / 21 / 2009 \\
4: 00\end{array}$ & $\begin{array}{r}6 / 21 / 2009 \\
5: 00\end{array}$ & 797.9 & 7996.8 & 3.0 & 2.3 & 535.5 & 1.1 & 764.7 & 753.8 & 306.8 & 299.6 & 2109.7 & 8.7 & 1.5 & 0.4 & 8.5 & \#N/A & \#N/A \\
\hline $\begin{array}{r}6 / 21 / 2009 \\
5: 00\end{array}$ & $\begin{array}{r}6 / 21 / 2009 \\
6: 00\end{array}$ & 770.6 & 7917.7 & 2.9 & 2.3 & 528.5 & 1.1 & 756.0 & 746.8 & 305.1 & 296.8 & 2086.1 & 7.5 & 1.5 & 0.4 & 13.4 & $\# \mathrm{~N} / \mathrm{A}$ & \#N/A \\
\hline $\begin{array}{r}6 / 21 / 2009 \\
6: 00\end{array}$ & $\begin{array}{r}6 / 21 / 2009 \\
7: 00\end{array}$ & 822.4 & 7907.3 & 2.9 & 2.6 & 567.8 & 1.1 & 768.8 & 758.3 & 304.7 & 296.4 & 2210.5 & 8.0 & 1.5 & 0.4 & 9.8 & $\# \mathrm{~N} / \mathrm{A}$ & $\# \mathrm{~N} / \mathrm{A}$ \\
\hline $\begin{array}{r}6 / 21 / 2009 \\
7: 00\end{array}$ & $\begin{array}{r}6 / 21 / 2009 \\
8: 00\end{array}$ & 896.5 & 7959.7 & 2.8 & 2.6 & 621.4 & 1.1 & 791.7 & 779.7 & 310.0 & 303.3 & 2341.4 & 7.3 & 1.5 & 0.4 & 10.2 & 12.1 & 14.1 \\
\hline $\begin{array}{r}6 / 21 / 2009 \\
8: 00 \\
\end{array}$ & $\begin{array}{r}6 / 21 / 2009 \\
9: 00 \\
\end{array}$ & 908.4 & 7979.1 & 2.7 & 2.6 & 631.9 & 1.1 & 800.4 & 782.8 & 314.5 & 306.8 & 2369.8 & 6.9 & 1.5 & 0.4 & 12.5 & 12.4 & 14.4 \\
\hline $\begin{array}{r}6 / 21 / 2009 \\
9: 00 \\
\end{array}$ & $\begin{array}{r}6 / 21 / 2009 \\
10: 00 \\
\end{array}$ & 908.6 & 7998.6 & 2.8 & 2.5 & 634.9 & 1.1 & 797.2 & 776.7 & 316.4 & 307.9 & 2370.3 & 7.0 & 1.5 & 0.4 & 15.7 & 12.1 & 14.1 \\
\hline $\begin{array}{r}6 / 21 / 2009 \\
10: 00\end{array}$ & $\begin{array}{r}6 / 21 / 2009 \\
11: 00\end{array}$ & 908.9 & 7972.8 & 2.7 & 2.6 & 635.1 & 1.1 & 789.1 & 767.6 & 315.5 & 306.4 & 2359.1 & 6.9 & 1.5 & 0.4 & 14.4 & 12.2 & 14.1 \\
\hline $\begin{array}{r}6 / 21 / 2009 \\
11: 00\end{array}$ & $\begin{array}{r}6 / 21 / 2009 \\
12: 00\end{array}$ & 907.2 & 8003.1 & 2.7 & 2.6 & 640.6 & 1.1 & 787.2 & 767.6 & 314.3 & 306.3 & 2363.8 & 6.9 & 1.5 & 0.4 & 10.6 & 12.4 & 14.4 \\
\hline
\end{tabular}




\begin{tabular}{|c|c|c|c|c|c|c|c|c|c|c|c|c|c|c|c|c|c|c|}
\hline $\begin{array}{l}\text { Start } \\
\text { Date/ } \\
\text { Time }\end{array}$ & $\begin{array}{l}\text { End } \\
\text { Date/ } \\
\text { Time }\end{array}$ & $\begin{array}{l}\text { Gross } \\
\text { Load }\end{array}$ & $\begin{array}{c}\text { Gross } \\
\text { HR }\end{array}$ & $\begin{array}{c}\text { A } \\
\text { Econ } \\
\text { O2 }\end{array}$ & $\begin{array}{c}\text { B } \\
\text { Econ } \\
\text { O2 }\end{array}$ & $\begin{array}{l}\text { Fuel } \\
\text { Flow }\end{array}$ & $\begin{array}{l}\text { BTU } \\
\text { Gain }\end{array}$ & $\begin{array}{c}\text { A } \\
\text { APH } \\
\text { In }\end{array}$ & $\begin{array}{l}\text { B } \\
\text { APH } \\
\text { In }\end{array}$ & $\begin{array}{c}\text { A } \\
\text { APH } \\
\text { Out }\end{array}$ & $\begin{array}{c}\text { B } \\
\text { APH } \\
\text { Out }\end{array}$ & $\begin{array}{l}\text { Stack } \\
\text { Flow }\end{array}$ & Opacity & SO2 In & $\begin{array}{l}\text { SO2 } \\
\text { Out }\end{array}$ & $\mathrm{CO}$ & $\begin{array}{c}\text { Stack } \\
\text { SCEM } \\
\text { Elemental } \\
\mathrm{Hg}\end{array}$ & $\begin{array}{c}\text { Stack } \\
\text { SCEM } \\
\text { Total Hg }\end{array}$ \\
\hline & & MW & Btu/kWh & $\%$ & $\%$ & Ton/hr & & DEGF & DEGF & DEGF & DEGF & KSCF & $\%$ & Ib/MMB & $\mathrm{Ib} / \mathrm{MMb}$ & PPM & $\begin{array}{c}(\mu \mathrm{g} / \mathrm{dNm} \text { ) } \\
\text { @ 3\%02 }\end{array}$ & $\begin{array}{c}(\mu \mathrm{g} / \mathrm{dNm} 3) \\
@ 3 \% 02\end{array}$ \\
\hline $\begin{array}{r}6 / 21 / 2009 \\
12: 00\end{array}$ & $\begin{array}{r}6 / 21 / 2009 \\
13: 00\end{array}$ & 911.6 & 8066.1 & 2.7 & 2.6 & 640.4 & 1.1 & 787.8 & 770.0 & 316.0 & 308.6 & 2367.6 & 6.8 & 1.5 & 0.4 & 11.1 & 12.8 & 14.8 \\
\hline $\begin{array}{r}6 / 21 / 2009 \\
13: 00\end{array}$ & $\begin{array}{r}6 / 21 / 2009 \\
14: 00\end{array}$ & 912.6 & 8051.5 & 2.7 & 2.5 & 630.9 & 1.1 & 790.8 & 771.7 & 318.4 & 310.8 & 2351.6 & 7.0 & 1.4 & 0.4 & 11.6 & 12.6 & 14.8 \\
\hline $\begin{array}{r}6 / 21 / 2009 \\
14: 00 \\
\end{array}$ & $\begin{array}{r}6 / 21 / 2009 \\
15: 00 \\
\end{array}$ & 911.5 & 8032.2 & 2.8 & 2.5 & 621.7 & 1.1 & 792.6 & 770.4 & 320.9 & 312.5 & 2344.6 & 7.0 & 1.4 & 0.4 & 10.8 & 12.1 & 14.4 \\
\hline $\begin{array}{r}6 / 21 / 2009 \\
15: 00 \\
\end{array}$ & $\begin{array}{r}6 / 21 / 2009 \\
16: 00 \\
\end{array}$ & 908.5 & 8023.2 & 2.8 & 2.5 & 617.4 & 1.1 & 793.8 & 776.3 & 322.2 & 314.9 & 2331.9 & 7.0 & 1.4 & 0.4 & 8.8 & 11.5 & 14.2 \\
\hline $\begin{array}{r}6 / 21 / 2009 \\
16: 00\end{array}$ & $\begin{array}{r}6 / 21 / 2009 \\
17: 00\end{array}$ & 908.0 & 8051.6 & 2.8 & 2.5 & 617.5 & 1.1 & 794.3 & 781.0 & 324.0 & 317.5 & 2335.4 & 7.4 & 1.4 & 0.4 & 8.6 & 11.1 & 14.1 \\
\hline $\begin{array}{r}6 / 21 / 2009 \\
17: 00\end{array}$ & $\begin{array}{r}6 / 21 / 2009 \\
18: 00\end{array}$ & 908.2 & 8051.5 & 2.8 & 2.5 & 613.4 & 1.1 & 796.7 & 784.4 & 324.1 & 318.6 & 2337.7 & 7.5 & 1.4 & 0.4 & 8.5 & 11.4 & 14.4 \\
\hline $\begin{array}{r}6 / 21 / 2009 \\
18: 00\end{array}$ & $\begin{array}{r}6 / 21 / 2009 \\
19: 00\end{array}$ & 908.1 & 8039.9 & 2.8 & 2.5 & 615.5 & 1.1 & 798.9 & 786.4 & 324.7 & 319.2 & 2338.3 & 7.5 & 1.4 & 0.4 & 8.2 & 11.8 & 14.6 \\
\hline $\begin{array}{r}6 / 21 / 2009 \\
19: 00\end{array}$ & $\begin{array}{r}6 / 21 / 2009 \\
20: 00\end{array}$ & 909.3 & 8047.8 & 2.8 & 2.5 & 610.5 & 1.1 & 793.0 & 778.1 & 324.7 & 318.8 & 2350.1 & 7.6 & 1.4 & 0.4 & 8.7 & 11.8 & 14.5 \\
\hline $\begin{array}{r}6 / 21 / 2009 \\
20: 00\end{array}$ & $\begin{array}{r}6 / 21 / 2009 \\
21: 00\end{array}$ & 909.6 & 8021.9 & 2.7 & 2.6 & 608.6 & 1.1 & 788.6 & 765.2 & 322.0 & 313.6 & 2330.7 & 8.0 & 1.4 & 0.4 & 9.8 & 11.7 & 14.4 \\
\hline $\begin{array}{r}6 / 21 / 2009 \\
21: 00\end{array}$ & $\begin{array}{r}6 / 21 / 2009 \\
22: 00\end{array}$ & 904.0 & 8010.4 & 2.7 & 2.5 & 605.9 & 1.1 & 785.8 & 770.2 & 319.3 & 312.6 & 2308.5 & 10.4 & 1.5 & 0.4 & 8.9 & 12.6 & 14.8 \\
\hline $\begin{array}{r}6 / 21 / 2009 \\
22: 00\end{array}$ & $\begin{array}{r}6 / 21 / 2009 \\
23: 00\end{array}$ & 898.5 & 8016.0 & 2.8 & 2.5 & 604.3 & 1.1 & 787.1 & 774.6 & 318.2 & 312.3 & 2312.7 & 10.5 & 1.5 & 0.4 & 8.8 & 13.1 & 15.0 \\
\hline $\begin{array}{r}6 / 21 / 2009 \\
23: 00\end{array}$ & $\begin{array}{r}6 / 22 / 2009 \\
0: 00\end{array}$ & 899.3 & 7988.9 & 2.7 & 2.5 & 607.0 & 1.1 & 790.1 & 778.9 & 318.1 & 311.8 & 2325.3 & 10.7 & 1.5 & 0.4 & 9.3 & 12.8 & 15.0 \\
\hline $\begin{array}{r}6 / 22 / 2009 \\
0: 00\end{array}$ & $\begin{array}{r}6 / 22 / 2009 \\
1: 00\end{array}$ & 896.7 & 8053.8 & 2.8 & 2.5 & 606.4 & 1.1 & 792.4 & 781.8 & 318.1 & 312.7 & 2313.4 & 10.7 & 1.5 & 0.4 & 9.9 & 13.1 & 15.5 \\
\hline $\begin{array}{r}6 / 22 / 2009 \\
1: 00 \\
\end{array}$ & $\begin{array}{r}6 / 22 / 2009 \\
2: 00 \\
\end{array}$ & 897.3 & 8029.3 & 2.8 & 2.5 & 605.9 & 1.1 & 794.6 & 782.3 & 317.9 & 311.5 & 2324.3 & 10.5 & 1.5 & 0.4 & 9.5 & 13.1 & 15.4 \\
\hline $\begin{array}{r}6 / 22 / 2009 \\
2: 00\end{array}$ & $\begin{array}{r}6 / 22 / 2009 \\
3: 00\end{array}$ & 897.9 & 8062.3 & 2.8 & 2.5 & 609.8 & 1.1 & 785.5 & 768.6 & 316.2 & 308.0 & 2334.2 & 10.7 & 1.5 & 0.4 & 9.6 & 12.8 & 15.1 \\
\hline $\begin{array}{r}6 / 22 / 2009 \\
3: 00\end{array}$ & $\begin{array}{r}6 / 22 / 2009 \\
4: 00\end{array}$ & 834.1 & 7946.9 & 2.6 & 2.5 & 557.3 & 1.1 & 756.8 & 742.3 & 307.7 & 297.7 & 2190.1 & 9.9 & 1.5 & 0.4 & 9.7 & 12.1 & 14.4 \\
\hline $\begin{array}{r}6 / 22 / 2009 \\
4: 00\end{array}$ & $\begin{array}{r}6 / 22 / 2009 \\
5: 00\end{array}$ & 803.4 & 7857.4 & 2.9 & 2.6 & 546.5 & 1.1 & 745.5 & 732.8 & 301.8 & 292.3 & 2161.6 & 8.9 & 1.5 & 0.4 & 8.7 & 11.5 & 13.7 \\
\hline $\begin{array}{r}6 / 22 / 2009 \\
5: 00\end{array}$ & $\begin{array}{r}6 / 22 / 2009 \\
6: 00\end{array}$ & 896.9 & 7967.7 & 2.7 & 2.4 & 607.2 & 1.1 & 774.6 & 763.3 & 304.1 & 297.8 & 2328.1 & 7.1 & 1.4 & 0.4 & 10.5 & $\# \mathrm{~N} / \mathrm{A}$ & $\# \mathrm{~N} / \mathrm{A}$ \\
\hline $\begin{array}{r}6 / 22 / 2009 \\
6: 00\end{array}$ & $\begin{array}{r}6 / 22 / 2009 \\
7: 00\end{array}$ & 907.0 & 7995.4 & 2.6 & 2.2 & 606.4 & 1.1 & 783.4 & 772.3 & 306.8 & 300.9 & 2330.9 & 6.2 & 1.4 & 0.4 & 13.7 & $\# \mathrm{~N} / \mathrm{A}$ & $\# \mathrm{~N} / \mathrm{A}$ \\
\hline $6 / 22 / 2009$ & $6 / 22 / 2009$ & 908.3 & 8003.3 & 2.7 & 2.2 & 612.5 & 1.1 & 788.6 & 778.0 & 307.9 & 301.6 & 2335.6 & 6.2 & 1.4 & 0.4 & 15.5 & 11.6 & 14.3 \\
\hline
\end{tabular}




\begin{tabular}{|c|c|c|c|c|c|c|c|c|c|c|c|c|c|c|c|c|c|c|}
\hline $\begin{array}{l}\text { Start } \\
\text { Date/ } \\
\text { Time }\end{array}$ & $\begin{array}{l}\text { End } \\
\text { Date/ } \\
\text { Time }\end{array}$ & $\begin{array}{l}\text { Gross } \\
\text { Load }\end{array}$ & $\begin{array}{c}\text { Gross } \\
\text { HR }\end{array}$ & $\begin{array}{c}\text { A } \\
\text { Econ } \\
\text { O2 }\end{array}$ & $\begin{array}{c}\text { B } \\
\text { Econ } \\
\text { O2 }\end{array}$ & $\begin{array}{l}\text { Fuel } \\
\text { Flow }\end{array}$ & $\begin{array}{l}\text { BTU } \\
\text { Gain }\end{array}$ & $\begin{array}{c}\text { A } \\
\text { APH } \\
\text { In }\end{array}$ & $\begin{array}{l}\text { B } \\
\text { APH } \\
\text { In }\end{array}$ & $\begin{array}{c}\text { A } \\
\text { APH } \\
\text { Out }\end{array}$ & $\begin{array}{c}\text { B } \\
\text { APH } \\
\text { Out }\end{array}$ & $\begin{array}{l}\text { Stack } \\
\text { Flow }\end{array}$ & Opacity & SO2 In & $\begin{array}{l}\text { SO2 } \\
\text { Out }\end{array}$ & $\mathrm{CO}$ & $\begin{array}{c}\text { Stack } \\
\text { SCEM } \\
\text { Elemental } \\
\mathrm{Hg}\end{array}$ & $\begin{array}{c}\text { Stack } \\
\text { SCEM } \\
\text { Total Hg }\end{array}$ \\
\hline & & MW & Btu/kWh & $\%$ & $\%$ & Ton/hr & & DEGF & DEGF & DEGF & DEGF & KSCF & $\%$ & $\mathrm{Ib} / \mathrm{MMB}$ & $\mathrm{Ib} / \mathrm{MMb}$ & PPM & $\begin{array}{c}(\mu \mathrm{g} / \mathrm{dNm} 3) \\
@ 3 \% 02\end{array}$ & $\begin{array}{c}(\mu \mathrm{g} / \mathrm{dNm} 3) \\
\text { @ 3\%O2 }\end{array}$ \\
\hline $7: 00$ & 8:00 & & & & & & & & & & & & & & & & & \\
\hline $\begin{array}{r}6 / 22 / 2009 \\
8: 00 \\
\end{array}$ & $\begin{array}{r}6 / 22 / 2009 \\
9: 00 \\
\end{array}$ & 907.9 & 8034.7 & 2.7 & 2.2 & 616.1 & 1.1 & 791.6 & 779.3 & 309.5 & 303.7 & 2333.1 & 6.4 & 1.4 & 0.4 & 16.5 & 12.0 & 14.5 \\
\hline $\begin{array}{r}6 / 22 / 2009 \\
9: 00\end{array}$ & $\begin{array}{r}6 / 22 / 2009 \\
10: 00\end{array}$ & 911.0 & 8061.3 & 2.7 & 2.2 & 619.7 & 1.1 & 782.9 & 771.8 & 310.3 & 304.8 & 2340.1 & 6.8 & 1.4 & 0.4 & 16.9 & 12.4 & 14.6 \\
\hline $\begin{array}{r}6 / 22 / 2009 \\
10: 00\end{array}$ & $\begin{array}{r}6 / 22 / 2009 \\
11: 00\end{array}$ & 910.8 & 8041.1 & 2.8 & 2.0 & 618.6 & 1.1 & 770.1 & 767.2 & 308.1 & 305.0 & 2318.3 & 7.5 & 1.4 & 0.4 & 14.8 & 12.4 & 14.7 \\
\hline $\begin{array}{r}6 / 22 / 2009 \\
11: 00\end{array}$ & $\begin{array}{r}6 / 22 / 2009 \\
12: 00\end{array}$ & 914.5 & 8032.8 & 2.8 & 2.0 & 617.1 & 1.1 & 768.1 & 763.1 & 309.0 & 305.0 & 2313.3 & 7.4 & 1.4 & 0.4 & 18.5 & 8.7 & 10.3 \\
\hline $\begin{array}{r}6 / 22 / 2009 \\
12: 00\end{array}$ & $\begin{array}{r}6 / 22 / 2009 \\
13: 00\end{array}$ & 912.8 & 8047.1 & 2.7 & 2.0 & 613.1 & 1.1 & 770.5 & 767.8 & 310.4 & 307.2 & 2316.0 & 7.5 & 1.4 & 0.4 & 18.9 & 6.8 & 8.3 \\
\hline $\begin{array}{r}6 / 22 / 2009 \\
13: 00\end{array}$ & $\begin{array}{r}6 / 22 / 2009 \\
14: 00\end{array}$ & 912.7 & 8033.3 & 2.7 & 2.0 & 611.4 & 1.1 & 769.4 & 766.1 & 312.4 & 309.9 & 2307.0 & 7.8 & 1.4 & 0.4 & 16.7 & 6.3 & 7.7 \\
\hline $\begin{array}{r}6 / 22 / 2009 \\
14: 00\end{array}$ & $\begin{array}{r}6 / 22 / 2009 \\
15: 00\end{array}$ & 914.4 & 7956.0 & 2.8 & 1.9 & 608.8 & 1.1 & 771.1 & 768.3 & 312.4 & 310.4 & 2292.6 & 7.6 & 1.4 & 0.4 & 16.3 & 6.1 & 7.5 \\
\hline $\begin{array}{r}6 / 22 / 2009 \\
15: 00\end{array}$ & $\begin{array}{r}6 / 22 / 2009 \\
16: 00\end{array}$ & 910.5 & 8011.4 & 2.8 & 1.9 & 609.1 & 1.1 & 772.9 & 771.2 & 315.0 & 313.1 & 2284.8 & 7.7 & 1.4 & 0.4 & 14.6 & 6.0 & 7.3 \\
\hline $\begin{array}{r}6 / 22 / 2009 \\
16: 00 \\
\end{array}$ & $\begin{array}{r}6 / 22 / 2009 \\
17: 00 \\
\end{array}$ & 910.5 & 8026.5 & 2.8 & 1.9 & 619.0 & 1.1 & 771.5 & 765.4 & 316.0 & 313.6 & 2290.5 & 7.7 & 1.4 & 0.4 & 15.6 & 6.3 & 7.6 \\
\hline $\begin{array}{r}6 / 22 / 2009 \\
17: 00\end{array}$ & $\begin{array}{r}6 / 22 / 2009 \\
18: 00\end{array}$ & 911.3 & 7994.6 & 2.8 & 1.9 & 627.5 & 1.1 & 777.2 & 769.3 & 317.3 & 314.4 & 2294.2 & 8.0 & 1.5 & 0.4 & 17.1 & 7.1 & 8.3 \\
\hline $\begin{array}{r}6 / 22 / 2009 \\
18: 00\end{array}$ & $\begin{array}{r}6 / 22 / 2009 \\
19: 00\end{array}$ & 916.4 & 7982.9 & 2.7 & 1.8 & 631.1 & 1.1 & 780.8 & 773.9 & 318.3 & 315.6 & 2307.4 & 8.1 & 1.5 & 0.4 & 27.7 & 7.4 & 8.6 \\
\hline $\begin{array}{r}6 / 22 / 2009 \\
19: 00\end{array}$ & $\begin{array}{r}6 / 22 / 2009 \\
20: 00\end{array}$ & 913.6 & 8016.5 & 2.8 & 1.9 & 628.6 & 1.1 & 777.1 & 771.9 & 318.4 & 316.1 & 2306.3 & 8.0 & 1.5 & 0.4 & 36.6 & 7.1 & 8.3 \\
\hline $\begin{array}{r}6 / 22 / 2009 \\
20: 00\end{array}$ & $\begin{array}{r}6 / 22 / 2009 \\
21: 00\end{array}$ & 912.7 & 7998.6 & 2.8 & 1.9 & 631.3 & 1.1 & 767.5 & 761.3 & 315.5 & 313.7 & 2315.8 & 8.4 & 1.5 & 0.4 & 29.2 & 7.1 & 8.3 \\
\hline $\begin{array}{r}6 / 22 / 2009 \\
21: 00\end{array}$ & $\begin{array}{r}6 / 22 / 2009 \\
22: 00\end{array}$ & 913.5 & 7964.7 & 2.8 & 1.9 & 626.7 & 1.1 & 770.2 & 764.0 & 313.3 & 311.8 & 2321.8 & 9.8 & 1.4 & 0.4 & 32.0 & 6.9 & 8.2 \\
\hline $\begin{array}{r}6 / 22 / 2009 \\
22: 00\end{array}$ & $\begin{array}{r}6 / 22 / 2009 \\
23: 00\end{array}$ & 904.5 & 7967.0 & 2.8 & 1.9 & 626.1 & 1.1 & 771.0 & 765.4 & 311.5 & 310.3 & 2301.6 & 9.8 & 1.4 & 0.4 & 49.4 & 8.1 & 9.8 \\
\hline $\begin{array}{r}6 / 22 / 2009 \\
23: 00 \\
\end{array}$ & $\begin{array}{r}6 / 23 / 2009 \\
0: 00 \\
\end{array}$ & 903.0 & 7972.4 & 2.7 & 1.9 & 622.4 & 1.1 & 775.1 & 768.4 & 311.3 & 309.9 & 2298.4 & 9.9 & 1.4 & 0.4 & 37.3 & 9.4 & 11.5 \\
\hline $\begin{array}{r}6 / 23 / 2009 \\
0: 00 \\
\end{array}$ & $\begin{array}{r}6 / 23 / 2009 \\
1: 00 \\
\end{array}$ & 899.5 & 7971.5 & 2.8 & 1.9 & 620.2 & 1.1 & 776.2 & 769.2 & 310.4 & 308.0 & 2290.9 & 9.8 & 1.4 & 0.4 & 34.2 & 9.7 & 11.8 \\
\hline $\begin{array}{r}6 / 23 / 2009 \\
1: 00\end{array}$ & $\begin{array}{r}6 / 23 / 2009 \\
2: 00\end{array}$ & 906.0 & 7992.4 & 2.7 & 1.9 & 624.5 & 1.1 & 779.4 & 773.0 & 310.2 & 307.9 & 2303.3 & 10.0 & 1.4 & 0.4 & 26.2 & 9.9 & 12.1 \\
\hline $\begin{array}{r}6 / 23 / 2009 \\
2: 00\end{array}$ & $\begin{array}{r}6 / 23 / 2009 \\
3: 00\end{array}$ & 905.1 & 8030.7 & 2.7 & 2.0 & 620.2 & 1.1 & 775.9 & 765.1 & 310.2 & 306.2 & 2305.2 & 10.2 & 1.4 & 0.4 & 20.7 & 9.8 & 12.1 \\
\hline
\end{tabular}




\begin{tabular}{|c|c|c|c|c|c|c|c|c|c|c|c|c|c|c|c|c|c|c|}
\hline $\begin{array}{l}\text { Start } \\
\text { Date/ } \\
\text { Time }\end{array}$ & $\begin{array}{l}\text { End } \\
\text { Date/ } \\
\text { Time }\end{array}$ & $\begin{array}{l}\text { Gross } \\
\text { Load }\end{array}$ & $\begin{array}{c}\text { Gross } \\
\text { HR }\end{array}$ & $\begin{array}{c}\text { A } \\
\text { Econ } \\
\text { O2 }\end{array}$ & $\begin{array}{c}\text { B } \\
\text { Econ } \\
\text { O2 }\end{array}$ & $\begin{array}{l}\text { Fuel } \\
\text { Flow }\end{array}$ & $\begin{array}{l}\text { BTU } \\
\text { Gain }\end{array}$ & $\begin{array}{c}\text { A } \\
\text { APH } \\
\text { In }\end{array}$ & $\begin{array}{l}\text { B } \\
\text { APH } \\
\text { In }\end{array}$ & $\begin{array}{c}\text { A } \\
\text { APH } \\
\text { Out }\end{array}$ & $\begin{array}{c}\text { B } \\
\text { APH } \\
\text { Out }\end{array}$ & $\begin{array}{l}\text { Stack } \\
\text { Flow }\end{array}$ & Opacity & SO2 In & $\begin{array}{l}\text { SO2 } \\
\text { Out }\end{array}$ & $\mathrm{CO}$ & $\begin{array}{c}\text { Stack } \\
\text { SCEM } \\
\text { Elemental } \\
\mathrm{Hg}\end{array}$ & $\begin{array}{c}\text { Stack } \\
\text { SCEM } \\
\text { Total Hg }\end{array}$ \\
\hline & & MW & Btu/kWh & $\%$ & $\%$ & Ton/hr & & DEGF & DEGF & DEGF & DEGF & KSCF & $\%$ & Ib/MMB & $\mathrm{Ib} / \mathrm{MMb}$ & PPM & $\begin{array}{c}(\mu \mathrm{g} / \mathrm{dNm} \text { ) } \\
\text { @ 3\%02 }\end{array}$ & $\begin{array}{c}(\mu \mathrm{g} / \mathrm{dNm} 3) \\
@ 3 \% 02\end{array}$ \\
\hline $\begin{array}{r}6 / 23 / 2009 \\
3: 00\end{array}$ & $\begin{array}{r}6 / 23 / 2009 \\
4: 00\end{array}$ & 894.9 & 7910.5 & 2.6 & 2.0 & 615.9 & 1.1 & 763.7 & 752.2 & 305.1 & 299.5 & 2299.3 & 9.7 & 1.4 & 0.4 & 27.9 & 9.6 & 11.8 \\
\hline $\begin{array}{r}6 / 23 / 2009 \\
4: 00\end{array}$ & $\begin{array}{r}6 / 23 / 2009 \\
5: 00\end{array}$ & 905.6 & 7948.6 & 2.7 & 1.9 & 622.0 & 1.1 & 768.4 & 757.3 & 304.0 & 298.6 & 2320.2 & 9.3 & 1.4 & 0.4 & 22.4 & $\# \mathrm{~N} / \mathrm{A}$ & $\# \mathrm{~N} / \mathrm{A}$ \\
\hline $\begin{array}{r}6 / 23 / 2009 \\
5: 00\end{array}$ & $\begin{array}{r}6 / 23 / 2009 \\
6: 00\end{array}$ & 905.6 & 8023.2 & 2.8 & 1.8 & 613.8 & 1.1 & 769.7 & 761.3 & 303.9 & 299.4 & 2314.4 & 7.4 & 1.3 & 0.4 & 13.4 & $\# \mathrm{~N} / \mathrm{A}$ & $\# \mathrm{~N} / \mathrm{A}$ \\
\hline $\begin{array}{r}6 / 23 / 2009 \\
6: 00\end{array}$ & $\begin{array}{r}6 / 23 / 2009 \\
7: 00\end{array}$ & 913.2 & 8005.9 & 2.8 & 1.9 & 618.2 & 1.1 & 768.7 & 758.5 & 303.8 & 298.7 & 2330.4 & 7.5 & 1.3 & 0.4 & 18.9 & $\# \mathrm{~N} / \mathrm{A}$ & $\# \mathrm{~N} / \mathrm{A}$ \\
\hline $\begin{array}{r}6 / 23 / 2009 \\
7: 00\end{array}$ & $\begin{array}{r}6 / 23 / 2009 \\
8: 00\end{array}$ & 914.1 & 7990.5 & 3.4 & 2.5 & 615.9 & 1.1 & 771.5 & 759.6 & 303.8 & 298.8 & 2334.7 & 7.7 & 1.3 & 0.4 & 17.5 & 8.9 & 11.1 \\
\hline $\begin{array}{r}6 / 23 / 2009 \\
8: 00\end{array}$ & $\begin{array}{r}6 / 23 / 2009 \\
9: 00\end{array}$ & 912.9 & 7993.7 & 4.4 & 2.9 & 616.0 & 1.1 & 765.2 & 757.0 & 304.0 & 300.0 & 2320.1 & 7.7 & 1.3 & 0.4 & 9.1 & 9.7 & 12.4 \\
\hline $\begin{array}{r}6 / 23 / 2009 \\
9: 00\end{array}$ & $\begin{array}{r}6 / 23 / 2009 \\
10: 00\end{array}$ & 914.0 & 8020.8 & 2.7 & 1.9 & 609.3 & 1.1 & 768.7 & 762.1 & 305.2 & 302.1 & 2282.2 & 7.6 & 1.3 & 0.4 & 6.7 & 10.0 & 13.1 \\
\hline $\begin{array}{r}6 / 23 / 2009 \\
10: 00\end{array}$ & $\begin{array}{r}6 / 23 / 2009 \\
11: 00\end{array}$ & 912.6 & 8013.3 & 2.7 & 1.9 & 608.2 & 1.1 & 772.0 & 763.9 & 308.5 & 305.3 & 2289.0 & 7.7 & 1.3 & 0.4 & 6.4 & 7.6 & 10.1 \\
\hline $\begin{array}{r}6 / 23 / 2009 \\
11: 00\end{array}$ & $\begin{array}{r}6 / 23 / 2009 \\
12: 00\end{array}$ & 912.6 & 8008.3 & 2.7 & 1.8 & 608.6 & 1.1 & 773.1 & 766.2 & 310.1 & 307.4 & 2276.1 & 7.1 & 1.3 & 0.4 & 7.7 & 4.5 & 5.9 \\
\hline $\begin{array}{r}6 / 23 / 2009 \\
12: 00\end{array}$ & $\begin{array}{r}6 / 23 / 2009 \\
13: 00\end{array}$ & 911.2 & 8009.2 & 2.6 & 1.8 & 612.8 & 1.1 & 777.1 & 767.5 & 313.0 & 309.9 & 2270.4 & 7.2 & 1.3 & 0.4 & 8.8 & 4.3 & 5.3 \\
\hline $\begin{array}{r}6 / 23 / 2009 \\
13: 00\end{array}$ & $\begin{array}{r}6 / 23 / 2009 \\
14: 00\end{array}$ & 912.9 & 7992.3 & 2.7 & 1.7 & 615.6 & 1.1 & 777.1 & 761.5 & 315.6 & 311.7 & 2299.8 & 7.8 & 1.4 & 0.3 & 8.8 & 4.6 & 5.5 \\
\hline $\begin{array}{r}6 / 23 / 2009 \\
14: 00\end{array}$ & $\begin{array}{r}6 / 23 / 2009 \\
15: 00\end{array}$ & 915.0 & 7987.5 & 2.7 & 1.7 & 614.2 & 1.1 & 772.3 & 761.7 & 315.3 & 311.6 & 2298.0 & 7.4 & 1.3 & 0.3 & 9.3 & 4.4 & 5.2 \\
\hline $\begin{array}{r}6 / 23 / 2009 \\
15: 00\end{array}$ & $\begin{array}{r}6 / 23 / 2009 \\
16: 00\end{array}$ & 913.3 & 8008.7 & 2.6 & 1.8 & 610.1 & 1.1 & 777.7 & 768.3 & 316.5 & 312.7 & 2280.1 & 7.2 & 1.3 & 0.4 & 8.2 & 3.9 & 4.9 \\
\hline $\begin{array}{r}6 / 23 / 2009 \\
16: 00 \\
\end{array}$ & $\begin{array}{r}6 / 23 / 2009 \\
17: 00 \\
\end{array}$ & 909.2 & 7993.6 & 2.7 & 1.7 & 607.9 & 1.1 & 782.4 & 774.8 & 318.5 & 315.0 & 2267.0 & 7.3 & 1.3 & 0.4 & 8.8 & 3.6 & 4.7 \\
\hline $\begin{array}{r}6 / 23 / 2009 \\
17: 00\end{array}$ & $\begin{array}{r}6 / 23 / 2009 \\
18: 00\end{array}$ & 911.2 & 8012.8 & 2.7 & 1.7 & 613.3 & 1.1 & 787.8 & 780.8 & 320.0 & 317.1 & 2278.9 & 7.3 & 1.2 & 0.4 & 14.5 & 3.4 & 4.7 \\
\hline $\begin{array}{r}6 / 23 / 2009 \\
18: 00\end{array}$ & $\begin{array}{r}6 / 23 / 2009 \\
19: 00\end{array}$ & 912.0 & 8016.3 & 2.7 & 1.8 & 620.3 & 1.1 & 787.5 & 780.4 & 320.8 & 318.5 & 2278.7 & 7.7 & 1.3 & 0.4 & 13.8 & 3.4 & 4.8 \\
\hline $\begin{array}{r}6 / 23 / 2009 \\
19: 00 \\
\end{array}$ & $\begin{array}{r}6 / 23 / 2009 \\
20: 00 \\
\end{array}$ & 912.5 & 8009.4 & 2.7 & 1.9 & 625.2 & 1.1 & 788.1 & 781.2 & 320.9 & 317.5 & 2300.5 & 7.7 & 1.3 & 0.4 & 16.7 & 4.2 & 5.5 \\
\hline $\begin{array}{r}6 / 23 / 2009 \\
20: 00\end{array}$ & $\begin{array}{r}6 / 23 / 2009 \\
21: 00\end{array}$ & 914.1 & 8029.0 & 3.1 & 2.3 & 628.1 & 1.1 & 788.7 & 782.8 & 320.5 & 317.4 & 2369.0 & 9.1 & 1.3 & 0.4 & 4.1 & 7.6 & 9.9 \\
\hline $\begin{array}{r}6 / 23 / 2009 \\
21: 00 \\
\end{array}$ & $\begin{array}{r}6 / 23 / 2009 \\
22: 00 \\
\end{array}$ & 916.2 & 8009.2 & 3.0 & 2.3 & 621.4 & 1.1 & 780.0 & 772.8 & 315.9 & 312.8 & 2357.0 & 10.2 & 1.3 & 0.4 & 5.4 & 9.3 & 11.8 \\
\hline $6 / 23 / 2009$ & $6 / 23 / 2009$ & 915.0 & 7979.2 & 3.1 & 2.3 & 615.6 & 1.1 & 784.8 & 778.2 & 314.8 & 312.4 & 2359.1 & 10.5 & 1.3 & 0.4 & 3.7 & 9.8 & 12.6 \\
\hline
\end{tabular}




\begin{tabular}{|c|c|c|c|c|c|c|c|c|c|c|c|c|c|c|c|c|c|c|}
\hline \multirow[t]{2}{*}{$\begin{array}{l}\text { Start } \\
\text { Date/ } \\
\text { Time }\end{array}$} & \multirow[t]{2}{*}{$\begin{array}{l}\text { End } \\
\text { Date/ } \\
\text { Time }\end{array}$} & $\begin{array}{l}\text { Gross } \\
\text { Load }\end{array}$ & $\begin{array}{c}\text { Gross } \\
\text { HR }\end{array}$ & $\begin{array}{c}\text { A } \\
\text { Econ } \\
\text { O2 }\end{array}$ & $\begin{array}{c}\text { B } \\
\text { Econ } \\
\text { O2 }\end{array}$ & $\begin{array}{l}\text { Fuel } \\
\text { Flow }\end{array}$ & $\begin{array}{l}\text { BTU } \\
\text { Gain }\end{array}$ & $\begin{array}{c}\text { A } \\
\text { APH } \\
\text { In }\end{array}$ & $\begin{array}{c}\text { B } \\
\text { APH } \\
\text { In }\end{array}$ & $\begin{array}{c}\text { A } \\
\text { APH } \\
\text { Out }\end{array}$ & $\begin{array}{c}\text { B } \\
\text { APH } \\
\text { Out }\end{array}$ & $\begin{array}{l}\text { Stack } \\
\text { Flow }\end{array}$ & Opacity & SO2 In & $\begin{array}{l}\text { SO2 } \\
\text { Out }\end{array}$ & $\mathrm{CO}$ & $\begin{array}{c}\text { Stack } \\
\text { SCEM } \\
\text { Elemental } \\
\mathrm{Hg}\end{array}$ & $\begin{array}{c}\text { Stack } \\
\text { SCEM } \\
\text { Total Hg }\end{array}$ \\
\hline & & MW & Btu/kWh & $\%$ & $\%$ & Ton/hr & & DEGF & DEGF & DEGF & DEGF & KSCF & $\%$ & $\mathrm{Ib} / \mathrm{MMB}$ & $\mathrm{Ib} / \mathrm{MMb}$ & PPM & $\begin{array}{c}(\mu \mathrm{g} / \mathrm{dNm} 3) \\
\text { @ 3\%O2 }\end{array}$ & $\begin{array}{c}(\mu \mathrm{g} / \mathrm{dNm} 3) \\
@ 3 \% 02\end{array}$ \\
\hline $22: 00$ & $23: 00$ & & & & & & & & & & & & & & & & & \\
\hline $\begin{array}{r}6 / 23 / 2009 \\
23: 00\end{array}$ & $\begin{array}{r}6 / 24 / 2009 \\
0: 00 \\
\end{array}$ & 907.3 & 7998.6 & 3.1 & 2.3 & 606.8 & 1.1 & 782.5 & 779.7 & 315.3 & 314.0 & 2327.5 & 10.2 & 1.3 & 0.4 & 2.8 & 9.9 & 12.9 \\
\hline $\begin{array}{r}6 / 24 / 2009 \\
0: 00\end{array}$ & $\begin{array}{r}/ 24 / 2009 \\
1: 00\end{array}$ & 905.7 & 8025.2 & 3.2 & 2.3 & 610.2 & 1.1 & 771.1 & 775.0 & 311.3 & 310.7 & 2342.0 & 10.3 & 1.3 & 0.4 & 3.1 & 10.3 & 13.3 \\
\hline $\begin{array}{r}6 / 24 / 2009 \\
1: 00 \\
\end{array}$ & $\begin{array}{r}6 / 24 / 2009 \\
2: 00 \\
\end{array}$ & 906.2 & 8013.2 & 3.1 & 2.3 & 609.2 & 1.1 & 776.3 & 777.8 & 310.0 & 309.3 & 2339.5 & 10.3 & 1.3 & 0.4 & 3.2 & 11.0 & 13.7 \\
\hline $\begin{array}{r}6 / 24 / 2009 \\
2: 00\end{array}$ & $\begin{array}{r}6 / 24 / 2009 \\
3: 00\end{array}$ & 900.7 & 7991.2 & 3.1 & 2.3 & 611.0 & 1.1 & 778.6 & 778.2 & 310.1 & 307.8 & 2332.7 & 10.9 & 1.3 & 0.4 & 3.5 & 11.4 & 14.0 \\
\hline $\begin{array}{r}6 / 24 / 2009 \\
3: 00\end{array}$ & $\begin{array}{r}6 / 24 / 2009 \\
4: 00\end{array}$ & 904.1 & 8016.7 & 3.0 & 2.4 & 616.2 & 1.1 & 782.2 & 779.8 & 310.2 & 308.3 & 2346.2 & 10.7 & 1.3 & 0.4 & 4.3 & 11.6 & 14.4 \\
\hline $\begin{array}{r}6 / 24 / 2009 \\
4: 00\end{array}$ & $\begin{array}{r}6 / 24 / 2009 \\
5: 00\end{array}$ & 907.7 & 8018.4 & 3.0 & 2.4 & 626.1 & 1.1 & 780.9 & 776.2 & 310.5 & 307.8 & 2364.2 & 10.3 & 1.3 & 0.4 & 6.2 & 11.5 & 14.6 \\
\hline $\begin{array}{r}6 / 24 / 2009 \\
5: 00\end{array}$ & $\begin{array}{r}6 / 24 / 2009 \\
6: 00 \\
\end{array}$ & 911.1 & 7983.8 & 2.8 & 2.1 & 626.6 & 1.1 & 774.9 & 769.0 & 309.4 & 306.3 & 2334.7 & 9.7 & 1.3 & 0.4 & 11.2 & $\# \mathrm{~N} / \mathrm{A}$ & $\# N / A$ \\
\hline $\begin{array}{r}6 / 24 / 2009 \\
6: 00\end{array}$ & $\begin{array}{r}6 / 24 / 2009 \\
7: 00 \\
\end{array}$ & 910.9 & 8021.2 & 2.7 & 2.1 & 625.4 & 1.1 & 767.8 & 762.5 & 307.5 & 304.2 & 2339.1 & 10.5 & 1.3 & 0.4 & 13.4 & $\# \mathrm{~N} / \mathrm{A}$ & $\# \mathrm{~N} / \mathrm{A}$ \\
\hline $\begin{array}{r}6 / 24 / 2009 \\
7: 00 \\
\end{array}$ & $\begin{array}{r}6 / 24 / 2009 \\
8: 00 \\
\end{array}$ & 914.6 & 7989.8 & 2.9 & 2.1 & 626.2 & 1.1 & 763.1 & 758.6 & 304.9 & 301.2 & 2356.5 & 10.0 & 1.3 & 0.3 & 8.3 & 11.7 & 14.0 \\
\hline $\begin{array}{r}6 / 24 / 2009 \\
8: 00 \\
\end{array}$ & $\begin{array}{r}6 / 24 / 2009 \\
9: 00 \\
\end{array}$ & 912.7 & 8011.1 & 3.0 & 2.0 & 627.2 & 1.1 & 765.4 & 759.6 & 304.1 & 301.8 & 2339.0 & 10.3 & 1.3 & 0.4 & 4.8 & 12.1 & 14.3 \\
\hline $\begin{array}{r}6 / 24 / 2009 \\
9: 00\end{array}$ & $\begin{array}{r}6 / 24 / 2009 \\
10: 00\end{array}$ & 912.8 & 8018.2 & 2.9 & 2.1 & 627.7 & 1.1 & 763.6 & 754.4 & 306.2 & 303.3 & 2327.4 & 10.7 & 1.4 & 0.4 & 7.7 & 12.2 & 14.4 \\
\hline $\begin{array}{r}6 / 24 / 2009 \\
10: 00\end{array}$ & $\begin{array}{r}6 / 24 / 2009 \\
11: 00\end{array}$ & 914.5 & 7967.0 & 2.8 & 2.1 & 626.4 & 1.1 & 768.9 & 755.4 & 307.8 & 303.5 & 2319.5 & 11.1 & 1.3 & 0.4 & 12.6 & 8.8 & 10.3 \\
\hline $\begin{array}{r}6 / 24 / 2009 \\
11: 00\end{array}$ & $\begin{array}{r}6 / 24 / 2009 \\
12: 00\end{array}$ & 913.9 & 7984.8 & 2.8 & 2.2 & 620.9 & 1.1 & 773.7 & 756.8 & 312.0 & 306.6 & 2317.1 & 11.1 & 1.4 & 0.4 & 11.1 & 7.2 & 8.5 \\
\hline $\begin{array}{r}6 / 24 / 2009 \\
12: 00\end{array}$ & $\begin{array}{r}6 / 24 / 2009 \\
13: 00 \\
\end{array}$ & 912.9 & 8022.9 & 2.8 & 2.1 & 622.9 & 1.1 & 774.2 & 758.9 & 316.7 & 310.4 & 2311.3 & 11.2 & 1.4 & 0.4 & 7.7 & 6.2 & 7.5 \\
\hline $\begin{array}{r}6 / 24 / 2009 \\
13: 00\end{array}$ & $\begin{array}{r}6 / 24 / 2009 \\
14: 00\end{array}$ & 913.6 & 8012.5 & 2.8 & 2.1 & 621.5 & 1.1 & 766.0 & 763.7 & 314.7 & 313.0 & 2319.9 & 10.5 & 1.4 & 0.4 & 10.5 & 5.3 & 6.8 \\
\hline $\begin{array}{r}6 / 24 / 2009 \\
14: 00\end{array}$ & $\begin{array}{r}6 / 24 / 2009 \\
15: 00\end{array}$ & 915.2 & 8002.4 & 3.0 & 1.9 & 614.5 & 1.1 & 764.2 & 761.6 & 314.4 & 314.1 & 2317.2 & 10.8 & 1.4 & 0.4 & 13.0 & 5.2 & 6.9 \\
\hline $\begin{array}{r}6 / 24 / 2009 \\
15: 00 \\
\end{array}$ & $\begin{array}{r}6 / 24 / 2009 \\
16: 00 \\
\end{array}$ & 880.0 & 7979.1 & 3.0 & 1.9 & 593.9 & 1.1 & 755.9 & 754.8 & 312.5 & 311.6 & 2238.8 & 10.2 & 1.4 & 0.4 & 7.8 & 5.1 & 6.7 \\
\hline $\begin{array}{r}6 / 24 / 2009 \\
16: 00\end{array}$ & $\begin{array}{r}6 / 24 / 2009 \\
17: 00\end{array}$ & 909.9 & 7991.4 & 3.0 & 2.0 & 615.4 & 1.1 & 767.0 & 765.3 & 313.9 & 313.9 & 2325.0 & 11.2 & 1.4 & 0.4 & 7.7 & 5.1 & 6.7 \\
\hline $\begin{array}{r}6 / 24 / 2009 \\
17: 00\end{array}$ & $\begin{array}{r}6 / 24 / 2009 \\
18: 00 \\
\end{array}$ & 913.9 & 8016.2 & 2.9 & 2.1 & 603.7 & 1.1 & 777.5 & 773.2 & 317.1 & 316.1 & 2324.2 & 10.9 & 1.3 & 0.4 & 10.9 & 4.7 & 6.3 \\
\hline
\end{tabular}




\begin{tabular}{|c|c|c|c|c|c|c|c|c|c|c|c|c|c|c|c|c|c|c|}
\hline \multirow[t]{2}{*}{$\begin{array}{l}\text { Start } \\
\text { Date/ } \\
\text { Time }\end{array}$} & \multirow[t]{2}{*}{$\begin{array}{l}\text { End } \\
\text { Date/ } \\
\text { Time }\end{array}$} & $\begin{array}{l}\text { Gross } \\
\text { Load }\end{array}$ & $\begin{array}{c}\text { Gross } \\
\text { HR }\end{array}$ & $\begin{array}{c}\text { A } \\
\text { Econ } \\
\text { O2 }\end{array}$ & $\begin{array}{c}\text { B } \\
\text { Econ } \\
\text { O2 }\end{array}$ & $\begin{array}{l}\text { Fuel } \\
\text { Flow }\end{array}$ & $\begin{array}{l}\text { BTU } \\
\text { Gain }\end{array}$ & $\begin{array}{c}\text { A } \\
\text { APH } \\
\text { In }\end{array}$ & $\begin{array}{c}\text { B } \\
\text { APH } \\
\text { In }\end{array}$ & $\begin{array}{c}\text { A } \\
\text { APH } \\
\text { Out }\end{array}$ & $\begin{array}{c}\text { B } \\
\text { APH } \\
\text { Out }\end{array}$ & $\begin{array}{l}\text { Stack } \\
\text { Flow }\end{array}$ & Opacity & SO2 In & $\begin{array}{l}\text { SO2 } \\
\text { Out }\end{array}$ & $\mathrm{CO}$ & $\begin{array}{c}\text { Stack } \\
\text { SCEM } \\
\text { Elemental } \\
\mathrm{Hg}\end{array}$ & $\begin{array}{c}\text { Stack } \\
\text { SCEM } \\
\text { Total Hg }\end{array}$ \\
\hline & & MW & Btu/kWh & $\%$ & $\%$ & Ton/hr & & DEGF & DEGF & DEGF & DEGF & KSCF & $\%$ & $\mathrm{Ib} / \mathrm{MMB}$ & $\mathrm{Ib} / \mathrm{MMb}$ & PPM & $\begin{array}{c}\text { ( } \mu \mathrm{g} / \mathrm{dNm} \text { ) } \\
@ 3 \% 02\end{array}$ & $\begin{array}{c}(\mu \mathrm{g} / \mathrm{dNm} 3) \\
@ 3 \% 02\end{array}$ \\
\hline $\begin{array}{r}6 / 24 / 2009 \\
18: 00\end{array}$ & $\begin{array}{r}6 / 24 / 2009 \\
19: 00\end{array}$ & 903.9 & 7989.4 & 3.0 & 2.2 & 584.0 & 1.1 & 782.6 & 778.7 & 318.2 & 316.5 & 2296.8 & 10.5 & 1.3 & 0.4 & 11.7 & 4.2 & 5.8 \\
\hline $\begin{array}{r}6 / 24 / 2009 \\
19: 00\end{array}$ & $\begin{array}{r}6 / 24 / 2009 \\
20: 00\end{array}$ & 899.2 & 8006.3 & 3.1 & 2.2 & 573.3 & 1.1 & 784.5 & 782.4 & 318.4 & 316.6 & 2301.0 & 10.7 & 1.2 & 0.3 & 10.5 & 5.5 & 7.6 \\
\hline $\begin{array}{r}6 / 24 / 2009 \\
20: 00\end{array}$ & $\begin{array}{r}6 / 24 / 2009 \\
21: 00\end{array}$ & 900.0 & 8030.8 & 3.2 & 2.2 & 566.6 & 1.1 & 787.2 & 785.9 & 318.3 & 316.5 & 2302.7 & 10.6 & 1.1 & 0.3 & 9.9 & 6.4 & 9.2 \\
\hline $\begin{array}{r}6 / 24 / 2009 \\
21: 00\end{array}$ & $\begin{array}{r}6 / 24 / 2009 \\
22: 00\end{array}$ & 909.0 & 8002.3 & 3.1 & 2.3 & 565.1 & 1.2 & 779.7 & 779.3 & 316.5 & 314.1 & 2320.5 & 10.4 & 1.0 & 0.2 & 9.7 & 8.0 & 9.8 \\
\hline $\begin{array}{r}6 / 24 / 2009 \\
22: 00\end{array}$ & $\begin{array}{r}6 / 24 / 2009 \\
23: 00\end{array}$ & 896.5 & 8039.9 & 3.1 & 2.2 & 549.4 & 1.2 & 780.0 & 779.7 & 315.1 & 312.6 & 2283.3 & 9.8 & 1.0 & 0.2 & 11.0 & 8.7 & 10.6 \\
\hline $\begin{array}{r}6 / 24 / 2009 \\
23: 00\end{array}$ & $\begin{array}{r}6 / 25 / 2009 \\
0: 00\end{array}$ & 895.0 & 8064.5 & 3.2 & 2.3 & 555.2 & 1.2 & 787.0 & 786.1 & 315.5 & 313.4 & 2280.5 & 9.9 & 1.0 & 0.2 & 18.0 & 7.9 & 10.4 \\
\hline $\begin{array}{r}6 / 25 / 2009 \\
0: 00\end{array}$ & $\begin{array}{r}6 / 25 / 2009 \\
1: 00\end{array}$ & 903.1 & 8074.5 & 3.1 & 2.3 & 559.1 & 1.2 & 791.6 & 786.8 & 316.2 & 313.1 & 2328.4 & 11.6 & 0.9 & 0.2 & 15.9 & 9.4 & 10.6 \\
\hline $\begin{array}{r}6 / 25 / 2009 \\
1: 00\end{array}$ & $\begin{array}{r}6 / 25 / 2009 \\
2: 00\end{array}$ & 909.7 & 8033.7 & 3.1 & 2.3 & 557.4 & 1.2 & 796.3 & 794.3 & 317.6 & 314.7 & 2310.0 & 11.5 & 0.9 & 0.2 & 8.6 & 10.1 & 11.4 \\
\hline $\begin{array}{r}6 / 25 / 2009 \\
2: 00\end{array}$ & $\begin{array}{r}6 / 25 / 2009 \\
3: 00\end{array}$ & 909.5 & 8061.0 & 3.1 & 2.3 & 552.6 & 1.2 & 779.9 & 786.1 & 315.4 & 315.2 & 2320.2 & 10.5 & 0.9 & 0.2 & 5.3 & 10.0 & 11.6 \\
\hline $\begin{array}{r}6 / 25 / 2009 \\
3: 00\end{array}$ & $\begin{array}{r}6 / 25 / 2009 \\
4: 00\end{array}$ & 908.6 & 7983.6 & 3.1 & 2.3 & 549.3 & 1.2 & 783.9 & 787.2 & 312.3 & 312.2 & 2316.9 & 9.9 & 0.9 & 0.2 & 4.9 & 9.8 & 11.3 \\
\hline $\begin{array}{r}6 / 25 / 2009 \\
4: 00\end{array}$ & $\begin{array}{r}6 / 25 / 2009 \\
5: 00\end{array}$ & 910.8 & 7964.8 & 3.1 & 2.3 & 555.6 & 1.2 & 799.8 & 803.1 & 316.9 & 316.7 & 2324.0 & 10.1 & 0.9 & 0.2 & 4.5 & $\# \mathrm{~N} / \mathrm{A}$ & $\# \mathrm{~N} / \mathrm{A}$ \\
\hline $\begin{array}{r}6 / 25 / 2009 \\
5: 00\end{array}$ & $\begin{array}{r}6 / 25 / 2009 \\
6: 00\end{array}$ & 912.3 & 7985.5 & 3.0 & 2.3 & 556.6 & 1.2 & 801.7 & 806.8 & 318.8 & 318.7 & 2313.6 & 10.2 & 0.9 & 0.2 & 3.7 & $\# \mathrm{~N} / \mathrm{A}$ & $\# \mathrm{~N} / \mathrm{A}$ \\
\hline $\begin{array}{r}6 / 25 / 2009 \\
6: 00\end{array}$ & $\begin{array}{r}6 / 25 / 2009 \\
7: 00\end{array}$ & 910.0 & 7995.8 & 2.8 & 2.1 & 558.4 & 1.2 & 790.7 & 794.1 & 315.4 & 314.7 & 2290.6 & 9.4 & 0.9 & 0.2 & 4.7 & $\# \mathrm{~N} / \mathrm{A}$ & $\# \mathrm{~N} / \mathrm{A}$ \\
\hline $\begin{array}{r}6 / 25 / 2009 \\
7: 00\end{array}$ & $\begin{array}{r}6 / 25 / 2009 \\
8: 00\end{array}$ & 910.8 & 8023.0 & 2.7 & 2.0 & 561.5 & 1.2 & 791.4 & 791.5 & 315.5 & 314.1 & 2285.8 & 9.2 & 0.9 & 0.2 & 7.0 & 10.0 & 11.7 \\
\hline $\begin{array}{r}6 / 25 / 2009 \\
8: 00\end{array}$ & $\begin{array}{r}6 / 25 / 2009 \\
9: 00\end{array}$ & 912.3 & 8002.0 & 2.7 & 2.0 & 566.8 & 1.2 & 794.9 & 793.9 & 316.8 & 314.6 & 2294.4 & 9.3 & 1.0 & 0.3 & 6.9 & 9.8 & 12.1 \\
\hline $\begin{array}{r}6 / 25 / 2009 \\
9: 00\end{array}$ & $\begin{array}{r}6 / 25 / 2009 \\
10: 00\end{array}$ & 909.2 & 8008.2 & 2.8 & 1.9 & 580.5 & 1.2 & 795.6 & 796.3 & 318.3 & 317.0 & 2278.7 & 9.3 & 1.0 & 0.3 & 9.6 & 10.4 & 13.0 \\
\hline $\begin{array}{r}6 / 25 / 2009 \\
10: 00\end{array}$ & $\begin{array}{r}6 / 25 / 2009 \\
11: 00\end{array}$ & 911.2 & 8029.2 & 2.8 & 2.0 & 595.7 & 1.2 & 800.0 & 797.2 & 322.0 & 321.4 & 2288.3 & 9.6 & 1.1 & 0.3 & 11.3 & 11.9 & 14.1 \\
\hline $\begin{array}{r}6 / 25 / 2009 \\
11: 00\end{array}$ & $\begin{array}{r}6 / 25 / 2009 \\
12: 00\end{array}$ & 913.4 & 8018.6 & 2.8 & 2.0 & 607.0 & 1.2 & 789.9 & 789.4 & 321.7 & 322.1 & 2305.4 & 9.9 & 1.2 & 0.3 & 17.2 & 12.2 & 14.3 \\
\hline $\begin{array}{r}6 / 25 / 2009 \\
12: 00\end{array}$ & $\begin{array}{r}6 / 25 / 2009 \\
13: 00\end{array}$ & 904.3 & 8033.7 & 2.9 & 2.0 & 607.5 & 1.1 & 779.0 & 783.9 & 318.3 & 320.1 & 2293.5 & 9.8 & 1.2 & 0.3 & 20.7 & 12.0 & 14.2 \\
\hline $6 / 25 / 2009$ & $6 / 25 / 2009$ & 844.9 & 8036.1 & 3.0 & 2.0 & 573.7 & 1.1 & 765.9 & 767.3 & 316.5 & 316.6 & 2176.8 & 9.0 & 1.3 & 0.3 & 15.0 & 11.9 & 14.0 \\
\hline
\end{tabular}




\begin{tabular}{|c|c|c|c|c|c|c|c|c|c|c|c|c|c|c|c|c|c|c|}
\hline $\begin{array}{l}\text { Start } \\
\text { Date/ } \\
\text { Time }\end{array}$ & $\begin{array}{l}\text { End } \\
\text { Date/ } \\
\text { Time }\end{array}$ & $\begin{array}{l}\text { Gross } \\
\text { Load }\end{array}$ & $\begin{array}{c}\text { Gross } \\
\text { HR }\end{array}$ & $\begin{array}{c}\text { A } \\
\text { Econ } \\
\text { O2 }\end{array}$ & $\begin{array}{c}\text { B } \\
\text { Econ } \\
\text { O2 }\end{array}$ & $\begin{array}{l}\text { Fuel } \\
\text { Flow }\end{array}$ & $\begin{array}{l}\text { BTU } \\
\text { Gain }\end{array}$ & $\begin{array}{c}\text { A } \\
\text { APH } \\
\text { In }\end{array}$ & $\begin{array}{l}\text { B } \\
\text { APH } \\
\text { In }\end{array}$ & $\begin{array}{c}\text { A } \\
\text { APH } \\
\text { Out }\end{array}$ & $\begin{array}{c}\text { B } \\
\text { APH } \\
\text { Out }\end{array}$ & $\begin{array}{l}\text { Stack } \\
\text { Flow }\end{array}$ & Opacity & SO2 In & $\begin{array}{l}\text { SO2 } \\
\text { Out }\end{array}$ & $\mathrm{CO}$ & $\begin{array}{c}\text { Stack } \\
\text { SCEM } \\
\text { Elemental } \\
\mathrm{Hg}\end{array}$ & $\begin{array}{c}\text { Stack } \\
\text { SCEM } \\
\text { Total Hg }\end{array}$ \\
\hline & & MW & Btu/kWh & $\%$ & $\%$ & Ton/hr & & DEGF & DEGF & DEGF & DEGF & KSCF & $\%$ & $\mathrm{Ib} / \mathrm{MMB}$ & $\mathrm{Ib} / \mathrm{MMb}$ & PPM & $\begin{array}{c}(\mu \mathrm{g} / \mathrm{dNm} 3) \\
@ 3 \% 02\end{array}$ & $\begin{array}{c}(\mu \mathrm{g} / \mathrm{dNm} 3) \\
\text { @ 3\%O2 }\end{array}$ \\
\hline $13: 00$ & $14: 00$ & & & & & & & & & & & & & & & & & \\
\hline $\begin{array}{r}6 / 25 / 2009 \\
14: 00 \\
\end{array}$ & $\begin{array}{r}6 / 25 / 2009 \\
15: 00 \\
\end{array}$ & 885.8 & 8013.8 & 3.0 & 2.3 & 612.3 & 1.1 & 779.1 & 776.2 & 319.8 & 318.2 & 2286.9 & 9.4 & 1.3 & 0.3 & 13.5 & 7.8 & 9.0 \\
\hline $\begin{array}{r}6 / 25 / 2009 \\
15: 00\end{array}$ & $\begin{array}{r}6 / 25 / 2009 \\
16: 00\end{array}$ & 891.3 & 8013.6 & 2.9 & 2.2 & 620.8 & 1.1 & 787.8 & 785.7 & 322.9 & 321.6 & 2292.3 & 9.0 & 1.3 & 0.3 & 8.9 & 6.1 & 7.0 \\
\hline $\begin{array}{r}6 / 25 / 2009 \\
16: 00\end{array}$ & $\begin{array}{r}6 / 25 / 2009 \\
17: 00\end{array}$ & 809.6 & 8071.2 & 3.0 & 2.0 & 567.6 & 1.1 & 763.0 & 762.3 & 319.0 & 317.0 & 2090.3 & 7.6 & 1.4 & 0.4 & 7.2 & 5.3 & 6.3 \\
\hline $\begin{array}{r}6 / 25 / 2009 \\
17: 00\end{array}$ & $\begin{array}{r}6 / 25 / 2009 \\
18: 00\end{array}$ & 775.6 & 8057.8 & 3.2 & 2.0 & 549.5 & 1.1 & 750.3 & 751.2 & 314.7 & 312.4 & 2032.2 & 6.9 & 1.4 & 0.4 & 7.7 & 4.9 & 5.9 \\
\hline $\begin{array}{r}6 / 25 / 2009 \\
18: 00\end{array}$ & $\begin{array}{r}6 / 25 / 2009 \\
19: 00\end{array}$ & 843.0 & 7965.5 & 3.1 & 2.3 & 607.5 & 1.1 & 770.6 & 766.1 & 318.7 & 316.3 & 2233.7 & 8.2 & 1.4 & 0.4 & 9.8 & 5.3 & 6.4 \\
\hline $\begin{array}{r}6 / 25 / 2009 \\
19: 00\end{array}$ & $\begin{array}{r}6 / 25 / 2009 \\
20: 00\end{array}$ & 912.9 & 8041.3 & 2.8 & 2.3 & 643.1 & 1.1 & 793.5 & 783.7 & 326.5 & 322.1 & 2339.2 & 8.7 & 1.4 & 0.4 & 14.0 & 5.9 & 7.1 \\
\hline $\begin{array}{r}6 / 25 / 2009 \\
20: 00\end{array}$ & $\begin{array}{r}6 / 25 / 2009 \\
21: 00\end{array}$ & 912.7 & 8004.0 & 3.0 & 2.2 & 632.5 & 1.1 & 785.1 & 777.9 & 322.3 & 318.9 & 2320.8 & 8.8 & 1.4 & 0.4 & 6.4 & 5.5 & 6.5 \\
\hline $\begin{array}{r}6 / 25 / 2009 \\
21: 00\end{array}$ & $\begin{array}{r}6 / 25 / 2009 \\
22: 00\end{array}$ & 909.4 & 7969.7 & 3.0 & 2.2 & 625.5 & 1.1 & 785.2 & 778.7 & 318.2 & 315.2 & 2326.4 & 8.9 & 1.4 & 0.4 & 5.7 & 5.1 & 6.0 \\
\hline $\begin{array}{r}6 / 25 / 2009 \\
22: 00\end{array}$ & $\begin{array}{r}6 / 25 / 2009 \\
23: 00\end{array}$ & 909.0 & 7963.4 & 3.0 & 2.2 & 620.5 & 1.1 & 788.1 & 782.6 & 317.4 & 315.1 & 2323.6 & 9.2 & 1.4 & 0.4 & 6.2 & 5.5 & 6.7 \\
\hline $\begin{array}{r}6 / 25 / 2009 \\
23: 00\end{array}$ & $\begin{array}{r}6 / 26 / 2009 \\
0: 00\end{array}$ & 903.2 & 7992.5 & 3.0 & 2.2 & 617.8 & 1.1 & 789.7 & 784.2 & 316.6 & 315.1 & 2310.8 & 9.2 & 1.4 & 0.4 & 10.1 & 8.3 & 10.1 \\
\hline $\begin{array}{r}6 / 26 / 2009 \\
0: 00\end{array}$ & $\begin{array}{r}6 / 26 / 2009 \\
1: 00\end{array}$ & 898.7 & 8013.4 & 3.0 & 2.2 & 619.5 & 1.1 & 782.5 & 775.2 & 317.0 & 315.6 & 2323.2 & 9.5 & 1.4 & 0.4 & 8.2 & 10.1 & 12.1 \\
\hline $\begin{array}{r}6 / 26 / 2009 \\
1: 00\end{array}$ & $\begin{array}{r}6 / 26 / 2009 \\
2: 00\end{array}$ & 912.6 & 7948.1 & 2.9 & 2.4 & 627.9 & 1.1 & 772.3 & 760.1 & 313.1 & 309.9 & 2343.9 & 9.6 & 1.4 & 0.4 & 10.1 & 11.1 & 13.1 \\
\hline $\begin{array}{r}6 / 26 / 2009 \\
2: 00\end{array}$ & $\begin{array}{r}6 / 26 / 2009 \\
3: 00\end{array}$ & 883.3 & 7950.3 & 2.8 & 2.3 & 602.7 & 1.1 & 759.4 & 748.2 & 307.9 & 304.4 & 2266.4 & 10.7 & 1.4 & 0.4 & 9.9 & 11.6 & 13.7 \\
\hline $\begin{array}{r}6 / 26 / 2009 \\
3: 00\end{array}$ & $\begin{array}{r}6 / 26 / 2009 \\
4: 00\end{array}$ & 825.3 & 7883.5 & 3.0 & 2.2 & 562.9 & 1.1 & 746.9 & 737.0 & 301.2 & 297.6 & 2130.4 & 10.3 & 1.4 & 0.4 & 7.9 & 11.5 & 13.6 \\
\hline $\begin{array}{r}6 / 26 / 2009 \\
4: 00\end{array}$ & $\begin{array}{r}6 / 26 / 2009 \\
5: 00\end{array}$ & 832.8 & 7828.7 & 3.1 & 2.1 & 558.3 & 1.1 & 750.5 & 742.2 & 299.6 & 297.0 & 2134.7 & 10.0 & 1.3 & 0.3 & 10.6 & 11.1 & 13.3 \\
\hline $\begin{array}{r}6 / 26 / 2009 \\
5: 00 \\
\end{array}$ & $\begin{array}{r}6 / 26 / 2009 \\
6: 00 \\
\end{array}$ & 827.2 & 7834.3 & 3.2 & 2.2 & 550.1 & 1.1 & 754.0 & 746.7 & 299.6 & 296.6 & 2124.3 & 9.2 & 1.3 & 0.3 & 7.9 & $\# \mathrm{~N} / \mathrm{A}$ & $\# \mathrm{~N} / \mathrm{A}$ \\
\hline $\begin{array}{r}6 / 26 / 2009 \\
6: 00 \\
\end{array}$ & $\begin{array}{r}6 / 26 / 2009 \\
7: 00 \\
\end{array}$ & 893.9 & 7888.6 & 3.0 & 2.4 & 599.4 & 1.1 & 775.1 & 765.1 & 303.8 & 300.9 & 2285.9 & 10.6 & 1.2 & 0.4 & 7.8 & $\# \mathrm{~N} / \mathrm{A}$ & $\# \mathrm{~N} / \mathrm{A}$ \\
\hline $\begin{array}{r}6 / 26 / 2009 \\
7: 00\end{array}$ & $\begin{array}{r}6 / 26 / 2009 \\
8: 00\end{array}$ & 910.9 & 7958.6 & 2.9 & 2.4 & 605.4 & 1.1 & 784.4 & 773.8 & 307.7 & 304.1 & 2307.0 & 10.9 & 1.2 & 0.4 & 12.2 & 11.0 & 14.0 \\
\hline $\begin{array}{r}6 / 26 / 2009 \\
8: 00\end{array}$ & $\begin{array}{r}6 / 26 / 2009 \\
9: 00\end{array}$ & 912.5 & 7995.4 & 2.9 & 2.3 & 602.9 & 1.1 & 788.2 & 777.6 & 311.3 & 307.4 & 2313.3 & 10.8 & 1.2 & 0.4 & 13.7 & 10.8 & 14.0 \\
\hline
\end{tabular}




\begin{tabular}{|c|c|c|c|c|c|c|c|c|c|c|c|c|c|c|c|c|c|c|}
\hline $\begin{array}{l}\text { Start } \\
\text { Date/ } \\
\text { Time }\end{array}$ & $\begin{array}{l}\text { End } \\
\text { Date/ } \\
\text { Time }\end{array}$ & $\begin{array}{l}\text { Gross } \\
\text { Load }\end{array}$ & $\begin{array}{c}\text { Gross } \\
\text { HR }\end{array}$ & $\begin{array}{c}\text { A } \\
\text { Econ } \\
\text { O2 }\end{array}$ & $\begin{array}{c}\text { B } \\
\text { Econ } \\
\text { O2 }\end{array}$ & $\begin{array}{l}\text { Fuel } \\
\text { Flow }\end{array}$ & $\begin{array}{l}\text { BTU } \\
\text { Gain }\end{array}$ & $\begin{array}{c}\text { A } \\
\text { APH } \\
\text { In }\end{array}$ & $\begin{array}{c}\text { B } \\
\text { APH } \\
\text { In }\end{array}$ & $\begin{array}{c}\text { A } \\
\text { APH } \\
\text { Out }\end{array}$ & $\begin{array}{c}\text { B } \\
\text { APH } \\
\text { Out }\end{array}$ & $\begin{array}{l}\text { Stack } \\
\text { Flow }\end{array}$ & Opacity & SO2 In & $\begin{array}{l}\text { SO2 } \\
\text { Out }\end{array}$ & $\mathrm{CO}$ & $\begin{array}{c}\text { Stack } \\
\text { SCEM } \\
\text { Elemental } \\
\mathrm{Hg}\end{array}$ & $\begin{array}{c}\text { Stack } \\
\text { SCEM } \\
\text { Total Hg }\end{array}$ \\
\hline & & MW & Btu/kWh & $\%$ & $\%$ & Ton/hr & & DEGF & DEGF & DEGF & DEGF & KSCF & $\%$ & Ib/MMB & $\mathrm{Ib} / \mathrm{MMb}$ & PPM & $\begin{array}{c}(\mu \mathrm{g} / \mathrm{dNm} 3) \\
@ 3 \% 02\end{array}$ & $\begin{array}{c}(\mu \mathrm{g} / \mathrm{dNm} 3) \\
\text { @ 3\%O2 }\end{array}$ \\
\hline $\begin{array}{r}6 / 26 / 2009 \\
9: 00\end{array}$ & $\begin{array}{r}6 / 26 / 2009 \\
10: 00\end{array}$ & 912.7 & 8013.1 & 2.9 & 2.3 & 600.3 & 1.1 & 785.8 & 777.0 & 314.9 & 311.5 & 2313.1 & 10.2 & 1.2 & 0.4 & 11.9 & 10.6 & 13.9 \\
\hline $\begin{array}{r}6 / 26 / 2009 \\
10: 00\end{array}$ & $\begin{array}{r}6 / 26 / 2009 \\
11: 00 \\
\end{array}$ & 913.3 & 8028.5 & 2.9 & 2.3 & 591.5 & 1.1 & 773.9 & 765.0 & 313.9 & 310.7 & 2316.7 & 10.1 & 1.2 & 0.3 & 12.1 & 10.0 & 13.4 \\
\hline $\begin{array}{r}6 / 26 / 2009 \\
11: 00\end{array}$ & $\begin{array}{r}6 / 26 / 2009 \\
12: 00\end{array}$ & 913.4 & 8020.3 & 2.9 & 2.3 & 588.1 & 1.1 & 775.4 & 766.6 & 314.4 & 311.3 & 2303.1 & 9.9 & 1.1 & 0.4 & 12.9 & 9.9 & 13.3 \\
\hline $\begin{array}{r}6 / 26 / 2009 \\
12: 00\end{array}$ & $\begin{array}{r}6 / 26 / 2009 \\
13: 00\end{array}$ & 913.6 & 8001.9 & 2.9 & 2.3 & 586.7 & 1.1 & 780.9 & 771.7 & 316.4 & 313.9 & 2294.3 & 9.2 & 1.1 & 0.4 & 11.6 & 9.8 & 13.1 \\
\hline $\begin{array}{r}6 / 26 / 2009 \\
13: 00\end{array}$ & $\begin{array}{r}6 / 26 / 2009 \\
14: 00\end{array}$ & 899.8 & 7993.0 & 2.9 & 2.3 & 576.5 & 1.2 & 783.4 & 774.2 & 318.5 & 315.4 & 2259.4 & 9.3 & 1.1 & 0.4 & 9.1 & 9.9 & 13.1 \\
\hline $\begin{array}{r}6 / 26 / 2009 \\
14: 00\end{array}$ & $\begin{array}{r}6 / 26 / 2009 \\
15: 00\end{array}$ & 895.7 & 8001.6 & 2.9 & 2.3 & 570.2 & 1.2 & 785.7 & 777.5 & 321.4 & 317.9 & 2255.3 & 9.0 & 1.1 & 0.4 & 6.3 & 10.0 & 13.1 \\
\hline $\begin{array}{r}6 / 26 / 2009 \\
15: 00\end{array}$ & $\begin{array}{r}6 / 26 / 2009 \\
16: 00 \\
\end{array}$ & 887.1 & 8020.4 & 2.9 & 2.3 & 561.8 & 1.2 & 785.5 & 779.5 & 322.9 & 319.6 & 2245.8 & 8.9 & 1.1 & 0.4 & 4.4 & 9.9 & 12.9 \\
\hline $\begin{array}{r}6 / 26 / 2009 \\
16: 00\end{array}$ & $\begin{array}{r}6 / 26 / 2009 \\
17: 00 \\
\end{array}$ & 896.1 & 8005.1 & 2.8 & 2.4 & 573.4 & 1.2 & 793.3 & 785.6 & 325.4 & 322.2 & 2270.7 & 8.8 & 1.1 & 0.4 & 6.2 & 10.0 & 13.1 \\
\hline $\begin{array}{r}6 / 26 / 2009 \\
17: 00\end{array}$ & $\begin{array}{r}6 / 26 / 2009 \\
18: 00 \\
\end{array}$ & 898.9 & 8003.0 & 2.8 & 2.4 & 584.2 & 1.2 & 798.2 & 788.6 & 327.6 & 323.4 & 2297.9 & 12.4 & 1.1 & 0.3 & 8.6 & 10.4 & 12.9 \\
\hline $\begin{array}{r}6 / 26 / 2009 \\
18: 00 \\
\end{array}$ & $\begin{array}{r}6 / 26 / 2009 \\
19: 00 \\
\end{array}$ & 895.4 & 7963.2 & 2.8 & 2.4 & 602.5 & 1.1 & 789.3 & 781.5 & 327.3 & 322.4 & 2287.4 & 10.4 & 1.1 & 0.3 & 18.2 & 10.6 & 12.8 \\
\hline $\begin{array}{r}6 / 26 / 2009 \\
19: 00\end{array}$ & $\begin{array}{r}6 / 26 / 2009 \\
20: 00\end{array}$ & 869.3 & 8064.2 & 3.1 & 2.5 & 569.8 & 1.1 & 764.3 & 758.0 & 320.3 & 319.2 & 2244.9 & 7.6 & 1.2 & 0.3 & 48.7 & 10.2 & 12.1 \\
\hline $\begin{array}{r}6 / 26 / 2009 \\
20: 00\end{array}$ & $\begin{array}{r}6 / 26 / 2009 \\
21: 00\end{array}$ & 881.9 & 8103.6 & 3.5 & 3.1 & 578.9 & 1.2 & 771.4 & 761.1 & 312.5 & 312.3 & 2355.3 & 8.5 & 1.2 & 0.3 & 6.7 & 10.3 & 12.0 \\
\hline $\begin{array}{r}6 / 26 / 2009 \\
21: 00\end{array}$ & $\begin{array}{r}6 / 26 / 2009 \\
22: 00\end{array}$ & 909.1 & 8084.5 & 3.3 & 3.0 & 583.1 & 1.2 & 779.3 & 767.5 & 313.9 & 313.7 & 2389.9 & 8.6 & 1.2 & 0.3 & 11.4 & 10.6 & 12.3 \\
\hline $\begin{array}{r}6 / 26 / 2009 \\
22: 00\end{array}$ & $\begin{array}{r}6 / 26 / 2009 \\
23: 00 \\
\end{array}$ & 875.8 & 8090.6 & 3.4 & 2.8 & 553.3 & 1.2 & 778.2 & 766.6 & 314.8 & 315.1 & 2299.4 & 9.2 & 1.2 & 0.3 & 10.1 & 10.8 & 12.6 \\
\hline $\begin{array}{r}6 / 26 / 2009 \\
23: 00 \\
\end{array}$ & $\begin{array}{r}6 / 27 / 2009 \\
0: 00 \\
\end{array}$ & 862.3 & 8038.5 & 3.6 & 2.9 & 553.8 & 1.2 & 776.9 & 767.7 & 323.2 & 326.6 & 2294.1 & 8.1 & 1.1 & 0.3 & 5.7 & 10.7 & 12.5 \\
\hline $\begin{array}{r}6 / 27 / 2009 \\
0: 00 \\
\end{array}$ & $\begin{array}{r}6 / 27 / 2009 \\
1: 00 \\
\end{array}$ & 898.2 & 8059.3 & 3.3 & 2.8 & 574.1 & 1.2 & 790.3 & 780.4 & 320.4 & 323.1 & 2353.6 & 8.7 & 1.1 & 0.3 & 12.4 & 10.4 & 12.3 \\
\hline $\begin{array}{r}6 / 27 / 2009 \\
1: 00 \\
\end{array}$ & $\begin{array}{r}6 / 27 / 2009 \\
2: 00 \\
\end{array}$ & 905.2 & 8032.6 & 2.5 & 1.9 & 575.0 & 1.2 & 787.4 & 777.8 & 316.7 & 318.0 & 2235.9 & 9.1 & 1.1 & 0.3 & 53.1 & $\# \mathrm{~N} / \mathrm{A}$ & $\# \mathrm{~N} / \mathrm{A}$ \\
\hline $\begin{array}{r}6 / 27 / 2009 \\
2: 00\end{array}$ & $\begin{array}{r}6 / 27 / 2009 \\
3: 00\end{array}$ & 904.5 & 8015.8 & 2.5 & 1.9 & 578.4 & 1.2 & 779.8 & 770.1 & 314.8 & 315.2 & 2261.2 & 9.6 & 1.1 & 0.3 & 52.2 & $\# \mathrm{~N} / \mathrm{A}$ & $\# \mathrm{~N} / \mathrm{A}$ \\
\hline $\begin{array}{r}6 / 27 / 2009 \\
3: 00\end{array}$ & $\begin{array}{r}6 / 27 / 2009 \\
4: 00\end{array}$ & 905.7 & 8040.4 & 2.6 & 1.9 & 577.1 & 1.2 & 779.2 & 769.2 & 313.0 & 313.0 & 2278.5 & 9.6 & 1.1 & 0.3 & 42.3 & 9.5 & 11.3 \\
\hline $6 / 27 / 2009$ & $6 / 27 / 2009$ & 902.2 & 8056.4 & 2.7 & 1.9 & 572.3 & 1.2 & 778.6 & 768.5 & 309.6 & 310.5 & 2280.6 & 8.1 & 1.1 & 0.3 & 36.4 & $\# \mathrm{~N} / \mathrm{A}$ & $\# \mathrm{~N} / \mathrm{A}$ \\
\hline
\end{tabular}




\begin{tabular}{|c|c|c|c|c|c|c|c|c|c|c|c|c|c|c|c|c|c|c|}
\hline \multirow[t]{2}{*}{$\begin{array}{l}\text { Start } \\
\text { Date/ } \\
\text { Time }\end{array}$} & \multirow[t]{2}{*}{$\begin{array}{l}\text { End } \\
\text { Date/ } \\
\text { Time }\end{array}$} & $\begin{array}{l}\text { Gross } \\
\text { Load }\end{array}$ & $\begin{array}{c}\text { Gross } \\
\text { HR }\end{array}$ & $\begin{array}{c}\text { A } \\
\text { Econ } \\
\text { O2 }\end{array}$ & $\begin{array}{c}\text { B } \\
\text { Econ } \\
\text { O2 }\end{array}$ & $\begin{array}{l}\text { Fuel } \\
\text { Flow }\end{array}$ & $\begin{array}{l}\text { BTU } \\
\text { Gain }\end{array}$ & $\begin{array}{c}\text { A } \\
\text { APH } \\
\text { In }\end{array}$ & $\begin{array}{c}\text { B } \\
\text { APH } \\
\text { In }\end{array}$ & $\begin{array}{c}\text { A } \\
\text { APH } \\
\text { Out }\end{array}$ & $\begin{array}{c}\text { B } \\
\text { APH } \\
\text { Out }\end{array}$ & $\begin{array}{l}\text { Stack } \\
\text { Flow }\end{array}$ & Opacity & SO2 In & $\begin{array}{l}\text { SO2 } \\
\text { Out }\end{array}$ & $\mathrm{CO}$ & $\begin{array}{c}\text { Stack } \\
\text { SCEM } \\
\text { Elemental } \\
\mathrm{Hg}\end{array}$ & $\begin{array}{c}\text { Stack } \\
\text { SCEM } \\
\text { Total Hg }\end{array}$ \\
\hline & & MW & Btu/kWh & $\%$ & $\%$ & Ton/hr & & DEGF & DEGF & DEGF & DEGF & KSCF & $\%$ & Ib/MMB & $\mathrm{Ib} / \mathrm{MMb}$ & PPM & $\begin{array}{c}(\mu \mathrm{g} / \mathrm{dNm} 3) \\
@ 3 \% 02\end{array}$ & $\begin{array}{c}(\mu \mathrm{g} / \mathrm{dNm} 3) \\
@ 3 \% 02\end{array}$ \\
\hline $4: 00$ & $5: 00$ & & & & & & & & & & & & & & & & & \\
\hline $\begin{array}{r}6 / 27 / 2009 \\
5: 00\end{array}$ & $\begin{array}{r}6 / 27 / 2009 \\
6: 00\end{array}$ & 837.9 & 7984.0 & 2.7 & 1.9 & 530.7 & 1.2 & 763.9 & 756.4 & 305.3 & 305.5 & 2106.6 & 5.9 & 1.1 & 0.3 & 30.2 & $\# \mathrm{~N} / \mathrm{A}$ & $\# \mathrm{~N} / \mathrm{A}$ \\
\hline $\begin{array}{r}6 / 27 / 2009 \\
6: 00\end{array}$ & $\begin{array}{r}6 / 27 / 2009 \\
7: 00\end{array}$ & 819.3 & 8028.8 & 3.0 & 2.2 & 519.4 & 1.2 & 761.4 & 753.6 & 302.2 & 300.8 & 2081.0 & 5.7 & 1.1 & 0.3 & 16.7 & $\# \mathrm{~N} / \mathrm{A}$ & $\# \mathrm{~N} / \mathrm{A}$ \\
\hline $\begin{array}{r}6 / 27 / 2009 \\
7: 00\end{array}$ & $\begin{array}{r}6 / 27 / 2009 \\
8: 00\end{array}$ & 811.4 & 7982.2 & 3.1 & 2.2 & 515.9 & 1.2 & 759.2 & 751.6 & 301.2 & 299.9 & 2081.4 & 5.5 & 1.1 & 0.3 & 12.7 & 8.8 & 10.6 \\
\hline $\begin{array}{r}6 / 27 / 2009 \\
8: 00\end{array}$ & $\begin{array}{r}6 / 27 / 2009 \\
9: 00\end{array}$ & 869.3 & 7970.3 & 3.0 & 2.3 & 553.7 & 1.2 & 764.3 & 752.4 & 304.1 & 302.7 & 2230.2 & 6.1 & 1.1 & 0.3 & 29.7 & 8.5 & 10.3 \\
\hline $\begin{array}{r}6 / 27 / 2009 \\
9: 00\end{array}$ & $\begin{array}{r}6 / 27 / 2009 \\
10: 00\end{array}$ & 897.6 & 8046.5 & 3.1 & 2.3 & 571.4 & 1.2 & 765.0 & 753.6 & 304.1 & 303.5 & 2291.8 & 6.5 & 1.1 & 0.3 & 32.2 & 8.2 & 9.9 \\
\hline $\begin{array}{r}6 / 27 / 2009 \\
10: 00\end{array}$ & $\begin{array}{r}6 / 27 / 2009 \\
11: 00\end{array}$ & 897.2 & 8079.4 & 3.0 & 2.1 & 569.7 & 1.2 & 771.5 & 761.9 & 307.7 & 308.8 & 2288.5 & 6.8 & 1.1 & 0.3 & 28.4 & 8.1 & 9.7 \\
\hline $\begin{array}{r}6 / 27 / 2009 \\
11: 00\end{array}$ & $\begin{array}{r}6 / 27 / 2009 \\
12: 00\end{array}$ & 890.8 & 8035.6 & 3.1 & 2.1 & 567.3 & 1.2 & 777.8 & 770.3 & 317.2 & 320.3 & 2269.7 & 7.4 & 1.1 & 0.3 & 28.8 & 6.5 & 7.7 \\
\hline $\begin{array}{r}6 / 27 / 2009 \\
12: 00\end{array}$ & $\begin{array}{r}6 / 27 / 2009 \\
13: 00\end{array}$ & 904.1 & 8044.5 & 3.1 & 2.1 & 583.7 & 1.2 & 783.4 & 776.1 & 317.6 & 320.6 & 2292.1 & 8.2 & 1.1 & 0.3 & 28.9 & 3.7 & 4.4 \\
\hline $\begin{array}{r}6 / 27 / 2009 \\
13: 00\end{array}$ & $\begin{array}{r}6 / 27 / 2009 \\
14: 00\end{array}$ & 910.8 & 8031.0 & 3.1 & 2.1 & 594.1 & 1.2 & 785.0 & 777.3 & 326.8 & 330.2 & 2315.3 & 8.7 & 1.1 & 0.3 & 35.9 & 3.3 & 3.9 \\
\hline $\begin{array}{r}6 / 27 / 2009 \\
14: 00 \\
\end{array}$ & $\begin{array}{r}6 / 27 / 2009 \\
15: 00 \\
\end{array}$ & 901.2 & 8001.8 & 3.0 & 2.2 & 590.9 & 1.2 & 787.3 & 778.6 & 323.6 & 324.1 & 2290.2 & 8.0 & 1.1 & 0.3 & 34.9 & 3.0 & 3.6 \\
\hline $\begin{array}{r}6 / 27 / 2009 \\
15: 00\end{array}$ & $\begin{array}{r}6 / 27 / 2009 \\
16: 00\end{array}$ & 860.9 & 7983.9 & 3.0 & 2.1 & 551.0 & 1.2 & 776.7 & 771.6 & 321.3 & 324.1 & 2208.4 & 7.7 & 1.1 & 0.3 & 67.5 & 2.7 & 3.3 \\
\hline $\begin{array}{r}6 / 27 / 2009 \\
16: 00\end{array}$ & $\begin{array}{r}6 / 27 / 2009 \\
17: 00\end{array}$ & 828.2 & 8017.6 & 3.2 & 2.3 & 528.1 & 1.2 & 767.7 & 763.9 & 318.4 & 322.7 & 2147.5 & 7.3 & 1.2 & 0.3 & 31.8 & 2.8 & 3.3 \\
\hline $\begin{array}{r}6 / 27 / 2009 \\
17: 00\end{array}$ & $\begin{array}{r}6 / 27 / 2009 \\
18: 00\end{array}$ & 870.8 & 7989.9 & 3.1 & 2.2 & 563.8 & 1.2 & 781.4 & 777.3 & 319.0 & 322.5 & 2238.6 & 7.6 & 1.2 & 0.3 & 14.4 & 3.1 & 3.6 \\
\hline $\begin{array}{r}6 / 27 / 2009 \\
18: 00 \\
\end{array}$ & $\begin{array}{r}6 / 27 / 2009 \\
19: 00 \\
\end{array}$ & 908.1 & 8028.6 & 3.0 & 2.3 & 584.9 & 1.2 & 786.0 & 780.4 & 320.8 & 323.8 & 2321.6 & 8.1 & 1.2 & 0.3 & 20.6 & 3.3 & 3.8 \\
\hline $\begin{array}{r}6 / 27 / 2009 \\
19: 00\end{array}$ & $\begin{array}{r}6 / 27 / 2009 \\
20: 00\end{array}$ & 913.6 & 8022.1 & 3.0 & 2.3 & 588.2 & 1.2 & 780.8 & 775.0 & 318.5 & 320.9 & 2316.7 & 7.9 & 1.2 & 0.3 & 21.9 & 3.1 & 3.7 \\
\hline $\begin{array}{r}6 / 27 / 2009 \\
20: 00 \\
\end{array}$ & $\begin{array}{r}6 / 27 / 2009 \\
21: 00 \\
\end{array}$ & 911.9 & 8005.8 & 3.0 & 2.3 & 588.4 & 1.2 & 781.6 & 775.1 & 317.9 & 320.6 & 2324.7 & 7.6 & 1.2 & 0.3 & 24.1 & 3.0 & $\# \mathrm{~N} / \mathrm{A}$ \\
\hline $\begin{array}{r}6 / 27 / 2009 \\
21: 00 \\
\end{array}$ & $\begin{array}{r}6 / 27 / 2009 \\
22: 00 \\
\end{array}$ & 912.7 & 8022.4 & 2.9 & 2.3 & 590.0 & 1.2 & 781.7 & 772.9 & 317.4 & 319.7 & 2324.7 & 7.4 & 1.3 & 0.3 & 23.9 & 3.2 & $\# \mathrm{~N} / \mathrm{A}$ \\
\hline $\begin{array}{r}6 / 27 / 2009 \\
22: 00\end{array}$ & $\begin{array}{r}6 / 27 / 2009 \\
23: 00\end{array}$ & 913.1 & 8021.8 & 2.9 & 2.3 & 592.7 & 1.2 & 785.1 & 775.1 & 317.0 & 319.2 & 2331.6 & 7.3 & 1.3 & 0.3 & 31.7 & 3.3 & 3.8 \\
\hline $\begin{array}{r}6 / 27 / 2009 \\
23: 00\end{array}$ & $\begin{array}{r}6 / 28 / 2009 \\
0: 00\end{array}$ & 914.4 & 8012.0 & 2.8 & 2.3 & 594.9 & 1.2 & 785.4 & 775.2 & 316.2 & 318.5 & 2334.5 & 7.1 & 1.3 & 0.3 & 37.4 & 3.4 & 3.9 \\
\hline
\end{tabular}




\begin{tabular}{|c|c|c|c|c|c|c|c|c|c|c|c|c|c|c|c|c|c|c|}
\hline $\begin{array}{l}\text { Start } \\
\text { Date/ } \\
\text { Time }\end{array}$ & $\begin{array}{l}\text { End } \\
\text { Date/ } \\
\text { Time }\end{array}$ & $\begin{array}{l}\text { Gross } \\
\text { Load }\end{array}$ & $\begin{array}{c}\text { Gross } \\
\text { HR }\end{array}$ & $\begin{array}{c}\text { A } \\
\text { Econ } \\
\text { O2 }\end{array}$ & $\begin{array}{c}\text { B } \\
\text { Econ } \\
\text { O2 }\end{array}$ & $\begin{array}{l}\text { Fuel } \\
\text { Flow }\end{array}$ & $\begin{array}{l}\text { BTU } \\
\text { Gain }\end{array}$ & $\begin{array}{c}\text { A } \\
\text { APH } \\
\text { In }\end{array}$ & $\begin{array}{l}\text { B } \\
\text { APH } \\
\text { In }\end{array}$ & $\begin{array}{c}\text { A } \\
\text { APH } \\
\text { Out }\end{array}$ & $\begin{array}{c}\text { B } \\
\text { APH } \\
\text { Out }\end{array}$ & $\begin{array}{l}\text { Stack } \\
\text { Flow }\end{array}$ & Opacity & SO2 In & $\begin{array}{l}\text { SO2 } \\
\text { Out }\end{array}$ & $\mathrm{CO}$ & $\begin{array}{c}\text { Stack } \\
\text { SCEM } \\
\text { Elemental } \\
\mathrm{Hg}\end{array}$ & $\begin{array}{c}\text { Stack } \\
\text { SCEM } \\
\text { Total Hg }\end{array}$ \\
\hline & & MW & Btu/kWh & $\%$ & $\%$ & Ton/hr & & DEGF & DEGF & DEGF & DEGF & KSCF & $\%$ & Ib/MMB & $\mathrm{Ib} / \mathrm{MMb}$ & PPM & $\begin{array}{c}(\mu \mathrm{g} / \mathrm{dNm} \text { ) } \\
\text { @ 3\%02 }\end{array}$ & $\begin{array}{c}(\mu \mathrm{g} / \mathrm{dNm} 3) \\
@ 3 \% 02\end{array}$ \\
\hline $\begin{array}{r}6 / 28 / 2009 \\
0: 00\end{array}$ & $\begin{array}{r}6 / 28 / 2009 \\
1: 00\end{array}$ & 910.6 & 8010.6 & 2.9 & 2.3 & 589.8 & 1.1 & 784.2 & 776.2 & 314.8 & 316.3 & 2330.9 & 6.9 & 1.4 & 0.3 & 37.8 & 3.5 & 4.1 \\
\hline $\begin{array}{r}6 / 28 / 2009 \\
1: 00\end{array}$ & $\begin{array}{r}6 / 28 / 2009 \\
2: 00\end{array}$ & 904.2 & 8062.5 & 2.9 & 2.3 & 592.4 & 1.1 & 772.3 & 762.3 & 311.3 & 311.8 & 2342.3 & 6.7 & 1.4 & 0.3 & 30.4 & $\# \mathrm{~N} / \mathrm{A}$ & 4.3 \\
\hline $\begin{array}{r}6 / 28 / 2009 \\
2: 00 \\
\end{array}$ & $\begin{array}{r}6 / 28 / 2009 \\
3: 00 \\
\end{array}$ & 907.1 & 8044.8 & 2.9 & 2.3 & 594.1 & 1.2 & 773.2 & 764.4 & 306.3 & 306.8 & 2340.1 & 6.5 & 1.4 & 0.3 & 30.3 & $\# \mathrm{~N} / \mathrm{A}$ & $\# \mathrm{~N} / \mathrm{A}$ \\
\hline $\begin{array}{r}6 / 28 / 2009 \\
3: 00\end{array}$ & $\begin{array}{r}6 / 28 / 2009 \\
4: 00\end{array}$ & 906.2 & 8042.2 & 2.9 & 2.3 & 595.2 & 1.1 & 778.3 & 768.7 & 305.4 & 305.9 & 2323.3 & 6.4 & 1.4 & 0.3 & 37.0 & $\# \mathrm{~N} / \mathrm{A}$ & 4.4 \\
\hline $\begin{array}{r}6 / 28 / 2009 \\
4: 00\end{array}$ & $\begin{array}{r}6 / 28 / 2009 \\
5: 00\end{array}$ & 902.2 & 8049.5 & 2.9 & 2.2 & 591.5 & 1.1 & 780.2 & 770.3 & 305.4 & 306.0 & 2324.2 & 6.3 & 1.5 & 0.3 & 39.3 & 3.8 & 4.4 \\
\hline $\begin{array}{r}6 / 28 / 2009 \\
5: 00\end{array}$ & $\begin{array}{r}6 / 28 / 2009 \\
6: 00\end{array}$ & 893.8 & 8072.4 & 2.9 & 2.3 & 587.9 & 1.2 & 780.6 & 771.2 & 305.3 & 306.2 & 2312.2 & 6.1 & 1.5 & 0.3 & 39.6 & $\# \mathrm{~N} / \mathrm{A}$ & $\# \mathrm{~N} / \mathrm{A}$ \\
\hline $\begin{array}{r}6 / 28 / 2009 \\
6: 00\end{array}$ & $\begin{array}{r}6 / 28 / 2009 \\
7: 00\end{array}$ & 826.1 & 8064.5 & 3.0 & 2.2 & 541.8 & 1.2 & 761.0 & 756.0 & 302.0 & 302.7 & 2124.2 & 5.4 & 1.5 & 0.3 & 19.2 & $\# \mathrm{~N} / \mathrm{A}$ & $\# \mathrm{~N} / \mathrm{A}$ \\
\hline $\begin{array}{r}6 / 28 / 2009 \\
7: 00\end{array}$ & $\begin{array}{r}6 / 28 / 2009 \\
8: 00\end{array}$ & 806.6 & 8035.2 & 3.1 & 2.2 & 532.2 & 1.1 & 752.2 & 749.4 & 299.1 & 299.9 & 2075.8 & 5.1 & 1.4 & 0.3 & 12.1 & 3.0 & 3.4 \\
\hline $\begin{array}{r}6 / 28 / 2009 \\
8: 00\end{array}$ & $\begin{array}{r}6 / 28 / 2009 \\
9: 00\end{array}$ & 881.0 & 8029.0 & 3.1 & 2.3 & 588.1 & 1.1 & 777.9 & 771.8 & 304.3 & 305.9 & 2283.8 & 6.0 & 1.5 & 0.4 & 20.9 & 3.4 & 4.0 \\
\hline $\begin{array}{r}6 / 28 / 2009 \\
9: 00\end{array}$ & $\begin{array}{r}6 / 28 / 2009 \\
10: 00\end{array}$ & 898.5 & 8108.1 & 3.0 & 2.3 & 599.2 & 1.1 & 776.2 & 769.6 & 307.5 & 310.4 & 2324.6 & 7.1 & 1.6 & 0.4 & 29.8 & 3.8 & 4.4 \\
\hline $\begin{array}{r}6 / 28 / 2009 \\
10: 00\end{array}$ & $\begin{array}{r}6 / 28 / 2009 \\
11: 00\end{array}$ & 893.7 & 8100.5 & 2.9 & 2.3 & 587.5 & 1.1 & 765.7 & 756.8 & 305.4 & 308.2 & 2294.0 & 6.8 & 1.6 & 0.3 & 33.6 & 3.0 & 3.5 \\
\hline $\begin{array}{r}6 / 28 / 2009 \\
11: 00\end{array}$ & $\begin{array}{r}6 / 28 / 2009 \\
12: 00\end{array}$ & 878.6 & 8079.1 & 2.9 & 2.3 & 577.9 & 1.1 & 768.8 & 760.7 & 312.3 & 315.6 & 2248.8 & 6.3 & 1.5 & 0.3 & 36.1 & 2.5 & 3.0 \\
\hline $\begin{array}{r}6 / 28 / 2009 \\
12: 00\end{array}$ & $\begin{array}{r}6 / 28 / 2009 \\
13: 00\end{array}$ & 899.8 & 8057.2 & 3.0 & 2.2 & 593.4 & 1.1 & 777.4 & 769.8 & 317.8 & 318.8 & 2304.9 & 6.4 & 1.4 & 0.3 & 31.5 & 2.3 & 2.7 \\
\hline $\begin{array}{r}6 / 28 / 2009 \\
13: 00 \\
\end{array}$ & $\begin{array}{r}6 / 28 / 2009 \\
14: 00 \\
\end{array}$ & 914.2 & 8063.3 & 3.0 & 2.2 & 598.2 & 1.1 & 783.3 & 775.5 & 320.2 & 321.2 & 2349.6 & 6.6 & 1.5 & 0.3 & 32.3 & 2.5 & 2.9 \\
\hline $\begin{array}{r}6 / 28 / 2009 \\
14: 00\end{array}$ & $\begin{array}{r}6 / 28 / 2009 \\
15: 00\end{array}$ & 913.4 & 8055.7 & 3.0 & 2.2 & 595.2 & 1.2 & 786.6 & 778.1 & 322.1 & 322.7 & 2342.1 & 7.1 & 1.5 & 0.4 & 28.4 & 2.4 & 2.8 \\
\hline $\begin{array}{r}6 / 28 / 2009 \\
15: 00\end{array}$ & $\begin{array}{r}6 / 28 / 2009 \\
16: 00\end{array}$ & 911.7 & 8053.5 & 3.0 & 2.2 & 592.9 & 1.2 & 787.8 & 780.1 & 323.8 & 324.7 & 2346.8 & 7.3 & 1.5 & 0.3 & 24.4 & 2.3 & 2.7 \\
\hline $\begin{array}{r}6 / 28 / 2009 \\
16: 00\end{array}$ & $\begin{array}{r}6 / 28 / 2009 \\
17: 00\end{array}$ & 909.2 & 8077.3 & 3.0 & 2.2 & 588.1 & 1.2 & 787.3 & 781.7 & 326.0 & 326.4 & 2344.5 & 7.1 & 1.5 & 0.3 & 22.6 & 2.3 & 2.8 \\
\hline $\begin{array}{r}6 / 28 / 2009 \\
17: 00\end{array}$ & $\begin{array}{r}6 / 28 / 2009 \\
18: 00\end{array}$ & 910.4 & 8072.9 & 3.0 & 2.2 & 585.9 & 1.2 & 785.3 & 780.5 & 327.3 & 327.8 & 2336.0 & 6.3 & 1.5 & 0.4 & 19.5 & 3.8 & 4.3 \\
\hline $\begin{array}{r}6 / 28 / 2009 \\
18: 00 \\
\end{array}$ & $\begin{array}{r}6 / 28 / 2009 \\
19: 00 \\
\end{array}$ & 909.9 & 8042.1 & 3.0 & 2.2 & 582.8 & 1.2 & 776.2 & 771.0 & 325.0 & 325.0 & 2322.4 & 5.9 & 1.5 & 0.4 & 17.0 & 5.0 & 6.2 \\
\hline $6 / 28 / 2009$ & $6 / 28 / 2009$ & 908.6 & 8043.1 & 3.0 & 2.2 & 582.5 & 1.2 & 781.4 & 774.7 & 324.6 & 323.8 & 2318.2 & 5.7 & 1.5 & 0.4 & 17.8 & 6.0 & 7.3 \\
\hline
\end{tabular}




\begin{tabular}{|c|c|c|c|c|c|c|c|c|c|c|c|c|c|c|c|c|c|c|}
\hline $\begin{array}{l}\text { Start } \\
\text { Date/ } \\
\text { Time }\end{array}$ & $\begin{array}{l}\text { End } \\
\text { Date/ } \\
\text { Time }\end{array}$ & $\begin{array}{l}\text { Gross } \\
\text { Load }\end{array}$ & $\begin{array}{c}\text { Gross } \\
\text { HR }\end{array}$ & $\begin{array}{c}\text { A } \\
\text { Econ } \\
\text { O2 }\end{array}$ & $\begin{array}{c}\text { B } \\
\text { Econ } \\
\text { O2 }\end{array}$ & $\begin{array}{l}\text { Fuel } \\
\text { Flow }\end{array}$ & $\begin{array}{l}\text { BTU } \\
\text { Gain }\end{array}$ & $\begin{array}{c}\text { A } \\
\text { APH } \\
\text { In }\end{array}$ & $\begin{array}{l}\text { B } \\
\text { APH } \\
\text { In }\end{array}$ & $\begin{array}{c}\text { A } \\
\text { APH } \\
\text { Out }\end{array}$ & $\begin{array}{c}\text { B } \\
\text { APH } \\
\text { Out }\end{array}$ & $\begin{array}{l}\text { Stack } \\
\text { Flow }\end{array}$ & Opacity & SO2 In & $\begin{array}{l}\text { SO2 } \\
\text { Out }\end{array}$ & $\mathrm{CO}$ & $\begin{array}{c}\text { Stack } \\
\text { SCEM } \\
\text { Elemental } \\
\mathrm{Hg}\end{array}$ & $\begin{array}{c}\text { Stack } \\
\text { SCEM } \\
\text { Total Hg }\end{array}$ \\
\hline & & MW & Btu/kWh & $\%$ & $\%$ & Ton/hr & & DEGF & DEGF & DEGF & DEGF & KSCF & $\%$ & $\mathrm{Ib} / \mathrm{MMB}$ & $\mathrm{Ib} / \mathrm{MMb}$ & PPM & $\begin{array}{c}(\mu \mathrm{g} / \mathrm{dNm} 3) \\
@ 3 \% 02\end{array}$ & $\begin{array}{c}(\mu \mathrm{g} / \mathrm{dNm} 3) \\
\text { @ 3\%O2 }\end{array}$ \\
\hline $19: 00$ & $20: 00$ & & & & & & & & & & & & & & & & & \\
\hline $\begin{array}{r}6 / 28 / 2009 \\
20: 00 \\
\end{array}$ & $\begin{array}{r}6 / 28 / 2009 \\
21: 00 \\
\end{array}$ & 908.6 & 8056.3 & 3.1 & 2.2 & 582.3 & 1.2 & 777.0 & 770.5 & 324.3 & 323.0 & 2314.6 & 5.7 & 1.4 & 0.4 & 16.2 & 6.8 & 8.1 \\
\hline $\begin{array}{r}6 / 28 / 2009 \\
21: 00\end{array}$ & $\begin{array}{r}6 / 28 / 2009 \\
22: 00\end{array}$ & 905.2 & 8057.0 & 3.1 & 2.2 & 587.5 & 1.2 & 774.8 & 767.1 & 320.7 & 319.1 & 2318.1 & 5.6 & 1.5 & 0.4 & 18.4 & 7.4 & 8.8 \\
\hline $\begin{array}{r}6 / 28 / 2009 \\
22: 00\end{array}$ & $\begin{array}{r}6 / 28 / 2009 \\
23: 00\end{array}$ & 909.7 & 8010.1 & 3.1 & 2.1 & 594.4 & 1.2 & 778.3 & 770.0 & 320.0 & 319.5 & 2316.1 & 6.0 & 1.5 & 0.4 & 19.5 & 8.4 & 9.8 \\
\hline $\begin{array}{r}6 / 28 / 2009 \\
23: 00\end{array}$ & $\begin{array}{r}6 / 29 / 2009 \\
0: 00\end{array}$ & 913.2 & 7991.4 & 3.1 & 2.1 & 591.8 & 1.1 & 781.0 & 775.0 & 319.6 & 319.3 & 2337.3 & 5.8 & 1.5 & 0.4 & 11.9 & 8.4 & 9.8 \\
\hline $\begin{array}{r}6 / 29 / 2009 \\
0: 00\end{array}$ & $\begin{array}{r}6 / 29 / 2009 \\
1: 00\end{array}$ & 905.3 & 8026.6 & 3.1 & 2.2 & 595.0 & 1.1 & 783.6 & 773.5 & 319.3 & 318.0 & 2348.4 & 5.7 & 1.4 & 0.4 & 8.9 & 8.2 & 9.7 \\
\hline $\begin{array}{r}6 / 29 / 2009 \\
1: 00\end{array}$ & $\begin{array}{r}6 / 29 / 2009 \\
2: 00\end{array}$ & 897.0 & 7965.1 & 3.1 & 2.1 & 591.5 & 1.1 & 772.6 & 760.6 & 320.2 & 314.0 & 2321.1 & 5.8 & 1.5 & 0.4 & 10.9 & 8.9 & 10.3 \\
\hline $\begin{array}{r}6 / 29 / 2009 \\
2: 00\end{array}$ & $\begin{array}{r}6 / 29 / 2009 \\
3: 00\end{array}$ & 903.1 & 7910.9 & 3.1 & 2.2 & 602.4 & 1.1 & 772.7 & 763.5 & 313.1 & 307.4 & 2331.5 & 6.3 & 1.6 & 0.4 & 6.0 & 9.4 & 10.7 \\
\hline $\begin{array}{r}6 / 29 / 2009 \\
3: 00\end{array}$ & $\begin{array}{r}6 / 29 / 2009 \\
4: 00\end{array}$ & 905.3 & 7995.5 & 3.1 & 2.1 & 614.6 & 1.1 & 778.2 & 768.6 & 309.8 & 304.7 & 2337.3 & 6.7 & 1.7 & 0.4 & 6.5 & 9.5 & 10.8 \\
\hline $\begin{array}{r}6 / 29 / 2009 \\
4: 00\end{array}$ & $\begin{array}{r}6 / 29 / 2009 \\
5: 00\end{array}$ & 900.1 & 8005.6 & 3.1 & 2.1 & 620.1 & 1.1 & 777.8 & 768.7 & 309.9 & 305.0 & 2328.9 & 6.9 & 1.8 & 0.4 & 6.2 & $\# \mathrm{~N} / \mathrm{A}$ & $\# \mathrm{~N} / \mathrm{A}$ \\
\hline $\begin{array}{r}6 / 29 / 2009 \\
5: 00 \\
\end{array}$ & $\begin{array}{r}6 / 29 / 2009 \\
6: 00 \\
\end{array}$ & 904.2 & 8038.9 & 3.0 & 2.2 & 630.4 & 1.1 & 775.0 & 765.2 & 310.2 & 305.7 & 2349.3 & 7.1 & 1.8 & 0.4 & 6.5 & \#N/A & \#N/A \\
\hline $\begin{array}{r}6 / 29 / 2009 \\
6: 00\end{array}$ & $\begin{array}{r}6 / 29 / 2009 \\
7: 00\end{array}$ & 907.9 & 8042.4 & 3.0 & 2.2 & 633.8 & 1.1 & 764.6 & 754.3 & 307.3 & 303.3 & 2374.0 & 7.6 & 1.9 & 0.4 & 6.8 & $\# \mathrm{~N} / \mathrm{A}$ & $\# \mathrm{~N} / \mathrm{A}$ \\
\hline $\begin{array}{r}6 / 29 / 2009 \\
7: 00\end{array}$ & $\begin{array}{r}6 / 29 / 2009 \\
8: 00\end{array}$ & 906.0 & 8048.3 & 3.1 & 2.1 & 632.5 & 1.1 & 760.0 & 749.9 & 305.1 & 301.7 & 2369.7 & 7.9 & 1.9 & 0.4 & 6.8 & 10.7 & 11.5 \\
\hline $\begin{array}{r}6 / 29 / 2009 \\
8: 00\end{array}$ & $\begin{array}{r}6 / 29 / 2009 \\
9: 00\end{array}$ & 907.5 & 8067.3 & 3.1 & 2.1 & 632.1 & 1.1 & 764.2 & 752.5 & 306.2 & 302.4 & 2377.7 & 7.4 & 1.9 & 0.4 & 7.3 & 10.8 & 11.8 \\
\hline $\begin{array}{r}6 / 29 / 2009 \\
9: 00\end{array}$ & $\begin{array}{r}6 / 29 / 2009 \\
10: 00\end{array}$ & 910.3 & 8115.2 & 3.1 & 2.2 & 634.0 & 1.1 & 762.4 & 749.9 & 308.0 & 304.2 & 2374.1 & 7.0 & 1.8 & 0.4 & 7.1 & 11.2 & 12.3 \\
\hline $\begin{array}{r}6 / 29 / 2009 \\
10: 00\end{array}$ & $\begin{array}{r}6 / 29 / 2009 \\
11: 00\end{array}$ & 896.4 & 8094.2 & 3.1 & 2.1 & 621.9 & 1.1 & 759.2 & 748.4 & 307.9 & 304.7 & 2331.6 & 6.4 & 1.7 & 0.4 & 6.6 & 11.4 & 12.6 \\
\hline $\begin{array}{r}6 / 29 / 2009 \\
11: 00 \\
\end{array}$ & $\begin{array}{r}6 / 29 / 2009 \\
12: 00 \\
\end{array}$ & 898.7 & 8066.4 & 3.1 & 2.1 & 625.7 & 1.1 & 762.5 & 752.2 & 309.3 & 306.4 & 2324.6 & 6.3 & 1.7 & 0.4 & 6.6 & 11.5 & 12.8 \\
\hline $\begin{array}{r}6 / 29 / 2009 \\
12: 00 \\
\end{array}$ & $\begin{array}{r}6 / 29 / 2009 \\
13: 00 \\
\end{array}$ & 853.9 & 8079.9 & 3.1 & 2.1 & 596.5 & 1.1 & 750.1 & 743.0 & 310.5 & 307.2 & 2218.0 & 6.3 & 1.7 & 0.4 & 19.4 & 11.0 & 12.4 \\
\hline $\begin{array}{r}6 / 29 / 2009 \\
13: 00\end{array}$ & $\begin{array}{r}6 / 29 / 2009 \\
14: 00\end{array}$ & 853.9 & 8027.1 & 3.3 & 1.9 & 591.2 & 1.1 & 739.6 & 736.5 & 306.6 & 304.3 & 2218.0 & 6.1 & 1.7 & 0.4 & 47.9 & 10.6 & 11.9 \\
\hline $\begin{array}{r}6 / 29 / 2009 \\
14: 00\end{array}$ & $\begin{array}{r}6 / 29 / 2009 \\
15: 00\end{array}$ & 729.6 & 8104.8 & 3.3 & 2.1 & 506.9 & 1.1 & 710.1 & 707.8 & 312.6 & 303.9 & 1978.1 & 5.7 & 1.8 & 0.4 & 40.2 & 9.5 & 10.7 \\
\hline
\end{tabular}




\begin{tabular}{|c|c|c|c|c|c|c|c|c|c|c|c|c|c|c|c|c|c|c|}
\hline \multirow[t]{2}{*}{$\begin{array}{l}\text { Start } \\
\text { Date/ } \\
\text { Time }\end{array}$} & \multirow[t]{2}{*}{$\begin{array}{l}\text { End } \\
\text { Date/ } \\
\text { Time }\end{array}$} & $\begin{array}{l}\text { Gross } \\
\text { Load }\end{array}$ & $\begin{array}{c}\text { Gross } \\
\text { HR }\end{array}$ & $\begin{array}{c}\text { A } \\
\text { Econ } \\
\text { O2 }\end{array}$ & $\begin{array}{c}\text { B } \\
\text { Econ } \\
\text { O2 }\end{array}$ & $\begin{array}{l}\text { Fuel } \\
\text { Flow }\end{array}$ & $\begin{array}{l}\text { BTU } \\
\text { Gain }\end{array}$ & $\begin{array}{c}\text { A } \\
\text { APH } \\
\text { In }\end{array}$ & $\begin{array}{c}\text { B } \\
\text { APH } \\
\text { In }\end{array}$ & $\begin{array}{c}\text { A } \\
\text { APH } \\
\text { Out }\end{array}$ & $\begin{array}{c}\text { B } \\
\text { APH } \\
\text { Out }\end{array}$ & $\begin{array}{l}\text { Stack } \\
\text { Flow }\end{array}$ & Opacity & SO2 In & $\begin{array}{l}\text { SO2 } \\
\text { Out }\end{array}$ & $\mathrm{CO}$ & $\begin{array}{c}\text { Stack } \\
\text { SCEM } \\
\text { Elemental } \\
\mathrm{Hg}\end{array}$ & $\begin{array}{c}\text { Stack } \\
\text { SCEM } \\
\text { Total Hg }\end{array}$ \\
\hline & & MW & Btu/kWh & $\%$ & $\%$ & Ton/hr & & DEGF & DEGF & DEGF & DEGF & KSCF & $\%$ & $\mathrm{Ib} / \mathrm{MMB}$ & $\mathrm{Ib} / \mathrm{MMb}$ & PPM & $\begin{array}{c}\text { ( } \mu \mathrm{g} / \mathrm{dNm} \text { ) } \\
@ 3 \% 02\end{array}$ & $\begin{array}{c}(\mu \mathrm{g} / \mathrm{dNm} 3) \\
@ 3 \% 02\end{array}$ \\
\hline $\begin{array}{r}6 / 29 / 2009 \\
15: 00\end{array}$ & $\begin{array}{r}6 / 29 / 2009 \\
16: 00\end{array}$ & 741.1 & 7998.4 & 3.4 & 2.2 & 527.3 & 1.1 & 704.4 & 701.4 & 310.5 & 303.8 & 2057.7 & 5.9 & 1.8 & 0.4 & 9.7 & 9.8 & 11.1 \\
\hline $\begin{array}{r}6 / 29 / 2009 \\
16: 00\end{array}$ & $\begin{array}{r}6 / 29 / 2009 \\
17: 00\end{array}$ & 889.7 & 8074.2 & 3.1 & 2.2 & 623.3 & 1.1 & 749.9 & 743.4 & 306.9 & 304.9 & 2347.9 & 6.1 & 1.7 & 0.4 & 11.0 & 10.6 & 11.9 \\
\hline $\begin{array}{r}6 / 29 / 2009 \\
17: 00\end{array}$ & $\begin{array}{r}6 / 29 / 2009 \\
18: 00\end{array}$ & 894.4 & 8135.9 & 3.0 & 2.2 & 617.6 & 1.1 & 756.7 & 750.5 & 308.1 & 305.0 & 2335.8 & 5.8 & 1.7 & 0.4 & 7.4 & 10.7 & 11.9 \\
\hline $\begin{array}{r}6 / 29 / 2009 \\
18: 00\end{array}$ & $\begin{array}{r}6 / 29 / 2009 \\
19: 00\end{array}$ & 895.9 & 8102.1 & 3.0 & 2.2 & 610.7 & 1.1 & 756.0 & 749.9 & 306.9 & 303.7 & 2331.1 & 5.7 & 1.7 & 0.4 & 7.0 & 10.7 & 11.9 \\
\hline $\begin{array}{r}6 / 29 / 2009 \\
19: 00\end{array}$ & $\begin{array}{r}6 / 29 / 2009 \\
20: 00\end{array}$ & 877.6 & 8080.0 & 2.9 & 2.2 & 591.5 & 1.1 & 749.1 & 743.5 & 303.3 & 300.5 & 2277.8 & 5.6 & 1.7 & 0.4 & 12.0 & 10.7 & 11.8 \\
\hline $\begin{array}{r}6 / 29 / 2009 \\
20: 00\end{array}$ & $\begin{array}{r}6 / 29 / 2009 \\
21: 00\end{array}$ & 826.0 & 8033.2 & 2.9 & 2.2 & 553.1 & 1.1 & 735.4 & 729.1 & 300.4 & 299.7 & 2145.6 & 5.6 & 1.7 & 0.4 & 26.3 & 10.4 & 11.6 \\
\hline $\begin{array}{r}6 / 29 / 2009 \\
21: 00\end{array}$ & $\begin{array}{r}6 / 29 / 2009 \\
22: 00\end{array}$ & 895.6 & 8019.9 & 3.1 & 2.3 & 604.3 & 1.1 & 754.3 & 747.8 & 303.0 & 300.6 & 2335.6 & 5.9 & 1.7 & 0.4 & 8.4 & 10.9 & 12.2 \\
\hline $\begin{array}{r}6 / 29 / 2009 \\
22: 00\end{array}$ & $\begin{array}{r}6 / 29 / 2009 \\
23: 00\end{array}$ & 902.0 & 8041.5 & 3.1 & 2.2 & 606.2 & 1.1 & 760.9 & 753.7 & 302.5 & 300.3 & 2341.1 & 6.1 & 1.7 & 0.4 & 9.4 & 11.2 & 12.4 \\
\hline $\begin{array}{r}6 / 29 / 2009 \\
23: 00\end{array}$ & $\begin{array}{r}6 / 30 / 2009 \\
0: 00\end{array}$ & 902.0 & 8026.5 & 3.0 & 2.2 & 602.0 & 1.1 & 764.5 & 756.8 & 303.2 & 300.6 & 2329.9 & 6.2 & 1.7 & 0.4 & 9.4 & 11.3 & 12.6 \\
\hline $\begin{array}{r}6 / 30 / 2009 \\
0: 00 \\
\end{array}$ & $\begin{array}{r}6 / 30 / 2009 \\
1: 00 \\
\end{array}$ & 901.8 & 8040.5 & 3.1 & 2.1 & 601.2 & 1.1 & 768.1 & 760.7 & 303.8 & 301.1 & 2335.7 & 6.1 & 1.7 & 0.4 & 9.2 & 11.4 & 12.7 \\
\hline $\begin{array}{r}6 / 30 / 2009 \\
1: 00\end{array}$ & $\begin{array}{r}6 / 30 / 2009 \\
2: 00\end{array}$ & 893.3 & 8004.2 & 3.1 & 2.1 & 594.2 & 1.1 & 769.6 & 761.9 & 303.3 & 300.8 & 2304.6 & 6.1 & 1.7 & 0.4 & 8.8 & 11.6 & 12.8 \\
\hline $\begin{array}{r}6 / 30 / 2009 \\
2: 00\end{array}$ & $\begin{array}{r}6 / 30 / 2009 \\
3: 00\end{array}$ & 893.3 & 7947.6 & 3.1 & 2.2 & 593.1 & 1.1 & 773.0 & 764.7 & 303.4 & 300.4 & 2298.6 & 6.0 & 1.7 & 0.4 & 8.5 & 11.7 & 13.0 \\
\hline $\begin{array}{r}6 / 30 / 2009 \\
3: 00\end{array}$ & $\begin{array}{r}6 / 30 / 2009 \\
4: 00\end{array}$ & 894.4 & 7992.9 & 3.1 & 2.2 & 591.8 & 1.1 & 775.4 & 767.9 & 303.6 & 300.4 & 2310.9 & 5.9 & 1.7 & 0.4 & 6.8 & 11.8 & 13.2 \\
\hline $\begin{array}{r}6 / 30 / 2009 \\
4: 00\end{array}$ & $\begin{array}{r}6 / 30 / 2009 \\
5: 00\end{array}$ & 901.0 & 7982.2 & 3.1 & 2.2 & 602.0 & 1.1 & 778.3 & 771.7 & 304.2 & 301.0 & 2330.8 & 6.0 & 1.8 & 0.4 & 4.7 & 12.1 & 13.4 \\
\hline $\begin{array}{r}6 / 30 / 2009 \\
5: 00 \\
\end{array}$ & $\begin{array}{r}6 / 30 / 2009 \\
6: 00 \\
\end{array}$ & 911.8 & 8000.5 & 3.0 & 2.2 & 613.3 & 1.1 & 775.7 & 765.5 & 305.2 & 301.5 & 2368.5 & 6.6 & 1.9 & 0.4 & 6.1 & $\# \mathrm{~N} / \mathrm{A}$ & $\# \mathrm{~N} / \mathrm{A}$ \\
\hline $\begin{array}{r}6 / 30 / 2009 \\
6: 00 \\
\end{array}$ & $\begin{array}{r}6 / 30 / 2009 \\
7: 00 \\
\end{array}$ & 912.5 & 7957.9 & 3.1 & 2.2 & 620.5 & 1.1 & 763.0 & 754.1 & 301.4 & 298.3 & 2366.4 & 6.9 & 1.9 & 0.4 & 7.9 & $\# \mathrm{~N} / \mathrm{A}$ & $\# \mathrm{~N} / \mathrm{A}$ \\
\hline $\begin{array}{r}6 / 30 / 2009 \\
7: 00\end{array}$ & $\begin{array}{r}6 / 30 / 2009 \\
8: 00\end{array}$ & 902.7 & 7976.1 & 3.0 & 2.2 & 623.7 & 1.1 & 763.1 & 754.4 & 299.2 & 296.4 & 2360.3 & 8.2 & 2.0 & 0.4 & 9.9 & 12.9 & 14.0 \\
\hline $\begin{array}{r}6 / 30 / 2009 \\
8: 00\end{array}$ & $\begin{array}{r}6 / 30 / 2009 \\
9: 00\end{array}$ & 906.9 & 7995.3 & 3.0 & 2.2 & 627.0 & 1.1 & 770.5 & 761.0 & 302.6 & 299.6 & 2362.9 & 9.3 & 2.1 & 0.4 & 11.2 & 13.4 & 14.2 \\
\hline $\begin{array}{r}6 / 30 / 2009 \\
9: 00\end{array}$ & $\begin{array}{r}6 / 30 / 2009 \\
10: 00\end{array}$ & 910.3 & 7980.1 & 3.0 & 2.2 & 631.1 & 1.1 & 775.8 & 766.0 & 304.4 & 301.4 & 2370.2 & 9.0 & 2.1 & 0.5 & 12.1 & 13.6 & 14.4 \\
\hline $6 / 30 / 2009$ & $6 / 30 / 2009$ & 901.7 & 7950.7 & 3.0 & 2.2 & 638.5 & 1.1 & 777.7 & 767.2 & 303.3 & 297.8 & 2371.4 & 7.5 & 2.1 & 0.5 & 11.0 & 13.8 & 14.9 \\
\hline
\end{tabular}




\begin{tabular}{|c|c|c|c|c|c|c|c|c|c|c|c|c|c|c|c|c|c|c|}
\hline $\begin{array}{l}\text { Start } \\
\text { Date/ } \\
\text { Time }\end{array}$ & $\begin{array}{l}\text { End } \\
\text { Date/ } \\
\text { Time }\end{array}$ & $\begin{array}{l}\text { Gross } \\
\text { Load }\end{array}$ & $\begin{array}{c}\text { Gross } \\
\text { HR }\end{array}$ & $\begin{array}{c}\text { A } \\
\text { Econ } \\
\text { O2 }\end{array}$ & $\begin{array}{c}\text { B } \\
\text { Econ } \\
\text { O2 }\end{array}$ & $\begin{array}{l}\text { Fuel } \\
\text { Flow }\end{array}$ & $\begin{array}{l}\text { BTU } \\
\text { Gain }\end{array}$ & $\begin{array}{c}\text { A } \\
\text { APH } \\
\text { In }\end{array}$ & $\begin{array}{c}\text { B } \\
\text { APH } \\
\text { In }\end{array}$ & $\begin{array}{c}\text { A } \\
\text { APH } \\
\text { Out }\end{array}$ & $\begin{array}{c}\text { B } \\
\text { APH } \\
\text { Out }\end{array}$ & $\begin{array}{l}\text { Stack } \\
\text { Flow }\end{array}$ & Opacity & SO2 In & $\begin{array}{l}\text { SO2 } \\
\text { Out }\end{array}$ & $\mathrm{CO}$ & $\begin{array}{c}\text { Stack } \\
\text { SCEM } \\
\text { Elemental } \\
\mathrm{Hg}\end{array}$ & $\begin{array}{c}\text { Stack } \\
\text { SCEM } \\
\text { Total Hg }\end{array}$ \\
\hline & & MW & Btu/kWh & $\%$ & $\%$ & Ton/hr & & DEGF & DEGF & DEGF & DEGF & KSCF & $\%$ & Ib/MMB & $\mathrm{Ib} / \mathrm{MMb}$ & PPM & $\begin{array}{c}(\mu \mathrm{g} / \mathrm{dNm} 3) \\
@ 3 \% 02\end{array}$ & $\begin{array}{c}(\mu \mathrm{g} / \mathrm{dNm} 3) \\
\text { @ } 3 \% 02\end{array}$ \\
\hline $10: 00$ & $11: 00$ & & & & & & & & & & & & & & & & & \\
\hline $\begin{array}{r}6 / 30 / 2009 \\
11: 00\end{array}$ & $\begin{array}{r}6 / 30 / 2009 \\
12: 00\end{array}$ & 898.4 & 7932.7 & 3.0 & 2.2 & 642.9 & 1.1 & 773.5 & 762.8 & 304.1 & 298.0 & 2361.8 & 6.5 & 2.2 & 0.6 & 10.3 & 13.8 & 15.0 \\
\hline $\begin{array}{r}6 / 30 / 2009 \\
12: 00 \\
\end{array}$ & $\begin{array}{r}6 / 30 / 2009 \\
13: 00 \\
\end{array}$ & 907.6 & 7958.1 & 4.3 & 3.7 & 646.7 & 1.1 & 772.0 & 760.4 & 303.8 & 298.2 & 2376.4 & 6.9 & 2.2 & 0.5 & 11.7 & 13.6 & 14.7 \\
\hline $\begin{array}{r}6 / 30 / 2009 \\
13: 00\end{array}$ & $\begin{array}{r}6 / 30 / 2009 \\
14: 00\end{array}$ & 907.7 & 8024.5 & 3.2 & 2.3 & 640.7 & 1.1 & 773.8 & 762.8 & 305.4 & 300.4 & 2369.3 & 6.2 & 2.2 & 0.5 & 12.8 & 13.5 & 14.5 \\
\hline $\begin{array}{r}6 / 30 / 2009 \\
14: 00\end{array}$ & $\begin{array}{r}6 / 30 / 2009 \\
15: 00\end{array}$ & 901.6 & 7953.8 & 2.9 & 2.3 & 641.7 & 1.1 & 775.1 & 762.8 & 305.8 & 300.5 & 2364.1 & 5.8 & 2.2 & 0.5 & 11.2 & 13.0 & 14.1 \\
\hline $\begin{array}{r}6 / 30 / 2009 \\
15: 00\end{array}$ & $\begin{array}{r}6 / 30 / 2009 \\
16: 00\end{array}$ & 912.1 & 8012.7 & 2.9 & 2.3 & 648.2 & 1.1 & 780.0 & 767.0 & 306.4 & 301.3 & 2390.9 & 5.6 & 2.1 & 0.5 & 11.2 & 13.2 & 14.4 \\
\hline $\begin{array}{r}6 / 30 / 2009 \\
16: 00\end{array}$ & $\begin{array}{r}6 / 30 / 2009 \\
17: 00\end{array}$ & 914.8 & 8066.6 & 2.9 & 2.3 & 640.7 & 1.1 & 772.3 & 761.3 & 307.6 & 303.1 & 2386.4 & 5.6 & 2.0 & 0.5 & 10.9 & 13.0 & 14.3 \\
\hline $\begin{array}{r}6 / 30 / 2009 \\
17: 00\end{array}$ & $\begin{array}{r}6 / 30 / 2009 \\
18: 00\end{array}$ & 912.8 & 8034.0 & 2.9 & 2.3 & 630.9 & 1.1 & 766.4 & 757.1 & 305.4 & 300.9 & 2370.7 & 5.7 & 2.0 & 0.6 & 18.1 & 12.6 & 14.0 \\
\hline $\begin{array}{r}6 / 30 / 2009 \\
18: 00\end{array}$ & $\begin{array}{r}6 / 30 / 2009 \\
19: 00\end{array}$ & 907.0 & 7990.8 & 3.0 & 2.3 & 626.5 & 1.1 & 767.6 & 758.7 & 304.4 & 299.9 & 2359.9 & 5.2 & 1.9 & 0.5 & 19.1 & 12.6 & 14.0 \\
\hline $\begin{array}{r}6 / 30 / 2009 \\
19: 00\end{array}$ & $\begin{array}{r}6 / 30 / 2009 \\
20: 00\end{array}$ & 902.8 & 8007.5 & 3.0 & 2.2 & 621.3 & 1.1 & 772.4 & 763.7 & 305.2 & 301.0 & 2324.5 & 4.5 & 1.9 & 0.5 & 20.4 & 12.0 & 15.3 \\
\hline $\begin{array}{r}6 / 30 / 2009 \\
20: 00\end{array}$ & $\begin{array}{r}6 / 30 / 2009 \\
21: 00\end{array}$ & 899.8 & 8010.8 & 3.0 & 2.2 & 624.2 & 1.1 & 774.2 & 766.7 & 304.8 & 301.6 & 2341.1 & 5.3 & 1.8 & 0.6 & 9.6 & 11.5 & 15.2 \\
\hline $\begin{array}{r}6 / 30 / 2009 \\
21: 00\end{array}$ & $\begin{array}{r}6 / 30 / 2009 \\
22: 00\end{array}$ & 866.9 & 7952.6 & 3.1 & 2.2 & 598.8 & 1.1 & 767.2 & 760.9 & 303.4 & 299.9 & 2265.1 & 6.6 & 1.7 & 0.5 & 5.1 & 11.5 & 13.8 \\
\hline $\begin{array}{r}6 / 30 / 2009 \\
22: 00\end{array}$ & $\begin{array}{r}6 / 30 / 2009 \\
23: 00\end{array}$ & 901.4 & 7999.6 & 3.0 & 2.2 & 627.0 & 1.1 & 778.2 & 770.9 & 305.2 & 302.7 & 2359.0 & 7.5 & 1.6 & 0.5 & 4.6 & 10.9 & 13.8 \\
\hline $\begin{array}{r}6 / 30 / 2009 \\
23: 00\end{array}$ & $\begin{array}{r}7 / 1 / 2009 \\
0: 00\end{array}$ & 901.3 & 7984.5 & 3.0 & 2.2 & 628.4 & 1.1 & 783.5 & 774.4 & 307.5 & 303.8 & 2355.4 & 8.4 & 1.6 & 0.5 & 5.1 & 11.1 & 13.9 \\
\hline $\begin{array}{r}7 / 1 / 2009 \\
0: 00\end{array}$ & $\begin{array}{r}7 / 1 / 2009 \\
1: 00\end{array}$ & 902.3 & 8015.2 & 3.0 & 2.2 & 627.7 & 1.1 & 784.4 & 772.1 & 309.6 & 304.9 & 2371.3 & 9.5 & 1.5 & 0.3 & 5.4 & 12.1 & 13.5 \\
\hline $\begin{array}{r}7 / 1 / 2009 \\
1: 00\end{array}$ & $\begin{array}{r}7 / 1 / 2009 \\
2: 00\end{array}$ & 882.9 & 7959.4 & 3.0 & 2.2 & 614.0 & 1.1 & 771.9 & 757.5 & 308.2 & 302.3 & 2315.7 & 8.8 & 1.5 & 0.3 & 6.7 & 11.9 & 13.2 \\
\hline $\begin{array}{r}7 / 1 / 2009 \\
2: 00\end{array}$ & $\begin{array}{r}7 / 1 / 2009 \\
3: 00\end{array}$ & 824.5 & 7784.8 & 3.1 & 2.2 & 577.2 & 1.1 & 749.8 & 739.7 & 301.0 & 295.7 & 2173.2 & 7.7 & 1.6 & 0.4 & 7.1 & 11.8 & 12.9 \\
\hline $\begin{array}{r}7 / 1 / 2009 \\
3: 00\end{array}$ & $\begin{array}{r}7 / 1 / 2009 \\
4: 00\end{array}$ & 801.2 & 7808.0 & 3.1 & 2.1 & 562.6 & 1.1 & 744.5 & 734.7 & 297.4 & 291.8 & 2113.3 & 7.3 & 1.6 & 0.4 & 6.1 & 11.8 & 12.9 \\
\hline $\begin{array}{r}7 / 1 / 2009 \\
4: 00\end{array}$ & $\begin{array}{r}7 / 1 / 2009 \\
5: 00\end{array}$ & 801.5 & 7806.1 & 3.1 & 2.2 & 567.4 & 1.1 & 748.9 & 739.4 & 296.8 & 292.2 & 2125.3 & 7.4 & 1.7 & 0.4 & 6.7 & $\# \mathrm{~N} / \mathrm{A}$ & 13.2 \\
\hline $\begin{array}{r}7 / 1 / 2009 \\
5: 00\end{array}$ & $\begin{array}{r}7 / 1 / 2009 \\
6: 00\end{array}$ & 859.0 & 7839.9 & 3.2 & 2.2 & 611.2 & 1.1 & 760.5 & 752.4 & 299.9 & 296.8 & 2273.9 & 6.8 & 1.8 & 0.4 & 6.3 & $\# \mathrm{~N} / \mathrm{A}$ & $\# \mathrm{~N} / \mathrm{A}$ \\
\hline
\end{tabular}




\begin{tabular}{|c|c|c|c|c|c|c|c|c|c|c|c|c|c|c|c|c|c|c|}
\hline $\begin{array}{l}\text { Start } \\
\text { Date/ } \\
\text { Time }\end{array}$ & $\begin{array}{l}\text { End } \\
\text { Date/ } \\
\text { Time }\end{array}$ & $\begin{array}{l}\text { Gross } \\
\text { Load }\end{array}$ & $\begin{array}{c}\text { Gross } \\
\text { HR }\end{array}$ & $\begin{array}{c}\text { A } \\
\text { Econ } \\
\text { O2 }\end{array}$ & $\begin{array}{c}\text { B } \\
\text { Econ } \\
\text { O2 }\end{array}$ & $\begin{array}{l}\text { Fuel } \\
\text { Flow }\end{array}$ & $\begin{array}{l}\text { BTU } \\
\text { Gain }\end{array}$ & $\begin{array}{l}\text { A } \\
\text { APH } \\
\text { In }\end{array}$ & $\begin{array}{c}\text { B } \\
\text { APH } \\
\text { In }\end{array}$ & $\begin{array}{c}\text { A } \\
\text { APH } \\
\text { Out }\end{array}$ & $\begin{array}{c}\text { B } \\
\text { APH } \\
\text { Out }\end{array}$ & $\begin{array}{l}\text { Stack } \\
\text { Flow }\end{array}$ & Opacity & SO2 In & $\begin{array}{l}\text { SO2 } \\
\text { Out }\end{array}$ & $\mathrm{CO}$ & $\begin{array}{c}\text { Stack } \\
\text { SCEM } \\
\text { Elemental } \\
\mathrm{Hg}\end{array}$ & $\begin{array}{c}\text { Stack } \\
\text { SCEM } \\
\text { Total Hg }\end{array}$ \\
\hline & & MW & Btu/kWh & $\%$ & $\%$ & Ton/hr & & DEGF & DEGF & DEGF & DEGF & KSCF & $\%$ & $\mathrm{Ib} / \mathrm{MMB}$ & $\mathrm{Ib} / \mathrm{MMb}$ & PPM & $\begin{array}{c}(\mu \mathrm{g} / \mathrm{dNm} 3) \\
@ 3 \% 02\end{array}$ & $\begin{array}{c}(\mu \mathrm{g} / \mathrm{dNm} 3) \\
@ 3 \% 02\end{array}$ \\
\hline $\begin{array}{r}7 / 1 / 2009 \\
6: 00\end{array}$ & $\begin{array}{r}7 / 1 / 2009 \\
7: 00\end{array}$ & 841.8 & 7915.2 & 3.2 & 2.1 & 597.8 & 1.0 & 757.0 & 749.5 & 299.1 & 295.9 & 2218.6 & 6.8 & 1.9 & 0.5 & 9.3 & $\# \mathrm{~N} / \mathrm{A}$ & $\# \mathrm{~N} / \mathrm{A}$ \\
\hline $\begin{array}{r}7 / 1 / 2009 \\
7: 00\end{array}$ & $\begin{array}{r}7 / 1 / 2009 \\
8: 00\end{array}$ & 893.4 & 7925.0 & 3.1 & 2.1 & 635.9 & 1.0 & 770.7 & 762.3 & 301.5 & 299.0 & 2344.7 & 6.8 & 1.8 & 0.5 & 8.5 & 12.4 & 13.8 \\
\hline $\begin{array}{r}7 / 1 / 2009 \\
8: 00\end{array}$ & $\begin{array}{r}7 / 1 / 2009 \\
9: 00\end{array}$ & 900.0 & 7979.6 & 3.0 & 2.1 & 621.0 & 1.1 & 771.6 & 762.1 & 305.1 & 301.5 & 2346.5 & 6.0 & 1.7 & 0.5 & 9.3 & 12.2 & 13.5 \\
\hline $\begin{array}{r}7 / 1 / 2009 \\
9: 00\end{array}$ & $\begin{array}{r}7 / 1 / 2009 \\
10: 00\end{array}$ & 913.0 & 8015.7 & 3.0 & 2.2 & 607.9 & 1.1 & 771.1 & 765.1 & 303.8 & 300.9 & 2351.3 & 5.5 & 1.5 & 0.4 & 7.0 & $\# \mathrm{~N} / \mathrm{A}$ & $\# \mathrm{~N} / \mathrm{A}$ \\
\hline $\begin{array}{r}7 / 1 / 2009 \\
10: 00\end{array}$ & $\begin{array}{r}7 / 1 / 2009 \\
11: 00\end{array}$ & 897.4 & 7970.4 & 3.1 & 2.4 & 613.6 & 1.1 & 774.1 & 766.0 & 306.4 & 303.7 & 2347.8 & 5.3 & 1.4 & 0.4 & 7.2 & 11.2 & 12.5 \\
\hline $\begin{array}{r}7 / 1 / 2009 \\
11: 00\end{array}$ & $\begin{array}{r}7 / 1 / 2009 \\
12: 00\end{array}$ & 903.2 & 7890.6 & 3.1 & 2.3 & 646.4 & 1.1 & 766.8 & 755.9 & 309.1 & 305.7 & 2352.0 & 5.2 & 1.6 & 0.4 & 6.4 & 12.5 & 13.9 \\
\hline $\begin{array}{r}7 / 1 / 2009 \\
12: 00\end{array}$ & $\begin{array}{r}7 / 1 / 2009 \\
13: 00\end{array}$ & 915.7 & 7983.1 & 3.0 & 2.1 & 652.5 & 1.1 & 760.0 & 751.3 & 308.7 & 306.1 & 2356.3 & 5.1 & 1.6 & 0.5 & 8.3 & 13.2 & 14.8 \\
\hline $\begin{array}{r}7 / 1 / 2009 \\
13: 00\end{array}$ & $\begin{array}{r}7 / 1 / 2009 \\
14: 00\end{array}$ & 913.8 & 8047.7 & 3.0 & 2.1 & 645.5 & 1.1 & 761.8 & 753.0 & 308.2 & 305.8 & 2352.1 & 5.3 & 1.5 & 0.4 & 10.6 & 12.9 & 14.5 \\
\hline $\begin{array}{r}7 / 1 / 2009 \\
14: 00\end{array}$ & $\begin{array}{r}7 / 1 / 2009 \\
15: 00\end{array}$ & 907.1 & 8022.6 & 3.0 & 2.1 & 630.3 & 1.1 & 766.5 & 759.3 & 310.0 & 307.6 & 2329.4 & 5.2 & 1.4 & 0.3 & 8.5 & 12.5 & 14.0 \\
\hline $\begin{array}{r}7 / 1 / 2009 \\
15: 00 \\
\end{array}$ & $\begin{array}{r}7 / 1 / 2009 \\
16: 00 \\
\end{array}$ & 895.5 & 7992.7 & 3.1 & 2.2 & 618.1 & 1.1 & 766.3 & 758.0 & 310.9 & 307.8 & 2325.3 & 5.2 & 1.4 & 0.3 & 6.8 & 12.3 & 13.7 \\
\hline $\begin{array}{r}7 / 1 / 2009 \\
16: 00\end{array}$ & $\begin{array}{r}7 / 1 / 2009 \\
17: 00\end{array}$ & 903.8 & 8039.9 & 3.0 & 2.2 & 612.6 & 1.1 & 771.2 & 762.8 & 312.3 & 308.3 & 2345.4 & 5.3 & 1.4 & 0.4 & 7.3 & 12.2 & 13.7 \\
\hline $\begin{array}{r}7 / 1 / 2009 \\
17: 00\end{array}$ & $\begin{array}{r}7 / 1 / 2009 \\
18: 00\end{array}$ & 896.1 & 8035.0 & 3.0 & 2.2 & 608.2 & 1.1 & 773.4 & 764.0 & 312.6 & 307.8 & 2323.4 & 5.1 & 1.4 & 0.4 & 6.9 & 12.0 & 13.5 \\
\hline $\begin{array}{r}7 / 1 / 2009 \\
18: 00\end{array}$ & $\begin{array}{r}7 / 1 / 2009 \\
19: 00\end{array}$ & 890.6 & 7973.6 & 3.0 & 2.2 & 609.6 & 1.1 & 763.2 & 754.3 & 310.4 & 306.4 & 2320.0 & 5.3 & 1.5 & 0.4 & 6.1 & 12.2 & 13.7 \\
\hline $\begin{array}{r}7 / 1 / 2009 \\
19: 00\end{array}$ & $\begin{array}{r}7 / 1 / 2009 \\
20: 00\end{array}$ & 895.9 & 7996.3 & 3.0 & 2.2 & 615.6 & 1.1 & 763.7 & 754.9 & 309.5 & 306.7 & 2325.5 & 5.3 & 1.6 & 0.4 & 5.3 & 12.5 & 14.1 \\
\hline $\begin{array}{r}7 / 1 / 2009 \\
20: 00\end{array}$ & $\begin{array}{r}7 / 1 / 2009 \\
21: 00\end{array}$ & 900.9 & 8027.3 & 3.1 & 2.1 & 619.4 & 1.1 & 763.4 & 755.7 & 308.7 & 306.5 & 2330.0 & 5.7 & 1.6 & 0.4 & 5.3 & 12.5 & 14.1 \\
\hline $\begin{array}{r}7 / 1 / 2009 \\
21: 00 \\
\end{array}$ & $\begin{array}{r}7 / 1 / 2009 \\
22: 00 \\
\end{array}$ & 901.7 & 7986.3 & 3.2 & 2.0 & 617.3 & 1.1 & 766.1 & 761.4 & 307.5 & 306.5 & 2322.1 & 7.8 & 1.6 & 0.4 & 5.2 & 12.6 & 14.2 \\
\hline $\begin{array}{r}7 / 1 / 2009 \\
22: 00 \\
\end{array}$ & $\begin{array}{r}7 / 1 / 2009 \\
23: 00 \\
\end{array}$ & 886.9 & 7994.0 & 3.1 & 1.9 & 597.8 & 1.1 & 768.2 & 763.0 & 307.1 & 306.2 & 2273.4 & 8.1 & 1.5 & 0.4 & 6.4 & 12.4 & 13.9 \\
\hline $\begin{array}{r}7 / 1 / 2009 \\
23: 00\end{array}$ & $\begin{array}{r}7 / 2 / 2009 \\
0: 00\end{array}$ & 869.9 & 7970.2 & 3.1 & 2.2 & 581.0 & 1.1 & 765.2 & 758.7 & 305.8 & 304.1 & 2246.6 & 8.0 & 1.5 & 0.4 & 6.3 & 11.8 & 13.2 \\
\hline $\begin{array}{r}7 / 2 / 2009 \\
0: 00\end{array}$ & $\begin{array}{r}7 / 2 / 2009 \\
1: 00\end{array}$ & 904.5 & 8039.6 & 3.1 & 2.2 & 597.1 & 1.1 & 779.1 & 772.5 & 308.7 & 306.8 & 2329.1 & 8.3 & 1.4 & 0.4 & 7.0 & 11.7 & 13.2 \\
\hline $7 / 2 / 2009$ & $7 / 2 / 2009$ & 911.0 & 8035.1 & 3.0 & 2.2 & 590.8 & 1.1 & 786.7 & 778.2 & 310.6 & 309.0 & 2343.7 & 8.6 & 1.3 & 0.3 & 7.8 & 11.6 & 13.0 \\
\hline
\end{tabular}




\begin{tabular}{|c|c|c|c|c|c|c|c|c|c|c|c|c|c|c|c|c|c|c|}
\hline $\begin{array}{l}\text { Start } \\
\text { Date/ } \\
\text { Time }\end{array}$ & $\begin{array}{l}\text { End } \\
\text { Date/ } \\
\text { Time }\end{array}$ & $\begin{array}{l}\text { Gross } \\
\text { Load }\end{array}$ & $\begin{array}{c}\text { Gross } \\
\text { HR }\end{array}$ & $\begin{array}{c}\text { A } \\
\text { Econ } \\
\text { O2 }\end{array}$ & $\begin{array}{c}\text { B } \\
\text { Econ } \\
\text { O2 }\end{array}$ & $\begin{array}{l}\text { Fuel } \\
\text { Flow }\end{array}$ & $\begin{array}{l}\text { BTU } \\
\text { Gain }\end{array}$ & $\begin{array}{c}\text { A } \\
\text { APH } \\
\text { In }\end{array}$ & $\begin{array}{c}\text { B } \\
\text { APH } \\
\text { In }\end{array}$ & $\begin{array}{c}\text { A } \\
\text { APH } \\
\text { Out }\end{array}$ & $\begin{array}{c}\text { B } \\
\text { APH } \\
\text { Out }\end{array}$ & $\begin{array}{l}\text { Stack } \\
\text { Flow }\end{array}$ & Opacity & SO2 In & $\begin{array}{l}\text { SO2 } \\
\text { Out }\end{array}$ & $\mathrm{CO}$ & $\begin{array}{c}\text { Stack } \\
\text { SCEM } \\
\text { Elemental } \\
\mathrm{Hg}\end{array}$ & $\begin{array}{c}\text { Stack } \\
\text { SCEM } \\
\text { Total Hg }\end{array}$ \\
\hline & & MW & Btu/kWh & $\%$ & $\%$ & Ton/hr & & DEGF & DEGF & DEGF & DEGF & KSCF & $\%$ & Ib/MMB & $\mathrm{Ib} / \mathrm{MMb}$ & PPM & $\begin{array}{c}(\mu \mathrm{g} / \mathrm{dNm} 3) \\
@ 3 \% 02\end{array}$ & $\begin{array}{c}(\mu \mathrm{g} / \mathrm{dNm} 3) \\
@ 3 \% 02\end{array}$ \\
\hline $1: 00$ & $2: 00$ & & & & & & & & & & & & & & & & & \\
\hline $\begin{array}{r}7 / 2 / 2009 \\
2: 00 \\
\end{array}$ & $\begin{array}{r}7 / 2 / 2009 \\
3: 00\end{array}$ & 905.6 & 8000.8 & 3.0 & 2.3 & 585.2 & 1.1 & 789.2 & 780.0 & 312.6 & 310.4 & 2308.2 & 8.6 & 1.3 & 0.3 & 8.9 & 11.6 & 12.9 \\
\hline $\begin{array}{r}7 / 2 / 2009 \\
3: 00\end{array}$ & $\begin{array}{r}7 / 2 / 2009 \\
4: 00\end{array}$ & 899.2 & 8004.4 & 3.1 & 2.2 & 590.4 & 1.1 & 787.6 & 780.9 & 313.0 & 310.9 & 2313.8 & 8.8 & 1.4 & 0.4 & 7.6 & 11.7 & 13.1 \\
\hline $\begin{array}{r}7 / 2 / 2009 \\
4: 00 \\
\end{array}$ & $\begin{array}{r}7 / 2 / 2009 \\
5: 00 \\
\end{array}$ & 909.2 & 8022.4 & 3.1 & 2.1 & 606.5 & 1.1 & 791.5 & 785.2 & 313.0 & 312.1 & 2337.1 & 9.2 & 1.4 & 0.4 & 6.7 & 12.3 & 13.6 \\
\hline $\begin{array}{r}7 / 2 / 2009 \\
5: 00 \\
\end{array}$ & $\begin{array}{r}7 / 2 / 2009 \\
6: 00 \\
\end{array}$ & 909.1 & 8003.1 & 3.2 & 2.1 & 614.0 & 1.1 & 791.3 & 786.1 & 312.1 & 311.2 & 2343.7 & 8.8 & 1.4 & 0.4 & 6.1 & $\# \mathrm{~N} / \mathrm{A}$ & $\# \mathrm{~N} / \mathrm{A}$ \\
\hline $\begin{array}{r}7 / 2 / 2009 \\
6: 00\end{array}$ & $\begin{array}{r}7 / 2 / 2009 \\
7: 00\end{array}$ & 899.3 & 8011.8 & 3.1 & 2.1 & 619.2 & 1.1 & 785.9 & 779.7 & 311.5 & 309.8 & 2336.3 & 9.3 & 1.5 & 0.4 & 7.0 & $\# \mathrm{~N} / \mathrm{A}$ & $\# N / A$ \\
\hline $\begin{array}{r}7 / 2 / 2009 \\
7: 00\end{array}$ & $\begin{array}{r}7 / 2 / 2009 \\
8: 00\end{array}$ & 895.5 & 7988.6 & 3.2 & 2.0 & 635.3 & 1.1 & 770.2 & 760.0 & 307.3 & 306.1 & 2343.1 & 9.3 & 1.5 & 0.4 & 7.3 & 11.9 & 15.0 \\
\hline $\begin{array}{r}7 / 2 / 2009 \\
8: 00\end{array}$ & $\begin{array}{r}7 / 2 / 2009 \\
9: 00\end{array}$ & 910.1 & 7973.0 & 3.2 & 2.0 & 647.7 & 1.1 & 764.1 & 755.3 & 305.5 & 304.0 & 2378.4 & 8.5 & 1.5 & 0.4 & 7.6 & 11.8 & 14.8 \\
\hline $\begin{array}{r}7 / 2 / 2009 \\
9: 00\end{array}$ & $\begin{array}{r}7 / 2 / 2009 \\
10: 00\end{array}$ & 906.4 & 8015.6 & 3.2 & 2.0 & 642.9 & 1.1 & 757.2 & 751.9 & 306.5 & 304.8 & 2347.2 & 8.7 & 1.5 & 0.4 & 9.7 & 12.6 & 14.0 \\
\hline $\begin{array}{r}7 / 2 / 2009 \\
10: 00\end{array}$ & $\begin{array}{r}7 / 2 / 2009 \\
11: 00\end{array}$ & 911.3 & 8013.8 & 3.2 & 2.1 & 635.0 & 1.1 & 753.3 & 751.3 & 304.9 & 304.6 & 2355.8 & 8.5 & 1.4 & 0.4 & 6.2 & 12.0 & 13.5 \\
\hline $\begin{array}{r}7 / 2 / 2009 \\
11: 00 \\
\end{array}$ & $\begin{array}{r}7 / 2 / 2009 \\
12: 00 \\
\end{array}$ & 908.3 & 8031.6 & 3.2 & 2.1 & 638.1 & 1.1 & 754.4 & 752.7 & 307.3 & 306.8 & 2348.9 & 8.6 & 1.4 & 0.4 & 4.6 & 11.5 & 13.0 \\
\hline $\begin{array}{r}7 / 2 / 2009 \\
12: 00\end{array}$ & $\begin{array}{r}7 / 2 / 2009 \\
13: 00\end{array}$ & 733.3 & 8248.0 & 4.0 & 3.2 & 518.0 & 1.1 & 710.9 & 708.4 & 314.2 & 305.9 & 2079.2 & 8.0 & 1.4 & 0.3 & 15.8 & 7.0 & 8.5 \\
\hline $\begin{array}{r}7 / 2 / 2009 \\
13: 00\end{array}$ & $\begin{array}{r}7 / 2 / 2009 \\
14: 00\end{array}$ & 720.9 & 8202.8 & 3.4 & 2.1 & 528.9 & 1.1 & 680.2 & 677.9 & 297.4 & 294.7 & 2004.3 & 6.4 & 1.4 & 0.3 & 9.7 & 5.3 & 6.8 \\
\hline $\begin{array}{r}7 / 2 / 2009 \\
14: 00\end{array}$ & $\begin{array}{r}7 / 2 / 2009 \\
15: 00\end{array}$ & 880.4 & 8053.1 & 3.1 & 2.0 & 613.9 & 1.1 & 744.6 & 739.2 & 305.3 & 305.6 & 2300.8 & 8.4 & 1.4 & 0.3 & 5.0 & 8.4 & 10.2 \\
\hline $\begin{array}{r}7 / 2 / 2009 \\
15: 00 \\
\end{array}$ & $\begin{array}{r}7 / 2 / 2009 \\
16: 00 \\
\end{array}$ & 897.6 & 8003.4 & 3.1 & 2.2 & 615.5 & 1.1 & 765.2 & 758.3 & 314.2 & 312.1 & 2320.7 & 9.1 & 1.4 & 0.4 & 6.0 & 10.0 & 12.0 \\
\hline $\begin{array}{r}7 / 2 / 2009 \\
16: 00 \\
\end{array}$ & $\begin{array}{r}7 / 2 / 2009 \\
17: 00 \\
\end{array}$ & 899.9 & 7949.8 & 3.1 & 2.3 & 624.8 & 1.1 & 772.8 & 766.4 & 317.3 & 315.3 & 2339.1 & 9.3 & 1.4 & 0.4 & 7.4 & 11.4 & 13.5 \\
\hline $\begin{array}{r}7 / 2 / 2009 \\
17: 00 \\
\end{array}$ & $\begin{array}{r}7 / 2 / 2009 \\
18: 00 \\
\end{array}$ & 912.8 & 8009.0 & 3.1 & 2.1 & 617.5 & 1.1 & 768.4 & 765.7 & 317.4 & 316.6 & 2346.6 & 9.3 & 1.4 & 0.4 & 3.1 & 12.3 & 14.5 \\
\hline $\begin{array}{r}7 / 2 / 2009 \\
18: 00 \\
\end{array}$ & $\begin{array}{r}7 / 2 / 2009 \\
19: 00 \\
\end{array}$ & 910.1 & 7994.0 & 3.1 & 2.2 & 595.9 & 1.1 & 767.8 & 766.7 & 314.7 & 314.0 & 2319.0 & 9.5 & 1.3 & 0.3 & 1.6 & 11.6 & 13.7 \\
\hline $\begin{array}{r}7 / 2 / 2009 \\
19: 00\end{array}$ & $\begin{array}{r}7 / 2 / 2009 \\
20: 00\end{array}$ & 900.9 & 7995.8 & 3.1 & 2.2 & 581.0 & 1.1 & 774.3 & 772.6 & 315.2 & 314.6 & 2297.2 & 10.1 & 1.2 & 0.3 & 1.1 & 10.7 & 12.5 \\
\hline $\begin{array}{r}7 / 2 / 2009 \\
20: 00\end{array}$ & $\begin{array}{r}7 / 2 / 2009 \\
21: 00\end{array}$ & 897.1 & 8021.1 & 3.2 & 2.2 & 579.0 & 1.1 & 780.0 & 777.8 & 316.3 & 317.1 & 2301.7 & 9.7 & 1.3 & 0.3 & 1.9 & 10.6 & 12.3 \\
\hline
\end{tabular}




\begin{tabular}{|c|c|c|c|c|c|c|c|c|c|c|c|c|c|c|c|c|c|c|}
\hline $\begin{array}{l}\text { Start } \\
\text { Date/ } \\
\text { Time }\end{array}$ & $\begin{array}{l}\text { End } \\
\text { Date/ } \\
\text { Time }\end{array}$ & $\begin{array}{l}\text { Gross } \\
\text { Load }\end{array}$ & $\begin{array}{c}\text { Gross } \\
\text { HR }\end{array}$ & $\begin{array}{c}\text { A } \\
\text { Econ } \\
\text { O2 }\end{array}$ & $\begin{array}{c}\text { B } \\
\text { Econ } \\
\text { O2 }\end{array}$ & $\begin{array}{l}\text { Fuel } \\
\text { Flow }\end{array}$ & $\begin{array}{l}\text { BTU } \\
\text { Gain }\end{array}$ & $\begin{array}{l}\text { A } \\
\text { APH } \\
\text { In }\end{array}$ & $\begin{array}{c}\text { B } \\
\text { APH } \\
\text { In }\end{array}$ & $\begin{array}{c}\text { A } \\
\text { APH } \\
\text { Out }\end{array}$ & $\begin{array}{c}\text { B } \\
\text { APH } \\
\text { Out }\end{array}$ & $\begin{array}{l}\text { Stack } \\
\text { Flow }\end{array}$ & Opacity & SO2 In & $\begin{array}{l}\text { SO2 } \\
\text { Out }\end{array}$ & $\mathrm{CO}$ & $\begin{array}{c}\text { Stack } \\
\text { SCEM } \\
\text { Elemental } \\
\mathrm{Hg}\end{array}$ & $\begin{array}{c}\text { Stack } \\
\text { SCEM } \\
\text { Total Hg }\end{array}$ \\
\hline & & MW & Btu/kWh & $\%$ & $\%$ & Ton/hr & & DEGF & DEGF & DEGF & DEGF & KSCF & $\%$ & Ib/MMB & $\mathrm{Ib} / \mathrm{MMb}$ & PPM & $\begin{array}{c}(\mu \mathrm{g} / \mathrm{dNm} 3) \\
@ 3 \% 02\end{array}$ & $\begin{array}{c}(\mu \mathrm{g} / \mathrm{dNm} 3) \\
@ 3 \% 02\end{array}$ \\
\hline $\begin{array}{r}7 / 2 / 2009 \\
21: 00\end{array}$ & $\begin{array}{r}7 / 2 / 2009 \\
22: 00\end{array}$ & 897.5 & 8023.3 & 3.1 & 2.3 & 578.8 & 1.1 & 782.9 & 779.3 & 316.6 & 316.2 & 2309.1 & 11.2 & 1.4 & 0.4 & 1.9 & 11.1 & 12.8 \\
\hline $\begin{array}{r}7 / 2 / 2009 \\
22: 00\end{array}$ & $\begin{array}{r}7 / 2 / 2009 \\
23: 00\end{array}$ & 903.8 & 8028.6 & 3.1 & 2.2 & 584.3 & 1.1 & 782.3 & 778.2 & 316.9 & 316.6 & 2318.1 & 10.5 & 1.4 & 0.4 & 1.3 & 11.3 & 12.9 \\
\hline $\begin{array}{r}7 / 2 / 2009 \\
23: 00\end{array}$ & $\begin{array}{r}7 / 3 / 2009 \\
0: 00\end{array}$ & 898.8 & 8016.4 & 3.1 & 2.2 & 571.6 & 1.2 & 777.7 & 772.0 & 313.9 & 312.9 & 2305.2 & 11.0 & 1.4 & 0.3 & 1.5 & 10.9 & 12.5 \\
\hline $\begin{array}{r}7 / 3 / 2009 \\
0: 00\end{array}$ & $\begin{array}{r}7 / 3 / 2009 \\
1: 00\end{array}$ & 899.4 & 8024.8 & 3.1 & 2.4 & 579.0 & 1.2 & 783.2 & 775.8 & 313.8 & 311.9 & 2312.0 & 11.2 & 1.4 & 0.3 & 1.1 & 11.0 & 12.7 \\
\hline $\begin{array}{r}7 / 3 / 2009 \\
1: 00\end{array}$ & $\begin{array}{r}7 / 3 / 2009 \\
2: 00\end{array}$ & 903.0 & 8014.6 & 3.1 & 2.2 & 590.0 & 1.2 & 787.7 & 782.5 & 314.0 & 312.6 & 2319.8 & 10.9 & 1.5 & 0.4 & 1.0 & 11.6 & 13.3 \\
\hline $\begin{array}{r}7 / 3 / 2009 \\
2: 00\end{array}$ & $\begin{array}{r}7 / 3 / 2009 \\
3: 00\end{array}$ & 899.6 & 7981.1 & 3.0 & 2.2 & 591.1 & 1.1 & 789.7 & 784.2 & 313.5 & 311.9 & 2302.6 & 10.9 & 1.5 & 0.4 & 1.1 & 12.2 & 14.0 \\
\hline $\begin{array}{r}7 / 3 / 2009 \\
3: 00\end{array}$ & $\begin{array}{r}7 / 3 / 2009 \\
4: 00\end{array}$ & 862.3 & 8040.2 & 3.0 & 2.2 & 576.5 & 1.1 & 770.5 & 765.0 & 310.0 & 306.8 & 2231.6 & 10.5 & 1.6 & 0.4 & 2.9 & 12.5 & 14.3 \\
\hline $\begin{array}{r}7 / 3 / 2009 \\
4: 00\end{array}$ & $\begin{array}{r}7 / 3 / 2009 \\
5: 00\end{array}$ & 804.9 & 8083.8 & 3.2 & 2.1 & 552.7 & 1.1 & 738.8 & 734.4 & 300.6 & 296.3 & 2102.8 & 9.2 & 1.6 & 0.4 & 1.1 & $\# \mathrm{~N} / \mathrm{A}$ & \#N/A \\
\hline $\begin{array}{r}7 / 3 / 2009 \\
5: 00\end{array}$ & $\begin{array}{r}7 / 3 / 2009 \\
6: 00\end{array}$ & 827.8 & 8007.9 & 3.2 & 2.2 & 576.3 & 1.1 & 741.6 & 737.4 & 296.4 & 292.7 & 2169.0 & 7.5 & 1.6 & 0.4 & 1.7 & $\# \mathrm{~N} / \mathrm{A}$ & $\# \mathrm{~N} / \mathrm{A}$ \\
\hline $\begin{array}{r}7 / 3 / 2009 \\
6: 00 \\
\end{array}$ & $\begin{array}{r}7 / 3 / 2009 \\
7: 00 \\
\end{array}$ & 866.7 & 7992.6 & 3.1 & 2.3 & 603.4 & 1.1 & 763.0 & 757.5 & 301.3 & 298.1 & 2262.9 & 6.1 & 1.7 & 0.5 & 4.3 & $\# \mathrm{~N} / \mathrm{A}$ & $\# \mathrm{~N} / \mathrm{A}$ \\
\hline $\begin{array}{r}7 / 3 / 2009 \\
7: 00\end{array}$ & $\begin{array}{r}7 / 3 / 2009 \\
8: 00\end{array}$ & 885.0 & 7986.3 & 3.1 & 2.2 & 628.3 & 1.1 & 771.1 & 765.3 & 304.5 & 302.0 & 2303.3 & 5.6 & 1.9 & 0.5 & 6.1 & 13.9 & 16.0 \\
\hline $\begin{array}{r}7 / 3 / 2009 \\
8: 00\end{array}$ & $\begin{array}{r}7 / 3 / 2009 \\
9: 00\end{array}$ & 899.3 & 8042.3 & 3.1 & 2.2 & 642.8 & 1.1 & 768.8 & 763.9 & 307.1 & 305.1 & 2342.7 & 5.5 & 2.0 & 0.6 & 3.2 & 14.4 & 16.2 \\
\hline $\begin{array}{r}7 / 3 / 2009 \\
9: 00\end{array}$ & $\begin{array}{r}7 / 3 / 2009 \\
10: 00\end{array}$ & 916.8 & 8054.8 & 3.0 & 2.2 & 642.4 & 1.1 & 767.9 & 761.3 & 306.6 & 304.3 & 2369.2 & 5.5 & 2.0 & 0.6 & 2.5 & 14.3 & 16.1 \\
\hline $\begin{array}{r}7 / 3 / 2009 \\
10: 00\end{array}$ & $\begin{array}{r}7 / 3 / 2009 \\
11: 00\end{array}$ & 916.9 & 8032.9 & 3.1 & 2.2 & 632.5 & 1.1 & 776.1 & 770.2 & 308.6 & 307.2 & 2361.3 & 5.7 & 1.9 & 0.5 & 1.8 & 14.8 & 16.7 \\
\hline $\begin{array}{r}7 / 3 / 2009 \\
11: 00\end{array}$ & $\begin{array}{r}7 / 3 / 2009 \\
12: 00\end{array}$ & 911.7 & 8029.8 & 3.1 & 2.2 & 629.7 & 1.1 & 776.8 & 772.9 & 311.7 & 311.4 & 2340.3 & 5.9 & 1.9 & 0.5 & 1.6 & 15.1 & 16.9 \\
\hline $\begin{array}{r}7 / 3 / 2009 \\
12: 00 \\
\end{array}$ & $\begin{array}{r}7 / 3 / 2009 \\
13: 00 \\
\end{array}$ & 909.9 & 8031.2 & 3.1 & 2.2 & 626.4 & 1.1 & 779.6 & 776.9 & 315.0 & 315.4 & 2347.2 & 6.1 & 1.8 & 0.5 & 2.3 & 15.3 & 17.1 \\
\hline $\begin{array}{r}7 / 3 / 2009 \\
13: 00 \\
\end{array}$ & $\begin{array}{r}7 / 3 / 2009 \\
14: 00 \\
\end{array}$ & 910.9 & 8029.5 & 3.1 & 2.2 & 622.6 & 1.1 & 780.6 & 776.2 & 317.8 & 317.9 & 2357.6 & 6.2 & 1.7 & 0.4 & 3.6 & 15.2 & 17.1 \\
\hline $\begin{array}{r}7 / 3 / 2009 \\
14: 00\end{array}$ & $\begin{array}{r}7 / 3 / 2009 \\
15: 00\end{array}$ & 909.3 & 8013.3 & 3.1 & 2.2 & 622.1 & 1.1 & 780.2 & 777.0 & 319.1 & 318.8 & 2348.4 & 6.1 & 1.6 & 0.4 & 4.7 & 15.0 & 16.8 \\
\hline $\begin{array}{r}7 / 3 / 2009 \\
15: 00\end{array}$ & $\begin{array}{r}7 / 3 / 2009 \\
16: 00\end{array}$ & 910.3 & 8018.9 & 3.1 & 2.2 & 620.0 & 1.1 & 784.8 & 783.8 & 326.6 & 327.3 & 2338.0 & 6.3 & 1.5 & 0.4 & 3.7 & 15.0 & 16.8 \\
\hline $7 / 3 / 2009$ & $7 / 3 / 2009$ & 911.1 & 8028.2 & 3.1 & 2.2 & 620.7 & 1.1 & 789.7 & 789.0 & 330.7 & 332.0 & 2355.7 & 6.3 & 1.5 & 0.4 & 2.5 & 14.9 & 16.8 \\
\hline
\end{tabular}




\begin{tabular}{|c|c|c|c|c|c|c|c|c|c|c|c|c|c|c|c|c|c|c|}
\hline $\begin{array}{l}\text { Start } \\
\text { Date/ } \\
\text { Time }\end{array}$ & $\begin{array}{l}\text { End } \\
\text { Date/ } \\
\text { Time }\end{array}$ & $\begin{array}{l}\text { Gross } \\
\text { Load }\end{array}$ & $\begin{array}{c}\text { Gross } \\
\text { HR }\end{array}$ & $\begin{array}{c}\text { A } \\
\text { Econ } \\
\text { O2 }\end{array}$ & $\begin{array}{c}\text { B } \\
\text { Econ } \\
\text { O2 }\end{array}$ & $\begin{array}{l}\text { Fuel } \\
\text { Flow }\end{array}$ & $\begin{array}{l}\text { BTU } \\
\text { Gain }\end{array}$ & $\begin{array}{c}\text { A } \\
\text { APH } \\
\text { In }\end{array}$ & $\begin{array}{c}\text { B } \\
\text { APH } \\
\text { In }\end{array}$ & $\begin{array}{c}\text { A } \\
\text { APH } \\
\text { Out }\end{array}$ & $\begin{array}{c}\text { B } \\
\text { APH } \\
\text { Out }\end{array}$ & $\begin{array}{l}\text { Stack } \\
\text { Flow }\end{array}$ & Opacity & SO2 In & $\begin{array}{l}\text { SO2 } \\
\text { Out }\end{array}$ & $\mathrm{CO}$ & $\begin{array}{c}\text { Stack } \\
\text { SCEM } \\
\text { Elemental } \\
\mathrm{Hg}\end{array}$ & $\begin{array}{c}\text { Stack } \\
\text { SCEM } \\
\text { Total Hg }\end{array}$ \\
\hline & & MW & Btu/kWh & $\%$ & $\%$ & Ton/hr & & DEGF & DEGF & DEGF & DEGF & KSCF & $\%$ & Ib/MMB & $\mathrm{Ib} / \mathrm{MMb}$ & PPM & $\begin{array}{c}(\mu \mathrm{g} / \mathrm{dNm} 3) \\
@ 3 \% 02\end{array}$ & $\begin{array}{c}(\mu \mathrm{g} / \mathrm{dNm} 3) \\
@ 3 \% 02\end{array}$ \\
\hline $16: 00$ & $17: 00$ & & & & & & & & & & & & & & & & & \\
\hline $\begin{array}{r}7 / 3 / 2009 \\
17: 00\end{array}$ & $\begin{array}{r}7 / 3 / 2009 \\
18: 00\end{array}$ & 909.6 & 8024.5 & 3.1 & 2.2 & 619.9 & 1.1 & 794.8 & 793.1 & 332.5 & 333.4 & 2338.7 & 6.3 & 1.4 & 0.3 & 1.7 & 14.7 & 16.7 \\
\hline $\begin{array}{r}7 / 3 / 2009 \\
18: 00\end{array}$ & $\begin{array}{r}7 / 3 / 2009 \\
19: 00\end{array}$ & 909.7 & 8043.9 & 3.0 & 2.1 & 616.3 & 1.1 & 786.4 & 782.4 & 332.5 & 332.5 & 2338.3 & 6.4 & 1.3 & 0.3 & 4.1 & 14.5 & 16.6 \\
\hline $\begin{array}{r}7 / 3 / 2009 \\
19: 00 \\
\end{array}$ & $\begin{array}{r}7 / 3 / 2009 \\
20: 00 \\
\end{array}$ & 909.6 & 8012.6 & 3.0 & 1.9 & 617.1 & 1.1 & 784.0 & 779.2 & 329.7 & 329.3 & 2316.9 & 6.1 & 1.3 & 0.3 & 8.0 & 14.5 & 16.3 \\
\hline $\begin{array}{r}7 / 3 / 2009 \\
20: 00 \\
\end{array}$ & $\begin{array}{r}7 / 3 / 2009 \\
21: 00 \\
\end{array}$ & 909.5 & 8048.9 & 3.0 & 1.9 & 618.9 & 1.1 & 789.8 & 785.9 & 330.0 & 330.5 & 2320.6 & 6.6 & 1.3 & 0.3 & 7.8 & 14.7 & 16.7 \\
\hline $\begin{array}{r}7 / 3 / 2009 \\
21: 00\end{array}$ & $\begin{array}{r}7 / 3 / 2009 \\
22: 00\end{array}$ & 911.7 & 8040.3 & 2.9 & 1.7 & 617.5 & 1.1 & 793.8 & 787.0 & 330.9 & 332.1 & 2321.6 & 8.1 & 1.3 & 0.3 & 16.6 & 14.8 & 16.6 \\
\hline $\begin{array}{r}7 / 3 / 2009 \\
22: 00\end{array}$ & $\begin{array}{r}7 / 3 / 2009 \\
23: 00\end{array}$ & 911.1 & 8072.4 & 2.9 & 1.7 & 613.4 & 1.1 & 779.9 & 769.7 & 328.8 & 327.5 & 2314.9 & 8.3 & 1.3 & 0.3 & 9.9 & 14.3 & 16.2 \\
\hline $\begin{array}{r}7 / 3 / 2009 \\
23: 00\end{array}$ & $\begin{array}{r}7 / 4 / 2009 \\
0: 00\end{array}$ & 910.9 & 8005.4 & 2.8 & 1.9 & 614.0 & 1.1 & 768.6 & 763.3 & 321.9 & 320.5 & 2288.8 & 8.5 & 1.3 & 0.3 & 3.6 & 14.2 & 16.0 \\
\hline $\begin{array}{r}7 / 4 / 2009 \\
0: 00\end{array}$ & $\begin{array}{r}7 / 4 / 2009 \\
1: 00\end{array}$ & 908.9 & 8043.9 & 2.7 & 1.8 & 621.2 & 1.1 & 773.7 & 766.0 & 321.6 & 318.9 & 2305.5 & 9.9 & 1.3 & 0.3 & 8.3 & 14.2 & 16.0 \\
\hline $\begin{array}{r}7 / 4 / 2009 \\
1: 00\end{array}$ & $\begin{array}{r}7 / 4 / 2009 \\
2: 00\end{array}$ & 910.4 & 8057.1 & 2.6 & 1.6 & 620.2 & 1.1 & 776.2 & 771.0 & 322.1 & 319.9 & 2304.3 & 10.1 & 1.3 & 0.3 & 22.5 & $\# \mathrm{~N} / \mathrm{A}$ & $\# \mathrm{~N} / \mathrm{A}$ \\
\hline $\begin{array}{r}7 / 4 / 2009 \\
2: 00 \\
\end{array}$ & $\begin{array}{r}7 / 4 / 2009 \\
3: 00 \\
\end{array}$ & 909.3 & 8050.9 & 2.6 & 1.7 & 620.1 & 1.1 & 780.9 & 775.0 & 322.5 & 320.5 & 2314.9 & 8.7 & 1.3 & 0.3 & 21.0 & $\# \mathrm{~N} / \mathrm{A}$ & $\# \mathrm{~N} / \mathrm{A}$ \\
\hline $\begin{array}{r}7 / 4 / 2009 \\
3: 00\end{array}$ & $\begin{array}{r}7 / 4 / 2009 \\
4: 00\end{array}$ & 904.4 & 8030.5 & 2.5 & 1.7 & 611.2 & 1.1 & 785.3 & 777.9 & 323.7 & 320.2 & 2287.3 & 5.3 & 1.3 & 0.3 & 14.3 & 13.5 & 15.5 \\
\hline $\begin{array}{r}7 / 4 / 2009 \\
4: 00\end{array}$ & $\begin{array}{r}7 / 4 / 2009 \\
5: 00\end{array}$ & 818.8 & 8063.6 & 2.5 & 1.7 & 553.4 & 1.1 & 763.8 & 756.1 & 321.3 & 316.0 & 2076.4 & 4.6 & 1.3 & 0.3 & 17.9 & 12.2 & 14.0 \\
\hline $\begin{array}{r}7 / 4 / 2009 \\
5: 00\end{array}$ & $\begin{array}{r}7 / 4 / 2009 \\
6: 00\end{array}$ & 805.0 & 8051.3 & 2.6 & 1.7 & 551.4 & 1.1 & 756.1 & 748.8 & 316.0 & 310.9 & 2054.4 & 4.5 & 1.3 & 0.3 & 32.3 & $\# \mathrm{~N} / \mathrm{A}$ & $\# N / A$ \\
\hline $\begin{array}{r}7 / 4 / 2009 \\
6: 00\end{array}$ & $\begin{array}{r}7 / 4 / 2009 \\
7: 00\end{array}$ & 841.1 & 8048.4 & 2.7 & 1.6 & 567.5 & 1.1 & 767.8 & 761.0 & 314.9 & 310.8 & 2148.1 & 4.5 & 1.4 & 0.3 & 39.9 & $\# \mathrm{~N} / \mathrm{A}$ & $\# \mathrm{~N} / \mathrm{A}$ \\
\hline $\begin{array}{r}7 / 4 / 2009 \\
7: 00\end{array}$ & $\begin{array}{r}7 / 4 / 2009 \\
8: 00\end{array}$ & 871.0 & 8036.9 & 2.6 & 1.7 & 588.9 & 1.1 & 776.3 & 768.7 & 317.7 & 314.2 & 2224.9 & 4.8 & 1.3 & 0.3 & 12.7 & 11.2 & 13.0 \\
\hline $\begin{array}{r}7 / 4 / 2009 \\
8: 00 \\
\end{array}$ & $\begin{array}{r}7 / 4 / 2009 \\
9: 00 \\
\end{array}$ & 907.3 & 8074.1 & 2.6 & 1.7 & 601.9 & 1.1 & 772.7 & 766.7 & 319.0 & 315.4 & 2306.2 & 5.1 & 1.3 & 0.3 & 8.0 & 11.7 & 13.2 \\
\hline $\begin{array}{r}7 / 4 / 2009 \\
9: 00 \\
\end{array}$ & $\begin{array}{r}7 / 4 / 2009 \\
10: 00 \\
\end{array}$ & 902.1 & 8064.0 & 2.6 & 1.7 & 604.3 & 1.1 & 774.2 & 767.4 & 317.9 & 313.9 & 2287.5 & 5.2 & 1.3 & 0.3 & 5.6 & 12.0 & 13.5 \\
\hline $\begin{array}{r}7 / 4 / 2009 \\
10: 00\end{array}$ & $\begin{array}{r}7 / 4 / 2009 \\
11: 00\end{array}$ & 901.9 & 8081.3 & 2.6 & 1.7 & 611.9 & 1.1 & 779.0 & 772.8 & 321.1 & 317.7 & 2298.2 & 5.1 & 1.3 & 0.3 & 7.4 & 12.4 & 14.0 \\
\hline $\begin{array}{r}7 / 4 / 2009 \\
11: 00\end{array}$ & $\begin{array}{r}7 / 4 / 2009 \\
12: 00\end{array}$ & 904.6 & 8077.1 & 2.6 & 1.6 & 617.6 & 1.1 & 780.1 & 774.0 & 322.7 & 320.2 & 2291.3 & 5.2 & 1.3 & 0.3 & 16.1 & 12.8 & 14.4 \\
\hline
\end{tabular}




\begin{tabular}{|c|c|c|c|c|c|c|c|c|c|c|c|c|c|c|c|c|c|c|}
\hline $\begin{array}{l}\text { Start } \\
\text { Date/ } \\
\text { Time }\end{array}$ & $\begin{array}{l}\text { End } \\
\text { Date/ } \\
\text { Time }\end{array}$ & $\begin{array}{l}\text { Gross } \\
\text { Load }\end{array}$ & $\begin{array}{c}\text { Gross } \\
\text { HR }\end{array}$ & $\begin{array}{c}\text { A } \\
\text { Econ } \\
\text { O2 }\end{array}$ & $\begin{array}{c}\text { B } \\
\text { Econ } \\
\text { O2 }\end{array}$ & $\begin{array}{l}\text { Fuel } \\
\text { Flow }\end{array}$ & $\begin{array}{l}\text { BTU } \\
\text { Gain }\end{array}$ & $\begin{array}{c}\text { A } \\
\text { APH } \\
\text { In }\end{array}$ & $\begin{array}{l}\text { B } \\
\text { APH } \\
\text { In }\end{array}$ & $\begin{array}{c}\text { A } \\
\text { APH } \\
\text { Out }\end{array}$ & $\begin{array}{c}\text { B } \\
\text { APH } \\
\text { Out }\end{array}$ & $\begin{array}{l}\text { Stack } \\
\text { Flow }\end{array}$ & Opacity & SO2 In & $\begin{array}{l}\text { SO2 } \\
\text { Out }\end{array}$ & $\mathrm{CO}$ & $\begin{array}{c}\text { Stack } \\
\text { SCEM } \\
\text { Elemental } \\
\mathrm{Hg}\end{array}$ & $\begin{array}{c}\text { Stack } \\
\text { SCEM } \\
\text { Total Hg }\end{array}$ \\
\hline & & MW & Btu/kWh & $\%$ & $\%$ & Ton/hr & & DEGF & DEGF & DEGF & DEGF & KSCF & $\%$ & Ib/MMB & Ib/MMb & PPM & $\begin{array}{c}(\mu \mathrm{g} / \mathrm{dNm} 3) \\
@ 3 \% 02\end{array}$ & $\begin{array}{c}(\mu \mathrm{g} / \mathrm{dNm} \text { ) } \\
@ 3 \% 02\end{array}$ \\
\hline $\begin{array}{r}/ 4 / 2009 \\
12: 00\end{array}$ & $\begin{array}{r}7 / 4 / 2009 \\
13: 00\end{array}$ & 904.3 & 8067.7 & 2.6 & 1.6 & 619.8 & 1.1 & 782.4 & 778.2 & 324.4 & 323.2 & 2279.1 & 5.1 & 1.3 & 0.3 & 18.9 & 12.8 & 14.4 \\
\hline $\begin{array}{r}7 / 4 / 2009 \\
13: 00\end{array}$ & $\begin{array}{r}7 / 4 / 2009 \\
14: 00\end{array}$ & 904.6 & 8061.6 & 2.6 & 1.6 & 622.7 & 1.1 & 783.4 & 777.1 & 327.4 & 325.8 & 2280.4 & 5.4 & 1.3 & 0.3 & 16.4 & 13.4 & 15.2 \\
\hline $\begin{array}{r}7 / 4 / 2009 \\
14: 00\end{array}$ & $\begin{array}{r}7 / 4 / 2009 \\
15: 00\end{array}$ & 908.2 & 8062.5 & 2.6 & 1.6 & 617.9 & 1.1 & 784.2 & 775.6 & 327.9 & 325.8 & 2280.6 & 5.4 & 1.4 & 0.3 & 17.7 & 13.5 & 15.2 \\
\hline $\begin{array}{r}7 / 4 / 2009 \\
15: 00\end{array}$ & $\begin{array}{r}7 / 4 / 2009 \\
16: 00\end{array}$ & 907.6 & 8064.1 & 2.6 & 1.7 & 610.1 & 1.1 & 788.2 & 780.5 & 330.0 & 327.9 & 2281.5 & 5.6 & 1.4 & 0.4 & 12.1 & 13.3 & 15.1 \\
\hline $\begin{array}{r}7 / 4 / 2009 \\
16: 00\end{array}$ & $\begin{array}{r}7 / 4 / 2009 \\
17: 00\end{array}$ & 905.8 & 8087.6 & 2.5 & 1.7 & 602.8 & 1.1 & 782.0 & 775.6 & 331.9 & 330.2 & 2275.0 & 5.7 & 1.4 & 0.3 & 10.4 & 13.0 & 14.8 \\
\hline $\begin{array}{r}7 / 4 / 2009 \\
17: 00 \\
\end{array}$ & $\begin{array}{r}7 / 4 / 2009 \\
18: 00 \\
\end{array}$ & 904.5 & 8055.7 & 2.5 & 1.7 & 598.9 & 1.1 & 780.1 & 773.7 & 330.9 & 328.8 & 2276.4 & 5.7 & 1.3 & 0.3 & 8.1 & 12.8 & 14.5 \\
\hline $\begin{array}{r}7 / 4 / 2009 \\
18: 00\end{array}$ & $\begin{array}{r}7 / 4 / 2009 \\
19: 00\end{array}$ & 901.8 & 8038.5 & 2.6 & 1.7 & 593.6 & 1.1 & 785.7 & 779.4 & 332.7 & 331.1 & 2264.5 & 5.9 & 1.3 & 0.3 & 9.4 & 13.1 & 14.8 \\
\hline $\begin{array}{r}7 / 4 / 2009 \\
19: 00\end{array}$ & $\begin{array}{r}7 / 4 / 2009 \\
20: 00\end{array}$ & 887.4 & 8063.5 & 2.6 & 1.7 & 584.9 & 1.1 & 775.0 & 768.2 & 331.7 & 329.3 & 2232.0 & 5.8 & 1.3 & 0.3 & 20.9 & 12.7 & 14.5 \\
\hline $\begin{array}{r}7 / 4 / 2009 \\
20: 00\end{array}$ & $\begin{array}{r}7 / 4 / 2009 \\
21: 00\end{array}$ & 907.5 & 8037.2 & 2.6 & 1.7 & 603.7 & 1.1 & 782.1 & 775.2 & 330.5 & 329.0 & 2282.1 & 6.3 & 1.3 & 0.3 & 23.3 & 12.8 & 14.5 \\
\hline $\begin{array}{r}7 / 4 / 2009 \\
21: 00\end{array}$ & $\begin{array}{r}7 / 4 / 2009 \\
22: 00\end{array}$ & 910.0 & 8051.3 & 2.6 & 1.7 & 605.9 & 1.1 & 771.4 & 764.2 & 328.3 & 327.1 & 2281.7 & 6.5 & 1.3 & 0.3 & 23.1 & 13.0 & 14.6 \\
\hline $\begin{array}{r}7 / 4 / 2009 \\
22: 00\end{array}$ & $\begin{array}{r}7 / 4 / 2009 \\
23: 00\end{array}$ & 909.5 & 8056.0 & 2.6 & 1.7 & 605.3 & 1.1 & 770.9 & 761.2 & 324.2 & 322.1 & 2287.2 & 6.4 & 1.3 & 0.3 & 15.4 & 12.9 & 14.5 \\
\hline $\begin{array}{r}7 / 4 / 2009 \\
23: 00 \\
\end{array}$ & $\begin{array}{r}7 / 5 / 2009 \\
0: 00 \\
\end{array}$ & 910.0 & 8050.3 & 2.6 & 1.6 & 607.9 & 1.1 & 775.0 & 767.2 & 324.5 & 322.3 & 2286.4 & 6.1 & 1.3 & 0.3 & 20.2 & 13.1 & 14.6 \\
\hline $\begin{array}{r}7 / 5 / 2009 \\
0: 00 \\
\end{array}$ & $\begin{array}{r}7 / 5 / 2009 \\
1: 00 \\
\end{array}$ & 909.4 & 8081.2 & 2.7 & 1.7 & 612.3 & 1.1 & 776.0 & 764.1 & 324.9 & 321.8 & 2303.1 & 6.1 & 1.4 & 0.3 & 39.7 & 12.6 & 14.1 \\
\hline $\begin{array}{r}7 / 5 / 2009 \\
1: 00\end{array}$ & $\begin{array}{r}7 / 5 / 2009 \\
2: 00\end{array}$ & 907.8 & 8068.4 & 2.8 & 1.9 & 609.2 & 1.1 & 771.0 & 756.2 & 320.6 & 315.2 & 2313.8 & 6.1 & 1.4 & 0.3 & 13.2 & $\# \mathrm{~N} / \mathrm{A}$ & 13.9 \\
\hline $\begin{array}{r}7 / 5 / 2009 \\
2: 00\end{array}$ & $\begin{array}{r}7 / 5 / 2009 \\
3: 00\end{array}$ & 903.9 & 8024.5 & 2.7 & 1.9 & 611.4 & 1.1 & 774.0 & 762.6 & 317.6 & 313.2 & 2309.0 & 5.9 & 1.4 & 0.3 & 7.2 & $\# \mathrm{~N} / \mathrm{A}$ & $\# \mathrm{~N} / \mathrm{A}$ \\
\hline $\begin{array}{r}7 / 5 / 2009 \\
3: 00\end{array}$ & $\begin{array}{r}7 / 5 / 2009 \\
4: 00\end{array}$ & 903.5 & 8047.6 & 2.6 & 1.7 & 613.3 & 1.1 & 769.1 & 760.5 & 317.8 & 313.5 & 2294.2 & 5.6 & 1.3 & 0.3 & 18.4 & $\# \mathrm{~N} / \mathrm{A}$ & 14.8 \\
\hline $\begin{array}{r}7 / 5 / 2009 \\
4: 00\end{array}$ & $\begin{array}{r}7 / 5 / 2009 \\
5: 00\end{array}$ & 904.2 & 8061.2 & 2.6 & 1.6 & 610.4 & 1.1 & 767.6 & 760.5 & 316.0 & 311.9 & 2297.6 & 5.5 & 1.3 & 0.3 & 13.2 & \#N/A & $\# \mathrm{~N} / \mathrm{A}$ \\
\hline $\begin{array}{r}7 / 5 / 2009 \\
5: 00 \\
\end{array}$ & $\begin{array}{r}7 / 5 / 2009 \\
6: 00 \\
\end{array}$ & 904.9 & 8038.8 & 2.5 & 1.7 & 608.2 & 1.1 & 773.0 & 766.9 & 316.6 & 312.9 & 2291.9 & 5.6 & 1.3 & 0.3 & 8.2 & $\# \mathrm{~N} / \mathrm{A}$ & $\# \mathrm{~N} / \mathrm{A}$ \\
\hline $\begin{array}{r}7 / 5 / 2009 \\
6: 00 \\
\end{array}$ & $\begin{array}{r}7 / 5 / 2009 \\
7: 00 \\
\end{array}$ & 903.8 & 8053.4 & 2.5 & 1.8 & 604.9 & 1.1 & 769.0 & 761.4 & 317.6 & 313.3 & 2295.5 & 5.5 & 1.3 & 0.3 & 6.7 & $\# \mathrm{~N} / \mathrm{A}$ & $\# \mathrm{~N} / \mathrm{A}$ \\
\hline $7 / 5 / 2009$ & $7 / 5 / 2009$ & 903.7 & 8018.3 & 2.5 & 1.7 & 601.2 & 1.1 & 765.6 & 757.5 & 316.0 & 311.4 & 2292.2 & 5.4 & 1.3 & 0.3 & 7.3 & 13.3 & 14.9 \\
\hline
\end{tabular}




\begin{tabular}{|c|c|c|c|c|c|c|c|c|c|c|c|c|c|c|c|c|c|c|}
\hline $\begin{array}{l}\text { Start } \\
\text { Date/ } \\
\text { Time }\end{array}$ & $\begin{array}{l}\text { End } \\
\text { Date/ } \\
\text { Time }\end{array}$ & $\begin{array}{l}\text { Gross } \\
\text { Load }\end{array}$ & $\begin{array}{c}\text { Gross } \\
\text { HR }\end{array}$ & $\begin{array}{c}\text { A } \\
\text { Econ } \\
\text { O2 }\end{array}$ & $\begin{array}{c}\text { B } \\
\text { Econ } \\
\text { O2 }\end{array}$ & $\begin{array}{l}\text { Fuel } \\
\text { Flow }\end{array}$ & $\begin{array}{l}\text { BTU } \\
\text { Gain }\end{array}$ & $\begin{array}{c}\text { A } \\
\text { APH } \\
\text { In }\end{array}$ & $\begin{array}{c}\text { B } \\
\text { APH } \\
\text { In }\end{array}$ & $\begin{array}{c}\text { A } \\
\text { APH } \\
\text { Out }\end{array}$ & $\begin{array}{c}\text { B } \\
\text { APH } \\
\text { Out }\end{array}$ & $\begin{array}{l}\text { Stack } \\
\text { Flow }\end{array}$ & Opacity & SO2 In & $\begin{array}{l}\text { SO2 } \\
\text { Out }\end{array}$ & $\mathrm{CO}$ & $\begin{array}{c}\text { Stack } \\
\text { SCEM } \\
\text { Elemental } \\
\mathrm{Hg} \\
\end{array}$ & $\begin{array}{c}\text { Stack } \\
\text { SCEM } \\
\text { Total Hg }\end{array}$ \\
\hline & & MW & Btu/kWh & $\%$ & $\%$ & Ton/hr & & DEGF & DEGF & DEGF & DEGF & KSCF & $\%$ & Ib/MMB & $\mathrm{Ib} / \mathrm{MMb}$ & PPM & $\begin{array}{c}(\mu \mathrm{g} / \mathrm{dNm} 3) \\
@ 3 \% 02\end{array}$ & $\begin{array}{c}(\mu \mathrm{g} / \mathrm{dNm} 3) \\
@ 3 \% 02\end{array}$ \\
\hline $7: 00$ & $8: 00$ & & & & & & & & & & & & & & & & & \\
\hline $\begin{array}{r}7 / 5 / 2009 \\
8: 00 \\
\end{array}$ & $\begin{array}{r}7 / 5 / 2009 \\
9: 00\end{array}$ & 902.5 & 8073.2 & 2.5 & 1.7 & 599.4 & 1.1 & 760.3 & 753.7 & 315.6 & 311.3 & 2296.0 & 5.4 & 1.3 & 0.3 & 6.4 & 13.2 & 14.7 \\
\hline $\begin{array}{r}7 / 5 / 2009 \\
9: 00\end{array}$ & $\begin{array}{r}7 / 5 / 2009 \\
10: 00\end{array}$ & 903.0 & 8070.3 & 2.6 & 1.7 & 597.6 & 1.1 & 758.9 & 751.7 & 312.5 & 308.3 & 2291.4 & 5.5 & 1.3 & 0.3 & 8.7 & 13.0 & 14.5 \\
\hline $\begin{array}{r}7 / 5 / 2009 \\
10: 00 \\
\end{array}$ & $\begin{array}{r}7 / 5 / 2009 \\
11: 00 \\
\end{array}$ & 902.3 & 8077.8 & 2.5 & 1.8 & 599.5 & 1.1 & 765.1 & 756.9 & 314.8 & 310.4 & 2271.2 & 5.7 & 1.3 & 0.3 & 11.8 & 13.0 & 14.6 \\
\hline $\begin{array}{r}7 / 5 / 2009 \\
11: 00\end{array}$ & $\begin{array}{r}7 / 5 / 2009 \\
12: 00\end{array}$ & 901.5 & 8053.9 & 2.6 & 1.7 & 601.2 & 1.1 & 767.9 & 760.9 & 316.7 & 313.2 & 2252.0 & 5.7 & 1.3 & 0.3 & 15.7 & 13.0 & 14.5 \\
\hline $\begin{array}{r}7 / 5 / 2009 \\
12: 00\end{array}$ & $\begin{array}{r}7 / 5 / 2009 \\
13: 00\end{array}$ & 901.6 & 8085.2 & 2.6 & 1.7 & 604.2 & 1.1 & 766.4 & 759.5 & 319.8 & 316.9 & 2283.6 & 5.8 & 1.3 & 0.3 & 13.7 & 13.0 & 14.6 \\
\hline $\begin{array}{r}7 / 5 / 2009 \\
13: 00\end{array}$ & $\begin{array}{r}7 / 5 / 2009 \\
14: 00\end{array}$ & 903.4 & 8057.0 & 2.5 & 1.7 & 607.0 & 1.1 & 767.0 & 756.7 & 320.3 & 317.3 & 2283.6 & 6.0 & 1.3 & 0.3 & 14.0 & 13.1 & 14.6 \\
\hline $\begin{array}{r}7 / 5 / 2009 \\
14: 00\end{array}$ & $\begin{array}{r}7 / 5 / 2009 \\
15: 00\end{array}$ & 903.5 & 8079.7 & 2.5 & 1.8 & 612.3 & 1.1 & 763.6 & 753.9 & 322.0 & 318.9 & 2270.7 & 6.1 & 1.3 & 0.3 & 24.1 & 12.8 & 14.4 \\
\hline $\begin{array}{r}7 / 5 / 2009 \\
15: 00\end{array}$ & $\begin{array}{r}7 / 5 / 2009 \\
16: 00\end{array}$ & 903.1 & 8064.6 & 2.6 & 1.7 & 614.8 & 1.1 & 763.8 & 757.4 & 320.6 & 318.4 & 2272.5 & 6.0 & 1.3 & 0.3 & 28.0 & 12.9 & 14.4 \\
\hline $\begin{array}{r}7 / 5 / 2009 \\
16: 00\end{array}$ & $\begin{array}{r}7 / 5 / 2009 \\
17: 00\end{array}$ & 903.4 & 8077.4 & 2.5 & 1.7 & 615.6 & 1.1 & 770.3 & 764.5 & 323.1 & 321.4 & 2281.5 & 6.0 & 1.3 & 0.3 & 26.5 & 12.8 & 14.3 \\
\hline $\begin{array}{r}7 / 5 / 2009 \\
17: 00 \\
\end{array}$ & $\begin{array}{r}7 / 5 / 2009 \\
18: 00 \\
\end{array}$ & 905.2 & 8056.1 & 2.5 & 1.8 & 613.8 & 1.1 & 776.7 & 771.4 & 318.9 & 316.6 & 2299.3 & 5.5 & 1.3 & 0.3 & 20.3 & 13.2 & 14.7 \\
\hline $\begin{array}{r}7 / 5 / 2009 \\
18: 00\end{array}$ & $\begin{array}{r}7 / 5 / 2009 \\
19: 00\end{array}$ & 902.7 & 8052.1 & 2.6 & 1.8 & 616.2 & 1.1 & 773.9 & 769.3 & 317.1 & 314.2 & 2295.3 & 9.2 & 1.3 & 0.3 & 15.4 & 13.5 & 15.1 \\
\hline $\begin{array}{r}7 / 5 / 2009 \\
19: 00\end{array}$ & $\begin{array}{r}7 / 5 / 2009 \\
20: 00\end{array}$ & 903.8 & 8051.4 & 2.6 & 1.8 & 617.3 & 1.1 & 767.6 & 762.6 & 316.0 & 311.4 & 2306.1 & 10.4 & 1.3 & 0.3 & 19.4 & 13.6 & 15.1 \\
\hline $\begin{array}{r}7 / 5 / 2009 \\
20: 00\end{array}$ & $\begin{array}{r}7 / 5 / 2009 \\
21: 00\end{array}$ & 905.7 & 8046.1 & 2.6 & 1.9 & 614.8 & 1.1 & 773.4 & 768.0 & 316.7 & 312.4 & 2297.1 & 7.2 & 1.3 & 0.3 & 18.9 & 13.8 & 15.3 \\
\hline $\begin{array}{r}7 / 5 / 2009 \\
21: 00 \\
\end{array}$ & $\begin{array}{r}7 / 5 / 2009 \\
22: 00 \\
\end{array}$ & 904.7 & 8033.9 & 2.7 & 1.8 & 611.1 & 1.1 & 775.5 & 771.8 & 317.9 & 313.7 & 2297.5 & 5.6 & 1.3 & 0.3 & 13.6 & 13.8 & 15.3 \\
\hline $\begin{array}{r}7 / 5 / 2009 \\
22: 00\end{array}$ & $\begin{array}{r}7 / 5 / 2009 \\
23: 00\end{array}$ & 904.8 & 8051.4 & 2.7 & 1.8 & 605.0 & 1.1 & 774.5 & 771.5 & 317.3 & 312.9 & 2303.9 & 5.4 & 1.3 & 0.3 & 9.0 & 13.5 & 15.0 \\
\hline $\begin{array}{r}7 / 5 / 2009 \\
23: 00 \\
\end{array}$ & $\begin{array}{r}7 / 6 / 2009 \\
0: 00 \\
\end{array}$ & 902.2 & 8028.7 & 2.7 & 1.8 & 604.0 & 1.1 & 777.8 & 773.5 & 317.3 & 313.0 & 2298.3 & 5.4 & 1.3 & 0.3 & 7.5 & 13.3 & 14.7 \\
\hline $\begin{array}{r}7 / 6 / 2009 \\
0: 00 \\
\end{array}$ & $\begin{array}{r}7 / 6 / 2009 \\
1: 00 \\
\end{array}$ & 903.5 & 8008.5 & 2.7 & 1.8 & 605.6 & 1.1 & 781.8 & 778.3 & 319.2 & 315.0 & 2298.6 & 5.5 & 1.3 & 0.3 & 9.0 & 13.2 & 14.6 \\
\hline $\begin{array}{r}7 / 6 / 2009 \\
1: 00\end{array}$ & $\begin{array}{r}7 / 6 / 2009 \\
2: 00\end{array}$ & 905.2 & 8021.1 & 2.6 & 1.7 & 605.9 & 1.1 & 771.6 & 767.2 & 318.6 & 313.0 & 2283.4 & 5.4 & 1.4 & 0.3 & 8.3 & 13.0 & 14.4 \\
\hline $\begin{array}{r}7 / 6 / 2009 \\
2: 00\end{array}$ & $\begin{array}{r}7 / 6 / 2009 \\
3: 00\end{array}$ & 904.0 & 8036.5 & 2.7 & 1.7 & 614.2 & 1.1 & 761.0 & 756.1 & 313.1 & 307.1 & 2291.7 & 5.3 & 1.3 & 0.3 & 12.1 & 12.8 & 14.2 \\
\hline
\end{tabular}




\begin{tabular}{|c|c|c|c|c|c|c|c|c|c|c|c|c|c|c|c|c|c|c|}
\hline $\begin{array}{l}\text { Start } \\
\text { Date/ } \\
\text { Time }\end{array}$ & $\begin{array}{l}\text { End } \\
\text { Date/ } \\
\text { Time }\end{array}$ & $\begin{array}{l}\text { Gross } \\
\text { Load }\end{array}$ & $\begin{array}{c}\text { Gross } \\
\text { HR }\end{array}$ & $\begin{array}{c}\text { A } \\
\text { Econ } \\
\text { O2 }\end{array}$ & $\begin{array}{c}\text { B } \\
\text { Econ } \\
\text { O2 }\end{array}$ & $\begin{array}{l}\text { Fuel } \\
\text { Flow }\end{array}$ & $\begin{array}{l}\text { BTU } \\
\text { Gain }\end{array}$ & $\begin{array}{c}\text { A } \\
\text { APH } \\
\text { In }\end{array}$ & $\begin{array}{l}\text { B } \\
\text { APH } \\
\text { In }\end{array}$ & $\begin{array}{c}\text { A } \\
\text { APH } \\
\text { Out }\end{array}$ & $\begin{array}{c}\text { B } \\
\text { APH } \\
\text { Out }\end{array}$ & $\begin{array}{l}\text { Stack } \\
\text { Flow }\end{array}$ & Opacity & SO2 In & $\begin{array}{l}\text { SO2 } \\
\text { Out }\end{array}$ & $\mathrm{CO}$ & $\begin{array}{c}\text { Stack } \\
\text { SCEM } \\
\text { Elemental } \\
\mathrm{Hg}\end{array}$ & $\begin{array}{c}\text { Stack } \\
\text { SCEM } \\
\text { Total Hg }\end{array}$ \\
\hline & & MW & Btu/kWh & $\%$ & $\%$ & Ton/hr & & DEGF & DEGF & DEGF & DEGF & KSCF & $\%$ & Ib/MMB & Ib/MMb & PPM & $\begin{array}{c}(\mu \mathrm{g} / \mathrm{dNm} 3) \\
@ 3 \% 02\end{array}$ & $\begin{array}{c}(\mu \mathrm{g} / \mathrm{dNm} \text { ) } \\
@ 3 \% 02\end{array}$ \\
\hline $\begin{array}{r}7 / 6 / 2009 \\
3: 00\end{array}$ & $\begin{array}{r}7 / 6 / 2009 \\
4: 00\end{array}$ & 908.1 & 8025.2 & 2.6 & 1.7 & 625.8 & 1.1 & 770.0 & 761.3 & 312.5 & 307.3 & 2310.1 & 5.2 & 1.3 & 0.3 & 11.7 & 13.1 & 14.5 \\
\hline $\begin{array}{r}7 / 6 / 2009 \\
4: 00\end{array}$ & $\begin{array}{r}7 / 6 / 2009 \\
5: 00\end{array}$ & 892.0 & 8062.7 & 2.6 & 1.7 & 612.7 & 1.1 & 769.9 & 757.9 & 314.9 & 309.2 & 2301.8 & 6.1 & 1.4 & 0.3 & 11.1 & 13.9 & 15.3 \\
\hline $\begin{array}{r}7 / 6 / 2009 \\
5: 00\end{array}$ & $\begin{array}{r}7 / 6 / 2009 \\
6: 00\end{array}$ & 823.3 & 8056.6 & 2.5 & 1.9 & 567.5 & 1.1 & 741.2 & 732.6 & 311.0 & 305.2 & 2141.0 & 5.8 & 1.4 & 0.3 & 3.5 & $\# \mathrm{~N} / \mathrm{A}$ & \#N/A \\
\hline $\begin{array}{r}7 / 6 / 2009 \\
6: 00\end{array}$ & $\begin{array}{r}7 / 6 / 2009 \\
7: 00\end{array}$ & 884.1 & 8015.4 & 2.6 & 2.0 & 609.1 & 1.1 & 756.0 & 748.5 & 300.7 & 298.4 & 2281.2 & 5.5 & 1.4 & 0.3 & 20.9 & $\# \mathrm{~N} / \mathrm{A}$ & \#N/A \\
\hline $\begin{array}{r}7 / 6 / 2009 \\
7: 00\end{array}$ & $\begin{array}{r}7 / 6 / 2009 \\
8: 00\end{array}$ & 912.5 & 8017.5 & 2.6 & 1.9 & 624.4 & 1.1 & 774.6 & 765.0 & 305.0 & 303.6 & 2343.1 & 5.2 & 1.4 & 0.3 & 55.6 & 13.1 & 14.7 \\
\hline $\begin{array}{r}7 / 6 / 2009 \\
8: 00 \\
\end{array}$ & $\begin{array}{r}7 / 6 / 2009 \\
9: 00 \\
\end{array}$ & 875.7 & 8054.5 & 2.6 & 1.8 & 596.6 & 1.1 & 768.1 & 761.0 & 307.4 & 303.3 & 2254.9 & 5.1 & 1.4 & 0.3 & 53.0 & 13.0 & 14.3 \\
\hline $\begin{array}{r}7 / 6 / 2009 \\
9: 00\end{array}$ & $\begin{array}{r}7 / 6 / 2009 \\
10: 00\end{array}$ & 880.8 & 8021.8 & 2.7 & 2.0 & 599.5 & 1.1 & 765.8 & 758.9 & 306.1 & 302.2 & 2265.6 & 5.1 & 1.4 & 0.3 & 22.3 & 13.3 & 14.6 \\
\hline $\begin{array}{r}7 / 6 / 2009 \\
10: 00\end{array}$ & $\begin{array}{r}7 / 6 / 2009 \\
11: 00\end{array}$ & 896.2 & 8002.7 & 2.6 & 1.9 & 605.2 & 1.1 & 776.3 & 768.7 & 304.9 & 304.2 & 2295.9 & 5.1 & 1.4 & 0.4 & 37.5 & 13.3 & 14.8 \\
\hline $\begin{array}{r}7 / 6 / 2009 \\
11: 00\end{array}$ & $\begin{array}{r}7 / 6 / 2009 \\
12: 00\end{array}$ & 907.9 & 8006.1 & 2.6 & 2.0 & 609.1 & 1.1 & 783.2 & 774.9 & 308.9 & 308.2 & 2316.2 & 5.2 & 1.4 & 0.3 & 48.6 & 13.0 & 14.4 \\
\hline $\begin{array}{r}7 / 6 / 2009 \\
12: 00\end{array}$ & $\begin{array}{r}7 / 6 / 2009 \\
13: 00\end{array}$ & 909.2 & 8016.1 & 2.6 & 2.0 & 606.4 & 1.1 & 787.9 & 778.9 & 313.3 & 312.0 & 2324.9 & 5.1 & 1.4 & 0.3 & 53.1 & 12.6 & 14.0 \\
\hline $\begin{array}{r}7 / 6 / 2009 \\
13: 00 \\
\end{array}$ & $\begin{array}{r}7 / 6 / 2009 \\
14: 00 \\
\end{array}$ & 909.3 & 8018.6 & 2.6 & 2.0 & 609.4 & 1.1 & 785.9 & 776.7 & 315.8 & 314.5 & 2300.4 & 5.3 & 1.4 & 0.3 & 47.4 & 12.8 & 14.2 \\
\hline $\begin{array}{r}7 / 6 / 2009 \\
14: 00 \\
\end{array}$ & $\begin{array}{r}7 / 6 / 2009 \\
15: 00 \\
\end{array}$ & 907.0 & 8036.9 & 2.6 & 1.9 & 615.9 & 1.1 & 782.1 & 774.2 & 315.5 & 315.1 & 2324.3 & 5.1 & 1.4 & 0.3 & 34.2 & 13.1 & 14.4 \\
\hline $\begin{array}{r}7 / 6 / 2009 \\
15: 00 \\
\end{array}$ & $\begin{array}{r}7 / 6 / 2009 \\
16: 00 \\
\end{array}$ & 909.7 & 8034.4 & 2.7 & 2.0 & 616.3 & 1.1 & 780.7 & 772.8 & 314.4 & 313.8 & 2355.8 & 5.2 & 1.4 & 0.4 & 28.5 & 13.2 & 14.6 \\
\hline $\begin{array}{r}7 / 6 / 2009 \\
16: 00\end{array}$ & $\begin{array}{r}7 / 6 / 2009 \\
17: 00\end{array}$ & 911.2 & 8087.2 & 2.7 & 2.1 & 618.8 & 1.1 & 780.1 & 772.2 & 315.8 & 314.9 & 2351.7 & 5.2 & 1.4 & 0.4 & 30.1 & 13.5 & 14.9 \\
\hline $\begin{array}{r}7 / 6 / 2009 \\
17: 00\end{array}$ & $\begin{array}{r}7 / 6 / 2009 \\
18: 00\end{array}$ & 910.9 & 8079.1 & 2.7 & 2.0 & 614.9 & 1.1 & 774.8 & 764.6 & 314.9 & 314.3 & 2353.3 & 5.1 & 1.4 & 0.4 & 57.4 & 12.8 & 14.3 \\
\hline $\begin{array}{r}7 / 6 / 2009 \\
18: 00\end{array}$ & $\begin{array}{r}7 / 6 / 2009 \\
19: 00\end{array}$ & 910.7 & 8087.3 & 2.8 & 2.3 & 608.5 & 1.1 & 771.8 & 757.9 & 311.1 & 309.2 & 2396.9 & 5.1 & 1.4 & 0.3 & 79.3 & 11.7 & 13.1 \\
\hline $\begin{array}{r}7 / 6 / 2009 \\
19: 00\end{array}$ & $\begin{array}{r}7 / 6 / 2009 \\
20: 00\end{array}$ & 909.8 & 8071.9 & 2.9 & 2.5 & 607.5 & 1.1 & 770.5 & 755.5 & 309.1 & 305.9 & 2388.1 & 5.2 & 1.3 & 0.3 & 48.1 & 11.7 & 13.2 \\
\hline $\begin{array}{r}7 / 6 / 2009 \\
20: 00 \\
\end{array}$ & $\begin{array}{r}7 / 6 / 2009 \\
21: 00 \\
\end{array}$ & 909.0 & 8064.8 & 3.0 & 2.6 & 612.5 & 1.1 & 778.5 & 761.8 & 309.9 & 306.5 & 2394.8 & 5.2 & 1.3 & 0.3 & 54.6 & 11.6 & 13.1 \\
\hline $\begin{array}{r}7 / 6 / 2009 \\
21: 00 \\
\end{array}$ & $\begin{array}{r}7 / 6 / 2009 \\
22: 00 \\
\end{array}$ & 910.5 & 8067.3 & 3.0 & 2.6 & 607.1 & 1.1 & 786.2 & 765.7 & 312.9 & 309.3 & 2391.5 & 5.2 & 1.3 & 0.3 & 56.8 & 12.0 & 13.4 \\
\hline $7 / 6 / 2009$ & $7 / 6 / 2009$ & 908.9 & 8071.9 & 3.0 & 2.6 & 606.9 & 1.1 & 791.8 & 764.0 & 314.6 & 309.2 & 2391.1 & 5.2 & 1.3 & 0.3 & 64.3 & 11.9 & 13.2 \\
\hline
\end{tabular}




\begin{tabular}{|c|c|c|c|c|c|c|c|c|c|c|c|c|c|c|c|c|c|c|}
\hline $\begin{array}{l}\text { Start } \\
\text { Date/ } \\
\text { Time }\end{array}$ & $\begin{array}{l}\text { End } \\
\text { Date/ } \\
\text { Time }\end{array}$ & $\begin{array}{l}\text { Gross } \\
\text { Load }\end{array}$ & $\begin{array}{c}\text { Gross } \\
\text { HR }\end{array}$ & $\begin{array}{c}\text { A } \\
\text { Econ } \\
\text { O2 }\end{array}$ & $\begin{array}{c}\text { B } \\
\text { Econ } \\
\text { O2 }\end{array}$ & $\begin{array}{l}\text { Fuel } \\
\text { Flow }\end{array}$ & $\begin{array}{l}\text { BTU } \\
\text { Gain }\end{array}$ & $\begin{array}{c}\text { A } \\
\text { APH } \\
\text { In }\end{array}$ & $\begin{array}{c}\text { B } \\
\text { APH } \\
\text { In }\end{array}$ & $\begin{array}{c}\text { A } \\
\text { APH } \\
\text { Out }\end{array}$ & $\begin{array}{c}\text { B } \\
\text { APH } \\
\text { Out }\end{array}$ & $\begin{array}{l}\text { Stack } \\
\text { Flow }\end{array}$ & Opacity & SO2 In & $\begin{array}{l}\text { SO2 } \\
\text { Out }\end{array}$ & $\mathrm{CO}$ & $\begin{array}{c}\text { Stack } \\
\text { SCEM } \\
\text { Elemental } \\
\mathrm{Hg}\end{array}$ & $\begin{array}{c}\text { Stack } \\
\text { SCEM } \\
\text { Total Hg }\end{array}$ \\
\hline & & MW & Btu/kWh & $\%$ & $\%$ & Ton/hr & & DEGF & DEGF & DEGF & DEGF & KSCF & $\%$ & Ib/MMB & $\mathrm{Ib} / \mathrm{MMb}$ & PPM & $\begin{array}{c}(\mu \mathrm{g} / \mathrm{dNm} 3) \\
@ 3 \% 02\end{array}$ & $\begin{array}{c}(\mu \mathrm{g} / \mathrm{dNm} 3) \\
@ 3 \% 02\end{array}$ \\
\hline $22: 00$ & $23: 00$ & & & & & & & & & & & & & & & & & \\
\hline $\begin{array}{r}7 / 6 / 2009 \\
23: 00\end{array}$ & $\begin{array}{r}7 / 7 / 2009 \\
0: 00\end{array}$ & 909.9 & 8055.2 & 3.0 & 2.5 & 608.9 & 1.1 & 795.7 & 767.5 & 315.6 & 310.5 & 2400.3 & 5.3 & 1.3 & 0.3 & 57.7 & 11.9 & 13.3 \\
\hline $\begin{array}{r}7 / 7 / 2009 \\
0: 00\end{array}$ & $\begin{array}{r}7 / 7 / 2009 \\
1: 00\end{array}$ & 909.5 & 8072.4 & 2.9 & 2.6 & 610.2 & 1.1 & 799.4 & 772.2 & 317.1 & 311.7 & 2399.3 & 5.4 & 1.3 & 0.3 & 63.7 & 12.1 & 13.4 \\
\hline $\begin{array}{r}7 / 7 / 2009 \\
1: 00\end{array}$ & $\begin{array}{r}7 / 7 / 2009 \\
2: 00\end{array}$ & 908.6 & 8106.0 & 3.0 & 2.6 & 607.8 & 1.1 & 786.3 & 762.1 & 314.3 & 309.5 & 2413.3 & 5.2 & 1.3 & 0.3 & 46.3 & 11.8 & 13.2 \\
\hline $\begin{array}{r}7 / 7 / 2009 \\
2: 00\end{array}$ & $\begin{array}{r}7 / 7 / 2009 \\
3: 00\end{array}$ & 909.1 & 8079.8 & 3.1 & 2.5 & 609.2 & 1.1 & 782.4 & 764.5 & 309.0 & 307.3 & 2413.8 & 5.0 & 1.3 & 0.3 & 31.6 & 11.9 & 13.3 \\
\hline $\begin{array}{r}7 / 7 / 2009 \\
3: 00\end{array}$ & $\begin{array}{r}7 / 7 / 2009 \\
4: 00\end{array}$ & 907.8 & 8075.0 & 3.1 & 2.5 & 610.1 & 1.1 & 786.0 & 769.0 & 309.9 & 309.1 & 2404.1 & 5.2 & 1.3 & 0.3 & 24.5 & 12.3 & 13.7 \\
\hline $\begin{array}{r}7 / 7 / 2009 \\
4: 00\end{array}$ & $\begin{array}{r}7 / 7 / 2009 \\
5: 00\end{array}$ & 906.3 & 8063.7 & 3.1 & 2.4 & 611.5 & 1.1 & 783.8 & 767.7 & 309.4 & 308.6 & 2392.2 & 5.1 & 1.3 & 0.3 & 20.0 & \#N/A & $\# \mathrm{~N} / \mathrm{A}$ \\
\hline $\begin{array}{r}7 / 7 / 2009 \\
5: 00\end{array}$ & $\begin{array}{r}7 / 7 / 2009 \\
6: 00\end{array}$ & 907.5 & 8027.3 & 3.1 & 2.4 & 609.0 & 1.1 & 787.0 & 770.5 & 309.1 & 307.3 & 2388.7 & 4.8 & 1.3 & 0.4 & 21.0 & $\# \mathrm{~N} / \mathrm{A}$ & $\# \mathrm{~N} / \mathrm{A}$ \\
\hline $\begin{array}{r}7 / 7 / 2009 \\
6: 00\end{array}$ & $\begin{array}{r}7 / 7 / 2009 \\
7: 00\end{array}$ & 905.8 & 8036.1 & 3.2 & 2.4 & 609.6 & 1.1 & 790.1 & 773.8 & 309.6 & 308.1 & 2391.6 & 4.7 & 1.3 & 0.4 & 27.7 & $\# \mathrm{~N} / \mathrm{A}$ & $\# \mathrm{~N} / \mathrm{A}$ \\
\hline $\begin{array}{r}7 / 7 / 2009 \\
7: 00\end{array}$ & $\begin{array}{r}7 / 7 / 2009 \\
8: 00\end{array}$ & 906.1 & 8031.3 & 3.2 & 2.4 & 610.0 & 1.1 & 793.0 & 776.6 & 310.7 & 309.5 & 2393.5 & 4.7 & 1.3 & 0.4 & 23.8 & 12.8 & 14.9 \\
\hline $\begin{array}{r}7 / 7 / 2009 \\
8: 00 \\
\end{array}$ & $\begin{array}{r}7 / 7 / 2009 \\
9: 00 \\
\end{array}$ & 905.7 & 8029.7 & 3.1 & 2.4 & 615.3 & 1.1 & 796.2 & 779.5 & 313.5 & 312.2 & 2396.3 & 4.8 & 1.3 & 0.4 & 26.5 & 12.7 & 14.7 \\
\hline $\begin{array}{r}7 / 7 / 2009 \\
9: 00\end{array}$ & $\begin{array}{r}7 / 7 / 2009 \\
10: 00\end{array}$ & 906.4 & 8063.0 & 3.2 & 2.4 & 611.4 & 1.1 & 794.9 & 779.4 & 316.9 & 315.3 & 2377.1 & 5.1 & 1.3 & 0.4 & 26.6 & 12.4 & 14.3 \\
\hline $\begin{array}{r}7 / 7 / 2009 \\
10: 00\end{array}$ & $\begin{array}{r}7 / 7 / 2009 \\
11: 00\end{array}$ & 905.1 & 8113.2 & 3.2 & 2.4 & 608.1 & 1.1 & 778.5 & 762.8 & 313.8 & 312.8 & 2367.5 & 5.1 & 1.3 & 0.4 & 24.1 & 11.7 & 13.5 \\
\hline $\begin{array}{r}7 / 7 / 2009 \\
11: 00\end{array}$ & $\begin{array}{r}7 / 7 / 2009 \\
12: 00\end{array}$ & 896.7 & 8068.2 & 3.2 & 2.4 & 604.4 & 1.1 & 772.9 & 757.8 & 310.8 & 309.8 & 2356.0 & 4.9 & 1.3 & 0.4 & 20.9 & 11.3 & 13.1 \\
\hline $\begin{array}{r}7 / 7 / 2009 \\
12: 00 \\
\end{array}$ & $\begin{array}{r}7 / 7 / 2009 \\
13: 00 \\
\end{array}$ & 903.9 & 8041.7 & 3.2 & 2.4 & 612.7 & 1.1 & 773.9 & 760.0 & 310.9 & 310.8 & 2369.8 & 5.1 & 1.3 & 0.4 & 21.1 & 11.1 & 12.9 \\
\hline $\begin{array}{r}7 / 7 / 2009 \\
13: 00\end{array}$ & $\begin{array}{r}7 / 7 / 2009 \\
14: 00\end{array}$ & 906.5 & 8016.7 & 3.2 & 2.3 & 612.6 & 1.1 & 780.7 & 766.3 & 312.7 & 312.9 & 2366.0 & 5.3 & 1.3 & 0.4 & 26.1 & 11.3 & 13.2 \\
\hline $\begin{array}{r}7 / 7 / 2009 \\
14: 00 \\
\end{array}$ & $\begin{array}{r}7 / 7 / 2009 \\
15: 00 \\
\end{array}$ & 905.3 & 8047.1 & 3.2 & 2.4 & 613.9 & 1.1 & 783.6 & 768.7 & 315.5 & 315.4 & 2352.1 & 5.4 & 1.3 & 0.4 & 26.6 & 11.6 & 13.5 \\
\hline $\begin{array}{r}7 / 7 / 2009 \\
15: 00 \\
\end{array}$ & $\begin{array}{r}7 / 7 / 2009 \\
16: 00 \\
\end{array}$ & 904.0 & 8026.4 & 3.2 & 2.3 & 620.8 & 1.1 & 787.5 & 772.4 & 317.9 & 317.8 & 2363.4 & 5.5 & 1.3 & 0.4 & 28.5 & 12.1 & 14.0 \\
\hline $\begin{array}{r}7 / 7 / 2009 \\
16: 00\end{array}$ & $\begin{array}{r}7 / 7 / 2009 \\
17: 00\end{array}$ & 903.8 & 8069.3 & 3.2 & 2.4 & 627.6 & 1.1 & 790.0 & 773.9 & 319.4 & 319.2 & 2375.8 & 5.5 & 1.3 & 0.4 & 33.9 & 12.4 & 14.5 \\
\hline $\begin{array}{r}7 / 7 / 2009 \\
17: 00\end{array}$ & $\begin{array}{r}7 / 7 / 2009 \\
18: 00\end{array}$ & 904.3 & 8069.2 & 3.2 & 2.4 & 632.9 & 1.1 & 790.7 & 775.1 & 320.5 & 320.1 & 2379.7 & 5.6 & 1.4 & 0.4 & 30.5 & 13.0 & 15.2 \\
\hline
\end{tabular}




\begin{tabular}{|c|c|c|c|c|c|c|c|c|c|c|c|c|c|c|c|c|c|c|}
\hline $\begin{array}{l}\text { Start } \\
\text { Date/ } \\
\text { Time }\end{array}$ & $\begin{array}{l}\text { End } \\
\text { Date/ } \\
\text { Time }\end{array}$ & $\begin{array}{l}\text { Gross } \\
\text { Load }\end{array}$ & $\begin{array}{c}\text { Gross } \\
\text { HR }\end{array}$ & $\begin{array}{c}\text { A } \\
\text { Econ } \\
\text { O2 }\end{array}$ & $\begin{array}{c}\text { B } \\
\text { Econ } \\
\text { O2 }\end{array}$ & $\begin{array}{l}\text { Fuel } \\
\text { Flow }\end{array}$ & $\begin{array}{l}\text { BTU } \\
\text { Gain }\end{array}$ & $\begin{array}{l}\text { A } \\
\text { APH } \\
\text { In }\end{array}$ & $\begin{array}{c}\text { B } \\
\text { APH } \\
\text { In }\end{array}$ & $\begin{array}{c}\text { A } \\
\text { APH } \\
\text { Out }\end{array}$ & $\begin{array}{c}\text { B } \\
\text { APH } \\
\text { Out }\end{array}$ & $\begin{array}{l}\text { Stack } \\
\text { Flow }\end{array}$ & Opacity & SO2 In & $\begin{array}{l}\text { SO2 } \\
\text { Out }\end{array}$ & $\mathrm{CO}$ & $\begin{array}{c}\text { Stack } \\
\text { SCEM } \\
\text { Elemental } \\
\mathrm{Hg}\end{array}$ & $\begin{array}{c}\text { Stack } \\
\text { SCEM } \\
\text { Total Hg }\end{array}$ \\
\hline & & MW & Btu/kWh & $\%$ & $\%$ & Ton/hr & & DEGF & DEGF & DEGF & DEGF & KSCF & $\%$ & $\mathrm{Ib} / \mathrm{MMB}$ & $\mathrm{Ib} / \mathrm{MMb}$ & PPM & $\begin{array}{c}(\mu \mathrm{g} / \mathrm{dNm} 3) \\
@ 3 \% 02\end{array}$ & $\begin{array}{c}(\mu \mathrm{g} / \mathrm{dNm} 3) \\
@ 3 \% 02\end{array}$ \\
\hline $\begin{array}{r}7 / 7 / 2009 \\
18: 00\end{array}$ & $\begin{array}{r}7 / 7 / 2009 \\
19: 00\end{array}$ & 906.6 & 8041.1 & 3.2 & 2.4 & 636.6 & 1.1 & 789.5 & 775.1 & 320.6 & 320.7 & 2382.2 & 5.6 & 1.4 & 0.4 & 37.5 & 13.3 & 15.5 \\
\hline $\begin{array}{r}7 / 7 / 2009 \\
19: 00\end{array}$ & $\begin{array}{r}7 / 7 / 2009 \\
20: 00\end{array}$ & 907.0 & 8068.0 & 3.2 & 2.4 & 634.3 & 1.1 & 788.4 & 775.5 & 319.9 & 319.6 & 2391.2 & 5.5 & 1.4 & 0.4 & 47.2 & 12.8 & 15.1 \\
\hline $\begin{array}{r}7 / 7 / 2009 \\
20: 00\end{array}$ & $\begin{array}{r}7 / 7 / 2009 \\
21: 00\end{array}$ & 897.3 & 8076.9 & 3.2 & 2.4 & 627.2 & 1.1 & 786.4 & 774.0 & 318.8 & 318.7 & 2384.6 & 5.2 & 1.4 & 0.4 & 38.5 & 12.6 & 14.8 \\
\hline $\begin{array}{r}7 / 7 / 2009 \\
21: 00\end{array}$ & $\begin{array}{r}7 / 7 / 2009 \\
22: 00\end{array}$ & 898.9 & 8065.5 & 3.2 & 2.5 & 625.4 & 1.1 & 779.6 & 769.1 & 315.5 & 316.5 & 2392.7 & 5.2 & 1.4 & 0.4 & 30.3 & 12.5 & 14.6 \\
\hline $\begin{array}{r}7 / 7 / 2009 \\
22: 00\end{array}$ & $\begin{array}{r}7 / 7 / 2009 \\
23: 00\end{array}$ & 901.3 & 8052.4 & 3.2 & 2.4 & 623.0 & 1.1 & 782.5 & 771.7 & 313.7 & 315.1 & 2397.0 & 5.4 & 1.4 & 0.4 & 30.6 & 12.3 & 14.3 \\
\hline $\begin{array}{r}7 / 7 / 2009 \\
23: 00\end{array}$ & $\begin{array}{r}7 / 8 / 2009 \\
0: 00\end{array}$ & 901.9 & 8075.6 & 3.2 & 2.4 & 618.5 & 1.1 & 786.5 & 776.2 & 313.7 & 315.1 & 2382.1 & 5.3 & 1.4 & 0.4 & 36.2 & 12.0 & 13.9 \\
\hline $\begin{array}{r}7 / 8 / 2009 \\
0: 00\end{array}$ & $\begin{array}{r}7 / 8 / 2009 \\
1: 00\end{array}$ & 895.3 & 8087.1 & 3.3 & 2.3 & 611.9 & 1.1 & 787.9 & 778.3 & 314.2 & 315.2 & 2379.2 & 5.2 & 1.3 & 0.4 & 35.9 & 11.5 & 13.3 \\
\hline $\begin{array}{r}7 / 8 / 2009 \\
1: 00\end{array}$ & $\begin{array}{r}7 / 8 / 2009 \\
2: 00\end{array}$ & 897.4 & 8093.8 & 3.3 & 2.3 & 606.3 & 1.1 & 782.2 & 779.6 & 314.0 & 315.8 & 2393.4 & 5.2 & 1.3 & 0.4 & 37.9 & 11.0 & 12.9 \\
\hline $\begin{array}{r}7 / 8 / 2009 \\
2: 00\end{array}$ & $\begin{array}{r}7 / 8 / 2009 \\
3: 00\end{array}$ & 853.1 & 8070.5 & 3.3 & 2.2 & 572.2 & 1.1 & 774.1 & 771.0 & 311.7 & 313.0 & 2272.7 & 4.7 & 1.3 & 0.4 & 26.1 & 10.7 & 12.5 \\
\hline $\begin{array}{r}7 / 8 / 2009 \\
3: 00 \\
\end{array}$ & $\begin{array}{r}7 / 8 / 2009 \\
4: 00 \\
\end{array}$ & 776.3 & 8082.1 & 3.3 & 2.3 & 522.8 & 1.1 & 751.4 & 740.4 & 311.9 & 307.2 & 2073.7 & 4.2 & 1.3 & 0.3 & 7.1 & 10.4 & 12.2 \\
\hline $\begin{array}{r}7 / 8 / 2009 \\
4: 00\end{array}$ & $\begin{array}{r}7 / 8 / 2009 \\
5: 00\end{array}$ & 770.2 & 8079.5 & 3.3 & 2.4 & 522.3 & 1.1 & 737.6 & 722.8 & 301.4 & 295.5 & 2059.6 & 4.2 & 1.3 & 0.3 & 14.0 & 9.9 & 11.8 \\
\hline $\begin{array}{r}7 / 8 / 2009 \\
5: 00\end{array}$ & $\begin{array}{r}7 / 8 / 2009 \\
6: 00\end{array}$ & 780.7 & 8045.3 & 3.3 & 2.4 & 535.6 & 1.1 & 730.4 & 719.7 & 294.8 & 290.4 & 2088.1 & 4.3 & 1.3 & 0.3 & 19.0 & $\# \mathrm{~N} / \mathrm{A}$ & $\# \mathrm{~N} / \mathrm{A}$ \\
\hline $\begin{array}{r}7 / 8 / 2009 \\
6: 00\end{array}$ & $\begin{array}{r}7 / 8 / 2009 \\
7: 00\end{array}$ & 854.8 & 8022.7 & 3.3 & 2.5 & 588.9 & 1.1 & 755.0 & 745.0 & 300.5 & 297.0 & 2271.0 & 4.8 & 1.3 & 0.4 & 61.0 & $\# \mathrm{~N} / \mathrm{A}$ & \#N/A \\
\hline $\begin{array}{r}7 / 8 / 2009 \\
7: 00\end{array}$ & $\begin{array}{r}7 / 8 / 2009 \\
8: 00\end{array}$ & 905.3 & 8056.0 & 3.2 & 2.5 & 625.4 & 1.1 & 774.4 & 763.1 & 308.3 & 302.6 & 2401.3 & 5.2 & 1.3 & 0.4 & 77.8 & 10.2 & 12.1 \\
\hline $\begin{array}{r}7 / 8 / 2009 \\
8: 00\end{array}$ & $\begin{array}{r}7 / 8 / 2009 \\
9: 00\end{array}$ & 905.3 & 8084.9 & 3.4 & 2.6 & 632.1 & 1.1 & 776.9 & 762.3 & 310.9 & 304.9 & 2419.4 & 5.3 & 1.3 & 0.4 & 51.2 & 11.0 & 12.8 \\
\hline $\begin{array}{r}7 / 8 / 2009 \\
9: 00 \\
\end{array}$ & $\begin{array}{r}7 / 8 / 2009 \\
10: 00 \\
\end{array}$ & 902.6 & 8105.0 & 3.4 & 2.6 & 626.7 & 1.1 & 777.1 & 761.6 & 313.2 & 306.7 & 2400.4 & 5.4 & 1.4 & 0.4 & 42.3 & 11.7 & 13.6 \\
\hline $\begin{array}{r}7 / 8 / 2009 \\
10: 00 \\
\end{array}$ & $\begin{array}{r}7 / 8 / 2009 \\
11: 00 \\
\end{array}$ & 901.3 & 8079.9 & 3.4 & 2.6 & 622.4 & 1.1 & 775.4 & 761.4 & 314.5 & 308.7 & 2385.9 & 5.3 & 1.4 & 0.4 & 67.0 & 11.8 & 13.8 \\
\hline $\begin{array}{r}7 / 8 / 2009 \\
11: 00\end{array}$ & $\begin{array}{r}7 / 8 / 2009 \\
12: 00\end{array}$ & 900.7 & 8080.6 & 3.3 & 2.7 & 621.4 & 1.1 & 774.2 & 763.9 & 315.8 & 311.8 & 2388.1 & 5.6 & 1.4 & 0.4 & 57.4 & 9.4 & 11.2 \\
\hline $\begin{array}{r}7 / 8 / 2009 \\
12: 00\end{array}$ & $\begin{array}{r}7 / 8 / 2009 \\
13: 00\end{array}$ & 899.6 & 8100.0 & 3.3 & 2.7 & 618.2 & 1.1 & 778.7 & 766.6 & 317.7 & 314.0 & 2392.1 & 5.8 & 1.4 & 0.4 & 43.3 & 8.5 & 9.9 \\
\hline $7 / 8 / 2009$ & $7 / 8 / 2009$ & 899.8 & 8086.4 & 3.3 & 2.7 & 614.3 & 1.1 & 780.1 & 768.9 & 319.7 & 315.7 & 2390.7 & 5.9 & 1.4 & 0.4 & 40.1 & 8.2 & 9.6 \\
\hline
\end{tabular}




\begin{tabular}{|c|c|c|c|c|c|c|c|c|c|c|c|c|c|c|c|c|c|c|}
\hline $\begin{array}{l}\text { Start } \\
\text { Date/ } \\
\text { Time }\end{array}$ & $\begin{array}{l}\text { End } \\
\text { Date/ } \\
\text { Time }\end{array}$ & $\begin{array}{l}\text { Gross } \\
\text { Load }\end{array}$ & $\begin{array}{c}\text { Gross } \\
\text { HR }\end{array}$ & $\begin{array}{c}\text { A } \\
\text { Econ } \\
\text { O2 }\end{array}$ & $\begin{array}{c}\text { B } \\
\text { Econ } \\
\text { O2 }\end{array}$ & $\begin{array}{l}\text { Fuel } \\
\text { Flow }\end{array}$ & $\begin{array}{l}\text { BTU } \\
\text { Gain }\end{array}$ & $\begin{array}{c}\text { A } \\
\text { APH } \\
\text { In }\end{array}$ & $\begin{array}{c}\text { B } \\
\text { APH } \\
\text { In }\end{array}$ & $\begin{array}{c}\text { A } \\
\text { APH } \\
\text { Out }\end{array}$ & $\begin{array}{c}\text { B } \\
\text { APH } \\
\text { Out }\end{array}$ & $\begin{array}{l}\text { Stack } \\
\text { Flow }\end{array}$ & Opacity & SO2 In & $\begin{array}{l}\text { SO2 } \\
\text { Out }\end{array}$ & $\mathrm{CO}$ & $\begin{array}{c}\text { Stack } \\
\text { SCEM } \\
\text { Elemental } \\
\mathrm{Hg}\end{array}$ & $\begin{array}{c}\text { Stack } \\
\text { SCEM } \\
\text { Total Hg }\end{array}$ \\
\hline & & MW & Btu/kWh & $\%$ & $\%$ & Ton/hr & & DEGF & DEGF & DEGF & DEGF & KSCF & $\%$ & Ib/MMB & $\mathrm{Ib} / \mathrm{MMb}$ & PPM & $\begin{array}{c}(\mu \mathrm{g} / \mathrm{dNm} 3) \\
@ 3 \% 02\end{array}$ & $\begin{array}{c}(\mu \mathrm{g} / \mathrm{dNm} 3) \\
@ 3 \% 02\end{array}$ \\
\hline $13: 00$ & $14: 00$ & & & & & & & & & & & & & & & & & \\
\hline $\begin{array}{r}7 / 8 / 2009 \\
14: 00\end{array}$ & $\begin{array}{r}7 / 8 / 2009 \\
15: 00\end{array}$ & 900.0 & 8097.4 & 3.3 & 2.7 & 611.5 & 1.1 & 782.8 & 771.5 & 321.5 & 317.2 & 2379.4 & 5.9 & 1.3 & 0.4 & 37.1 & 7.5 & 8.9 \\
\hline $\begin{array}{r}7 / 8 / 2009 \\
15: 00\end{array}$ & $\begin{array}{r}7 / 8 / 2009 \\
16: 00\end{array}$ & 899.5 & 8105.7 & 3.2 & 2.6 & 607.4 & 1.1 & 785.3 & 773.2 & 324.2 & 319.4 & 2371.0 & 5.9 & 1.3 & 0.3 & 39.5 & 5.9 & 7.0 \\
\hline $\begin{array}{r}7 / 8 / 2009 \\
16: 00 \\
\end{array}$ & $\begin{array}{r}7 / 8 / 2009 \\
17: 00 \\
\end{array}$ & 896.7 & 8101.8 & 3.2 & 2.7 & 605.4 & 1.1 & 787.4 & 772.3 & 326.8 & 320.6 & 2365.8 & 5.7 & 1.2 & 0.3 & 33.4 & 4.3 & 5.1 \\
\hline $\begin{array}{r}7 / 8 / 2009 \\
17: 00 \\
\end{array}$ & $\begin{array}{r}7 / 8 / 2009 \\
18: 00 \\
\end{array}$ & 898.0 & 8076.9 & 3.2 & 2.7 & 610.7 & 1.1 & 789.3 & 775.3 & 327.7 & 321.8 & 2393.5 & 5.7 & 1.2 & 0.3 & 35.2 & 4.6 & 5.3 \\
\hline $\begin{array}{r}7 / 8 / 2009 \\
18: 00\end{array}$ & $\begin{array}{r}7 / 8 / 2009 \\
19: 00\end{array}$ & 908.9 & 8078.0 & 3.2 & 2.7 & 620.4 & 1.1 & 794.7 & 781.0 & 328.5 & 323.3 & 2427.2 & 5.7 & 1.2 & 0.3 & 38.1 & 6.3 & 7.4 \\
\hline $\begin{array}{r}7 / 8 / 2009 \\
19: 00\end{array}$ & $\begin{array}{r}7 / 8 / 2009 \\
20: 00\end{array}$ & 900.7 & 8113.1 & 3.2 & 2.6 & 611.3 & 1.1 & 794.1 & 780.4 & 327.9 & 322.2 & 2395.8 & 5.5 & 1.2 & 0.3 & 34.4 & 7.2 & 8.9 \\
\hline $\begin{array}{r}7 / 8 / 2009 \\
20: 00\end{array}$ & $\begin{array}{r}7 / 8 / 2009 \\
21: 00\end{array}$ & 901.2 & 8101.9 & 3.3 & 2.7 & 610.4 & 1.1 & 789.8 & 777.7 & 323.4 & 317.9 & 2409.7 & 5.6 & 1.2 & 0.3 & 28.8 & 7.7 & 9.5 \\
\hline $\begin{array}{r}7 / 8 / 2009 \\
21: 00\end{array}$ & $\begin{array}{r}7 / 8 / 2009 \\
22: 00\end{array}$ & 901.6 & 8091.2 & 3.3 & 2.7 & 608.1 & 1.1 & 786.5 & 775.4 & 319.9 & 314.5 & 2387.0 & 5.7 & 1.3 & 0.3 & 37.1 & 8.3 & 10.0 \\
\hline $\begin{array}{r}7 / 8 / 2009 \\
22: 00\end{array}$ & $\begin{array}{r}7 / 8 / 2009 \\
23: 00\end{array}$ & 901.3 & 8058.9 & 3.3 & 2.7 & 605.6 & 1.1 & 781.4 & 775.1 & 316.8 & 313.0 & 2381.9 & 5.7 & 1.3 & 0.3 & 34.4 & 8.8 & 10.5 \\
\hline $\begin{array}{r}7 / 8 / 2009 \\
23: 00\end{array}$ & $\begin{array}{r}7 / 9 / 2009 \\
0: 00\end{array}$ & 901.1 & 8078.9 & 3.3 & 2.7 & 607.5 & 1.1 & 778.1 & 771.0 & 314.4 & 310.6 & 2385.5 & 5.6 & 1.3 & 0.3 & 33.0 & 9.2 & 11.0 \\
\hline $\begin{array}{r}7 / 9 / 2009 \\
0: 00\end{array}$ & $\begin{array}{r}7 / 9 / 2009 \\
1: 00\end{array}$ & 899.9 & 8085.0 & 3.3 & 2.7 & 605.6 & 1.1 & 779.4 & 768.0 & 313.4 & 308.4 & 2393.4 & 5.3 & 1.3 & 0.3 & 29.8 & 9.7 & 11.5 \\
\hline $\begin{array}{r}7 / 9 / 2009 \\
1: 00\end{array}$ & $\begin{array}{r}7 / 9 / 2009 \\
2: 00\end{array}$ & 893.2 & 8107.5 & 3.2 & 2.7 & 594.5 & 1.1 & 774.7 & 761.8 & 312.2 & 305.6 & 2376.7 & 5.2 & 1.3 & 0.4 & 26.6 & 9.9 & 11.8 \\
\hline $\begin{array}{r}7 / 9 / 2009 \\
2: 00\end{array}$ & $\begin{array}{r}7 / 9 / 2009 \\
3: 00\end{array}$ & 803.6 & 8107.0 & 3.4 & 2.5 & 532.9 & 1.1 & 746.2 & 737.4 & 306.3 & 299.1 & 2179.5 & 4.5 & 1.3 & 0.3 & 6.6 & 9.7 & 11.7 \\
\hline $\begin{array}{r}7 / 9 / 2009 \\
3: 00 \\
\end{array}$ & $\begin{array}{r}7 / 9 / 2009 \\
4: 00 \\
\end{array}$ & 798.2 & 8072.2 & 3.5 & 2.5 & 536.9 & 1.1 & 739.8 & 730.7 & 298.4 & 292.6 & 2179.6 & 4.5 & 1.4 & 0.4 & 2.9 & 9.9 & 11.9 \\
\hline $\begin{array}{r}7 / 9 / 2009 \\
4: 00\end{array}$ & $\begin{array}{r}7 / 9 / 2009 \\
5: 00\end{array}$ & 797.3 & 8073.8 & 3.5 & 2.5 & 539.3 & 1.1 & 740.8 & 733.7 & 298.5 & 292.7 & 2156.5 & 4.3 & 1.4 & 0.4 & 3.0 & $\# \mathrm{~N} / \mathrm{A}$ & $\# N / A$ \\
\hline $\begin{array}{r}7 / 9 / 2009 \\
5: 00 \\
\end{array}$ & $\begin{array}{r}7 / 9 / 2009 \\
6: 00 \\
\end{array}$ & 802.9 & 8043.7 & 3.6 & 2.5 & 547.2 & 1.1 & 739.5 & 732.7 & 297.1 & 290.8 & 2168.3 & 4.4 & 1.4 & 0.4 & 3.5 & $\# \mathrm{~N} / \mathrm{A}$ & $\# \mathrm{~N} / \mathrm{A}$ \\
\hline $\begin{array}{r}7 / 9 / 2009 \\
6: 00 \\
\end{array}$ & $\begin{array}{r}7 / 9 / 2009 \\
7: 00 \\
\end{array}$ & 848.6 & 8044.4 & 3.4 & 2.7 & 576.5 & 1.1 & 754.3 & 745.9 & 299.2 & 293.6 & 2264.9 & 4.8 & 1.4 & 0.4 & 11.6 & $\# \mathrm{~N} / \mathrm{A}$ & $\# \mathrm{~N} / \mathrm{A}$ \\
\hline $\begin{array}{r}7 / 9 / 2009 \\
7: 00\end{array}$ & $\begin{array}{r}7 / 9 / 2009 \\
8: 00\end{array}$ & 871.2 & 8062.5 & 5.6 & 4.7 & 594.1 & 1.1 & 766.0 & 755.6 & 302.5 & 297.2 & 2339.0 & 5.1 & 1.5 & 0.4 & 17.1 & 12.3 & 14.4 \\
\hline $\begin{array}{r}7 / 9 / 2009 \\
8: 00\end{array}$ & $\begin{array}{r}7 / 9 / 2009 \\
9: 00\end{array}$ & 898.0 & 8108.8 & 3.3 & 2.8 & 613.3 & 1.1 & 775.9 & 762.1 & 306.5 & 300.3 & 2410.7 & 5.4 & 1.5 & 0.4 & 23.2 & 12.4 & 14.5 \\
\hline
\end{tabular}




\begin{tabular}{|c|c|c|c|c|c|c|c|c|c|c|c|c|c|c|c|c|c|c|}
\hline $\begin{array}{l}\text { Start } \\
\text { Date/ } \\
\text { Time }\end{array}$ & $\begin{array}{l}\text { End } \\
\text { Date/ } \\
\text { Time }\end{array}$ & $\begin{array}{l}\text { Gross } \\
\text { Load }\end{array}$ & $\begin{array}{c}\text { Gross } \\
\text { HR }\end{array}$ & $\begin{array}{c}\text { A } \\
\text { Econ } \\
\text { O2 }\end{array}$ & $\begin{array}{c}\text { B } \\
\text { Econ } \\
\text { O2 }\end{array}$ & $\begin{array}{l}\text { Fuel } \\
\text { Flow }\end{array}$ & $\begin{array}{l}\text { BTU } \\
\text { Gain }\end{array}$ & $\begin{array}{l}\text { A } \\
\text { APH } \\
\text { In }\end{array}$ & $\begin{array}{c}\text { B } \\
\text { APH } \\
\text { In }\end{array}$ & $\begin{array}{c}\text { A } \\
\text { APH } \\
\text { Out }\end{array}$ & $\begin{array}{c}\text { B } \\
\text { APH } \\
\text { Out }\end{array}$ & $\begin{array}{l}\text { Stack } \\
\text { Flow }\end{array}$ & Opacity & SO2 In & $\begin{array}{l}\text { SO2 } \\
\text { Out }\end{array}$ & $\mathrm{CO}$ & $\begin{array}{c}\text { Stack } \\
\text { SCEM } \\
\text { Elemental } \\
\mathrm{Hg}\end{array}$ & $\begin{array}{c}\text { Stack } \\
\text { SCEM } \\
\text { Total Hg }\end{array}$ \\
\hline & & MW & Btu/kWh & $\%$ & $\%$ & Ton/hr & & DEGF & DEGF & DEGF & DEGF & KSCF & $\%$ & $\mathrm{Ib} / \mathrm{MMB}$ & $\mathrm{Ib} / \mathrm{MMb}$ & PPM & $\begin{array}{c}(\mu \mathrm{g} / \mathrm{dNm} 3) \\
@ 3 \% 02\end{array}$ & $\begin{array}{c}(\mu \mathrm{g} / \mathrm{dNm} 3) \\
@ 3 \% 02\end{array}$ \\
\hline $\begin{array}{r}7 / 9 / 2009 \\
9: 00\end{array}$ & $\begin{array}{r}7 / 9 / 2009 \\
10: 00\end{array}$ & 892.6 & 8133.2 & 3.2 & 2.7 & 610.4 & 1.1 & 777.3 & 760.7 & 309.5 & 302.1 & 2381.0 & 5.4 & 1.5 & 0.4 & 19.8 & 12.4 & 14.4 \\
\hline $\begin{array}{r}7 / 9 / 2009 \\
10: 00\end{array}$ & $\begin{array}{r}7 / 9 / 2009 \\
11: 00\end{array}$ & 886.7 & 8111.4 & 3.1 & 2.4 & 604.4 & 1.1 & 776.0 & 761.2 & 311.6 & 305.4 & 2322.8 & 5.4 & 1.5 & 0.4 & 25.1 & 12.5 & 14.6 \\
\hline $\begin{array}{r}7 / 9 / 2009 \\
11: 00\end{array}$ & $\begin{array}{r}7 / 9 / 2009 \\
12: 00\end{array}$ & 887.2 & 8102.1 & 3.1 & 2.3 & 600.7 & 1.1 & 777.3 & 763.6 & 315.3 & 308.9 & 2297.7 & 5.6 & 1.4 & 0.4 & 35.1 & 5.8 & 7.5 \\
\hline $\begin{array}{r}7 / 9 / 2009 \\
12: 00\end{array}$ & $\begin{array}{r}7 / 9 / 2009 \\
13: 00\end{array}$ & 888.0 & 8106.9 & 3.1 & 2.3 & 594.6 & 1.1 & 773.5 & 763.7 & 317.5 & 312.2 & 2304.4 & 6.0 & 1.4 & 0.4 & 36.0 & 2.9 & 4.5 \\
\hline $\begin{array}{r}7 / 9 / 2009 \\
13: 00\end{array}$ & $\begin{array}{r}7 / 9 / 2009 \\
14: 00\end{array}$ & 886.7 & 8085.2 & 3.1 & 2.3 & 588.8 & 1.1 & 767.9 & 757.6 & 317.1 & 312.1 & 2303.5 & 5.9 & 1.3 & 0.4 & 31.0 & 2.9 & 4.6 \\
\hline $\begin{array}{r}7 / 9 / 2009 \\
14: 00\end{array}$ & $\begin{array}{r}7 / 9 / 2009 \\
15: 00\end{array}$ & 885.1 & 8074.1 & 3.1 & 2.2 & 587.6 & 1.1 & 759.8 & 750.0 & 315.5 & 310.7 & 2297.4 & 5.8 & 1.3 & 0.3 & 37.4 & 2.3 & 4.0 \\
\hline $\begin{array}{r}7 / 9 / 2009 \\
15: 00\end{array}$ & $\begin{array}{r}7 / 9 / 2009 \\
16: 00\end{array}$ & 894.0 & 8073.0 & 3.1 & 2.2 & 595.5 & 1.1 & 762.3 & 753.6 & 316.9 & 312.4 & 2313.0 & 6.0 & 1.3 & 0.3 & 40.1 & 2.2 & 3.9 \\
\hline $\begin{array}{r}7 / 9 / 2009 \\
16: 00\end{array}$ & $\begin{array}{r}7 / 9 / 2009 \\
17: 00\end{array}$ & 899.8 & 8059.6 & 3.1 & 2.2 & 598.8 & 1.1 & 767.7 & 760.2 & 318.7 & 314.4 & 2335.5 & 6.1 & 1.2 & 0.3 & 46.3 & 2.5 & 4.3 \\
\hline $\begin{array}{r}7 / 9 / 2009 \\
17: 00\end{array}$ & $\begin{array}{r}7 / 9 / 2009 \\
18: 00\end{array}$ & 907.7 & 8064.3 & 3.1 & 2.3 & 605.1 & 1.1 & 777.7 & 768.8 & 322.3 & 317.3 & 2349.2 & 6.6 & 1.3 & 0.3 & 42.7 & 2.6 & 4.4 \\
\hline $\begin{array}{r}7 / 9 / 2009 \\
18: 00 \\
\end{array}$ & $\begin{array}{r}7 / 9 / 2009 \\
19: 00 \\
\end{array}$ & 909.7 & 8067.8 & 3.1 & 2.3 & 600.6 & 1.1 & 780.8 & 772.9 & 323.4 & 318.9 & 2345.8 & 6.6 & 1.2 & 0.3 & 48.2 & 2.9 & 4.8 \\
\hline $\begin{array}{r}7 / 9 / 2009 \\
19: 00\end{array}$ & $\begin{array}{r}7 / 9 / 2009 \\
20: 00\end{array}$ & 903.6 & 8077.2 & 3.1 & 2.3 & 597.0 & 1.1 & 779.0 & 773.2 & 322.8 & 318.8 & 2348.7 & 6.4 & 1.2 & 0.3 & 40.9 & 3.4 & 5.5 \\
\hline $\begin{array}{r}7 / 9 / 2009 \\
20: 00\end{array}$ & $\begin{array}{r}7 / 9 / 2009 \\
21: 00\end{array}$ & 905.1 & 8052.5 & 3.1 & 2.3 & 598.1 & 1.1 & 777.8 & 775.1 & 321.5 & 317.7 & 2336.9 & 6.3 & 1.3 & 0.3 & 44.1 & 3.7 & 6.0 \\
\hline $\begin{array}{r}7 / 9 / 2009 \\
21: 00\end{array}$ & $\begin{array}{r}7 / 9 / 2009 \\
22: 00\end{array}$ & 904.1 & 8031.4 & 3.1 & 2.3 & 599.4 & 1.1 & 782.7 & 779.4 & 321.3 & 317.9 & 2329.0 & 6.3 & 1.3 & 0.3 & 49.3 & 3.8 & 6.1 \\
\hline $\begin{array}{r}7 / 9 / 2009 \\
22: 00\end{array}$ & $\begin{array}{r}7 / 9 / 2009 \\
23: 00\end{array}$ & 906.0 & 8029.0 & 3.2 & 2.5 & 609.6 & 1.1 & 780.9 & 776.9 & 320.0 & 316.4 & 2354.8 & 6.4 & 1.4 & 0.4 & 41.4 & 3.9 & 6.1 \\
\hline $\begin{array}{r}7 / 9 / 2009 \\
23: 00\end{array}$ & $\begin{array}{r}7 / 10 / 2009 \\
0: 00\end{array}$ & 904.9 & 8028.1 & 3.2 & 2.6 & 614.6 & 1.1 & 779.3 & 775.3 & 317.6 & 313.7 & 2371.6 & 6.4 & 1.4 & 0.4 & 31.0 & 4.2 & 6.3 \\
\hline $\begin{array}{r}7 / 10 / 2009 \\
0: 00 \\
\end{array}$ & $\begin{array}{r}7 / 10 / 2009 \\
1: 00 \\
\end{array}$ & 899.7 & 8047.8 & 3.2 & 2.6 & 610.1 & 1.1 & 783.7 & 772.0 & 317.3 & 311.8 & 2368.5 & 6.0 & 1.5 & 0.4 & 32.6 & 4.3 & 6.6 \\
\hline $\begin{array}{r}7 / 10 / 2009 \\
1: 00 \\
\end{array}$ & $\begin{array}{r}7 / 10 / 2009 \\
2: 00 \\
\end{array}$ & 848.2 & 8070.5 & 3.3 & 2.5 & 577.8 & 1.1 & 766.5 & 752.0 & 314.6 & 306.7 & 2239.2 & 5.3 & 1.5 & 0.4 & 18.6 & 4.3 & 6.5 \\
\hline $\begin{array}{r}7 / 10 / 2009 \\
2: 00\end{array}$ & $\begin{array}{r}7 / 10 / 2009 \\
3: 00\end{array}$ & 887.8 & 8037.9 & 3.2 & 2.7 & 607.1 & 1.1 & 775.3 & 759.8 & 312.8 & 305.4 & 2343.7 & 5.6 & 1.5 & 0.4 & 35.5 & 4.3 & 6.5 \\
\hline $\begin{array}{r}7 / 10 / 2009 \\
3: 00\end{array}$ & $\begin{array}{r}7 / 10 / 2009 \\
4: 00\end{array}$ & 829.4 & 8064.0 & 3.2 & 2.5 & 563.7 & 1.1 & 752.8 & 745.0 & 308.9 & 301.7 & 2211.3 & 5.0 & 1.5 & 0.4 & 16.4 & 4.3 & 6.5 \\
\hline $7 / 10 / 2009$ & $7 / 10 / 2009$ & 774.8 & 7990.9 & 3.4 & 2.4 & 531.1 & 1.1 & 734.3 & 727.9 & 302.9 & 293.7 & 2093.1 & 4.6 & 1.5 & 0.4 & 3.0 & 4.4 & 6.6 \\
\hline
\end{tabular}




\begin{tabular}{|c|c|c|c|c|c|c|c|c|c|c|c|c|c|c|c|c|c|c|}
\hline $\begin{array}{l}\text { Start } \\
\text { Date/ } \\
\text { Time }\end{array}$ & $\begin{array}{l}\text { End } \\
\text { Date/ } \\
\text { Time }\end{array}$ & $\begin{array}{l}\text { Gross } \\
\text { Load }\end{array}$ & $\begin{array}{c}\text { Gross } \\
\text { HR }\end{array}$ & $\begin{array}{c}\text { A } \\
\text { Econ } \\
\text { O2 }\end{array}$ & $\begin{array}{c}\text { B } \\
\text { Econ } \\
\text { O2 }\end{array}$ & $\begin{array}{l}\text { Fuel } \\
\text { Flow }\end{array}$ & $\begin{array}{l}\text { BTU } \\
\text { Gain }\end{array}$ & $\begin{array}{c}\text { A } \\
\text { APH } \\
\text { In }\end{array}$ & $\begin{array}{l}\text { B } \\
\text { APH } \\
\text { In }\end{array}$ & $\begin{array}{c}\text { A } \\
\text { APH } \\
\text { Out }\end{array}$ & $\begin{array}{c}\text { B } \\
\text { APH } \\
\text { Out }\end{array}$ & $\begin{array}{l}\text { Stack } \\
\text { Flow }\end{array}$ & Opacity & SO2 In & $\begin{array}{l}\text { SO2 } \\
\text { Out }\end{array}$ & $\mathrm{CO}$ & $\begin{array}{c}\text { Stack } \\
\text { SCEM } \\
\text { Elemental } \\
\mathrm{Hg}\end{array}$ & $\begin{array}{c}\text { Stack } \\
\text { SCEM } \\
\text { Total Hg }\end{array}$ \\
\hline & & MW & Btu/kWh & $\%$ & $\%$ & Ton/hr & & DEGF & DEGF & DEGF & DEGF & KSCF & $\%$ & $\mathrm{Ib} / \mathrm{MMB}$ & $\mathrm{Ib} / \mathrm{MMb}$ & PPM & $\begin{array}{c}\text { ( } \mu \mathrm{g} / \mathrm{dNm}) \\
@ 3 \% 02\end{array}$ & $\begin{array}{c}(\mu \mathrm{g} / \mathrm{dNm} 3) \\
\text { @ 3\%O2 }\end{array}$ \\
\hline $4: 00$ & $5: 00$ & & & & & & & & & & & & & & & & & \\
\hline $\begin{array}{r}7 / 10 / 2009 \\
5: 00\end{array}$ & $\begin{array}{r}7 / 10 / 2009 \\
6: 00\end{array}$ & 810.3 & 7970.9 & 3.4 & 2.7 & 558.8 & 1.1 & 740.0 & 732.4 & 302.1 & 293.5 & 2191.5 & 5.0 & 1.5 & 0.4 & 8.2 & $\# \mathrm{~N} / \mathrm{A}$ & $\# \mathrm{~N} / \mathrm{A}$ \\
\hline $\begin{array}{r}7 / 10 / 2009 \\
6: 00\end{array}$ & $\begin{array}{r}7 / 10 / 2009 \\
7: 00\end{array}$ & 891.2 & 8029.1 & 3.1 & 2.8 & 600.6 & 1.1 & 764.3 & 752.0 & 303.7 & 296.1 & 2363.6 & 5.3 & 1.5 & 0.4 & 38.4 & \#N/A & $\# \mathrm{~N} / \mathrm{A}$ \\
\hline $\begin{array}{r}7 / 10 / 2009 \\
7: 00\end{array}$ & $\begin{array}{r}7 / 10 / 2009 \\
8: 00\end{array}$ & 892.4 & 8066.2 & 3.1 & 2.8 & 600.5 & 1.1 & 772.8 & 759.8 & 305.5 & 297.6 & 2375.2 & 5.3 & 1.5 & 0.4 & 42.8 & 4.6 & 6.5 \\
\hline $\begin{array}{r}7 / 10 / 2009 \\
8: 00\end{array}$ & $\begin{array}{r}7 / 10 / 2009 \\
9: 00\end{array}$ & 892.2 & 8104.2 & 3.1 & 2.7 & 599.2 & 1.1 & 774.8 & 763.4 & 308.0 & 300.4 & 2376.6 & 5.3 & 1.5 & 0.4 & 42.8 & 4.3 & 6.3 \\
\hline $\begin{array}{r}7 / 10 / 2009 \\
9: 00\end{array}$ & $\begin{array}{r}7 / 10 / 2009 \\
10: 00\end{array}$ & 888.1 & 8122.3 & 3.2 & 2.7 & 593.0 & 1.1 & 769.5 & 759.8 & 308.4 & 301.4 & 2361.6 & 5.3 & 1.5 & 0.4 & 42.9 & 4.2 & 6.1 \\
\hline $\begin{array}{r}7 / 10 / 2009 \\
10: 00\end{array}$ & $\begin{array}{r}7 / 10 / 2009 \\
11: 00\end{array}$ & 884.3 & 8101.4 & 3.2 & 2.7 & 593.1 & 1.1 & 770.3 & 761.7 & 308.8 & 302.7 & 2343.3 & 5.4 & 1.5 & 0.4 & 38.2 & 4.2 & 6.2 \\
\hline $\begin{array}{r}7 / 10 / 2009 \\
11: 00\end{array}$ & $\begin{array}{r}7 / 10 / 2009 \\
12: 00\end{array}$ & 891.4 & 8112.3 & 3.2 & 2.7 & 600.0 & 1.1 & 775.6 & 766.4 & 312.0 & 306.5 & 2353.2 & 5.6 & 1.4 & 0.4 & 33.1 & 4.2 & 6.3 \\
\hline $\begin{array}{r}7 / 10 / 2009 \\
12: 00\end{array}$ & $\begin{array}{r}7 / 10 / 2009 \\
13: 00\end{array}$ & 893.8 & 8116.6 & 3.1 & 2.7 & 602.4 & 1.1 & 775.0 & 769.8 & 314.8 & 310.3 & 2352.1 & 5.9 & 1.3 & 0.4 & 37.7 & 3.7 & 5.8 \\
\hline $\begin{array}{r}7 / 10 / 2009 \\
13: 00\end{array}$ & $\begin{array}{r}7 / 10 / 2009 \\
14: 00\end{array}$ & 893.7 & 8103.7 & 3.1 & 2.7 & 600.5 & 1.1 & 775.9 & 771.1 & 316.5 & 312.2 & 2347.5 & 5.9 & 1.3 & 0.4 & 40.2 & 3.0 & 4.6 \\
\hline $\begin{array}{r}7 / 10 / 2009 \\
14: 00\end{array}$ & $\begin{array}{r}7 / 10 / 2009 \\
15: 00\end{array}$ & 889.5 & 8098.6 & 3.0 & 2.8 & 597.9 & 1.1 & 778.2 & 772.2 & 318.9 & 314.4 & 2343.7 & 5.9 & 1.3 & 0.3 & 32.7 & 2.6 & 4.1 \\
\hline $\begin{array}{r}7 / 10 / 2009 \\
15: 00\end{array}$ & $\begin{array}{r}7 / 10 / 2009 \\
16: 00\end{array}$ & 893.5 & 8093.6 & 2.9 & 2.9 & 597.7 & 1.1 & 783.9 & 775.2 & 322.4 & 316.6 & 2347.6 & 6.0 & 1.3 & 0.3 & 35.3 & 2.5 & 3.9 \\
\hline $\begin{array}{r}7 / 10 / 2009 \\
16: 00\end{array}$ & $\begin{array}{r}7 / 10 / 2009 \\
17: 00\end{array}$ & 894.1 & 8115.0 & 2.9 & 2.9 & 595.7 & 1.1 & 787.6 & 777.3 & 325.1 & 318.8 & 2348.8 & 6.2 & 1.3 & 0.3 & 33.9 & 2.5 & 3.8 \\
\hline $\begin{array}{r}7 / 10 / 2009 \\
17: 00\end{array}$ & $\begin{array}{r}7 / 10 / 2009 \\
18: 00\end{array}$ & 894.7 & 8108.3 & 2.9 & 2.9 & 593.5 & 1.1 & 789.8 & 777.6 & 326.7 & 320.4 & 2352.1 & 6.8 & 1.3 & 0.3 & 35.2 & 1.8 & 2.9 \\
\hline $\begin{array}{r}7 / 10 / 2009 \\
18: 00 \\
\end{array}$ & $\begin{array}{r}7 / 10 / 2009 \\
19: 00 \\
\end{array}$ & 895.1 & 8110.4 & 2.9 & 2.9 & 592.2 & 1.2 & 786.4 & 771.7 & 327.0 & 320.0 & 2350.7 & 6.7 & 1.3 & 0.4 & 34.1 & 1.7 & 2.6 \\
\hline $\begin{array}{r}7 / 10 / 2009 \\
19: 00\end{array}$ & $\begin{array}{r}7 / 10 / 2009 \\
20: 00\end{array}$ & 899.2 & 8083.7 & 2.8 & 3.0 & 595.3 & 1.2 & 775.5 & 763.7 & 323.4 & 317.3 & 2353.8 & 6.6 & 1.4 & 0.4 & 32.3 & 1.9 & 2.9 \\
\hline $\begin{array}{r}7 / 10 / 2009 \\
20: 00 \\
\end{array}$ & $\begin{array}{r}7 / 10 / 2009 \\
21: 00 \\
\end{array}$ & 904.0 & 8100.9 & 2.7 & 3.1 & 600.3 & 1.2 & 769.5 & 757.9 & 318.6 & 312.7 & 2357.0 & 6.1 & 1.4 & 0.4 & 30.3 & 2.0 & 3.3 \\
\hline $\begin{array}{r}7 / 10 / 2009 \\
21: 00 \\
\end{array}$ & $\begin{array}{r}7 / 10 / 2009 \\
22: 00 \\
\end{array}$ & 904.7 & 8087.7 & 2.7 & 3.2 & 604.0 & 1.2 & 771.1 & 751.5 & 316.4 & 307.9 & 2359.6 & 6.2 & 1.4 & 0.4 & 30.3 & 2.3 & 3.8 \\
\hline $\begin{array}{r}7 / 10 / 2009 \\
22: 00\end{array}$ & $\begin{array}{r}7 / 10 / 2009 \\
23: 00\end{array}$ & 905.8 & 8100.2 & 2.9 & 2.9 & 600.5 & 1.2 & 776.0 & 754.5 & 316.0 & 306.6 & 2363.4 & 5.9 & 1.4 & 0.4 & 39.6 & 2.4 & 3.9 \\
\hline $\begin{array}{r}7 / 10 / 2009 \\
23: 00\end{array}$ & $\begin{array}{r}7 / 11 / 2009 \\
0: 00\end{array}$ & 903.5 & 8087.8 & 3.0 & 2.8 & 594.1 & 1.2 & 778.9 & 760.5 & 315.9 & 307.7 & 2366.5 & 5.6 & 1.4 & 0.4 & 39.7 & 2.5 & 4.1 \\
\hline
\end{tabular}




\begin{tabular}{|c|c|c|c|c|c|c|c|c|c|c|c|c|c|c|c|c|c|c|}
\hline $\begin{array}{l}\text { Start } \\
\text { Date/ } \\
\text { Time }\end{array}$ & $\begin{array}{l}\text { End } \\
\text { Date/ } \\
\text { Time }\end{array}$ & $\begin{array}{l}\text { Gross } \\
\text { Load }\end{array}$ & $\begin{array}{c}\text { Gross } \\
\text { HR }\end{array}$ & $\begin{array}{c}\text { A } \\
\text { Econ } \\
\text { O2 }\end{array}$ & $\begin{array}{c}\text { B } \\
\text { Econ } \\
\text { O2 }\end{array}$ & $\begin{array}{l}\text { Fuel } \\
\text { Flow }\end{array}$ & $\begin{array}{l}\text { BTU } \\
\text { Gain }\end{array}$ & $\begin{array}{l}\text { A } \\
\text { APH } \\
\text { In }\end{array}$ & $\begin{array}{c}\text { B } \\
\text { APH } \\
\text { In }\end{array}$ & $\begin{array}{c}\text { A } \\
\text { APH } \\
\text { Out }\end{array}$ & $\begin{array}{c}\text { B } \\
\text { APH } \\
\text { Out }\end{array}$ & $\begin{array}{l}\text { Stack } \\
\text { Flow }\end{array}$ & Opacity & SO2 In & $\begin{array}{l}\text { SO2 } \\
\text { Out }\end{array}$ & $\mathrm{CO}$ & $\begin{array}{c}\text { Stack } \\
\text { SCEM } \\
\text { Elemental } \\
\mathrm{Hg}\end{array}$ & $\begin{array}{c}\text { Stack } \\
\text { SCEM } \\
\text { Total Hg }\end{array}$ \\
\hline & & MW & Btu/kWh & $\%$ & $\%$ & Ton/hr & & DEGF & DEGF & DEGF & DEGF & KSCF & $\%$ & $\mathrm{Ib} / \mathrm{MMB}$ & $\mathrm{Ib} / \mathrm{MMb}$ & PPM & $\begin{array}{c}(\mu \mathrm{g} / \mathrm{dNm} 3) \\
@ 3 \% 02\end{array}$ & $\begin{array}{c}(\mu \mathrm{g} / \mathrm{dNm} 3) \\
@ 3 \% 02\end{array}$ \\
\hline $\begin{array}{r}7 / 11 / 2009 \\
0: 00\end{array}$ & $\begin{array}{r}7 / 11 / 2009 \\
1: 00\end{array}$ & 898.5 & 8113.4 & 3.1 & 2.8 & 590.9 & 1.2 & 781.1 & 764.7 & 315.9 & 307.9 & 2368.5 & 5.4 & 1.4 & 0.4 & 37.7 & 2.5 & 4.2 \\
\hline $\begin{array}{r}7 / 11 / 2009 \\
1: 00\end{array}$ & $\begin{array}{r}7 / 11 / 2009 \\
2: 00\end{array}$ & 897.2 & 8114.1 & 3.1 & 2.7 & 592.1 & 1.2 & 777.7 & 762.9 & 315.6 & 307.4 & 2370.3 & 5.4 & 1.4 & 0.4 & 31.8 & $\# \mathrm{~N} / \mathrm{A}$ & \#N/A \\
\hline $\begin{array}{r}7 / 11 / 2009 \\
2: 00\end{array}$ & $\begin{array}{r}7 / 11 / 2009 \\
3: 00\end{array}$ & 894.1 & 8120.5 & 3.1 & 2.6 & 586.8 & 1.2 & 767.3 & 753.8 & 309.8 & 301.6 & 2371.1 & 5.3 & 1.4 & 0.4 & 34.8 & $\# \mathrm{~N} / \mathrm{A}$ & $\# \mathrm{~N} / \mathrm{A}$ \\
\hline $\begin{array}{r}7 / 11 / 2009 \\
3: 00\end{array}$ & $\begin{array}{r}7 / 11 / 2009 \\
4: 00\end{array}$ & 807.6 & 8156.5 & 3.1 & 2.4 & 531.6 & 1.2 & 737.2 & 728.0 & 299.8 & 291.0 & 2140.3 & 4.9 & 1.4 & 0.4 & 14.6 & 2.9 & 4.5 \\
\hline $\begin{array}{r}7 / 11 / 2009 \\
4: 00\end{array}$ & $\begin{array}{r}7 / 11 / 2009 \\
5: 00\end{array}$ & 707.3 & 8173.1 & 3.2 & 2.6 & 475.0 & 1.2 & 706.6 & 698.4 & 291.7 & 281.8 & 1985.0 & 4.7 & 1.5 & 0.4 & 4.3 & $\# \mathrm{~N} / \mathrm{A}$ & $\# \mathrm{~N} / \mathrm{A}$ \\
\hline $\begin{array}{r}7 / 11 / 2009 \\
5: 00\end{array}$ & $\begin{array}{r}7 / 11 / 2009 \\
6: 00\end{array}$ & 708.8 & 8067.7 & 3.2 & 2.7 & 481.1 & 1.1 & 704.4 & 696.8 & 289.1 & 278.2 & 1986.8 & 4.7 & 1.5 & 0.4 & 4.0 & $\# \mathrm{~N} / \mathrm{A}$ & $\# \mathrm{~N} / \mathrm{A}$ \\
\hline $\begin{array}{r}7 / 11 / 2009 \\
6: 00\end{array}$ & $\begin{array}{r}7 / 11 / 2009 \\
7: 00\end{array}$ & 846.0 & 8036.6 & 3.2 & 2.8 & 574.6 & 1.1 & 745.0 & 736.1 & 293.8 & 285.9 & 2284.3 & 5.3 & 1.4 & 0.4 & 21.8 & $\# \mathrm{~N} / \mathrm{A}$ & $\# \mathrm{~N} / \mathrm{A}$ \\
\hline $\begin{array}{r}7 / 11 / 2009 \\
7: 00\end{array}$ & $\begin{array}{r}7 / 11 / 2009 \\
8: 00\end{array}$ & 886.1 & 8084.3 & 3.0 & 2.7 & 605.0 & 1.1 & 765.2 & 755.1 & 300.8 & 293.0 & 2328.8 & 5.1 & 1.5 & 0.4 & 32.0 & 3.4 & 5.0 \\
\hline $\begin{array}{r}7 / 11 / 2009 \\
8: 00\end{array}$ & $\begin{array}{r}7 / 11 / 2009 \\
9: 00\end{array}$ & 895.4 & 8121.4 & 3.0 & 2.7 & 606.8 & 1.1 & 769.3 & 758.2 & 303.1 & 295.9 & 2370.6 & 5.1 & 1.5 & 0.4 & 30.4 & 3.6 & 5.5 \\
\hline $\begin{array}{r}7 / 11 / 2009 \\
9: 00 \\
\end{array}$ & $\begin{array}{r}7 / 11 / 2009 \\
10: 00 \\
\end{array}$ & 895.0 & 8142.9 & 3.1 & 2.6 & 606.1 & 1.1 & 768.1 & 756.5 & 304.2 & 297.3 & 2353.9 & 5.3 & 1.5 & 0.4 & 27.9 & 3.7 & 5.9 \\
\hline $\begin{array}{r}7 / 11 / 2009 \\
10: 00\end{array}$ & $\begin{array}{r}7 / 11 / 2009 \\
11: 00\end{array}$ & 890.9 & 8132.9 & 3.1 & 2.6 & 602.7 & 1.1 & 768.9 & 758.7 & 305.6 & 299.5 & 2333.7 & 5.4 & 1.5 & 0.4 & 27.8 & 3.8 & 6.1 \\
\hline $\begin{array}{r}7 / 11 / 2009 \\
11: 00\end{array}$ & $\begin{array}{r}7 / 11 / 2009 \\
12: 00\end{array}$ & 886.0 & 8139.6 & 3.1 & 2.5 & 600.3 & 1.1 & 764.5 & 754.5 & 307.2 & 301.3 & 2337.9 & 5.5 & 1.5 & 0.4 & 29.2 & 3.7 & 6.2 \\
\hline $\begin{array}{r}7 / 11 / 2009 \\
12: 00\end{array}$ & $\begin{array}{r}7 / 11 / 2009 \\
13: 00\end{array}$ & 895.0 & 8102.0 & 3.1 & 2.5 & 602.5 & 1.1 & 760.9 & 751.3 & 307.4 & 302.4 & 2340.5 & 5.7 & 1.4 & 0.4 & 29.0 & 4.0 & 6.7 \\
\hline $\begin{array}{r}7 / 11 / 2009 \\
13: 00\end{array}$ & $\begin{array}{r}7 / 11 / 2009 \\
14: 00\end{array}$ & 901.0 & 8131.0 & 3.2 & 2.6 & 602.9 & 1.1 & 760.0 & 750.2 & 309.2 & 304.0 & 2358.7 & 5.8 & 1.4 & 0.4 & 25.7 & 3.3 & 5.7 \\
\hline $\begin{array}{r}7 / 11 / 2009 \\
14: 00\end{array}$ & $\begin{array}{r}7 / 11 / 2009 \\
15: 00\end{array}$ & 898.5 & 8146.7 & 3.1 & 2.6 & 594.4 & 1.1 & 751.9 & 745.6 & 309.2 & 303.8 & 2342.5 & 5.8 & 1.3 & 0.4 & 27.1 & 2.3 & 4.3 \\
\hline $\begin{array}{r}7 / 11 / 2009 \\
15: 00 \\
\end{array}$ & $\begin{array}{r}7 / 11 / 2009 \\
16: 00 \\
\end{array}$ & 884.9 & 8120.2 & 3.1 & 2.5 & 581.1 & 1.2 & 751.9 & 746.9 & 308.0 & 304.0 & 2302.6 & 5.6 & 1.3 & 0.3 & 24.4 & 1.8 & 3.3 \\
\hline $\begin{array}{r}7 / 11 / 2009 \\
16: 00\end{array}$ & $\begin{array}{r}7 / 11 / 2009 \\
17: 00\end{array}$ & 879.8 & 8088.5 & 3.2 & 2.6 & 581.0 & 1.2 & 758.5 & 752.7 & 310.3 & 306.1 & 2294.7 & 5.4 & 1.3 & 0.3 & 23.4 & 1.6 & 2.9 \\
\hline $\begin{array}{r}7 / 11 / 2009 \\
17: 00\end{array}$ & $\begin{array}{r}7 / 11 / 2009 \\
18: 00\end{array}$ & 887.9 & 8075.1 & 3.2 & 2.5 & 593.0 & 1.2 & 765.0 & 759.1 & 312.6 & 308.5 & 2318.3 & 5.4 & 1.3 & 0.4 & 27.8 & 1.8 & 3.1 \\
\hline $\begin{array}{r}7 / 11 / 2009 \\
18: 00\end{array}$ & $\begin{array}{r}7 / 11 / 2009 \\
19: 00\end{array}$ & 890.5 & 8083.4 & 3.2 & 2.5 & 600.9 & 1.1 & 768.7 & 763.5 & 314.1 & 310.1 & 2331.8 & 5.3 & 1.3 & 0.4 & 30.6 & 2.9 & 4.6 \\
\hline $7 / 11 / 2009$ & $7 / 11 / 2009$ & 895.8 & 8077.6 & 3.2 & 2.4 & 601.4 & 1.1 & 771.5 & 766.5 & 314.5 & 310.8 & 2333.9 & 5.5 & 1.3 & 0.4 & 32.5 & 4.0 & 6.4 \\
\hline
\end{tabular}




\begin{tabular}{|c|c|c|c|c|c|c|c|c|c|c|c|c|c|c|c|c|c|c|}
\hline \multirow[t]{2}{*}{$\begin{array}{l}\text { Start } \\
\text { Date/ } \\
\text { Time }\end{array}$} & \multirow[t]{2}{*}{$\begin{array}{l}\text { End } \\
\text { Date/ } \\
\text { Time }\end{array}$} & $\begin{array}{l}\text { Gross } \\
\text { Load }\end{array}$ & $\begin{array}{c}\text { Gross } \\
\text { HR }\end{array}$ & $\begin{array}{c}A \\
\text { Econ } \\
\text { O2 }\end{array}$ & $\begin{array}{c}\text { B } \\
\text { Econ } \\
\text { O2 }\end{array}$ & $\begin{array}{l}\text { Fuel } \\
\text { Flow }\end{array}$ & $\begin{array}{l}\text { BTU } \\
\text { Gain }\end{array}$ & $\begin{array}{c}\text { A } \\
\text { APH } \\
\text { In }\end{array}$ & $\begin{array}{c}\text { B } \\
\text { APH } \\
\text { In }\end{array}$ & $\begin{array}{c}\text { A } \\
\text { APH } \\
\text { Out }\end{array}$ & $\begin{array}{c}\text { B } \\
\text { APH } \\
\text { Out }\end{array}$ & $\begin{array}{l}\text { Stack } \\
\text { Flow }\end{array}$ & Opacity & SO2 In & $\begin{array}{l}\text { SO2 } \\
\text { Out }\end{array}$ & $\mathrm{CO}$ & $\begin{array}{c}\text { Stack } \\
\text { SCEM } \\
\text { Elemental } \\
\mathrm{Hg}\end{array}$ & $\begin{array}{c}\text { Stack } \\
\text { SCEM } \\
\text { Total Hg }\end{array}$ \\
\hline & & MW & Btu/kWh & $\%$ & $\%$ & Ton/hr & & DEGF & DEGF & DEGF & DEGF & KSCF & $\%$ & Ib/MMB & $\mathrm{Ib} / \mathrm{MMb}$ & PPM & $\begin{array}{c}\text { ( } \mu \mathrm{g} / \mathrm{dNm}) \\
@ 3 \% 02\end{array}$ & $\begin{array}{c}(\mu \mathrm{g} / \mathrm{dNm} 3) \\
@ 3 \% 02\end{array}$ \\
\hline $19: 00$ & $20: 00$ & & & & & & & & & & & & & & & & & \\
\hline $\begin{array}{r}7 / 11 / 2009 \\
20: 00\end{array}$ & $\begin{array}{r}7 / 11 / 2009 \\
21: 00\end{array}$ & 893.9 & 8098.1 & 3.1 & 2.4 & 597.6 & 1.1 & 773.5 & 768.0 & 314.4 & 311.2 & 2313.2 & 5.4 & 1.3 & 0.4 & 32.3 & 4.8 & 7.4 \\
\hline $\begin{array}{r}7 / 11 / 2009 \\
21: 00\end{array}$ & $\begin{array}{r}7 / 11 / 2009 \\
22: 00\end{array}$ & 892.9 & 8082.3 & 3.0 & 2.4 & 590.9 & 1.1 & 765.1 & 759.0 & 312.9 & 308.6 & 2304.5 & 5.2 & 1.3 & 0.4 & 30.8 & 5.1 & 7.9 \\
\hline $\begin{array}{r}7 / 11 / 2009 \\
22: 00\end{array}$ & $\begin{array}{r}7 / 11 / 2009 \\
23: 00\end{array}$ & 891.5 & 8070.1 & 3.0 & 2.4 & 592.9 & 1.1 & 758.6 & 751.5 & 309.7 & 304.8 & 2302.2 & 5.0 & 1.3 & 0.4 & 38.1 & 5.1 & 7.8 \\
\hline $\begin{array}{r}7 / 11 / 2009 \\
23: 00\end{array}$ & $\begin{array}{r}7 / 12 / 2009 \\
0: 00\end{array}$ & 893.5 & 8066.9 & 2.9 & 2.3 & 594.8 & 1.1 & 762.7 & 755.3 & 309.3 & 303.4 & 2296.9 & 5.0 & 1.4 & 0.4 & 52.8 & 5.1 & 7.7 \\
\hline $\begin{array}{r}7 / 12 / 2009 \\
0: 00\end{array}$ & $\begin{array}{r}7 / 12 / 2009 \\
1: 00\end{array}$ & 893.5 & 8077.5 & 2.9 & 2.2 & 595.7 & 1.1 & 760.3 & 752.7 & 308.1 & 301.7 & 2298.9 & 5.2 & 1.4 & 0.4 & 55.1 & 5.1 & 7.5 \\
\hline $\begin{array}{r}7 / 12 / 2009 \\
1: 00\end{array}$ & $\begin{array}{r}7 / 12 / 2009 \\
2: 00\end{array}$ & 894.8 & 8060.7 & 3.0 & 2.2 & 601.0 & 1.1 & 761.4 & 753.8 & 305.6 & 299.5 & 2295.8 & 5.7 & 1.4 & 0.4 & 53.1 & $\# \mathrm{~N} / \mathrm{A}$ & 7.3 \\
\hline $\begin{array}{r}7 / 12 / 2009 \\
2: 00\end{array}$ & $\begin{array}{r}7 / 12 / 2009 \\
3: 00\end{array}$ & 892.6 & 8056.1 & 3.0 & 2.2 & 595.7 & 1.1 & 768.3 & 760.2 & 305.8 & 299.9 & 2307.6 & 5.6 & 1.4 & 0.4 & 47.2 & $\# \mathrm{~N} / \mathrm{A}$ & $\# \mathrm{~N} / \mathrm{A}$ \\
\hline $\begin{array}{r}7 / 12 / 2009 \\
3: 00\end{array}$ & $\begin{array}{r}7 / 12 / 2009 \\
4: 00\end{array}$ & 797.2 & 8059.6 & 3.0 & 2.1 & 536.5 & 1.1 & 746.3 & 741.0 & 303.6 & 294.7 & 2069.7 & 5.9 & 1.4 & 0.4 & 15.3 & $\# \mathrm{~N} / \mathrm{A}$ & 7.2 \\
\hline $\begin{array}{r}7 / 12 / 2009 \\
4: 00\end{array}$ & $\begin{array}{r}7 / 12 / 2009 \\
5: 00\end{array}$ & 719.5 & 7991.0 & 3.1 & 2.3 & 486.7 & 1.1 & 724.2 & 719.4 & 300.5 & 289.1 & 1950.8 & 6.3 & 1.4 & 0.4 & 5.2 & 4.4 & 6.3 \\
\hline $\begin{array}{r}7 / 12 / 2009 \\
5: 00\end{array}$ & $\begin{array}{r}7 / 12 / 2009 \\
6: 00\end{array}$ & 709.7 & 7941.2 & 3.2 & 2.4 & 489.9 & 1.1 & 712.7 & 703.8 & 296.4 & 284.5 & 1984.3 & 6.2 & 1.4 & 0.4 & 4.6 & $\# \mathrm{~N} / \mathrm{A}$ & $\# \mathrm{~N} / \mathrm{A}$ \\
\hline $\begin{array}{r}7 / 12 / 2009 \\
6: 00\end{array}$ & $\begin{array}{r}7 / 12 / 2009 \\
7: 00\end{array}$ & 793.1 & 7912.7 & 3.1 & 2.4 & 540.4 & 1.1 & 736.0 & 724.5 & 295.7 & 285.2 & 2119.0 & 7.2 & 1.4 & 0.4 & 11.9 & $\# \mathrm{~N} / \mathrm{A}$ & $\# \mathrm{~N} / \mathrm{A}$ \\
\hline $\begin{array}{r}7 / 12 / 2009 \\
7: 00\end{array}$ & $\begin{array}{r}7 / 12 / 2009 \\
8: 00\end{array}$ & 795.1 & 7938.4 & 3.2 & 2.5 & 542.2 & 1.1 & 741.2 & 730.2 & 298.3 & 287.6 & 2090.7 & 7.4 & 1.5 & 0.4 & 6.7 & 3.4 & 4.7 \\
\hline $\begin{array}{r}7 / 12 / 2009 \\
8: 00\end{array}$ & $\begin{array}{r}7 / 12 / 2009 \\
9: 00\end{array}$ & 854.1 & 8046.9 & 3.1 & 2.7 & 581.4 & 1.1 & 752.2 & 740.2 & 302.0 & 292.7 & 2240.9 & 7.8 & 1.5 & 0.4 & 19.1 & 3.0 & 4.2 \\
\hline $\begin{array}{r}7 / 12 / 2009 \\
9: 00 \\
\end{array}$ & $\begin{array}{r}7 / 12 / 2009 \\
10: 00 \\
\end{array}$ & 887.3 & 8067.3 & 3.0 & 2.6 & 599.8 & 1.1 & 767.0 & 754.2 & 304.8 & 297.4 & 2302.6 & 6.9 & 1.5 & 0.4 & 26.3 & 2.8 & 4.1 \\
\hline $\begin{array}{r}7 / 12 / 2009 \\
10: 00 \\
\end{array}$ & $\begin{array}{r}7 / 12 / 2009 \\
11: 00 \\
\end{array}$ & 890.6 & 8084.8 & 3.1 & 2.6 & 602.7 & 1.1 & 772.9 & 760.2 & 307.2 & 300.5 & 2318.1 & 6.5 & 1.5 & 0.4 & 22.4 & 2.7 & 4.1 \\
\hline $\begin{array}{r}7 / 12 / 2009 \\
11: 00 \\
\end{array}$ & $\begin{array}{r}7 / 12 / 2009 \\
12: 00 \\
\end{array}$ & 891.0 & 8070.7 & 3.0 & 2.6 & 602.7 & 1.1 & 776.3 & 763.8 & 310.4 & 303.7 & 2327.6 & 5.9 & 1.5 & 0.4 & 21.9 & 2.7 & 4.2 \\
\hline $\begin{array}{r}7 / 12 / 2009 \\
12: 00 \\
\end{array}$ & $\begin{array}{r}7 / 12 / 2009 \\
13: 00 \\
\end{array}$ & 892.3 & 8083.3 & 3.0 & 2.6 & 607.1 & 1.1 & 779.7 & 766.8 & 313.5 & 307.2 & 2334.2 & 6.0 & 1.5 & 0.4 & 22.5 & 2.7 & 4.3 \\
\hline $\begin{array}{r}7 / 12 / 2009 \\
13: 00\end{array}$ & $\begin{array}{r}7 / 12 / 2009 \\
14: 00\end{array}$ & 894.5 & 8061.5 & 3.1 & 2.5 & 604.3 & 1.1 & 782.6 & 769.6 & 316.0 & 310.2 & 2321.7 & 6.0 & 1.5 & 0.4 & 22.6 & 2.6 & 4.2 \\
\hline $\begin{array}{r}7 / 12 / 2009 \\
14: 00\end{array}$ & $\begin{array}{r}7 / 12 / 2009 \\
15: 00\end{array}$ & 893.7 & 8072.7 & 3.1 & 2.5 & 603.0 & 1.1 & 783.9 & 772.8 & 318.5 & 313.0 & 2316.5 & 6.1 & 1.5 & 0.4 & 20.7 & 2.5 & 4.2 \\
\hline
\end{tabular}




\begin{tabular}{|c|c|c|c|c|c|c|c|c|c|c|c|c|c|c|c|c|c|c|}
\hline $\begin{array}{l}\text { Start } \\
\text { Date/ } \\
\text { Time }\end{array}$ & $\begin{array}{l}\text { End } \\
\text { Date/ } \\
\text { Time }\end{array}$ & $\begin{array}{l}\text { Gross } \\
\text { Load }\end{array}$ & $\begin{array}{c}\text { Gross } \\
\text { HR }\end{array}$ & $\begin{array}{c}\text { A } \\
\text { Econ } \\
\text { O2 }\end{array}$ & $\begin{array}{c}\text { B } \\
\text { Econ } \\
\text { O2 }\end{array}$ & $\begin{array}{l}\text { Fuel } \\
\text { Flow }\end{array}$ & $\begin{array}{l}\text { BTU } \\
\text { Gain }\end{array}$ & $\begin{array}{c}\text { A } \\
\text { APH } \\
\text { In }\end{array}$ & $\begin{array}{c}\text { B } \\
\text { APH } \\
\text { In }\end{array}$ & $\begin{array}{c}\text { A } \\
\text { APH } \\
\text { Out }\end{array}$ & $\begin{array}{c}\text { B } \\
\text { APH } \\
\text { Out }\end{array}$ & $\begin{array}{l}\text { Stack } \\
\text { Flow }\end{array}$ & Opacity & SO2 In & $\begin{array}{l}\text { SO2 } \\
\text { Out }\end{array}$ & $\mathrm{CO}$ & $\begin{array}{c}\text { Stack } \\
\text { SCEM } \\
\text { Elemental } \\
\mathrm{Hg}\end{array}$ & $\begin{array}{c}\text { Stack } \\
\text { SCEM } \\
\text { Total Hg }\end{array}$ \\
\hline & & MW & Btu/kWh & $\%$ & $\%$ & Ton/hr & & DEGF & DEGF & DEGF & DEGF & KSCF & $\%$ & $\mathrm{Ib} / \mathrm{MMB}$ & $\mathrm{Ib} / \mathrm{MMb}$ & PPM & $\begin{array}{c}(\mu \mathrm{g} / \mathrm{dNm} 3) \\
@ 3 \% 02\end{array}$ & $\begin{array}{c}(\mu \mathrm{g} / \mathrm{dNm} 3) \\
@ 3 \% 02\end{array}$ \\
\hline $\begin{array}{r}7 / 12 / 2009 \\
15: 00\end{array}$ & $\begin{array}{r}/ 12 / 2009 \\
16: 00\end{array}$ & 894.9 & 8065.7 & 3.1 & 2.5 & 602.6 & 1.1 & 786.1 & 776.6 & 321.3 & 315.8 & 2333.1 & 6.1 & 1.4 & 0.4 & 16.7 & 2.5 & 4.2 \\
\hline $\begin{array}{r}7 / 12 / 2009 \\
16: 00\end{array}$ & $\begin{array}{r}7 / 12 / 2009 \\
17: 00\end{array}$ & 901.4 & 8078.3 & 3.1 & 2.6 & 608.2 & 1.1 & 790.0 & 780.8 & 323.2 & 318.4 & 2351.9 & 6.3 & 1.4 & 0.4 & 18.3 & 2.5 & 4.0 \\
\hline $\begin{array}{r}7 / 12 / 2009 \\
17: 00\end{array}$ & $\begin{array}{r}7 / 12 / 2009 \\
18: 00\end{array}$ & 902.1 & 8085.0 & 3.0 & 2.5 & 606.7 & 1.1 & 792.0 & 783.2 & 324.6 & 319.4 & 2329.4 & 6.1 & 1.4 & 0.4 & 27.4 & 3.0 & 4.7 \\
\hline $\begin{array}{r}7 / 12 / 2009 \\
18: 00\end{array}$ & $\begin{array}{r}7 / 12 / 2009 \\
19: 00\end{array}$ & 901.5 & 8064.9 & 2.8 & 2.3 & 602.9 & 1.1 & 792.6 & 783.0 & 324.8 & 319.3 & 2309.8 & 5.9 & 1.4 & 0.4 & 43.9 & 3.8 & 5.9 \\
\hline $\begin{array}{r}7 / 12 / 2009 \\
19: 00\end{array}$ & $\begin{array}{r}7 / 12 / 2009 \\
20: 00\end{array}$ & 900.9 & 8077.0 & 2.8 & 2.4 & 598.7 & 1.1 & 783.1 & 773.5 & 324.3 & 319.3 & 2311.2 & 6.0 & 1.4 & 0.4 & 38.7 & 3.5 & 5.7 \\
\hline $\begin{array}{r}7 / 12 / 2009 \\
20: 00\end{array}$ & $\begin{array}{r}7 / 12 / 2009 \\
21: 00\end{array}$ & 900.4 & 8078.5 & 2.9 & 2.3 & 598.1 & 1.1 & 769.8 & 761.0 & 318.6 & 313.9 & 2317.3 & 7.0 & 1.4 & 0.4 & 39.9 & 3.5 & 5.6 \\
\hline $\begin{array}{r}7 / 12 / 2009 \\
21: 00\end{array}$ & $\begin{array}{r}7 / 12 / 2009 \\
22: 00\end{array}$ & 902.6 & 8038.3 & 2.8 & 2.2 & 598.6 & 1.1 & 766.7 & 759.2 & 315.2 & 310.2 & 2302.5 & 9.5 & 1.4 & 0.4 & 37.3 & 7.2 & 10.2 \\
\hline $\begin{array}{r}7 / 12 / 2009 \\
22: 00\end{array}$ & $\begin{array}{r}7 / 12 / 2009 \\
23: 00\end{array}$ & 904.6 & 8013.9 & 2.7 & 2.0 & 600.5 & 1.1 & 771.3 & 764.9 & 314.0 & 309.4 & 2284.1 & 9.5 & 1.4 & 0.4 & 42.3 & 9.2 & 12.6 \\
\hline $\begin{array}{r}7 / 12 / 2009 \\
23: 00\end{array}$ & $\begin{array}{r}7 / 13 / 2009 \\
0: 00\end{array}$ & 904.7 & 8028.8 & 2.8 & 2.0 & 605.2 & 1.1 & 774.4 & 769.9 & 314.9 & 311.0 & 2277.4 & 10.0 & 1.4 & 0.4 & 45.9 & 9.6 & 12.9 \\
\hline $\begin{array}{r}7 / 13 / 2009 \\
0: 00 \\
\end{array}$ & $\begin{array}{r}7 / 13 / 2009 \\
1: 00 \\
\end{array}$ & 905.2 & 8023.5 & 2.7 & 2.0 & 606.2 & 1.1 & 773.0 & 767.8 & 313.6 & 308.7 & 2292.7 & 10.2 & 1.4 & 0.4 & 42.8 & 9.7 & 12.9 \\
\hline $\begin{array}{r}7 / 13 / 2009 \\
1: 00\end{array}$ & $\begin{array}{r}7 / 13 / 2009 \\
2: 00\end{array}$ & 905.6 & 8042.3 & 2.8 & 2.0 & 605.7 & 1.1 & 776.4 & 771.9 & 313.1 & 307.6 & 2298.2 & 10.5 & 1.4 & 0.4 & 39.5 & 10.0 & 13.0 \\
\hline $\begin{array}{r}7 / 13 / 2009 \\
2: 00\end{array}$ & $\begin{array}{r}7 / 13 / 2009 \\
3: 00\end{array}$ & 883.0 & 8076.4 & 2.8 & 1.9 & 588.8 & 1.1 & 773.3 & 768.6 & 311.9 & 305.7 & 2245.7 & 10.1 & 1.4 & 0.4 & 31.0 & 10.1 & 13.0 \\
\hline $\begin{array}{r}7 / 13 / 2009 \\
3: 00\end{array}$ & $\begin{array}{r}7 / 13 / 2009 \\
4: 00\end{array}$ & 739.5 & 8095.5 & 2.9 & 2.0 & 494.3 & 1.1 & 737.3 & 730.9 & 307.5 & 298.2 & 1960.6 & 8.1 & 1.4 & 0.4 & 8.4 & 9.5 & 12.0 \\
\hline $\begin{array}{r}7 / 13 / 2009 \\
4: 00\end{array}$ & $\begin{array}{r}7 / 13 / 2009 \\
5: 00\end{array}$ & 714.5 & 7996.4 & 3.0 & 2.0 & 486.1 & 1.1 & 726.6 & 719.3 & 301.7 & 293.5 & 1951.0 & 7.8 & 1.4 & 0.4 & 5.1 & $\# \mathrm{~N} / \mathrm{A}$ & \#N/A \\
\hline $\begin{array}{r}7 / 13 / 2009 \\
5: 00\end{array}$ & $\begin{array}{r}7 / 13 / 2009 \\
6: 00\end{array}$ & 773.5 & 7954.5 & 3.0 & 1.9 & 528.4 & 1.1 & 746.0 & 737.6 & 303.0 & 296.1 & 2078.0 & 8.0 & 1.5 & 0.4 & 7.4 & \#N/A & $\# \mathrm{~N} / \mathrm{A}$ \\
\hline $\begin{array}{r}7 / 13 / 2009 \\
6: 00 \\
\end{array}$ & $\begin{array}{r}7 / 13 / 2009 \\
7: 00 \\
\end{array}$ & 887.2 & 8009.8 & 2.9 & 2.0 & 599.8 & 1.1 & 782.3 & 771.9 & 308.2 & 302.3 & 2290.5 & 9.5 & 1.5 & 0.4 & 28.0 & $\# \mathrm{~N} / \mathrm{A}$ & $\# \mathrm{~N} / \mathrm{A}$ \\
\hline $\begin{array}{r}7 / 13 / 2009 \\
7: 00\end{array}$ & $\begin{array}{r}7 / 13 / 2009 \\
8: 00\end{array}$ & 905.0 & 8034.0 & 2.8 & 2.0 & 609.4 & 1.1 & 788.0 & 780.0 & 312.5 & 306.2 & 2304.3 & 8.2 & 1.5 & 0.4 & 42.9 & 10.9 & 13.4 \\
\hline $\begin{array}{r}7 / 13 / 2009 \\
8: 00\end{array}$ & $\begin{array}{r}7 / 13 / 2009 \\
9: 00\end{array}$ & 907.9 & 8034.7 & 2.8 & 2.0 & 615.1 & 1.1 & 785.3 & 779.5 & 312.6 & 307.2 & 2312.3 & 7.5 & 1.5 & 0.4 & 56.3 & 10.8 & 13.3 \\
\hline $\begin{array}{r}7 / 13 / 2009 \\
9: 00\end{array}$ & $\begin{array}{r}7 / 13 / 2009 \\
10: 00\end{array}$ & 909.0 & 8060.5 & 2.8 & 2.0 & 613.0 & 1.1 & 781.7 & 776.2 & 313.4 & 309.1 & 2330.8 & 7.2 & 1.5 & 0.4 & 59.0 & 10.6 & 13.2 \\
\hline $7 / 13 / 2009$ & $7 / 13 / 2009$ & 910.9 & 8048.6 & 2.8 & 2.2 & 613.7 & 1.1 & 779.6 & 773.1 & 313.3 & 307.9 & 2307.6 & 7.0 & 1.5 & 0.4 & 57.9 & 10.7 & 13.3 \\
\hline
\end{tabular}




\begin{tabular}{|c|c|c|c|c|c|c|c|c|c|c|c|c|c|c|c|c|c|c|}
\hline $\begin{array}{l}\text { Start } \\
\text { Date/ } \\
\text { Time }\end{array}$ & $\begin{array}{l}\text { End } \\
\text { Date/ } \\
\text { Time }\end{array}$ & $\begin{array}{l}\text { Gross } \\
\text { Load }\end{array}$ & $\begin{array}{c}\text { Gross } \\
\text { HR }\end{array}$ & $\begin{array}{c}\text { A } \\
\text { Econ } \\
\mathrm{O} 2\end{array}$ & $\begin{array}{c}\text { B } \\
\text { Econ } \\
\text { O2 }\end{array}$ & $\begin{array}{l}\text { Fuel } \\
\text { Flow }\end{array}$ & $\begin{array}{l}\text { BTU } \\
\text { Gain }\end{array}$ & $\begin{array}{c}\text { A } \\
\text { APH } \\
\text { In }\end{array}$ & $\begin{array}{c}\text { B } \\
\text { APH } \\
\text { In }\end{array}$ & $\begin{array}{c}\text { A } \\
\text { APH } \\
\text { Out }\end{array}$ & $\begin{array}{c}\text { B } \\
\text { APH } \\
\text { Out }\end{array}$ & $\begin{array}{l}\text { Stack } \\
\text { Flow }\end{array}$ & Opacity & $\mathrm{SO} 2 \mathrm{In}$ & $\begin{array}{l}\text { SO2 } \\
\text { Out }\end{array}$ & $\mathrm{CO}$ & $\begin{array}{c}\text { Stack } \\
\text { SCEM } \\
\text { Elemental } \\
\mathrm{Hg}\end{array}$ & $\begin{array}{c}\text { Stack } \\
\text { SCEM } \\
\text { Total Hg }\end{array}$ \\
\hline & & MW & Btu/kWh & $\%$ & $\%$ & Ton/hr & & DEGF & DEGF & DEGF & DEGF & KSCF & $\%$ & Ib/MMB & $\mathrm{Ib} / \mathrm{MMb}$ & PPM & $\begin{array}{c}(\mu \mathrm{g} / \mathrm{dNm} 3) \\
@ 3 \% 02\end{array}$ & $\begin{array}{c}(\mu \mathrm{g} / \mathrm{dNm} 3) \\
@ \text { @ 3\%02 }\end{array}$ \\
\hline $10: 00$ & $11: 00$ & & & & & & & & & & & & & & & & & \\
\hline $\begin{array}{r}7 / 13 / 2009 \\
11: 00\end{array}$ & $\begin{array}{r}7 / 13 / 2009 \\
12: 00\end{array}$ & 910.7 & 8055.3 & 2.9 & 2.2 & 609.1 & 1.1 & 783.5 & 777.3 & 315.7 & 311.2 & 2312.7 & 6.9 & 1.5 & 0.4 & 65.2 & 10.5 & 13.2 \\
\hline $\begin{array}{r}7 / 13 / 2009 \\
12: 00 \\
\end{array}$ & $\begin{array}{r}7 / 13 / 2009 \\
13: 00 \\
\end{array}$ & 912.8 & 8066.6 & 2.9 & 2.2 & 602.3 & 1.1 & 784.3 & 779.7 & 317.9 & 314.4 & 2325.8 & 6.4 & 1.4 & 0.4 & 56.7 & 10.2 & 12.9 \\
\hline $\begin{array}{r}7 / 13 / 2009 \\
13: 00 \\
\end{array}$ & $\begin{array}{r}7 / 13 / 2009 \\
14: 00 \\
\end{array}$ & 911.9 & 8065.2 & 2.9 & 2.2 & 596.4 & 1.1 & 777.0 & 771.2 & 318.7 & 315.0 & 2308.4 & 6.3 & 1.4 & 0.4 & 48.3 & 10.3 & 12.8 \\
\hline $\begin{array}{r}7 / 13 / 2009 \\
14: 00 \\
\end{array}$ & $\begin{array}{r}7 / 13 / 2009 \\
15: 00 \\
\end{array}$ & 909.0 & 8045.9 & 2.9 & 2.1 & 594.0 & 1.1 & 764.9 & 759.0 & 317.1 & 312.8 & 2295.8 & 6.1 & 1.4 & 0.4 & 39.6 & 10.1 & 12.4 \\
\hline $\begin{array}{r}7 / 13 / 2009 \\
15: 00 \\
\end{array}$ & $\begin{array}{r}7 / 13 / 2009 \\
16: 00 \\
\end{array}$ & 906.8 & 8063.7 & 2.9 & 2.0 & 597.5 & 1.1 & 765.5 & 761.3 & 316.8 & 313.4 & 2288.7 & 6.4 & 1.4 & 0.4 & 38.9 & 10.4 & 12.8 \\
\hline $\begin{array}{r}7 / 13 / 2009 \\
16: 00 \\
\end{array}$ & $\begin{array}{r}7 / 13 / 2009 \\
17: 00 \\
\end{array}$ & 908.7 & 8030.8 & 2.8 & 2.0 & 605.2 & 1.1 & 763.8 & 758.7 & 316.8 & 313.4 & 2303.3 & 6.2 & 1.5 & 0.4 & 42.1 & 11.1 & 13.6 \\
\hline $\begin{array}{r}7 / 13 / 2009 \\
17: 00 \\
\end{array}$ & $\begin{array}{r}7 / 13 / 2009 \\
18: 00 \\
\end{array}$ & 910.0 & 8054.2 & 2.8 & 2.1 & 615.6 & 1.1 & 771.6 & 765.4 & 318.0 & 314.6 & 2310.5 & 6.3 & 1.4 & 0.4 & 38.7 & 11.8 & 14.4 \\
\hline $\begin{array}{r}7 / 13 / 2009 \\
18: 00 \\
\end{array}$ & $\begin{array}{r}7 / 13 / 2009 \\
19: 00 \\
\end{array}$ & 911.0 & 8049.6 & 2.8 & 2.1 & 617.7 & 1.1 & 777.2 & 770.2 & 319.3 & 315.8 & 2313.0 & 6.3 & 1.4 & 0.4 & 52.0 & 12.4 & 14.9 \\
\hline $\begin{array}{r}7 / 13 / 2009 \\
19: 00 \\
\end{array}$ & $\begin{array}{r}7 / 13 / 2009 \\
20: 00 \\
\end{array}$ & 912.5 & 8032.9 & 2.7 & 2.1 & 614.3 & 1.1 & 781.4 & 774.6 & 320.8 & 316.9 & 2314.1 & 6.3 & 1.4 & 0.4 & 61.5 & 12.5 & 15.0 \\
\hline $\begin{array}{r}7 / 13 / 2009 \\
20: 00 \\
\end{array}$ & $\begin{array}{r}7 / 13 / 2009 \\
21: 00 \\
\end{array}$ & 909.6 & 8063.8 & 2.7 & 2.2 & 611.0 & 1.1 & 773.4 & 764.4 & 319.8 & 314.7 & 2312.4 & 7.4 & 1.5 & 0.4 & 45.8 & 12.4 & 15.0 \\
\hline $\begin{array}{r}7 / 13 / 2009 \\
21: 00 \\
\end{array}$ & $\begin{array}{r}7 / 13 / 2009 \\
22: 00 \\
\end{array}$ & 911.1 & 8056.7 & 2.6 & 2.3 & 614.9 & 1.1 & 771.0 & 762.8 & 316.4 & 310.7 & 2309.9 & 10.7 & 1.5 & 0.4 & 41.0 & 12.4 & 15.0 \\
\hline $\begin{array}{r}7 / 13 / 2009 \\
22: 00 \\
\end{array}$ & $\begin{array}{r}7 / 13 / 2009 \\
23: 00 \\
\end{array}$ & 910.0 & 8049.8 & 2.6 & 2.3 & 611.3 & 1.1 & 775.4 & 767.8 & 315.7 & 310.6 & 2307.2 & 10.9 & 1.5 & 0.4 & 39.6 & 12.5 & 15.1 \\
\hline $\begin{array}{r}7 / 13 / 2009 \\
23: 00 \\
\end{array}$ & $\begin{array}{r}7 / 14 / 2009 \\
0: 00 \\
\end{array}$ & 908.7 & 8034.6 & 2.6 & 2.3 & 608.2 & 1.1 & 773.1 & 766.0 & 315.0 & 309.8 & 2310.0 & 10.3 & 1.5 & 0.4 & 37.8 & 12.7 & 15.2 \\
\hline $\begin{array}{r}7 / 14 / 2009 \\
0: 00 \\
\end{array}$ & $\begin{array}{r}7 / 14 / 2009 \\
1: 00 \\
\end{array}$ & 909.8 & 8039.0 & 2.6 & 2.2 & 610.4 & 1.1 & 770.8 & 763.7 & 313.0 & 308.0 & 2322.1 & 10.4 & 1.5 & 0.4 & 49.8 & 12.7 & 15.1 \\
\hline $\begin{array}{r}7 / 14 / 2009 \\
1: 00 \\
\end{array}$ & $\begin{array}{r}7 / 14 / 2009 \\
2: 00 \\
\end{array}$ & 910.8 & 8055.3 & 2.6 & 2.2 & 610.0 & 1.1 & 768.4 & 760.5 & 310.8 & 304.7 & 2323.7 & 10.8 & 1.5 & 0.4 & 51.2 & 12.5 & 15.1 \\
\hline $\begin{array}{r}7 / 14 / 2009 \\
2: 00 \\
\end{array}$ & $\begin{array}{r}7 / 14 / 2009 \\
3: 00 \\
\end{array}$ & 901.5 & 8035.9 & 2.7 & 2.1 & 599.2 & 1.1 & 768.8 & 761.1 & 309.3 & 302.4 & 2294.7 & 10.6 & 1.5 & 0.4 & 49.7 & 12.6 & 15.1 \\
\hline $\begin{array}{r}7 / 14 / 2009 \\
3: 00 \\
\end{array}$ & $\begin{array}{r}7 / 14 / 2009 \\
4: 00 \\
\end{array}$ & 883.4 & 8038.2 & 2.8 & 2.1 & 598.2 & 1.1 & 768.2 & 760.2 & 311.9 & 308.9 & 2275.2 & 10.6 & 1.6 & 0.4 & 16.6 & 13.3 & 15.8 \\
\hline $\begin{array}{r}7 / 14 / 2009 \\
4: 00 \\
\end{array}$ & $\begin{array}{r}7 / 14 / 2009 \\
5: 00 \\
\end{array}$ & 904.1 & 8071.2 & 2.7 & 2.2 & 612.8 & 1.1 & 778.1 & 766.5 & 306.1 & 305.2 & 2319.5 & 10.7 & 1.5 & 0.4 & 25.7 & 13.2 & 15.6 \\
\hline $\begin{array}{r}7 / 14 / 2009 \\
5: 00\end{array}$ & $\begin{array}{r}7 / 14 / 2009 \\
6: 00\end{array}$ & 910.4 & 8062.3 & 2.7 & 2.0 & 618.2 & 1.1 & 776.6 & 765.8 & 305.0 & 304.5 & 2327.1 & 9.8 & 1.5 & 0.4 & 26.4 & $\# \mathrm{~N} / \mathrm{A}$ & $\# \mathrm{~N} / \mathrm{A}$ \\
\hline
\end{tabular}




\begin{tabular}{|c|c|c|c|c|c|c|c|c|c|c|c|c|c|c|c|c|c|c|}
\hline \multirow[t]{2}{*}{$\begin{array}{l}\text { Start } \\
\text { Date/ } \\
\text { Time }\end{array}$} & \multirow[t]{2}{*}{$\begin{array}{l}\text { End } \\
\text { Date/ } \\
\text { Time }\end{array}$} & $\begin{array}{l}\text { Gross } \\
\text { Load }\end{array}$ & $\begin{array}{c}\text { Gross } \\
\text { HR }\end{array}$ & $\begin{array}{c}\text { A } \\
\text { Econ } \\
\text { O2 }\end{array}$ & $\begin{array}{c}\text { B } \\
\text { Econ } \\
\text { O2 }\end{array}$ & $\begin{array}{l}\text { Fuel } \\
\text { Flow }\end{array}$ & $\begin{array}{l}\text { BTU } \\
\text { Gain }\end{array}$ & $\begin{array}{c}\text { A } \\
\text { APH } \\
\text { In }\end{array}$ & $\begin{array}{c}\text { B } \\
\text { APH } \\
\text { In }\end{array}$ & $\begin{array}{c}\text { A } \\
\text { APH } \\
\text { Out }\end{array}$ & $\begin{array}{c}\text { B } \\
\text { APH } \\
\text { Out }\end{array}$ & $\begin{array}{l}\text { Stack } \\
\text { Flow }\end{array}$ & Opacity & SO2 In & $\begin{array}{l}\text { SO2 } \\
\text { Out }\end{array}$ & $\mathrm{CO}$ & $\begin{array}{c}\text { Stack } \\
\text { SCEM } \\
\text { Elemental } \\
\mathrm{Hg}\end{array}$ & $\begin{array}{c}\text { Stack } \\
\text { SCEM } \\
\text { Total Hg }\end{array}$ \\
\hline & & MW & Btu/kWh & $\%$ & $\%$ & Ton/hr & & DEGF & DEGF & DEGF & DEGF & KSCF & $\%$ & $\mathrm{Ib} / \mathrm{MMB}$ & $\mathrm{Ib} / \mathrm{MMb}$ & PPM & $\begin{array}{c}\text { ( } \mu \mathrm{g} / \mathrm{dNm} \text { ) } \\
@ 3 \% 02\end{array}$ & $\begin{array}{c}(\mu \mathrm{g} / \mathrm{dNm} 3) \\
@ 3 \% 02\end{array}$ \\
\hline $\begin{array}{r}7 / 14 / 2009 \\
6: 00\end{array}$ & $\begin{array}{r}7 / 14 / 2009 \\
7: 00\end{array}$ & 911.6 & 8045.5 & 2.7 & 2.0 & 618.2 & 1.1 & 770.3 & 760.5 & 301.8 & 301.5 & 2330.0 & 10.3 & 1.6 & 0.4 & 28.2 & $\# \mathrm{~N} / \mathrm{A}$ & $\# \mathrm{~N} / \mathrm{A}$ \\
\hline $\begin{array}{r}7 / 14 / 2009 \\
7: 00\end{array}$ & $\begin{array}{r}7 / 14 / 2009 \\
8: 00\end{array}$ & 910.3 & 8046.0 & 2.8 & 2.0 & 618.9 & 1.1 & 767.4 & 757.6 & 301.0 & 300.9 & 2337.2 & 9.9 & 1.6 & 0.4 & 50.6 & 8.1 & 9.6 \\
\hline $\begin{array}{r}7 / 14 / 2009 \\
8: 00\end{array}$ & $\begin{array}{r}7 / 14 / 2009 \\
9: 00\end{array}$ & 909.3 & 8055.3 & 2.8 & 2.0 & 622.9 & 1.1 & 768.0 & 756.1 & 301.1 & 300.8 & 2340.0 & 10.2 & 1.6 & 0.4 & 38.9 & 7.3 & 9.2 \\
\hline $\begin{array}{r}7 / 14 / 2009 \\
9: 00\end{array}$ & $\begin{array}{r}7 / 14 / 2009 \\
10: 00\end{array}$ & 909.5 & 8064.0 & 3.1 & 2.8 & 626.0 & 1.1 & 769.1 & 756.6 & 302.9 & 302.8 & 2316.3 & 10.0 & 1.6 & 0.4 & 38.8 & 5.8 & 7.1 \\
\hline $\begin{array}{r}7 / 14 / 2009 \\
10: 00\end{array}$ & $\begin{array}{r}7 / 14 / 2009 \\
11: 00\end{array}$ & 910.4 & 8071.6 & 2.8 & 1.9 & 629.7 & 1.1 & 771.6 & 758.9 & 305.0 & 305.7 & 2320.5 & 10.3 & 1.6 & 0.4 & 37.4 & 5.5 & 6.5 \\
\hline $\begin{array}{r}7 / 14 / 2009 \\
11: 00\end{array}$ & $\begin{array}{r}7 / 14 / 2009 \\
12: 00\end{array}$ & 911.3 & 8087.8 & 2.7 & 2.0 & 629.7 & 1.1 & 770.2 & 757.9 & 307.2 & 307.9 & 2328.3 & 10.7 & 1.6 & 0.5 & 41.5 & 5.6 & 6.7 \\
\hline $\begin{array}{r}7 / 14 / 2009 \\
12: 00\end{array}$ & $\begin{array}{r}7 / 14 / 2009 \\
13: 00\end{array}$ & 912.8 & 8056.7 & 2.7 & 2.0 & 626.3 & 1.1 & 767.3 & 754.8 & 308.0 & 308.7 & 2303.2 & 10.9 & 1.6 & 0.5 & 49.1 & 6.6 & 7.6 \\
\hline $\begin{array}{r}7 / 14 / 2009 \\
13: 00\end{array}$ & $\begin{array}{r}7 / 14 / 2009 \\
14: 00\end{array}$ & 911.0 & 8031.0 & 2.7 & 2.0 & 622.1 & 1.1 & 772.3 & 759.2 & 310.1 & 311.3 & 2300.9 & 10.9 & 1.7 & 0.5 & 52.2 & 5.7 & 6.8 \\
\hline $\begin{array}{r}7 / 14 / 2009 \\
14: 00\end{array}$ & $\begin{array}{r}7 / 14 / 2009 \\
15: 00\end{array}$ & 908.5 & 8056.4 & 2.8 & 2.0 & 624.8 & 1.1 & 773.1 & 761.5 & 312.6 & 315.0 & 2299.4 & 8.8 & 1.7 & 0.5 & 47.5 & 5.5 & 6.4 \\
\hline $\begin{array}{r}7 / 14 / 2009 \\
15: 00 \\
\end{array}$ & $\begin{array}{r}7 / 14 / 2009 \\
16: 00 \\
\end{array}$ & 908.9 & 8040.2 & 2.8 & 1.9 & 626.8 & 1.1 & 774.3 & 763.9 & 314.1 & 316.9 & 2315.4 & 7.1 & 1.8 & 0.5 & 53.0 & 5.7 & 6.8 \\
\hline $\begin{array}{r}7 / 14 / 2009 \\
16: 00\end{array}$ & $\begin{array}{r}7 / 14 / 2009 \\
17: 00\end{array}$ & 911.1 & 8041.8 & 2.7 & 2.0 & 627.3 & 1.1 & 773.4 & 763.4 & 315.5 & 318.3 & 2328.3 & 6.7 & 1.9 & 0.5 & 41.6 & 5.9 & 7.1 \\
\hline $\begin{array}{r}7 / 14 / 2009 \\
17: 00\end{array}$ & $\begin{array}{r}7 / 14 / 2009 \\
18: 00\end{array}$ & 910.7 & 8060.4 & 2.8 & 2.0 & 619.4 & 1.1 & 773.4 & 763.4 & 315.4 & 318.2 & 2324.2 & 6.4 & 1.9 & 0.5 & 39.7 & 7.3 & 8.5 \\
\hline $\begin{array}{r}7 / 14 / 2009 \\
18: 00\end{array}$ & $\begin{array}{r}7 / 14 / 2009 \\
19: 00\end{array}$ & 909.3 & 8066.8 & 2.8 & 2.1 & 616.1 & 1.1 & 777.5 & 765.6 & 316.9 & 319.6 & 2325.8 & 6.8 & 2.0 & 0.5 & 50.1 & 10.3 & 11.8 \\
\hline $\begin{array}{r}7 / 14 / 2009 \\
19: 00\end{array}$ & $\begin{array}{r}7 / 14 / 2009 \\
20: 00\end{array}$ & 905.4 & 8060.7 & 2.9 & 2.1 & 615.1 & 1.1 & 779.6 & 768.8 & 324.2 & 322.7 & 2336.9 & 7.2 & 1.9 & 0.5 & 47.8 & 11.7 & 13.4 \\
\hline $\begin{array}{r}7 / 14 / 2009 \\
20: 00 \\
\end{array}$ & $\begin{array}{r}7 / 14 / 2009 \\
21: 00 \\
\end{array}$ & 909.7 & 8043.4 & 2.9 & 2.2 & 619.0 & 1.1 & 782.3 & 773.4 & 324.0 & 319.1 & 2350.7 & 6.9 & 1.9 & 0.5 & 49.0 & 12.5 & 14.2 \\
\hline $\begin{array}{r}7 / 14 / 2009 \\
21: 00 \\
\end{array}$ & $\begin{array}{r}7 / 14 / 2009 \\
22: 00 \\
\end{array}$ & 908.2 & 8056.1 & 2.9 & 2.2 & 618.4 & 1.1 & 774.5 & 762.4 & 323.9 & 318.0 & 2340.7 & 6.7 & 2.0 & 0.5 & 37.8 & 13.2 & 15.0 \\
\hline $\begin{array}{r}7 / 14 / 2009 \\
22: 00 \\
\end{array}$ & $\begin{array}{r}7 / 14 / 2009 \\
23: 00 \\
\end{array}$ & 909.0 & 8066.9 & 2.9 & 2.2 & 623.8 & 1.1 & 763.0 & 751.7 & 318.3 & 312.3 & 2330.2 & 6.6 & 2.0 & 0.5 & 41.5 & 13.4 & 15.1 \\
\hline $\begin{array}{r}7 / 14 / 2009 \\
23: 00\end{array}$ & $\begin{array}{r}7 / 15 / 2009 \\
0: 00\end{array}$ & 908.3 & 8081.3 & 2.9 & 2.2 & 624.3 & 1.1 & 762.4 & 753.1 & 314.0 & 309.3 & 2350.4 & 6.4 & 2.0 & 0.5 & 58.8 & 13.6 & 15.3 \\
\hline $\begin{array}{r}7 / 15 / 2009 \\
0: 00\end{array}$ & $\begin{array}{r}7 / 15 / 2009 \\
1: 00\end{array}$ & 892.8 & 8095.8 & 2.9 & 2.1 & 615.4 & 1.1 & 763.4 & 755.0 & 313.4 & 307.8 & 2315.1 & 6.2 & 2.0 & 0.5 & 51.5 & 13.6 & 15.6 \\
\hline $7 / 15 / 2009$ & $7 / 15 / 2009$ & 882.8 & 8079.5 & 3.0 & 1.9 & 608.7 & 1.1 & 763.4 & 755.2 & 315.9 & 308.5 & 2307.3 & 6.2 & 2.0 & 0.5 & 31.1 & 13.8 & 15.6 \\
\hline
\end{tabular}




\begin{tabular}{|c|c|c|c|c|c|c|c|c|c|c|c|c|c|c|c|c|c|c|}
\hline $\begin{array}{l}\text { Start } \\
\text { Date/ } \\
\text { Time }\end{array}$ & $\begin{array}{l}\text { End } \\
\text { Date/ } \\
\text { Time }\end{array}$ & $\begin{array}{l}\text { Gross } \\
\text { Load }\end{array}$ & $\begin{array}{c}\text { Gross } \\
\text { HR }\end{array}$ & $\begin{array}{c}\text { A } \\
\text { Econ } \\
\text { O2 }\end{array}$ & $\begin{array}{c}\text { B } \\
\text { Econ } \\
\text { O2 }\end{array}$ & $\begin{array}{l}\text { Fuel } \\
\text { Flow }\end{array}$ & $\begin{array}{l}\text { BTU } \\
\text { Gain }\end{array}$ & $\begin{array}{c}\text { A } \\
\text { APH } \\
\text { In }\end{array}$ & $\begin{array}{c}\text { B } \\
\text { APH } \\
\text { In }\end{array}$ & $\begin{array}{c}\text { A } \\
\text { APH } \\
\text { Out }\end{array}$ & $\begin{array}{c}\text { B } \\
\text { APH } \\
\text { Out }\end{array}$ & $\begin{array}{l}\text { Stack } \\
\text { Flow }\end{array}$ & Opacity & SO2 In & $\begin{array}{l}\text { SO2 } \\
\text { Out }\end{array}$ & $\mathrm{CO}$ & $\begin{array}{c}\text { Stack } \\
\text { SCEM } \\
\text { Elemental } \\
\mathrm{Hg}\end{array}$ & $\begin{array}{c}\text { Stack } \\
\text { SCEM } \\
\text { Total Hg }\end{array}$ \\
\hline & & MW & Btu/kWh & $\%$ & $\%$ & Ton/hr & & DEGF & DEGF & DEGF & DEGF & KSCF & $\%$ & $\mathrm{Ib} / \mathrm{MMB}$ & $\mathrm{lb} / \mathrm{MMb}$ & PPM & $\begin{array}{c}(\mu \mathrm{g} / \mathrm{dNm} 3) \\
@ 3 \% 02\end{array}$ & $\begin{array}{c}(\mu \mathrm{g} / \mathrm{dNm} 3) \\
\text { @ 3\%O2 }\end{array}$ \\
\hline $1: 00$ & $2: 00$ & & & & & & & & & & & & & & & & & \\
\hline $\begin{array}{r}7 / 15 / 2009 \\
2: 00\end{array}$ & $\begin{array}{r}7 / 15 / 2009 \\
3: 00\end{array}$ & 843.5 & 8080.3 & 3.1 & 2.0 & 582.2 & 1.1 & 755.0 & 746.0 & 314.5 & 304.9 & 2228.2 & 6.0 & 2.0 & 0.5 & 15.7 & 13.8 & 15.6 \\
\hline $\begin{array}{r}7 / 15 / 2009 \\
3: 00\end{array}$ & $\begin{array}{r}7 / 15 / 2009 \\
4: 00\end{array}$ & 861.0 & 8081.8 & 3.1 & 2.0 & 595.2 & 1.1 & 744.0 & 736.5 & 304.2 & 296.6 & 2273.1 & 6.1 & 2.0 & 0.5 & 17.4 & 13.9 & 15.5 \\
\hline $\begin{array}{r}7 / 15 / 2009 \\
4: 00\end{array}$ & $\begin{array}{r}7 / 15 / 2009 \\
5: 00\end{array}$ & 844.8 & 8131.9 & 3.1 & 1.9 & 576.8 & 1.1 & 737.2 & 730.9 & 298.5 & 291.8 & 2238.7 & 6.1 & 2.0 & 0.5 & 16.3 & $\# \mathrm{~N} / \mathrm{A}$ & $\# \mathrm{~N} / \mathrm{A}$ \\
\hline $\begin{array}{r}7 / 15 / 2009 \\
5: 00\end{array}$ & $\begin{array}{r}7 / 15 / 2009 \\
6: 00\end{array}$ & 770.7 & 8113.3 & 3.1 & 1.9 & 524.3 & 1.1 & 718.6 & 714.0 & 294.3 & 286.0 & 2057.0 & 6.1 & 2.0 & 0.5 & 9.6 & $\# \mathrm{~N} / \mathrm{A}$ & $\# \mathrm{~N} / \mathrm{A}$ \\
\hline $\begin{array}{r}7 / 15 / 2009 \\
6: 00\end{array}$ & $\begin{array}{r}7 / 15 / 2009 \\
7: 00\end{array}$ & 869.0 & 8022.6 & 2.9 & 1.9 & 592.4 & 1.1 & 746.0 & 739.5 & 295.8 & 289.2 & 2303.3 & 7.6 & 2.0 & 0.5 & 34.2 & $\# \mathrm{~N} / \mathrm{A}$ & $\# \mathrm{~N} / \mathrm{A}$ \\
\hline $\begin{array}{r}7 / 15 / 2009 \\
7: 00\end{array}$ & $\begin{array}{r}7 / 15 / 2009 \\
8: 00\end{array}$ & 893.9 & 8099.0 & 2.8 & 2.0 & 597.3 & 1.1 & 759.5 & 751.4 & 298.6 & 292.4 & 2320.4 & 7.6 & 2.0 & 0.5 & 40.7 & 13.1 & 14.6 \\
\hline $\begin{array}{r}7 / 15 / 2009 \\
8: 00\end{array}$ & $\begin{array}{r}7 / 15 / 2009 \\
9: 00\end{array}$ & 886.2 & 8139.4 & 2.9 & 2.0 & 586.7 & 1.1 & 753.5 & 746.4 & 298.8 & 292.7 & 2304.5 & 7.8 & 1.9 & 0.5 & 36.3 & 12.3 & 13.7 \\
\hline $\begin{array}{r}7 / 15 / 2009 \\
9: 00\end{array}$ & $\begin{array}{r}7 / 15 / 2009 \\
10: 00\end{array}$ & 886.4 & 8142.2 & 2.9 & 1.9 & 577.9 & 1.1 & 747.0 & 741.9 & 297.7 & 291.9 & 2277.3 & 7.8 & 1.8 & 0.4 & 28.0 & 10.1 & 11.4 \\
\hline $\begin{array}{r}7 / 15 / 2009 \\
10: 00 \\
\end{array}$ & $\begin{array}{r}7 / 15 / 2009 \\
11: 00 \\
\end{array}$ & 881.7 & 8114.0 & 2.9 & 1.8 & 577.8 & 1.2 & 750.9 & 746.3 & 299.8 & 294.2 & 2249.0 & 7.7 & 1.8 & 0.4 & 29.5 & 8.0 & 9.1 \\
\hline $\begin{array}{r}7 / 15 / 2009 \\
11: 00\end{array}$ & $\begin{array}{r}7 / 15 / 2009 \\
12: 00\end{array}$ & 885.7 & 8103.6 & 2.8 & 1.9 & 586.4 & 1.2 & 756.5 & 751.7 & 304.6 & 298.7 & 2256.8 & 8.0 & 1.8 & 0.5 & 25.7 & 7.9 & 8.9 \\
\hline $\begin{array}{r}7 / 15 / 2009 \\
12: 00\end{array}$ & $\begin{array}{r}7 / 15 / 2009 \\
13: 00\end{array}$ & 888.2 & 8098.7 & 2.7 & 1.9 & 594.4 & 1.2 & 759.6 & 753.0 & 308.7 & 302.9 & 2262.5 & 8.2 & 2.0 & 0.5 & 26.6 & 8.3 & 9.3 \\
\hline $\begin{array}{r}7 / 15 / 2009 \\
13: 00\end{array}$ & $\begin{array}{r}7 / 15 / 2009 \\
14: 00\end{array}$ & 894.3 & 8061.1 & 2.7 & 1.9 & 600.4 & 1.1 & 758.7 & 752.9 & 310.2 & 304.9 & 2265.2 & 7.6 & 2.0 & 0.5 & 30.8 & 7.9 & 8.8 \\
\hline $\begin{array}{r}7 / 15 / 2009 \\
14: 00\end{array}$ & $\begin{array}{r}7 / 15 / 2009 \\
15: 00\end{array}$ & 902.1 & 8071.4 & 2.8 & 1.9 & 610.5 & 1.1 & 762.2 & 756.3 & 312.1 & 307.9 & 2295.4 & 6.8 & 2.0 & 0.5 & 32.8 & 6.8 & 7.8 \\
\hline $\begin{array}{r}7 / 15 / 2009 \\
15: 00 \\
\end{array}$ & $\begin{array}{r}7 / 15 / 2009 \\
16: 00 \\
\end{array}$ & 906.6 & 8096.3 & 2.8 & 1.8 & 608.5 & 1.1 & 762.4 & 758.0 & 315.0 & 311.1 & 2303.2 & 6.9 & 2.0 & 0.5 & 31.3 & 6.1 & 7.1 \\
\hline $\begin{array}{r}7 / 15 / 2009 \\
16: 00 \\
\end{array}$ & $\begin{array}{r}7 / 15 / 2009 \\
17: 00 \\
\end{array}$ & 901.3 & 8097.5 & 2.8 & 1.9 & 605.7 & 1.1 & 757.2 & 751.4 & 314.5 & 310.5 & 2289.5 & 6.7 & 2.0 & 0.5 & 29.3 & 7.5 & 8.6 \\
\hline $\begin{array}{r}7 / 15 / 2009 \\
17: 00 \\
\end{array}$ & $\begin{array}{r}7 / 15 / 2009 \\
18: 00 \\
\end{array}$ & 901.9 & 8078.0 & 2.9 & 2.0 & 609.5 & 1.1 & 764.3 & 757.1 & 315.1 & 311.6 & 2304.2 & 6.8 & 1.9 & 0.5 & 24.0 & 9.9 & 11.0 \\
\hline $\begin{array}{r}7 / 15 / 2009 \\
18: 00 \\
\end{array}$ & $\begin{array}{r}7 / 15 / 2009 \\
19: 00 \\
\end{array}$ & 900.6 & 8073.9 & 2.9 & 2.0 & 608.4 & 1.1 & 767.5 & 759.3 & 317.3 & 313.7 & 2301.3 & 6.8 & 1.9 & 0.5 & 20.8 & 10.9 & 12.3 \\
\hline $\begin{array}{r}7 / 15 / 2009 \\
19: 00\end{array}$ & $\begin{array}{r}7 / 15 / 2009 \\
20: 00\end{array}$ & 900.4 & 8069.8 & 2.9 & 2.0 & 607.0 & 1.1 & 767.8 & 761.7 & 318.0 & 314.4 & 2306.0 & 6.7 & 1.9 & 0.4 & 20.8 & 11.5 & 12.9 \\
\hline $\begin{array}{r}7 / 15 / 2009 \\
20: 00 \\
\end{array}$ & $\begin{array}{r}7 / 15 / 2009 \\
21: 00 \\
\end{array}$ & 900.0 & 8070.6 & 2.9 & 2.0 & 608.4 & 1.1 & 768.6 & 763.6 & 318.0 & 314.5 & 2312.2 & 6.6 & 1.8 & 0.4 & 19.8 & 12.0 & 13.4 \\
\hline
\end{tabular}




\begin{tabular}{|c|c|c|c|c|c|c|c|c|c|c|c|c|c|c|c|c|c|c|}
\hline $\begin{array}{l}\text { Start } \\
\text { Date/ } \\
\text { Time }\end{array}$ & $\begin{array}{l}\text { End } \\
\text { Date/ } \\
\text { Time }\end{array}$ & $\begin{array}{l}\text { Gross } \\
\text { Load }\end{array}$ & $\begin{array}{c}\text { Gross } \\
\text { HR }\end{array}$ & $\begin{array}{c}\text { A } \\
\text { Econ } \\
\text { O2 }\end{array}$ & $\begin{array}{c}\text { B } \\
\text { Econ } \\
\text { O2 }\end{array}$ & $\begin{array}{l}\text { Fuel } \\
\text { Flow }\end{array}$ & $\begin{array}{l}\text { BTU } \\
\text { Gain }\end{array}$ & $\begin{array}{l}\text { A } \\
\text { APH } \\
\text { In }\end{array}$ & $\begin{array}{c}\text { B } \\
\text { APH } \\
\text { In }\end{array}$ & $\begin{array}{c}\text { A } \\
\text { APH } \\
\text { Out }\end{array}$ & $\begin{array}{c}\text { B } \\
\text { APH } \\
\text { Out }\end{array}$ & $\begin{array}{l}\text { Stack } \\
\text { Flow }\end{array}$ & Opacity & SO2 In & $\begin{array}{l}\text { SO2 } \\
\text { Out }\end{array}$ & $\mathrm{CO}$ & $\begin{array}{c}\text { Stack } \\
\text { SCEM } \\
\text { Elemental } \\
\mathrm{Hg}\end{array}$ & $\begin{array}{c}\text { Stack } \\
\text { SCEM } \\
\text { Total Hg }\end{array}$ \\
\hline & & MW & Btu/kWh & $\%$ & $\%$ & Ton/hr & & DEGF & DEGF & DEGF & DEGF & KSCF & $\%$ & Ib/MMB & $\mathrm{Ib} / \mathrm{MMb}$ & PPM & $\begin{array}{c}(\mu \mathrm{g} / \mathrm{dNm} 3) \\
@ 3 \% 02\end{array}$ & $\begin{array}{c}(\mu \mathrm{g} / \mathrm{dNm} 3) \\
@ 3 \% 02\end{array}$ \\
\hline $\begin{array}{r}7 / 15 / 2009 \\
21: 00\end{array}$ & $\begin{array}{r}7 / 15 / 2009 \\
22: 00\end{array}$ & 902.4 & 8089.3 & 2.9 & 2.0 & 609.2 & 1.1 & 771.4 & 766.1 & 317.2 & 313.6 & 2323.8 & 9.2 & 1.7 & 0.4 & 20.5 & 12.2 & 13.6 \\
\hline $\begin{array}{r}7 / 15 / 2009 \\
22: 00\end{array}$ & $\begin{array}{r}7 / 15 / 2009 \\
23: 00\end{array}$ & 900.7 & 8100.2 & 2.9 & 2.1 & 607.3 & 1.1 & 771.8 & 767.3 & 317.0 & 313.1 & 2306.3 & 10.4 & 1.6 & 0.4 & 19.9 & 12.2 & 13.5 \\
\hline $\begin{array}{r}7 / 15 / 2009 \\
23: 00\end{array}$ & $\begin{array}{r}7 / 16 / 2009 \\
0: 00\end{array}$ & 899.1 & 8117.1 & 2.8 & 2.0 & 597.4 & 1.1 & 772.0 & 767.2 & 316.6 & 312.2 & 2303.2 & 10.3 & 1.6 & 0.3 & 27.0 & 11.8 & 13.1 \\
\hline $\begin{array}{r}7 / 16 / 2009 \\
0: 00\end{array}$ & $\begin{array}{r}7 / 16 / 2009 \\
1: 00\end{array}$ & 878.6 & 8100.9 & 2.9 & 1.9 & 590.0 & 1.1 & 768.0 & 763.8 & 323.7 & 316.6 & 2294.5 & 10.5 & 1.6 & 0.3 & 22.3 & 12.3 & 13.6 \\
\hline $\begin{array}{r}7 / 16 / 2009 \\
1: 00\end{array}$ & $\begin{array}{r}7 / 16 / 2009 \\
2: 00\end{array}$ & 892.5 & 8053.9 & 3.0 & 1.9 & 596.4 & 1.1 & 766.8 & 762.1 & 316.6 & 310.5 & 2299.1 & 10.5 & 1.6 & 0.3 & 24.3 & 12.3 & 13.6 \\
\hline $\begin{array}{r}7 / 16 / 2009 \\
2: 00\end{array}$ & $\begin{array}{r}7 / 16 / 2009 \\
3: 00\end{array}$ & 897.3 & 8018.1 & 3.0 & 1.9 & 594.4 & 1.1 & 771.9 & 768.4 & 313.3 & 308.5 & 2298.5 & 10.3 & 1.6 & 0.3 & 25.2 & 12.1 & 13.4 \\
\hline $\begin{array}{r}7 / 16 / 2009 \\
3: 00\end{array}$ & $\begin{array}{r}7 / 16 / 2009 \\
4: 00\end{array}$ & 875.4 & 8006.4 & 3.0 & 1.9 & 585.5 & 1.1 & 769.3 & 765.1 & 311.8 & 306.0 & 2251.3 & 10.0 & 1.6 & 0.4 & 21.6 & 12.1 & 13.4 \\
\hline $\begin{array}{r}7 / 16 / 2009 \\
4: 00\end{array}$ & $\begin{array}{r}7 / 16 / 2009 \\
5: 00\end{array}$ & 898.9 & 8024.1 & 3.0 & 1.9 & 598.2 & 1.1 & 777.8 & 773.0 & 312.5 & 307.1 & 2301.6 & 10.2 & 1.7 & 0.4 & 22.1 & 12.4 & 13.7 \\
\hline $\begin{array}{r}7 / 16 / 2009 \\
5: 00\end{array}$ & $\begin{array}{r}7 / 16 / 2009 \\
6: 00\end{array}$ & 899.7 & 8030.9 & 3.0 & 1.9 & 592.9 & 1.1 & 780.3 & 775.4 & 312.7 & 307.0 & 2307.8 & 7.4 & 1.8 & 0.4 & 21.6 & $\# \mathrm{~N} / \mathrm{A}$ & $\# \mathrm{~N} / \mathrm{A}$ \\
\hline $\begin{array}{r}7 / 16 / 2009 \\
6: 00 \\
\end{array}$ & $\begin{array}{r}7 / 16 / 2009 \\
7: 00 \\
\end{array}$ & 902.4 & 8039.8 & 2.9 & 1.8 & 601.6 & 1.1 & 780.2 & 774.9 & 312.7 & 307.0 & 2319.1 & 7.3 & 2.0 & 0.4 & 23.2 & $\# \mathrm{~N} / \mathrm{A}$ & $\# \mathrm{~N} / \mathrm{A}$ \\
\hline $\begin{array}{r}7 / 16 / 2009 \\
7: 00\end{array}$ & $\begin{array}{r}7 / 16 / 2009 \\
8: 00\end{array}$ & 906.1 & 8034.9 & 2.9 & 1.8 & 600.8 & 1.1 & 778.5 & 773.4 & 312.3 & 306.7 & 2325.1 & 7.6 & 2.1 & 0.4 & 26.0 & 12.6 & 13.9 \\
\hline $\begin{array}{r}7 / 16 / 2009 \\
8: 00\end{array}$ & $\begin{array}{r}7 / 16 / 2009 \\
9: 00\end{array}$ & 904.0 & 8048.3 & 2.9 & 1.8 & 600.7 & 1.1 & 774.8 & 773.4 & 312.3 & 307.0 & 2317.6 & 7.5 & 2.0 & 0.5 & 26.7 & 12.8 & 14.0 \\
\hline $\begin{array}{r}7 / 16 / 2009 \\
9: 00\end{array}$ & $\begin{array}{r}7 / 16 / 2009 \\
10: 00\end{array}$ & 903.7 & 8064.2 & 2.9 & 1.8 & 602.7 & 1.1 & 769.1 & 772.9 & 310.5 & 307.1 & 2307.6 & 7.2 & 2.3 & 0.5 & 30.2 & 10.7 & 11.9 \\
\hline $\begin{array}{r}7 / 16 / 2009 \\
10: 00\end{array}$ & $\begin{array}{r}7 / 16 / 2009 \\
11: 00\end{array}$ & 903.7 & 8055.4 & 3.0 & 1.9 & 601.3 & 1.1 & 769.7 & 766.4 & 308.8 & 303.7 & 2293.4 & 7.7 & 2.2 & 0.5 & 35.8 & 8.9 & 9.9 \\
\hline $\begin{array}{r}7 / 16 / 2009 \\
11: 00\end{array}$ & $\begin{array}{r}7 / 16 / 2009 \\
12: 00\end{array}$ & 905.3 & 8052.7 & 2.9 & 1.8 & 597.4 & 1.1 & 772.8 & 767.5 & 311.2 & 306.3 & 2287.8 & 8.7 & 2.2 & 0.5 & 43.2 & 3.6 & 4.3 \\
\hline $\begin{array}{r}7 / 16 / 2009 \\
12: 00 \\
\end{array}$ & $\begin{array}{r}7 / 16 / 2009 \\
13: 00 \\
\end{array}$ & 903.6 & 8073.7 & 2.9 & 1.8 & 597.7 & 1.1 & 767.1 & 759.7 & 312.2 & 306.9 & 2304.4 & 8.6 & 2.2 & 0.5 & 39.3 & 2.1 & 2.6 \\
\hline $\begin{array}{r}7 / 16 / 2009 \\
13: 00\end{array}$ & $\begin{array}{r}7 / 16 / 2009 \\
14: 00\end{array}$ & 904.7 & 8058.7 & 2.9 & 1.9 & 601.4 & 1.1 & 769.0 & 762.5 & 312.8 & 308.0 & 2305.4 & 8.8 & 2.2 & 0.5 & 40.5 & 1.6 & 2.0 \\
\hline $\begin{array}{r}7 / 16 / 2009 \\
14: 00\end{array}$ & $\begin{array}{r}7 / 16 / 2009 \\
15: 00\end{array}$ & 904.5 & 8061.0 & 2.9 & 1.9 & 600.9 & 1.1 & 772.7 & 766.2 & 315.7 & 311.0 & 2300.2 & 8.8 & 2.2 & 0.5 & 42.0 & 1.6 & 1.9 \\
\hline $\begin{array}{r}7 / 16 / 2009 \\
15: 00\end{array}$ & $\begin{array}{r}7 / 16 / 2009 \\
16: 00\end{array}$ & 906.9 & 8051.2 & 2.9 & 1.8 & 602.4 & 1.1 & 773.2 & 768.1 & 317.3 & 312.6 & 2300.2 & 8.1 & 2.2 & 0.5 & 38.5 & 1.9 & 2.4 \\
\hline $7 / 16 / 2009$ & $7 / 16 / 2009$ & 906.8 & 8034.8 & 2.9 & 1.8 & 602.2 & 1.1 & 766.9 & 762.9 & 317.5 & 312.4 & 2310.1 & 7.4 & 2.2 & 0.5 & 32.6 & 2.1 & 2.6 \\
\hline
\end{tabular}




\begin{tabular}{|c|c|c|c|c|c|c|c|c|c|c|c|c|c|c|c|c|c|c|}
\hline \multirow[t]{2}{*}{$\begin{array}{l}\text { Start } \\
\text { Date/ } \\
\text { Time }\end{array}$} & \multirow[t]{2}{*}{$\begin{array}{l}\text { End } \\
\text { Date/ } \\
\text { Time }\end{array}$} & $\begin{array}{l}\text { Gross } \\
\text { Load }\end{array}$ & $\begin{array}{c}\text { Gross } \\
\text { HR }\end{array}$ & $\begin{array}{c}\text { A } \\
\text { Econ } \\
\text { O2 }\end{array}$ & $\begin{array}{c}\text { B } \\
\text { Econ } \\
\text { O2 }\end{array}$ & $\begin{array}{l}\text { Fuel } \\
\text { Flow }\end{array}$ & $\begin{array}{l}\text { BTU } \\
\text { Gain }\end{array}$ & $\begin{array}{c}\text { A } \\
\text { APH } \\
\text { In }\end{array}$ & $\begin{array}{c}\text { B } \\
\text { APH } \\
\text { In }\end{array}$ & $\begin{array}{c}\text { A } \\
\text { APH } \\
\text { Out }\end{array}$ & $\begin{array}{c}\text { B } \\
\text { APH } \\
\text { Out }\end{array}$ & $\begin{array}{l}\text { Stack } \\
\text { Flow }\end{array}$ & Opacity & SO2 In & $\begin{array}{l}\text { SO2 } \\
\text { Out }\end{array}$ & $\mathrm{CO}$ & $\begin{array}{c}\text { Stack } \\
\text { SCEM } \\
\text { Elemental } \\
\mathrm{Hg}\end{array}$ & $\begin{array}{c}\text { Stack } \\
\text { SCEM } \\
\text { Total Hg }\end{array}$ \\
\hline & & MW & Btu/kWh & $\%$ & $\%$ & Ton/hr & & DEGF & DEGF & DEGF & DEGF & KSCF & $\%$ & $\mathrm{Ib} / \mathrm{MMB}$ & $\mathrm{lb} / \mathrm{MMb}$ & PPM & $\begin{array}{c}(\mu \mathrm{g} / \mathrm{dNm} 3) \\
@ 3 \% 02\end{array}$ & $\begin{array}{c}(\mu \mathrm{g} / \mathrm{dNm} 3) \\
\text { @ 3\%O2 }\end{array}$ \\
\hline $16: 00$ & $17: 00$ & & & & & & & & & & & & & & & & & \\
\hline $\begin{array}{r}7 / 16 / 2009 \\
17: 00\end{array}$ & $\begin{array}{r}7 / 16 / 2009 \\
18: 00\end{array}$ & 905.8 & 7989.3 & 2.9 & 1.9 & 599.5 & 1.1 & 765.7 & 761.2 & 316.6 & 311.6 & 2291.4 & 6.6 & 2.2 & 0.5 & 30.4 & 3.9 & 4.4 \\
\hline $\begin{array}{r}7 / 16 / 2009 \\
18: 00\end{array}$ & $\begin{array}{r}7 / 16 / 2009 \\
19: 00\end{array}$ & 904.2 & 8031.5 & 2.8 & 1.9 & 600.2 & 1.1 & 771.2 & 766.4 & 319.3 & 314.0 & 2296.6 & 6.4 & 2.1 & 0.5 & 29.1 & 4.7 & 5.1 \\
\hline $\begin{array}{r}7 / 16 / 2009 \\
19: 00 \\
\end{array}$ & $\begin{array}{r}7 / 16 / 2009 \\
20: 00 \\
\end{array}$ & 906.5 & 8040.2 & 2.8 & 1.9 & 605.1 & 1.1 & 771.9 & 766.9 & 320.7 & 315.8 & 2304.2 & 6.4 & 1.9 & 0.5 & 30.3 & 4.8 & 5.2 \\
\hline $\begin{array}{r}7 / 16 / 2009 \\
20: 00\end{array}$ & $\begin{array}{r}7 / 16 / 2009 \\
21: 00\end{array}$ & 909.5 & 8044.3 & 2.9 & 1.9 & 608.0 & 1.1 & 766.4 & 760.0 & 318.6 & 313.7 & 2312.2 & 7.2 & 1.9 & 0.5 & 31.8 & 5.5 & 5.9 \\
\hline $\begin{array}{r}7 / 16 / 2009 \\
21: 00\end{array}$ & $\begin{array}{r}7 / 16 / 2009 \\
22: 00\end{array}$ & 909.2 & 8011.4 & 2.8 & 1.9 & 615.7 & 1.1 & 769.1 & 761.5 & 317.6 & 312.1 & 2303.8 & 9.2 & 1.8 & 0.5 & 37.3 & 7.5 & 8.0 \\
\hline $\begin{array}{r}7 / 16 / 2009 \\
22: 00\end{array}$ & $\begin{array}{r}7 / 16 / 2009 \\
23: 00\end{array}$ & 909.3 & 8023.7 & 2.8 & 1.9 & 622.2 & 1.1 & 772.8 & 766.0 & 317.0 & 311.5 & 2309.6 & 9.7 & 1.8 & 0.5 & 30.7 & 8.8 & 9.7 \\
\hline $\begin{array}{r}7 / 16 / 2009 \\
23: 00\end{array}$ & $\begin{array}{r}7 / 17 / 2009 \\
0: 00\end{array}$ & 911.6 & 8032.0 & 2.9 & 1.8 & 621.7 & 1.1 & 776.9 & 771.0 & 316.7 & 311.5 & 2332.3 & 9.7 & 1.8 & 0.4 & 26.8 & 9.8 & 10.7 \\
\hline $\begin{array}{r}7 / 17 / 2009 \\
0: 00\end{array}$ & $\begin{array}{r}7 / 17 / 2009 \\
1: 00\end{array}$ & 907.0 & 8053.4 & 3.0 & 2.0 & 615.3 & 1.1 & 776.4 & 767.5 & 317.4 & 311.4 & 2337.8 & 9.7 & 1.7 & 0.4 & 23.0 & 10.4 & 11.5 \\
\hline $\begin{array}{r}7 / 17 / 2009 \\
1: 00\end{array}$ & $\begin{array}{r}7 / 17 / 2009 \\
2: 00\end{array}$ & 872.4 & 7942.8 & 3.0 & 1.9 & 592.4 & 1.1 & 764.2 & 751.6 & 313.2 & 303.4 & 2244.6 & 9.2 & 1.7 & 0.4 & 22.3 & 10.2 & 11.4 \\
\hline $\begin{array}{r}7 / 17 / 2009 \\
2: 00\end{array}$ & $\begin{array}{r}7 / 17 / 2009 \\
3: 00\end{array}$ & 840.1 & 7915.8 & 2.8 & 1.9 & 567.5 & 1.1 & 754.5 & 743.8 & 310.7 & 300.5 & 2155.9 & 8.7 & 1.7 & 0.4 & 27.8 & 10.0 & 11.3 \\
\hline $\begin{array}{r}7 / 17 / 2009 \\
3: 00\end{array}$ & $\begin{array}{r}7 / 17 / 2009 \\
4: 00\end{array}$ & 745.0 & 7947.3 & 2.9 & 1.9 & 501.5 & 1.1 & 720.5 & 712.2 & 304.9 & 294.2 & 1971.1 & 8.0 & 1.7 & 0.4 & 11.6 & 9.5 & 10.7 \\
\hline $\begin{array}{r}7 / 17 / 2009 \\
4: 00\end{array}$ & $\begin{array}{r}7 / 17 / 2009 \\
5: 00\end{array}$ & 744.2 & 7798.1 & 3.0 & 1.9 & 510.3 & 1.1 & 716.4 & 709.5 & 299.2 & 289.6 & 2014.3 & 7.9 & 1.6 & 0.4 & 12.9 & $\# \mathrm{~N} / \mathrm{A}$ & $\# \mathrm{~N} / \mathrm{A}$ \\
\hline $\begin{array}{r}7 / 17 / 2009 \\
5: 00\end{array}$ & $\begin{array}{r}7 / 17 / 2009 \\
6: 00\end{array}$ & 882.6 & 7895.4 & 2.8 & 1.9 & 591.4 & 1.1 & 757.8 & 749.4 & 304.4 & 296.9 & 2262.3 & 7.6 & 1.6 & 0.4 & 23.2 & $\# \mathrm{~N} / \mathrm{A}$ & $\# \mathrm{~N} / \mathrm{A}$ \\
\hline $\begin{array}{r}7 / 17 / 2009 \\
6: 00 \\
\end{array}$ & $\begin{array}{r}7 / 17 / 2009 \\
7: 00 \\
\end{array}$ & 908.4 & 8019.5 & 2.8 & 1.9 & 605.5 & 1.1 & 771.9 & 762.2 & 307.2 & 300.8 & 2305.6 & 7.8 & 1.6 & 0.4 & 24.2 & $\# \mathrm{~N} / \mathrm{A}$ & $\# \mathrm{~N} / \mathrm{A}$ \\
\hline $\begin{array}{r}7 / 17 / 2009 \\
7: 00 \\
\end{array}$ & $\begin{array}{r}7 / 17 / 2009 \\
8: 00 \\
\end{array}$ & 908.3 & 8049.0 & 2.9 & 2.0 & 606.8 & 1.1 & 765.1 & 753.7 & 306.7 & 299.5 & 2345.5 & 7.8 & 1.6 & 0.4 & 19.3 & 10.1 & 11.4 \\
\hline $\begin{array}{r}7 / 17 / 2009 \\
8: 00 \\
\end{array}$ & $\begin{array}{r}7 / 17 / 2009 \\
9: 00 \\
\end{array}$ & 906.7 & 8075.3 & 2.9 & 2.0 & 605.9 & 1.1 & 757.1 & 747.4 & 302.5 & 296.1 & 2362.3 & 7.8 & 1.6 & 0.4 & 16.9 & 10.1 & 11.3 \\
\hline $\begin{array}{r}7 / 17 / 2009 \\
9: 00 \\
\end{array}$ & $\begin{array}{r}7 / 17 / 2009 \\
10: 00 \\
\end{array}$ & 911.1 & 8053.3 & 2.9 & 1.9 & 604.2 & 1.1 & 757.5 & 746.8 & 300.2 & 294.2 & 2351.9 & 7.9 & 1.6 & 0.4 & 22.5 & 9.9 & 11.3 \\
\hline $\begin{array}{r}7 / 17 / 2009 \\
10: 00\end{array}$ & $\begin{array}{r}7 / 17 / 2009 \\
11: 00\end{array}$ & 912.3 & 8021.6 & 2.9 & 1.9 & 601.3 & 1.1 & 762.7 & 751.3 & 300.5 & 294.5 & 2340.4 & 7.8 & 1.5 & 0.4 & 25.8 & 9.1 & 10.4 \\
\hline $\begin{array}{r}7 / 17 / 2009 \\
11: 00\end{array}$ & $\begin{array}{r}7 / 17 / 2009 \\
12: 00\end{array}$ & 908.8 & 7995.0 & 2.9 & 2.0 & 599.0 & 1.1 & 765.3 & 754.0 & 302.6 & 296.2 & 2320.8 & 7.6 & 1.5 & 0.4 & 26.6 & 8.7 & 9.9 \\
\hline
\end{tabular}




\begin{tabular}{|c|c|c|c|c|c|c|c|c|c|c|c|c|c|c|c|c|c|c|}
\hline $\begin{array}{l}\text { Start } \\
\text { Date/ } \\
\text { Time }\end{array}$ & $\begin{array}{l}\text { End } \\
\text { Date/ } \\
\text { Time }\end{array}$ & $\begin{array}{l}\text { Gross } \\
\text { Load }\end{array}$ & $\begin{array}{c}\text { Gross } \\
\text { HR }\end{array}$ & $\begin{array}{c}\text { A } \\
\text { Econ } \\
\text { O2 }\end{array}$ & $\begin{array}{c}\text { B } \\
\text { Econ } \\
\text { O2 }\end{array}$ & $\begin{array}{l}\text { Fuel } \\
\text { Flow }\end{array}$ & $\begin{array}{l}\text { BTU } \\
\text { Gain }\end{array}$ & $\begin{array}{c}\text { A } \\
\text { APH } \\
\text { In }\end{array}$ & $\begin{array}{c}\text { B } \\
\text { APH } \\
\text { In }\end{array}$ & $\begin{array}{c}\text { A } \\
\text { APH } \\
\text { Out }\end{array}$ & $\begin{array}{c}\text { B } \\
\text { APH } \\
\text { Out }\end{array}$ & $\begin{array}{l}\text { Stack } \\
\text { Flow }\end{array}$ & Opacity & SO2 In & $\begin{array}{l}\text { SO2 } \\
\text { Out }\end{array}$ & $\mathrm{CO}$ & $\begin{array}{c}\text { Stack } \\
\text { SCEM } \\
\text { Elemental } \\
\mathrm{Hg}\end{array}$ & $\begin{array}{c}\text { Stack } \\
\text { SCEM } \\
\text { Total Hg }\end{array}$ \\
\hline & & MW & Btu/kWh & $\%$ & $\%$ & Ton/hr & & DEGF & DEGF & DEGF & DEGF & KSCF & $\%$ & Ib/MMB & $\mathrm{Ib} / \mathrm{MMb}$ & PPM & $\begin{array}{c}(\mu \mathrm{g} / \mathrm{dNm} 3) \\
@ 3 \% 02\end{array}$ & $\begin{array}{c}(\mu \mathrm{g} / \mathrm{dNm} 3) \\
@ 3 \% 02\end{array}$ \\
\hline $\begin{array}{r}7 / 17 / 2009 \\
12: 00\end{array}$ & $\begin{array}{r}/ 17 / 2009 \\
13: 00\end{array}$ & 904.8 & 8013.8 & 2.9 & 2.0 & 611.1 & 1.1 & 767.5 & 757.1 & 305.0 & 298.3 & 2308.6 & 8.2 & 1.5 & 0.4 & 23.7 & 9.5 & 10.9 \\
\hline $\begin{array}{r}7 / 17 / 2009 \\
13: 00\end{array}$ & $\begin{array}{r}7 / 17 / 2009 \\
14: 00\end{array}$ & 907.7 & 8031.2 & 2.9 & 1.9 & 624.4 & 1.1 & 761.5 & 752.4 & 305.4 & 299.7 & 2315.6 & 8.4 & 1.6 & 0.4 & 27.3 & 10.6 & 11.9 \\
\hline $\begin{array}{r}7 / 17 / 2009 \\
14: 00\end{array}$ & $\begin{array}{r}7 / 17 / 2009 \\
15: 00\end{array}$ & 913.8 & 8046.7 & 2.9 & 1.9 & 623.0 & 1.1 & 757.0 & 750.4 & 306.4 & 301.5 & 2316.1 & 8.5 & 1.6 & 0.4 & 31.8 & 11.0 & 12.3 \\
\hline $\begin{array}{r}7 / 17 / 2009 \\
15: 00\end{array}$ & $\begin{array}{r}7 / 17 / 2009 \\
16: 00\end{array}$ & 912.1 & 8052.3 & 2.9 & 1.9 & 615.1 & 1.1 & 753.4 & 750.2 & 305.9 & 302.1 & 2315.9 & 7.9 & 1.5 & 0.4 & 35.6 & 10.3 & 11.5 \\
\hline $\begin{array}{r}7 / 17 / 2009 \\
16: 00\end{array}$ & $\begin{array}{r}7 / 17 / 2009 \\
17: 00\end{array}$ & 908.2 & 8051.8 & 2.9 & 1.9 & 619.2 & 1.1 & 757.7 & 753.6 & 308.6 & 304.7 & 2320.1 & 7.4 & 1.5 & 0.4 & 35.3 & 10.2 & 11.5 \\
\hline $\begin{array}{r}7 / 17 / 2009 \\
17: 00\end{array}$ & $\begin{array}{r}7 / 17 / 2009 \\
18: 00\end{array}$ & 909.5 & 8049.1 & 2.9 & 1.9 & 625.9 & 1.1 & 760.5 & 755.4 & 310.1 & 305.1 & 2313.3 & 7.4 & 1.6 & 0.4 & 32.9 & 10.9 & 12.2 \\
\hline $\begin{array}{r}7 / 17 / 2009 \\
18: 00\end{array}$ & $\begin{array}{r}7 / 17 / 2009 \\
19: 00\end{array}$ & 912.7 & 8066.9 & 2.9 & 1.9 & 630.1 & 1.1 & 763.0 & 757.0 & 310.7 & 305.3 & 2318.4 & 7.5 & 1.6 & 0.4 & 25.0 & 12.0 & 13.0 \\
\hline $\begin{array}{r}7 / 17 / 2009 \\
19: 00\end{array}$ & $\begin{array}{r}7 / 17 / 2009 \\
20: 00\end{array}$ & 911.1 & 8077.5 & 2.9 & 1.9 & 625.7 & 1.1 & 757.1 & 751.2 & 308.9 & 303.7 & 2326.2 & 7.6 & 1.6 & 0.4 & 27.6 & 12.3 & 13.4 \\
\hline $\begin{array}{r}7 / 17 / 2009 \\
20: 00\end{array}$ & $\begin{array}{r}7 / 17 / 2009 \\
21: 00\end{array}$ & 911.0 & 8063.8 & 2.9 & 1.9 & 619.5 & 1.1 & 759.5 & 753.7 & 307.7 & 302.2 & 2335.7 & 7.6 & 1.6 & 0.4 & 33.6 & 12.1 & 13.3 \\
\hline $\begin{array}{r}7 / 17 / 2009 \\
21: 00 \\
\end{array}$ & $\begin{array}{r}7 / 17 / 2009 \\
22: 00 \\
\end{array}$ & 911.8 & 8056.8 & 2.9 & 1.9 & 616.7 & 1.1 & 765.0 & 757.9 & 307.8 & 302.3 & 2335.8 & 8.3 & 1.7 & 0.4 & 31.8 & 12.5 & 13.7 \\
\hline $\begin{array}{r}7 / 17 / 2009 \\
22: 00\end{array}$ & $\begin{array}{r}7 / 17 / 2009 \\
23: 00\end{array}$ & 897.7 & 8080.3 & 2.8 & 1.9 & 602.2 & 1.1 & 767.2 & 760.4 & 308.5 & 303.7 & 2296.3 & 9.2 & 1.8 & 0.4 & 29.5 & 12.7 & 13.9 \\
\hline $\begin{array}{r}7 / 17 / 2009 \\
23: 00\end{array}$ & $\begin{array}{r}7 / 18 / 2009 \\
0: 00\end{array}$ & 861.9 & 8004.7 & 2.9 & 1.9 & 579.3 & 1.1 & 755.4 & 747.9 & 311.1 & 304.5 & 2221.5 & 8.4 & 1.7 & 0.4 & 31.2 & 12.0 & 13.2 \\
\hline $\begin{array}{r}7 / 18 / 2009 \\
0: 00\end{array}$ & $\begin{array}{r}7 / 18 / 2009 \\
1: 00\end{array}$ & 893.9 & 8014.3 & 2.9 & 1.9 & 601.2 & 1.1 & 761.3 & 751.4 & 311.1 & 303.9 & 2302.9 & 7.5 & 1.7 & 0.5 & 35.8 & 11.6 & 12.7 \\
\hline $\begin{array}{r}7 / 18 / 2009 \\
1: 00\end{array}$ & $\begin{array}{r}7 / 18 / 2009 \\
2: 00\end{array}$ & 901.3 & 8009.0 & 2.9 & 1.9 & 607.1 & 1.1 & 756.1 & 749.6 & 307.9 & 302.4 & 2311.3 & 7.9 & 1.7 & 0.4 & 32.4 & $\# \mathrm{~N} / \mathrm{A}$ & $\# \mathrm{~N} / \mathrm{A}$ \\
\hline $\begin{array}{r}7 / 18 / 2009 \\
2: 00\end{array}$ & $\begin{array}{r}7 / 18 / 2009 \\
3: 00\end{array}$ & 892.1 & 8001.7 & 3.0 & 1.9 & 595.3 & 1.1 & 758.6 & 753.0 & 307.9 & 301.9 & 2274.9 & 8.2 & 1.7 & 0.4 & 29.0 & \#N/A & $\# \mathrm{~N} / \mathrm{A}$ \\
\hline $\begin{array}{r}7 / 18 / 2009 \\
3: 00 \\
\end{array}$ & $\begin{array}{r}7 / 18 / 2009 \\
4: 00 \\
\end{array}$ & 796.1 & 8031.5 & 3.0 & 2.1 & 528.7 & 1.1 & 734.5 & 729.2 & 300.5 & 292.5 & 2080.8 & 7.6 & 1.7 & 0.4 & 13.1 & 11.1 & 12.6 \\
\hline $\begin{array}{r}7 / 18 / 2009 \\
4: 00\end{array}$ & $\begin{array}{r}7 / 18 / 2009 \\
5: 00\end{array}$ & 795.2 & 8001.6 & 2.9 & 2.0 & 529.6 & 1.1 & 725.8 & 719.4 & 298.6 & 289.2 & 2030.5 & 6.9 & 1.6 & 0.4 & 13.8 & 10.8 & 12.1 \\
\hline $\begin{array}{r}7 / 18 / 2009 \\
5: 00\end{array}$ & $\begin{array}{r}7 / 18 / 2009 \\
6: 00\end{array}$ & 778.8 & 8011.5 & 3.0 & 1.9 & 510.4 & 1.1 & 723.6 & 717.2 & 297.0 & 286.9 & 1979.0 & 6.0 & 1.6 & 0.4 & 13.0 & $\# \mathrm{~N} / \mathrm{A}$ & $\# \mathrm{~N} / \mathrm{A}$ \\
\hline $\begin{array}{r}7 / 18 / 2009 \\
6: 00\end{array}$ & $\begin{array}{r}7 / 18 / 2009 \\
7: 00\end{array}$ & 710.7 & 8014.6 & 3.1 & 2.1 & 470.4 & 1.1 & 708.3 & 703.3 & 291.8 & 281.5 & 1903.4 & 5.6 & 1.5 & 0.4 & 10.3 & $\# \mathrm{~N} / \mathrm{A}$ & $\# \mathrm{~N} / \mathrm{A}$ \\
\hline $7 / 18 / 2009$ & $7 / 18 / 2009$ & 703.6 & 7877.2 & 3.0 & 2.2 & 470.9 & 1.1 & 709.1 & 703.9 & 290.1 & 279.4 & 1920.7 & 5.6 & 1.5 & 0.4 & 9.1 & 9.8 & 11.4 \\
\hline
\end{tabular}




\begin{tabular}{|c|c|c|c|c|c|c|c|c|c|c|c|c|c|c|c|c|c|c|}
\hline $\begin{array}{l}\text { Start } \\
\text { Date/ } \\
\text { Time }\end{array}$ & $\begin{array}{l}\text { End } \\
\text { Date/ } \\
\text { Time }\end{array}$ & $\begin{array}{l}\text { Gross } \\
\text { Load }\end{array}$ & $\begin{array}{c}\text { Gross } \\
\text { HR }\end{array}$ & $\begin{array}{c}\text { A } \\
\text { Econ } \\
\text { O2 }\end{array}$ & $\begin{array}{c}\text { B } \\
\text { Econ } \\
\text { O2 }\end{array}$ & $\begin{array}{l}\text { Fuel } \\
\text { Flow }\end{array}$ & $\begin{array}{l}\text { BTU } \\
\text { Gain }\end{array}$ & $\begin{array}{c}\text { A } \\
\text { APH } \\
\text { In }\end{array}$ & $\begin{array}{c}\text { B } \\
\text { APH } \\
\text { In }\end{array}$ & $\begin{array}{c}\text { A } \\
\text { APH } \\
\text { Out }\end{array}$ & $\begin{array}{c}\text { B } \\
\text { APH } \\
\text { Out }\end{array}$ & $\begin{array}{l}\text { Stack } \\
\text { Flow }\end{array}$ & Opacity & SO2 In & $\begin{array}{l}\text { SO2 } \\
\text { Out }\end{array}$ & $\mathrm{CO}$ & $\begin{array}{c}\text { Stack } \\
\text { SCEM } \\
\text { Elemental } \\
\mathrm{Hg}\end{array}$ & $\begin{array}{c}\text { Stack } \\
\text { SCEM } \\
\text { Total Hg }\end{array}$ \\
\hline & & MW & Btu/kWh & $\%$ & $\%$ & Ton/hr & & DEGF & DEGF & DEGF & DEGF & KSCF & $\%$ & $\mathrm{Ib} / \mathrm{MMB}$ & $\mathrm{lb} / \mathrm{MMb}$ & PPM & $\begin{array}{c}(\mu \mathrm{g} / \mathrm{dNm} 3) \\
@ 3 \% 02\end{array}$ & $\begin{array}{c}(\mu \mathrm{g} / \mathrm{dNm} 3) \\
\text { @ 3\%O2 }\end{array}$ \\
\hline $7: 00$ & $8: 00$ & & & & & & & & & & & & & & & & & \\
\hline $\begin{array}{r}7 / 18 / 2009 \\
8: 00\end{array}$ & $\begin{array}{r}7 / 18 / 2009 \\
9: 00\end{array}$ & 850.4 & 7838.4 & 2.9 & 2.1 & 569.7 & 1.1 & 755.6 & 749.2 & 300.7 & 292.6 & 2226.3 & 7.5 & 1.5 & 0.4 & 19.3 & 11.1 & 12.7 \\
\hline $\begin{array}{r}7 / 18 / 2009 \\
9: 00\end{array}$ & $\begin{array}{r}7 / 18 / 2009 \\
10: 00\end{array}$ & 905.6 & 8017.6 & 2.9 & 2.0 & 603.8 & 1.1 & 781.2 & 775.5 & 311.7 & 305.1 & 2289.4 & 8.4 & 1.5 & 0.4 & 35.4 & 11.4 & 12.7 \\
\hline $\begin{array}{r}7 / 18 / 2009 \\
10: 00 \\
\end{array}$ & $\begin{array}{r}7 / 18 / 2009 \\
11: 00 \\
\end{array}$ & 906.0 & 8038.3 & 3.0 & 1.9 & 613.7 & 1.1 & 784.2 & 779.3 & 314.4 & 308.9 & 2305.2 & 8.7 & 1.6 & 0.4 & 41.1 & 11.3 & 12.6 \\
\hline $\begin{array}{r}7 / 18 / 2009 \\
11: 00\end{array}$ & $\begin{array}{r}7 / 18 / 2009 \\
12: 00\end{array}$ & 909.0 & 8058.5 & 3.1 & 2.0 & 618.1 & 1.1 & 773.4 & 770.7 & 315.1 & 310.4 & 2313.9 & 8.4 & 1.6 & 0.4 & 42.5 & 11.2 & 12.5 \\
\hline $\begin{array}{r}7 / 18 / 2009 \\
12: 00\end{array}$ & $\begin{array}{r}7 / 18 / 2009 \\
13: 00\end{array}$ & 910.9 & 8040.9 & 3.0 & 2.1 & 617.9 & 1.1 & 766.7 & 760.3 & 313.4 & 307.4 & 2310.8 & 8.3 & 1.6 & 0.4 & 31.9 & 11.1 & 12.2 \\
\hline $\begin{array}{r}7 / 18 / 2009 \\
13: 00\end{array}$ & $\begin{array}{r}7 / 18 / 2009 \\
14: 00\end{array}$ & 909.9 & 8044.1 & 3.0 & 2.1 & 621.7 & 1.1 & 770.6 & 763.5 & 314.3 & 308.1 & 2317.4 & 8.6 & 1.7 & 0.4 & 23.1 & 11.4 & 12.6 \\
\hline $\begin{array}{r}7 / 18 / 2009 \\
14: 00\end{array}$ & $\begin{array}{r}7 / 18 / 2009 \\
15: 00\end{array}$ & 909.9 & 8051.0 & 3.0 & 2.1 & 623.0 & 1.1 & 770.3 & 764.2 & 315.1 & 309.4 & 2325.2 & 9.0 & 1.8 & 0.4 & 37.1 & 12.0 & 13.2 \\
\hline $\begin{array}{r}7 / 18 / 2009 \\
15: 00\end{array}$ & $\begin{array}{r}7 / 18 / 2009 \\
16: 00\end{array}$ & 909.1 & 8061.1 & 3.1 & 2.5 & 628.7 & 1.1 & 777.0 & 770.1 & 314.5 & 309.8 & 2372.8 & 9.1 & 1.8 & 0.4 & 13.7 & 12.2 & 13.5 \\
\hline $\begin{array}{r}7 / 18 / 2009 \\
16: 00 \\
\end{array}$ & $\begin{array}{r}7 / 18 / 2009 \\
17: 00 \\
\end{array}$ & 912.5 & 8059.4 & 3.2 & 2.4 & 635.0 & 1.1 & 780.5 & 775.4 & 316.8 & 311.6 & 2391.5 & 7.6 & 1.8 & 0.4 & 12.1 & 12.2 & 13.4 \\
\hline $\begin{array}{r}7 / 18 / 2009 \\
17: 00\end{array}$ & $\begin{array}{r}7 / 18 / 2009 \\
18: 00\end{array}$ & 910.4 & 8063.2 & 3.3 & 2.4 & 627.6 & 1.1 & 779.5 & 777.2 & 315.7 & 311.3 & 2385.6 & 7.2 & 1.7 & 0.4 & 11.9 & 12.1 & 13.1 \\
\hline $\begin{array}{r}7 / 18 / 2009 \\
18: 00\end{array}$ & $\begin{array}{r}7 / 18 / 2009 \\
19: 00\end{array}$ & 905.1 & 8055.0 & 3.3 & 2.4 & 621.3 & 1.1 & 782.0 & 779.3 & 315.1 & 310.7 & 2381.6 & 7.4 & 1.7 & 0.4 & 10.3 & 12.4 & 13.4 \\
\hline $\begin{array}{r}7 / 18 / 2009 \\
19: 00\end{array}$ & $\begin{array}{r}7 / 18 / 2009 \\
20: 00\end{array}$ & 890.0 & 8073.0 & 3.2 & 2.3 & 610.6 & 1.1 & 782.5 & 777.5 & 314.8 & 310.3 & 2345.2 & 7.3 & 1.7 & 0.4 & 10.9 & 13.0 & 13.9 \\
\hline $\begin{array}{r}7 / 18 / 2009 \\
20: 00\end{array}$ & $\begin{array}{r}7 / 18 / 2009 \\
21: 00\end{array}$ & 769.3 & 8082.1 & 3.4 & 2.3 & 527.1 & 1.1 & 750.6 & 745.6 & 311.1 & 305.1 & 2072.2 & 7.2 & 1.7 & 0.4 & 9.9 & 12.2 & 13.2 \\
\hline $\begin{array}{r}7 / 18 / 2009 \\
21: 00 \\
\end{array}$ & $\begin{array}{r}7 / 18 / 2009 \\
22: 00 \\
\end{array}$ & 698.1 & 7985.6 & 3.5 & 2.6 & 486.6 & 1.1 & 725.9 & 720.1 & 305.6 & 297.8 & 1968.8 & 7.1 & 1.6 & 0.4 & 6.2 & 11.5 & 12.5 \\
\hline $\begin{array}{r}7 / 18 / 2009 \\
22: 00\end{array}$ & $\begin{array}{r}7 / 18 / 2009 \\
23: 00\end{array}$ & 755.6 & 7832.0 & 3.4 & 2.5 & 528.0 & 1.1 & 739.8 & 733.6 & 302.7 & 296.0 & 2108.4 & 7.4 & 1.6 & 0.4 & 7.3 & 12.0 & 13.1 \\
\hline $\begin{array}{r}7 / 18 / 2009 \\
23: 00 \\
\end{array}$ & $\begin{array}{r}7 / 19 / 2009 \\
0: 00 \\
\end{array}$ & 893.8 & 7958.8 & 3.2 & 2.5 & 611.5 & 1.1 & 784.0 & 776.8 & 307.1 & 302.2 & 2383.2 & 7.8 & 1.6 & 0.4 & 11.5 & 13.5 & 14.5 \\
\hline $\begin{array}{r}7 / 19 / 2009 \\
0: 00 \\
\end{array}$ & $\begin{array}{r}7 / 19 / 2009 \\
1: 00 \\
\end{array}$ & 911.1 & 8015.7 & 3.1 & 2.2 & 611.8 & 1.1 & 790.5 & 784.1 & 311.2 & 306.2 & 2375.0 & 7.9 & 1.6 & 0.4 & 15.6 & 14.0 & 15.0 \\
\hline $\begin{array}{r}7 / 19 / 2009 \\
1: 00\end{array}$ & $\begin{array}{r}7 / 19 / 2009 \\
2: 00\end{array}$ & 903.2 & 8052.0 & 3.1 & 2.2 & 609.4 & 1.1 & 769.7 & 762.1 & 307.7 & 302.8 & 2355.5 & 8.4 & 1.7 & 0.4 & 18.7 & $\# \mathrm{~N} / \mathrm{A}$ & 14.9 \\
\hline $\begin{array}{r}7 / 19 / 2009 \\
2: 00\end{array}$ & $\begin{array}{r}7 / 19 / 2009 \\
3: 00\end{array}$ & 839.7 & 8070.1 & 3.1 & 2.2 & 568.1 & 1.1 & 746.3 & 737.1 & 301.2 & 293.8 & 2211.8 & 8.4 & 1.9 & 0.5 & 20.2 & $\# \mathrm{~N} / \mathrm{A}$ & $\# \mathrm{~N} / \mathrm{A}$ \\
\hline
\end{tabular}




\begin{tabular}{|c|c|c|c|c|c|c|c|c|c|c|c|c|c|c|c|c|c|c|}
\hline \multirow[t]{2}{*}{$\begin{array}{l}\text { Start } \\
\text { Date/ } \\
\text { Time }\end{array}$} & \multirow[t]{2}{*}{$\begin{array}{l}\text { End } \\
\text { Date/ } \\
\text { Time }\end{array}$} & $\begin{array}{l}\text { Gross } \\
\text { Load }\end{array}$ & $\begin{array}{c}\text { Gross } \\
\text { HR }\end{array}$ & $\begin{array}{c}\text { A } \\
\text { Econ } \\
\text { O2 }\end{array}$ & $\begin{array}{c}\text { B } \\
\text { Econ } \\
\text { O2 }\end{array}$ & $\begin{array}{l}\text { Fuel } \\
\text { Flow }\end{array}$ & $\begin{array}{l}\text { BTU } \\
\text { Gain }\end{array}$ & $\begin{array}{c}\text { A } \\
\text { APH } \\
\text { In }\end{array}$ & $\begin{array}{c}\text { B } \\
\text { APH } \\
\text { In }\end{array}$ & $\begin{array}{c}\text { A } \\
\text { APH } \\
\text { Out }\end{array}$ & $\begin{array}{c}\text { B } \\
\text { APH } \\
\text { Out }\end{array}$ & $\begin{array}{l}\text { Stack } \\
\text { Flow }\end{array}$ & Opacity & SO2 In & $\begin{array}{l}\text { SO2 } \\
\text { Out }\end{array}$ & $\mathrm{CO}$ & $\begin{array}{c}\text { Stack } \\
\text { SCEM } \\
\text { Elemental } \\
\mathrm{Hg}\end{array}$ & $\begin{array}{c}\text { Stack } \\
\text { SCEM } \\
\text { Total Hg }\end{array}$ \\
\hline & & MW & Btu/kWh & $\%$ & $\%$ & Ton/hr & & DEGF & DEGF & DEGF & DEGF & KSCF & $\%$ & $\mathrm{Ib} / \mathrm{MMB}$ & $\mathrm{Ib} / \mathrm{MMb}$ & PPM & $\begin{array}{c}\text { ( } \mu \mathrm{g} / \mathrm{dNm} \text { ) } \\
@ 3 \% 02\end{array}$ & $\begin{array}{c}(\mu \mathrm{g} / \mathrm{dNm} 3) \\
@ 3 \% 02\end{array}$ \\
\hline $\begin{array}{r}7 / 19 / 2009 \\
3: 00\end{array}$ & $\begin{array}{r}7 / 19 / 2009 \\
4: 00\end{array}$ & 748.1 & 8094.2 & 3.2 & 2.2 & 513.1 & 1.1 & 711.5 & 703.1 & 292.9 & 283.7 & 2027.7 & 6.1 & 2.0 & 0.5 & 9.5 & $\# \mathrm{~N} / \mathrm{A}$ & 14.8 \\
\hline $\begin{array}{r}7 / 19 / 2009 \\
4: 00\end{array}$ & $\begin{array}{r}7 / 19 / 2009 \\
5: 00\end{array}$ & 710.8 & 8047.7 & 3.3 & 2.2 & 496.7 & 1.1 & 701.0 & 691.3 & 292.1 & 281.7 & 1970.3 & 5.6 & 1.8 & 0.5 & 9.2 & $\# \mathrm{~N} / \mathrm{A}$ & $\# \mathrm{~N} / \mathrm{A}$ \\
\hline $\begin{array}{r}7 / 19 / 2009 \\
5: 00\end{array}$ & $\begin{array}{r}7 / 19 / 2009 \\
6: 00\end{array}$ & 768.7 & 7990.2 & 3.1 & 2.1 & 535.1 & 1.1 & 716.1 & 706.2 & 296.2 & 284.5 & 2087.9 & 5.0 & 1.7 & 0.5 & 14.4 & $\# \mathrm{~N} / \mathrm{A}$ & $\# \mathrm{~N} / \mathrm{A}$ \\
\hline $\begin{array}{r}7 / 19 / 2009 \\
6: 00\end{array}$ & $\begin{array}{r}7 / 19 / 2009 \\
7: 00\end{array}$ & 745.5 & 8013.6 & 3.2 & 2.2 & 504.7 & 1.1 & 711.9 & 701.9 & 288.9 & 278.6 & 2048.4 & 4.4 & 1.6 & 0.5 & 10.0 & $\# \mathrm{~N} / \mathrm{A}$ & $\# \mathrm{~N} / \mathrm{A}$ \\
\hline $\begin{array}{r}7 / 19 / 2009 \\
7: 00\end{array}$ & $\begin{array}{r}7 / 19 / 2009 \\
8: 00\end{array}$ & 741.0 & 8035.0 & 3.2 & 2.3 & 495.8 & 1.1 & 709.8 & 699.7 & 288.7 & 278.3 & 2061.9 & 4.3 & 1.5 & 0.4 & 8.2 & 11.0 & 12.6 \\
\hline $\begin{array}{r}7 / 19 / 2009 \\
8: 00\end{array}$ & $\begin{array}{r}7 / 19 / 2009 \\
9: 00\end{array}$ & 844.9 & 7990.6 & 3.0 & 2.4 & 562.7 & 1.1 & 740.2 & 730.1 & 294.6 & 285.8 & 2265.6 & 4.9 & 1.4 & 0.4 & 12.7 & 11.2 & 12.6 \\
\hline $\begin{array}{r}7 / 19 / 2009 \\
9: 00\end{array}$ & $\begin{array}{r}7 / 19 / 2009 \\
10: 00\end{array}$ & 905.0 & 8049.9 & 2.8 & 2.5 & 596.6 & 1.1 & 767.0 & 755.5 & 306.3 & 297.5 & 2328.5 & 5.1 & 1.4 & 0.4 & 23.4 & 10.4 & 11.9 \\
\hline $\begin{array}{r}7 / 19 / 2009 \\
10: 00\end{array}$ & $\begin{array}{r}7 / 19 / 2009 \\
11: 00\end{array}$ & 905.5 & 8049.1 & 2.8 & 2.5 & 603.9 & 1.1 & 769.7 & 757.6 & 308.9 & 300.3 & 2331.3 & 4.9 & 1.4 & 0.4 & 29.4 & 9.7 & 11.1 \\
\hline $\begin{array}{r}7 / 19 / 2009 \\
11: 00\end{array}$ & $\begin{array}{r}7 / 19 / 2009 \\
12: 00\end{array}$ & 908.9 & 8088.8 & 2.8 & 2.4 & 607.0 & 1.1 & 772.1 & 759.3 & 311.9 & 303.6 & 2338.4 & 5.3 & 1.4 & 0.4 & 35.0 & 10.0 & 11.4 \\
\hline $\begin{array}{r}7 / 19 / 2009 \\
12: 00 \\
\end{array}$ & $\begin{array}{r}7 / 19 / 2009 \\
13: 00 \\
\end{array}$ & 908.9 & 8059.0 & 2.8 & 2.4 & 613.1 & 1.1 & 772.0 & 759.6 & 313.5 & 305.9 & 2331.3 & 6.0 & 1.5 & 0.4 & 40.0 & 10.6 & 12.0 \\
\hline $\begin{array}{r}7 / 19 / 2009 \\
13: 00\end{array}$ & $\begin{array}{r}7 / 19 / 2009 \\
14: 00\end{array}$ & 911.4 & 8068.8 & 2.7 & 2.3 & 616.7 & 1.1 & 769.3 & 757.6 & 315.4 & 307.7 & 2351.3 & 7.0 & 1.7 & 0.4 & 47.6 & 12.4 & 13.6 \\
\hline $\begin{array}{r}7 / 19 / 2009 \\
14: 00\end{array}$ & $\begin{array}{r}7 / 19 / 2009 \\
15: 00\end{array}$ & 910.4 & 8070.7 & 2.7 & 2.2 & 612.7 & 1.1 & 766.4 & 756.3 & 315.0 & 307.8 & 2339.7 & 8.6 & 1.8 & 0.4 & 44.6 & 12.4 & 13.6 \\
\hline $\begin{array}{r}7 / 19 / 2009 \\
15: 00\end{array}$ & $\begin{array}{r}7 / 19 / 2009 \\
16: 00\end{array}$ & 910.6 & 8051.8 & 2.7 & 2.2 & 612.8 & 1.1 & 766.6 & 756.8 & 315.5 & 308.6 & 2334.1 & 9.3 & 1.8 & 0.4 & 42.3 & 11.9 & 12.9 \\
\hline $\begin{array}{r}7 / 19 / 2009 \\
16: 00\end{array}$ & $\begin{array}{r}7 / 19 / 2009 \\
17: 00\end{array}$ & 909.9 & 8068.6 & 2.7 & 2.2 & 615.6 & 1.1 & 771.5 & 761.8 & 313.4 & 306.8 & 2340.1 & 6.3 & 1.7 & 0.4 & 35.7 & 11.6 & 12.5 \\
\hline $\begin{array}{r}7 / 19 / 2009 \\
17: 00 \\
\end{array}$ & $\begin{array}{r}7 / 19 / 2009 \\
18: 00 \\
\end{array}$ & 911.7 & 8027.4 & 2.7 & 2.2 & 614.7 & 1.1 & 771.3 & 762.6 & 313.3 & 307.8 & 2329.8 & 5.3 & 1.6 & 0.5 & 38.6 & 11.0 & 12.0 \\
\hline $\begin{array}{r}7 / 19 / 2009 \\
18: 00 \\
\end{array}$ & $\begin{array}{r}7 / 19 / 2009 \\
19: 00 \\
\end{array}$ & 911.8 & 8005.4 & 2.7 & 2.1 & 612.9 & 1.1 & 774.5 & 766.4 & 313.7 & 308.3 & 2333.5 & 5.5 & 1.7 & 0.5 & 36.7 & 11.5 & 12.7 \\
\hline $\begin{array}{r}7 / 19 / 2009 \\
19: 00 \\
\end{array}$ & $\begin{array}{r}7 / 19 / 2009 \\
20: 00 \\
\end{array}$ & 912.2 & 8028.1 & 2.8 & 2.1 & 609.3 & 1.1 & 777.6 & 771.0 & 314.4 & 309.3 & 2334.5 & 6.1 & 1.8 & 0.5 & 38.5 & 11.9 & 13.2 \\
\hline $\begin{array}{r}7 / 19 / 2009 \\
20: 00\end{array}$ & $\begin{array}{r}7 / 19 / 2009 \\
21: 00\end{array}$ & 910.5 & 8047.6 & 2.7 & 2.2 & 603.2 & 1.1 & 779.5 & 772.6 & 314.8 & 309.3 & 2328.1 & 7.9 & 2.0 & 0.5 & 40.4 & 12.7 & 13.9 \\
\hline $\begin{array}{r}7 / 19 / 2009 \\
21: 00\end{array}$ & $\begin{array}{r}7 / 19 / 2009 \\
22: 00\end{array}$ & 910.5 & 8056.9 & 2.7 & 2.2 & 608.6 & 1.1 & 778.3 & 771.3 & 314.5 & 308.4 & 2339.8 & 9.6 & 2.1 & 0.5 & 39.3 & 13.4 & 14.4 \\
\hline $7 / 19 / 2009$ & $7 / 19 / 2009$ & 911.2 & 8025.4 & 2.7 & 2.2 & 603.8 & 1.1 & 776.6 & 769.1 & 312.7 & 305.7 & 2338.3 & 9.7 & 2.1 & 0.5 & 37.8 & 13.9 & 14.8 \\
\hline
\end{tabular}




\begin{tabular}{|c|c|c|c|c|c|c|c|c|c|c|c|c|c|c|c|c|c|c|}
\hline $\begin{array}{l}\text { Start } \\
\text { Date/ } \\
\text { Time }\end{array}$ & $\begin{array}{l}\text { End } \\
\text { Date/ } \\
\text { Time }\end{array}$ & $\begin{array}{l}\text { Gross } \\
\text { Load }\end{array}$ & $\begin{array}{c}\text { Gross } \\
\text { HR }\end{array}$ & $\begin{array}{c}\text { A } \\
\text { Econ } \\
\text { O2 }\end{array}$ & $\begin{array}{c}\text { B } \\
\text { Econ } \\
\text { O2 }\end{array}$ & $\begin{array}{l}\text { Fuel } \\
\text { Flow }\end{array}$ & $\begin{array}{l}\text { BTU } \\
\text { Gain }\end{array}$ & $\begin{array}{c}\text { A } \\
\text { APH } \\
\text { In }\end{array}$ & $\begin{array}{c}\text { B } \\
\text { APH } \\
\text { In }\end{array}$ & $\begin{array}{c}\text { A } \\
\text { APH } \\
\text { Out }\end{array}$ & $\begin{array}{c}\text { B } \\
\text { APH } \\
\text { Out }\end{array}$ & $\begin{array}{l}\text { Stack } \\
\text { Flow }\end{array}$ & Opacity & SO2 In & $\begin{array}{l}\text { SO2 } \\
\text { Out }\end{array}$ & $\mathrm{CO}$ & $\begin{array}{c}\text { Stack } \\
\text { SCEM } \\
\text { Elemental } \\
\mathrm{Hg}\end{array}$ & $\begin{array}{c}\text { Stack } \\
\text { SCEM } \\
\text { Total Hg }\end{array}$ \\
\hline & & MW & Btu/kWh & $\%$ & $\%$ & Ton/hr & & DEGF & DEGF & DEGF & DEGF & KSCF & $\%$ & $\mathrm{Ib} / \mathrm{MMB}$ & $\mathrm{Ib} / \mathrm{MMb}$ & PPM & $\begin{array}{c}(\mu \mathrm{g} / \mathrm{dNm} 3) \\
@ 3 \% 02\end{array}$ & $\begin{array}{c}(\mu \mathrm{g} / \mathrm{dNm} 3) \\
@ 3 \% 02\end{array}$ \\
\hline $22: 00$ & $23: 00$ & & & & & & & & & & & & & & & & & \\
\hline $\begin{array}{r}7 / 19 / 2009 \\
23: 00\end{array}$ & $\begin{array}{r}7 / 20 / 2009 \\
0: 00\end{array}$ & 903.9 & 8007.8 & 2.7 & 2.2 & 597.2 & 1.1 & 776.2 & 769.2 & 312.0 & 304.3 & 2314.4 & 9.8 & 2.1 & 0.5 & 41.2 & 14.1 & 15.1 \\
\hline $\begin{array}{r}7 / 20 / 2009 \\
0: 00\end{array}$ & $\begin{array}{r}7 / 20 / 2009 \\
1: 00\end{array}$ & 899.3 & 8018.6 & 2.7 & 2.2 & 597.6 & 1.1 & 777.0 & 770.8 & 311.9 & 304.7 & 2312.8 & 9.9 & 2.1 & 0.5 & 39.9 & 14.6 & 15.4 \\
\hline $\begin{array}{r}7 / 20 / 2009 \\
1: 00 \\
\end{array}$ & $\begin{array}{r}7 / 20 / 2009 \\
2: 00 \\
\end{array}$ & 904.4 & 8007.9 & 2.7 & 2.2 & 599.0 & 1.1 & 779.8 & 773.6 & 312.1 & 304.9 & 2333.1 & 10.0 & 2.1 & 0.5 & 37.7 & 14.7 & 15.5 \\
\hline $\begin{array}{r}7 / 20 / 2009 \\
2: 00\end{array}$ & $\begin{array}{r}7 / 20 / 2009 \\
3: 00\end{array}$ & 827.7 & 8029.6 & 2.7 & 2.1 & 548.0 & 1.1 & 754.5 & 748.4 & 310.9 & 301.6 & 2169.0 & 9.6 & 2.2 & 0.5 & 19.9 & 14.1 & 14.8 \\
\hline $\begin{array}{r}7 / 20 / 2009 \\
3: 00\end{array}$ & $\begin{array}{r}7 / 20 / 2009 \\
4: 00\end{array}$ & 733.5 & 7937.0 & 2.8 & 2.3 & 492.1 & 1.1 & 715.3 & 708.3 & 300.2 & 290.9 & 2022.7 & 9.1 & 2.1 & 0.5 & 8.6 & 12.6 & 13.3 \\
\hline $\begin{array}{r}7 / 20 / 2009 \\
4: 00\end{array}$ & $\begin{array}{r}7 / 20 / 2009 \\
5: 00\end{array}$ & 720.4 & 7900.0 & 2.7 & 2.4 & 490.2 & 1.1 & 712.1 & 704.5 & 295.5 & 288.0 & 2015.4 & 6.8 & 2.0 & 0.5 & 9.2 & 11.9 & 12.7 \\
\hline $\begin{array}{r}7 / 20 / 2009 \\
5: 00\end{array}$ & $\begin{array}{r}7 / 20 / 2009 \\
6: 00\end{array}$ & 818.4 & 7888.2 & 2.5 & 2.6 & 551.9 & 1.1 & 735.5 & 726.2 & 298.4 & 291.1 & 2224.3 & 6.0 & 1.8 & 0.5 & 17.3 & $\# \mathrm{~N} / \mathrm{A}$ & \#N/A \\
\hline $\begin{array}{r}7 / 20 / 2009 \\
6: 00\end{array}$ & $\begin{array}{r}7 / 20 / 2009 \\
7: 00\end{array}$ & 889.9 & 8044.0 & 2.5 & 2.5 & 584.6 & 1.1 & 761.0 & 750.5 & 302.8 & 294.6 & 2294.3 & 5.8 & 1.8 & 0.5 & 24.9 & $\# \mathrm{~N} / \mathrm{A}$ & $\# \mathrm{~N} / \mathrm{A}$ \\
\hline $\begin{array}{r}7 / 20 / 2009 \\
7: 00\end{array}$ & $\begin{array}{r}7 / 20 / 2009 \\
8: 00\end{array}$ & 896.6 & 7985.0 & 2.6 & 2.4 & 584.0 & 1.1 & 766.6 & 757.5 & 305.2 & 297.3 & 2309.2 & 6.4 & 1.9 & 0.5 & 33.0 & 13.0 & 14.0 \\
\hline $\begin{array}{r}7 / 20 / 2009 \\
8: 00\end{array}$ & $\begin{array}{r}7 / 20 / 2009 \\
9: 00\end{array}$ & 901.4 & 7907.7 & 2.6 & 2.4 & 588.3 & 1.1 & 769.9 & 760.2 & 306.5 & 299.1 & 2338.3 & 6.9 & 2.0 & 0.5 & 40.1 & 13.2 & 14.1 \\
\hline $\begin{array}{r}7 / 20 / 2009 \\
9: 00\end{array}$ & $\begin{array}{r}7 / 20 / 2009 \\
10: 00\end{array}$ & 908.7 & 8044.9 & 2.6 & 2.4 & 592.5 & 1.2 & 779.8 & 763.9 & 310.7 & 303.3 & 2355.1 & 9.1 & 2.1 & 0.5 & 47.6 & 13.7 & 14.5 \\
\hline $\begin{array}{r}7 / 20 / 2009 \\
10: 00\end{array}$ & $\begin{array}{r}7 / 20 / 2009 \\
11: 00\end{array}$ & 891.1 & 8089.3 & 2.6 & 2.3 & 580.8 & 1.2 & 777.2 & 761.5 & 312.4 & 303.1 & 2317.2 & 8.9 & 2.2 & 0.6 & 47.3 & 6.9 & 7.9 \\
\hline $\begin{array}{r}7 / 20 / 2009 \\
11: 00\end{array}$ & $\begin{array}{r}7 / 20 / 2009 \\
12: 00\end{array}$ & 887.9 & 8027.3 & 2.6 & 2.3 & 581.9 & 1.2 & 770.0 & 755.6 & 311.6 & 302.2 & 2298.9 & 8.9 & 2.3 & 0.6 & 46.5 & 4.9 & 5.9 \\
\hline $\begin{array}{r}7 / 20 / 2009 \\
12: 00 \\
\end{array}$ & $\begin{array}{r}7 / 20 / 2009 \\
13: 00 \\
\end{array}$ & 895.6 & 8027.0 & 2.6 & 2.3 & 582.6 & 1.2 & 777.2 & 763.0 & 313.2 & 304.8 & 2309.9 & 9.1 & 2.3 & 0.6 & 54.4 & 4.8 & 5.9 \\
\hline $\begin{array}{r}7 / 20 / 2009 \\
13: 00 \\
\end{array}$ & $\begin{array}{r}7 / 20 / 2009 \\
14: 00 \\
\end{array}$ & 901.3 & 7994.4 & 2.6 & 2.3 & 590.4 & 1.1 & 778.9 & 766.2 & 312.2 & 303.8 & 2339.5 & 9.4 & 2.3 & 0.6 & 54.2 & 5.1 & 6.1 \\
\hline $\begin{array}{r}7 / 20 / 2009 \\
14: 00 \\
\end{array}$ & $\begin{array}{r}7 / 20 / 2009 \\
15: 00 \\
\end{array}$ & 903.2 & 8011.0 & 2.6 & 2.4 & 592.3 & 1.1 & 782.3 & 770.0 & 310.2 & 301.3 & 2338.8 & 9.2 & 2.4 & 0.6 & 52.4 & 5.3 & 6.3 \\
\hline $\begin{array}{r}7 / 20 / 2009 \\
15: 00 \\
\end{array}$ & $\begin{array}{r}7 / 20 / 2009 \\
16: 00 \\
\end{array}$ & 838.6 & 7974.9 & 2.6 & 2.3 & 557.8 & 1.1 & 755.2 & 745.3 & 307.8 & 298.1 & 2178.5 & 7.4 & 2.4 & 0.6 & 24.5 & 4.9 & 5.9 \\
\hline $\begin{array}{r}7 / 20 / 2009 \\
16: 00\end{array}$ & $\begin{array}{r}7 / 20 / 2009 \\
17: 00\end{array}$ & 875.8 & 7911.9 & 2.7 & 2.4 & 581.6 & 1.1 & 755.7 & 746.3 & 307.1 & 297.7 & 2292.0 & 6.2 & 2.2 & 0.6 & 34.8 & 4.8 & 5.7 \\
\hline $\begin{array}{r}7 / 20 / 2009 \\
17: 00\end{array}$ & $\begin{array}{r}7 / 20 / 2009 \\
18: 00\end{array}$ & 906.7 & 8064.2 & 2.6 & 2.3 & 596.5 & 1.1 & 767.8 & 762.7 & 309.7 & 302.4 & 2351.5 & 5.4 & 2.0 & 0.5 & 54.8 & 8.0 & 8.9 \\
\hline
\end{tabular}




\begin{tabular}{|c|c|c|c|c|c|c|c|c|c|c|c|c|c|c|c|c|c|c|}
\hline $\begin{array}{l}\text { Start } \\
\text { Date/ } \\
\text { Time }\end{array}$ & $\begin{array}{l}\text { End } \\
\text { Date/ } \\
\text { Time }\end{array}$ & $\begin{array}{l}\text { Gross } \\
\text { Load }\end{array}$ & $\begin{array}{c}\text { Gross } \\
\text { HR }\end{array}$ & $\begin{array}{c}\text { A } \\
\text { Econ } \\
\text { O2 }\end{array}$ & $\begin{array}{c}\text { B } \\
\text { Econ } \\
\text { O2 }\end{array}$ & $\begin{array}{l}\text { Fuel } \\
\text { Flow }\end{array}$ & $\begin{array}{l}\text { BTU } \\
\text { Gain }\end{array}$ & $\begin{array}{l}\text { A } \\
\text { APH } \\
\text { In }\end{array}$ & $\begin{array}{c}\text { B } \\
\text { APH } \\
\text { In }\end{array}$ & $\begin{array}{c}\text { A } \\
\text { APH } \\
\text { Out }\end{array}$ & $\begin{array}{c}\text { B } \\
\text { APH } \\
\text { Out }\end{array}$ & $\begin{array}{l}\text { Stack } \\
\text { Flow }\end{array}$ & Opacity & SO2 In & $\begin{array}{l}\text { SO2 } \\
\text { Out }\end{array}$ & $\mathrm{CO}$ & $\begin{array}{c}\text { Stack } \\
\text { SCEM } \\
\text { Elemental } \\
\mathrm{Hg}\end{array}$ & $\begin{array}{c}\text { Stack } \\
\text { SCEM } \\
\text { Total Hg }\end{array}$ \\
\hline & & MW & Btu/kWh & $\%$ & $\%$ & Ton/hr & & DEGF & DEGF & DEGF & DEGF & KSCF & $\%$ & $\mathrm{Ib} / \mathrm{MMB}$ & $\mathrm{Ib} / \mathrm{MMb}$ & PPM & $\begin{array}{c}(\mu \mathrm{g} / \mathrm{dNm} 3) \\
@ 3 \% 02\end{array}$ & $\begin{array}{c}(\mu \mathrm{g} / \mathrm{dNm} 3) \\
@ 3 \% 02\end{array}$ \\
\hline $\begin{array}{r}7 / 20 / 2009 \\
18: 00\end{array}$ & $\begin{array}{r}/ 20 / 2009 \\
19: 00\end{array}$ & 886.3 & 8053.8 & 2.6 & 2.3 & 576.6 & 1.1 & 768.1 & 766.3 & 311.2 & 303.1 & 2286.9 & 4.7 & 1.8 & 0.5 & 40.0 & 9.1 & 10.3 \\
\hline $\begin{array}{r}7 / 20 / 2009 \\
19: 00\end{array}$ & $\begin{array}{r}7 / 20 / 2009 \\
20: 00\end{array}$ & 889.7 & 8018.3 & 2.8 & 2.3 & 586.0 & 1.1 & 768.8 & 770.0 & 312.0 & 303.5 & 2308.5 & 4.7 & 1.7 & 0.5 & 43.0 & 8.8 & 10.5 \\
\hline $\begin{array}{r}7 / 20 / 2009 \\
20: 00\end{array}$ & $\begin{array}{r}7 / 20 / 2009 \\
21: 00\end{array}$ & 901.8 & 8060.4 & 2.7 & 2.3 & 598.0 & 1.1 & 776.5 & 775.2 & 314.5 & 307.9 & 2340.4 & 5.1 & 1.6 & 0.5 & 43.7 & 9.5 & 11.2 \\
\hline $\begin{array}{r}7 / 20 / 2009 \\
21: 00\end{array}$ & $\begin{array}{r}7 / 20 / 2009 \\
22: 00\end{array}$ & 899.2 & 8034.3 & 2.6 & 2.4 & 594.2 & 1.1 & 766.7 & 760.6 & 314.0 & 305.1 & 2322.7 & 5.2 & 1.6 & 0.4 & 30.9 & 9.5 & 11.0 \\
\hline $\begin{array}{r}7 / 20 / 2009 \\
22: 00\end{array}$ & $\begin{array}{r}7 / 20 / 2009 \\
23: 00\end{array}$ & 900.6 & 7992.9 & 2.7 & 2.3 & 595.1 & 1.1 & 771.8 & 764.4 & 311.6 & 301.2 & 2313.6 & 5.1 & 1.6 & 0.4 & 38.1 & 9.6 & 11.1 \\
\hline $\begin{array}{r}7 / 20 / 2009 \\
23: 00\end{array}$ & $\begin{array}{r}7 / 21 / 2009 \\
0: 00\end{array}$ & 900.4 & 8003.1 & 2.8 & 2.2 & 596.6 & 1.1 & 773.4 & 769.5 & 312.1 & 302.7 & 2311.7 & 5.1 & 1.7 & 0.5 & 41.9 & 10.1 & 11.6 \\
\hline $\begin{array}{r}7 / 21 / 2009 \\
0: 00\end{array}$ & $\begin{array}{r}7 / 21 / 2009 \\
1: 00\end{array}$ & 883.8 & 8017.4 & 2.8 & 2.2 & 588.4 & 1.1 & 771.2 & 769.2 & 312.2 & 303.0 & 2279.0 & 5.1 & 1.7 & 0.5 & 36.4 & 10.1 & 11.7 \\
\hline $\begin{array}{r}7 / 21 / 2009 \\
1: 00\end{array}$ & $\begin{array}{r}7 / 21 / 2009 \\
2: 00\end{array}$ & 886.3 & 8050.3 & 2.7 & 2.3 & 596.4 & 1.1 & 767.2 & 759.5 & 312.6 & 302.6 & 2309.0 & 5.0 & 1.7 & 0.5 & 30.5 & 10.1 & 11.6 \\
\hline $\begin{array}{r}7 / 21 / 2009 \\
2: 00\end{array}$ & $\begin{array}{r}7 / 21 / 2009 \\
3: 00\end{array}$ & 885.0 & 7975.9 & 2.5 & 2.3 & 589.9 & 1.1 & 763.1 & 754.1 & 308.8 & 298.4 & 2310.5 & 5.0 & 1.6 & 0.4 & 26.9 & 9.9 & 11.5 \\
\hline $\begin{array}{r}7 / 21 / 2009 \\
3: 00 \\
\end{array}$ & $\begin{array}{r}7 / 21 / 2009 \\
4: 00 \\
\end{array}$ & 758.4 & 7994.3 & 2.8 & 2.2 & 510.3 & 1.1 & 732.5 & 724.0 & 303.8 & 291.8 & 2060.4 & 4.7 & 1.6 & 0.4 & 10.9 & 9.0 & 10.5 \\
\hline $\begin{array}{r}7 / 21 / 2009 \\
4: 00\end{array}$ & $\begin{array}{r}7 / 21 / 2009 \\
5: 00\end{array}$ & 844.4 & 7972.3 & 2.8 & 2.2 & 571.6 & 1.1 & 750.3 & 741.4 & 303.5 & 294.8 & 2259.7 & 5.1 & 1.6 & 0.4 & 33.4 & $\# \mathrm{~N} / \mathrm{A}$ & $\# \mathrm{~N} / \mathrm{A}$ \\
\hline $\begin{array}{r}7 / 21 / 2009 \\
5: 00\end{array}$ & $\begin{array}{r}7 / 21 / 2009 \\
6: 00\end{array}$ & 880.2 & 8046.6 & 2.7 & 2.2 & 588.1 & 1.1 & 759.6 & 750.7 & 305.9 & 296.2 & 2293.9 & 6.6 & 1.6 & 0.4 & 32.3 & $\# \mathrm{~N} / \mathrm{A}$ & $\# \mathrm{~N} / \mathrm{A}$ \\
\hline $\begin{array}{r}7 / 21 / 2009 \\
6: 00\end{array}$ & $\begin{array}{r}7 / 21 / 2009 \\
7: 00\end{array}$ & 906.4 & 8021.2 & 2.6 & 2.3 & 604.4 & 1.1 & 773.0 & 761.7 & 307.8 & 298.7 & 2364.2 & 8.3 & 1.5 & 0.4 & 35.9 & $\# \mathrm{~N} / \mathrm{A}$ & \#N/A \\
\hline $\begin{array}{r}7 / 21 / 2009 \\
7: 00\end{array}$ & $\begin{array}{r}7 / 21 / 2009 \\
8: 00\end{array}$ & 907.5 & 8049.5 & 2.6 & 2.3 & 602.1 & 1.1 & 774.9 & 761.7 & 310.0 & 299.4 & 2372.9 & 8.9 & 1.6 & 0.4 & 35.1 & 9.9 & 11.3 \\
\hline $\begin{array}{r}7 / 21 / 2009 \\
8: 00\end{array}$ & $\begin{array}{r}7 / 21 / 2009 \\
9: 00\end{array}$ & 906.4 & 8089.4 & 2.8 & 2.2 & 600.8 & 1.1 & 773.5 & 761.6 & 309.1 & 298.7 & 2364.7 & 9.4 & 1.6 & 0.4 & 45.4 & 10.4 & 11.6 \\
\hline $\begin{array}{r}7 / 21 / 2009 \\
9: 00 \\
\end{array}$ & $\begin{array}{r}7 / 21 / 2009 \\
10: 00 \\
\end{array}$ & 909.1 & 8053.5 & 2.8 & 2.2 & 597.7 & 1.1 & 782.0 & 768.5 & 310.5 & 300.7 & 2364.0 & 8.6 & 1.7 & 0.4 & 51.4 & 10.8 & 11.9 \\
\hline $\begin{array}{r}7 / 21 / 2009 \\
10: 00\end{array}$ & $\begin{array}{r}7 / 21 / 2009 \\
11: 00\end{array}$ & 908.9 & 8040.3 & 2.8 & 2.1 & 597.1 & 1.1 & 785.3 & 772.9 & 312.8 & 302.7 & 2368.6 & 6.5 & 1.7 & 0.5 & 57.7 & 11.2 & 12.3 \\
\hline $\begin{array}{r}7 / 21 / 2009 \\
11: 00\end{array}$ & $\begin{array}{r}7 / 21 / 2009 \\
12: 00\end{array}$ & 910.6 & 8044.9 & 2.8 & 2.2 & 596.2 & 1.1 & 789.4 & 776.7 & 315.7 & 304.8 & 2373.9 & 6.4 & 1.7 & 0.4 & 51.8 & 11.0 & 12.0 \\
\hline $\begin{array}{r}7 / 21 / 2009 \\
12: 00\end{array}$ & $\begin{array}{r}7 / 21 / 2009 \\
13: 00\end{array}$ & 910.3 & 8073.3 & 2.8 & 2.2 & 595.1 & 1.1 & 788.9 & 776.8 & 318.1 & 307.7 & 2370.1 & 6.5 & 1.7 & 0.4 & 50.1 & 11.1 & 12.1 \\
\hline $7 / 21 / 2009$ & $7 / 21 / 2009$ & 910.0 & 8036.4 & 2.8 & 2.2 & 595.6 & 1.1 & 790.4 & 778.6 & 319.4 & 309.4 & 2346.6 & 6.7 & 1.7 & 0.4 & 47.2 & 11.1 & 12.0 \\
\hline
\end{tabular}




\begin{tabular}{|c|c|c|c|c|c|c|c|c|c|c|c|c|c|c|c|c|c|c|}
\hline \multirow[t]{2}{*}{$\begin{array}{l}\text { Start } \\
\text { Date/ } \\
\text { Time }\end{array}$} & \multirow[t]{2}{*}{$\begin{array}{l}\text { End } \\
\text { Date/ } \\
\text { Time }\end{array}$} & $\begin{array}{l}\text { Gross } \\
\text { Load }\end{array}$ & $\begin{array}{c}\text { Gross } \\
\text { HR }\end{array}$ & $\begin{array}{c}\text { A } \\
\text { Econ } \\
\text { O2 }\end{array}$ & $\begin{array}{c}\text { B } \\
\text { Econ } \\
\text { O2 }\end{array}$ & $\begin{array}{l}\text { Fuel } \\
\text { Flow }\end{array}$ & $\begin{array}{l}\text { BTU } \\
\text { Gain }\end{array}$ & $\begin{array}{c}\text { A } \\
\text { APH } \\
\text { In }\end{array}$ & $\begin{array}{c}\text { B } \\
\text { APH } \\
\text { In }\end{array}$ & $\begin{array}{c}\text { A } \\
\text { APH } \\
\text { Out }\end{array}$ & $\begin{array}{c}\text { B } \\
\text { APH } \\
\text { Out }\end{array}$ & $\begin{array}{l}\text { Stack } \\
\text { Flow }\end{array}$ & Opacity & SO2 In & $\begin{array}{l}\text { SO2 } \\
\text { Out }\end{array}$ & $\mathrm{CO}$ & $\begin{array}{c}\text { Stack } \\
\text { SCEM } \\
\text { Elemental } \\
\mathrm{Hg}\end{array}$ & $\begin{array}{c}\text { Stack } \\
\text { SCEM } \\
\text { Total Hg }\end{array}$ \\
\hline & & MW & Btu/kWh & $\%$ & $\%$ & Ton/hr & & DEGF & DEGF & DEGF & DEGF & KSCF & $\%$ & $\mathrm{Ib} / \mathrm{MMB}$ & $\mathrm{lb} / \mathrm{MMb}$ & PPM & $\begin{array}{c}(\mu \mathrm{g} / \mathrm{dNm} 3) \\
@ 3 \% 02\end{array}$ & $\begin{array}{c}(\mu \mathrm{g} / \mathrm{dNm} 3) \\
\text { @ 3\%O2 }\end{array}$ \\
\hline $13: 00$ & $14: 00$ & & & & & & & & & & & & & & & & & \\
\hline $\begin{array}{r}7 / 21 / 2009 \\
14: 00\end{array}$ & $\begin{array}{r}7 / 21 / 2009 \\
15: 00\end{array}$ & 909.4 & 8037.5 & 2.8 & 2.2 & 595.0 & 1.1 & 793.4 & 781.8 & 322.2 & 312.4 & 2349.4 & 6.9 & 1.7 & 0.4 & 48.0 & 11.1 & 12.0 \\
\hline $\begin{array}{r}7 / 21 / 2009 \\
15: 00\end{array}$ & $\begin{array}{r}7 / 21 / 2009 \\
16: 00\end{array}$ & 908.3 & 8093.9 & 2.8 & 2.2 & 594.0 & 1.1 & 779.1 & 770.4 & 321.3 & 313.2 & 2357.2 & 7.1 & 1.8 & 0.5 & 39.9 & 11.0 & 11.9 \\
\hline $\begin{array}{r}7 / 21 / 2009 \\
16: 00 \\
\end{array}$ & $\begin{array}{r}7 / 21 / 2009 \\
17: 00 \\
\end{array}$ & 909.2 & 8063.5 & 2.8 & 2.2 & 598.7 & 1.1 & 776.4 & 766.6 & 318.7 & 310.9 & 2352.0 & 7.0 & 1.8 & 0.5 & 46.8 & 10.6 & 11.4 \\
\hline $\begin{array}{r}7 / 21 / 2009 \\
17: 00\end{array}$ & $\begin{array}{r}7 / 21 / 2009 \\
18: 00\end{array}$ & 911.2 & 8064.2 & 2.8 & 2.1 & 598.8 & 1.1 & 782.2 & 772.8 & 320.6 & 313.6 & 2348.0 & 7.1 & 1.8 & 0.5 & 52.9 & 10.2 & 11.1 \\
\hline $\begin{array}{r}7 / 21 / 2009 \\
18: 00\end{array}$ & $\begin{array}{r}7 / 21 / 2009 \\
19: 00\end{array}$ & 910.7 & 8073.1 & 2.8 & 2.1 & 599.8 & 1.1 & 774.4 & 761.1 & 321.0 & 312.6 & 2345.4 & 7.0 & 1.8 & 0.5 & 38.2 & 10.2 & 11.0 \\
\hline $\begin{array}{r}7 / 21 / 2009 \\
19: 00\end{array}$ & $\begin{array}{r}7 / 21 / 2009 \\
20: 00\end{array}$ & 907.9 & 8092.5 & 2.8 & 2.2 & 601.3 & 1.1 & 763.2 & 751.7 & 315.9 & 308.0 & 2358.5 & 6.9 & 1.9 & 0.5 & 34.9 & 11.2 & 12.1 \\
\hline $\begin{array}{r}7 / 21 / 2009 \\
20: 00\end{array}$ & $\begin{array}{r}7 / 21 / 2009 \\
21: 00\end{array}$ & 909.3 & 8094.5 & 2.7 & 2.2 & 600.6 & 1.1 & 764.1 & 751.8 & 313.1 & 305.8 & 2342.7 & 7.0 & 1.9 & 0.5 & 37.1 & 11.7 & 12.6 \\
\hline $\begin{array}{r}7 / 21 / 2009 \\
21: 00\end{array}$ & $\begin{array}{r}7 / 21 / 2009 \\
22: 00\end{array}$ & 910.4 & 8044.5 & 2.8 & 2.1 & 606.0 & 1.1 & 764.8 & 753.4 & 311.7 & 304.9 & 2342.3 & 7.0 & 2.0 & 0.5 & 39.6 & 12.6 & 13.6 \\
\hline $\begin{array}{r}7 / 21 / 2009 \\
22: 00 \\
\end{array}$ & $\begin{array}{r}7 / 21 / 2009 \\
23: 00 \\
\end{array}$ & 904.1 & 8051.1 & 2.8 & 2.1 & 605.4 & 1.1 & 763.5 & 751.8 & 310.0 & 302.7 & 2325.9 & 8.3 & 2.1 & 0.5 & 35.8 & 14.0 & 15.1 \\
\hline $\begin{array}{r}7 / 21 / 2009 \\
23: 00\end{array}$ & $\begin{array}{r}7 / 22 / 2009 \\
0: 00\end{array}$ & 909.0 & 8025.5 & 2.8 & 2.2 & 610.6 & 1.1 & 769.6 & 758.4 & 309.9 & 301.7 & 2345.5 & 9.0 & 2.2 & 0.5 & 36.1 & 14.8 & 15.7 \\
\hline $\begin{array}{r}7 / 22 / 2009 \\
0: 00\end{array}$ & $\begin{array}{r}7 / 22 / 2009 \\
1: 00\end{array}$ & 910.1 & 8025.7 & 2.7 & 2.2 & 610.9 & 1.1 & 775.3 & 762.6 & 310.9 & 302.2 & 2359.9 & 7.6 & 2.2 & 0.6 & 42.7 & 14.9 & 15.8 \\
\hline $\begin{array}{r}7 / 22 / 2009 \\
1: 00\end{array}$ & $\begin{array}{r}7 / 22 / 2009 \\
2: 00\end{array}$ & 909.5 & 8061.1 & 2.7 & 2.2 & 606.3 & 1.1 & 775.3 & 760.8 & 311.9 & 302.8 & 2370.0 & 7.9 & 2.1 & 0.5 & 35.3 & 14.5 & 15.4 \\
\hline $\begin{array}{r}7 / 22 / 2009 \\
2: 00\end{array}$ & $\begin{array}{r}7 / 22 / 2009 \\
3: 00\end{array}$ & 910.1 & 8070.9 & 2.7 & 2.3 & 602.2 & 1.1 & 766.9 & 752.0 & 310.1 & 300.7 & 2368.4 & 7.7 & 2.1 & 0.5 & 30.5 & 14.0 & 14.9 \\
\hline $\begin{array}{r}7 / 22 / 2009 \\
3: 00 \\
\end{array}$ & $\begin{array}{r}7 / 22 / 2009 \\
4: 00 \\
\end{array}$ & 907.6 & 8078.9 & 2.7 & 2.2 & 602.4 & 1.1 & 761.3 & 750.6 & 306.9 & 298.6 & 2366.3 & 7.7 & 2.1 & 0.5 & 36.4 & 13.7 & 14.6 \\
\hline $\begin{array}{r}7 / 22 / 2009 \\
4: 00 \\
\end{array}$ & $\begin{array}{r}7 / 22 / 2009 \\
5: 00 \\
\end{array}$ & 910.3 & 8054.8 & 2.7 & 2.2 & 602.8 & 1.1 & 767.5 & 757.4 & 306.5 & 298.8 & 2378.3 & 7.3 & 2.1 & 0.5 & 48.1 & 13.5 & 14.4 \\
\hline $\begin{array}{r}7 / 22 / 2009 \\
5: 00 \\
\end{array}$ & $\begin{array}{r}7 / 22 / 2009 \\
6: 00 \\
\end{array}$ & 910.3 & 8053.0 & 2.8 & 2.2 & 601.6 & 1.1 & 774.7 & 764.7 & 307.2 & 299.3 & 2366.4 & 6.9 & 2.0 & 0.5 & 46.6 & $\# \mathrm{~N} / \mathrm{A}$ & $\# \mathrm{~N} / \mathrm{A}$ \\
\hline $\begin{array}{r}7 / 22 / 2009 \\
6: 00 \\
\end{array}$ & $\begin{array}{r}7 / 22 / 2009 \\
7: 00 \\
\end{array}$ & 905.5 & 8030.4 & 2.8 & 2.2 & 594.7 & 1.1 & 775.7 & 769.6 & 307.7 & 299.1 & 2347.5 & 6.8 & 2.0 & 0.5 & 57.0 & $\# \mathrm{~N} / \mathrm{A}$ & $\# \mathrm{~N} / \mathrm{A}$ \\
\hline $\begin{array}{r}7 / 22 / 2009 \\
7: 00\end{array}$ & $\begin{array}{r}7 / 22 / 2009 \\
8: 00\end{array}$ & 900.3 & 7990.4 & 5.6 & 4.6 & 597.0 & 1.1 & 771.2 & 771.7 & 307.6 & 300.4 & 2328.8 & 8.6 & 2.0 & 0.6 & 47.2 & 14.3 & 15.4 \\
\hline $\begin{array}{r}7 / 22 / 2009 \\
8: 00\end{array}$ & $\begin{array}{r}7 / 22 / 2009 \\
9: 00\end{array}$ & 901.0 & 7984.0 & 3.7 & 2.5 & 601.3 & 1.1 & 776.8 & 775.4 & 309.6 & 303.2 & 2328.5 & 9.5 & 2.0 & 0.5 & 68.1 & 14.8 & 15.8 \\
\hline
\end{tabular}




\begin{tabular}{|c|c|c|c|c|c|c|c|c|c|c|c|c|c|c|c|c|c|c|}
\hline \multirow[t]{2}{*}{$\begin{array}{l}\text { Start } \\
\text { Date/ } \\
\text { Time }\end{array}$} & \multirow[t]{2}{*}{$\begin{array}{l}\text { End } \\
\text { Date/ } \\
\text { Time }\end{array}$} & $\begin{array}{l}\text { Gross } \\
\text { Load }\end{array}$ & $\begin{array}{c}\text { Gross } \\
\text { HR }\end{array}$ & $\begin{array}{c}\text { A } \\
\text { Econ } \\
\text { O2 }\end{array}$ & $\begin{array}{c}\text { B } \\
\text { Econ } \\
\text { O2 }\end{array}$ & $\begin{array}{l}\text { Fuel } \\
\text { Flow }\end{array}$ & $\begin{array}{l}\text { BTU } \\
\text { Gain }\end{array}$ & $\begin{array}{c}\text { A } \\
\text { APH } \\
\text { In }\end{array}$ & $\begin{array}{c}\text { B } \\
\text { APH } \\
\text { In }\end{array}$ & $\begin{array}{c}\text { A } \\
\text { APH } \\
\text { Out }\end{array}$ & $\begin{array}{c}\text { B } \\
\text { APH } \\
\text { Out }\end{array}$ & $\begin{array}{l}\text { Stack } \\
\text { Flow }\end{array}$ & Opacity & SO2 In & $\begin{array}{l}\text { SO2 } \\
\text { Out }\end{array}$ & $\mathrm{CO}$ & $\begin{array}{c}\text { Stack } \\
\text { SCEM } \\
\text { Elemental } \\
\mathrm{Hg}\end{array}$ & $\begin{array}{c}\text { Stack } \\
\text { SCEM } \\
\text { Total Hg }\end{array}$ \\
\hline & & MW & Btu/kWh & $\%$ & $\%$ & Ton/hr & & DEGF & DEGF & DEGF & DEGF & KSCF & $\%$ & Ib/MMB & $\mathrm{Ib} / \mathrm{MMb}$ & PPM & $\begin{array}{c}(\mu \mathrm{g} / \mathrm{dNm} 3) \\
@ 3 \% 02\end{array}$ & $\begin{array}{c}(\mu \mathrm{g} / \mathrm{dNm} 3) \\
\text { @ 3\%O2 }\end{array}$ \\
\hline $\begin{array}{r}7 / 22 / 2009 \\
9: 00\end{array}$ & $\begin{array}{r}7 / 22 / 2009 \\
10: 00\end{array}$ & 903.0 & 7982.7 & 3.1 & 2.1 & 602.9 & 1.1 & 776.2 & 774.8 & 310.4 & 304.9 & 2332.8 & 7.4 & 2.0 & 0.5 & 73.2 & 14.8 & 16.0 \\
\hline $\begin{array}{r}7 / 22 / 2009 \\
10: 00\end{array}$ & $\begin{array}{r}7 / 22 / 2009 \\
11: 00 \\
\end{array}$ & 899.7 & 7989.8 & 3.1 & 2.2 & 598.9 & 1.1 & 775.0 & 774.0 & 310.0 & 303.8 & 2319.4 & 6.7 & 2.1 & 0.5 & 51.9 & 14.4 & 15.6 \\
\hline $\begin{array}{r}7 / 22 / 2009 \\
11: 00\end{array}$ & $\begin{array}{r}7 / 22 / 2009 \\
12: 00\end{array}$ & 893.0 & 8001.5 & 3.1 & 2.3 & 598.1 & 1.1 & 774.7 & 773.8 & 311.5 & 305.0 & 2318.6 & 6.7 & 2.1 & 0.5 & 46.3 & 14.2 & 15.4 \\
\hline $\begin{array}{r}7 / 22 / 2009 \\
12: 00\end{array}$ & $\begin{array}{r}7 / 22 / 2009 \\
13: 00\end{array}$ & 907.8 & 8026.0 & 3.1 & 2.3 & 605.7 & 1.1 & 782.7 & 780.7 & 314.4 & 308.3 & 2359.0 & 6.8 & 2.1 & 0.6 & 47.3 & 14.2 & 15.2 \\
\hline $\begin{array}{r}7 / 22 / 2009 \\
13: 00\end{array}$ & $\begin{array}{r}7 / 22 / 2009 \\
14: 00\end{array}$ & 906.6 & 8044.1 & 3.1 & 2.3 & 609.9 & 1.1 & 783.9 & 781.3 & 317.2 & 311.0 & 2362.7 & 6.9 & 2.1 & 0.6 & 49.2 & 14.5 & 15.5 \\
\hline $\begin{array}{r}7 / 22 / 2009 \\
14: 00\end{array}$ & $\begin{array}{r}7 / 22 / 2009 \\
15: 00\end{array}$ & 907.7 & 8056.0 & 3.1 & 2.3 & 610.9 & 1.1 & 772.6 & 769.1 & 316.9 & 310.6 & 2362.4 & 7.0 & 2.2 & 0.6 & 61.8 & 14.5 & 15.6 \\
\hline $\begin{array}{r}7 / 22 / 2009 \\
15: 00\end{array}$ & $\begin{array}{r}7 / 22 / 2009 \\
16: 00 \\
\end{array}$ & 908.3 & 8022.8 & 3.0 & 2.3 & 610.0 & 1.1 & 773.4 & 767.9 & 314.7 & 308.2 & 2350.2 & 7.0 & 2.2 & 0.6 & 59.4 & 14.5 & 15.5 \\
\hline $\begin{array}{r}7 / 22 / 2009 \\
16: 00 \\
\end{array}$ & $\begin{array}{r}7 / 22 / 2009 \\
17: 00 \\
\end{array}$ & 908.4 & 8023.9 & 3.1 & 2.3 & 608.0 & 1.1 & 777.8 & 774.2 & 316.6 & 310.3 & 2335.1 & 6.9 & 2.2 & 0.5 & 37.5 & 14.6 & 15.5 \\
\hline $\begin{array}{r}7 / 22 / 2009 \\
17: 00\end{array}$ & $\begin{array}{r}7 / 22 / 2009 \\
18: 00 \\
\end{array}$ & 909.3 & 8031.3 & 3.1 & 2.3 & 602.8 & 1.1 & 782.1 & 777.4 & 317.7 & 311.4 & 2339.7 & 6.9 & 2.2 & 0.5 & 38.1 & 14.6 & 15.6 \\
\hline $\begin{array}{r}7 / 22 / 2009 \\
18: 00 \\
\end{array}$ & $\begin{array}{r}7 / 22 / 2009 \\
19: 00 \\
\end{array}$ & 908.6 & 8034.7 & 3.0 & 2.4 & 598.1 & 1.1 & 785.8 & 780.4 & 318.3 & 311.6 & 2352.4 & 6.8 & 2.1 & 0.5 & 39.7 & 14.7 & 15.7 \\
\hline $\begin{array}{r}7 / 22 / 2009 \\
19: 00\end{array}$ & $\begin{array}{r}7 / 22 / 2009 \\
20: 00\end{array}$ & 907.8 & 8030.0 & 2.9 & 2.3 & 596.8 & 1.1 & 783.8 & 779.3 & 317.8 & 310.8 & 2338.8 & 6.7 & 2.1 & 0.5 & 46.5 & 14.4 & 15.5 \\
\hline $\begin{array}{r}7 / 22 / 2009 \\
20: 00\end{array}$ & $\begin{array}{r}7 / 22 / 2009 \\
21: 00\end{array}$ & 907.7 & 8009.7 & 2.9 & 2.2 & 598.3 & 1.1 & 786.3 & 781.0 & 317.7 & 310.5 & 2339.7 & 6.7 & 2.1 & 0.5 & 53.0 & 14.5 & 15.6 \\
\hline $\begin{array}{r}7 / 22 / 2009 \\
21: 00\end{array}$ & $\begin{array}{r}7 / 22 / 2009 \\
22: 00\end{array}$ & 909.8 & 8001.8 & 2.9 & 2.3 & 604.4 & 1.1 & 789.8 & 784.0 & 317.5 & 309.9 & 2344.7 & 6.8 & 2.1 & 0.5 & 62.4 & 14.7 & 15.7 \\
\hline $\begin{array}{r}7 / 22 / 2009 \\
22: 00 \\
\end{array}$ & $\begin{array}{r}7 / 22 / 2009 \\
23: 00 \\
\end{array}$ & 913.1 & 8009.6 & 2.9 & 2.3 & 607.7 & 1.1 & 793.1 & 787.2 & 317.5 & 309.8 & 2361.8 & 6.8 & 2.1 & 0.5 & 58.0 & 14.8 & 15.8 \\
\hline $\begin{array}{r}7 / 22 / 2009 \\
23: 00\end{array}$ & $\begin{array}{r}7 / 23 / 2009 \\
0: 00\end{array}$ & 908.6 & 8015.5 & 2.9 & 2.3 & 603.2 & 1.1 & 783.9 & 778.0 & 316.0 & 307.8 & 2357.1 & 6.7 & 2.1 & 0.5 & 46.7 & 14.8 & 15.8 \\
\hline $\begin{array}{r}7 / 23 / 2009 \\
0: 00 \\
\end{array}$ & $\begin{array}{r}7 / 23 / 2009 \\
1: 00 \\
\end{array}$ & 903.0 & 8010.5 & 3.0 & 2.3 & 599.5 & 1.1 & 772.2 & 766.4 & 311.6 & 303.4 & 2339.7 & 6.6 & 2.1 & 0.5 & 53.7 & 14.6 & 15.5 \\
\hline $\begin{array}{r}7 / 23 / 2009 \\
1: 00 \\
\end{array}$ & $\begin{array}{r}7 / 23 / 2009 \\
2: 00 \\
\end{array}$ & 912.9 & 7996.8 & 3.0 & 2.3 & 603.6 & 1.1 & 780.1 & 772.4 & 310.8 & 303.1 & 2349.1 & 6.7 & 2.0 & 0.5 & 71.5 & 14.4 & 15.3 \\
\hline $\begin{array}{r}7 / 23 / 2009 \\
2: 00\end{array}$ & $\begin{array}{r}7 / 23 / 2009 \\
3: 00\end{array}$ & 892.6 & 8008.9 & 3.0 & 2.3 & 592.0 & 1.1 & 778.0 & 770.6 & 311.4 & 302.9 & 2300.1 & 6.7 & 2.0 & 0.5 & 56.6 & 14.6 & 15.5 \\
\hline $\begin{array}{r}7 / 23 / 2009 \\
3: 00\end{array}$ & $\begin{array}{r}7 / 23 / 2009 \\
4: 00\end{array}$ & 854.7 & 7903.0 & 3.1 & 2.3 & 569.4 & 1.1 & 760.9 & 754.8 & 307.5 & 297.0 & 2212.7 & 6.6 & 2.0 & 0.5 & 29.9 & 14.4 & 15.2 \\
\hline $7 / 23 / 2009$ & $7 / 23 / 2009$ & 913.2 & 7978.3 & 3.0 & 2.3 & 607.5 & 1.1 & 781.6 & 774.1 & 308.3 & 300.4 & 2367.2 & 6.8 & 2.0 & 0.5 & 47.3 & $\# \mathrm{~N} / \mathrm{A}$ & $\# \mathrm{~N} / \mathrm{A}$ \\
\hline
\end{tabular}




\begin{tabular}{|c|c|c|c|c|c|c|c|c|c|c|c|c|c|c|c|c|c|c|}
\hline $\begin{array}{l}\text { Start } \\
\text { Date/ } \\
\text { Time }\end{array}$ & $\begin{array}{l}\text { End } \\
\text { Date/ } \\
\text { Time }\end{array}$ & $\begin{array}{l}\text { Gross } \\
\text { Load }\end{array}$ & $\begin{array}{c}\text { Gross } \\
\text { HR }\end{array}$ & $\begin{array}{c}\text { A } \\
\text { Econ } \\
\text { O2 }\end{array}$ & $\begin{array}{c}\text { B } \\
\text { Econ } \\
\text { O2 }\end{array}$ & $\begin{array}{l}\text { Fuel } \\
\text { Flow }\end{array}$ & $\begin{array}{l}\text { BTU } \\
\text { Gain }\end{array}$ & $\begin{array}{c}\text { A } \\
\text { APH } \\
\text { In }\end{array}$ & $\begin{array}{c}\text { B } \\
\text { APH } \\
\text { In }\end{array}$ & $\begin{array}{c}\text { A } \\
\text { APH } \\
\text { Out }\end{array}$ & $\begin{array}{c}\text { B } \\
\text { APH } \\
\text { Out }\end{array}$ & $\begin{array}{l}\text { Stack } \\
\text { Flow }\end{array}$ & Opacity & SO2 In & $\begin{array}{l}\text { SO2 } \\
\text { Out }\end{array}$ & $\mathrm{CO}$ & $\begin{array}{c}\text { Stack } \\
\text { SCEM } \\
\text { Elemental } \\
\mathrm{Hg}\end{array}$ & $\begin{array}{c}\text { Stack } \\
\text { SCEM } \\
\text { Total Hg }\end{array}$ \\
\hline & & MW & Btu/kWh & $\%$ & $\%$ & Ton/hr & & DEGF & DEGF & DEGF & DEGF & KSCF & $\%$ & $\mathrm{Ib} / \mathrm{MMB}$ & $\mathrm{lb} / \mathrm{MMb}$ & PPM & $\begin{array}{c}(\mu \mathrm{g} / \mathrm{dNm} 3) \\
@ 3 \% 02\end{array}$ & $\begin{array}{c}(\mu \mathrm{g} / \mathrm{dNm} 3) \\
\text { @ 3\%O2 }\end{array}$ \\
\hline $4: 00$ & $5: 00$ & & & & & & & & & & & & & & & & & \\
\hline $\begin{array}{r}7 / 23 / 2009 \\
5: 00\end{array}$ & $\begin{array}{r}7 / 23 / 2009 \\
6: 00\end{array}$ & 913.0 & 8013.3 & 3.0 & 2.3 & 609.6 & 1.1 & 784.3 & 776.9 & 309.2 & 302.2 & 2371.9 & 6.6 & 2.0 & 0.5 & 40.0 & $\# \mathrm{~N} / \mathrm{A}$ & $\# \mathrm{~N} / \mathrm{A}$ \\
\hline $\begin{array}{r}7 / 23 / 2009 \\
6: 00\end{array}$ & $\begin{array}{r}7 / 23 / 2009 \\
7: 00\end{array}$ & 912.8 & 8007.9 & 3.0 & 2.3 & 610.4 & 1.1 & 773.5 & 768.5 & 306.7 & 300.2 & 2385.4 & 6.5 & 2.0 & 0.5 & 42.1 & $\# \mathrm{~N} / \mathrm{A}$ & $\# \mathrm{~N} / \mathrm{A}$ \\
\hline $\begin{array}{r}7 / 23 / 2009 \\
7: 00\end{array}$ & $\begin{array}{r}7 / 23 / 2009 \\
8: 00\end{array}$ & 912.8 & 7983.2 & 3.0 & 2.3 & 609.8 & 1.1 & 775.4 & 769.0 & 306.1 & 299.6 & 2368.9 & 6.6 & 2.0 & 0.5 & 43.2 & 15.0 & 16.0 \\
\hline $\begin{array}{r}7 / 23 / 2009 \\
8: 00\end{array}$ & $\begin{array}{r}7 / 23 / 2009 \\
9: 00\end{array}$ & 910.0 & 8032.6 & 3.0 & 2.3 & 611.2 & 1.1 & 764.6 & 757.1 & 306.3 & 299.1 & 2357.7 & 6.6 & 2.0 & 0.5 & 44.9 & 15.1 & 16.2 \\
\hline $\begin{array}{r}7 / 23 / 2009 \\
9: 00\end{array}$ & $\begin{array}{r}7 / 23 / 2009 \\
10: 00\end{array}$ & 903.0 & 8025.8 & 3.0 & 2.3 & 613.3 & 1.1 & 762.5 & 754.7 & 305.7 & 297.9 & 2355.0 & 6.5 & 2.0 & 0.5 & 49.6 & 15.0 & 16.0 \\
\hline $\begin{array}{r}7 / 23 / 2009 \\
10: 00\end{array}$ & $\begin{array}{r}7 / 23 / 2009 \\
11: 00\end{array}$ & 907.8 & 8012.8 & 3.0 & 2.3 & 613.9 & 1.1 & 767.4 & 759.7 & 306.5 & 298.8 & 2355.4 & 6.5 & 2.0 & 0.5 & 52.4 & 14.8 & 15.8 \\
\hline $\begin{array}{r}7 / 23 / 2009 \\
11: 00\end{array}$ & $\begin{array}{r}7 / 23 / 2009 \\
12: 00\end{array}$ & 909.6 & 8024.8 & 3.0 & 2.3 & 613.0 & 1.1 & 772.6 & 765.4 & 309.1 & 301.5 & 2349.2 & 6.6 & 2.0 & 0.5 & 55.1 & 14.3 & 15.3 \\
\hline $\begin{array}{r}7 / 23 / 2009 \\
12: 00\end{array}$ & $\begin{array}{r}7 / 23 / 2009 \\
13: 00\end{array}$ & 906.2 & 8044.9 & 3.0 & 2.3 & 619.3 & 1.1 & 771.5 & 769.4 & 311.7 & 305.0 & 2356.9 & 6.7 & 2.0 & 0.5 & 47.6 & 14.4 & 15.3 \\
\hline $\begin{array}{r}7 / 23 / 2009 \\
13: 00 \\
\end{array}$ & $\begin{array}{r}7 / 23 / 2009 \\
14: 00 \\
\end{array}$ & 912.4 & 8047.7 & 3.0 & 2.3 & 627.1 & 1.1 & 773.7 & 771.6 & 313.6 & 307.0 & 2357.8 & 6.9 & 2.0 & 0.5 & 43.3 & 14.7 & 15.6 \\
\hline $\begin{array}{r}7 / 23 / 2009 \\
14: 00\end{array}$ & $\begin{array}{r}7 / 23 / 2009 \\
15: 00\end{array}$ & 911.5 & 8071.8 & 3.0 & 2.3 & 621.6 & 1.1 & 774.8 & 771.5 & 314.8 & 308.8 & 2375.6 & 7.0 & 1.9 & 0.5 & 42.5 & 13.7 & 14.3 \\
\hline $\begin{array}{r}7 / 23 / 2009 \\
15: 00\end{array}$ & $\begin{array}{r}7 / 23 / 2009 \\
16: 00\end{array}$ & 899.3 & 8083.9 & 3.0 & 2.3 & 621.3 & 1.1 & 769.0 & 761.0 & 315.5 & 308.7 & 2354.9 & 6.9 & 1.8 & 0.4 & 30.9 & 13.4 & 13.2 \\
\hline $\begin{array}{r}7 / 23 / 2009 \\
16: 00\end{array}$ & $\begin{array}{r}7 / 23 / 2009 \\
17: 00\end{array}$ & 902.2 & 8060.0 & 3.0 & 2.2 & 631.8 & 1.1 & 766.3 & 758.4 & 313.9 & 306.4 & 2347.9 & 6.8 & 1.8 & 0.5 & 31.6 & 13.1 & 13.0 \\
\hline $\begin{array}{r}7 / 23 / 2009 \\
17: 00\end{array}$ & $\begin{array}{r}7 / 23 / 2009 \\
18: 00\end{array}$ & 910.5 & 8087.1 & 2.9 & 2.2 & 644.0 & 1.1 & 769.6 & 761.5 & 313.4 & 306.5 & 2384.0 & 6.8 & 1.8 & 0.5 & 28.6 & 13.6 & 14.4 \\
\hline $\begin{array}{r}7 / 23 / 2009 \\
18: 00 \\
\end{array}$ & $\begin{array}{r}7 / 23 / 2009 \\
19: 00 \\
\end{array}$ & 911.0 & 8125.9 & 2.9 & 2.3 & 643.1 & 1.1 & 763.8 & 756.6 & 312.0 & 305.0 & 2386.1 & 6.8 & 1.8 & 0.5 & 34.6 & 13.6 & 14.4 \\
\hline $\begin{array}{r}7 / 23 / 2009 \\
19: 00 \\
\end{array}$ & $\begin{array}{r}7 / 23 / 2009 \\
20: 00 \\
\end{array}$ & 909.1 & 8094.8 & 2.9 & 2.2 & 644.7 & 1.1 & 760.5 & 753.1 & 310.8 & 303.6 & 2370.0 & 6.6 & 1.7 & 0.4 & 43.6 & 13.1 & 14.0 \\
\hline $\begin{array}{r}7 / 23 / 2009 \\
20: 00 \\
\end{array}$ & $\begin{array}{r}7 / 23 / 2009 \\
21: 00 \\
\end{array}$ & 908.8 & 8124.7 & 2.9 & 2.2 & 648.1 & 1.1 & 757.2 & 748.7 & 309.7 & 302.2 & 2376.5 & 6.5 & 1.8 & 0.5 & 48.7 & 13.3 & 14.3 \\
\hline $\begin{array}{r}7 / 23 / 2009 \\
21: 00 \\
\end{array}$ & $\begin{array}{r}7 / 23 / 2009 \\
22: 00 \\
\end{array}$ & 909.4 & 8132.8 & 2.9 & 2.2 & 645.0 & 1.1 & 759.7 & 750.6 & 308.7 & 300.8 & 2368.5 & 6.4 & 1.8 & 0.5 & 56.0 & 13.7 & 14.7 \\
\hline $\begin{array}{r}7 / 23 / 2009 \\
22: 00\end{array}$ & $\begin{array}{r}7 / 23 / 2009 \\
23: 00\end{array}$ & 892.3 & 8130.1 & 2.9 & 2.2 & 625.9 & 1.1 & 758.5 & 750.1 & 307.3 & 299.2 & 2301.9 & 6.3 & 1.8 & 0.5 & 39.8 & 13.9 & 14.8 \\
\hline $\begin{array}{r}7 / 23 / 2009 \\
23: 00\end{array}$ & $\begin{array}{r}7 / 24 / 2009 \\
0: 00\end{array}$ & 858.8 & 8092.2 & 3.0 & 2.1 & 612.6 & 1.1 & 750.5 & 743.0 & 305.5 & 295.5 & 2247.8 & 6.2 & 1.9 & 0.5 & 15.6 & 14.1 & 15.1 \\
\hline
\end{tabular}




\begin{tabular}{|c|c|c|c|c|c|c|c|c|c|c|c|c|c|c|c|c|c|c|}
\hline $\begin{array}{l}\text { Start } \\
\text { Date/ } \\
\text { Time }\end{array}$ & $\begin{array}{l}\text { End } \\
\text { Date/ } \\
\text { Time }\end{array}$ & $\begin{array}{l}\text { Gross } \\
\text { Load }\end{array}$ & $\begin{array}{c}\text { Gross } \\
\text { HR }\end{array}$ & $\begin{array}{c}\text { A } \\
\text { Econ } \\
\text { O2 }\end{array}$ & $\begin{array}{c}\text { B } \\
\text { Econ } \\
\text { O2 }\end{array}$ & $\begin{array}{l}\text { Fuel } \\
\text { Flow }\end{array}$ & $\begin{array}{l}\text { BTU } \\
\text { Gain }\end{array}$ & $\begin{array}{c}\text { A } \\
\text { APH } \\
\text { In }\end{array}$ & $\begin{array}{c}\text { B } \\
\text { APH } \\
\text { In }\end{array}$ & $\begin{array}{c}\text { A } \\
\text { APH } \\
\text { Out }\end{array}$ & $\begin{array}{c}\text { B } \\
\text { APH } \\
\text { Out }\end{array}$ & $\begin{array}{l}\text { Stack } \\
\text { Flow }\end{array}$ & Opacity & SO2 In & $\begin{array}{l}\text { SO2 } \\
\text { Out }\end{array}$ & $\mathrm{CO}$ & $\begin{array}{c}\text { Stack } \\
\text { SCEM } \\
\text { Elemental } \\
\mathrm{Hg}\end{array}$ & $\begin{array}{c}\text { Stack } \\
\text { SCEM } \\
\text { Total Hg }\end{array}$ \\
\hline & & MW & Btu/kWh & $\%$ & $\%$ & Ton/hr & & DEGF & DEGF & DEGF & DEGF & KSCF & $\%$ & $\mathrm{Ib} / \mathrm{MMB}$ & $\mathrm{Ib} / \mathrm{MMb}$ & PPM & $\begin{array}{c}(\mu \mathrm{g} / \mathrm{dNm} 3) \\
@ 3 \% 02\end{array}$ & $\begin{array}{c}(\mu \mathrm{g} / \mathrm{dNm} 3) \\
@ 3 \% 02\end{array}$ \\
\hline $\begin{array}{r}7 / 24 / 2009 \\
0: 00\end{array}$ & $\begin{array}{r}7 / 24 / 2009 \\
1: 00\end{array}$ & 898.7 & 8111.2 & 2.9 & 2.2 & 637.6 & 1.1 & 761.3 & 753.1 & 306.7 & 298.1 & 2337.0 & 6.4 & 1.9 & 0.5 & 40.9 & 14.7 & 15.8 \\
\hline $\begin{array}{r}7 / 24 / 2009 \\
1: 00\end{array}$ & $\begin{array}{r}7 / 24 / 2009 \\
2: 00\end{array}$ & 881.5 & 8103.3 & 2.9 & 2.2 & 616.6 & 1.1 & 761.1 & 752.4 & 306.6 & 297.2 & 2305.9 & 6.5 & 1.9 & 0.5 & 24.3 & 14.3 & 15.3 \\
\hline $\begin{array}{r}7 / 24 / 2009 \\
2: 00\end{array}$ & $\begin{array}{r}7 / 24 / 2009 \\
3: 00\end{array}$ & 877.0 & 8079.0 & 2.8 & 1.9 & 609.6 & 1.1 & 761.2 & 751.9 & 306.8 & 296.8 & 2272.1 & 6.4 & 1.8 & 0.5 & 27.7 & 14.2 & 15.2 \\
\hline $\begin{array}{r}7 / 24 / 2009 \\
3: 00\end{array}$ & $\begin{array}{r}7 / 24 / 2009 \\
4: 00\end{array}$ & 862.3 & 8054.1 & 2.7 & 1.8 & 601.9 & 1.1 & 758.0 & 750.7 & 307.3 & 297.9 & 2228.5 & 6.3 & 1.8 & 0.5 & 28.6 & 14.6 & 15.5 \\
\hline $\begin{array}{r}7 / 24 / 2009 \\
4: 00\end{array}$ & $\begin{array}{r}7 / 24 / 2009 \\
5: 00\end{array}$ & 863.9 & 8022.1 & 2.7 & 1.8 & 608.5 & 1.1 & 759.0 & 752.2 & 307.0 & 297.4 & 2219.3 & 6.3 & 1.9 & 0.5 & 29.7 & 14.7 & 15.7 \\
\hline $\begin{array}{r}7 / 24 / 2009 \\
5: 00\end{array}$ & $\begin{array}{r}7 / 24 / 2009 \\
6: 00\end{array}$ & 880.0 & 8031.3 & 2.6 & 1.8 & 623.2 & 1.1 & 764.7 & 757.1 & 307.9 & 298.1 & 2271.6 & 6.4 & 1.9 & 0.5 & 31.8 & $\# \mathrm{~N} / \mathrm{A}$ & $\# \mathrm{~N} / \mathrm{A}$ \\
\hline $\begin{array}{r}7 / 24 / 2009 \\
6: 00\end{array}$ & $\begin{array}{r}7 / 24 / 2009 \\
7: 00\end{array}$ & 882.5 & 8053.0 & 2.7 & 1.8 & 625.1 & 1.1 & 765.3 & 758.5 & 308.1 & 298.4 & 2273.0 & 6.5 & 1.8 & 0.5 & 30.3 & $\# \mathrm{~N} / \mathrm{A}$ & $\# \mathrm{~N} / \mathrm{A}$ \\
\hline $\begin{array}{r}7 / 24 / 2009 \\
7: 00\end{array}$ & $\begin{array}{r}7 / 24 / 2009 \\
8: 00\end{array}$ & 883.5 & 8059.8 & 2.7 & 1.8 & 624.1 & 1.1 & 756.9 & 749.8 & 308.5 & 298.8 & 2279.6 & 6.5 & 1.8 & 0.5 & 29.5 & 14.0 & 15.1 \\
\hline $\begin{array}{r}7 / 24 / 2009 \\
8: 00\end{array}$ & $\begin{array}{r}7 / 24 / 2009 \\
9: 00\end{array}$ & 881.7 & 8061.8 & 2.7 & 1.8 & 624.2 & 1.1 & 750.1 & 742.1 & 304.5 & 294.3 & 2272.6 & 6.4 & 1.8 & 0.5 & 31.4 & 13.6 & 14.7 \\
\hline $\begin{array}{r}7 / 24 / 2009 \\
9: 00 \\
\end{array}$ & $\begin{array}{r}7 / 24 / 2009 \\
10: 00 \\
\end{array}$ & 883.9 & 8074.1 & 2.6 & 1.8 & 617.6 & 1.1 & 751.0 & 742.3 & 304.1 & 294.0 & 2267.3 & 6.2 & 1.7 & 0.4 & 33.9 & 13.4 & 14.3 \\
\hline $\begin{array}{r}7 / 24 / 2009 \\
10: 00\end{array}$ & $\begin{array}{r}7 / 24 / 2009 \\
11: 00\end{array}$ & 873.1 & 8042.4 & 2.7 & 1.8 & 612.3 & 1.1 & 747.3 & 739.6 & 302.2 & 292.1 & 2242.3 & 6.6 & 1.7 & 0.4 & 28.3 & 12.8 & 13.7 \\
\hline $\begin{array}{r}7 / 24 / 2009 \\
11: 00\end{array}$ & $\begin{array}{r}7 / 24 / 2009 \\
12: 00\end{array}$ & 887.7 & 8055.9 & 2.7 & 1.8 & 621.6 & 1.1 & 752.3 & 744.3 & 305.7 & 296.0 & 2275.1 & 6.4 & 1.7 & 0.4 & 40.6 & 12.6 & 13.6 \\
\hline $\begin{array}{r}7 / 24 / 2009 \\
12: 00\end{array}$ & $\begin{array}{r}7 / 24 / 2009 \\
13: 00\end{array}$ & 886.2 & 8082.0 & 2.7 & 1.9 & 626.7 & 1.1 & 748.7 & 740.9 & 308.5 & 299.1 & 2283.5 & 6.5 & 1.6 & 0.4 & 33.6 & 12.5 & 13.4 \\
\hline $\begin{array}{r}7 / 24 / 2009 \\
13: 00\end{array}$ & $\begin{array}{r}7 / 24 / 2009 \\
14: 00\end{array}$ & 893.6 & 8067.8 & 2.6 & 1.8 & 638.8 & 1.1 & 752.4 & 746.2 & 309.7 & 301.1 & 2292.4 & 6.5 & 1.7 & 0.4 & 40.8 & 12.6 & 13.5 \\
\hline $\begin{array}{r}7 / 24 / 2009 \\
14: 00\end{array}$ & $\begin{array}{r}7 / 24 / 2009 \\
15: 00\end{array}$ & 896.5 & 8082.6 & 2.6 & 1.8 & 636.5 & 1.1 & 756.4 & 749.4 & 312.1 & 304.0 & 2299.6 & 6.6 & 1.7 & 0.4 & 44.1 & 13.1 & 14.1 \\
\hline $\begin{array}{r}7 / 24 / 2009 \\
15: 00 \\
\end{array}$ & $\begin{array}{r}7 / 24 / 2009 \\
16: 00 \\
\end{array}$ & 896.6 & 8084.6 & 2.6 & 1.9 & 631.3 & 1.1 & 760.3 & 752.1 & 314.4 & 305.6 & 2270.9 & 6.6 & 1.6 & 0.4 & 48.2 & 12.0 & 13.0 \\
\hline $\begin{array}{r}7 / 24 / 2009 \\
16: 00 \\
\end{array}$ & $\begin{array}{r}7 / 24 / 2009 \\
17: 00 \\
\end{array}$ & 894.9 & 8115.1 & 2.6 & 1.9 & 618.7 & 1.1 & 763.2 & 754.4 & 315.4 & 307.0 & 2285.3 & 6.7 & 1.5 & 0.4 & 50.5 & 10.4 & 11.3 \\
\hline $\begin{array}{r}7 / 24 / 2009 \\
17: 00\end{array}$ & $\begin{array}{r}7 / 24 / 2009 \\
18: 00\end{array}$ & 891.6 & 8139.6 & 2.6 & 1.9 & 596.3 & 1.1 & 759.6 & 750.4 & 314.7 & 306.2 & 2271.3 & 6.9 & 1.3 & 0.3 & 44.1 & 9.0 & 9.7 \\
\hline $\begin{array}{r}7 / 24 / 2009 \\
18: 00\end{array}$ & $\begin{array}{r}7 / 24 / 2009 \\
19: 00\end{array}$ & 887.2 & 8102.5 & 2.6 & 1.9 & 577.7 & 1.1 & 760.7 & 751.5 & 313.9 & 304.9 & 2241.1 & 5.8 & 1.1 & 0.3 & 38.0 & 7.9 & 8.7 \\
\hline $7 / 24 / 2009$ & $7 / 24 / 2009$ & 892.2 & 8058.1 & 2.6 & 1.9 & 567.0 & 1.2 & 769.7 & 760.1 & 316.0 & 306.3 & 2249.5 & 6.0 & 0.9 & 0.2 & 45.0 & 7.0 & 8.0 \\
\hline
\end{tabular}




\begin{tabular}{|c|c|c|c|c|c|c|c|c|c|c|c|c|c|c|c|c|c|c|}
\hline \multirow[t]{2}{*}{$\begin{array}{l}\text { Start } \\
\text { Date/ } \\
\text { Time }\end{array}$} & \multirow[t]{2}{*}{$\begin{array}{l}\text { End } \\
\text { Date/ } \\
\text { Time }\end{array}$} & $\begin{array}{l}\text { Gross } \\
\text { Load }\end{array}$ & $\begin{array}{c}\text { Gross } \\
\text { HR }\end{array}$ & $\begin{array}{c}A \\
\text { Econ } \\
\text { O2 }\end{array}$ & $\begin{array}{c}\text { B } \\
\text { Econ } \\
\text { O2 }\end{array}$ & $\begin{array}{l}\text { Fuel } \\
\text { Flow }\end{array}$ & $\begin{array}{l}\text { BTU } \\
\text { Gain }\end{array}$ & $\begin{array}{c}\text { A } \\
\text { APH } \\
\text { In }\end{array}$ & $\begin{array}{c}\text { B } \\
\text { APH } \\
\text { In }\end{array}$ & $\begin{array}{c}\text { A } \\
\text { APH } \\
\text { Out }\end{array}$ & $\begin{array}{c}\text { B } \\
\text { APH } \\
\text { Out }\end{array}$ & $\begin{array}{l}\text { Stack } \\
\text { Flow }\end{array}$ & Opacity & SO2 In & $\begin{array}{l}\text { SO2 } \\
\text { Out }\end{array}$ & $\mathrm{CO}$ & $\begin{array}{c}\text { Stack } \\
\text { SCEM } \\
\text { Elemental } \\
\mathrm{Hg}\end{array}$ & $\begin{array}{c}\text { Stack } \\
\text { SCEM } \\
\text { Total Hg }\end{array}$ \\
\hline & & MW & Btu/kWh & $\%$ & $\%$ & Ton/hr & & DEGF & DEGF & DEGF & DEGF & KSCF & $\%$ & Ib/MMB & $\mathrm{Ib} / \mathrm{MMb}$ & PPM & $\begin{array}{c}\text { ( } \mu \mathrm{g} / \mathrm{dNm}) \\
@ 3 \% 02\end{array}$ & $\begin{array}{c}(\mu \mathrm{g} / \mathrm{dNm} 3) \\
@ 3 \% 02\end{array}$ \\
\hline 19:00 & $20: 00$ & & & & & & & & & & & & & & & & & \\
\hline $\begin{array}{r}7 / 24 / 2009 \\
20: 00\end{array}$ & $\begin{array}{r}7 / 24 / 2009 \\
21: 00\end{array}$ & 886.6 & 8076.2 & 2.6 & 1.9 & 554.8 & 1.2 & 765.6 & 757.3 & 316.0 & 307.1 & 2224.1 & 5.5 & 0.9 & 0.2 & 36.1 & 6.1 & 7.3 \\
\hline $\begin{array}{r}7 / 24 / 2009 \\
21: 00\end{array}$ & $\begin{array}{r}7 / 24 / 2009 \\
22: 00\end{array}$ & 852.0 & 8090.2 & 2.7 & 1.9 & 527.5 & 1.2 & 756.0 & 745.3 & 312.5 & 303.0 & 2157.7 & 5.4 & 0.8 & 0.2 & 19.1 & 5.9 & 7.4 \\
\hline $\begin{array}{r}7 / 24 / 2009 \\
22: 00 \\
\end{array}$ & $\begin{array}{r}7 / 24 / 2009 \\
23: 00 \\
\end{array}$ & 788.5 & 8061.2 & 2.8 & 1.9 & 484.3 & 1.2 & 736.3 & 727.2 & 308.5 & 296.6 & 2018.7 & 5.1 & 0.8 & 0.2 & 2.0 & 5.3 & 6.7 \\
\hline $\begin{array}{r}7 / 24 / 2009 \\
23: 00\end{array}$ & $\begin{array}{r}7 / 25 / 2009 \\
0: 00\end{array}$ & 838.7 & 7972.4 & 2.9 & 1.9 & 513.5 & 1.2 & 753.8 & 745.6 & 308.4 & 297.4 & 2120.3 & 5.7 & 0.7 & 0.2 & 10.0 & 5.2 & 6.4 \\
\hline $\begin{array}{r}7 / 25 / 2009 \\
0: 00\end{array}$ & $\begin{array}{r}7 / 25 / 2009 \\
1: 00\end{array}$ & 892.3 & 8011.0 & 2.7 & 1.9 & 538.2 & 1.2 & 782.0 & 771.9 & 316.0 & 305.2 & 2223.9 & 6.7 & 0.7 & 0.2 & 34.3 & 5.1 & 6.4 \\
\hline $\begin{array}{r}7 / 25 / 2009 \\
1: 00\end{array}$ & $\begin{array}{r}7 / 25 / 2009 \\
2: 00\end{array}$ & 855.8 & 7972.1 & 2.8 & 1.8 & 514.4 & 1.2 & 779.7 & 770.6 & 318.4 & 306.8 & 2153.9 & 6.7 & 0.7 & 0.2 & 22.6 & 4.8 & 6.2 \\
\hline $\begin{array}{r}7 / 25 / 2009 \\
2: 00\end{array}$ & $\begin{array}{r}7 / 25 / 2009 \\
3: 00\end{array}$ & 789.8 & 7882.2 & 2.9 & 1.8 & 473.7 & 1.2 & 762.8 & 755.4 & 317.9 & 304.0 & 2011.1 & 6.0 & 0.7 & 0.2 & 5.4 & 4.8 & 6.2 \\
\hline $\begin{array}{r}7 / 25 / 2009 \\
3: 00\end{array}$ & $\begin{array}{r}7 / 25 / 2009 \\
4: 00\end{array}$ & 779.1 & 7836.5 & 2.9 & 1.8 & 473.3 & 1.2 & 764.3 & 756.6 & 315.5 & 301.8 & 1990.4 & 6.1 & 0.7 & 0.2 & 2.6 & 4.8 & 6.2 \\
\hline $\begin{array}{r}7 / 25 / 2009 \\
4: 00 \\
\end{array}$ & $\begin{array}{r}7 / 25 / 2009 \\
5: 00 \\
\end{array}$ & 765.2 & 7800.4 & 3.0 & 1.8 & 469.4 & 1.2 & 767.6 & 760.1 & 321.9 & 305.6 & 1992.0 & 6.3 & 0.7 & 0.2 & 4.2 & 4.8 & 6.2 \\
\hline $\begin{array}{r}7 / 25 / 2009 \\
5: 00\end{array}$ & $\begin{array}{r}7 / 25 / 2009 \\
6: 00\end{array}$ & 810.6 & 7854.5 & 2.9 & 1.9 & 503.9 & 1.2 & 782.5 & 772.6 & 317.4 & 302.4 & 2118.0 & 6.8 & 0.8 & 0.2 & 21.6 & 4.8 & 6.2 \\
\hline $\begin{array}{r}7 / 25 / 2009 \\
6: 00\end{array}$ & $\begin{array}{r}7 / 25 / 2009 \\
7: 00\end{array}$ & 868.6 & 7918.8 & 2.8 & 1.9 & 543.0 & 1.2 & 807.2 & 796.8 & 327.0 & 312.3 & 2219.2 & 8.2 & 0.9 & 0.2 & 23.3 & 4.8 & 6.2 \\
\hline $\begin{array}{r}7 / 25 / 2009 \\
7: 00\end{array}$ & $\begin{array}{r}7 / 25 / 2009 \\
8: 00\end{array}$ & 896.6 & 7979.1 & 2.8 & 1.9 & 558.1 & 1.2 & 803.0 & 798.3 & 329.1 & 317.9 & 2294.9 & 9.9 & 1.0 & 0.2 & 40.5 & 4.8 & 6.2 \\
\hline $\begin{array}{r}7 / 25 / 2009 \\
8: 00\end{array}$ & $\begin{array}{r}7 / 25 / 2009 \\
9: 00\end{array}$ & 906.3 & 8024.3 & 2.7 & 1.9 & 565.1 & 1.2 & 788.8 & 788.1 & 322.1 & 312.9 & 2303.5 & 8.7 & 1.0 & 0.2 & 51.1 & 4.8 & 6.2 \\
\hline $\begin{array}{r}7 / 25 / 2009 \\
9: 00 \\
\end{array}$ & $\begin{array}{r}7 / 25 / 2009 \\
10: 00 \\
\end{array}$ & 905.8 & 7985.5 & 2.8 & 2.0 & 575.9 & 1.2 & 795.7 & 794.0 & 322.2 & 313.9 & 2308.0 & 8.8 & 1.1 & 0.3 & 47.7 & 4.8 & 6.2 \\
\hline $\begin{array}{r}7 / 25 / 2009 \\
10: 00 \\
\end{array}$ & $\begin{array}{r}7 / 25 / 2009 \\
11: 00 \\
\end{array}$ & 907.9 & 8013.2 & 2.8 & 2.0 & 589.1 & 1.2 & 795.6 & 792.9 & 324.9 & 317.2 & 2333.0 & 9.9 & 1.3 & 0.3 & 28.5 & 4.8 & 6.2 \\
\hline $\begin{array}{r}7 / 25 / 2009 \\
11: 00 \\
\end{array}$ & $\begin{array}{r}7 / 25 / 2009 \\
12: 00 \\
\end{array}$ & 912.9 & 8060.9 & 2.8 & 2.0 & 592.7 & 1.2 & 777.7 & 773.9 & 321.7 & 314.1 & 2327.1 & 9.8 & 1.3 & 0.3 & 20.8 & 4.8 & 6.2 \\
\hline $\begin{array}{r}7 / 25 / 2009 \\
12: 00 \\
\end{array}$ & $\begin{array}{r}7 / 25 / 2009 \\
13: 00 \\
\end{array}$ & 908.0 & 8046.5 & 2.9 & 2.0 & 596.7 & 1.2 & 780.9 & 776.3 & 321.7 & 314.0 & 2314.4 & 9.5 & 1.4 & 0.3 & 26.1 & 4.8 & 6.2 \\
\hline $\begin{array}{r}7 / 25 / 2009 \\
13: 00\end{array}$ & $\begin{array}{r}7 / 25 / 2009 \\
14: 00\end{array}$ & 908.0 & 8050.3 & 2.9 & 2.0 & 603.8 & 1.1 & 784.5 & 778.8 & 324.7 & 317.1 & 2319.3 & 11.4 & 1.6 & 0.3 & 19.0 & 4.8 & 6.2 \\
\hline $\begin{array}{r}7 / 25 / 2009 \\
14: 00 \\
\end{array}$ & $\begin{array}{r}7 / 25 / 2009 \\
15: 00 \\
\end{array}$ & 910.7 & 8036.1 & 2.8 & 2.1 & 609.4 & 1.1 & 778.1 & 772.8 & 324.0 & 317.7 & 2331.5 & 12.6 & 1.7 & 0.4 & 28.9 & 4.8 & 6.2 \\
\hline
\end{tabular}




\begin{tabular}{|c|c|c|c|c|c|c|c|c|c|c|c|c|c|c|c|c|c|c|}
\hline $\begin{array}{l}\text { Start } \\
\text { Date/ } \\
\text { Time }\end{array}$ & $\begin{array}{l}\text { End } \\
\text { Date/ } \\
\text { Time }\end{array}$ & $\begin{array}{l}\text { Gross } \\
\text { Load }\end{array}$ & $\begin{array}{c}\text { Gross } \\
\text { HR }\end{array}$ & $\begin{array}{c}\text { A } \\
\text { Econ } \\
\text { O2 }\end{array}$ & $\begin{array}{c}\text { B } \\
\text { Econ } \\
\text { O2 }\end{array}$ & $\begin{array}{l}\text { Fuel } \\
\text { Flow }\end{array}$ & $\begin{array}{l}\text { BTU } \\
\text { Gain }\end{array}$ & $\begin{array}{c}\text { A } \\
\text { APH } \\
\text { In }\end{array}$ & $\begin{array}{c}\text { B } \\
\text { APH } \\
\text { In }\end{array}$ & $\begin{array}{c}\text { A } \\
\text { APH } \\
\text { Out }\end{array}$ & $\begin{array}{c}\text { B } \\
\text { APH } \\
\text { Out }\end{array}$ & $\begin{array}{l}\text { Stack } \\
\text { Flow }\end{array}$ & Opacity & SO2 In & $\begin{array}{l}\text { SO2 } \\
\text { Out }\end{array}$ & $\mathrm{CO}$ & $\begin{array}{c}\text { Stack } \\
\text { SCEM } \\
\text { Elemental } \\
\mathrm{Hg}\end{array}$ & $\begin{array}{c}\text { Stack } \\
\text { SCEM } \\
\text { Total Hg }\end{array}$ \\
\hline & & MW & Btu/kWh & $\%$ & $\%$ & Ton/hr & & DEGF & DEGF & DEGF & DEGF & KSCF & $\%$ & Ib/MMB & $\mathrm{Ib} / \mathrm{MMb}$ & PPM & $\begin{array}{c}(\mu \mathrm{g} / \mathrm{dNm} 3) \\
@ 3 \% 02\end{array}$ & $\begin{array}{c}(\mu \mathrm{g} / \mathrm{dNm} 3) \\
\text { @ 3\%O2 }\end{array}$ \\
\hline $\begin{array}{r}7 / 25 / 2009 \\
15: 00\end{array}$ & $\begin{array}{r}7 / 25 / 2009 \\
16: 00\end{array}$ & 910.8 & 7990.8 & 2.9 & 2.0 & 615.6 & 1.1 & 774.0 & 770.0 & 322.7 & 316.6 & 2314.5 & 9.9 & 1.7 & 0.4 & 29.7 & 4.8 & 6.2 \\
\hline $\begin{array}{r}7 / 25 / 2009 \\
16: 00 \\
\end{array}$ & $\begin{array}{r}7 / 25 / 2009 \\
17: 00 \\
\end{array}$ & 911.0 & 8016.8 & 2.8 & 2.0 & 620.5 & 1.1 & 771.7 & 767.9 & 323.5 & 317.9 & 2329.1 & 9.1 & 1.7 & 0.4 & 35.9 & 4.8 & 6.2 \\
\hline $\begin{array}{r}7 / 25 / 2009 \\
17: 00\end{array}$ & $\begin{array}{r}7 / 25 / 2009 \\
18: 00\end{array}$ & 910.9 & 8043.0 & 2.9 & 2.0 & 623.3 & 1.1 & 773.2 & 769.1 & 322.9 & 317.6 & 2344.4 & 8.8 & 1.6 & 0.4 & 44.0 & 4.8 & 6.2 \\
\hline $\begin{array}{r}7 / 25 / 2009 \\
18: 00\end{array}$ & $\begin{array}{r}7 / 25 / 2009 \\
19: 00\end{array}$ & 912.4 & 8006.3 & 2.9 & 2.1 & 625.7 & 1.1 & 777.7 & 772.2 & 323.4 & 318.1 & 2363.4 & 8.4 & 1.6 & 0.4 & 34.6 & 4.8 & 6.2 \\
\hline $\begin{array}{r}7 / 25 / 2009 \\
19: 00\end{array}$ & $\begin{array}{r}7 / 25 / 2009 \\
20: 00\end{array}$ & 912.1 & 8014.4 & 2.9 & 2.2 & 623.5 & 1.1 & 773.6 & 768.0 & 322.1 & 316.9 & 2358.8 & 8.1 & 1.6 & 0.4 & 26.0 & 4.8 & 6.2 \\
\hline $\begin{array}{r}7 / 25 / 2009 \\
20: 00\end{array}$ & $\begin{array}{r}7 / 25 / 2009 \\
21: 00\end{array}$ & 908.5 & 8031.2 & 2.9 & 2.2 & 628.8 & 1.1 & 769.6 & 763.6 & 318.3 & 313.3 & 2368.3 & 7.9 & 1.6 & 0.4 & 18.0 & 4.8 & 6.2 \\
\hline $\begin{array}{r}7 / 25 / 2009 \\
21: 00\end{array}$ & $\begin{array}{r}7 / 25 / 2009 \\
22: 00 \\
\end{array}$ & 910.2 & 8018.3 & 2.9 & 2.2 & 625.4 & 1.1 & 769.3 & 762.2 & 313.4 & 308.4 & 2375.3 & 7.9 & 1.6 & 0.4 & 14.8 & 4.8 & 6.2 \\
\hline $\begin{array}{r}7 / 25 / 2009 \\
22: 00\end{array}$ & $\begin{array}{r}7 / 25 / 2009 \\
23: 00 \\
\end{array}$ & 896.0 & 7997.1 & 2.9 & 2.2 & 615.5 & 1.1 & 765.9 & 757.9 & 312.9 & 306.4 & 2331.2 & 7.6 & 1.6 & 0.4 & 12.3 & 4.8 & 6.2 \\
\hline $\begin{array}{r}7 / 25 / 2009 \\
23: 00\end{array}$ & $\begin{array}{r}7 / 26 / 2009 \\
0: 00 \\
\end{array}$ & 870.7 & 8091.4 & 2.9 & 2.2 & 601.1 & 1.1 & 752.8 & 740.9 & 309.7 & 300.5 & 2278.4 & 7.0 & 1.5 & 0.4 & 6.8 & 4.8 & 6.2 \\
\hline $\begin{array}{r}7 / 26 / 2009 \\
0: 00 \\
\end{array}$ & $\begin{array}{r}7 / 26 / 2009 \\
1: 00 \\
\end{array}$ & 889.5 & 8108.2 & 2.9 & 2.3 & 619.7 & 1.1 & 750.0 & 741.9 & 306.4 & 298.6 & 2318.8 & 7.1 & 1.5 & 0.4 & 11.5 & 4.8 & 6.2 \\
\hline $\begin{array}{r}7 / 26 / 2009 \\
1: 00\end{array}$ & $\begin{array}{r}7 / 26 / 2009 \\
2: 00\end{array}$ & 891.9 & 8103.6 & 2.8 & 2.3 & 623.4 & 1.1 & 751.7 & 742.7 & 305.7 & 297.4 & 2349.1 & 7.1 & 1.5 & 0.4 & 11.9 & 4.8 & 6.2 \\
\hline $\begin{array}{r}7 / 26 / 2009 \\
2: 00\end{array}$ & $\begin{array}{r}7 / 26 / 2009 \\
3: 00\end{array}$ & 902.2 & 8103.9 & 2.8 & 2.3 & 626.6 & 1.1 & 753.2 & 743.9 & 304.8 & 296.5 & 2365.3 & 6.9 & 1.5 & 0.4 & 16.3 & 4.8 & 6.2 \\
\hline $\begin{array}{r}7 / 26 / 2009 \\
3: 00\end{array}$ & $\begin{array}{r}7 / 26 / 2009 \\
4: 00\end{array}$ & 884.6 & 8101.9 & 2.9 & 2.2 & 613.8 & 1.1 & 750.3 & 741.9 & 303.1 & 293.8 & 2322.7 & 6.5 & 1.4 & 0.4 & 8.8 & 4.8 & 6.2 \\
\hline $\begin{array}{r}7 / 26 / 2009 \\
4: 00\end{array}$ & $\begin{array}{r}7 / 26 / 2009 \\
5: 00 \\
\end{array}$ & 884.0 & 8121.0 & 2.9 & 2.1 & 610.1 & 1.1 & 752.5 & 744.9 & 302.3 & 293.8 & 2329.1 & 6.4 & 1.3 & 0.4 & 8.3 & 4.8 & 6.2 \\
\hline $\begin{array}{r}7 / 26 / 2009 \\
5: 00 \\
\end{array}$ & $\begin{array}{r}7 / 26 / 2009 \\
6: 00 \\
\end{array}$ & 888.5 & 8127.9 & 2.7 & 2.0 & 600.7 & 1.1 & 755.1 & 746.6 & 302.8 & 294.0 & 2299.0 & 5.9 & 1.2 & 0.3 & 23.5 & 4.8 & 6.2 \\
\hline $\begin{array}{r}7 / 26 / 2009 \\
6: 00 \\
\end{array}$ & $\begin{array}{r}7 / 26 / 2009 \\
7: 00 \\
\end{array}$ & 884.7 & 8112.7 & 2.7 & 2.0 & 586.9 & 1.1 & 758.5 & 748.9 & 304.2 & 294.1 & 2289.9 & 5.6 & 1.2 & 0.3 & 20.1 & 4.8 & 6.2 \\
\hline $\begin{array}{r}7 / 26 / 2009 \\
7: 00 \\
\end{array}$ & $\begin{array}{r}7 / 26 / 2009 \\
8: 00 \\
\end{array}$ & 887.7 & 8122.5 & 2.7 & 2.0 & 590.5 & 1.1 & 761.2 & 752.8 & 305.3 & 294.9 & 2288.4 & 5.5 & 1.1 & 0.3 & 29.1 & 4.8 & 6.2 \\
\hline $\begin{array}{r}7 / 26 / 2009 \\
8: 00\end{array}$ & $\begin{array}{r}7 / 26 / 2009 \\
9: 00\end{array}$ & 874.9 & 8139.2 & 2.7 & 1.9 & 584.1 & 1.2 & 761.5 & 754.0 & 307.2 & 297.1 & 2258.0 & 5.4 & 1.1 & 0.3 & 33.9 & 4.8 & 6.2 \\
\hline $\begin{array}{r}7 / 26 / 2009 \\
9: 00\end{array}$ & $\begin{array}{r}7 / 26 / 2009 \\
10: 00\end{array}$ & 866.5 & 8144.8 & 2.7 & 1.9 & 583.3 & 1.1 & 757.8 & 751.0 & 309.4 & 299.0 & 2236.8 & 5.5 & 1.1 & 0.3 & 27.7 & 4.8 & 6.2 \\
\hline $7 / 26 / 2009$ & $7 / 26 / 2009$ & 884.7 & 8155.0 & 2.7 & 1.9 & 596.8 & 1.1 & 757.2 & 748.7 & 310.8 & 300.7 & 2273.4 & 5.7 & 1.1 & 0.3 & 34.8 & 4.8 & 6.2 \\
\hline
\end{tabular}




\begin{tabular}{|c|c|c|c|c|c|c|c|c|c|c|c|c|c|c|c|c|c|c|}
\hline $\begin{array}{l}\text { Start } \\
\text { Date/ } \\
\text { Time }\end{array}$ & $\begin{array}{l}\text { End } \\
\text { Date/ } \\
\text { Time }\end{array}$ & $\begin{array}{l}\text { Gross } \\
\text { Load }\end{array}$ & $\begin{array}{c}\text { Gross } \\
\text { HR }\end{array}$ & $\begin{array}{c}\text { A } \\
\text { Econ } \\
\text { O2 }\end{array}$ & $\begin{array}{c}\text { B } \\
\text { Econ } \\
\text { O2 }\end{array}$ & $\begin{array}{l}\text { Fuel } \\
\text { Flow }\end{array}$ & $\begin{array}{l}\text { BTU } \\
\text { Gain }\end{array}$ & $\begin{array}{c}\text { A } \\
\text { APH } \\
\text { In }\end{array}$ & $\begin{array}{c}\text { B } \\
\text { APH } \\
\text { In }\end{array}$ & $\begin{array}{c}\text { A } \\
\text { APH } \\
\text { Out }\end{array}$ & $\begin{array}{c}\text { B } \\
\text { APH } \\
\text { Out }\end{array}$ & $\begin{array}{l}\text { Stack } \\
\text { Flow }\end{array}$ & Opacity & SO2 In & $\begin{array}{l}\text { SO2 } \\
\text { Out }\end{array}$ & $\mathrm{CO}$ & $\begin{array}{c}\text { Stack } \\
\text { SCEM } \\
\text { Elemental } \\
\mathrm{Hg}\end{array}$ & $\begin{array}{c}\text { Stack } \\
\text { SCEM } \\
\text { Total Hg }\end{array}$ \\
\hline & & MW & Btu/kWh & $\%$ & $\%$ & Ton/hr & & DEGF & DEGF & DEGF & DEGF & KSCF & $\%$ & Ib/MMB & $\mathrm{Ib} / \mathrm{MMb}$ & PPM & $\begin{array}{c}(\mu \mathrm{g} / \mathrm{dNm}) \\
@ 3 \% 02\end{array}$ & $\begin{array}{c}(\mu \mathrm{g} / \mathrm{dNm} 3) \\
@ 3 \% 02\end{array}$ \\
\hline $10: 00$ & $11: 00$ & & & & & & & & & & & & & & & & & \\
\hline $\begin{array}{r}7 / 26 / 2009 \\
11: 00\end{array}$ & $\begin{array}{r}7 / 26 / 2009 \\
12: 00\end{array}$ & 887.5 & 8136.6 & 2.7 & 2.0 & 600.5 & 1.2 & 757.3 & 748.0 & 311.7 & 302.0 & 2265.5 & 5.9 & 1.2 & 0.3 & 39.9 & 4.8 & 6.2 \\
\hline $\begin{array}{r}7 / 26 / 2009 \\
12: 00\end{array}$ & $\begin{array}{r}7 / 26 / 2009 \\
13: 00 \\
\end{array}$ & 889.6 & 8145.8 & 2.7 & 1.9 & 598.0 & 1.2 & 750.2 & 742.5 & 313.0 & 304.3 & 2263.4 & 6.1 & 1.2 & 0.3 & 41.8 & 4.8 & 6.2 \\
\hline $\begin{array}{r}7 / 26 / 2009 \\
13: 00\end{array}$ & $\begin{array}{r}7 / 26 / 2009 \\
14: 00\end{array}$ & 891.5 & 8114.6 & 2.7 & 1.9 & 594.0 & 1.2 & 748.1 & 741.6 & 312.4 & 304.2 & 2257.5 & 6.0 & 1.1 & 0.3 & 44.9 & 4.8 & 6.2 \\
\hline $\begin{array}{r}7 / 26 / 2009 \\
14: 00\end{array}$ & $\begin{array}{r}7 / 26 / 2009 \\
15: 00 \\
\end{array}$ & 888.1 & 8110.0 & 2.8 & 1.9 & 587.9 & 1.2 & 754.2 & 747.8 & 314.9 & 306.8 & 2236.1 & 6.1 & 1.1 & 0.3 & 41.3 & 4.8 & 6.2 \\
\hline $\begin{array}{r}7 / 26 / 2009 \\
15: 00\end{array}$ & $\begin{array}{r}7 / 26 / 2009 \\
16: 00\end{array}$ & 884.6 & 8106.0 & 2.8 & 1.9 & 588.1 & 1.2 & 758.3 & 753.2 & 317.9 & 310.2 & 2229.8 & 6.1 & 1.1 & 0.3 & 37.6 & 4.8 & 6.2 \\
\hline $\begin{array}{r}7 / 26 / 2009 \\
16: 00 \\
\end{array}$ & $\begin{array}{r}7 / 26 / 2009 \\
17: 00 \\
\end{array}$ & 885.0 & 8111.4 & 2.8 & 1.9 & 589.9 & 1.2 & 761.5 & 756.7 & 320.9 & 313.2 & 2246.5 & 6.1 & 1.1 & 0.3 & 41.2 & 4.8 & 6.2 \\
\hline $\begin{array}{r}7 / 26 / 2009 \\
17: 00\end{array}$ & $\begin{array}{r}7 / 26 / 2009 \\
18: 00\end{array}$ & 888.4 & 8124.4 & 2.7 & 1.9 & 590.6 & 1.2 & 757.7 & 752.7 & 318.2 & 310.2 & 2257.0 & 5.9 & 1.1 & 0.3 & 42.5 & 4.8 & 6.2 \\
\hline $\begin{array}{r}7 / 26 / 2009 \\
18: 00\end{array}$ & $\begin{array}{r}7 / 26 / 2009 \\
19: 00\end{array}$ & 888.7 & 8098.9 & 2.7 & 1.9 & 587.0 & 1.2 & 753.1 & 746.4 & 315.1 & 306.6 & 2258.3 & 5.9 & 1.1 & 0.3 & 39.8 & 4.8 & 6.2 \\
\hline $\begin{array}{r}7 / 26 / 2009 \\
19: 00\end{array}$ & $\begin{array}{r}7 / 26 / 2009 \\
20: 00 \\
\end{array}$ & 885.9 & 8079.8 & 2.7 & 1.9 & 581.8 & 1.2 & 754.5 & 746.3 & 313.8 & 304.8 & 2254.6 & 5.9 & 1.1 & 0.3 & 41.8 & 4.8 & 6.2 \\
\hline $\begin{array}{r}7 / 26 / 2009 \\
20: 00\end{array}$ & $\begin{array}{r}7 / 26 / 2009 \\
21: 00 \\
\end{array}$ & 889.7 & 8084.1 & 2.7 & 2.0 & 587.0 & 1.2 & 755.7 & 747.5 & 312.4 & 304.2 & 2268.0 & 6.0 & 1.1 & 0.3 & 48.2 & 4.8 & 6.2 \\
\hline $\begin{array}{r}7 / 26 / 2009 \\
21: 00\end{array}$ & $\begin{array}{r}7 / 26 / 2009 \\
22: 00\end{array}$ & 892.7 & 8066.4 & 2.8 & 2.1 & 588.0 & 1.2 & 763.7 & 754.3 & 313.1 & 304.8 & 2292.8 & 6.1 & 1.1 & 0.3 & 40.2 & 4.8 & 6.2 \\
\hline $\begin{array}{r}7 / 26 / 2009 \\
22: 00\end{array}$ & $\begin{array}{r}7 / 26 / 2009 \\
23: 00\end{array}$ & 892.0 & 8099.5 & 2.9 & 2.1 & 587.5 & 1.2 & 767.8 & 758.8 & 313.9 & 305.2 & 2295.2 & 6.1 & 1.1 & 0.3 & 37.3 & 4.8 & 6.2 \\
\hline $\begin{array}{r}7 / 26 / 2009 \\
23: 00\end{array}$ & $\begin{array}{r}7 / 27 / 2009 \\
0: 00\end{array}$ & 890.3 & 8100.4 & 2.9 & 2.1 & 586.0 & 1.2 & 766.7 & 758.2 & 313.9 & 304.7 & 2290.7 & 6.1 & 1.1 & 0.3 & 42.1 & 4.8 & 6.2 \\
\hline $\begin{array}{r}7 / 27 / 2009 \\
0: 00\end{array}$ & $\begin{array}{r}7 / 27 / 2009 \\
1: 00\end{array}$ & 871.4 & 8104.6 & 2.9 & 2.1 & 573.0 & 1.2 & 765.2 & 752.8 & 316.2 & 306.1 & 2255.0 & 5.8 & 1.1 & 0.3 & 30.1 & 4.8 & 6.2 \\
\hline $\begin{array}{r}7 / 27 / 2009 \\
1: 00\end{array}$ & $\begin{array}{r}7 / 27 / 2009 \\
2: 00 \\
\end{array}$ & 888.6 & 8082.5 & 2.9 & 2.2 & 582.1 & 1.2 & 764.3 & 747.4 & 316.4 & 309.6 & 2317.0 & 6.3 & 1.1 & 0.3 & 13.5 & 4.8 & 6.2 \\
\hline $\begin{array}{r}7 / 27 / 2009 \\
2: 00\end{array}$ & $\begin{array}{r}7 / 27 / 2009 \\
3: 00 \\
\end{array}$ & 893.0 & 8119.3 & 2.8 & 2.2 & 579.2 & 1.2 & 763.3 & 747.7 & 307.8 & 303.4 & 2326.7 & 6.3 & 1.2 & 0.3 & 16.7 & 4.8 & 6.2 \\
\hline $\begin{array}{r}7 / 27 / 2009 \\
3: 00\end{array}$ & $\begin{array}{r}7 / 27 / 2009 \\
4: 00 \\
\end{array}$ & 891.9 & 8094.3 & 2.8 & 2.2 & 574.0 & 1.2 & 768.5 & 753.2 & 307.4 & 302.9 & 2317.1 & 6.3 & 1.2 & 0.3 & 23.2 & 4.8 & 6.2 \\
\hline $\begin{array}{r}7 / 27 / 2009 \\
4: 00\end{array}$ & $\begin{array}{r}7 / 27 / 2009 \\
5: 00\end{array}$ & 885.9 & 8129.3 & 2.8 & 2.2 & 569.3 & 1.2 & 772.0 & 756.8 & 309.6 & 304.7 & 2306.7 & 6.1 & 1.1 & 0.3 & 19.5 & 4.8 & 6.2 \\
\hline $\begin{array}{r}7 / 27 / 2009 \\
5: 00\end{array}$ & $\begin{array}{r}7 / 27 / 2009 \\
6: 00\end{array}$ & 774.7 & 8196.7 & 2.9 & 2.3 & 496.0 & 1.2 & 747.9 & 735.0 & 316.8 & 304.1 & 2064.4 & 5.7 & 1.1 & 0.3 & 6.1 & 4.8 & 6.2 \\
\hline
\end{tabular}




\begin{tabular}{|c|c|c|c|c|c|c|c|c|c|c|c|c|c|c|c|c|c|c|}
\hline $\begin{array}{l}\text { Start } \\
\text { Date/ } \\
\text { Time }\end{array}$ & $\begin{array}{l}\text { End } \\
\text { Date/ } \\
\text { Time }\end{array}$ & $\begin{array}{l}\text { Gross } \\
\text { Load }\end{array}$ & $\begin{array}{c}\text { Gross } \\
\text { HR }\end{array}$ & $\begin{array}{c}\text { A } \\
\text { Econ } \\
\text { O2 }\end{array}$ & $\begin{array}{c}\text { B } \\
\text { Econ } \\
\text { O2 }\end{array}$ & $\begin{array}{l}\text { Fuel } \\
\text { Flow }\end{array}$ & $\begin{array}{l}\text { BTU } \\
\text { Gain }\end{array}$ & $\begin{array}{c}\text { A } \\
\text { APH } \\
\text { In }\end{array}$ & $\begin{array}{c}\text { B } \\
\text { APH } \\
\text { In }\end{array}$ & $\begin{array}{c}\text { A } \\
\text { APH } \\
\text { Out }\end{array}$ & $\begin{array}{c}\text { B } \\
\text { APH } \\
\text { Out }\end{array}$ & $\begin{array}{l}\text { Stack } \\
\text { Flow }\end{array}$ & Opacity & SO2 In & $\begin{array}{l}\text { SO2 } \\
\text { Out }\end{array}$ & $\mathrm{CO}$ & $\begin{array}{c}\text { Stack } \\
\text { SCEM } \\
\text { Elemental } \\
\mathrm{Hg}\end{array}$ & $\begin{array}{c}\text { Stack } \\
\text { SCEM } \\
\text { Total Hg }\end{array}$ \\
\hline & & MW & Btu/kWh & $\%$ & $\%$ & Ton/hr & & DEGF & DEGF & DEGF & DEGF & KSCF & $\%$ & $\mathrm{Ib} / \mathrm{MMB}$ & Ib/MMb & PPM & $\begin{array}{c}(\mu \mathrm{g} / \mathrm{dNm} 3) \\
@ 3 \% 02\end{array}$ & $\begin{array}{c}(\mu \mathrm{g} / \mathrm{dNm} 3) \\
@ 3 \% 02\end{array}$ \\
\hline $\begin{array}{r}7 / 27 / 2009 \\
6: 00\end{array}$ & $\begin{array}{r}/ 27 / 2009 \\
7: 00\end{array}$ & 675.0 & 7959.6 & 3.2 & 2.4 & 438.1 & 1.2 & 713.4 & 704.1 & 313.6 & 292.9 & 1886.6 & 5.1 & 1.1 & 0.3 & 21.5 & 4.8 & 6.2 \\
\hline $\begin{array}{r}7 / 27 / 2009 \\
7: 00\end{array}$ & $\begin{array}{r}7 / 27 / 2009 \\
8: 00\end{array}$ & 764.4 & 7936.2 & 3.1 & 2.3 & 504.6 & 1.2 & 737.2 & 726.8 & 306.4 & 293.5 & 2091.3 & 5.5 & 1.1 & 0.3 & 16.1 & 4.8 & 6.2 \\
\hline $\begin{array}{r}7 / 27 / 2009 \\
8: 00\end{array}$ & $\begin{array}{r}7 / 27 / 2009 \\
9: 00\end{array}$ & 894.4 & 8029.7 & 3.0 & 2.1 & 590.8 & 1.2 & 777.1 & 763.0 & 310.9 & 302.6 & 2346.7 & 6.2 & 1.1 & 0.3 & 12.1 & 4.8 & 6.2 \\
\hline $\begin{array}{r}7 / 27 / 2009 \\
9: 00\end{array}$ & $\begin{array}{r}7 / 27 / 2009 \\
10: 00\end{array}$ & 899.5 & 8067.8 & 3.0 & 1.9 & 595.5 & 1.1 & 772.5 & 760.6 & 311.8 & 303.1 & 2309.7 & 6.3 & 1.2 & 0.3 & 24.5 & 4.8 & 6.2 \\
\hline $\begin{array}{r}7 / 27 / 2009 \\
10: 00\end{array}$ & $\begin{array}{r}7 / 27 / 2009 \\
11: 00\end{array}$ & 898.6 & 8043.3 & 3.1 & 1.9 & 600.8 & 1.1 & 777.5 & 764.9 & 314.3 & 306.0 & 2321.0 & 6.6 & 1.2 & 0.3 & 27.4 & 4.8 & 6.2 \\
\hline $\begin{array}{r}7 / 27 / 2009 \\
11: 00 \\
\end{array}$ & $\begin{array}{r}7 / 27 / 2009 \\
12: 00 \\
\end{array}$ & 903.0 & 8042.9 & 3.1 & 1.9 & 608.6 & 1.1 & 776.6 & 765.6 & 315.8 & 307.8 & 2351.7 & 7.0 & 1.2 & 0.3 & 19.3 & 4.8 & 6.2 \\
\hline $\begin{array}{r}7 / 27 / 2009 \\
12: 00\end{array}$ & $\begin{array}{r}7 / 27 / 2009 \\
13: 00\end{array}$ & 906.4 & 8059.6 & 3.1 & 1.9 & 612.8 & 1.1 & 779.4 & 762.7 & 317.7 & 309.4 & 2345.1 & 7.4 & 1.3 & 0.3 & 17.6 & 4.8 & 6.2 \\
\hline $\begin{array}{r}7 / 27 / 2009 \\
13: 00\end{array}$ & $\begin{array}{r}7 / 27 / 2009 \\
14: 00\end{array}$ & 909.1 & 8042.4 & 3.2 & 1.9 & 617.0 & 1.1 & 783.5 & 762.3 & 318.6 & 309.1 & 2339.8 & 7.4 & 1.3 & 0.3 & 21.3 & 4.8 & 6.2 \\
\hline $\begin{array}{r}7 / 27 / 2009 \\
14: 00\end{array}$ & $\begin{array}{r}7 / 27 / 2009 \\
15: 00\end{array}$ & 909.7 & 8027.8 & 3.2 & 1.8 & 617.8 & 1.1 & 782.7 & 766.5 & 320.3 & 311.9 & 2333.2 & 7.2 & 1.3 & 0.3 & 22.5 & 4.8 & 6.2 \\
\hline $\begin{array}{r}7 / 27 / 2009 \\
15: 00\end{array}$ & $\begin{array}{r}7 / 27 / 2009 \\
16: 00\end{array}$ & 910.2 & 8024.3 & 3.0 & 1.7 & 615.9 & 1.1 & 780.6 & 768.8 & 320.8 & 313.8 & 2315.6 & 7.3 & 1.3 & 0.3 & 35.6 & 4.8 & 6.2 \\
\hline $\begin{array}{r}7 / 27 / 2009 \\
16: 00\end{array}$ & $\begin{array}{r}7 / 27 / 2009 \\
17: 00\end{array}$ & 907.2 & 8022.7 & 2.6 & 1.5 & 621.8 & 1.1 & 772.6 & 763.1 & 321.5 & 314.3 & 2274.6 & 7.0 & 1.3 & 0.3 & 58.7 & 4.8 & 6.2 \\
\hline $\begin{array}{r}7 / 27 / 2009 \\
17: 00 \\
\end{array}$ & $\begin{array}{r}7 / 27 / 2009 \\
18: 00 \\
\end{array}$ & 909.9 & 8028.0 & 2.8 & 1.7 & 631.7 & 1.1 & 774.5 & 765.0 & 318.9 & 312.1 & 2312.8 & 7.1 & 1.3 & 0.3 & 48.5 & 4.8 & 6.2 \\
\hline $\begin{array}{r}7 / 27 / 2009 \\
18: 00 \\
\end{array}$ & $\begin{array}{r}7 / 27 / 2009 \\
19: 00 \\
\end{array}$ & 895.5 & 8092.4 & 3.0 & 1.9 & 623.4 & 1.1 & 764.9 & 756.7 & 313.5 & 306.5 & 2343.2 & 6.7 & 1.3 & 0.3 & 16.5 & 4.8 & 6.2 \\
\hline $\begin{array}{r}7 / 27 / 2009 \\
19: 00\end{array}$ & $\begin{array}{r}7 / 27 / 2009 \\
20: 00\end{array}$ & 889.1 & 8042.9 & 3.0 & 1.9 & 618.5 & 1.1 & 763.7 & 753.5 & 309.3 & 302.6 & 2327.2 & 6.6 & 1.3 & 0.3 & 16.9 & 4.8 & 6.2 \\
\hline $\begin{array}{r}7 / 27 / 2009 \\
20: 00\end{array}$ & $\begin{array}{r}7 / 27 / 2009 \\
21: 00\end{array}$ & 900.3 & 8037.8 & 3.0 & 1.9 & 621.4 & 1.1 & 767.9 & 757.5 & 309.1 & 302.8 & 2352.3 & 6.8 & 1.3 & 0.3 & 26.9 & 4.8 & 6.2 \\
\hline $\begin{array}{r}7 / 27 / 2009 \\
21: 00\end{array}$ & $\begin{array}{r}7 / 27 / 2009 \\
22: 00\end{array}$ & 903.6 & 8039.5 & 3.1 & 1.9 & 621.0 & 1.1 & 770.5 & 760.4 & 308.0 & 302.9 & 2368.2 & 7.1 & 1.4 & 0.3 & 26.2 & 4.8 & 6.2 \\
\hline $\begin{array}{r}7 / 27 / 2009 \\
22: 00\end{array}$ & $\begin{array}{r}7 / 27 / 2009 \\
23: 00\end{array}$ & 905.7 & 8045.0 & 3.1 & 1.9 & 619.0 & 1.1 & 771.2 & 761.1 & 307.3 & 302.8 & 2373.8 & 7.1 & 1.4 & 0.3 & 18.1 & 4.8 & 6.2 \\
\hline $\begin{array}{r}7 / 27 / 2009 \\
23: 00 \\
\end{array}$ & $\begin{array}{r}7 / 28 / 2009 \\
0: 00 \\
\end{array}$ & 903.6 & 8065.5 & 3.1 & 2.0 & 615.6 & 1.1 & 771.4 & 759.7 & 306.4 & 301.6 & 2357.5 & 7.3 & 1.4 & 0.3 & 17.8 & 4.8 & 6.2 \\
\hline $\begin{array}{r}7 / 28 / 2009 \\
0: 00 \\
\end{array}$ & $\begin{array}{r}7 / 28 / 2009 \\
1: 00 \\
\end{array}$ & 892.3 & 8097.8 & 3.0 & 1.9 & 603.4 & 1.1 & 763.6 & 748.0 & 307.7 & 299.5 & 2327.3 & 7.2 & 1.4 & 0.3 & 17.8 & 4.8 & 6.2 \\
\hline $7 / 28 / 2009$ & $7 / 28 / 2009$ & 886.1 & 8085.8 & 3.1 & 2.0 & 596.9 & 1.1 & 754.6 & 748.5 & 305.1 & 296.6 & 2319.9 & 6.7 & 1.3 & 0.3 & 13.5 & 4.8 & 6.2 \\
\hline
\end{tabular}




\begin{tabular}{|c|c|c|c|c|c|c|c|c|c|c|c|c|c|c|c|c|c|c|}
\hline $\begin{array}{l}\text { Start } \\
\text { Date/ } \\
\text { Time }\end{array}$ & $\begin{array}{l}\text { End } \\
\text { Date/ } \\
\text { Time }\end{array}$ & $\begin{array}{l}\text { Gross } \\
\text { Load }\end{array}$ & $\begin{array}{c}\text { Gross } \\
\text { HR }\end{array}$ & $\begin{array}{c}\text { A } \\
\text { Econ } \\
\text { O2 }\end{array}$ & $\begin{array}{c}\text { B } \\
\text { Econ } \\
\text { O2 }\end{array}$ & $\begin{array}{l}\text { Fuel } \\
\text { Flow }\end{array}$ & $\begin{array}{l}\text { BTU } \\
\text { Gain }\end{array}$ & $\begin{array}{c}\text { A } \\
\text { APH } \\
\text { In }\end{array}$ & $\begin{array}{c}\text { B } \\
\text { APH } \\
\text { In }\end{array}$ & $\begin{array}{c}\text { A } \\
\text { APH } \\
\text { Out }\end{array}$ & $\begin{array}{c}\text { B } \\
\text { APH } \\
\text { Out }\end{array}$ & $\begin{array}{l}\text { Stack } \\
\text { Flow }\end{array}$ & Opacity & SO2 In & $\begin{array}{l}\text { SO2 } \\
\text { Out }\end{array}$ & $\mathrm{CO}$ & $\begin{array}{c}\text { Stack } \\
\text { SCEM } \\
\text { Elemental } \\
\mathrm{Hg}\end{array}$ & $\begin{array}{c}\text { Stack } \\
\text { SCEM } \\
\text { Total Hg }\end{array}$ \\
\hline & & MW & Btu/kWh & $\%$ & $\%$ & Ton/hr & & DEGF & DEGF & DEGF & DEGF & KSCF & $\%$ & Ib/MMB & $\mathrm{Ib} / \mathrm{MMb}$ & PPM & $\begin{array}{c}(\mu \mathrm{g} / \mathrm{dNm} 3) \\
@ 3 \% 02\end{array}$ & $\begin{array}{c}(\mu \mathrm{g} / \mathrm{dNm} 3) \\
\text { @ 3\%O2 }\end{array}$ \\
\hline $1: 00$ & $2: 00$ & & & & & & & & & & & & & & & & & \\
\hline $\begin{array}{r}7 / 28 / 2009 \\
2: 00\end{array}$ & $\begin{array}{r}7 / 28 / 2009 \\
3: 00 \\
\end{array}$ & 893.0 & 8051.8 & 3.1 & 1.9 & 601.3 & 1.1 & 761.9 & 755.9 & 304.7 & 296.9 & 2327.0 & 6.5 & 1.3 & 0.3 & 16.0 & 4.8 & 6.2 \\
\hline $\begin{array}{r}7 / 28 / 2009 \\
3: 00\end{array}$ & $\begin{array}{r}7 / 28 / 2009 \\
4: 00\end{array}$ & 898.2 & 8032.7 & 3.1 & 1.9 & 605.9 & 1.1 & 768.3 & 761.8 & 305.5 & 298.0 & 2342.4 & 6.4 & 1.3 & 0.3 & 18.7 & 4.8 & 6.2 \\
\hline $\begin{array}{r}7 / 28 / 2009 \\
4: 00 \\
\end{array}$ & $\begin{array}{r}7 / 28 / 2009 \\
5: 00 \\
\end{array}$ & 894.9 & 8027.8 & 3.1 & 1.9 & 610.7 & 1.1 & 773.6 & 765.7 & 307.1 & 299.6 & 2347.6 & 6.8 & 1.4 & 0.3 & 13.6 & 4.8 & 6.2 \\
\hline $\begin{array}{r}7 / 28 / 2009 \\
5: 00\end{array}$ & $\begin{array}{r}7 / 28 / 2009 \\
6: 00\end{array}$ & 902.8 & 8022.3 & 2.9 & 1.6 & 621.9 & 1.1 & 768.7 & 762.7 & 309.1 & 301.4 & 2349.0 & 7.4 & 1.4 & 0.3 & 36.5 & 4.8 & 6.2 \\
\hline $\begin{array}{r}7 / 28 / 2009 \\
6: 00\end{array}$ & $\begin{array}{r}7 / 28 / 2009 \\
7: 00\end{array}$ & 911.4 & 8021.2 & 2.8 & 1.6 & 626.0 & 1.1 & 762.9 & 759.4 & 306.1 & 299.6 & 2360.7 & 7.8 & 1.5 & 0.3 & 50.7 & 4.8 & 6.2 \\
\hline $\begin{array}{r}7 / 28 / 2009 \\
7: 00\end{array}$ & $\begin{array}{r}7 / 28 / 2009 \\
8: 00\end{array}$ & 911.8 & 8006.5 & 5.1 & 2.7 & 625.6 & 1.1 & 769.4 & 764.5 & 306.9 & 300.4 & 2363.9 & 9.3 & 1.5 & 0.3 & 46.5 & 4.8 & 6.2 \\
\hline $\begin{array}{r}7 / 28 / 2009 \\
8: 00\end{array}$ & $\begin{array}{r}7 / 28 / 2009 \\
9: 00 \\
\end{array}$ & 907.7 & 8006.0 & 4.4 & 2.0 & 631.7 & 1.1 & 764.6 & 759.8 & 307.0 & 300.4 & 2373.8 & 11.0 & 1.6 & 0.4 & 31.2 & 4.8 & 6.2 \\
\hline $\begin{array}{r}7 / 28 / 2009 \\
9: 00\end{array}$ & $\begin{array}{r}7 / 28 / 2009 \\
10: 00 \\
\end{array}$ & 909.3 & 8002.7 & 2.9 & 1.5 & 637.7 & 1.1 & 755.7 & 751.1 & 304.2 & 298.1 & 2361.4 & 10.0 & 1.7 & 0.4 & 34.2 & 4.8 & 6.2 \\
\hline $\begin{array}{r}7 / 28 / 2009 \\
10: 00 \\
\end{array}$ & $\begin{array}{r}7 / 28 / 2009 \\
11: 00 \\
\end{array}$ & 909.9 & 8041.8 & 2.8 & 1.7 & 641.0 & 1.1 & 757.1 & 751.1 & 305.1 & 298.8 & 2354.7 & 7.9 & 1.7 & 0.4 & 36.2 & 4.8 & 6.2 \\
\hline $\begin{array}{r}7 / 28 / 2009 \\
11: 00 \\
\end{array}$ & $\begin{array}{r}7 / 28 / 2009 \\
12: 00 \\
\end{array}$ & 910.7 & 8050.5 & 2.8 & 1.6 & 643.9 & 1.1 & 754.3 & 747.7 & 305.7 & 298.9 & 2363.6 & 7.2 & 1.7 & 0.4 & 28.6 & 4.8 & 6.2 \\
\hline $\begin{array}{r}7 / 28 / 2009 \\
12: 00\end{array}$ & $\begin{array}{r}7 / 28 / 2009 \\
13: 00\end{array}$ & 914.6 & 8043.7 & 2.8 & 1.5 & 635.8 & 1.1 & 757.8 & 752.2 & 307.4 & 301.3 & 2349.8 & 6.9 & 1.6 & 0.4 & 35.4 & 4.8 & 6.2 \\
\hline $\begin{array}{r}7 / 28 / 2009 \\
13: 00\end{array}$ & $\begin{array}{r}7 / 28 / 2009 \\
14: 00\end{array}$ & 909.7 & 8031.7 & 2.8 & 1.4 & 626.1 & 1.1 & 762.0 & 756.7 & 309.4 & 303.4 & 2326.3 & 6.5 & 1.4 & 0.4 & 47.6 & 4.8 & 6.2 \\
\hline $\begin{array}{r}7 / 28 / 2009 \\
14: 00\end{array}$ & $\begin{array}{r}7 / 28 / 2009 \\
15: 00\end{array}$ & 909.8 & 8031.9 & 2.8 & 1.4 & 631.3 & 1.1 & 762.0 & 757.8 & 311.3 & 305.2 & 2329.0 & 6.5 & 1.4 & 0.4 & 54.1 & 4.8 & 6.2 \\
\hline $\begin{array}{r}7 / 28 / 2009 \\
15: 00\end{array}$ & $\begin{array}{r}7 / 28 / 2009 \\
16: 00 \\
\end{array}$ & 912.1 & 8013.2 & 2.8 & 1.4 & 634.9 & 1.1 & 761.0 & 756.4 & 311.6 & 305.6 & 2319.1 & 6.5 & 1.4 & 0.4 & 55.4 & 4.8 & 6.2 \\
\hline $\begin{array}{r}7 / 28 / 2009 \\
16: 00\end{array}$ & $\begin{array}{r}7 / 28 / 2009 \\
17: 00\end{array}$ & 912.5 & 8027.2 & 2.8 & 1.4 & 636.8 & 1.1 & 765.2 & 758.4 & 313.3 & 307.5 & 2328.2 & 6.7 & 1.4 & 0.4 & 53.9 & 4.8 & 6.2 \\
\hline $\begin{array}{r}7 / 28 / 2009 \\
17: 00 \\
\end{array}$ & $\begin{array}{r}7 / 28 / 2009 \\
18: 00 \\
\end{array}$ & 914.5 & 8011.6 & 2.8 & 1.4 & 627.6 & 1.1 & 767.2 & 761.5 & 314.3 & 308.6 & 2321.8 & 6.9 & 1.4 & 0.4 & 59.6 & 4.8 & 6.2 \\
\hline $\begin{array}{r}7 / 28 / 2009 \\
18: 00 \\
\end{array}$ & $\begin{array}{r}7 / 28 / 2009 \\
19: 00 \\
\end{array}$ & 913.0 & 8002.8 & 2.8 & 1.4 & 617.6 & 1.1 & 772.2 & 766.9 & 315.0 & 310.3 & 2303.9 & 6.6 & 1.3 & 0.4 & 59.9 & 4.8 & 6.2 \\
\hline $\begin{array}{r}7 / 28 / 2009 \\
19: 00\end{array}$ & $\begin{array}{r}7 / 28 / 2009 \\
20: 00\end{array}$ & 911.2 & 7989.8 & 2.8 & 1.4 & 617.5 & 1.1 & 777.3 & 771.9 & 316.2 & 312.1 & 2293.9 & 6.3 & 1.3 & 0.4 & 57.7 & 4.8 & 6.2 \\
\hline $\begin{array}{r}7 / 28 / 2009 \\
20: 00\end{array}$ & $\begin{array}{r}7 / 28 / 2009 \\
21: 00 \\
\end{array}$ & 911.0 & 8019.5 & 2.8 & 1.4 & 611.4 & 1.1 & 771.2 & 767.6 & 316.7 & 312.7 & 2288.5 & 6.2 & 1.3 & 0.4 & 42.6 & 4.8 & 6.2 \\
\hline
\end{tabular}




\begin{tabular}{|c|c|c|c|c|c|c|c|c|c|c|c|c|c|c|c|c|c|c|}
\hline \multirow[t]{2}{*}{$\begin{array}{l}\text { Start } \\
\text { Date/ } \\
\text { Time }\end{array}$} & \multirow[t]{2}{*}{$\begin{array}{l}\text { End } \\
\text { Date/ } \\
\text { Time }\end{array}$} & $\begin{array}{l}\text { Gross } \\
\text { Load }\end{array}$ & $\begin{array}{c}\text { Gross } \\
\text { HR }\end{array}$ & $\begin{array}{c}\text { A } \\
\text { Econ } \\
\text { O2 }\end{array}$ & $\begin{array}{c}\text { B } \\
\text { Econ } \\
\text { O2 }\end{array}$ & $\begin{array}{l}\text { Fuel } \\
\text { Flow }\end{array}$ & $\begin{array}{l}\text { BTU } \\
\text { Gain }\end{array}$ & $\begin{array}{c}\text { A } \\
\text { APH } \\
\text { In }\end{array}$ & $\begin{array}{c}\text { B } \\
\text { APH } \\
\text { In }\end{array}$ & $\begin{array}{c}\text { A } \\
\text { APH } \\
\text { Out }\end{array}$ & $\begin{array}{c}\text { B } \\
\text { APH } \\
\text { Out }\end{array}$ & $\begin{array}{l}\text { Stack } \\
\text { Flow }\end{array}$ & Opacity & SO2 In & $\begin{array}{l}\text { SO2 } \\
\text { Out }\end{array}$ & $\mathrm{CO}$ & $\begin{array}{c}\text { Stack } \\
\text { SCEM } \\
\text { Elemental } \\
\mathrm{Hg}\end{array}$ & $\begin{array}{c}\text { Stack } \\
\text { SCEM } \\
\text { Total Hg }\end{array}$ \\
\hline & & MW & Btu/kWh & $\%$ & $\%$ & Ton/hr & & DEGF & DEGF & DEGF & DEGF & KSCF & $\%$ & $\mathrm{Ib} / \mathrm{MMB}$ & $\mathrm{Ib} / \mathrm{MMb}$ & PPM & $\begin{array}{c}\text { ( } \mu \mathrm{g} / \mathrm{dNm} \text { ) } \\
@ 3 \% 02\end{array}$ & $\begin{array}{c}(\mu \mathrm{g} / \mathrm{dNm} 3) \\
@ 3 \% 02\end{array}$ \\
\hline $\begin{array}{r}7 / 28 / 2009 \\
21: 00\end{array}$ & $\begin{array}{r}7 / 28 / 2009 \\
22: 00\end{array}$ & 909.2 & 8012.8 & 2.8 & 1.5 & 609.5 & 1.1 & 764.2 & 759.0 & 312.3 & 307.1 & 2283.9 & 6.0 & 1.3 & 0.4 & 32.7 & 4.8 & 6.2 \\
\hline $\begin{array}{r}7 / 28 / 2009 \\
22: 00\end{array}$ & $\begin{array}{r}7 / 28 / 2009 \\
23: 00\end{array}$ & 910.5 & 8005.7 & 2.7 & 1.5 & 610.0 & 1.1 & 772.9 & 767.4 & 312.6 & 307.1 & 2289.6 & 6.0 & 1.3 & 0.4 & 31.8 & 4.8 & 6.2 \\
\hline $\begin{array}{r}7 / 28 / 2009 \\
23: 00\end{array}$ & $\begin{array}{r}7 / 29 / 2009 \\
0: 00\end{array}$ & 911.6 & 8010.4 & 2.7 & 1.5 & 608.4 & 1.1 & 780.3 & 774.4 & 313.9 & 307.8 & 2304.6 & 6.0 & 1.3 & 0.4 & 30.0 & 4.8 & 6.2 \\
\hline $\begin{array}{r}7 / 29 / 2009 \\
0: 00\end{array}$ & $\begin{array}{r}7 / 29 / 2009 \\
1: 00\end{array}$ & 911.4 & 8011.7 & 2.7 & 1.5 & 607.0 & 1.1 & 775.0 & 769.3 & 314.2 & 307.4 & 2314.1 & 5.9 & 1.3 & 0.4 & 22.5 & 4.8 & 6.2 \\
\hline $\begin{array}{r}7 / 29 / 2009 \\
1: 00\end{array}$ & $\begin{array}{r}7 / 29 / 2009 \\
2: 00\end{array}$ & 910.9 & 8006.9 & 2.7 & 1.5 & 601.7 & 1.1 & 768.1 & 760.9 & 309.5 & 302.1 & 2297.5 & 5.8 & 1.2 & 0.4 & 22.0 & 4.8 & 6.2 \\
\hline $\begin{array}{r}7 / 29 / 2009 \\
2: 00\end{array}$ & $\begin{array}{r}7 / 29 / 2009 \\
3: 00\end{array}$ & 900.4 & 7986.7 & 2.7 & 1.6 & 591.9 & 1.1 & 774.7 & 755.0 & 309.6 & 299.2 & 2269.6 & 5.7 & 1.2 & 0.4 & 21.8 & 4.8 & 6.2 \\
\hline $\begin{array}{r}7 / 29 / 2009 \\
3: 00\end{array}$ & $\begin{array}{r}7 / 29 / 2009 \\
4: 00\end{array}$ & 896.8 & 7990.6 & 3.0 & 1.9 & 600.5 & 1.1 & 773.8 & 761.5 & 308.9 & 299.6 & 2333.1 & 5.7 & 1.2 & 0.4 & 10.9 & 4.8 & 6.2 \\
\hline $\begin{array}{r}7 / 29 / 2009 \\
4: 00\end{array}$ & $\begin{array}{r}7 / 29 / 2009 \\
5: 00\end{array}$ & 907.6 & 8041.7 & 3.1 & 2.1 & 603.5 & 1.1 & 770.5 & 762.2 & 307.2 & 299.7 & 2382.7 & 6.0 & 1.2 & 0.4 & 4.2 & 4.8 & 6.2 \\
\hline $\begin{array}{r}7 / 29 / 2009 \\
5: 00\end{array}$ & $\begin{array}{r}7 / 29 / 2009 \\
6: 00\end{array}$ & 910.5 & 8041.3 & 3.1 & 2.1 & 606.4 & 1.1 & 773.8 & 763.8 & 305.0 & 296.9 & 2394.5 & 6.2 & 1.2 & 0.3 & 6.7 & 4.8 & 6.2 \\
\hline $\begin{array}{r}7 / 29 / 2009 \\
6: 00 \\
\end{array}$ & $\begin{array}{r}7 / 29 / 2009 \\
7: 00 \\
\end{array}$ & 910.7 & 8041.3 & 3.1 & 2.1 & 608.0 & 1.1 & 783.2 & 772.2 & 308.7 & 299.0 & 2398.5 & 8.5 & 1.2 & 0.3 & 6.5 & 4.8 & 6.2 \\
\hline $\begin{array}{r}7 / 29 / 2009 \\
7: 00\end{array}$ & $\begin{array}{r}7 / 29 / 2009 \\
8: 00\end{array}$ & 909.9 & 8041.3 & 3.1 & 2.0 & 605.4 & 1.1 & 777.0 & 765.6 & 308.0 & 299.8 & 2390.1 & 11.1 & 1.2 & 0.3 & 6.6 & 4.8 & 6.2 \\
\hline $\begin{array}{r}7 / 29 / 2009 \\
8: 00\end{array}$ & $\begin{array}{r}7 / 29 / 2009 \\
9: 00\end{array}$ & 909.0 & 8041.3 & 3.2 & 2.0 & 609.8 & 1.1 & 780.8 & 769.1 & 307.8 & 299.7 & 2392.0 & 11.3 & 1.2 & 0.3 & 10.1 & 4.8 & 6.2 \\
\hline $\begin{array}{r}7 / 29 / 2009 \\
9: 00\end{array}$ & $\begin{array}{r}7 / 29 / 2009 \\
10: 00\end{array}$ & 910.7 & 8041.3 & 3.2 & 2.0 & 614.4 & 1.1 & 786.6 & 774.9 & 310.1 & 302.4 & 2381.1 & 11.3 & 1.2 & 0.3 & 7.8 & 4.8 & 6.2 \\
\hline $\begin{array}{r}7 / 29 / 2009 \\
10: 00\end{array}$ & $\begin{array}{r}7 / 29 / 2009 \\
11: 00\end{array}$ & 913.6 & 8041.3 & 3.2 & 2.0 & 615.8 & 1.1 & 790.8 & 779.1 & 312.6 & 304.8 & 2398.8 & 11.3 & 1.2 & 0.3 & 6.0 & 4.8 & 6.2 \\
\hline $\begin{array}{r}7 / 29 / 2009 \\
11: 00 \\
\end{array}$ & $\begin{array}{r}7 / 29 / 2009 \\
12: 00 \\
\end{array}$ & 915.1 & 8041.3 & 3.1 & 2.0 & 614.6 & 1.1 & 794.4 & 783.5 & 314.8 & 307.1 & 2385.0 & 11.0 & 1.3 & 0.3 & 7.0 & 4.8 & 6.2 \\
\hline $\begin{array}{r}7 / 29 / 2009 \\
12: 00 \\
\end{array}$ & $\begin{array}{r}7 / 29 / 2009 \\
13: 00 \\
\end{array}$ & 913.3 & 8041.3 & 3.1 & 2.1 & 612.3 & 1.1 & 797.1 & 786.5 & 316.9 & 309.4 & 2378.8 & 10.9 & 1.2 & 0.3 & 8.1 & 4.8 & 6.2 \\
\hline $\begin{array}{r}7 / 29 / 2009 \\
13: 00 \\
\end{array}$ & $\begin{array}{r}7 / 29 / 2009 \\
14: 00 \\
\end{array}$ & 914.0 & 8041.3 & 3.1 & 2.1 & 609.5 & 1.1 & 799.7 & 789.0 & 318.5 & 311.7 & 2367.6 & 10.6 & 1.2 & 0.3 & 11.0 & 4.8 & 6.2 \\
\hline $\begin{array}{r}7 / 29 / 2009 \\
14: 00\end{array}$ & $\begin{array}{r}7 / 29 / 2009 \\
15: 00\end{array}$ & 912.1 & 8041.3 & 3.1 & 2.1 & 609.2 & 1.1 & 799.0 & 788.6 & 320.7 & 314.0 & 2370.8 & 9.8 & 1.2 & 0.3 & 11.1 & 4.8 & 6.2 \\
\hline $\begin{array}{r}7 / 29 / 2009 \\
15: 00\end{array}$ & $\begin{array}{r}7 / 29 / 2009 \\
16: 00\end{array}$ & 912.8 & 8041.3 & 3.1 & 2.1 & 608.4 & 1.1 & 788.4 & 777.7 & 320.0 & 313.3 & 2367.5 & 8.5 & 1.2 & 0.3 & 11.3 & 4.8 & 6.2 \\
\hline $7 / 29 / 2009$ & $7 / 29 / 2009$ & 914.3 & 8041.3 & 3.2 & 2.0 & 605.4 & 1.1 & 777.7 & 767.9 & 318.0 & 311.7 & 2364.3 & 8.3 & 1.2 & 0.3 & 8.5 & 4.8 & 6.2 \\
\hline
\end{tabular}




\begin{tabular}{|c|c|c|c|c|c|c|c|c|c|c|c|c|c|c|c|c|c|c|}
\hline $\begin{array}{l}\text { Start } \\
\text { Date/ } \\
\text { Time }\end{array}$ & $\begin{array}{l}\text { End } \\
\text { Date/ } \\
\text { Time }\end{array}$ & $\begin{array}{l}\text { Gross } \\
\text { Load }\end{array}$ & $\begin{array}{c}\text { Gross } \\
\text { HR }\end{array}$ & $\begin{array}{c}\text { A } \\
\text { Econ } \\
\text { O2 }\end{array}$ & $\begin{array}{c}\text { B } \\
\text { Econ } \\
\text { O2 }\end{array}$ & $\begin{array}{l}\text { Fuel } \\
\text { Flow }\end{array}$ & $\begin{array}{l}\text { BTU } \\
\text { Gain }\end{array}$ & $\begin{array}{l}\text { A } \\
\text { APH } \\
\text { In }\end{array}$ & $\begin{array}{c}\text { B } \\
\text { APH } \\
\text { In }\end{array}$ & $\begin{array}{c}\text { A } \\
\text { APH } \\
\text { Out }\end{array}$ & $\begin{array}{c}\text { B } \\
\text { APH } \\
\text { Out }\end{array}$ & $\begin{array}{l}\text { Stack } \\
\text { Flow }\end{array}$ & Opacity & SO2 In & $\begin{array}{l}\text { SO2 } \\
\text { Out }\end{array}$ & $\mathrm{CO}$ & $\begin{array}{c}\text { Stack } \\
\text { SCEM } \\
\text { Elemental } \\
\mathrm{Hg}\end{array}$ & $\begin{array}{c}\text { Stack } \\
\text { SCEM } \\
\text { Total Hg }\end{array}$ \\
\hline & & MW & Btu/kWh & $\%$ & $\%$ & Ton/hr & & DEGF & DEGF & DEGF & DEGF & KSCF & $\%$ & Ib/MMB & $\mathrm{Ib} / \mathrm{MMb}$ & PPM & $\begin{array}{c}(\mu \mathrm{g} / \mathrm{dNm} 3) \\
@ 3 \% 02\end{array}$ & $\begin{array}{c}(\mu \mathrm{g} / \mathrm{dNm} 3) \\
@ 3 \% 02\end{array}$ \\
\hline $16: 00$ & $17: 00$ & & & & & & & & & & & & & & & & & \\
\hline $\begin{array}{r}7 / 29 / 2009 \\
17: 00\end{array}$ & $\begin{array}{r}7 / 29 / 2009 \\
18: 00\end{array}$ & 912.1 & 8041.3 & 3.1 & 2.1 & 606.0 & 1.1 & 774.3 & 764.3 & 316.2 & 309.8 & 2349.8 & 8.2 & 1.2 & 0.3 & 8.5 & 4.8 & 6.2 \\
\hline $\begin{array}{r}7 / 29 / 2009 \\
18: 00\end{array}$ & $\begin{array}{r}7 / 29 / 2009 \\
19: 00\end{array}$ & 911.9 & 8041.3 & 3.1 & 2.1 & 608.9 & 1.1 & 774.4 & 765.4 & 315.8 & 309.7 & 2334.7 & 8.2 & 1.2 & 0.3 & 7.1 & 4.8 & 6.2 \\
\hline $\begin{array}{r}7 / 29 / 2009 \\
19: 00 \\
\end{array}$ & $\begin{array}{r}7 / 29 / 2009 \\
20: 00 \\
\end{array}$ & 911.8 & 8041.3 & 3.1 & 2.1 & 611.9 & 1.1 & 775.7 & 766.2 & 316.2 & 309.9 & 2326.2 & 7.9 & 1.2 & 0.3 & 6.8 & 4.8 & 6.2 \\
\hline $\begin{array}{r}7 / 29 / 2009 \\
20: 00\end{array}$ & $\begin{array}{r}7 / 29 / 2009 \\
21: 00\end{array}$ & 913.2 & 8041.3 & 3.1 & 2.0 & 613.5 & 1.1 & 779.1 & 769.9 & 313.3 & 307.5 & 2342.0 & 7.7 & 1.2 & 0.3 & 9.1 & 4.8 & 6.2 \\
\hline $\begin{array}{r}7 / 29 / 2009 \\
21: 00\end{array}$ & $\begin{array}{r}7 / 29 / 2009 \\
22: 00\end{array}$ & 914.0 & 8041.3 & 3.1 & 2.0 & 612.7 & 1.1 & 779.3 & 772.4 & 306.5 & 299.6 & 2375.9 & 8.4 & 1.2 & 0.3 & 8.8 & 4.8 & 6.2 \\
\hline $\begin{array}{r}7 / 29 / 2009 \\
22: 00\end{array}$ & $\begin{array}{r}7 / 29 / 2009 \\
23: 00\end{array}$ & 913.6 & 8041.3 & 3.2 & 2.0 & 612.7 & 1.1 & 782.6 & 774.6 & 306.4 & 299.2 & 2373.7 & 7.3 & 1.2 & 0.3 & 10.6 & 4.8 & 6.2 \\
\hline $\begin{array}{r}7 / 29 / 2009 \\
23: 00\end{array}$ & $\begin{array}{r}7 / 30 / 2009 \\
0: 00\end{array}$ & 915.1 & 8041.3 & 3.1 & 2.0 & 617.3 & 1.1 & 786.0 & 777.5 & 308.3 & 301.8 & 2374.4 & 7.3 & 1.1 & 0.3 & 10.6 & 4.8 & 6.2 \\
\hline $\begin{array}{r}7 / 30 / 2009 \\
0: 00\end{array}$ & $\begin{array}{r}7 / 30 / 2009 \\
1: 00\end{array}$ & 906.2 & 8041.3 & 3.1 & 2.0 & 607.2 & 1.1 & 787.1 & 778.1 & 310.5 & 303.5 & 2363.9 & 7.2 & 1.1 & 0.3 & 11.9 & 4.8 & 6.2 \\
\hline $\begin{array}{r}7 / 30 / 2009 \\
1: 00\end{array}$ & $\begin{array}{r}7 / 30 / 2009 \\
2: 00\end{array}$ & 907.6 & 8041.3 & 3.1 & 2.0 & 605.4 & 1.1 & 790.0 & 781.1 & 312.2 & 304.9 & 2360.9 & 7.3 & 1.1 & 0.3 & 10.2 & 4.8 & 6.2 \\
\hline $\begin{array}{r}7 / 30 / 2009 \\
2: 00 \\
\end{array}$ & $\begin{array}{r}7 / 30 / 2009 \\
3: 00 \\
\end{array}$ & 903.8 & 8041.3 & 3.1 & 2.0 & 597.5 & 1.1 & 790.7 & 782.8 & 312.3 & 305.1 & 2361.7 & 7.1 & 1.1 & 0.3 & 9.0 & 4.8 & 6.2 \\
\hline $\begin{array}{r}7 / 30 / 2009 \\
3: 00\end{array}$ & $\begin{array}{r}7 / 30 / 2009 \\
4: 00\end{array}$ & 901.4 & 8041.3 & 3.1 & 2.1 & 598.4 & 1.1 & 792.7 & 785.1 & 312.6 & 305.5 & 2363.4 & 7.2 & 1.1 & 0.3 & 8.6 & 4.8 & 6.2 \\
\hline $\begin{array}{r}7 / 30 / 2009 \\
4: 00\end{array}$ & $\begin{array}{r}7 / 30 / 2009 \\
5: 00\end{array}$ & 901.7 & 8041.3 & 3.1 & 2.1 & 599.3 & 1.1 & 796.3 & 788.0 & 313.9 & 306.9 & 2376.0 & 7.4 & 1.1 & 0.3 & 9.0 & 4.8 & 6.2 \\
\hline $\begin{array}{r}7 / 30 / 2009 \\
5: 00\end{array}$ & $\begin{array}{r}7 / 30 / 2009 \\
6: 00\end{array}$ & 908.4 & 8041.3 & 3.0 & 1.9 & 599.2 & 1.1 & 790.9 & 782.8 & 314.7 & 307.1 & 2371.5 & 7.8 & 1.1 & 0.3 & 14.2 & 4.8 & 6.2 \\
\hline $\begin{array}{r}7 / 30 / 2009 \\
6: 00 \\
\end{array}$ & $\begin{array}{r}7 / 30 / 2009 \\
7: 00 \\
\end{array}$ & 910.8 & 8041.3 & 3.0 & 1.9 & 600.1 & 1.1 & 777.6 & 769.1 & 310.0 & 302.5 & 2365.8 & 8.0 & 1.2 & 0.3 & 19.5 & 4.8 & 6.2 \\
\hline $\begin{array}{r}7 / 30 / 2009 \\
7: 00 \\
\end{array}$ & $\begin{array}{r}7 / 30 / 2009 \\
8: 00 \\
\end{array}$ & 913.5 & 8041.3 & 2.9 & 1.8 & 599.7 & 1.1 & 775.5 & 765.9 & 305.6 & 298.0 & 2367.3 & 8.5 & 1.2 & 0.3 & 26.8 & 4.8 & 6.2 \\
\hline $\begin{array}{r}7 / 30 / 2009 \\
8: 00 \\
\end{array}$ & $\begin{array}{r}7 / 30 / 2009 \\
9: 00 \\
\end{array}$ & 911.2 & 8041.3 & 2.9 & 1.8 & 595.1 & 1.1 & 774.1 & 766.3 & 302.6 & 293.3 & 2351.7 & 7.6 & 1.2 & 0.3 & 28.5 & 4.8 & 6.2 \\
\hline $\begin{array}{r}7 / 30 / 2009 \\
9: 00 \\
\end{array}$ & $\begin{array}{r}7 / 30 / 2009 \\
10: 00 \\
\end{array}$ & 909.9 & 8041.3 & 2.7 & 1.7 & 598.7 & 1.1 & 776.4 & 767.4 & 303.3 & 292.3 & 2338.2 & 7.6 & 1.2 & 0.3 & 38.0 & 4.8 & 6.2 \\
\hline $\begin{array}{r}7 / 30 / 2009 \\
10: 00\end{array}$ & $\begin{array}{r}7 / 30 / 2009 \\
11: 00\end{array}$ & 912.3 & 8041.3 & 2.8 & 1.6 & 599.8 & 1.1 & 778.5 & 769.1 & 303.1 & 293.4 & 2344.3 & 7.7 & 1.2 & 0.3 & 49.1 & 4.8 & 6.2 \\
\hline $\begin{array}{r}7 / 30 / 2009 \\
11: 00\end{array}$ & $\begin{array}{r}7 / 30 / 2009 \\
12: 00\end{array}$ & 911.2 & 8041.3 & 2.9 & 1.7 & 604.6 & 1.1 & 784.8 & 775.3 & 304.9 & 296.4 & 2344.3 & 7.8 & 1.2 & 0.3 & 49.7 & 4.8 & 6.2 \\
\hline
\end{tabular}




\begin{tabular}{|c|c|c|c|c|c|c|c|c|c|c|c|c|c|c|c|c|c|c|}
\hline $\begin{array}{l}\text { Start } \\
\text { Date/ } \\
\text { Time }\end{array}$ & $\begin{array}{l}\text { End } \\
\text { Date/ } \\
\text { Time }\end{array}$ & $\begin{array}{l}\text { Gross } \\
\text { Load }\end{array}$ & $\begin{array}{c}\text { Gross } \\
\text { HR }\end{array}$ & $\begin{array}{c}\text { A } \\
\text { Econ } \\
\text { O2 }\end{array}$ & $\begin{array}{c}\text { B } \\
\text { Econ } \\
\text { O2 }\end{array}$ & $\begin{array}{l}\text { Fuel } \\
\text { Flow }\end{array}$ & $\begin{array}{l}\text { BTU } \\
\text { Gain }\end{array}$ & $\begin{array}{c}\text { A } \\
\text { APH } \\
\text { In }\end{array}$ & $\begin{array}{c}\text { B } \\
\text { APH } \\
\text { In }\end{array}$ & $\begin{array}{c}\text { A } \\
\text { APH } \\
\text { Out }\end{array}$ & $\begin{array}{c}\text { B } \\
\text { APH } \\
\text { Out }\end{array}$ & $\begin{array}{l}\text { Stack } \\
\text { Flow }\end{array}$ & Opacity & SO2 In & $\begin{array}{l}\text { SO2 } \\
\text { Out }\end{array}$ & $\mathrm{CO}$ & $\begin{array}{c}\text { Stack } \\
\text { SCEM } \\
\text { Elemental } \\
\mathrm{Hg}\end{array}$ & $\begin{array}{c}\text { Stack } \\
\text { SCEM } \\
\text { Total Hg }\end{array}$ \\
\hline & & MW & Btu/kWh & $\%$ & $\%$ & Ton/hr & & DEGF & DEGF & DEGF & DEGF & KSCF & $\%$ & $\mathrm{lb} / \mathrm{MMB}$ & $\mathrm{lb} / \mathrm{MMb}$ & PPM & $\begin{array}{c}(\mu \mathrm{g} / \mathrm{dNm} 3) \\
@ 3 \% 02\end{array}$ & $\begin{array}{c}(\mu \mathrm{g} / \mathrm{dNm} 3) \\
@ 3 \% \mathrm{O} 2\end{array}$ \\
\hline $\begin{array}{r}7 / 30 / 2009 \\
12: 00\end{array}$ & $\begin{array}{r}7 / 30 / 2009 \\
13: 00\end{array}$ & 912.9 & 8041.3 & 2.9 & 1.7 & 607.1 & 1.1 & 790.3 & 780.9 & 309.6 & 301.2 & 2345.2 & 8.9 & 1.3 & 0.3 & 45.1 & 4.8 & 6.2 \\
\hline $\begin{array}{r}7 / 30 / 2009 \\
13: 00\end{array}$ & $\begin{array}{r}7 / 30 / 2009 \\
14: 00\end{array}$ & 913.7 & 8041.3 & 2.7 & 1.7 & 609.5 & 1.1 & 780.5 & 771.3 & 310.8 & 302.6 & 2330.7 & 9.7 & 1.3 & 0.3 & 38.3 & 4.8 & 6.2 \\
\hline $\begin{array}{r}7 / 30 / 2009 \\
14: 00 \\
\end{array}$ & $\begin{array}{r}7 / 30 / 2009 \\
15: 00 \\
\end{array}$ & 910.3 & 8041.3 & 2.7 & 1.8 & 609.5 & 1.1 & 772.1 & 762.3 & 309.6 & 301.1 & 2341.7 & 9.8 & 1.4 & 0.3 & 33.3 & 4.8 & 6.2 \\
\hline $\begin{array}{r}7 / 30 / 2009 \\
15: 00\end{array}$ & $\begin{array}{r}7 / 30 / 2009 \\
16: 00\end{array}$ & 910.8 & 8041.3 & 2.8 & 2.0 & 611.1 & 1.1 & 782.3 & 771.2 & 312.7 & 304.0 & 2342.3 & 9.8 & 1.3 & 0.3 & 19.0 & 4.8 & 6.2 \\
\hline $\begin{array}{r}730 / 2009 \\
16: 00 \\
\end{array}$ & $\begin{array}{r}7 / 30 / 2009 \\
17: 00 \\
\end{array}$ & 909.5 & 8041.3 & 2.6 & 1.7 & 612.5 & 1.1 & 779.1 & 769.8 & 314.7 & 306.4 & 2315.9 & 9.7 & 1.4 & 0.3 & 40.5 & 4.8 & 6.2 \\
\hline $\begin{array}{r}7 / 30 / 2009 \\
17: 00 \\
\end{array}$ & $\begin{array}{r}7 / 30 / 2009 \\
18: 00 \\
\end{array}$ & 910.9 & 8041.3 & 2.8 & 1.7 & 622.5 & 1.1 & 777.5 & 768.6 & 313.0 & 305.7 & 2333.9 & 10.0 & 1.4 & 0.3 & 44.2 & 4.8 & 6.2 \\
\hline $\begin{array}{r}7 / 30 / 2009 \\
18: 00\end{array}$ & $\begin{array}{r}7 / 30 / 2009 \\
19: 00\end{array}$ & 911.7 & 8041.3 & 2.7 & 1.7 & 630.9 & 1.1 & 782.5 & 773.7 & 313.8 & 306.8 & 2338.3 & 10.5 & 1.5 & 0.3 & 42.3 & 4.8 & 6.2 \\
\hline $\begin{array}{r}7 / 30 / 2009 \\
19: 00\end{array}$ & $\begin{array}{r}7 / 30 / 2009 \\
20: 00\end{array}$ & 915.5 & 8041.3 & 2.7 & 1.6 & 631.3 & 1.1 & 785.3 & 777.9 & 315.1 & 308.1 & 2354.6 & 11.0 & 1.5 & 0.3 & 44.8 & 4.8 & 6.2 \\
\hline $\begin{array}{r}7 / 30 / 2009 \\
20: 00\end{array}$ & $\begin{array}{r}7 / 30 / 2009 \\
21: 00\end{array}$ & 915.2 & 8041.3 & 2.7 & 1.6 & 623.2 & 1.1 & 782.3 & 774.1 & 315.3 & 307.9 & 2354.6 & 10.5 & 1.5 & 0.3 & 42.1 & 4.8 & 6.2 \\
\hline $\begin{array}{r}7 / 30 / 2009 \\
21: 00 \\
\end{array}$ & $\begin{array}{r}7 / 30 / 2009 \\
22: 00 \\
\end{array}$ & 849.6 & 8041.3 & 2.7 & 1.9 & 576.0 & 1.1 & 752.6 & 744.1 & 310.0 & 303.1 & 2193.5 & 7.7 & 1.5 & 0.4 & 26.1 & 4.8 & 6.2 \\
\hline $\begin{array}{r}7 / 30 / 2009 \\
22: 00 \\
\end{array}$ & $\begin{array}{r}7 / 30 / 2009 \\
23: 00 \\
\end{array}$ & 855.6 & 8041.3 & 2.6 & 1.7 & 581.5 & 1.1 & 754.7 & 745.4 & 306.7 & 299.4 & 2197.9 & 7.2 & 1.5 & 0.4 & 31.5 & 4.8 & 6.2 \\
\hline $\begin{array}{r}7 / 30 / 2009 \\
23: 00 \\
\end{array}$ & $\begin{array}{r}7 / 31 / 2009 \\
0: 00 \\
\end{array}$ & 906.1 & 8041.3 & 2.6 & 1.8 & 610.7 & 1.1 & 777.4 & 767.8 & 308.8 & 300.3 & 2314.2 & 7.5 & 1.4 & 0.4 & 44.3 & 4.8 & 6.2 \\
\hline
\end{tabular}




\section{APPENDIX K DAILY SCEM PLOTS}




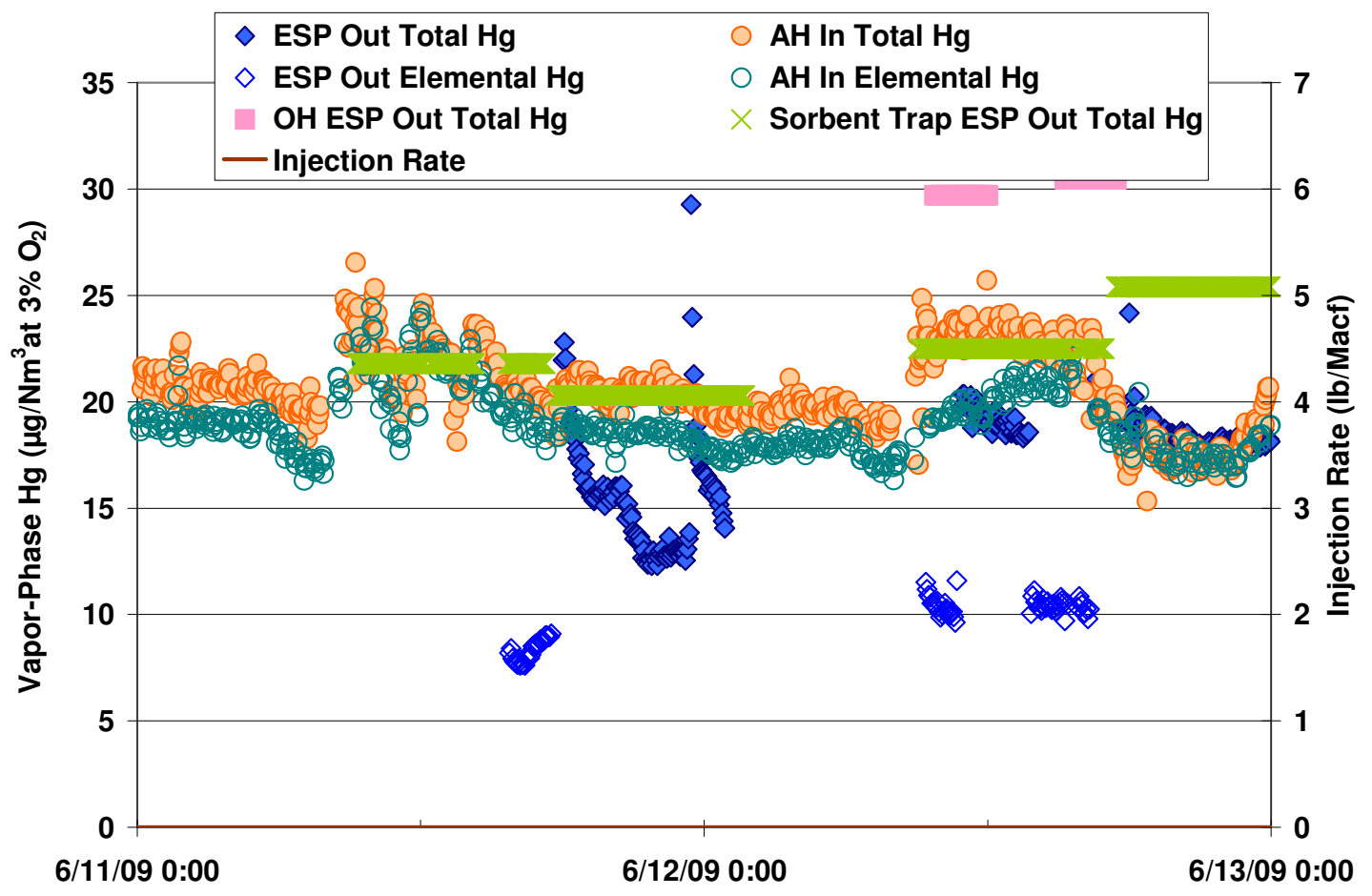

Figure K-1. Flue Gas Hg Concentrations for AH Inlet and ESP Outlet 6/11-6/13

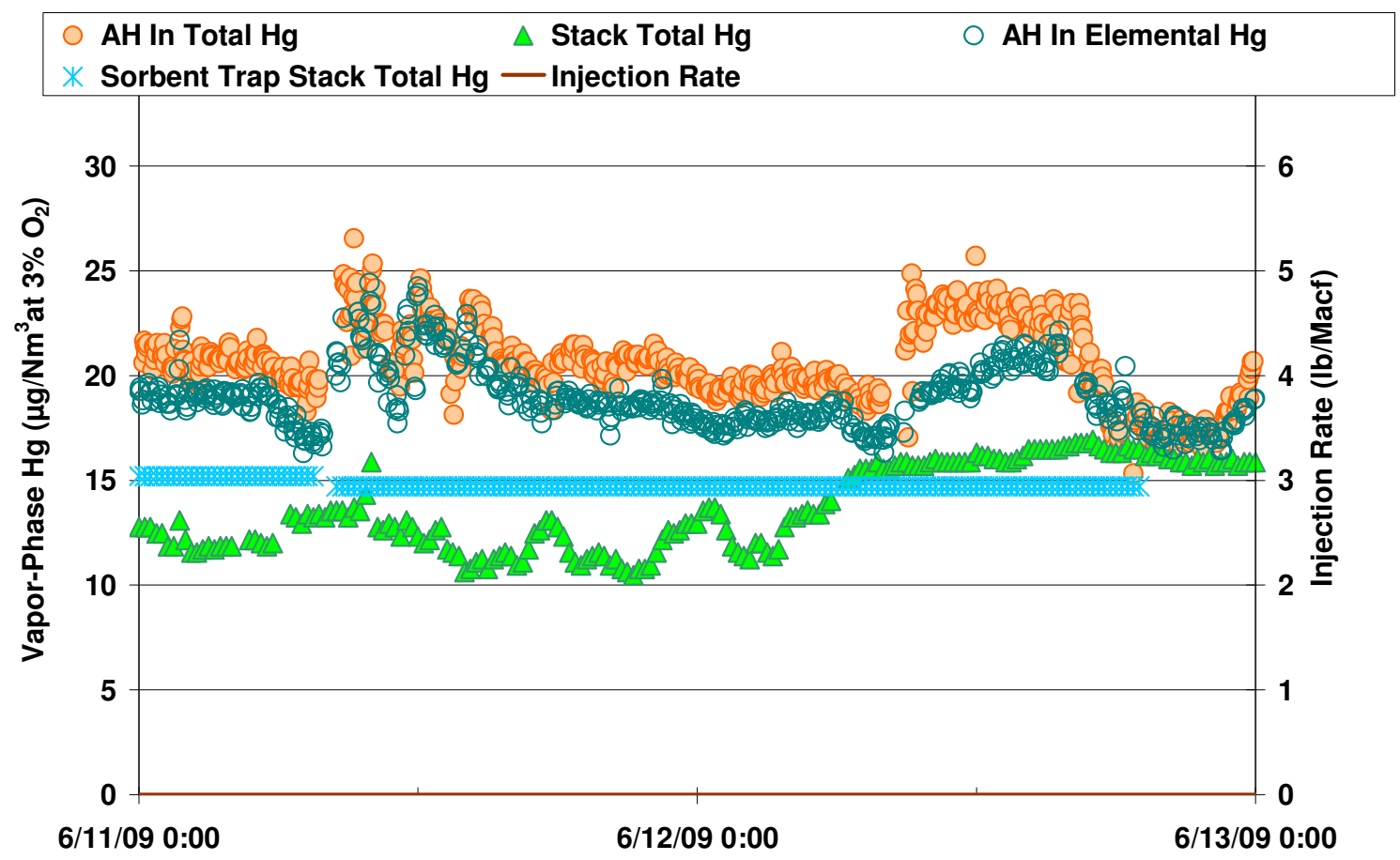

Figure K-2. Flue Gas Hg Concentrations for AH Inlet and Stack 6/11-6/13 


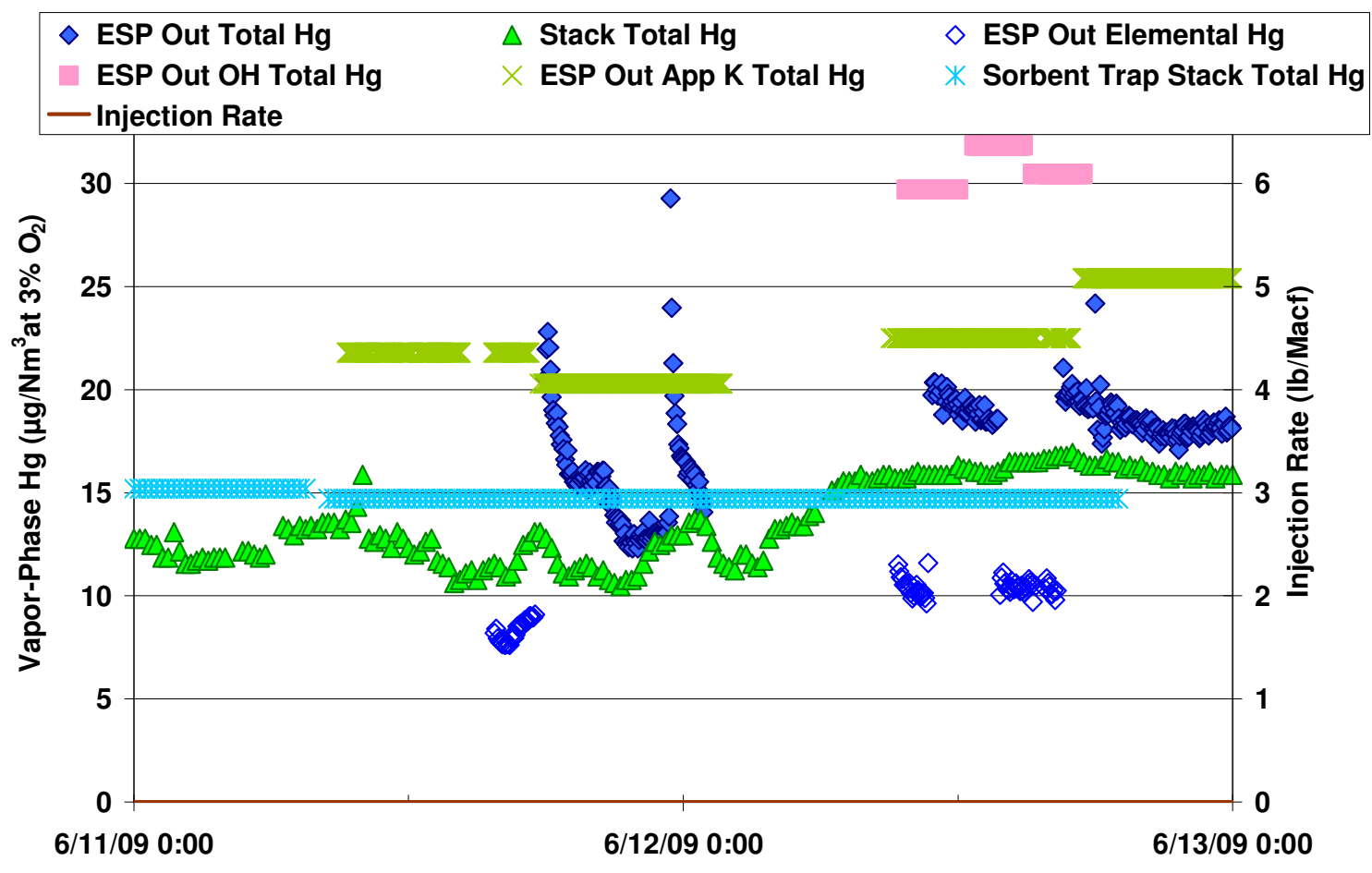

Figure K-3. Flue Gas Hg Concentrations for ESP Outlet and Stack 6/11-6/13

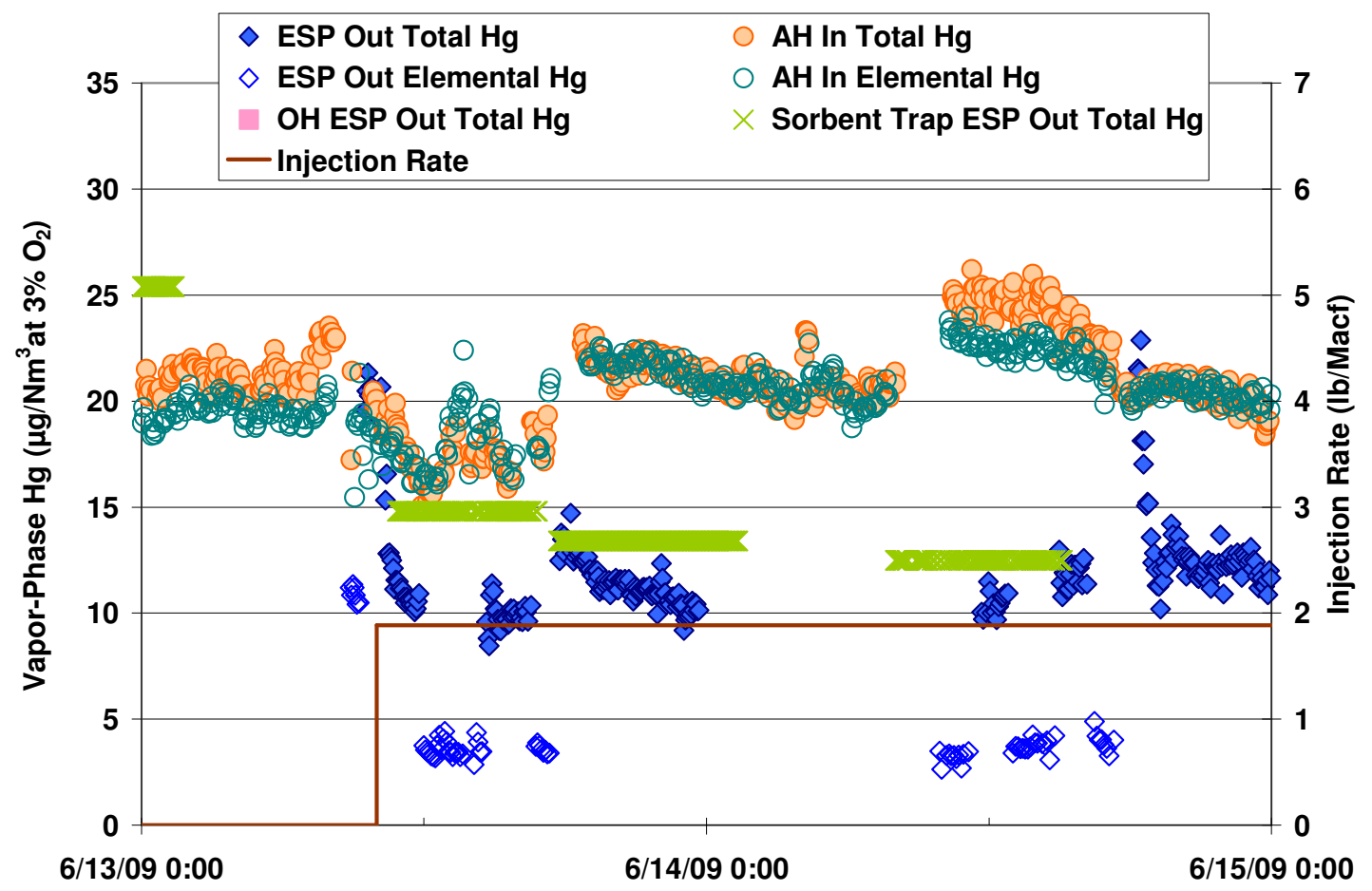

Figure K-4. Flue Gas Hg Concentrations for AH Inlet and ESP Outlet 6/13-6/15 


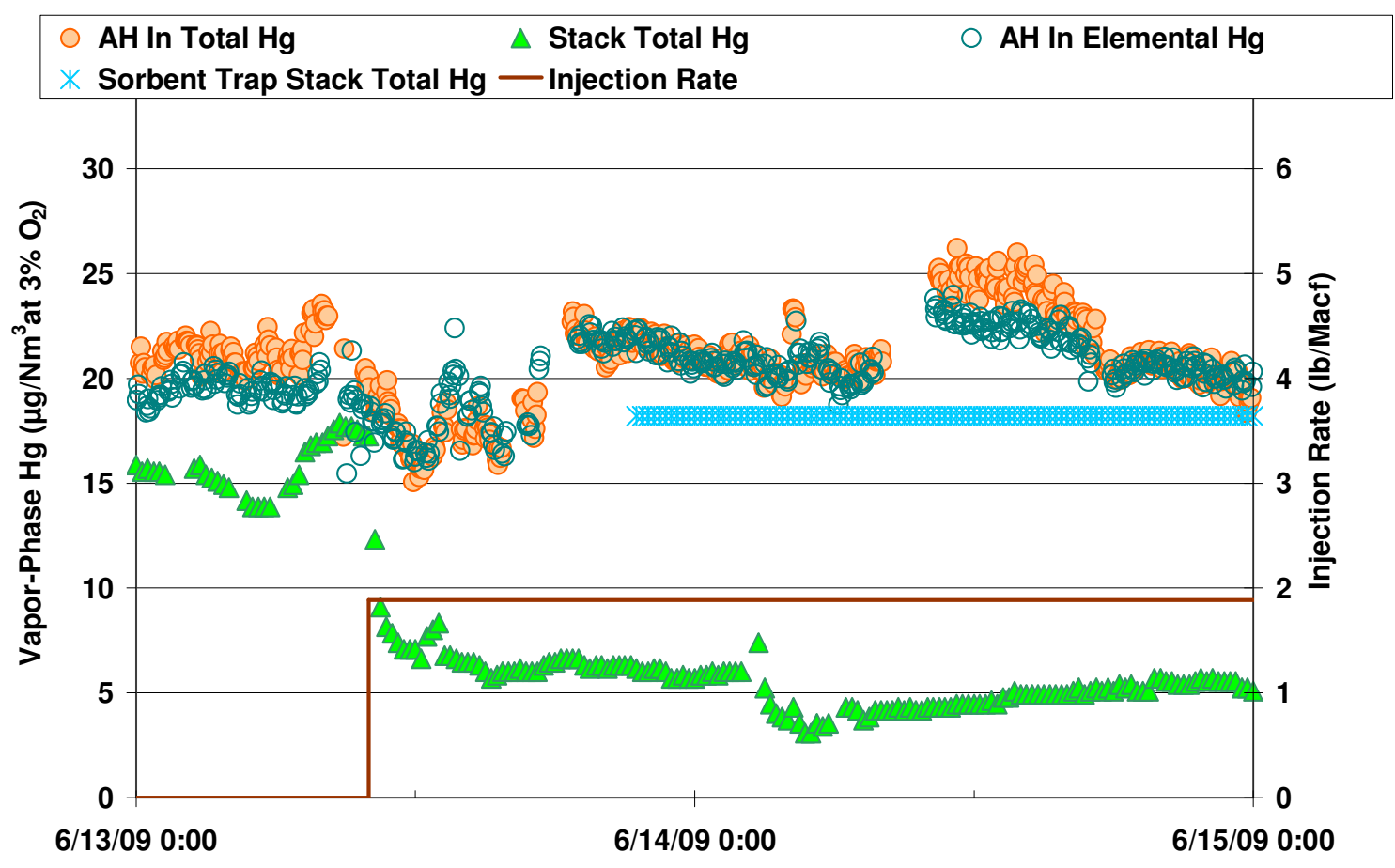

Figure K-5. Flue Gas Hg Concentrations for AH Inlet and Stack 6/13-6/15

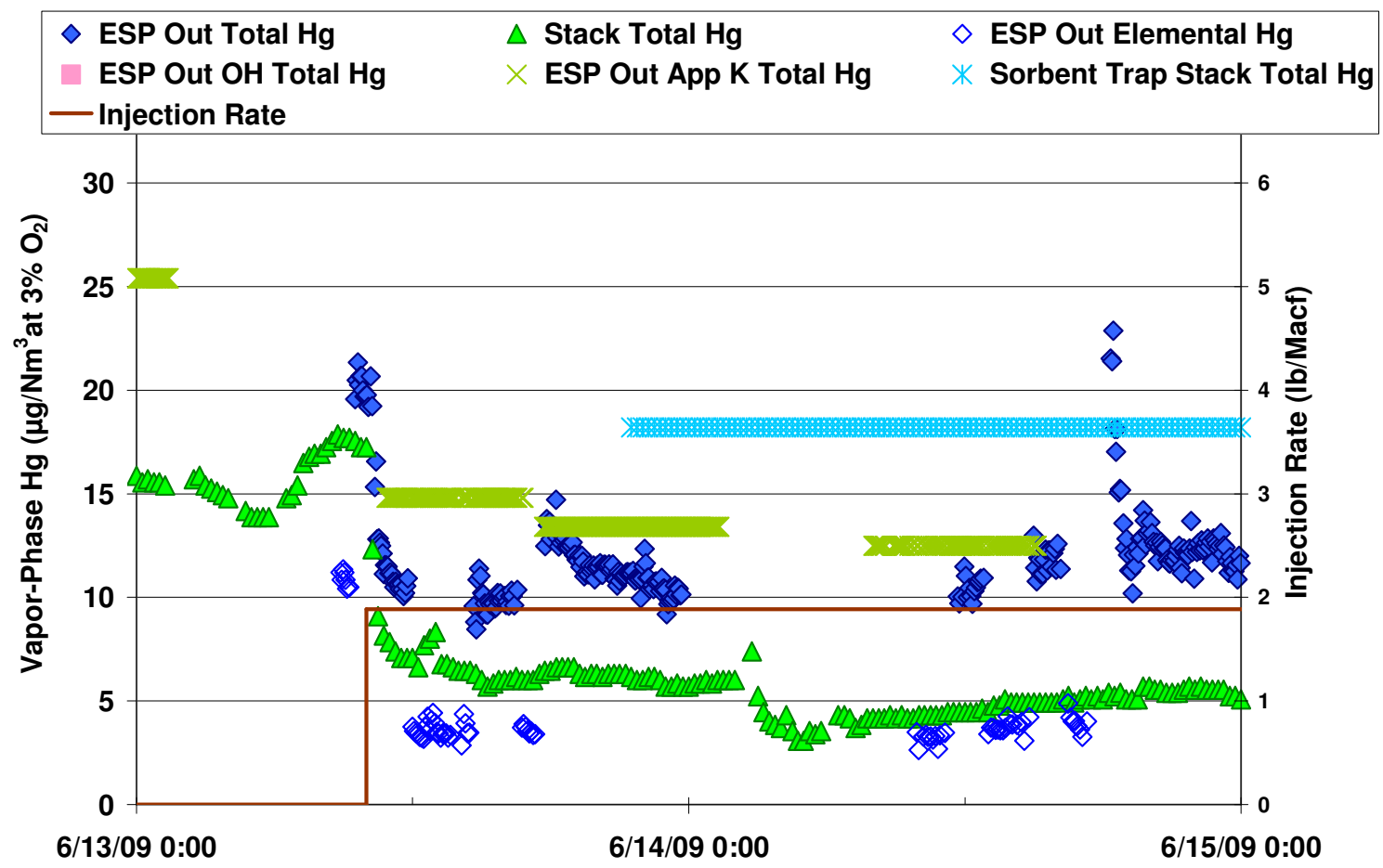

Figure K-6. Flue Gas Hg Concentrations for ESP Outlet and Stack 6/13-6/15 


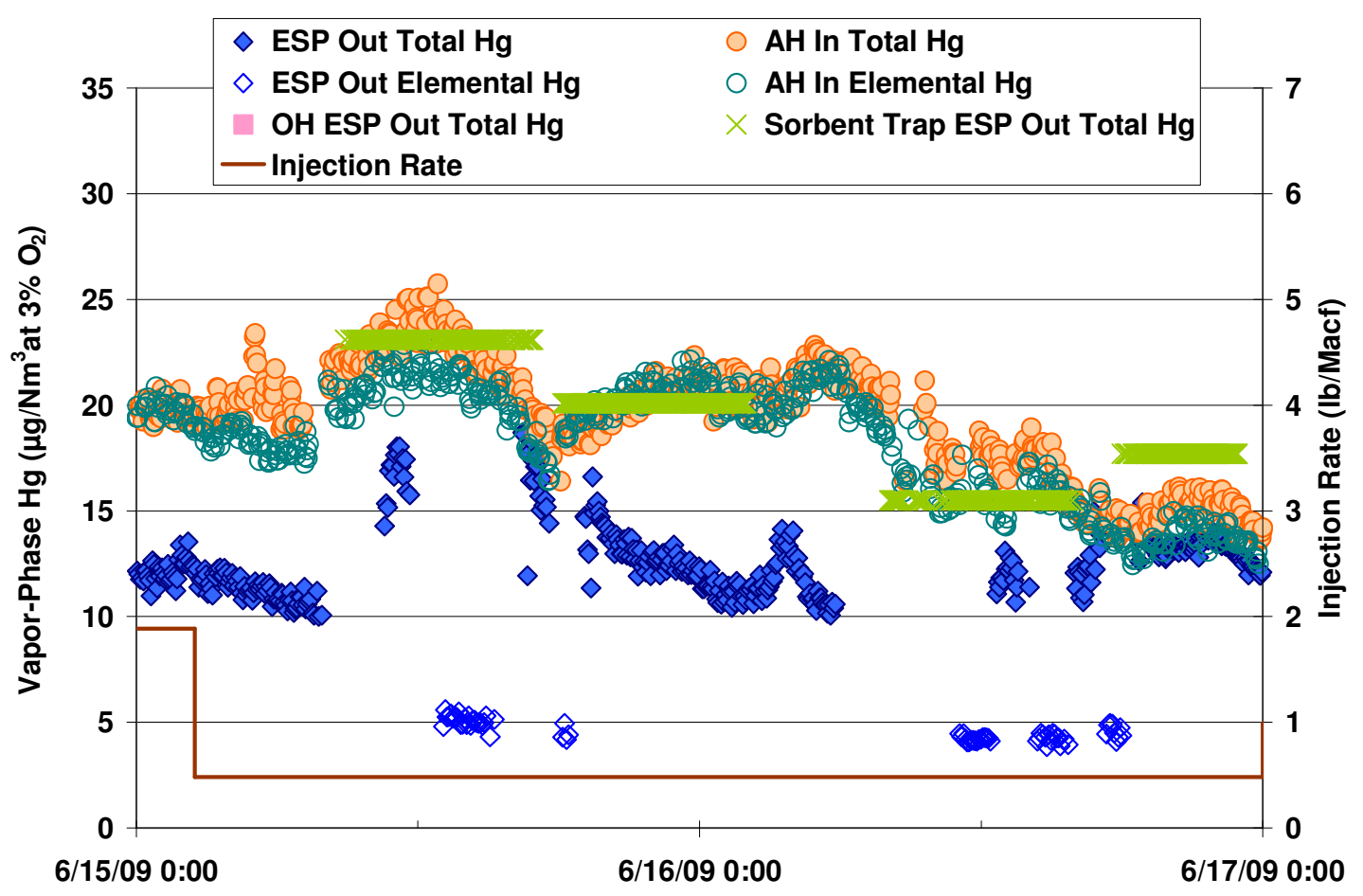

Figure K-7. Flue Gas Hg Concentrations for AH Inlet and ESP Outlet 6/15-6/17

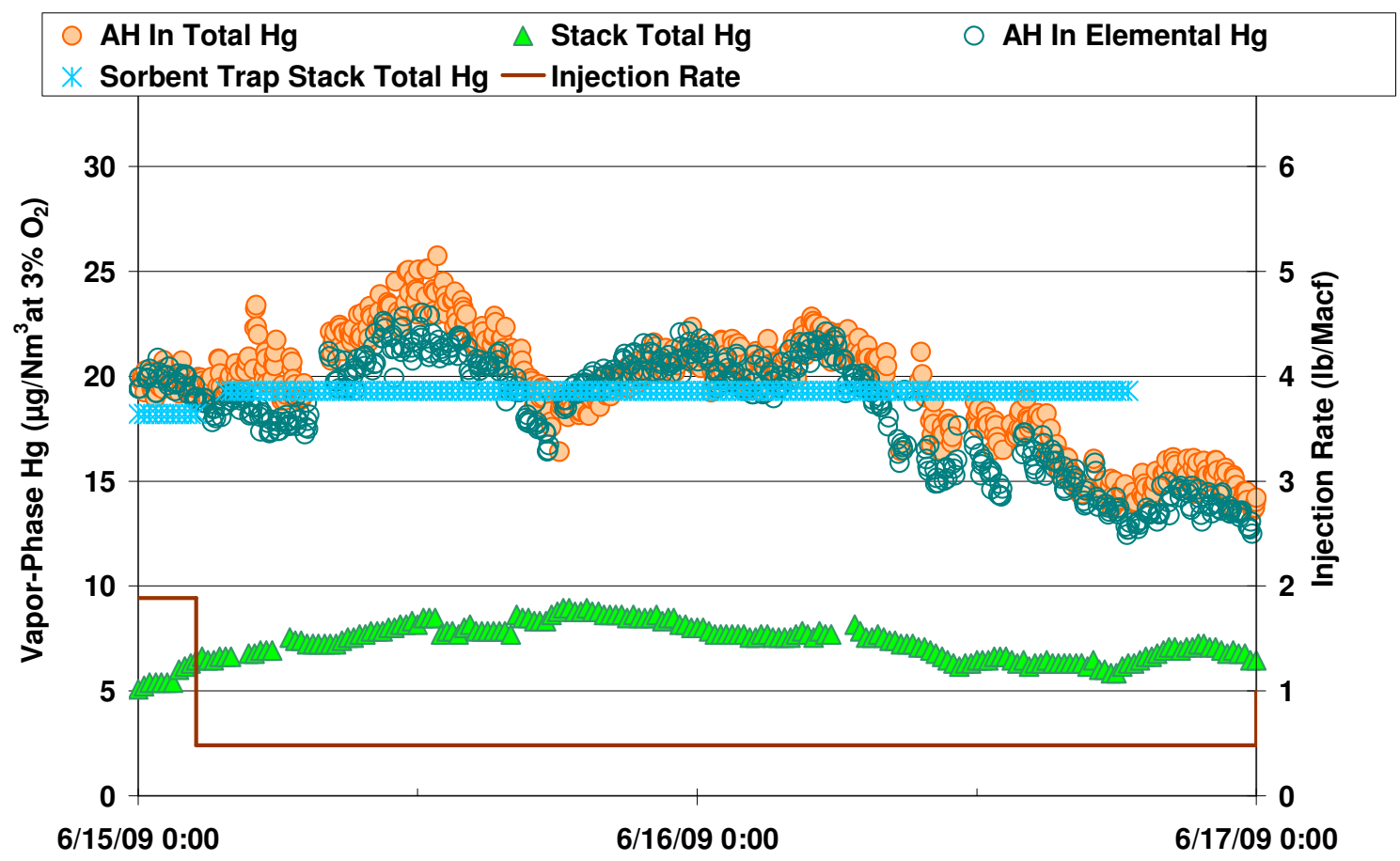

Figure K-8. Flue Gas Hg Concentrations for AH Inlet and Stack 6/15-6/17 


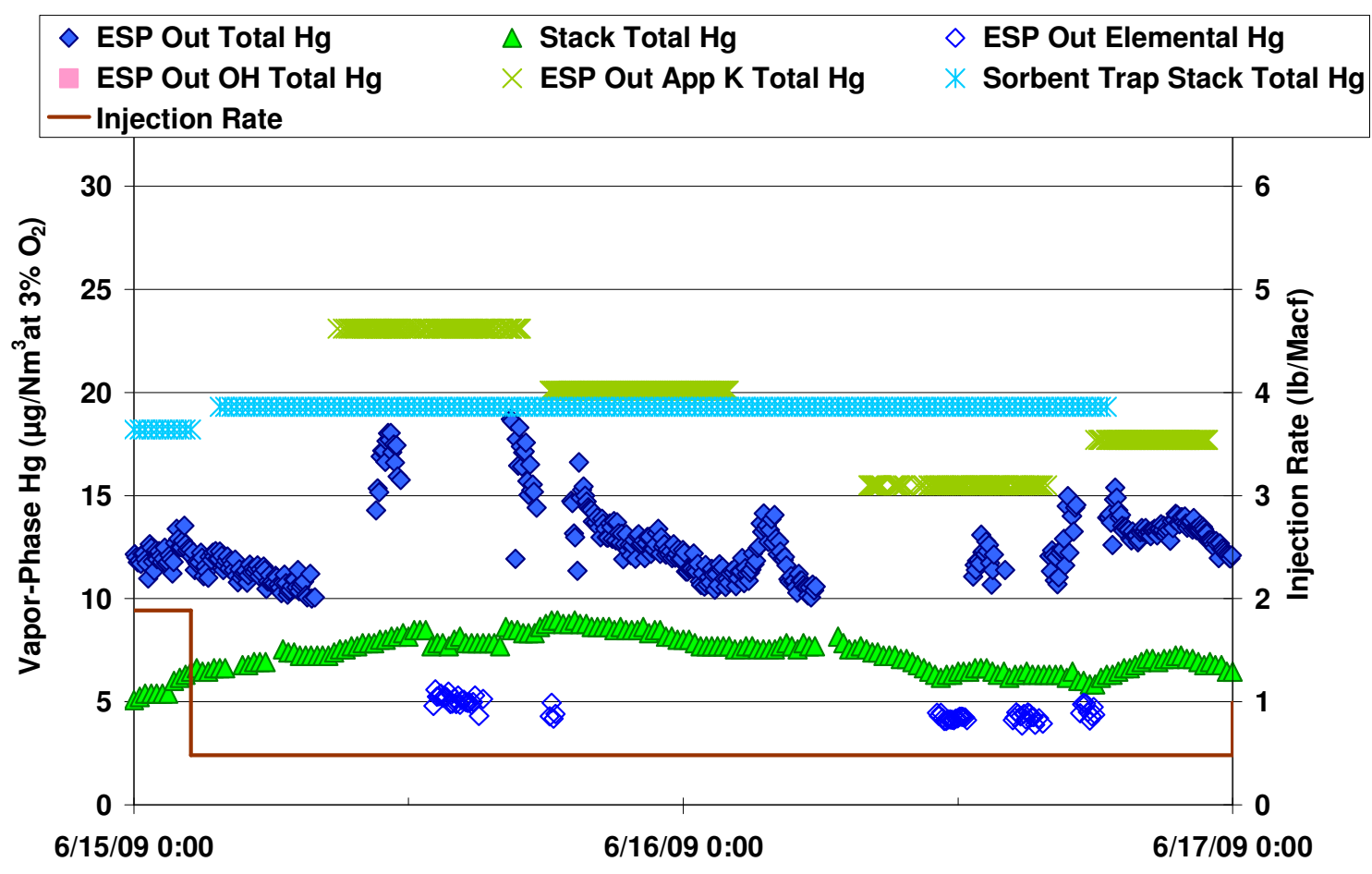

Figure K-9. Flue Gas Hg Concentrations for ESP Outlet and Stack 6/15-6/17

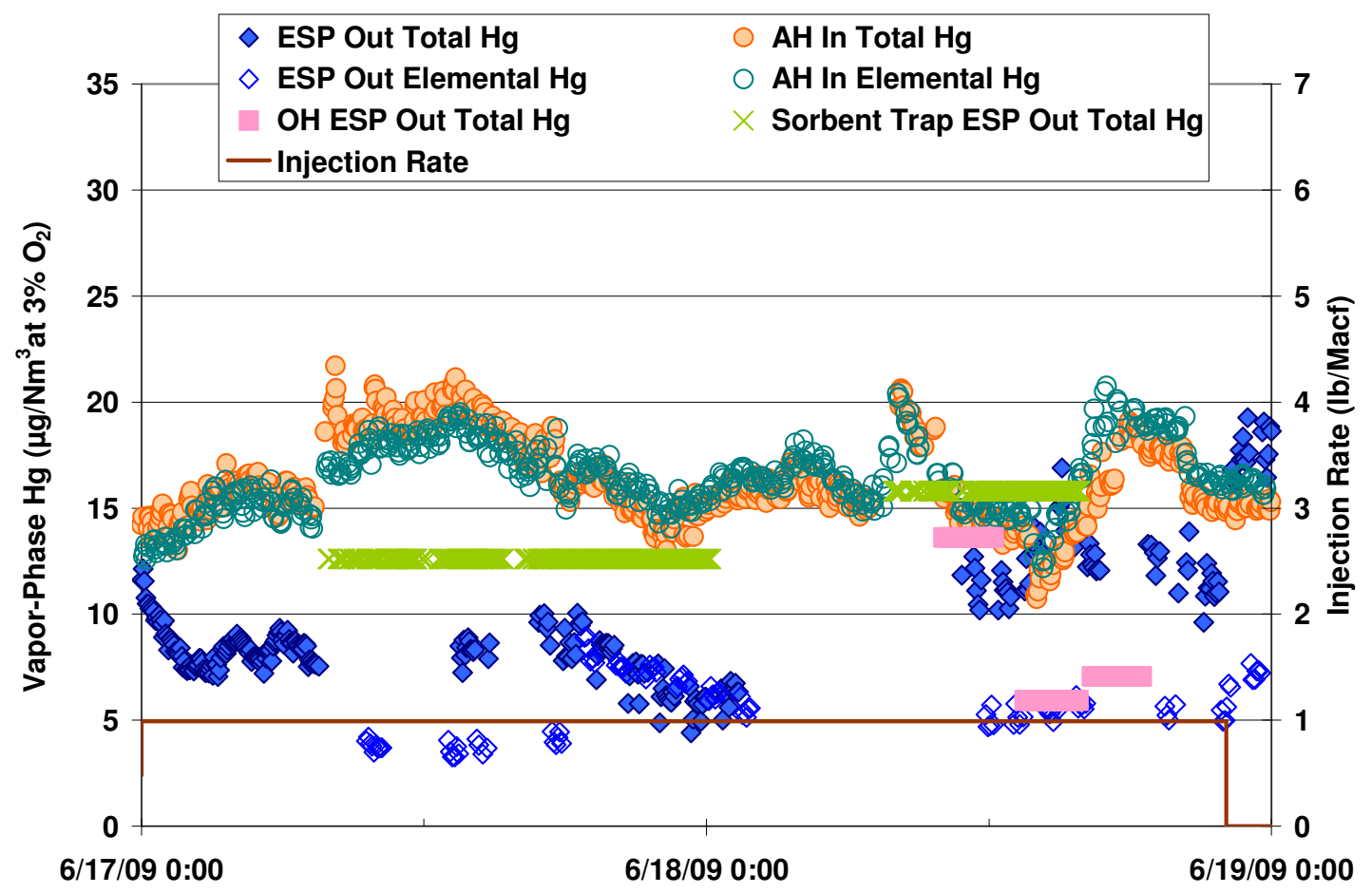

Figure K-10. Flue Gas Hg Concentrations for AH Inlet and ESP Outlet 6/17-6/19 


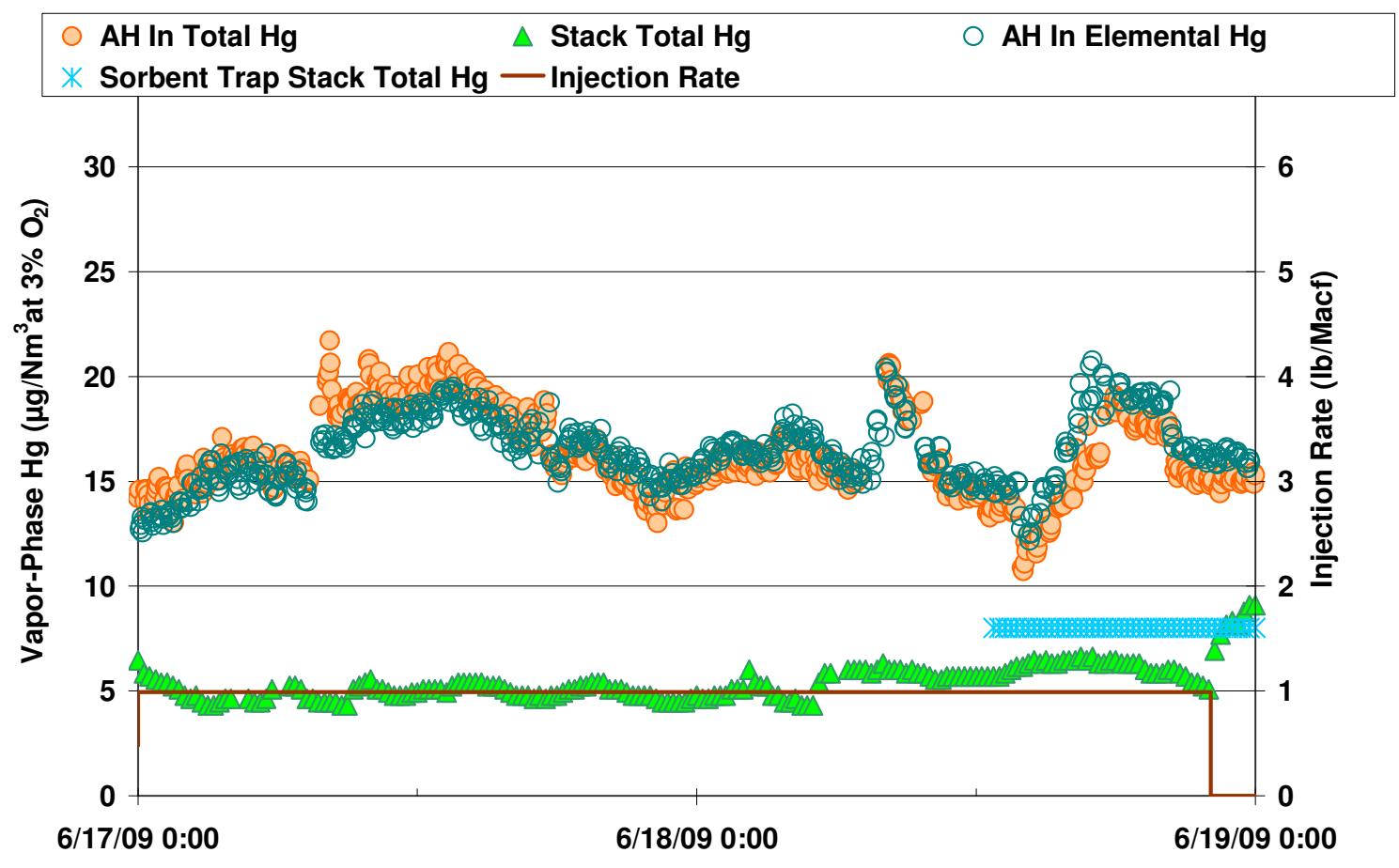

Figure K-11. Flue Gas Hg Concentrations for AH Inlet and Stack 6/17-6/19

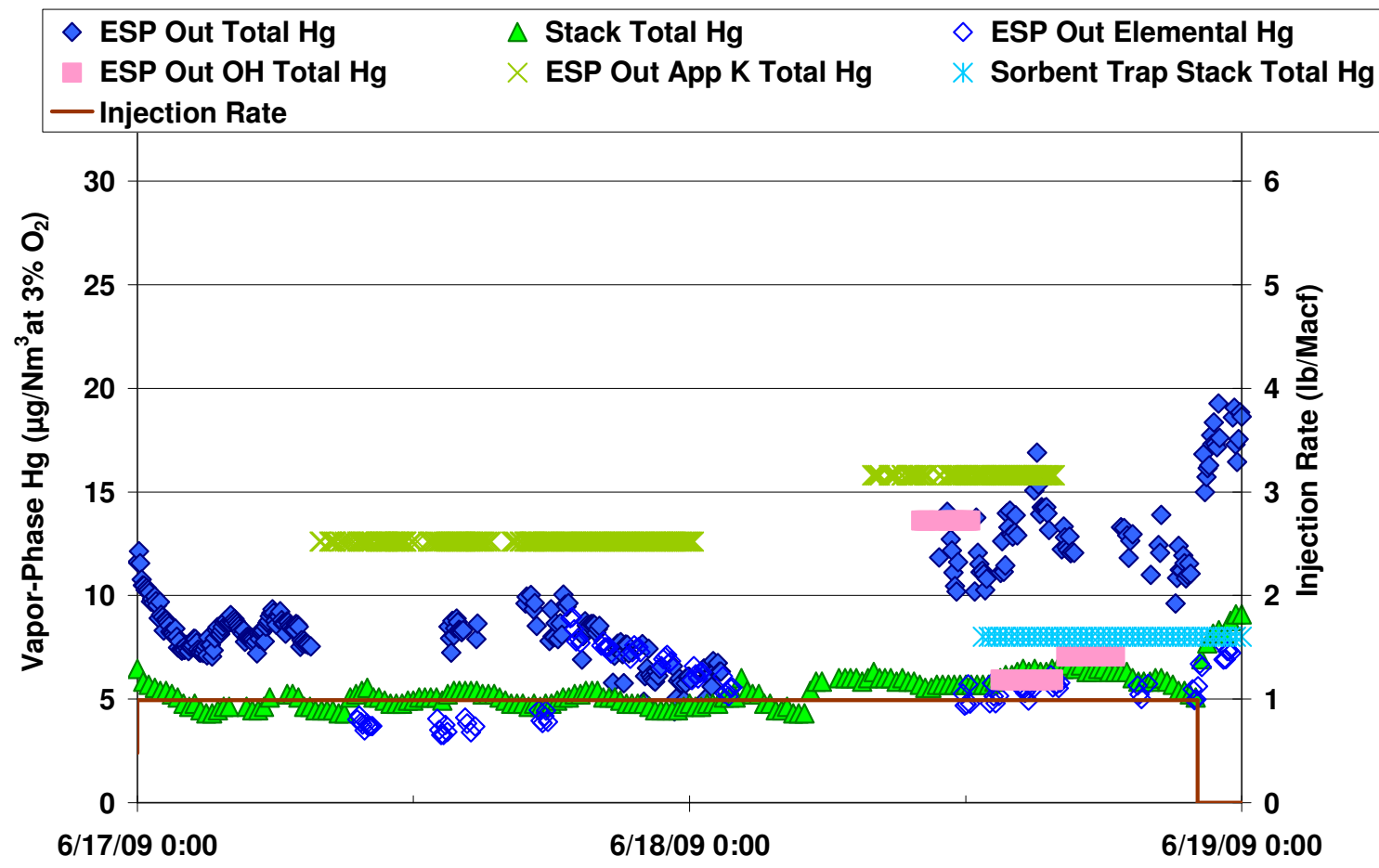

Figure K-12. Flue Gas Hg Concentrations for ESP Outlet and Stack 6/17-6/19 


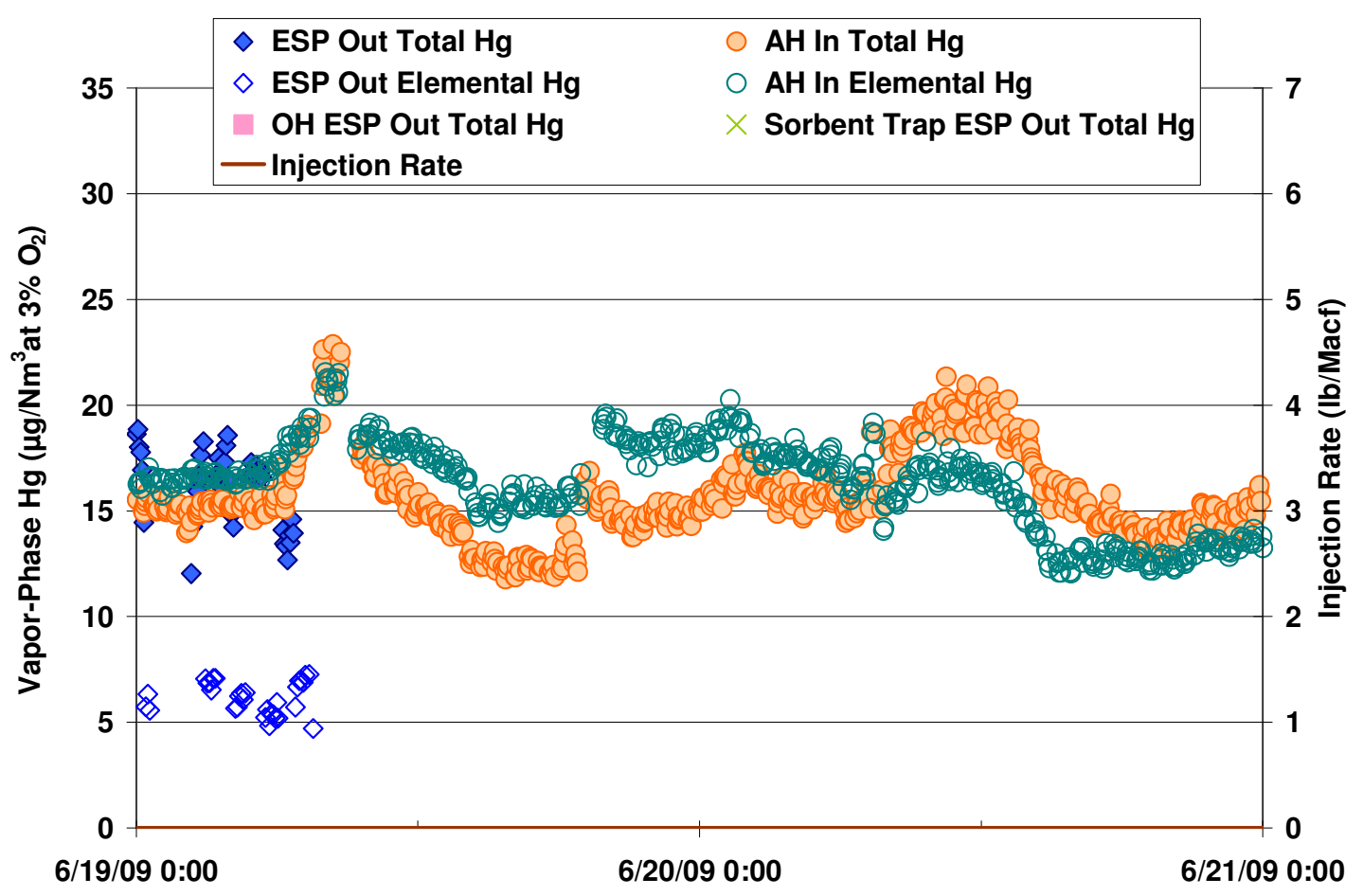

Figure K-13. Flue Gas Hg Concentrations for AH Inlet and ESP Outlet 6/19-6/21

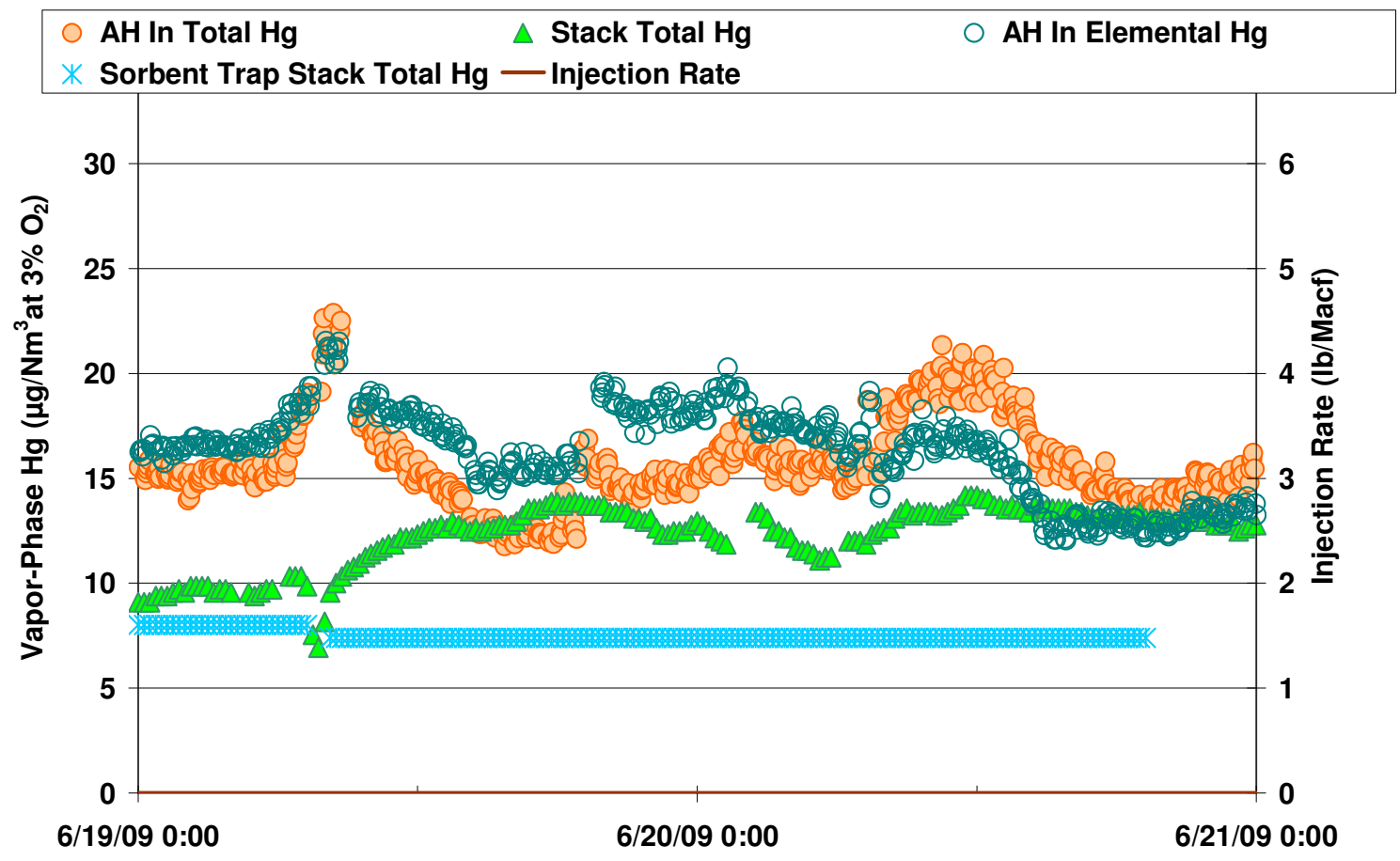

Figure K-14. Flue Gas Hg Concentrations for AH Inlet and Stack 6/19-6/21 


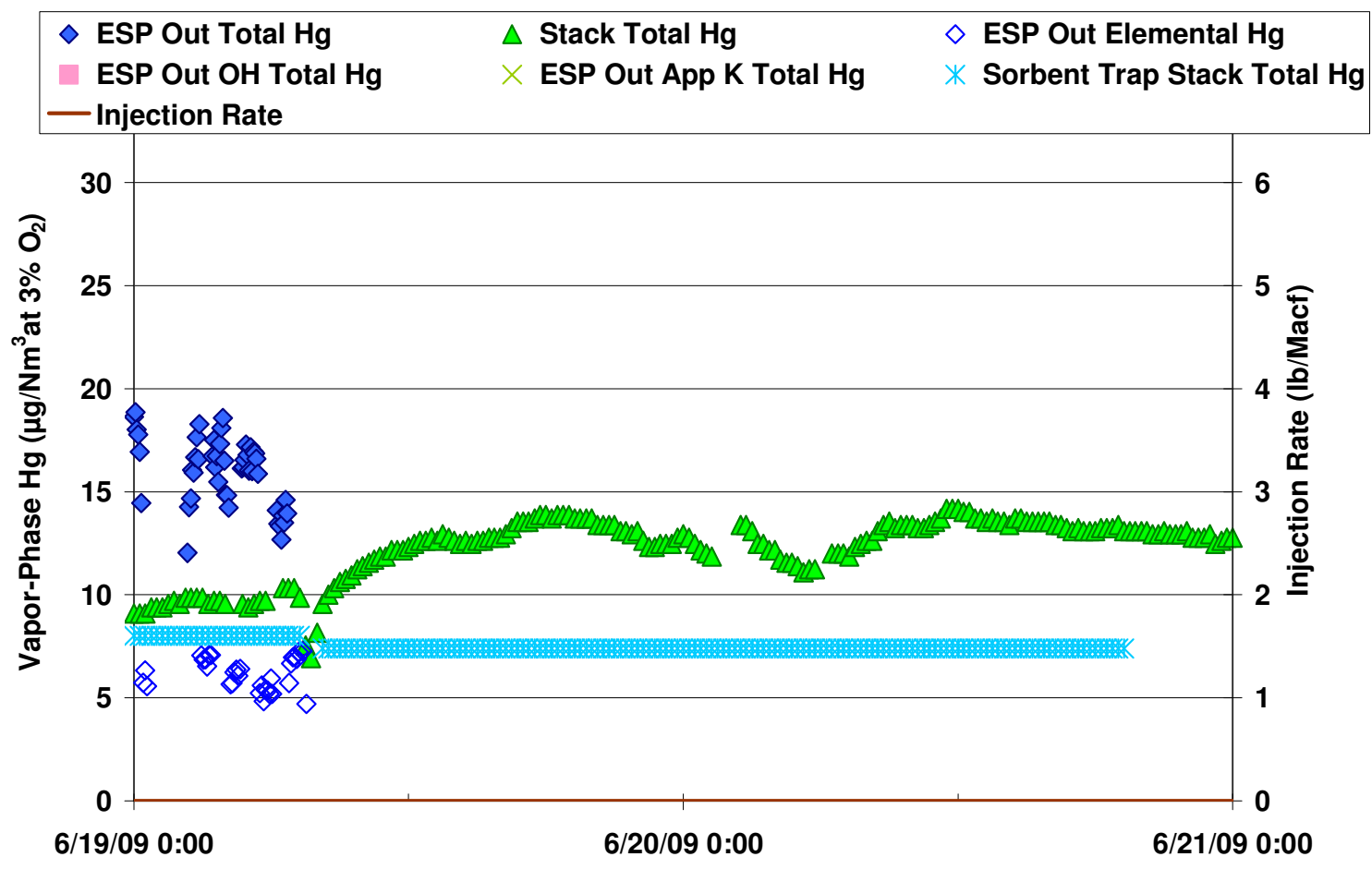

Figure K-15. Flue Gas Hg Concentrations for ESP Outlet and Stack 6/19-6/21

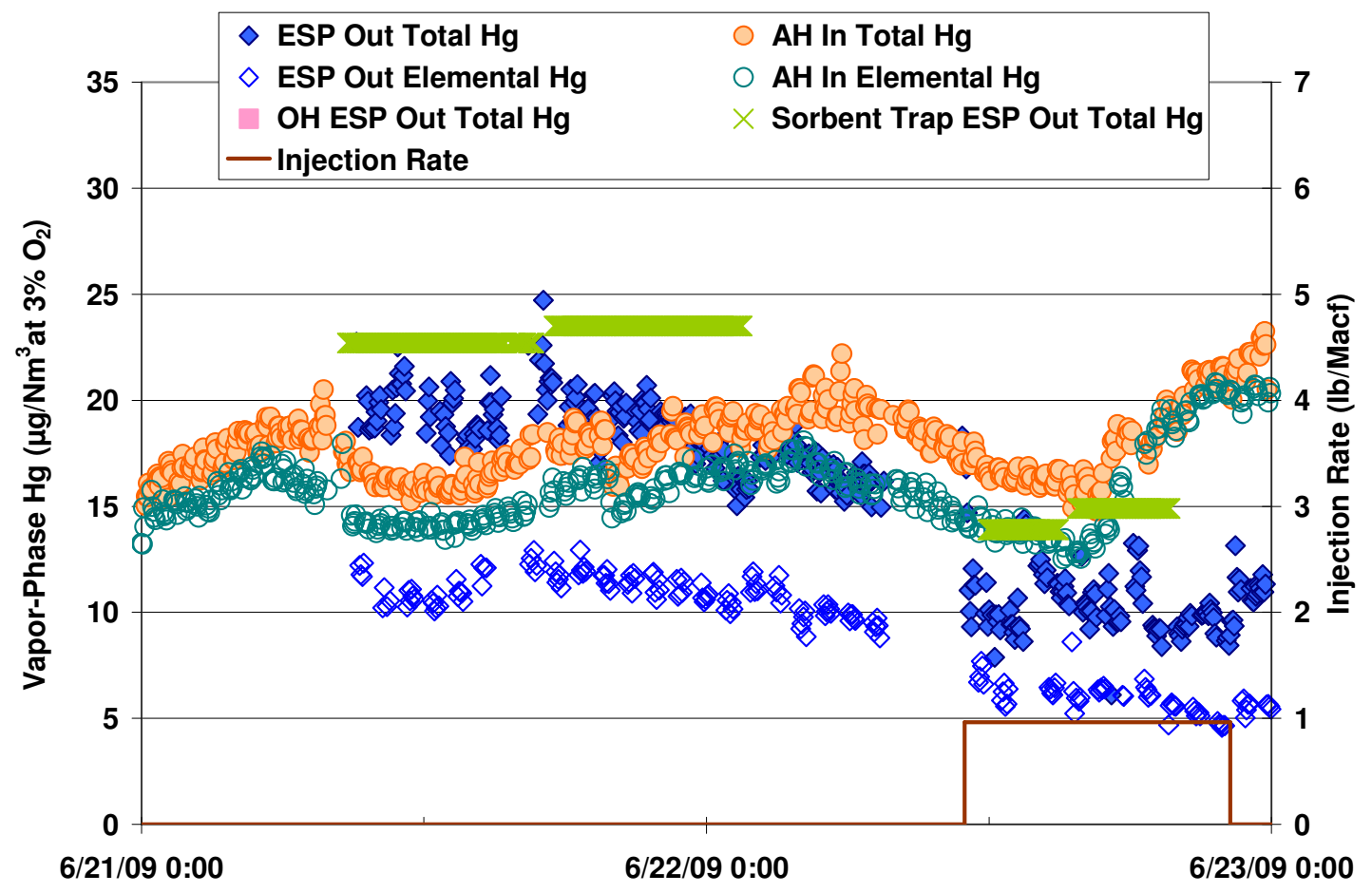

Figure K-16. Flue Gas Hg Concentrations for AH Inlet and ESP Outlet 6/21-6/23 


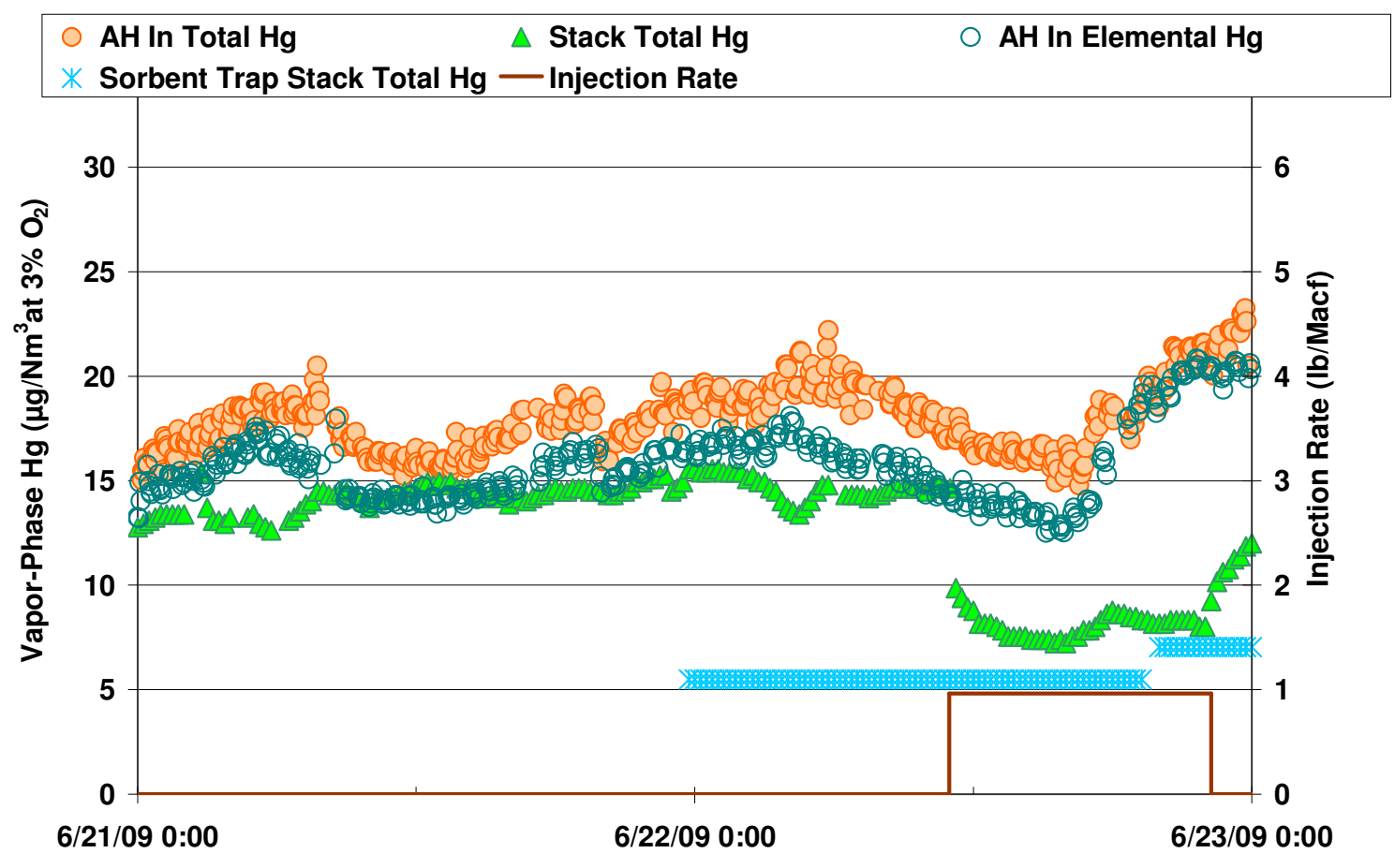

Figure K-17. Flue Gas Hg Concentrations for AH Inlet and Stack 6/21-6/23

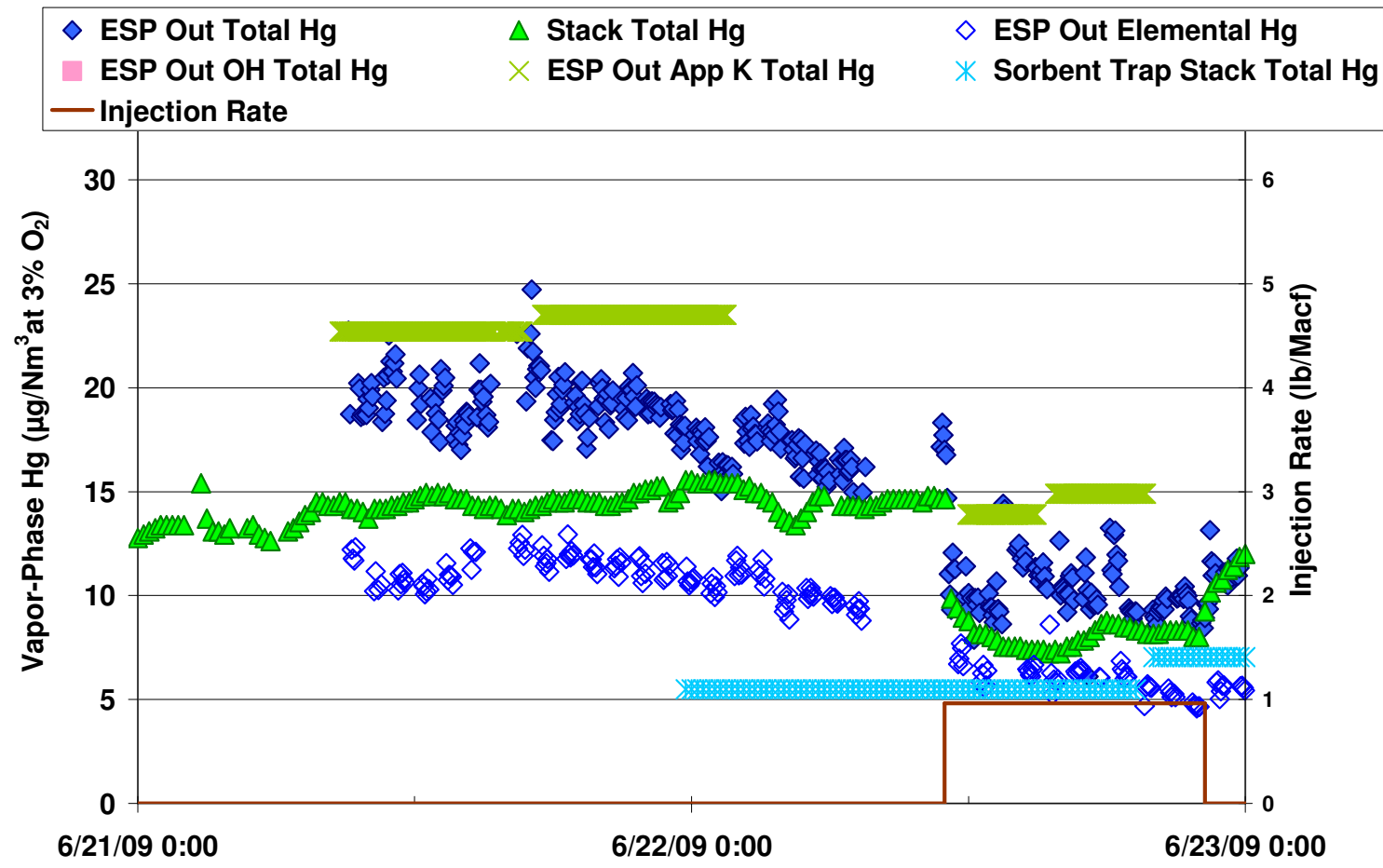

Figure K-18. Flue Gas Hg Concentrations for ESP Outlet and Stack 6/21-6/23 


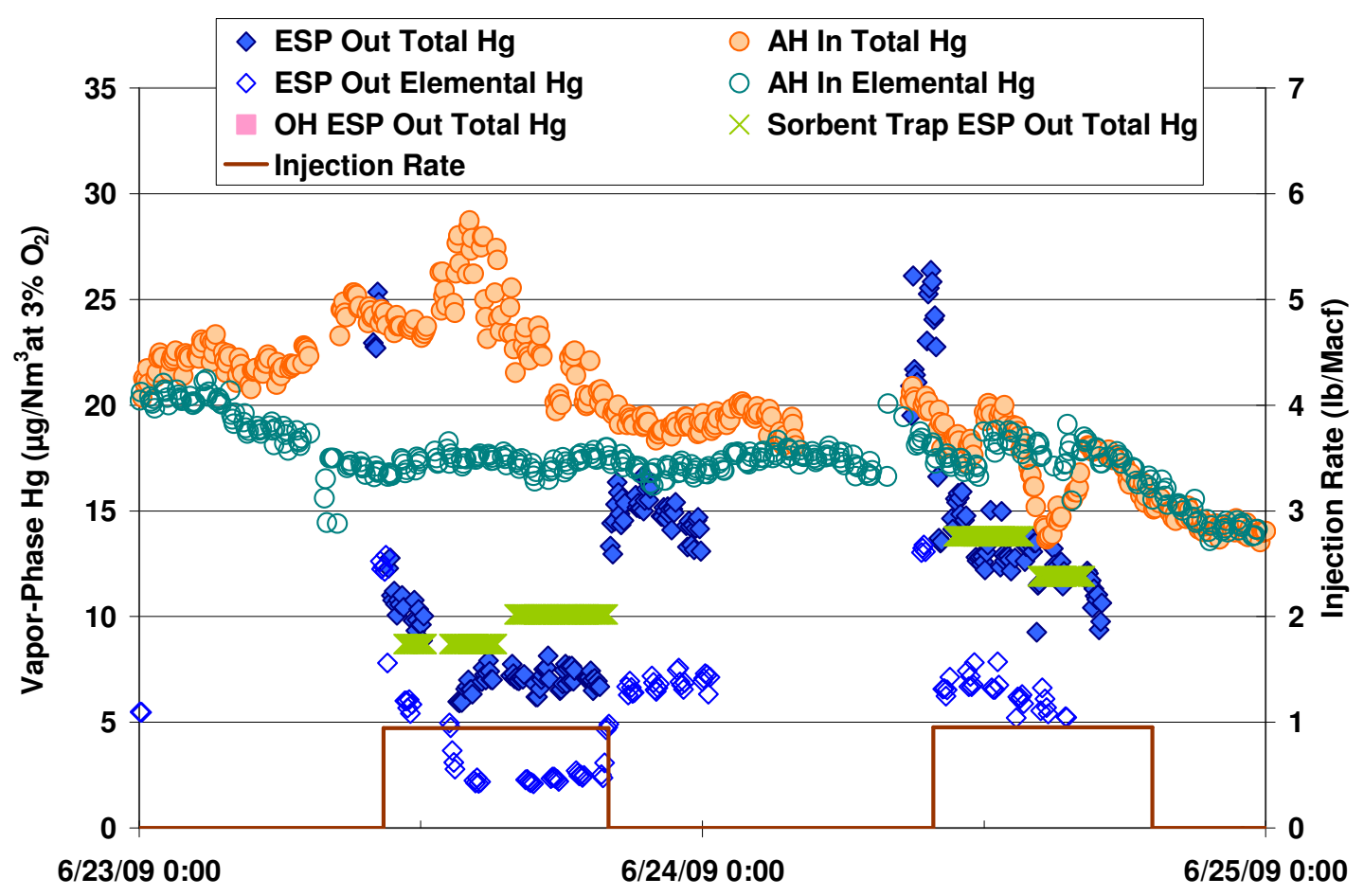

Figure K-19. Flue Gas Hg Concentrations for AH Inlet and ESP Outlet 6/23-6/25

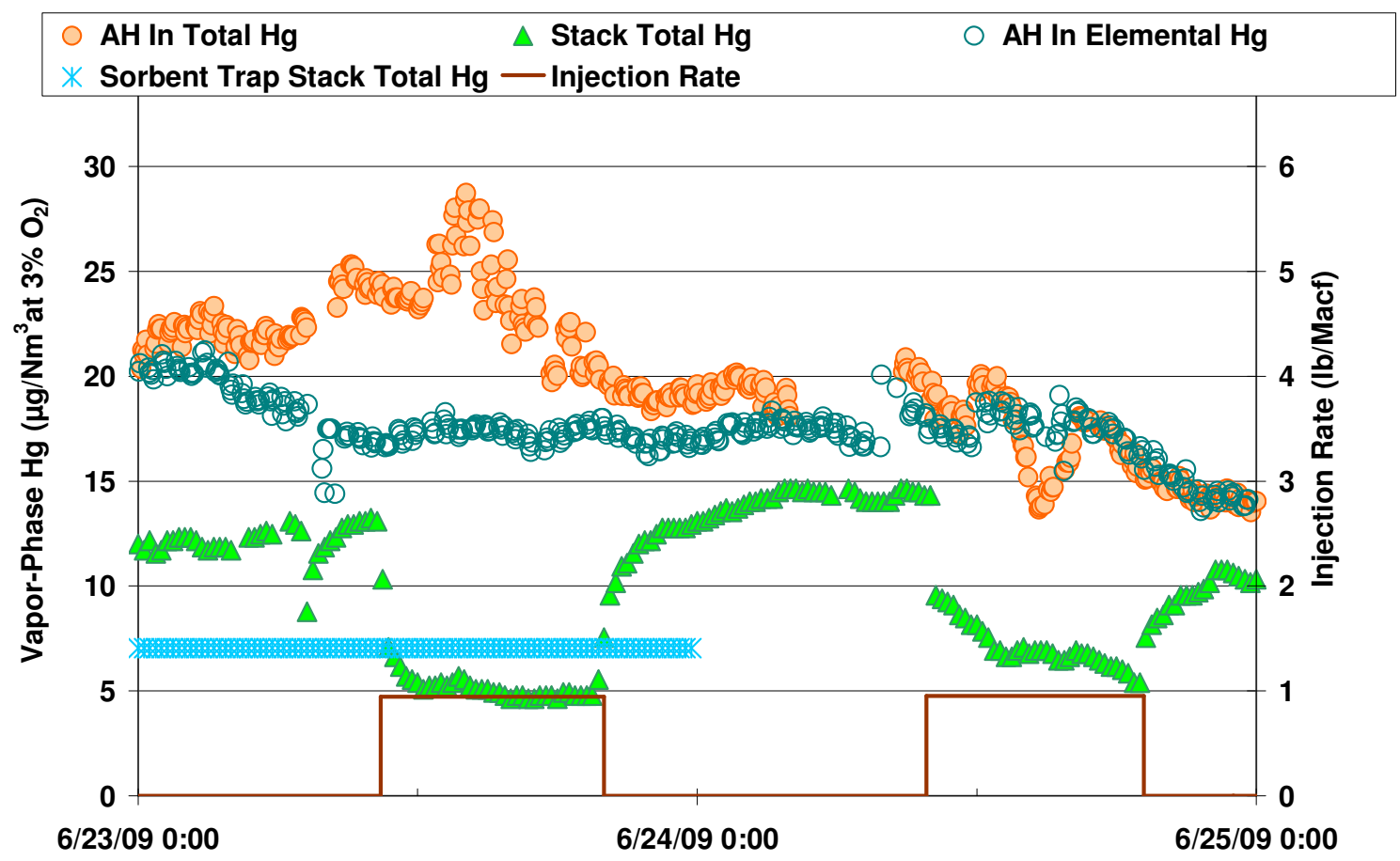

Figure K-20. Flue Gas Hg Concentrations for AH Inlet and Stack 6/23-6/25 


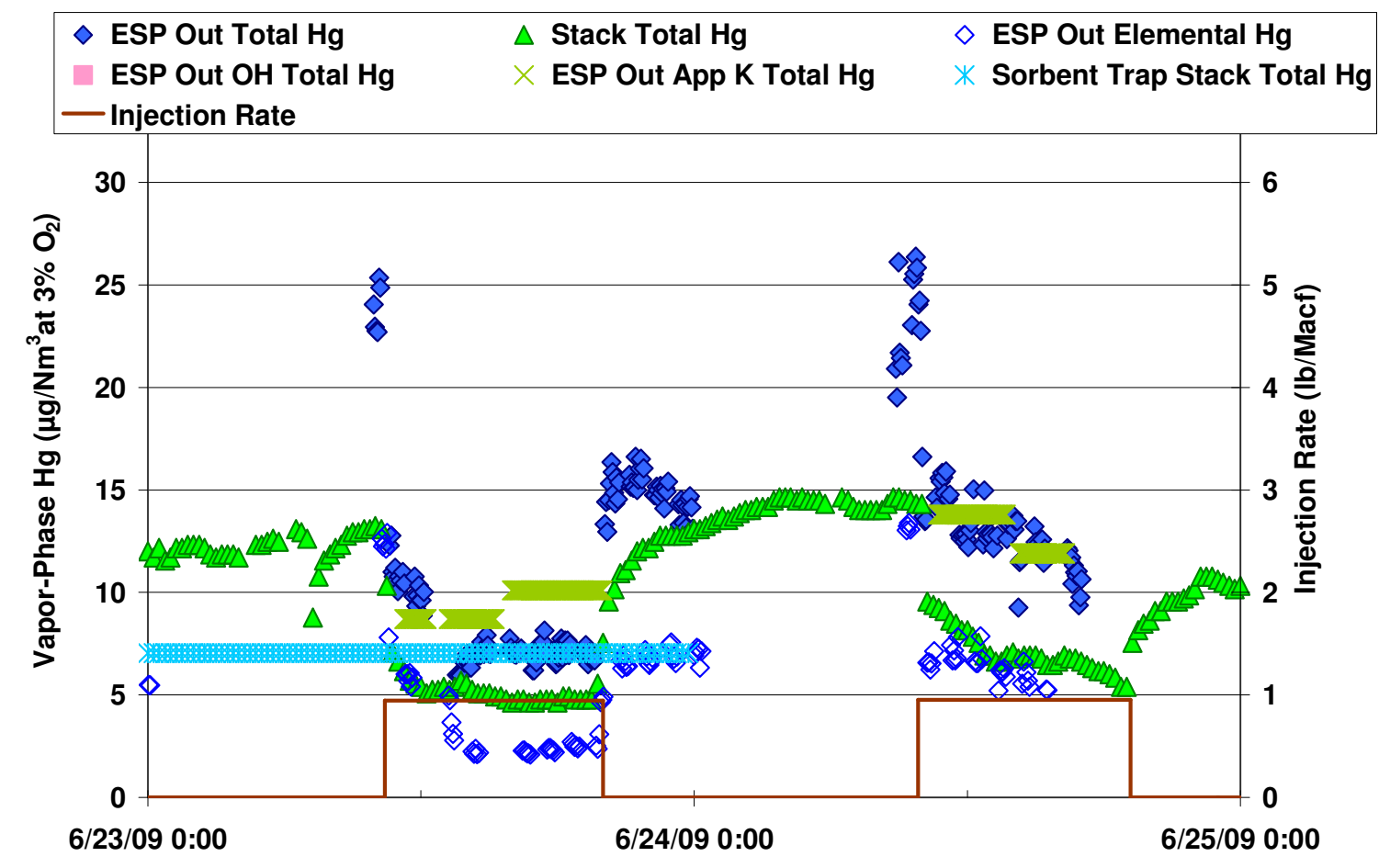

Figure K-21. Flue Gas Hg Concentrations for ESP Outlet and Stack 6/23-6/25

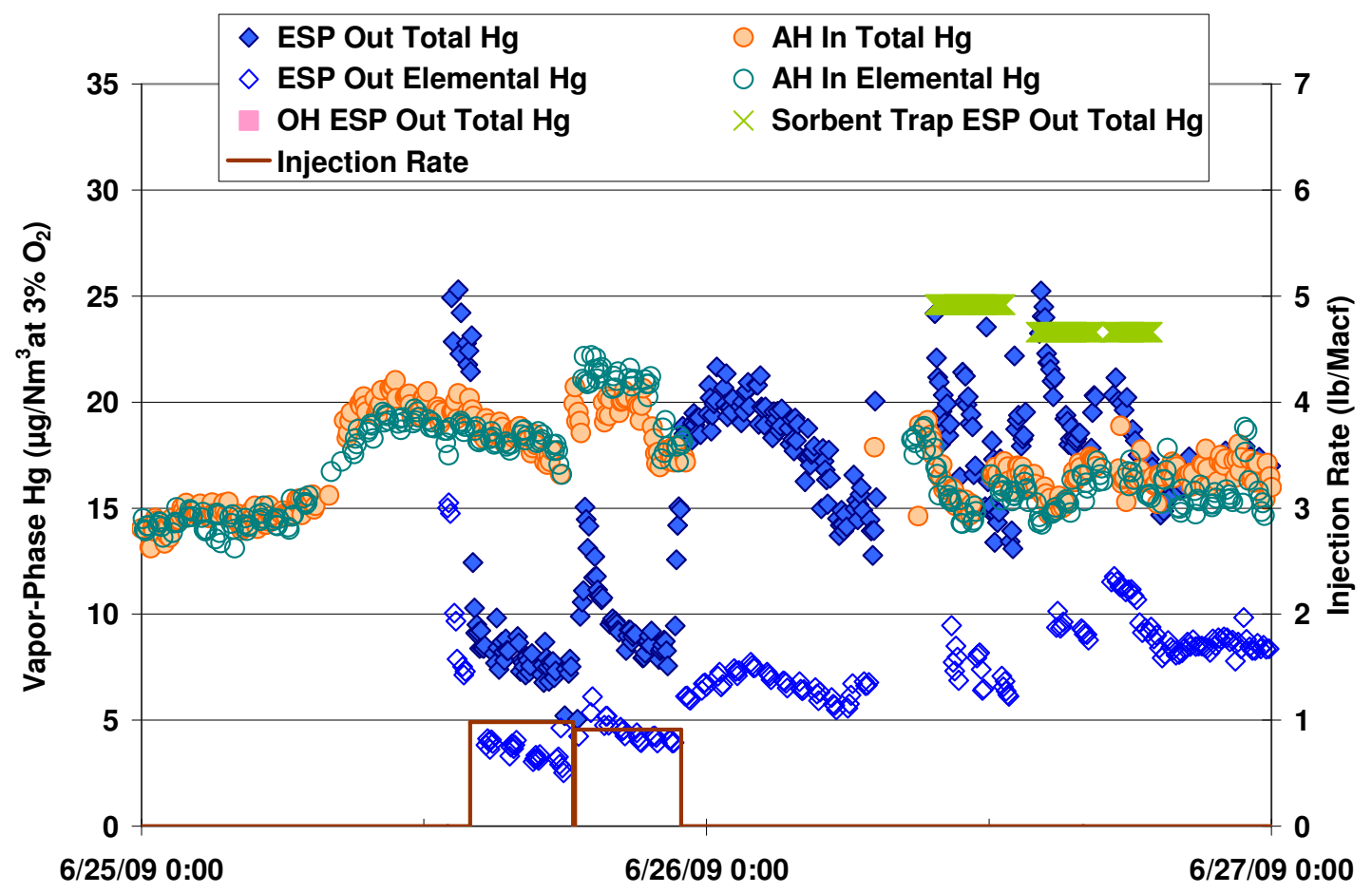

Figure K-22. Flue Gas Hg Concentrations for AH Inlet and ESP Outlet 6/25-6/27 


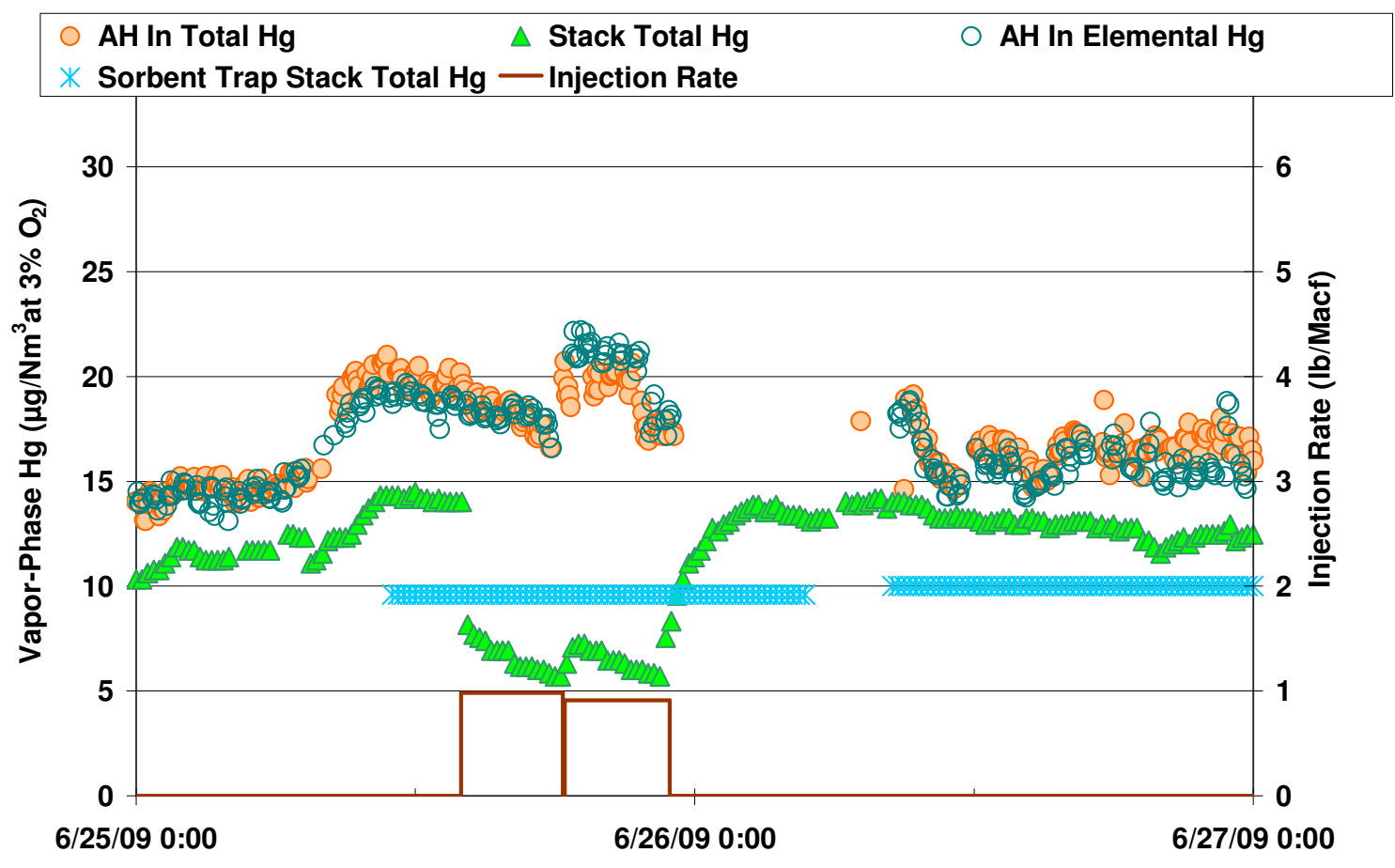

Figure K-23. Flue Gas Hg Concentrations for AH Inlet and Stack 6/25-6/27

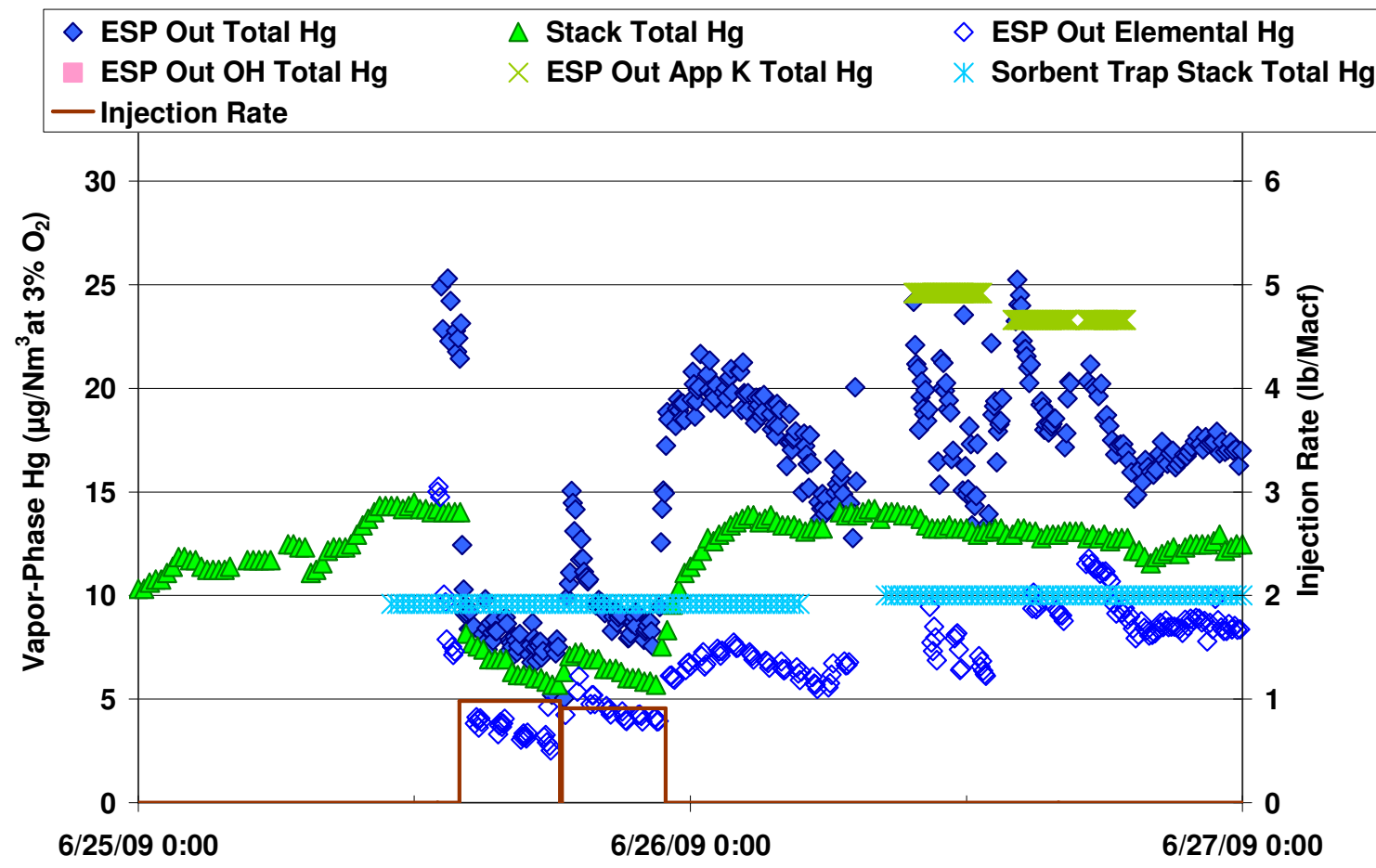

Figure K-24. Flue Gas Hg Concentrations for ESP Outlet and Stack 6/25-6/27 


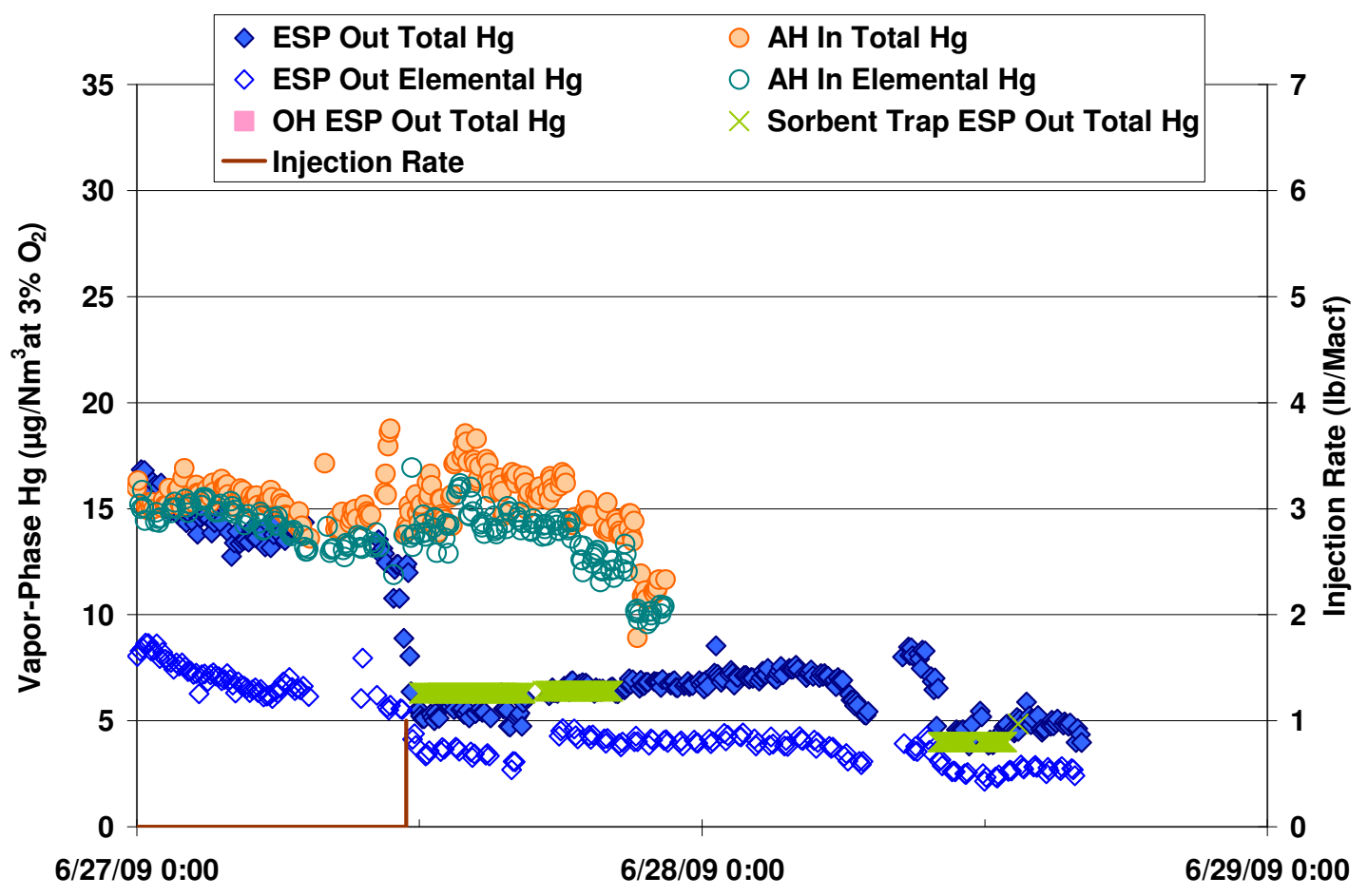

Figure K-25. Flue Gas Hg Concentrations for AH Inlet and ESP Outlet 6/27-6/29

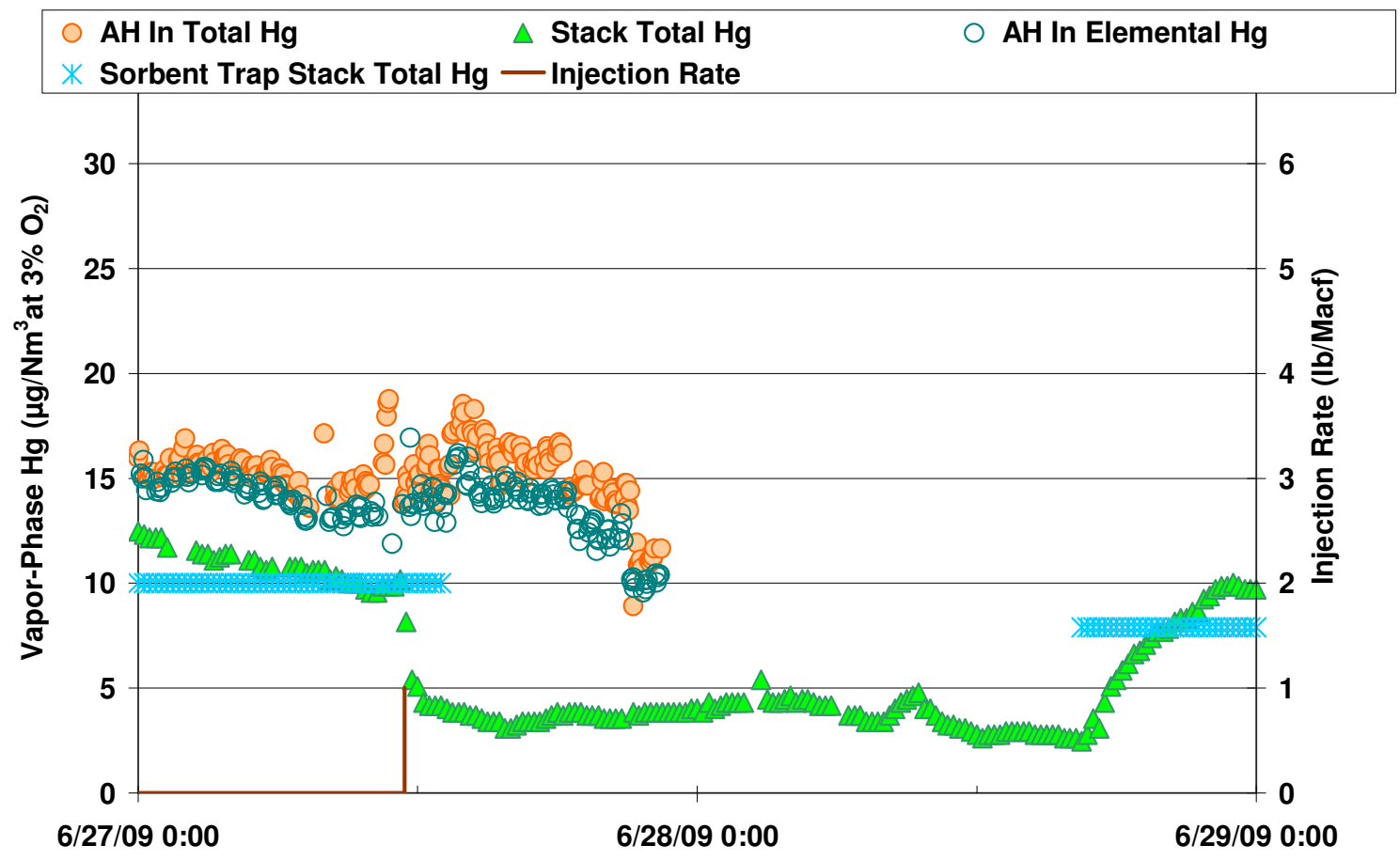

Figure K-26. Flue Gas Hg Concentrations for AH Inlet and Stack 6/27-6/29 


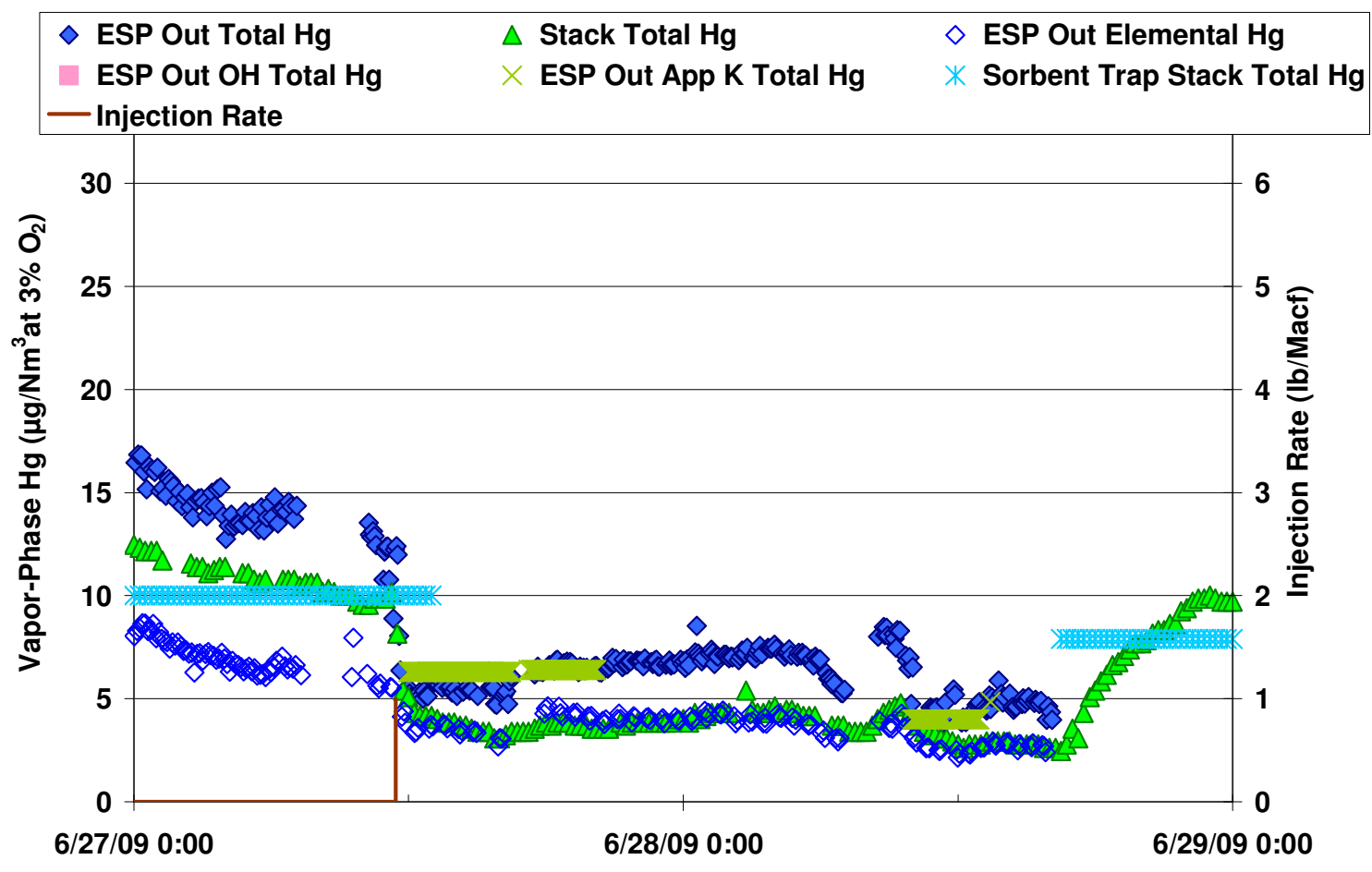

Figure K-27. Flue Gas Hg Concentrations for ESP Outlet and Stack 6/27-6/29

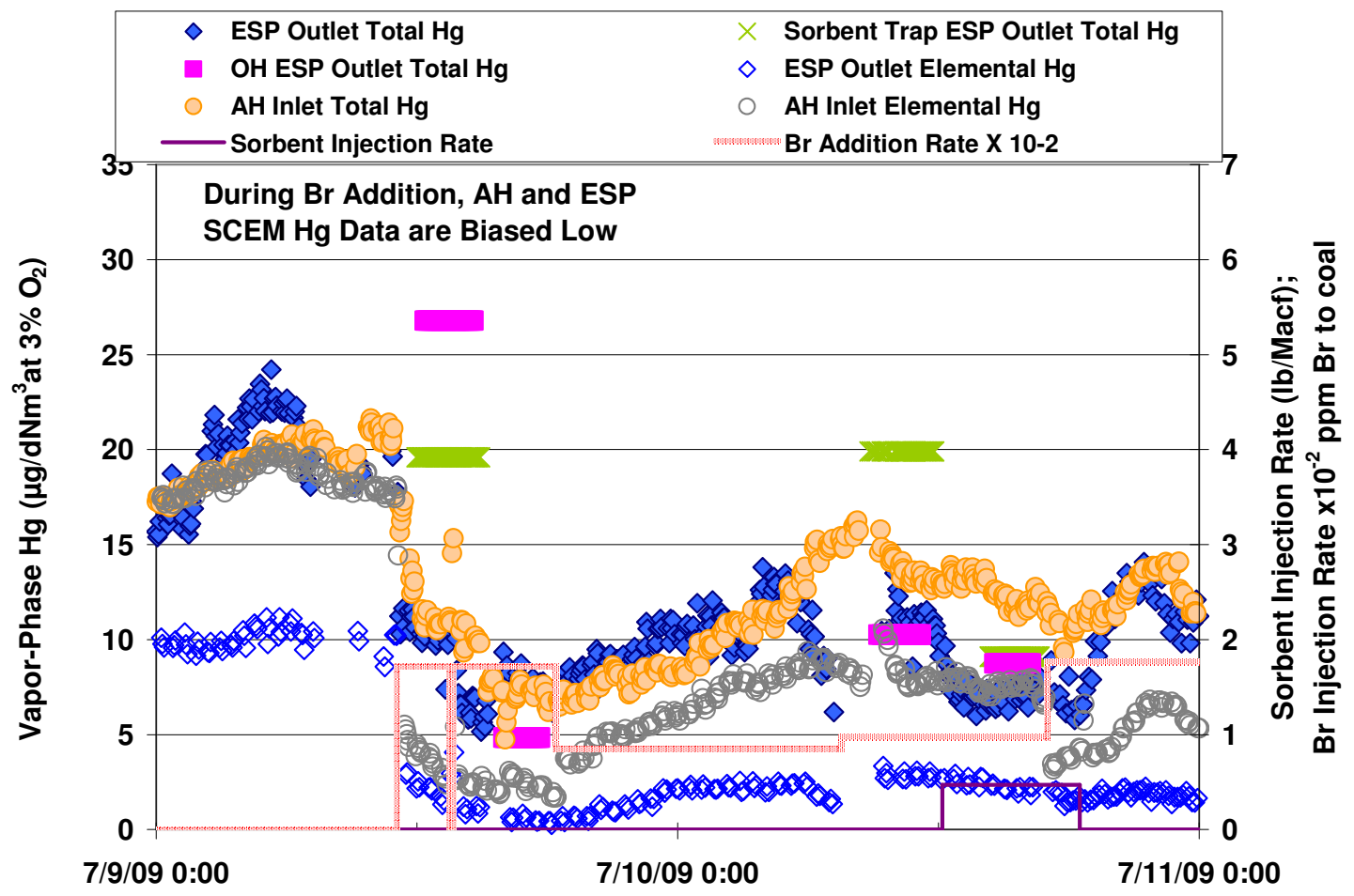

Figure K-28. Flue Gas Hg Concentrations for AH Inlet and ESP Outlet 7/9-7/11 


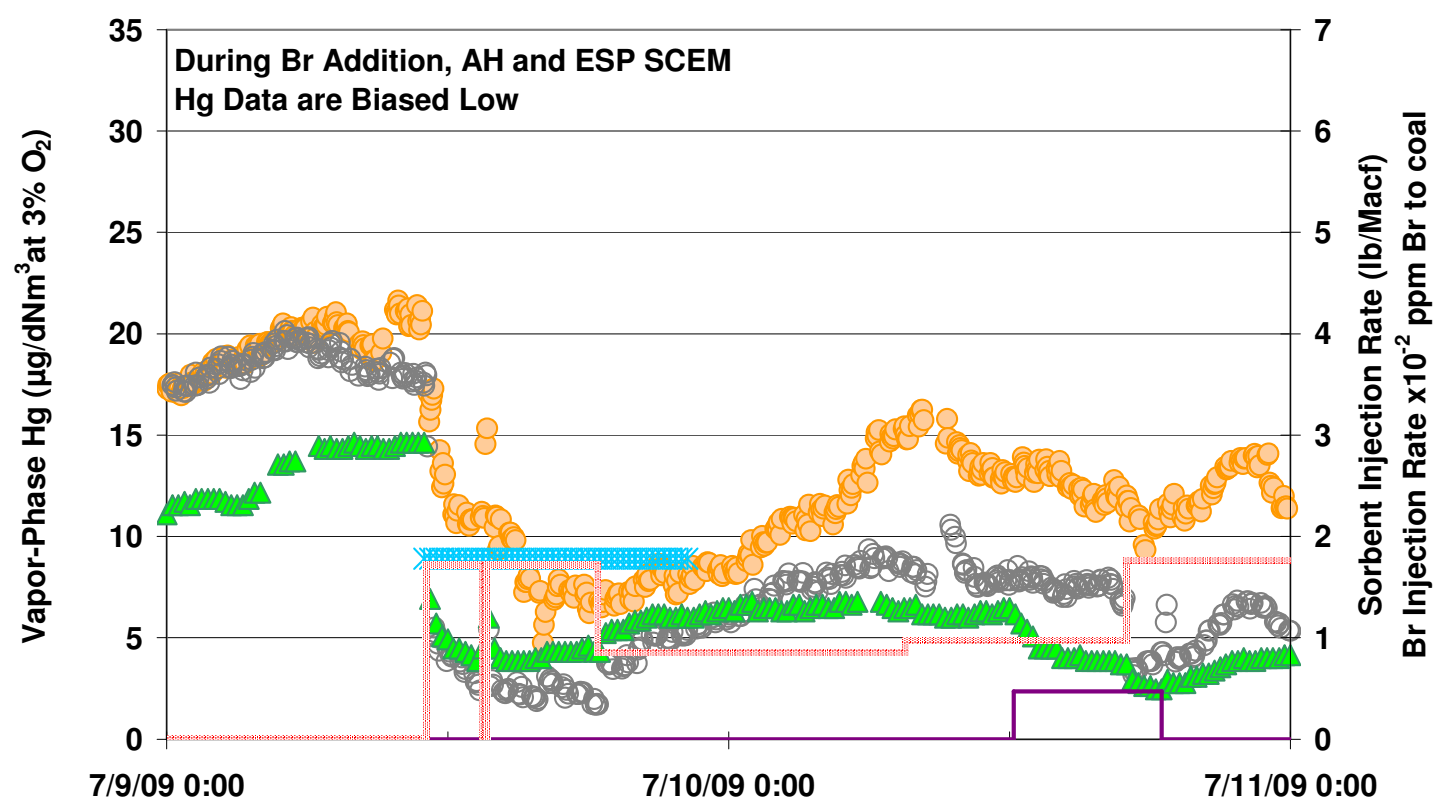

Figure K-29. Flue Gas Hg Concentrations for AH Inlet and Stack 7/9-7/11

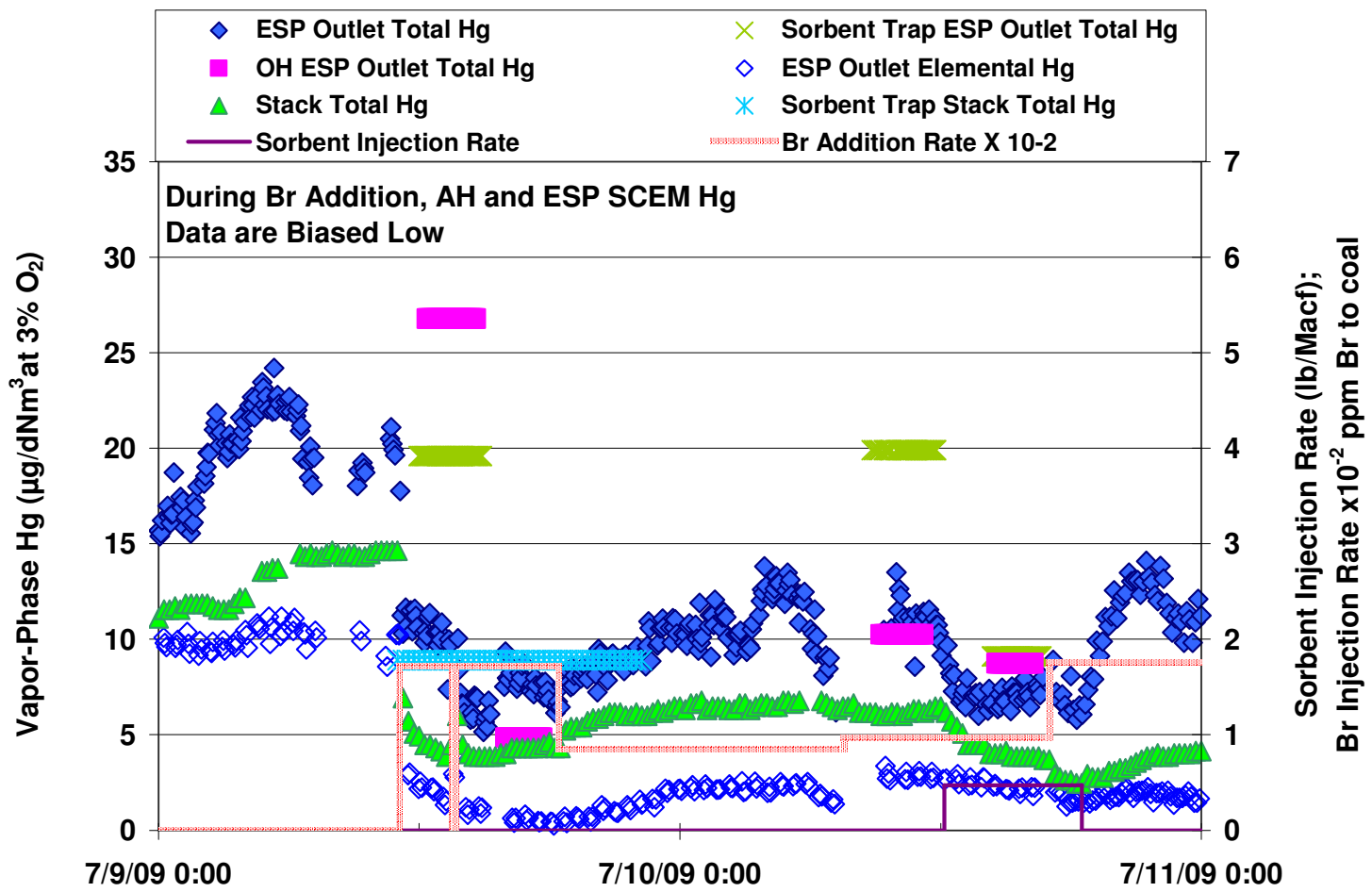

Figure K-30. Flue Gas Hg Concentrations for ESP Outlet and Stack 7/9-7/11 


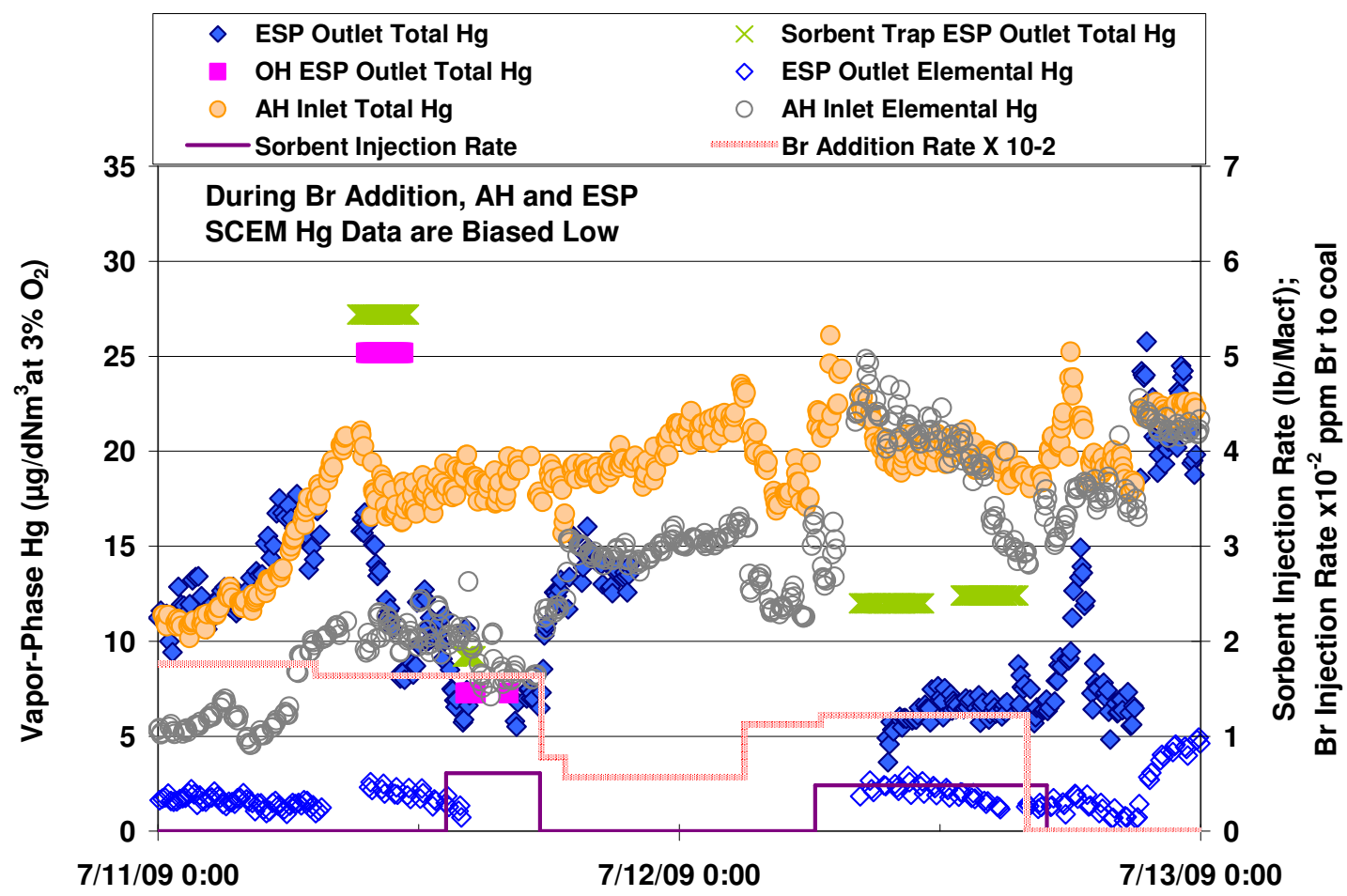

Figure K-31. Flue Gas Hg Concentrations for AH Inlet and ESP Outlet 7/11-7/13

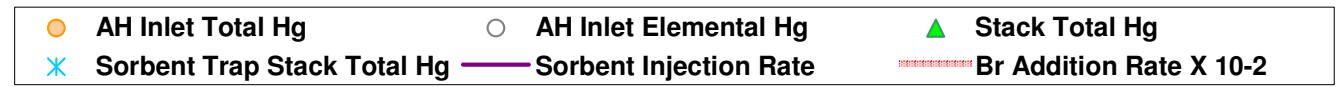

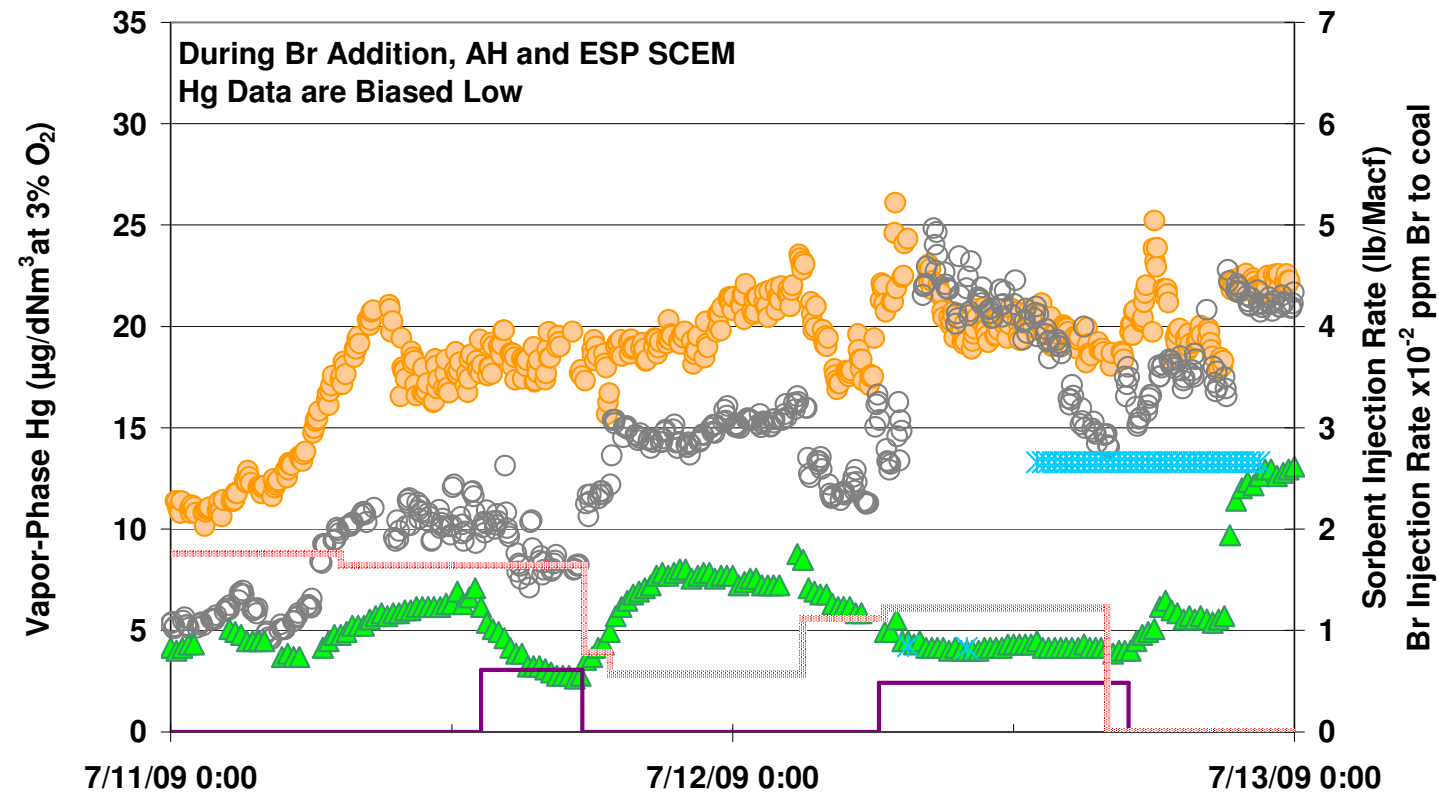

Figure K-32. Flue Gas Hg Concentrations for AH Inlet and Stack 7/11-7/13 


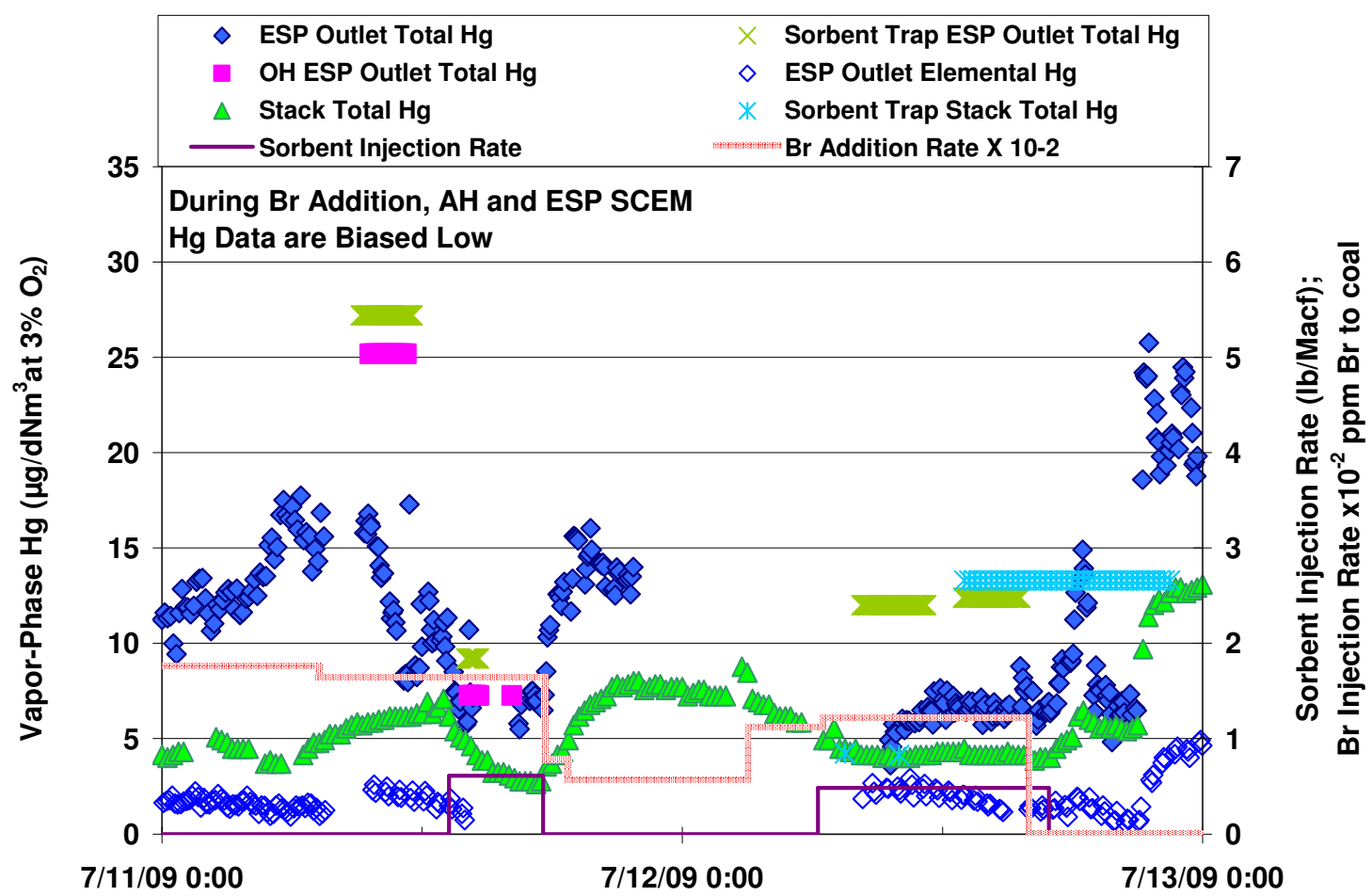

Figure K-33. Flue Gas Hg Concentrations for ESP Outlet and Stack 7/11-7/13

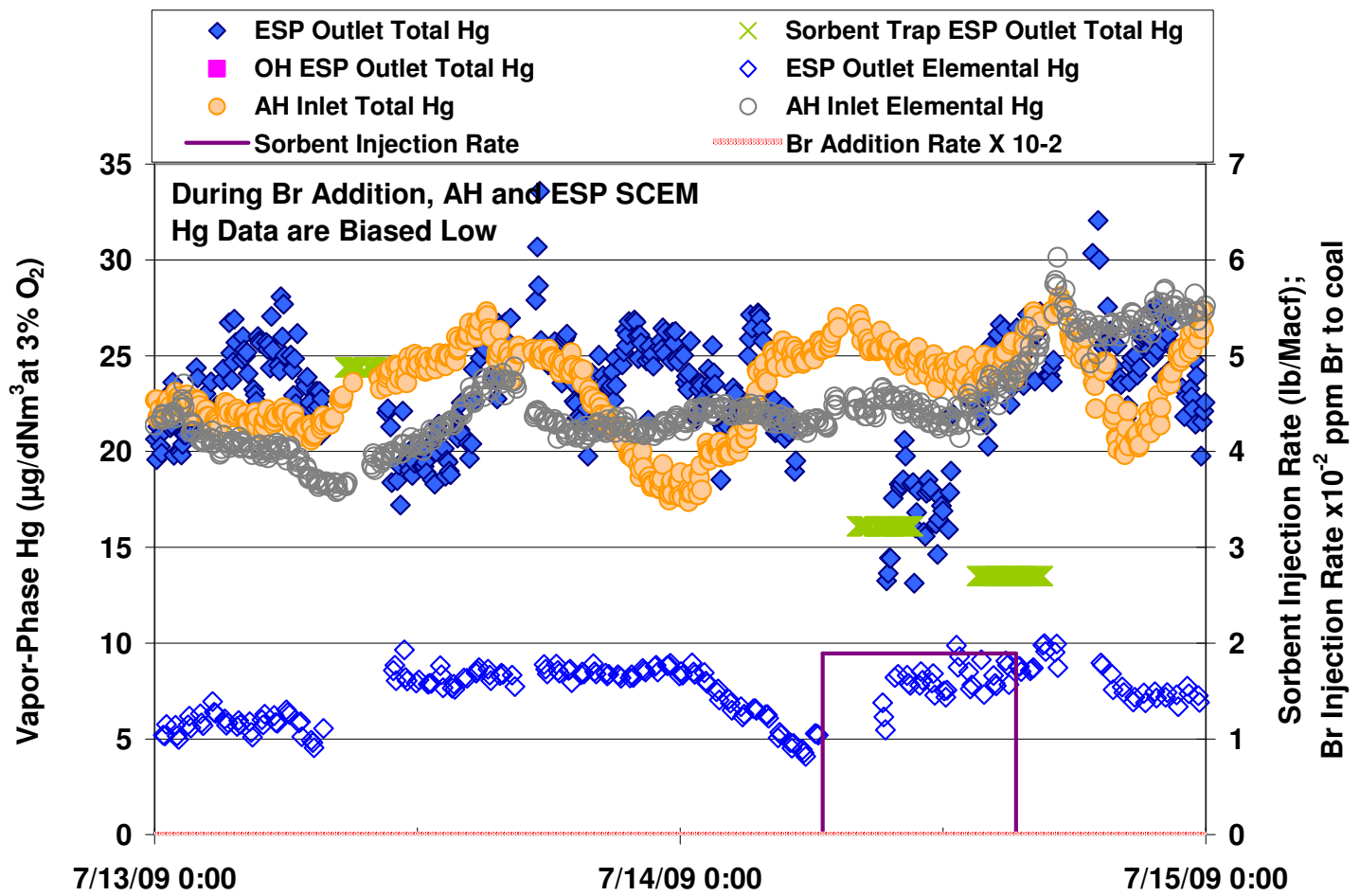

Figure K-34. Flue Gas Hg Concentrations for AH Inlet and ESP Outlet 7/13-7/15 


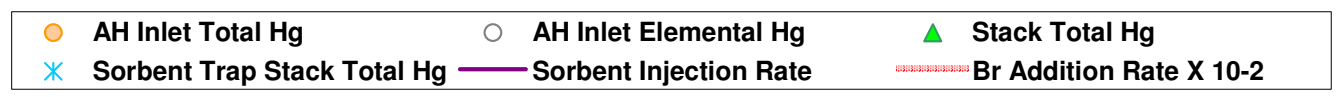

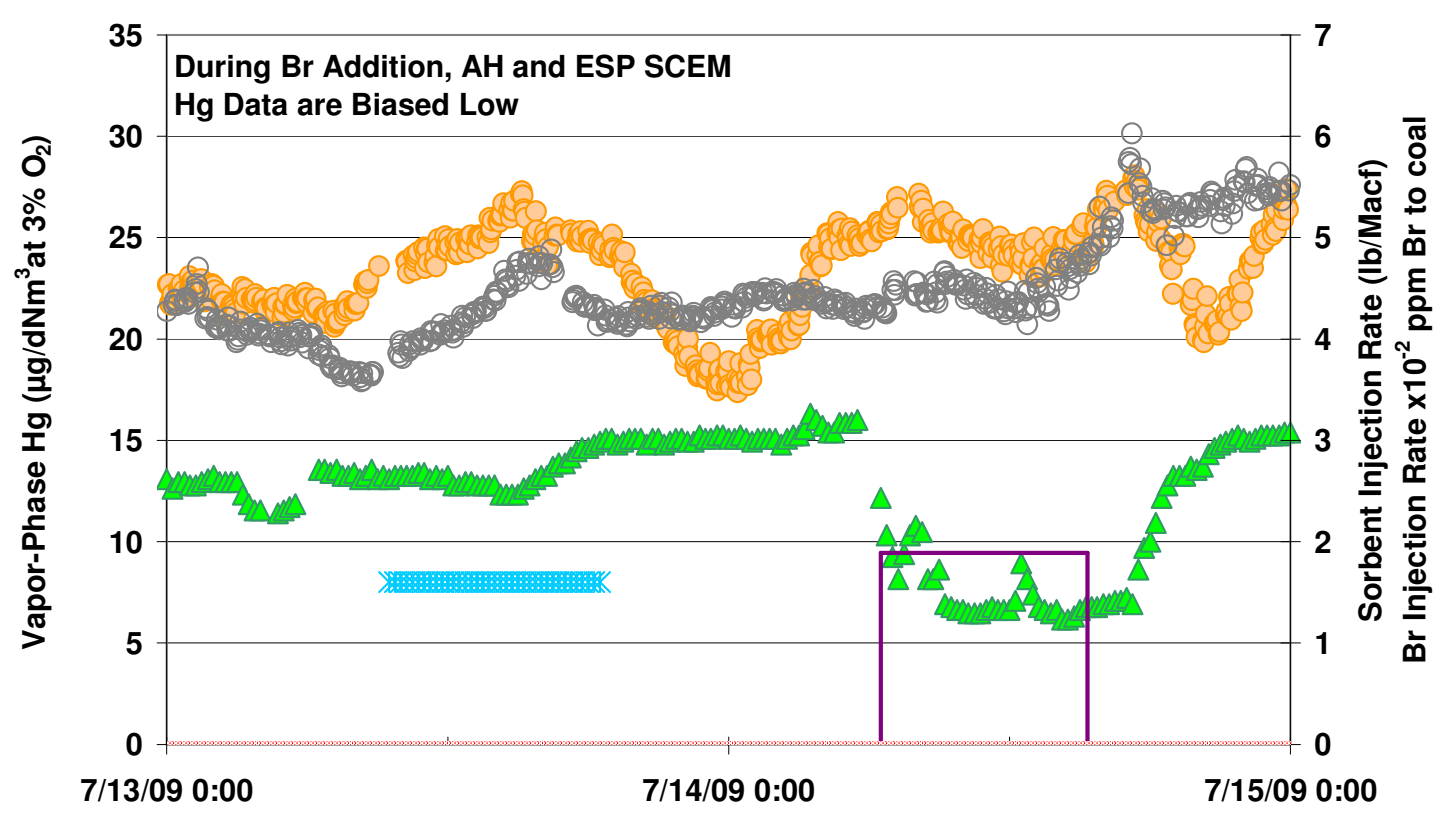

Figure K-35. Flue Gas Hg Concentrations for AH Inlet and Stack 7/13-7/15

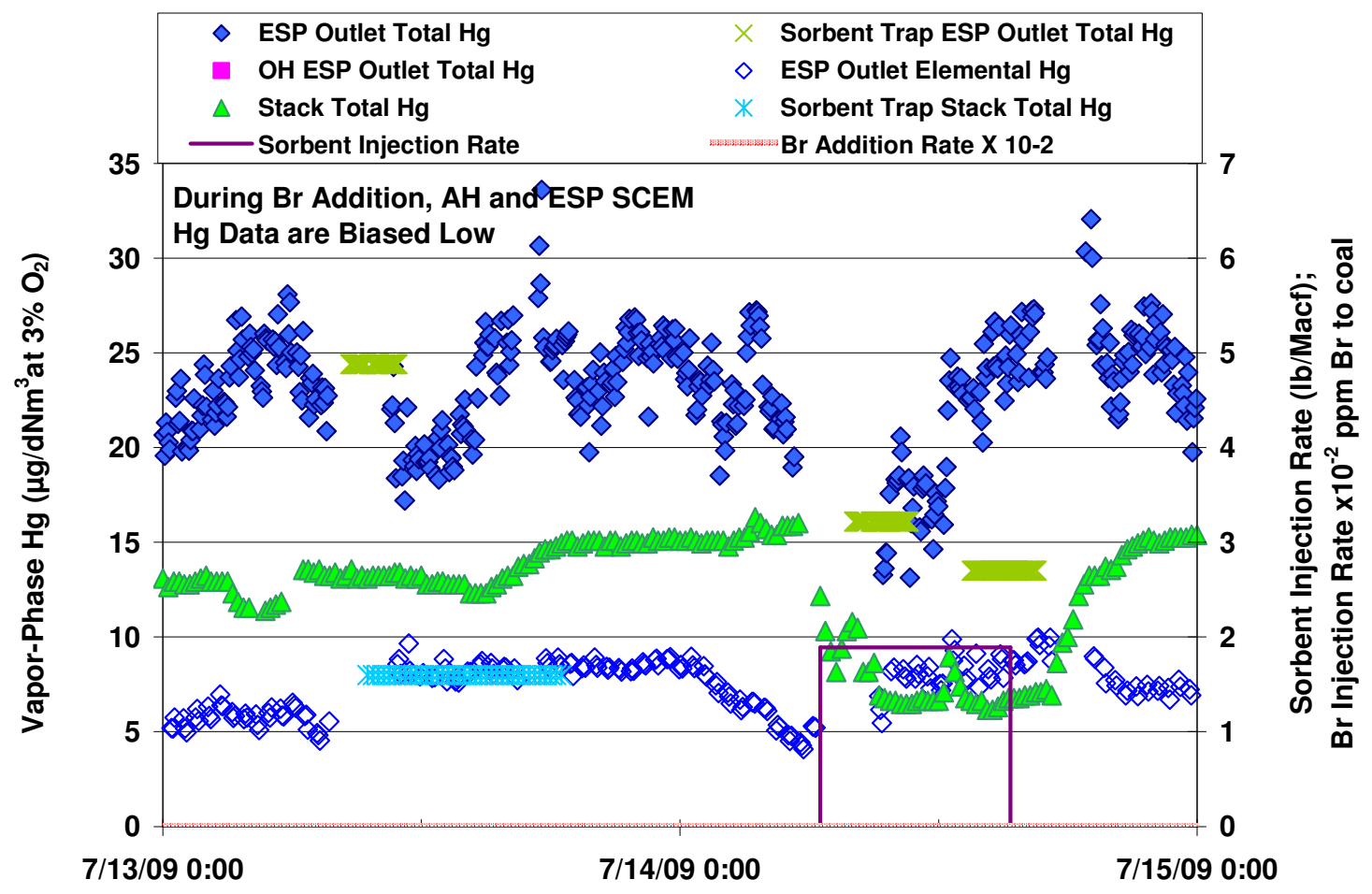

Figure K-36. Flue Gas Hg Concentrations for ESP Outlet and Stack 7/13-7/15 


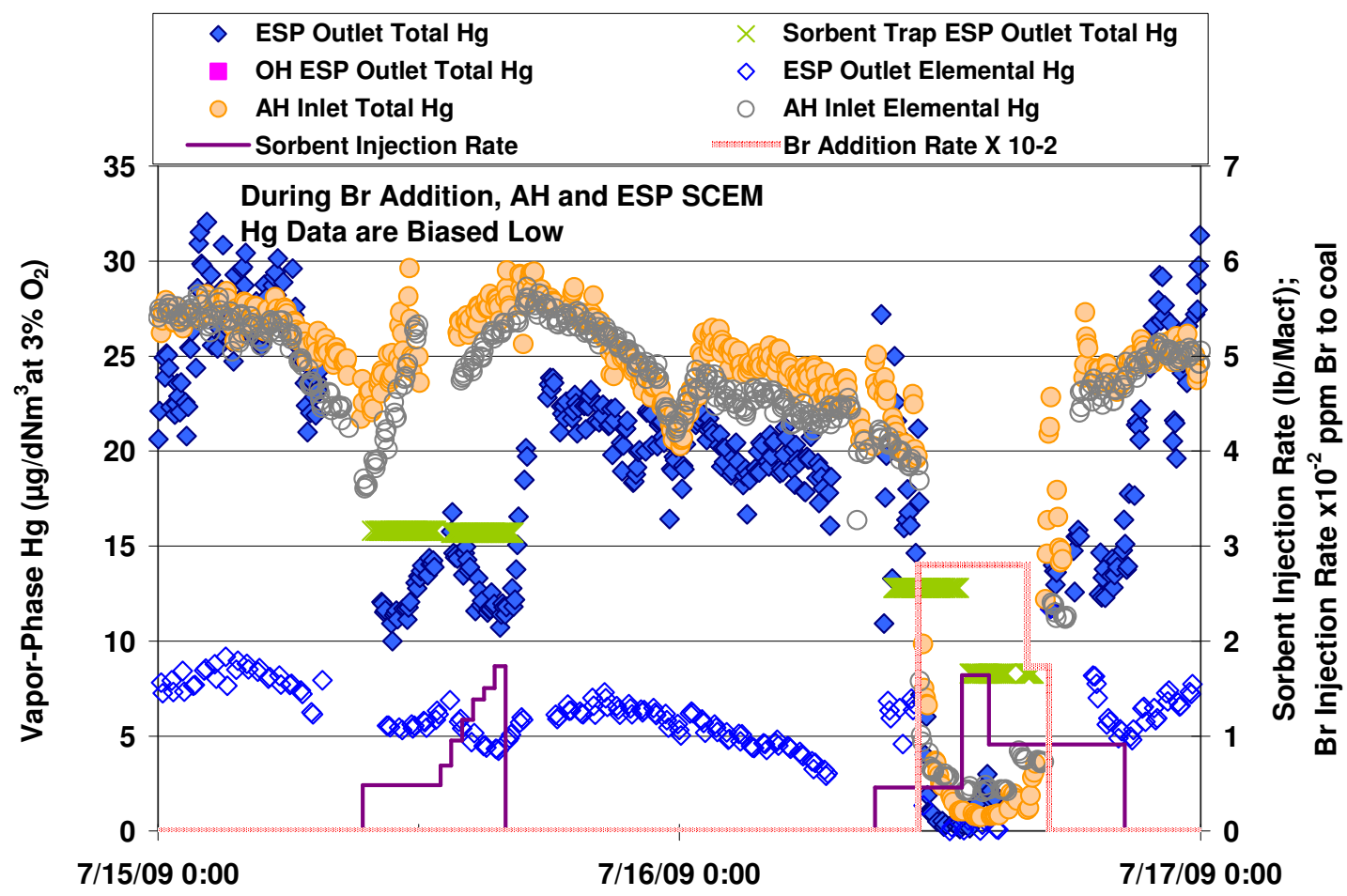

Figure K-37. Flue Gas Hg Concentrations for AH Inlet and ESP Outlet 7/15-7/17

\begin{tabular}{|c|c|c|c|c|}
\hline 0 & AH Inlet Total Hg & O & $\mathrm{AH}$ Inlet Elemental Hg & $\triangle \quad$ Stack Total Hg \\
\hline * & Sorbent Trap Stack Total Hg & 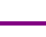 & -Sorbent Injection Rate & Br Addition Rate X 10-2 \\
\hline
\end{tabular}

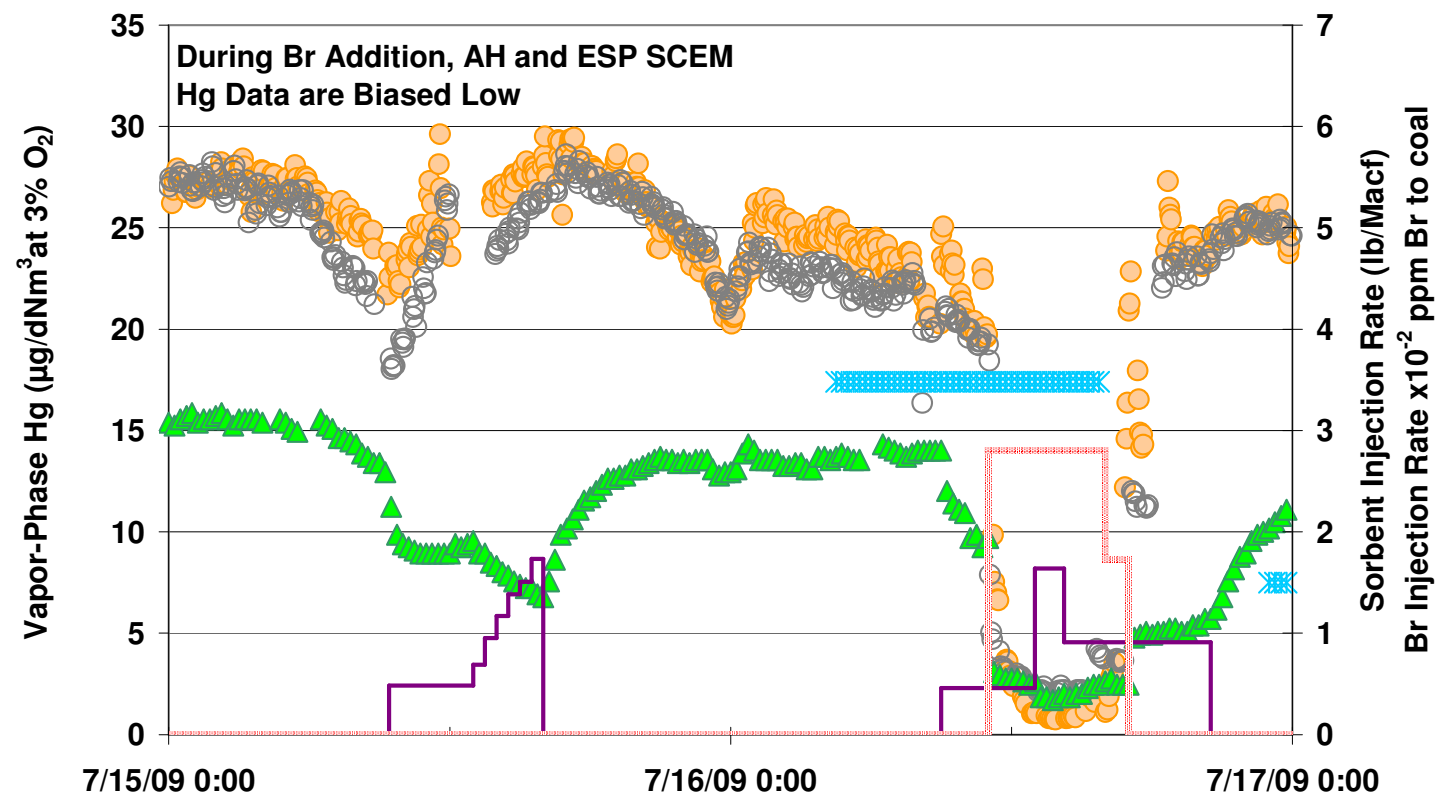

Figure K-38. Flue Gas Hg Concentrations for AH Inlet and Stack 7/15-7/17 


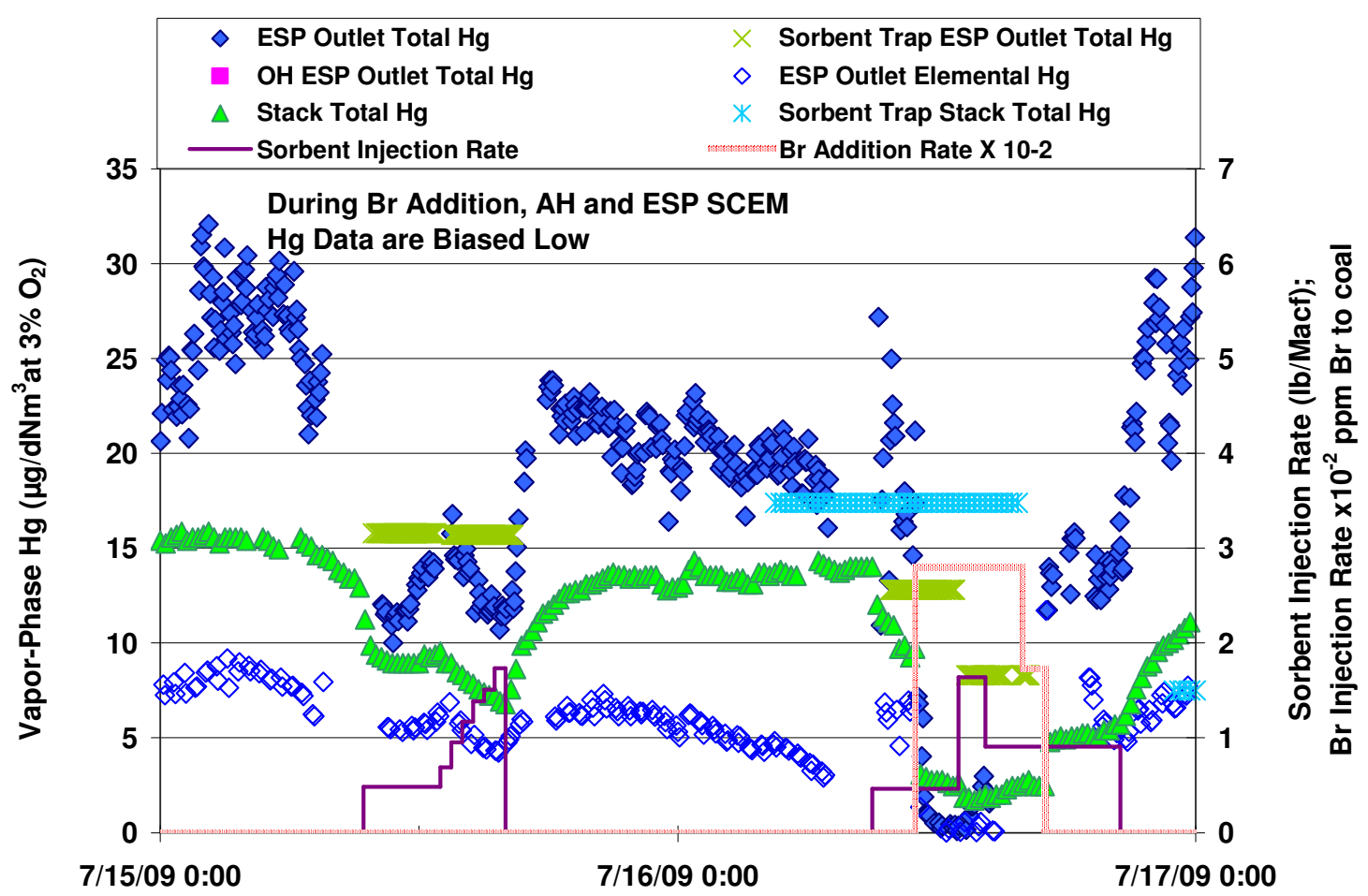

Figure K-39. Flue Gas Hg Concentrations for ESP Outlet and Stack 7/15-7/17

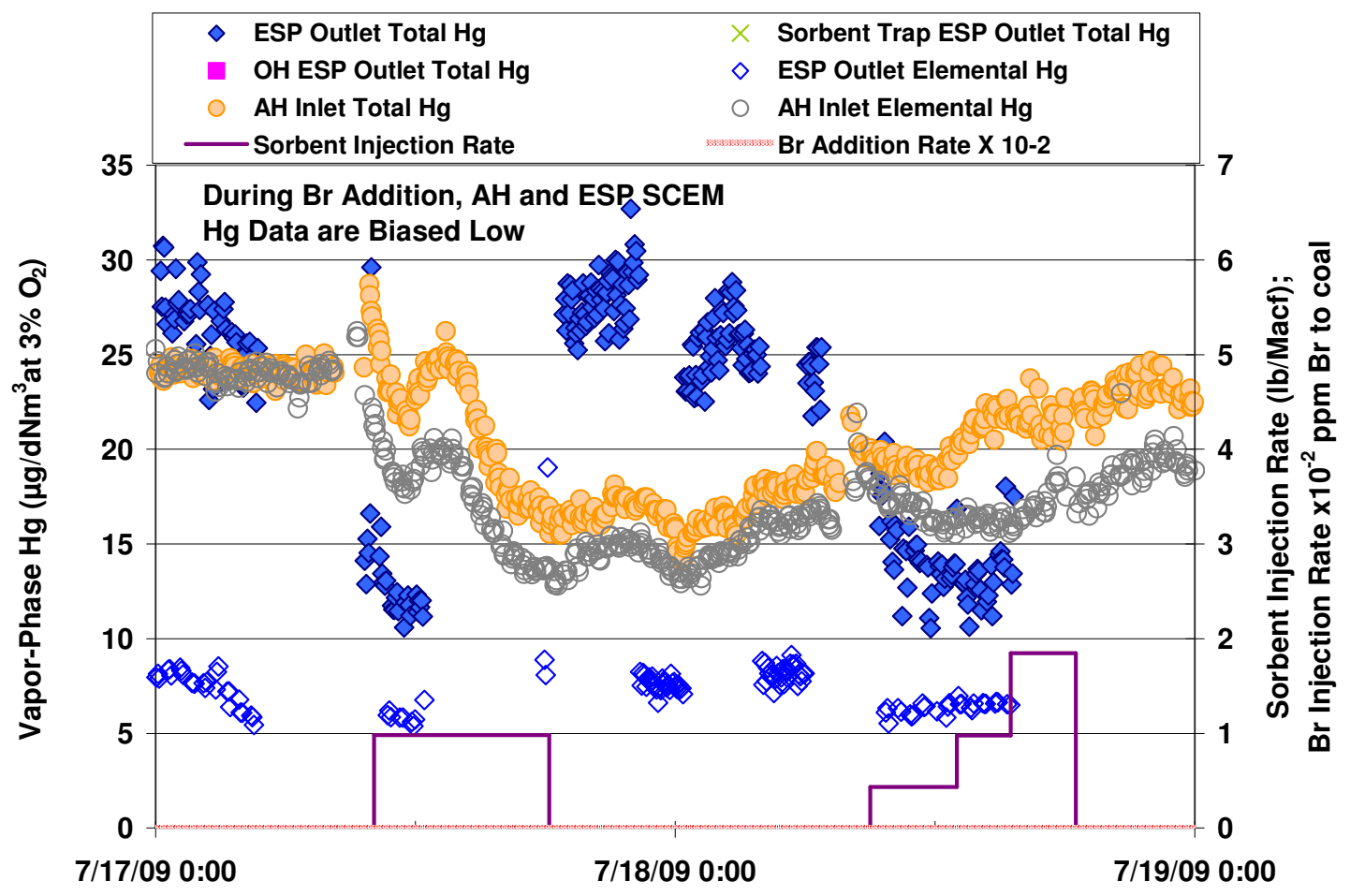

Figure K-40. Flue Gas Hg Concentrations for AH Inlet and ESP Outlet 7/17-7/19 


\begin{tabular}{|clccc|}
\hline \multirow{2}{*}{ AH Inlet Total Hg } & AH Inlet Elemental Hg & Stack Total Hg \\
$*$ & Sorbent Trap Stack Total Hg & & Sorbent Injection Rate & Br Addition Rate X 10-2 \\
\cline { 2 - 4 }
\end{tabular}

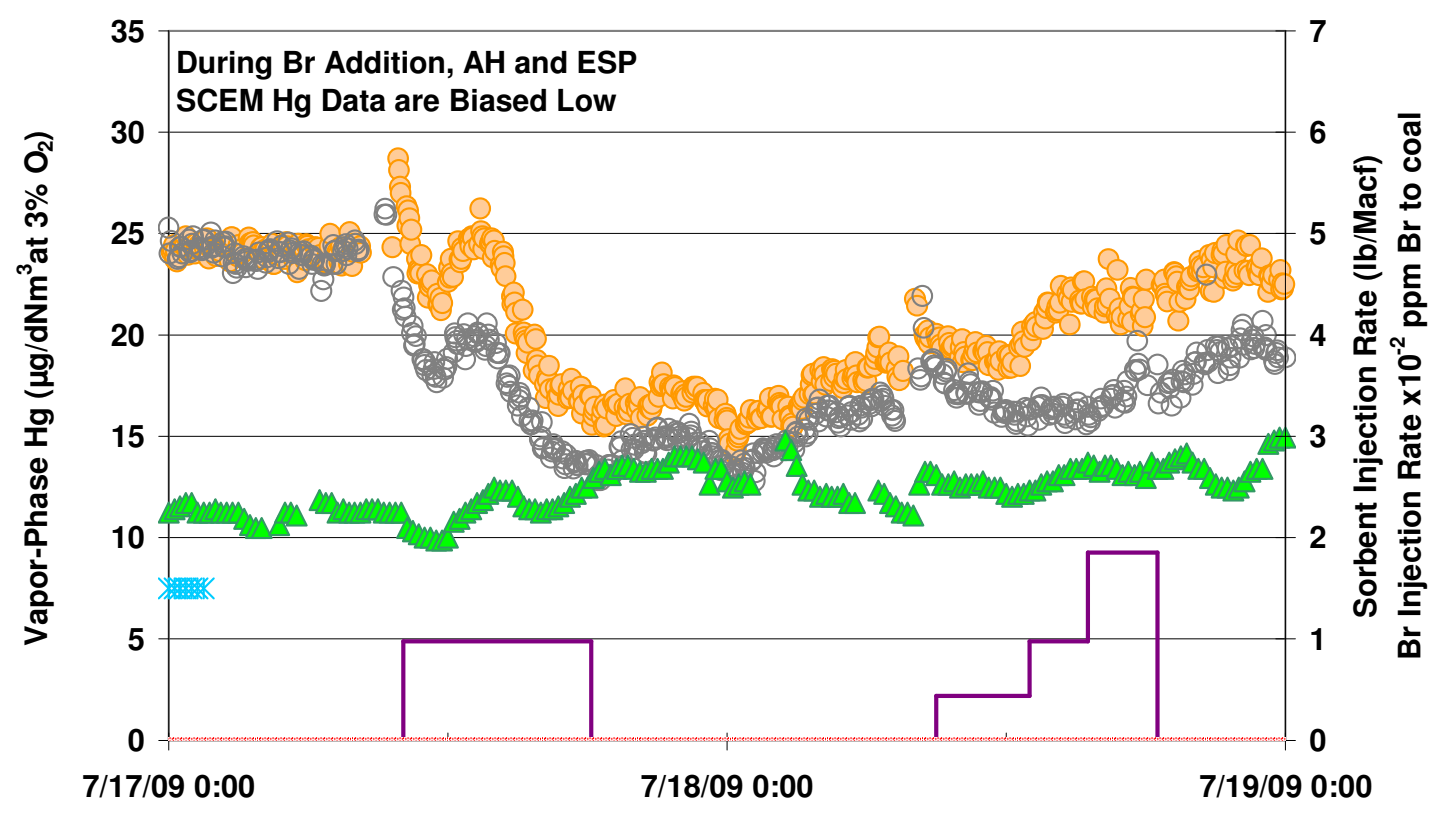

Figure K-41. Flue Gas Hg Concentrations for AH Inlet and Stack 7/17-7/19

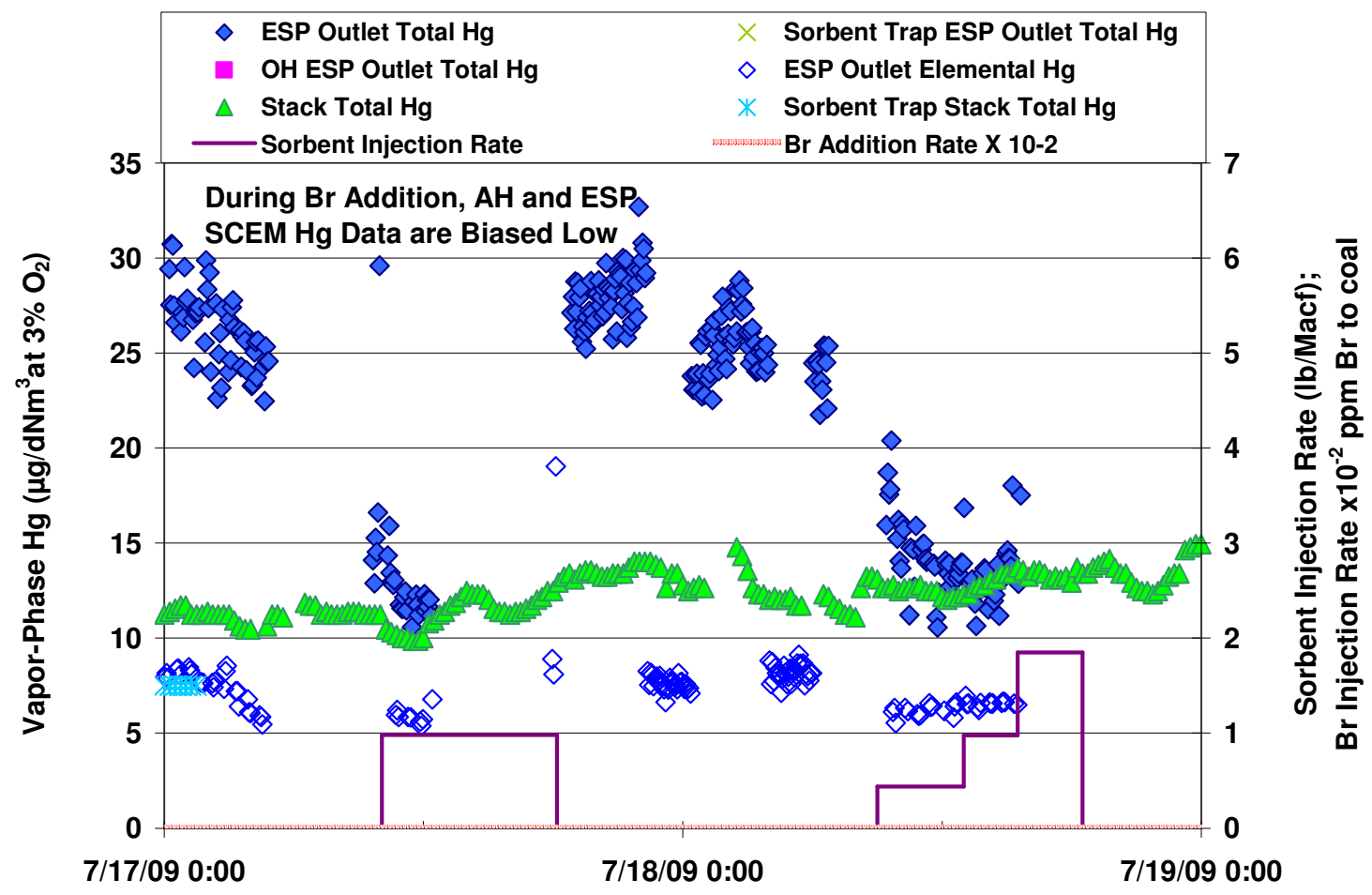

Figure K-42. Flue Gas Hg Concentrations for ESP Outlet and Stack 7/17-7/19 


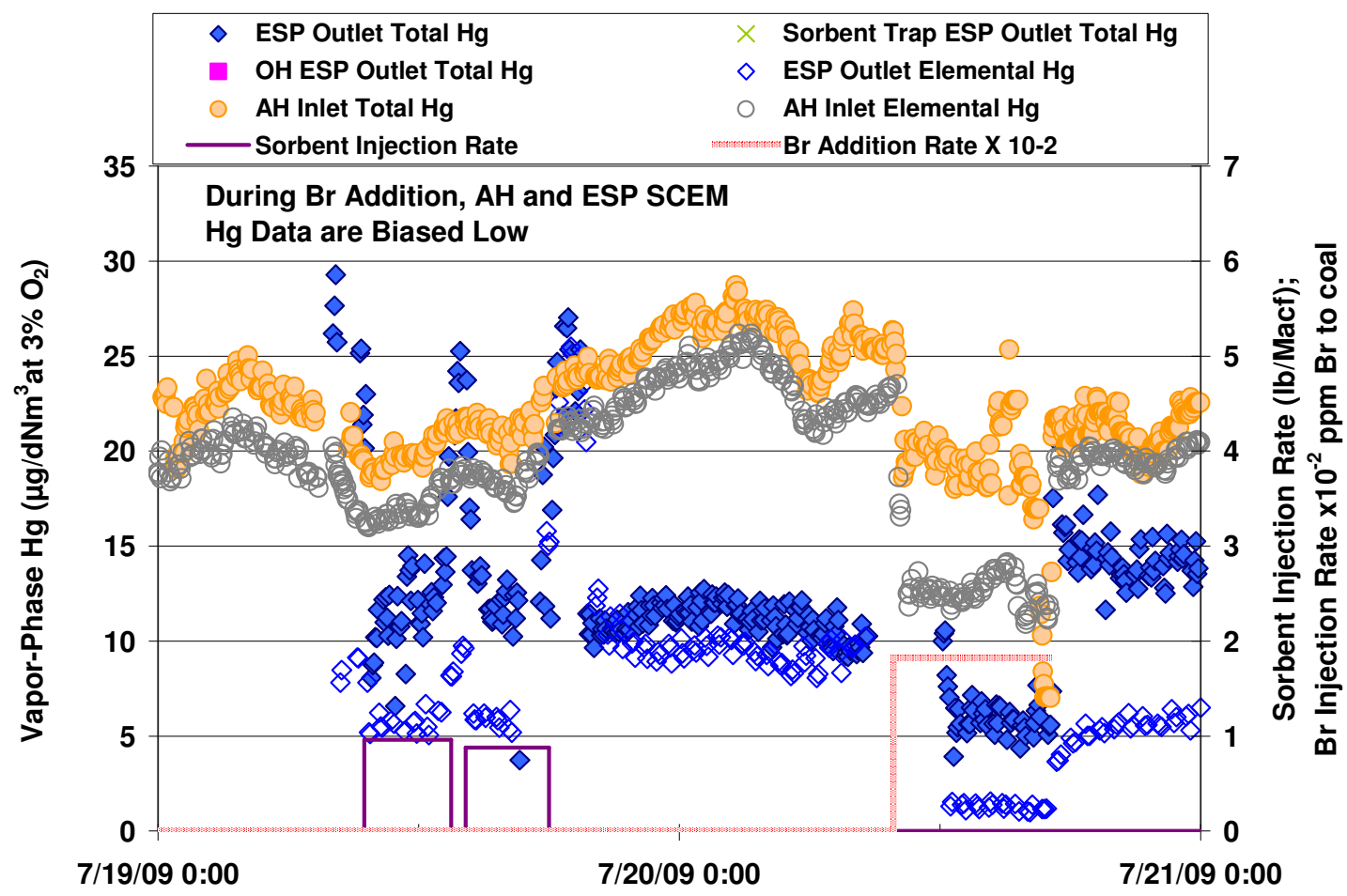

Figure K-43. Flue Gas Hg Concentrations for AH Inlet and ESP Outlet 7/19-7/21

\begin{tabular}{|c|c|c|c|c|}
\hline 0 & AH Inlet Total Hg & O & $\mathrm{AH}$ Inlet Elemental Hg & $\triangle \quad$ Stack Total Hg \\
\hline * & Sorbent Trap Stack Total Hg & 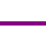 & -Sorbent Injection Rate & Br Addition Rate X 10-2 \\
\hline
\end{tabular}

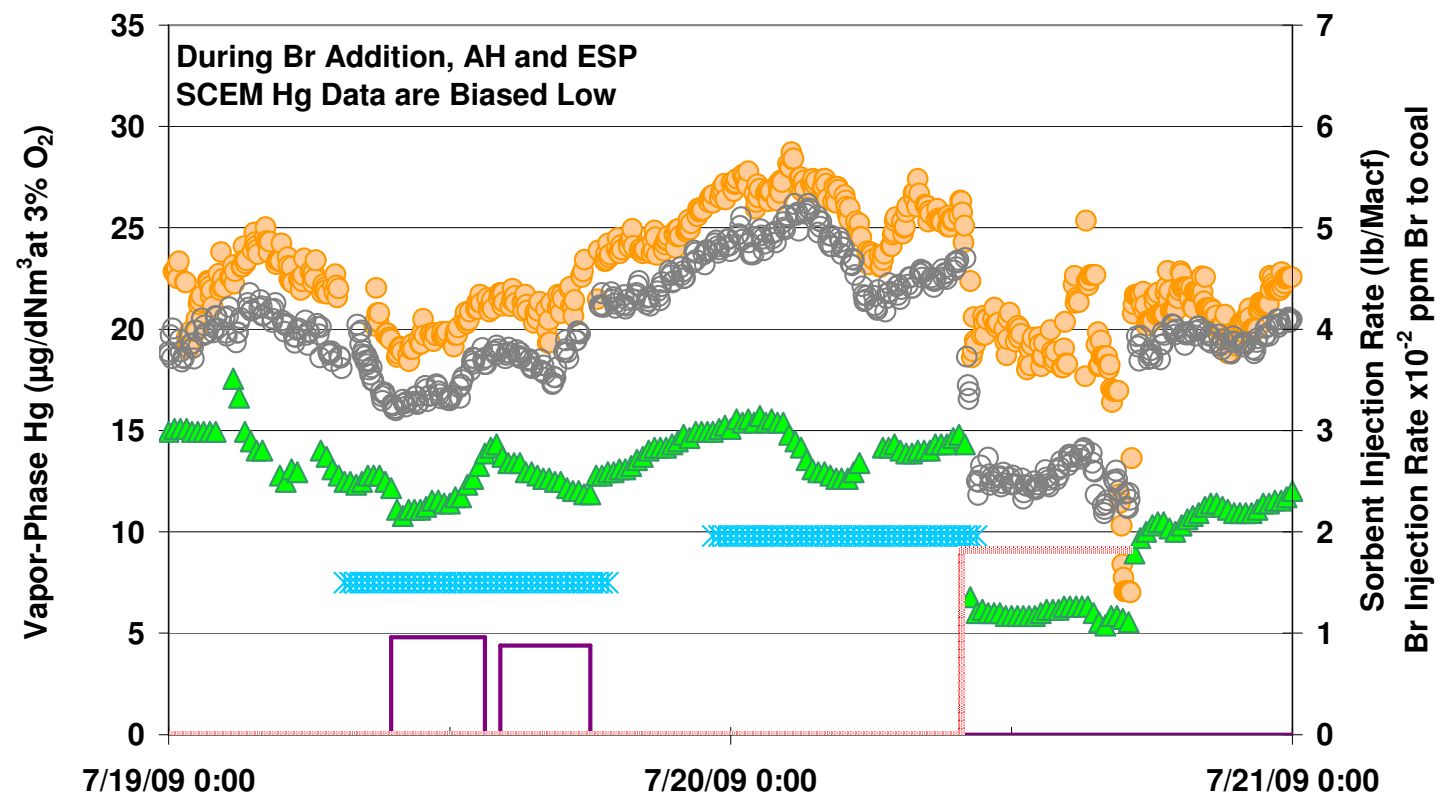

Figure K-44. Flue Gas Hg Concentrations for AH Inlet and Stack 7/19-7/21 


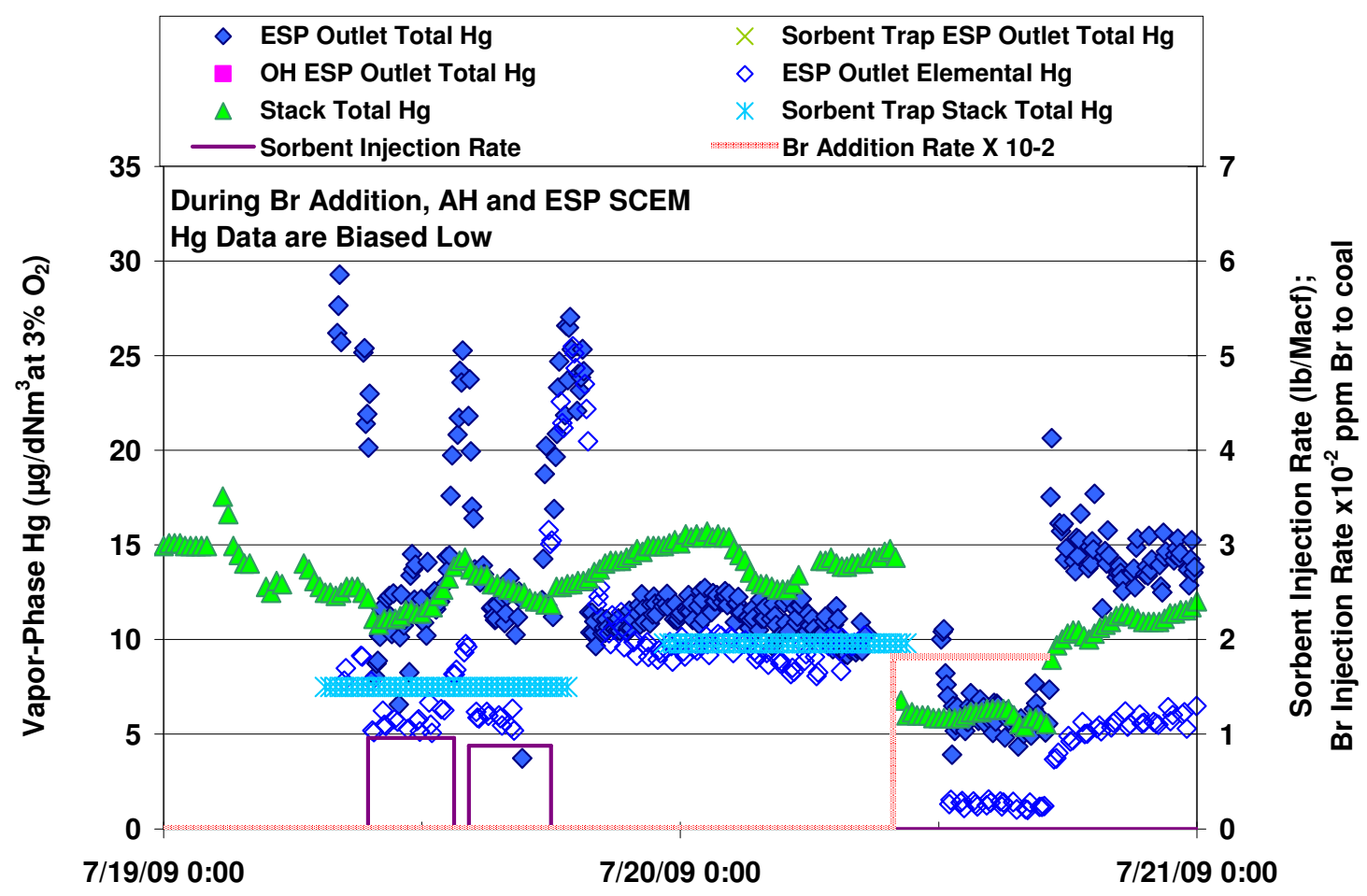

Figure K-45. Flue Gas Hg Concentrations for ESP Outlet and Stack 7/19-7/21

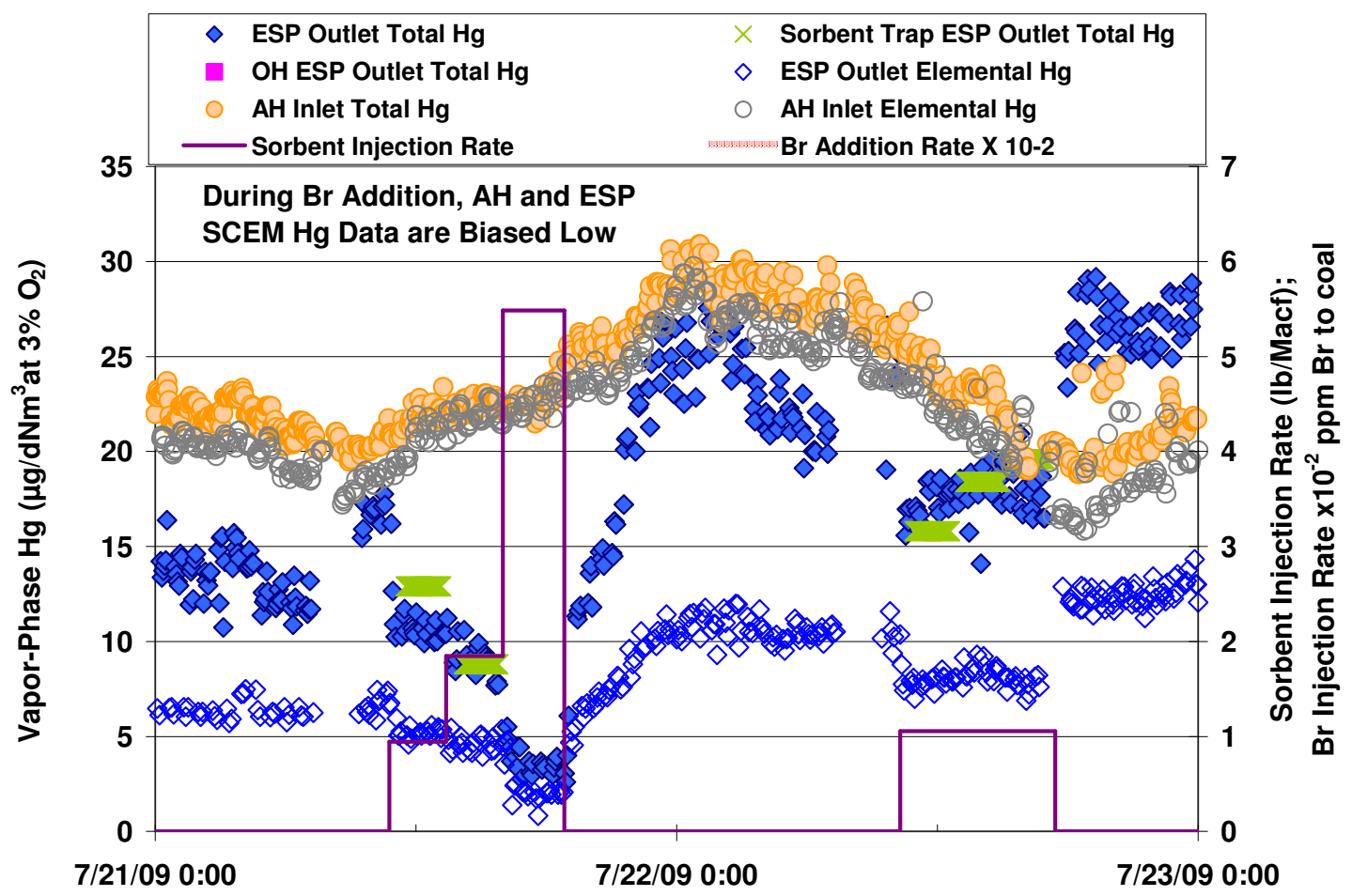

Figure K-46. Flue Gas Hg Concentrations for AH Inlet and ESP Outlet 7/21-7/23 


\begin{tabular}{|clccc|}
\hline \multirow{2}{*}{} & AH Inlet Total Hg & AH Inlet Elemental Hg & $\Delta$ & Stack Total Hg \\
$*$ & Sorbent Trap STack Total Hg & & Sorbent Injection Rate & Br Addition Rate X 10-2 \\
\hline
\end{tabular}

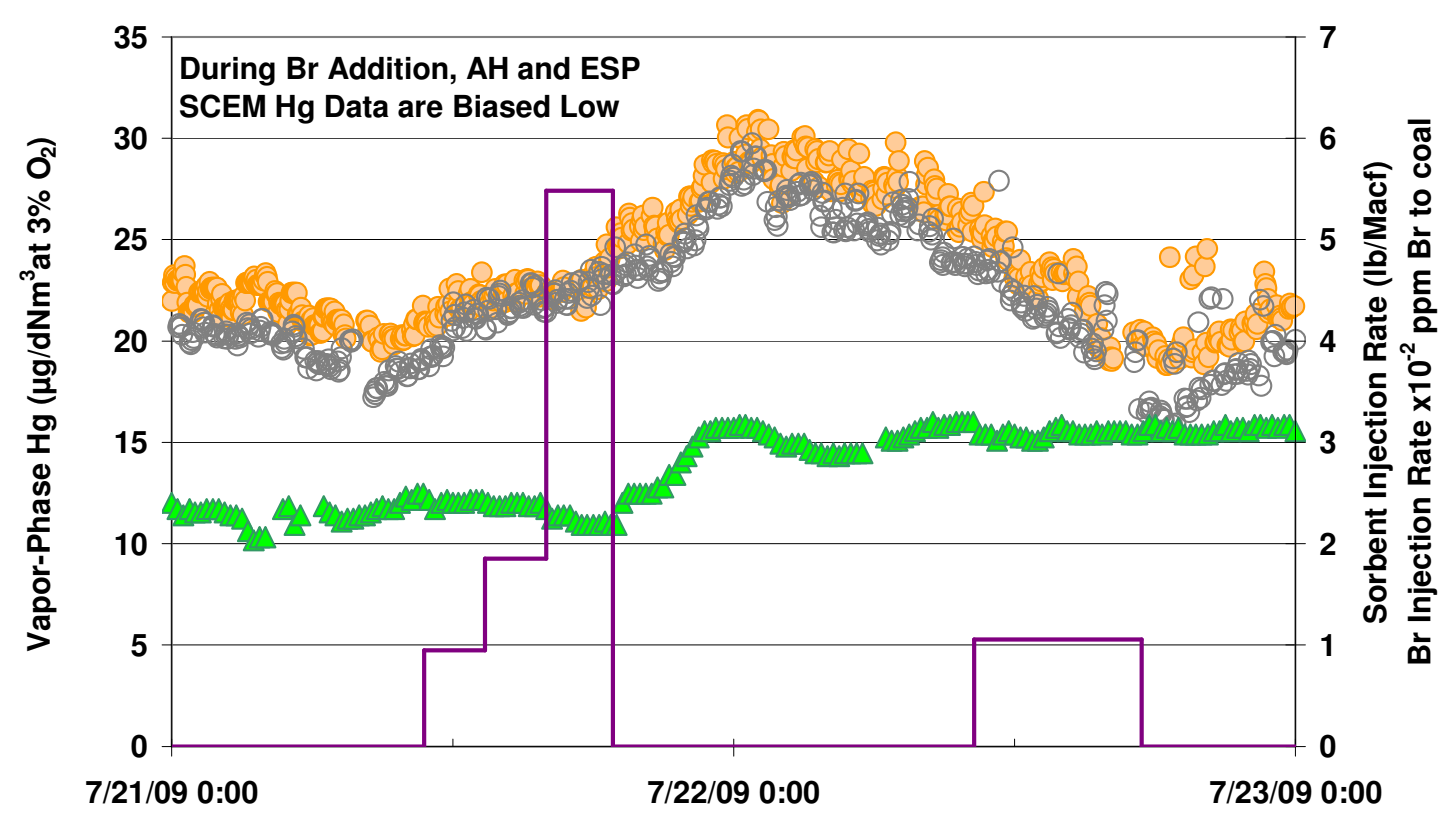

Figure K-47. Flue Gas Hg Concentrations for AH Inlet and Stack 7/21-7/23

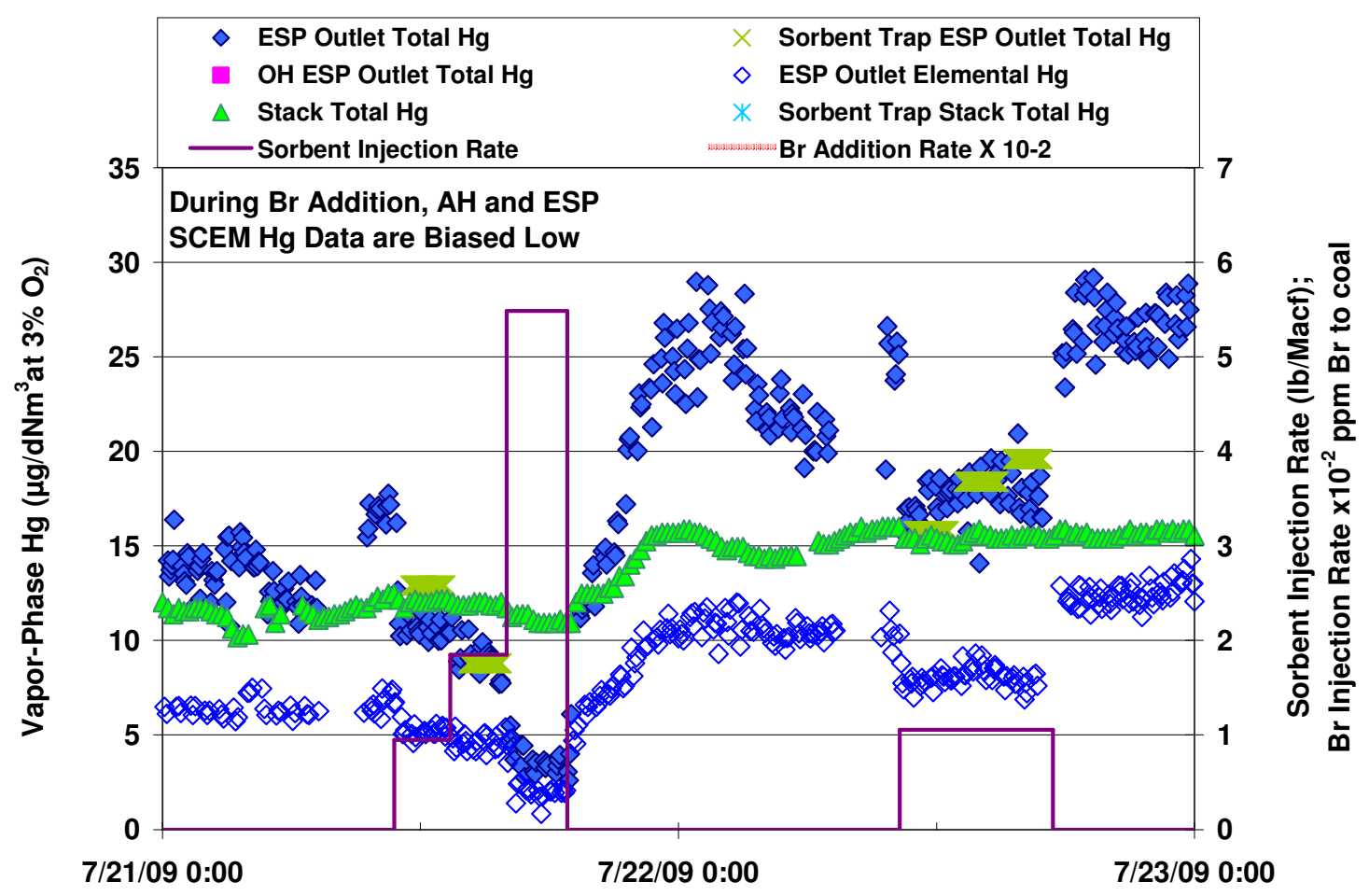

Figure K-48. Flue Gas Hg Concentrations for ESP Outlet and Stack 7/21-7/23 


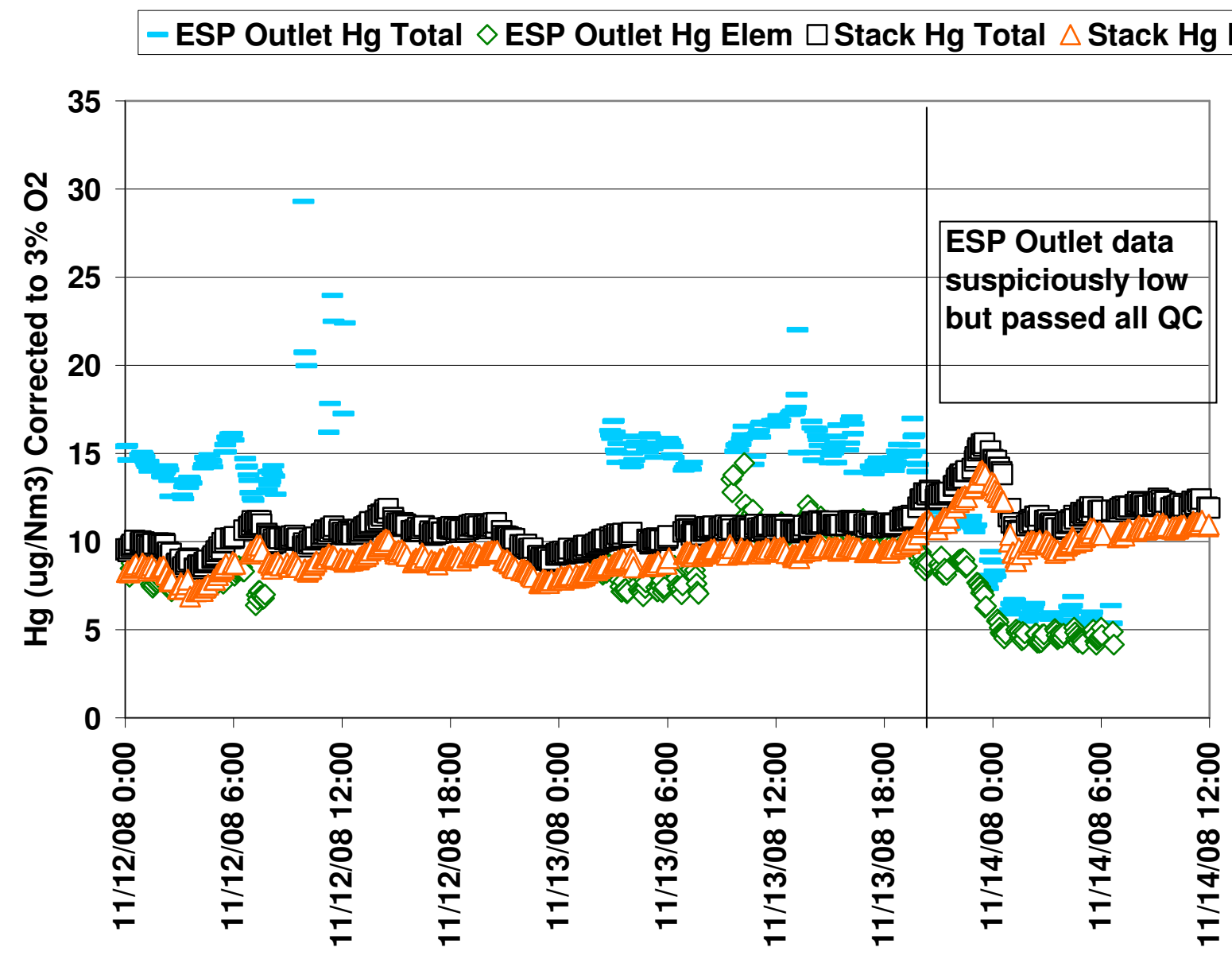

Figure K-49. Baseline Flue Gas Hg Concentrations with FGD in Inhibited Oxidation Mode 
APPENDIX L M29 RUN DATA 
Table L-1. Summary of Method 29 ESP Outlet Data for TRI Metals (ug/ $\mathrm{Nm}^{3}$, dry, $3 \% \mathrm{O}_{2}$ )

\begin{tabular}{|c|c|c|c|c|c|c|c|c|c|c|c|c|}
\hline $\begin{array}{c}\text { Date/Run } \\
\text { number }\end{array}$ & $\begin{array}{c}\mathbf{A s} \\
\text { particulate }\end{array}$ & $\begin{array}{l}\text { As } \\
\text { gas }\end{array}$ & $\begin{array}{c}\text { As } \\
\text { gas+part }\end{array}$ & $\begin{array}{c}\text { Be } \\
\text { gas+part }\end{array}$ & $\begin{array}{c}\text { Cd } \\
\text { gas+part }\end{array}$ & $\begin{array}{c}\text { Co } \\
\text { gas+part }\end{array}$ & $\begin{array}{c}\mathbf{C r} \\
\text { gas+part }\end{array}$ & $\begin{array}{c}\text { Mn } \\
\text { gas+part }\end{array}$ & $\begin{array}{c}\mathbf{N i} \\
\text { gas+part }\end{array}$ & $\begin{array}{c}\mathbf{P b} \\
\text { gas+part }\end{array}$ & $\begin{array}{c}\text { Sb } \\
\text { gas+part }\end{array}$ & $\begin{array}{c}\text { Se } \\
\text { gas+part }\end{array}$ \\
\hline $7 / 12 / 09-1$ & $<0.038$ & $<0.838$ & $<0.876$ & 0.07 & $<0.115$ & 0.77 & 5.56 & 15.62 & 5.40 & 7.30 & $<0.58$ & 815.91 \\
\hline 7/12/09-2 & $<0.038$ & $<0.878$ & $<0.915$ & 0.03 & $<0.111$ & 0.30 & 4.33 & 22.37 & 7.07 & $<1.88$ & $<0.52$ & 931.07 \\
\hline $7 / 12 / 09-3$ & $<0.039$ & $<0.851$ & $<0.890$ & 0.03 & $<0.101$ & 0.32 & $<5.31$ & 29.10 & $<4.37$ & $<1.70$ & $<0.50$ & 859.34 \\
\hline $7 / 13 / 09-1$ & 0.500 & $<0.834$ & $<1.334$ & 0.17 & $<0.157$ & 1.81 & 5.87 & 43.74 & $<5.05$ & 8.68 & $<0.78$ & 883.21 \\
\hline $7 / 13 / 09-2$ & $<0.039$ & $<0.886$ & $<0.925$ & 0.06 & $<0.114$ & 0.97 & $<5.63$ & 72.11 & $<4.39$ & 1.80 & $<0.57$ & 865.13 \\
\hline 7/13/09-3 & $<0.037$ & $<0.908$ & $<0.945$ & 0.04 & $<0.121$ & 0.62 & $<5.71$ & 17.33 & $<4.21$ & 1.84 & $<0.55$ & 368.28 \\
\hline $7 / 14 / 09-1$ & 1.07 & $<0.955$ & $<2.024$ & 0.23 & $<0.168$ & 3.25 & 9.93 & 144.68 & $<6.64$ & 7.32 & $<1.11$ & 876.06 \\
\hline 7/14/09-2 & 1.40 & $<0.920$ & $<2.309$ & 0.25 & $<0.249$ & 3.61 & 9.82 & 63.39 & $<6.46$ & 7.34 & $<1.14$ & 852.77 \\
\hline 7/14/09-3 & 1.14 & $<0.938$ & $<2.081$ & 0.20 & $<0.175$ & 3.37 & 9.16 & 113.35 & $<6.30$ & 6.39 & $<1.05$ & 734.88 \\
\hline
\end{tabular}

Table L-2. Summary of Method 29 ESP Outlet Data for Mercury (ug/ $\mathrm{Nm}^{3}$, dry, $3 \% \mathrm{O}_{2}$ )

\begin{tabular}{|c|c|c|c|}
\hline $\begin{array}{c}\text { Date/Run } \\
\text { number }\end{array}$ & $\begin{array}{c}\text { Hg } \\
\text { particulate. }\end{array}$ & $\begin{array}{c}\text { Hg } \\
\text { gas }\end{array}$ & $\begin{array}{c}\text { Hg } \\
\text { gas+part }\end{array}$ \\
\hline $7 / 12 / 09-1$ & 0.01 & 14.77 & 14.78 \\
\hline $7 / 12 / 09-2$ & 0.05 & 14.05 & 14.10 \\
\hline $7 / 12 / 09-3$ & 0.09 & 13.17 & 13.26 \\
\hline $7 / 13 / 09-1$ & 0.01 & 18.24 & 18.25 \\
\hline $7 / 13 / 09-2$ & 0.01 & 26.99 & 27.00 \\
\hline $7 / 13 / 09-3$ & 0.00 & 33.74 & 33.75 \\
\hline $7 / 14 / 09-1$ & 0.10 & 15.61 & 15.72 \\
\hline $7 / 14 / 09-2$ & 0.14 & 11.52 & 11.66 \\
\hline $7 / 14 / 09-3$ & 0.04 & 15.64 & 15.68 \\
\hline
\end{tabular}

Table L-3. Summary of Method 29 ESP Outlet Data for Other Metals (ug/ $/ \mathrm{Nm}^{3}$, dry, $3 \% \mathrm{O}_{2}$ )

\begin{tabular}{|c|c|c|c|c|c|c|c|c|c|c|c|c|}
\hline $\begin{array}{c}\text { Date/Run } \\
\text { number }\end{array}$ & $\begin{array}{c}\text { Al } \\
\text { gas+part }\end{array}$ & $\begin{array}{c}\text { Ag } \\
\text { gas+part }\end{array}$ & $\begin{array}{c}\text { Ba } \\
\text { gas+part }\end{array}$ & $\begin{array}{c}\mathbf{C u} \\
\text { gas+part }\end{array}$ & $\begin{array}{c}\mathbf{F e} \\
\text { gas+part }\end{array}$ & $\begin{array}{c}\text { Mo } \\
\text { gas+part }\end{array}$ & $\begin{array}{c}\text { Sn } \\
\text { gas+part }\end{array}$ & $\begin{array}{c}\mathbf{S r} \\
\text { gas+part }\end{array}$ & $\begin{array}{c}\mathbf{T i} \\
\text { gas+part }\end{array}$ & $\begin{array}{c}\mathbf{T l} \\
\text { gas+part }\end{array}$ & $\begin{array}{c}\mathbf{V} \\
\text { gas+part }\end{array}$ & $\begin{array}{c}\mathbf{Z n} \\
\text { gas+part }\end{array}$ \\
\hline $7 / 12 / 09-1$ & 2046.1 & $<0.36$ & 76.81 & 4.10 & 732.7 & 5.62 & $<6.98$ & 64.31 & 131.05 & $<0.126$ & 7.54 & 20.99 \\
\hline $7 / 12 / 09-2$ & 902.7 & $<0.34$ & 38.87 & 4.09 & 274.1 & 4.95 & $<6.00$ & 29.24 & 59.70 & $<0.106$ & 3.57 & 15.31 \\
\hline $7 / 12 / 09-3$ & 809.0 & $<0.31$ & 38.95 & 2.41 & 394.8 & 6.15 & 7.13 & 28.06 & 53.08 & $<0.101$ & 3.06 & 8.44 \\
\hline $7 / 13 / 09-1$ & 5553.7 & $<0.53$ & 243.39 & 6.56 & 1327.9 & 6.11 & 5.97 & 193.62 & 340.71 & $<0.170$ & 19.45 & 17.22 \\
\hline $7 / 13 / 09-2$ & 1681.8 & $<0.41$ & 87.81 & 3.51 & 824.0 & 6.66 & $<2.60$ & 71.81 & 100.24 & $<0.116$ & 6.16 & 13.65 \\
\hline 7/13/09-3 & 1309.0 & $<0.35$ & 57.01 & 2.97 & 558.1 & 5.49 & $<2.65$ & 48.10 & 82.71 & $<0.112$ & 4.96 & 18.26 \\
\hline $7 / 14 / 09-1$ & 9136.4 & 0.66 & 336.51 & 10.30 & 2016.5 & 7.34 & $<3.43$ & 330.39 & 574.49 & $<0.236$ & 30.85 & 18.94 \\
\hline $7 / 14 / 09-2$ & 9707.4 & 0.62 & 344.39 & 9.89 & 2352.1 & 7.41 & $<3.55$ & 329.90 & 594.76 & $<0.252$ & 31.68 & 20.99 \\
\hline $7 / 14 / 09-3$ & 7394.3 & 0.59 & 281.48 & 8.89 & 2003.4 & 7.12 & $<3.22$ & 277.69 & 484.34 & $<0.222$ & 26.48 & 21.81 \\
\hline
\end{tabular}


Table L-4. Summary of Method 29 Stack data for TRI metals ( $\mathrm{ug} / \mathrm{Nm}^{3}$, dry, $3 \% \mathrm{O}_{2}$ )

\begin{tabular}{|c|c|c|c|c|c|c|c|c|c|c|c|c|}
\hline $\begin{array}{c}\text { Date/Run } \\
\text { number }\end{array}$ & $\begin{array}{c}\mathbf{A s} \\
\text { particulate }\end{array}$ & $\begin{array}{l}\text { As } \\
\text { gas }\end{array}$ & $\begin{array}{c}\text { As } \\
\text { gas+part }\end{array}$ & $\begin{array}{c}\text { Be } \\
\text { gas+part }\end{array}$ & $\begin{array}{c}\text { Cd } \\
\text { gas+part }\end{array}$ & $\begin{array}{c}\text { Co } \\
\text { gas+part }\end{array}$ & $\begin{array}{c}\mathbf{C r} \\
\text { gas+part }\end{array}$ & $\begin{array}{c}\text { Mn } \\
\text { gas+part }\end{array}$ & $\begin{array}{c}\mathbf{N i} \\
\text { gas+part }\end{array}$ & $\begin{array}{c}\mathbf{P b} \\
\text { gas+part }\end{array}$ & $\begin{array}{c}\text { Sb } \\
\text { gas+part }\end{array}$ & $\begin{array}{c}\text { Se } \\
\text { gas+part }\end{array}$ \\
\hline $7 / 12 / 09-1$ & $<0.038$ & $<0.946$ & $<0.984$ & $<0.01$ & $<0.150$ & 0.24 & $<4.45$ & 29.1 & $<3.74$ & $<2.42$ & $<0.56$ & 117.59 \\
\hline $7 / 12 / 09-2$ & $<0.038$ & $<0.942$ & $<0.980$ & $<0.01$ & $<0.162$ & 0.19 & $<4.61$ & 20.3 & $<3.42$ & $<2.12$ & $<0.55$ & 108.05 \\
\hline $7 / 12 / 09-3$ & $<0.038$ & $<1.009$ & $<1.047$ & $<0.02$ & 0.439 & 0.20 & $<5.32$ & 19.0 & $<4.41$ & $<2.45$ & $<0.58$ & 138.15 \\
\hline $7 / 13 / 09-1$ & $<0.040$ & $<0.975$ & $<1.015$ & $<0.01$ & $<0.126$ & 0.23 & $<4.48$ & 59.5 & 5.60 & $<1.92$ & $<0.57$ & 100.70 \\
\hline $7 / 13 / 09-2$ & $<0.039$ & $<0.995$ & $<1.034$ & $<0.02$ & $<0.118$ & 0.22 & $<4.68$ & 82.6 & $<4.00$ & $<1.88$ & $<0.58$ & 89.15 \\
\hline $7 / 13 / 09-3$ & $<0.039$ & $<0.983$ & $<1.022$ & $<0.01$ & $<0.123$ & $<0.26$ & $<3.80$ & 76.3 & $<3.57$ & $<1.70$ & $<0.57$ & 92.85 \\
\hline $7 / 14 / 09-1$ & $<0.037$ & $<1.025$ & $<1.062$ & 0.02 & $<0.139$ & 0.55 & 43.47 & 130.1 & 9.14 & $<2.53$ & $<0.66$ & 87.01 \\
\hline $7 / 14 / 09-2$ & $<0.038$ & $<0.998$ & $<1.036$ & 0.02 & $<0.126$ & 0.48 & 5.34 & 65.3 & $<5.57$ & $<2.33$ & $<0.64$ & 83.37 \\
\hline 7/14/09-3 & $<0.037$ & $<0.972$ & $<1.009$ & $<0.01$ & $<0.112$ & 0.35 & $<5.07$ & 62.7 & $<4.42$ & 2.34 & $<0.58$ & 91.03 \\
\hline
\end{tabular}

Table L-5. Summary of Method 29 Stack data for Mercury (ug/ $/ \mathrm{Nm}^{3}$, dry, $3 \% \mathrm{O}_{2}$ )

\begin{tabular}{|c|c|c|c|}
\hline $\begin{array}{c}\text { Date/Run } \\
\text { number }\end{array}$ & $\begin{array}{c}\text { Hg } \\
\text { particulate. }\end{array}$ & $\begin{array}{c}\text { Hg } \\
\text { gas }\end{array}$ & $\begin{array}{c}\text { Hg } \\
\text { gas+part }\end{array}$ \\
\hline $7 / 12 / 09-1$ & 0.53 & 7.11 & 7.64 \\
\hline $7 / 12 / 09-2$ & 0.39 & 7.87 & 8.25 \\
\hline $7 / 12 / 09-3$ & 0.35 & 7.41 & 7.76 \\
\hline $7 / 13 / 09-1$ & 0.24 & 15.28 & 15.52 \\
\hline $7 / 13 / 09-2$ & 0.14 & 14.02 & 14.17 \\
\hline $7 / 13 / 09-3$ & 0.28 & 21.11 & 21.39 \\
\hline $7 / 14 / 09-1$ & 0.13 & 9.45 & 9.58 \\
\hline $7 / 14 / 09-2$ & 0.24 & 6.91 & 7.15 \\
\hline $7 / 14 / 09-3$ & 0.18 & 8.54 & 8.72 \\
\hline
\end{tabular}

Table L-6. Summary of Method 29 Stack data for other trace metals (ug/ $/ \mathrm{Nm}^{3}$, dry, $3 \% \mathrm{O}_{2}$ )

\begin{tabular}{|c|c|c|c|c|c|c|c|c|c|c|c|c|}
\hline $\begin{array}{c}\text { Date/Run } \\
\text { number }\end{array}$ & $\begin{array}{c}\text { Al } \\
\text { gas+part }\end{array}$ & $\begin{array}{c}\mathbf{A g} \\
\text { gas+part }\end{array}$ & $\begin{array}{c}\text { Ba } \\
\text { gas+part }\end{array}$ & $\begin{array}{c}\mathbf{C u} \\
\text { gas+part }\end{array}$ & $\begin{array}{c}\mathbf{F e} \\
\text { gas+part }\end{array}$ & $\begin{array}{c}\text { Mo } \\
\text { gas+part }\end{array}$ & $\begin{array}{c}\text { Sn } \\
\text { gas+part }\end{array}$ & $\begin{array}{c}\mathbf{S r} \\
\text { gas+part }\end{array}$ & $\begin{array}{c}\mathbf{T i} \\
\text { gas+part }\end{array}$ & $\begin{array}{c}\mathbf{T l} \\
\text { gas+part }\end{array}$ & $\begin{array}{c}\mathbf{V} \\
\text { gas+part }\end{array}$ & $\begin{array}{c}\mathbf{Z n} \\
\text { gas+part }\end{array}$ \\
\hline $7 / 12 / 09-1$ & 684.10 & $<0.47$ & 30.39 & 2.15 & 180.81 & 5.3 & $<2.75$ & 21.04 & 43.76 & $<0.11$ & 2.81 & 15.96 \\
\hline $7 / 12 / 09-2$ & 572.45 & $<0.35$ & 25.74 & 1.70 & 164.16 & 5.2 & $<2.73$ & 17.42 & 35.08 & $<0.11$ & 2.19 & 15.91 \\
\hline $7 / 12 / 09-3$ & 574.22 & $<0.41$ & 28.13 & 2.18 & 295.33 & 5.8 & $<2.90$ & 17.77 & 36.39 & $<0.12$ & 2.27 & 21.23 \\
\hline $7 / 13 / 09-1$ & 816.29 & $<0.34$ & 41.79 & 1.84 & 207.03 & 5.5 & $<2.85$ & 24.51 & 48.45 & $<0.11$ & 3.12 & 8.60 \\
\hline $7 / 13 / 09-2$ & 720.37 & $<0.33$ & 34.03 & 2.03 & 185.24 & 5.3 & $<2.88$ & 21.77 & 42.32 & $<0.12$ & 2.73 & 12.31 \\
\hline $7 / 13 / 09-3$ & 540.48 & $<0.32$ & 25.98 & 1.62 & 152.38 & 5.5 & $<2.85$ & 18.41 & 32.30 & $<0.11$ & 2.04 & 9.52 \\
\hline $7 / 14 / 09-1$ & 1521.75 & $<0.34$ & 64.20 & 2.89 & 573.23 & 7.7 & $<2.93$ & 53.37 & 94.36 & $<0.13$ & 6.29 & 12.70 \\
\hline $7 / 14 / 09-2$ & 1507.44 & $<0.33$ & 64.08 & 3.26 & 360.03 & 5.8 & $<2.87$ & 48.04 & 94.55 & $<0.13$ & 6.46 & 10.54 \\
\hline $7 / 14 / 09-3$ & 1019.34 & $<0.32$ & 43.99 & 2.72 & 261.07 & 5.5 & $<2.94$ & 32.27 & 66.32 & $<0.11$ & 4.34 & 7.04 \\
\hline
\end{tabular}


Table L-7. Comparison Summary of ESP Outlet XFM and Method 29 Results for TRI Metals (ug/ $\mathrm{Nm}^{3}, \mathrm{dry}, 3 \% \mathrm{O}_{2}$ )

\begin{tabular}{|c|c|c|c|c|c|c|c|c|c|c|c|c|c|c|c|c|c|c|c|c|}
\hline Date & \multicolumn{2}{|c|}{ Hg } & \multicolumn{2}{|c|}{ As } & \multicolumn{2}{|c|}{ Cd } & \multicolumn{2}{|c|}{ Co } & \multicolumn{2}{|c|}{ Cr } & \multicolumn{2}{c|}{ Mn } & \multicolumn{2}{|c|}{ Ni } & \multicolumn{2}{|c|}{ Pb } & \multicolumn{2}{|c|}{ Sb } & \multicolumn{2}{|c|}{ Se } \\
\hline Method & XFM & M29 & XFM & M29 & XFM & M29 & XFM & M29 & XFM & M29 & XFM & M29 & XFM & M29 & XFM & M29 & XFM & M29 & XFM & M29 \\
\hline $7 / 12 / 09$ & 12.3 & 14.0 & $<0.7$ & $<0.9$ & $<1.0$ & $<0.1$ & 1.6 & 0.5 & 6.4 & 5.1 & 14.5 & 22.4 & 8.1 & 5.6 & 3.4 & 3.6 & $<0.7$ & $<0.5$ & 372.7 & 868.8 \\
\hline $7 / 13 / 09$ & 25.7 & 26.3 & $<0.3$ & $<1.1$ & $<0.6$ & $<0.1$ & 0.8 & 1.1 & 6.9 & $<5.7$ & 16.2 & 44.4 & 15.7 & $<4.5$ & 2.8 & 4.1 & $<2.8$ & $<0.6$ & 684.4 & 705.5 \\
\hline $7 / 14 / 09$ & 13.7 & 9.9 & 0.6 & $<2.1$ & $<1.1$ & $<0.2$ & 0.5 & 3.4 & 6.3 & 9.6 & 20.3 & 107.1 & 4.9 & $<6.5$ & 4.1 & 7.0 & $<6.4$ & $<1.1$ & 684.2 & 821.2 \\
\hline
\end{tabular}

Table L-8. Comparison Summary of ESP Outlet XFM and Method 29 Results for Other Trace Metals (ug/Nm ${ }^{3}, \mathrm{dry}, 3 \% \mathrm{O}_{2}$ )

\begin{tabular}{|c|c|c|c|c|c|c|c|c|c|c|c|c|c|c|c|c|c|c|c|c|}
\hline Date & \multicolumn{2}{|c|}{ Ag } & \multicolumn{2}{|c|}{$\mathbf{B a}$} & \multicolumn{2}{|c|}{$\mathrm{Cu}$} & \multicolumn{2}{|c|}{$\mathbf{F e}$} & \multicolumn{2}{|c|}{ Mo } & \multicolumn{2}{|c|}{ Sn } & \multicolumn{2}{|c|}{$\mathrm{Sr}$} & \multicolumn{2}{|c|}{$\mathbf{T i}$} & \multicolumn{2}{|c|}{$\mathbf{V}$} & \multicolumn{2}{|c|}{ Zn } \\
\hline Method & XFM & M29 & XFM & M29 & XFM & M29 & XFM & M29 & $\overline{X F M}$ & M29 & XFM & M29 & XFM & M29 & $\overline{X F M}$ & M29 & XFM & M29 & XFM & M29 \\
\hline $\begin{array}{l}7 / 12 / 09 \\
\end{array}$ & $<1.5$ & $<0.3$ & $<68.1$ & 51.5 & 2.3 & 3.5 & 512.4 & 467.2 & $<0.7$ & 5.6 & $<2.5$ & $<6.7$ & & & & & & & & \\
\hline $7 / 13 / 09$ & $<1.0$ & $<0.4$ & 95.0 & 129.4 & 2.3 & 4.3 & 557.0 & 903.3 & $<1.0$ & 6.1 & $<3.7$ & $<3.7$ & & & & & & & & \\
\hline $7 / 14 / 09$ & $<0.7$ & 0.6 & 121.9 & 320.8 & 3.1 & 9.7 & 705.3 & 2124.0 & 1.3 & 7.3 & $<2.8$ & $<3.4$ & & & & & & & & \\
\hline
\end{tabular}

Table L-9. Comparison Summary of Stack XFM and Method 29 Results for TRI Metals (ug/Nm ${ }^{3}$, dry, $3 \% \mathrm{O}_{2}$ )

\begin{tabular}{|c|c|c|c|c|c|c|c|c|c|c|c|c|c|c|c|c|c|c|c|c|}
\hline Date & \multicolumn{2}{|c|}{ Hg } & \multicolumn{2}{|c|}{ As } & \multicolumn{2}{|c|}{ Cd } & \multicolumn{2}{|c|}{ Co } & \multicolumn{2}{|c|}{$\mathrm{Cr}$} & \multicolumn{2}{|c|}{ Mn } & \multicolumn{2}{|c|}{$\mathbf{N i}$} & \multicolumn{2}{|c|}{$\mathbf{P b}$} & \multicolumn{2}{|c|}{$\mathrm{Sb}$} & \multicolumn{2}{|c|}{$\mathrm{Se}$} \\
\hline Method & XFM & $\overline{\text { M29 }}$ & XFM & M29 & XFM & M29 & XFM & M29 & XFM & M29 & XFM & M29 & XFM & M29 & XFM & M29 & $\overline{X F M}$ & M29 & XFM & M29 \\
\hline $7 / 12 / 09$ & 10.6 & 7.9 & N/A & $<1.0$ & $<1.0$ & $<0.3$ & $<0.2$ & 0.5 & $<1.1$ & $<4.8$ & 15.8 & 22.8 & 0.5 & $<3.9$ & $<1.5$ & $<2.3$ & $<2.8$ & $<0.6$ & 83.6 & 121.3 \\
\hline $7 / 13 / 09$ & 17.9 & 17.0 & N/A & $<1.0$ & $<0.4$ & $<0.1$ & 0.4 & 0.2 & $<1.3$ & $<4.3$ & 16.9 & 72.8 & 0.8 & $<4.4$ & 1.5 & $<1.8$ & $<1.7$ & $<0.6$ & 80.6 & 94.2 \\
\hline $7 / 14 / 09$ & 9.9 & 8.5 & N/A & $<1.0$ & $<0.8$ & $<0.1$ & 0.4 & 0.2 & 1.8 & $<5.2$ & 18.4 & 86.0 & 0.7 & $<6.4$ & 1.1 & $<2.4$ & $<2.7$ & $<0.6$ & 88.3 & 87.1 \\
\hline
\end{tabular}

Table L-10.

\begin{tabular}{|c|c|c|c|c|c|c|c|c|c|c|c|c|c|c|c|c|c|c|c|c|}
\hline Date & \multicolumn{2}{|c|}{ Ag } & \multicolumn{2}{|c|}{$\mathbf{B a}$} & \multicolumn{2}{|c|}{$\mathrm{Cu}$} & \multicolumn{2}{|c|}{$\mathbf{F e}$} & \multicolumn{2}{|c|}{ Mo } & \multicolumn{2}{|c|}{ Sn } & \multicolumn{2}{|c|}{$\mathbf{S r}$} & \multicolumn{2}{|c|}{$\mathbf{T i}$} & \multicolumn{2}{|c|}{$\mathbf{V}$} & \multicolumn{2}{|c|}{ Zn } \\
\hline Method & XFM & M29 & XFM & M29 & XFM & M29 & XFM & M29 & XFM & M29 & XFM & M29 & XFM & M29 & XFM & M29 & XFM & M29 & XFM & M29 \\
\hline $7 / 12 / 09$ & $<1.1$ & $<0.4$ & $<17.4$ & 28.1 & 0.5 & 2.0 & 106.6 & 213.4 & $<0.1$ & 5.5 & $<3.7$ & $<2.8$ & 13.4 & 18.7 & 30.7 & 38.4 & $<2.1$ & 2.4 & 2.1 & 17.7 \\
\hline $7 / 13 / 09$ & $<0.7$ & $<0.3$ & $<25.6$ & 33.9 & 0.7 & 1.8 & 128.0 & 181.6 & $<0.6$ & 5.4 & $<2.4$ & $<2.9$ & 17.5 & 21.6 & 37.1 & 41.0 & $<2.5$ & 2.6 & 3.9 & 10.1 \\
\hline $7 / 14 / 09$ & $<2.2$ & $<0.3$ & 57.1 & 57.4 & 1.1 & 3.0 & 229.4 & 398.1 & 1.1 & 6.3 & $<1.0$ & $<2.9$ & 29.6 & 44.6 & 67.2 & 85.1 & $<4.7$ & 5.7 & 3.1 & 10.1 \\
\hline
\end{tabular}


$\square \mathrm{BL} \square \mathrm{Br}+\mathbf{A C l} \square \mathrm{ACl}$

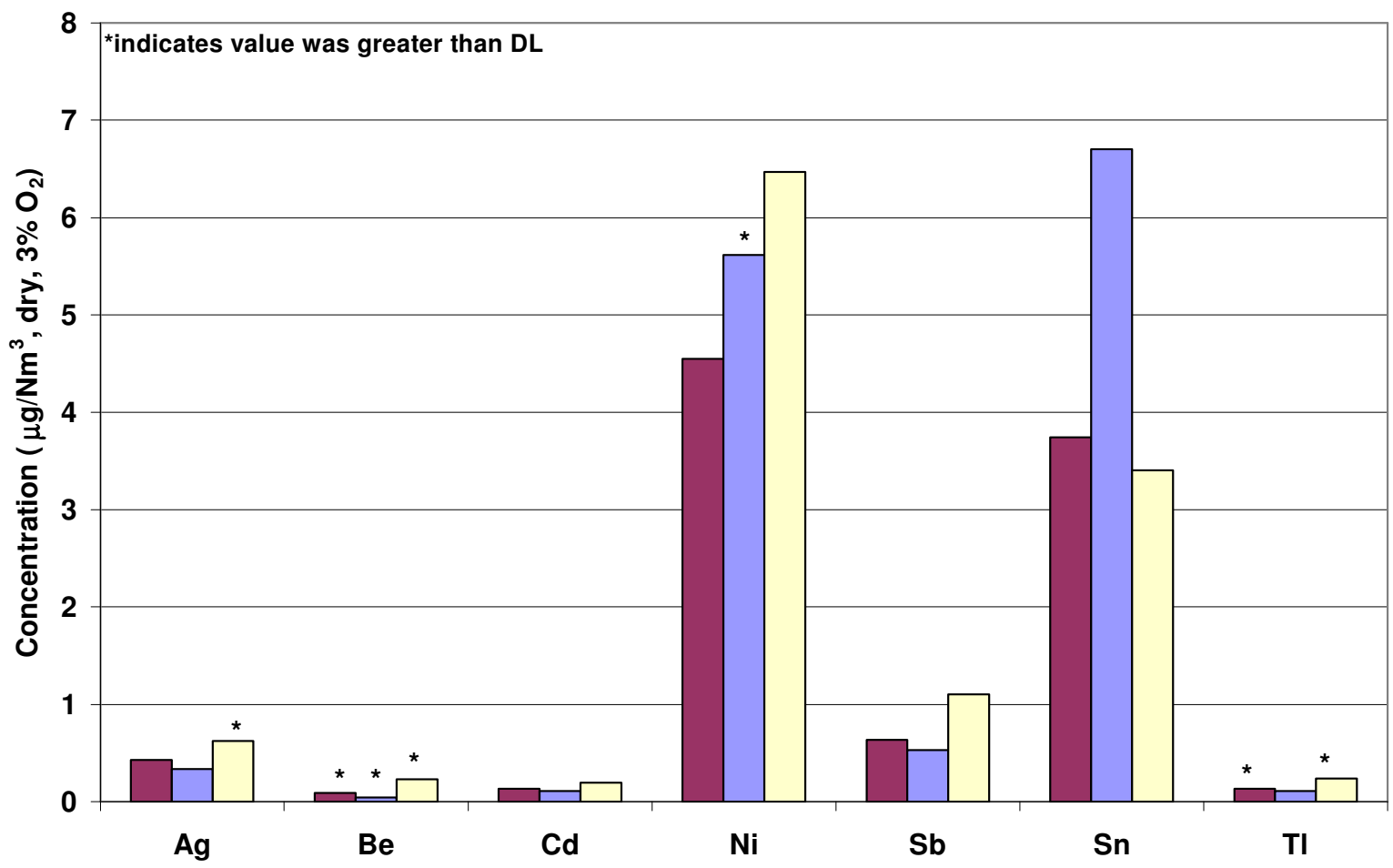

Figure L-1. Method 29 ESP Outlet Metals Below Detection Limit

$\square \mathrm{BL} \square \mathrm{Br}+\mathrm{ACl} \square \mathrm{ACl}$

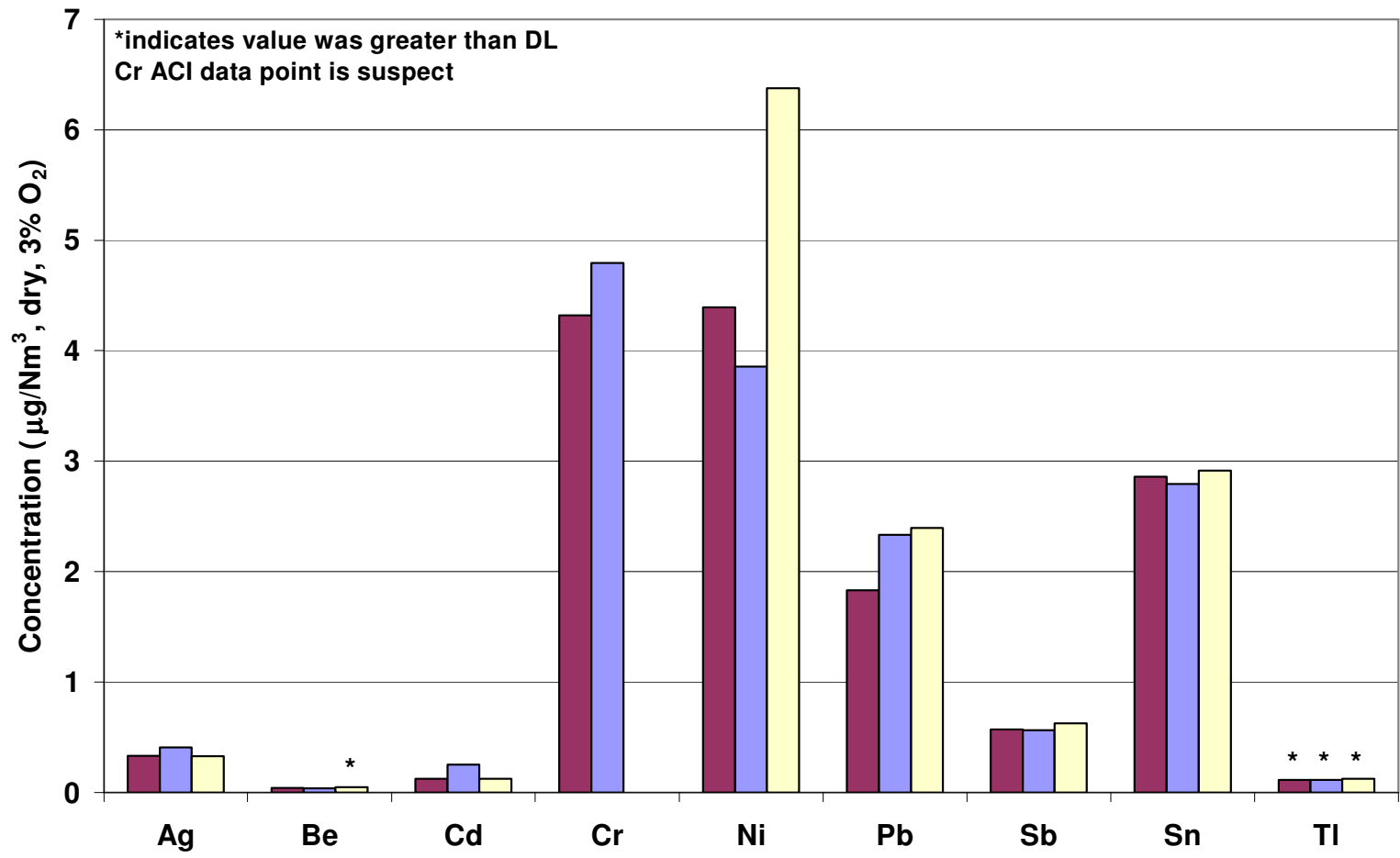

Figure L-2. Method 29 Stack Metals Below Detection Limit 
$\square \mathrm{BL} \square \mathrm{Br}+\mathrm{ACl} \square \mathrm{ACl}$

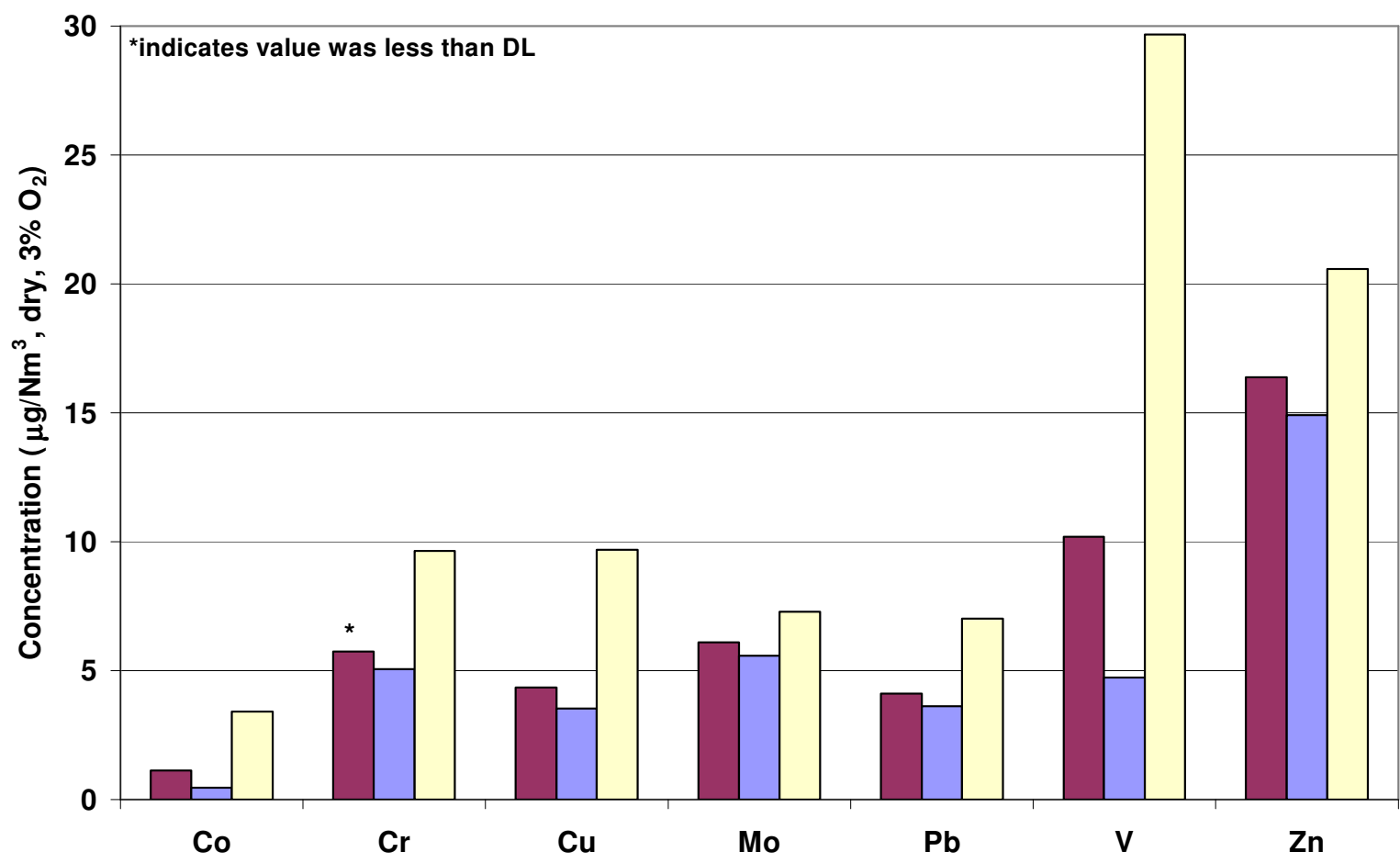

Figure L-3. Method 29 ESP Outlet Metals Near Detection Limit

$\square \mathrm{BL} \square \mathrm{Br}+\mathrm{ACl} \square \mathrm{ACl}$

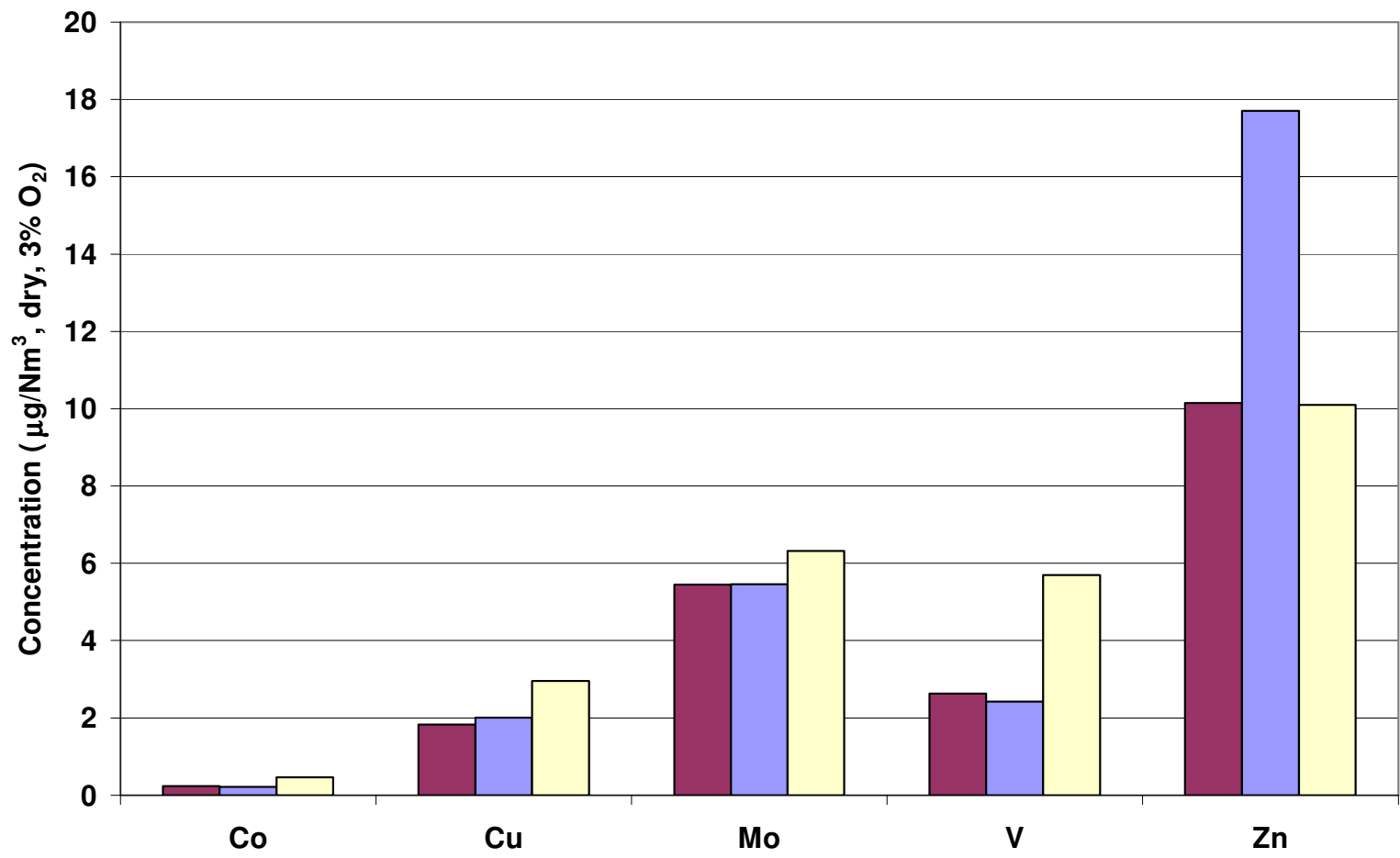

Figure L-4. Method 29 Stack Metals Near Detection Limit 


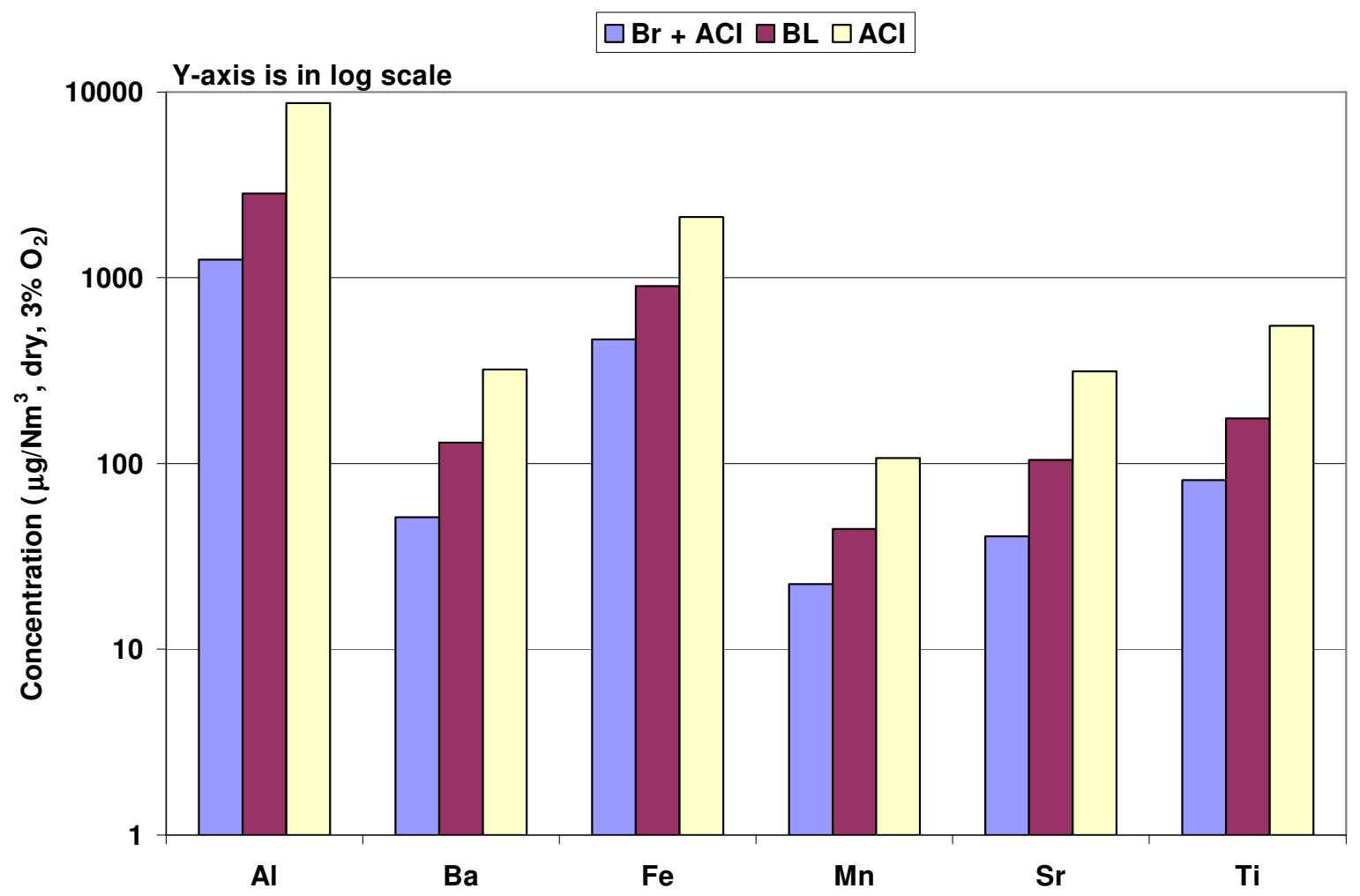

Figure L-5. Method 29 ESP Outlet Metals Greater than Detection Limit $\square \mathrm{BL} \square \mathrm{Br}+\mathrm{ACl} \square \mathrm{ACl}$

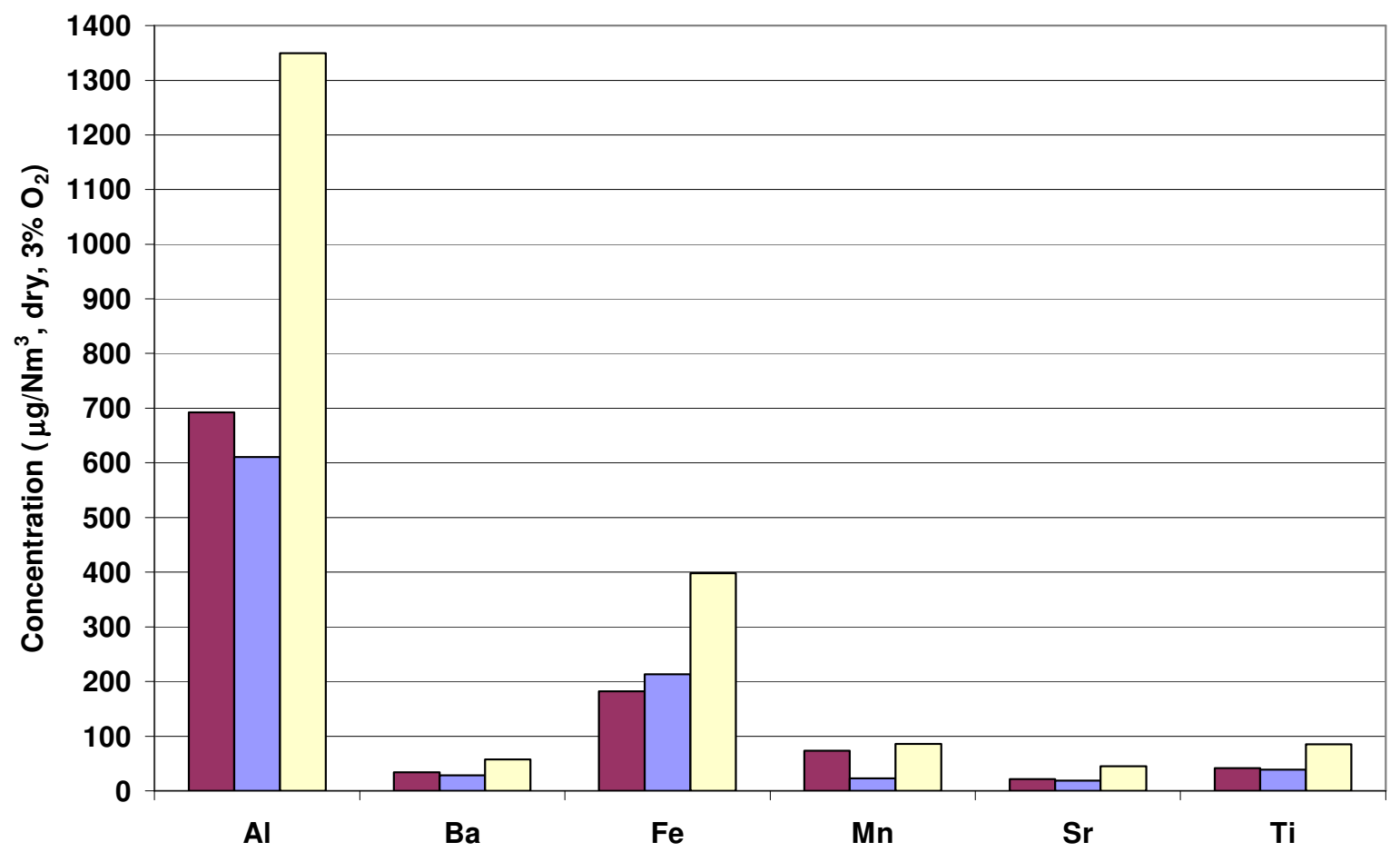

Figure L-6. Method 29 Stack Metals Greater than Detection Limit 


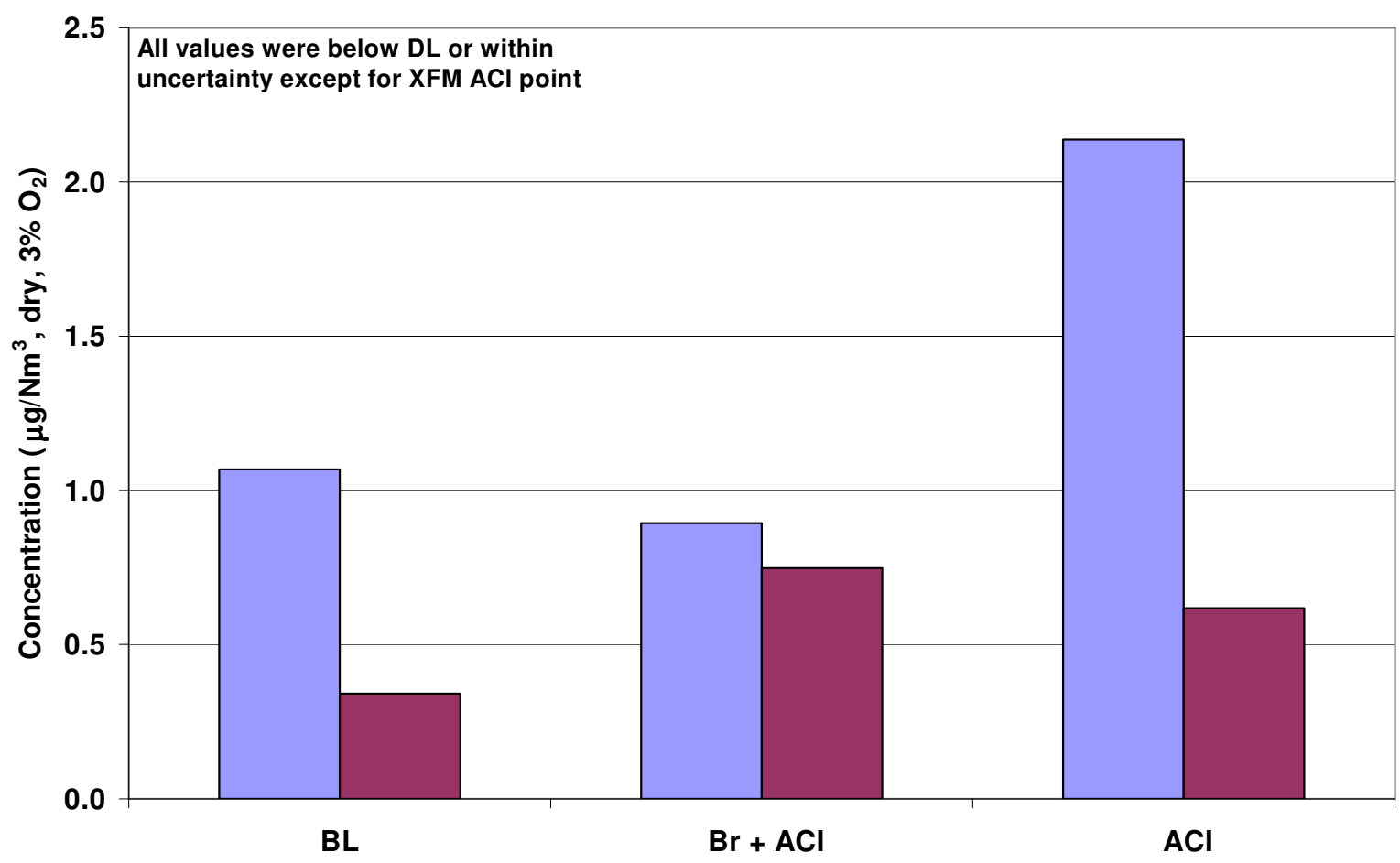

Figure L-7. Arsenic ESP Outlet Data

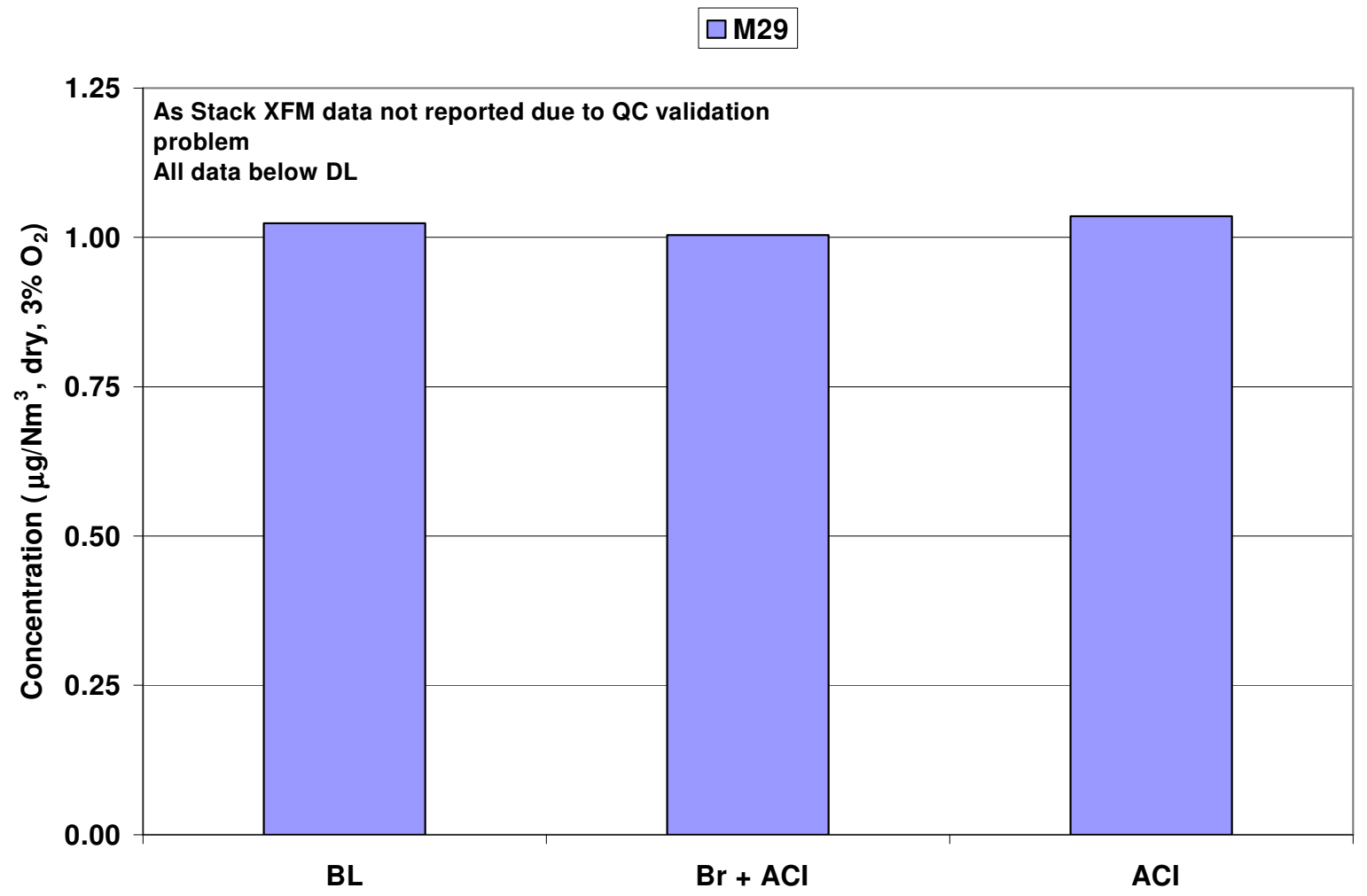

Figure L-8. Arsenic Stack Data 


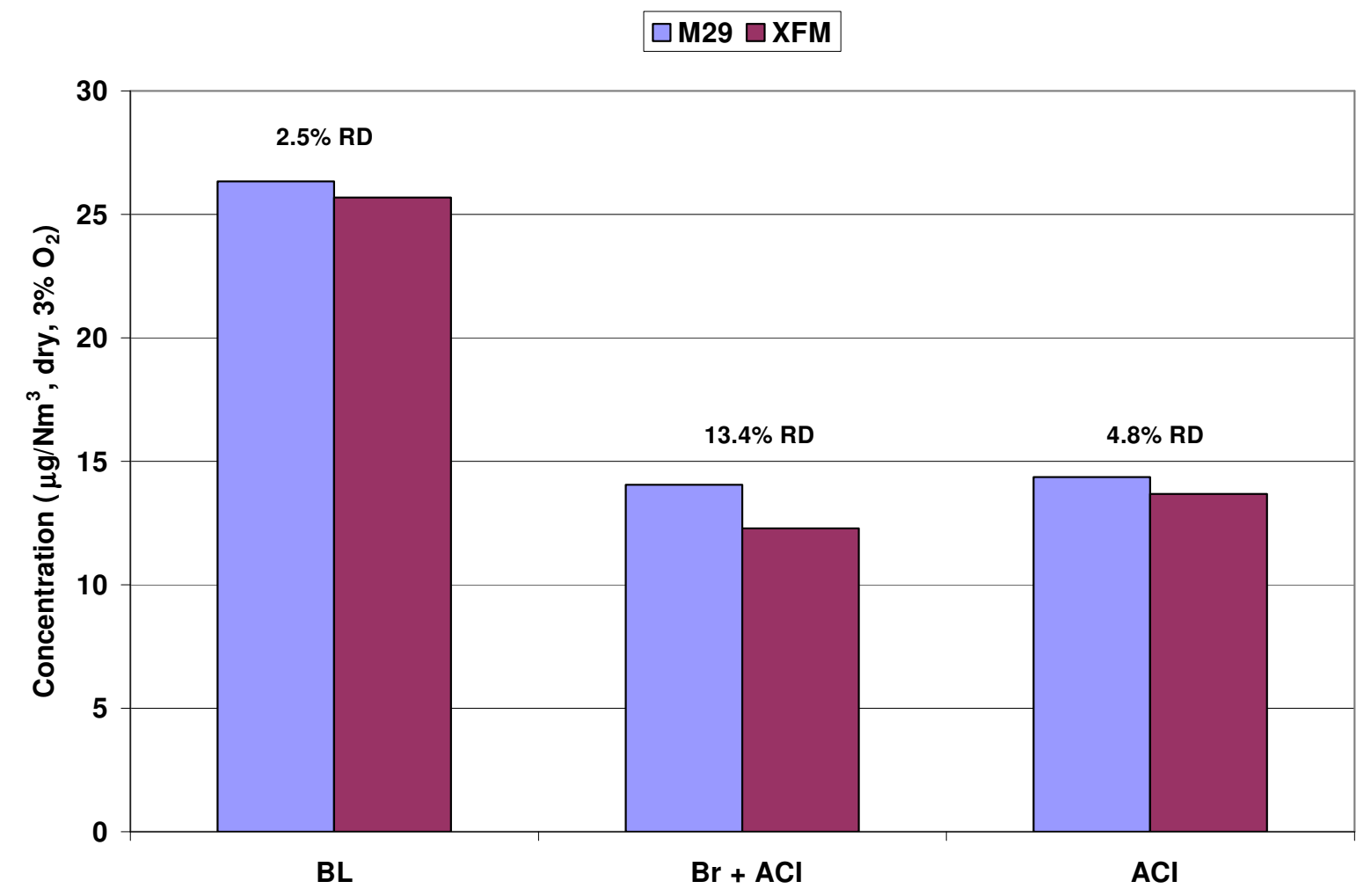

Figure L-9. Mercury ESP Outlet Data

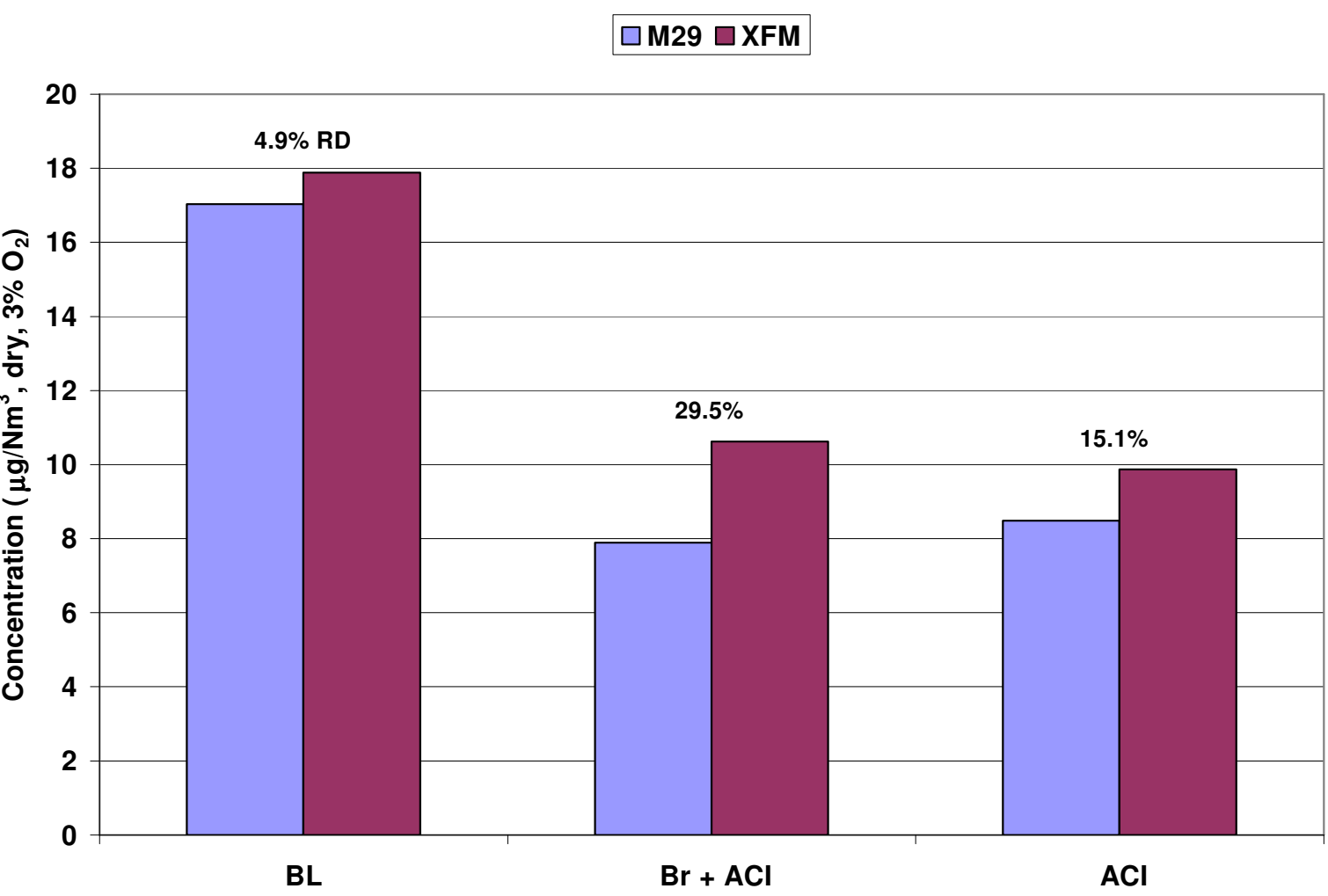

Figure L-10. Mercury Stack Data 


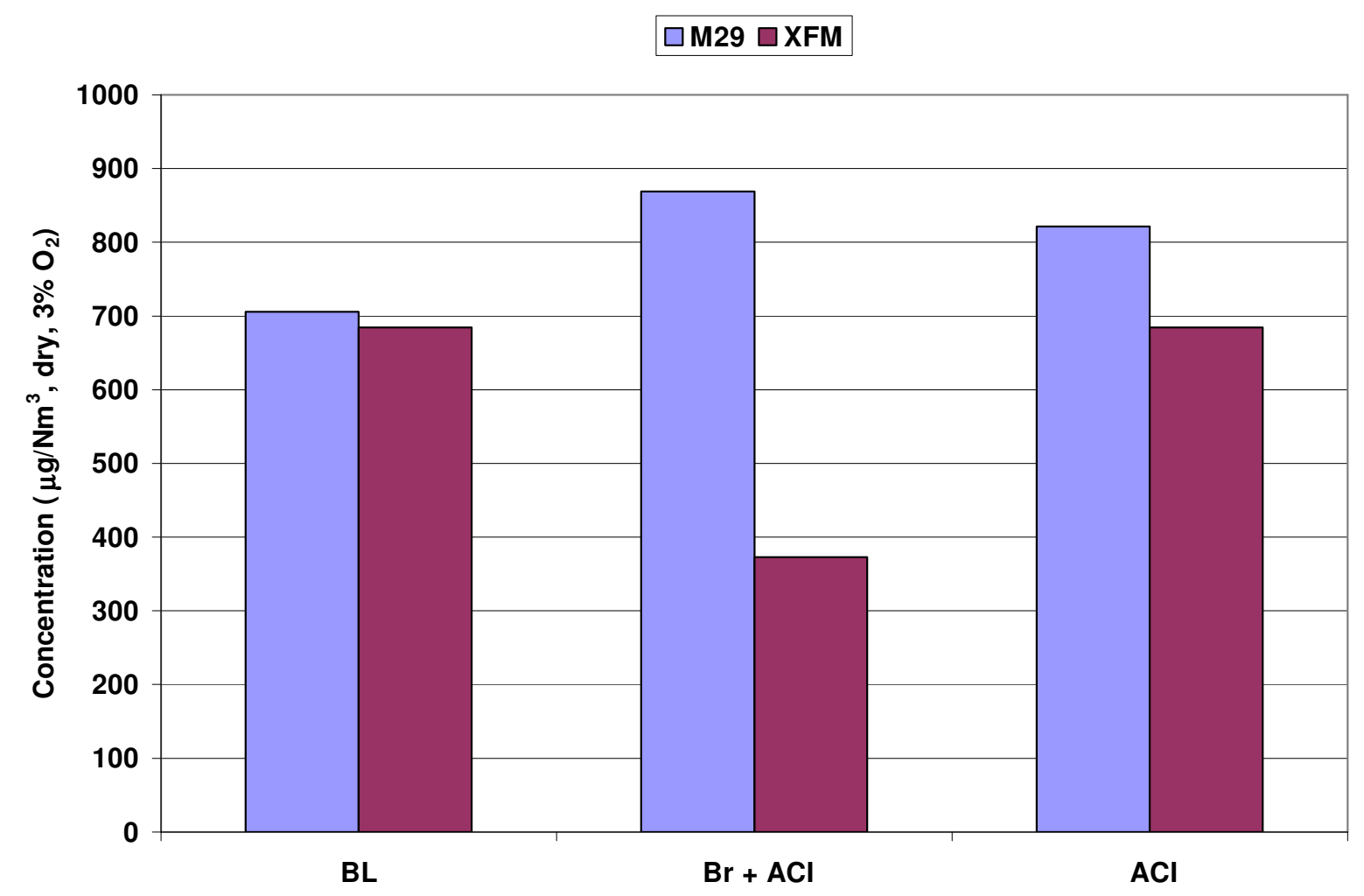

Figure L-11. Selenium ESP Outlet Data

$\square$ M29 $\square$ XFM

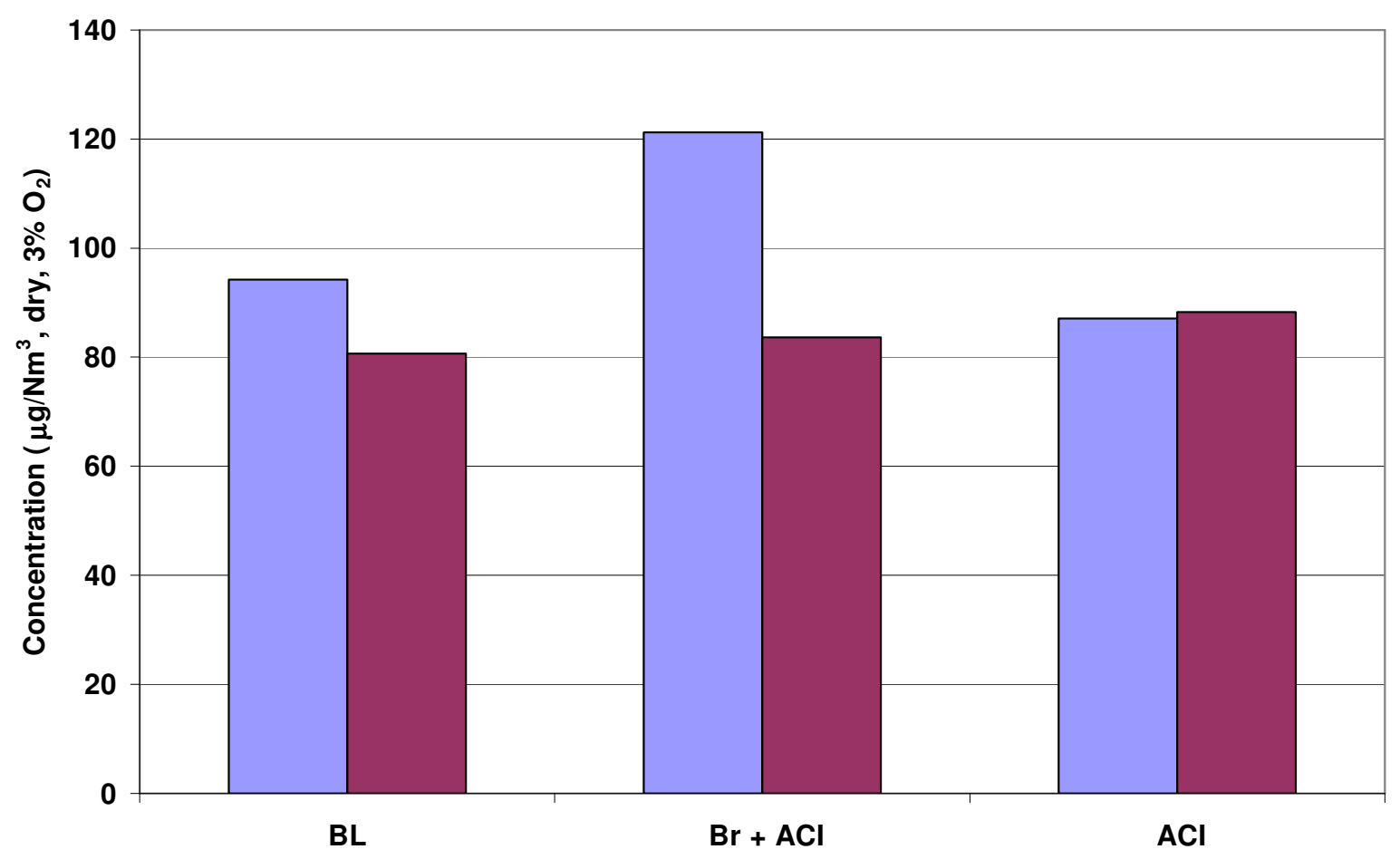

Figure L-12. Selenium Stack Data 


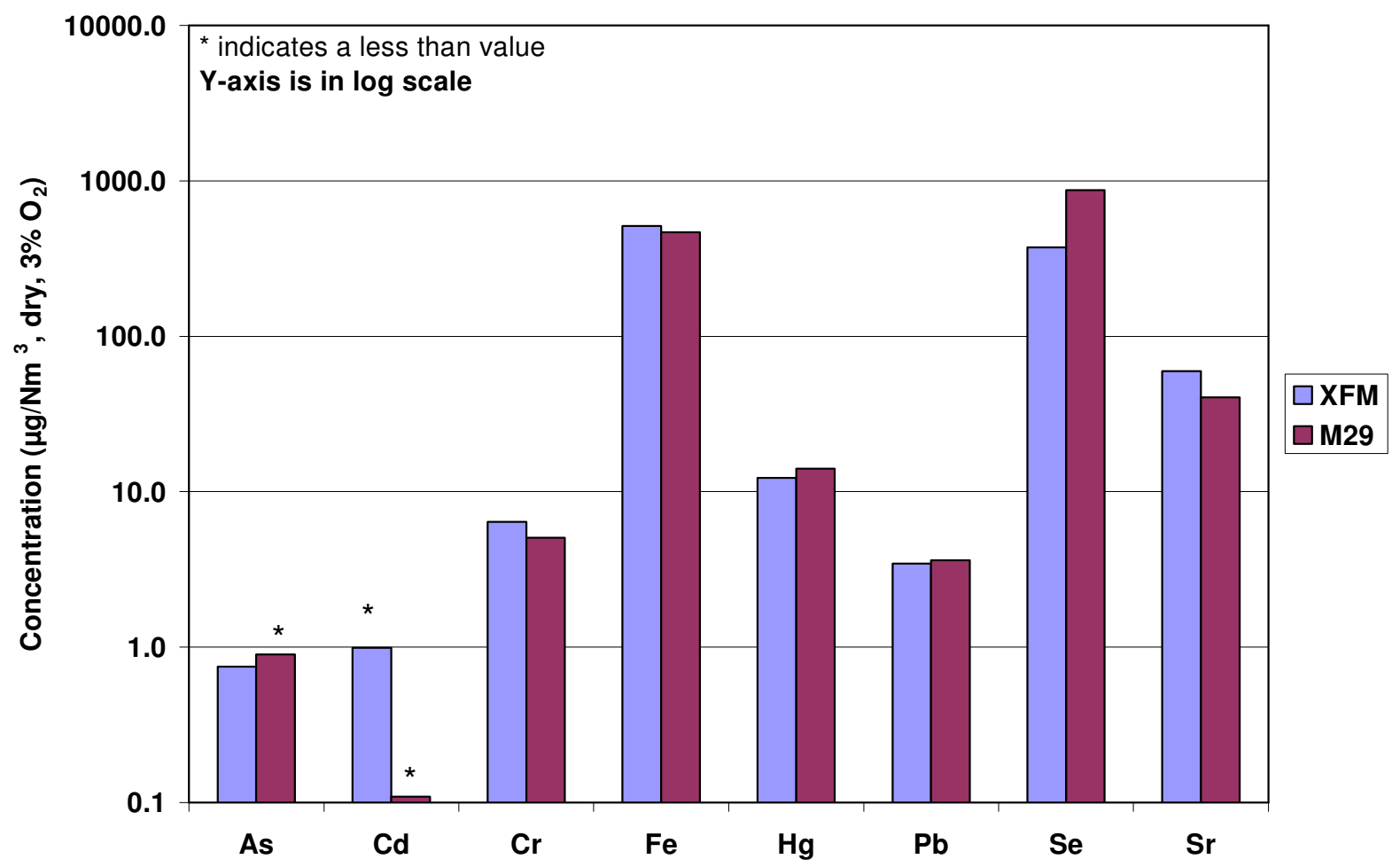

Figure L-13. Comparison of Averages from XFM and M29 for ESP Outlet 7/12/09 $\left(\mathrm{CaBr}_{2}+0.48 \mathrm{lb} / \mathrm{MMacf} \mathrm{ACl}\right)$

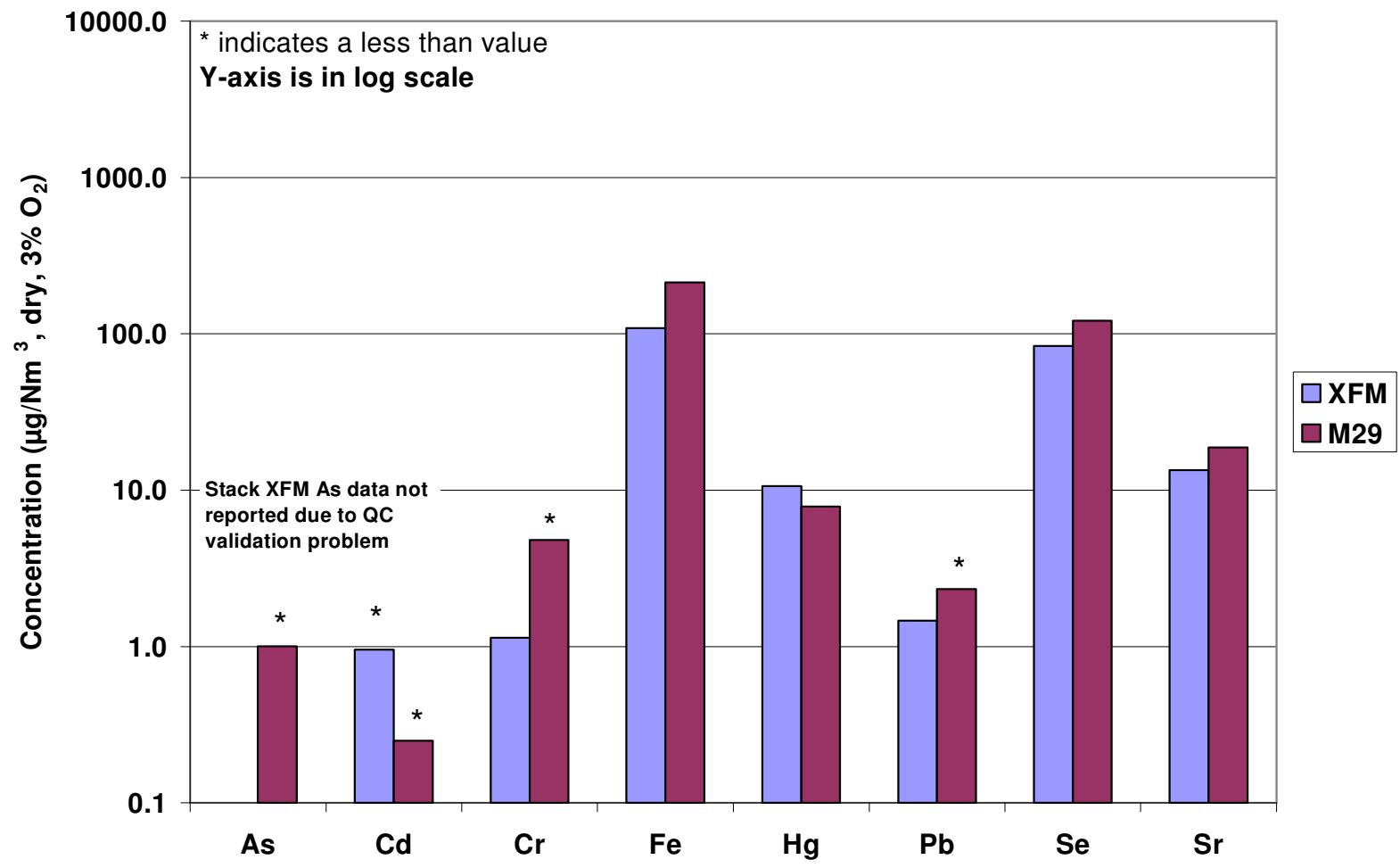

Figure L-14. Comparison of Averages from XFM and M29 for Stack 7/12/09 $\left(\mathrm{CaBr}_{2}+0.48 \mathrm{Ib} / \mathrm{MMacf} \mathrm{ACl}\right)$ 


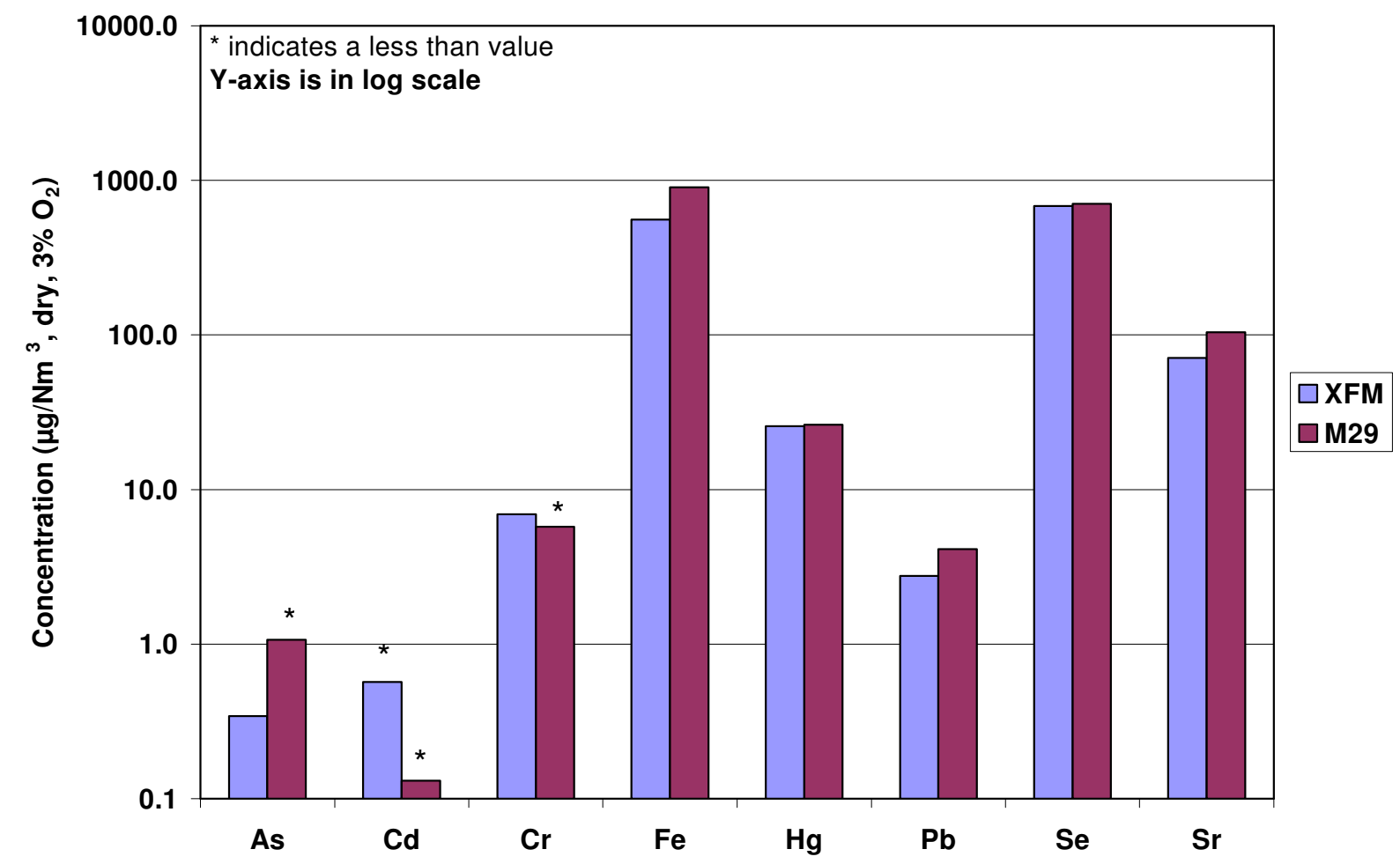

Figure L-15. Comparison of Averages from XFM and M29 for ESP Outlet 7/13/09 (Baseline Conditions)

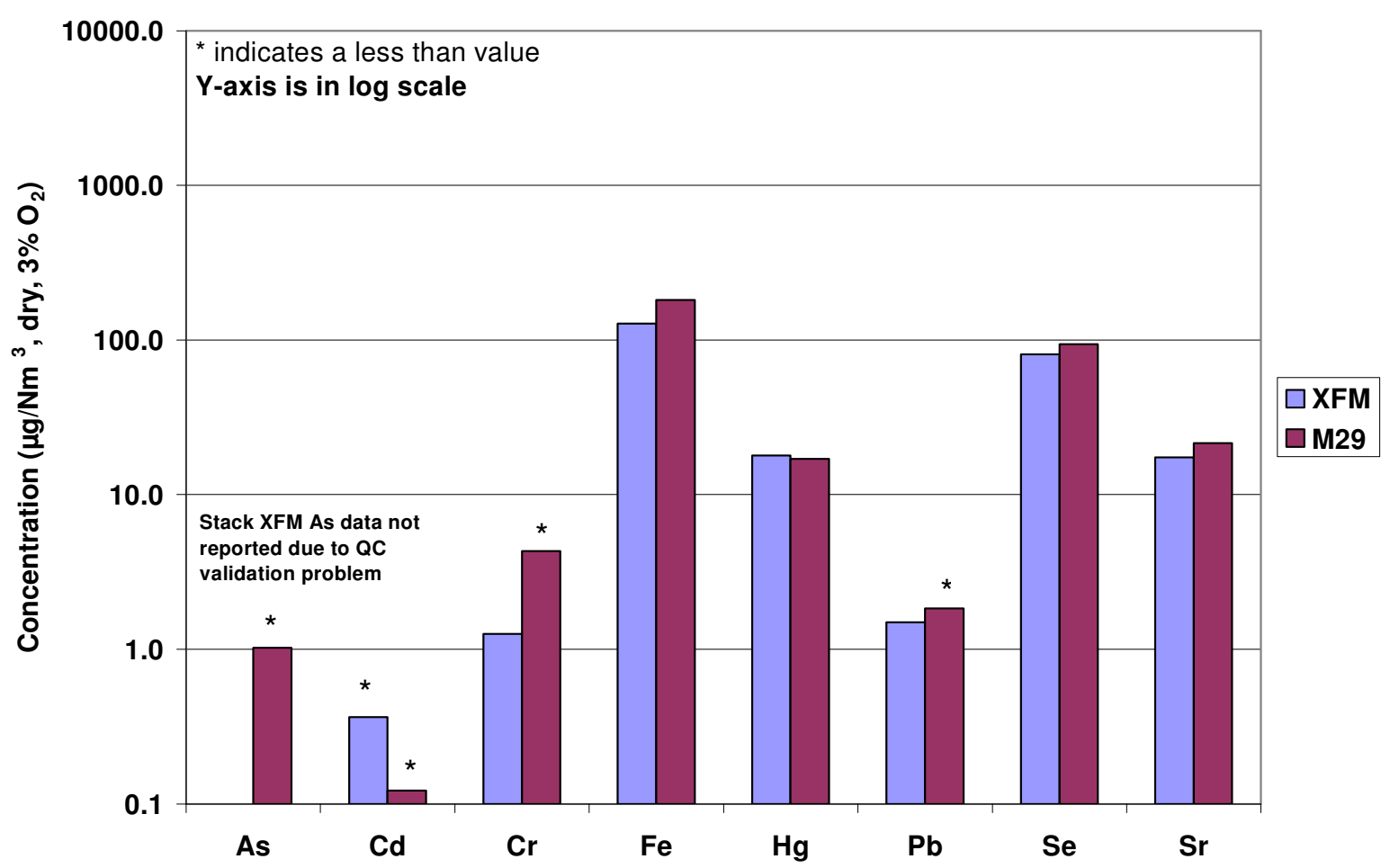

Figure L-16. Comparison of Averages from XFM and M29 for Stack 7/13/09 (Baseline Conditions) 


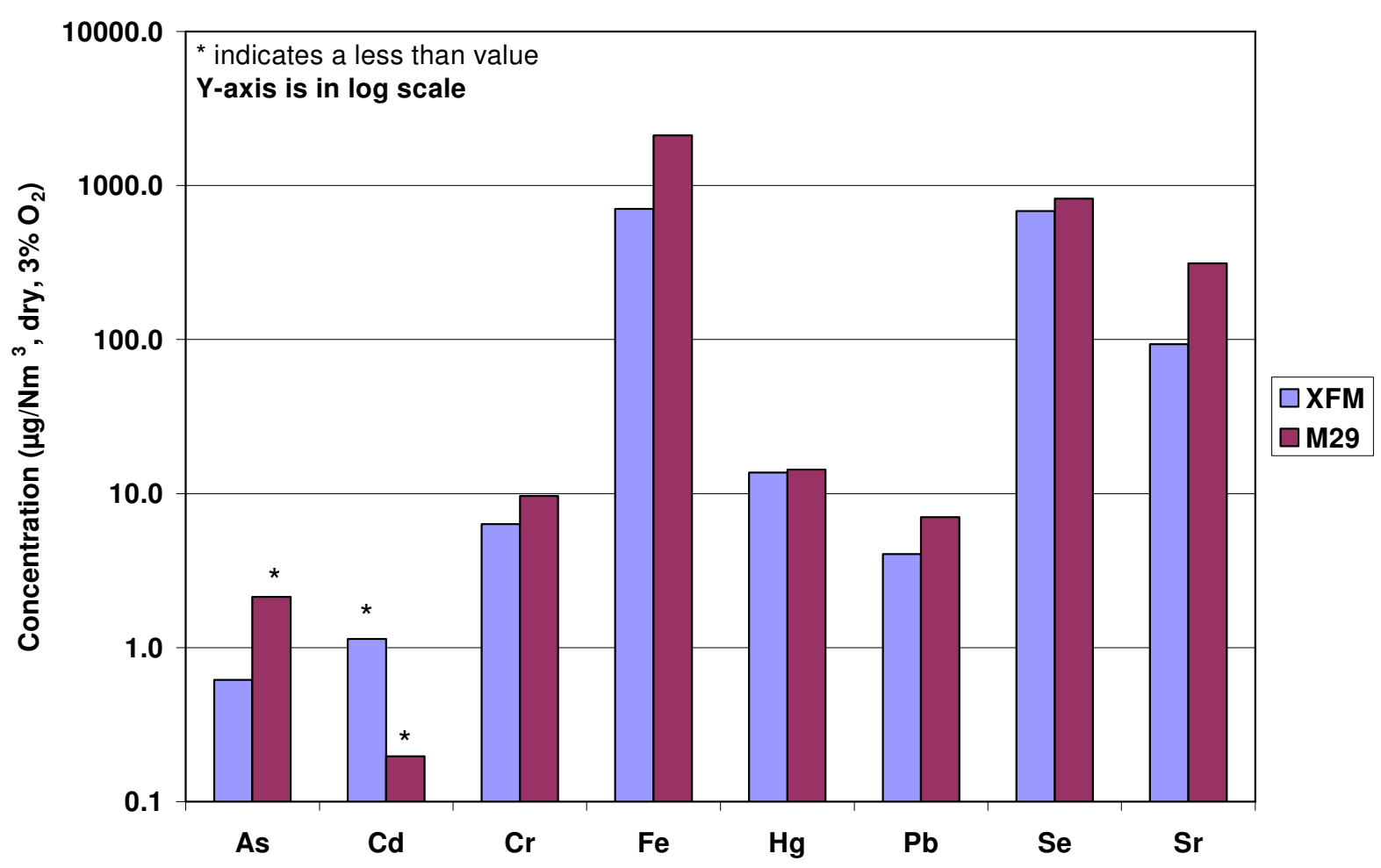

Figure L-17. Comparison of Averages from XFM and M29 for ESP Outlet 7/14/09 (1.9 Ib/MMacf ACl)

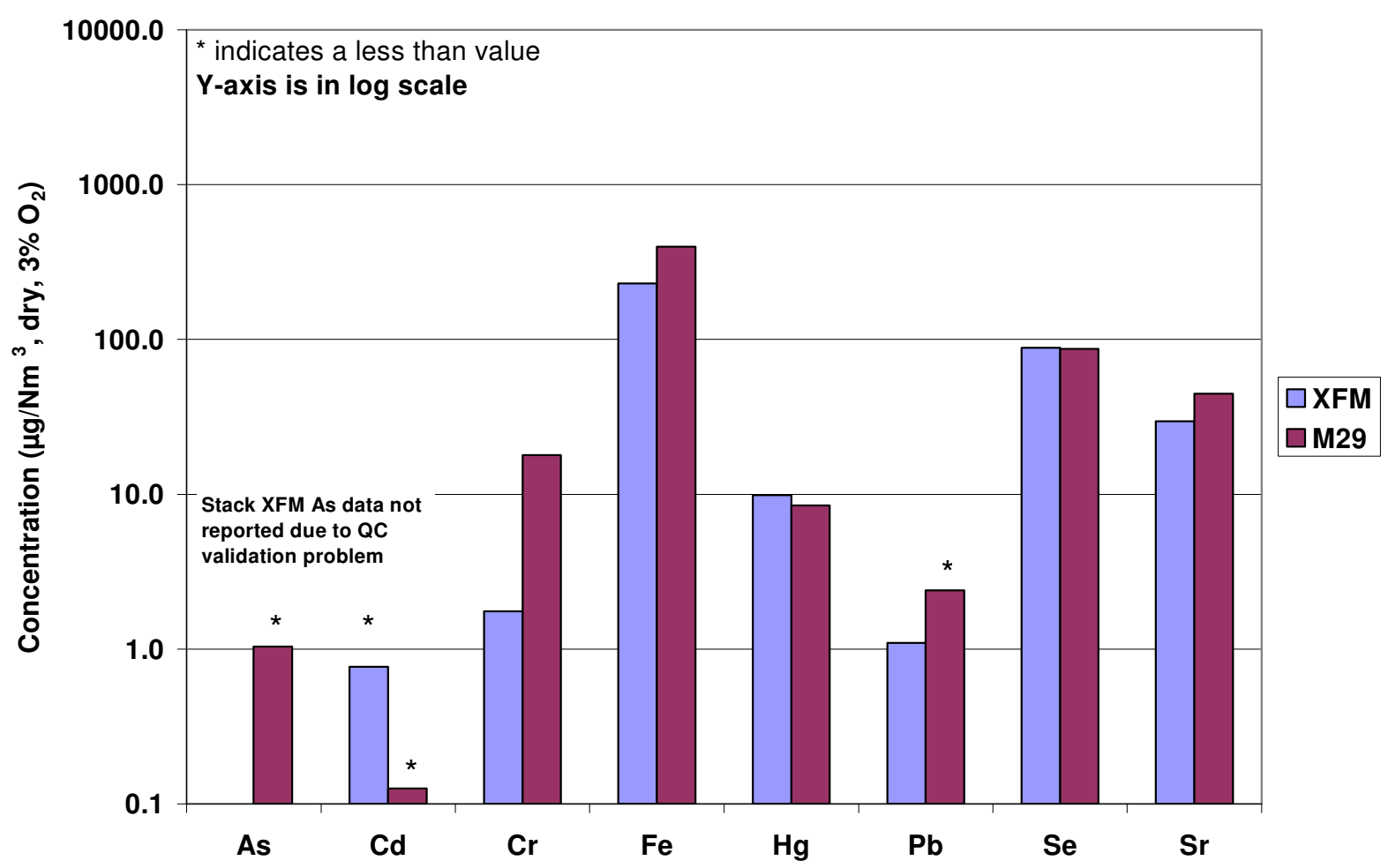

Figure L-18. Comparison of Averages from XFM and M29 for Stack 7/14/09 (1.9 lb/MMacf ACl) 


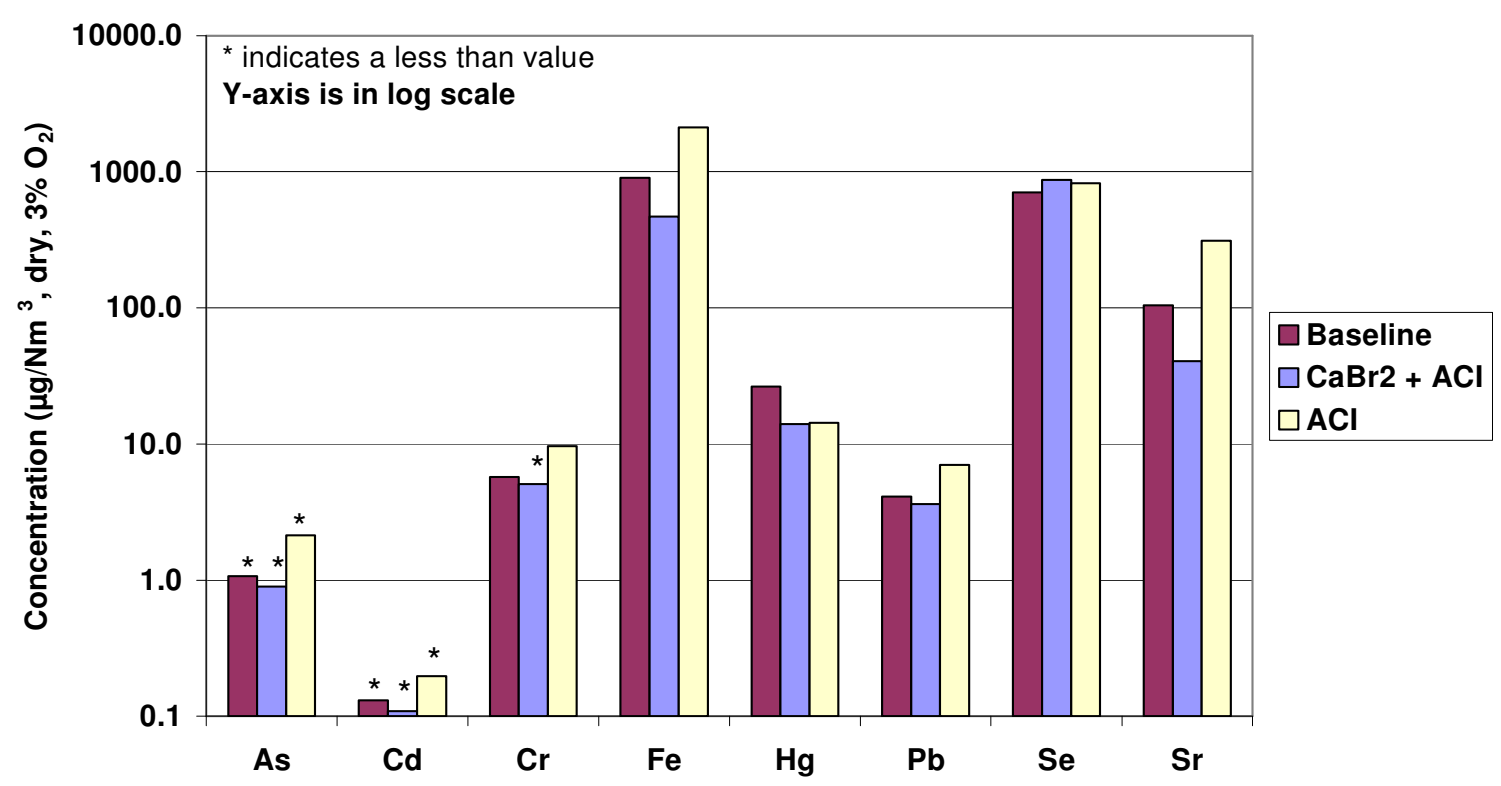

Figure L-19. Method 29 ESP Outlet Data for all Three Conditions

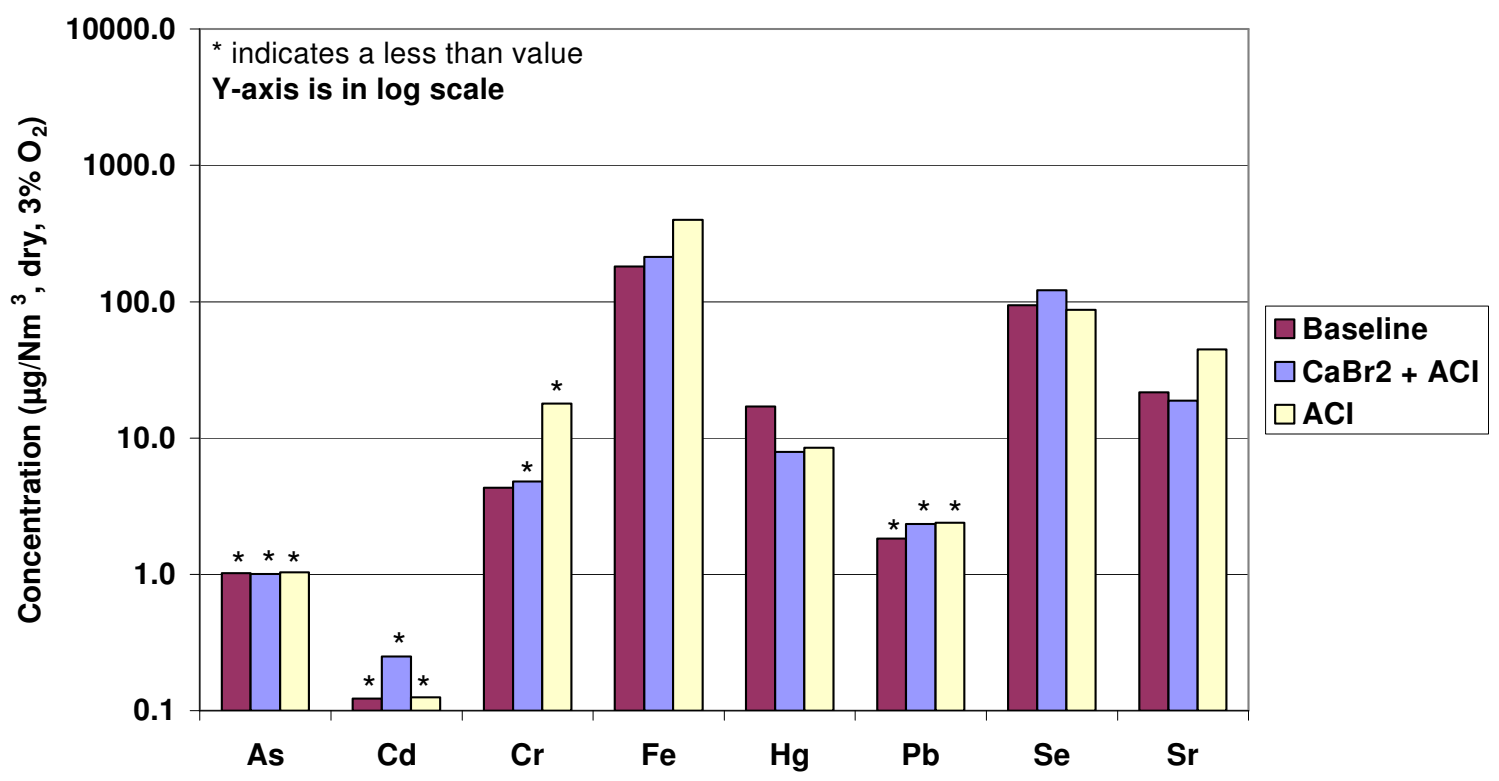

Figure L-20. Method 29 Stack Data for all Three Conditions 
Table L-11Aluminum Comparison Summary for $\mathrm{Br}+\mathrm{ACl}$ Conditions

\begin{tabular}{|c|c|c|c|c|c|c|}
\hline Metal & \multicolumn{2}{|l|}{ Al } & \multicolumn{3}{|c|}{ Cooper Units: $\mu \mathrm{g} / \mathrm{Nm}^{3}$ dry, $3 \% \mathrm{O}_{2}$} \\
\hline Date & \multicolumn{2}{|c|}{ 7/12/2009 } & \multicolumn{3}{|c|}{ M29 Units: $\mu \mathrm{g} / \mathrm{Nm}^{3}$ dry, $3 \% \mathrm{O}_{2}$} \\
\hline Location & \multicolumn{3}{|c|}{ ESPO } \\
\hline Run & $\begin{array}{c}\text { Cooper } \\
\text { Total }\end{array}$ & Cooper Unc & M29 Total & $\begin{array}{c}\text { Cooper } \\
\text { Total }\end{array}$ & Cooper Unc & M29 Total \\
\hline $\mathbf{1}$ & N/A & N/A & 2046.1 & N/A & N/A & 684.1 \\
\hline $\mathbf{2}$ & N/A & N/A & 902.7 & N/A & N/A & 572.4 \\
\hline $\mathbf{3}$ & N/A & N/A & 809.0 & N/A & N/A & 574.2 \\
\hline Average & N/A & N/A & 1252.6 & N/A & N/A & 610.3 \\
\hline RPD & \multicolumn{3}{|c|}{ N/A } & & N/A \\
\hline
\end{tabular}

Table L-12. Aluminum Comparison Summary for Baseline Conditions

\begin{tabular}{|c|c|c|c|c|c|c|}
\hline Metal & \multicolumn{3}{|l|}{$\mathbf{A l}$} & \multicolumn{3}{|c|}{ Cooper Units: $\mu \mathrm{g} / \mathrm{Nm}^{3}$ dry, $3 \% \mathrm{O}_{2}$} \\
\hline Date & \multicolumn{3}{|l|}{$7 / 13 / 2009$} & \multicolumn{3}{|c|}{ M29 Units: $\mu \mathrm{g} / \mathrm{Nm}^{3}$ dry, $3 \% \mathrm{O}_{2}$} \\
\hline Location & \multicolumn{3}{|c|}{ ESPO } & \multicolumn{3}{|c|}{ Stack } \\
\hline Run & $\begin{array}{c}\text { Cooper } \\
\text { Total }\end{array}$ & Cooper Unc & M29 Total & $\begin{array}{c}\text { Cooper } \\
\text { Total }\end{array}$ & Cooper Unc & M29 Total \\
\hline 1 & N/A & N/A & 5553.7 & N/A & N/A & 816.3 \\
\hline 2 & N/A & N/A & 1681.8 & N/A & N/A & 720.4 \\
\hline 3 & N/A & N/A & 1309.0 & N/A & N/A & 540.5 \\
\hline Average & N/A & N/A & 2848.2 & N/A & N/A & 692.4 \\
\hline RPD & \multicolumn{3}{|c|}{ N/A } & \multicolumn{3}{|c|}{ N/A } \\
\hline
\end{tabular}

Table L-13. Aluminum Comparison Summary for ACI Conditions

\begin{tabular}{|c|c|c|c|c|c|c|}
\hline Metal & \multicolumn{3}{|l|}{ Al } & \multicolumn{3}{|c|}{ Cooper Units: $\mu \mathrm{g} / \mathrm{Nm}^{3}$ dry, $3 \% \mathrm{O}_{2}$} \\
\hline Date & \multicolumn{3}{|l|}{ 7/14/2009 } & \multicolumn{3}{|c|}{ M29 Units: $\mu \mathrm{g} / \mathrm{Nm}^{3}$ dry, $3 \% \mathrm{O}_{2}$} \\
\hline Location & \multicolumn{3}{|c|}{ ESPO } & \multicolumn{3}{|c|}{ Stack } \\
\hline Run & $\begin{array}{c}\text { Cooper } \\
\text { Total }\end{array}$ & Cooper Unc & M29 Total & $\begin{array}{c}\text { Cooper } \\
\text { Total }\end{array}$ & Cooper Unc & M29 Total \\
\hline 1 & N/A & N/A & 9136.4 & N/A & N/A & 1521.8 \\
\hline 2 & N/A & N/A & 9707.4 & N/A & N/A & 1507.4 \\
\hline 3 & N/A & N/A & 7394.3 & N/A & N/A & 1019.3 \\
\hline Average & N/A & N/A & 8746.0 & N/A & N/A & 1349.5 \\
\hline$\overline{R P D}$ & \multicolumn{3}{|c|}{ N/A } & \multicolumn{3}{|c|}{ N/A } \\
\hline
\end{tabular}


Table L-14. Silver Comparison Summary for $\mathrm{Br}+\mathrm{ACl}$ Conditions

\begin{tabular}{|c|c|c|c|c|c|c|}
\hline Metal & \multicolumn{3}{|l|}{ Ag } & \multicolumn{3}{|c|}{ Cooper Units: $\mu \mathrm{g} / \mathrm{Nm}^{3}$ dry, $3 \% \mathrm{O}_{2}$} \\
\hline Date & \multicolumn{3}{|l|}{$7 / 12 / 2009$} & \multicolumn{3}{|c|}{ M29 Units: $\mu \mathrm{g} / \mathrm{Nm}^{3}$ dry, $3 \% \mathrm{O}_{2}$} \\
\hline Location & \multicolumn{3}{|c|}{ ESPO } & \multicolumn{3}{|c|}{ Stack } \\
\hline Run & $\begin{array}{c}\text { Cooper } \\
\text { Total } \\
\end{array}$ & Cooper Unc & M29 Total & $\begin{array}{c}\text { Cooper } \\
\text { Total } \\
\end{array}$ & Cooper Unc & M29 Total \\
\hline 1 & 0.9 & 3.1 & $<0.4$ & 0.0 & 2.4 & $<0.5$ \\
\hline 2 & 3.6 & 8.6 & $<0.3$ & 1.5 & 2.6 & $<0.4$ \\
\hline 3 & 0.1 & 2.8 & $<0.3$ & 1.7 & 2.5 & $<0.4$ \\
\hline Average & 1.5 & 4.8 & $<0.3$ & 1.1 & 2.5 & $<0.4$ \\
\hline RPD & \multicolumn{3}{|c|}{$\mathrm{N} / \mathrm{A}$} & \multicolumn{3}{|c|}{ N/A } \\
\hline
\end{tabular}

Table L-15. Silver Comparison Summary for Baseline Conditions

\begin{tabular}{|c|c|c|c|c|c|c|}
\hline Metal & \multicolumn{2}{|l|}{ Ag } & \multicolumn{3}{c|}{ Cooper Units: $\mu \mathrm{g} / \mathrm{Nm}^{3} \mathrm{dry}, 3 \% \mathrm{O}_{2}$} \\
\hline Date & $\mathbf{7 / 1 3 / 2 0 0 9}$ & \multicolumn{2}{|c|}{ M29 Units: $\mu \mathrm{g} / \mathrm{Nm}^{3} \mathrm{dry}, 3 \% \mathrm{O}_{2}$} \\
\hline Location & \multicolumn{3}{|c|}{ ESPO } & \multicolumn{3}{c|}{ Stack } \\
\hline Run & $\begin{array}{c}\text { Cooper } \\
\text { Total }\end{array}$ & Cooper Unc & M29 Total & $\begin{array}{c}\text { Cooper } \\
\text { Total }\end{array}$ & Cooper Unc & M29 Total \\
\hline $\mathbf{1}$ & 0.2 & 3.8 & $<0.5$ & 0.4 & 2.6 & $<0.3$ \\
\hline $\mathbf{2}$ & 1.6 & 3.6 & $<0.4$ & 1.4 & 2.6 & $<0.3$ \\
\hline $\mathbf{3}$ & 1.4 & 3.7 & $<0.3$ & 0.2 & 2.5 & $<0.3$ \\
\hline Average & 1.0 & 3.7 & $<0.4$ & 0.7 & 2.5 & $<0.3$ \\
\hline RPD & & N/A & & N/A & \\
\hline
\end{tabular}

Table L-16. Silver Comparison Summary for ACI Conditions

\begin{tabular}{|c|c|c|c|c|c|c|}
\hline Metal & \multicolumn{3}{|l|}{ Ag } & \multicolumn{3}{|c|}{ Cooper Units: $\mu \mathrm{g} / \mathrm{Nm}^{3}$ dry, $3 \% \mathrm{O}_{2}$} \\
\hline Date & \multicolumn{3}{|l|}{$7 / 14 / 2009$} & \multicolumn{3}{|c|}{ M29 Units: $\mu \mathrm{g} / \mathrm{Nm}^{3}$ dry, $3 \% \mathrm{O}_{2}$} \\
\hline Location & \multicolumn{3}{|c|}{ ESPO } & \multicolumn{3}{|c|}{ Stack } \\
\hline Run & $\begin{array}{c}\text { Cooper } \\
\text { Total } \\
\end{array}$ & Cooper Unc & M29 Total & $\begin{array}{c}\text { Cooper } \\
\text { Total } \\
\end{array}$ & Cooper Unc & M29 Total \\
\hline 1 & 0.2 & 2.9 & 0.7 & 2.4 & 3.0 & $<0.3$ \\
\hline 2 & 0.1 & 2.9 & 0.6 & 2.3 & 2.3 & $<0.3$ \\
\hline 3 & 1.8 & 2.7 & 0.6 & 1.9 & 2.3 & $<0.3$ \\
\hline Average & 0.7 & 2.8 & 0.6 & 2.2 & 2.5 & $<0.3$ \\
\hline RPD & \multicolumn{3}{|c|}{11.8} & \multicolumn{3}{|c|}{ N/A } \\
\hline
\end{tabular}


Table L-17. Arsenic Comparison Summary for $\mathrm{Br}+\mathrm{ACl}$ Conditions

\begin{tabular}{|c|c|c|c|c|c|c|}
\hline Metal & \multicolumn{2}{|l|}{ As } & \multicolumn{3}{|c|}{ Cooper Units: $\mu \mathrm{g} / \mathrm{Nm}^{3}$ dry, $3 \% \mathrm{O}_{2}$} \\
\hline Date & \multicolumn{2}{|c|}{$\mathbf{7 / 1 2 / 2 0 0 9}$} & \multicolumn{3}{|c|}{ M29 Units: $\mu \mathrm{g} / \mathrm{Nm}^{3}$ dry, $3 \% \mathrm{O}_{2}$} \\
\hline Location & \multicolumn{3}{|c|}{ ESPO } \\
\hline Run & $\begin{array}{c}\text { Cooper } \\
\text { Total }\end{array}$ & Cooper Unc & M29 Total & $\begin{array}{c}\text { Cooper } \\
\text { Total }\end{array}$ & Cooper Unc & M29 Total \\
\hline $\mathbf{1}$ & 1.6 & 0.5 & $<0.9$ & 104.9 & 1.0 & $<1.0$ \\
\hline $\mathbf{2}$ & 0.5 & 1.4 & $<0.9$ & 116.2 & 1.2 & $<1.0$ \\
\hline $\mathbf{3}$ & 0.1 & 0.4 & $<0.9$ & 70.5 & 0.8 & $<1.0$ \\
\hline Average & 0.7 & 0.8 & $<0.9$ & 97.2 & 1.0 & $<1.0$ \\
\hline RPD & \multicolumn{3}{|c|}{ N/A } & & N/A & \\
\hline
\end{tabular}

Table L-18. Arsenic Comparison Summary for Baseline Conditions

\begin{tabular}{|c|c|c|c|c|c|c|}
\hline Metal & \multicolumn{3}{|l|}{ As } & \multicolumn{3}{|c|}{ Cooper Units: $\mu \mathrm{g} / \mathrm{Nm}^{3}$ dry, $3 \% \mathrm{O}_{2}$} \\
\hline Date & \multicolumn{3}{|l|}{$7 / 13 / 2009$} & \multicolumn{3}{|c|}{ M29 Units: $\mu \mathrm{g} / \mathrm{Nm}^{3}$ dry, $3 \% \mathrm{O}_{2}$} \\
\hline Location & \multicolumn{3}{|c|}{ ESPO } & \multicolumn{3}{|c|}{ Stack } \\
\hline Run & $\begin{array}{c}\text { Cooper } \\
\text { Total }\end{array}$ & Cooper Unc & M29 Total & $\begin{array}{c}\text { Cooper } \\
\text { Total }\end{array}$ & Cooper Unc & M29 Total \\
\hline 1 & 0.5 & 0.8 & $<1.3$ & 46.5 & 0.7 & $<1.0$ \\
\hline 2 & 0.2 & 0.5 & $<0.9$ & 35.2 & 0.6 & $<1.0$ \\
\hline 3 & 0.3 & 0.5 & $<0.9$ & 28.9 & 0.6 & $<1.0$ \\
\hline Average & 0.3 & 0.6 & $<1.1$ & 36.8 & 0.6 & $<1.0$ \\
\hline RPD & \multicolumn{3}{|c|}{ N/A } & \multicolumn{3}{|c|}{ N/A } \\
\hline
\end{tabular}

Table L-19. Arsenic Comparison Summary for ACI Conditions

\begin{tabular}{|c|c|c|c|c|c|c|}
\hline Metal & \multicolumn{2}{|l|}{ As } & \multicolumn{3}{|c|}{ Cooper Units: $\mu \mathrm{g} / \mathrm{Nm}^{3} \mathrm{dry}, 3 \% \mathrm{O}_{2}$} \\
\hline Date & \multicolumn{3}{|c|}{$\mathbf{7 / 1 4 / 2 0 0 9}$} & \multicolumn{3}{|c|}{ M29 Units: $\mu \mathrm{g} / \mathrm{Nm}^{3} \mathrm{dry}, 3 \% \mathrm{O}_{2}$} \\
\hline Location & \multicolumn{3}{|c|}{ ESPO } \\
\hline Run & $\begin{array}{c}\text { Cooper } \\
\text { Total }\end{array}$ & Cooper Unc & M29 Total & $\begin{array}{c}\text { Cooper } \\
\text { Total }\end{array}$ & Cooper Unc & M29 Total \\
\hline $\mathbf{1}$ & 0.8 & 0.4 & $<2.0$ & 36.4 & 0.8 & $<1.1$ \\
\hline $\mathbf{2}$ & 0.8 & 0.4 & $<2.3$ & 32.1 & 0.6 & $<1.0$ \\
\hline $\mathbf{3}$ & 0.2 & 0.4 & $<2.1$ & 23.8 & 0.5 & $<1.0$ \\
\hline Average & 0.6 & 0.4 & $<2.1$ & 30.8 & 0.6 & $<1.0$ \\
\hline RPD & \multicolumn{3}{|c|}{ N/A } & & N/A & \\
\hline
\end{tabular}


Table L-20. Barium Comparison Summary for $\mathrm{Br}+\mathrm{ACl}$ Conditions

\begin{tabular}{|c|c|c|c|c|c|c|}
\hline Metal & \multicolumn{3}{|l|}{$\mathbf{B a}$} & \multicolumn{3}{|c|}{ Cooper Units: $\mu \mathrm{g} / \mathrm{Nm}^{3}$ dry, $3 \% \mathrm{O}_{2}$} \\
\hline Date & \multicolumn{3}{|l|}{$7 / 12 / 2009$} & \multicolumn{3}{|c|}{ M29 Units: $\mu \mathrm{g} / \mathrm{Nm}^{3}$ dry, $3 \% \mathrm{O}_{2}$} \\
\hline Location & \multicolumn{3}{|c|}{ ESPO } & \multicolumn{3}{|c|}{ Stack } \\
\hline Run & $\begin{array}{c}\text { Cooper } \\
\text { Total }\end{array}$ & Cooper Unc & M29 Total & $\begin{array}{c}\text { Cooper } \\
\text { Total }\end{array}$ & Cooper Unc & M29 Total \\
\hline 1 & 116.2 & 59.6 & 76.8 & 24.1 & 47.2 & 30.4 \\
\hline 2 & 49.4 & 165.9 & 38.9 & 12.5 & 49.5 & 25.7 \\
\hline 3 & 38.8 & 53.9 & 39.0 & 15.7 & 48.1 & 28.1 \\
\hline Average & 68.1 & 93.1 & 51.5 & 17.4 & 48.3 & 28.1 \\
\hline RPD & \multicolumn{3}{|c|}{ N/A } & \multicolumn{3}{|c|}{ N/A } \\
\hline
\end{tabular}

Table L-21. Barium Comparison Summary for Baseline Conditions

\begin{tabular}{|c|c|c|c|c|c|c|}
\hline Metal & \multicolumn{2}{|l|}{ Ba } & \multicolumn{3}{|c|}{ Cooper Units: $\mu \mathrm{g} / \mathrm{Nm}^{3}$ dry, $3 \% \mathrm{O}_{2}$} \\
\hline Date & \multicolumn{2}{|c|}{$7 / \mathbf{1 3 / 2 0 0 9}$} & \multicolumn{2}{|c|}{ M29 Units: $\mu \mathrm{g} / \mathrm{Nm}^{3}$ dry, 3\% $\mathrm{O}_{2}$} \\
\hline Location & \multicolumn{2}{|c|}{ ESPO } \\
\hline Run & $\begin{array}{c}\text { Cooper } \\
\text { Total }\end{array}$ & Cooper Unc & M29 Total & $\begin{array}{c}\text { Cooper } \\
\text { Total }\end{array}$ & Cooper Unc & M29 Total \\
\hline $\mathbf{1}$ & 139.2 & 73.3 & 243.4 & 30.4 & 49.3 & 41.8 \\
\hline $\mathbf{2}$ & 77.4 & 69.2 & 87.8 & 28.5 & 50.3 & 34.0 \\
\hline $\mathbf{3}$ & 68.3 & 71.9 & 57.0 & 17.9 & 47.6 & 26.0 \\
\hline Average & 95.0 & 71.5 & 129.4 & 25.6 & 49.1 & 33.9 \\
\hline RPD & & 30.7 & & N/A & \\
\hline
\end{tabular}

Table L-22. Barium Comparison Summary for $\mathrm{ACl}$ Conditions

\begin{tabular}{|c|c|c|c|c|c|c|}
\hline Metal & \multicolumn{1}{|l|}{ Ba } & \multicolumn{3}{|c|}{ Cooper Units: $\mu \mathrm{g} / \mathrm{Nm}^{3}$ dry, $3 \% \mathrm{O}_{2}$} \\
\hline Date & \multicolumn{2}{|c|}{$\mathbf{7 / 1 4 / 2 0 0 9}$} & \multicolumn{2}{|c|}{ M29 Units: $\mu \mathrm{g} / \mathrm{Nm}^{3}$ dry, $3 \% \mathrm{O}_{2}$} \\
\hline Location & \multicolumn{2}{|c|}{ ESPO } \\
\hline Run & $\begin{array}{c}\text { Cooper } \\
\text { Total }\end{array}$ & Cooper Unc & M29 Total & $\begin{array}{c}\text { Cooper } \\
\text { Total }\end{array}$ & Cooper Unc & M29 Total \\
\hline $\mathbf{1}$ & 160.6 & 55.6 & 336.5 & 47.9 & 48.0 & 64.2 \\
\hline $\mathbf{2}$ & 149.7 & 56.0 & 344.4 & 45.9 & 45.3 & 64.1 \\
\hline $\mathbf{3}$ & 55.6 & 52.7 & 281.5 & 77.6 & 45.3 & 44.0 \\
\hline Average & 121.9 & 54.7 & 320.8 & 57.1 & 46.2 & 57.4 \\
\hline RPD & & 89.8 & & & 0.5 & \\
\hline
\end{tabular}


Table L-23. Beryllium Comparison Summary for $\mathrm{Br}+\mathrm{ACl}$ Conditions

\begin{tabular}{|c|c|c|c|c|c|c|}
\hline Metal & \multicolumn{2}{|l|}{ Be } & \multicolumn{3}{|c|}{ Cooper Units: $\mu \mathrm{g} / \mathrm{Nm}^{3}$ dry, $3 \% \mathrm{O}_{2}$} \\
\hline Date & \multicolumn{2}{|c|}{ 7/12/2009 } & \multicolumn{3}{|c|}{ M29 Units: $\mu \mathrm{g} / \mathrm{Nm}^{3}$ dry, $3 \% \mathrm{O}_{2}$} \\
\hline Location & \multicolumn{3}{|c|}{ ESPO } \\
\hline Run & $\begin{array}{c}\text { Cooper } \\
\text { Total }\end{array}$ & Cooper Unc & M29 Total & $\begin{array}{c}\text { Cooper } \\
\text { Total }\end{array}$ & Cooper Unc & M29 Total \\
\hline $\mathbf{1}$ & N/A & N/A & 0.07 & N/A & N/A & $<0.04$ \\
\hline $\mathbf{2}$ & N/A & N/A & 0.03 & N/A & N/A & $<0.04$ \\
\hline $\mathbf{3}$ & N/A & N/A & 0.03 & N/A & N/A & $<0.04$ \\
\hline Average & N/A & N/A & 0.04 & N/A & N/A & $<0.04$ \\
\hline RPD & \multicolumn{3}{|c|}{ N/A } & & N/A & \\
\hline
\end{tabular}

Table L-24. Beryllium Comparison Summary for Baseline Conditions

\begin{tabular}{|c|c|c|c|c|c|c|}
\hline Metal & \multicolumn{3}{|l|}{ Be } & \multicolumn{3}{|c|}{ Cooper Units: $\mu \mathrm{g} / \mathrm{Nm}^{3}$ dry, $3 \% \mathrm{O}_{2}$} \\
\hline Date & \multicolumn{3}{|l|}{$7 / 13 / 2009$} & \multicolumn{3}{|c|}{ M29 Units: $\mu \mathrm{g} / \mathrm{Nm}^{3}$ dry, $3 \% \mathrm{O}_{2}$} \\
\hline Location & \multicolumn{3}{|c|}{ ESPO } & \multicolumn{3}{|c|}{ Stack } \\
\hline Run & $\begin{array}{c}\text { Cooper } \\
\text { Total }\end{array}$ & Cooper Unc & M29 Total & $\begin{array}{c}\text { Cooper } \\
\text { Total }\end{array}$ & Cooper Unc & M29 Total \\
\hline 1 & N/A & N/A & 0.2 & N/A & N/A & $<0.04$ \\
\hline 2 & N/A & N/A & 0.1 & N/A & N/A & $<0.04$ \\
\hline 3 & N/A & N/A & 0.0 & N/A & N/A & $<0.03$ \\
\hline Average & N/A & N/A & 0.1 & N/A & N/A & $<0.04$ \\
\hline RPD & \multicolumn{3}{|c|}{ N/A } & \multicolumn{3}{|c|}{ N/A } \\
\hline
\end{tabular}

Table L-25. Beryllium Comparison Summary for ACl Conditions

\begin{tabular}{|c|c|c|c|c|c|c|}
\hline Metal & \multicolumn{2}{|l|}{ Be } & \multicolumn{3}{|c|}{ Cooper Units: $\mu \mathrm{g} / \mathrm{Nm}^{3} \mathrm{dry}, 3 \% \mathrm{O}_{2}$} \\
\hline Date & \multicolumn{2}{|c|}{ 7/14/2009 } & \multicolumn{3}{|c|}{ M29 Units: $\mu \mathrm{g} / \mathrm{Nm}^{3} \mathrm{dry}, 3 \% \mathrm{O}_{2}$} \\
\hline Location & \multicolumn{3}{|c|}{ Stack } \\
\hline Run & $\begin{array}{c}\text { Cooper } \\
\text { Total }\end{array}$ & Cooper Unc & M29 Total & $\begin{array}{c}\text { Cooper } \\
\text { Total }\end{array}$ & Cooper Unc & M29 Total \\
\hline $\mathbf{1}$ & N/A & N/A & 0.2 & N/A & N/A & 0.06 \\
\hline $\mathbf{2}$ & N/A & N/A & 0.3 & N/A & N/A & 0.05 \\
\hline $\mathbf{3}$ & N/A & N/A & 0.2 & N/A & N/A & $<0.03$ \\
\hline Average & N/A & N/A & 0.2 & N/A & N/A & 0.05 \\
\hline RPD & \multicolumn{3}{|c|}{ N/A } & & N/A & \\
\hline
\end{tabular}


Table L-26. Cadmium Comparison Summary for $\mathrm{Br}+\mathrm{ACl}$ Conditions

\begin{tabular}{|c|c|c|c|c|c|c|}
\hline Metal & \multicolumn{2}{|l|}{ Cd } & \multicolumn{3}{|c|}{ Cooper Units: $\mu \mathrm{g} / \mathrm{Nm}^{3}$ dry, $3 \% \mathrm{O}_{2}$} \\
\hline Date & \multicolumn{2}{|c|}{$\mathbf{7 / 1 2 / 2 0 0 9}$} & \multicolumn{3}{|c|}{ S29 Units: $\mu \mathrm{g} / \mathrm{Nm}^{3}$ dry, $3 \% \mathrm{O}_{2}$} \\
\hline Location & \multicolumn{3}{|c|}{ ESPO } \\
\hline Run & $\begin{array}{c}\text { Cooper } \\
\text { Total }\end{array}$ & Cooper Unc & M29 Total & $\begin{array}{c}\text { Cooper } \\
\text { Total }\end{array}$ & Cooper Unc & M29 Total \\
\hline $\mathbf{1}$ & 0.1 & 4.2 & $<0.1$ & 2.5 & 3.3 & $<0.2$ \\
\hline $\mathbf{2}$ & 2.3 & 11.6 & $<0.1$ & 0.0 & 3.5 & $<0.2$ \\
\hline $\mathbf{3}$ & 0.5 & 3.8 & $<0.1$ & 0.3 & 3.4 & 0.4 \\
\hline Average & 1.0 & 6.5 & $<0.1$ & 1.0 & 3.4 & $<0.3$ \\
\hline RPD & \multicolumn{3}{|c|}{ N/A } & & N/A & \\
\hline
\end{tabular}

Table L-27. Cadmium Comparison Summary for Baseline Conditions

\begin{tabular}{|c|c|c|c|c|c|c|}
\hline Metal & \multicolumn{2}{|l|}{ Cd } & \multicolumn{3}{|c|}{ Cooper Units: $\mu \mathrm{g} / \mathrm{Nm}^{3} \mathrm{dry}, 3 \% \mathrm{O}_{2}$} \\
\hline Date & \multicolumn{2}{|c|}{ 7/13/2009 } & \multicolumn{3}{|c|}{ M29 Units: $\mu \mathrm{g} / \mathrm{Nm}^{3} \mathrm{dry}, 3 \% \mathrm{O}_{2}$} \\
\hline Location & \multicolumn{3}{|c|}{ ESPO } \\
\hline Run & $\begin{array}{c}\text { Cooper } \\
\text { Total }\end{array}$ & Cooper Unc & M29 Total & $\begin{array}{c}\text { Cooper } \\
\text { Total }\end{array}$ & Cooper Unc & M29 Total \\
\hline $\mathbf{1}$ & 0.2 & 5.1 & $<0.2$ & 0.5 & 3.5 & $<0.1$ \\
\hline $\mathbf{2}$ & 0.4 & 4.8 & $<0.1$ & 0.4 & 3.5 & $<0.1$ \\
\hline $\mathbf{3}$ & 1.1 & 5.0 & $<0.1$ & 0.2 & 3.3 & $<0.1$ \\
\hline Average & 0.6 & 5.0 & $<0.1$ & 0.4 & 3.4 & $<0.1$ \\
\hline RPD & \multicolumn{7}{|c|}{ N/A } & & N/A & \\
\hline
\end{tabular}

Table L-28. Cadmium Comparison Summary for ACI Conditions

\begin{tabular}{|c|c|c|c|c|c|c|}
\hline Metal & \multicolumn{3}{|l|}{ Cd } & \multicolumn{3}{|c|}{ Cooper Units: $\mu \mathrm{g} / \mathrm{Nm}^{3}$ dry, $3 \% \mathrm{O}_{2}$} \\
\hline Date & \multicolumn{3}{|l|}{ 7/14/2009 } & \multicolumn{3}{|c|}{ M29 Units: $\mu \mathrm{g} / \mathrm{Nm}^{3}$ dry, $3 \% \mathrm{O}_{2}$} \\
\hline Location & \multicolumn{3}{|c|}{ ESPO } & \multicolumn{3}{|c|}{ Stack } \\
\hline Run & $\begin{array}{c}\text { Cooper } \\
\text { Total }\end{array}$ & Cooper Unc & M29 Total & $\begin{array}{c}\text { Cooper } \\
\text { Total }\end{array}$ & Cooper Unc & M29 Total \\
\hline 1 & 0.05 & 3.9 & $<0.2$ & 1.9 & 3.6 & $<0.1$ \\
\hline 2 & 3.0 & 3.9 & $<0.2$ & 0.0 & 3.2 & $<0.1$ \\
\hline 3 & 0.3 & 3.7 & $<0.2$ & 0.4 & 3.2 & $<0.1$ \\
\hline Average & 1.1 & 3.8 & $<0.2$ & 0.8 & 3.3 & $<0.1$ \\
\hline RPD & \multicolumn{3}{|c|}{ N/A } & \multicolumn{3}{|c|}{ N/A } \\
\hline
\end{tabular}


Table L-29. Cobalt Comparison Summary for $\mathrm{Br}+\mathrm{ACl}$ Conditions

\begin{tabular}{|c|c|c|c|c|c|c|}
\hline Metal & \multicolumn{2}{|l|}{ Co } & \multicolumn{3}{|c|}{ Cooper Units: $\mu \mathrm{g} / \mathrm{Nm}^{3}$ dry, $3 \% \mathrm{O}_{2}$} \\
\hline Date & \multicolumn{2}{|c|}{ 7/12/2009 } & \multicolumn{3}{|c|}{ M29 Units: $\mu \mathrm{g} / \mathrm{Nm}^{3}$ dry, $3 \% \mathrm{O}_{2}$} \\
\hline Location & \multicolumn{3}{|c|}{ ESPO } \\
\hline Run & $\begin{array}{c}\text { Cooper } \\
\text { Total }\end{array}$ & Cooper Unc & M29 Total & $\begin{array}{c}\text { Cooper } \\
\text { Total }\end{array}$ & Cooper Unc & M29 Total \\
\hline $\mathbf{1}$ & 1.7 & 0.6 & 0.8 & 0.4 & 0.3 & 0.2 \\
\hline $\mathbf{2}$ & 2.0 & 1.1 & 0.3 & 0.4 & 0.3 & 0.2 \\
\hline $\mathbf{3}$ & 1.0 & 0.4 & 0.3 & 0.4 & 0.3 & 0.2 \\
\hline Average & 1.6 & 0.7 & 0.5 & 0.4 & 0.3 & 0.2 \\
\hline RPD & \multicolumn{7}{|c|}{108.9} & & 62.8 & \\
\hline
\end{tabular}

Table L-30. Cobalt Comparison Summary for Baseline Conditions

\begin{tabular}{|c|c|c|c|c|c|c|}
\hline Metal & \multicolumn{2}{|l|}{ Co } & \multicolumn{3}{|c|}{ Cooper Units: $\mu \mathrm{g} / \mathrm{Nm}^{3} \mathrm{dry}, 3 \% \mathrm{O}_{2}$} \\
\hline Date & \multicolumn{2}{|c|}{$\mathbf{7 / 1 3 / 2 0 0 9}$} & \multicolumn{3}{|c|}{$\mathrm{M} 29$ Units: $\mu \mathrm{g} / \mathrm{Nm}^{3} \mathrm{dry}, 3 \% \mathrm{O}_{2}$} \\
\hline Location & \multicolumn{3}{|c|}{ ESPO } \\
\hline Run & $\begin{array}{c}\text { Cooper } \\
\text { Total }\end{array}$ & Cooper Unc & M29 Total & $\begin{array}{c}\text { Cooper } \\
\text { Total }\end{array}$ & Cooper Unc & M29 Total \\
\hline $\mathbf{1}$ & 1.4 & 0.6 & 1.8 & 0.8 & 0.3 & 0.2 \\
\hline $\mathbf{2}$ & 1.0 & 0.6 & 1.0 & 0.3 & 0.3 & 0.2 \\
\hline $\mathbf{3}$ & 0.2 & 0.5 & 0.6 & 0.1 & 0.3 & $<0.3$ \\
\hline Average & 0.8 & 0.5 & 1.1 & 0.4 & 0.3 & 0.2 \\
\hline RPD & \multicolumn{7}{|c|}{29.0} & & & 56.5 & \\
\hline
\end{tabular}

Table L-31. Cobalt Comparison Summary for ACI Conditions

\begin{tabular}{|c|c|c|c|c|c|c|}
\hline Metal & \multicolumn{3}{|l|}{ Co } & \multicolumn{3}{|c|}{ Cooper Units: $\mu \mathrm{g} / \mathrm{Nm}^{3}$ dry, $3 \% \mathrm{O}_{2}$} \\
\hline Date & \multicolumn{3}{|l|}{$7 / 14 / 2009$} & \multicolumn{3}{|c|}{ M29 Units: $\mu \mathrm{g} / \mathrm{Nm}^{3}$ dry, $3 \% \mathrm{O}_{2}$} \\
\hline Location & \multicolumn{3}{|c|}{ ESPO } & \multicolumn{3}{|c|}{ Stack } \\
\hline Run & $\begin{array}{c}\text { Cooper } \\
\text { Total }\end{array}$ & Cooper Unc & M29 Total & $\begin{array}{c}\text { Cooper } \\
\text { Total }\end{array}$ & Cooper Unc & M29 Total \\
\hline 1 & 0.3 & 0.4 & 3.3 & 0.2 & 0.3 & 0.6 \\
\hline 2 & 0.5 & 0.4 & 3.6 & 0.0 & 0.3 & 0.5 \\
\hline 3 & 0.7 & 0.4 & 3.4 & 0.3 & 0.3 & 0.4 \\
\hline Average & 0.5 & 0.4 & 3.4 & 0.2 & 0.3 & 0.5 \\
\hline RPD & \multicolumn{3}{|c|}{$\overline{148.6}$} & \multicolumn{3}{|c|}{ N/A } \\
\hline
\end{tabular}


Table L-32. Chromium Comparison Summary for $\mathrm{Br}+\mathrm{ACl}$ Conditions

\begin{tabular}{|c|c|c|c|c|c|c|}
\hline Metal & \multicolumn{3}{|l|}{$\mathrm{Cr}$} & \multicolumn{3}{|c|}{ Cooper Units: $\mu \mathrm{g} / \mathrm{Nm}^{3}$ dry, $3 \% \mathrm{O}_{2}$} \\
\hline Date & \multicolumn{3}{|l|}{$7 / 12 / 2009$} & \multicolumn{3}{|c|}{ M29 Units: $\mu \mathrm{g} / \mathrm{Nm}^{3}$ dry, $3 \% \mathrm{O}_{2}$} \\
\hline Location & \multicolumn{3}{|c|}{ ESPO } & \multicolumn{3}{|c|}{ Stack } \\
\hline Run & $\begin{array}{c}\text { Cooper } \\
\text { Total }\end{array}$ & Cooper Unc & M29 Total & $\begin{array}{c}\text { Cooper } \\
\text { Total }\end{array}$ & Cooper Unc & M29 Total \\
\hline 1 & 9.7 & 2.0 & 5.6 & 1.9 & 1.6 & $<4.5$ \\
\hline 2 & 6.9 & 5.6 & 4.3 & 0.5 & 1.7 & $<4.6$ \\
\hline 3 & 2.7 & 1.8 & $<5.3$ & 1.0 & 1.6 & $<5.3$ \\
\hline Average & 6.4 & 3.1 & 5.1 & 1.1 & 1.6 & $<4.8$ \\
\hline RPD & \multicolumn{3}{|c|}{23.5} & \multicolumn{3}{|c|}{ N/A } \\
\hline
\end{tabular}

Table L-33. Chromium Comparison Summary for Baseline Conditions

\begin{tabular}{|c|c|c|c|c|c|c|}
\hline Metal & \multicolumn{3}{|l|}{$\mathbf{C r}$} & \multicolumn{3}{|c|}{ Cooper Units: $\mu \mathrm{g} / \mathrm{Nm}^{3}$ dry, $3 \% \mathrm{O}_{2}$} \\
\hline Date & \multicolumn{3}{|l|}{ 7/13/2009 } & \multicolumn{3}{|c|}{ M29 Units: $\mu \mathrm{g} / \mathrm{Nm}^{3}$ dry, $3 \% \mathrm{O}_{2}$} \\
\hline Location & \multicolumn{3}{|c|}{ ESPO } & \multicolumn{3}{|c|}{ Stack } \\
\hline Run & $\begin{array}{c}\text { Cooper } \\
\text { Total }\end{array}$ & Cooper Unc & M29 Total & $\begin{array}{c}\text { Cooper } \\
\text { Total }\end{array}$ & Cooper Une & M29 Total \\
\hline 1 & 8.6 & 4.7 & 5.9 & 2.1 & 1.7 & $<4.5$ \\
\hline 2 & 10.0 & 2.3 & $<5.6$ & 0.8 & 1.7 & $<4.7$ \\
\hline 3 & 2.1 & 2.4 & $<5.7$ & 0.9 & 1.6 & $<3.8$ \\
\hline Average & 6.9 & 3.1 & $<5.7$ & 1.3 & 1.7 & $<4.3$ \\
\hline RPD & \multicolumn{3}{|c|}{ N/A } & \multicolumn{3}{|c|}{ N/A } \\
\hline
\end{tabular}

Table L-34. Chromium Comparison Summary for ACI Conditions

\begin{tabular}{|c|c|c|c|c|c|c|}
\hline Metal & \multicolumn{3}{|l|}{$\mathbf{C r}$} & \multicolumn{3}{|c|}{ Cooper Units: $\mu \mathrm{g} / \mathrm{Nm}^{3}$ dry, $3 \% \mathrm{O}_{2}$} \\
\hline Date & \multicolumn{3}{|l|}{$7 / 14 / 2009$} & \multicolumn{3}{|c|}{ M29 Units: $\mu \mathrm{g} / \mathrm{Nm}^{3}$ dry, $3 \% \mathrm{O}_{2}$} \\
\hline Location & \multicolumn{3}{|c|}{ ESPO } & \multicolumn{3}{|c|}{ Stack } \\
\hline Run & $\begin{array}{c}\text { Cooper } \\
\text { Total }\end{array}$ & Cooper Unc & M29 Total & $\begin{array}{c}\text { Cooper } \\
\text { Total }\end{array}$ & Cooper Unc & M29 Total \\
\hline 1 & 10.9 & 1.9 & 9.9 & 1.9 & 1.6 & - \\
\hline 2 & 5.2 & 1.9 & 9.8 & 2.3 & 1.5 & 5.3 \\
\hline 3 & 2.9 & 1.8 & 9.2 & 1.1 & 1.5 & $<5.1$ \\
\hline Average & 6.3 & 1.8 & 9.6 & 1.8 & 1.6 & $<5.2$ \\
\hline RPD & \multicolumn{3}{|c|}{41.5} & \multicolumn{3}{|c|}{ N/A ?? } \\
\hline
\end{tabular}


Table L-35. Copper Comparison Summary for $\mathrm{Br}+\mathrm{ACl}$ Conditions

\begin{tabular}{|c|c|c|c|c|c|c|}
\hline Metal & \multicolumn{3}{|l|}{$\mathbf{C u}$} & \multicolumn{3}{|c|}{ Cooper Units: $\mu \mathrm{g} / \mathrm{Nm}^{3}$ dry, $3 \% \mathrm{O}_{2}$} \\
\hline Date & \multicolumn{3}{|l|}{$7 / 12 / 2009$} & \multicolumn{3}{|c|}{ M29 Units: $\mu \mathrm{g} / \mathrm{Nm}^{3}$ dry, $3 \% \mathrm{O}_{2}$} \\
\hline Location & \multicolumn{3}{|c|}{ ESPO } & \multicolumn{3}{|c|}{ Stack } \\
\hline Run & $\begin{array}{c}\text { Cooper } \\
\text { Total }\end{array}$ & Cooper Unc & M29 Total & $\begin{array}{c}\text { Cooper } \\
\text { Total }\end{array}$ & Cooper Unc & M29 Total \\
\hline 1 & 3.5 & 0.5 & 4.1 & 0.6 & 0.4 & 2.1 \\
\hline 2 & 2.1 & 1.3 & 4.1 & 0.2 & 0.4 & 1.7 \\
\hline 3 & 1.3 & 0.4 & 2.4 & 0.5 & 0.4 & 2.2 \\
\hline Average & 2.3 & 0.8 & 3.5 & 0.5 & 0.4 & 2.0 \\
\hline RPD & \multicolumn{3}{|c|}{43.7} & \multicolumn{3}{|c|}{124.7} \\
\hline
\end{tabular}

Table L-36. Copper Comparison Summary for Baseline Conditions

\begin{tabular}{|c|c|c|c|c|c|c|}
\hline Metal & \multicolumn{2}{|l|}{ Cu } & \multicolumn{3}{|c|}{ Cooper Units: $\mu \mathrm{g} / \mathrm{Nm}^{3} \mathrm{dry}, 3 \% \mathrm{O}_{2}$} \\
\hline Date & \multicolumn{2}{|c|}{ 7/13/2009 } & \multicolumn{3}{|c|}{ M29 Units: $\mu \mathrm{g} / \mathrm{Nm}^{3} \mathrm{dry}, 3 \% \mathrm{O}_{2}$} \\
\hline Location & \multicolumn{3}{|c|}{ ESPO } \\
\hline Run & $\begin{array}{c}\text { Cooper } \\
\text { Total }\end{array}$ & Cooper Unc & M29 Total & $\begin{array}{c}\text { Cooper } \\
\text { Total }\end{array}$ & Cooper Unc & M29 Total \\
\hline $\mathbf{1}$ & 3.2 & 0.6 & 6.6 & 1.0 & 0.4 & 1.8 \\
\hline $\mathbf{2}$ & 1.8 & 0.6 & 3.5 & 0.7 & 0.4 & 2.0 \\
\hline $\mathbf{3}$ & 1.9 & 0.6 & 3.0 & 0.3 & 0.4 & 1.6 \\
\hline Average & 2.3 & 0.6 & 4.3 & 0.7 & 0.4 & 1.8 \\
\hline RPD & \multicolumn{7}{|c|}{61.4} & & 93.8 & \\
\hline
\end{tabular}

Table L-37. Copper Comparison Summary for ACl Conditions

\begin{tabular}{|c|c|c|c|c|c|c|}
\hline Metal & \multicolumn{2}{|l|}{$\mathbf{C u}$} & \multicolumn{3}{|c|}{ Cooper Units: $\mu \mathrm{g} / \mathrm{Nm}^{3} \mathrm{dry}, 3 \% \mathrm{O}_{2}$} \\
\hline Date & \multicolumn{3}{|c|}{$\mathbf{7 / 1 4 / 2 0 0 9}$} & \multicolumn{3}{|c|}{ M29 Units: $\mu \mathrm{g} / \mathrm{Nm}^{3} \mathrm{dry}, 3 \% \mathrm{O}_{2}$} \\
\hline Location & \multicolumn{3}{|c|}{ ESPO } \\
\hline Run & $\begin{array}{c}\text { Cooper } \\
\text { Total }\end{array}$ & Cooper Unc & M29 Total & $\begin{array}{c}\text { Cooper } \\
\text { Total }\end{array}$ & Cooper Unc & M29 Total \\
\hline $\mathbf{1}$ & 4.9 & 0.5 & 10.3 & 1.5 & 0.4 & 2.9 \\
\hline $\mathbf{2}$ & 2.6 & 0.5 & 9.9 & 1.0 & 0.4 & 3.3 \\
\hline $\mathbf{3}$ & 1.6 & 0.4 & 8.9 & 0.8 & 0.4 & 2.7 \\
\hline Average & 3.1 & 0.4 & 9.7 & 1.1 & 0.4 & 3.0 \\
\hline RPD & \multicolumn{7}{|c|}{104.2} & & 92.2 & \\
\hline
\end{tabular}


Table L-38. Iron Comparison Summary for $\mathrm{Br}+\mathrm{ACl}$ Conditions

\begin{tabular}{|c|c|c|c|c|c|c|}
\hline Metal & \multicolumn{2}{|l|}{ Fe } & \multicolumn{3}{|c|}{ Cooper Units: $\mu \mathrm{g} / \mathrm{Nm}^{3} \mathrm{dry}, 3 \% \mathrm{O}_{2}$} \\
\hline Date & \multicolumn{2}{|c|}{$\mathbf{7 / 1 2 / 2 0 0 9}$} & \multicolumn{3}{|c|}{ M29 Units: $\mu \mathrm{g} / \mathrm{Nm}^{3} \mathrm{dry}, 3 \% \mathrm{O}_{2}$} \\
\hline Location & \multicolumn{3}{|c|}{ ESPO } \\
\hline Run & $\begin{array}{c}\text { Cooper } \\
\text { Total }\end{array}$ & Cooper Unc & M29 Total & $\begin{array}{c}\text { Cooper } \\
\text { Total }\end{array}$ & Cooper Unc & M29 Total \\
\hline $\mathbf{1}$ & 803.2 & 1.7 & 732.7 & 140.4 & 0.6 & 180.8 \\
\hline $\mathbf{2}$ & 453.0 & 2.7 & 274.1 & 89.3 & 0.4 & 164.2 \\
\hline $\mathbf{3}$ & 281.1 & 0.8 & 394.8 & 96.2 & 0.4 & 295.3 \\
\hline Average & 512.4 & 1.7 & 467.2 & 108.6 & 0.5 & 213.4 \\
\hline RPD & \multicolumn{7}{|c|}{} & & 65.1 & \\
\hline
\end{tabular}

Table L-39. Iron Comparison Summary for Baseline Conditions

\begin{tabular}{|c|c|c|c|c|c|c|}
\hline Metal & \multicolumn{2}{|l|}{ Fe } & \multicolumn{3}{|c|}{ Cooper Units: $\mu \mathrm{g} / \mathrm{Nm}^{3} \mathrm{dry}, 3 \% \mathrm{O}_{2}$} \\
\hline Date & \multicolumn{2}{|c|}{$\mathbf{7 / 1 3 / 2 0 0 9}$} & \multicolumn{3}{|c|}{$\mathrm{M} 29$ Units: $\mu \mathrm{g} / \mathrm{Nm}^{3} \mathrm{dry}, 3 \% \mathrm{O}_{2}$} \\
\hline Location & \multicolumn{3}{|c|}{ ESPO } \\
\hline Run & $\begin{array}{c}\text { Cooper } \\
\text { Total }\end{array}$ & Cooper Unc & M29 Total & $\begin{array}{c}\text { Cooper } \\
\text { Total }\end{array}$ & Cooper Unc & M29 Total \\
\hline $\mathbf{1}$ & 774.6 & 9.7 & 1327.9 & 169.5 & 0.7 & 207.0 \\
\hline $\mathbf{2}$ & 484.2 & 1.7 & 824.0 & 122.6 & 0.5 & 185.2 \\
\hline $\mathbf{3}$ & 412.2 & 1.5 & 558.1 & 92.0 & 0.5 & 152.4 \\
\hline Average & 557.0 & 4.3 & 903.3 & 128.0 & 0.6 & 181.6 \\
\hline RPD & \multicolumn{7}{|c|}{47.4} & & 34.6 & \\
\hline
\end{tabular}

Table L-40. Iron Comparison Summary for ACl Conditions

\begin{tabular}{|c|c|c|c|c|c|c|}
\hline Metal & \multicolumn{3}{|l|}{$\mathbf{F e}$} & \multicolumn{3}{|c|}{ Cooper Units: $\mu \mathrm{g} / \mathrm{Nm}^{3}$ dry, $3 \% \mathrm{O}_{2}$} \\
\hline Date & \multicolumn{3}{|l|}{ 7/14/2009 } & \multicolumn{3}{|c|}{ M29 Units: $\mu \mathrm{g} / \mathrm{Nm}^{3}$ dry, $3 \% \mathrm{O}_{2}$} \\
\hline Location & \multicolumn{3}{|c|}{ ESPO } & \multicolumn{3}{|c|}{ Stack } \\
\hline Run & $\begin{array}{c}\text { Cooper } \\
\text { Total }\end{array}$ & Cooper Unc & M29 Total & $\begin{array}{c}\text { Cooper } \\
\text { Total }\end{array}$ & Cooper Unc & M29 Total \\
\hline 1 & 1085.4 & 2.5 & 2016.5 & 254.2 & 0.9 & 573.2 \\
\hline 2 & 629.8 & 1.6 & 2352.1 & 255.9 & 0.8 & 360.0 \\
\hline 3 & 400.6 & 1.2 & 2003.4 & 178.0 & 0.7 & 261.1 \\
\hline Average & 705.3 & 1.8 & 2124.0 & 229.4 & 0.8 & 398.1 \\
\hline RPD & \multicolumn{3}{|c|}{100.3} & \multicolumn{3}{|c|}{$\overline{53.8}$} \\
\hline
\end{tabular}


Table L-41. Mercury Comparison Summary for $\mathrm{Br}+\mathrm{ACl}$ Conditions

\begin{tabular}{|c|c|c|c|c|c|c|}
\hline Metal & \multicolumn{1}{|l|}{ Hg } & \multicolumn{3}{|c|}{ Cooper Units: $\mu \mathrm{g} / \mathrm{Nm}^{3} \mathrm{dry}, 3 \% \mathrm{O}_{2}$} \\
\hline Date & \multicolumn{2}{|c|}{ 7/12/2009 } & \multicolumn{3}{|c|}{ M29 Units: $\mu \mathrm{g} / \mathrm{Nm}^{3} \mathrm{dry}, 3 \% \mathrm{O}_{2}$} \\
\hline Location & \multicolumn{3}{|c|}{ ESPO } \\
\hline Run & $\begin{array}{c}\text { Cooper } \\
\text { Total }\end{array}$ & Cooper Unc & M29 Total & $\begin{array}{c}\text { Cooper } \\
\text { Total }\end{array}$ & Cooper Unc & M29 Total \\
\hline $\mathbf{1}$ & 12.6 & 1.2 & 14.8 & 12.6 & 0.9 & 7.6 \\
\hline $\mathbf{2}$ & 12.7 & 2.9 & 14.1 & 11.2 & 0.9 & 8.3 \\
\hline $\mathbf{3}$ & 11.5 & 1.0 & 13.3 & 8.0 & 0.8 & 7.8 \\
\hline Average & 12.3 & 1.7 & 14.0 & 10.6 & 0.9 & 7.9 \\
\hline RPD & \multicolumn{7}{|c|}{13.4} & & 29.5 & \\
\hline
\end{tabular}

Table L-42. Mercury Comparison Summary for Baseline Conditions

\begin{tabular}{|c|c|c|c|c|c|c|}
\hline Metal & \multicolumn{3}{|l|}{$\mathrm{Hg}$} & \multicolumn{3}{|c|}{ Cooper Units: $\mu \mathrm{g} / \mathrm{Nm}^{3}$ dry, $3 \% \mathrm{O}_{2}$} \\
\hline Date & \multicolumn{3}{|l|}{$7 / 13 / 2009$} & \multicolumn{3}{|c|}{ M29 Units: $\mu \mathrm{g} / \mathrm{Nm}^{3}$ dry, $3 \% \mathrm{O}_{2}$} \\
\hline Location & \multicolumn{3}{|c|}{ ESPO } & \multicolumn{3}{|c|}{ Stack } \\
\hline Run & $\begin{array}{c}\text { Cooper } \\
\text { Total }\end{array}$ & Cooper Unc & M29 Total & $\begin{array}{c}\text { Cooper } \\
\text { Total }\end{array}$ & Cooper Une & M29 Total \\
\hline 1 & 27.0 & 1.8 & 18.2 & 18.4 & 0.8 & 15.5 \\
\hline 2 & 25.6 & 1.2 & 27.0 & 17.3 & 0.8 & 14.2 \\
\hline 3 & 24.4 & 1.2 & 33.7 & 18.0 & 0.8 & 21.4 \\
\hline Average & 25.7 & 1.4 & 26.3 & 17.9 & 0.8 & 17.0 \\
\hline RPD & \multicolumn{3}{|c|}{2.5} & \multicolumn{3}{|c|}{4.9} \\
\hline
\end{tabular}

Table L-43. Mercury Comparison Summary for ACI Conditions

\begin{tabular}{|c|c|c|c|c|c|c|}
\hline Metal & \multicolumn{3}{|l|}{$\mathrm{Hg}$} & \multicolumn{3}{|c|}{ Cooper Units: $\mu \mathrm{g} / \mathrm{Nm}^{3}$ dry, $3 \% \mathrm{O}_{2}$} \\
\hline Date & \multicolumn{3}{|l|}{$7 / 14 / 2009$} & \multicolumn{3}{|c|}{ M29 Units: $\mu \mathrm{g} / \mathrm{Nm}^{3}$ dry, $3 \% \mathrm{O}_{2}$} \\
\hline Location & \multicolumn{3}{|c|}{ ESPO } & \multicolumn{3}{|c|}{ Stack } \\
\hline Run & $\begin{array}{c}\text { Cooper } \\
\text { Total }\end{array}$ & Cooper Unc & M29 Total & $\begin{array}{c}\text { Cooper } \\
\text { Total }\end{array}$ & Cooper Unc & M29 Total \\
\hline 1 & 17.4 & 1.0 & 15.7 & 11.0 & 1.1 & 9.6 \\
\hline 2 & 11.0 & 0.9 & 11.7 & 9.4 & 0.7 & 7.1 \\
\hline 3 & 12.6 & 0.9 & 15.7 & 9.2 & 0.7 & 8.7 \\
\hline Average & 13.7 & 0.9 & 14.4 & 9.9 & 0.9 & 8.5 \\
\hline$\overline{R P D}$ & \multicolumn{3}{|c|}{4.8} & \multicolumn{3}{|c|}{15.1} \\
\hline
\end{tabular}


Table L-44. Molybdenum Comparison Summary for $\mathrm{Br}+\mathrm{ACl}$ Conditions

\begin{tabular}{|c|c|c|c|c|c|c|}
\hline Metal & \multicolumn{2}{|l|}{ Mo } & \multicolumn{3}{|c|}{ Cooper Units: $\mu \mathrm{g} / \mathrm{Nm}^{3}$ dry, $3 \% \mathrm{O}_{2}$} \\
\hline Date & \multicolumn{2}{|c|}{$\mathbf{7 / 1 2 / 2 0 0 9}$} & \multicolumn{3}{|c|}{ M29 Units: $\mu \mathrm{g} / \mathrm{Nm}^{3}$ dry, $3 \% \mathrm{O}_{2}$} \\
\hline Location & \multicolumn{3}{|c|}{ ESPO } \\
\hline Run & $\begin{array}{c}\text { Cooper } \\
\text { Total }\end{array}$ & Cooper Unc & M29 Total & $\begin{array}{c}\text { Cooper } \\
\text { Total }\end{array}$ & Cooper Unc & M29 Total \\
\hline $\mathbf{1}$ & 0.6 & 1.2 & 5.6 & 0.1 & 0.9 & 5.3 \\
\hline $\mathbf{2}$ & 0.6 & 3.3 & 4.9 & 0.1 & 1.0 & 5.2 \\
\hline $\mathbf{3}$ & 0.9 & 1.1 & 6.1 & 0.0 & 1.0 & 5.8 \\
\hline Average & 0.7 & 1.8 & 5.6 & 0.1 & 1.0 & 5.5 \\
\hline RPD & \multicolumn{7}{|c|}{ N/A } & & N/A \\
\hline
\end{tabular}

Table L-45. Molybdenum Comparison Summary for Baseline Conditions

\begin{tabular}{|c|c|c|c|c|c|c|}
\hline Metal & \multicolumn{2}{|l|}{ Mo } & \multicolumn{3}{|c|}{ Cooper Units: $\mu \mathrm{g} / \mathrm{Nm}^{3} \mathrm{dry}, 3 \% \mathrm{O}_{2}$} \\
\hline Date & \multicolumn{2}{|c|}{ 7/13/2009 } & \multicolumn{3}{|c|}{ M29 Units: $\mu \mathrm{g} / \mathrm{Nm}^{3} \mathrm{dry}, 3 \% \mathrm{O}_{2}$} \\
\hline Location & \multicolumn{3}{|c|}{ ESPO } \\
\hline Run & $\begin{array}{c}\text { Cooper } \\
\text { Total }\end{array}$ & Cooper Unc & M29 Total & $\begin{array}{c}\text { Cooper } \\
\text { Total }\end{array}$ & Cooper Unc & M29 Total \\
\hline $\mathbf{1}$ & 2.0 & 1.7 & 6.1 & 0.7 & 1.0 & 5.5 \\
\hline $\mathbf{2}$ & 0.9 & 1.4 & 6.7 & 0.7 & 1.0 & 5.3 \\
\hline $\mathbf{3}$ & 0.2 & 1.4 & 5.5 & 0.4 & 0.9 & 5.5 \\
\hline Average & 1.0 & 1.5 & 6.1 & 0.6 & 1.0 & 5.4 \\
\hline RPD & \multicolumn{7}{|c|}{ N/A } & & N/A & \\
\hline
\end{tabular}

Table L-46. Molybdenum Comparison Summary for ACI Conditions

\begin{tabular}{|c|c|c|c|c|c|c|}
\hline Metal & \multicolumn{3}{|l|}{ Mo } & \multicolumn{3}{|c|}{ Cooper Units: $\mu \mathrm{g} / \mathrm{Nm}^{3}$ dry, $3 \% \mathrm{O}_{2}$} \\
\hline Date & \multicolumn{3}{|l|}{$7 / 14 / 2009$} & \multicolumn{3}{|c|}{ M29 Units: $\mu \mathrm{g} / \mathrm{Nm}^{3}$ dry, $3 \% \mathrm{O}_{2}$} \\
\hline Location & \multicolumn{3}{|c|}{ ESPO } & \multicolumn{3}{|c|}{ Stack } \\
\hline Run & $\begin{array}{c}\text { Cooper } \\
\text { Total }\end{array}$ & Cooper Unc & M29 Total & $\begin{array}{c}\text { Cooper } \\
\text { Total }\end{array}$ & Cooper Unc & M29 Total \\
\hline 1 & 2.4 & 1.1 & 7.3 & 1.5 & 1.2 & 7.7 \\
\hline 2 & 1.1 & 1.1 & 7.4 & 0.9 & 0.9 & 5.8 \\
\hline 3 & 0.4 & 1.0 & 7.1 & 0.8 & 0.9 & 5.5 \\
\hline Average & 1.3 & 1.1 & 7.3 & 1.1 & 1.0 & 6.3 \\
\hline$\overline{R P D}$ & \multicolumn{3}{|c|}{138.7} & \multicolumn{3}{|c|}{142.0} \\
\hline
\end{tabular}


Table L-47. Manganese Comparison Summary for $\mathrm{Br}+\mathrm{ACl}$ Conditions

\begin{tabular}{|c|c|c|c|c|c|c|}
\hline Metal & \multicolumn{2}{|l|}{ Mn } & \multicolumn{3}{|c|}{ Cooper Units: $\mu \mathrm{g} / \mathrm{Nm}^{3} \mathrm{dry}, 3 \% \mathrm{O}_{2}$} \\
\hline Date & \multicolumn{2}{|c|}{$\mathbf{7 / 1 2 / 2 0 0 9}$} & \multicolumn{3}{|c|}{ M29 Units: $\mu \mathrm{g} / \mathrm{Nm}^{3} \mathrm{dry}, 3 \% \mathrm{O}_{2}$} \\
\hline Location & \multicolumn{3}{|c|}{ ESPO } \\
\hline Run & $\begin{array}{c}\text { Cooper } \\
\text { Total }\end{array}$ & Cooper Unc & M29 Total & $\begin{array}{c}\text { Cooper } \\
\text { Total }\end{array}$ & Cooper Unc & M29 Total \\
\hline $\mathbf{1}$ & 21.8 & 1.6 & 15.6 & 16.3 & 1.3 & 29.1 \\
\hline $\mathbf{2}$ & 13.8 & 4.5 & 22.4 & 14.7 & 1.3 & 20.3 \\
\hline $\mathbf{3}$ & 7.9 & 1.5 & 29.1 & 16.4 & 1.3 & 19.0 \\
\hline Average & 14.5 & 2.5 & 22.4 & 15.8 & 1.3 & 22.8 \\
\hline RPD & \multicolumn{7}{|c|}{42.8} & & 36.2 & \\
\hline
\end{tabular}

Table L-48. Manganese Comparison Summary for Baseline Conditions

\begin{tabular}{|c|c|c|c|c|c|c|}
\hline Metal & \multicolumn{3}{|l|}{ Mn } & \multicolumn{3}{|c|}{ Cooper Units: $\mu \mathrm{g} / \mathrm{Nm}^{3}$ dry, $3 \% \mathrm{O}_{2}$} \\
\hline Date & \multicolumn{3}{|l|}{$7 / 13 / 2009$} & \multicolumn{3}{|c|}{ M29 Units: $\mu \mathrm{g} / \mathrm{Nm}^{3}$ dry, $3 \% \mathrm{O}_{2}$} \\
\hline Location & \multicolumn{3}{|c|}{ ESPO } & \multicolumn{3}{|c|}{ Stack } \\
\hline Run & $\begin{array}{c}\text { Cooper } \\
\text { Total }\end{array}$ & Cooper Unc & M29 Total & $\begin{array}{c}\text { Cooper } \\
\text { Total }\end{array}$ & Cooper Une & M29 Total \\
\hline 1 & 21.7 & 3.3 & 43.7 & 18.1 & 1.3 & 59.5 \\
\hline 2 & 13.8 & 1.9 & 72.1 & 17.2 & 1.4 & 82.6 \\
\hline 3 & 13.0 & 1.9 & 17.3 & 15.3 & 1.3 & 76.3 \\
\hline Average & 16.2 & 2.4 & 44.4 & 16.9 & 1.3 & 72.8 \\
\hline RPD & \multicolumn{3}{|c|}{93.2} & \multicolumn{3}{|c|}{124.7} \\
\hline
\end{tabular}

Table L-49. Manganese Comparison Summary for ACI Conditions

\begin{tabular}{|c|c|c|c|c|c|c|}
\hline Metal & \multicolumn{3}{|l|}{ Mn } & \multicolumn{3}{|c|}{ Cooper Units: $\mu \mathrm{g} / \mathrm{Nm}^{3}$ dry, $3 \% \mathrm{O}_{2}$} \\
\hline Date & \multicolumn{3}{|l|}{ 7/14/2009 } & \multicolumn{3}{|c|}{ M29 Units: $\mu \mathrm{g} / \mathrm{Nm}^{3}$ dry, $3 \% \mathrm{O}_{2}$} \\
\hline Location & \multicolumn{3}{|c|}{ ESPO } & \multicolumn{3}{|c|}{ Stack } \\
\hline Run & $\begin{array}{c}\text { Cooper } \\
\text { Total }\end{array}$ & Cooper Unc & M29 Total & $\begin{array}{c}\text { Cooper } \\
\text { Total }\end{array}$ & Cooper Unc & M29 Total \\
\hline 1 & 31.6 & 1.5 & 144.7 & 20.4 & 1.3 & 130.1 \\
\hline 2 & 18.5 & 1.5 & 63.4 & 19.6 & 1.2 & 65.3 \\
\hline 3 & 10.8 & 1.4 & 113.3 & 15.4 & 1.2 & 62.7 \\
\hline Average & 20.3 & 1.5 & 107.1 & 18.4 & 1.3 & 86.0 \\
\hline$\overline{R P D}$ & \multicolumn{3}{|c|}{136.3} & \multicolumn{3}{|c|}{129.4} \\
\hline
\end{tabular}


Table L-50. Nickel Comparison Summary for $\mathrm{Br}+\mathrm{ACl}$ Conditions

\begin{tabular}{|c|c|c|c|c|c|c|}
\hline Metal & \multicolumn{3}{|l|}{$\mathbf{N i}$} & \multicolumn{3}{|c|}{ Cooper Units: $\mu \mathrm{g} / \mathrm{Nm}^{3}$ dry, $3 \% \mathrm{O}_{2}$} \\
\hline Date & \multicolumn{3}{|l|}{$7 / 12 / 2009$} & \multicolumn{3}{|c|}{ M29 Units: $\mu \mathrm{g} / \mathrm{Nm}^{3}$ dry, $3 \% \mathrm{O}_{2}$} \\
\hline Location & \multicolumn{3}{|c|}{ ESPO } & \multicolumn{3}{|c|}{ Stack } \\
\hline Run & $\begin{array}{c}\text { Cooper } \\
\text { Total }\end{array}$ & Cooper Unc & M29 Total & $\begin{array}{c}\text { Cooper } \\
\text { Total }\end{array}$ & Cooper Unc & M29 Total \\
\hline 1 & 7.3 & 0.5 & 5.4 & 0.6 & 0.3 & $<3.7$ \\
\hline 2 & 9.6 & 1.1 & 7.1 & 0.3 & 0.3 & $<3.4$ \\
\hline 3 & 7.3 & 0.4 & $<4.4$ & 0.6 & 0.3 & $<4.4$ \\
\hline Average & 8.1 & 0.7 & 5.6 & 0.5 & 0.3 & $<3.9$ \\
\hline RPD & \multicolumn{3}{|c|}{35.9} & \multicolumn{3}{|c|}{ N/A } \\
\hline
\end{tabular}

Table L-51. Nickel Comparison Summary for Baseline Conditions

\begin{tabular}{|c|c|c|c|c|c|c|}
\hline Metal & \multicolumn{2}{|l|}{$\mathbf{N i}$} & \multicolumn{3}{|c|}{ Cooper Units: $\mu \mathrm{g} / \mathrm{Nm}^{3} \mathrm{dry}, 3 \% \mathrm{O}_{2}$} \\
\hline Date & \multicolumn{2}{|c|}{ 7/13/2009 } & \multicolumn{3}{|c|}{ M29 Units: $\mu \mathrm{g} / \mathrm{Nm}^{3} \mathrm{dry}, 3 \% \mathrm{O}_{2}$} \\
\hline Location & \multicolumn{3}{|c|}{ ESPO } \\
\hline Run & $\begin{array}{c}\text { Cooper } \\
\text { Total }\end{array}$ & Cooper Unc & M29 Total & $\begin{array}{c}\text { Cooper } \\
\text { Total }\end{array}$ & Cooper Unc & M29 Total \\
\hline $\mathbf{1}$ & 11.3 & 9.6 & $<5.0$ & 1.6 & 0.3 & 5.6 \\
\hline $\mathbf{2}$ & 33.2 & 0.8 & $<4.4$ & 0.3 & 0.3 & $<4.0$ \\
\hline $\mathbf{3}$ & 2.5 & 0.4 & $<4.2$ & 0.4 & 0.3 & $<3.6$ \\
\hline Average & 15.7 & 3.6 & $<4.5$ & 0.8 & 0.3 & $<4.4$ \\
\hline RPD & \multicolumn{7}{|c|}{ N/A } & & N/A & \\
\hline
\end{tabular}

Table L-52. Nickel Comparison Summary for ACl Conditions

\begin{tabular}{|c|c|c|c|c|c|c|}
\hline Metal & \multicolumn{3}{|l|}{$\mathbf{N i}$} & \multicolumn{3}{|c|}{ Cooper Units: $\mu \mathrm{g} / \mathrm{Nm}^{3}$ dry, $3 \% \mathrm{O}_{2}$} \\
\hline Date & \multicolumn{3}{|l|}{ 7/14/2009 } & \multicolumn{3}{|c|}{ M29 Units: $\mu \mathrm{g} / \mathrm{Nm}^{3}$ dry, $3 \% \mathrm{O}_{2}$} \\
\hline Location & \multicolumn{3}{|c|}{ ESPO } & \multicolumn{3}{|c|}{ Stack } \\
\hline Run & $\begin{array}{c}\text { Cooper } \\
\text { Total }\end{array}$ & Cooper Unc & M29 Total & $\begin{array}{c}\text { Cooper } \\
\text { Total }\end{array}$ & Cooper Unc & M29 Total \\
\hline 1 & 8.9 & 0.4 & $<6.6$ & 1.1 & 0.3 & 9.1 \\
\hline 2 & 2.9 & 0.3 & $<6.5$ & 0.5 & 0.3 & $<5.6$ \\
\hline 3 & 2.9 & 0.3 & $<6.3$ & 0.5 & 0.3 & $<4.4$ \\
\hline Average & 4.9 & 0.4 & $<6.5$ & 0.7 & 0.3 & $<6.4$ \\
\hline RPD & \multicolumn{3}{|c|}{ N/A } & \multicolumn{3}{|c|}{ N/A } \\
\hline
\end{tabular}


Table L-53. Lead Comparison Summary for $\mathrm{Br}+\mathrm{ACl}$ Conditions

\begin{tabular}{|c|c|c|c|c|c|c|}
\hline Metal & \multicolumn{2}{|l|}{ Pb } & \multicolumn{3}{|c|}{ Cooper Units: $\mu \mathrm{g} / \mathrm{Nm}^{3} \mathrm{dry}, 3 \% \mathrm{O}_{2}$} \\
\hline Date & \multicolumn{2}{|c|}{$\mathbf{7 / 1 2 / 2 0 0 9}$} & \multicolumn{3}{|c|}{ M29 Units: $\mu \mathrm{g} / \mathrm{Nm}^{3} \mathrm{dry}, 3 \% \mathrm{O}_{2}$} \\
\hline Location & \multicolumn{3}{|c|}{ ESPO } \\
\hline Run & $\begin{array}{c}\text { Cooper } \\
\text { Total }\end{array}$ & Cooper Unc & M29 Total & $\begin{array}{c}\text { Cooper } \\
\text { Total }\end{array}$ & Cooper Unc & M29 Total \\
\hline $\mathbf{1}$ & 4.2 & 1.0 & 7.3 & 2.3 & 1.7 & $<2.4$ \\
\hline $\mathbf{2}$ & 4.2 & 2.6 & $<1.9$ & 1.1 & 2.3 & $<2.1$ \\
\hline $\mathbf{3}$ & 2.0 & 0.9 & $<1.7$ & 1.0 & 1.7 & $<2.5$ \\
\hline Average & 3.4 & 1.5 & 3.6 & 1.5 & 1.9 & $<2.3$ \\
\hline RPD & \multicolumn{7}{|c|}{} & 5.0 & & N/A & \\
\hline
\end{tabular}

Table L-54. Lead Comparison Summary for Baseline Conditions

\begin{tabular}{|c|c|c|c|c|c|c|}
\hline Metal & \multicolumn{3}{|l|}{$\mathbf{P b}$} & \multicolumn{3}{|c|}{ Cooper Units: $\mu \mathrm{g} / \mathrm{Nm}^{3}$ dry, $3 \% \mathrm{O}_{2}$} \\
\hline Date & \multicolumn{3}{|l|}{$7 / 13 / 2009$} & \multicolumn{3}{|c|}{ M29 Units: $\mu \mathrm{g} / \mathrm{Nm}^{3}$ dry, $3 \% \mathrm{O}_{2}$} \\
\hline Location & \multicolumn{3}{|c|}{ ESPO } & \multicolumn{3}{|c|}{ Stack } \\
\hline Run & $\begin{array}{c}\text { Cooper } \\
\text { Total }\end{array}$ & Cooper Unc & M29 Total & $\begin{array}{c}\text { Cooper } \\
\text { Total }\end{array}$ & Cooper Une & M29 Total \\
\hline 1 & 3.5 & 1.2 & 8.7 & 2.0 & 0.8 & $<1.9$ \\
\hline 2 & 2.1 & 1.1 & 1.8 & 1.5 & 1.2 & $<1.9$ \\
\hline 3 & 2.7 & 1.1 & 1.8 & 1.1 & 0.8 & $<1.7$ \\
\hline Average & 2.8 & 1.1 & 4.1 & 1.5 & 0.9 & $<1.8$ \\
\hline RPD & \multicolumn{3}{|c|}{39.4} & \multicolumn{3}{|c|}{ N/A } \\
\hline
\end{tabular}

Table L-55. Lead Comparison Summary for ACl Conditions

\begin{tabular}{|c|c|c|c|c|c|c|}
\hline Metal & \multicolumn{3}{|l|}{$\mathbf{P b}$} & \multicolumn{3}{|c|}{ Cooper Units: $\mu \mathrm{g} / \mathrm{Nm}^{3}$ dry, $3 \% \mathrm{O}_{2}$} \\
\hline Date & \multicolumn{3}{|l|}{$7 / 14 / 2009$} & \multicolumn{3}{|c|}{ M29 Units: $\mu \mathrm{g} / \mathrm{Nm}^{3}$ dry, $3 \% \mathrm{O}_{2}$} \\
\hline Location & \multicolumn{3}{|c|}{ ESPO } & \multicolumn{3}{|c|}{ Stack } \\
\hline Run & $\begin{array}{c}\text { Cooper } \\
\text { Total }\end{array}$ & Cooper Unc & M29 Total & $\begin{array}{c}\text { Cooper } \\
\text { Total }\end{array}$ & Cooper Unc & M29 Total \\
\hline 1 & 6.0 & 0.9 & 7.3 & 1.2 & 0.8 & $<2.5$ \\
\hline 2 & 3.2 & 0.9 & 7.3 & 1.4 & 1.2 & $<2.3$ \\
\hline 3 & 2.9 & 0.8 & 6.4 & 0.7 & 0.7 & 2.3 \\
\hline Average & 4.1 & 0.9 & 7.0 & 1.1 & 0.9 & $<2.4$ \\
\hline RPD & \multicolumn{3}{|c|}{$\overline{53.6}$} & \multicolumn{3}{|c|}{ N/A } \\
\hline
\end{tabular}


Table L-56. Antimony Comparison Summary for $\mathrm{Br}+\mathrm{ACl}$ Conditions

\begin{tabular}{|c|c|c|c|c|c|c|}
\hline Metal & \multicolumn{2}{|l|}{ Sb } & \multicolumn{3}{|c|}{ Cooper Units: $\mu \mathrm{g} / \mathrm{Nm}^{3}$ dry, $3 \% \mathrm{O}_{2}$} \\
\hline Date & \multicolumn{2}{|c|}{$\mathbf{7 / 1 2 / 2 0 0 9}$} & \multicolumn{3}{|c|}{ S29 Units: $\mu \mathrm{g} / \mathrm{Nm}^{3}$ dry, $3 \% \mathrm{O}_{2}$} \\
\hline Location & \multicolumn{3}{|c|}{ ESPO } \\
\hline Run & $\begin{array}{c}\text { Cooper } \\
\text { Total }\end{array}$ & Cooper Unc & M29 Total & $\begin{array}{c}\text { Cooper } \\
\text { Total }\end{array}$ & Cooper Unc & M29 Total \\
\hline $\mathbf{1}$ & 1.9 & 7.9 & $<0.6$ & 2.3 & 6.3 & $<0.6$ \\
\hline $\mathbf{2}$ & 0.1 & 22.1 & $<0.5$ & 2.8 & 6.6 & $<0.5$ \\
\hline $\mathbf{3}$ & 0.2 & 7.2 & $<0.5$ & 3.2 & 6.4 & $<0.6$ \\
\hline Average & 0.7 & 12.4 & $<0.5$ & 2.8 & 6.4 & $<0.6$ \\
\hline RPD & \multicolumn{7}{|c|}{ N/A } & & N/A & \\
\hline
\end{tabular}

Table L-57. Antimony Comparison Summary for Baseline Conditions

\begin{tabular}{|c|c|c|c|c|c|c|}
\hline Metal & \multicolumn{3}{|l|}{$\mathbf{S b}$} & \multicolumn{3}{|c|}{ Cooper Units: $\mu \mathrm{g} / \mathrm{Nm}^{3}$ dry, $3 \% \mathrm{O}_{2}$} \\
\hline Date & \multicolumn{3}{|l|}{$7 / 13 / 2009$} & \multicolumn{3}{|c|}{ M29 Units: $\mu \mathrm{g} / \mathrm{Nm}^{3}$ dry, $3 \% \mathrm{O}_{2}$} \\
\hline Location & \multicolumn{3}{|c|}{ ESPO } & \multicolumn{3}{|c|}{ Stack } \\
\hline Run & $\begin{array}{c}\text { Cooper } \\
\text { Total }\end{array}$ & Cooper Unc & M29 Total & $\begin{array}{c}\text { Cooper } \\
\text { Total }\end{array}$ & Cooper Unc & M29 Total \\
\hline 1 & 0.5 & 9.8 & $<0.8$ & 3.9 & 6.6 & $<0.6$ \\
\hline 2 & 3.4 & 9.2 & $<0.6$ & 0.1 & 6.7 & $<0.6$ \\
\hline 3 & 4.6 & 9.6 & $<0.6$ & 1.0 & 6.3 & $<0.6$ \\
\hline Average & 2.8 & 9.5 & $<0.6$ & 1.7 & 6.5 & $<0.6$ \\
\hline RPD & \multicolumn{3}{|c|}{ N/A } & \multicolumn{3}{|c|}{ N/A } \\
\hline
\end{tabular}

Table L-58. Antimony Comparison Summary for ACl Conditions

\begin{tabular}{|c|c|c|c|c|c|c|}
\hline Metal & \multicolumn{3}{|l|}{$\mathbf{S b}$} & \multicolumn{3}{|c|}{ Cooper Units: $\mu \mathrm{g} / \mathrm{Nm}^{3}$ dry, $3 \% \mathrm{O}_{2}$} \\
\hline Date & \multicolumn{3}{|l|}{$7 / 14 / 2009$} & \multicolumn{3}{|c|}{ M29 Units: $\mu \mathrm{g} / \mathrm{Nm}^{3}$ dry, $3 \% \mathrm{O}_{2}$} \\
\hline Location & \multicolumn{3}{|c|}{ ESPO } & \multicolumn{3}{|c|}{ Stack } \\
\hline Run & $\begin{array}{c}\text { Cooper } \\
\text { Total }\end{array}$ & Cooper Unc & M29 Total & $\begin{array}{c}\text { Cooper } \\
\text { Total }\end{array}$ & Cooper Unc & M29 Total \\
\hline 1 & 8.2 & 7.4 & $<1.1$ & 1.4 & 6.4 & $<0.7$ \\
\hline 2 & 5.1 & 7.5 & $<1.1$ & 4.2 & 6.0 & $<0.6$ \\
\hline 3 & 5.9 & 7.0 & $<1.1$ & 2.6 & 6.0 & $<0.6$ \\
\hline Average & 6.4 & 7.3 & $<1.1$ & 2.7 & 6.1 & $<0.6$ \\
\hline RPD & \multicolumn{3}{|c|}{ N/A } & \multicolumn{3}{|c|}{ N/A } \\
\hline
\end{tabular}


Table L-59. Selenium Comparison Summary for $\mathrm{Br}+\mathrm{ACl}$ Conditions

\begin{tabular}{|c|c|c|c|c|c|c|}
\hline Metal & \multicolumn{2}{|l|}{ Se } & \multicolumn{3}{|c|}{ Cooper Units: $\mu \mathrm{g} / \mathrm{Nm}^{3}$ dry, $3 \% \mathrm{O}_{2}$} \\
\hline Date & \multicolumn{3}{|c|}{$\mathbf{7 / 1 2 / 2 0 0 9}$} & \multicolumn{3}{|c|}{ M29 Units: $\mu \mathrm{g} / \mathrm{Nm}^{3}$ dry, $3 \% \mathrm{O}_{2}$} \\
\hline Location & \multicolumn{3}{|c|}{ ESPO } \\
\hline Run & $\begin{array}{c}\text { Cooper } \\
\text { Total }\end{array}$ & Cooper Unc & M29 Total & $\begin{array}{c}\text { Cooper } \\
\text { Total }\end{array}$ & Cooper Unc & M29 Total \\
\hline $\mathbf{1}$ & 243.2 & 1.9 & 815.9 & 81.0 & 0.6 & 117.6 \\
\hline $\mathbf{2}$ & 548.1 & 5.0 & 931.1 & 81.3 & 0.8 & 108.1 \\
\hline $\mathbf{3}$ & 326.9 & 2.1 & 859.3 & 88.6 & 0.7 & 138.1 \\
\hline Average & 372.7 & 3.0 & 868.8 & 83.6 & 0.7 & 121.3 \\
\hline RPD & \multicolumn{7}{|c|}{} & & 36.7 & \\
\hline
\end{tabular}

Table L-60. Selenium Comparison Summary for Baseline Conditions

\begin{tabular}{|c|c|c|c|c|c|c|}
\hline Metal & \multicolumn{3}{|l|}{$\mathbf{S e}$} & \multicolumn{3}{|c|}{ Cooper Units: $\mu \mathrm{g} / \mathrm{Nm}^{3}$ dry, $3 \% \mathrm{O}_{2}$} \\
\hline Date & \multicolumn{3}{|l|}{$7 / 13 / 2009$} & \multicolumn{3}{|c|}{ M29 Units: $\mu \mathrm{g} / \mathrm{Nm}^{3}$ dry, $3 \% \mathrm{O}_{2}$} \\
\hline Location & \multicolumn{3}{|c|}{ ESPO } & \multicolumn{3}{|c|}{ Stack } \\
\hline Run & $\begin{array}{c}\text { Cooper } \\
\text { Total }\end{array}$ & Cooper Unc & M29 Total & $\begin{array}{c}\text { Cooper } \\
\text { Total }\end{array}$ & Cooper Unc & M29 Total \\
\hline 1 & 654.7 & 4.3 & 883.2 & 85.9 & 0.6 & 100.7 \\
\hline 2 & 718.2 & 3.3 & 865.1 & 81.9 & 0.6 & 89.1 \\
\hline 3 & 680.4 & 3.3 & 368.3 & 74.2 & 0.6 & 92.9 \\
\hline Average & 684.4 & 3.6 & 705.5 & 80.6 & 0.6 & 94.2 \\
\hline RPD & \multicolumn{3}{|c|}{3.0} & \multicolumn{3}{|c|}{15.5} \\
\hline
\end{tabular}

Table L-61. Selenium Comparison Summary for ACI Conditions

\begin{tabular}{|c|c|c|c|c|c|c|}
\hline Metal & \multicolumn{3}{|l|}{ Se } & \multicolumn{3}{|c|}{ Cooper Units: $\mu \mathrm{g} / \mathrm{Nm}^{3}$ dry, $3 \% \mathrm{O}_{2}$} \\
\hline Date & \multicolumn{3}{|l|}{$7 / 14 / 2009$} & \multicolumn{3}{|c|}{ M29 Units: $\mu \mathrm{g} / \mathrm{Nm}^{3}$ dry, $3 \% \mathrm{O}_{2}$} \\
\hline Location & \multicolumn{3}{|c|}{ ESPO } & \multicolumn{3}{|c|}{ Stack } \\
\hline Run & $\begin{array}{c}\text { Cooper } \\
\text { Total }\end{array}$ & Cooper Unc & M29 Total & $\begin{array}{c}\text { Cooper } \\
\text { Total }\end{array}$ & Cooper Unc & M29 Total \\
\hline 1 & 643.1 & 2.5 & 876.1 & 93.5 & 0.7 & 87.0 \\
\hline 2 & 709.1 & 2.7 & 852.8 & 92.7 & 0.5 & 83.4 \\
\hline 3 & 700.3 & 2.6 & 734.9 & 78.6 & 0.6 & 91.0 \\
\hline Average & 684.2 & 2.6 & 821.2 & 88.3 & 0.6 & 87.1 \\
\hline RPD & \multicolumn{3}{|c|}{18.2} & \multicolumn{3}{|c|}{1.3} \\
\hline
\end{tabular}


Table L-62. Tin Comparison Summary for $\mathrm{Br}+\mathrm{ACl}$ Conditions

\begin{tabular}{|c|c|c|c|c|c|c|}
\hline Metal & \multicolumn{2}{|l|}{ Sn } & \multicolumn{3}{|c|}{ Cooper Units: $\mu \mathrm{g} / \mathrm{Nm}^{3} \mathrm{dry}, 3 \% \mathrm{O}_{2}$} \\
\hline Date & \multicolumn{3}{|c|}{$\mathbf{7 / 1 2 / 2 0 0 9}$} & \multicolumn{3}{|c|}{ M29 Units: $\mu \mathrm{g} / \mathrm{Nm}^{3} \mathrm{dry}, 3 \% \mathrm{O}_{2}$} \\
\hline Location & \multicolumn{3}{|c|}{ ESPO } \\
\hline Run & $\begin{array}{c}\text { Cooper } \\
\text { Total }\end{array}$ & Cooper Unc & M29 Total & $\begin{array}{c}\text { Cooper } \\
\text { Total }\end{array}$ & Cooper Unc & M29 Total \\
\hline $\mathbf{1}$ & 1.5 & 5.5 & $<7.0$ & 1.6 & 4.4 & $<2.8$ \\
\hline $\mathbf{2}$ & 2.7 & 15.3 & $<6.0$ & 6.7 & 4.6 & $<2.7$ \\
\hline $\mathbf{3}$ & 3.4 & 5.0 & 7.1 & 2.8 & 4.4 & $<2.9$ \\
\hline Average & 2.5 & 8.6 & $<6.7$ & 3.7 & 4.5 & $<2.8$ \\
\hline RPD & \multicolumn{7}{|c|}{ N/A } & & N/A & \\
\hline
\end{tabular}

Table L-63. Tin Comparison Summary for Baseline Conditions

\begin{tabular}{|c|c|c|c|c|c|c|}
\hline Metal & \multicolumn{2}{|l|}{ Sn } & \multicolumn{3}{|c|}{ Cooper Units: $\mu \mathrm{g} / \mathrm{Nm}^{3} \mathrm{dry}, 3 \% \mathrm{O}_{2}$} \\
\hline Date & \multicolumn{2}{|c|}{$\mathbf{7 / 1 3 / 2 0 0 9}$} & \multicolumn{3}{|c|}{ M29 Units: $\mu \mathrm{g} / \mathrm{Nm}^{3} \mathrm{dry}, 3 \% \mathrm{O}_{2}$} \\
\hline Location & \multicolumn{3}{|c|}{ ESPO } \\
\hline Run & $\begin{array}{c}\text { Cooper } \\
\text { Total }\end{array}$ & Cooper Unc & M29 Total & $\begin{array}{c}\text { Cooper } \\
\text { Total }\end{array}$ & Cooper Unc & M29 Total \\
\hline $\mathbf{1}$ & 5.3 & 6.8 & 6.0 & 2.1 & 4.5 & $<2.8$ \\
\hline $\mathbf{2}$ & 0.6 & 6.4 & $<2.6$ & 2.1 & 4.6 & $<2.9$ \\
\hline $\mathbf{3}$ & 5.1 & 6.6 & $<2.7$ & 3.1 & 4.4 & $<2.8$ \\
\hline Average & 3.7 & 6.6 & $<3.7$ & 2.4 & 4.5 & $<2.9$ \\
\hline RPD & \multicolumn{7}{|c|}{ N/A } & & N/A & \\
\hline
\end{tabular}

Table L-64. Tin Comparison Summary for ACI Conditions

\begin{tabular}{|c|c|c|c|c|c|c|}
\hline Metal & \multicolumn{3}{|l|}{ Sn } & \multicolumn{3}{|c|}{ Cooper Units: $\mu \mathrm{g} / \mathrm{Nm}^{3}$ dry, $3 \% \mathrm{O}_{2}$} \\
\hline Date & \multicolumn{3}{|l|}{$7 / 14 / 2009$} & \multicolumn{3}{|c|}{ M29 Units: $\mu \mathrm{g} / \mathrm{Nm}^{3}$ dry, $3 \% \mathrm{O}_{2}$} \\
\hline Location & \multicolumn{3}{|c|}{ ESPO } & \multicolumn{3}{|c|}{ Stack } \\
\hline Run & $\begin{array}{c}\text { Cooper } \\
\text { Total }\end{array}$ & Cooper Unc & M29 Total & $\begin{array}{c}\text { Cooper } \\
\text { Total }\end{array}$ & Cooper Unc & M29 Total \\
\hline 1 & 3.8 & 5.1 & $<3.4$ & 1.9 & 4.4 & $<2.9$ \\
\hline 2 & 1.1 & 5.2 & $<3.6$ & 0.0 & 4.2 & $<2.9$ \\
\hline 3 & 3.6 & 4.9 & $<3.2$ & 1.1 & 4.2 & $<2.9$ \\
\hline Average & 2.8 & 5.0 & $<3.4$ & 1.0 & 4.3 & $<2.9$ \\
\hline RPD & \multicolumn{3}{|c|}{ N/A } & \multicolumn{3}{|c|}{ N/A } \\
\hline
\end{tabular}


Table L-65. Strontium Comparison Summary for $\mathrm{Br}+\mathrm{ACl}$ Conditions

\begin{tabular}{|c|c|c|c|c|c|c|}
\hline Metal & \multicolumn{3}{|l|}{ Sr } & \multicolumn{3}{|c|}{ Cooper Units: $\mu \mathrm{g} / \mathrm{Nm}^{3} \mathrm{dry}, 3 \% \mathrm{O}_{2}$} \\
\hline Date & \multicolumn{2}{|c|}{$\mathbf{7 / 1 2 / 2 0 0 9}$} & \multicolumn{3}{|c|}{ M29 Units: $\mu \mathrm{g} / \mathrm{Nm}^{3} \mathrm{dry}, 3 \% \mathrm{O}_{2}$} \\
\hline Location & \multicolumn{3}{|c|}{ ESPO } \\
\hline Run & $\begin{array}{c}\text { Cooper } \\
\text { Total }\end{array}$ & Cooper Unc & M29 Total & $\begin{array}{c}\text { Cooper } \\
\text { Total }\end{array}$ & Cooper Unc & M29 Total \\
\hline $\mathbf{1}$ & 96.0 & 0.8 & 64.3 & 17.3 & 0.6 & 21.0 \\
\hline $\mathbf{2}$ & 49.5 & 2.2 & 29.2 & 10.9 & 0.7 & 17.4 \\
\hline $\mathbf{3}$ & 33.2 & 0.7 & 28.1 & 12.2 & 0.6 & 17.8 \\
\hline Average & 59.6 & 1.2 & 40.5 & 13.4 & 0.6 & 18.7 \\
\hline RPD & \multicolumn{7}{|c|}{38.0} & & 32.9 & \\
\hline
\end{tabular}

Table L-66. Strontium Comparison Summary for Baseline Conditions

\begin{tabular}{|c|c|c|c|c|c|c|}
\hline Metal & \multicolumn{3}{|l|}{ Sr } & \multicolumn{3}{|c|}{ Cooper Units: $\mu \mathrm{g} / \mathrm{Nm}^{3} \mathrm{dry}, 3 \% \mathrm{O}_{2}$} \\
\hline Date & \multicolumn{2}{|c|}{$\mathbf{7 / 1 3 / 2 0 0 9}$} & \multicolumn{3}{|c|}{$\mathrm{M} 29$ Units: $\mu \mathrm{g} / \mathrm{Nm}^{3} \mathrm{dry}, 3 \% \mathrm{O}_{2}$} \\
\hline Location & \multicolumn{3}{|c|}{ ESPO } \\
\hline Run & $\begin{array}{c}\text { Cooper } \\
\text { Total }\end{array}$ & Cooper Unc & M29 Total & $\begin{array}{c}\text { Cooper } \\
\text { Total }\end{array}$ & Cooper Unc & M29 Total \\
\hline $\mathbf{1}$ & 96.0 & 1.0 & 193.6 & 21.1 & 0.7 & 24.5 \\
\hline $\mathbf{2}$ & 59.1 & 0.9 & 71.8 & 16.9 & 0.7 & 21.8 \\
\hline $\mathbf{3}$ & 57.7 & 1.0 & 48.1 & 14.3 & 0.6 & 18.4 \\
\hline Average & 71.0 & 1.0 & 104.5 & 17.5 & 0.7 & 21.6 \\
\hline RPD & \multicolumn{7}{|c|}{38.2} & & 20.9 & \\
\hline
\end{tabular}

Table L-67. Strontium Comparison Summary for ACI Conditions

\begin{tabular}{|c|c|c|c|c|c|c|}
\hline Metal & \multicolumn{3}{|l|}{ Sr } & \multicolumn{3}{|c|}{ Cooper Units: $\mu \mathrm{g} / \mathrm{Nm}^{3} \mathrm{dry}, 3 \% \mathrm{O}_{2}$} \\
\hline Date & \multicolumn{3}{|c|}{$\mathbf{7 / 1 4 / 2 0 0 9}$} & \multicolumn{3}{|c|}{ M29 Units: $\mu \mathrm{g} / \mathrm{Nm}^{3} \mathrm{dry}, 3 \% \mathrm{O}_{2}$} \\
\hline Location & \multicolumn{3}{|c|}{ ESPO } \\
\hline Run & $\begin{array}{c}\text { Cooper } \\
\text { Total }\end{array}$ & Cooper Unc & M29 Total & $\begin{array}{c}\text { Cooper } \\
\text { Total }\end{array}$ & Cooper Unc & M29 Total \\
\hline $\mathbf{1}$ & 153.5 & 0.8 & 330.4 & 33.8 & 0.6 & 53.4 \\
\hline $\mathbf{2}$ & 79.9 & 0.7 & 329.9 & 33.3 & 0.6 & 48.0 \\
\hline $\mathbf{3}$ & 47.0 & 0.7 & 277.7 & 21.8 & 0.6 & 32.3 \\
\hline Average & 93.5 & 0.7 & 312.7 & 29.6 & 0.6 & 44.6 \\
\hline RPD & \multicolumn{7}{|c|}{108.0} & & 40.2 & \\
\hline
\end{tabular}


Table L-68. Titanium Comparison Summary for $\mathrm{Br}+\mathrm{ACl}$ Conditions

\begin{tabular}{|c|c|c|c|c|c|c|}
\hline Metal & \multicolumn{3}{|l|}{$\mathbf{T i}$} & \multicolumn{3}{|c|}{ Cooper Units: $\mu \mathrm{g} / \mathrm{Nm}^{3}$ dry, $3 \% \mathrm{O}_{2}$} \\
\hline Date & \multicolumn{3}{|l|}{$7 / 12 / 2009$} & \multicolumn{3}{|c|}{ M29 Units: $\mu \mathrm{g} / \mathrm{Nm}^{3}$ dry, $3 \% \mathrm{O}_{2}$} \\
\hline Location & \multicolumn{3}{|c|}{ ESPO } & \multicolumn{3}{|c|}{ Stack } \\
\hline Run & $\begin{array}{c}\text { Cooper } \\
\text { Total }\end{array}$ & Cooper Unc & M29 Total & $\begin{array}{c}\text { Cooper } \\
\text { Total }\end{array}$ & Cooper Unc & M29 Total \\
\hline 1 & 203.8 & 22.1 & 131.1 & 41.4 & 17.5 & 43.8 \\
\hline 2 & 116.6 & 61.5 & 59.7 & 25.0 & 18.4 & 35.1 \\
\hline 3 & 76.6 & 20.0 & 53.1 & 25.7 & 17.8 & 36.4 \\
\hline Average & 132.3 & 34.5 & 81.3 & 30.7 & 17.9 & 38.4 \\
\hline RPD & \multicolumn{3}{|c|}{47.8} & \multicolumn{3}{|c|}{22.4} \\
\hline
\end{tabular}

Table L-69. Titanium Comparison Summary for Baseline Conditions

\begin{tabular}{|c|c|c|c|c|c|c|}
\hline Metal & \multicolumn{2}{|l|}{ Ti } & \multicolumn{3}{|c|}{ Cooper Units: $\mu \mathrm{g} / \mathrm{Nm}^{3} \mathrm{dry}, 3 \% \mathrm{O}_{2}$} \\
\hline Date & \multicolumn{2}{|c|}{ 7/13/2009 } & \multicolumn{3}{|c|}{ M29 Units: $\mu \mathrm{g} / \mathrm{Nm}^{3} \mathrm{dry}, 3 \% \mathrm{O}_{2}$} \\
\hline Location & \multicolumn{3}{|c|}{ SSPO } \\
\hline Run & $\begin{array}{c}\text { Cooper } \\
\text { Total }\end{array}$ & Cooper Unc & M29 Total & $\begin{array}{c}\text { Cooper } \\
\text { Total }\end{array}$ & Cooper Unc & M29 Total \\
\hline $\mathbf{1}$ & 201.1 & 27.2 & 340.7 & 47.2 & 18.3 & 48.4 \\
\hline $\mathbf{2}$ & 124.6 & 25.7 & 100.2 & 34.7 & 18.7 & 42.3 \\
\hline $\mathbf{3}$ & 114.6 & 26.7 & 82.7 & 29.4 & 17.6 & 32.3 \\
\hline Average & 146.8 & 26.5 & 174.6 & 37.1 & 18.2 & 41.0 \\
\hline RPD & \multicolumn{7}{|c|}{17.3} & & 10.0 & \\
\hline
\end{tabular}

Table L-70. Titanium Comparison Summary for ACI Conditions

\begin{tabular}{|c|c|c|c|c|c|c|}
\hline Metal & \multicolumn{3}{|l|}{$\mathbf{T i}$} & \multicolumn{3}{|c|}{ Cooper Units: $\mu \mathrm{g} / \mathrm{Nm}^{3}$ dry, $3 \% \mathrm{O}_{2}$} \\
\hline Date & \multicolumn{3}{|l|}{$7 / 14 / 2009$} & \multicolumn{3}{|c|}{ M29 Units: $\mu \mathrm{g} / \mathrm{Nm}^{3}$ dry, $3 \% \mathrm{O}_{2}$} \\
\hline Location & \multicolumn{3}{|c|}{ ESPO } & \multicolumn{3}{|c|}{ Stack } \\
\hline Run & $\begin{array}{c}\text { Cooper } \\
\text { Total } \\
\end{array}$ & Cooper Unc & M29 Total & $\begin{array}{c}\text { Cooper } \\
\text { Total }\end{array}$ & Cooper Une & M29 Total \\
\hline 1 & 268.9 & 20.6 & 574.5 & 74.9 & 17.8 & 94.4 \\
\hline 2 & 172.0 & 20.8 & 594.8 & 76.6 & 16.8 & 94.5 \\
\hline 3 & 108.2 & 19.5 & 484.3 & 50.1 & 16.8 & 66.3 \\
\hline Average & 183.0 & 20.3 & 551.2 & 67.2 & 17.1 & 85.1 \\
\hline RPD & \multicolumn{3}{|c|}{100.3} & \multicolumn{3}{|c|}{23.5} \\
\hline
\end{tabular}


Table L-71. Thallium Comparison Summary for $\mathrm{Br}+\mathrm{ACl}$ Conditions

\begin{tabular}{|c|c|c|c|c|c|c|}
\hline Metal & \multicolumn{3}{|l|}{$\mathrm{Tl}$} & \multicolumn{3}{|c|}{ Cooper Units: $\mu \mathrm{g} / \mathrm{Nm}^{3}$ dry, $3 \% \mathrm{O}_{2}$} \\
\hline Date & \multicolumn{3}{|l|}{$7 / 12 / 2009$} & \multicolumn{3}{|c|}{ M29 Units: $\mu \mathrm{g} / \mathrm{Nm}^{3}$ dry, $3 \% \mathrm{O}_{2}$} \\
\hline Location & \multicolumn{3}{|c|}{ ESPO } & \multicolumn{3}{|c|}{ Stack } \\
\hline Run & $\begin{array}{c}\text { Cooper } \\
\text { Total }\end{array}$ & Cooper Unc & M29 Total & $\begin{array}{c}\text { Cooper } \\
\text { Total }\end{array}$ & Cooper Unc & M29 Total \\
\hline 1 & N/A & N/A & $<0.1$ & N/A & N/A & 0.1 \\
\hline 2 & N/A & N/A & $<0.1$ & N/A & N/A & 0.1 \\
\hline 3 & N/A & N/A & $<0.1$ & N/A & N/A & 0.1 \\
\hline Average & N/A & N/A & $<0.1$ & N/A & N/A & 0.1 \\
\hline RPD & \multicolumn{3}{|c|}{ N/A } & \multicolumn{3}{|c|}{ N/A } \\
\hline
\end{tabular}

Table L-72. Thallium Comparison Summary for Baseline Conditions

\begin{tabular}{|c|c|c|c|c|c|c|}
\hline Metal & \multicolumn{2}{|l|}{ Tl } & \multicolumn{3}{c|}{ Cooper Units: $\mu \mathrm{g} / \mathrm{Nm}^{3}$ dry, 3\% $\mathrm{O}_{2}$} \\
\hline Date & \multicolumn{2}{|c|}{ ESPO } & \multicolumn{3}{|c|}{ M29 Units: $\mu \mathrm{g} / \mathrm{Nm}^{3}$ dry, 3\% $\mathrm{O}_{2}$} \\
\hline Location & \multicolumn{3}{|c|}{ Stack } \\
\hline Run & $\begin{array}{c}\text { Cooper } \\
\text { Total }\end{array}$ & Cooper Unc & $\mathbf{M 2 9}$ Total & $\begin{array}{c}\text { Cooper } \\
\text { Total }\end{array}$ & Cooper Unc & M29 Total \\
\hline $\mathbf{1}$ & N/A & N/A & $<0.2$ & N/A & N/A & 0.1 \\
\hline $\mathbf{2}$ & N/A & N/A & 0.1 & N/A & N/A & 0.1 \\
\hline $\mathbf{3}$ & N/A & N/A & 0.1 & N/A & N/A & 0.1 \\
\hline Average & N/A & N/A & 0.1 & N/A & N/A & 0.1 \\
\hline RPD & \multicolumn{3}{|c|}{ N/A } & & N/A & \\
\hline
\end{tabular}

Table L-73. Thallium Comparison Summary for ACI Conditions

\begin{tabular}{|c|c|c|c|c|c|c|}
\hline Metal & \multicolumn{3}{|l|}{$\mathbf{T l}$} & \multicolumn{3}{|c|}{ Cooper Units: $\mu \mathrm{g} / \mathrm{Nm}^{3}$ dry, $3 \% \mathrm{O}_{2}$} \\
\hline Date & \multicolumn{3}{|l|}{$7 / 14 / 2009$} & \multicolumn{3}{|c|}{ M29 Units: $\mu \mathrm{g} / \mathrm{Nm}^{3}$ dry, $3 \% \mathrm{O}_{2}$} \\
\hline Location & \multicolumn{3}{|c|}{ ESPO } & \multicolumn{3}{|c|}{ Stack } \\
\hline Run & $\begin{array}{c}\text { Cooper } \\
\text { Total }\end{array}$ & Cooper Unc & M29 Total & $\begin{array}{c}\text { Cooper } \\
\text { Total }\end{array}$ & Cooper Une & M29 Total \\
\hline 1 & N/A & N/A & 0.2 & N/A & N/A & 0.1 \\
\hline 2 & N/A & N/A & 0.3 & N/A & N/A & 0.1 \\
\hline 3 & N/A & N/A & 0.2 & N/A & N/A & 0.1 \\
\hline Average & N/A & N/A & 0.2 & N/A & N/A & 0.1 \\
\hline RPD & \multicolumn{3}{|c|}{ N/A } & \multicolumn{3}{|c|}{ N/A } \\
\hline
\end{tabular}


Table L-74. Vandium Comparison Summary for $\mathrm{Br}+\mathrm{ACl}$ Conditions

\begin{tabular}{|c|c|c|c|c|c|c|}
\hline Metal & \multicolumn{3}{|c|}{ V } & \multicolumn{3}{|c|}{ Cooper Units: $\mu \mathrm{g} / \mathrm{Nm}^{3}$ dry, $3 \% \mathrm{O}_{2}$} \\
\hline Date & \multicolumn{2}{|c|}{$\mathbf{7 / 1 2 / 2 0 0 9}$} & \multicolumn{3}{|c|}{ S29 Units: $\mu \mathrm{g} / \mathrm{Nm}^{3}$ dry, $3 \% \mathrm{O}_{2}$} \\
\hline Location & \multicolumn{3}{|c|}{ ESPO } \\
\hline Run & $\begin{array}{c}\text { Cooper } \\
\text { Total }\end{array}$ & Cooper Unc & M29 Total & $\begin{array}{c}\text { Cooper } \\
\text { Total }\end{array}$ & Cooper Unc & M29 Total \\
\hline $\mathbf{1}$ & 12.0 & 11.0 & 7.5 & 2.7 & 8.7 & 2.8 \\
\hline $\mathbf{2}$ & 7.1 & 30.6 & 3.6 & 1.8 & 9.1 & 2.2 \\
\hline $\mathbf{3}$ & 5.1 & 10.0 & 3.1 & 1.9 & 8.9 & 2.3 \\
\hline Average & 8.0 & 17.2 & 4.7 & 2.1 & 8.9 & 2.4 \\
\hline RPD & \multicolumn{3}{|c|}{ N/A } & & N/A \\
\hline
\end{tabular}

Table L-75. Vandium Comparison Summary for Baseline Conditions

\begin{tabular}{|c|c|c|c|c|c|c|}
\hline Metal & \multicolumn{4}{|c|}{ V } & \multicolumn{3}{|c|}{ Cooper Units: $\mu \mathrm{g} / \mathrm{Nm}^{3} \mathrm{dry}, 3 \% \mathrm{O}_{2}$} \\
\hline Date & \multicolumn{2}{|c|}{$\mathbf{7 / 1 3 / 2 0 0 9}$} & \multicolumn{3}{|c|}{ M29 Units: $\mu \mathrm{g} / \mathrm{Nm}^{3} \mathrm{dry}, 3 \% \mathrm{O}_{2}$} \\
\hline Location & \multicolumn{3}{|c|}{ ESPO } \\
\hline Run & $\begin{array}{c}\text { Cooper } \\
\text { Total }\end{array}$ & Cooper Unc & M29 Total & $\begin{array}{c}\text { Cooper } \\
\text { Total }\end{array}$ & Cooper Unc & M29 Total \\
\hline $\mathbf{1}$ & 12.6 & 13.5 & 19.5 & 2.9 & 9.1 & 3.1 \\
\hline $\mathbf{2}$ & 7.8 & 12.8 & 6.2 & 2.7 & 9.3 & 2.7 \\
\hline $\mathbf{3}$ & 7.1 & 13.3 & 5.0 & 1.9 & 8.8 & 2.0 \\
\hline Average & 9.2 & 13.2 & 10.2 & 2.5 & 9.1 & 2.6 \\
\hline RPD & \multicolumn{7}{|c|}{ N/A } & & N/A & \\
\hline
\end{tabular}

Table L-76. Vandium Comparison Summary for ACI Conditions

\begin{tabular}{|c|c|c|c|c|c|c|}
\hline Metal & \multicolumn{3}{|l|}{$\mathbf{V}$} & \multicolumn{3}{|c|}{ Cooper Units: $\mu \mathrm{g} / \mathrm{Nm}^{3}$ dry, $3 \% \mathrm{O}_{2}$} \\
\hline Date & \multicolumn{3}{|l|}{$7 / 14 / 2009$} & \multicolumn{3}{|c|}{ M29 Units: $\mu \mathrm{g} / \mathrm{Nm}^{3}$ dry, $3 \% \mathrm{O}_{2}$} \\
\hline Location & \multicolumn{3}{|c|}{ ESPO } & \multicolumn{3}{|c|}{ Stack } \\
\hline Run & $\begin{array}{c}\text { Cooper } \\
\text { Total }\end{array}$ & Cooper Unc & M29 Total & $\begin{array}{c}\text { Cooper } \\
\text { Total }\end{array}$ & Cooper Unc & M29 Total \\
\hline 1 & 18.8 & 10.3 & 30.8 & 5.2 & 8.9 & 6.3 \\
\hline 2 & 11.0 & 10.3 & 31.7 & 5.3 & 8.4 & 6.5 \\
\hline 3 & 6.5 & 9.7 & 26.5 & 3.6 & 8.4 & 4.3 \\
\hline Average & 12.1 & 10.1 & 29.7 & 4.7 & 8.5 & 5.7 \\
\hline RPD & \multicolumn{3}{|c|}{84.0} & \multicolumn{3}{|c|}{ N/A } \\
\hline
\end{tabular}


Table L-77. Zinc Comparison Summary for $\mathrm{Br}+\mathrm{ACl}$ Conditions

\begin{tabular}{|c|c|c|c|c|c|c|}
\hline Metal & \multicolumn{3}{|l|}{ Zn } & \multicolumn{3}{|c|}{ Cooper Units: $\mu \mathrm{g} / \mathrm{Nm}^{3}$ dry, $3 \% \mathrm{O}_{2}$} \\
\hline Date & \multicolumn{3}{|l|}{ 7/12/2009 } & \multicolumn{3}{|c|}{ M29 Units: $\mu \mathrm{g} / \mathrm{Nm}^{3}$ dry, $3 \% \mathrm{O}_{2}$} \\
\hline Location & \multicolumn{3}{|c|}{ ESPO } & \multicolumn{3}{|c|}{ Stack } \\
\hline Run & $\begin{array}{c}\text { Cooper } \\
\text { Total }\end{array}$ & Cooper Unc & M29 Total & $\begin{array}{c}\text { Cooper } \\
\text { Total }\end{array}$ & Cooper Unc & M29 Total \\
\hline 1 & 5.5 & 0.6 & 21.0 & 1.1 & 0.5 & 16.0 \\
\hline 2 & 3.3 & 1.6 & 15.3 & 2.4 & 0.5 & 15.9 \\
\hline 3 & 2.7 & 0.5 & 8.4 & 2.8 & 0.5 & 21.2 \\
\hline Average & 3.8 & 0.9 & 14.9 & 2.1 & 0.5 & 17.7 \\
\hline RPD & \multicolumn{3}{|c|}{118.2} & \multicolumn{3}{|c|}{157.7} \\
\hline
\end{tabular}

Table L-78. Zinc Comparison Summary for Baseline Conditions

\begin{tabular}{|c|c|c|c|c|c|c|}
\hline Metal & \multicolumn{2}{|l|}{ Zn } & \multicolumn{3}{|c|}{ Cooper Units: $\mu \mathrm{g} / \mathrm{Nm}^{3}$ dry, $3 \% \mathrm{O}_{2}$} \\
\hline Date & \multicolumn{2}{|l|}{$7 / \mathbf{1 3 / 2 0 0 9}$} & \multicolumn{2}{|c|}{ M29 Units: $\mu \mathrm{g} / \mathrm{Nm}^{3}$ dry, $3 \% \mathrm{O}_{2}$} \\
\hline Location & \multicolumn{2}{|c|}{ ESPO } \\
\hline Run & $\begin{array}{c}\text { Cooper } \\
\text { Total }\end{array}$ & Cooper Unc & M29 Total & $\begin{array}{c}\text { Cooper } \\
\text { Total }\end{array}$ & Cooper Unc & M29 Total \\
\hline $\mathbf{1}$ & 5.5 & 1.5 & 17.2 & 7.0 & 0.5 & 8.6 \\
\hline $\mathbf{2}$ & 5.9 & 0.7 & 13.7 & 3.4 & 0.5 & 12.3 \\
\hline $\mathbf{3}$ & 5.4 & 0.7 & 18.3 & 1.1 & 0.5 & 9.5 \\
\hline Average & 5.6 & 0.9 & 16.4 & 3.9 & 0.5 & 10.1 \\
\hline RPD & & 97.7 & & & 89.8 & \\
\hline
\end{tabular}

Table L-79. Zinc Comparison Summary for ACI Conditions

\begin{tabular}{|c|c|c|c|c|c|c|}
\hline Metal & \multicolumn{2}{|l|}{ Zn } & \multicolumn{3}{|c|}{ Cooper Units: $\mu \mathrm{g} / \mathrm{Nm}^{3}$ dry, $3 \% \mathrm{O}_{2}$} \\
\hline Date & \multicolumn{2}{|l|}{$7 / \mathbf{1 4} / \mathbf{2 0 0 9}$} & \multicolumn{2}{|c|}{ M29 Units: $\mu \mathrm{g} / \mathrm{Nm}^{3}$ dry, $3 \% \mathrm{O}_{2}$} \\
\hline Location & \multicolumn{3}{|c|}{ ESPO } \\
\hline Run & $\begin{array}{c}\text { Cooper } \\
\text { Total }\end{array}$ & Cooper Unc & M29 Total & $\begin{array}{c}\text { Cooper } \\
\text { Total }\end{array}$ & Cooper Unc & M29 Total \\
\hline $\mathbf{1}$ & 8.6 & 0.5 & 18.9 & 3.4 & 0.5 & 12.7 \\
\hline $\mathbf{2}$ & 6.2 & 0.5 & 21.0 & 2.5 & 0.4 & 10.5 \\
\hline $\mathbf{3}$ & 5.0 & 0.5 & 21.8 & 3.4 & 0.4 & 7.0 \\
\hline Average & 6.6 & 0.5 & 20.6 & 3.1 & 0.4 & 10.1 \\
\hline RPD & & 103.2 & & 106.0 & \\
\hline
\end{tabular}




\section{APPENDIX M - ASH TRACE ELEMENT DATA}


Table M-2 below shows the trace element concentrations for the collected fly ash by field. To calculate an average trace metal concentration of the fly ash, a weighted average of the individual field concentrations was used. Table M-1 shows the fraction of the fly ash captured by field. Since data for only fields 1 and 4 and 5 were available, new weighted fractions had to be calculated. The equation below shows how the new weighted averages of fly action fraction captured by field were calculated.

\section{Table M-1. Fraction of Fly Ash Captured by Field}

Field Fraction of Fly Ash Captured

$\begin{array}{ll}1 & 0.94 \\ 2 & 0.042 \\ 3 & 0.01 \\ 4 \& 5 & 0.004 \\ 6 \& 7 & 0.002\end{array}$

Field 1 New $=0.94 / 0.944=0.996$

Field $4 \& 5$ New $=\frac{0.004}{0.944}=0.004$

To calculate the average trace metal concentration the concentration for each field was multiplied by the fraction of captured fly ash from that field. The equation below shows this calculation.

Avg $=0.996 *$ Field 1 Concentration $+0.004 *$ Field $4 \& 5$ Concentration

Table M-2. Trace Element Concentration in the Fly Ash by ESP Field

\begin{tabular}{|c|c|c|c|c|c|c|c|c|}
\hline Date & \multicolumn{2}{|c|}{$6 / 11 / 2009$} & \multicolumn{2}{|c|}{$6 / 12 / 2009$} & \multicolumn{2}{|c|}{$7 / 12 / 2009$} & \multicolumn{2}{|c|}{$7 / 14 / 2009$} \\
\hline Element & Field 1 & $\begin{array}{c}\text { Field } \\
4 \& 5\end{array}$ & Field 1 & $\begin{array}{c}\text { Field } \\
4 \& 5\end{array}$ & Field 1 & $\begin{array}{c}\text { Field } \\
4 \& 5\end{array}$ & Field 1 & $\begin{array}{c}\text { Field } \\
4 \& 5\end{array}$ \\
\hline $\mathrm{Ag}$ & 1.2 & 1.4 & 1.2 & 1.4 & 1.1 & 1.4 & 1.2 & 1.5 \\
\hline As & 16.7 & 41.8 & 20.4 & 40.2 & 13.9 & 39.3 & 15.1 & 39.0 \\
\hline $\mathrm{Ba}$ & 2480 & 2970 & 2750 & 3010 & 1880 & 3350 & 1770 & 3300 \\
\hline $\mathrm{Be}$ & 5.5 & 6.1 & 5.8 & 6.1 & 4.4 & 5.9 & 4.6 & 5.9 \\
\hline $\mathrm{Cd}$ & 0.7 & 1.7 & 0.8 & 1.7 & 0.7 & 1.9 & 0.8 & 1.9 \\
\hline Co & 23.8 & 31.4 & 24.8 & 31.8 & 21.1 & 32.5 & 21.7 & 30.8 \\
\hline $\mathrm{Cr}$ & 94.4 & 120 & 96.5 & 125 & 89.4 & 131 & 89.4 & 128 \\
\hline $\mathrm{Cu}$ & 100 & 203 & 120 & 165 & 108 & 170 & 110 & 153 \\
\hline $\mathrm{Hg}$ & 0.04 & 0.04 & 0.05 & 0.04 & 0.71 & 0.59 & 0.63 & 0.65 \\
\hline $\mathrm{Mn}$ & 380 & 667 & 402 & 617 & 561 & 575 & 530 & 574 \\
\hline $\mathrm{Ni}$ & 70.2 & 85.6 & 70.7 & 83.6 & 61.5 & 91.6 & 63.3 & 85.7 \\
\hline $\mathrm{Pb}$ & 37.7 & 68.9 & 42.5 & 64.5 & 38.2 & 70.5 & 41.7 & 66.7 \\
\hline $\mathrm{Sb}$ & 3.4 & 7.4 & 3.5 & 7.1 & 3.4 & 7.6 & 3.6 & 7.7 \\
\hline $\mathrm{Se}$ & 21.4 & 192 & 16.4 & 213 & 15.2 & 176 & 20.2 & 188 \\
\hline $\mathrm{TI}$ & 1.0 & 1.8 & 1.3 & 1.8 & 0.6 & 2.0 & 0.9 & 1.9 \\
\hline V & 199 & 330 & 206 & 340 & 199 & 379 & 201 & 381 \\
\hline $\mathrm{Zn}$ & 83.5 & 203 & 91.9 & 176 & 87.2 & 186 & 83.0 & 178 \\
\hline
\end{tabular}


Table M-3. Fly Ash Trace Element Concentrations

\begin{tabular}{|c|c|c|c|}
\hline & \multicolumn{3}{|c|}{ Ash Trace Element Concentration (lb/TBTU) } \\
\hline Date & $6 / 12 / 09$ & $7 / 14 / 09$ & $7 / 12 / 09$ \\
\hline Condition & Baseline & ACI & $\mathrm{ACI}+\mathrm{Br}$ \\
\hline Ag & 17.3 & 18.2 & 15.9 \\
\hline As & 300 & 225 & 198 \\
\hline Ba & 40278 & 26274 & 26676 \\
\hline Be & 85.5 & 68.3 & 62.2 \\
\hline Cd & 11.9 & 12.4 & 9.9 \\
\hline Co & 364 & 322 & 299 \\
\hline $\mathrm{Cr}$ & 1414 & 1325 & 1266 \\
\hline $\mathbf{C u}$ & 1764 & 1627 & 1538 \\
\hline Hg & 0.5 & 8.8 & 11.7 \\
\hline Mn & 5894 & 7836 & 7931 \\
\hline $\mathbf{N i}$ & 1036 & 937 & 871 \\
\hline $\mathbf{P b}$ & 623 & 619 & 542 \\
\hline $\mathbf{S b}$ & 51.3 & 54.2 & 48.3 \\
\hline Se & 253 & 309 & 225 \\
\hline Tl & 19.1 & 12.8 & 8.9 \\
\hline $\mathbf{V}$ & 3020 & 2984 & 2819 \\
\hline $\mathbf{Z n}$ & 1350 & 1234 & 1239 \\
\hline
\end{tabular}




\section{APPENDIX N - XFM RUN DATA}


$\square \mathrm{BL} \square \mathrm{Br}+\mathrm{ACl} \square \mathrm{ACl}$

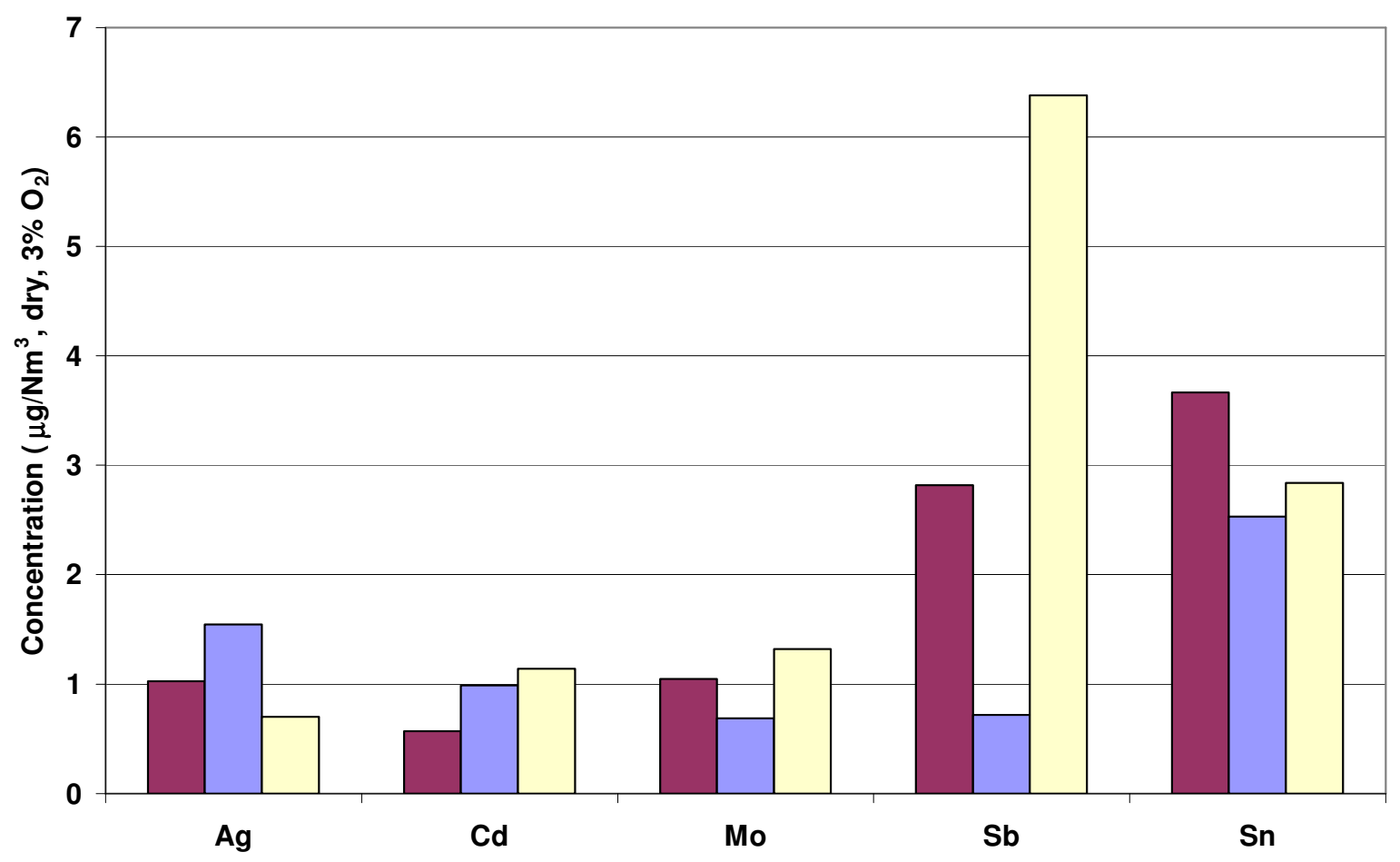

Figure N-1. XFM ESP Outlet Metals within Uncertainty

$\square \mathrm{BL} \square \mathrm{Br}+\mathrm{ACl} \square \mathrm{ACl}$

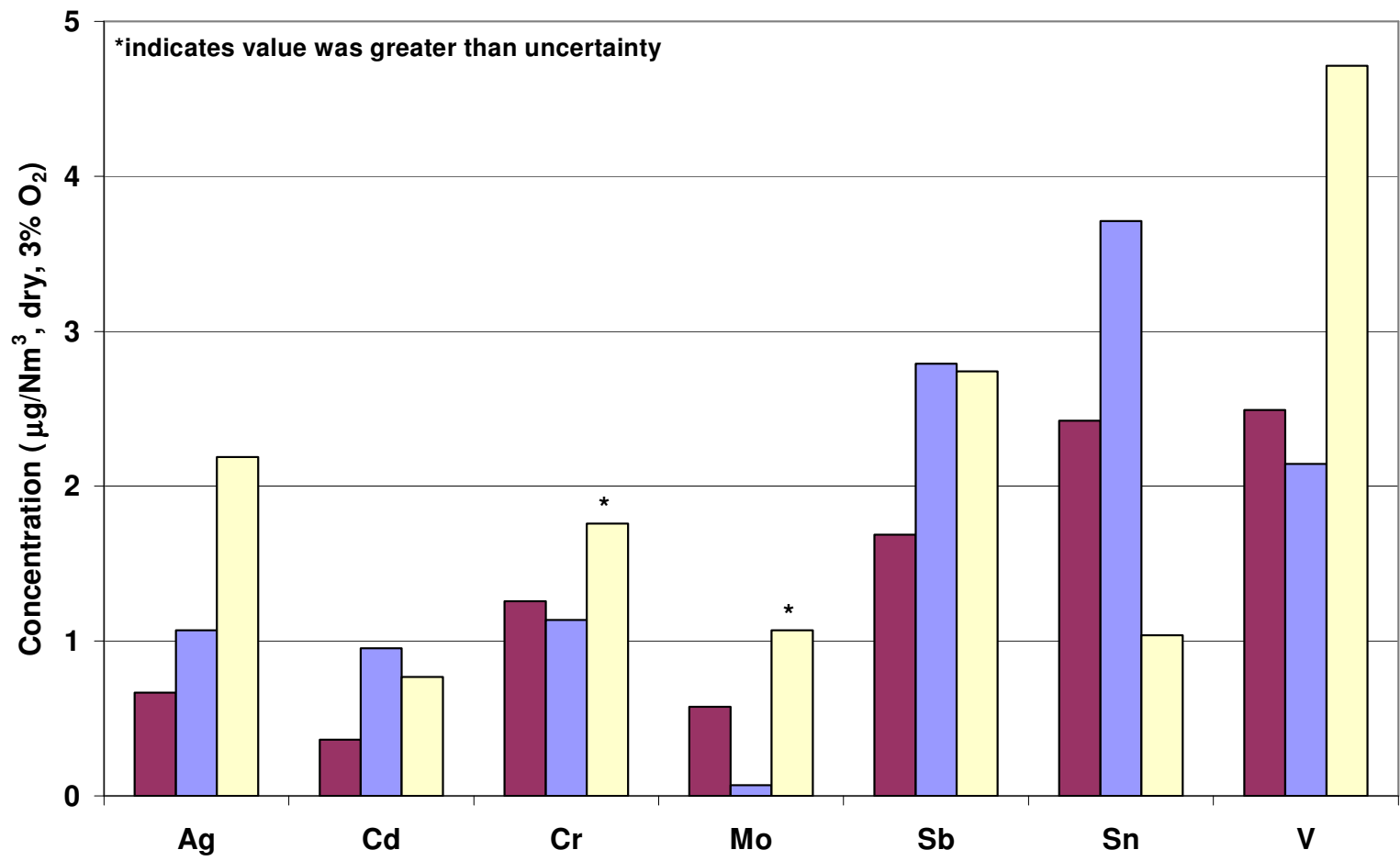

Figure N-2. XFM Stack Metals within Uncertainty 
$\square \mathrm{BL} \square \mathrm{Br}+\mathrm{ACl} \square \mathrm{ACl}$

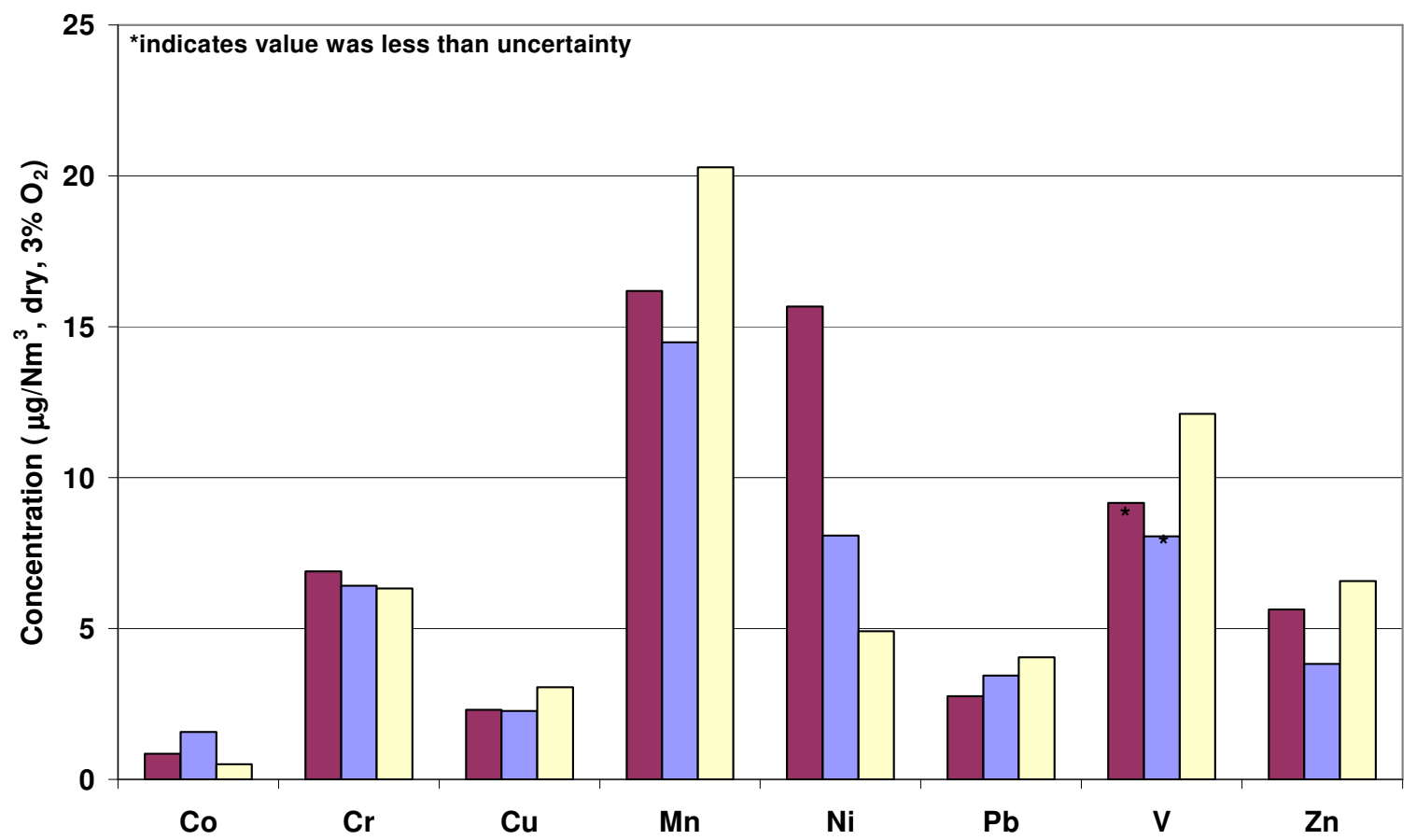

Figure N-3. XFM ESP Outlet Metals near Uncertainty

$\square \mathrm{BL} \square \mathrm{Br}+\mathrm{ACl} \square \mathrm{ACl}$

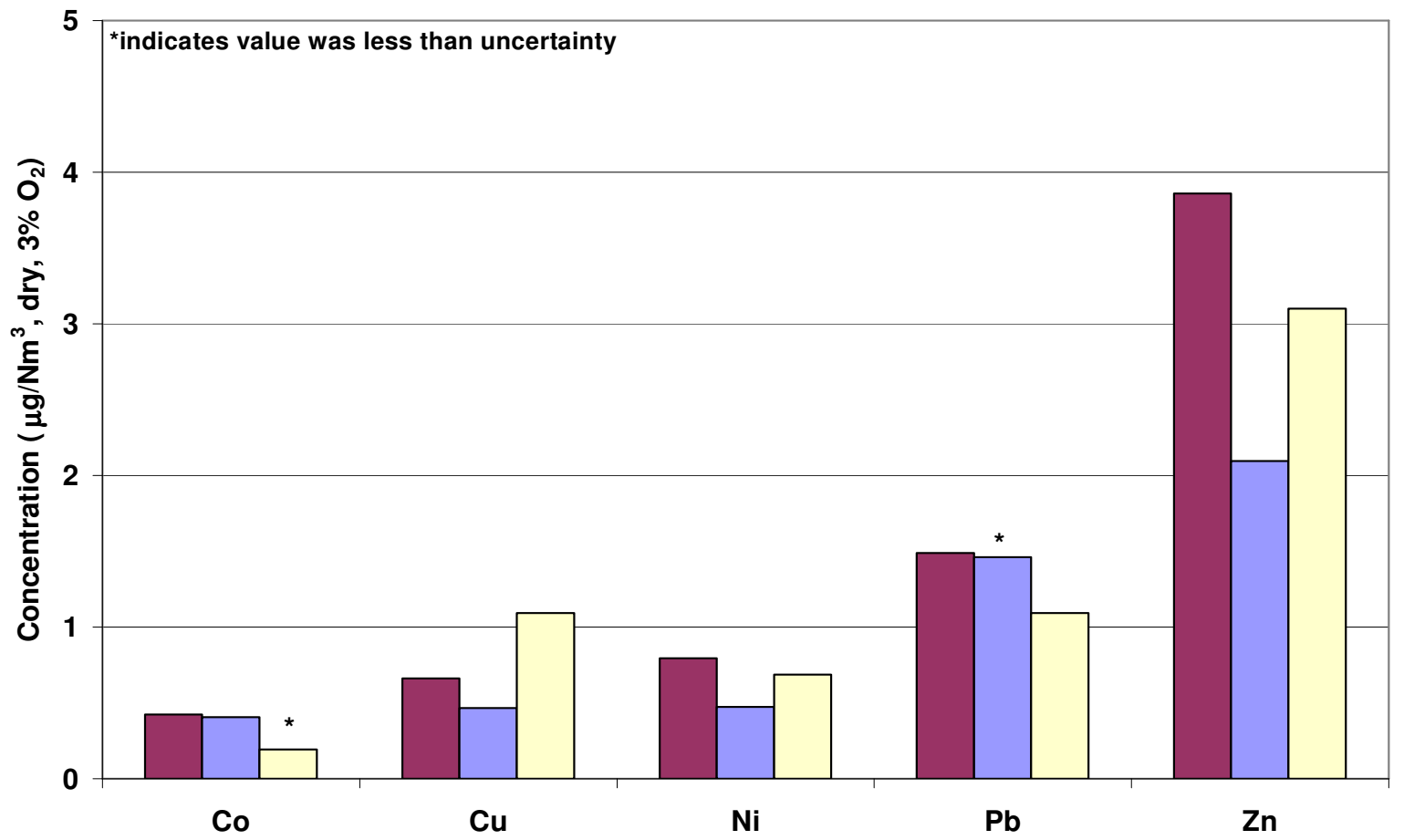

Figure N-4. XFM Stack Metals near Uncertainty 


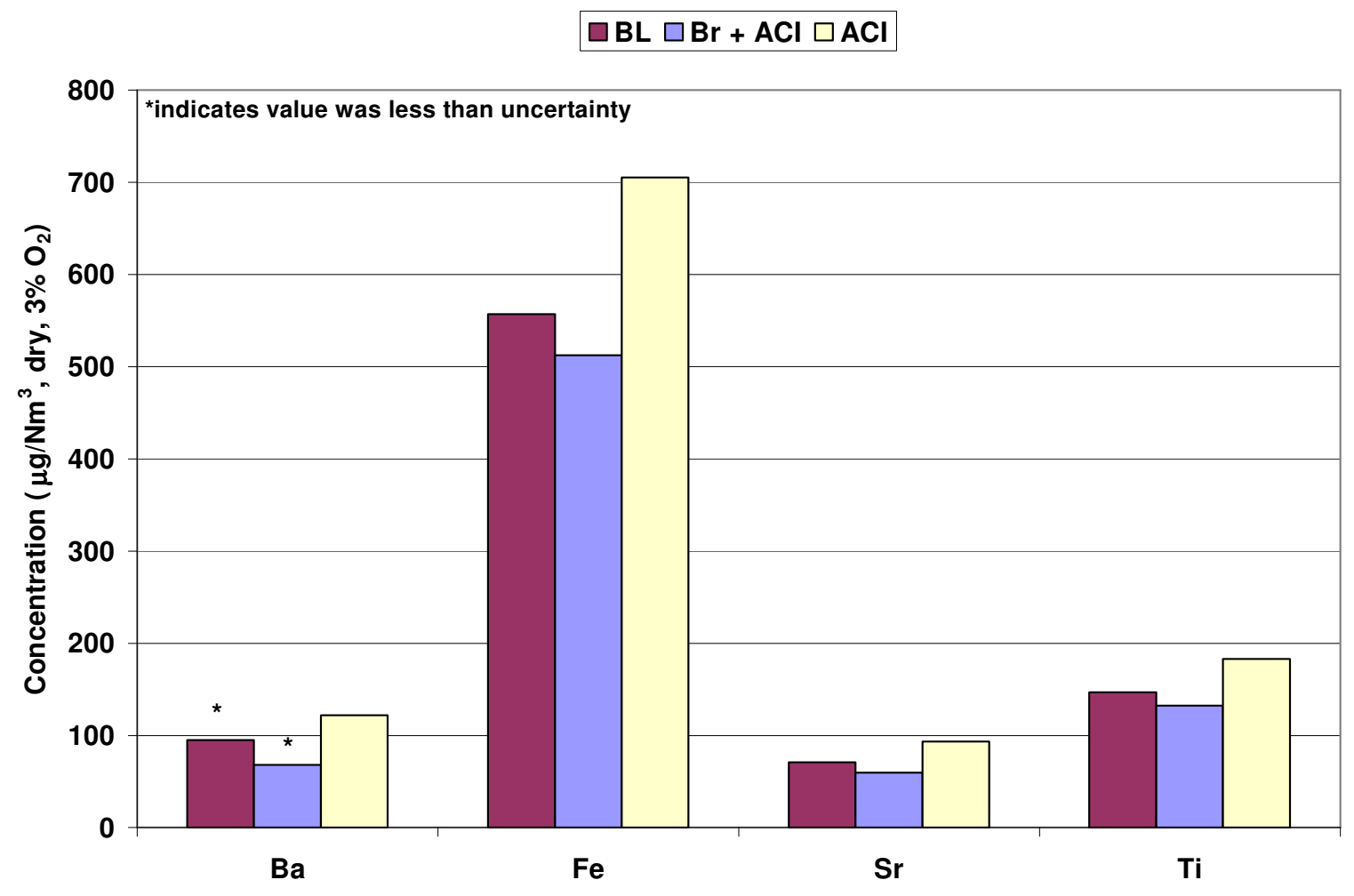

Figure N-5. XFM ESP Outlet Metals Greater than Uncertainty

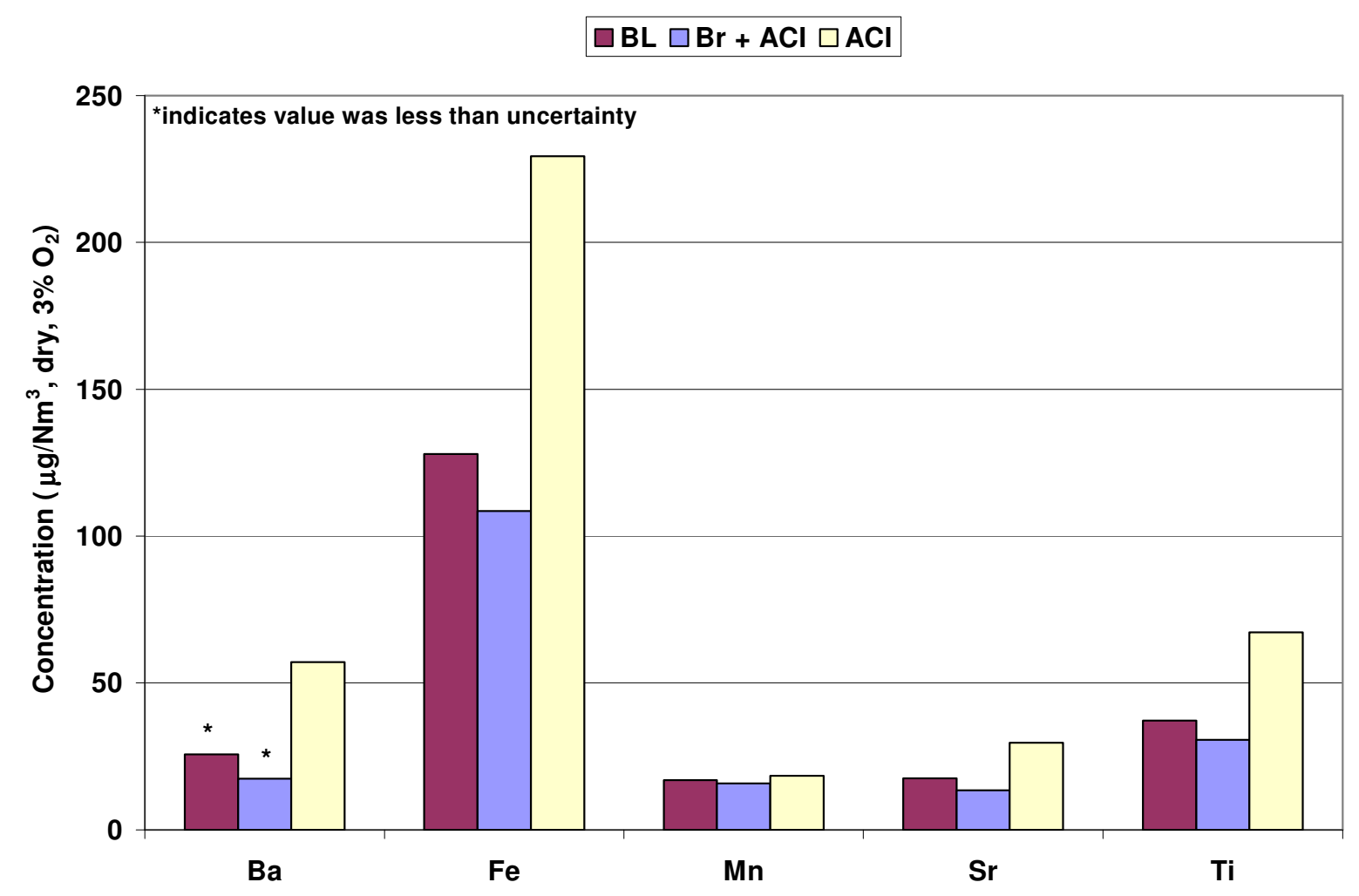

Figure N-6. XFM Stack Metals Greater than Uncertainty 
APPENDIX O - M5 AND M17 RESULTS 
Table 0-1. Outlet Particulate Loading Measurements for $\mathrm{CaBr}_{2}$ Injection (Method 5)

\begin{tabular}{|c|c|c|c|c|}
\hline Date & Start Time & End Time & $\begin{array}{c}\text { Outlet Particulate } \\
\text { Loading } \\
\text { (milligrain/dscf at } \\
7 \% \mathrm{O}_{2} \text { ) }\end{array}$ & $\begin{array}{c}\text { Outlet Particulate } \\
\text { Loading } \\
\left(\mathbf{1 0}^{-3} \mathrm{lb} / \mathrm{MMBtu}\right)\end{array}$ \\
\hline $7 / 12 / 2009$ & 8:01 & 10:01 & 3.99 & 8.45 \\
\hline $7 / 12 / 2009$ & $10: 45$ & $12: 45$ & 1.44 & 3.04 \\
\hline $7 / 12 / 2009$ & $13: 35$ & $15: 35$ & 1.81 & 3.84 \\
\hline Average & & & 2.41 & 5.11 \\
\hline Std Dev & & & 1.38 & 2.92 \\
\hline
\end{tabular}

Table 0-2. Baseline Outlet Particulate Loading Measurements (Method 5)

$\begin{array}{ccccc}\text { Date } & \text { Start Time } & \text { End Time } & \begin{array}{c}\text { Outlet Particulate } \\ \text { Loading } \\ \text { (milligrain/dscf at }\end{array} & \begin{array}{c}\text { Outlet Particulate } \\ \text { Loading } \\ \left(\mathbf{1 0} \mathbf{O}^{-3} \mathbf{l b} / \mathbf{M M B} \text { M) }\right.\end{array} \\ 7 / 13 / 2009 & & & 11.80 & 25.00 \\ 7 / 13 / 2009 & 7: 44 & 12: 32 & 3.91 & 8.28 \\ 7 / 13 / 2009 & 10: 32 & 15: 04 & 2.57 & 5.44 \\ \text { Average } & 13: 04 & & \mathbf{6 . 0 9} & \mathbf{1 2 . 9 1} \\ \text { Std Dev } & & & \mathbf{4 . 9 9} & \mathbf{1 0 . 5 7}\end{array}$

Table 0-3. Outlet Particulate Loading Measurements for Sorbent Injected at $1.9 \mathrm{lb} /$ MMacf (Method 5)

$\begin{array}{ccccc}\text { Date } & \text { Start Time } & \text { End Time } & \begin{array}{c}\text { Outlet Particulate } \\ \text { Loading } \\ \text { (milligrain/dscf at }\end{array} & \begin{array}{c}\text { Outlet Particulate } \\ \text { Loading } \\ (\mathbf{1 0}-\mathbf{3} \text { lb/MMBtu) }\end{array} \\ 7 / 14 / 2009 & & & 20.99 & 44.46 \\ 7 / 14 / 2009 & 7: 30 & 12: 05 & 20.90 & 44.26 \\ 7 / 14 / 2009 & 10: 05 & 15: 27 & 15.86 & 33.59 \\ \text { Average } & 13: 27 & & \mathbf{1 9 . 2 5} & \mathbf{4 0 . 7 7} \\ \text { Std Dev } & & & \mathbf{2 . 9 4} & \mathbf{6 . 2 2}\end{array}$

Table 0-4. Comparison of Average Baseline and Sorbent Injection Particulate Loading Measurements (Method 5)

Ave. Outlet (milligrain/dscf at $7 \% \mathrm{O}_{2}$ ) Ave. Outlet $\left(1^{-3} \mathrm{lb} / \mathrm{MMBtu}\right)$

Baseline
6.09
12.94
$\mathrm{CaBr}_{2}$ injection
2.41

5.11
ACI 1.9 lb/MMacf

19.25

40.77 
Table 0-5. Comparison of Method 5 and Method 17 Average Particulate Loading Measurements at the ESPO

$\begin{array}{ccccc} & \begin{array}{c}\text { Date } \\ \mathbf{( 2 0 0 9 )}\end{array} & \text { Condition } & \begin{array}{c}\text { Outlet Particulate } \\ \text { Loading } \\ \text { (milligrain/dscf at }\end{array} & \begin{array}{c}\text { Outlet Particulate } \\ \text { Loading } \\ (\mathbf{1 0}-\mathbf{3} \mathbf{l b} / \mathbf{M M B t u})\end{array} \\ \text { Method 17 } & 6 / 10-6 / 11 & \text { Baseline } & 3.01 & 6.38 \\ \text { Method 5 } & 7 / 13 & \text { Baseline } & 6.09 & 12.91 \\ \text { Method 17 } & 6 / 13-6 / 15 & \text { ACI } & 1.93 & 4.10 \\ \text { Method 5 } & 7 / 14 & \text { ACI } & 19.25 & 40.77\end{array}$

Table 0-6. Baseline Particulate Loading Measurements at ESP Inlet

\begin{tabular}{|c|c|c|c|c|c|c|}
\hline Run \# & Port \# & Date & $\begin{array}{c}\text { Start } \\
\text { Time }\end{array}$ & $\begin{array}{c}\text { End } \\
\text { Time }\end{array}$ & $\begin{array}{c}\text { Inlet Particulate } \\
\text { Loading } \\
\text { (milligrain/dscf at 7\% } \\
\mathbf{O}_{2} \text { ) }\end{array}$ & $\begin{array}{c}\text { Inlet Particulate } \\
\text { Loading } \\
\text { (10-3 lb/MMBtu) }\end{array}$ \\
\hline 1 & $2 \mathrm{D} 2-2$ & $6 / 10 / 2009$ & $9: 08$ & $9: 33$ & 4357 & 9227 \\
\hline 2 & $2 \mathrm{D} 2-5$ & $6 / 10 / 2009$ & $10: 25$ & $10: 50$ & 5853 & 12396 \\
\hline 3 & $2 \mathrm{D} 2-9$ & $6 / 10 / 2009$ & $11: 09$ & $11: 34$ & 4458 & 9443 \\
\hline 4 & $2 \mathrm{D} 2-11$ & $6 / 10 / 2009$ & $12: 11$ & $12: 36$ & 4593 & 9728 \\
\hline 5 & $2 \mathrm{D} 2-11$ & $6 / 10 / 2009$ & $14: 11$ & $14: 36$ & 6589 & 13956 \\
\hline 6 & $2 \mathrm{D} 2-9$ & $6 / 10 / 2009$ & $14: 54$ & $15: 19$ & 3944 & 10253 \\
\hline 7 & $2 \mathrm{D} 2-5$ & $6 / 10 / 2009$ & $15: 42$ & $16: 07$ & 4841 & 6752 \\
\hline 8 & $2 \mathrm{D} 2-2$ & $6 / 10 / 2009$ & $17: 11$ & $17: 36$ & 3188 & 8300 \\
\hline 9 & $2 \mathrm{D} 2-2$ & $6 / 11 / 2009$ & $8: 18$ & $8: 43$ & 3919 & 8852 \\
\hline 10 & $2 \mathrm{D} 2-5$ & $6 / 11 / 2009$ & $9: 27$ & $9: 52$ & 4180 & 7684 \\
\hline 11 & $2 \mathrm{D} 2-9$ & $6 / 11 / 2009$ & $10: 11$ & $10: 36$ & 3628 & 8301 \\
\hline 12 & $2 \mathrm{D} 2-11$ & $6 / 11 / 2009$ & $11: 00$ & $11: 25$ & 3920 & 10076 \\
\hline 13 & $2 \mathrm{D} 2-11$ & $6 / 11 / 2009$ & $13: 43$ & $14: 08$ & 3945 & 9888 \\
\hline 14 & $2 \mathrm{D} 2-9$ & $6 / 11 / 2009$ & $14: 23$ & $14: 48$ & 4758 & 9289 \\
\hline 15 & $2 \mathrm{D} 2-5$ & $6 / 11 / 2009$ & $14: 58$ & $15: 23$ & 4669 & $\mathbf{9 4 2 8}$ \\
\hline 16 & $2 \mathrm{D} 2-2$ & $6 / 11 / 2009$ & $15: 35$ & $16: 00$ & 4386 & $\mathbf{1 7 5 4}$ \\
\hline Average & & & & & $\mathbf{4 4 5 2}$ & $\mathbf{9 4 8}$ \\
\hline Std Dev & & & & & & \\
\hline
\end{tabular}

Table 0-7. Inlet Particulate Loading Measurements during Sorbent Injection Test at $0.5 \mathrm{lb} /$ MMacf (Method 17) 


\begin{tabular}{|c|c|c|c|c|c|c|}
\hline Run \# & Port \# & Date & $\begin{array}{c}\text { Start } \\
\text { Time }\end{array}$ & $\begin{array}{c}\text { End } \\
\text { Time }\end{array}$ & $\begin{array}{c}\text { Inlet Particulate } \\
\text { Loading } \\
\text { (milligrain/dscf at 7\% } \\
\left.\mathbf{O}_{\mathbf{2}}\right)\end{array}$ & $\begin{array}{c}\text { Inlet Particulate } \\
\text { Loading } \\
(\mathbf{1 0} \text { lb/MMBtu) }\end{array}$ \\
\hline 1 & $2 \mathrm{D} 2-11$ & $6 / 16 / 2009$ & $09: 01$ & $09: 26$ & 4153 & 8796 \\
\hline 2 & $2 \mathrm{D} 2-9$ & $6 / 16 / 2009$ & $10: 23$ & $10: 48$ & 5380 & 11394 \\
\hline 3 & $2 \mathrm{D} 2-5$ & $6 / 16 / 2009$ & $11: 38$ & $12: 03$ & 4105 & 8693 \\
\hline 4 & $2 \mathrm{D} 2-2$ & $6 / 16 / 2009$ & $12: 18$ & $12: 43$ & 3793 & 1033 \\
\hline 5 & $2 \mathrm{D} 2-11$ & $6 / 16 / 2009$ & $14: 10$ & $14: 35$ & 5140 & 10491 \\
\hline 6 & $2 \mathrm{D} 2-9$ & $6 / 16 / 2009$ & $14: 49$ & $15: 14$ & 4954 & 11491 \\
\hline 7 & $2 \mathrm{D} 2-5$ & $6 / 16 / 2009$ & $15: 29$ & $15: 54$ & 5425 & 11301 \\
\hline 8 & $2 \mathrm{D} 2-2$ & $6 / 16 / 2009$ & $16: 10$ & $16: 35$ & 5336 & $\mathbf{1 0 1 3 6}$ \\
\hline Average & & & & & $\mathbf{4 7 8 6}$ & $\mathbf{1 4 0 2}$ \\
\hline Std Dev & & & & & $\mathbf{6 6 2}$ & \\
\hline
\end{tabular}

Table 0-8. Outlet Particulate Loading Measurements for Sorbent Injection Test at $0.5 \mathrm{lb} / \mathrm{MMacf}$

\begin{tabular}{|c|c|c|c|c|c|}
\hline $\begin{array}{c}\text { Top or } \\
\text { Bottom Half } \\
\text { Traverse of } \\
\text { Duct? }\end{array}$ & Date & $\begin{array}{c}\text { Start } \\
\text { Time }\end{array}$ & $\begin{array}{c}\text { End } \\
\text { Time }\end{array}$ & $\begin{array}{c}\text { Outlet Particulate Loading } \\
(\text { milligrain/dscf at 7\% O })\end{array}$ & $\begin{array}{c}\text { Outlet Particulate Loading } \\
\left(\mathbf{1 0}^{-3} \text { lb/MMBtu) }\right.\end{array}$ \\
\hline Bottom & $6 / 16 / 2009$ & $08: 55$ & $13: 16$ & 3.69 & 7.82 \\
\hline Top & $6 / 16 / 2009$ & $14: 10$ & $18: 00$ & 1.22 & 2.58 \\
\hline Average & & & & $\mathbf{2 . 5 3}$ & $\mathbf{5 . 3 7}$ \\
\hline
\end{tabular}

Table 0-9. Outlet Particulate Loading Measurements for Sorbent Injection Test at $1.0 \mathrm{lb} / \mathrm{MMacf}$

\begin{tabular}{|c|c|c|c|c|c|}
\hline $\begin{array}{c}\text { Top or } \\
\text { Bottom Half } \\
\text { Traverse of } \\
\text { Duct? }\end{array}$ & Date & $\begin{array}{c}\text { Start } \\
\text { Time }\end{array}$ & $\begin{array}{c}\text { End } \\
\text { Time }\end{array}$ & $\begin{array}{c}\text { Outlet Particulate Loading } \\
(\text { milligrain/dscf at 7\% O }\end{array}$ & $\begin{array}{c}\text { Outlet Particulate Loading } \\
\left(\mathbf{1 0}^{-3} \mathbf{~ l b / M M B t u}\right)\end{array}$ \\
\hline Bottom & $6 / 17 / 2009$ & $08: 30$ & $12: 20$ & 1.69 & 3.58 \\
\hline Top & $6 / 17 / 2009$ & $13: 10$ & $17: 00$ & 1.59 & 3.37 \\
\hline Average & & & & $\mathbf{1 . 6 4}$ & $\mathbf{3 . 4 8}$ \\
\hline
\end{tabular}

Table 0-10. Outlet Particulate Loading Measurements for Sorbent Injection Test at $1.9 \mathrm{lb} / \mathrm{MMacf}$ 


\begin{tabular}{|c|c|c|c|c|c|}
\hline $\begin{array}{c}\text { Top or } \\
\text { Bottom Half } \\
\text { Traverse of } \\
\text { Duct? }\end{array}$ & Date & $\begin{array}{c}\text { Start } \\
\text { Time }\end{array}$ & $\begin{array}{c}\text { End } \\
\text { Time }\end{array}$ & $\begin{array}{c}\text { Outlet Particulate Loading } \\
\text { (milligrain/dscf at 7\% O2) }\end{array}$ & $\begin{array}{c}\text { Outlet Particulate Loading } \\
(\mathbf{1 0}-\mathbf{3} \text { lb/MMBtu) }\end{array}$ \\
\hline Bottom & $6 / 13 / 2009$ & $10: 50$ & $14: 00$ & 2.31 & 4.90 \\
\hline Top & $6 / 13 / 2009$ & $14: 22$ & $17: 00$ & 1.34 & 2.85 \\
\hline Bottom & $6 / 14 / 2009$ & $07: 40$ & $11: 20$ & 1.35 & 2.86 \\
\hline Top & $6 / 14 / 2009$ & $11: 42$ & $15: 21$ & 0.76 & 1.60 \\
\hline Bottom & $6 / 15 / 2009$ & $08: 05$ & $11: 43$ & 4.73 & 1.02 \\
\hline Top & $6 / 15 / 2009$ & $12: 42$ & $16: 19$ & 0.80 & $\mathbf{4 . 1 0}$ \\
\hline Average & & & & $\mathbf{1 . 9 3}$ & $\mathbf{2 . 9 1}$ \\
\hline Std Dev & & & & $\mathbf{1 . 3 7}$ & \\
\hline
\end{tabular}

Table 0-11. Comparison of Average Baseline and Sorbent Injection Particulate Loading Measurements (Method 17)

\begin{tabular}{|c|c|c|c|c|}
\hline & Baseline & $0.5 \mathrm{lb} / \mathrm{MMacf}$ & $1.0 \mathrm{lb} / \mathrm{MMacf}$ & $1.9 \mathrm{lb} / \mathrm{MMacf}$ \\
\hline Ave. Inlet (milligrain/dscf at $7 \% \mathrm{O}_{2}$ ) & 4452 & 4786 & 3986 & N/A \\
\hline Ave. Outlet (milligrain/dscf at $\left.7 \% \mathrm{O}_{2}\right)$ & 3.01 & 2.53 & 1.64 & 1.93 \\
\hline \% Removal & 99.93 & 99.95 & 99.96 & N/A \\
\hline Ave. Inlet $\left(10^{-3} \mathrm{lb} / \mathrm{MMBtu}\right.$ at $\left.7 \% \mathrm{O}_{2}\right)$ & 9428 & 10136 & 8442 & N/A \\
\hline Ave. Outlet $\left(10^{-3} \mathrm{lb} / \mathrm{MMBtu}\right.$ at $\left.7 \% \mathrm{O}_{2}\right)$ & 6.38 & 5.37 & 3.48 & 4.10 \\
\hline
\end{tabular}

N/A = not available; no inlet data 